\title{
Evaluated kinetic and photochemical data for atmospheric chemistry: Volume II - gas phase reactions of organic species
}

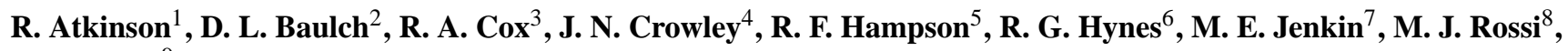 \\ and J. Troe ${ }^{9}$ \\ ${ }^{1}$ Air Pollution Research Center, University of California, Riverside, California 92521, USA \\ ${ }^{2}$ School of Chemistry, University of Leeds, Leeds LS2 9JT, UK \\ ${ }^{3}$ Centre for Atmospheric Science, Dept. of Chemistry, University of Cambridge, Lensfield Road Cambridge CB2 1EP, UK \\ ${ }^{4}$ Max-Planck-Institut für Chemie, Division of Atmospheric Chemistry, Postfach 3060, 55020 Mainz, Germany \\ ${ }^{5}$ U.S. Dept. of Commerce, National Institute of Standards and Technology, Bldg. 221, Rm A111, Gaithersburg, MD 20899, \\ USA \\ ${ }^{6}$ CSIRO Energy Technology, Lucas Heights Science and Technology Centre, Building 2, PMB 7, Bangor, NSW 2234, \\ Australia \\ ${ }^{7}$ Dept. of Environmental Science and Technology, Imperial College London, Silwood Park, Ascot, Berkshire SL5 7PY, UK \\ ${ }^{8}$ Laboratoire de Pollution Atmosphérique et Sol (LPAS/ENAC), Ecole Polytechnique Fédérale de Lausanne (EPFL), Bât CH \\ H5, Station 6, CH-1015 Lausanne, Switzerland \\ ${ }^{9}$ Institute of Physical Chemistry, University of Göttingen, Tammannstr. 6, D-37077 Göttingen, Germany \\ *The IUPAC Subcommittee on Gas Kinetic Data Evaluation for Atmospheric Chemistry
}

Received: 1 February 2005 - Published in Atmos. Chem. Phys. Discuss.: 19 August 2005

Revised: 20 January 2006 - Accepted: 10 February 2006 - Published: 6 September 2006

\begin{abstract}
This article, the second in the series, presents kinetic and photochemical data evaluated by the IUPAC Subcommittee on Gas Kinetic Data Evaluation for Atmospheric Chemistry. It covers the gas phase and photochemical reactions of Organic species, which were last published in 1999, and were updated on the IUPAC website in late 2002, and subsequently during the preparation of this article. The article consists of a summary table of the recommended rate coefficients, containing the recommended kinetic parameters for the evaluated reactions, and eight appendices containing the data sheets, which provide information upon which the recommendations are made.
\end{abstract}

\section{Introduction}

In the mid 1970s it was appreciated that there was a need for the establishment of an international panel to produce a set of critically evaluated rate parameters for reactions of interest for atmospheric chemistry. To this end the CODATA Task Group on Chemical Kinetics, under the auspices of the International Council of Scientific Unions (ICSU), was constituted in 1977, and tasked to produce an evaluation of relevant, available kinetic and photochemical data. The first evaluation by this international committee was published in J. Phys. Chem. Ref. Data in 1980 (Baulch et al., 1980), followed by Supplements in 1982 (Baulch et al., 1982) and 1984 (Baulch et al., 1984). In 1986 the IUPAC Subcommittee on Data Evaluation superseded the original CODATA Task Group for Atmospheric Chemistry, and the Subcommittee has continued its data evaluation program with Supplements published in 1989 (Atkinson et al., 1989), 1992 (Atkinson et al., 1992), 1997 (Atkinson et al., 1997a), 1997 (Atkinson et al., 1997b), 1999 (Atkinson et al., 1999), and 2000 (Atkinson et al., 2000). Following the last of these reports, Supplement VIII (Atkinson et al., 2000), the evaluation has continued to be updated and published on the worldwide web (http://www.iupac-kinetic.ch.cam.ac.uk/). The IUPAC website hosts an interactive data base with a search facility and implemented hyperlinks between the summary table and the data sheets, both of which can be downloaded as individual PDF files. In order to further enhance the accessibility of this updated material to the scientific community, the evaluation is being published as a series of articles in Atmospheric Chemistry and Physics. This article is the second of the series, Volume II.

Correspondence to: R. A. Cox

(rac26@cam.ac.uk)

Published by Copernicus GmbH on behalf of the European Geosciences Union. 
2 Table of the summary of recommended rate coefficients for organic reactions

The ordering of families in the summary table of the recommended rate coefficients is $\mathrm{O}\left({ }^{3} \mathrm{P}\right)$ and $\mathrm{O}\left({ }^{1} \mathrm{D}\right)$ atom reactions, $\mathrm{HO}$ radical reactions, $\mathrm{RO}$ reactions, $\mathrm{RO}_{2}$ reactions, $\mathrm{O}_{3}$ reactions, halogen atom reactions and photochemical reactions.
Reactions are numbered sequentially in each family. Chemical reactions are listed as first reactant (usually an atom or radical) + second reactant (usually a molecule). Each datasheet has a unique identifier: 'Volume: Appendix number: reaction number'. For example, the first reaction in the summary sheet below refers to Datasheet 'II.A1.1'.

\begin{tabular}{|c|c|c|c|c|c|c|}
\hline $\begin{array}{l}\text { reaction } \\
\text { number }\end{array}$ & Reaction & $\begin{array}{l}k_{298} \\
\mathrm{~cm}^{3} \text { molecule }{ }^{-1} \mathrm{~s}^{-1}\end{array}$ & $\Delta \log k_{298}^{a}$ & $\begin{array}{l}\text { Temp. dependence of } \\
k / \mathrm{cm}^{3} \text { molecule }{ }^{-1} \mathrm{~s}^{-1}\end{array}$ & $\begin{array}{l}\text { Temp. } \\
\text { range/K }\end{array}$ & $\Delta(E / R) / \mathrm{K}^{a}$ \\
\hline \multicolumn{7}{|c|}{$O$ atom Reactions based on data sheets in Appendix A1 } \\
\hline 1 & $\mathrm{O}+\mathrm{CH}_{3} \rightarrow$ products & $1.3 \times 10^{-10}$ & \pm 0.1 & $1.3 \times 10^{-10}$ & $290-900$ & \pm 100 \\
\hline \multirow[t]{4}{*}{2} & $\mathrm{O}\left({ }^{1} \mathrm{D}\right)+\mathrm{CH}_{4} \rightarrow \mathrm{HO}+\mathrm{CH}_{3}$ & $1.05 \times 10^{-10}$ & & $1.05 \times 10^{-10}$ & $200-350$ & \\
\hline & $\rightarrow \mathrm{CH}_{3} \mathrm{O}$ or $\mathrm{CH}_{2} \mathrm{OH}+\mathrm{H}$ & $3.45 \times 10^{-11}$ & & $3.45 \times 10^{-11}$ & $200-350$ & \\
\hline & $\rightarrow \mathrm{HCHO}+\mathrm{H}_{2}$ & $7.50 \times 10^{-12}$ & & $7.50 \times 10^{-12}$ & $200-350$ & \\
\hline & overall & $1.50 \times 10^{-10}$ & \pm 0.10 & $1.50 \times 10^{-10}$ & $200-350$ & \pm 100 \\
\hline
\end{tabular}

HO Reactions based on data sheets in Appendix A2

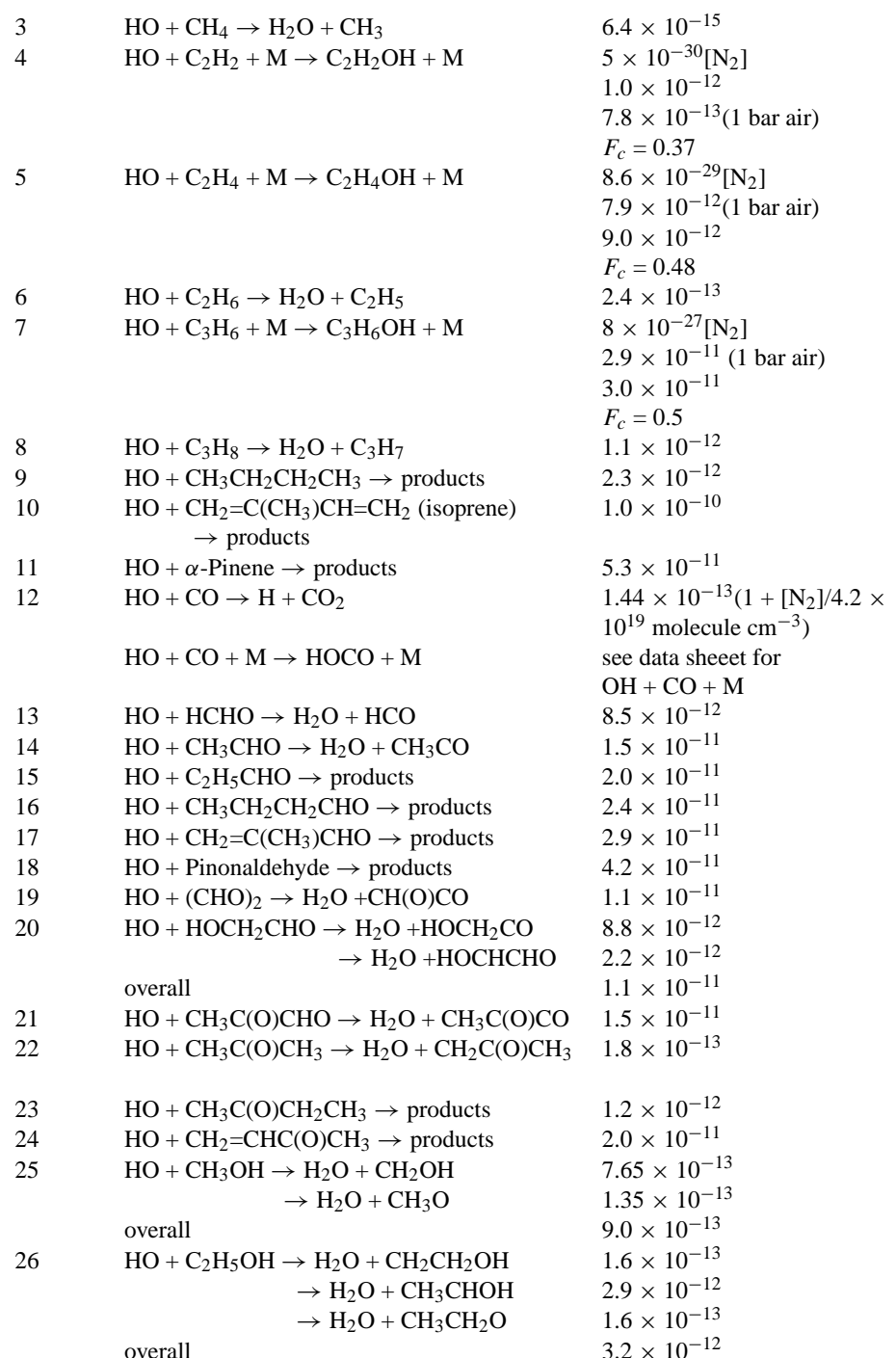

overall

$\begin{array}{lllll} & \pm 0.08 & 1.85 \times 10^{-12} \exp (-1690 / T) & 200-300 & \pm 100 \\ \left(k_{0}\right) & \pm 0.1 & 5 \times 10^{-30}(T / 300)^{-1.5}\left[\mathrm{~N}_{2}\right] & 300-800 & \Delta \mathrm{n}= \pm 1.5 \\ \left(k_{\infty}\right) & \pm 0.3 & & & \\ & \pm 0.15 & & & \\ & & & \\ \left(k_{0}\right) & \pm 0.3 & 8.6 \times 10^{-29}(T / 300)^{-3.1}\left[\mathrm{~N}_{2}\right] & 200-300 & \Delta n= \pm 2 \\ & \pm 0.1 & & & \\ \left(k_{\infty}\right) & \pm 0.3 & 9 \times 10^{-12}(T / 300)^{-0.85} & 100-500 & \Delta n= \pm 0.3 \\ & & & & \\ & \pm 0.08 & 6.9 \times 10^{-12} \exp (-1000 / T) & 200-300 & \pm 100 \\ \left(k_{0}\right) & \pm 0.5 & 8 \times 10^{-27}(T / 300)^{-3.5}\left[\mathrm{~N}_{2}\right] & 200-300 & \Delta n= \pm 1 \\ & \pm 0.1 & & & \\ \left(k_{\infty}\right) & \pm 0.1 & 3.0 \times 10^{-11}(T / 300)^{-1} & 200-300 & \Delta n= \pm 1 \\ & \pm 0.08 & 7.6 \times 10^{-12} \exp (-585 / T) & 200-300 & \pm 100 \\ & \pm 0.10 & 9.1 \times 10^{-12} \exp (-405 / T) & 230-300 & \pm 150 \\ & \pm 0.10 & 2.7 \times 10^{-11} \exp (390 / T) & 240-430 & \pm 100 \\ & & & \\ & \pm 0.15 & 1.2 \times 10^{-11} \exp (440 / T) & 290-430 & \pm 200 \\ & \pm 0.05 & 1.3 \times 10^{-13}(1+0.6 \mathrm{P} / \mathrm{bar}) & 200-300 & \Delta \log k \pm 0.2\end{array}$

\section{$\pm 0.08$}

$\pm 0.08$

$\pm 0.1$

$\pm 0.1$

$\pm 0.10$

$\pm 0.25$

$\pm 0.3$

$\pm 0.15$

$\pm 0.15$

$\pm 0.2$

$\pm 0.08 \quad 8.8 \times 10^{-12} \exp (-1320 / T)$

$+1.7 \times 10^{-14} \exp (423 / T)$

$1.3 \times 10^{-12} \exp (-25 / T)$

$\pm 0.15$

$\pm 0.10$

$2.6 \times 10^{-12} \exp (610 / T)$

$195-440 \quad \Delta \log k= \pm 0.08$

$240-300 \quad \pm 200$

$230-380 \quad \pm 200$

$\pm 0.08$

$2.85 \times 10^{-12} \exp (-345 / T)$

$210-300 \quad \pm 150$

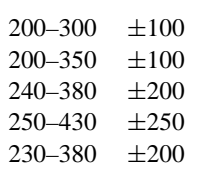

$\begin{array}{ll}250-430 & \pm 250 \\ 230-380 & \pm 200\end{array}$

$\pm 0.08 \quad 3.0 \times 10^{-12} \exp (20 / T) \quad 210-300 \quad \pm 150$ 


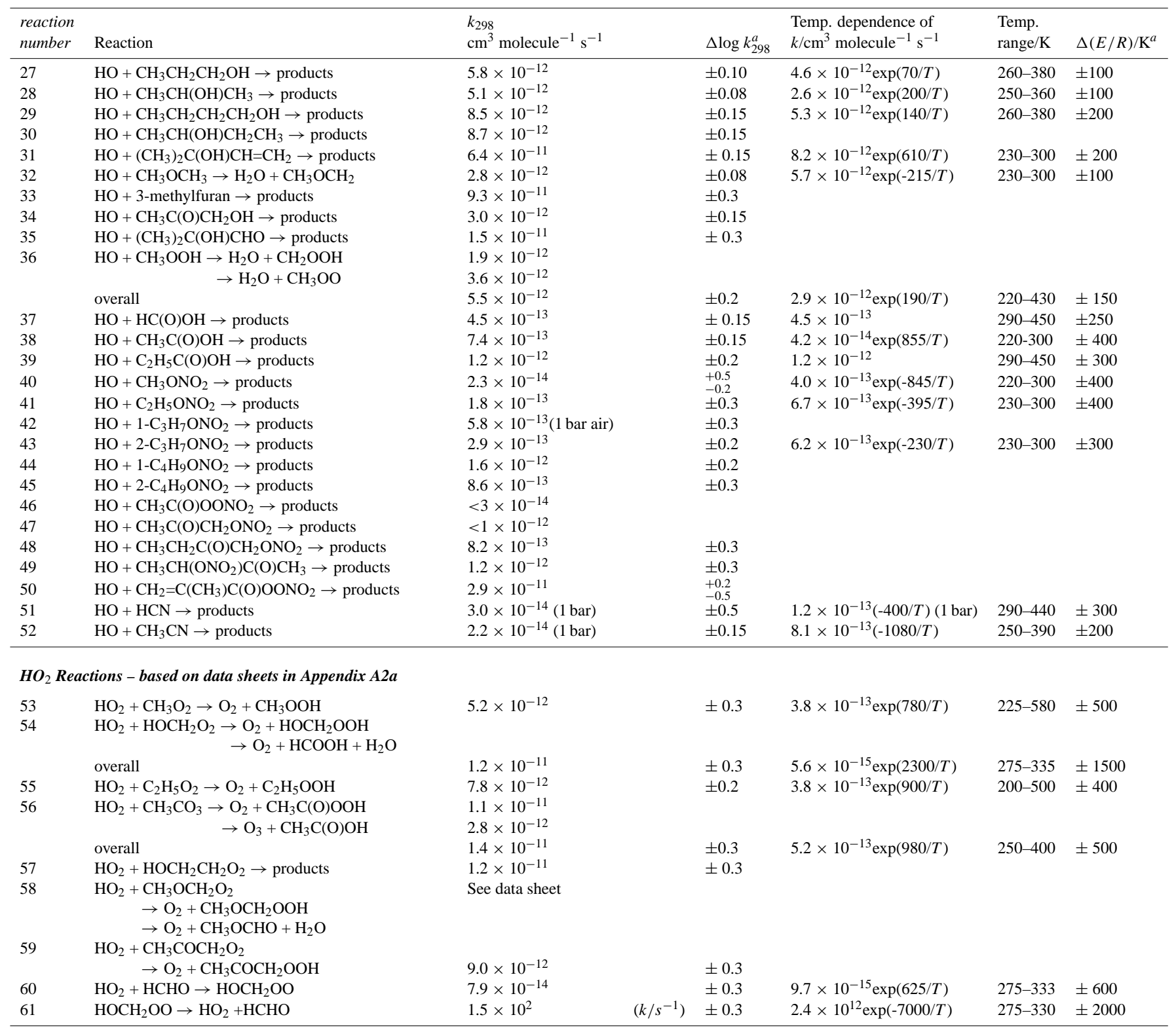

\section{$\mathrm{NO}_{3}$ Reactions - based on data sheets in Appendix $\mathrm{A3}$}

\begin{tabular}{|c|c|c|c|c|c|c|}
\hline 62 & $\mathrm{NO}_{3}+\mathrm{CH}_{4} \rightarrow \mathrm{HNO}_{3}+\mathrm{CH}_{3}$ & $<1 \times 10^{-18}$ & & & & \\
\hline 63 & $\mathrm{NO}_{3}+\mathrm{C}_{2} \mathrm{H}_{2} \rightarrow$ products & $<1 \times 10^{-16}$ & & & & \\
\hline 64 & $\mathrm{NO}_{3}+\mathrm{C}_{2} \mathrm{H}_{4} \rightarrow$ products & $2.1 \times 10^{-16}$ & \pm 0.2 & $3.3 \times 10^{-12} \exp (-2880 / T)$ & $270-340$ & \pm 500 \\
\hline 65 & $\mathrm{NO}_{3}+\mathrm{C}_{2} \mathrm{H}_{6} \rightarrow \mathrm{HNO}_{3}+\mathrm{C}_{2} \mathrm{H}_{5}$ & $<1 \times 10^{-17}$ & & & & \\
\hline 66 & $\mathrm{NO}_{3}+\mathrm{C}_{3} \mathrm{H}_{6} \rightarrow$ products & $9.5 \times 10^{-15}$ & \pm 0.2 & $4.6 \times 10^{-13} \exp (-1155 / T)$ & $290-430$ & \pm 300 \\
\hline 67 & $\mathrm{NO}_{3}+\mathrm{C}_{3} \mathrm{H}_{8} \rightarrow \mathrm{HNO}_{3}+\mathrm{C}_{3} \mathrm{H}_{7}$ & $<7 \times 10^{-17}$ & & & & \\
\hline 68 & $\mathrm{NO}_{3}+n-\mathrm{C}_{4} \mathrm{H}_{10} \rightarrow$ products & $4.6 \times 10^{-17}$ & \pm 0.2 & $2.8 \times 10^{-12} \exp (-3280 / T)$ & $290-430$ & \pm 400 \\
\hline 69 & $\mathrm{NO}_{3}+\mathrm{CH}_{2}=\mathrm{C}\left(\mathrm{CH}_{3}\right) \mathrm{CH}=\mathrm{CH}_{2}$ (isoprene) $\rightarrow$ products & $7.0 \times 10^{-13}$ & \pm 0.2 & $3.15 \times 10^{-12} \exp (-450 / T)$ & $250-390$ & \pm 200 \\
\hline 70 & $\mathrm{NO}_{3}+\alpha$-Pinene $\rightarrow$ products & $6.2 \times 10^{-12}$ & \pm 0.1 & $1.2 \times 10^{-12} \exp (490 / T)$ & $260-390$ & \pm 300 \\
\hline 71 & $\mathrm{NO}_{3}+\mathrm{HCHO} \rightarrow \mathrm{HNO}_{3}+\mathrm{HCO}$ & $5.6 \times 10^{-16}$ & \pm 0.3 & & & \\
\hline 72 & $\mathrm{NO}_{3}+\mathrm{CH}_{3} \mathrm{CHO} \rightarrow \mathrm{HNO}_{3}+\mathrm{CH}_{3} \mathrm{CO}$ & $2.7 \times 10^{-15}$ & \pm 0.2 & $1.4 \times 10^{-12} \exp (-1860 / T)$ & $260-380$ & \pm 500 \\
\hline 73 & $\mathrm{NO}_{3}+\mathrm{C}_{2} \mathrm{H}_{5} \mathrm{CHO} \rightarrow$ products & $6.4 \times 10^{-15}$ & \pm 0.2 & & & \\
\hline 74 & $\mathrm{NO}_{3}+\mathrm{C}_{3} \mathrm{H}_{7} \mathrm{CHO} \rightarrow$ products & $1.1 \times 10^{-14}$ & \pm 0.15 & $1.7 \times 10^{-12} \exp (-1500 / T)$ & $260-340$ & \pm 500 \\
\hline 75 & $\mathrm{NO}_{3}+\mathrm{CH}_{2}=\mathrm{C}\left(\mathrm{CH}_{3}\right) \mathrm{CHO} \rightarrow$ products & $3.4 \times 10^{-15}$ & \pm 0.15 & & & \\
\hline
\end{tabular}




\begin{tabular}{|c|c|c|c|c|c|c|c|}
\hline $\begin{array}{l}\text { reaction } \\
\text { number }\end{array}$ & Reaction & $\begin{array}{l}k_{298} \\
\mathrm{~cm}^{3} \text { molecule }^{-1} \mathrm{~s}^{-1}\end{array}$ & & $\Delta \log k_{298}^{a}$ & $\begin{array}{l}\text { Temp. dependence of } \\
k / \mathrm{cm}^{3} \text { molecule }{ }^{-1} \mathrm{~s}^{-1}\end{array}$ & $\begin{array}{l}\text { Temp. } \\
\text { range/K }\end{array}$ & $\Delta(E / R) / \mathrm{K}^{a}$ \\
\hline 76 & $\mathrm{NO}_{3}+\mathrm{CH}_{3} \mathrm{C}(\mathrm{O}) \mathrm{CH}=\mathrm{CH}_{2} \rightarrow$ products & $<6.0 \times 10^{-16}$ & & & & & \\
\hline 77 & $\mathrm{NO}_{3}+$ Pinonaldehyde $\rightarrow$ products & $2.0 \times 10^{-14}$ & & \pm 0.25 & & & \\
\hline 78 & $\mathrm{NO}_{3}+\mathrm{CH}_{3} \mathrm{C}(\mathrm{O}) \mathrm{CH}_{3} \rightarrow \mathrm{HNO}_{3}+\mathrm{CH}_{3} \mathrm{COCH}_{2}$ & $<3 \times 10^{-17}$ & & & & & \\
\hline 79 & $\mathrm{NO}_{3}+3$-methylfuran $\rightarrow$ products & $1.9 \times 10^{-11}$ & & \pm 0.5 & & & \\
\hline 80 & $\mathrm{NO}_{3}+\mathrm{CH}_{2}=\mathrm{C}\left(\mathrm{CH}_{3}\right) \mathrm{C}(\mathrm{O}) \mathrm{OONO}_{2} \rightarrow$ products & $1.6 \times 10^{-16}$ & & \pm 0.7 & & & \\
\hline 81 & $\mathrm{NO}_{3}+\mathrm{CH}_{3} \mathrm{OH} \rightarrow$ products & $1.3 \times 10^{-16}$ & & \pm 0.5 & $9.4 \times 10^{-13} \exp (-2650 / T)$ & $250-370$ & \pm 700 \\
\hline 82 & $\mathrm{NO}_{3}+\mathrm{C}_{2} \mathrm{H}_{5} \mathrm{OH} \rightarrow$ products & $<2 \times 10^{-15}$ & & & & & \\
\hline 83 & $\mathrm{NO}_{3}+\mathrm{CH}_{3} \mathrm{CH}(\mathrm{OH}) \mathrm{CH}_{3} \rightarrow$ products & $1.4 \times 10^{-15}$ & & \pm 0.3 & & & \\
\hline 84 & $\mathrm{NO}_{3}+\mathrm{CH}_{3} \mathrm{CH}(\mathrm{OH}) \mathrm{CH}_{2} \mathrm{CH}_{3} \rightarrow$ products & $2.0 \times 10^{-15}$ & & \pm 0.3 & & & \\
\hline 85 & $\mathrm{NO}_{3}+\left(\mathrm{CH}_{3}\right)_{2} \mathrm{C}(\mathrm{OH}) \mathrm{CH}=\mathrm{CH}_{2} \rightarrow$ products & $1.2 \times 10^{-14}$ & & \pm 0.2 & $\left.4.6 \times 10^{-14} \exp (-400) / T\right)$ & $260-400$ & \pm 200 \\
\hline \multicolumn{8}{|c|}{ Carbon Radical Reactions - based on data sheets in Appendix A4 } \\
\hline 86 & $\mathrm{CH}_{3}+\mathrm{O}_{2}+\mathrm{M} \rightarrow \mathrm{CH}_{3} \mathrm{O}_{2}+\mathrm{M}$ & $\begin{array}{l}1.0 \times 10^{-30}\left[\mathrm{~N}_{2}\right] \\
1.8 \times 10^{-12} \\
F_{c}=0.27\end{array}$ & $\begin{array}{l}\left(k_{0}\right) \\
\left(k_{\infty}\right)\end{array}$ & $\begin{array}{l} \pm 0.2 \\
\pm 0.3\end{array}$ & $\begin{array}{l}1.0 \times 10^{-30}(T / 300)^{-3.3}\left[\mathrm{~N}_{2}\right] \\
1.8 \times 10^{-12}(T / 300)^{1.1}\end{array}$ & $\begin{array}{l}200-300 \\
200-300\end{array}$ & $\begin{array}{l}\Delta n= \pm 1 \\
\Delta n= \pm 1\end{array}$ \\
\hline 87 & $\mathrm{CH}_{3}+\mathrm{O}_{3} \rightarrow$ products & $2.3 \times 10^{-12}$ & & \pm 0.3 & $4.7 \times 10^{-12} \exp (-210 / T)$ & $240-400$ & \pm 200 \\
\hline 88 & $\mathrm{C}_{2} \mathrm{H}_{5}+\mathrm{O}_{2} \rightarrow \mathrm{C}_{2} \mathrm{H}_{4}+\mathrm{HO}_{2}$ & $\begin{array}{l}3.8 \times 10^{-15} \\
1.9 \times 10^{-14}\end{array}$ & $\begin{array}{l}\text { ( } 1 \text { bar air }) \\
(0.133 \text { bar air })\end{array}$ & $\begin{array}{l} \pm 0.5 \\
\pm 0.5\end{array}$ & & & \\
\hline 89 & $\mathrm{C}_{2} \mathrm{H}_{5}+\mathrm{O}_{2}+\mathrm{M} \rightarrow \mathrm{C}_{2} \mathrm{H}_{5} \mathrm{O}_{2}+\mathrm{M}$ & $\begin{array}{l}5.9 \times 10^{-29}\left[\mathrm{~N}_{2}\right] \\
7.8 \times 10^{-12}\end{array}$ & $\begin{array}{l}\left(k_{0}\right) \\
\left(k_{\infty}\right)\end{array}$ & $\begin{array}{l} \pm 0.3 \\
\pm 0.2\end{array}$ & $\begin{array}{l}5.9 \times 10^{-29}(T / 300)^{-3.8}\left[\mathrm{~N}_{2}\right] \\
7.8 \times 10^{-12} \\
F_{c}=0.58 \exp (-T / 1250) \\
+0.42 \exp (-T / 183)\end{array}$ & $\begin{array}{l}200-300 \\
200-300 \\
200-300 \\
200-300\end{array}$ & $\Delta n= \pm 1$ \\
\hline 90 & $n-\mathrm{C}_{3} \mathrm{H}_{7}+\mathrm{O}_{2}+\mathrm{M} \rightarrow n-\mathrm{C}_{3} \mathrm{H}_{7} \mathrm{O}_{2}+\mathrm{M}$ & $8.0 \times 10^{-12}$ & $\left(k_{\infty}\right)$ & \pm 0.2 & $8.0 \times 10^{-12}$ & $200-300$ & \\
\hline 91 & $i-\mathrm{C}_{3} \mathrm{H}_{7}+\mathrm{O}_{2}+\mathrm{M} \rightarrow i-\mathrm{C}_{3} \mathrm{H}_{7} \mathrm{O}_{2}+\mathrm{M}$ & $1.1 \times 10^{-11}$ & $\left(k_{\infty}\right)$ & \pm 0.3 & $1.1 \times 10^{-11}$ & $200-300$ & \\
\hline 92 & $1-\mathrm{C}_{4} \mathrm{H}_{9}+\mathrm{O}_{2}+\mathrm{M} \rightarrow 1-\mathrm{C}_{4} \mathrm{H}_{9} \mathrm{O}_{2}+\mathrm{M}$ & $7.5 \times 10^{-12}$ & $\left(k_{\infty}\right)$ & \pm 0.5 & & & \\
\hline 93 & $2-\mathrm{C}_{4} \mathrm{H}_{9}+\mathrm{O}_{2}+\mathrm{M} \rightarrow 2-\mathrm{C}_{4} \mathrm{H}_{9} \mathrm{O}_{2}+\mathrm{M}$ & $1.7 \times 10^{-11}$ & $\left(k_{\infty}\right)$ & \pm 0.5 & & & \\
\hline 94 & $\begin{array}{l}\mathrm{CH}_{3} \mathrm{C}(\mathrm{O}) \mathrm{CH}_{2}+\mathrm{O}_{2}+\mathrm{M} \\
\quad \rightarrow \mathrm{CH}_{3} \mathrm{C}(\mathrm{O}) \mathrm{CH}_{2} \mathrm{O}_{2}+\mathrm{M}\end{array}$ & $1.5 \times 10^{-12}$ & $\left(k_{\infty}\right)$ & \pm 0.5 & & & \\
\hline 95 & $\mathrm{HCO}+\mathrm{O}_{2} \rightarrow \mathrm{CO}+\mathrm{HO}_{2}$ & $5.1 \times 10^{-12}$ & & \pm 0.15 & $5.1 \times 10^{-12}$ & $200-300$ & \\
\hline 96 & $\mathrm{CH}_{3} \mathrm{CO}+\mathrm{O}_{2}+\mathrm{M} \rightarrow \mathrm{CH}_{3} \mathrm{C}(\mathrm{O}) \mathrm{O}_{2}+\mathrm{M}$ & $5.1 \times 10^{-12}$ & $\left(k_{\infty}\right)$ & \pm 0.2 & $5.1 \times 10^{-12}$ & $220-300$ & \\
\hline 97 & $\mathrm{CH}_{2} \mathrm{OH}+\mathrm{O}_{2} \rightarrow \mathrm{HCHO}+\mathrm{HO}_{2}$ & $9.7 \times 10^{-12}$ & & \pm 0.12 & & & \\
\hline 98 & $\mathrm{CH}_{3} \mathrm{CHOH}+\mathrm{O}_{2} \rightarrow \mathrm{CH}_{3} \mathrm{CHO}+\mathrm{HO}_{2}$ & $1.9 \times 10^{-11}$ & & \pm 0.3 & & & \\
\hline 99 & $\mathrm{CH}_{2} \mathrm{CH}_{2} \mathrm{OH}+\mathrm{O}_{2} \rightarrow$ products & $3.0 \times 10^{-12}$ & & \pm 0.3 & & & \\
\hline
\end{tabular}

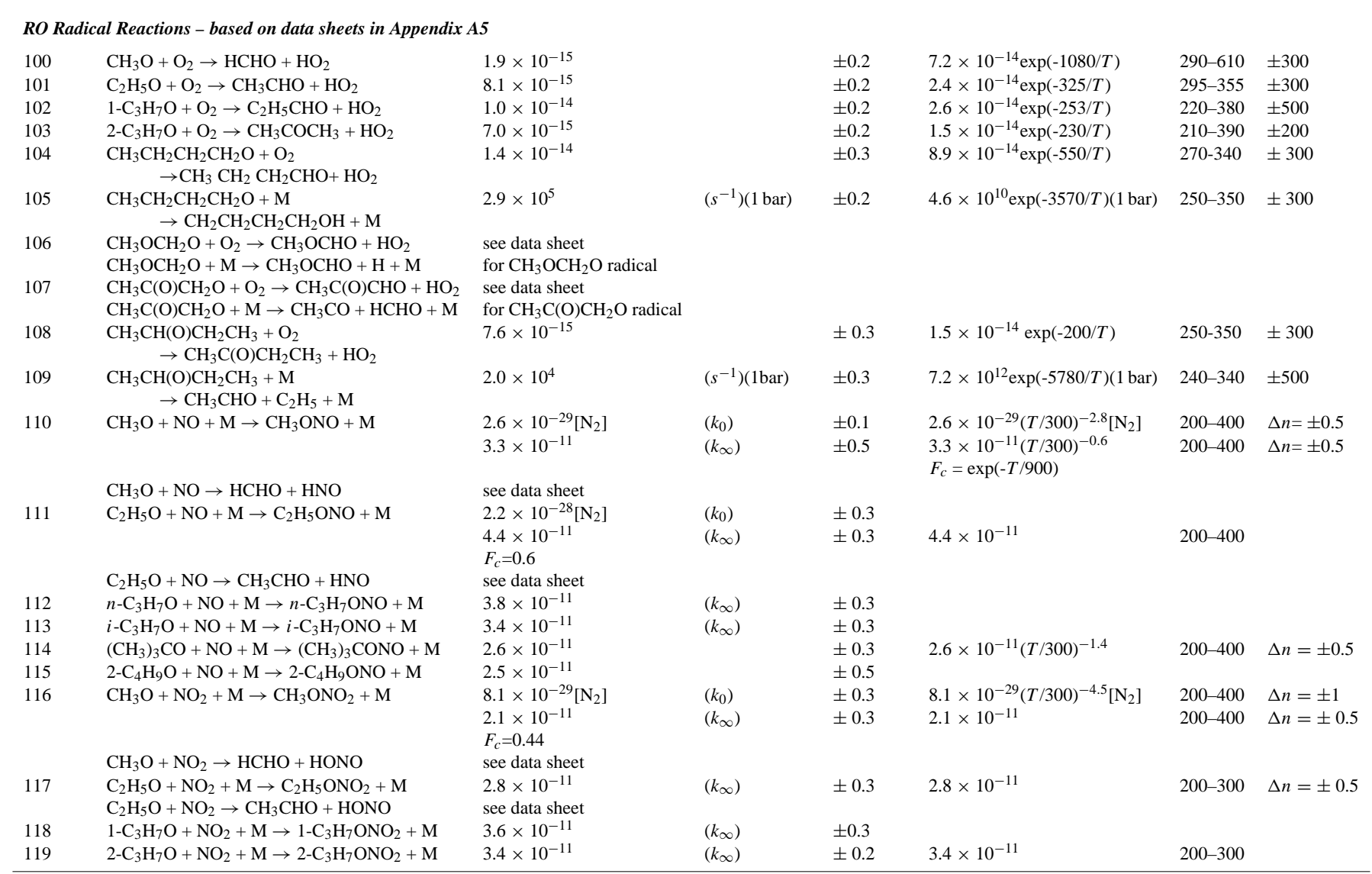




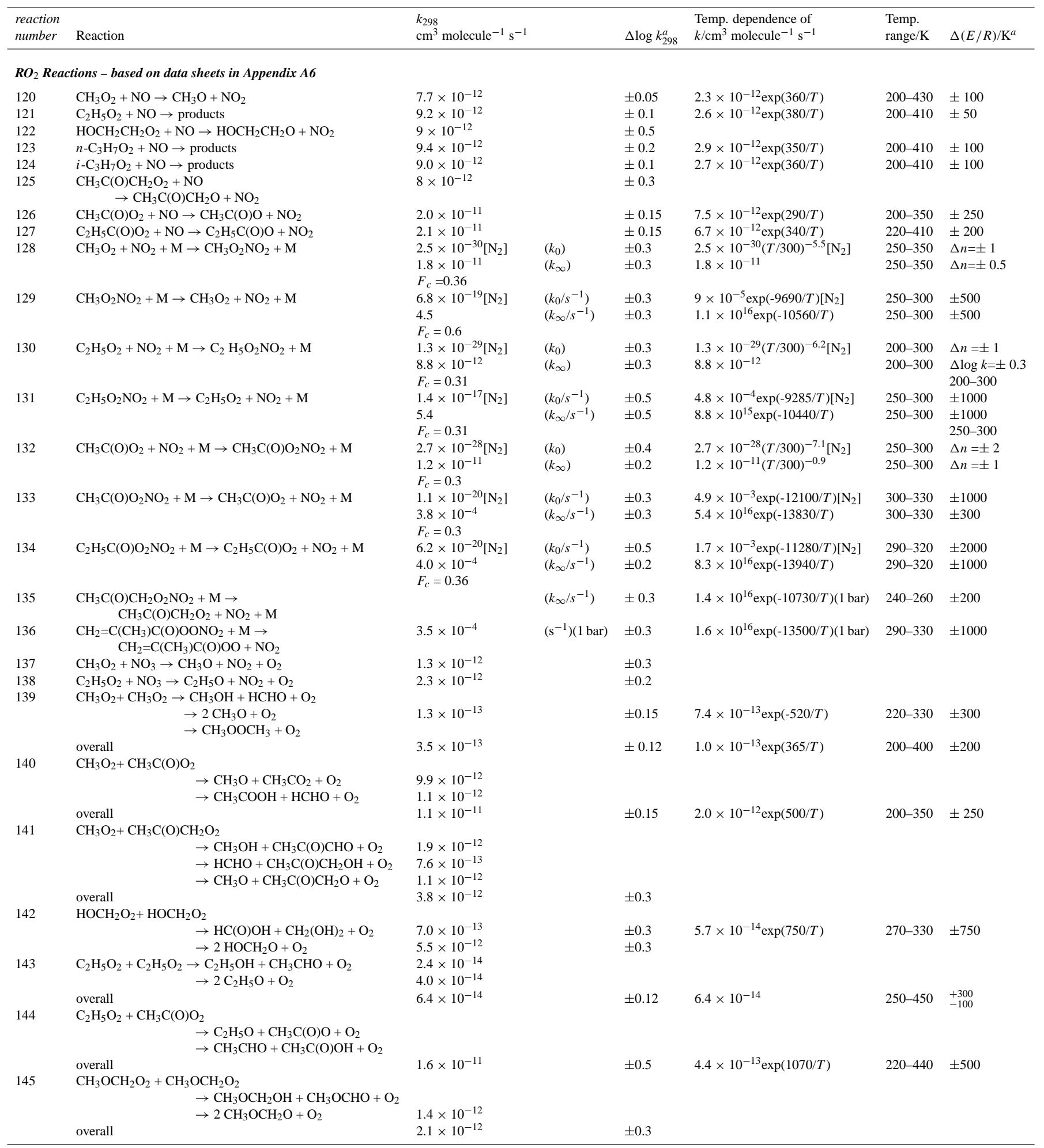




\begin{tabular}{|c|c|c|c|c|c|c|}
\hline $\begin{array}{l}\text { reaction } \\
\text { number }\end{array}$ & Reaction & $\begin{array}{l}k_{298} \\
\mathrm{~cm}^{3} \text { molecule }^{-1} \mathrm{~s}^{-1}\end{array}$ & $\Delta \log k_{298}^{a}$ & $\begin{array}{l}\text { Temp. dependence of } \\
k / \mathrm{cm}^{3} \text { molecule }^{-1} \mathrm{~s}^{-1}\end{array}$ & $\begin{array}{l}\text { Temp. } \\
\text { range/K }\end{array}$ & $\Delta(E / R) / \mathrm{K}^{a}$ \\
\hline 146 & $\mathrm{CH}_{3} \mathrm{C}(\mathrm{O}) \mathrm{O}_{2}+\mathrm{CH}_{3} \mathrm{C}(\mathrm{O}) \mathrm{O}_{2} \rightarrow 2 \mathrm{CH}_{3} \mathrm{C}(\mathrm{O}) \mathrm{O}+\mathrm{O}_{2}$ & $1.6 \times 10^{-11}$ & \pm 0.1 & $2.9 \times 10^{-12} \exp (500 / T)$ & $200-370$ & \pm 200 \\
\hline \multirow[t]{4}{*}{147} & $\mathrm{CH}_{3} \mathrm{CO}_{3}+\mathrm{CH}_{3} \mathrm{C}(\mathrm{O}) \mathrm{CH}_{2} \mathrm{O}_{2}$ & & & & & \\
\hline & $\rightarrow \mathrm{CH}_{3} \mathrm{C}(\mathrm{O}) \mathrm{OH}+\mathrm{CH}_{3} \mathrm{C}(\mathrm{O}) \mathrm{CHO}+\mathrm{O}_{2}$ & & & & & \\
\hline & $\rightarrow \mathrm{CH}_{3} \mathrm{CO}_{2}+\mathrm{CH}_{3} \mathrm{C}(\mathrm{O}) \mathrm{CH}_{2} \mathrm{O}+\mathrm{O}_{2}$ & $2.5 \times 10^{-12}$ & & & & \\
\hline & overall & $5.0 \times 10^{-12}$ & \pm 0.3 & & & \\
\hline \multirow[t]{4}{*}{148} & $\mathrm{HOCH}_{2} \mathrm{CH}_{2} \mathrm{O}_{2}+\mathrm{HOCH}_{2} \mathrm{CH}_{2} \mathrm{O}_{2}$ & & & & & \\
\hline & $\rightarrow \mathrm{HOCH}_{2} \mathrm{CH}_{2} \mathrm{OH}+\mathrm{HOCH}_{2} \mathrm{CHO}+\mathrm{O}_{2}$ & $1.1 \times 10^{-12}$ & & & & \\
\hline & $\rightarrow 2 \mathrm{HOCH}_{2} \mathrm{CH}_{2} \mathrm{O}+\mathrm{O}_{2}$ & $1.1 \times 10^{-12}$ & & & & \\
\hline & overall & $2.2 \times 10^{-12}$ & \pm 0.1 & $7.8 \times 10^{-14} \exp (1000 / T)$ & $250-450$ & \pm 300 \\
\hline \multirow[t]{2}{*}{149} & $\begin{aligned} n-\mathrm{C}_{3} \mathrm{H}_{7} \mathrm{O}_{2}+n-\mathrm{C}_{3} \mathrm{H}_{7} \mathrm{O}_{2} \rightarrow & n-\mathrm{C}_{3} \mathrm{H}_{7} \mathrm{OH}+\mathrm{C}_{2} \mathrm{H}_{5} \mathrm{CHO}+\mathrm{O}_{2} \\
& \rightarrow 2 n-\mathrm{C}_{3} \mathrm{H}_{7} \mathrm{O}+\mathrm{O}_{2}\end{aligned}$ & & & & & \\
\hline & overall & $3.0 \times 10^{-13}$ & \pm 0.5 & & & \\
\hline \multirow[t]{3}{*}{150} & $i-\mathrm{C}_{3} \mathrm{H}_{7} \mathrm{O}_{2}+i-\mathrm{C}_{3} \mathrm{H}_{7} \mathrm{O}_{2} \rightarrow i-\mathrm{C}_{3} \mathrm{H}_{7} \mathrm{OH}+\mathrm{CH}_{3} \mathrm{C}(\mathrm{O}) \mathrm{CH}_{3}+\mathrm{O}_{2}$ & $4.4 \times 10^{-16}$ & & & & \\
\hline & $\rightarrow 2 i-\mathrm{C}_{3} \mathrm{H}_{7} \mathrm{O}+\mathrm{O}_{2}$ & $5.6 \times 10^{-16}$ & & & & \\
\hline & overall & $1.0 \times 10^{-15}$ & \pm 0.3 & $1.6 \times 10^{-12} \exp (-2200 / T)$ & $300-400$ & \pm 300 \\
\hline \multirow[t]{4}{*}{151} & $\mathrm{CH}_{3} \mathrm{C}(\mathrm{O}) \mathrm{CH}_{2} \mathrm{O}_{2}+\mathrm{CH}_{3} \mathrm{C}(\mathrm{O}) \mathrm{CH}_{2} \mathrm{O}_{2}$ & & & & & \\
\hline & $\rightarrow \mathrm{CH}_{3} \mathrm{C}(\mathrm{O}) \mathrm{CH}_{2} \mathrm{OH}+\mathrm{CH}_{3} \mathrm{C}(\mathrm{O}) \mathrm{CHO}+\mathrm{O}_{2}$ & $2.0 \times 10^{-12}$ & & & & \\
\hline & $\rightarrow 2 \mathrm{CH}_{3} \mathrm{C}(\mathrm{O}) \mathrm{CH}_{2} \mathrm{O}+\mathrm{O}_{2}$ & $6.0 \times 10^{-12}$ & & & & \\
\hline & overall & $8.0 \times 10^{-12}$ & \pm 0.3 & & & \\
\hline \multirow[t]{12}{*}{152} & $\mathrm{RCHOO}+\mathrm{O}_{3} \rightarrow \mathrm{RCHO}+2 \mathrm{O}_{2}$ & & & & & \\
\hline & $\mathrm{RCHOO}+\mathrm{H}_{2} \mathrm{O} \rightarrow$ products & & & & & \\
\hline & $\mathrm{RCHOO}+\mathrm{CO} \rightarrow$ products & & & & & \\
\hline & $\mathrm{RCHOO}+\mathrm{HCHO} \rightarrow$ products & & & & & \\
\hline & $\mathrm{RCHOO}+\mathrm{C}_{2} \mathrm{H}_{4} \rightarrow$ products & No recommendations & & & & \\
\hline & $\mathrm{RCHOO}+\mathrm{NO} \rightarrow \mathrm{RCHO}+\mathrm{NO}_{2}$ & (see data sheet) & & & & \\
\hline & $\mathrm{RCHOO}+\mathrm{NO}_{2} \rightarrow \mathrm{RCHO}+\mathrm{NO}_{3}$ & & & & & \\
\hline & $\mathrm{RCHOO}+\mathrm{SO}_{2} \rightarrow$ products & & & & & \\
\hline & $\mathrm{RCHOO}+\mathrm{HC}(\mathrm{O}) \mathrm{OH} \rightarrow$ products & & & & & \\
\hline & $\mathrm{RCHOO}+\mathrm{CH}_{3} \mathrm{CHO} \rightarrow$ secondary ozonide & & & & & \\
\hline & $\mathrm{RCHOO} \rightarrow$ products & & & & & \\
\hline & $\mathrm{RRCOO} \rightarrow$ products & & & & & \\
\hline
\end{tabular}

\section{$\mathrm{O}_{3}$ Reactions - based on data sheets in Appendix AI}

$\begin{array}{ll}153 & \mathrm{O}_{3}+\text { alkene } \rightarrow \text { HO }+ \text { products } \\ 154 & \mathrm{O}_{3}+\mathrm{C}_{2} \mathrm{H}_{2} \rightarrow \text { products } \\ 155 & \mathrm{O}_{3}+\mathrm{C}_{2} \mathrm{H}_{4} \rightarrow \text { products } \\ 156 & \mathrm{O}_{3}+\mathrm{C}_{3} \mathrm{H}_{6} \rightarrow \text { products } \\ 157 & \mathrm{O}_{3}+\mathrm{CH}_{2}=\mathrm{C}\left(\mathrm{CH}_{3}\right) \mathrm{CH}=\mathrm{CH}_{2} \rightarrow \text { products } \\ 158 & \mathrm{O}_{3}+\alpha-\mathrm{Pinene} \rightarrow \text { products } \\ 159 & \mathrm{O}_{3}+\mathrm{CH}_{2}=\mathrm{C}\left(\mathrm{CH}_{3}\right) \mathrm{CHO} \rightarrow \text { products } \\ 160 & \mathrm{O}_{3}+\mathrm{CH}_{2}=\mathrm{CHC}(\mathrm{O}) \mathrm{CH}_{3} \rightarrow \text { products } \\ 161 & \mathrm{O}_{3}+3-\text { methylfuran } \rightarrow \text { products } \\ 162 & \mathrm{O}_{3}+\mathrm{CH}_{2}=\mathrm{C}\left(\mathrm{CH}_{3}\right) \mathrm{C}(\mathrm{O}) \text { OONO} \\ 163 & \mathrm{O}_{3}+\text { Pinonaldehyde } \rightarrow \text { products } \\ 164 & \mathrm{O}_{3}+\left(\mathrm{CH}_{3}\right)_{2} \mathrm{C}(\mathrm{OH}) \mathrm{CH}=\mathrm{CH}_{2} \rightarrow \text { products }\end{array}$

$\pm 1.0$

$\pm 0.1$

$\pm 0.1$

$\pm 0.1$

$\pm 0.2$

$\pm 0.2$

$\pm 0.2$

$\pm 0.3$

$\pm 0.3$

$\pm 0.2$

$\begin{array}{lll}9.1 \times 10^{-15} \exp (-2580 / T) & 180-360 & \pm 100 \\ 5.5 \times 10^{-15} \exp (-1880 / T) & 230-370 & \pm 200 \\ 1.03 \times 10^{-14} \exp (-1995 / T) & 240-360 & \pm 200 \\ 6.3 \times 10^{-16} \exp (-580 / T) & 270-370 & \pm 300 \\ 1.4 \times 10^{-15} \exp (-2100 / T) & 240-330 & \pm 300 \\ 8.5 \times 10^{-16} \exp (-1520 / T) & 240-330 & \pm 200\end{array}$

Halogen atom Reactions - based on data sheets in Appendix A7

\begin{tabular}{|c|c|c|c|c|c|c|c|}
\hline 165 & $\mathrm{~F}+\mathrm{CH}_{4} \rightarrow \mathrm{HF}+\mathrm{CH}_{3}$ & $6.3 \times 10^{-11}$ & & \pm 0.15 & $1.3 \times 10^{-10} \exp (-215 / T)$ & $180-410$ & \pm 200 \\
\hline 166 & $\mathrm{Cl}+\mathrm{CH}_{4} \rightarrow \mathrm{HCl}+\mathrm{CH}_{3}$ & $1.0 \times 10^{-13}$ & & \pm 0.06 & $6.6 \times 10^{-12} \exp (-1240 / T)$ & $200-300$ & \pm 200 \\
\hline \multirow[t]{2}{*}{167} & $\mathrm{Cl}+\mathrm{C}_{2} \mathrm{H}_{2}+\mathrm{M} \rightarrow \mathrm{C}_{2} \mathrm{H}_{2} \mathrm{Cl}+\mathrm{M}$ & $6.1 \times 10^{-30}\left[\mathrm{~N}_{2}\right]$ & $\left(k_{0}\right)$ & \pm 0.3 & $6.1 \times 10^{-30}(T / 300)^{-3}\left[\mathrm{~N}_{2}\right]$ & $200-300$ & $\Delta n= \pm 1$ \\
\hline & & $\begin{array}{l}2.0 \times 10^{-10} \\
F_{c}=0.6\end{array}$ & $\left(k_{\infty}\right)$ & \pm 0.3 & $2.0 \times 10^{-10}$ & $200-400$ & $\Delta n= \pm 1$ \\
\hline \multirow[t]{2}{*}{168} & $\mathrm{Cl}+\mathrm{C}_{2} \mathrm{H}_{4}+\mathrm{M} \rightarrow \mathrm{C}_{2} \mathrm{H}_{4} \mathrm{Cl}+\mathrm{M}$ & $1.85 \times 10^{-29}[$ air $]$ & $\left(k_{0}\right)$ & \pm 0.5 & $1.85 \times 10^{-29}(T / 300)^{-3.3}[$ air $]$ & $250-300$ & $\Delta n= \pm 1$ \\
\hline & & $\begin{array}{l}6 \times 10^{-10}[\text { air }] \\
F_{c}=0.4\end{array}$ & $\left(k_{\infty}\right)$ & \pm 0.3 & $6 \times 10^{-10}$ & $250-300$ & $\Delta n= \pm 1$ \\
\hline 169 & $\mathrm{Cl}+\mathrm{C}_{2} \mathrm{H}_{6} \rightarrow \mathrm{HCl}+\mathrm{C}_{2} \mathrm{H}_{5}$ & $5.9 \times 10^{-11}$ & & \pm 0.06 & $8.3 \times 10^{-11} \exp (-100 / T)$ & $220-600$ & \pm 100 \\
\hline \multirow[t]{2}{*}{170} & $\mathrm{Cl}+\mathrm{C}_{3} \mathrm{H}_{6}+\mathrm{M} \rightarrow \mathrm{C}_{3} \mathrm{H}_{6} \mathrm{Cl}+\mathrm{M}$ & $4.0 \times 10^{-28}\left[\mathrm{~N}_{2}\right]$ & $\left(k_{0}\right)$ & \pm 0.5 & & & \\
\hline & & $2.8 \times 10^{-10}$ & $\left(k_{\infty}\right)$ & \pm 0.3 & & & \\
\hline 171 & $\mathrm{Cl}+\mathrm{C}_{3} \mathrm{H}_{8} \rightarrow \mathrm{HCl}+\mathrm{C}_{3} \mathrm{H}_{7}$ & $1.4 \times 10^{-10}$ & & \pm 0.06 & $1.4 \times 10^{-10}$ & $200-700$ & \pm 100 \\
\hline 172 & $\mathrm{Cl}+n-\mathrm{C}_{4} \mathrm{H}_{10} \rightarrow \mathrm{HCl}+\mathrm{C}_{4} \mathrm{H}_{9}$ & $2.05 \times 10^{-10}$ & & \pm 0.06 & $2.05 \times 10^{-10}$ & $290-600$ & \pm 100 \\
\hline 173 & $\mathrm{Cl}+\mathrm{HCHO} \rightarrow \mathrm{HCl}+\mathrm{HCO}$ & $7.2 \times 10^{-11}$ & & \pm 0.06 & $8.1 \times 10^{-11} \exp (-34 / T)$ & $200-500$ & \pm 100 \\
\hline 174 & $\mathrm{Cl}+\mathrm{CH}_{3} \mathrm{CHO} \rightarrow \mathrm{HCl}+\mathrm{CH}_{3} \mathrm{CO}$ & $8.0 \times 10^{-11}$ & & \pm 0.07 & $8.0 \times 10^{-11}$ & $210-340$ & \pm 300 \\
\hline 175 & $\mathrm{Cl}+\mathrm{C}_{2} \mathrm{H}_{5} \mathrm{CHO} \rightarrow$ products & $1.3 \times 10^{-10}$ & & \pm 0.2 & & & \\
\hline 176 & $\mathrm{Cl}+\mathrm{CH}_{3} \mathrm{C}(\mathrm{O}) \mathrm{CH}_{3} \rightarrow \mathrm{HCl}+\mathrm{CH}_{3} \mathrm{C}(\mathrm{O}) \mathrm{CH}_{2}$ & $2.1 \times 10^{-12}$ & & \pm 0.15 & $3.2 \times 10^{-11} \exp (-815 / T)$ & $215-300$ & \pm 300 \\
\hline 177 & $\mathrm{Cl}+\mathrm{CH}_{3} \mathrm{C}(\mathrm{O}) \mathrm{C}_{2} \mathrm{H}_{5} \rightarrow$ products & $3.6 \times 10^{-11}$ & & \pm 0.15 & & & \\
\hline 178 & $\mathrm{Cl}+\mathrm{CH}_{3} \mathrm{OH} \rightarrow \mathrm{HCl}+\mathrm{CH}_{2} \mathrm{OH}$ & $5.5 \times 10^{-11}$ & & \pm 0.07 & $5.5 \times 10^{-11}$ & $200-500$ & \pm 200 \\
\hline 179 & $\mathrm{Cl}+\mathrm{C}_{2} \mathrm{H}_{5} \mathrm{OH} \rightarrow$ products & $1.0 \times 10^{-10}$ & & \pm 0.08 & $8.6 \times 10^{-11} \exp (45 / T)$ & $295-600$ & \pm 100 \\
\hline
\end{tabular}


R. Atkinson et al.: Evaluated kinetic and photochemical data for atmospheric chemistry

\begin{tabular}{|c|c|c|c|c|c|c|c|}
\hline $\begin{array}{l}\text { reaction } \\
\text { number }\end{array}$ & Reaction & $\begin{array}{l}k_{298} \\
\mathrm{~cm}^{3} \text { molecule }{ }^{-1} \mathrm{~s}^{-1}\end{array}$ & & $\Delta \log k_{298}^{a}$ & $\begin{array}{l}\text { Temp. dependence of } \\
k / \mathrm{cm}^{3} \text { molecule }^{-1} \mathrm{~s}^{-1}\end{array}$ & $\begin{array}{l}\text { Temp. } \\
\text { range/K }\end{array}$ & $\Delta(E / R) / \mathrm{K}^{c}$ \\
\hline 180 & $\mathrm{Cl}+n-\mathrm{C}_{3} \mathrm{H}_{7} \mathrm{OH} \rightarrow$ products & $1.6 \times 10^{-10}$ & & \pm 0.15 & $2.5 \times 10^{-10} \exp (-130 / T)$ & $270-350$ & \pm 100 \\
\hline 181 & $\mathrm{Cl}+i-\mathrm{C}_{3} \mathrm{H}_{7} \mathrm{OH} \rightarrow$ products & $8.6 \times 10^{-11}$ & & \pm 0.1 & & & \\
\hline 182 & $\mathrm{Cl}+\mathrm{CH}_{3} \mathrm{OOH} \rightarrow$ products & $5.9 \times 10^{-11}$ & & \pm 0.5 & & & \\
\hline 183 & $\mathrm{Cl}+\mathrm{HC}(\mathrm{O}) \mathrm{OH} \rightarrow$ products & $1.9 \times 10^{-13}$ & & \pm 0.15 & & & \\
\hline 184 & $\mathrm{Cl}+\mathrm{CH}_{3} \mathrm{C}(\mathrm{O}) \mathrm{OH} \rightarrow$ products & $2.65 \times 10^{-14}$ & & \pm 0.2 & & & \\
\hline 185 & $\mathrm{Cl}+\mathrm{CH}_{3} \mathrm{ONO}_{2} \rightarrow$ products & $2.4 \times 10^{-13}$ & & \pm 0.15 & & & \\
\hline 186 & $\mathrm{Cl}+\mathrm{C}_{2} \mathrm{H}_{5} \mathrm{ONO}_{2} \rightarrow$ products & $4.7 \times 10^{-12}$ & & \pm 0.2 & & & \\
\hline 187 & $\mathrm{Cl}+n-\mathrm{C}_{3} \mathrm{H}_{7} \mathrm{ONO}_{2} \rightarrow$ products & $2.2 \times 10^{-11}$ & & \pm 0.2 & & & \\
\hline 188 & $\mathrm{Cl}+i-\mathrm{C}_{3} \mathrm{H}_{7} \mathrm{ONO}_{2} \rightarrow$ products & $3.8 \times 10^{-12}$ & & \pm 0.3 & & & \\
\hline 189 & $\mathrm{Cl}+1-\mathrm{C}_{4} \mathrm{H}_{9} \mathrm{ONO}_{2} \rightarrow$ products & $8.5 \times 10^{-11}$ & & \pm 0.3 & & & \\
\hline 190 & $\mathrm{Cl}+\mathrm{CH}_{3} \mathrm{C}(\mathrm{O}) \mathrm{OONO}_{2} \rightarrow$ products & $<2 \times 10^{-14}$ & & & & & \\
\hline 191 & $\mathrm{Cl}+\mathrm{CH}_{3} \mathrm{CN} \rightarrow$ products & $1.2 \times 10^{-14}$ & & \pm 0.3 & $1.6 \times 10^{-11} \exp (-2140 / T)$ & $270-350$ & \pm 300 \\
\hline 192 & $\mathrm{Br}+\mathrm{C}_{2} \mathrm{H}_{2} \rightarrow$ products & $2.6 \times 10^{-14}$ & (1 bar air) & \pm 0.2 & $6.35 \times 10^{-15} \exp (440 / T)$ & $230-300$ & \pm 200 \\
\hline 193 & $\mathrm{Br}+\mathrm{C}_{2} \mathrm{H}_{4} \rightarrow$ products & $1.3 \times 10^{-13}$ & (1 bar air) & \pm 0.15 & $\begin{array}{l}2.80 \times 10^{-13} \exp (224 / T) \mathrm{B} / \\
\left(\mathrm{B}+8.5 \times 10^{12} \exp (-3200 / T)\right) \\
\mathrm{B}=7.5 \times 10^{-12}\left[\mathrm{O}_{2}\right] s^{-1}\end{array}$ & $240-300$ & \\
\hline 194 & $\mathrm{Br}+\mathrm{C}_{3} \mathrm{H}_{6} \rightarrow$ products & $3.6 \times 10^{-12}$ & (1 bar air) & \pm 0.2 & & & \\
\hline 195 & $\mathrm{Br}+\mathrm{HCHO} \rightarrow \mathrm{HBr}+\mathrm{HCO}$ & $1.1 \times 10^{-12}$ & & \pm 0.15 & $7.7 \times 10^{-12} \exp (-580 / T)$ & $220-300$ & \pm 200 \\
\hline 196 & $\mathrm{Br}+\mathrm{CH}_{3} \mathrm{CHO} \rightarrow \mathrm{HBr}+\mathrm{CH}_{3} \mathrm{CO}$ & $3.9 \times 10^{-12}$ & & \pm 0.2 & $1.8 \times 10^{-11} \exp (-460 / T)$ & $250-400$ & \pm 200 \\
\hline
\end{tabular}

Data for the following Photochemical Reactions are based on data sheets in Appendix A8

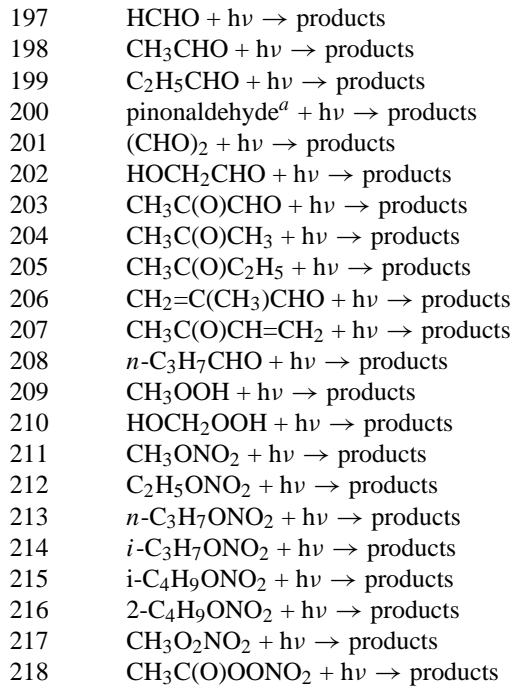

${ }^{a}$ The cited uncertainty is an expanded uncertainty corresponding approximately to a $95 \%$ confidence limit. 


\section{Guide to the data sheets}

The data sheets are principally of two types: (i) those for individual thermal reactions and (ii) those for the individual photochemical reactions.

\subsection{Thermal reactions}

The data sheets begin with a statement of the reactions including all pathways which are considered feasible. This is followed by the corresponding enthalpy changes at $298 \mathrm{~K}$, calculated from the enthalpies of formation summarized in the Thermodynamics Data summary.

The available kinetic data on the reactions are summarized under two headings: (i) Absolute Rate Coefficients, and (ii) Relative Rate Coefficients. Under these headings, we include new data which have been published since the last published IUPAC evaluation as well as the data used in deriving the preferred values. Under both of the headings above, the data are presented as absolute rate coefficients. If the temperature coefficient has been measured, the results are given in a temperature dependent form over a stated temperature range. For bimolecular reactions, the temperature dependence is usually expressed in the normal Arrhenius form, $k=A \exp (-B / T)$, where $B=E / R$. For a few bimolecular reactions, we have listed temperature dependences in the alternative form, $k=A^{\prime} T^{n}$ or $C T^{n} \exp (-D / T)$, where the original authors have found this to give a better fit to the data. For pressure dependent combination and dissociation reactions, the non-Arrhenius temperature dependence is used. This is discussed more fully in a subsequent section of this Introduction.

Single temperature data are presented as such and wherever possible the rate coefficient at, or close to, $298 \mathrm{~K}$ is quoted directly as measured by the original authors. This means that the listed rate coefficient at $298 \mathrm{~K}$ may differ slightly from that calculated from the Arrhenius parameters determined by the same authors. Rate coefficients at $298 \mathrm{~K}$ marked with an asterisk indicate that the value was calculated by extrapolation of a measured temperature range which did not include $298 \mathrm{~K}$. The tables of data are supplemented by a series of comments summarizing the experimental details. The following list of abbreviations, relating to experimental techniques, is used in the Techniques and Comments sections:
A - absorption
AS - absorption spectroscopy
CCD - charge coupled detector
CIMS - chemical ionization mass spectroscopy/spectrometric
$\mathrm{CL}$ - chemiluminescence
CRDS - cavity ring-down spectroscopy
DF - discharge flow
EPR - electron paramagnetic resonance
$\mathrm{F}$ - flow system
FP - flash photolysis

FTIR - Fourier transform infrared

FTS - Fourier transform spectroscopy

GC - gas chromatography/gas chromatographic

HPLC - high-performance liquid chromatography

IR - infrared

LIF - laser induced fluorescence

LMR - laser magnetic resonance

LP - laser photolysis

$\mathrm{MM}$ - molecular modulation

MS - mass spectrometry/mass spectrometric

$\mathrm{P}$ - steady state photolysis

PLP - pulsed laser photolysis

$\mathrm{PR}$ - pulse radiolysis

RA - resonance absorption

$\mathrm{RF}$ - resonance fluorescence

$\mathrm{RR}$ - relative rate

$\mathrm{S}-$ static system

TDLS - tunable diode laser spectroscopy

UV - ultraviolet

UVA - ultraviolet absorption

VUVA - vacuum ultraviolet absorption

For measurements of relative rate coefficients, wherever possible the comments contain the actual measured ratio of rate coefficients together with the rate coefficient of the reference reaction used to calculate the absolute rate coefficient listed in the data table. The absolute value of the rate coefficient given in the table may be different from that reported by the original author owing to a different choice of rate coefficient of the reference reaction. Whenever possible the reference rate data are those preferred in the present evaluation.

The preferred rate coefficients are presented (i) at a temperature of $298 \mathrm{~K}$ and (ii) in temperature dependent form over a stated temperature range. This is followed by a statement of the uncertainty limits in $\log k$ at $298 \mathrm{~K}$ and the uncertainty limits either in $(E / R)$ or in $n$, for the mean temperature in the range. Some comments on the assignment of uncertainties are given later in this introduction.

The "Comments on Preferred Values" describe how the selection was made and give any other relevant information. The extent of the comments depends upon the present state of our knowledge of the particular reaction in question. The data sheets are concluded with a list of the relevant references.

\subsection{Conventions concerning rate coefficients}

All of the reactions in the table are elementary processes. Thus the rate expression is derived from a statement of the reaction, e.g.

$\mathrm{A}+\mathrm{A} \rightarrow \mathrm{B}+\mathrm{C}$

$-\frac{1}{2} \frac{\mathrm{d}[\mathrm{A}]}{\mathrm{d} t}=\frac{\mathrm{d}[\mathrm{B}]}{\mathrm{d} t}=\frac{\mathrm{d}[\mathrm{C}]}{\mathrm{d} t}=k[\mathrm{~A}]^{2}$. 
Note that the stoichiometric coefficient for A, i.e. 2, appears in the denominator before the rate of change of $[\mathrm{A}]$ (which is equal to $2 k[\mathrm{~A}]^{2}$ ) and as a power on the right-hand side.

Representations of $k$ as a function of temperature characterize simple "direct" bimolecular reactions. Sometimes it is found that $k$ also depends on the pressure and the nature of the bath gas. This may be an indication of complex formation during the course of the bimolecular reaction, which is always the case in combination reactions. In the following sections the representations of $k$ which are adopted in these cases are explained.

\subsection{Treatment of combination and dissociation reactions}

Unlike simple bimolecular reactions such as those considered in Sect. 1.2, combination reactions

$\mathrm{A}+\mathrm{B}+\mathrm{M} \rightarrow \mathrm{AB}+\mathrm{M}$

and the reverse dissociation reactions

$\mathrm{AB}+\mathrm{M} \rightarrow \mathrm{A}+\mathrm{B}+\mathrm{M}$

are composed of sequences of different types of physical and chemical elementary processes. Their rate coefficients reflect the more complicated sequential mechanism and depend on the temperature, $T$, and the nature and concentration of the third body, $[\mathrm{M}]$. In this evaluation, the combination reactions are described by a formal second order rate law:

$\frac{\mathrm{d}[\mathrm{AB}]}{\mathrm{d} t}=k[\mathrm{~A}][\mathrm{B}]$

while dissociation reactions are described by a formal firstorder rate law:

$\frac{-\mathrm{d}[\mathrm{AB}]}{\mathrm{d} t}=k[\mathrm{AB}]$

In both cases, $k$ depends on the temperature and on [M].

In order to rationalize the representations of the rate coefficients used in this evaluation, we first consider the Lindemann-Hinshelwood reaction scheme. The combination reactions follow an elementary mechanism of the form,

$\mathrm{A}+\mathrm{B} \rightarrow \mathrm{AB}^{*}$

$\mathrm{AB}^{*} \rightarrow \mathrm{A}+\mathrm{B}$

$\mathrm{AB}^{*}+\mathrm{M} \rightarrow \mathrm{AB}+\mathrm{M}$

while the dissociation reactions are characterized by:

$$
\begin{aligned}
& \mathrm{AB}+\mathrm{M} \rightarrow \mathrm{AB}^{*}+\mathrm{M} \\
& \mathrm{AB}^{*}+\mathrm{M} \rightarrow \mathrm{AB}+\mathrm{M} \\
& \mathrm{AB}^{*} \rightarrow \mathrm{A}+\mathrm{B}
\end{aligned}
$$

Assuming quasi-stationary concentrations for the highly excited unstable species $\mathrm{AB}^{*}$ (i.e. that $\mathrm{d}\left[\mathrm{AB}^{*}\right] / \mathrm{d} t \sim 0$ ), it follows that the rate coefficient for the combination reaction is given by:

$k=k_{1}\left(\frac{k_{2}[\mathrm{M}]}{k_{-1}+k_{2}[\mathrm{M}]}\right)$

while that for the dissociation reaction is given by:

$k=k_{-2}[\mathrm{M}]\left(\frac{k_{-1}}{k_{-1}+k_{2}[\mathrm{M}]}\right)$

In these equations the expressions before the parentheses represent the rate coefficients of the process initiating the reaction, whereas the expressions within the parentheses denote the fraction of reaction events which, after initiation, complete the reaction to products.

In the low pressure limit $([\mathrm{M}] \rightarrow 0)$ the rate coefficients are proportional to $[\mathrm{M}]$; in the high pressure limit $([\mathrm{M}] \rightarrow \infty)$ they are independent of $[\mathrm{M}]$. It is useful to express $k$ in terms of the limiting low pressure and high pressure rate coefficients,

$$
\begin{array}{ccc}
k_{0}=\lim k([\mathrm{M}]) & \text { and, } & k_{\infty}=\lim k([\mathrm{M}]) \\
{[\mathrm{M}] \rightarrow 0} & {[\mathrm{M}] \rightarrow \infty}
\end{array}
$$

respectively. From this convention, the LindemannHinshelwood equation is obtained

$k=\frac{k_{o} k_{\infty}}{k_{o}+k_{\infty}}$

It follows that for combination reactions, $k_{0}=k_{1} k_{2}[\mathrm{M}] / k_{-1}$ and $k_{\infty}=k_{1}$, while for dissociation reactions, $k_{0}=k_{-2}[\mathrm{M}]$ and $k_{\infty}=k_{-1} k_{-2} / k_{2}$. Since detailed balancing applies, the ratio of the rate coefficients for combination and dissociation at a fixed $T$ and [M] is given by the equilibrium constant $K_{c}=k_{1} k_{2} / k_{-1} k_{-2}$.

Starting from the high-pressure limit, the rate coefficients fall-off with decreasing third body concentration $[\mathrm{M}]$ and the corresponding representation of $k$ as a function of [M] is termed the "falloff curve" of the reaction. In practice, the above Lindemann-Hinshelwood expressions do not suffice to characterize the falloff curves completely. Because of the multistep character of the collisional deactivation $\left(k_{2}[\mathrm{M}]\right)$ and activation $\left(k_{-2}[\mathrm{M}]\right)$ processes, and energy- and angular momentum-dependencies of the association $\left(k_{1}\right)$ and dissociation $\left(k_{-1}\right)$ steps, as well as other phenomena, the falloff expressions have to be modified. This can be done by including a broadening factor $F$ to the Lindemann-Hinshelwood expression (Troe, 1979):

$k=\frac{k_{o} k_{\infty}}{k_{o}+k_{\infty}} F=k_{o}\left(\frac{1}{1+\frac{k_{o}}{k_{\infty}}}\right) F=k_{\infty}\left(\frac{\frac{k_{o}}{k_{\infty}}}{1+\frac{k_{o}}{k_{\infty}}}\right) F$

The broadening factor $F$ depends on the ratio $k_{0} / k_{\infty}$, which is proportional to [M], and can be used as a measure of "reduced pressure". The first factors on the right-hand side rep- 
resent the Lindemann-Hinshelwood expression and the additional broadening factor $F$, at not too high temperatures, is approximately given by (Troe, 1979):

$\log F \cong \frac{\log F_{c}}{1+\left[\log \left(k_{0} / k_{\infty}\right) / N\right]^{2}}$

where $\log =\log _{10}$ and $N=\left[0.75-1.27 \log F_{c}\right]$. In this way the three quantities $k_{0}, k_{\infty}$, and $F_{c}$ characterise the falloff curve for the present application.

The given approximate expression for the broadening factor $F$ was obtained from statistical unimolecular rate theory in its simplest form (Troe, 1979). More rigorous representations require detailed information on the potential energy surfaces and on the collisional energy transfer step of the reaction. If this information is not available, one may assume typical behaviour and rely on the theoretical analysis given by Cobos and Troe (2003). For $T=200-300 \mathrm{~K}$ and the collider $\mathrm{M}=\mathrm{N}_{2}$ (with a collision efficiency $\beta_{c} \approx 0.3$ ), this treatment predicts $F_{c} \approx 0.49,0.44,0.39$, and 0.35 , if the reactants $\mathrm{A}$ and $\mathrm{B}$ in total have $r=3,4,5$, or 6 rotational degrees of freedom, respectively (e.g. for the reaction $\mathrm{HO}+\mathrm{NO}_{2}$, one would have $r=5$ and hence $F_{c} \approx 0.39$ ). It is also predicted that $F_{c}$, for the present applications, should be nearly temperature independent. Finally, more rigorous expressions for the broadening factors $F$ are given in Cobos and Troe (2003) which, in general do not differ from the above formula by more than about 10 percent. Since the special properties of each reaction system may lead to some deviations from the given values of $F_{c}$, these should only be used for a first orientation. Larger deviations of experimentally fitted $F_{c}$-values from the given "standard values", however, may be an indication for inadequate falloff extrapolations to $k_{0}$ and $k_{\infty}$. In this case, the apparent values for $F_{c}, k_{0}$, and $k_{\infty}$ obtained by fitting still can provide a satisfactory representation of the considered experimental data, in spite of the fact that inadequate values of $k_{0}$ and $k_{\infty}$ are obtained by extrapolation.

If a given falloff curve is fitted in different ways, changes in $F_{c}$ require changes in the limiting $k_{0}$ and $k_{\infty}$ values. For the purpose of this evaluation, this is irrelevant if the preferred $k_{0}$ and $k_{\infty}$ are used consistently together with the preferred $F_{c}$ values. If the selected $F_{c}$ value is too large, the values of $k_{0}$ and $k_{\infty}$ obtained by fitting the falloff expression to the experimental data are underestimated. If $F_{c}$ is too small, $k_{0}$ and $k_{\infty}$ are overestimated. However uncertainties in $F_{c}$ influence the fitted $k_{0}$ and $k_{\infty}$ in different ways. A simpler policy of fitting falloff was chosen by the NASA/JPL panel (Sander et al., 2003) in putting $F=0.6$ and $\mathrm{N}=1$. This generally leads to different values of the fitted $k_{0}$ and $k_{\infty}$ and their temperature dependencies than derived here, although experimental data over the range of atmospheric interest can generally be reproduced equally well. However the derived $k_{0}$ and $k_{\infty}$ may differ from the true limiting rate coefficients and thus should be interpreted by theory only with caution.

In the present evaluation, we generally follow the experimentally fitted values for $F_{c}, k_{0}$, and $k_{\infty}$, provided $F_{c}$ does not differ too much from the values given above. If large deviations are encountered, the experimental data are reevaluated using the $F_{c}$-values given above.

Besides the energy-transfer mechanism, i.e. Reactions (1), $(-1)$, and (2), a second mechanism appears to be relevant for some reactions considered here. This is the radical-complex (or chaperon) mechanism

$$
\begin{aligned}
& \mathrm{A}+\mathrm{M} \rightarrow \mathrm{AM} \\
& \mathrm{AM} \rightarrow \mathrm{A}+\mathrm{M} \\
& \mathrm{B}+\mathrm{AM} \rightarrow \mathrm{AB}+\mathrm{M}
\end{aligned}
$$

which, in the low pressure range, leads to

$k_{0}=\left(k_{3} / k_{-3}\right) k_{4}[\mathrm{M}]$.

For some tri- and tetra-atomic adducts $\mathrm{AB}$, this value of $k_{0}$ may exceed that from the energy-transfer mechanism and show stronger temperature dependencies. This mechanism may also influence high pressure experiments when $k_{0}$ from the radical-complex mechanism exceeds $\mathrm{k}_{\infty}$ from the energy-transfer mechanism (Oum et al., 2003). In this case falloff over wide pressure ranges cannot be represented by contributions from the energy-transfer mechanism alone, in particular when measurements at pressures above about 10 bar are taken into consideration.

The dependence of $k_{0}$ and $k_{\infty}$ on the temperature $T$ is represented in the form $k \propto T^{-n}$ except for cases with an established energy barrier in the potential. We have used this form of temperature dependence because it usually gives a better fit to the data over a wider range of temperature than does the Arrhenius expression. It should be emphasised that the chosen form of the temperature dependence is often only adequate over limited temperature ranges such as $200-300 \mathrm{~K}$. Obviously, the relevant values of $n$ are different for $k_{0}$ and $k_{\infty}$. In this evaluation, values of $k_{0}$ are given for selected examples of third bodies $\mathrm{M}$, and if possible for $\mathrm{M}=\mathrm{N}_{2}, \mathrm{O}_{2}$ or air.

\subsection{Treatment of complex-forming bimolecular reactions}

Bimolecular reactions may follow the "direct" pathway

$\mathrm{A}+\mathrm{B} \rightarrow \mathrm{C}+\mathrm{D}$

and/or involve complex formation,

$$
\begin{gathered}
\mathrm{A}+\mathrm{B} \Leftrightarrow \\
\mathrm{AB}^{*} \rightarrow \mathrm{C}+\mathrm{D} \\
\downarrow \mathrm{M} \\
\mathrm{AB}
\end{gathered}
$$

We designate the rate coefficients of the individual steps as in Sect. 1.3, above:

$$
\begin{aligned}
& \mathrm{A}+\mathrm{B} \rightarrow \mathrm{AB}^{*} \\
& \mathrm{AB}^{*} \rightarrow \mathrm{A}+\mathrm{B}
\end{aligned}
$$


$\mathrm{AB}^{*}+\mathrm{M} \rightarrow \mathrm{AB}+\mathrm{M}$

$\mathrm{AB}^{*} \rightarrow \mathrm{C}+\mathrm{D}$

Assuming quasi-stationary concentrations of $\mathrm{AB}^{*}$ (i.e. $\left.\mathrm{d}\left[\mathrm{AB}^{*}\right] / \mathrm{d} t \sim 0\right)$, a Lindemann-Hinshelwood type of analysis leads to,

$$
\begin{aligned}
& \frac{\mathrm{d}[\mathrm{AB}]}{\mathrm{d} t}=k_{S}[\mathrm{~A}][\mathrm{B}] \\
& \frac{\mathrm{d}[\mathrm{C}]}{\mathrm{d} t}=k_{D}[\mathrm{~A}][\mathrm{B}] \\
& \frac{\mathrm{d}[\mathrm{A}]}{\mathrm{d} t}=\left(k_{S}+k_{D}\right)[\mathrm{A}][\mathrm{B}]
\end{aligned}
$$

where

$k_{S}=k_{1}\left(\frac{k_{2}}{k_{-1}+k_{2}+k_{3}}\right)$

$k_{D}=k_{1}\left(\frac{k_{3}}{k_{-1}+k_{2}+k_{3}}\right)$

Note that since $k_{2}$ is proportional to [M], $k_{S}$ and $k_{D}$ are dependent on the nature and concentration of the third body $\mathrm{M}$, in addition to their temperature dependence. In reality, as for the combination and dissociation reactions, the given expressions for $k_{S}$ and $k_{D}$ have to be extended by suitable broadening factors $F$ in order to account for the multistep character of process (2) and the energy dependencies of processes (1), (-1) and (3). These broadening factors, however, differ from those for combination and dissociation reactions. For simplicity, they are ignored in this evaluation such that $k_{D}$ at high pressure approaches

$k_{D} \rightarrow k_{1} k_{3} / k_{2}$

which is inversely proportional to $[\mathrm{M}] . k_{D}$ may also be expressed by

$k_{D} \approx k_{D 0} k_{S} / k_{S 0}$

where $k_{D 0}$ and $k_{S 0}$ are the respective limiting low-pressure rate coefficients for the formation of $\mathrm{C}+\mathrm{D}$ or $\mathrm{A}+\mathrm{B}$ at the considered $[\mathrm{M}]$. When it is established that complex-formation is involved, this equation is used to characterize the increasing suppression of $\mathrm{C}+\mathrm{D}$ formation with increasing $[\mathrm{M}]$.

\subsection{Photochemical reactions}

The data sheets begin with a list of feasible primary photochemical transitions for wavelengths usually down to $170 \mathrm{~nm}$, along with the corresponding enthalpy changes at $0 \mathrm{~K}$ where possible or alternatively at $298 \mathrm{~K}$, calculated from the data in the Thermodynamic Data summary. Calculated threshold wavelengths corresponding to these enthalpy changes are also listed, bearing in mind that the values calculated from the enthalpy changes at $298 \mathrm{~K}$ are not true "threshold values".
This is followed by tables which summarise the available experimental data for: (i) absorption cross-sections and (ii) quantum yields. These data are supplemented by a series of comments.

The next table lists the preferred absorption cross-section data and the preferred quantum yields at appropriate wavelength intervals. For absorption cross-sections the intervals are usually $1 \mathrm{~nm}, 5 \mathrm{~nm}$ or $10 \mathrm{~nm}$. Any temperature dependence of the absorption cross-sections is also given where possible. The aim in presenting these preferred data is to provide a basis for calculating atmospheric photolysis rates. For absorption continua the temperature dependence is often represented by Sulzer-Wieland type expressions (Astholz et al., 1981). Alternately a simple empirical expression of the form: $\log _{10}\left(\sigma_{T 1} / \sigma_{T 2}\right)=\mathrm{B}\left(T_{1}-T_{2}\right)$ is used.

The comments again describe how the preferred data were selected and include other relevant points. The photochemical data sheets are also concluded with a list of references.

\subsection{Conventions concerning absorption cross-sections}

These are presented in the data sheets as "absorption crosssections per molecule, base e". They are defined according to the equations:

$\mathrm{I} / \mathrm{I}_{0}=\exp (-\sigma[\mathrm{N}] l)$

$\sigma=\{1 /([\mathrm{N}] l)\} \ln \left(\mathrm{I}_{0} / \mathrm{I}\right)$,

where $\mathrm{I}_{0}$ and $\mathrm{I}$ are the incident and transmitted light intensities, $\sigma$ is the absorption cross-section per molecule (expressed in this paper in units of $\mathrm{cm}^{2}$ ), [N] is the number concentration of absorber (expressed in molecule $\mathrm{cm}^{-3}$ ), and $l$ is the path length (expressed in $\mathrm{cm}$ ). Other definitions and units are frequently quoted. The closely related quantities "absorption coefficient" and "extinction coefficient" are often used, but care must be taken to avoid confusion in their definition. It is always necessary to know the units of concentration and of path length and the type of logarithm (base e or base 10) corresponding to the definition. To convert an absorption cross-section to the equivalent Naperian (base e) absorption coefficient (expressed in $\mathrm{cm}^{-1}$ ) of a gas at a pressure of one standard atmosphere and temperature of $273 \mathrm{~K}$, multiply the value of $\sigma$ in $\mathrm{cm}^{2}$ by $2.69 \times 10^{19}$.

\subsection{Assignment of uncertainties}

Under the heading "reliability," estimates have been made of the absolute accuracies of the preferred values of $k$ at $298 \mathrm{~K}$ and of the preferred values of $E / R$ over the quoted temperature range. The accuracy of the preferred rate coefficient at $298 \mathrm{~K}$ is quoted as the term $\Delta \log k$, where $\Delta \log k=D$ and $D$ is defined by the equation, $\log _{10} k=C \pm D$. This is equivalent to the statement that $k$ is uncertain to a factor of $F$, where $D=\log _{10} F$. The accuracy of the preferred value of 
$E / R$ is quoted as the term $\Delta(E / R)$, where $\Delta(E / R)=G$ and $G$ is defined by the equation $E / R=H \pm G$. $D$ and $G$ are expanded uncertainties corresponding approximately to a $95 \%$ confidence limit.

For second-order rate coefficients listed in this evaluation, an estimate of the uncertainty at any given temperature within the recommended temperature range may be obtained from the equation:

$$
\Delta \log k(T)=\Delta \log k(298 \mathrm{~K})+0.4343\{\Delta E / R(1 / T-1 / 298)\}
$$

The assignment of these absolute uncertainties in $k$ and $E / R$ is a subjective assessment of the evaluators. They are not determined by a rigorous, statistical analysis of the database, which is generally too limited to permit such an analysis. Rather, the uncertainties are based on a knowledge of the techniques, the difficulties of the experimental measurements, the potential for systematic errors, and the number of studies conducted and their agreement or lack thereof. Experience shows that for rate measurements of atomic and free radical reactions in the gas phase, the precision of the measurement, i.e. the reproducibility, is usually good. Thus, for single studies of a particular reaction involving one technique, standard deviations, or even $90 \%$ confidence limits, of $\pm 10 \%$ or less are frequently reported in the literature. Unfortunately, when evaluators come to compare data for the same reaction studied by more than one group of investigators and involving different techniques, the rate coefficients often differ by a factor of 2 or even more. This can only mean that one or more of the studies has involved large systematic uncertainty which is difficult to detect. This is hardly surprising since, unlike molecular reactions, it is not always possible to study atomic and free radical reactions in isolation, and consequently mechanistic and other difficulties frequently arise.

The arbitrary assignment of uncertainties made here is based mainly on our state of knowledge of a particular reaction which is dependent upon factors such as the number of independent investigations carried out and the number of different techniques used. On the whole, our assessment of uncertainty limits tends towards the cautious side. Thus, in the case where a rate coefficient has been measured by a single investigation using one particular technique and is unconfirmed by independent work, we suggest that minimum uncertainty limits of a factor of 2 are appropriate.

In contrast to the usual situation for the rate coefficients of thermal reactions, where intercomparison of results of a number of independent studies permits a realistic assessment of reliability, for many photochemical processes there is a scarcity of apparently reliable data. Thus, we do not feel justified at present in assigning uncertainty limits to the parameters reported for the photochemical reactions.

Acknowledgements. The Chairman and members of the Committee wish to express their appreciation to I.U.P.A.C. for the financial help which facilitated the preparation of this evaluation. We also acknowledge financial support from the following organisations: EU
Framework Program 6, ACCENT network of excellence; University of California Agricultural Experimental Station; the UK Natural Environmental Research Council; the Standard Reference Data Program (N.I.S.T); the Fonds National Suisse de la Recherche Scientifique (F.N.S.R.S.) and the Office Fédéral de l'Education et de la Science, and the Deutsche Forschungsgemeinschaft (SFB 357). We also thank B. Cox for preparing and editing the manuscript.

\section{References}

Astholz, D. C., Brouwer, L., and Troe, J.: High-Temperature Ultraviolet-Absorption Spectra of Polyatomic Molecules in Shock Waves, Ber. Bunsenges. Phys. Chem., 85, 559-564, 1981. Atkinson, R., Baulch, D. L., Cox, R. A., Hampson Jr., R. F., Kerr, J. A., and Troe, J.: Evaluated Kinetic and Photochemical Data for Atmospheric Chemistry: Supplement III, IUPAC Subcommittee on Gas Kinetic Data Evaluation for Atmospheric Chemistry, J. Phys. Chem. Ref. Data, 18, 881-1097, 1989.

Atkinson, R., Baulch, D. L., Cox, R. A., Hampson Jr., R. F., Kerr, J. A., and Troe, J.: Evaluated Kinetic and Photochemical Data for Atmospheric Chemistry: Supplement IV, IUPAC Subcommittee on Gas Kinetic Data Evaluation for Atmospheric Chemistry, J. Phys. Chem. Ref. Data, 21, 1125-1568, 1992.

Atkinson, R., Baulch, D. L., Cox, R. A., Hampson Jr., R. F., Kerr, J. A., Rossi, M. J., and Troe, J.: Evaluated Kinetic, Photochemical, and Heterogeneous Data for Atmospheric Chemistry: Supplement V, IUPAC Subcommittee on Gas Kinetic Data Evaluation for Atmospheric Chemistry, J. Phys. Chem. Ref. Data, 26, 5211011, 1997a.

Atkinson, R., Baulch, D. L., Cox, R. A., Hampson Jr., R. F., Kerr, J. A., Rossi, M. J., and Troe, J.: Evaluated Kinetic and Photochemical Data for Atmospheric Chemistry: Supplement VI, IUPAC Subcommittee on Gas Kinetic Data Evaluation for Atmospheric Chemistry, J. Phys. Chem. Ref. Data, 26, 1329-1499, 1997b.

Atkinson, R., Baulch, D. L., Cox, R. A., Hampson Jr., R. F., Kerr, J. A., Rossi, M. J., and Troe, J.: Evaluated Kinetic and Photochemical Data for Atmospheric Chemistry: Supplement VII, IUPAC Subcommittee on Gas Kinetic Data Evaluation for Atmospheric Chemistry, J. Phys. Chem. Ref. Data, 28, 191-393, 1999.

Atkinson, R., Baulch, D. L., Cox, R. A., Hampson Jr., R. F., Kerr, J. A., Rossi, M. J., and Troe, J.: Evaluated Kinetic and Photochemical Data for Atmospheric Chemistry, Supplement VIII, IUPAC Subcommittee on Gas Kinetic Data Evaluation for Atmospheric Chemistry, J. Phys. Chem. Ref. Data, 29, 167-266, 2000.

Baulch, D. L., Cox, R. A., Hampson Jr., R. F., Kerr, J. A., Troe, J., and Watson, R. T.: Evaluated Kinetic and Photochemical Data for Atmospheric Chemistry, CODATA Task Group on Chemical Kinetics, J. Phys. Chem. Ref. Data, 9, 295-471, 1980.

Baulch, D. L., Cox, R. A., Crutzen, P. J., Hampson Jr., R. F., Kerr, J. A., Troe, J., and Watson, R. T.: Evaluated Kinetic and Photochemical Data for Atmospheric Chemistry: Supplement I, CODATA Task Group on Chemical Kinetics, J. Phys. Chem. Ref. Data, 11, 327-496, 1982.

Baulch, D. L., Cox, R. A., Hampson Jr., R. F., Kerr, J. A., Troe, J., and Watson, R. T.: Evaluated Kinetic and Photochemical Data for Atmospheric Chemistry: Supplement II, CODATA Task Group on Gas Phase Chemical Kinetics, J. Phys. Chem. Ref. Data, 13, 1259-1380, 1984. 
Cobos, C. J. and Troe, J.: "Prediction of Reduced Falloff Curves for Recombination, Reactions at Low Temperatures", Z. Phys. Chem., 217, 1-14, 2003.

Oum, K., Sekiguchi, K., Luther, K., and Troe, J.: Observation of Unique Pressure Effects in the Combination Reaction of Benzyl Radicals in the Gas to Liquid Transition Region, Phys. Chem. Chem. Phys., 5, 2931-2933, 2003.

Sander, S. P., Friedl, R. R., Golden, D. M., Kurylo, M. J., Huie, R. E., Orkin, V. L., Moortgat, G. K., Ravishankara, A. R., Kolb, C. E., Molina, M. J., and Finlayson-Pitts, B. J.: "Chemical Kinetics and Photochemical Data for Use in Atmospheric Studies, NASA Panel for Data Evaluation, Evaluation Number 14, JPL Publication 02-25, 2003.

Troe, J.: Predictive Possibilities of Unimolecular Rate Theory, J. Phys. Chem., 83, 114-126, 1979.

\section{APPENDIX A1}

Data Sheets for $\mathrm{O}\left({ }^{3} \mathrm{P}\right)$ and $\mathrm{O}\left({ }^{1} \mathrm{D}\right)$ atom, and $\mathrm{O}_{3}$ reactions

APPENDIX A2

Data Sheets for $\mathrm{HO}$ and $\mathrm{HO}_{2}$ radical reactions

\section{APPENDIX A3}

Data Sheets for $\mathrm{NO}_{3}$ reactions

APPENDIX A4

Carbon radical reactions

APPENDIX A5

Data sheets for RO radical reactions

APPENDIX A6

Data Sheets for $\mathrm{RO}_{2}$ reactions

APPENDIX A7

Halogen atom reactions

APPENDIX A8

Photochemical reactions 
Appendix A1: $O_{x}+$ VOC reactions

\section{II.A1.1}

$$
\begin{aligned}
\mathrm{O}+\mathrm{CH}_{3} & \rightarrow \mathrm{HCHO}+\mathrm{H} \\
& \rightarrow \mathrm{HCO}+\mathrm{H}_{2} \\
& \rightarrow \mathrm{CO}+\mathrm{H}_{2}+\mathrm{H}
\end{aligned}
$$

$\Delta H^{\circ}(1)=-286.2 \mathrm{~kJ} \cdot \mathrm{mol}^{-1}$

$\Delta H^{\circ}(2)=-352.5 \mathrm{~kJ} \cdot \mathrm{mol}^{-1}$

$\Delta H^{\circ}(3)=-288.1 \mathrm{~kJ} \cdot \mathrm{mol}^{-1}$

Rate coefficient data $\left(k=k_{1}+k_{2}+k_{3}\right)$

\begin{tabular}{llll}
\hline$k / \mathrm{cm}^{3}$ molecule ${ }^{-1} \mathrm{~s}^{-1}$ & Temp./K & Reference & Technique/Comments \\
\hline $\begin{array}{l}\text { Absolute Rate Coefficients } \\
(1.2 \pm 0.17) \times 10^{-10}\end{array}$ & $1700-2300$ & Bhaskaran et al., 1979 & \\
$(1.14 \pm 0.29) \times 10^{-10}$ & 295 & Plumb and Ryan, 1982 & SH-RA (a) \\
$(1.4 \pm 0.3) \times 10^{-10}$ & $294-900$ & Slagle et al., 1987 & DF-MS (b) \\
$k_{1}=(1.1 \pm 0.4) \times 10^{-10}$ & 298 & Zellner et al., 1988 & F-MS (c) \\
$(1.3 \pm 0.2) \times 10^{-10}$ & 300 & Oser et al., 1991 & LP-LIF (d) \\
$(9.4 \pm 3.0) \times 10^{-11}$ & $\sim 298$ & Seakins and Leone, 1992 & DF-MS (e) \\
$(1.4 \pm 0.3) \times 10^{-10}$ & $1609-2002$ & Lim and Michael, 1993 & PLP-FTIR (f) \\
$(1.7 \pm 0.3) \times 10^{-10}$ & 299 & Fockenberg et al., 1999 & SH-RA (g) \\
& & & PLP-MS (h) \\
Branching Ratios & 300 & Niki et al., 1968 & \\
$k_{1} / k>0.85$ & 300 & Hoyermann and Sievert, 1979 & DF-MS (i) \\
$k_{2} / k \leq 0.2$ & 299 & Fockenberg et al., 1999 & F-MS (j) \\
$k_{1} / k=0.84 \pm 0.15$ & 299 & & PLP-MS (h) \\
$k_{3} / k=0.17 \pm 0.11$ & 296 & Preses et al., 2000 & PLP-IRA (k) \\
$k_{3} / k=0.18 \pm 0.04$ & & & \\
\hline
\end{tabular}

\section{Comments}

(a) Decomposition of $\mathrm{C}_{2} \mathrm{H}_{6}-\mathrm{O}_{2}$ mixtures in a shock tube. $k$ was derived from computer simulation of $[\mathrm{O}]$ and $[\mathrm{H}]$ profiles determined by RA.

(b) Discharge flow system with MS detection of $\mathrm{O}$ and $\mathrm{CH}_{3}, k$ was determined from the decay of $\left[\mathrm{CH}_{3}\right]$ with $[\mathrm{O}] \gg\left[\mathrm{CH}_{3}\right]$.

(c) Flow system with generation of $\mathrm{CH}_{3}$ radicals and $\mathrm{O}\left({ }^{3} \mathrm{P}\right)$ atoms from simultaneous in situ photolysis of $\mathrm{CH}_{3} \mathrm{C}(\mathrm{O}) \mathrm{CH}_{3}$ and $\mathrm{SO}_{2}$, and determination of $\left[\mathrm{CH}_{3}\right]$ and $[\mathrm{O}]$ by photoionization MS. Experiments were performed under conditions such that $[\mathrm{O}] /\left[\mathrm{CH}_{3}\right]>20$, and rate coefficients were determined from the decay of $\mathrm{CH}_{3}$ radicals. The rate coefficient $k$ was found to be independent of pressure over the range $1.3 \mathrm{mbar}$ to $15 \mathrm{mbar}$ (1 Torr to 11 Torr), and its value was confirmed by measurement of the rate of formation of $\mathrm{HCHO}$. $\mathrm{HCO}$ and $\mathrm{CH}_{2}$ were not detected as products but the analytical system could not detect $\mathrm{CO}$ or $\mathrm{H}_{2}$.

(d) Laser photolysis at $193 \mathrm{~nm}$ of flowing mixtures of $\mathrm{N}_{2}-\mathrm{N}_{2} \mathrm{O}-\left(\mathrm{CH}_{3}\right)_{2} \mathrm{~N}_{2} . k$ was determined from the rate of formation of $\mathrm{HCHO}$ (using LIF) with $[\mathrm{O}]>\left[\mathrm{CH}_{3}\right]$. Mass balance estimates indicated that channel (1) predominates.

(e) Discharge flow system with generation of $\mathrm{CH}_{3}$ from $\mathrm{F}+\mathrm{CH}_{4}$ in $\mathrm{He}-\mathrm{O}_{2}$ mixtures at pressures of 0.25 mbar to $1.0 \mathrm{mbar}$ (0.17 Torr to 0.78 Torr). $k$ was determined from the decay of $\left[\mathrm{CH}_{3}\right]$ by MS with $[\mathrm{O}] /\left[\mathrm{CH}_{3}\right]>10$.

(f) Obtained from the rate of formation of $\mathrm{HCHO}$ product by monitoring the $\mathrm{C}-\mathrm{H}$ stretch emission by FTIR spectroscopy. 
(g) Shock heating of $\mathrm{CH}_{3} \mathrm{Cl}$ in $\mathrm{Ar}$ coupled with laser photolysis of $\mathrm{SO}_{2} . k$ was determined from computer simulation of [O] profiles measured by RA.

(h) Pulsed laser photolysis at $193 \mathrm{~nm}$ of mixtures of $\mathrm{CH}_{3} \mathrm{C}(\mathrm{O}) \mathrm{CH}_{3}, \mathrm{CH}_{3} \mathrm{Br}$ and $\mathrm{SO}_{2}$ at 1.3 mbar pressure. Product analysis by time-of-flight mass spectrometry.

(i) DF-MS study of $\mathrm{O}+\mathrm{C}_{2} \mathrm{H}_{4}$ reaction in which $\mathrm{CH}_{3}$ is a product. $\mathrm{HCHO}$ assumed to arise from channel (1).

(j) Discharge flow system with $\mathrm{CH}_{3}$ being generated from $\mathrm{F}+\mathrm{CH}_{4}$ and $\mathrm{O}$ from a microwave discharge. Electron impact $\mathrm{MS}$ analysis of $\mathrm{HCO}$ and $\mathrm{HCHO}$. No evidence found for channel (2).

(k) Pulsed laser photolysis at $193 \mathrm{~nm}$ of mixtures of $\mathrm{CH}_{3} \mathrm{COCH}_{3}, \mathrm{SO}_{2}$, and Ar at 6.6 mbar pressure. Product analysis by tunable infrared diode laser absorption.

\section{Preferred Values}

$k=1.3 \times 10^{-10} \mathrm{~cm}^{3}$ molecule ${ }^{-1} \mathrm{~s}^{-1}$, independent of temperature over the range $290-900 \mathrm{~K}$.

$k_{1} / k=0.83$ at $298 \mathrm{~K}$.

$k_{3} / k=0.17$ at $298 \mathrm{~K}$.

\section{Reliability}

$\Delta \log k= \pm 0.1$ at $298 \mathrm{~K}$.

$\Delta(E / R)= \pm 100 \mathrm{~K}$.

$\Delta k_{1} / k= \pm 0.15$ at $298 \mathrm{~K}$.

$\Delta k_{3} / k= \pm 0.11$ at $298 \mathrm{~K}$.

\section{Comments on Preferred Values}

The recommended value of $k$ is the mean of the results of Plumb and Ryan (1982), Slagle et al. (1987), Zellner et al. (1988), Oser et al. (1991), Seakins and Leone (1992) and Fockenberg et al. (1999) which are in good agreement. The data of Bhaskaran et al. (1980) and Lim and Michael (1993) indicate that the rate coefficient is independent of temperature up to at least $2300 \mathrm{~K}$.

The preferred branching ratios are based on the studies of Fockenberg et al. (1999) and Preses et al. (2000). The values of the branching ratio $k_{3} / k$ reported in these studies, using completely different detection methods, are in excellent agreement. These results are consistent with earlier results reported in Niki et al. (1968), Hoyermann and Sievert (1979) and Seakins and Leone (1992). Seakins and Leone (1992) found CO to be a primary product, and they also estimated the overall branching ratio for CO formation to be $0.40 \pm 0.10$. Fockenberg et al. (1999) and Preses et al. (2000) suggest that the overall branching ratio for CO formation estimated in Seakins and Leone (1992) includes CO formed in an oxidation chain beginning with HCHO.

\section{References}

Bhaskaran, K. A., Franck, P., and Just, Th.: Proc. 12th Symp. on Shock Tubes and Waves, The Magnes Press, Jerusalem, 503, 1980.

Fockenberg, C., Hall, G. E., Preses, J. M., Sears, T. J., and Muckerman, J. T.: J. Phys. Chem. A, 103, $5722,1999$.

Hoyermann, K. and Sievert, R.: 17th Symp. (Int.) Combust., The Combustion Institute, Pittsburgh, $517,1979$.

Lim, K. P. and Michael, J. V.: J. Chem. Phys., 98, 3919, 1993.

Niki, H., Daby, E. E., and Weinstock, B.: J. Chem. Phys., 48, 5729, 1968.

Oser, H., Walter, D., Stothard, N. D., Grotheer, O., and Grotheer, H. H.: Chem. Phys. Lett., 181, $521,1991$.

Plumb, I. C. and Ryan, K. R.: Int. J. Chem. Kinet., 14, 861, 1982.

Preses, J. M., Fockenberg, C., and Flynn, G. W.: J. Phys. Chem. A, 104, 6758, 2000.

Seakins, P. W. and Leone, S. R.: J. Phys. Chem., 96, 4478, 1992.

Slagle, I. R., Sarzynski, D., and Gutman, D.: J. Phys. Chem., 91, 4375, 1987.

Zellner, R., Hartmann, D., Karthäuser, J., Rhäsa, D., and Weibring, G.: J. Chem. Soc. Faraday Trans., 2, 84, 549, 1988. 
II.A1.2

$$
\begin{aligned}
\mathrm{O}\left({ }^{1} \mathrm{D}\right)+\mathrm{CH}_{4} & \rightarrow \mathrm{HO}+\mathrm{CH}_{3} \\
& \rightarrow \mathrm{CH}_{3} \mathrm{O} \text { or } \mathrm{CH}_{2} \mathrm{OH}+\mathbf{H} \\
& \rightarrow \mathrm{HCHO}+\mathrm{H}_{2}
\end{aligned}
$$

$\Delta H^{\circ}(1)=-180.5 \mathrm{~kJ} \cdot \mathrm{mol}^{-1}$

$\Delta H^{\circ}(2)=-128.9$ or $-163.0 \mathrm{~kJ} \cdot \mathrm{mol}^{-1}$

\begin{tabular}{|c|c|c|c|}
\hline$k / \mathrm{cm}^{3}$ molecule $^{-1} \mathrm{~s}^{-1}$ & Temp./K & Reference & Technique/Comments \\
\hline \multicolumn{4}{|l|}{ Absolute Rate Coefficients } \\
\hline$(1.4 \pm 0.4) \times 10^{-10}$ & $200-350$ & Davidson et al., 1977 & PLP (a) \\
\hline$(1.57 \pm 0.13) \times 10^{-10}$ & 295 & Amimoto et al., 1979 & PLP-RA (b) \\
\hline \multicolumn{4}{|l|}{ Branching Ratios } \\
\hline$k_{1} / k=0.9$ & 295 & Lin and DeMore, 1973 & P-GC (c) \\
\hline$k_{3} / k=0.09$ & 295 & & \\
\hline$k_{1} / k=0.90 \pm 0.02$ & 298 & Jayanty et al., 1976 & P-GC (d) \\
\hline$k_{3} / k=0.11 \pm 0.02$ & 298 & & \\
\hline$k_{1} / k=0.8$ & 293 & Addison et al., 1979 & FP-AS (e) \\
\hline$k_{3} / k_{2}<0.25$ & - & Casavecchia et al., 1980 & (f) \\
\hline$k_{1} / k=0.75 \pm 0.08$ & - & Sataypal et al., 1989 & PLP-LIF (g) \\
\hline$k_{2} / k=0.25 \pm 0.08$ & - & & \\
\hline$k_{2} / k=0.15 \pm 0.03$ & - & Matsumi et al., 1993 & PLP-LIF \\
\hline$k_{1} / k=0.90_{-0.2}^{+0.1}$ & 298 & Hack and Thiesemann, 1995 & PLP-LIF \\
\hline$k_{2} / k=0.30 \pm 0.11$ & 298 & Brownsword et al., 1998 & PLP-LIF \\
\hline$k_{1} / k=0.71 \pm 0.05$ & 298 & Ausfelder et al., 2000 & PLP-LIF \\
\hline
\end{tabular}

$\Delta H^{\circ}(3)=-472.7 \mathrm{~kJ} \cdot \mathrm{mol}^{-1}$

Rate coefficient data $\left(k=k_{1}+k_{2}+k_{3}\right)$

\section{Comments}

(a) Pulsed laser photolysis of $\mathrm{O}_{2}$ at $266 \mathrm{~nm} . \mathrm{O}\left({ }^{1} \mathrm{D}\right)$ atoms were monitored by time-resolved emission from the transition $\mathrm{O}\left({ }^{1} \mathrm{D}\right) \rightarrow \mathrm{O}\left({ }^{3} \mathrm{P}\right)$ at $630 \mathrm{~nm}$.

(b) Pulsed laser photolysis at $248 \mathrm{~nm}$ of $\mathrm{O}_{3}-\mathrm{CH}_{4}-\mathrm{He}$ mixtures with time-resolved measurement of $\mathrm{O}\left({ }^{3} \mathrm{P}\right)$ atoms by resonance absorption.

(c) Photolysis of $\mathrm{N}_{2} \mathrm{O}-\mathrm{CH}_{4}$ mixtures at $184.9 \mathrm{~nm}$ with end-product analysis by GC.

(d) Photolysis of $\mathrm{N}_{2} \mathrm{O}-\mathrm{CH}_{4}-\mathrm{O}_{2}$ mixtures at $216 \mathrm{~nm}$ with measurement of $\mathrm{H}_{2}$ by GC.

(e) Flash photolysis of $\mathrm{O}_{3}$ at $200 \mathrm{~nm}$ to $300 \mathrm{~nm}$ with [OH] monitored by absorption at $308.15 \mathrm{~nm}$.

(f) Molecular beam study with MS detection of $\mathrm{CH}_{3} \mathrm{O}$ or $\mathrm{CH}_{2} \mathrm{OH}$. Experimental temperature not stated.

(g) Pulsed laser photolysis of $\mathrm{O}_{3}$ at $248.4 \mathrm{~nm}$ with LIF determination of [H]. Experimental temperature not stated.

\section{Preferred Values $\left(k=k_{1}+k_{2}+k_{3}\right)$}

$k=1.5 \times 10^{-10} \mathrm{~cm}^{3}$ molecule $\mathrm{e}^{-1} \mathrm{~s}^{-1}$ independent of temperature over the range $200-350 \mathrm{~K}$.

$k_{1} / k=0.70$ at $298 \mathrm{~K}$.

$k_{2} / k=0.23$ at $298 \mathrm{~K}$.

$k_{3} / k=0.05$ at $298 \mathrm{~K}$. 


\section{Reliability}

$\Delta \log k= \pm 0.10$ at $298 \mathrm{~K}$. $\Delta k_{1} / k= \pm 0.15$ at $298 \mathrm{~K}$. $\Delta k_{2} / k= \pm 0.07$ at $298 \mathrm{~K}$. $\Delta k_{3} / k= \pm 0.05$ at $298 \mathrm{~K}$. $\Delta(E / R)= \pm 100 \mathrm{~K}$.

\section{Comments on Preferred Values}

The preferred value of $k$ at $298 \mathrm{~K}$ is the mean of the results of Davidson et al. (1977) and Amimoto et al. (1979), and the temperature dependence is that from Davidson et al. (1977).

The preferred branching ratios are based on the critical review by Lee and co-workers (1999) of the results of Hack and Thiesemann (1995), Brownsword et al. (1998), Satayapal et al. (1989) and their own crossed-beam experiments (Casavecchia et al., 1980; Lin et al., 1998, 1999). Reaction channel (2) has been shown by Lee and co-workers (Lin et al., 1998, 1999, 2000) to produce mainly $\mathrm{CH}_{2} \mathrm{OH}+\mathrm{H}$, and the production of $\mathrm{CH}_{3} \mathrm{O}+\mathrm{H}$ is at most a minor channel. In addition, the experiments of Wine and Ravishankara (1982), Matsumi et al. (1993) and Takahashi et al. (1996) have shown that the yield of $\mathrm{O}\left({ }^{3} \mathrm{P}\right)$ atoms is small or zero. The $248 \mathrm{~nm}$ pulsed laser photolysis study of Aker et al. (1986), of $\mathrm{O}_{3}-\mathrm{CH}_{4}$ mixtures with low-pressure FTIR emission spectroscopy to monitor the $\mathrm{HO}^{*}$ product, has provided evidence that the partitioning of energy in the vibrationally excited $\mathrm{HO}$ radical (up to $n=4$, the maximum allowable based on the energetics of the reaction) is non-statistical.

A discussion of kinetic isotope effects in this reaction can be found in the publication of Saueressig et al. (2001) and references cited therein.

\section{References}

Addison, M. C., Donovan, R. J., and Garraway, J.: J. Chem. Soc. Faraday Disc., 67, 286, 1979.

Aker, P. M., O'Brien, J. J. A., and Sloan, J. J.: J. Chem. Phys., 84, 745, 1986.

Amimoto, S. T., Force, A. P., Gulotty, R. G., and Wiesenfeld, J. R.: J. Chem. Phys., 71, 3640, 1979.

Ausfelder, F., Hippler, H., and Striebel, F.: Zeitschr. Phys. Chem., 214, 403, 2000.

Brownsword, R. A., Hillenkamp, M., Schmiechen, P., Volpp, H.-R., and Upadhyaya, H. P.: J. Phys. Chem. A, 102, 4438, 1998.

Casavecchia, P., Buss, R. J., Sibener, S. J., and Lee, Y. T.: J. Chem. Phys., 73, 6351, 1980.

Davidson, J. A., Sadowski, C. M., Schiff, H. I., Streit, G. E., Howard, C. J., Jennings, D. A., and Schmeltekopf, A. L.: J. Chem. Phys., 64, 57, 1976.

Davidson, J. A., Schiff, H. I., Streit, G. E., McAfee, J. R., Schmeltekopf, A. L., and Howard, C. J.: J. Chem. Phys., 67, 5021, 1977.

Hack, W. and Thiesemann, H.: J. Phys. Chem., 99, 17 364, 1995.

Jayanty, R. K. M., Simonaitis, R., and Heicklen, J.: Int. J. Chem. Kinet., 8, 107, 1976.

Lin, C. L. and DeMore, W. B.: J. Phys. Chem., 77, 863, 1973.

Lin, J. J., Lee, Y. T., and Yang, X.: J. Chem. Phys., 109, 2975, 1998.

Lin, J. J., Harich, S., Lee, Y. T., and Yang, X.: J. Chem. Phys., 110, 10 821, 1999.

Lin, J. J., Shu, J., Lee, Y. T., and Yang, X.: J. Chem. Phys., 113, 5287, 2000.

Matsumi, Y., Tonokura, K., Inagaki, Y., and Kawasaki, M.: J. Phys. Chem., 97, 6816, 1993.

Saueressig, G., Crowley, J. N., Bergamaschi, P., Brühl, C., Brenninkmeijer, C. A. M., and Fischer, H.: J. Geophys. Res., 106, $23127,2001$.

Stayapal, S., Park, J., Bersohn, R., and Katz, B.: J. Chem. Phys., 91, 6873, 1989.

Takahashi, K., Wada, R., Matsumi, Y., and Kawasaki, M.: J. Phys. Chem., 100, 10 145, 1996.

Wine, P. H. and Ravishankara, A. R.: Chem. Phys., 69, 365, 1982. 


\section{$\mathrm{O}_{3}$ Reactions - Appendix A1}

\section{II.A1.153}

$$
\mathrm{O}_{3}+\mathrm{R}_{1} \mathbf{R}_{2} \mathrm{C}=\mathrm{CR} \mathbf{R}_{4} \rightarrow \mathrm{HO}+\text { products }
$$

\section{$\left(\mathrm{R}=\mathrm{H}\right.$ or $\left.\mathrm{CH}_{3}\right)$}

\section{Product yield data}

\begin{tabular}{|c|c|c|c|c|}
\hline Alkene & $\begin{array}{l}\text { Criegee } \\
\text { Intermediate(s) }\end{array}$ & $\begin{array}{l}\text { HO Yield ( } 1 \text { bar }) \\
\left(\Delta[\mathrm{HO}] / \Delta\left[\mathrm{R}_{1} \mathrm{R}_{2} \mathrm{C}=\mathrm{CR}_{3} \mathrm{R}_{4}\right]\right)\end{array}$ & Reference & $\begin{array}{l}\text { Technique } \\
\text { Comments }\end{array}$ \\
\hline Ethene & $\mathrm{CH}_{2} \mathrm{OO}$ & $0.18 \pm 0.06$ & Paulson et al., 1999a & Tracer (a) \\
\hline Ethene & $\mathrm{CH}_{2} \mathrm{OO}$ & $0.14 \pm 0.07$ & Rickard et al., 1999 & Tracer (b) \\
\hline Ethene & $\mathrm{CH}_{2} \mathrm{OO}$ & $0.20 \pm 0.02$ & Mihelcic et al., 1999 & MI-ESR (c) \\
\hline Ethene & $\mathrm{CH}_{2} \mathrm{OO}$ & (ca. 0.14) & Kroll et al., 2001a & $\begin{array}{l}\text { Low pressure LIF } \\
\text { see comment (d) }\end{array}$ \\
\hline Propene & $\begin{array}{l}\mathrm{CH}_{2} \mathrm{OO}, \\
\mathrm{CH}_{3} \mathrm{CHOO}\end{array}$ & $0.35 \pm 0.07$ & Paulson et al., 1999a & Tracer (a) \\
\hline Propene & $\begin{array}{l}\mathrm{CH}_{2} \mathrm{OO} \\
\mathrm{CH}_{3} \mathrm{CHOO}\end{array}$ & $0.32 \pm 0.08$ & Rickard et al., 1999 & Tracer (b) \\
\hline Propene & $\begin{array}{l}\mathrm{CH}_{2} \mathrm{OO}, \\
\mathrm{CH}_{3} \mathrm{CHOO}\end{array}$ & $0.34_{-0.06}^{+0.03}$ & $\begin{array}{l}\text { Neeb and Moorgat, } \\
1999\end{array}$ & $\begin{array}{l}\text { Kinetic/ } \\
\text { Scavenger (e) }\end{array}$ \\
\hline$Z$-2-butene & $\mathrm{CH}_{3} \mathrm{CHOO}$ & $0.33 \pm 0.07$ & McGill et al., 1999 & Tracer (b) \\
\hline$Z$-2-butene & $\mathrm{CH}_{3} \mathrm{CHOO}$ & $0.33 \pm 0.05$ & $\begin{array}{l}\text { Orzechowska and } \\
\text { Paulson, } 2002\end{array}$ & Tracer (a) \\
\hline$E$-2-butene & $\mathrm{CH}_{3} \mathrm{CHOO}$ & $0.61 \pm 0.28$ & Fenske et al., 2000 & Tracer (a) \\
\hline$E$-2-butene & $\mathrm{CH}_{3} \mathrm{CHOO}$ & $0.64 \pm 0.12$ & $\begin{array}{l}\text { Orzechowska and } \\
\text { Paulson, } 2002\end{array}$ & Tracer (a) \\
\hline$E$-2-butene & $\mathrm{CH}_{3} \mathrm{CHOO}$ & $0.54 \pm 0.11$ & McGill et al., 2000 & Tracer (b) \\
\hline$E$-2-butene & $\mathrm{CH}_{3} \mathrm{CHOO}$ & ca. 0.60 & Kroll et al., 2001a & $\begin{array}{l}\text { Low pressure LIF } \\
\text { see comment (d) }\end{array}$ \\
\hline$E$-2-butene & $\mathrm{CH}_{3} \mathrm{CHOO}$ & $0.75 \pm 0.19$ & Siese et al., 2001 & $\operatorname{LIF}(f)$ \\
\hline $\begin{array}{l}\text { 2-Methyl } \\
\text {-propene }\end{array}$ & $\begin{array}{l}\mathrm{CH}_{2} \mathrm{OO}, \\
\left(\mathrm{CH}_{3}\right)_{2} \mathrm{COO}\end{array}$ & $0.72 \pm 0.12$ & Paulson et al., 1999b & Tracer (a) \\
\hline 2-Methylpropene & $\begin{array}{l}\mathrm{CH}_{2} \mathrm{OO} \\
\left(\mathrm{CH}_{3}\right)_{2} \mathrm{COO}\end{array}$ & $0.60 \pm 0.15$ & Rickard et al., 1999 & Tracer (b) \\
\hline 2-Methylpropene & $\begin{array}{l}\mathrm{CH}_{2} \mathrm{OO} \\
\left(\mathrm{CH}_{3}\right)_{2} \mathrm{COO}\end{array}$ & $0.60_{-0.02}^{+0.05}$ & $\begin{array}{l}\text { Neeb and Moortgat, } \\
1999\end{array}$ & $\begin{array}{l}\text { Kinetic/ } \\
\text { Scavenger (e) }\end{array}$ \\
\hline$Z$-2-Pentene & $\begin{array}{l}\mathrm{CH}_{3} \mathrm{CHOO}, \\
\mathrm{CH}_{3} \mathrm{CH}_{2} \mathrm{CHOO}\end{array}$ & $0.29 \pm 0.06$ & $\begin{array}{l}\text { Orzechowska } \\
\text { and Paulson, } 2002\end{array}$ & Tracer (a) \\
\hline$Z$-2-Pentene & $\begin{array}{l}\mathrm{CH}_{3} \mathrm{CHOO}, \\
\mathrm{CH}_{3} \mathrm{CH}_{2} \mathrm{CHOO}\end{array}$ & $0.27 \pm 0.07$ & $\begin{array}{l}\text { Orzechowska } \\
\text { and Paulson, } 2002\end{array}$ & Scavenger (g) \\
\hline$E$-2-Pentene & $\begin{array}{l}\mathrm{CH}_{3} \mathrm{CHOO}, \\
\mathrm{CH}_{3} \mathrm{CH}_{2} \mathrm{CHOO}\end{array}$ & $0.46 \pm 0.08$ & $\begin{array}{l}\text { Orzechowska } \\
\text { and Paulson, } 2002\end{array}$ & Tracer (a) \\
\hline 2-Methyl-2-butene & $\begin{array}{l}\mathrm{CH}_{3} \mathrm{CHOO} \\
\left(\mathrm{CH}_{3}\right)_{2} \mathrm{COO}\end{array}$ & $0.93 \pm 0.14$ & $\begin{array}{l}\text { Chew and Atkinson, } \\
1996\end{array}$ & Scavenger (g) \\
\hline 2-Methyl-2-butene & $\begin{array}{l}\mathrm{CH}_{3} \mathrm{CHOO}, \\
\left(\mathrm{CH}_{3}\right)_{2} \mathrm{COO}\end{array}$ & $0.81 \pm 0.16$ & McGill et al., 1999 & Tracer (b) \\
\hline 2-Methyl-2-butene & $\begin{array}{l}\mathrm{CH}_{3} \mathrm{CHOO}, \\
\left(\mathrm{CH}_{3}\right)_{2} \mathrm{COO}\end{array}$ & (ca. 0.6) & Kroll et al., 2001a & $\begin{array}{l}\text { Low pressure LIF } \\
\text { see comment (d) }\end{array}$ \\
\hline 2-Methyl-2-butene & $\begin{array}{l}\mathrm{CH}_{3} \mathrm{CHOO}, \\
\left(\mathrm{CH}_{3}\right)_{2} \mathrm{COO}\end{array}$ & $0.89 \pm 0.22$ & Siese et al., 2001 & $\operatorname{LIF}(f)$ \\
\hline 2-Methyl-2-butene & $\begin{array}{l}\mathrm{CH}_{3} \mathrm{CHOO}, \\
\left(\mathrm{CH}_{3}\right)_{2} \mathrm{COO}\end{array}$ & $0.98 \pm 0.24$ & $\begin{array}{l}\text { Orzechowska } \\
\text { and Paulson, } 2002\end{array}$ & Tracer (a) \\
\hline 2-Methyl-2-butene & $\begin{array}{l}\mathrm{CH}_{3} \mathrm{CHOO}, \\
\left(\mathrm{CH}_{3}\right)_{2} \mathrm{COO}\end{array}$ & $0.80 \pm 0.12$ & $\begin{array}{l}\text { Orzechowska } \\
\text { and Paulson, } 2002\end{array}$ & Scavenger (a) \\
\hline $\begin{array}{l}\text { 2,3-Dimethyl-2 } \\
\text {-butene }\end{array}$ & $\left(\mathrm{CH}_{3}\right)_{2} \mathrm{COO}$ & $0.80 \pm 0.12$ & $\begin{array}{l}\text { Chew and Atkinson, } \\
1996\end{array}$ & Scavenger (g) \\
\hline
\end{tabular}




\begin{tabular}{|c|c|c|c|c|}
\hline Alkene & $\begin{array}{l}\text { Criegee } \\
\text { Intermediate(s) }\end{array}$ & $\begin{array}{l}\text { HO Yield (1 bar) } \\
(\Delta[\mathrm{HO}] / \Delta \\
\left.\left[\mathrm{R}_{1} \mathrm{R}_{2} \mathrm{C}=\mathrm{CR}_{3} \mathrm{R}_{4}\right]\right)\end{array}$ & Reference & $\begin{array}{l}\text { Technique } \\
\text { Comments }\end{array}$ \\
\hline 2,3-Dimethyl-2-butene & $\left(\mathrm{CH}_{3}\right)_{2} \mathrm{COO}$ & $0.89 \pm 0.22$ & $\begin{array}{l}\text { Rickard et al., } \\
1999\end{array}$ & Tracer (b) \\
\hline 2,3-Dimethyl-2-butene & $\left(\mathrm{CH}_{3}\right)_{2} \mathrm{COO}$ & (ca. 1.00) & Kroll et al., 2001 & $\begin{array}{l}\text { Low pressure LIF } \\
\text { see comment (d) }\end{array}$ \\
\hline 2,3-Dimethyl-2-butene & $\left(\mathrm{CH}_{3}\right)_{2} \mathrm{COO}$ & $1.00 \pm 0.25$ & Siese et al., 2001 & LIF (f) \\
\hline 2,3-Dimethyl-2-butene & $\left(\mathrm{CH}_{3}\right)_{2} \mathrm{COO}$ & $0.91 \pm 0.14$ & $\begin{array}{l}\text { Orzechowska } \\
\text { and Paulson, } 2002\end{array}$ & Scavenger (a) \\
\hline $\begin{array}{l}\text { Isoprene (2-methyl-1 } \\
\text {,3-butadiene ) }\end{array}$ & $\begin{array}{l}\mathrm{H}_{2} \mathrm{COO}, \\
\mathrm{H}_{2} \mathrm{C}=\mathrm{C}\left(\mathrm{CH}_{3}\right) \mathrm{CHOO}, \\
\mathrm{OOC}\left(\mathrm{CH}_{3}\right) \mathrm{CH}=\mathrm{CH}_{2}\end{array}$ & $0.25 \pm 0.06$ & $\begin{array}{l}\text { Paulson et al., } \\
1998\end{array}$ & Tracer (a) \\
\hline Isoprene (2-methyl-1 & $\mathrm{H}_{2} \mathrm{COO}$ & & Neeb and & Kinetic/ \\
\hline ,3-butadiene) & $\begin{array}{l}\mathrm{H}_{2} \mathrm{C}=\mathrm{C}\left(\mathrm{CH}_{3}\right) \mathrm{CHOO}, \\
\mathrm{OOC}\left(\mathrm{CH}_{3}\right) \mathrm{CH}=\mathrm{CH}_{2}\end{array}$ & $0.26_{-0.06}^{+0.03}$ & $\begin{array}{l}\text { Moortgat, } \\
1999\end{array}$ & Scavenger (e) \\
\hline $\begin{array}{l}\text { Isoprene (2-methyl-1 } \\
\text {,3-butadiene) }\end{array}$ & $\begin{array}{l}\mathrm{H}_{2} \mathrm{COO}, \\
\mathrm{H}_{2} \mathrm{C}=\mathrm{C}\left(\mathrm{CH}_{3}\right) \mathrm{CHOO}, \\
\mathrm{OOC}\left(\mathrm{CH}_{3}\right) \mathrm{CH}=\mathrm{CH}_{2}\end{array}$ & (ca. 0.25 ) & $\begin{array}{l}\text { Kroll et al., } \\
\text { 2001a }\end{array}$ & $\begin{array}{l}\text { Low pressure LIF } \\
\text { see comment (d) }\end{array}$ \\
\hline Methylvinyl ketone & $\begin{array}{l}\mathrm{H}_{2} \mathrm{COO}, \\
\mathrm{CH}_{3} \mathrm{C}(\mathrm{O}) \mathrm{CHOO}\end{array}$ & $0.16 \pm 0.08$ & $\begin{array}{l}\text { Aschmann et al., } \\
1996\end{array}$ & Scavenger (g) \\
\hline Methylvinyl ketone & $\begin{array}{l}\mathrm{H}_{2} \mathrm{COO}, \\
\mathrm{CH}_{3} \mathrm{C}(\mathrm{O}) \mathrm{CHOO}\end{array}$ & $0.16 \pm 0.05$ & $\begin{array}{l}\text { Paulson et al., } \\
1998\end{array}$ & Tracer (a) \\
\hline Methacrolein & $\begin{array}{l}\mathrm{H}_{2} \mathrm{COO}, \\
\mathrm{HC}(\mathrm{O}) \mathrm{C}\left(\mathrm{CH}_{3}\right) \mathrm{OO}\end{array}$ & $0.20_{-0.13}^{+0.10}$ & $\begin{array}{l}\text { Aschmann et al., } \\
1996\end{array}$ & Scavenger $(\mathrm{g})$ \\
\hline$\alpha$-Pinene & $\begin{array}{l}\mathrm{R}_{1} \mathrm{CHOO} \\
\mathrm{R}_{2} \mathrm{R}_{3} \mathrm{COO}\end{array}$ & $0.76 \pm 0.11$ & $\begin{array}{l}\text { Chew and } \\
\text { Atkinson, } 1996\end{array}$ & Scavenger $(\mathrm{g})$ \\
\hline$\alpha$-Pinene & $\begin{array}{l}\mathrm{R}_{1} \mathrm{CHOO}, \\
\mathrm{R}_{2} \mathrm{R}_{3} \mathrm{COO}\end{array}$ & $0.70 \pm 0.17$ & Paulson et al., 1998 & Tracer (a) \\
\hline$\alpha$-Pinene & $\begin{array}{l}\mathrm{R}_{1} \mathrm{CHOO}, \\
\mathrm{R}_{2} \mathrm{R}_{3} \mathrm{COO}\end{array}$ & 1.00 & Pfeiffer et al., 1998 & $\begin{array}{l}\text { Absorption } \\
\text { detection of } \mathrm{HO}(\mathrm{h})\end{array}$ \\
\hline$\alpha$-Pinene & $\begin{array}{l}\mathrm{R}_{1} \mathrm{CHOO} \\
\mathrm{R}_{2} \mathrm{R}_{3} \mathrm{COO}\end{array}$ & $0.83 \pm 0.21$ & Rickard et al., 1999 & Tracer (b) \\
\hline$\alpha$-Pinene & $\begin{array}{l}\mathrm{R}_{1} \mathrm{CHOO} \\
\mathrm{R}_{2} \mathrm{R}_{3} \mathrm{COO}\end{array}$ & $0.91 \pm 0.23$ & Siese et al., 2001 & $\operatorname{LIF}(f)$ \\
\hline$\beta$-Pinene & $\begin{array}{l}\mathrm{H}_{2} \mathrm{COO} \\
\mathrm{R}_{1} \mathrm{R}_{2} \mathrm{COO}\end{array}$ & $0.24 \pm 0.06$ & Rickard et al., 1999 & Tracer (b) \\
\hline Sabinene & $\begin{array}{l}\mathrm{H}_{2} \mathrm{COO} \\
\mathrm{R}_{1} \mathrm{R}_{2} \mathrm{COO}\end{array}$ & $0.33 \pm 0.06$ & $\begin{array}{l}\text { Chew and Atkinson, } \\
1996\end{array}$ & Scavenger (g) \\
\hline
\end{tabular}

\section{Comments}

(a) Small quantities of a tracer compound (1,3,5-trimethylbenzene, $m$-xylene and di- $n$-butyl ether), that react rapidly with $\mathrm{HO}$ and very slowly with ozone, were added to the ozone/alkene reaction mixture. HO yields were determined from the diminution in concentration of the added tracer.

(b) Similar study to comment (b) using 1,3,5-trimethylbenzene as an $\mathrm{HO}$ tracer compound.

(c) Matrix Isolation Electron Spin Resonance (MI-ESR) study in which $\mathrm{HO}_{2}$ was quantitatively detected. $\mathrm{HO}$ was converted to $\mathrm{HO}_{2}$ by reaction with $\mathrm{CO}$.

(d) Steady-state HO concentrations in a flow-tube were measured directly by laser induced fluorescence (LIF). The reported $\mathrm{HO}$ yields correspond to prompt $\mathrm{HO}$ production over short time-scales (within ca. $30 \mathrm{~ms}$ ) at total pressures of a few Torr. Although prompt HO yields were seen to decrease rapidly with increasing pressure, the HO yield for 2,3-dimethyl-2butene at atmospheric pressure was seen to approach the prompt, low-pressure yield over much longer time-scales. Thus although the reported yields are for prompt HO production, it is assumed that the long-time-scale yields of HO due to thermal decomposition of the carbonyl oxide are the same. 
(e) The rate of alkene consumption was observed under pseudo-first order conditions with an excess concentration of ozone. The decrease in observed rate in the presence of excess cyclohexane (to scavenge any HO formed) was used to derive HO formation yields.

(f) HO detected by LIF in the EUPHORE outdoor simulation chamber in Valencia. Time-dependent $\mathrm{HO}$ and $\mathrm{O}_{3}$ concentration data were numerically simulated to obtain $\mathrm{HO}$ yields.

(g) Ozonolysis reactions carried out in the presence of sufficient 2-butanol to scavenge $\geq 95 \%$ of all adventitiously formed HO. $\mathrm{HO}$ yields derived from the amount of 2-butanone formed. This method superseded earlier experiments in the laboratory of Atkinson and co-workers in which ozonolysis reactions were carried out in the presence of excess cyclohexane, and from which $\mathrm{HO}$ formation efficiencies were derived from measured yields of cyclohexanol and cyclohexanone (Atkinson et al., 1992; Atkinson and Aschmann, 1993). However, due to the complex peroxy radical chemistry giving rise to these observed products, an uncertainty of around a factor of 1.5 was estimated for the HO yields determined from these studies.

\section{Preferred Values}

\begin{tabular}{|c|c|c|c|}
\hline Alkene & $\begin{array}{l}k_{\text {ozone }+ \text { alkene }}(298 \mathrm{~K}) \\
/ \mathrm{cm}^{3} \text { molecule }{ }^{-1} \mathrm{~s}^{-1}\end{array}$ & Preferred HO Yield & References \\
\hline Ethene & $1.6 \times 10^{-18}$ & 0.16 & $\begin{array}{l}\text { Paulson et al., 1999a } \\
\text { Rickard et al., } 1999\end{array}$ \\
\hline Propene & $1.0 \times 10^{-17}$ & 0.34 & $\begin{array}{c}\text { Paulson et al., 1999a } \\
\text { Rickard et al., 1999 } \\
\text { Neeb and Moortgat, } 1999\end{array}$ \\
\hline$Z$-2-butene & $1.3 \times 10^{-16}$ & 0.33 & $\begin{array}{l}\text { McGill et al., } 1999 \\
\text { Orzechowska and Paulson, } 2002\end{array}$ \\
\hline$E$-2-butene & $1.9 \times 10^{-16}$ & 0.64 & $\begin{array}{c}\text { McGill et al., } 1999 \\
\text { Orzechowska and Paulson, } 2002 \\
\text { Fenske et al., } 2000 \\
\text { Siese et al., } 2001\end{array}$ \\
\hline 2-Methylpropene & $1.1 \times 10^{-17}$ & 0.62 & $\begin{array}{c}\text { Rickard et al., } 1999 \\
\text { Neeb and Moortgat, } 1999 \\
\text { Paulson et al., } 1999\end{array}$ \\
\hline 2-Methyl-2-butene & $4.1 \times 10^{-16}$ & 0.88 & $\begin{array}{c}\text { McGill et al., } 1999 \\
\text { Orzechowska and Paulson, } 2002 \\
\text { Siese et al., } 2001 \\
\text { Chew and Atkinson, } 1996\end{array}$ \\
\hline 2,3-Dimethyl-2-butene & $1.1 \times 10^{-15}$ & 0.90 & $\begin{array}{c}\text { Rickard et al., } 1999 \\
\text { Orzechowska and Paulson, } 2002 \\
\text { Siese et al., } 2001 \\
\text { Chew and Atkinson, } 1996\end{array}$ \\
\hline Isoprene & $1.27 \times 10^{-17}$ & 0.25 & $\begin{array}{l}\text { Neeb and Moortgat, } 1999 \\
\text { Paulson et al., } 1998\end{array}$ \\
\hline$\alpha$-Pinene & $9.0 \times 10^{-17}$ & 0.80 & $\begin{array}{c}\text { Rickard et al., } 1999 \\
\text { Siese et al., } 2001 \\
\text { Chew and Atkinson, } 1996 \\
\text { Paulson et al., } 1998\end{array}$ \\
\hline
\end{tabular}

$\Delta \log ($ yield $)=0.15$

${ }^{a}$ Rate coefficients taken from Atkinson (1997) 


\section{Comments on Preferred Values}

The currently accepted mechanism of HO production from ozone-alkene reactions involves the following steps:

$$
\begin{array}{ll}
\mathrm{O}_{3}+\mathrm{R}_{1} \mathrm{R}_{2} \mathrm{C}=\mathrm{R}_{3} \mathrm{R}_{4} & \rightarrow \mathrm{R}_{1} \mathrm{R}_{2} \mathrm{C}(\mathrm{OOO}) \mathrm{R}_{3} \mathrm{R}_{4} \text { (primary ozonide) } \\
\mathrm{R}_{1} \mathrm{R}_{2} \mathrm{C}(\mathrm{OOO}) \mathrm{R}_{3} \mathrm{R}_{4} & \rightarrow \mathrm{R}_{1} \mathrm{R}_{2} \mathrm{COO}+\mathrm{R}_{3} \mathrm{C}(\mathrm{O}) \mathrm{R}_{4} \\
\mathrm{R}_{1} \mathrm{R}_{2} \mathrm{C}(\mathrm{OOO}) \mathrm{R}_{3} \mathrm{R}_{4} & \rightarrow \mathrm{R}_{1} \mathrm{C}(\mathrm{O}) \mathrm{R}_{2}+\mathrm{R}_{3} \mathrm{R}_{4} \mathrm{COO} \\
\left.\mathrm{R}_{1} \mathrm{R}_{2} \mathrm{COO} \text { (and } \mathrm{R}_{3} \mathrm{R}_{4} \mathrm{COO}\right) & \rightarrow \mathrm{HO}+\text { products } \\
\left.\mathrm{R}_{1} \mathrm{R}_{2} \mathrm{COO} \text { (and } \mathrm{R}_{3} \mathrm{R}_{4} \mathrm{COO}\right) & \rightarrow \text { other products }
\end{array}
$$

Until recently it was generally accepted that $\mathrm{HO}$ radicals were produced as a decomposition product of vibrationally excited carbonyl oxide (Criegee) intermediates. In the case of methyl-substituted Criegee intermediates (methylcarbonyl oxide and dimethylcarbonyl oxide) the HO yield varies with the number of methyl-groups in a manner that is consistent with isomerisation of the Criegee intermediate to a hydroperoxide intermediate followed by decomposition and HO release (Rickard et al., 1999; Niki et al., 1987; Martinez and Herron, 1988, Kroll et al., 2001b). However, experimental studies by Kroll et al. (2001a) looked directly at the formation of HO by LIF over short-timescales, as a function of pressure. As the pressure was increased from a few Torr to around atmospheric pressure, the yields of prompt $\mathrm{HO}$ (i.e. that formed within $30 \mathrm{~ms}$ or so) were seen to decrease to essentially zero. It was concluded that the majority of HO production reported in previous experimental studies of ozone-alkene reactions was due to the thermal decomposition of stabilised Criegee intermediates. This assertion was supported by further LIF studies in which HO production in the ozonolysis of 2,3-dimethyl-2-butene, at one atmosphere of pressure, was seen to increase over significantly longer time-scales (Kroll et al., 2001b). A study by Johnson et al. (2001) looked at the HO production efficiency of the reaction of ozone with 2-methyl-2-butene in the presence of relatively high concentrations of scavenger species believed to react with Criegee intermediates. Under the conditions of these latter experiments (with concentrations of scavenger species in excess of those that would be encountered in the troposphere), no effect upon the yield of HO was observed. Thus, it is concluded that, the bimolecular reactions of stabilised Criegee intermediates produced in the ozonolysis of 2-methyl-2-butene (methylcarbonyl oxide and dimethylcarbonyl oxide) will not under atmospheric conditions compete with the formation of $\mathrm{HO}$ due to their thermal decomposition. It is further concluded that the $\mathrm{HO}$ yield measurements summarised above are applicable to the chemistry of the troposphere. The preferred HO yield data listed above are the average values of the measurements for each individual compound.

\section{References}

Aschmann, S. M., Arey, J., and Atkinson, R.: Atmos. Environ. 30, 2939, 1996.

Atkinson, R.: J. Phys. Chem. Ref. Data, 26, 215, 1997.

Atkinson, R. and Aschmann, S. M.: Environ. Sci. Technol., 27, 1357, 1993.

Atkinson, R., Aschmann, S. M., Arey, J., and Shorees, B.: J. Geophys. Res., 97, 6065, 1992.

Chew, A. A. and Atkinson, R.: J. Geophys. Res., 101, 28 649, 1996.

Fenske, J. D., Hasson, A. S., Paulson, S. E., Kuwata, K. T., Ho, A., and Houk, K. N.: J. Phys. Chem. A, 104, 7821, 2000.

Johnson, D., Lewin, A. G., and Marston, G.: J. Phys. Chem. A, 105, 2933, 2001.

Kroll, J. H., Hanisco, T. F., Donahue, N. M., Demerjian, K. L., and Anderson, J. G.: Geophys. Res. Lett., 28, 3863, $2001 \mathrm{a}$.

Kroll, J. H., Sahay, S. R., Anderson, J. G., Demerjian, K. L., and Donahue, N. M.: J. Phys. Chem. A, 105, 4446, $2001 b$.

Martinez, R. I., Huie, R. E., and Herron, J. T.: J. Phys. Chem., 75, 5975, 1981.

Martinez, R. I. and Herron, J. T.: J. Phys. Chem., 92, 4644, 1988.

McGill, D. D., Rickard, A. R., Johnson, D., and Marston, G.: Chemosphere, 38, 1205, 1999.

Mihelcic, D., Heitlinger, M., Kley, D., Mugsen, P., and Volz-Thomas, A.: Chem. Phys. Lett., 301, 559, 1999.

Neeb, P. and Moortgat, G. K.: J. Phys. Chem. A, 103, 9003, 1999.

Niki, H., Maker, P. D., Savage, C. M., Breitenbach, L. P., and Hurley, M. D.: J. Phys. Chem. 91, 941, 1987.

Orzechowska, G. E. and Paulson, S. E.: Atmos. Environ., 36, 571, 2002.

Paulson, S. E., Chung, M., Sen, A. D., and Orzechowska, G.: J. Geophys. Res.-Atmos, 103, 25 533, 1998.

Paulson, S. E., Fenske, J. D., Sen, A. D., and Callahan, T. W.: J. Phys. Chem. A, 103, 2050, 1999a.

Paulson, S. E., Chung, M. Y., and Hasson, A. S.: J. Phys. Chem. A, 103, 8125, 1999 b.

Pfeiffer, T., Forberich, O., and Comes, F. J.: Chem. Phys. Lett., 298, 351, 1998.

Rickard, A. R., Johnson, D., McGill, C. D., and Marston, G.: J. Phys. Chem. A, 103, 7656, 1999.

Siese, M., Becker, K. H., Brockmann, K. J., Geiger, H., Hofzumahaus, A., Holland, F., Mihelcic, D., and Wirtz, K.: Environ. Sci. Technol., 35, 4660, 2001. 
II.A1.154

$$
\mathbf{O}_{3}+\mathbf{C}_{2} \mathbf{H}_{2} \rightarrow \text { products }
$$

\section{Rate coefficient data}

\begin{tabular}{lllc}
\hline $\mathrm{k} / \mathrm{cm}^{3}$ molecule & & \\
\hline $\begin{array}{l}\text { Absolute Rate Coefficients } \\
(7.8 \pm 1.2) \times 10^{-21}\end{array}$ & Temp./K & Reference & Technique/Comments \\
\hline
\end{tabular}

\section{Comments}

(a) Static system, with $\left[\mathrm{O}_{3}\right]$ being monitored by chemiluminescence in large excess of $\mathrm{C}_{2} \mathrm{H}_{2}$ at a total pressure of 980 mbar.

\section{Preferred Values}

$k=1 \times 10^{-20} \mathrm{~cm}^{3}$ molecule ${ }^{-1} \mathrm{~s}^{-1}$ at $298 \mathrm{~K}$.

\section{Reliability}

$\Delta \log k= \pm 1.0$ at $298 \mathrm{~K}$.

\section{Comments on Preferred Values}

The literature data at room temperature (Atkinson and Aschmann, 1984; Cadle and Schadt, 1953; DeMore, 1969, 1971; Pate et al., 1976; Stedman and Niki, 1973) exhibit a large degree of scatter covering the range $k=(0.78-7.8) \times 10^{-20} \mathrm{~cm}^{3}$ molecule $\mathrm{e}^{-1} \mathrm{~s}^{-1}$ at $298 \mathrm{~K}$. The preferred value at $298 \mathrm{~K}$ is based upon the value obtained by Atkinson and Aschmann (1984). This is the most recent study; it gives the lowest of the values so far obtained and is likely to be the most accurate (any impurities are likely to lead to higher values).

There has been one study of the temperature dependence of the rate coefficient (DeMore, 1969) giving a value of $E / R=5435 \mathrm{~K}$ over the temperature range $243-283 \mathrm{~K}$. However, in view of the difficulties in studying this reaction and the small temperature range covered, no recommendation is made concerning the temperature dependence of this rate coefficient. A large uncertainty is assigned to the preferred value at $298 \mathrm{~K}$ to encompass the wide scatter in the results.

\section{References}

Atkinson, R. and Aschmann, S. M.: Int. J. Chem. Kinet. 16, 259, 1984.

Cadle, R. D. and Schadt, C.: J. Phys. Chem. 21, 163, 1953.

DeMore, W. B.: Int. J. Chem. Kinet. 1, 209, 1969.

DeMore, W. B.: Int. J. Chem. Kinet. 3, 161, 1971.

Pate, C. T., Atkinson, R. and Pitts Jr., J. N.: J. Environ. Sci. Health A11, 1, 1976.

Stedman, D. H. and Niki, H.: Environ. Lett. 4, 303, 1973. 
II.A1.155

$$
\mathbf{O}_{3}+\mathbf{C}_{2} \mathbf{H}_{4} \rightarrow \text { products }
$$

\section{Rate coefficient data}

\begin{tabular}{lllc}
\hline$k / \mathrm{cm}^{3}$ molecule ${ }^{-1} \mathrm{~s}^{-1}$ & Temp./K & Reference & Technique/Comments \\
\hline Absolute Rate Coefficients & & & \\
$3.3 \times 10^{-15} \exp [-(2365 \pm 101) / T]$ & $178-233$ & DeMore, 1969 & S-UVA (a) \\
$1.18 \times 10^{-18}$ & $298^{*}$ & & \\
$(1.55 \pm 0.15) \times 10^{-18}$ & 299 & Stedman et al., 1973 & S-CL (b) \\
$9.00 \times 10^{-15} \exp [-(2557 \pm 167) / T]$ & $235-362$ & Herron and Huie, 1974 & (c) \\
$1.69 \times 10^{-18}$ & 298 & & \\
$(1.9 \pm 0.1) \times 10^{-18}$ & 299 & Japar et al., 1974 & S-CL (b) \\
$(1.9 \pm 0.1) \times 10^{-18}$ & 299 & Japar et al., 1976 & S-CL (b) \\
$(1.69 \pm 0.13) \times 10^{-18}$ & 303 & Toby et al., 1976 & S-UVA (a) \\
$(1.43 \pm 0.19) \times 10^{-18}$ & 296 & Atkinson et al., 1982 & S-CL (b) \\
$7.72 \times 10^{-15} \exp [-(2557 \pm 30) / T]$ & $232-298$ & Bahta et al., 1984 & S-UVA (a) \\
$(1.45 \pm 0.10) \times 10^{-18}$ & 298 & & \\
$5.1 \times 10^{-15} \exp [-(2446 \pm 91) / T]$ & $240-324$ & Treacy et al., 1992 & S-CL (b) \\
$(1.37 \pm 0.08) \times 10^{-18}$ & 298 & & \\
\hline
\end{tabular}

\section{Comments}

(a) Static system, with UV absorption detection of $\mathrm{O}_{3}$ at $253.7 \mathrm{~nm}$.

(b) Static system with chemiluminescence detection of $\mathrm{O}_{3}$.

(c) Stopped flow system with MS detection of $\mathrm{O}_{3}$. Carried out at a total pressure of $\sim 5 \mathrm{mbar}$ but with sufficient $\mathrm{O}_{2}$ present to minimize the occurrence of secondary reactions removing $\mathrm{O}_{3}$.

\section{Preferred Values}

$k=1.6 \times 10^{-18} \mathrm{~cm}^{3}$ molecule ${ }^{-1} \mathrm{~s}^{-1}$ at $298 \mathrm{~K}$.

$k=9.1 \times 10^{-15} \exp (-2580 / T) \mathrm{cm}^{3}$ molecule $\mathrm{s}^{-1} \mathrm{~s}^{-1}$ over the temperature range 180-360 K.

\section{Reliability}

$\Delta \log k= \pm 0.10$ at $298 \mathrm{~K}$.

$\Delta(E / R)= \pm 100 \mathrm{~K}$.

\section{Comments on Preferred Values}

The temperature dependent kinetic studies of Bahta et al. (1984) and Treacy et al. (1992) are in good agreement. These two studies result in rate coefficients (Bahta et al., 1984; Treacy et al., 1992) which are somewhat lower than many of the previous determinations, including those of Su et al. (1980) and Kan et al. (1981) which are not used in this evaluation. Since Treacy et al. (1992) did not tabulate the individual rate coefficients at the various temperatures studied, only their $298 \mathrm{~K}$ value can be used in the evaluation of the rate coefficient for this reaction. The preferred values are obtained from a least-squares analysis of the rate coefficients of DeMore (1969), Stedman et al. (1973), Herron and Huie (1974), Japar et al. (1974, 1976), Toby et al. (1976), Atkinson et al. (1982), Bahta et al. (1984) (averaging the rate coefficients at each of the four temperatures studied) and the $298 \mathrm{~K}$ rate coefficient of Treacy et al. (1992).

As discussed by Atkinson (1997), the initial reaction forms the energy-rich 'primary ozonide' which rapidly decomposes (see Fig. 1a) to yield $\mathrm{HCHO}$ and the energy-rich Criegee intermediate $\left[\mathrm{CH}_{2} \mathrm{OO}\right]^{*}$. Grosjean and Grosjean (1996) and Grosjean et al. (1996) have measured a formation yield of $\mathrm{HCHO}$ of unity at atmospheric pressure of air. 
1.a)

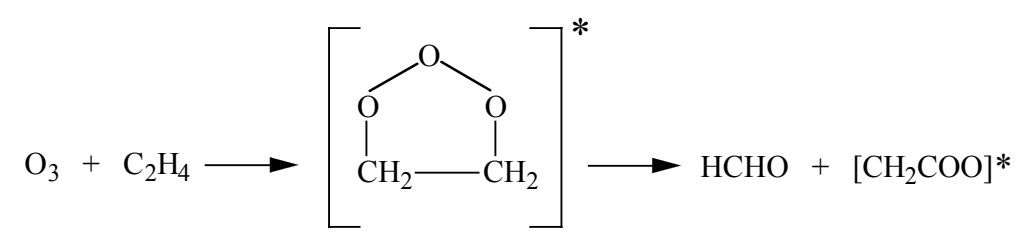

\section{(a)}

$$
\left[\mathrm{CH}_{2} \mathrm{OO}\right]^{*}+\mathrm{M} \longrightarrow \mathrm{CH}_{2} \mathrm{OO}+\mathrm{M}
$$

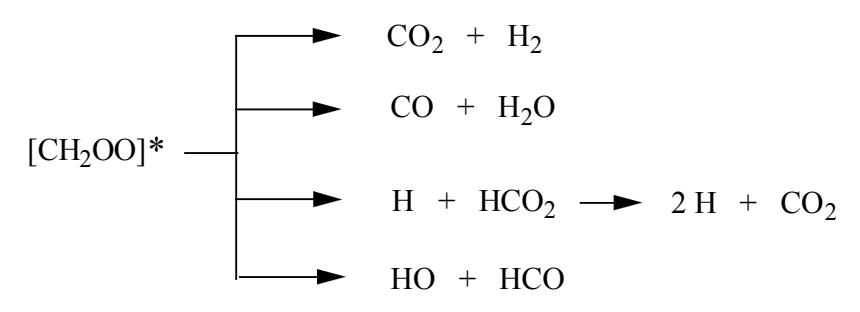

1.b)

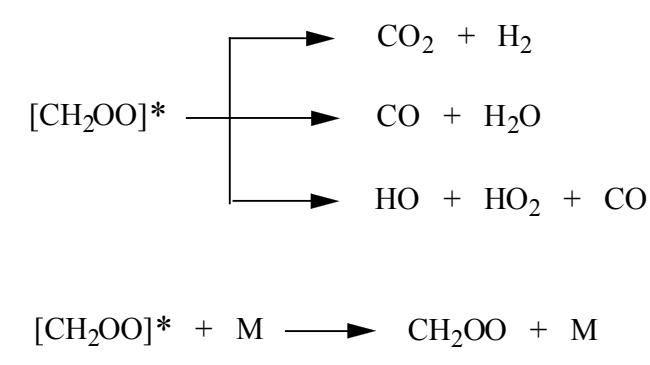

1.c)

Fig. 1. See text.

The energy-rich Criegee intermediate can either be stabilized or decompose, with the decomposition channels (b) through (e) having been postulated (see Fig. 1b).

There have been a number of determinations of the yield of the stabilized Criegee intermediate. The values obtained at room temperature and atmospheric pressure by $\mathrm{Su}$ et al. (1980) (35 $\pm 5 \%$ ), Kan et al. (1981) (37 $\pm 2 \%$ ), Niki et al. (1981) $(35 \pm 5 \%)$, Hatakeyama et al. (1984, 1986) (39.0 $\pm 5.3 \%)$ and Hasson et al. (2001) (39 $\pm 11 \%)$ are in good agreement (with an average yield of 37\%) and are preferred to the slightly higher value of $47 \%$ obtained by Horie and Moortgat (1991). The yield of stabilized Criegee intermediate appears to be pressure dependent although a significant fraction have been reported to be formed thermally "cold" at low pressures; by extrapolation of measurements over the range 13 mbar to 1.5 bar, Hatakeyama et al. (1986) found this fraction to be $20 \pm 3 \%$ at zero pressure.

The formation of $\mathrm{HO}$ radicals has been observed from the reaction of $\mathrm{O}_{3}$ with ethene at atmospheric pressure of air, with the measured HO radical yield being in the range 12-18\% (Atkinson et al., 1992; Paulson et al., 1999; Rickard et al., 1999) (see the data sheet in this article on the reactions of $\mathrm{O}_{3}+\mathrm{R}_{1} \mathrm{R}_{2} \mathrm{C}=\mathrm{CR}_{3} \mathrm{R}_{4} \rightarrow \mathrm{HO}+$ products). This observed formation of HO radicals (Atkinson et al., 1992; Paulson et al., 1999; Rickard et al., 1999), presumably via pathway (e), suggests that pathway (d) does not occur, since the low pressure study of Herron and Huie (1977) which invoked pathway (d) could not differentiate between formation of $\mathrm{H}$ atoms and $\mathrm{HO}$ radicals (any $\mathrm{H}$ atoms formed would rapidly react with $\mathrm{O}_{3}$ in the reaction system used by Herron and Huie (1977) to produce HO radicals). Hence a possible reaction sequence at atmospheric pressure of air is depicted in Fig. 1c. 
Under typical lower tropospheric conditions, the stabilized Criegee intermediate $\mathrm{CH}_{2} \mathrm{OO}$ is expected to react with water vapor to form hydroxymethyl hydroperoxide, $\mathrm{HOCH}_{2} \mathrm{OOH}$ (Neeb et al., 1996; Hasson et al., 2001),

$$
\mathrm{CH}_{2} \mathrm{OO}+\mathrm{H}_{2} \mathrm{O} \rightarrow \mathrm{HOCH}_{2} \mathrm{OOH}
$$

which may decompose on surfaces to formic acid plus water vapor (Neeb et al., 1996; Hasson et al., 2001).

\section{References}

Atkinson, R.: J. Phys. Chem. Ref. Data, 26, 215, 1997.

Atkinson, R., Aschmann, S. M., Arey, J., and Shorees, B.: J. Geophys. Res., 97, 6065, 1992.

Atkinson, R., Aschmann, S. M., Fitz, D. R., Winer, A. M., and Pitts Jr., J. N.: Int. J. Chem. Kinet., 14, $13,1982$.

Bahta, A., Simonaitis, R., and Heicklen, J.: Int. J. Chem. Kinet., 16, 1227, 1984.

DeMore, W. B.: Int. J. Chem. Kinet., 1, 209, 1969.

Grosjean, E. and Grosjean, D.: Environ. Sci. Technol., 30, 2036, 1996.

Grosjean, E., de Andrade, J. B., and Grosjean, D.: Eviron. Sci. Technol., 30, 975, 1996.

Hasson, A. S., Orzechowska, G., and Paulson, S. E.: J. Geophys. Res., 106, 34 131, 2001.

Hatakeyama, S., Kobayashi, H., and Akimoto, H.: J. Phys. Chem., 88, 4736, 1984.

Hatakeyama, S., Kobayashi, H., Lin, Z.-Y., Takagi, H., and Akimoto, H.: J. Phys. Chem., 90, 4131, 1986.

Herron, J. T. and Huie, R. E.: J. Phys. Chem., 78, $2085,1974$.

Herron, J. T. and Huie, R. E.: J. Am. Chem. Soc., 99, 5430, 1977.

Horie, O. and Moortgat, G. K.: Atmos. Environ., 25A, 1881, 1991.

Japar, S. M., Wu, C. H., and Niki, H.: J. Phys. Chem., 78, 2318, 1974.

Japar, S. M., Wu, C. H., and Niki, H.: J. Phys. Chem., 80, 2057, 1976.

Kan, C. S., Su, F., Calvert, J. G., and Shaw, J. H.: J. Phys. Chem., 85, 2359, 1981.

Neeb, P., Horie, O., and Moortgat, G. K.: Int. J. Chem. Kinet., 28, 721, 1996.

Niki, H., Maker, P. D., Savage, C. M., and Breitenbach, L. P.: J. Phys. Chem., 85, 1024, 1981.

Paulson, S. E., Fenske, J. D., Sen, A. D., and Callahan, T. W.: J. Phys. Chem. A, 103, 2050, 1999.

Rickard, A. R., Johnson, D., McGill, C. D., and Marston, G.: J. Phys. Chem. A 103, 7656, 1999.

Stedman, D. H., Wu, C. H., and Niki, H.: J. Phys. Chem., 77, 2511, 1973.

Su, F., Calvert, J. G., and Shaw, J. H.: J. Phys. Chem., 84, 239, 1980.

Toby, F. S., Toby, S., and O’Neal, H. E.: Int. J. Chem. Kinet., 8, 25, 1976.

Treacy, J., El Hag, M., O’Farrell, D., and Sidebottom, H.: Ber. Bunsenges. Phys. Chem., 96, 422, 1992. 
II.A1.156

$$
\mathbf{O}_{3}+\mathbf{C}_{3} \mathbf{H}_{6} \rightarrow \text { products }
$$

\section{Rate coefficient data}

\begin{tabular}{lllc}
\hline$k / \mathrm{cm}^{3}$ molecule $\mathrm{s}^{-1}$ & Temp./K & Reference & Technique/Comments \\
\hline Absolute Rate Coefficients & & & \\
$6.14 \times 10^{-15} \exp [-(1897 \pm 109) / T]$ & $235-362$ & Herron and Huie, 1974 & (a) \\
$1.06 \times 10^{-17}$ & 298 & & S-CL (b) \\
$4.9 \times 10^{-15} \exp [-(1858 \pm 70) / T]$ & $240-324$ & Treacy et al., 1992 & \\
$(9.4 \pm 0.4) \times 10^{-18}$ & 298 & & \\
\hline
\end{tabular}

\section{Comments}

(a) Stopped flow system, with MS detection of $\mathrm{O}_{3}$. Carried out at a total pressure of $\sim 5$ mbar, but with sufficient $\mathrm{O}_{2}$ present to minimize the occurrence of secondary reactions removing $\mathrm{O}_{3}$. Due to a typographical error, the lowest temperature studied was $235.0 \mathrm{~K}$ and not $250.0 \mathrm{~K}$ as originally stated (Herron and Huie, 1974).

(b) Static system, with chemiluminescence detection of $\mathrm{O}_{3} \cdot \mathrm{C}_{3} \mathrm{H}_{6}$ in large excess over $\mathrm{O}_{3}$.

\section{Preferred Values}

$k=1.0 \times 10^{-17} \mathrm{~cm}^{3}$ molecule ${ }^{-1} \mathrm{~s}^{-1}$ at $298 \mathrm{~K}$.

$k=5.5 \times 10^{-15} \exp (-1880 / T) \mathrm{cm}^{3}$ molecule $\mathrm{e}^{-1} \mathrm{~s}^{-1}$ over the temperature range $230-370 \mathrm{~K}$.

\section{Reliability}

$\Delta \log k= \pm 0.10$ at $298 \mathrm{~K}$.

$\Delta(E / R)= \pm 200 \mathrm{~K}$.

\section{Comments on Preferred Values}

The absolute rate coefficients of Herron and Huie (1974) (note that the lowest temperature studied was $235.0 \mathrm{~K}$ and not 250.0 K as given by Herron and Huie, 1974) and Treacy et al. (1992) are in excellent agreement for propene, 1-butene, cis- and trans-2-butene, 2-methylpropene and 2-methyl-2-butene over the temperature ranges common to both studies. Accordingly, the $298 \mathrm{~K}$ rate coefficients and temperature dependencies of Herron and Huie (1974) and Treacy et al. (1992) have been averaged to yield the preferred Arrhenius expression (note that the individual rate coefficients at the various temperatures studied by Treacy et al. (1992) were not tabulated).

The reaction proceeds via the initial formation of the 'primary ozonide' (Atkinson, 1997), which rapidly decomposes to two sets of 'primary' carbonyl plus Criegee intermediate (see Fig. 2a).

For 1-alkenes measured product yields suggest that the rate coefficient ratio $k_{b} /\left(k_{a}+k_{b}\right)$ is in the range $0.65-0.50$ at room temperature (Atkinson, 1997; Grosjean et al., 1996; Tuazon et al., 1997; Rickard et al., 1999). For propene, yields of $\mathrm{CH}_{3} \mathrm{CHO}$ have been measured in the presence of an HO radical scavenger (see below) by Grosjean et al. (1996) (0.520 \pm 0.026 at $55 \pm 10 \%$ relative humidity), Tuazon et al. (1997) $(0.446 \pm 0.092$ at $\sim 5 \%$ relative humidity) and Rickard et al. (1999) (0.34 \pm 0.01 in dry air). Higher yields of HCHO were obtained by Grosjean et al. (1996) and Tuazon et al. (1997), but these include any formation of $\mathrm{HCHO}$ from subsequent reactions of the $\left[\mathrm{CH}_{3} \mathrm{CHOO}\right]^{*}$ intermediates. The energy-rich Criegee intermediates are believed to be carbonyl oxides, and the Criegee intermediate $\left[\mathrm{CH}_{3} \mathrm{CHOO}\right]^{*}$ can exist in the anti- or syn-configuration (Fenske et al., 2000a) (see Fig. 2b).

It is assumed (in the absence of other information; Rickard et al., 1999) that the reactions of the energy-rich Criegee intermediate $\left[\mathrm{CH}_{2} \mathrm{OO}\right]^{*}$ formed from propene are similar to those for $\left[\mathrm{CH}_{2} \mathrm{OO}\right]^{*}$ formed from ethene. Hence, as for the $\mathrm{O}_{3}+\mathrm{C}_{2} \mathrm{H}_{4}$ reaction at room temperature and 1 bar of air, the reactions are as shown in Fig. 2c.

Less data are available concerning the stabilization and decomposition reactions of the $\left[\mathrm{CH}_{3} \mathrm{CHOO}\right]^{*}$ intermediate. Based upon the $\mathrm{SO}_{2}$ to $\mathrm{H}_{2} \mathrm{SO}_{4}$ conversion yield in an $\mathrm{O}_{3}$ + propene reaction system, Hatakeyama et al. (1984) determined an overall 


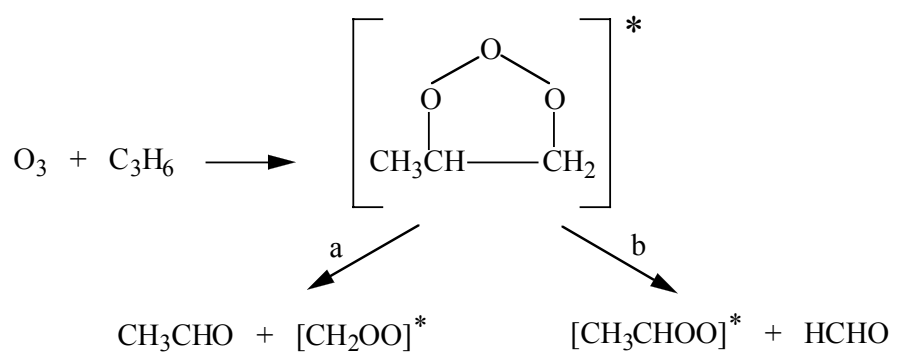

2.a)<smiles>CCOO</smiles>

anti-<smiles>CCOO</smiles>

syn-

2.b)

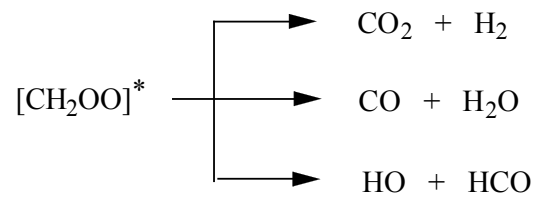

$$
\left[\mathrm{CH}_{2} \mathrm{OO}\right]^{*}+\mathrm{M} \longrightarrow \mathrm{CH}_{2} \mathrm{OO}+\mathrm{M}
$$

2.c)

Fig. 2. (a), (b) and (c) - see text.

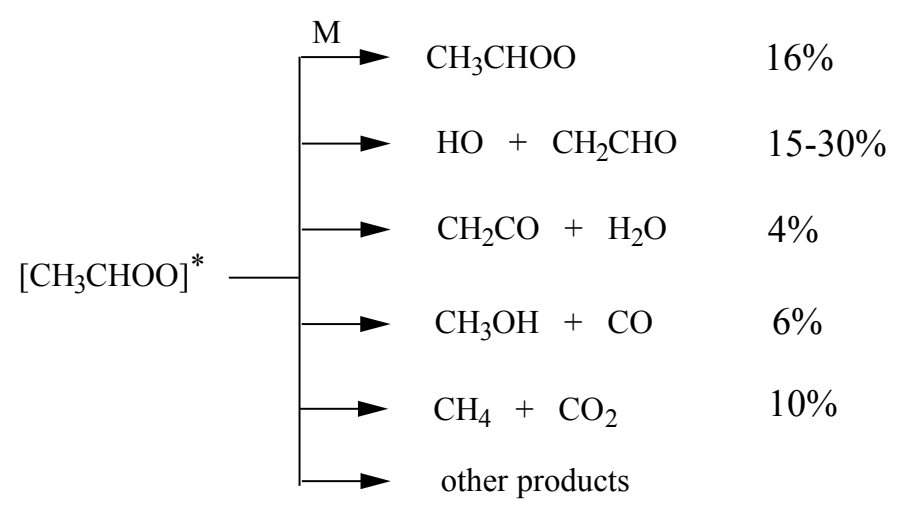

Fig. 3. See text. 
stabilized Criegee intermediate $\left[\mathrm{CH}_{2} \mathrm{OO}+\mathrm{CH}_{3} \mathrm{CHOO}\right]$ yield of $0.254 \pm 0.023$ at room temperature and atmospheric pressure, while Horie and Moortgat (1991) obtained a stabilized Criegee intermediate yield of 0.44. Rickard et al. (1999) measured

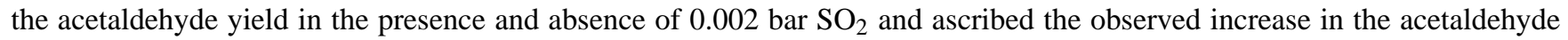
yield to the reaction $\mathrm{SO}_{2}+\mathrm{CH}_{3} \mathrm{CHOO} \rightarrow \mathrm{SO}_{3}+\mathrm{CH}_{3} \mathrm{CHO}$ (similar to the assumptions made by Hatakeyama et al., 1984) which corresponds to a yield of stabilized $\mathrm{CH}_{3} \mathrm{CHOO}$ of $0.12-0.16$ for rate coefficient ratios $k_{b} /\left(k_{a}+k_{b}\right)$ of $0.65-0.50$. For rate coefficient ratios $k_{b} /\left(k_{a}+k_{b}\right)$ of $0.65-0.50$ and asuming that the $\left[\mathrm{CH}_{2} \mathrm{OO}\right]^{*}$ stabilization yield is 0.37 , the data of Hatakeyama et al. (1984) lead to a fraction of the $\left[\mathrm{CH}_{3} \mathrm{CHOO}\right]^{*}$ intermediate which is stabilized at $\sim 298 \mathrm{~K}$ and 1 bar of air of $0.14-0.19$, reasonably consistent with the study of Rickard et al. (1999). While the stabilization/decomposition yields are expected to depend on the individual alkene reacting with $\mathrm{O}_{3}$ (and on the total pressure and temperature), this fraction of $\left[\mathrm{CH}_{3} \mathrm{CHOO}^{*}\right.$ biradicals which are stabilized at $298 \mathrm{~K}$ and 1 bar of air $(0.12-0.19)$ is similar to the measured yields of stabilized $\mathrm{CH}_{3} \mathrm{CHOO}$ from trans-2-butene of 0.185 (Hatakeyama et al., 1984) and 0.13 (Rickard et al., 1999) and from cis-2-butene of 0.18 (Niki et al., 1977) and 0.19 (Rickard et al., 1999). A yield of stabilized $\mathrm{CH}_{3} \mathrm{CHOO}$ from $\left[\mathrm{CH}_{3} \mathrm{CHOO}\right]^{*}$ of 0.16 at $298 \mathrm{~K}$ and 1 bar of air is recommended, with it being likely that this stabilized $\mathrm{CH}_{3} \mathrm{CHOO}$ intermediate is anti-C $\mathrm{CH}_{3} \mathrm{CHOO}$.

The $\left[\mathrm{CH}_{3} \mathrm{CHOO}\right]^{*}$ decomposition pathways include the formation of $\mathrm{HO}$ radicals through the 'hydroperoxide' channel (see the data sheet on the reactions of $\mathrm{O}_{3}+\mathrm{R}_{1} \mathrm{R}_{2} \mathrm{C}=\mathrm{CR}_{3} \mathrm{R}_{4} \rightarrow \mathrm{HO}+$ products).

$$
\left[\mathrm{CH}_{3} \mathrm{CHOO}\right] \rightarrow\left[\mathrm{CH}_{2}=\mathrm{CHOOH}\right] \rightarrow \mathrm{CH}_{2} \mathrm{CHO}+\mathrm{HO}
$$

and this reaction pathway is believed to occur for the initially energy-rich Criegee intermediate and possibly for the stabilized syn- $\mathrm{CH}_{3} \mathrm{CHOO}$ intermediate (Fenske et al., 2000a; Kroll et al., 2001). At atmospheric pressure, the measured HO radical formation yield is in the range 0.32-0.37 (Atkinson and Aschmann, 1993; Neeb and Moortgat, 1999; Paulson et al., 1999; Rickard et al., 1999; Fenske et al., 2000b). Other decomposition pathways include (Atkinson, 1997; Tuazon et al., 1997):

$$
\begin{array}{lll}
{\left[\mathrm{CH}_{3} \mathrm{CHOO}\right]^{*}} & \rightarrow \mathrm{CH}_{4}+\mathrm{CO}_{2} \\
{\left[\mathrm{CH}_{3} \mathrm{CHOO}\right]^{*}} & \rightarrow \mathrm{CH}_{3} \mathrm{OH}+\mathrm{CO} \\
{\left[\mathrm{CH}_{3} \mathrm{CHOO}\right]^{*}} & \rightarrow \mathrm{CH}_{2} \mathrm{CO}+\mathrm{H}_{2} \mathrm{O}
\end{array}
$$

with measured methane, methanol and ketene yields at atmospheric pressure (in the presence of an HO radical scavenger) of 0.096 \pm 0.010 (Tuazon et al., 1997), $0.055 \pm 0.007$ (Tuazon et al., 1997) and 0.036 \pm 0.008 (Tuazon et al., 1997), respectively. Considering that subsequent reaction of the vinoxy $\left(\mathrm{CH}_{2} \mathrm{CHO}\right)$ radical in air may lead to the formation of $\mathrm{HO}$ radicals (Atkinson, 1997), then a possible overall reaction sequence involves the initial formation of $35-40 \%\left(\left[\mathrm{CH}_{2} \mathrm{OO}\right]^{*}+\mathrm{CH}_{3} \mathrm{CHO}\right)$ and $65-60 \%\left(\left[\mathrm{CH}_{3} \mathrm{CHOO}\right]^{*}+\mathrm{HCHO}\right)$, followed by the reactions of the $\left[\mathrm{CH}_{2} \mathrm{OO}\right]^{*}$ intermediate shown above (leading to an $\mathrm{HO}$ radical yield, relative to the propene reacted, of $\sim 0.05$ ) and the following reactions of the $\left[\mathrm{CH}_{3} \mathrm{CHOO}\right]^{*}$ intermediate (the yields are given relative to the propene reacted, and that for the $\mathrm{HO}+\mathrm{CH}_{2} \mathrm{CHO}$ pathway depends on the amount of $\mathrm{HO}$ radicals formed from subsequent reactions of the vinoxy radical) (see Fig. 3).

Under lower tropospheric conditions, the stabilized Criegee intermediate $\mathrm{CH}_{3} \mathrm{CHOO}$ (expected to be in the anticonfiguration) is anticipated to react with water vapor to form the hydroxyhydroperoxide (Neeb et al., 1999; Sauer et al., 1999; Baker et al., 2002).

$$
\mathrm{CH}_{3} \mathrm{CHOO}+\mathrm{H}_{2} \mathrm{O} \rightarrow \mathrm{CH}_{3} \mathrm{CH}(\mathrm{OH}) \mathrm{OOH}
$$

This hydroxyhydroperoxide may decompose (possibly heterogeneously) to $\mathrm{CH}_{3} \mathrm{C}(\mathrm{O}) \mathrm{OH}+\mathrm{H}_{2} \mathrm{O}$ or to $\mathrm{CH}_{3} \mathrm{CHO}+\mathrm{H}_{2} \mathrm{O}_{2}$ (Neeb et al., 1999; Sauer et al., 1999).

\section{References}

Atkinson, R.: J. Phys. Chem. Ref. Data, 26, 215, 1997.

Atkinson, R. and Aschmann, S. M.: Environ. Sci. Technol., 27, 1357, 1993.

Baker, J., Aschmann, S. M., Arey, J., and Atkinson, R.: Int. J. Chem. Kinet., 34, 73, 2002.

Fenske, J. D., Hasson, A. S., Ho, A. W., and Paulson, S. E.: J. Phys. Chem. A, 104, 9921, 2000a.

Fenske, J. D., Hasson, A. S., Paulson, S. E., Kuwata, K. T., Ho, A., and Houk, K.N.: J. Phys. Chem. A, 104, 7821, 2000 b.

Grosjean, E., de Andrade, J. B., and Grosjean, D.: Eviron. Sci. Technol., 30, 975, 1996.

Hatakeyama, S., Kobayashi, H., and Akimoto, H.: J. Phys. Chem., 88, 4736, 1984.

Herron, J. T. and Huie, R. E.: J. Phys. Chem., 78, 2085, 1974.

Horie, O. and Moortgat, G. K.: Atmos. Environ., 25A, 1881, 1991.

Kroll, J. H., Sahay, S. R., Anderson, J. G., Demerjian, K. L., and Donahue, N. M.: J. Phys. Chem. A, 105, 4446, 2001. 
Neeb, P. and Moortgat, G. K.: J. Phys. Chem. A, 103, 9003, 1999.

Neeb, P., Horie, O., and Moortgat, G. K.: Int. J. Chem. Kinet., 28, 721, 1996.

Niki, H., Maker, P. D., Savage, C. M., and Breitenbach, L. P.: Chem. Phys. Lett., 46, 327, 1977.

Paulson, S. E., Fenske, J. D., Sen, A. D., and Callahan, T. W.: J. Phys. Chem. A, 103, 2050, 1999.

Rickard, A. R., Johnson, D., McGill, C. D., and Marston, G.: J. Phys. Chem. A, 103, 7656, 1999.

Sauer, R., Schäfer, C., Neeb, P., Horie, O., and Moortgat, G. K.: Atmos. Environ., 33, 229, 1999.

Treacy, J., El Hag, M., O’Farrell, D., and Sidebottom, H.: Ber. Bunsenges. Phys. Chem., 96, 422, 1992.

Tuazon, E. C., Aschmann, S. M., Arey, J., and Atkinson, R.: Environ. Sci. Technol., 31, 3004, 1997. 
II.A1.157

$$
\mathrm{O}_{3}+\mathrm{CH}_{2}=\mathrm{C}\left(\mathrm{CH}_{3}\right) \mathrm{CH}=\mathrm{CH}_{2} \rightarrow \text { products }
$$

\section{Rate coefficient data}

\begin{tabular}{lllc}
\hline$k / \mathrm{cm}^{3}$ molecule ${ }^{-1} \mathrm{~s}^{-1}$ & Temp./K & Reference & Technique/Comments \\
\hline Absolute Rate Coefficients & & & \\
$1.27 \times 10^{-17}$ & $295 \pm 1$ & Arnts and Gay, 1979 & S-CL/GC (a) \\
$7.0 \times 10^{-18}$ & $260 \pm 2$ & Adeniji et al., 1981 & S-CL \\
$1.65 \times 10^{-17}$ & $294 \pm 2$ & & \\
$1.1 \times 10^{-17}$ & 291 & Kamens et al., 1982 & (b) \\
$1.54 \times 10^{-14} \exp [-(2153 \pm 430) / T]$ & $278-323$ & Atkinson, et al., 1982 & S-CL \\
$(1.17 \pm 0.19) \times 10^{-17}$ & $296 \pm 2$ & & \\
$7.8 \times 10^{-15} \exp [-(1913 \pm 139) / T]$ & $242-323$ & Treacy et al., 1992 & S-UVA \\
$(1.28 \pm 0.12) \times 10^{-17}$ & 298 & & \\
$(8.95 \pm 0.25) \times 10^{-18}$ & $293 \pm 2$ & Grosjean et al., 1993 & S-UVA \\
$(1.13 \pm 0.32) \times 10^{-17}$ & $291 \pm 2$ & Grosjean and Grosjean, 1996 & S-UVA \\
& & & \\
Relative Rate Coefficients & & & \\
$(1.16 \pm 0.02) \times 10^{-17}$ & $296 \pm 2$ & Greene and Atkinson, 1992 & RR (c) \\
$9.21 \times 10^{-15} \exp [-(1955 \pm 42) / T]$ & $242-324$ & Khamaganov and Hites, 2001 & RR (d,e) \\
$(1.29 \pm 0.08) \times 10^{-17}$ & 298 & & \\
$1.62 \times 10^{-14} \exp [-(2078 \pm 120) / T]$ & $242-324$ & Khamaganov and Hites, 2001 & RR (d,f) \\
$(1.50 \pm 0.13) \times 10^{-17}$ & 298 & & \\
$1.24 \times 10^{-14} \exp [-(2050 \pm 87) / T]$ & $257-324$ & Khamaganov and Hites, 2001 & RR (d,g) \\
$(1.26 \pm 0.07) \times 10^{-17}$ & 298 & & \\
$9.45 \times 10^{-15} \exp [-(1963 \pm 72) / T]$ & $258-324$ & Khamaganov and Hites, 2001 & RR (d,h) \\
$(1.35 \pm 0.08) \times 10^{-17}$ & 298 & & \\
$1.36 \times 10^{-14} \exp [-(2015 \pm 149) / T]$ & $278-353$ & Avzianova and Ariya, 2002 & RR (i) \\
$(1.22 \pm 0.03) \times 10^{-17}$ & 298 & & \\
\hline
\end{tabular}

\section{Comments}

(a) Carried out in one atmosphere of air in 330 liter volume reaction chambers. The $\mathrm{O}_{3}$ and isoprene concentrations were measured by chemiluminescence and GC, respectively.

(b) Carried out at atmospheric pressure of air in a large outdoor chamber at night. $\mathrm{O}_{3}$ was introduced continually over a period of $1.4 \mathrm{~h}$ to an isoprene-air mixture. The isoprene and $\mathrm{O}_{3}$ concentrations were monitored by GC and chemiluminescence, respectively, and the rate coefficient obtained by fitting the measured isoprene and $\mathrm{O}_{3}$ concentrations to a computer model.

(c) Relative rate study, with $n$-octane being present to scavenge the $\mathrm{OH}$ radicals formed from the $\mathrm{O}_{3}$ reactions. The concentrations of isoprene and propene (the reference compound) were measured by GC. The measured rate coefficient ratio of $k\left(\mathrm{O}_{3}+\right.$ isoprene $) / k\left(\mathrm{O}_{3}+\right.$ propene $)=1.21 \pm 0.02$ is placed on an absolute basis by use of a rate coefficient of $k\left(\mathrm{O}_{3}\right.$ +propene $)=9.6 \times 10^{-18} \mathrm{~cm}^{3}$ molecule $\mathrm{s}^{-1} \mathrm{~s}^{-1}$ at $296 \mathrm{~K}$ (IUPAC, current recomendation).

(d) Relative rate method carried out at 760 Torr $\left(1.013\right.$ bar) of helium diluent in a $192 \mathrm{~cm}^{3}$ volume cylindrical quartz reactor, with ethanol or acetaldehyde being present to scavenge the $\mathrm{OH}$ radicals formed. The concentrations of isoprene and the reference compound were monitored by MS.

(e) With 2-methylpropene as the reference compound. The measured rate coefficient ratios $k\left(\mathrm{O}_{3}+\mathrm{isoprene}\right) / k\left(\mathrm{O}_{3}+2-\right.$ methylpropene $)$ are placed on an absolute basis by use of a rate coefficient of $k\left(\mathrm{O}_{3}+2\right.$-methylpropene $)=2.70 \times 10^{-15}$ $\exp (-1632 / T) \mathrm{cm}^{3}$ molecule ${ }^{-1} \mathrm{~s}^{-1}$ (Atkinson, 1997). 
(f) With cis-2-butene as the reference compound. The measured rate coefficient ratios $k\left(\mathrm{O}_{3}+\right.$ isoprene $) / k\left(\mathrm{O}_{3}+c i s\right.$-2-butene $)$ are placed on an absolute basis by use of a rate coefficient of $k\left(\mathrm{O}_{3}+\right.$ cis-2-butene $)=3.22 \times 10^{-15} \exp (-968 / T) \mathrm{cm}^{3}$ molecule $\mathrm{e}^{-1} \mathrm{~s}^{-1}$ (Atkinson, 1997).

(g) With 1-butene as the reference compound. The measured rate coefficient ratios $k\left(\mathrm{O}_{3}+\right.$ isoprene $) / k\left(\mathrm{O}_{3}+1\right.$-butene $)$ are placed on an absolute basis by use of a rate coefficient of $k\left(\mathrm{O}_{3}+1\right.$-butene $)=3.36 \times 10^{-15} \exp (-1744 / T) \mathrm{cm}^{3}$ molecule $^{-1}$ $\mathrm{s}^{-1}$ (Atkinson, 1997).

(h) With 2,3-dimethyl-1,3-butadiene as the reference compound. The measured rate coefficient ratios $k\left(\mathrm{O}_{3}+\right.$ isoprene $) / k\left(\mathrm{O}_{3}+2,3\right.$-dimethyl-1,3-butadiene $)$ are placed on an absolute basis by use of a rate coefficient of $k\left(\mathrm{O}_{3}+2,3\right.$-dimethyl-1,3-butadiene) $=6.9 \times 10^{-15} \exp (-1668 / T) \mathrm{cm}^{3}$ molecule $^{-1} \mathrm{~s}^{-1}$ (Atkinson, 1997).

(i) Relative rate method carried out at 760 Torr (1.013 bar) of air diluent in a 3 liter volume Pyrex reactor, with 1,3,5trimethylbenzene being present to scavenge the $\mathrm{OH}$ radicals formed. The concentrations of isoprene and propene (the reference compound) were monitored by GC. The measured rate coefficient ratios $k\left(\mathrm{O}_{3}+\right.$ isoprene $) / k\left(\mathrm{O}_{3}+\right.$ propene $)$ are placed on an absolute basis by use of a rate coefficient of $k\left(\mathrm{O}_{3}\right.$ +propene $)=5.5 \times 10^{-15} \exp (-1880 / T) \mathrm{cm}^{3}$ molecule $^{-1}$ $\mathrm{s}^{-1}$ (IUPAC, current recomendation). Note that the $298 \mathrm{~K}$ rate coefficient calculated from the Arrhenius expression is $1.57 \times 10^{-17} \mathrm{~cm}^{3}$ molecule $\mathrm{e}^{-1} \mathrm{~s}^{-1}, 29 \%$ higher than the measured value (see table).

\section{Preferred Values}

$k=1.27 \times 10^{-17} \mathrm{~cm}^{3}$ molecule $\mathrm{e}^{-1} \mathrm{~s}^{-1}$ at $298 \mathrm{~K}$.

$k=1.03 \times 10^{-14} \exp (-1995 / T) \mathrm{cm}^{3}$ molecule $\mathrm{e}^{-1} \mathrm{~s}^{-1}$ over the temperature range $240-360 \mathrm{~K}$.

\section{Reliability}

$\Delta \log k= \pm 0.10$ at $298 \mathrm{~K}$.

$\Delta(E / R)= \pm 200 \mathrm{~K}$.

\section{Comments on Preferred Values}

The measured room temperature rate coefficients (Arnts and Gay, 1979; Adeniji et al., 1981; Atkinson et al., 1982; Kamens et al., 1982; Greene and Atkinson, 1992; Treacy et al., 1992; Grosjean et al., 1993; Grosjean and Grosjean, 1996; Khamaganov and Hites, 2001; Avzianova and Ariya, 2002) and temperature dependencies (Atkinson et al., 1982; Treacy et al., 1992; Khamaganov and Hites, 2001; Avzianova and Ariya, 2002) are in good agreement. The preferred temperature dependence is the average of those determined by Treacy et al. (1992), Khamaganov and Hites (2001) and Avzianova and Ariya (2002). The preferred $298 \mathrm{~K}$ rate coefficient is the average of the rate coefficients of Atkinson et al. (1982), Greene and Atkinson (1992), Treacy et al. (1992), Grosjean et al. (1993), Grosjean and Grosjean (1996), Khamaganov and Hites (2001) and Avzianova and Ariya (2002) adjusted to $298 \mathrm{~K}$ where necessary (Atkinson et al., 1982; Greene and Atkinson, 1992; Grosjean et al., 1993; Grosjean and Grosjean, 1996) using the preferred temperature dependence. The preferred temperature dependence is combined with the preferred rate coefficient at $298 \mathrm{~K}$ to obtain the pre-exponential factor.

The reaction proceeds by initial addition of $\mathrm{O}_{3}$ to the $\mathrm{C}=\mathrm{C}$ bonds to form one of two primary ozonides, which rapidly decompose to form four possible sets of carbonyl + Criegee intermediate (see data sheets on the reactions of $\mathrm{O}_{3}$ with ethene and propene). Methacrolein, methyl vinyl ketone and formaldehyde are significant products of this reaction, with measured formation yields of 39-44\%, 16-17\%, and 90\%, respectively (Atkinson, 1997). HO radicals are also formed from the reaction of $\mathrm{O}_{3}$ with isoprene, in $25 \%$ yield (see the data sheet on the $\mathrm{O}_{3}+\mathrm{R}_{1} \mathrm{R}_{2} \mathrm{C}=\mathrm{CR}_{3} \mathrm{R}_{4} \rightarrow \mathrm{HO}+$ products reaction).

\section{References}

Adeniji, S. A., Kerr, J. A., and Williams, M. R.: Int. J. Chem. Kinet., 13, 209, 1981.

Arnts, R. R. and Gay Jr., R. W.: Photochemistry of Some Naturally Emitted Hydrocarbons, U.S. Environmental Protection Agency Report No. EPA-600/3-79-081, Environmental Sciences Research Laboratory, Office of Research and Development, Research Triangle Park, NC, September 1979.

Atkinson, R.: J. Phys. Chem. Ref. Data, 26, 215, 1997.

Atkinson, R., Winer, A. M., and Pitts Jr., J. N.: Atmos. Environ., 16, 1017, 1982. 
Avzianova, E. V. and Ariya, P. A.: Int. J. Chem. Kinet., 34, 678, 2002.

Greene, C. R. and Atkinson, R.: Int. J. Chem. Kinet., 24, 803, 1992.

Grosjean, D., Williams II, E. L., and Grosjean, E.: Environ. Sci. Technol., 27, 830, 1993.

Grosjean, E. and Grosjean, D.: Int. J. Chem. Kinet., 28, 911, 1996.

IUPAC: http://www.iupac-kinetic.ch.cam.ac.uk/, 2005.

Kamens, R. M., Gery, M. W., Jeffries, H. E., Jackson, M., and Cole, E. I.: Int. J. Chem. Kinet., 14, 955, 1982.

Khamaganov, V. G. and Hites, R. A.: J. Phys. Chem. A, 105, 815, 2001.

Treacy, J., El Haag, M., O’Farrell, D., and Sidebottom, H.: Ber. Bunsenges. Phys. Chem., 96, 422, 1992. 
II.A1.158

$$
\mathbf{O}_{3}+\alpha \text {-Pinene } \rightarrow \text { products }
$$

\section{Rate coefficient data}

\begin{tabular}{llll}
\hline$k / \mathrm{cm}^{3}$ molecule ${ }^{-1} \mathrm{~s}^{-1}$ & Temp./K & Reference & Technique/Comments \\
\hline $\begin{array}{l}\text { Absolute Rate Coefficients } \\
1.6 \times 10^{-16}\end{array}$ & 294 & Ripperton et al., 1972 & \\
$1.45 \times 10^{-16}$ & $295 \pm 1$ & Grimsrud et al., 1975 & S-CL \\
$(3.3 \pm 0.3) \times 10^{-16}$ & 298 & Japar et al., 1974 & F-CL \\
$9.4 \times 10^{-16} \exp [-(731 \pm 173) T]$ & $276-324$ & Atkinson et al., 1982 & S-CL \\
$(8.4 \pm 1.9) \times 10^{-17}$ & $296 \pm 2$ & & S-CL \\
$(9.71 \pm 1.06) \times 10^{-17}$ & $296 \pm 2$ & Atkinson et al., 1990 & S-CL (a) \\
& & & \\
Relative Rate Coefficients & & & \\
$(8.20 \pm 1.24) \times 10^{-17}$ & $297 \pm 2$ & Nolting et al., 1988 & RR (b) \\
$5.7 \times 10^{-16} \exp [-(584 \pm 87) T]$ & $288-363$ & Khamaganov and Hites, 2001 & RR (c,d) \\
$(9.05 \pm 0.45) \times 10^{-17}$ & 298 & & \\
$3.5 \times 10^{-16} \exp [-(429 \pm 303) T]$ & $288-343$ & Khamaganov and Hites, 2001 & RR (c,e) \\
$(8.11 \pm 0.33) \times 10^{-17}$ & 298 & & \\
$(1.06 \pm 0.09) \times 10^{-16}$ & $295 \pm 0.5$ & Witter et al., 2002 & RR (f) \\
\hline
\end{tabular}

\section{Comments}

(a) From measurements of the absolute rate coefficient for the reaction of $\mathrm{O}_{3}$ with sabinene and the rate coefficient ratio $k\left(\mathrm{O}_{3}+\alpha\right.$-pinene $) / k\left(\mathrm{O}_{3}+\right.$ sabinene $)$, a rate coefficient of $k\left(\mathrm{O}_{3}+\alpha\right.$-pinene $)=(7.99 \pm 1.20) \times 10^{-17} \mathrm{~cm}^{3}$ molecule $\mathrm{s}^{-1}$ was also derived.

(b) The concentrations of a series of alkenes (including $\alpha$-pinene and cis-2-butene, the reference compound) were monitored by GC in a $520 \mathrm{~L}$ Pyrex chamber at $\sim 1$ bar pressure of purified air in the presence of $\mathrm{O}_{3}$. The measured rate coefficient ratio $k\left(\mathrm{O}_{3}+\alpha\right.$-pinene $) / k\left(\mathrm{O}_{3}+c i s\right.$-2-butene $)$ is placed on an absolute basis by use of a rate coefficient at $297 \mathrm{~K}$ of $k\left(\mathrm{O}_{3}+c i s-\right.$ 2-butene) $=1.24 \times 10^{-16} \mathrm{~cm}^{3}$ molecule $\mathrm{e}^{-1} \mathrm{~s}^{-1}$ (Atkinson and Arey, 2003a). Details concerning the reactant mixtures and the presence or absence of an $\mathrm{HO}$ radical scavenger were not reported.

(c) The concentrations of $\alpha$-pinene and 1-butene or 2-methylpropene (the reference compounds) were monitored by MS in reacting $\mathrm{O}_{3}-\alpha$-pinene - 1-butene (or 2-methylpropene) - acetaldehyde (or ethanol) [HO radical scavengers] - He mixtures in a $192 \mathrm{~cm}^{3}$ volume quartz vessel at $\sim 1$ bar pressure. The measured rate coefficient ratios $k\left(\mathrm{O}_{3}+\alpha\right.$-pinene $) / k\left(\mathrm{O}_{3}+1\right.$ butene $)=0.17 \exp [(1190 \pm 87) / T]$ and $k\left(\mathrm{O}_{3}+\alpha\right.$-pinene $) / k\left(\mathrm{O}_{3}+2\right.$-methylpropene $)=0.13 \exp [(1203 \pm 303) / T]$ are placed on an absolute basis by use of rate coefficients of $k\left(\mathrm{O}_{3}+1\right.$-butene $)=3.36 \times 10^{-15} \exp (-1774 / T) \mathrm{cm}^{3} \mathrm{molecule}^{-1} \mathrm{~s}^{-1}$ and $k\left(\mathrm{O}_{3}+2\right.$-methylpropene $)=2.70 \times 10^{-15} \exp (-1632 / T) \mathrm{cm}^{3}$ molecule $\mathrm{e}^{-1} \mathrm{~s}^{-1}$ (Atkinson and Arey, 2003a). The combined data lead to the Arrhenius expression $k\left(\mathrm{O}_{3}+\alpha\right.$-pinene $)=4.8 \times 10^{-16} \exp [-(530 \pm 150) / T) \mathrm{cm}^{3}$ molecule $\mathrm{c}^{-1} \mathrm{~s}^{-1}$ over the temperature range $288-363 \mathrm{~K}$ and $k\left(\mathrm{O}_{3}+\alpha\right.$-pinene $)=(8.41 \pm 0.74) \times 10^{-17} \mathrm{~cm}^{3}$ molecule ${ }^{-1} \mathrm{~s}^{-1}$ at $298 \mathrm{~K}$ (Khamaganov and Hites, 2001).

(d) Relative to $k\left(\mathrm{O}_{3}+1\right.$-butene $)$.

(e) Relative to $k\left(\mathrm{O}_{3}+2\right.$-methylpropene).

(f) The concentrations of $\alpha$-pinene and 2-methyl-2-butene (the reference compounds) were monitored by GC in reacting $\mathrm{O}_{3}-$ $\alpha$-pinene - 2-methyl-2-butene - $m$-xylene (the $\mathrm{HO}$ radical scavenger) - air mixtures in a flow system at 1.00 bar pressure. The measured rate coefficient ratio of $k\left(\mathrm{O}_{3}+\alpha\right.$-pinene $) / k\left(\mathrm{O}_{3}+2\right.$-methyl-2-butene $)=0.270 \pm 0.022$ is placed on an absolute basis by use of a rate coefficient at $295 \mathrm{~K}$ of $k\left(\mathrm{O}_{3}+2\right.$-methyl-2-butene) $=3.92 \times 10^{-16} \mathrm{~cm}^{3}$ molecule ${ }^{-1} \mathrm{~s}^{-1}$ (Atkinson and Arey, 2003a). 


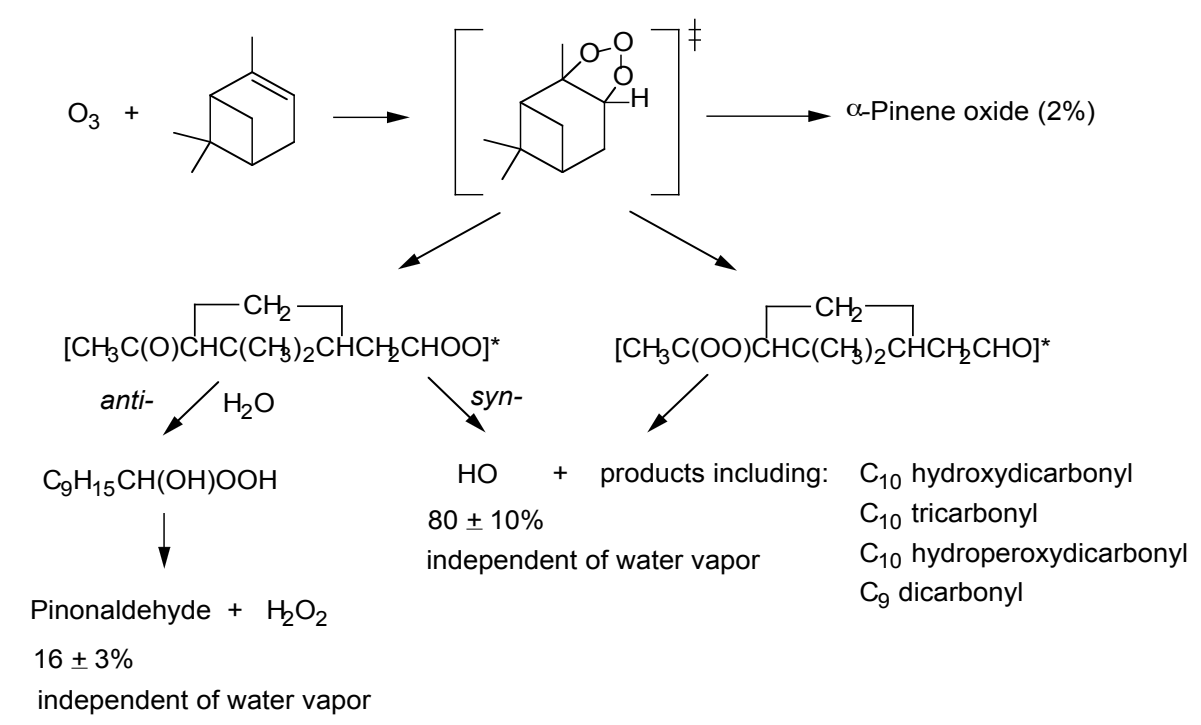

Fig. 4. See text.

\section{Preferred Values}

$k=9.0 \times 10^{-17} \mathrm{~cm}^{3}$ molecule ${ }^{-1} \mathrm{~s}^{-1}$ at $298 \mathrm{~K}$.

$k=6.3 \times 10^{-16} \exp (-580 / T) \mathrm{cm}^{3}$ molecule ${ }^{-1} \mathrm{~s}^{-1}$ over the temperature range $270-370 \mathrm{~K}$.

\section{Reliability}

$\Delta \log k= \pm 0.2$ at $298 \mathrm{~K}$.

$\Delta(E / R)= \pm 300 \mathrm{~K}$.

\section{Comments on Preferred Values}

The room temperature rate coefficients reported by Ripperton et al. (1972), Grimsrud et al. (1975) and Japar et al. (1974) are significantly higher than the more recent measurements of Atkinson et al. (1982, 1990), Nolting et al. (1988), Khamaganov and Hites (2001) and Witter et al. (2002), although there is still a significant amount of scatter between the room temperature rate coefficients of Atkinson et al. (1982, 1990), Nolting et al. (1988), Khamaganov and Hites (2001) and Witter et al. (2002). The preferred temperature dependence is obtained from a simple average of the temperature dependencies obtained by Atkinson et al. (1982) and Khamaganov and Hites (2001). The preferred $298 \mathrm{~K}$ rate coefficient is an average of those of Atkinson et al. (1982, 1990), Nolting et al. (1988), Khamaganov and Hites (2001) and Witter et al. (2002), corrected to $298 \mathrm{~K}$ where necessary using the preferred temperature dependence. The pre-exponential factor is adjusted to fit the $298 \mathrm{~K}$ preferred value.

The reaction proceeds by initial addition of $\mathrm{O}_{3}$ to the $\mathrm{C}=\mathrm{C}$ bond to form a 'primary ozonide' which rapidly decomposes to two Criegee intermediates. Subsequent reactions of these lead to pinonaldehyde, $\mathrm{HO}$ radicals, formaldehyde, acetone, $\alpha$-pinene oxide and a number of other products. A schematic reaction scheme is shown below (Fig. 4), noting that the pinonaldehyde yield shown is derived from product studies employing GC analyses (see Atkinson and Arey, 2003a, b).

\section{References}

Atkinson, R. and Arey, J.: Chem. Rev., 103, 4605, 2003a.

Atkinson, R. and Arey, J.: Atmos. Environ., 37 Suppl. 2, S197, 2003b.

Atkinson, R., Winer, A. M. and Pitts Jr., J. N.: Atmos. Environ., 16, 1017, 1982.

Atkinson, R., Hasegawa, D. and Aschmann, S. M.: Int. J. Chem. Kinet., 22, 871, 1990.

Grimsrud, E. P., Westberg, H. H. and Rasmussen, R. A.: Int. J. Chem. Kinet., Symp. 1, 183, 1975.

Japar, S. M., Wu, C. H. and Niki, H.: Environ. Lett., 7, 245, 1974.

Khamaganov, V. G. and Hites, R. A.: J. Phys. Chem. A, 105, 815, 2001. 
Nolting, F., Behnke, W. and Zetzsch, C.: J. Atmos. Chem., 6, 47, 1988.

Ripperton, L. A., Jeffries, H. E. and White, O.: Adv. Chem. Ser., 113, 219, 1972.

Witter, M., Berndt, T., Böge, O., Stratmann, F. and Heintzenberg, J.: Int. J. Chem. Kinet., 34, 394, 2002. 
II.A1.159

$$
\mathrm{O}_{3}+\mathrm{CH}_{2}=\mathrm{C}\left(\mathrm{CH}_{3}\right) \mathrm{CHO} \rightarrow \text { products }
$$

\section{Rate coefficient data}

\begin{tabular}{lllc}
\hline$k / \mathrm{cm}^{3}$ molecule ${ }^{-1} \mathrm{~s}^{-1}$ & Temp./K & Reference & Technique/Comments \\
\hline Absolute Rate Coefficients & & & \\
$(1.12 \pm 0.13) \times 10^{-18}$ & $296 \pm 2$ & Atkinson et al., 1981 & S-CL \\
$1.1 \times 10^{-18}$ & $\sim 294$ & Kamens et al., 1982 & S-CL/GC (a) \\
$1.3 \times 10^{-15} \exp [-(2112 \pm 131) / T]$ & $240-324$ & Treacy et al., 1992 & S-UVA \\
$(1.1 \pm 0.2) \times 10^{-18}$ & 298 & & \\
$(1.02 \pm 0.05) \times 10^{-18}$ & $291 \pm 2$ & Grosjean et al., 1993 & S-UVA \\
$(1.08 \pm 0.20) \times 10^{-18}$ & $290 \pm 1$ & Grosjean and Grosjean, 1998 & S-UVA \\
$(1.3 \pm 0.14) \times 10^{-18}$ & $296 \pm 2$ & Neeb et al., 1998 & S-FTIR (b) \\
\hline
\end{tabular}

\section{Comments}

(a) Carried out at atmospheric pressure of air in a large outdoor chamber at night. $\mathrm{O}_{3}$ was introduced continually over a period of $\sim 5 \mathrm{~h}$ to a methacrolein-air mixture. The methacrolein and $\mathrm{O}_{3}$ concentrations were monitored by GC and chemiluminescence, respectively, and the rate coefficient obtained by fitting the measured methacrolein and $\mathrm{O}_{3}$ concentrations to a computer model.

(b) The decays of methacrolein were measured in the presence of excess concentrations of $\mathrm{O}_{3}$, with cyclohexane also being present as an $\mathrm{HO}$ radical scavenger.

\section{Preferred Values}

$k=1.2 \times 10^{-18} \mathrm{~cm}^{3}$ molecule $\mathrm{e}^{-1} \mathrm{~s}^{-1}$ at $298 \mathrm{~K}$.

$k=1.4 \times 10^{-15} \exp (-2100 / T) \mathrm{cm}^{3}$ molecule $\mathrm{e}^{-1} \mathrm{~s}^{-1}$ over the temperature range $240-330 \mathrm{~K}$.

\section{Reliability}

$\Delta \log k= \pm 0.2$ at $298 \mathrm{~K}$.

$\Delta(E / R)= \pm 300 \mathrm{~K}$.

\section{Comments on Preferred Values}

The measured room temperature rate coefficients (Atkinson et al., 1981; Kamens et al., 1982; Treacy et al., 1992; Grosjean et al., 1993; Grosjean and Grosjean, 1998; Neeb et al., 1998) are in good agreement. The preferred 298 K rate coefficient is the average of all of the measured rate coefficients (Atkinson et al., 1981; Kamens et al., 1982; Treacy et al., 1992; Grosjean et al., 1993; Grosjean and Grosjean, 1998; Neeb et al., 1998), adjusted to $298 \mathrm{~K}$ where necessary (Atkinson et al., 1981; Kamens et al., 1982; Grosjean et al., 1993; Grosjean and Grosjean, 1998; Neeb et al., 1998) using the temperature dependence of Treacy et al. (1992). The temperature dependence measured by Treacy et al. (1992) is accepted, and is combined with the $298 \mathrm{~K}$ preferred value to obtain the pre-exponential factor.

The reaction proceeds by initial addition of $\mathrm{O}_{3}$ to the $\mathrm{C}=\mathrm{C}$ bond to form a primary ozonide which rapidly decomposes to methylglyoxal $+\left[\mathrm{CH}_{2} \mathrm{OO}\right]^{*}$ or to formaldehyde $+\left[\mathrm{CH}_{3} \mathrm{C}(\mathrm{OO}) \mathrm{CHO}\right]^{*}$ (see data sheets on the reactions of $\mathrm{O}_{3}$ with ethene and propene). Methylglyoxal and formaldehyde have been observed as significant products of this reaction, with formation yields of $52-64 \%$ and $9-15 \%$, respectively (Grosjean et al., 1993), indicating that formation of methylglyoxal $+\left[\mathrm{CH}_{2} \mathrm{OO}\right]^{*}$ dominates. HO radicals are also formed, with a reported yield of $20_{-13}^{+10} \%$ (Aschmann et al., 1996). 


\section{References}

Aschmann, S. M., Arey, J., and Atkinson, R.: Atmos. Environ., 30, 2939, 1996.

Atkinson, R., Aschmann, S. M., Winer, A. M., and Pitts Jr., J. N.: Int. J. Chem. Kinet., 13, $1133,1981$.

Grosjean, D., Williams II, E. L., and Grosjean, E.: Environ. Sci. Technol., 27, 830, 1993.

Grosjean, E. and Grosjean, D.: Int. J. Chem. Kinet., 28, 911, 1996.

Kamens, R. M., Gery, M. W., Jeffries, H. E., Jackson, M., and Cole, E. I.: Int. J. Chem. Kinet., 14, 955, 1982.

Neeb, P., Kolloff, A., Koch, S., and Moortgat, G. K.: Int. J. Chem. Kinet., 30, 769, 1998.

Treacy, J., El Hag, M., O’Farrell, D., and Sidebottom, H.: Ber. Bunsenges. Phys. Chem., 96, 422, 1992. 
II.A1.160

$$
\mathrm{O}_{3}+\mathrm{CH}_{3} \mathrm{C}(\mathrm{O}) \mathrm{CH}=\mathrm{CH}_{2} \rightarrow \text { products }
$$

\section{Rate coefficient data}

\begin{tabular}{lllc}
\hline$k / \mathrm{cm}^{3}$ molecule ${ }^{-1} \mathrm{~s}^{-1}$ & Temp./K & Reference & Technique/Comments \\
\hline Absolute Rate Coefficients & & & \\
$(4.77 \pm 0.59) \times 10^{-18}$ & $296 \pm 2$ & Atkinson et al., 1981 & S-CL \\
$4.0 \times 10^{-18}$ & $\sim 294$ & Kamens et al., 1982 & S-CL/GC (a) \\
$6.9 \times 10^{-16} \exp [-(1521 \pm 78) / T]$ & $240-324$ & Treacy et al., 1992 & S-UVA \\
$(4.2 \pm 0.4) \times 10^{-18}$ & 298 & & \\
$(4.72 \pm 0.09) \times 10^{-18}$ & $291 \pm 2$ & Grosjean et al., 1993 & S-UVA \\
$(5.84 \pm 0.39) \times 10^{-18}$ & $291 \pm 1$ & Grosjean and Grosjean, 1998 & S-UVA \\
$(5.4 \pm 0.6) \times 10^{-18}$ & $296 \pm 2$ & Neeb et al., 1998 & S-FTIR (b) \\
\hline
\end{tabular}

\section{Comments}

(a) Carried out at atmospheric pressure of air in a large outdoor chamber at night. $\mathrm{O}_{3}$ was introduced continually over a period of $\sim 5 \mathrm{~h}$ to a methyl vinyl ketone-air mixture. The methyl vinyl ketone and $\mathrm{O}_{3}$ concentrations were monitored by $\mathrm{GC}$ and chemiluminescence, respectively, and the rate coefficient obtained by fitting the measured methyl vinyl ketone and $\mathrm{O}_{3}$ concentrations to a computer model.

(b) The decays of methyl vinyl ketone were measured in the presence of excess concentrations of $\mathrm{O}_{3}$, with cyclohexane also being present as an $\mathrm{HO}$ radical scavenger.

\section{Preferred Values}

$k=5.2 \times 10^{-18} \mathrm{~cm}^{3}$ molecule ${ }^{-1} \mathrm{~s}^{-1}$ at $298 \mathrm{~K}$.

$k=8.5 \times 10^{-16} \exp (-1520 / T) \mathrm{cm}^{3}$ molecule $\mathrm{e}^{-1} \mathrm{~s}^{-1}$ over the temperature range $240-330 \mathrm{~K}$.

\section{Reliability}

$\Delta \log k= \pm 0.2$ at $298 \mathrm{~K}$.

$\Delta(E / R)= \pm 200 \mathrm{~K}$.

\section{Comments on Preferred Values}

The measured room temperature rate coefficients (Atkinson et al., 1981; Kamens et al., 1982; Treacy et al., 1992; Grosjean et al., 1993; Grosjean and Grosjean, 1998; Neeb et al., 1998) range over a factor of 1.5, with the temperature dependent study of Treacy et al. (1992) having the lowest measured rate coefficient (taking into account the actual value of room temperature in the various studies). The preferred $298 \mathrm{~K}$ rate coefficient is the average of all of the measured rate coefficients (Atkinson et al., 1981; Kamens et al., 1982; Treacy et al., 1992; Grosjean et al., 1993; Grosjean and Grosjean, 1998; Neeb et al., 1998), adjusted to $298 \mathrm{~K}$ where necessary (Atkinson et al., 1981; Kamens et al., 1982; Grosjean et al., 1993; Grosjean and Grosjean, 1998; Neeb et al., 1998) using the temperature dependence of Treacy et al. (1992). The temperature dependence measured by Treacy et al. (1992) is accepted, and is combined with the $298 \mathrm{~K}$ preferred value to obtain the pre-exponential factor.

The reaction proceeds by initial addition of $\mathrm{O}_{3}$ to the $\mathrm{C}=\mathrm{C}$ bond to form a primary ozonide which rapidly decomposes to methylglyoxal $+\left[\mathrm{CH}_{2} \mathrm{OO}\right]^{*}$ or to formaldehyde $+\left[\mathrm{CH}_{3} \mathrm{C}(\mathrm{O}) \mathrm{CHOO}\right]^{*}$ (see data sheets on the reactions of $\mathrm{O}_{3}$ with ethene and propene). Methylglyoxal has been observed as a major product of this reaction, with a formation yield of $82-92 \%$ (Grosjean et al., 1993), indicating that formation of methylglyoxal $+\left[\mathrm{CH}_{2} \mathrm{OO}\right]^{*}$ dominates. HO radicals are also formed, with measured yields of $16 \pm 8 \%$ (Aschmann et al, 1996) and 16 $\pm 5 \%$ (Paulson et al., 1998). 


\section{References}

Aschmann, S. M., Arey, J., and Atkinson, R.: Atmos. Environ., 30, 2939, 1996.

Atkinson, R., Aschmann, S. M., Winer, A. M., and Pitts Jr., J. N.: Int. J. Chem. Kinet., 13, $1133,1981$.

Grosjean, D., Williams II, E. L., and Grosjean, E.: Environ. Sci. Technol., 27, 830, 1993.

Grosjean, E. and Grosjean, D.: Int. J. Chem. Kinet., 28, 911, 1996.

Kamens, R. M., Gery, M. W., Jeffries, H. E., Jackson, M., and Cole, E. I.: Int. J. Chem. Kinet., 14, 955, 1982.

Neeb, P., Kolloff, A., Koch, S., and Moortgat, G. K.: Int. J. Chem. Kinet., 30, 769, 1998.

Paulson, S. E., Chung, M., Sen, A. D., and Orzechowska, G.: J. Geophys. Res., 103, 25 533, 1998.

Treacy, J., El Hag, M., O’Farrell, D., and Sidebottom, H.: Ber. Bunsenges. Phys. Chem., 96, 422, 1992. 
II.A1.161

$$
\mathrm{O}_{3}+\text { 3-methylfuran } \rightarrow \text { products }
$$

\section{Rate coefficient data}

\begin{tabular}{|c|c|c|c|}
\hline $\mathrm{k} / \mathrm{cm}^{3}$ molecule $^{-1} \mathrm{~s}^{-1}$ & Temp./K & Reference & Technique/Comments \\
\hline $\begin{array}{l}\text { Relative Rate Coefficients } \\
(2.04 \pm 0.08) \times 10^{-17}\end{array}$ & $296 \pm 2$ & Alvarado et al., 1996 & RR (a) \\
\hline
\end{tabular}

\section{Comments}

(a) Relative rate method carried out at atmospheric pressure of air. The concentrations of 3-methylfuran and propene (the reference compound) were measured by GC, and cyclohexane was added to the reactant mixtures to scavenge the $\mathrm{HO}$ radicals formed (Atkinson, 1997). The measured rate coefficient ratio of $k\left(\mathrm{O}_{3}+3\right.$-methylfuran $) / k\left(\mathrm{O}_{3}+\right.$ propene $)=$ $2.12 \pm 0.08$ is placed on an absolute basis by use of a rate coefficient of $k\left(\mathrm{O}_{3}+\right.$ propene $)=9.6 \times 10^{-18} \mathrm{~cm}^{3}$ molecule ${ }^{-1}$ $\mathrm{s}^{-1}$ at $296 \mathrm{~K}$ (IUPAC, current recommendation).

\section{Preferred Values}

$k=2.0 \times 10^{-17} \mathrm{~cm}^{3}$ molecule $\mathrm{s}^{-1} \mathrm{~s}^{-1}$ at $298 \mathrm{~K}$.

\section{Reliability}

$\Delta \log k= \pm 0.3$ at $298 \mathrm{~K}$.

\section{Comments on Preferred Values}

The preferred value is based on the sole study of this reaction by Alvarado et al. (1996). The reaction proceeds by initial addition of $\mathrm{O}_{3}$ to the $\mathrm{C}=\mathrm{C}$ bonds. $\mathrm{HO}$ radicals were observed to be formed from the reaction of $\mathrm{O}_{3}$ with 3-methylfuran, in $\sim 60 \%$ yield (Alvarado et al., 1996).

\section{References}

Alvarado, A., Atkinson, R., and Arey, J.: Int. J. Chem. Kinet., 28, 905, 1996.

Atkinson, R.: J. Phys. Chem. Ref. Data, 26, 215, 1997.

IUPAC: http://www.iupac-kinetic.ch.cam.ac.uk/, 2005. 
II.A1.162

$$
\mathrm{O}_{3}+\mathrm{CH}_{2}=\mathrm{C}\left(\mathrm{CH}_{3}\right) \mathrm{C}(\mathrm{O}) \mathrm{OONO}_{2} \rightarrow \text { products }
$$

\section{Rate coefficient data}

\begin{tabular}{lclc}
\hline$k / \mathrm{cm}^{3}$ molecule & \\
\hline $\begin{array}{l}\text { Absolute Rate Coefficients } \\
\mathrm{s}^{-1}\end{array}$ & Temp./K & Reference & Technique/Comments \\
\hline $8.2 \pm 2.0) \times 10^{-18}$ & $295 \pm 5$ & Grosjean et al., 1993 & (a) \\
\hline
\end{tabular}

\section{Comments}

(a) Experiments were carried out at atmospheric pressure of air, by monitoring the decay rates of $\mathrm{CH}_{2}=\mathrm{C}\left(\mathrm{CH}_{3}\right) \mathrm{C}(\mathrm{O}) \mathrm{OONO}{ }_{2}$ (MPAN) in the presence of known excess concentrations of $\mathrm{O}_{3}$. Cyclohexane was added to the reactant mixtures to scavenge any $\mathrm{OH}$ radicals present. MPAN concentrations were measured by GC with electron capture detection.

\section{Preferred Values}

$k=8.2 \times 10^{-18} \mathrm{~cm}^{3}$ molecule ${ }^{-1} \mathrm{~s}^{-1}$ at $298 \mathrm{~K}$.

\section{Reliability}

$\Delta \log k= \pm 0.3$ at $298 \mathrm{~K}$.

\section{Comments on Preferred Values}

The preferred value is based on the sole study of this reaction by Grosjean et al. (1993). The rate coefficient for this reaction is similar in magnitude to those for the reactions of $\mathrm{O}_{3}$ with propene (Atkinson, 1997; IUPAC, current recommendation) and 2methylpropene (Atkinson, 1997) and a factor of 5 higher than that for the reaction of $\mathrm{O}_{3}$ with ethene (Atkinson, 1997; IUPAC, current recommendation). This reactivity of MPAN towards $\mathrm{O}_{3}$ is consistent with the recommended rate coefficient for the reaction of MPAN with $\mathrm{HO}$ radicals (IUPAC, current recommendation). The reaction of $\mathrm{O}_{3}$ with MPAN proceeds by initial addition of $\mathrm{O}_{3}$ to the $\mathrm{C}=\mathrm{C}$ bond, and formaldehyde has been observed as a reaction product with a formation yield of $60 \pm 10 \%$ (Grosjean et al., 1993).

\section{References}

Atkinson, R.: J. Phys. Chem. Ref. Data, 26, 215, 1997.

Grosjean, D., Grosjean, E., and Williams II, E. L.: Environ. Sci. Technol., 27, 2548, 1993.

IUPAC: http://www.iupac-kinetic.ch.cam.ac.uk/, 2005. 
II.A1.163

$$
\mathrm{O}_{3}+\text { Pinonaldehyde } \rightarrow \text { products }
$$

\section{Rate coefficient data}

\begin{tabular}{|c|c|c|c|}
\hline$k / \mathrm{cm}^{3}$ molecule ${ }^{-1} \mathrm{~s}^{-1}$ & Temp./K & Reference & Technique/Comments \\
\hline $\begin{array}{l}\text { Absolute Rate Coefficients } \\
(8.9 \pm 1.3) \times 10^{-20} \\
<2 \times 10^{-20}\end{array}$ & $\begin{array}{l}300 \pm 5 \\
296 \pm 2\end{array}$ & $\begin{array}{l}\text { Glasius et al., } 1997 \\
\text { Alvarado et al., } 1998\end{array}$ & $\begin{array}{l}\text { S-FTIR }(a, b) \\
\text { S-GC }(a, c)\end{array}$ \\
\hline
\end{tabular}

\section{Comments}

(a) Decays of pinonaldehyde monitored in the presence of an excess concentration of $\mathrm{O}_{3}$ in the presence of $\sim 1$ bar of air.

(b) Pinonaldehyde was observed to decay to the $480 \mathrm{~L}$ reaction chamber walls in the absence of $\mathrm{O}_{3}$, and these measured dark decays were taken into account in the data analysis.

(c) No decays of pinonaldehyde $(<5 \%)$ were observed in the $7000 \mathrm{~L}$ Teflon chamber used.

\section{Preferred Values}

$k<2 \times 10^{-20} \mathrm{~cm}^{3}$ molecule ${ }^{-1} \mathrm{~s}^{-1}$ at $298 \mathrm{~K}$.

\section{Comments on Preferred Values}

The preferred upper limit to the $298 \mathrm{~K}$ rate coefficient is based on the study of Alvarado et al. (1998) carried out in a large volume Teflon chamber in which no wall losses of pinonaldehyde were observed.

\section{References}

Alvarado, A., Arey, J., and Atkinson, R.: J. Atmos. Chem., 31, 281, 1998.

Glasius, M., Calogirou, A., Jensen, N. R., Hjorth, J., and Nielsen, C. J.: Int. J. Chem. Kinet., 29, 527, 1997. 
II.A1.164

$$
\mathrm{O}_{3}+\left(\mathrm{CH}_{3}\right)_{2} \mathrm{C}(\mathrm{OH}) \mathrm{CH}=\mathrm{CH}_{2} \rightarrow \text { products }
$$

\section{Rate coefficient data}

\begin{tabular}{|c|c|c|c|}
\hline$k / \mathrm{cm}^{3}$ molecule $^{-1} \mathrm{~s}^{-1}$ & Temp./K & Reference & Technique/Comments \\
\hline $\begin{array}{l}\text { Absolute Rate Coefficients } \\
(1.00 \pm 0.3) \times 10^{-17}\end{array}$ & $291 \pm 1$ & Grosjean and Grosjean, 1994 & S-UV \\
\hline $\begin{array}{l}\text { Relative Rate Coefficients } \\
9 \times 10^{-18}\end{array}$ & $298 \pm 2$ & Fantechi et al., 1998a & RR (a) \\
\hline
\end{tabular}

\section{Comments}

(a) $\mathrm{O}_{3}$ was reacted with 2-methyl-3-buten-2-ol and propene or 2-methylpropene (the reference compounds) in the presence of propane as an $\mathrm{OH}$ radical scavenger. The concentrations of 2-methyl-3-buten-2-ol and propene or 2-methylpropene were monitored by FTIR spectroscopy. The measured rate coefficient ratios (which were not reported) were placed on an absolute basis by use of rate coefficients at $298 \mathrm{~K}$ of $k\left(\mathrm{O}_{3}+\right.$ propene) $=1.2 \times 10^{-17} \mathrm{~cm}^{3}$ molecule ${ }^{-1} \mathrm{~s}^{-1}$ (Atkinson et al., 1992) and $k\left(\mathrm{O}_{3}+2\right.$-methylpropene) $=1.13 \times 10^{-17} \mathrm{~cm}^{3}$ molecule ${ }^{-1} \mathrm{~s}^{-1}$ (Atkinson, 1997). The reference compound corresponding to each of the two reported rate coefficients of $k\left(\mathrm{O}_{3}+2\right.$-methyl-3-buten-2-ol $)=(1.15 \pm 0.22) \times 10^{-17} \mathrm{~cm}^{3}$ molecule $\mathrm{s}^{-1} \mathrm{~s}^{-1}$ and $(8.0 \pm 1.0) \times 10^{-18} \mathrm{~cm}^{3}$ molecule ${ }^{-1} \mathrm{~s}^{-1}$ was not reported; however, using the currently recommended rate coefficients at $298 \mathrm{~K}$ of $k\left(\mathrm{O}_{3}+\right.$ propene) $=1.01 \times 10^{-17} \mathrm{~cm}^{3}$ molecule $\mathrm{e}^{-1} \mathrm{~s}^{-1}$ (Atkinson and Arey, 2003a; IUPAC, current recommendation) and $k\left(\mathrm{O}_{3}+2\right.$-methylpropene) $=1.13 \times 10^{-17} \mathrm{~cm}^{3}$ molecule ${ }^{-1} \mathrm{~s}^{-1}$ (Atkinson and Arey, 2003a) results in the approximate average rate coefficient cited in the table.

\section{Preferred Values}

$k=1.0 \times 10^{-17} \mathrm{~cm}^{3}$ molecule ${ }^{-1} \mathrm{~s}^{-1}$ at $298 \mathrm{~K}$.

\section{Reliability}

$\Delta \log k= \pm 0.2$ at $298 \mathrm{~K}$.

\section{Comments on Preferred Values}

The rate coefficients of Grosjean and Grosjean (1994) at $291 \pm 1 \mathrm{~K}$ and of Fantechi et al. (1998a) at $298 \pm 2 \mathrm{~K}$ are in reasonable agreement. However, as noted in comment (a), the lack of detail in the Fantechi et al. (1998a) publication makes re-evaluation of their data somewhat uncertain, especially the derivation of the associated uncertainty. Assuming that the reaction of $\mathrm{O}_{3}$ with 2-methyl-3-buten-2-ol has a similar temperature dependence to the reactions of $\mathrm{O}_{3}$ with propene and 2-methylpropene (which have similar room temperature rate coefficients as noted in comment (a)), then the Grosjean and Grosjean (1994) rate coefficient corresponds to a $298 \mathrm{~K}$ rate coefficient of $\sim 1.16 \times 10^{-17} \mathrm{~cm}^{3}$ molecule ${ }^{-1} \mathrm{~s}^{-1}$. The preferred value is an average of the $298 \mathrm{~K}$ rate coefficients obtained from the studies of Grosjean and Grosjean (1994) and Fantechi et al. (1998a).

The reaction proceeds by initial addition of $\mathrm{O}_{3}$ across the $\mathrm{C}=\mathrm{C}$ bond to form a 'primary ozonide' which rapidly decomposes to $\left(\mathrm{CH}_{3}\right)_{2} \mathrm{C}(\mathrm{OH}) \mathrm{CHO}+\left[\mathrm{CH}_{2} \mathrm{OO}\right]^{*}$ and to $\mathrm{HCHO}+\left[\left(\mathrm{CH}_{3}\right)_{2} \mathrm{C}(\mathrm{OH}) \mathrm{CHOO}\right]^{*}$ (Grosjean and Grosjean, 1995; Fantechi et al., 1998b; Alvarado et al., 1999). Product studies of this reaction have been carried out by Grosjean and Grosjean (1995), Fantechi et al. (1998b) and Alvarado et al. (1999) (see also Atkinson and Arey, 2003b), and the observed products are HCHO, $\left(\mathrm{CH}_{3}\right)_{2} \mathrm{C}(\mathrm{OH}) \mathrm{CHO}$ (2-hydroxy-2-methylpropanal), acetone, formic acid, and $\mathrm{HO}$ radicals. There are significant discrepancies in the measured yields of formaldehyde, 2-hydroxy-2-methylpropanal and acetone (Grosjean and Grosjean, 1995; Fantechi et al., 1998b; Alvarado et al., 1999; Atkinson and Arey, 2003b), with the most recent and extensive study of Alvarado et al. (1999) reporting molar formation yields of: $\mathrm{HCHO}, 29 \pm 3 \% ;\left(\mathrm{CH}_{3}\right)_{2} \mathrm{C}(\mathrm{OH}) \mathrm{CHO}, \sim 47 \%$; acetone, initially $\sim 15 \%$ and apparently increasing with the extent of reaction; and $\mathrm{HO}$ radicals, $19_{-7}^{+10} \%$. As discussed by Grosjean and Grosjean (1995) 
and Alvarado et al. (1999), acetone is presumably formed from the $\left[\left(\mathrm{CH}_{3}\right)_{2} \mathrm{C}(\mathrm{OH}) \mathrm{CHOO}\right]^{*}$ Criegee intermediate, and this may account for the variable yields reported (Grosjean and Grosjean, 1995; Fantechi et al., 1998b; Alvarado et al., 1999; Atkinson and Arey, 2003b) and for the observation of Alvarado et al. (1999) of an increasing yield with extent of reaction. Note that the reported yields of 2-hydroxy-2-methylpropanal (Grosjean and Grosjean, 1995; Alvarado et al., 1999) are likely to be lower limits because of the difficulties in quantitatively analyzing this hydroxyaldehyde, which is not commercially available and does not elute from GC columns without prior derivatization.

\section{References}

Alvarado, A., Tuazon, E. C., Aschmann, S. M., Arey, J., and Atkinson, R.: Atmos. Environ., 33, 2893, 1999.

Atkinson, R.: J. Phys. Chem. Ref. Data, 26, 215, 1997.

Atkinson, R., Baulch, D. L., Cox, R. A., Hampson Jr., R. F., Kerr, J. A., and Troe, J.: J. Phys. Chem. Ref. Data, 21, 1125, 1992.

Atkinson, R. and Arey, J.: Chem. Rev., 103, 4605, 2003a.

Atkinson, R. and Arey, J.: Atmos. Environ., 37, Suppl. 2, S197, $2003 \mathrm{~b}$.

Grosjean, E. and Grosjean, D.: Int. J. Chem. Kinet., 26, 1185, 1994.

Grosjean, D. and Grosjean, E.: J. Geophys. Res., 100, 22 815, 1995.

Fantechi, G., Jensen, N. R., Hjorth, J., and Peeters, J.: Int. J. Chem. Kinet., 30, 589, 1998a.

Fantechi, G., Jensen, N. R., Hjorth, J., and Peeters, J.: Atmos. Environ., 32, 3547, 1998b.

IUPAC: http://www.iupac-kinetic.ch.cam.ac.uk/, 2005. 


\section{Appendix A2: $\mathrm{HO}_{\mathrm{x}}+\mathrm{VOC}$ reactions}

\section{II.A2.3}

$$
\mathrm{HO}+\mathrm{CH}_{4} \rightarrow \mathrm{H}_{2} \mathrm{O}+\mathrm{CH}_{3}
$$

$\Delta H^{\circ}=-57.8 \mathrm{~kJ} \cdot \mathrm{mol}^{-1}$

\section{Rate coefficient data}

\begin{tabular}{lllc}
\hline$k / \mathrm{cm}^{3}$ molecule $\mathrm{s}^{-1}$ & Temp./K & Reference & Technique/Comments \\
\hline Absolute Rate Coefficients & & & \\
$(4.3 \pm 0.9) \times 10^{-12}$ & $1234 \pm 15$ & Bott and Cohen, 1989 & SH-RA \\
$1.59 \times 10^{-20} T^{2.84} \exp (-978 / T)$ & $223-420$ & Vaghjiana and & PLP-LIF \\
$6.35 \times 10^{-15}$ & 298 & Ravishankara, 1991 & \\
$4.0 \times 10^{-12} \exp [-(1994 \pm 114) / T]$ & $278-378$ & Finlayson-Pitts et al., 1992 & DF-RF \\
$5.87 \times 10^{-15}$ & 298 & & \\
$9.65 \times 10^{-20} T^{2.58} \exp (-1082 / T)$ & $293-800$ & Dunlop and Tully, 1993 & PLP-LIF (a) \\
$(5.62 \pm 0.43) \times 10^{-15}$ & 293 & & \\
$2.56 \times 10^{-12} \exp [-(1765 \pm 146) / T]$ & $233-343$ & Mellouki et al., 1994 & PLP-LIF \\
$(6.34 \pm 0.88) \times 10^{-15}$ & 298 & & \\
$1.85 \times 10^{-20} T^{+2.82} \exp [-(987 \pm 6) / T]$ & $195-296$ & Gierczak et al., 1997 & PLP-LIF \\
$(6.40 \pm 0.38) \times 10^{-15}$ & 298 & & FP-LIF (b) \\
$5.65 \times 10^{-21} T^{3.01} \exp [-(959 \pm 36) / T]$ & $295-668$ & Bonard et al., 2002 & PLP-LIF \\
$(6.23 \pm 0.20) \times 10^{-15}$ & 295 & & \\
\hline
\end{tabular}

\section{Comments}

(a) The temperature-dependent expression cited is that for the rate coefficients of Dunlop and Tully (1993) ( $T=293-800 \mathrm{~K})$ combined with those of Vaghjiani and Ravishankara (1991) ( $T=223-420 \mathrm{~K})$ and as such covers the temperature range $223-800 \mathrm{~K}$.

(b) The temperature-dependent expression cited is that for the rate coefficients of Gierczak et al. (1997) (T=195-296 K) combined with those of Vaghjiani and Ravishankara (1991) ( $T=223-420 \mathrm{~K})$ obtained using a similar technique, and therefore covers the temperature range $195-420 \mathrm{~K}$.

\section{Preferred Values}

$k=6.4 \times 10^{-15} \mathrm{~cm}^{3}$ molecule ${ }^{-1} \mathrm{~s}^{-1}$ at $298 \mathrm{~K}$.

$k=1.85 \times 10^{-12} \exp (-1690 / T) \mathrm{cm}^{3}$ molecule $\mathrm{e}^{-1} \mathrm{~s}^{-1}$ over the temperature range $200-300 \mathrm{~K}$.

\section{Reliability}

$\Delta \log k= \pm 0.08$ at $298 \mathrm{~K}$.

$\Delta(E / R)= \pm 100 \mathrm{~K}$.

\section{Comments on Preferred Values}

The absolute rate coefficients of Vaghjiani and Ravishankara (1991), Finlayson-Pitts et al. (1992), Dunlop and Tully (1993), Mellouki et al. (1994), Gierczak et al. (1997) and Bonard et al. (2002) are in good agreement. However, over the temperature range $\sim 250-420 \mathrm{~K}$ these rate coefficients of Vaghjiani and Ravishankara (1991), Finlayson-Pitts et al. (1992), Dunlop and Tully (1993), Mellouki et al. (1994), Gierczak et al. (1997) and Bonard et al. (2002) are 20\% lower than most of the previously reported absolute rate coefficients (Atkinson, 1994). 
The preferred values are derived from the absolute rate coefficient data of Vaghjiani and Ravishankara (1991) and Gierczak et al. (1997), both conducted over significant and overlapping temperature ranges. The temperature-dependent expression obtained by Gierczak et al. (1997) from a fit of their data and those of Vaghjiani and Ravishankara (1991) to the three-parameter equation $k=C T^{n} \exp (-D / T)$ is accepted, of $k=1.85 \times 10^{-20} T^{2.82} \exp (-987 / T) \mathrm{cm}^{3}$ molecule $^{-1} \mathrm{~s}^{-1}$ over the temperature range $195-420 \mathrm{~K}$ (Gierczak et al., 1997). The preferred Arrhenius expression, $k=A \exp (-B / T)$, is centered at $250 \mathrm{~K}$ and is derived from the three-parameter equation with $A=C e^{n} T^{n}$ and $B=D+n T$. The recommended three-parameter expression leads to calculated rate coefficients at $800 \mathrm{~K}$ and $1234 \mathrm{~K}$ which are within $12 \%$ and $3 \%$, respectively of the values measured by Dunlop and Tully (1993) at $800 \mathrm{~K}$ and Bott and Cohen (1989) at $1234 \mathrm{~K}$, and agrees to within $8 \%$ with the rate coefficients measured by Bonard et al. (2002) over the temperature range 295-668 K.

\section{References}

Atkinson, R.: J. Phys. Chem. Ref. Data Monograph, 2, 1, 1994.

Bonard, A., Daële, V., Delfau, J.-L., and Vovelle, C.: J. Phys. Chem. A, 106, 4384, 2002.

Bott, J. F. and Cohen, N.: Int. J. Chem. Kinet., 21, 485, 1989.

Dunlop, J. R. and Tully, F. P. : J. Phys. Chem., 97, 11 148, 1993.

Finlayson-Pitts, B. J. , Ezell, M. J., Jayaweera, T. M., Berko, H. N., and Lai, C. C.: Geophys. Res. Lett., 19, 1371, 1992.

Gierczak, T., Talukdar, R. K., Herndon, S. C., Vaghjiani, G. L., and Ravishankara, A. R.: J. Phys. Chem. A, 101, 3125, 1997.

Mellouki, A., Téton, S., Laverdet, G., Quilgars, A., and Le Bras, G.: J. Chim. Phys., 91, 473, 1994.

Vaghjiani, G. L. and Ravishankara, A. R.: Nature, 350, 406, 1991. 


\section{II.A2.4}

$$
\mathrm{HO}+\mathrm{C}_{2} \mathrm{H}_{2}+\mathrm{M} \rightarrow \mathrm{C}_{2} \mathrm{H}_{2} \mathrm{OH}+\mathrm{M}
$$

$\Delta H^{\circ}=-145 \mathrm{~kJ} \cdot \mathrm{mol}^{-1}$

\section{Low-pressure Rate coefficients}

\section{Rate coefficient data}

\begin{tabular}{lllc}
\hline$k_{0} / \mathrm{cm}^{3}$ molecule ${ }^{-1} \mathrm{~s}^{-1}$ & Temp./K & Reference & Technique/Comments \\
\hline Absolute Rate Coefficients & & & \\
$(3 \pm 1) \times 10^{-30}(\mathrm{~T} / 300)^{1.0}[\mathrm{Ar}]$ & $297-429$ & Perry and Williamson, 1982 & FP-RF (a) \\
$(6 \pm 3) \times 10^{-30}[\mathrm{He}]$ & 298 & Hack et al., 1983 & DF-EPR (b) \\
$(2.5 \pm 0.3) \times 10^{-30}[\mathrm{Ar}]$ & 295 & Schmidt et al., 1985 & PLP-LIF (c) \\
$5 \times 10^{-30}\left[\mathrm{~N}_{2}\right]$ & 298 & Wahner and Zetzsch, 1985 & PLP-A (d) \\
$(4.1 \pm 1.6) \times 10^{-30}\left[\mathrm{~N}_{2}\right]$ & 298 & Bohn et al., 1996 & PLP-A (e) \\
$4.3 \times 10^{-29}(\mathrm{~T} / 300)^{-3.1} \exp (-910 / T)[\mathrm{He}]$ & $300-814$ & Fulle et al., 1997 & PLP-LIF (f) \\
$2.1 \times 10^{-30}[\mathrm{He}]$ & 298 & & \\
& & & \\
Absolute Rate Coefficients & 296 & Sørenson et al., 2003 & RR (g) \\
$(2.92 \pm 0.55) \times 10^{-30}[$ air] & & & \\
\hline
\end{tabular}

\section{Comments}

(a) Photolysis of $\mathrm{H}_{2} \mathrm{O}-\mathrm{C}_{2} \mathrm{H}_{2}$ mixtures at 26-530 mbar Ar diluent. Pressure dependence observed is in agreement with earlier work (Perry et al., 1977; Michael et al., 1980). Evaluation of the falloff curve with $F_{c}=0.5$.

(b) Pressures of 2.0-2.6 mbar were used. By the use of data from Perry and Williamson (1982) and $F_{c}=0.5$, a falloff analysis of the measured $k$ leads to the given $k_{0}$ value.

(c) Experiments in $\mathrm{He}, \mathrm{Ar}$ and $\mathrm{N}_{2}$ at pressures between $1 \mathrm{mbar}$ and $1000 \mathrm{mbar}$ (in Ar). Construction of falloff curve with $F_{c}=0.6$ leads to $k_{\infty}=(8.3 \pm 0.8) \times 10^{-13} \mathrm{~cm}^{3}$ molecule ${ }^{-1} \mathrm{~s}^{-1}$.

(d) Experiments in $\mathrm{N}_{2}$ over the range $20 \mathrm{mbar}$ to $1000 \mathrm{mbar}$. Falloff curve constructed with $F_{c}=0.6$ leading to $k_{\infty}=9 \times 10^{-13} \mathrm{~cm}^{3}$ molecule ${ }^{-1} \mathrm{~s}^{-1}$.

(e) Experiments with $\mathrm{M}=\mathrm{N}_{2}, \mathrm{O}_{2}$ and synthetic air at pressures from $15 \mathrm{mbar}$ to 1 bar. Falloff extrapolation with $F_{c}=0.6$. Effective rate coefficients for $\mathrm{HO}$ radical removal in $\mathrm{O}_{2}$ and synthetic air were markedly lower than in $\mathrm{N}_{2}$ due to $\mathrm{HO}$ radical regeneration by the reaction $\mathrm{C}_{2} \mathrm{H}_{2} \mathrm{OH}+\mathrm{O}_{2} \rightarrow \mathrm{HO}+$ products, which shows evidence for an influence of the extent of vibrational de-excitation of $\mathrm{C}_{2} \mathrm{H}_{2} \mathrm{OH}$.

(f) Pressure range 2 mbar to 130 bar of He. Combined with the data of (Schmidt et al., 1985), falloff curves were constructed using a calculated $F_{c}=[0.17 \exp (-51 / T)+\exp (-T / 204)]$, i.e., $F_{c}(298 \mathrm{~K})=0.37$. From a third-law analysis of the equilibrium constant, the value $\Delta \mathrm{H}^{\circ}(0 \mathrm{~K})=-(146 \pm 10) \mathrm{kJ} \mathrm{mol}^{-1}$ was derived. The equilibrium constant obtained at temperatures above $700 \mathrm{~K}$ is given by $K_{c}=5.4 \times 10^{-2} T^{-1.7} \exp (17560 / T) \mathrm{bar}^{-1}$.

(g) $\mathrm{HO}$ radicals were generated by the photolysis of $\mathrm{CH}_{3} \mathrm{ONO}$ in air. The concentrations of $\mathrm{C}_{2} \mathrm{H}_{2}$ and dimethyl ether or propane (the reference compounds) were monitored by in situ FTIR spectroscopy or GC-FID, respectively. The measured rate coefficient ratios $k\left(\mathrm{HO}+\mathrm{C}_{2} \mathrm{H} 2\right) / k(\mathrm{HO}+$ dimethyl ether $)$ and $k\left(\mathrm{HO}+\mathrm{C}_{2} \mathrm{H}_{2}\right) / k(\mathrm{HO}+$ propane $)$ were placed on an absolute basis using rate coefficients of $k(\mathrm{HO}+$ dimethyl ether $)=2.98 \times 10^{-12} \mathrm{~cm}^{3}$ molecule ${ }^{-1} \mathrm{~s}^{-1}$ and $\mathrm{k}(\mathrm{HO}+$ propane $)$ $=1.11 \times 10^{-12} \mathrm{~cm}^{3}$ molecule ${ }^{-1} \mathrm{~s}^{-1}$ (Sørensen et al., 2003). Experiments were carried out over the pressure range 25750 Torr (33-1000 mbar) of air or $\mathrm{O}_{2}$ with analysis by FTIR spectroscopy and dimethyl ether as the reference compound, and over the pressure range 25-7905 Torr (33 mbar to 10.5 bar) of $\mathrm{O}_{2}-\mathrm{N}_{2}$ diluent, with propane as the reference organic. Falloff curve was constructed with $F_{c}=0.6$. Use of $F_{c}=0.4$ led to $k_{0}=(7.00 \pm 1.30) \times 10^{-30}$ [air] $\mathrm{cm}^{3}$ molecule $^{-1} \mathrm{~s}^{-1}$ and $k_{\infty}=(1.06 \pm 0.034) \times 10^{-12} \mathrm{~cm}^{3}$ molecule ${ }^{-1} \mathrm{~s}^{-1}$. 


\section{Preferred Values}

$k_{0}=5 \times 10^{-30}(T / 300)^{-1.5}\left[\mathrm{~N}_{2}\right] \mathrm{cm}^{3}$ molecule $\mathrm{e}^{-1} \mathrm{~s}^{-1}$ over the temperature range $300-800 \mathrm{~K}$.

\section{Reliability}

$\Delta \log k_{0}= \pm 0.1$ at $298 \mathrm{~K}$.

$\Delta n= \pm 1.5$.

\section{Comments on Preferred Values}

The preferred rate coefficient at $298 \mathrm{~K}$ is based on the experimental data of Schmidt et al. (1985), Wahner and Zetzsch (1985) and Bohn et al. (1996) and the theoretical analysis of Smith et al. (1984). The temperature dependence is based on the data of Perry et al. (1977), Michael et al. (1980) and Perry and Williamson (1982) as discussed and evaluated by Atkinson (1989). At temperatures above $\sim 500 \mathrm{~K}$ another component of the rate coefficient with a much stronger temperature dependence also has to be taken into account (Atkinson, 1989). The preferred values should be used in connection with the calculated $F_{c}$ values from Fulle et al. (1997) such as given in comment (f) of $k_{0}\left(F_{c}=0.37\right.$ at $298 \mathrm{~K}$ ).

A comparison of the data of Perry et al. (1977), Michael et al. (1980), Perry and Williamson (1982), Hack et al. (1983), Atkinson and Aschmann (1984), Schmidt et al. (1985), Wahner and Zetzsch (1985), Hatakeyama et al. (1986), Liu et al. (1988), Arnts et al. (1989) and Bohn et al. (1996) at pressures between 0.01-1 bar with the results from Fulle et al. (1997) at 2-80 bar shows considerable discrepancies, with the data of Fulle et al. (1997) leading to $k_{\infty}$ considerably higher than the lower pressure data. This influences the construction of falloff curves and the extrapolation to $k_{0}$. The recent study of Sørensen et al. (2003) confirms the earlier data of Perry et al. (1977), Michael et al. (1980), Perry and Williamson (1982), Hack et al. (1983), Atkinson and Aschmann (1984), Schmidt et al. (1985), Wahner and Zetzsch (1985), Hatakeyama et al. (1986), Liu et al. (1988), Arnts et al. (1989) and Bohn et al. (1996) [see below].

\section{High-pressure Rate coefficients}

\section{Rate coefficient data}

\begin{tabular}{lllc}
\hline$k_{\infty} / \mathrm{cm}^{3}$ molecule ${ }^{-1} \mathrm{~s}^{-1}$ & Temp./K & Reference & Technique/Comments \\
\hline $\begin{array}{l}\text { Absolute Rate Coefficients } \\
(6.91 \pm 0.90) \times 10^{-13}\end{array}$ & 297 & Perry and Williamson, 1982 & FP-RF (a) \\
$(8.3 \pm 0.8) \times 10^{-13}$ & 295 & Schmidt et al., 1985 & PLP-LIF (b) \\
$9 \times 10^{-13}$ & 298 & Wahner and Zetzsch, 1985 & PLP-A (c) \\
$(8.5 \pm 0.6) \times 10^{-13}$ & 298 & Bohn et al., 1996 & PLP-A (d) \\
$8.5 \times 10^{-12} \exp (-705 / T)$ & $333-1273$ & Liu et al., 1988 & PR-RA (e) \\
$8.0 \times 10^{-13}$ & $298^{*}$ & & \\
$3.8 \times 10^{-11} \exp (-910 / T)$ & $300-814$ & Fulle et al., 1997 & PLP-LIF (f) \\
$1.8 \times 10^{-12}$ & $298^{*}$ & & \\
& & & \\
Relative Rate Coefficients & & & \\
$(8.1 \pm 1.3) \times 10^{-13}(1$ bar air $)$ & 298 & Atkinson and Aschmann, 1984 & RR (g) \\
$(8.1 \pm 1.8) \times 10^{-13}(1$ bar air) & $297 \pm 2$ & Hatakeyama et al., 1986 & RR (h) \\
$(7.0 \pm 0.7) \times 10^{-13}(1$ bar air $)$ & $297 \pm 2$ & Arnts et al., 1989 & RR (i) \\
$(9.69 \pm 0.30) \times 10^{-13}$ & 296 & Sørensen et al., 2003 & RR (j) \\
$(7.67 \pm 0.06) \times 10^{-13}(1$ bar air $)$ & 296 & Sørensen et al., 2003 & RR (k,l) \\
$(8.2 \pm 1.0) \times 10^{-13}\left(1\right.$ bar $\left.\mathrm{N}_{2}-\mathrm{O}_{2}\right)$ & 296 & Sørensen et al., 2003 & RR (k,m) \\
\hline
\end{tabular}

\section{Comments}

(a) See comment (a) for $k_{0}$.

(b) See comment (c) for $k_{0}$. 
(c) See comment (d) for $k_{0}$.

(d) See comment (e) for $k_{0}$.

(e) Measurements were conducted at 1 bar of Ar.

(f) See comment (e) for $k_{0}$.

(g) $\mathrm{HO}$ radicals were generated by the photolysis of $\mathrm{CH}_{3} \mathrm{ONO}$ in $\mathrm{CH}_{3} \mathrm{ONO}-\mathrm{NO}-\mathrm{C}_{2} \mathrm{H}_{2}$-cyclohexane-air mixtures at 1 bar total pressure. The concentrations of acetylene and cyclohexane (the reference compound) were measured by GC. The measured rate coefficient ratio is placed on an absolute basis by use of a rate coefficient of $k(\mathrm{HO}+$ cyclohexane) $=6.97 \times 10^{-12} \mathrm{~cm}^{3}$ molecule $\mathrm{s}^{-1} \mathrm{~s}^{-1}$ (Atkinson, 1997).

(h) $\mathrm{HO}$ radicals were generated by photolysis of $\mathrm{H}_{2} \mathrm{O}_{2}$ in air at $254 \mathrm{~nm}$. The concentrations of acetylene and cyclohexane (the reference compound) were monitored by FTIR spectrometry. Measurements were carried out at 1 bar pressure in air. The measured rate coefficient ratio $k\left(\mathrm{HO}+\mathrm{C}_{2} \mathrm{H}_{2}\right) / k(\mathrm{HO}+$ cyclohexane $)=0.116 \pm 0.025$ is placed on an absolute basis by use of a rate coefficient of $k\left(\mathrm{HO}+\right.$ cyclohexane) $=6.95 \times 10^{-12} \mathrm{~cm}^{3}$ molecule ${ }^{-1} \mathrm{~s}^{-1}$ (Atkinson, 2003).

(i) $\mathrm{HO}$ radicals were generated by the photolysis of $\mathrm{CH}_{3} \mathrm{ONO}$ in air at 1 bar pressure. The concentrations of acetylene and ethane (the reference compound) were measured by GC. The measured rate coefficient ratio of $k\left(\mathrm{HO}+\mathrm{C}_{2} \mathrm{H}_{2}\right) / k(\mathrm{HO}+$ ethane) $=2.84 \pm 0.26$ (two standard deviations) is placed on an absolute basis by use of a rate coefficient of $k(\mathrm{HO}+$ ethane $)=2.45 \times 10^{-13} \mathrm{~cm}^{3}$ molecule $\mathrm{s}^{-1}$ (IUPAC, 2005).

(j) See comment (g) for $k_{0}$.

(k) $\mathrm{HO}$ radicals were generated by the photolysis of $\mathrm{CH}_{3} \mathrm{ONO}$ in air at $928-1013$ mbar of $\mathrm{O}_{2}-\mathrm{N}_{2}$ diluent. The concentrations of $\mathrm{C}_{2} \mathrm{H}_{2}$ and dimethyl ether or propane (the reference compounds) were monitored by in situ FTIR spectroscopy or GCFID, respectively. The measured rate coefficient ratios $k\left(\mathrm{HO}+\mathrm{C}_{2} \mathrm{H}_{2}\right) / k(\mathrm{HO}+$ dimethyl ether $)=0.276 \pm 0.021$ and $k(\mathrm{HO}$ $\left.+\mathrm{C}_{2} \mathrm{H}_{2}\right) / k(\mathrm{HO}+$ propane $)=0.761 \pm 0.09$ were placed on an absolute basis using rate coefficients of $k(\mathrm{HO}+$ dimethyl ether $=2.78 \times 10^{-12} \mathrm{~cm}^{3}$ molecule $\mathrm{s}^{-1}\left(\right.$ IUPAC, 2005) and $k(\mathrm{HO}+$ propane $)=1.08 \times 10^{-12} \mathrm{~cm}^{3}$ molecule $^{-1} \mathrm{~s}^{-1}$ (IUPAC, 2005).

(1) Relative to dimethyl ether.

(m) Relative to propane.

\section{Preferred Values}

$k=7.8 \times 10^{-13} \mathrm{~cm}^{3}$ molecule ${ }^{-1} \mathrm{~s}^{-1}$ at $298 \mathrm{~K}$ and 1 bar of air.

$k_{\infty}=1.0 \times 10^{-12} \mathrm{~cm}^{3}$ molecule $\mathrm{s}^{-1} \mathrm{~s}^{-1}$ at $298 \mathrm{~K}$.

\section{Reliability}

$\Delta \log k= \pm 0.15$ at 1 bar air and $298 \mathrm{~K}$.

$\Delta \log k_{\infty}= \pm 0.3$ at $298 \mathrm{~K}$.

\section{Comments on Preferred Values}

The recent study of Sørensen et al. (2003) confirms the earlier data of Perry et al. (1977), Michael et al. (1980), Perry and Williamson (1982), Atkinson and Aschmann (1984), Schmidt et al. (1985), Wahner and Zetzsch (1985), Hatakeyama et al. (1986), Liu et al. (1988), Arnts et al. (1989) and Bohn et al. (1996), all of which indicate a rate coefficient at room temperature and 1 bar of air or $\mathrm{N}_{2}$ of $\sim 8 \times 10^{-13} \mathrm{~cm}^{3}$ molecule $\mathrm{e}^{-1} \mathrm{~s}^{-1}$ and a value of $k_{\infty} \sim 1.0 \times 10^{-12} \mathrm{~cm}^{3}$ molecule $\mathrm{s}^{-1}$ at $298 \mathrm{~K}$. These data are, however, inconsistent with those from the study of Fulle et al. (1997), for reasons which are presently not understood (at $298 \mathrm{~K}$ and $1 \mathrm{bar}$ of He, the data of Fulle et al. (1997) lead to $k=1.12 \times 10^{-12} \mathrm{~cm}^{3}$ molecule $\mathrm{s}^{-1}$, with $k_{\infty}=$ $1.8 \times 10^{-12} \mathrm{~cm}^{3}$ molecule $\mathrm{s}^{-1} \mathrm{~s}^{-1}$ at $\left.298 \mathrm{~K}\right)$.

The preferred values are based on the data of Perry and Williamson (1982), Atkinson and Aschmann (1984), Schmidt et al. (1985), Wahner and Zetzsch (1985), Hatakeyama et al. (1986), Liu et al. (1988), Arnts et al. (1989), Bohn et al. (1996) and Sørensen et al. (2003) and are applicable to room temperature only. 


\section{References}

Arnts, R. R., Seila, R. L. and Bufalini, J. J.: J. Air Pollut. Control Assoc., 39, 453, 1989.

Atkinson, R.: J. Phys. Chem. Ref. Data, Monograph, 1, 1, 1989.

Atkinson, R.: Atmos. Chem. Phys. 3, 2233, 2003.

Atkinson, R. and Aschmann, S. M.: Int. J. Chem. Kinet., 16, 259, 1984.

Bohn, B., Siese, M. and Zetzsch, C.: J. Chem. Soc. Faraday Trans., 92, 1459, 1996.

Fulle, D., Hamann, H. F., Hippler, H. and Jänsch, C. P.: Ber. Bunsenges. Phys. Chem., 101, 1433, 1997.

Hack, W., Hoyermann, K., Sievert, R. and Wagner, H. Gg.: Oxid. Comm., 5, 101, 1983.

Hatakeyama, S., Washida, N. and Akimoto, H.: J. Phys. Chem., 90, 173, 1986.

IUPAC: http://www.iupac-kinetic.ch.cam.ac.uk/, 2005.

Liu, A., Mulac, W. A. and Jonah, C. D.: J. Phys. Chem., 92, 5942, 1988.

Michael, J. V., Nava, D. F., Borkowski, R. P., Payne, W. A. and Stief, L. J.: J. Chem. Phys., 73, 6108, 1980.

Pastrana, A. V. and Carr, R. W. : Int. J. Chem. Kinet., 6, 587, 1974.

Perry, R. A. and Williamson, D.: Chem. Phys. Lett., 93, 331, 1982.

Perry, R. A., Atkinson, R. and Pitts Jr., J. N.: J. Chem. Phys., 67, 5577, 1977.

Schmidt, V., Zhu, G. Y., Becker, K. H. and Fink, E. H.: Ber. Bunsenges. Phys. Chem., 89, 321, 1985.

Smith, G. P., Fairchild, P. W., and Crosley, D. R.: J. Chem. Phys., 81, 2667, 1984.

Sørensen, M., Kaiser, E. W., Hurley, M. D., Wallington, T. J. and Nielsen, O. J. Int. J. Chem. Kinet. 35, 191, 2003.

Wahner, A. and Zetzsch, C.: Ber. Bunsenges. Phys. Chem., 89, 323, 1985. 


\section{II.A2.5}

$$
\mathrm{HO}+\mathrm{C}_{2} \mathrm{H}_{4}+\mathrm{M} \rightarrow \mathrm{C}_{2} \mathrm{H}_{4} \mathrm{OH}+\mathrm{M}
$$

$\Delta H^{\circ}=-23 \mathrm{~kJ} \cdot \mathrm{mol}^{-1}$

\section{Low-pressure Rate coefficients}

\section{Rate coefficient data}

\begin{tabular}{|c|c|c|c|}
\hline$k_{0} / \mathrm{cm}^{3}$ molecule $^{-1} \mathrm{~s}^{-1}$ & Temp./K & Reference & Technique/Comments \\
\hline \multicolumn{4}{|l|}{ Absolute Rate Coefficients } \\
\hline $5.5 \times 10^{-29}[\mathrm{Ar}]$ & 296 & Zellner and Lorenz, 1984 & PLP-RF (a) \\
\hline$(6.1 \pm 1.2) \times 10^{-29}\left[\mathrm{~N}_{2}\right]$ & 300 & Kuo and Lee, 1991 & DF-RF (b) \\
\hline$(5.2 \pm 1.1) \times 10^{-29}\left[\mathrm{O}_{2}\right]$ & 300 & & \\
\hline $4.1 \times 10^{-29}(T / 300)^{-3.4}[\mathrm{He}]$ & $300-800$ & Fulle et al., 1997 & PLP-LIF (c) \\
\hline$(2.8 \pm 0.1) \times 10^{-29}(T / 300)^{-3.5}[\mathrm{He}]$ & $300-423$ & Chuong and Stevens, 2000 & DF-LIF (d) \\
\hline$(11.6 \pm 1.8) \times 10^{-29}\left[\mathrm{~N}_{2}\right]$ & 296 & Vakhtin et al., 2003 & PLP-LIF (e) \\
\hline \multicolumn{4}{|l|}{ Relative Rate Coefficients } \\
\hline$\left(9.5_{-2.4}^{+3.2}\right) \times 10^{-29}[$ air $]$ & 295 & Klein et al., 1984 & $\mathrm{RR}(\mathrm{f})$ \\
\hline$\left(5.9_{-1.0}^{+3.0}\right) \times 10^{-29}[\mathrm{Ar}]$ & 295 & & \\
\hline
\end{tabular}

\section{Comments}

(a) Pressure range 4 mbar to $130 \mathrm{mbar}$, temperature range $296 \mathrm{~K}$ to $524 \mathrm{~K}$. Falloff extrapolation using $F_{c}=0.8$.

(b) Pressure range 0.4 mbar to 66 mbar. $\mathrm{HO}$ radicals were generated by reaction of $\mathrm{H}$ atoms with excess $\mathrm{NO}_{2}$. Data extrapolated using $F_{c}=0.7$.

(c) The pressure was varied between 1 mbar and 150 bar. Falloff curves were also constructed using earlier rate data with a calculated $F_{c}=0.21 \exp (-220 / T)+\exp (-T / 305)$ and $F_{c}(300)=0.47$. The value $\Delta \mathrm{H}^{\circ}(0 \mathrm{~K})=-(123 \pm 6) \mathrm{kJ}^{-10 l^{-1}}$ was derived from a third-law analysis of the equilibrium constant $\mathrm{K}_{c}$ for which $\mathrm{K}_{c}=2.1 \times 10^{-2} T^{-0.95} \exp (14780 / T) \mathrm{bar}^{-1}$ was obtained from measurements performed at 646-803 K and He pressures up to $140 \mathrm{bar}$.

(d) Pressure range 2.6 mbar to 8 mbar. Falloff extrapolation using $F_{c}=0.6$ and $k_{\infty}=1.96 \times 10^{-12} \exp (438 / T) \mathrm{cm}^{3}$ molecule ${ }^{-1}$ $\mathrm{s}^{-1}$ from Klein et al. (1984). Differences to the results from Fulle et al. (1997) due to the use of a larger $F_{c}$.

(e) Experiments with pulsed Laval nozzle supersonic expansion over the range $2 \times 10^{16} \leq\left[\mathrm{N}_{2}\right] \leq 3 \times 10^{18} \mathrm{~cm}^{3}$ molecule $^{-1}$ $\mathrm{s}^{-1}$ at $296 \mathrm{~K}$. Single experiments at (2-3) $\times 10^{16} \mathrm{~cm}^{3}$ molecule $\mathrm{e}^{-1} \mathrm{~s}^{-1}$ also at 96,110 , and $165 \mathrm{~K}$. Falloff extrapolation with $F_{c}=0.65$ and $k_{\infty}(296 \mathrm{~K})=7.5 \times 10^{-12} \mathrm{~cm}^{3}$ molecule $^{-1} \mathrm{~s}^{-1}$.

(f) $\mathrm{HO}_{2} \mathrm{NO}_{2}-\mathrm{NO}$ system used as source of $\mathrm{HO}$ radicals. Reaction of $\mathrm{HO}$ radicals with $\mathrm{C}_{2} \mathrm{H}_{4}$ was studied in $420 \mathrm{~L}$ glass reactor relative to $\mathrm{HO}+n$-hexane where the latter reaction was calibrated against absolute measurements of the reaction $\mathrm{HO}+n$-butane $\left[k(295 \mathrm{~K})=2.53 \times 10^{-12} \mathrm{~cm}^{3}\right.$ molecule $\mathrm{s}^{-1} \mathrm{~s}^{-1}$. Pressure range $1.3-1000 \mathrm{mbar}$, falloff curves constructed with $F_{c}=0.7$.

\section{Preferred Values}

$k_{0}=8.6 \times 10^{-29}(T / 300)^{-3.1}\left[\mathrm{~N}_{2}\right] \mathrm{cm}^{3}$ molecule ${ }^{-1} \mathrm{~s}^{-1}$ over the temperature range 200-300 K.

\section{Reliability}

$\Delta \log k_{0}= \pm 0.3$ at $298 \mathrm{~K}$.

$\Delta n= \pm 2$. 


\section{Comments on Preferred Values}

Preferred values are based on an average of the data from Zellner and Lorenz (1984), Kuo and Lee (1991), Fulle et al. (1997), Chuong and Stevens (2000), Klein et al. (1984), Atkinson (1994), Tully (1983), Davis et al. (1975), Howard (1976), Greiner (1970), Morris et al. (1971), Overend and Paraskevopoulos (1977), Atkinson et al. (1977), Lloyd et al. (1976), Cox (1975) and Vakhtin et al. (2003), where the latter work showed the lowest scatter and, therefore, is given the highest weight. Falloff curves are constructed with the calculated $F_{c}=0.48$ from Fulle et al. (1997).

\section{High-pressure Rate coefficients}

\section{Rate coefficient data}

\begin{tabular}{lllc}
\hline$k_{0} / \mathrm{cm}^{3}$ molecule ${ }^{-1} \mathrm{~s}^{-1}$ & Temp./K & Reference & Technique/Comments \\
\hline $\begin{array}{l}\text { Absolute Rate Coefficients } \\
(8.47 \pm 0.24) \times 10^{-12}\end{array}$ & 291 & Tully, 1993 & PLP-LIF (a) \\
$3.3 \times 10^{-12} \exp [(320 \pm 150) / T]$ & $296-524$ & Zellner and Lorenz, 1984 & PLP-RF (b) \\
$9.7 \times 10^{-12}$ & 298 & & \\
$(9.4 \pm 1.6) \times 10^{-12}$ & 298 & Nielsen et al., 1990 & $(\mathrm{c})$ \\
$(7.7 \pm 1.0) \times 10^{-12}$ & 298 & Becker et al., 1991 & PLP-LIF (d) \\
$1.0 \times 10^{-11}$ & $300-800$ & Fulle et al., 1997 & PLP-LIF (e) \\
$(8.7 \pm 0.7) \times 10^{-12}(\text { T/300 })^{-0.85}$ & $96-296$ & Vakhtin et al., 2003 & PLP-LIF (f) \\
& & & \\
Relative Rate Coefficients & & & RR (g) \\
$(7.84 \pm 0.35) \times 10^{-12}$ & $299 \pm 2$ & Atkinson et al., 1982 & RR (h) \\
$(8.5 \pm 0.6) \times 10^{-12}$ & 295 & Klein et al., 1984 & \\
\hline
\end{tabular}

\section{Comments}

(a) Higher end of falloff curve at 66 mbar to 790 mbar; temperature range 291-591 K.

(b) See comment (a) for $k_{0}$.

(c) Pulse radiolysis of $\mathrm{H}_{2} \mathrm{O}-\mathrm{Ar}$ mixtures. $\mathrm{HO}$ monitored by UV absorption at $309 \mathrm{~nm}$. Rate coefficient determined at a total pressure of 1 bar.

(d) Experiments were carried out at a total pressure of 1 bar of synthetic air. Numerical simulation with a mechanism of 12 reactions.

(e) See comment (c) for $k_{0}$.

(f) See comment (e) for $k_{0}$.

(g) $\mathrm{HO}$ radicals were generated by photolysis of $\mathrm{CH}_{3} \mathrm{ONO}$ in presence of air containing NO. Concentrations of ethene and cyclohexane (the reference compound) were measured by GC. The rate coefficient ratio of $k(\mathrm{HO}+\mathrm{ethene}) / k(\mathrm{HO}+$ cyclohexane $)=1.12 \pm 0.05$ is placed on an absolute basis by use of a rate coefficient of $k(\mathrm{HO}+$ cyclohexane $)=7.00$ $\times 10^{-12} \mathrm{~cm}^{3}$ molecule ${ }^{-1} \mathrm{~s}^{-1}$ (Atkinson, 2003).

(h) See comment (e) for $k_{0}$.

\section{Preferred Values}

$k=7.9 \times 10^{-12} \mathrm{~cm}^{3}$ molecule ${ }^{-1} \mathrm{~s}^{-1}$ at $298 \mathrm{~K}$ and 1 bar of air.

$k_{\infty}=9.0 \times 10^{-12}(T / 300)^{-0.85} \mathrm{~cm}^{3}$ molecule ${ }^{-1} \mathrm{~s}^{-1}$ over the temperature range $100-500 \mathrm{~K}$. 


\section{Reliability}

$\Delta \log k_{\infty}= \pm 0.3$ at $298 \mathrm{~K}$.

$\Delta n= \pm 0.3$.

\section{Comments on Preferred Values}

The preferred value is from Vakhtin et al. (2003), being similar to those selected in Fulle et al. (1997), Lloyd et al. (1976) and Nielsen et al. (1990). Falloff curves should be calculated with the theoretical expression for $F_{0}=0.48$ which probably applies to $\mathrm{M}=\mathrm{He}$ as well as $\mathrm{N}_{2}$ and is practically constant over the indicated temperature range.

\section{References}

Atkinson, R.: J. Phys. Chem. Ref. Data Monograph, 2, 1, 1994.

Atkinson, R.: Atmos. Chem. Phys., 3, 2233, 2003.

Atkinson, R., Perry, R. A., and Pitts Jr., J. N.: J. Chem. Phys., 66, 1197, 1977.

Atkinson, R., Aschmann, S. M., Winer, A. M., and Pitts Jr., J. N.: Int. J. Chem. Kinet., 14, 507, 1982.

Becker, K. H., Geiger, H., and Wiesen, P.: Chem. Phys. Lett., 184, 256, 1991.

Chuong, B. and Stevens, P. S.: J. Phys. Chem. A, 104, 5230, 2000.

Cox, R. A.: Int. J. Chem. Kinet. Symp., 1, 379, 1975.

Davis, D. D., Fischer, S., Schiff, R., Watson, R. T., and Bollinger, W.: J. Chem. Phys., 63, 1707, 1975.

Fulle, D., Hamann, H. F., Hippler, H., and Jänsch, C. P.: Ber. Bunsenges. Phys. Chem., 101, 1433, 1997.

Greiner, N. R.: J. Chem. Phys., 53, 1284, 1970.

Howard, C. J.: J. Chem. Phys., 65, 4771, 1976.

Klein, Th., Barnes, I., Becker, K. H., Fink, E. H., and Zabel, F.: J. Phys. Chem., 88, 5020, 1984.

Kuo, C.-H. and Lee, Y.-P.: J. Phys. Chem., 95, 1253, 1991.

Lloyd, A. C., Darnall, K. R., Winer, A. M., and Pitts Jr., J. N.: J. Phys. Chem., 80, 789, 1976.

Morris Jr., E. D., Stedman, D. H., and Niki, H.: J. Am. Chem. Soc., 93, 3570, 1971.

Nielsen, O. J., Jørgensen, O., Donlon, M., Sidebottom, H. W., O’Farrell, D. J., and Treacy, J.: Chem. Phys. Lett., 168, 319, 1990.

Overend, R. P. and Paraskevopoulos, G.: J. Chem. Phys., 67, 674, 1977.

Tully, F. P.: Chem. Phys. Lett., 96, 198, 1983.

Vakhtin, A. B., Murphy, J. E. and Leone, S. R.: J. Phys. Chem. A, 107, 10055, 2003. Zellner, R. and Lorenz, K.: J. Phys. Chem., 88, 984, 1984. 
II.A2.6

$$
\mathrm{HO}+\mathrm{C}_{2} \mathrm{H}_{6} \rightarrow \mathrm{H}_{2} \mathrm{O}+\mathrm{C}_{2} \mathrm{H}_{5}
$$

$\Delta H^{\circ}=-74.1 \mathrm{~kJ} \cdot \mathrm{mol}^{-1}$

\section{Rate coefficient data}

\begin{tabular}{|c|c|c|c|}
\hline$k / \mathrm{cm}^{3}$ molecule $^{-1} \mathrm{~s}^{-1}$ & Temp./K & Reference & Technique/Comments \\
\hline \multicolumn{4}{|l|}{ Absolute Rate Coefficients } \\
\hline $\begin{array}{l}(2.90 \pm 0.60) \times 10^{-13} \\
(2.6 \pm 0.4) \times 10^{-13}\end{array}$ & $\begin{array}{l}290 \\
298\end{array}$ & $\begin{array}{l}\text { Leu, } 1979 \\
\text { Low }\end{array}$ & $\begin{array}{l}\text { DF-LMMR } \\
\text { DF-RF }\end{array}$ \\
\hline $8.0 \times 10^{-14}$ & 238 & Margitan amd Watson, 1982 & PLP-RF \\
\hline $1.43 \times 10^{-14} T^{1.05} \exp (-911 / T)$ & $297-800$ & Tully et al., 1983 & FP-RF \\
\hline$(2.59 \pm 0.21) \times 10^{-13}$ & 297 & & \\
\hline $1.80 \times 10^{-11} \exp [-(1240 \pm 110) T]$ & $240-295$ & Smith et al., 1984 & FP-RF \\
\hline$(2.63 \pm 0.10) \times 10^{-13}$ & 295 & & \\
\hline $2.75 \times 10^{-13}$ & 295 & Devolder et al., 1984 & DF-RF \\
\hline$(2.67 \pm 0.40) \times 10^{-13}$ & $295 \pm 2$ & Baulch et al., 1985 & DF-RF \\
\hline $8.51 \times 10^{-18} T^{2.06} \exp (-430 / T)$ & $293-705$ & Tully et al., 1986 & PLP-LIF \\
\hline$(2.39 \pm 0.10) \times 10^{-13}$ & 292.5 & & \\
\hline$(1.27 \pm 0.08) \times 10^{-13}$ & 248 & Stachnik et al., 1986 & PLP-RA \\
\hline$(1.29 \pm 0.09) \times 10^{-13}$ & 248 & & \\
\hline$(2.51 \pm 0.06) \times 10^{-13}$ & 297 & & \\
\hline$(2.50 \pm 0.06) \times 10^{-13}$ & 297 & & \\
\hline$(2.77 \pm 0.3) \times 10^{-13}$ & $296 \pm 2$ & Bourmada et al., 1987 & DF-RF \\
\hline $8.4 \times 10^{-12} \exp [-(1050 \pm 100) T]$ & $226-363$ & Wallington et al., 1987 & FP-RF \\
\hline$(2.30 \pm 0.26) \times 10^{-13}$ & 296 & & \\
\hline$(2.61 \pm 0.13) \times 10^{-13}$ & 296 & Zabarnick et al., 1988 & PLP-LIF \\
\hline$(2.38 \pm 0.16) \times 10^{-13}$ & $297 \pm 2$ & Abbatt et al., 1990 & DF-LIF \\
\hline$(1.54 \pm 0.24) \times 10^{-11}$ & $1225 \pm 16$ & Bolt and Cohen, 1991 & SH-RA \\
\hline $1.03 \times 10^{-11} \exp [-(1108 \pm 40) / T]$ & $231-377$ & Talukdar et al., 1994 & PLP-LIF \\
\hline$(2.43 \pm 0.13) \times 10^{-13}$ & 298 & & \\
\hline $8.37 \times 10^{-12}$ & $974 \pm 16$ & Koffend and Cohen, 1996 & SH-RA \\
\hline$(2.55 \pm 0.3) \times 10^{-13}$ & 300 & Donahue et al., 1996 & DF-LIF \\
\hline$(2.59 \pm 0.08) \times 10^{-13}$ & 300 & Donahue et al., 1998 & DF-LIF \\
\hline$(3.55 \pm 0.11) \times 10^{-13}$ & 325 & & \\
\hline$(3.90 \pm 0.12) \times 10^{-13}$ & 340 & & \\
\hline$(4.38 \pm 0.23) \times 10^{-13}$ & 360 & & \\
\hline$(5.61 \pm 0.17) \times 10^{-13}$ & 375 & & \\
\hline$(6.04 \pm 0.18) \times 10^{-13}$ & 390 & & \\
\hline$(2.69 \pm 0.27) \times 10^{-14}$ & 180 & Clarke et al., 1998 & DF-LIF \\
\hline$(3.77 \pm 0.04) \times 10^{-14}$ & 190 & & \\
\hline$(4.54 \pm 0.25) \times 10^{-14}$ & 200 & & \\
\hline$(6.51 \pm 0.07) \times 10^{-14}$ & 213 & & \\
\hline$(8.08 \pm 0.12) \times 10^{-14}$ & 225 & & \\
\hline$(9.67 \pm 0.18) \times 10^{-14}$ & 238 & & \\
\hline$(1.251 \pm 0.014) \times 10^{-13}$ & 250 & & \\
\hline$(1.640 \pm 0.018) \times 10^{-13}$ & 265 & & \\
\hline$(2.081 \pm 0.016) \times 10^{-13}$ & 280 & & \\
\hline$(2.515 \pm 0.021) \times 10^{-13}$ & 295 & & \\
\hline$(2.953 \pm 0.050) \times 10^{-13}$ & 310 & & \\
\hline$(3.464 \pm 0.037) \times 10^{-13}$ & 325 & & \\
\hline$(3.744 \pm 0.038) \times 10^{-13}$ & 340 & & \\
\hline$(4.637 \pm 0.164) \times 10^{-13}$ & 360 & & \\
\hline
\end{tabular}




\section{Preferred Values}

$k=2.4 \times 10^{-13} \mathrm{~cm}^{3}$ molecule ${ }^{-1} \mathrm{~s}^{-1}$ at $298 \mathrm{~K}$.

$k=6.9 \times 10^{-12} \exp (-1000 / T) \mathrm{cm}^{3}$ molecule ${ }^{-1} \mathrm{~s}^{-1}$ over the temperature range $200-300 \mathrm{~K}$.

\section{Reliability}

$\Delta \log k= \pm 0.08$ at $298 \mathrm{~K}$.

$\Delta(E / R)= \pm 100 \mathrm{~K}$.

\section{Comments on Preferred Values}

The preferred values were obtained by using the absolute rate coefficient data of Smith et al. (1984), Tully et al. (1986) (this study being judged to supersede that of Tully et al., 1983), Stachnick et al. (1986), Wallington et al. (1987), Abbatt et al. (1990), Bott and Cohen (1991), Talukdar et al. (1994), Koffend and Cohen (1996), Donahue et al. (1996, 1998) and Clarke et al. (1998). The absolute rate coefficients used in the evaluation (Smith et al., 1984; Tully et al., 1986; Stachnik et al., 1986; Wallington et al., 1987; Abbatt et al., 1990; Bott and Cohen, 1991; Talukdar et al., 1994; Koffend and Cohen, 1996; Donahue et al., 1996, 1998; Clarke et al., 1998) were fitted to the three-parameter equation $k=C T^{2} \exp (-D / T)$, resulting in $k=1.49 \times 10^{-17} T^{2} \exp (-$ $499 / T) \mathrm{cm}^{3}$ molecule ${ }^{-1} \mathrm{~s}^{-1}$ over the temperature range 180-1230 K. The preferred Arrhenius expression, $k=A \exp (-B / T)$, is centered at $250 \mathrm{~K}$ and is derived from the three-parameter equation with $A=C e^{2} T^{2}$ and $B=D+2 T$. The preferred Arrhenius expression predicts rate coefficients at $180 \mathrm{~K}$ and $190 \mathrm{~K}$ which agree to within $6 \%$ with those measured by Clarke et al. (1998).

The absolute rate coefficients of Howard and Evenson (1976), Leu (1979), Margitan and Watson (1982), Devolder et al. (1984), Baulch et al. (1985), Bourmada et al. (1987), Zabarnick et al. (1988) and Schiffman et al. (1991) (at room temperature, the precise temperature not being specified), which are not used in the evaluation of the rate coefficient, are in good agreement with the preferred values, as are the relative rate coefficients of Baulch et al. (1983), Edney et al. (1986) and Finlayson-Pitts et al. (1993).

\section{References}

Abbatt, J. P. D., Demerjian, K. L., and Anderson, J. G.: J. Phys. Chem., 94, 4566, 1990.

Baulch, D. L., Craven, R. J. B., Din, M., Drysdale, D. D., Grant, S., Richardson, D. J., Walker, A., and Watling, G.: J. Chem. Soc. Faraday Trans., 1, 79, 689, 1983.

Baulch, D. L., Campbell, I. M., and Saunders, S. M.: J. Chem. Soc. Faraday Trans., 1, 81, 259, 1985.

Bott, J. F. and Cohen, N.: Int. J. Chem. Kinet., 23, 1017, 1991.

Bourmada, N., Lafage, C., and Devolder, P.: Chem. Phys. Lett., 136, 209, 1987.

Clarke, J. S., Kroll, J. H., Donahue, N. M., and Anderson, J. G.: J. Phys. Chem. A, 102, 9847, 1998.

Devolder, P., Carlier, M., Pauwels, J. F., and Sochet, L. R.: Chem. Phys. Lett., 111, 94, 1984.

Donahue, N. M., Clarke, J. S., Demerjian, K. L., and Anderson, J. G.: J. Phys. Chem., 100, 5821, 1996.

Donahue, N. M., Anderson, J. G., and Demerjian, K. L.: J. Phys. Chem. A., 102, 3121, 1998.

Edney, E. O., Kleindienst, T. E., and Corse, E. W.: Int. J. Chem. Kinet., 18, 1355, 1986.

Finlayson-Pitts, B. J., Hernandez, S. K., and Berko, H. N.: J. Phys. Chem., 97, 1172, 1993.

Howard, C. J. and Evenson, K. M.: J. Chem. Phys., 64, 4303, 1976.

Koffend, J. B. and Cohen, N.: Int. J. Chem. Kinet., 28, 79, 1996.

Leu, M.-T.: J. Chem. Phys., 70, 1662, 1979.

Margitan, J. J. and Watson, R. T.: J. Phys. Chem., 86, 3819, 1982.

Schiffman, A., Nelson, Jr., D. D., Robinson, M. S., and Nesbitt, D. J.: J. Phys. Chem., 95, 2629, 1991.

Smith, C. A., Molina, L. T., Lamb, J. J., and Molina, M. J.: Int. J. Chem. Kinet., 16, 41, 1984.

Stachnik, R. A., Molina, L. T., and Molina, M. J.: J. Phys. Chem., 90, 2777, 1986.

Talukdar, R. K., Mellouki, A., Gierczak, T., Barone, S., Chiang, S.-Y., and Ravishankara, A. R.: Int. J. Chem. Kinet., 26, 973, 1994.

Tully, F. P., Ravishankara, A. R., and Carr, K.: Int. J. Chem. Kinet., 15, 1111, 1983.

Tully, F. P., Droege, A. T., Koszykowski, M. L., and Melius, C. F.: J. Phys. Chem., 90, 691, 1986.

Wallington, T. J., Neuman, D. M., and Kurylo, M. J.: Int. J. Chem. Kinet., 19, 725, 1987.

Zabarnick, S., Fleming, J. W., and Lin, M. C.: Int. J. Chem. Kinet., 20, 117, 1988. 
II.A2.7

$$
\mathbf{H O}+\mathrm{C}_{3} \mathbf{H}_{6}+\mathrm{M} \rightarrow \mathrm{C}_{3} \mathbf{H}_{6} \mathrm{OH}+\mathbf{M}
$$

$\Delta H^{\circ}=-134 \mathrm{~kJ} \cdot \mathrm{mol}^{-1}$

\section{Low-pressure Rate coefficients}

\section{Rate coefficient data}

\begin{tabular}{lclc}
\hline$k_{0} / \mathrm{cm}^{3}$ molecule ${ }^{-1} \mathrm{~s}^{-1}$ & Temp./K & Reference & Technique/Comments \\
\hline $\begin{array}{l}\text { Absolute Rate Coefficients } \\
8 \times 10^{-28}[\mathrm{Ar}]\end{array}$ & 298 & Zellner and Lorenz, 1983 & PLP-RF (a) \\
$9 \times 10^{-27}\left[\mathrm{~N}_{2}\right]$ & 298 & Vakhtin et al., 2003 & PLP-LIF (b) \\
& & & \\
Relative Rate Coefficients & & & \\
$8 \times 10^{-27}[\mathrm{Ar}]$ & 298 & Klein et al., 1984 & (c) \\
$8 \times 10^{-27}[$ air] & & & \\
\hline
\end{tabular}

\section{Comments}

(a) Pressure range $1.3 \mathrm{mbar}$ to $170 \mathrm{mbar}$. Falloff behavior detected, and evaluated with $F_{c}=0.8$. Rough estimate of $k_{0}$ because of the only limited extent of observed falloff.

(b) Experiments with pulsed Laval nozzle supersonic expansion over the range $2 \times 10^{-16} \leq\left[\mathrm{N}_{2}\right] \leq 3 \times 10^{18}$ molecule $\mathrm{cm}^{-3}$ at $296 \mathrm{~K}$. Single experiments at (2-3) $\times 10^{16}$ molecule $\mathrm{cm}^{-3}$ of $\mathrm{N}_{2}$ were also carried out at 96,103 , and $165 \mathrm{~K}$. Rough estimate of $k_{0}$ because of limited extent of observed falloff. Falloff curves constructed with $F_{c}=0.5$ and $k_{\infty}(296 \mathrm{~K})=$ $2.6 \times 10^{-11} \mathrm{~cm}^{3}$ molecule ${ }^{-1} \mathrm{~s}^{-1}$. See also comment (d) for $k_{\infty}$.

(c) $\mathrm{HO}_{2} \mathrm{NO}_{2}-\mathrm{NO}$ system used as source of $\mathrm{HO}$ radicals. Reaction studied relative to $\mathrm{HO}+n$-hexane, with the latter reaction calibrated against absolute measurements of the reaction $\mathrm{HO}+n$-butane $\left(k=2.53 \times 10^{-12} \mathrm{~cm}^{3}\right.$ molecule $\mathrm{e}^{-1} \mathrm{~s}^{-1}$ at $\left.295 \mathrm{~K}\right)$. Pressure range 1.3 mbar to 1000 mbar; falloff effects could be detected. Evaluation with $F_{c}=0.5$ gives the present $k_{0}$ value. Rough estimate of $k_{0}$ because of the only limited extent of observed falloff.

\section{Preferred Values}

$k_{0}=8 \times 10^{-27}(T / 300)^{-3.5}\left[\mathrm{~N}_{2}\right] \mathrm{cm}^{3}$ molecule ${ }^{-1} \mathrm{~s}^{-1}$ over the temperature range $200-300 \mathrm{~K}$.

\section{Reliability}

$\Delta \log k_{0}= \pm 1.0$ at $298 \mathrm{~K}$.

$\Delta n= \pm 1$.

\section{Comments on Preferred Values}

The uncertainty of the extrapolated $k_{0}$ is large, because the reaction is close to the high-pressure limit at the pressures studied. The preferred values follow the falloff extrapolation from Klein et al. (1984) which shows the smallest scatter. Falloff extrapolations are made using $F_{c}=0.5$ at $300 \mathrm{~K}$. The temperature coefficient of $k_{0}$ is estimated by analogy to the reaction $\mathrm{HO}+\mathrm{C}_{2} \mathrm{H}_{4}+\mathrm{M} \rightarrow \mathrm{C}_{2} \mathrm{H}_{4} \mathrm{OH}+\mathrm{M}$. 


\section{High-pressure Rate coefficients}

\section{Rate coefficient data}

\begin{tabular}{lllc}
\hline$k_{\infty} / \mathrm{cm}^{3}$ molecule ${ }^{-1} \mathrm{~s}^{-1}$ & Temp./K & Reference & Technique/Comments \\
\hline $\begin{array}{l}\text { Absolute Rate Coefficients } \\
(3.0 \pm 0.5) \times 10^{-11}\end{array}$ & 298 & Zellner and Lorenz, 1984 & PLP-RF (a) \\
$(8.1 \pm 1.8) \times 10^{-11}$ & 103 & Vakhtin et al., 2001 & (b) \\
$(2.95 \pm 0.10) \times 10^{-11}(T / 300)^{-1.06}$ & $96-296$ & Vakhtin et al., 2003 & PLP-LIF (c) \\
& & & \\
$\begin{array}{l}\text { Relative Rate Coefficients } \\
(3.0 \pm 0.2) \times 10^{-11}\end{array}$ & 295 & Klein et al., 1984 & (d) \\
\hline
\end{tabular}

\section{Comments}

(a) See comment (a) for $k_{0}$.

(b) Pulsed Laval nozzle supersonic expansion of nitrogen with admixed reactants. $\mathrm{HO}$ generated by photolysis of $\mathrm{H}_{2} \mathrm{O}_{2}$ $\left[\mathrm{N}_{2}\right]=2.1 \times 10^{16}$ molecule $\mathrm{cm}^{-3}$. Reaction observed very close to the high pressure limit.

(c) See comment (b) for $k_{0}$.

(d) See comment (c) for $k_{0}$.

\section{Preferred Values}

$k=2.9 \times 10^{-11} \mathrm{~cm}^{3}$ molecule ${ }^{-1} \mathrm{~s}^{-1}$ at $298 \mathrm{~K}$ and 1 bar of air.

$k_{\infty}=3.0 \times 10^{-11}(T / 300)^{-1} \mathrm{~cm}^{3}$ molecule ${ }^{-1} \mathrm{~s}^{-1}$ over the temperature range $200-300 \mathrm{~K}$.

\section{Reliability}

$\Delta \log k_{\infty}= \pm 0.1$ over the temperature range $200-300 \mathrm{~K}$.

$\Delta n= \pm 1$.

\section{Comments on Preferred Values}

The preferred values are based on Zellner and Lorenz (1984), Klein et al. (1984), Vakhtin et al. (2003), Nielsen et al. (1990) and Tully and Goldsmith (1985). There is an uncertainty about the extent of falloff at temperatures above $300 \mathrm{~K}$ and there is the possibility of a small activation barrier, such as observed in the reaction $\mathrm{HO}+\mathrm{C}_{2} \mathrm{H}_{2}+\mathrm{M} \rightarrow \mathrm{C}_{2} \mathrm{H}_{2} \mathrm{OH}+\mathrm{M}$. The preferred temperature dependence is derived by combining the results from Zellner and Lorenz (1984), Klein et al. (1984) and Vakhtin et al. (2003), confirming the suggestions from Atkinson (1994) and Tsang (1991). $F_{c}=0.5$ serves for estimating the extent of falloff.

\section{References}

Atkinson, R.: J. Phys. Chem. Ref. Data Monograph, 2, 1, 1994.

Klein, Th., Barnes, I., Becker, K. H., Fink, E. H., and Zabel, F.: J. Phys. Chem., 88, 5020, 1984.

Nielsen, O. J., Jørgensen, O., Donlon, M., Sidebottom, H. W., O’Farrell, D. J., and Treacy, J.: Chem. Phys. Lett, 168, 319, 1990.

Tsang, W.: J. Phys. Chem. Ref. Data, 20, 221, 1991.

Tully, F. P. and Goldsmith, J. E. M.: Chem. Phys. Lett., 116, 345, 1985.

Vakhtin, A. B., Lee, S., Heard, D. E., Smith, I. W. M., and Leone, S. R.: J. Phys. Chem. A, 105, 7889, 2001.

Vakhtin, A. B., Murphy, J. E. and Leone, S. R.: J. Phys. Chem. A, 107, 10055, 2003.

Zellner, R. and Lorenz, K.: J. Phys. Chem., 88, 984, 1984. 
II.A2.8

$$
\begin{aligned}
\mathrm{HO}+\mathrm{C}_{3} \mathrm{H}_{8} & \rightarrow \mathrm{H}_{2} \mathrm{O}+\mathrm{CH}_{3} \mathrm{CH}_{2} \mathrm{CH}_{2} \\
& \rightarrow \mathrm{H}_{2} \mathrm{O}+\mathrm{CH}_{3} \mathrm{CHCH}_{3}
\end{aligned}
$$

$\Delta H^{0}(1)=-73.7 \mathrm{~kJ} \cdot \mathrm{mol}^{-1}$

$\Delta H^{0}(2)=-87.9 \mathrm{~kJ} \cdot \mathrm{mol}^{-1}$

\begin{tabular}{|c|c|c|c|}
\hline$k / \mathrm{cm}^{3}$ molecule $^{-1} \mathrm{~s}^{-1}$ & Temp./K & Reference & Technique/Comments \\
\hline \multicolumn{4}{|l|}{ Absolute Rate Coefficients } \\
\hline$(2.62 \pm 0.67) \times 10^{-11}$ & $1220 \pm 15$ & Bott and Cohen, 1984 & SH-RA \\
\hline$(2.19 \pm 0.60) \times 10^{-11}$ & 1074 & Smith et al., 1985 & LH-LIF \\
\hline$(1.20 \pm 0.18) \times 10^{-12}$ & $295 \pm 2$ & Baulch et al., 1985 & DF-RF \\
\hline $1.04 \times 10^{-16} T^{1.72} \exp (-145 / T)$ & $293-854$ & Droege and Tully, 1986 & PLP-LIF \\
\hline$(1.10 \pm 0.04) \times 10^{-12}$ & 293 & & \\
\hline$(1.21 \pm 0.10) \times 10^{-12}$ & $297 \pm 2$ & Abbatt et al., 1990 & DF-LIF \\
\hline$(1.22 \pm 0.08) \times 10^{-12}$ & 298 & Mac Leod et al., 1990 & PLP-LIF \\
\hline $9.81 \times 10^{-12} \exp [-(650 \pm 30) / T]$ & $233-363$ & Mellouki et al., 1994 & PLP-LIF \\
\hline$(1.05 \pm 0.09) \times 10^{-12}$ & 295 & & \\
\hline $1.01 \times 10^{-11} \exp [-(657 \pm 46) / T]$ & $233-376$ & Talukdar et al., 1994 & PLP-LIF \\
\hline$(1.11 \pm 0.04) \times 10^{-12}$ & 298 & & \\
\hline$(1.09 \pm 0.03) \times 10^{-12}$ & 300 & Donahue et al., 1998 & DF-LIF \\
\hline$(1.37 \pm 0.04) \times 10^{-12}$ & 325 & & \\
\hline$(1.46 \pm 0.04) \times 10^{-12}$ & 340 & & \\
\hline$(1.60 \pm 0.09) \times 10^{-12}$ & 360 & & \\
\hline$(1.85 \pm 0.06) \times 10^{-12}$ & 375 & & \\
\hline$(1.83 \pm 0.10) \times 10^{-12}$ & 390 & & \\
\hline$(3.626 \pm 0.247) \times 10^{-13}$ & 190 & Clarke et al., 1998 & DF-LIF \\
\hline$(4.136 \pm 0.127) \times 10^{-13}$ & 200 & & \\
\hline$(4.864 \pm 0.095) \times 10^{-13}$ & 213 & & \\
\hline$(5.602 \pm 0.063) \times 10^{-13}$ & 225 & & \\
\hline$(6.475 \pm 0.053) \times 10^{-13}$ & 238 & & \\
\hline$(7.532 \pm 0.051) \times 10^{-13}$ & 250 & & \\
\hline$(8.691 \pm 0.147) \times 10^{-13}$ & 265 & & \\
\hline$(1.129 \pm 0.0159) \times 10^{-12}$ & 295 & & \\
\hline$(1.276 \pm 0.0182) \times 10^{-12}$ & 310 & & \\
\hline$(1.356 \pm 0.0140) \times 10^{-12}$ & 325 & & \\
\hline$(1.480 \pm 0.0136) \times 10^{-12}$ & 340 & & \\
\hline$(1.640 \pm 0.0229) \times 10^{-12}$ & 360 & & \\
\hline$(1.15 \pm 0.1) \times 10^{-12}$ & 298 & Carl and Crowley, 2001 & PLP-RF \\
\hline$(1.17 \pm 0.1) \times 10^{-12}$ & 298 & & \\
\hline $5.81 \times 10^{-12} T^{1.83} \exp (-167 / T)$ & $210-480$ & Kozlov et al., 2003 & FP-RF \\
\hline$(1.13 \pm 0.02) \times 10^{-12}$ & 298 & & \\
\hline
\end{tabular}

Rate coefficient data $\left(k=k_{1}+k_{2}\right)$

\section{Preferred Values}

$k=1.1 \times 10^{-12} \mathrm{~cm}^{3}$ molecule $\mathrm{e}^{-1} \mathrm{~s}^{-1}$ at $298 \mathrm{~K}$.

$k=7.6 \times 10^{-12} \exp (-585 / T) \mathrm{cm}^{3}$ molecule ${ }^{-1} \mathrm{~s}^{-1}$ over the temperature range $200-300 \mathrm{~K}$. 


\section{Reliability}

$\Delta \log k= \pm 0.08$ at $298 \mathrm{~K}$.

$\Delta(E / R)= \pm 100 \mathrm{~K}$.

\section{Comments on Preferred Values}

The absolute rate coefficient data of Bott and Cohen (1984), Smith et al. (1985), Droege and Tully (1986), Abbatt et al. (1990), Mac Leod et al. (1990), Mellouki et al. (1994), Talukdar et al. (1994), Donahue et al. (1998) and Clarke et al. (1998) were used to derive the preferred value. These data were fitted to the three-parameter equation $k=C T^{2} \exp (-D / T)$, resulting in $k=1.65 \times 10^{-17} T^{2} \exp (-87 / T) \mathrm{cm}^{3}$ molecule ${ }^{-1} \mathrm{~s}^{-1}$ over the temperature range $190-1220 \mathrm{~K}$. The rate coefficients recently measured by Kozlov et al. (2003) are in agreement with the preferred value to within $5 \%$ over the entire temperature range studied $(210-480 \mathrm{~K})$. The preferred Arrhenius expression, $k=\mathrm{A} \exp (-B / T)$, is centered at $250 \mathrm{~K}$, and is derived from the three-parameter equation with $\mathrm{A}=C e^{2} T^{2}$ and $B=D+2 T$. The preferred Arrhenius expression predicts a rate coefficient at $190 \mathrm{~K}$ which is within $4 \%$ of that measured by Clarke et al. (1998). The relative rate coefficients of Atkinson et al. (1982), Baulch et al. (1983), Edney et al. (1986), Nielsen et al. (1991), Finlayson-Pitts et al. (1993) and DeMore and Bayes (1999) are in good agreement with the recommended expression, as are the absolute rate coefficients of Tully et al. (1983) (judged to be superseded by the study of Droege and Tully, 1986), Baulch et al. (1985), Schiffman et al. (1991) and Carl and Crowley (2001).

Droege and Tully (1986) also measured rate coefficients for the reaction of the HO radical with fully and partially deuterated propanes, and derived a value of $k_{1} / k_{2}=226 T^{-0.64} \exp (-816 / T)$, leading to $k_{1}=3.0 \times 10^{-13} \mathrm{~cm}^{3} \mathrm{molecule}^{-1} \mathrm{~s}^{-1}$ at $298 \mathrm{~K}$ and $k_{2}=8.0 \times 10^{-13} \mathrm{~cm}^{3}$ molecule ${ }^{-1} \mathrm{~s}^{-1}$ at $298 \mathrm{~K}$.

\section{References}

Abbatt, J. P. D., Demerjian, K. L., and Anderson, J. G.: J. Phys. Chem., 94, 4566, 1990.

Atkinson, R., Aschmann, S. M., Carter, W. P. L., Winer, A. M., and Pitts Jr., J. N.: Int. J. Chem. Kinet., 14, 781, 1982.

Baulch, D. L., Craven, R. J. B., Din, M., Drysdale, D. D., Grant, S., Richardson, D. J., Walker, A., and Watling, G.: J. Chem. Soc. Faraday Trans., 1, 79, 689, 1983.

Baulch, D. L., Campbell, I. M., and Saunders, S. M.: J. Chem. Soc. Faraday Trans., 1, 81, 259, 1985.

Bott, J. F. and Cohen, N.: Int. J. Chem. Kinet., 16, 1557, 1984.

Carl, S. A. and Crowley, J. N.: Atmos. Chem. Phys., 1, 1, 2001.

Clarke, J. S., Kroll, J. H., Donahue, N. M., and Anderson, J. G.: J. Phys. Chem. A, 102, 9847, 1998.

DeMore, W. B. and Bayes, K. D.: J. Phys. Chem. A, 103, 2649, 1999.

Donahue, N. M., Anderson, J. G., and Demerjian, K. L.: J. Phys. Chem. A., 102, 3121, 1998.

Droege, A. T. and Tully, F. P.: J. Phys. Chem., 90, 1949, 1986.

Edney, E. O., Kleindienst, T. E., and Corse, E. W.: Int. J. Chem. Kinet., 18, 1355, 1986.

Finlayson-Pitts, B. J., Hernandez, S. K., and Berko, H. N.: J. Phys. Chem., 97, 1172, 1993.

Kozlov, S. N., Orkin, V. L., Huie, R. E., and Kurylo, M. J.: J. Phys. Chem. A, 107, 1333, 2003.

Mac Leod, H., Balestra, C., Jourdain, J. L., Laverdet, G., and Le Bras, G.: Int. J. Chem. Kinet., 22, 1167, 1990.

Mellouki, A., Téton, S., Laverdet, G., Quilgars, A., and Le Bras, G.: J. Chim. Phys., 91, 473, 1994.

Nielsen, O. J., Sidebottom, H. W., Donlon, M., and Treacy, J.: Int. J. Chem. Kinet., 23, 1095, 1991.

Schiffman, A., Nelson Jr., D. D., Robinson, M. S., and Nesbitt, D. J.: J. Phys. Chem., 95, 2629, 1991.

Smith, G. P., Fairchild, P. W., Jeffries, J. B., and. Crosley, D. R.: J. Phys. Chem., 89, 1269, 1985.

Talukdar, R. K., Mellouki, A., Gierczak, T., Barone, S., Chiang, S.-Y., and Ravishankara, A. R.: Int. J. Chem. Kinet., 26, 973, 1994.

Tully, F. P., Ravishankara, A. R., and Carr, K.: Int. J. Chem. Kinet., 15, 1111, 1983. 
II.A2.9

$$
\begin{aligned}
\mathrm{HO}+\mathrm{CH}_{3} \mathrm{CH}_{2} \mathrm{CH}_{2} \mathrm{CH}_{3} & \rightarrow \mathrm{H}_{2} \mathrm{O}+\mathrm{CH}_{2} \mathrm{CH}_{2} \mathrm{CH}_{2} \mathrm{CH}_{3} \\
& \rightarrow \mathrm{H}_{2} \mathrm{O}+\mathrm{CH}_{3} \mathrm{CHCH}_{2} \mathrm{CH}_{3}
\end{aligned}
$$

$\Delta H^{0}(1)=-72.4 \mathrm{~kJ} \cdot \mathrm{mol}^{-1}$

$\Delta H^{0}(2)=-86.6 \mathrm{~kJ} \cdot \mathrm{mol}^{-1}$

\begin{tabular}{|c|c|c|c|}
\hline$k / \mathrm{cm}^{3}$ molecule $^{-1} \mathrm{~s}^{-1}$ & Temp./K & Reference & Technique/Comments \\
\hline \multicolumn{4}{|l|}{ Absolute Rate Coefficients } \\
\hline $1.41 \times 10^{-11} \exp [-(524 \pm 93) / T]$ & $298-495$ & Greiner, 1970 & FP-AS \\
\hline$(2.56 \pm 0.08) \times 10^{-12}$ & 298 & & \\
\hline$(2.35 \pm 0.35) \times 10^{-12}$ & 298 & Stuhl, 1973 & FP-RF \\
\hline$(4.22 \pm 0.17) \times 10^{-12}$ & 298 & Gordon and Mulac, 1975 & PR-RA \\
\hline$(4.15 \pm 0.17) \times 10^{-12}$ & 381 & & \\
\hline$(4.98 \pm 0.17) \times 10^{-12}$ & 416 & & \\
\hline $1.76 \times 10^{-11} \exp [-(559 \pm 151) / T]$ & $298-420$ & Perry et al., 1976 & FP-RF \\
\hline$(2.72 \pm 0.27) \times 10^{-12}$ & 298 & & \\
\hline$(2.67 \pm 0.22) \times 10^{-12}$ & $297 \pm 2$ & Paraskevopoulos and Nip, 1980 & FP-RA \\
\hline$(2.3 \pm 0.3) \times 10^{-12}$ & 295 & Schmidt et al., 1985 & PLP-LIF \\
\hline $2.34 \times 10^{-17} T^{1.95} \exp (134 / T)$ & $294-509$ & Droege and Tully, 1986 & PLP-LIF \\
\hline$(2.42 \pm 0.10) \times 10^{-12}$ & 294 & & \\
\hline$(2.25 \pm 0.10) \times 10^{-12}$ & $297 \pm 2$ & Abbatt et al., 1990 & DF-LIF \\
\hline$(2.32 \pm 0.08) \times 10^{-12}$ & $\sim 298$ & Schiffman et al., 1991 & PLP-IR \\
\hline $2.04 \times 10^{-17} T^{2} \exp [(85 \pm 8) / T]$ & $231-378$ & Talukdar et al., 1994 & PLP-LIF \\
\hline$(2.459 \pm 0.018) \times 10^{-12}$ & 299 & & \\
\hline$(2.43 \pm 0.07) \times 10^{-12}$ & 300 & Donahue et al., 1998 & DF-LIF \\
\hline$(2.74 \pm 0.08) \times 10^{-12}$ & 325 & & \\
\hline$(2.87 \pm 0.09) \times 10^{-12}$ & 340 & & \\
\hline$(3.48 \pm 0.10) \times 10^{-12}$ & 375 & & \\
\hline$(3.54 \pm 0.11) \times 10^{-12}$ & 390 & & \\
\hline$(2.6 \pm 0.5) \times 10^{-12}$ & 300 & Chuong and Stevens, 2002 & DF-LIF \\
\hline$(2.6 \pm 0.2) \times 10^{-12}$ & 300 & & \\
\hline \multicolumn{4}{|l|}{ Relative Rate Coefficients } \\
\hline $9.9 \times 10^{-12}$ & 753 & Baker et al., 1970; & $\mathrm{RR}(\mathrm{a})$ \\
\hline & & Baldwin and Walker, 1979 & \\
\hline$(9.3 \pm 0.8) \times 10^{-12}$ & 653 & Hucknell et al., 1975 & $\mathrm{RR}(\mathrm{b})$ \\
\hline$(2.52 \pm 0.25) \times 10^{-12}$ & $299 \pm 2$ & Atkinson et al., 1981 & $\mathrm{RR}(\mathrm{c})$ \\
\hline$(2.71 \pm 0.32) \times 10^{-12}$ & $295 \pm 1$ & Atkinson and Aschmann, 1984 & $\mathrm{RR}(\mathrm{c})$ \\
\hline$(2.70 \pm 0.34) \times 10^{-12}$ & $300 \pm 2$ & Barnes et al., 1986 & $\mathrm{RR}(\mathrm{d})$ \\
\hline$(2.36 \pm 0.04) \times 10^{-12}$ & $300 \pm 2$ & Behnke et al., 1988 & $\mathrm{RR}(\mathrm{e})$ \\
\hline $1.39 \times 10^{-11} \exp (-526 / T)$ & $235-361$ & DeMore and Bayes, 1999 & $\mathrm{RR}(\mathrm{f})$ \\
\hline $2.33 \times 10^{-12}$ & 298 & & \\
\hline
\end{tabular}

Rate coefficient data $\left(k=k_{1}+k_{2}\right)$

\section{Comments}

(a) Derived from the effects of the addition of small amounts of $n$-butane to slowly reacting mixtures of $\mathrm{H}_{2}+\mathrm{O}_{2}$. The loss of $\mathrm{H}_{2}$ was followed by monitoring the pressure change due to the reaction $2 \mathrm{H}_{2}+\mathrm{O}_{2} \rightarrow 2 \mathrm{H}_{2} \mathrm{O}$, and the loss of $n$-butane was 
measured by GC. The rate coefficient ratio $k(\mathrm{HO}+n$-butane $) / k\left(\mathrm{HO}+\mathrm{H}_{2}\right)=13.2$ is placed on an absolute basis by use of a rate coefficient of $k\left(\mathrm{HO}+\mathrm{H}_{2}\right)=7.87 \times 10^{-13} \mathrm{~cm}^{3}$ molecule ${ }^{-1} \mathrm{~s}^{-1}$ at $753 \mathrm{~K}$ (Atkinson, 2003).

(b) $\mathrm{HO}$ radicals were generated by the decomposition of $\mathrm{H}_{2} \mathrm{O}_{2}$ in a boric acid-coated reaction vessel, and the concentrations of $n$-butane and propane (the reference compound) were measured by GC. The measured rate coefficient ratios of $k(\mathrm{HO}$ $+n$-butane $) / k(\mathrm{HO}+$ propane $)=1.54 \pm 0.13$ is placed on an absolute value using a rate coefficient of $k(\mathrm{HO}+$ propane $)=$ $6.16 \times 10^{-12} \mathrm{~cm}^{3}$ molecule ${ }^{-1} \mathrm{~s}^{-1}$ at $653 \mathrm{~K}$ (IUPAC, 2005).

(c) $\mathrm{HO}$ radicals were generated by the photolysis of $\mathrm{CH}_{3} \mathrm{ONO}$ in one atmosphere of air. The concentrations of $n$-butane and propene (the reference compound) were measured by GC. The measured rate coefficient ratios of $k(\mathrm{HO}+n$-butane) $/ k(\mathrm{HO}$ + propene) $=0.0962 \pm 0.0093$ at $299 \pm 2 \mathrm{~K}$ (Atkinson et al., 1981) and $0.101 \pm 0.012$ at $295 \pm 1 \mathrm{~K}$ (Atkinson and Aschmann, 1984) are placed on an absolute value using a rate coefficient of $k(\mathrm{HO}+$ propene $)=4.85 \times 10^{-12} \exp (504 / T) \mathrm{cm}^{3}$ molecule $\mathrm{s}^{-1} \mathrm{~s}^{-1}$ at atmospheric pressure of air (Atkinson, 1997).

(d) $\mathrm{HO}$ radicals were generated by the photolysis of $\mathrm{H}_{2} \mathrm{O}_{2}$ in air at atmospheric pressure, and the concentrations of $n$ butane and ethene (the reference compound) were measured by GC. The measured rate coefficient ratio of $k(\mathrm{HO}+$ $n$-butane $) / k(\mathrm{HO}+$ ethene $)=0.32 \pm 0.04$ is placed on an absolute basis by use of a rate coefficient of $k(\mathrm{HO}+$ ethene $)$ $=8.44 \times 10^{-12} \mathrm{~cm}^{3}$ molecule $\mathrm{e}^{-1} \mathrm{~s}^{-1}$ at $300 \mathrm{~K}$ and atmospheric pressure of air (Atkinson, 1997).

(e) $\mathrm{HO}$ radicals were generated by the photolysis of $\mathrm{NO}_{\mathrm{x}}$-organic-air mixtures at atmospheric pressure. The concentrations of $n$-butane and $n$-octane (the reference compound) were measured by GC, and the measured rate coefficient ratio of $k(\mathrm{HO}+n$-butane $) / k(\mathrm{HO}+n$-octane $)$ is placed on an absolute basis by use of a rate coefficient of $k(\mathrm{HO}+n$-octane $)=$ $8.15 \times 10^{-12} \mathrm{~cm}^{3}$ molecule ${ }^{-1} \mathrm{~s}^{-1}$ at $300 \mathrm{~K}$ (Atkinson, 2003).

(f) $\mathrm{HO}$ radicals were generated by the photolysis of $\mathrm{H}_{2} \mathrm{O}$ at $185 \mathrm{~nm}$ or, at low temperatures, by the photolysis of $\mathrm{N}_{2} \mathrm{O}$ at $185 \mathrm{~nm}$ in the presence of $\mathrm{H}_{2}$. The concentrations of $n$-butane and propane (the reference compound) were measured by GC. The measured rate coefficient ratios $k(\mathrm{HO}+\mathrm{n}$-butane $) / k(\mathrm{HO}+$ propane $)$ are placed on an absolute basis using a rate coefficient of $k(\mathrm{HO}+$ propane $)=1.65 \times 10^{-17} T^{2} \exp (-87 / T) \mathrm{cm}^{3}$ molecule $\mathrm{c}^{-1} \mathrm{~s}^{-1}$ (IUPAC, 2005).

\section{Preferred Values}

$k=2.3 \times 10^{-12} \mathrm{~cm}^{3}$ molecule ${ }^{-1} \mathrm{~s}^{-1}$ at $298 \mathrm{~K}$.

$k=9.1 \times 10^{-12} \exp (-405 / T) \mathrm{cm}^{3}$ molecule ${ }^{-1} \mathrm{~s}^{-1}$ over the temperature range $230-300 \mathrm{~K}$.

\section{Reliability}

$\Delta \log k= \pm 0.10$ at $298 \mathrm{~K}$.

$\Delta(E / R)= \pm 150 \mathrm{~K}$.

\section{Comments on Preferred Values}

The preferred values are based on the absolute rate coefficients of Droege and Tully (1986), Abbatt et al. (1990), Talukdar et al. (1994) and Donahue et al. (1998) and the relative rate coefficients of Baker et al. (1970) (as re-evaluated by Baldwin and Walker, 1979), Hucknall et al. (1975) and DeMore and Bayes (1999). The rate coefficients from these studies (Droege and Tully, 1986; Abbatt et al., 1990; Talukdar et al., 1994; Donahue et al., 1998; Baker et al., 1970; Baldwin and Walker, 1979; Hucknall et al., 1975; DeMore and Bayes, 1999) are fitted to the three parameter expression, $k=C T^{2} \exp (-D / T)$, resulting in $k=1.81 \times 10^{-17} T^{2} \exp (114 / T) \mathrm{cm}^{3}$ molecule ${ }^{-1} \mathrm{~s}^{-1}$ over the temperature range $230-760 \mathrm{~K}$. The preferred Arrhenius expression, $k=A \exp (-B / T)$, is centered at $260 \mathrm{~K}$ and is derived from the three parameter expression with $A=C e^{2} T^{2}$ and $B=D+2 T$. The preferred values are in good agreement with the room temperature absolute and relative rate coefficients of Greiner (1970), Stuhl (1973), Perry et al. (1976), Paraskevopoulos and Nip (1980), Schmidt et al. (1985), Schiffman et al. (1991), Atkinson et al. (1981), Atkinson and Aschmann (1984), Barnes et al. (1986), Behnke et al. (1988) and Chuong and Stevens (2002), which were not used in the evaluation of the rate coefficient.

Droege and Tully (1986) also measured rate coefficients for the reaction of the HO radical with $n$-butane- $\mathrm{d}_{10}$, and derived a value of $k_{1} / k_{2}=1.035 \exp (-536 / T)$, leading to $k_{1}=3.4 \times 10^{-13} \mathrm{~cm}^{3}$ molecule ${ }^{-1} \mathrm{~s}^{-1}$ at $298 \mathrm{~K}$ and $k_{2}=2.00 \times 10^{-12} \mathrm{~cm}^{3}$ molecule ${ }^{-1} \mathrm{~s}^{-1}$ at $298 \mathrm{~K}$. 


\section{References}

Abbatt, J. P. D., Demerjian, K. L., and Anderson, J. G. :J. Phys. Chem., 94, 4566, 1990.

Atkinson, R.: J. Phys. Chem. Ref. Data, 26, 215, 1997.

Atkinson, R.: Atmos. Chem. Phys., 3, 2233, 2003.

Atkinson, R. and Aschmann, S. M.: Int. J. Chem. Kinet., 16, 1175, 1984.

Atkinson, R., Carter, W. P. L., Winer, A. M., and Pitts Jr., J. N.: J. Air Pollut. Contr. Assoc., 31, 1090, 1981.

Baker, R. R., Baldwin, R. R., and Walker, R. W.: Trans. Faraday Soc., 66, 2812, 1970.

Baldwin, R. R. and Walker, R. W.: J. Chem. Soc. Faraday Trans., 1, 75, 140, 1979.

Barnes, I., Bastian, V., Becker, K. H., Fink, E. H., and Nelsen, W.: J. Atmos. Chem., 4, 445, 1986.

Behnke, W., Holländer, H., Koch, W., Nolting, F., and Zetzsch, C.: Atmos. Environ., 22, 1113, 1988.

Chuong, B. and Stevens, P. S.: J. Geophys. Res., 107(D13), ACH-2, 2002.

DeMore, W. B. and Bayes, K. D. : J. Phys. Chem. A, 103, 2649, 1999.

Donahue, N. M., Anderson, J. G., and Demerjian, K. L.: J. Phys. Chem. A., 102, 3121, 1998.

Droege, A. T. and Tully, F. P. : J. Phys. Chem., 90, 5937, 1986.

Gordon, S. and Mulac, W. A : Int. J. Chem. Kinet. Symp., 1, 289, 1975.

Greiner, N. R.: J. Chem. Phys., 53, 1070, 1970.

Hucknall, D. J., Booth, D., and Sampson, R. J.: Int. J. Chem. Kinet. Symp., 1, 301, 1975.

IUPAC: http://www.iupac-kinetic.ch.cam.ac.uk/, 2005.

Paraskevopoulos, G. and Nip, W. S.: Can. J. Chem., 58, 2146, 1980.

Perry, R. A., Atkinson, R., and Pitts Jr., J. N.: J. Chem. Phys., 64, 5314, 1976.

Schiffman, A., Nelson Jr., D. D., Robinson, M. S., and Nesbitt, D. J.: J. Phys. Chem., 95, 2629, 1991.

Schmidt, V., Zhu, G. Y., Becker, K. H., and Fink, E. H.: Ber. Bunsenges. Phys. Chem., 89, 321, 1985.

Stuhl, F.: Z. Naturforsch., 28A, 1383, 1973.

Talukdar, R. K., Mellouki, A., Gierczak, T., Barone, S., Chiang, S.-Y., and Ravishankara, A. R.: Int. J. Chem. Kinet., 26, 973, 1994. 
II.A2.10

$$
\mathrm{HO}+\mathrm{CH}_{2}=\mathrm{C}\left(\mathrm{CH}_{3}\right) \mathrm{CH}=\mathrm{CH}_{2} \rightarrow \text { products }
$$

\section{Rate coefficient data}

\begin{tabular}{llll}
\hline$k / \mathrm{cm}^{3}$ molecule ${ }^{-1} \mathrm{~s}^{-1}$ & Temp./K & Reference & Technique/Comments \\
\hline Absolute Rate Coefficients & & & \\
$2.36 \times 10^{-11} \exp [(409 \pm 28) / T]$ & $299-422$ & Kleindienst et al., 1982 & FP-RF \\
$(9.26 \pm 1.5) \times 10^{-11}$ & 299 & & \\
$9.7 \times 10^{-11}(T / 298)^{-1.36}$ & $249-348$ & Siese et al., 1994 & FP-RF \\
$9.7 \times 10^{-11}$ & 298 & & \\
$(1.10 \pm 0.05) \times 10^{-10}$ & 298 & Stevens et al., 1999 & DF-LIF \\
$2.70 \times 10^{-11} \exp [(336 \pm 74) / T]$ & $251-341$ & Campuzano-Jost et al., 2000 & PLP-LIF (a) \\
$(8.56 \pm 0.26) \times 10^{-11}$ & 297 & & \\
$(1.10 \pm 0.04) \times 10^{-10}$ & 300 & Chuong and Stevens, 2000 & DF-LIF (b) \\
$(9.6 \pm 0.5) \times 10^{-11}$ & 295 & McGivern et al., 2000 & PLP-LIF (c) \\
$(1.01 \pm 0.08) \times 10^{-10}$ & $298 \pm 2$ & Zhang et al., 2000 & DF-CIMS (d) \\
$9.1 \times 10^{-11}$ & $298 \pm 2$ & Zhang et al., 2001 & DF-CIMS (e) \\
$(1.08 \pm 0.05) \times 10^{-10}$ & 300 & Chuong and Stevens, 2002 & DF-LIF (f) \\
& & & \\
Relative Rate Coefficients & & & \\
$7.8 \times 10^{-11}$ & 300 & Cox et al., 1980 & RR (g) \\
$(9.98 \pm 0.45) \times 10^{-11}$ & $299 \pm 2$ & Atkinson et al., 1982 & RR (h) \\
$(9.90 \pm 0.27) \times 10^{-11}$ & $297 \pm 2$ & Ohta, 1983 & RR (i) \\
$(1.02 \pm 0.04) \times 10^{-10}$ & $295 \pm 1$ & Atkinson and Aschmann, 1984 & RR (j) \\
$(1.01 \pm 0.02) \times 10^{-10}$ & $297 \pm 1$ & Edney et al., 1986 & RR (k) \\
$(1.11 \pm 0.23) \times 10^{-10}$ & 298 & McQuaid et al., 2002 & RR (l) \\
$2.56 \times 10^{-11} \exp [(408 \pm 42) / T]$ & $298-363$ & Gill and Hites, 2002 & RR (m) \\
$(1.01 \pm 0.05) \times 10^{-10}$ & 298 & & \\
\hline
\end{tabular}

\section{Comments}

(a) Rate coefficients for the reactions of $\mathrm{HO}$ radicals with isoprene- $\mathrm{d}_{6}$ and DO radicals with isoprene were also measured at $297 \mathrm{~K}$, these being $(8.31 \pm 0.10) \times 10^{-11} \mathrm{~cm}^{3}$ molecule ${ }^{-1} \mathrm{~s}^{-1}$ and $(8.27 \pm 0.10) \times 10^{-11} \mathrm{~cm}^{3}$ molecule $\mathrm{s}^{-1} \mathrm{~s}^{-1}$, respectively.

(b) Carried out at total pressures of 2-6 Torr (2.7-8.0 mbar) of helium diluent. No pressure dependence of the rate coefficient was observed at $300 \mathrm{~K}$. However, at higher temperatures (321-423 K) the rate coefficient increased with increasing total pressure, with the effect being more pronounced at higher temperature.

(c) Carried out at total pressures of 0.5-20 Torr $(0.7-27 \mathrm{mbar})$ of argon diluent. The rate coefficient was observed to be pressure dependent below 10 Torr total pressure; the value cited in the table is that measured at 20 Torr total pressure.

(d) Carried out at total pressures of 72.7-112.7 Torr (97-150 mbar) of $\mathrm{N}_{2}$ diluent. The measured rate coefficient was independent of pressure over this range.

(e) Based on a very limited kinetic study carried out at a total pressure of 1.9 Torr (2.5 mbar) of helium diluent (the focus of the study was on formation of HO-isoprene adducts and their subsequent reactions).

(f) Carried out at total pressures of argon diluent of 100 Torr (133 mbar) and 150 Torr ( 200 mbar). The measured rate coefficient was independent of total pressure over this range.

(g) Relative rate method carried out at atmospheric pressure of air. HO radicals were generated by photolysis of HONO at wavelengths $>300 \mathrm{~nm}$. The concentrations of isoprene and ethene (the reference compound) were measured by GC. The 
measured rate coefficient ratio $k(\mathrm{HO}+$ isoprene $) / k(\mathrm{HO}+$ ethene $)$ is placed on an absolute basis by use of a rate coefficient of $k(\mathrm{HO}+$ ethene $)=8.44 \times 10^{-12} \mathrm{~cm}^{3}$ molecule $\mathrm{e}^{-1} \mathrm{~s}^{-1}$ at $300 \mathrm{~K}$ and atmospheric pressure of air (Atkinson, 1997).

(h) Relative rate method carried out at atmospheric pressure of air. $\mathrm{HO}$ radicals were generated by photolysis of $\mathrm{CH}_{3} \mathrm{ONO}$ at wavelengths $>300 \mathrm{~nm}$. The concentrations of isoprene and propene (the reference compound) were measured by GC. The measured rate coefficient ratio of $k(\mathrm{HO}+$ isoprene $) / k(\mathrm{HO}+$ propene $)=3.81 \pm 0.17$ is placed on an absolute basis by use of a rate coefficient of $k(\mathrm{HO}+$ propene $)=2.62 \times 10^{-11} \mathrm{~cm}^{3}$ molecule $\mathrm{e}^{-1} \mathrm{~s}^{-1}$ at $299 \mathrm{~K}$ and atmospheric pressure of air (Atkinson, 1997).

(i) Relative rate method carried out at atmospheric pressure of $\mathrm{N}_{2}+\mathrm{O}_{2}$. $\mathrm{HO}$ radicals were generated by photolysis of $\mathrm{H}_{2} \mathrm{O}_{2}$ at $253.7 \mathrm{~nm}$. The concentrations of isoprene and 1,3-butadiene (the reference compound) were measured by GC. The measured rate coefficient ratio of $k(\mathrm{HO}+$ isoprene $) / k(\mathrm{HO}+1,3$-butadiene $)=1.48 \pm 0.04$ is placed on an absolute basis by use of a rate coefficient of $k(\mathrm{HO}+1,3$-butadiene $)=6.69 \times 10^{-11} \mathrm{~cm}^{3}$ molecule ${ }^{-1} \mathrm{~s}^{-1}$ at $297 \mathrm{~K}$ and atmospheric pressure of air (Atkinson, 1997).

(j) Relative rate method carried out at atmospheric pressure of air. $\mathrm{HO}$ radicals were generated by photolysis of $\mathrm{CH}_{3} \mathrm{ONO}$ at wavelengths $>300 \mathrm{~nm}$. The concentrations of isoprene and propene (the reference compound) were measured by GC. The measured rate coefficient ratio of $k(\mathrm{HO}+$ isoprene $) / k(\mathrm{HO}+$ propene $)=3.81 \pm 0.15$ is placed on an absolute basis by use of a rate coefficient of $k(\mathrm{HO}+$ propene $)=2.68 \times 10^{-11} \mathrm{~cm}^{3}$ molecule $\mathrm{e}^{-1} \mathrm{~s}^{-1}$ at $295 \mathrm{~K}$ and atmospheric pressure of air (Atkinson, 1997).

(k) Relative rate method carried out at atmospheric pressure of air. $\mathrm{HO}$ radicals were generated by photolysis of $\mathrm{CH}_{3} \mathrm{ONO}$ at wavelengths $>300 \mathrm{~nm}$. The concentrations of isoprene and propene (the reference compound) were measured by GC. The measured rate coefficient ratio of $k(\mathrm{HO}+$ isoprene $) / k(\mathrm{HO}+$ propene $)$ is placed on an absolute basis by use of a rate coefficient of $k(\mathrm{HO}+$ propene $)=2.65 \times 10^{-11} \mathrm{~cm}^{3}$ molecule $\mathrm{e}^{-1} \mathrm{~s}^{-1}$ at $297 \mathrm{~K}$ and atmospheric pressure of air (Atkinson, 1997).

(1) Relative rate method carried out at atmospheric pressure of air. $\mathrm{HO}$ radicals were generated by photolysis of $\mathrm{CH}_{3} \mathrm{ONO}$. The concentrations of isoprene and trans-2-butene (the reference compound) were measured by GC. The measured rate coefficient ratio of $k(\mathrm{HO}+$ isoprene $) / k(\mathrm{HO}+$ trans-butene $)=1.74 \pm 0.14$ is placed on an absolute basis by use of a rate coefficient of $k(\mathrm{HO}+$ trans-2-butene $)=6.40 \times 10^{-11} \mathrm{~cm}^{3}$ molecule ${ }^{-1} \mathrm{~s}^{-1}$ at $298 \mathrm{~K}$ and atmospheric pressure of air (Atkinson, 1997). The cited error limits are the 95\% confidence intervals (McQuaid et al., 2002).

(m) Relative rate method carried out in a $192 \mathrm{~cm}^{3}$ volume quartz reaction vessel at atmospheric pressure of helium diluent. $\mathrm{HO}$ radicals were generated by photolysis of $\mathrm{H}_{2} \mathrm{O}_{2}$. The concentrations of isoprene and 2-methylpropene (the reference compound) were measured by MS. The measured rate coefficient ratios of $k(\mathrm{HO}+$ isoprene $) / k(\mathrm{HO}+2$-methylpropene $)$ are placed on an absolute basis by use of a rate coefficient of $k(\mathrm{HO}+2$-methylpropene $)=9.47 \times 10^{-12} \exp (504 / T) \mathrm{cm}^{3}$ molecule $\mathrm{e}^{-1} \mathrm{~s}^{-1}$ (Atkinson, 1997). The error limits for the $298 \mathrm{~K}$ rate coefficient cited in the table are based on those associated with the rate coefficient ratio (Gill and Hites, 2002).

\section{Preferred Values}

$k=1.0 \times 10^{-10} \mathrm{~cm}^{3}$ molecule ${ }^{-1} \mathrm{~s}^{-1}$ at $298 \mathrm{~K}$.

$k=2.7 \times 10^{-11} \exp (390 / T) \mathrm{cm}^{3}$ molecule $\mathrm{s}^{-1} \mathrm{~s}^{-1}$ over the temperature range $240-430 \mathrm{~K}$.

\section{Reliability}

$\Delta \log k= \pm 0.10$ at $298 \mathrm{~K}$.

$\Delta(E / R)= \pm 100 \mathrm{~K}$.

\section{Comments on Preferred Values}

The measured room temperature rate coefficients (Kleindienst et al., 1982; Siese et al., 1994; Stevens et al., 1999; Campuzano-Jost et al., 2000; Chuong and Stevens, 2000, 2002; McGivern et al., 2000; Zhang et al., 2000, 2001; Cox et al., 1980; Atkinson et al., 1982; Ohta, 1983; Atkinson and Aschmann, 1984; Edney et al., 1986; McQuaid et al., 2002; Gill and Hites, 2002) and temperature dependencies (Kleindienst et al., 1982; Siese et al., 1994; Campuzano-Jost et al., 2000; Gill and Hites, 2002) are good agreement (the temperature dependence measured by Siese et al. (1994) corresponds to $E / R=$ 
$-400 \mathrm{~K}$ over the temperature range $249-349 \mathrm{~K})$. The preferred $298 \mathrm{~K}$ rate coefficient is an average of the room temperature rate coefficients of Kleindienst et al.(1982), Siese et al. (1994), Stevens et al. (1999), Campuzano-Jost et al. (2000), Chuong and Stevens (2000, 2002), McGivern et al. (2000), Zhang et al. (2000), Atkinson et al. (1982), Ohta (1983), Atkinson and Aschmann (1984), Edney et al. (1986), McQuaid et al. (2002), and Gill and Hites (2002). The preferred temperature dependence is an average of those obtained from the four temperature dependent studies (Kleindienst et al., 1982; Siese et al., 1994; Campuzano-Jost et al., 2000; Gill and Hites, 2002). The pre-exponential factor is calculated from the preferred $298 \mathrm{~K}$ rate coefficient and the preferred temperature dependence.

The reaction proceeds by initial addition of the $\mathrm{HO}$ radical to the two $\mathrm{C}=\mathrm{C}$ bonds, followed by addition of $\mathrm{O}_{2}$ to form six possible hydroxyalkyl radicals (Atkinson, 1997). The subsequent chemistry of these radicals in the atmosphere and the products observed is discussed by Atkinson (1997) and Calvert et al. (2000). In the presence of NO (so that organic peroxy radicals react dominantly with NO) the products observed (Atkinson, 1997; Atkinson et al., 1989; Tuazon and Atkinson, 1990; Paulson et al., 1992; Miyoshi et al., 1994; Kwok et al., 1995; Chen et al., 1998) are methyl vinyl ketone (33\%), methacrolein (23\%), formaldehyde $(60 \%)$, 3-methylfuran (4.8\%), hydroxynitrates such as $\mathrm{HOCH}_{2} \mathrm{C}\left(\mathrm{CH}_{3}\right)=\mathrm{CHCH}_{2} \mathrm{ONO}_{2}$ (and isomers) (4.4\%), and the hydroxycarbonyls $\mathrm{HOCH}_{2} \mathrm{C}\left(\mathrm{CH}_{3}\right)=\mathrm{CHCHO}$ and/or $\mathrm{HOCH}_{2} \mathrm{CH}=\mathrm{C}\left(\mathrm{CH}_{3}\right) \mathrm{CHO}$.

\section{References}

Atkinson, R.: J. Phys. Chem. Ref. Data, 26, 215, 1997.

Atkinson, R. and Aschmann, S. M.: Int. J. Chem. Kinet., 16, 1175, 1984.

Atkinson, R., Aschmann, S. M., Tuazon, E. C., Arey, J., and Zielinska, B.: Int. J. Chem. Kinet., 21, 593, 1989.

Atkinson, R., Aschmann, S. M., Winer, A. M., and Pitts Jr., J. N.: Int. J. Chem. Kinet., 14, 507, 1982.

Calvert, J. G., Atkinson, R., Kerr, J. A., Madronich, S., Moortgat, G. K., Wallington, T. J., and Yarwood, G.: The Mechanisms of Atmospheric Oxidation of the Alkenes, Oxford University Press, New York, NY, 2000.

Campuzano-Jost, P., Williams, M. B., D’Ottone, L., and Hynes, A. J.: Geophys. Res. Lett., 27, 693, 2000.

Chen, X., Hulbert, D., and Shepson, P. B.: J. Geophys. Res., 103, 25 563, 1998.

Chuong, B. and Stevens, P. S.: J. Phys. Chem. A, 104, 5230, 2000.

Chuong, B. and Stevens, P. S.: J. Geophys. Res., 107(D13), ACH 2-1, 2002.

Cox, R. A., Derwent, R. G., and Williams, M. R.: Environ. Sci. Technol., 14, 57, 1980.

Edney, E. O., Kleindienst, T. E., and Corse, E. W.: Int. J. Chem. Kinet., 18, 1355, 1986.

Gill, K. J. and Hites, R. A.: J. Phys. Chem. A, 106, 2538, 2002.

Kleindienst, T. E., Harris, G. W., and Pitts Jr., J. N.: Environ. Sci. Technol., 16, 844, 1982.

Kwok, E. S. C., Atkinson, R., and Arey, J.: Environ. Sci. Technol., 29, 2467, 1995.

McGivern, W. S., Suh, I., Clinkenbeard, A. D., Zhang, R., and North, S. W.: J. Phys. Chem. A, 104, 6609, 2000.

McQuaid, J. B., Stocker, D. W., and Pilling, M. J.: Int. J. Chem. Kinet., 34, 7, 2002.

Miyoshi, A., Hatakeyama, S., and Washida, N.: J. Geophys. Res., 99, 18 799, 1994.

Ohta, T.: J. Phys. Chem., 87, 1209, 1983.

Paulson, S. E., Flagan, R. C., and Seinfeld, J. H.: Int. J. Chem. Kinet., 24, 79, 1992.

Siese, M., Koch, R., Fittschen, C., and Zetzsch, C.: Proceedings of the EUROTRAC Symposium '94, edited by: Borrell, P. M., Borrell, P., Cvita, T., and Seiler, W., SPB Academic Publishing BV, Den Haag, The Netherlands, pp. 115-119, 1994.

Stevens, P., L'Esperance, D., Chuong, B., and Martin, G.: Int. J. Chem. Kinet., 31, 637, 1999.

Tuazon, E. C. and Atkinson, R.: Int. J. Chem. Kinet., 22, 1121, 1990.

Zhang, D., Zhang, R., Church, C., and North, S. W.: Chem. Phys. Lett., 343, 49, 2001.

Zhang, R., Suh, I., Lei, W., Clinkenbeard, A. D., and North, S. W.: J. Geophys. Res., 105, 24 627, 2000. 
II.A2.11

$$
\text { HO }+\alpha \text {-Pinene } \rightarrow \text { products }
$$

\section{Rate coefficient data}

\begin{tabular}{lllc}
\hline$k / \mathrm{cm}^{3}$ molecule ${ }^{-1} \mathrm{~s}^{-1}$ & Temp./K & Reference & Technique/Comments \\
\hline $\begin{array}{l}\text { Absolute Rate Coefficients } \\
1.37 \times 10^{-11} \exp [(446 \pm 76) / T]\end{array}$ & $298-422$ & Kleindienst et al., 1982 & FP-RF \\
$(6.01 \pm 0.82) \times 10^{-11}$ & 298 & & \\
$1.63 \times 10^{-12} \exp [(1080 \pm 50) / T]$ & $300-435$ & Chuong et al., 2002 & DF-RF (a) \\
$(6.08 \pm 0.24) \times 10^{-11}$ & 300 & & \\
& & & \\
Relative Rate Coefficients & $305 \pm 2$ & Winer et al., 1976 & RR (b) \\
$(5.6 \pm 1.7) \times 10^{-11}$ & $294 \pm 1$ & Atkinson et al., 1986 & RR (c) \\
$(5.35 \pm 0.31) \times 10^{-11}$ & $295-364$ & Gill and Hites, 2002 & RR (d) \\
$1.17 \times 10^{-11} \exp [(436 \pm 53) / T]$ & 298 & & \\
$(5.05 \pm 1.23) \times 10^{-11}$ & & \\
\hline
\end{tabular}

\section{Comments}

(a) Experiments carried out at 5 Torr $(6.7 \mathrm{mbar})$ of $\mathrm{He}$ or $90 \% \mathrm{He}+10 \% \mathrm{O}_{2}$.

(b) $\mathrm{HO}$ radicals were generated by the photolysis of $\mathrm{NO}_{\mathrm{x}}$-organic-air mixtures in a $5870 \mathrm{~L}$ chamber at $\sim 1$ bar pressure. The concentrations of $\alpha$-pinene and 2-methylpropene (the reference compound) were analyzed by GC during the experiments. The measured rate coefficient ratio $k(\mathrm{HO}+\alpha$-pinene $) / k(\mathrm{HO}+2$-methylpropene $)=1.14( \pm 30 \%)$ is placed on an absolute basis by use of a rate coefficient at $305 \mathrm{~K}$ of $k\left(\mathrm{HO}+2\right.$-methylpropene) $=4.94 \times 10^{-11} \mathrm{~cm}^{3}$ molecule $\mathrm{e}^{-1} \mathrm{~s}^{-1}$ (Atkinson and Arey, 2003a).

(c) $\mathrm{HO}$ radicals were generated by the photolysis of $\mathrm{CH}_{3} \mathrm{ONO}$ in air at wavelengths $>300 \mathrm{~nm}$ in a $6400 \mathrm{~L}$ Teflon chamber at $\sim 980$ mbar pressure. The concentrations of $\alpha$-pinene and 2,3-dimethyl-2-butene (the reference compound) were analyzed by $\mathrm{GC}$ during the $\mathrm{CH}_{3} \mathrm{ONO}-\mathrm{NO}-\alpha$-pinene-2,3-dimethyl-2-butene-air irradiations. The measured rate coefficient ratio $k(\mathrm{HO}+\alpha$-pinene $) / \mathrm{k}(\mathrm{HO}+2,3$-dimethyl-2-butene $)=0.487 \pm 0.028$ is placed on an absolute basis by use of a rate coefficient at $294 \mathrm{~K}$ of $k(\mathrm{HO}+2,3$-dimethyl-2-butene $)=1.10 \times 10^{-10} \mathrm{~cm}^{3}$ molecule ${ }^{-1} \mathrm{~s}^{-1}$ (Atkinson and Arey, 2003a).

(d) $\mathrm{HO}$ radicals were generated by the photolysis of $\mathrm{H}_{2} \mathrm{O}_{2}$ in helium diluent in a $192 \mathrm{~cm}^{3}$ volume quartz vessel. The concentrations of $\alpha$-pinene and 1-butene, 2-methylpropene or trans-2-butene (the reference compounds) were analyzed by MS during the experiments. The measured rate coefficient ratios $k(\mathrm{HO}+\alpha$-pinene $) / k(\mathrm{HO}+1$-butene $), k(\mathrm{HO}+\alpha$ pinene $) / k(\mathrm{HO}+2$-methylpropene $)$ and $k(\mathrm{HO}+\alpha$-pinene $) / k(\mathrm{HO}+$ trans-2-butene $)$ are placed placed on an absolute basis by use of rate coefficients of $k(\mathrm{HO}+1$-butene $)=6.55 \times 10^{-12} \exp (467 / T) \mathrm{cm}^{3}$ molecule ${ }^{-1} \mathrm{~s}^{-1}, k(\mathrm{HO}+2$-methylpropene $)$ $=9.47 \times 10^{-12} \exp (504 / T) \mathrm{cm}^{3}$ molecule ${ }^{-1} \mathrm{~s}^{-1}$ and $k(\mathrm{HO}+$ trans-2-butene $)=1.01 \times 10^{-11} \exp (550 / T) \mathrm{cm}^{3} \mathrm{molecule}^{-1}$ $\mathrm{s}^{-1}$ (Atkinson and Arey, 2003a).

\section{Preferred Values}

$k=1.2 \times 10^{-11} \exp (440 / T) \mathrm{cm}^{3}$ molecule ${ }^{-1} \mathrm{~s}^{-1}$ over the temperature range $290-430 \mathrm{~K}$.

$k=5.3 \times 10^{-11} \mathrm{~cm}^{3}$ molecule $\mathrm{e}^{-1} \mathrm{~s}^{-1}$ at $298 \mathrm{~K}$.

\section{Reliability}

$\Delta \log k= \pm 0.15$ at $298 \mathrm{~K}$.

$\Delta(E / R)= \pm 200 \mathrm{~K}$. 


\section{Comments on Preferred Values}

At room temperature, the rate coefficients of Winer et al. (1976), Kleindienst et al. (1982), Atkinson et al. (1986), Gill and Hites (2002) and Chuong et al. (2002) are in good agremeent, as are the temperature dependencies obtained by Kleindienst et al. (1982) and Gill and Hites (2002). The temperature dependence obtained by Chuong et al. (2002) at 6.7 mbar pressure is significantly higher than those of Kleindienst et al. (1982) and Gill and Hites (2002), possibly because of fall-off effects above $300 \mathrm{~K}$ (although no evidence was obtained to support this conclusion). The preferred temperature dependence is based on those obtained by Kleindienst et al. (1982) and Gill and Hites (2002), and the preferred $298 \mathrm{~K}$ rate coefficient is the average of the measurements of Kleindienst et al. (1982), Atkinson et al. (1986) (corrected to $298 \mathrm{~K}$ using the preferred temperature dependence) and Gill and Hites (2002). The pre-exponential factor is adjusted to fit the $298 \mathrm{~K}$ preferred value.

A number of product studies have been carried out at room temperature and atmospheric pressure of air (see Atkinson and Arey, 2003b, and references therein). The reaction proceeds mainly by initial addition of the $\mathrm{HO}$ radical to the $\mathrm{C}=\mathrm{C}$ bond, resulting in two hydroxyalkyl radicals which then add $\mathrm{O}_{2}$ to form two 1,2-hydroxyalkyl peroxy radicals. $\mathrm{H}$-atom abstraction almost certainly occurs to a minor extent, with acetone (Aschmann et al., 1998; Reissell et al., 1999; Nozière et al., 1999; Orlando et al., 2000) being one of the likely products. Subsequent reactions of these 1,2-hydroxyalkyl peroxy radicals with $\mathrm{NO}, \mathrm{NO}_{2}, \mathrm{HO}_{2}$ radicals, organic peroxy radicals and $\mathrm{NO}_{3}$ radicals will lead to the products formed in the atmosphere. In the presence of NO such that organic peroxy radicals react dominantly with NO, the products observed (and their reported yields) are: pinonaldehyde, $28 \pm 5 \%$ to $87 \pm 20 \%$ (Arey et al., 1990; Hatakeyama et al., 1991; Hakola et al., 1994; Nozière et al., 1999; Wisthaler et al., 2001; Aschmann et al., 2002) with the lower yields being obtained by GC analyses (Arey et al., 1990; Hakola et al., 1994; Aschmann et al., 2002) and by proton-transfer mass spectrometry (Wisthaler et al., 2001) and the higher values by in situ FTIR spectroscopy (Hatakeyama et al., 1991; Nozière et al., 1999); acetone, 5-11\% (Aschmann et al., 1998; Reissell et al., 1999; Nozière et al., 1999; Orlando et al., 2000), formic acid, 7\% (Orlando et al., 2000); organic nitrates, 18 $\pm 9 \%$ (Nozière et al., 1999); a molecular weight 184 dihydroxycarbonyl, 19\% (Aschmann et al., 2002); a molecular weight 200 product, $\sim 11 \%$ (Aschmann et al., 2002), and molecular weight $215 \mathrm{C}_{10}$-hydroxynitrates and molecular weight 231 $\mathrm{C}_{10}$-dihydroxynitrates (Aschmann et al., 1998, 2002).

\section{References}

Arey, J., Atkinson, R., and Aschmann, S. M.: J. Geophys. Res., 95, 18 546, 1990

Aschmann, S. M., Reissell, A., Atkinson, R., and Arey, J.: J. Geophys. Res., 103, 25 553, 1998.

Aschmann, S. M., Atkinson, R., and Arey, J.: J. Geophys. Res., 107(D14), ACH 6, 2002.

Atkinson, R. and Arey, J.: Chem. Rev., 103, 4605, 2003 a.

Atkinson, R. and Arey, J.: Atmos. Environ., 37, Suppl. 2, S197, $2003 \mathrm{~b}$.

Atkinson, R., Aschmann, S. M., and Pitts Jr., J. N.: Int. J. Chem. Kinet., 18, 287, 1986.

Chuong, B., Davis, M., Edwards, M., and Stevens, P. S.: Int. J. Chem. Kinet., 34, 300, 2002.

Gill, K. J. and Hites, R. A.: J. Phys. Chem. A, 106, 2538, 2002.

Hakola, H., Arey, J., Aschmann, S. M., and Atkinson, R.: J. Atmos. Chem., 18, 75, 1994.

Hatakeyama, S., Izumi, K., Fukuyama, T., Akimoto, H., and Washida, N.: J. Geophys. Res., 96, 947, 1991.

Kleindienst, T. E., Harris, G. W., and Pitts Jr., J. N.: Environ. Sci. Technol., 16, 844, 1982.

Nozière, B., Barnes, I., and Becker, K.-H.: J. Geophys. Res., 104, 23 645, 1999.

Orlando, J. J., Nozière, B., Tyndall, G. S., Orzechowska, G., Paulson, S. E., and Rudich, Y.: J. Geophys. Res., 105, 11 561, 2000.

Reissell, A., Harry, C., Aschmann, S. M., Atkinson, R., and Arey, J.: J. Geophys. Res., 104, 13 869, 1999.

Winer, A. M., Lloyd, A. C., Darnall, K. R., and Pitts Jr., J. N.: J. Phys. Chem., 80, 1635, 1976.

Wisthaler, A., Jensen, N. R., Winterhalter, R., Lindinger, W., and Hjorth, J.: Atmos. Environ., 35, 618, 2001 
II.A2.12

$$
\begin{array}{ll}
\mathrm{HO}+\mathrm{CO} & \rightarrow \mathrm{H}+\mathrm{CO}_{2} \\
\mathrm{HO}+\mathrm{CO}+\mathrm{M} & \rightarrow \mathrm{HOCO}+\mathrm{M}
\end{array}
$$

$\Delta H^{0}(1)=-102.3 \mathrm{~kJ} \cdot \mathrm{mol}^{-1}$

$\Delta H^{0}(2)=-114.6 \mathrm{~kJ} \cdot \mathrm{mol}^{-1}$

\begin{tabular}{|c|c|c|c|}
\hline$k / \mathrm{cm}^{3}$ molecule $^{-1} \mathrm{~s}^{-1}$ & Temp./K & Reference & Technique/Comments \\
\hline \multicolumn{4}{|c|}{ Absolute Rate Coefficients } \\
\hline \multicolumn{4}{|c|}{$k(P \rightarrow 0)$} \\
\hline $1.37 \times 10^{-13}$ & 300 & Greiner, 1969 & FP-RA $(a, c)$ \\
\hline $1.35 \times 10^{-13}$ & 300 & Stuhl and Niki, 1972 & FP-RF \\
\hline $1.66 \times 10^{-13}$ & 300 & Mulcahy and Smith, 1971 & DF-MS \\
\hline $1.33 \times 10^{-13}$ & 298 & Westenberg and deHaas, 1973 & DF-EPR \\
\hline $1.39 \times 10^{-13}$ & 298 & Smith and Zellner, 1973 & FP-RA $(a, c)$ \\
\hline $1.58 \times 10^{-13}$ & 298 & Davis et al., 1974 & FP-RF \\
\hline $1.56 \times 10^{-13}$ & 296 & Howard and Evenson, 1974 & DF-LMR \\
\hline $1.20 \times 10^{-13}$ & 298 & Trainor and von Rosenberg, 1974 & FP-RA $(a, c)$ \\
\hline $0.90 \times 10^{-13}$ & 298 & Gordon and Mulac, 1975 & PR-RA (b,d) \\
\hline $1.54 \times 10^{-13}$ & 299 & Atkinson et al., 1977 & FP-RF (e) \\
\hline $1.63 \times 10^{-13}$ & 296 & Overend and Paraskevopoulos, 1977 & FP-RA $(b, f)$ \\
\hline $1.41 \times 10^{-13}$ & 299 & Perry et al., 1977 & FP-RF (g) \\
\hline $1.46 \times 10^{-13}$ & 300 & Biermann et al., 1978 & FP-RA (h) \\
\hline $1.50 \times 10^{-13}$ & 298 & Dreier and Wolfrum, 1981 & DF (i) \\
\hline $1.46 \times 10^{-13}$ & 298 & Husain et al., 1982 & FP-RF \\
\hline $1.28 \times 10^{-13}$ & 298 & Ravishankara and Thompson, 1983 & FP-RF (j) \\
\hline $1.50 \times 10^{-13}$ & 298 & Paraskevopoulos and Irwin, 1984 & FP-RA \\
\hline $1.58 \times 10^{-13}$ & 298 & Hofzumahaus and Stuhl, 1984 & FP-RA (k) \\
\hline $1.23 \times 10^{-13}$ & 298 & Jonah et al., 1984 & PR-RA (l) \\
\hline $0.88 \times 10^{-13}$ & 298 & Beno et al., 1985 & PR-RA (l) \\
\hline $1.47 \times 10^{-13}$ & 299 & Hynes et al., 1986 & PLP-LIF \\
\hline $1.50 \times 10^{-13}$ & 298 & Stacknik and Molina, 1988 & PLP-RA \\
\hline $1.26 \times 10^{-13}$ & 298 & Wahner and Zetsch, 1988 & PLP-A (m) \\
\hline $1.49 \times 10^{-13}$ & 298 & Brunning et al., 1988 & FP-LIF (n) \\
\hline $1.30 \times 10^{-13}$ & 298 & Forster et al., 1995 & PLP-LIF \\
\hline $1.53 \times 10^{-13}$ & 298 & Golden et al., 1998 & PLP-LIF \\
\hline $1.57 \times 10^{-13}$ & $220-400$ & McCabe et al., 2001 & PLP-LIF \\
\hline \multicolumn{4}{|c|}{$k / k(P \rightarrow 0)$ with $\left[N_{2}\right]$ in molecule $\mathrm{cm}^{-3}$} \\
\hline $1+\left[\mathrm{N}_{2}\right] / 5.4 \times 10^{19}$ & 298 & Paraskevopoulos and Irwin, 1984 & FP-RA \\
\hline $1+\left[\mathrm{N}_{2}\right] / 4.1 \times 10^{19}$ & 298 & Hofzumahaus and Stuhl, 1984 & FP-RA (o) \\
\hline $1+\left[\mathrm{N}_{2}\right] / 4.8 \times 10^{19}$ & 298 & Hynes et al., 1986 & PLP-LIF \\
\hline $1+\left[\mathrm{N}_{2}\right] / 4.6 \times 10^{19}$ & 298 & Wahner and Zetsch, 1988 & PLP-A (m) \\
\hline $1+\left[\mathrm{N}_{2}\right] / 4.4 \times 10^{19}$ & $220-400$ & McCabe et al., 2001 & PLP-LIF \\
\hline $1+\left[\mathrm{N}_{2}\right] / 4.0 \times 10^{19}$ & $200-300$ & Fulle et al., 1996 & PLP-LIF (p) \\
\hline
\end{tabular}

\section{Rate coefficient data}




\section{Comments}

(a) Extrapolation for $\mathrm{P} \rightarrow 0$ with pressure dependence from Golden et al. (1998).

(b) Extrapolation for $\mathrm{P} \rightarrow 0$ with pressure dependence from Paraskevopoulos and Irwin (1984).

(c) Measurements at 100 Torr of He giving $k=1.43 \times 10^{-13} \mathrm{~cm}^{3}$ molecule $\mathrm{e}^{-1} \mathrm{~s}^{-1}$.

(d) Measurements at 760 Torr of Ar giving $k=1.54 \times 10^{-13} \mathrm{~cm}^{3}$ molecule $\mathrm{e}^{-1} \mathrm{~s}^{-1}$.

(e) No pressure dependence detected between 25 and 650 Torr of Ar. Value taken as indicated.

(f) Measurements at 50 Torr of He giving $k=1.66 \times 10^{-13} \mathrm{~cm}^{3}$ molecule $\mathrm{e}^{-1} \mathrm{~s}^{-1}$.

(g) Measurements at 25 Torr of $\mathrm{SF}_{6}$ giving $k=1.53 \times 10^{-13} \mathrm{~cm}^{3}$ molecule ${ }^{-1} \mathrm{~s}^{-1}$.

(h) Measurements at 25 Torr of $\mathrm{N}_{2}$ giving $k=1.51 \times 10^{-13} \mathrm{~cm}^{3}$ molecule $\mathrm{l}^{-1} \mathrm{~s}^{-1}$.

(i) Measurements of $\mathrm{CO}_{2}$ yields accounting for loss of $\mathrm{HO}$ by other reactions.

(j) Measurements at 100 Torr of Ar giving $k=1.4 \times 10^{-13} \mathrm{~cm}^{3}$ molecule ${ }^{-1} \mathrm{~s}^{-1}$.

(k) Measurements at 760 Torr of $\mathrm{N}_{2}$ giving $k=2.3 \times 10^{-13} \mathrm{~cm}^{3}$ molecule $\mathrm{e}^{-1} \mathrm{~s}^{-1}$.

(1) Measurements at 760 Torr of Ar giving $k=2.1 \times 10^{-13} \mathrm{~cm}^{3}$ molecule $\mathrm{s}^{-1} \mathrm{~s}^{-1}$.

(m) Measurements at 760 Torr of $\mathrm{N}_{2}$ giving $k=2.15 \times 10^{-13} \mathrm{~cm}^{3}$ molecule $\mathrm{e}^{-1} \mathrm{~s}^{-1}$.

(n) Measurements at 25 Torr of Ar giving $k=1.53 \times 10^{-13} \mathrm{~cm}^{3}$ molecule ${ }^{-1} \mathrm{~s}^{-1}$.

(o) Referred to $k_{0}=1.44 \times 10^{-13} \mathrm{~cm}^{3}$ molecule $\mathrm{e}^{-1} \mathrm{~s}^{-1}$.

(p) Measurements up to 700 bar of $\mathrm{He}$ with data representation between 90 and $3000 \mathrm{~K}$. Conversion to the bath gas $\mathrm{N}_{2}$ with efficiency relative to $\mathrm{He}$ at $298 \mathrm{~K}$, see comments on preferred values. Temperature dependence from theoretical modelling of the experimental results, see Troe (1998).

\section{Preferred Values}

$k=1.44 \times 10^{-13}\left(1+\left[\mathrm{N}_{2}\right] / 4.2 \times 10^{19}\right.$ molecule $\left.\mathrm{cm}^{-3}\right) \mathrm{cm}^{3}$ molecule ${ }^{-1} \mathrm{~s}^{-1}$ over the temperature range $200-300 \mathrm{~K}$ and the pressure range $0-1$ bar of $\mathrm{N}_{2}$.

\section{Reliability}

$\Delta \log k= \pm 0.05$ at $298 \mathrm{~K}$.

$\Delta \log k= \pm 0.1$ over the temperature range $200-300 \mathrm{~K}$ and the pressure range $0-1 \mathrm{bar}$.

\section{Comments on Preferred Values}

The preferred values at $\mathrm{P} \rightarrow 0$ represent a weighted average of all low pressure data excluding pulse radiolysis results which show larger scatter. The preferred values at $\mathrm{P}=1$ bar of $\mathrm{N}_{2}$ correspond to an average over those results for which $k / k(\mathrm{P} \rightarrow 0)$ is given in the table (except the results from Fulle et al., 1996, which were obtained in the bath gas He).

The preferred values for $k$ cannot be used over larger pressure and temperature ranges where more complicated expressions have to be employed. One may, e.g. take the representation $k_{1}=k_{1,0}\left[1-[\mathrm{x} /(\mathrm{x}+1)] \mathrm{F}_{c}^{1 /\left[1+(\log x)^{2}\right]}\right], k_{2}=k_{2,0}$ $\left.[1+\mathrm{y} /(1+\mathrm{x})] \mathrm{F}_{c}^{1 /\left[1+(\log x)^{2}\right]}\right]$ with $\mathrm{x}=k_{2,0} /\left(k_{2, \infty}-k_{1.0}\right)$ and $\mathrm{y}=k_{1,0} /\left(k_{2, \infty}-k_{1.0}\right), \mathrm{F}_{c} \approx 0.7, \quad k_{1,0}=1.8 \times 10^{-12} \exp (-2720 / T)+$ $1.6 \times 10^{-13} \exp (-60 / T), k_{2,0}=[\mathrm{He}] 2.0 \times 10^{-32}(T / 300)^{-2.7} \exp (-490 / T)$ and $k_{2, \infty}=1.8 \times 10^{-11} \exp (-1850 / T)+1.5 \times 10^{-12} \exp (-$ $130 / T$ ), see Fulle et al. (1996) and Troe (1998). For $\mathrm{N}_{2}$ instead of He, $k_{2,0}$ should be increased by a factor of 1.6. These expressions also give the partitioning of $k$ into $k_{1}$ and $k_{2}$. For the limited temperature and pressure range of the present evaluation, the simplified model from the introduction for complex-forming bimolecular reactions can be used. At low pressures this gives a relative $\mathrm{HOCO}$ yield of approximately $[k-k(\mathrm{P} \rightarrow 0)] /[k(\mathrm{P} \rightarrow \infty)-k(\mathrm{P} \rightarrow 0)]$ which at $298 \mathrm{~K}$ and 1 bar of $\mathrm{N}_{2}$ corresponds to 
about $12 \%$ (Troe, 1998). As $\mathrm{HOCO}$ under excess of $\mathrm{O}_{2}$ rapidly reacts to $\mathrm{HO}_{2}+\mathrm{CO}_{2}$ (Miyoshi et al., 1994) and as other reactions of $\mathrm{HOCO}$ presumably proceed similarly as reactions of $\mathrm{H}, k$ probably in effect can be used as if it would correspond to Reaction (1) alone. At higher temperatures, thermal decomposition of HOCO would occur which would lead to more complex kinetic rate laws, see Forster et al. (1996). This can be neglected at temperatures below $300 \mathrm{~K}$.

The present evaluation was based on absolute rate coefficients only, neglecting relative rate measurements and measurements in other bath gases such as $\mathrm{H}_{2} \mathrm{O}$. Reference to this work is found in the given literature. Since the reaction has been studied very extensively, the present evaluation also cannot be exhaustive. The thermochemistry of HOCO is based on the new determination by Feller et al. (2003). There is extensive modelling of the reaction, see Golden et al. (1998) and Troe (1998), which provide excellent representations of the experimental data with empirically fitted potential parameters. Increasingly reliable quantumchemical determinations of the HOCO potential (see e.g. Yu et al., 2001 and Lakin et al., 2003) allows also for more basic treatments of the dynamics, see e.g. Medvedev et al. (2004), He et al. (2004), Valero and Kroes (2002), Valero et al. (2004). However, this work does not yet replace the experiments on which this evaluation is based.

\section{References}

Atkinson, R., Perry, R. A., and Pitts Jr., J. N.: Chem. Phys. Lett., 44, 206, 1976.

Beno, M. F., Jonah, C. D., and Mulac, W. A.: Int. J. Chem. Kinet., 17, 1091, 1985.

Biermann, H. W., Zetsch, C., and Stuhl, F.: Ber. Bunsenges. Phys. Chem., 82, 633, 1978.

Brunning, J., Derbyshire, D. W., Smith, I. W. M., and Williams, M. D.: J. Chem. Soc. Faraday Trans., 2, 84, 105, 1988.

Davis, D. D., Fischer, S., and Schiff, R.: J. Chem. Phys., 61, 2243, 1974.

Dreier, T. and Wolfrum, J.: Proc. Combust. Inst., 18, 801, 1981.

Feller, D., Dixon, D. A., and Francisco, J. S.: J. Phys. Chem. A, 107, 1604, 2003.

Forster, R., Frost, M., Fulle, D., Hamann, H. F., Hippler, H., Schlepegrell, A., and Troe, J.: J. Chem. Phys., 103, $2949,1995$.

Fulle, D., Hamann, H. F., Hippler, H., and Troe, J.: J. Chem. Phys., 105, 983, 1996.

Golden, D. M., Smith, G. P., McEwen, A. B., Yu, C.-L., Eiteneer, B., Frencklach, M., Vaghjiani, G. L., Ravishankara, A. R., and Tully, F. P.: J. Phys. Chem. A, 102, 8598, 1998.

Gordon, S. and Mulac, W. A.: Int. J. Chem. Kin., 7, 289, 1975.

Greiner, N. R.: J. Chem. Phys., 51, 5049, 1969.

He, Y., Goldfield, E. M., and Gray, S. K.: J. Chem. Phys., 121, 823, 2004.

Hofzumahaus, A. and Stuhl, F.: Ber. Bunsenges. Phys. Chem., 88, 557, 1984.

Howard, C. J. and Evenson, K. M.: J. Chem. Phys., 61, 1943, 1974.

Husain, D., Plane, J. M. C., and Slater, N. K. H.: J. Chem. Soc. Faraday Trans., 2, 77, 1949, 1981.

Hynes, A. J., Wine, P. H., and Ravishankara, A. R.: J. Geophys. Res., 91, 11 815, 1986.

Jonah, C. D., Mulac, W. A., and Zeglinski, P.: J. Phys. Chem., 88, 4100, 1984.

Lakin, M. J., Troya, D., Schatz, G. C., and Harding, L. B.: J. Chem. Phys., 119, 5848, 2003.

McCabe, D. C., Gierczak, T., Talukdar, R. K., and Ravishankara, A. R.: Geophys. Res. Lett., 28, 3135, 2001.

Medvedev, D., Gray, S. K., Goldfield, E. M., Lakin, M. J., Troya, D., and Schatz, G. C.: J. Chem. Phys., 120, 1231, 2004.

Miyoshi, A., Matsui, H., and Washida, N.: J. Chem. Phys., 100, 3532, 1994.

Mulcahy, M. F. R. and Smith, R. H.: J. Chem. Phys., 54, 5215, 1971.

Overend, R. and Paraskevopoulos, G.: Chem. Phys. Lett., 49, 109, 1977.

Paraskevopoulos, G. and Irwin, R. S.: J. Chem. Phys., 80, 259, 1984.

Perry, R. A., Atkinson, R., and Pitts Jr., J. N.: J. Chem. Phys., 67, 5577, 1977.

Ravishankara, A. R. and Thompson, R. L.: Chem. Phys. Lett., 99, 377, 1983.

Smith, I. W. M. and Zellner, R.: J. Chem. Soc. Faraday Trans., 2, 69, 1617, 1973.

Stachnik, R. A. and Molina, M. J.: Private communication, 1988.

Stuhl, F. and Niki, H.: J. Chem. Phys., 57, 3671, 1972.

Trainor, D. W. and von Rosenberg Jr., C. W.: Chem. Phys. Lett., 29, 35, 1974.

Troe, J.: Proc. Combust. Inst., 27, 167, 1998.

Valero, R. and Kroes, G.-J.: J. Chem. Phys., 117, 8736, 2002.

Valero, R., van Hemert, M. C. and Kroes, G.-J.: Chem. Phys. Lett., 393, 236, 2004.

Wahner, A. and Zetzsch, C.: Abstract Informal Photochemistry Meeting, Boulder, June, 1986.

Westenberg, A. A. and deHaas, N.: J. Chem. Phys., 58, 4061, 1973.

Yu, H. G., Zuckerman, J. T. and Sears, T. J.: Chem. Phys. Lett., 349, 547, 2001. 
II.A2.13

$$
\mathrm{HO}+\mathrm{HCHO} \rightarrow \mathrm{H}_{2} \mathrm{O}+\mathrm{HCO}
$$

$\Delta H^{\circ}=-127.3 \mathrm{~kJ} \cdot \mathrm{mol}^{-1}$

\section{Rate coefficient data}

\begin{tabular}{lllc}
\hline$k / \mathrm{cm}^{3}$ molecule ${ }^{-1} \mathrm{~s}^{-1}$ & Temp./K & Reference & Technique/Comments \\
\hline Absolute Rate Coefficients & & & \\
$1.25 \times 10^{-11} \exp [-(88 \pm 151) / T]$ & $299-426$ & Atkinson and Pitts, 1978 & FP-RF \\
$(9.4 \pm 1.0) \times 10^{-12}$ & 299 & & \\
$(1.05 \pm 0.11) \times 10^{-11}$ & $228-362$ & Stief et al., 1980 & FP-RF \\
$(9.86 \pm 1.13) \times 10^{-12}$ & 298 & & \\
$(8.1 \pm 1.7) \times 10^{-12}$ & 296 & Temps and Wagner, 1984 & DF-LMR \\
$1.66 \times 10^{-11} \exp [-(86 \pm 40) / T]$ & $296-576$ & Zabarnick et al., 1988 & PLP-LIF \\
$(1.25 \pm 0.11) \times 10^{-11}$ & $298 \pm 3$ & & \\
$\left(7.95_{-1.44}^{+2.04}\right) \times 10^{-12}$ & 298 & Yetter et al., 1989 & DF-RF \\
$(1.94 \pm 0.30) \times 10^{-11}$ & $1205 \pm 16$ & Bott and Cohen, 1991 & SH-RA \\
$9.52 \times 10^{-18} T^{2.03} \exp (636 / T)$ & $202-399$ & Sivakumaran et al., 2003 & PLP-LIF (a) \\
$(8.46 \pm 0.5) \times 10^{-12}$ & 298 & & \\
& & & \\
Relative Rate Coefficients & & & RR (b) \\
$(8.40 \pm 0.51) \times 10^{-12}$ & $299 \pm 2$ & Niki et al., 1984 & \\
\hline
\end{tabular}

\section{Comments}

(a) The authors combined their data with previous room temperature data of Atkinson and Pitts (1978), Stief et al. (1980), Temps and Wagner (1984), Niki et al. (1984), Zabarnick et al. (1988) and Yetter et al. (1989) to obtain a $298 \mathrm{~K}$ rate coefficient of $k=8.6 \times 10^{-12} \mathrm{~cm}^{3}$ molecule $\mathrm{s}^{-1}$ and a temperature-dependent expression of $k=9.65 \times 10^{-18} T^{2.03}$ $\exp (636 / T) \mathrm{cm}^{3}$ molecule ${ }^{-1} \mathrm{~s}^{-1}$ over the temperature range $200-400 \mathrm{~K}$. Using resonance fluorescence detection of $\mathrm{H}$ atoms, an upper limit of $4 \%$ was determined for the production of $\mathrm{H}$ atoms at $298 \mathrm{~K}$.

(a) $\mathrm{HO}$ radicals were generated by the photolysis of methyl or ethyl nitrite in air, and the concentration of ${ }^{13} \mathrm{CH}_{2} \mathrm{O}$ and ethene (the reference compound) were measured by FTIR absorption spectroscopy during the experiments. The measured rate coefficient ratio of $k\left(\mathrm{HO}+{ }^{13} \mathrm{CH}_{2} \mathrm{O}\right) / k(\mathrm{HO}+$ ethene $)=0.99 \pm 0.06$ is placed on an absolute basis by use of a rate coefficient of $k(\mathrm{HO}+$ ethene $)=8.48 \times 10^{-12} \mathrm{~cm}^{3}$ molecule ${ }^{-1} \mathrm{~s}^{-1}$ at $299 \mathrm{~K}$ and atmospheric pressure (Atkinson and Arey, 2003).

\section{Preferred Values}

$k=8.5 \times 10^{-12} \mathrm{~cm}^{3}$ molecule $\mathrm{e}^{-1} \mathrm{~s}^{-1}$ at $298 \mathrm{~K}$.

$k=5.4 \times 10^{-12} \exp (135 / T) \mathrm{cm}^{3}$ molecule ${ }^{-1} \mathrm{~s}^{-1}$ over the temperature range $200-300 \mathrm{~K}$.

\section{Reliability}

$\Delta \log k= \pm 0.08$ at $298 \mathrm{~K}$.

$\Delta(E / R)= \pm 100 \mathrm{~K}$.

\section{Comments on Preferred Values}

The absolute rate coefficients of Atkinson and Pitts (1978), Stief et al. (1980), Temps and Wagner (1984), Yetter et al. (1989) and Sivakumaran et al. (2003) and the relative rate coefficient of Niki et al. (1984) at $299 \pm 2 \mathrm{~K}$ are in good agreement (to within $\sim 20 \%$ or better at any given temperature) over the temperature range common to two or more of these studies (228-399 K). 
The absolute rate coefficients of Zabarnick et al. (1988) over the temperature range 296-378 K are consistently higher than those of Atkinson and Pitts (1978), Stief et al. (1980), Temps and Wagner (1984), Niki et al. (1984), Yetter et al. (1989) and Sivakumaran et al. (2003), and are not used in the evaluation.

The absolute rate coefficients of Atkinson and Pitts (1978), Stief et al. (1980), Temps and Wagner (1984), Yetter et al. (1989) and Sivakumaran et al. (2003), and the relative rate coefficient of Niki et al. (1984) for formaldehyde- ${ }^{13} \mathrm{C}$, have been fitted to the three parameter expression $k=C T^{2} \exp (-D / T)$, resulting in $k=1.25 \times 10^{-17} T^{2} \exp (615 / T) \mathrm{cm}^{3}$ molecule ${ }^{-1} \mathrm{~s}^{-1}$ over the temperature range $202-426 \mathrm{~K}$. This expression yields rate coefficients which are within $3 \%$ of those calculated from the three parameter expression recommended by Sivakumaran et al. (2003) for the temperature range 200-430 K (see comment (a) above) and predicts a rate coefficient at $1205 \mathrm{~K}$ a factor of 1.56 higher that that measured by Bott and Cohen (1991). The preferred Arrhenius expression, $k=A \exp (-B / T)$, is centered at $240 \mathrm{~K}$ and is derived from the three parameter expression with $A=C \mathrm{e}^{2} T^{2}$ and $B=D+2 T$. Note that the preferred Arrhenius expression should not be used outside of the specified temperature range (200-300 K); rather the full three parameter expression should be used.

The product data of Temps and Wagner (1984), Niki et al. (1984) and Sivakumaran et al. (2003) and the kinetic/modeling results of Yetter et al. (1989) show that at $298 \mathrm{~K}$ this reaction yields $\mathrm{H}_{2} \mathrm{O}+\mathrm{HCO}$, as also concluded by Butkovskaya and Setser (1998) from an infrared chemiluminescence study of the reaction at $0.67-1.3$ mbar.

\section{References}

Atkinson, R. and Arey, J.: Chem. Rev., 103, 4605, 2003.

Atkinson, R. and Pitts Jr., J. N.: J. Chem. Phys., 68, 3581, 1978.

Bott, J. F. and Cohen, N.: Int. J. Chem. Kinet., 23, 1075, 1991.

Butkovskaya, N. I. and Setser, D. W.: J. Phys. Chem. A, 102, 9715, 1998.

Niki, H., Maker, P. D., Savage, C. M., and Breitenbach, L. P.: J. Phys. Chem., 88, 5342, 1984.

Sivakumaran, V., Hölscher, D., Dillon, T. J., and Crowley, J. N.: Phys. Chem. Chem. Phys., 5, 4821, 2003.

Stief, L. J., Nava, D. F., Payne, W. A., and Michael, J. V.: J. Chem. Phys., 73, 2254, 1980.

Temps, F. and Wagner, H. Gg.: Ber. Bunsenges. Phys. Chem., 88, 415, 1984.

Yetter, R. A., Rabitz, H., Dryer, F. L., Maki, R. G., and Klemm, R. B.: J. Chem. Phys., 91, 4088, 1989.

Zabarnick, S., Fleming, J. W., and Lin, M. C.: Int. J. Chem. Kinet., 20, 117, 1988. 
II.A2.14

$$
\mathrm{HO}+\mathrm{CH}_{3} \mathrm{CHO} \rightarrow \mathrm{H}_{2} \mathrm{O}+\mathrm{CH}_{3} \mathrm{CO}
$$

$\Delta H^{\circ}=-123.2 \mathrm{~kJ} \cdot \mathrm{mol}^{-1}$

\section{Rate coefficient data}

\begin{tabular}{llll}
\hline$k / \mathrm{cm}^{3}$ molecule $\mathrm{s}^{-1}$ & Temp./K & Reference & Technique/Comments \\
\hline Absolute Rate Coefficients & & & \\
$(1.55 \pm 0.39) \times 10^{-11}$ & 300 & Morris et al., 1971 & DF-MS \\
$6.87 \times 10^{-12} \exp [(257 \pm 151) / T]$ & $299-426$ & Atkinson and Pitts, 1978 & FP-RF \\
$(1.60 \pm 0.16) \times 10^{-11}$ & 299 & & \\
$7.1 \times 10^{-12} \exp [(165 \pm 91) / T]$ & $253-424$ & Semmes et al., 1985 & FP-RF \\
$(1.22 \pm 0.27) \times 10^{-11}$ & 298 & & \\
$5.52 \times 10^{-12} \exp [(307 \pm 52) / T]$ & $244-528$ & Michael et al., 1985 & DF-RF \\
$(1.47 \pm 0.28) \times 10^{-11}$ & 298 & & \\
$8.6 \times 10^{-12} \exp [(200 \pm 60) / T]$ & $297-517$ & Dóbé et al., 1989 & DF-RF/LIF \\
$(1.69 \pm 0.34) \times 10^{-11}$ & $298 \pm 2$ & & \\
$(1.7 \pm 0.3) \times 10^{-11}$ & 298 & Balestra-Garcia et al., 1992 & PLP-RF \\
$(1.44 \pm 0.25) \times 10^{-11}$ & 298 & Tyndall et al., 1995 & DF-LIF \\
$4.31 \times 10^{-12} \exp [(309 \pm 19) / T]$ & $295-550$ & Taylor et al., 1996 & PLP-LIF \\
$1.23 \times 10^{-11}$ & 295 & & \\
$4.4 \times 10^{-12} \exp [(366 \pm 30) / T]$ & $202-348$ & Sivakumaran and Crowley, 2003 & PLP-LIF \\
$1.50 \times 10^{-11}$ & 298 & & \\
& & & \\
Relative Rate Coefficients & & & \\
$(1.62 \pm 0.18) \times 10^{-11}$ & $298 \pm 2$ & Niki et al., 1978 & RR (a) \\
$(1.28 \pm 0.43) \times 10^{-11}$ & $298 \pm 4$ & Kerr and Sheppard, 1981 & RR (b) \\
$(1.62 \pm 0.10) \times 10^{-11}$ & $298 \pm 2$ & Scollard et al., 1993 & RR (c) \\
$(1.44 \pm 0.08) \times 10^{-11}$ & $298 \pm 2$ & D'Anna et al., 2001 & RR (d) \\
\hline
\end{tabular}

\section{Comments}

(a) $\mathrm{HO}$ radicals were generated by the photolysis of $\mathrm{HONO}$ in air, and the concentrations of $\mathrm{CH}_{3} \mathrm{CHO}$ and ethene (the reference compound) were measured by FTIR absorption spectroscopy. The measured rate coefficient ratio of $k(\mathrm{HO}+$ $\left.\mathrm{CH}_{3} \mathrm{CHO}\right) / k(\mathrm{HO}+$ ethene $)=1.9 \pm 0.2$ is placed on an absolute basis by use of a rate coefficient of $k(\mathrm{HO}+$ ethene $)=$ $8.52 \times 10^{-12} \mathrm{~cm}^{3}$ molecule $\mathrm{s}^{-1} \mathrm{~s}^{-1}$ at $298 \mathrm{~K}$ and atmospheric pressure (Atkinson, 1997).

(b) $\mathrm{HO}$ radicals were generated by the photolysis of $\mathrm{HONO}$ in air, and the concentrations of $\mathrm{CH}_{3} \mathrm{CHO}$ and ethene (the reference compound) were measured by GC. The measured rate coefficient ratio of $k\left(\mathrm{HO}+\mathrm{CH}_{3} \mathrm{CHO}\right) / k(\mathrm{HO}+$ ethene $)=$ $1.50 \pm 0.50$ is placed on an absolute basis by use of a rate coefficient of $k(\mathrm{HO}+$ ethene $)=8.52 \times 10^{-12} \mathrm{~cm}^{3} \mathrm{molecule}^{-1}$ $\mathrm{s}^{-1}$ at $298 \mathrm{~K}$ and atmospheric pressure (Atkinson, 1997).

(c) $\mathrm{HO}$ radicals were generated from the photolysis of $\mathrm{CH}_{3} \mathrm{ONO}$ in air, and the concentrations of $\mathrm{CH}_{3} \mathrm{CHO}$ and ethene (the reference compound) were measured during the experiments by GC. The measured rate coefficient ratio is placed on an absolute basis by use of a rate coefficient of $k(\mathrm{HO}+$ ethene $)=8.52 \times 10^{-12} \mathrm{~cm}^{3}$ molecule ${ }^{-1} \mathrm{~s}^{-1}$ at $298 \mathrm{~K}$ and atmospheric pressure (Atkinson, 1997).

(d) HO radicals were generated by the photolysis of an organic nitrite in air and the concentrations of acetaldehyde and 1-butene (the reference compound) were measured by FTIR spectroscopy. The measured rate coefficient ratio of $k(\mathrm{HO}$ $\left.+\mathrm{CH}_{3} \mathrm{CHO}\right) / k(\mathrm{HO}+1$-butene $)=0.458 \pm 0.024$ is placed on an absolute basis by use of a rate coefficient of $k(\mathrm{HO}+$ 1-butene) $=3.14 \times 10^{-11} \mathrm{~cm}^{3}$ molecule $\mathrm{s}^{-1}$ at $298 \mathrm{~K}$ and atmospheric pressure of air (Atkinson, 1997). 


\section{Preferred Values}

$k=1.5 \times 10^{-11} \mathrm{~cm}^{3}$ molecule ${ }^{-1} \mathrm{~s}^{-1}$ at $298 \mathrm{~K}$.

$k=4.4 \times 10^{-12} \exp (365 / T) \mathrm{cm}^{3}$ molecule ${ }^{-1} \mathrm{~s}^{-1}$ over the temperature range $200-350 \mathrm{~K}$.

\section{Reliability}

$\Delta \log k= \pm 0.08$ at $298 \mathrm{~K}$.

$\Delta(E / R)= \pm 100 \mathrm{~K}$.

\section{Comments on Preferred Values}

The room temperature rate coefficients range from $(1.2-1.7) \times 10^{-11} \mathrm{~cm}^{3}$ molecule ${ }^{-1} \mathrm{~s}^{-1}$, with the absolute rate coefficients of Atkinson and Pitts (1978), Michael et al. (1985), Tyndall et al. (1995) and Sivakumaran and Crowley (2003) being in reasonably good agreement. The temperature dependences of Michael et al. (1985), Taylor et al. (1996) and Sivakumaran and Crowley (2003) are in excellent agreement and also agree well with the temperature dependence measured over a smaller temperature range by Atkinson and Pitts (1978). The extensive study of Sivakumaran and Crowley (2003), which extends to significantly lower temperatures than the other temperature-dependent studies (Atkinson and Pitts, 1978; Semmes et al., 1985; Michael et al., 1985; Dóbé et al., 1989; Taylor et al., 1996), is used as the basis for the preferred values. The data of Semmes et al. (1985) are lower than the preferred values by up to $\sim 20 \%$, possibly because of the reported difficulties in accurately determining the acetaldehyde concentrations (Semmes et al., 1985). While the absolute rate coefficients measured by Dóbé et al. (1989) for $\mathrm{CH}_{3} \mathrm{CHO}$ are in good agreement with the preferred values, their measured rate coefficients for the reactions of the $\mathrm{HO}$ radical with the higher aldehydes $\left(\mathrm{CH}_{3}\right)_{2} \mathrm{CHCHO}$ and $\left(\mathrm{CH}_{3}\right)_{3} \mathrm{CCHO}$ are significantly higher, by factors of $\sim 1.5$ to 2.3 , than the rate coefficients of Kerr and Sheppard (1981) and Semmes et al. (1985) (which are in good agreement).

Cameron et al. (2002) have investigated the products of this reaction, using absorption spectroscopy to detect $\mathrm{CH}_{3}$ and $\mathrm{CH}_{3} \mathrm{CO}$ radicals and resonance fluorescence to detect $\mathrm{H}$ atoms. Upper limits for the formation of $\mathrm{CH}_{3}+\mathrm{HC}(\mathrm{O}) \mathrm{OH}(<3 \%$ at $296 \mathrm{~K})$ and $\mathrm{H}+\mathrm{CH}_{3} \mathrm{C}(\mathrm{O}) \mathrm{OH}(<2 \%$ over the temperature range $237-296 \mathrm{~K})$ were obtained, and the major reaction pathway was determined to be formation of $\mathrm{CH}_{3} \mathrm{CO}+\mathrm{H}_{2} \mathrm{O}$, with a measured yield of $93 \pm 18 \%$ at $296 \mathrm{~K}$ (Cameron et al., 2002). H-atom abstraction from the $\mathrm{CH}_{3}$ group therefore accounts for $<25 \%$ of the overall reaction at room temperature.

\section{References}

Atkinson, R. and Pitts Jr., J. N.: J. Chem. Phys., 68, 3581, 1978.

Atkinson, R.: J. Phys. Chem. Ref. Data, 26, 215, 1997.

Balestra-Garcia, C., Le Bras, G., and Mac Leod, H.: J. Phys. Chem., 96, 3312, 1992.

Cameron, M., Sivakumaran, V., Dillon, T. J., and Crowley, J. N.: Phys. Chem. Chem. Phys., 4, 3628, 2002.

D’Anna, B., Andresen, O., Gefen, Z., and Nielsen, C. J.: Phys. Chem. Chem. Phys., 3, 3057, 2001.

Dóbé, S., Khachatryan, L. A., and Bérces, T.: Ber. Bunsenges. Phys. Chem., 93, 847, 1989.

Kerr, J. A. and Sheppard, D. W.: Environ. Sci. Technol., 15, 960, 1981.

Michael, J. V., Keil, D. G., and Klemm, R. B.: J. Chem. Phys., 83, 1630, 1985.

Morris Jr., E. D., Stedman, D. H., and Niki, H.: J. Am. Chem. Soc., 93, 3570, 1971.

Niki, H., Maker, P. D., Savage, C. M., and Breitenbach, L. P.: J. Phys. Chem., 82, 132, 1978.

Scollard, D. J., Treacy, J. J., Sidebottom, H. W., Balestra-Garcia, C., Laverdet, G., LeBras, G., MacLeod, H., and Téton, S.: J. Phys. Chem., 97, 4683, 1993.

Semmes, D. H., Ravishankara, A. R., Gump-Perkins, C. A., and Wine, P. H.: Int. J. Chem. Kinet., 17, 303, 1985.

Sivakumaran, V. and Crowley, J. N.: Phys. Chem. Chem. Phys., 5, 106, 2003.

Taylor, P. H., Rahman, M. S., Arif, M., Dellinger, B., and Marshall, P.: 26th International Symposium on Combustion, The Combustion Institute, Pittsburgh, PA, pp. 497-504, 1996.

Tyndall, G. S., Staffelbach, T. A., Orlando, J. J., and Calvert, J. G.: Int. J. Chem. Kinet., 27, 1009, 1995. 
II.A2.15

$$
\mathrm{HO}+\mathrm{C}_{2} \mathrm{H}_{5} \mathrm{CHO} \rightarrow \text { products }
$$

\section{Rate coefficient data}

\begin{tabular}{lllc}
\hline$k / \mathrm{cm}^{3}$ molecule $\mathrm{s}^{-1}$ & Temp./K & Reference & Technique/Comments \\
\hline $\begin{array}{l}\text { Absolute Rate Coefficients } \\
(1.71 \pm 0.24) \times 10^{-11}\end{array}$ & 298 & Semmes et al., 1985 & FP-RF \\
$5.3 \times 10^{-11} \exp [(405 \pm 30) / T]$ & $240-372$ & Thévenet et al., 2000 & PLP-LIF \\
$(2.0 \pm 0.3) \times 10^{-11}$ & 298 & & \\
& & & \\
Relative Rate Coefficients & & & RR (a) \\
$(2.22 \pm 0.09) \times 10^{-11}$ & $298 \pm 2$ & Niki et al., 1978 & RR (b) \\
$(1.94 \pm 0.15) \times 10^{-11}$ & $298 \pm 4$ & Kerr and Sheppard, 1981 & RR (c) \\
$(2.00 \pm 0.14) \times 10^{-11}$ & $296 \pm 2$ & Papagni et al., 2000 & RR (d) \\
$(1.89 \pm 0.16) \times 10^{-11}$ & $298 \pm 2$ & D'Anna et al., 2001 & \\
\hline
\end{tabular}

\section{Comments}

(a) HO radicals were generated by the photolysis of HONO in air and the concentrations of propanal and ethene (the reference compound) were measured by FTIR absorption spectroscopy during the experiments. The measured rate coefficient ratio of $k(\mathrm{HO}+$ propanal $) / k(\mathrm{HO}+$ ethene $)=2.6 \pm 0.1$ is placed on an absolute basis by use of a rate coefficient of $k(\mathrm{HO}+$ ethene) $=8.52 \times 10^{-12} \mathrm{~cm}^{3}$ molecule $\mathrm{e}^{-1} \mathrm{~s}^{-1}$ at $298 \mathrm{~K}$ and atmospheric pressure (Atkinson, 1997).

(b) HO radicals were generated by the photolysis of HONO in air and the concentrations of propanal and ethene (the reference compound) were measured by GC. The measured rate coefficient ratio of $k(\mathrm{HO}+$ propanal $) / k(\mathrm{HO}+$ ethene $)=2.28 \pm 0.17$ is placed on an absolute basis by use of a rate coefficient of $k(\mathrm{HO}+$ ethene $)=8.52 \times 10^{-12} \mathrm{~cm}^{3}$ molecule $\mathrm{e}^{-1} \mathrm{~s}^{-1}$ at $298 \mathrm{~K}$ and atmospheric pressure (Atkinson, 1997).

(c) $\mathrm{HO}$ radicals were generated by the photolysis of $\mathrm{CH}_{3} \mathrm{ONO}$ in air and the concentrations of propanal and methyl vinyl ketone (the reference compound) were measured by GC. The measured rate coefficient ratio of $k(\mathrm{HO}+$ propanal $) / k(\mathrm{HO}$ + methyl vinyl ketone $)=0.982 \pm 0.065$ is placed on an absolute basis by use of a rate coefficient of $k(\mathrm{HO}+$ methyl vinyl ketone) $=2.04 \times 10^{-11} \mathrm{~cm}^{3}$ molecule ${ }^{-1} \mathrm{~s}^{-1}$ at $296 \mathrm{~K}$ (IUPAC, current recommendation).

(d) HO radicals were generated by the photolysis of an organic nitrite in air and the concentrations of propanal and propene (the reference compound) were measured by FTIR spectroscopy. The measured rate coefficient ratio of $k(\mathrm{HO}+$ propanal $) / k(\mathrm{HO}+$ propene $)=0.72 \pm 0.06$ is placed on an absolute basis by use of a rate coefficient of $k(\mathrm{HO}+$ propene $)=$ $2.63 \times 10^{-11} \mathrm{~cm}^{3}$ molecule $\mathrm{s}^{-1} \mathrm{~s}^{-1}$ at $298 \mathrm{~K}$ and atmospheric pressure of air (Atkinson, 1997).

\section{Preferred Values}

$k=2.0 \times 10^{-11} \mathrm{~cm}^{3}$ molecule ${ }^{-1} \mathrm{~s}^{-1}$ at $298 \mathrm{~K}$.

$k=5.1 \times 10^{-12} \exp (405 / T) \mathrm{cm}^{3}$ molecule ${ }^{-1} \mathrm{~s}^{-1}$ over the temperature range $240-380 \mathrm{~K}$.

\section{Reliability}

$\Delta \log k= \pm 0.10$ at $298 \mathrm{~K}$.

$\Delta(E / R)= \pm 200 \mathrm{~K}$. 


\section{Comments on Preferred Values}

The preferred $298 \mathrm{~K}$ rate coefficient is derived from the mean of the room temperature absolute rate coefficients of Semmes et al. (1985) and Thévenet et al. (2000) and the relative rate coefficients of Niki et al. (1978), Kerr and Sheppard (1981), Papagni et al. (2000) and D'Anna et al. (2001). The temperature dependence is that measured by Thévenet et al. (2000) and the pre-exponential factor is adjusted to fit the $298 \mathrm{~K}$ preferred value. The relative rate coefficient of Audley et al. (1981) was not used in the evaluation, due to questions concerning the applicability of the experimental technique used (Semmes et al., 1985; Atkinson, 1989).

The major reaction channel is expected to be $\mathrm{H}$-atom abstraction from the - $\mathrm{CHO}$ group to form $\mathrm{H}_{2} \mathrm{O}+\mathrm{C}_{2} \mathrm{H}_{5} \mathrm{CO}$.

\section{References}

Atkinson, R.: J. Phys. Chem. Ref. Data Monograph, 1, 1, 1989.

Atkinson, R.: J. Phys. Chem. Ref. Data, 26, 215, 1997.

Audley, G. J., Baulch, D. L., and Campbell, I. M.: J. Chem. Soc. Faraday Trans., 1, 77, 2541, 1981.

D’Anna, B., Andresen, O., Gefen, Z., and Nielsen, C. J.: Phys. Chem. Chem. Phys., 3, 3057, 2001.

IUPAC: http://www.iupac-kinetic.ch.cam.ac.uk/.

Kerr, J. A. and Sheppard, D. W.: Environ. Sci. Technol., 15, 960, 1981.

Niki, H., Maker, P. D., Savage, C. M., and Breitenbach, L. P.: J. Phys. Chem., 82, 132, 1978.

Papagni, C., Arey, J., and Atkinson, R.: Int. J. Chem. Kinet., 32, 79, 2000.

Semmes, D. H., Ravishankara, A. R., Gump-Perkins, C. A., and Wine, P. H.: Int. J. Chem. Kinet., 17, 303, 1985.

Thévenet, R., Mellouki, A., and Le Bras, G.: Int. J. Chem. Kinet., 32, 676, 2000. 
II.A2.16

$$
\mathrm{HO}+\mathrm{CH}_{3} \mathrm{CH}_{2} \mathrm{CH}_{2} \mathrm{CHO} \rightarrow \text { products }
$$

\section{Rate coefficient data}

\begin{tabular}{llll}
\hline$k / \mathrm{cm}^{3}$ molecule ${ }^{-1} \mathrm{~s}^{-1}$ & Temp./K & Reference & Technique/Comments \\
\hline $\begin{array}{l}\text { Absolute Rate Coefficients } \\
5.7 \times 10^{-12} \exp [(411 \pm 164) / T]\end{array}$ & $258-422$ & Semmes et al., 1985 & FP-RF \\
$(2.06 \pm 0.30) \times 10^{-11}$ & 298 & & \\
& & & \\
Relative Rate Coefficients & & & RR (a) \\
$(2.52 \pm 0.06) \times 10^{-11}$ & $298 \pm 4$ & Kerr and Sheppard, 1981 & RR (b) \\
$(2.45 \pm 0.15) \times 10^{-11}$ & $296 \pm 2$ & Papagni et al., 2000 & RR (c) \\
$(2.39 \pm 0.16) \times 10^{-11}$ & $298 \pm 2$ & D'Anna et al., 2001 & \\
\hline
\end{tabular}

\section{Comments}

(a) $\mathrm{HO}$ radicals were generated by the photolysis of HONO in air and the concentrations of butanal and ethene (the reference compound) were measured by GC. The measured rate coefficient ratio of $k(\mathrm{HO}+$ butanal $) / k(\mathrm{HO}+$ ethene $)=2.96 \pm 0.07$ is placed on an absolute basis by use of a rate coefficient of $k(\mathrm{HO}+$ ethene $)=8.52 \times 10^{-12} \mathrm{~cm}^{3}$ molecule ${ }^{-1} \mathrm{~s}^{-1}$ at $298 \mathrm{~K}$ and atmospheric pressure (Atkinson, 1997).

(b) $\mathrm{HO}$ radicals were generated by the photolysis of $\mathrm{CH}_{3} \mathrm{ONO}$ in air and the concentrations of butanal and methyl vinyl ketone (the reference compound) were measured by GC. The measured rate coefficient ratio of $k(\mathrm{HO}+$ butanal $) / k(\mathrm{HO}$ + methyl vinyl ketone $)=1.20 \pm 0.07$ is placed on an absolute basis by use of a rate coefficient of $k(\mathrm{HO}+$ methyl vinyl ketone) $=2.04 \times 10^{-11} \mathrm{~cm}^{3}$ molecule ${ }^{-1} \mathrm{~s}^{-1}$ at $296 \mathrm{~K}$ (IUPAC, current recommendation).

(c) HO radicals were generated by the photolysis of an organic nitrite in air and the concentrations of butanal and 1-butene (the reference compound) were measured by FTIR spectroscopy. The measured rate coefficient ratio of $k(\mathrm{HO}+$ butanal $) / k(\mathrm{HO}$ +1 -butene $)=0.76 \pm 0.05$ is placed on an absolute basis by use of a rate coefficient of $k(\mathrm{HO}+1$-butene $)=3.14 \times 10^{-11} \mathrm{~cm}^{3}$ molecule $\mathrm{e}^{-1} \mathrm{~s}^{-1}$ at $298 \mathrm{~K}$ and atmospheric pressure of air (Atkinson, 1997).

\section{Preferred Values}

$k=2.4 \times 10^{-11} \mathrm{~cm}^{3}$ molecule ${ }^{-1} \mathrm{~s}^{-1}$ at $298 \mathrm{~K}$.

$k=6.0 \times 10^{-12} \exp (410 / T) \mathrm{cm}^{3}$ molecule $\mathrm{e}^{-1} \mathrm{~s}^{-1}$ over the temperature range $250-430 \mathrm{~K}$.

\section{Reliability}

$\Delta \log k= \pm 0.10$ at $298 \mathrm{~K}$.

$\Delta(E / R)= \pm 250 \mathrm{~K}$.

\section{Comments on Preferred Values}

The preferred $298 \mathrm{~K}$ rate coefficient is the mean of the room temperature absolute rate coefficient of Semmes et al. (1985) and the relative rate coefficients of Kerr and Sheppard (1981), Papagni et al. (2000) and D'Anna et al. (2001). The temperature dependence is that measured by Semmes et al. (1985), with the pre-exponential factor being adjusted to fit the $298 \mathrm{~K}$ preferred value. The relative rate coefficient of Audley et al. (1981) has not been used in the evaluation because, while it is in good agreement with the preferred $298 \mathrm{~K}$ rate coefficient, the rate coefficients of Audley et al. (1981) for 2-methyl-1-propanal, 1pentanal and 2, 2-dimethyl-1-propanal are significantly lower than the values of Semmes et al. (1985) and Kerr and Sheppard (1981). At room temperature and below, the reaction is expected to proceed primarily by $\mathrm{H}$-atom abstraction from the -CHO group. 


\section{References}

Atkinson, R.: J. Phys. Chem. Ref. Data, 26, 215, 1997.

Audley, G. J., Baulch, D. L., and Campbell, I. M.: J. Chem. Soc. Faraday Trans., 1 77, 2541, 1981.

D’Anna, B., Andresen, O., Gefen, Z., and Nielsen, C. J.: Phys. Chem. Chem. Phys., 3, 3057, 2001.

IUPAC: http://www.iupac-kinetic.ch.cam.ac.uk/.

Kerr, J. A. and Sheppard, D. W.: Environ. Sci. Technol., 15, 960, 1981.

Papagni, C., Arey, J., and Atkinson, R.: Int. J. Chem. Kinet., 32, 79, 2000.

Semmes, D. H., Ravishankara, A. R., Gump-Perkins, C. A., and Wine, P. H.: Int. J. Chem. Kinet., 17, 303, 1985. 
II.A2.17

$$
\mathrm{HO}+\mathrm{CH}_{2}=\mathrm{C}\left(\mathrm{CH}_{3}\right) \mathrm{CHO} \rightarrow \text { products }
$$

\section{Rate coefficient data}

\begin{tabular}{|c|c|c|c|}
\hline$k / \mathrm{cm}^{3}$ molecule $^{-1} \mathrm{~s}^{-1}$ & Temp./K & Reference & Technique/Comments \\
\hline \multicolumn{4}{|l|}{ Absolute Rate Coefficients } \\
\hline $1.77 \times 10^{-11} \exp [(175 \pm 52) / T]$ & $300-423$ & Kleindienst et al., 1982 & FP-RF \\
\hline$(3.14 \pm 0.49) \times 10^{-11}$ & 300 & & \\
\hline $7.73 \times 10^{-12} \exp [(379 \pm 46) / T]$ & $234-373$ & Gierczak et al., 1997 & PLP-LIF \\
\hline$(2.79 \pm 0.12) \times 10^{-11}$ & 298 & & \\
\hline $9.8 \times 10^{-13} \exp [(1050 \pm 120) / T]$ & $300-422$ & Chuong and Stevens, 2003 & DF-RF/LIF (a) \\
\hline$(3.23 \pm 0.36) \times 10^{-11}$ & 300 & & \\
\hline$(3.22 \pm 0.10) \times 10^{-11}$ & 300 & Chuong and Stevens, 2004 & DF-LIF (b) \\
\hline \multicolumn{4}{|l|}{ Relative Rate Coefficients } \\
\hline$(2.96 \pm 0.24) \times 10^{-11}$ & $299 \pm 2$ & Atkinson et al., 1983 & $\mathrm{RR}(\mathrm{c})$ \\
\hline$(3.90 \pm 0.31) \times 10^{-11}$ & $298 \pm 2$ & Edney et al., 1986 & $\mathrm{RR}(\mathrm{d})$ \\
\hline
\end{tabular}

\section{Comments}

(a) No variation in the rate coefficient was observed over the pressure range 2.7-6.7 mbar (2-5 Torr) of He diluent at any of the temperatures studied (300-422 K). The cited temperature-dependent rate expression uses data at $6.7 \mathrm{mbar}$ pressure of $\mathrm{He}$ (Chuong and Stevens, 2003). Problems ascribed to reversible wall adsorption of methacrolein and heterogeneous wall reactions were observed; these were avoided or minimized by addition of $\sim 10 \% \mathrm{O}_{2}$ or by conditioning the reactor with high $\mathrm{F}$ atom concentrations

(b) At 133 mbar (100 Torr) of $\mathrm{N}_{2}$ diluent, using a turbulent flow reactor.

(c) Relative rate study carried out at atmospheric pressure of air. The concentrations of methacrolein and propene (the reference compound) were measured by GC. The measured rate coefficient ratio $k(\mathrm{HO}+$ methacrolein $) / k(\mathrm{HO}+$ propene $)$ $=1.13 \pm 0.09$ is placed on an absolute basis by using a rate coefficient of $k(\mathrm{HO}+$ propene $)=2.62 \times 10^{-11} \mathrm{~cm}^{3}$ molecule $\mathrm{s}^{-1}$ at $299 \mathrm{~K}$ and atmospheric pressure of air (Atkinson, 1997).

(d) Relative rate study carried out at atmospheric pressure of air. The concentrations of methacrolein and propene and trans2-butene (the reference compounds) were measured by GC. The measured rate coefficient ratios are placed on an absolute basis by using rate coefficients of $k(\mathrm{HO}+$ propene $)=2.63 \times 10^{-11} \mathrm{~cm}^{3}$ molecule ${ }^{-1} \mathrm{~s}^{-1}$ and $k(\mathrm{HO}+$ trans-2-butene $)=$ $6.40 \times 10^{-11} \mathrm{~cm}^{3}$ molecule ${ }^{-1} \mathrm{~s}^{-1}$ at $298 \mathrm{~K}$ and atmospheric pressure of air (Atkinson, 1997). The indicated uncertainty is one standard deviation (Edney et al., 1986).

\section{Preferred Values}

$k=2.9 \times 10^{-11} \mathrm{~cm}^{3}$ molecule $\mathrm{e}^{-1} \mathrm{~s}^{-1}$ at $298 \mathrm{~K}$.

$k=8.0 \times 10^{-12} \exp (380 / T) \mathrm{cm}^{3}$ molecule $\mathrm{e}^{-1} \mathrm{~s}^{-1}$ over the temperature range $230-380 \mathrm{~K}$.

\section{Reliability}

$\Delta \log k= \pm 0.10$ at $298 \mathrm{~K}$.

$\Delta(E / R)= \pm 200 \mathrm{~K}$. 


\section{Comments on Preferred Values}

The room temperature rate coefficients of Kleindienst et al. (1982), Atkinson et al. (1983), Gierczak et al. (1997) and Chuong and Stevens $(2003,2004)$ are in good agreement, with the relative rate measurement of Edney et al. (1986) being 20 $\sim 30 \%$ higher. The temperature dependence obtained by Kleindienst et al. (1982) [300-423 K] and Chuong and Stevens (2003) [300-422 K] are respectively lower and higher than that determined by Gierczak et al. (1997) over the wider temperature range of 234-373 K. In the Chuong and Stevens (2003) study, the rate coefficients at 300, 328 and $361 \mathrm{~K}$ are in good agreement with the rate expression of Gierczak et al. (1997); those 390 and $422 \mathrm{~K}$ (Chuong and Stevens, 2003) are lower than predicted from the Arrhenius expression of Gierczak et al. (1997). Because of the wider temperature range used by Gierczak et al. (1997) and the fact that it extends below room temperature, the temperature dependence of Gierczak et al. (1997) is accepted. The preferred $298 \mathrm{~K}$ rate coefficient is based on the room temperature rate coefficients of Atkinson et al. (1983) and Gierczak et al. (1997), and the pre-exponential factor is calculated from the preferred $298 \mathrm{~K}$ rate coefficient and the temperature dependence.

The products of the reaction of HO radicals with methacrolein in the presence of NO have been investigated by Tuazon and Atkinson (1990) and Orlando and Tyndall (1999). The reaction proceeds by two pathways: H-atom abstraction from the $\mathrm{CHO}$ group, and initial addition of the $\mathrm{HO}$ radical to the carbon atoms of the $\mathrm{C}=\mathrm{C}$ bond. $\mathrm{H}$-atom abstraction from the $\mathrm{CHO}$ group accounts for 50-55\% of the overall reaction at room temperature (Tuazon and Atkinson, 1990; Orlando and Tyndall, 1999), forming the acyl radical $\mathrm{CH}_{2}=\mathrm{C}\left(\mathrm{CH}_{3}\right) \mathrm{CO}$ which then adds $\mathrm{O}_{2}$ to form the acyl peroxy radical $\mathrm{CH}_{2}=\mathrm{C}\left(\mathrm{CH}_{3}\right) \mathrm{C}(\mathrm{O}) \mathrm{OO}$. This acyl peroxy radical reacts with $\mathrm{NO}_{2}$, to form the peroxyacyl nitrate $\mathrm{CH}_{2}=\mathrm{C}\left(\mathrm{CH}_{3}\right) \mathrm{C}(\mathrm{O}) \mathrm{OONO}_{2}(\mathrm{MPAN})$, or with NO (Tuazon and Atkinson, 1990; Orlando and Tyndall, 1999).

$$
\begin{array}{ll}
\mathrm{CH}_{2}=\mathrm{C}\left(\mathrm{CH}_{3}\right) \mathrm{C}(\mathrm{O}) \mathrm{OO}+\mathrm{NO}_{2} & \rightarrow \mathrm{CH}_{2}=\mathrm{C}\left(\mathrm{CH}_{3}\right) \mathrm{C}(\mathrm{O}) \mathrm{OONO}_{2} \\
\mathrm{CH}_{2}=\mathrm{C}\left(\mathrm{CH}_{3}\right) \mathrm{C}(\mathrm{O}) \mathrm{OO}+\mathrm{NO} & \rightarrow \mathrm{CH}_{2}=\mathrm{CCH}_{3}+\mathrm{CO}_{2}+\mathrm{NO}_{2}
\end{array}
$$

The $\mathrm{CH}_{2}=\mathrm{CCH}_{3}$ radical reacts to form $\mathrm{HCHO}, \mathrm{CO}$ and $\mathrm{CO}_{2}$ (Orlando and Tyndall, 1999).

Initial $\mathrm{HO}$ radical addition to the $\mathrm{C}=\mathrm{C}$ bond leads (in the presence of $\mathrm{NO}$ ) to the intermediate hydroxyalkoxy radicals $\mathrm{HOCH}_{2} \mathrm{C}(\mathrm{O})\left(\mathrm{CH}_{3}\right) \mathrm{CHO}$ and $\mathrm{OCH}_{2} \mathrm{C}(\mathrm{OH})\left(\mathrm{CH}_{3}\right) \mathrm{CHO}$, which decompose by the pathways (Tuazon and Atkinson, 1990; Orlando and Tyndall, 1999):

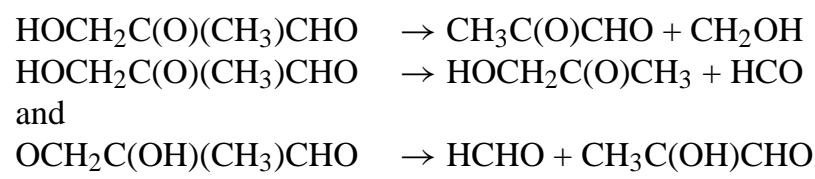

followed by reactions of $\mathrm{CH}_{2} \mathrm{OH}$ and $\mathrm{CH}_{3} \mathrm{C}(\mathrm{OH}) \mathrm{CHO}$ radicals with $\mathrm{O}_{2}$ to form $\mathrm{HCHO}+\mathrm{HO}_{2}$ and $\mathrm{CH}_{3} \mathrm{C}(\mathrm{O}) \mathrm{CHO}+\mathrm{HO}_{2}$, respectively. The $\mathrm{HO}$ radical addition reaction appears to be in the high-pressure region above $\sim 2.7$ mbar ( 2 Torr) pressure (Gierczak et al., 1997; Chuong and Stevens, 2003). The first generation products from the HO radical addition pathways are therefore $\mathrm{HCHO}+\mathrm{CH}_{3} \mathrm{C}(\mathrm{O}) \mathrm{CHO}$ and $\mathrm{HOCH}_{2} \mathrm{C}(\mathrm{O}) \mathrm{CH}_{3}+\mathrm{CO}$ (the $\mathrm{CO}$ arising from reaction of $\mathrm{HCO}$ with $\mathrm{O}_{2}$ ). The studies of Tuazon and Atkinson (1990) and Orlando and Tyndall (1999) measured formation yields of methylglyoxal and hydroxyacetone of $8.4 \%$ and $44 \%$, respectively, showing that initial $\mathrm{HO}$ radical addition occurs mainly at the terminal $\mathrm{CH}_{2}$ moiety (Tuazon and Atkinson, 1990).

\section{References}

Atkinson, R.: J. Phys. Chem. Ref. Data, 26, 215, 1997.

Atkinson, R., Aschmann, S. M., and Pitts, Jr., J. N.: Int. J. Chem. Kinet., 15, 75, 1983.

Chuong, B. and Stevens, P. S.: J. Phys. Chem. A. 107, 2185. 2003.

Chuong, B. and Stevens, P. S.: Int. J. Chem. Kinet. 36, 12, 2004.

Edney, E. O., Kleindienst, T. E., and Corse, E. W.: Int. J. Chem. Kinet., 18, 1355, 1986.

Gierczak, T., Burkholder, J. B., Talukdar, R. K., Mellouki, A., Barone, S. B., and Ravishankara, A. R.: J. Photochem. Photobiol. A: Chem., 110, 1, 1997.

Kleindienst, T. E., Harris, G. W., and Pitts Jr., J. N.: Environ. Sci. Technol., 16, 844, 1982.

Orlando, J. J. and Tyndall, G. S.: Geophys. Res. Lett., 26, 2191, 1999.

Tuazon, E. C. and Atkinson, R.: Int. J. Chem. Kinet., 22, 591, 1990. 
II.A2.18

$$
\text { OH }+ \text { Pinonaldehyde } \rightarrow \text { products }
$$

\section{Rate coefficient data}

\begin{tabular}{|c|c|c|c|}
\hline$k / \mathrm{cm}^{3}$ molecule $^{-1} \mathrm{~s}^{-1}$ & Temp./K & Reference & Technique/Comments \\
\hline \multicolumn{4}{|l|}{ Relative Rate Coefficients } \\
\hline$(8.72 \pm 1.14) \times 10^{-11}$ & $298 \pm 2$ & Hallquist et al., 1997 & $\mathrm{RR}(\mathrm{a})$ \\
\hline$(8.9 \pm 2.6) \times 10^{-11}$ & $300 \pm 5$ & Glasius et al., 1997 & $\mathrm{RR}(\mathrm{b}, \mathrm{c})$ \\
\hline$(9.0 \pm 1.3) \times 10^{-11}$ & $300 \pm 5$ & Glasius et al., 1997 & $\mathrm{RR}(\mathrm{b}, \mathrm{d})$ \\
\hline$(4.5 \pm 0.8) \times 10^{-11}$ & $296 \pm 2$ & Alvarado et al., 1998 & $\mathrm{RR}(\mathrm{e}, \mathrm{f})$ \\
\hline$(4.9 \pm 1.1) \times 10^{-11}$ & $296 \pm 2$ & Alvarado et al., 1998 & $\mathrm{RR}(\mathrm{e}, \mathrm{g})$ \\
\hline$(5.4 \pm 0.9) \times 10^{-11}$ & $296 \pm 2$ & Alvarado et al., 1998 & $\mathrm{RR}(\mathrm{e}, \mathrm{h})$ \\
\hline$(3.0 \pm 0.8) \times 10^{-11}$ & $295 \pm 3$ & Nozière et al., 1999 & $\mathrm{RR}(\mathrm{c}, \mathrm{i})$ \\
\hline$(5.5 \pm 1.5) \times 10^{-11}$ & $295 \pm 3$ & Nozière et al., 1999 & $\mathrm{RR}(\mathrm{d}, \mathrm{i})$ \\
\hline$(4.7 \pm 0.6) \times 10^{-11}$ & $295 \pm 3$ & & \\
\hline$(2.8 \pm 1.0) \times 10^{-11}$ & $295 \pm 3$ & & \\
\hline$(2.7 \pm 0.6) \times 10^{-11}$ & $295 \pm 3$ & Nozière et al., 1999 & $\operatorname{RR}(\mathrm{i}, \mathrm{j})$ \\
\hline$(3.3 \pm 0.3) \times 10^{-11}$ & $295 \pm 3$ & & \\
\hline$(2.8 \pm 0.3) \times 10^{-11}$ & $295 \pm 3$ & & \\
\hline$(3.9 \pm 0.4) \times 10^{-11}$ & $295 \pm 3$ & & \\
\hline$(3.7 \pm 1.1) \times 10^{-11}$ & $299 \pm 2$ & Nozière et al., 1999 & $R R(j, k)$ \\
\hline$(4.2 \pm 1.1) \times 10^{-11}$ & $290 \pm 2$ & & \\
\hline$(3.8 \pm 1.5) \times 10^{-11}$ & $288 \pm 1$ & & \\
\hline$(4.4 \pm 0.8) \times 10^{-11}$ & $287 \pm 1$ & & \\
\hline$(4.4 \pm 1.0) \times 10^{-11}$ & $289 \pm 2$ & & \\
\hline
\end{tabular}

\section{Comments}

(a) $\mathrm{HO}$ radicals were generated by the photolysis of $\mathrm{CH}_{3} \mathrm{ONO}-\mathrm{NO}$-air mixtures at $1013 \pm 5$ mbar pressure. The concentrations of pinonaldehyde and propene (the reference compound) were measured by FTIR spectroscopy. Wall losses of pinonaldehyde in the $153 \mathrm{~L}$ chamber were observed and measured in separate experiments and taken into account in the data analysis. The measured rate coefficient ratio of $k(\mathrm{HO}+$ pinonaldehyde $) / k(\mathrm{HO}+$ propene $)$ is placed on an absolute basis by use of a rate coefficient at $298 \mathrm{~K}$ and atmospheric pressure of air of $k(\mathrm{HO}+$ propene $)=2.63 \times 10^{-11} \mathrm{~cm}^{3}$ molecule ${ }^{-1} \mathrm{~s}^{-1}$ (Atkinson and Arey, 2003).

(b) $\mathrm{HO}$ radicals were generated by the photolysis of $\mathrm{CH}_{3} \mathrm{ONO}-\mathrm{NO}$-air or $\mathrm{H}_{2} \mathrm{O}_{2}$-air mixtures at $987 \pm 7$ mbar pressure. The concentrations of pinonaldehyde and isoprene or 1,3-butadiene (the reference compounds) were measured by FTIR spectroscopy. Decays of pinonaldehyde in the dark and due to photolysis were observed in the $480 \mathrm{~L}$ reaction chamber used and were taken into account in the data analysis. The measured rate coefficient ratios of $k(\mathrm{HO}+$ pinonaldehyde $) / k(\mathrm{HO}$ + isoprene $)=0.896 \pm 0.260$ and $k(\mathrm{HO}+$ pinonaldehyde $) / k(\mathrm{HO}+1,3$-butadiene $)=1.37 \pm 0.19$ are placed on an absolute basis by use of rate coefficients at $300 \mathrm{~K}$ of $k\left(\mathrm{HO}+\right.$ isoprene) $=9.91 \times 10^{-11} \mathrm{~cm}^{3}$ molecule ${ }^{-1} \mathrm{~s}^{-1}$ (IUPAC, current recommendation) and $k(\mathrm{HO}+1,3$-butadiene $)=6.59 \times 10^{-11} \mathrm{~cm}^{3}$ molecule ${ }^{-1} \mathrm{~s}^{-1}$ (Atkinson and Arey, 2003).

(c) Relative to $k(\mathrm{HO}+$ isoprene $)$.

(d) Relative to $k(\mathrm{HO}+1,3$-butadiene $)$.

(e) $\mathrm{HO}$ radicals were generated by the photolysis of $\mathrm{CH}_{3} \mathrm{ONO}-\mathrm{NO}$-air mixtures at 987 mbar pressure. The concentrations of pinonaldehyde and propene, 1-butene or $m$-xylene (the reference compounds) were measured by GC. No measurable decays $(<5 \%)$ of pinonaldehyde were observed due to dark decays to the walls of the $7000 \mathrm{~L}$ Teflon chamber used or due to photolysis at wavelengths $>300 \mathrm{~nm}$. The measured rate coefficient ratios of $k(\mathrm{HO}+$ pinonaldehyde $) / k(\mathrm{HO}+$ propene $)$ $=1.70 \pm 0.29, k(\mathrm{HO}+$ pinonaldehyde $) / k(\mathrm{HO}+1$-butene $)=1.56 \pm 0.33$ and $k(\mathrm{HO}+$ pinonaldehyde $) / k(\mathrm{HO}+m$-xylene $)$ 
$=2.35 \pm 0.35$ are placed on an absolute basis by use of rate coefficients at $296 \mathrm{~K}$ and atmospheric pressure of air of $k(\mathrm{HO}+$ propene $)=2.66 \times 10^{-11} \mathrm{~cm}^{3}$ molecule $\mathrm{e}^{-1} \mathrm{~s}^{-1}, k(\mathrm{HO}+1$-butene $)=3.17 \times 10^{-11} \mathrm{~cm}^{3}$ molecule ${ }^{-1} \mathrm{~s}^{-1}$ and $k(\mathrm{HO}+$ $m$-xylene) $=2.31 \times 10^{-11} \mathrm{~cm}^{3}$ molecule ${ }^{-1} \mathrm{~s}^{-1}$ (Atkinson and Arey, 2003).

(f) Relative to $k(\mathrm{HO}+$ propene $)$.

(g) Relative to $k(\mathrm{HO}+1$-butene $)$.

(h) Relative to $k(\mathrm{HO}+m$-xylene $)$.

(i) $\mathrm{HO}$ radicals were generated by the photolysis of $\mathrm{CH}_{3} \mathrm{ONO}-\mathrm{NO}$-air or $\mathrm{H}_{2} \mathrm{O}_{2}$-air mixtures at 1013 mbar pressure. The concentrations of pinonaldehyde and reference compound (isoprene, 1,3-butadiene or cyclohexane) were measured by FTIR spectroscopy. Wall losses and photolysis was observed in the various chambers used (ranging from 405 to $1080 \mathrm{~L}$ volume) and were taken into account in the data analysis. The measured rate coefficient ratios of $k(\mathrm{HO}+$ pinonaldehyde $) / k(\mathrm{HO}+$ isoprene $), k(\mathrm{HO}+$ pinonaldehyde $) / k(\mathrm{HO}+1,3$-butadiene $)$ and

$k(\mathrm{HO}+$ pinonaldehyde $) / k(\mathrm{HO}+$ cyclohexane $)$ are placed on an absolute basis by use of rate coefficients at $295 \mathrm{~K}$ of $k(\mathrm{HO}+$ isoprene $)=1.01 \times 10^{-11} \mathrm{~cm}^{3}$ molecule ${ }^{-1} \mathrm{~s}^{-1}$ (IUPAC, current recommendation), $k(\mathrm{HO}+1,3$-butadiene $)=$ $6.76 \times 10^{-11} \mathrm{~cm}^{3}$ molecule ${ }^{-1} \mathrm{~s}^{-1}$ (Atkinson and Arey, 2003) and $k(\mathrm{HO}+$ cyclohexane $)=6.90 \times 10^{-12} \mathrm{~cm}^{3} \mathrm{molecule}^{-1}$ $\mathrm{s}^{-1}$ (Atkinson, 2003; Atkinson and Arey, 2003).

(j) Relative to $k(\mathrm{HO}+$ cyclohexane $)$.

(k) Experiments carried out in the $\sim 180000 \mathrm{~L}$ volume EUPHORE chamber with HO radicals being generated by the dark reaction of ozone with 2,3-dimethyl-2-butene in air at $\sim 1$ bar pressure. The concentrations of pinonaldehyde and cyclohexane were monitored during the experiments by FTIR spectroscopy (pinonaldehyde and cyclohexane) and also by HPLC after derivatization for pinonaldehyde and by GC for cyclohexane. The measured rate coefficient ratios of $k(\mathrm{HO}+$ pinonaldehyde $) / k(\mathrm{HO}+$ cyclohexane $)$ are placed on an absolute basis by use of a rate coefficient of $k(\mathrm{HO}+$ cyclohexane $)$ $=3.26 \times 10^{-17} T^{2} \exp (262 / T) \mathrm{cm}^{3}$ molecule ${ }^{-1} \mathrm{~s}^{-1}$ (Atkinson, 2003; Atkinson and Arey, 2003).

\section{Preferred Values}

$k=4.2 \times 10^{-11} \mathrm{~cm}^{3}$ molecule $\mathrm{e}^{-1} \mathrm{~s}^{-1}$ at $298 \mathrm{~K}$.

\section{Reliability}

$\Delta \log k= \pm 0.25$ at $298 \mathrm{~K}$.

\section{Comments on Preferred Values}

Pinonaldehyde is a low volatility product of the atmospheric reactions of $\alpha$-pinene which is prone to wall losses, making measurement of its reaction rate coefficients difficult. The available rate coefficients are all from relative rate studies carried out at around room temperature, and range over a factor of $\sim 3$ (Hallquist et al., 1997; Glasius et al., 1997; Alvarado et al., 1998; Nozière et al., 1999). The rate coefficients measured by Hallquist et al. (1997) and Glasius et al. (1997) are a factor of $\sim 2$ higher than those of Alvarado et al. (1998) and Nozière et al. (1999), possibly because of unresolved wall adsorption problems. The preferred values are based on the study of Alvarado et al. (1998) carried out in a large volume Teflon chamber and the extensive study of Nozière et al. (1999) carried out in various chambers of volume ranging from $405 \mathrm{~L}$ to $\sim 180000 \mathrm{~L}$. The rate coefficients measured by Alvarado et al. (1998) have been aggregated into an average rate coefficient of $4.9 \times 10^{-11} \mathrm{~cm}^{3}$ molecule $\mathrm{e}^{-1} \mathrm{~s}^{-1}$, and those measured by Nozière et al. (1999) have been aggregated into an average rate coefficient from the indoor chambers with photolytic production of $\mathrm{HO}$ radicals of $3.6 \times 10^{-11} \mathrm{~cm}^{3}$ molecule ${ }^{-1} \mathrm{~s}^{-1}$ and an average rate coefficient from the EUPHORE chamber study (with dark production of HO radicals) of $4.1 \times 10^{-11} \mathrm{~cm}^{3}$ molecule $\mathrm{s}^{-1}$. A simple average of these three rate coefficients, which are in agreement within their large experimental uncertainties, leads to the preferred $298 \mathrm{~K}$ rate coefficient.

The reaction proceeds by $\mathrm{H}$-atom abstraction from the various $\mathrm{C}-\mathrm{H}$ bonds, including from the -CHO group. 


\section{References}

Alvarado, A., Arey, J., and Atkinson, R.: J. Atmos. Chem., 31, 281, 1998.

Atkinson, R.: Atmos. Chem. Phys., 3, 2233, 2003.

Atkinson, R. and Arey, J.: Chem. Rev., 103, 4605, 2003.

Glasius, M., Calogirou, A., Jensen, N. R., Hjorth, J., and Nielsen, C. J.: Int. J. Chem. Kinet., 29, 527, 1997.

Hallquist, M., Wängberg, I., and Ljungström, E.: Environ. Sci. Technol., 31, 3166, 1997.

IUPAC: http://www.iupac-kinetic.ch.cam.ac.uk/.

Nozière, B., Spittler, M., Ruppert, L., Barnes, I., Becker, K. H., Pons, M., and Wirtz, K.: Int. J. Chem. Kinet., 31, 291 , 1999. 
II.A2.19

$$
\mathrm{HO}+(\mathrm{CHO})_{2} \rightarrow \mathrm{H}_{2} \mathrm{O}+\mathrm{HC}(\mathrm{O}) \mathrm{CO}
$$

\section{Rate coefficient data}

\begin{tabular}{|c|c|c|c|}
\hline $\mathrm{k} / \mathrm{cm}^{3}$ molecule $^{-1} \mathrm{~s}^{-1}$ & Temp./K & Reference & Technique/Comments \\
\hline $\begin{array}{l}\text { Absolute Rate Coefficients } \\
(1.06 \pm 0.04) \times 10^{-11}\end{array}$ & $298 \pm 2$ & Plum et al., 1983 & RR (a) \\
\hline
\end{tabular}

\section{Comments}

(a) $\mathrm{HO}$ radicals were generated by the photolysis of $\mathrm{CH}_{3} \mathrm{ONO}$ in air, and the concentrations of glyoxal and cyclohexane (the reference compound) were measured by differential optical absorption spectroscopy and GC, respectively. The measured rate coefficient ratio of $k(\mathrm{HO}+$ glyoxal $) / k(\mathrm{HO}+$ cyclohexane $)=1.52 \pm 0.05$ is placed on an absolute basis by use of a rate coefficient of $k(\mathrm{HO}+$ cyclohexane $)=6.97 \times 10^{-12} \mathrm{~cm}^{3}$ molecule $\mathrm{s}^{-1} \mathrm{~s}^{-1}$ at $298 \mathrm{~K}$ (Atkinson, 2003).

\section{Preferred Values}

$k=1.1 \times 10^{-11} \mathrm{~cm}^{3}$ molecule ${ }^{-1} \mathrm{~s}^{-1}$ at $298 \mathrm{~K}$.

\section{Reliability}

$\Delta \log k= \pm 0.3$ at $298 \mathrm{~K}$.

\section{Comments on Preferred Values}

The preferred rate coefficient is based on the study of Plum et al. (1983), with increased uncertainty limits. The rate coefficient at $298 \mathrm{~K}$ is similar to those for other aldehydes. A close to zero temperature dependence is expected at around $298 \mathrm{~K}$. The reaction is assumed to proceed via overall $\mathrm{H}$-atom abstraction to yield $\mathrm{H}_{2} \mathrm{O}+\mathrm{HC}(\mathrm{O}) \mathrm{CO}$. Niki et al. (1985) and Orlando and Tyndall (2001) have shown, from product studies of the $\mathrm{Cl}$ atom- and $\mathrm{HO}$ radical-initiated reactions of glyoxal using FTIR spectroscopy, that the $\mathrm{HC}(\mathrm{O}) \mathrm{CO}$ radical reacts by the pathways:

$$
\begin{aligned}
& \mathrm{HC}(\mathrm{O}) \mathrm{CO} \rightarrow \mathrm{HCO}+\mathrm{CO} \\
& \mathrm{HC}(\mathrm{O}) \mathrm{CO}+\mathrm{O}_{2} \rightarrow \mathrm{HC}(\mathrm{O}) \mathrm{C}(\mathrm{O}) \mathrm{OO} \\
& \mathrm{HC}(\mathrm{O}) \mathrm{CO}+\mathrm{O}_{2} \rightarrow 2 \mathrm{CO}+\mathrm{HO}_{2}
\end{aligned}
$$

Niki et al. (1985) determined that at $298 \mathrm{~K}$ and $933 \mathrm{mbar}$ (700 Torr) total pressure, $k_{b} \sim k_{c}$ and $k_{a} / k_{b}=3.5 \times 10^{18}$ molecule $\mathrm{cm}^{3}$. More recently, Orlando and Tyndall (2001) measured the rate coefficient ratio $k_{c} / k_{b}$ to be $k_{c} / k_{b}=1.0 \pm 0.2$, independent of temperature over the range $224-317 \mathrm{~K}$ at $933 \mathrm{mbar}$ (700 Torr) total pressure, in good agreement with the earlier measurement of Niki et al. (1985). Assuming an temperature-independent rate coefficient of $k_{b}\left(=k_{c}\right)=5 \times 10^{-12} \mathrm{~cm}^{3}$ molecule $^{-1} \mathrm{~s}^{-1}$, Orlando and Tyndall (2001) also derived a rate coefficient at 933 mbar pressure for the $\mathrm{HC}(\mathrm{O}) \mathrm{CO}$ decomposition of $k_{a}=1.4$ $\times 10^{-12} \exp [-(3160 \pm 500) / T] \mathrm{s}^{-1}$. This results in a rate coefficient ratio $k_{a} / k_{b}$ at $298 \mathrm{~K}$ a factor of 2 higher than that derived by Niki et al. (1985).

In the presence of $\mathrm{NO}_{2}$, Orlando and Tyndall (2001) observed no evidence for the formation of the PAN-type compound $\mathrm{HC}(\mathrm{O}) \mathrm{C}(\mathrm{O}) \mathrm{OONO}_{2}$, even at $224 \mathrm{~K}$. Based on the observed formation of $\mathrm{CO}, \mathrm{CO}_{2}, \mathrm{HO}_{2} \mathrm{NO}_{2}$ and $\mathrm{N}_{2} \mathrm{O}_{5}$, Orlando and Tyndall (2001) postulated that the $\mathrm{HC}(\mathrm{O}) \mathrm{C}(\mathrm{O}) \mathrm{OO}$ radical reacts with $\mathrm{NO}_{2}$ as follows,

$$
\mathrm{HC}(\mathrm{O}) \mathrm{C}(\mathrm{O}) \mathrm{OO}+\mathrm{NO}_{2}(+\mathrm{M}) \rightarrow \mathrm{HCO}+\mathrm{CO}_{2}+\mathrm{NO}_{3}(+\mathrm{M})
$$

with subsequent reactions of $\mathrm{HCO}$ with $\mathrm{O}_{2}$ to form $\mathrm{HO}_{2}+\mathrm{CO}$, of $\mathrm{HO}_{2}$ with $\mathrm{NO}_{2}$ to form $\mathrm{HO}_{2} \mathrm{NO}_{2}$, and of $\mathrm{NO}_{3}$ with $\mathrm{NO}_{2}$ to form $\mathrm{N}_{2} \mathrm{O}_{5}$ leading to the observed products. 
R. Atkinson et al.: Evaluated kinetic and photochemical data for atmospheric chemistry

\section{References}

Atkinson, R.: Atmos. Chem. Phys. 3, 2233, 2003.

Niki, H., Maker, P. D., Savage, C. M., and Breitenbach, L. P.: Int. J. Chem. Kinet. 17, 547, 1985.

Orlando, J. J. and Tyndall, G. S.: Int. J. Chem. Kinet. 33, 149, 2001.

Plum, C. N. Sanhueza, E., Atkinson, R., Carter, W. P. L., and Pitts, Jr., J. N.: Environ. Sci. Technol. $17,479,1983$. 
II.A2.20 $\begin{aligned} \mathrm{HO}+\mathrm{HOCH}_{2} \mathrm{CHO} & \rightarrow \mathrm{H}_{2} \mathrm{O}+\mathrm{HOCH}_{2} \mathrm{CO} \\ & \rightarrow \mathrm{H}_{2} \mathrm{O}+\mathrm{HOCHCHO}\end{aligned}$

Rate coefficient data $\left(k=k_{1}+k_{2}\right)$

\begin{tabular}{llll}
\hline$k / \mathrm{cm}^{3}$ molecule & \\
\hline Relative Rate Coefficients & Temp./K & Reference & Technique/Comments \\
$(9.4 \pm 0.9) \times 10^{-12}$ & $298 \pm 2$ & Niki et al., 1987 & RR (a) \\
$(1.24 \pm 0.16) \times 10^{-11}$ & 298 & Bacher et al., 2001 & RR (a,b) \\
$(1.03 \pm 0.07) \times 10^{-11}$ & 298 & Bacher et al., 2001 & RR (b,c) \\
$(1.22 \pm 0.20) \times 10^{-11}$ & $296 \pm 2$ & Baker et al., 2004 & RR (d,e) \\
$(8.0 \pm 1.7) \times 10^{-12}$ & $296 \pm 2$ & Baker et al., 2004 & RR (d,f) \\
$(1.08 \pm 0.08) \times 10^{-11}$ & $298 \pm 3$ & Magneron et al., 2005 & RR (g,h) \\
$(1.33 \pm 0.15) \times 10^{-11}$ & $298 \pm 3$ & Magneron et al., 2005 & RR (g,i) \\
$(1.09 \pm 0.09) \times 10^{-11}$ & $298 \pm 3$ & Magneron et al., 2005 & RR (g,j) \\
$(1.38 \pm 0.17) \times 10^{-11}$ & $298 \pm 3$ & Magneron et al., 2005 & RR (g,k) \\
& & & \\
Branching Ratios & & & $(\mathrm{l})$ \\
$k_{1} / k=0.80$ & $298 \pm 2$ & Niki et al., 1987 & $(\mathrm{l})$ \\
$k_{2} / k=0.20$ & $298 \pm 2$ & Niki et al., 1987 & $(\mathrm{m})$ \\
$k_{2} / k=0.22 \pm 0.06$ & $\sim 298$ & Magneron et al., 2005 & \\
\hline
\end{tabular}

\section{Comments}

(a) $\mathrm{HO}$ radicals were generated by the photolysis of $\mathrm{CH}_{3} \mathrm{ONO}$ in air and the concentrations of $\mathrm{HOCH}_{2} \mathrm{CHO}$ and acetaldehyde (the reference compound) measured by FTIR absorption spectroscopy. The measured rate coefficient ratios of $k\left(\mathrm{HO}+\mathrm{CH}_{3} \mathrm{CHO}\right) / k\left(\mathrm{HO}+\mathrm{HOCH}_{2} \mathrm{CHO}\right)=1.6 \pm 0.15$ (Niki et al., 1987) and $k\left(\mathrm{HO}+\mathrm{HOCH}_{2} \mathrm{CHO}\right) / k\left(\mathrm{HO}+\mathrm{CH}_{3} \mathrm{CHO}\right)$ $=1.03 \pm 0.13$ (Bacher et al., 2001) are placed on an absolute basis by use of a rate constant of $k\left(\mathrm{HO}+\mathrm{CH}_{3} \mathrm{CHO}\right)=$ $1.5 \times 10^{-11} \mathrm{~cm}^{3}$ molecule ${ }^{-1} \mathrm{~s}^{-1}$ at $298 \mathrm{~K}$ (IUPAC, current recommendation).

(b) Wall losses were estimated (Bacher et al., 2001) to have led to a $\sim 20 \%$ overestimation of the HO radical reaction rate coefficients. The rate coefficients cited in the table are the rate coefficients calculated from the measured rate coefficient ratios, reduced by $20 \%$.

(c) $\mathrm{HO}$ radicals were generated by the photolysis of $\mathrm{CH}_{3} \mathrm{ONO}$ in air and the concentrations of $\mathrm{HOCH}_{2} \mathrm{CHO}_{\text {and }}$ propene (the reference compound) measured by FTIR absorption spectroscopy. The measured rate coefficient ratio of $k(\mathrm{HO}+$ $\left.\mathrm{HOCH}_{2} \mathrm{CHO}\right) / k(\mathrm{HO}+$ propene $)=0.49 \pm 0.03$ is placed on an absolute basis by use of a rate coefficient of $k(\mathrm{HO}+$ propene) $=2.63 \times 10^{-11} \mathrm{~cm}^{3}$ molecule ${ }^{-1} \mathrm{~s}^{-1}$ at $298 \mathrm{~K}$ and atmospheric pressure of air (Atkinson, 1997).

(d) $\mathrm{HO}$ radicals were generated by the photolysis of $\mathrm{CH}_{3} \mathrm{ONO}$ in air. $\mathrm{HOCH}_{2} \mathrm{CHO}$ was generated in situ from the $\mathrm{OH}$ radical-initiated reaction of 1,2-butanediol or 2-methyl-3-buten-2-ol, and the concentrations of $\mathrm{HOCH}_{2} \mathrm{CHO}$ and its precursor measured by GC. From comparison of the measured time-concentration behavior of $\mathrm{HOCH}_{2} \mathrm{CHO}$ and its precursor with calculations, rate coefficient ratios of $k\left(\mathrm{HO}+\mathrm{HOCH}_{2} \mathrm{CHO}\right) / k(\mathrm{HO}+1,2$-butanediol $)=0.485 \pm 0.073$ and $k(\mathrm{HO}+$ $\left.\mathrm{HOCH}_{2} \mathrm{CHO}\right) / k(\mathrm{HO}+2$-methyl-3-buten-2-ol $)=0.124 \pm 0.025$ were derived. These rate coefficient ratios are placed on an absolute basis by use of rate coefficients at $296 \mathrm{~K}$ of $k(\mathrm{HO}+1,2$-butanediol $)=(2.51 \pm 0.13) \times 10^{-11} \mathrm{~cm}^{3} \mathrm{molecule}^{-1}$ $\mathrm{s}^{-1}$ (Baker et al., 2004) and $k\left(\mathrm{HO}+2\right.$-methyl-3-buten-2-ol) $=6.44 \times 10^{-11} \mathrm{~cm}^{3}$ molecule ${ }^{-1} \mathrm{~s}^{-1}$ (IUPAC, current recommendation).

(e) Relative to 1,2-butanediol.

(f) Relative to 2-methyl-3-buten-2-ol. 
(g) $\mathrm{HO}$ radicals were generated by the photolysis of $\mathrm{HONO}$ in air and the concentrations of $\mathrm{HOCH}_{2} \mathrm{CHO}$ and diisopropyl ether, diethyl ether, 1,3-dioxolane or acetaldehyde (the reference compounds) measured by FTIR absorption spectroscopy. The measured rate coefficient ratios of $k\left(\mathrm{HO}+\mathrm{HOCH}_{2} \mathrm{CHO}\right) / k(\mathrm{HO}+$ diisopropyl ether $)=1.06 \pm 0.07, k(\mathrm{HO}+$ $\left.\mathrm{HOCH}_{2} \mathrm{CHO}\right) / k(\mathrm{HO}+$ diethyl ether $)=0.98 \pm 0.11, k\left(\mathrm{HO}+\mathrm{HOCH}_{2} \mathrm{CHO}\right) / k(\mathrm{HO}+1,3$-dioxolane $)=0.98 \pm 0.08$ and $k\left(\mathrm{HO}+\mathrm{HOCH}_{2} \mathrm{CHO}\right) / k(\mathrm{HO}+$ acetaldehyde $)=0.92 \pm 0.11$ are placed on an absolute basis by use of rate coefficients at $298 \mathrm{~K}$ of $k(\mathrm{HO}+$ diisopropyl ether $)=1.02 \times 10^{-11} \mathrm{~cm}^{3}$ molecule ${ }^{-1} \mathrm{~s}^{-1}$ (Magneron et al., 2005), $k(\mathrm{HO}+$ diethyl ether) $=1.36 \times 10^{-11} \mathrm{~cm}^{3}$ molecule $\mathrm{s}^{-1} \mathrm{~s}^{-1}$ (Magneron et al., 2005), $k\left(\mathrm{HO}+1,3\right.$-dioxolane) $=1.11 \times 10^{-11} \mathrm{~cm}^{3} \mathrm{molecule}^{-1} \mathrm{~s}^{-1}$ (Magneron et al., 2005) and $k\left(\mathrm{HO}+\right.$ acetaldehyde) $=1.5 \times 10^{-11} \mathrm{~cm}^{3}$ molecule ${ }^{-1} \mathrm{~s}^{-1}$ (IUPAC, current recommendation).

(h) Relative to diisopropyl ether.

(i) Relative to diethyl ether.

(j) Relative to 1,3-dioxolane.

(k) Relative to acetaldehyde.

(1) $\mathrm{HO}$ radicals were generated by the photolysis of ethyl nitrite in air, and $\mathrm{HOCH}_{2} \mathrm{CHO}$ and products $\left[(\mathrm{CHO})_{2}, \mathrm{CO}_{2}\right.$ and $\mathrm{HCHO}]$ were measured by FTIR absorption spectroscopy. Product formation yields of $(\mathrm{CHO})_{2}, 21.1 \pm 2.4 \% ; \mathrm{CO}_{2}, 81.3$ $\pm 3.2 \%$; and $\mathrm{HCHO}, 82.4 \pm 4.6 \%$ were obtained, leading to branching ratios of $k_{1} / k=0.80$ and $k_{2} / k=0.20$.

(m) $\mathrm{HO}$ radicals were generated by photolysis of $\mathrm{HONO}$ in air in the EUPHORE chamber, and $\mathrm{HOCH}_{2} \mathrm{CHO}$ and products [HCHO, $\mathrm{CO}$ and $\left.(\mathrm{CHO})_{2}\right]$ monitored by FTIR spectroscopy. The measured glyoxal yield of $22 \pm 6 \%$ was attributed to channel (2). The initial HCHO yield was $64 \pm 5 \%$.

\section{Preferred Values}

$k=1.1 \times 10^{-11} \mathrm{~cm}^{3}$ molecule ${ }^{-1} \mathrm{~s}^{-1}$ at $298 \mathrm{~K}$.

$k_{1} / k=0.80$ at $298 \mathrm{~K}$.

$k_{2} / k=0.20$ at $298 \mathrm{~K}$.

\section{Reliability}

$\Delta \log k= \pm 0.15$ at $298 \mathrm{~K}$.

$\Delta\left(k_{1} / k\right)=\Delta\left(k_{2} / k\right) \pm 0.10$ at $298 \mathrm{~K}$.

\section{Comments on Preferred Values}

All the reported rate coefficients are from relative rate studies conducted at room temperature, and as evident from the table there is a substantial amount of scatter in the rate coefficients obtained. The preferred $298 \mathrm{~K}$ rate coefficient is the mean of the room temperature rate coefficients of Niki et al. (1987), Bacher et al. (2001), Baker et al. (2004) and Magneron et al. (2005). The branching ratios $k_{1} / k$ and $k_{2} / k$ are taken from the studies of Niki et al. (1987) and Magneron et al. (2005), which are in good agreement.

\section{References}

Atkinson, R.: J. Phys. Chem. Ref. Data, 26, 215, 1997.

Bacher, C., Tyndall, G. S., and Orlando, J. J.: J. Atmos. Chem., 39, 171, 2001.

Baker, J., Arey, J. and Atkinson, R.: J. Phys. Chem. A 108, 7032, 2004.

IUPAC: http://www.iupac-kinetic.ch.cam.ac.uk/, 2005.

Magneron, I., Mellouki, A., Le Bras, G., Moortgat, G. K., Horowitz, A. and Wirtz, K.: J. Phys. Chem. A 109, 4552, 2005.

Niki, H., Maker, P. D., Savage, C. M., and Hurley, M. D.: J. Phys. Chem., 91, 2174, 1987. 
II.A2.21

$$
\mathrm{HO}+\mathrm{CH}_{3} \mathrm{C}(\mathrm{O}) \mathrm{CHO} \rightarrow \mathrm{H}_{2} \mathrm{O}+\mathrm{CH}_{3} \mathrm{C}(\mathrm{O}) \mathrm{CO}
$$

\section{Rate coefficient data}

\begin{tabular}{lllc}
\hline$k / \mathrm{cm}^{3}$ molecule $\mathrm{s}^{-1}$ & Temp./K & Reference & Technique/Comments \\
\hline $\begin{array}{l}\text { Absolute Rate Coefficients } \\
(7.1 \pm 1.6) \times 10^{-12}\end{array}$ & $297 \pm 2$ & Kleindienst et al., 1982 & FP-RF \\
$8.4 \times 10^{-13} \exp [(830 \pm 300) / T]$ & $260-333$ & Tyndall et al., 1995 & DF-LIF \\
$(1.32 \pm 0.30) \times 10^{-11}$ & 298 & & \\
& & & \\
$\begin{array}{l}\text { Relative Rate Coefficients } \\
(1.60 \pm 0.12) \times 10^{-11}\end{array}$ & $298 \pm 2$ & Plum et al., 1983 & RR (a) \\
\hline
\end{tabular}

\section{Comments}

(a) $\mathrm{HO}$ radicals were generated by the photolysis of $\mathrm{CH}_{3} \mathrm{ONO}$ in air. The concentrations of $\mathrm{CH}_{3} \mathrm{C}(\mathrm{O}) \mathrm{CHO}$ and cyclohexane (the reference compound) were measured by differential optical absorption spectroscopy and GC, respectively. The measured rate coefficient ratio of $k\left(\mathrm{HO}+\mathrm{CH}_{3} \mathrm{C}(\mathrm{O}) \mathrm{CHO}\right) / k(\mathrm{HO}+$ cyclohexane $)=2.29 \pm 0.16$ is placed on an absolute basis by use of a rate coefficient $k(\mathrm{HO}+$ cyclohexane $)=6.97 \times 10^{-12} \mathrm{~cm}^{3}$ molecule ${ }^{-1} \mathrm{~s}^{-1}$ at $298 \mathrm{~K}$ (Atkinson, 2003).

\section{Preferred Values}

$k=1.5 \times 10^{-11} \mathrm{~cm}^{3}$ molecule ${ }^{-1} \mathrm{~s}^{-1}$ at $298 \mathrm{~K}$.

\section{Reliability}

$\Delta \log k= \pm 0.2$ at $298 \mathrm{~K}$.

\section{Comments on Preferred Values}

The preferred $298 \mathrm{~K}$ rate coefficient is an average of the relative rate coefficient of Plum et al. (1983) and the absolute rate coefficient of Tyndall et al. (1995). The absolute rate coefficient measured by Kleindienst et al. (1982) may have been low due to the presence of significant levels of low reactivity impurities in the methylglyoxal samples used. The data of Tyndall et al. (1995) indicate a significant negative temperature dependence; while no recommendation is made concerning the temperature dependence of this reaction a negative temperature dependence is expected at around room temperature (see, for example, the $\mathrm{HO}+\mathrm{CH}_{3} \mathrm{CHO}$ reaction (IUPAC, this evaluation). The reaction is assumed to proceed via $\mathrm{H}$-atom abstraction to form $\mathrm{H}_{2} \mathrm{O}+\mathrm{CH}_{3} \mathrm{C}(\mathrm{O}) \mathrm{CO}$. Green et al. (1990) have shown that the dominant fate of the $\mathrm{CH}_{3} \mathrm{C}(\mathrm{O}) \mathrm{CO}$ radical under atmospheric conditions is decomposition to form $\mathrm{CH}_{3} \mathrm{CO}+\mathrm{CO}$.

\section{References}

Atkinson, R.: Atmos. Chem. Phys., 3, 2233, 2003.

Green, M., Yarwood, G., and Niki, H.: Int. J. Chem. Kinet., 22, 689, 1990.

Kleindienst, T. E., Harris, G. W., and Pitts Jr., J. N.: Environ. Sci. Technol., 16, 844, 1982.

Plum, C. N., Sanhueza, E., Atkinson, R., Carter, W. P. L., and Pitts Jr., J. N.: Environ. Sci. Technol., 17, 479, 1983.

Tyndall, G. S., Staffelbach, T. A., Orlando, J. J., and Calvert, J. G.: Int. J. Chem. Kinet., 27, 1009, 1995. 


\section{II.A2.22}

\section{$\mathrm{HO}+\mathrm{CH}_{3} \mathrm{C}(\mathrm{O}) \mathrm{CH}_{3} \rightarrow \mathrm{H}_{2} \mathrm{O}+\mathrm{CH}_{2} \mathrm{C}(\mathrm{O}) \mathrm{CH}_{3}$}

$\Delta H^{\circ}=-87.8 \mathrm{~kJ} \cdot \mathrm{mol}^{-1}$

\section{Rate coefficient data}

\begin{tabular}{lllc}
\hline$k / \mathrm{cm}^{3}$ molecule $\mathrm{s}^{-1}$ & Temp./K & Reference & Technique/Comments \\
\hline Absolute Rate Coefficients & & & \\
$1.7 \times 10^{-12} \exp [-(600 \pm 75) / T]$ & $240-440$ & Wallington and Kurylo, 1987 & FP-RF \\
$(2.16 \pm 0.16) \times 10^{-13}$ & 296 & & \\
$(8.80 \pm 1.32) \times 10^{-12}$ & 1217 & Bott and Cohen, 1991 & SH-RA \\
$1.25 \times 10^{-12} \exp [-(561 \pm 57) / T]$ & $243-372$ & Le Calvé et al., 1998 & PLP-LIF \\
$(1.84 \pm 0.24) \times 10^{-13}$ & 298 & & \\
$8.8 \times 10^{-12} \exp [-(1320 \pm 163) / T]$ & $202-395$ & Wollenhaupt et al., 2000 & PLP-LIF/RF \\
$+1.7 \times 10^{-14} \exp [(423 \pm 109) / T]$ & & & \\
$(1.73 \pm 0.09) \times 10^{-13}$ & 298 & & \\
$(1.73 \pm 0.05) \times 10^{-13}$ & 298 & Vasvári et al., 2001 & DF-RF \\
$1.38 \times 10^{-13}+3.86 \times 10^{-11} \exp [-1997 / T]$ & $199-383$ & Gierczak et al., 2003 & PLP-LIF/DF-CIMS (a) \\
$(1.77 \pm 0.18) \times 10^{-13}$ & 298 & & \\
$3.99 \times 10^{-24} T^{4.00} \exp [(453 \pm 44) / T]$ & $298-832$ & Yamama et al., 2003 & PLP-LIF \\
$(1.56 \pm 0.08) \times 10^{-13}$ & 298 & & SH-RA (b) \\
$4.90 \times 10^{-11} \exp [-2297 / T]$ & $982-1300$ & Vasudevan et al., 2005 & \\
Relative Rate Coefficients & & & RR (c) \\
$(2.7 \pm 0.1) \times 10^{-13}$ & & & RR (d) \\
$1.39 \times 10^{-12} \exp [-(604 \pm 44) / T]$ & $303 \pm 2$ & Kerr and Stocker, 1986 & \\
$1.83 \times 10^{-13}$ & $253-373$ & Raff et al., 2005 & \\
\hline
\end{tabular}

\section{Comments}

(a) Rate coefficients for the reaction of $\mathrm{HO}$ radicals with acetone were shown to be independent of pressure over the range 1.1 Torr (1.5 mbar) of He diluent to 490 Torr (653 mbar) of SF6 diluent. Rate coefficients were also measured for the reactions $\mathrm{HO}+\mathrm{CD}_{3} \mathrm{C}(\mathrm{O}) \mathrm{CD}_{3}(211-383 \mathrm{~K}), \mathrm{DO}+\mathrm{CD}_{3} \mathrm{C}(\mathrm{O}) \mathrm{CD}_{3}(213-324 \mathrm{~K}), \mathrm{H}^{18} \mathrm{O}+\mathrm{CH}_{3} \mathrm{C}(\mathrm{O}) \mathrm{CH}_{3}(240-296 \mathrm{~K})$ and $\mathrm{DO}+\mathrm{CH}_{3} \mathrm{C}(\mathrm{O}) \mathrm{CH}_{3}(223-296 \mathrm{~K})$ over the indicated temperature ranges. The measured $\mathrm{H} / \mathrm{D}$ isotope effect, $k(\mathrm{HO}+$ $\left.\mathrm{CH}_{3} \mathrm{C}(\mathrm{O}) \mathrm{CH}_{3}\right) / k\left(\mathrm{HO}+\mathrm{CD}_{3} \mathrm{C}(\mathrm{O}) \mathrm{CD}_{3}\right)$, increased from $5.9 \pm 0.9$ at $298 \mathrm{~K}$ to $8.6 \pm 0.8$ at $212 \mathrm{~K}$.

(b) HO radicals were generated by shock-heating of tert-butyl hydroperoxide and monitored by laser absorption at 306.7 nm. A fit of the absolute rate data of Wallington and Kurylo (1987), Bott and Cohen (1991), Le Calvé et al. (1998), Wollenhaupt et al. (2000), Gierczak et al. (2003) and Vasudevan et al. (2005) and the relative rate data of Tranter et al. (2001) to a multi-parameter expression yielded $k=\left\{1.33 \times 10^{-13}+1.01 \times 10^{-15} T^{1.41} \exp (-1289 / T)\right\} \mathrm{cm}^{3} \mathrm{molecule}^{-1}$ $\mathrm{s}^{-1}$ over the temperature range $199-1300 \mathrm{~K}$.

(c) HO radicals were generated by the photolysis of $\mathrm{HONO}$ in air, and the concentrations of acetone and ethene (the reference compound) were measured by GC. The measured rate coefficient ratio of $k(\mathrm{HO}+$ acetone $) / k(\mathrm{HO}+$ ethene $)=0.032 \pm 0.001$ is placed on an absolute basis by use of a rate coefficient of $k(\mathrm{HO}+$ ethene $)=8.32 \times 10^{-12} \mathrm{~cm}^{3}$ molecule ${ }^{-1} \mathrm{~s}^{-1}$ at $303 \mathrm{~K}$ and atmospheric pressure (Atkinson, 1997).

(d) $\mathrm{HO}$ radicals were generated by the photolysis at $<315 \mathrm{~nm}$ of $\mathrm{O}_{3}-\mathrm{O}_{2}-\mathrm{H}_{2} \mathrm{O}-\mathrm{He}$ mixtures at $735-750$ Torr (980-1000 mbar) total pressure in 0.16 or $0.50 \mathrm{~L}$ quartz reaction vessels. The concentrations of acetone and $\mathrm{CH}_{3} \mathrm{CHF}_{2}$ (the reference compound) were measured by MS. The measured rate coefficient ratios of $k(\mathrm{HO}+$ acetone $) / k\left(\mathrm{HO}+\mathrm{CH}_{3} \mathrm{CHF}_{2}\right)$ are placed on an absolute basis by use of a rate coefficient of $k\left(\mathrm{HO}+\mathrm{CH}_{3} \mathrm{CHF}_{2}\right)=2.80 \times 10^{-18} T^{2} \exp (-580 / T) \mathrm{cm}^{3} \mathrm{molecule}^{-1}$ $\mathrm{s}^{-1}$ (IUPAC, 2005). Rate coefficients were also measured for the reaction of $\mathrm{HO}$ radicals with $\mathrm{CD}_{3} \mathrm{C}(\mathrm{O}) \mathrm{CD}_{3}$, relative to 
those for $\mathrm{CH}_{2} \mathrm{~F}_{3}$, over the temperature range 293-373 K. Use of $k\left(\mathrm{HO}+\mathrm{CH}_{2} \mathrm{~F}_{2}\right)=4.80 \times 10^{-18} T^{2} \exp (-1080 / T) \mathrm{cm}^{3}$ molecule $\mathrm{s}^{-1}$ (IUPAC, 2005) leads to $k\left(\mathrm{HO}+\mathrm{CD}_{3} \mathrm{C}(\mathrm{O}) \mathrm{CD}_{3}\right)=5.06 \times 10^{-13} \exp (-819 / T) \mathrm{cm}^{3}$ molecule $\mathrm{s}^{-1} \mathrm{~s}^{-1}$ over the temperature range $293-373 \mathrm{~K}$. Acetic acid was observed as a product of the reaction of $\mathrm{HO}$ radicals with $\mathrm{CH}_{3} \mathrm{C}(\mathrm{O}) \mathrm{CH}_{3}$, but was attributed mainly or wholly to secondary chemistry.

\section{Preferred Values}

$k=1.8 \times 10^{-13} \mathrm{~cm}^{3}$ molecule ${ }^{-1} \mathrm{~s}^{-1}$ at $298 \mathrm{~K}$. $k=\left\{8.8 \times 10^{-12} \exp (-1320 / T)+1.7 \times 10^{-14} \exp (423 / T)\right\} \mathrm{cm}^{3}$ molecule ${ }^{-1} \mathrm{~s}^{-1}$ over the temperature range $195-440 \mathrm{~K}$.

\section{Reliability}

$\Delta \log k= \pm 0.08$ over the temperature range $200-400 \mathrm{~K}$.

\section{Comments on Preferred Values}

The absolute rate studies of Wallington and Kurylo (1987), Bott and Cohen (1991), Le Calvé et al. (1998), Wollenhaupt et al. (2000), Vasvári et al. (2001), Gierczak et al. (2003), Yamada et al. (2003) and Vasudevan et al. (2005) lead to a generally consistent temperature-dependent set of rate coefficients for the reaction of HO radicals with acetone over the range 199-1300 K, and the relative rate coefficients measured by Raff et al. (2005) over the temperature range 253-373 are also in good agreement with these absolute studies. In particular, the rate coefficients of Wollenhaupt et al. (2000) and Gierczak et al. (2003) are in excellent agreement over the temperature range common to both studies (202-383 K), and the low temperature $(<240 \mathrm{~K})$ data of Wollenhaupt et al. (2000) have been confirmed by Gierczak et al. (2003). In these studies of Wollenhaupt et al. (2000) and Gierczak et al. (2003), the concentration of acetone in the flow stream was measured by UV absorption. The preferred rate expression uses the non-linear least-squares analysis presented by Wollenhaupt et al. (2000), which leads to a generally excellent fit of the rate coefficients of Wallington and Kurylo (1987), Le Calvé et al. (1998), Wollenhaupt et al. (2000) and Gierczak et al. (2003) over the range 199-440 K. Note that the temperature-dependence of the rate coefficient for this reaction at $\leq 200 \mathrm{~K}$ is not well established, and the preferred expression should not be used below $195 \mathrm{~K}$.

The measured deuterium isotope effect, $k\left(\mathrm{HO}+\mathrm{CH}_{3} \mathrm{C}(\mathrm{O}) \mathrm{CH}_{3}\right) / k\left(\mathrm{HO}+\mathrm{CD}_{3} \mathrm{C}(\mathrm{O}) \mathrm{CD}_{3}\right)$, is substantial, being $5.9 \pm 0.9$ (Gierczak et al., 2003), $6.8 \pm 1.0$ (Yamada et al., 2003) and 5.65 (Raff et al., 2005) at $298 \mathrm{~K}$, increasing to $8.6 \pm 0.8$ at $212 \mathrm{~K}$ (Gierczak et al., 2003). The magnitude of this deuterium isotope effect indicates that the rate-determining step involves $\mathrm{C}-\mathrm{H}$ (or C-D) bond breakage.

Products of this reaction have been investigated by Wollenhaupt and Crowley (2000), Vasvári et al. (2001), Vandenberk et al. (2002), Tyndall et al. (2002), Turpin et al. (2003) and Talukdar et al. (2003), with conflicting results in some cases. Wollenhaupt and Crowley (2000) measured the amount of $\mathrm{CH}_{3}$ radicals formed in the pathway

$$
\mathrm{HO}+\mathrm{CH}_{3} \mathrm{C}(\mathrm{O}) \mathrm{CH}_{3} \rightarrow \mathrm{CH}_{3} \mathrm{C}(\mathrm{O}) \mathrm{OH}+\mathrm{CH}_{3}
$$

by converting methyl radicals to methoxy radicals by reaction with $\mathrm{NO}_{2}$ and monitoring $\mathrm{CH}_{3} \mathrm{O}$ by $\mathrm{LIF}$, and concluded that the channel forming $\mathrm{CH}_{3} \mathrm{C}(\mathrm{O}) \mathrm{OH}+\mathrm{CH}_{3}$ accounted for $\sim 50 \%$ of the overall reaction at $298 \mathrm{~K}$ and $\sim 30 \%$ at $233 \mathrm{~K}$. Vasvári et al. (2001) used a DF system with LIF detection of $\mathrm{HO}$ radicals and $\mathrm{CH}_{3} \mathrm{C}(\mathrm{O}) \mathrm{CH}_{2}$ radicals to obtain a branching ratio for the H-atom abstraction pathway of $0.50 \pm 0.04$ at $298 \mathrm{~K}$, apparently consistent with the data of Wollenhaupt and Crowley (2000). However, Vandenberk et al. (2002), Tyndall et al. (2002) and Talukdar et al. (2003) measured upper limits to acetic acid formation of $<5 \%$ at $298 \mathrm{~K}$ (Vandenberk et al., 2002), $<10 \%$ at $296 \mathrm{~K}$ and $251 \mathrm{~K}$ (Tyndall et al., 2002), and $<1 \%$ over the range 237-353 K (Talukdar et al., 2003). Furthermore, Talukdar et al. (2003) and Turpin et al. (2003) measured yields of $\mathrm{CH}_{3} \mathrm{C}(\mathrm{O}) \mathrm{CH}_{2}$ radicals of $96 \pm 11 \%$, independent of temperature over the range $242-350 \mathrm{~K}$, and $90 \pm 10 \%$ at $298 \mathrm{~K}$, respectively. The results of these recent product studies of Vandenberk et al. (2002), Tyndall et al. (2002), Turpin et al. (2003) and Talukdar et al. (2003), together with the large deuterium isotope effect observed by Gierczak et al. (2003), Yamada et al. (2003) and Raff et al. (2005) and the lack of a pressure dependence (Gierczak et al., 2003), indicate that the reaction proceeds by H-atom abstraction.

\section{References}

Atkinson, R.: J. Phys. Chem. Ref. Data, 26, 215, 1997.

Bott, J. F. and Cohen, N.: Int. J. Chem. Kinet., 23, 1017, 1991. 
Gierczak, T., Gilles, M. K., Bauerle, S., and Ravishankara, A. R.: J. Phys. Chem. A, 107, 5014, 2003.

Kerr, J. A. and Stocker, D. W.: J. Atmos. Chem., 4, 253, 1986.

Le Calvé, S., Hitier, D., Le Bras, G., and Mellouki, A.: J. Phys. Chem. A., 102, 4579, 1998.

Raff, J. D., Stevens, P. S. and Hites, R. A.: J. Phys. Chem. A 109, 4728, 2005.

Talukdar, R. K., Gierczak, T., McCabe, D. C., and Ravishankara, A. R.: J. Phys. Chem. A, 107, 5021, 2003.

Tranter, R. S. and Walker, R. W.: Phys. Chem. Chem. Phys. 3, 1262, 2001.

Turpin, E., Fittschen, C., Tomas, A and Devolder, P.: J. Atmos. Chem. 46, 1, 2003.

Tyndall, G. S., Orlando, J. J., Wallington, T. J., Hurley, M. D., Goto, M. and Kawasaki, M.: Phys. Chem. Chem. Phys. 4, 2189, 2002.

Vandenberk, S., Vereecken, L., and Peeters, J.: Phys. Chem. Chem. Phys., 4, 461, 2002.

Vasvári, G., Szilágyi, I., Dóbé, S., Bérces, T., Henon, E., Canneaux, S., and Bohr, F.: Phys. Chem. Chem. Phys., 3, 551, 2001. Wallington, T. J. and Kurylo, M. J.: J. Phys. Chem., 91, 5050, 1987.

Wollenhaupt, M. and Crowley, J. N.: J. Phys. Chem. A ,104, 6429, 2000.

Wollenhaupt, M., Carl, S. A., Horowitz, A., and Crowley, J. N.: J. Phys. Chem. A, 104, 2695, 2000.

Yamada, T., Taylor, P. H., Goumri, A. and Marshall, P.: J. Chem. Phys. 119, 10600, 2003. 
II.A2.23

$$
\mathrm{HO}+\mathrm{CH}_{3} \mathrm{C}(\mathrm{O}) \mathrm{CH}_{2} \mathrm{CH}_{3} \rightarrow \text { products }
$$

\section{Rate coefficient data}

\begin{tabular}{lllc}
\hline$k / \mathrm{cm}^{3}$ molecule ${ }^{-1} \mathrm{~s}^{-1}$ & Temp./K & Reference & Technique/Comments \\
\hline $\begin{array}{l}\text { Absolute Rate Coefficients } \\
2.3 \times 10^{-12} \exp [-(170 \pm 120) / T]\end{array}$ & $240-440$ & Wallington and Kurylo, 1987 & FP-RF \\
$(1.15 \pm 0.10) \times 10^{-12}$ & 296 & & \\
$1.51 \times 10^{-12} \exp [-(60 \pm 61) / T]$ & $243-372$ & Le Calvé et al., 1998 & PLP-LIF \\
$(1.19 \pm 0.18) \times 10^{-12}$ & 298 & & \\
& & & \\
Relative Rate Coefficients & $305 \pm 2$ & Winer et al., 1976 & \\
$(3.5 \pm 1.0) \times 10^{-12}$ & 300 & Cox et al., 1980 & RR (a) \\
$2.74 \times 10^{-12}$ & $295 \pm 2$ & Cox et al., 1981 & RR (b) \\
$(9.5 \pm 0.9) \times 10^{-13}$ & 297 & Edney et al., 1986 & RR (b) \\
$(9.1 \pm 1.6) \times 10^{-13}$ & & & RR (c) \\
\hline
\end{tabular}

\section{Comments}

(a) $\mathrm{HO}$ radicals were generated by the photolysis of $\mathrm{NO}_{\mathrm{x}}$-organic-air mixtures, and the concentrations of 2-butanone and 2-methylpropene (the reference compound) were measured by GC. The measured rate coefficient ratio of $k(\mathrm{HO}+2-$ butanone $) / k(\mathrm{HO}+2$-methylpropene $)=0.07( \pm 30 \%)$ is placed on an absolute basis by use of a rate coefficient of $k(\mathrm{HO}+$ 2-methylpropene) $=4.94 \times 10^{-11} \mathrm{~cm}^{3}$ molecule ${ }^{-1} \mathrm{~s}^{-1}$ at $305 \mathrm{~K}$ (Atkinson, 1997).

(b) HO radicals were generated by the photolysis of HONO in air, and the concentrations of 2-butanone and ethene (the reference compound) were measured by GC. The measured rate coefficient ratios $k(\mathrm{HO}+2$-butanone $) / k(\mathrm{HO}+$ ethene $)$ are placed on an absolute basis by use of rate coefficients at atmospheric pressure of $k(\mathrm{HO}+$ ethene $)=8.44 \times 10^{-12} \mathrm{~cm}^{3}$ molecule $\mathrm{s}^{-1}$ at $300 \mathrm{~K}$ and $8.65 \times 10^{-12} \mathrm{~cm}^{3}$ molecule ${ }^{-1} \mathrm{~s}^{-1}$ at $295 \mathrm{~K}$ (Atkinson, 1997).

(c) $\mathrm{HO}$ radicals were generated from the photolysis of $\mathrm{CH}_{3} \mathrm{ONO}$ in air, and the concentrations of 2-butanone and propane (the reference compound) were measured by GC. The measured rate coefficient ratio of $k(\mathrm{HO}+2$-butanone $) / k(\mathrm{HO}+$ propane $)$ is placed on an absolute basis by use of a rate coefficient of $k(\mathrm{HO}+$ propane $)=1.07 \times 10^{-12} \mathrm{~cm}^{3}$ molecule ${ }^{-1} \mathrm{~s}^{-1}$ at $297 \mathrm{~K}$ (IUPAC, current recommendation).

\section{Preferred Values}

$k=1.2 \times 10^{-12} \mathrm{~cm}^{3}$ molecule ${ }^{-1} \mathrm{~s}^{-1}$ at $298 \mathrm{~K}$.

$k=1.3 \times 10^{-12} \exp (-25 / T) \mathrm{cm}^{3}$ molecule $\mathrm{s}^{-1} \mathrm{~s}^{-1}$ over the temperature range 240-300 K.

\section{Reliability}

$\Delta \log k= \pm 0.15$ at $298 \mathrm{~K}$.

$\Delta(E / R)= \pm 200 \mathrm{~K}$.

\section{Comments on Preferred Values}

Photolysis of 2-butanone may have contributed to the measured 2-butanone loss rates in the relative rate studies of Winer et al. (1976) and Cox et al. (1980). A unit-weighted least-squares analysis of the absolute rate coefficients of Wallington et al. (1987) and Le Calvé et al. (1998), using the three-parameter expression $k=C T^{2} \exp (-D / T)$, results in $k=2.53 \times 10^{-18} T^{2}$ $\exp (503 / T) \mathrm{cm}^{3}$ molecule $\mathrm{s}^{-1} \mathrm{~s}^{-1}$ over the temperature range $240-440 \mathrm{~K}$. The preferred Arrhenius expression, $k=A \exp (-B / T)$, is centered at $265 \mathrm{~K}$ and is derived from the above three-parameter expression with $A=C \mathrm{e}^{2} T^{2}$ and $B=D+2 T$. 
Cox et al. (1981) observed acetaldehyde as a product of the HO radical reaction with 2-butanone, with a formation yield of $0.62 \pm 0.02$. Acetaldehyde is expected to arise from 2-butanone after $\mathrm{H}$-atom abstraction from the $\mathrm{CH}_{2}$ group, and hence the fraction of the overall $\mathrm{HO}$ radical reaction with 2-butanone proceeding via

$$
\mathrm{HO}+\mathrm{CH}_{3} \mathrm{C}(\mathrm{O}) \mathrm{CH}_{2} \mathrm{CH}_{3} \rightarrow \mathrm{H}_{2} \mathrm{O}+\mathrm{CH}_{3} \mathrm{C}(\mathrm{O}) \mathrm{CHCH}_{3}
$$

is $\sim 0.62$.

\section{References}

Atkinson, R.: J. Phys. Chem. Ref. Data, 26, 215, 1997.

Cox, R. A., Derwent, R. G., and Williams, M. R.: Environ. Sci. Technol., 14, 57, 1980.

Cox, R. A., Patrick, K. F., and Chant, S. A.: Environ. Sci. Technol., 15, 587, 1981.

Edney, E. O., Kleindienst, T. E., and Corse, E. W.: Int. J. Chem. Kinet., 18, 1355, 1986.

IUPAC: http://www.iupac-kinetic.ch.cam.ac.uk/.

Le Calvé, S., Hitier, D., Le Bras, G., and Mellouki, A.: J. Phys. Chem. A., 102, 4579, 1998.

Wallington, T. J. and Kurylo, M. J.: J. Phys. Chem., 91, 5050, 1987.

Winer, A. M., Lloyd, A. C., Darnall K. R., and Pitts Jr., J. N.: J. Phys. Chem., 80, 1635, 1976. 
II.A2.24

$$
\mathrm{HO}+\mathrm{CH}_{3} \mathrm{C}(\mathrm{O}) \mathrm{CH}=\mathrm{CH}_{2} \rightarrow \text { products }
$$

\section{Rate coefficient data}

\begin{tabular}{lllc}
\hline$k / \mathrm{cm}^{3}$ molecule ${ }^{-1} \mathrm{~s}^{-1}$ & Temp./K & Reference & Technique/Comments \\
\hline Absolute Rate Coefficients & & & \\
$3.85 \times 10^{-12} \exp [(456 \pm 73) / T]$ & $298-424$ & Kleindienst et al., 1982 & FP-RF \\
$(1.79 \pm 0.28) \times 10^{-11}$ & 298 & & \\
$2.67 \times 10^{-12} \exp [(612 \pm 49) / T]$ & $232-378$ & Gierczak et al., 1997 & PLP-LIF \\
$(2.03 \pm 0.17) \times 10^{-11}$ & 298 & & \\
$(1.73 \pm 0.21) \times 10^{-11}$ & 300 & Chuong and Stevens, 2003 & DF-RF/LIF (a) \\
$(1.78 \pm 0.08) \times 10^{-11}$ & 300 & Chuong and Stevens, 2004 & DF-LF (b) \\
$(1.86 \pm 0.12) \times 10^{-11}$ & $298 \pm 2$ & Holloway et al.,, 2005 & PLP-LIF (c) \\
Relative Rate Coefficients & & & \\
$1.48 \times 10^{-11}$ & 300 & Cox et al., 1980 & RR (d) \\
$(1.96 \pm 0.15) \times 10^{-11}$ & $299 \pm 2$ & Atkinson et al., 1983 & RR (e) \\
\hline
\end{tabular}

\section{Comments}

(a) At $300 \mathrm{~K}$ no measurable variation in the rate coefficient was observed over the pressure range 2.7-6.7 mbar (2-5 Torr) of He diluent; the cited rate coefficient is that obtained at 6.7 mbar (5 Torr) of He diluent. However, at the other temperatures studied $(328,361,390$ and $422 \mathrm{~K})$ the measured rate coefficients increased with increasing pressure over the range 2.7$6.7 \mathrm{mbar}$ of $\mathrm{He}$, showing that the reaction was in the fall-off regime under these temperature and pressure conditions. Problems ascribed to reversible wall adsorption of methyl vinyl ketone and heterogeneous wall reactions were observed; these were avoided or minimized by addition of $\sim 10 \% \mathrm{O}_{2}$ or by conditioning the reactor with high $\mathrm{F}$ atom concentrations

(b) At 133 mbar (100 Torr) of $\mathrm{N}_{2}$ diluent, using a turbulent flow reactor.

(c) The pulsed laser photolysis of 3-methyl-2,4-dione at $248 \mathrm{~nm}$ was used to generate HO radicals.

(d) Relative rate study carried out at atmospheric pressure of air. The concentrations of methyl vinyl ketone and ethene (the reference compound) were measured by GC. The measured rate coefficient ratio is placed on an absolute basis by using a rate coefficient of $k(\mathrm{HO}+$ ethene $)=8.44 \times 10^{-12} \mathrm{~cm}^{3}$ molecule $\mathrm{e}^{-1} \mathrm{~s}^{-1}$ at $300 \mathrm{~K}$ and atmospheric pressure of air (Atkinson, 1997).

(e) Relative rate study carried out at atmospheric pressure of air. The concentrations of methyl vinyl ketone and propene (the reference compound) were measured by GC. The measured rate coefficient ratio $k(\mathrm{HO}+$ methyl vinyl ketone $) / k(\mathrm{HO}$ + propene $)=0.747 \pm 0.055$ is placed on an absolute basis by using a rate coefficient of $k(\mathrm{HO}+$ propene $)=2.62 \times$ $10^{-11} \mathrm{~cm}^{3}$ molecule $\mathrm{s}^{-1}$ at $299 \mathrm{~K}$ and atmospheric pressure of air (Atkinson, 1997).

\section{Preferred Values}

$k=2.0 \times 10^{-11} \mathrm{~cm}^{3}$ molecule ${ }^{-1} \mathrm{~s}^{-1}$ at $298 \mathrm{~K}$.

$k=2.6 \times 10^{-12} \exp (610 / T) \mathrm{cm}^{3}$ molecule ${ }^{-1} \mathrm{~s}^{-1}$ over the temperature range $230-380 \mathrm{~K}$.

\section{Reliability}

$\Delta \log k= \pm 0.10$ at $298 \mathrm{~K}$.

$\Delta(E / R)= \pm 200 \mathrm{~K}$. 


\section{Comments on Preferred Values}

The room temperature rate coefficients of Kleindienst et al. (1982), Atkinson et al. (1983), Gierczak et al. (1997), Chuong and Stevens $(2003,2004)$ and Holloway et al. (2005) are in good agreement, but are higher by $\sim 20-35 \%$ than the earlier relative rate measurement of Cox et al. (1980). The preferred $298 \mathrm{~K}$ rate coefficient is based on the room temperature rate coefficients of Atkinson et al. (1983), Gierczak et al. (1997) and Holloway et al. (2005). The temperature dependence measured by Gierczak et al. (1997) is accepted and the pre-exponential factor is calculated from the preferred $298 \mathrm{~K}$ rate coefficient and the temperature dependence.

The products of the reaction of $\mathrm{HO}$ radicals with methyl vinyl ketone in the presence of NO have been investigated by Tuazon and Atkinson (1989). The reaction proceeds by initial addition of the HO radical to the carbon atoms of the $\mathrm{C}=\mathrm{C}$ bond, forming (in the presence of $\mathrm{NO}$ ) the intermediate hydroxyalkoxy radicals $\mathrm{CH}_{3} \mathrm{C}(\mathrm{O}) \mathrm{CH}(\mathrm{O}) \mathrm{CH}_{2} \mathrm{OH}$ and $\mathrm{CH}_{3} \mathrm{C}(\mathrm{O}) \mathrm{CH}(\mathrm{OH}) \mathrm{CH}_{2} \mathrm{O}$, which decompose by the pathways:

$$
\begin{array}{ll}
\mathrm{CH}_{3} \mathrm{C}(\mathrm{O}) \mathrm{CH}(\mathrm{O}) \mathrm{CH}_{2} \mathrm{OH} & \rightarrow \mathrm{CH}_{3} \mathrm{C}(\mathrm{O}) \mathrm{CHO}+\mathrm{CH}_{2} \mathrm{OH} \\
\mathrm{CH}_{3} \mathrm{C}(\mathrm{O}) \mathrm{CH}(\mathrm{O}) \mathrm{CH}_{2} \mathrm{OH} & \rightarrow \mathrm{CH}_{3} \mathrm{CO}+\mathrm{HOCH}_{2} \mathrm{CHO}
\end{array}
$$

and

$$
\mathrm{CH}_{3} \mathrm{C}(\mathrm{O}) \mathrm{CH}(\mathrm{OH}) \mathrm{CH}_{2} \mathrm{O} \rightarrow \mathrm{HCHO}+\mathrm{CH}_{3} \mathrm{C}(\mathrm{O}) \mathrm{CHOH}
$$

followed by reactions of $\mathrm{CH}_{2} \mathrm{OH}$ and $\mathrm{CH}_{3} \mathrm{C}(\mathrm{O}) \mathrm{CHOH}$ radicals with $\mathrm{O}_{2}$ to form $\mathrm{HCHO}+\mathrm{HO}_{2}$ and $\mathrm{CH}_{3} \mathrm{C}(\mathrm{O}) \mathrm{CHO}+\mathrm{HO}_{2}$, respectively. The first generation products are therefore $\mathrm{HCHO}+\mathrm{CH}_{3} \mathrm{C}(\mathrm{O}) \mathrm{CHO}$ and $\mathrm{HOCH}_{2} \mathrm{CHO}+\mathrm{CH}_{3} \mathrm{CO}$ (with the acetyl radical reacting to form peroxyacetyl nitrate $\left[\mathrm{CH}_{3} \mathrm{C}(\mathrm{O}) \mathrm{OONO}_{2}\right.$; $\left.\mathrm{PAN}\right]$ or $\mathrm{HCHO}$ (Tuazon and Atkinson, 1989; IUPAC, 2005). Tuazon and Atkinson (1989) measured formation yields of methylglyoxal and glycolaldehyde of $25 \pm 8 \%$ and $64 \pm 16 \%$, respectively, showing that initial $\mathrm{HO}$ radical addition occurs mainly at the terminal $\mathrm{CH}_{2}$ group (Tuazon and Atkinson, 1989).

\section{References}

Atkinson, R.: J. Phys. Chem. Ref. Data, 26, 215, 1997.

Atkinson, R., Aschmann, S. M., and Pitts Jr., J. N.: Int. J. Chem. Kinet., 15, 75, 1983.

Chuong, B. and Stevens, P. S.: J. Phys. Chem. A 107, 2185, 2003.

Chuong, B. and Stevens, P. S.: Int. J. Chem. Kinet. 36, 12, 2004.

Edney, E. O., Kleindienst, T. E., and Corse, E. W.: Int. J. Chem. Kinet., 18, 1355, 1986.

Gierczak, T., Burkholder, J. B., Talukdar, R. K., Mellouki, A., Barone, S. B., and Ravishankara, A. R.: J. Photochem. Photobiol. A: Chem., 110, 1, 1997.

Holloway, A.-L., Treacy, J., Sidebottom, H., Mellouki, A., Dale, V., Le Bras, G. and Barnes, I.: J. Photochem. Photobiol. A: Chem. 176, 183, 2005.

IUPAC: http://www.iupac-kinetic.ch.cam.ac.uk/, 2005.

Kleindienst, T. E., Harris, G. W., and Pitts Jr., J. N.: Environ. Sci. Technol., 16, 844, 1982.

Tuazon, E. C. and Atkinson, R.: Int. J. Chem. Kinet., 21, 1141, 1989. 
II.A2.25

$$
\begin{aligned}
\mathrm{HO}+\mathrm{CH}_{3} \mathrm{OH} & \rightarrow \mathrm{H}_{2} \mathrm{O}+\mathrm{CH}_{2} \mathrm{OH} \\
& \rightarrow \mathrm{H}_{2} \mathrm{O}+\mathrm{CH}_{3} \mathrm{O}
\end{aligned}
$$

$$
\begin{aligned}
& \Delta H^{\circ}(1)=-95.2 \mathrm{~kJ} \cdot \mathrm{mol}^{-1} \\
& \Delta H^{\circ}(2)=-60.2 \mathrm{~kJ} \cdot \mathrm{mol}^{-1}
\end{aligned}
$$

Rate coefficient data $\left(k=k_{1}+k_{2}\right)$

\begin{tabular}{llll}
\hline$k / \mathrm{cm}^{3}$ molecule ${ }^{-1} \mathrm{~s}^{-1}$ & Temp./K & Reference & Technique/Comments \\
\hline Absolute Rate Coefficients & & & \\
$(1.06 \pm 0.10) \times 10^{-12}$ & $296 \pm 2$ & Overend and Paraskevopoulos, 1978 & FP-RA \\
$(1.00 \pm 0.10) \times 10^{-12}$ & 298 & Ravishankara and Davis, 1978 & FP-RF \\
$4.8 \times 10^{-12} \exp [-(480 \pm 70) / T]$ & $240-440$ & Wallington and Kurylo, 1987 & FP-RF \\
$(8.61 \pm 0.47) \times 10^{-13}$ & 296 & & \\
$(1.01 \pm 0.10) \times 10^{-12}$ & $298 \pm 2$ & McCaulley et al., 1989 & DF-LIF \\
$5.89 \times 10^{-20} T^{2.65} \exp (444 / T)$ & $294-866$ & Hess and Tully, 1989 & PLP-LIF \\
$(9.34 \pm 0.41) \times 10^{-13}$ & 294 & & \\
$(9.0 \pm 0.9) \times 10^{-13}$ & $298 \pm 2$ & Nelson et al., 1990 & PR-RA \\
$(8.64 \pm 1.30) \times 10^{-12}$ & $1205 \pm 16$ & Bott and Cohen, 1991 & SH-RA \\
$3.6 \times 10^{-12} \exp [-(415 \pm 70 / T)]$ & $235-360$ & Jiménez et al. 2003 & PLP-LIF \\
$(9.3 \pm 1.1) \times 10^{-13}$ & 298 & & \\
$6.67 \times 10^{-18} T^{2}$ exp[(140 $\left.\left.\pm 14 / T\right)\right]$ & $210-351$ & Dillon et al. 2005 & PLP-LIF \\
$(9.3 \pm 0.7) \times 10^{-13}$ & $298 \pm 1$ & & \\
& & & \\
Relative Rate Coefficients & & & RR (a) \\
$(9.0 \pm 0.7) \times 10^{-13}$ & $300 \pm 3$ & Tuazon et al., 1983 & RR (b) \\
$(9.3 \pm 2.2) \times 10^{-13}$ & $298 \pm 2$ & Nelson et al., 1990 & RR (c) \\
$(8.6 \pm 0.8) \times 10^{-13}$ & $298 \pm 4$ & Picquet et al., 1998 & RR (d) \\
$(9.6 \pm 1.0) \times 10^{-13}$ & $298 \pm 2$ & Oh and Andino, 2001 & RR (b) \\
$(8.4 \pm 0.7) \times 10^{-13}$ & $298 \pm 2$ & Oh and Andino, 2001 & RR (e,f) \\
$(7.88 \pm 0.47) \times 10^{-13}$ & $296 \pm 2$ & Sørensen et al., 2002 & RR (e,g) \\
$(8.18 \pm 0.52) \times 10^{-13}$ & $296 \pm 2$ & Sørensen et al., 2002 & \\
Branching Ratios & & & (h) \\
$k_{2} / k=0.15 \pm 0.08$ & $298 \pm 2$ & McCaulley et al., 1989 & \\
\hline
\end{tabular}

\section{Comments}

(a) $\mathrm{HO}$ radicals were generated by the dark reaction of hydrazine with $\mathrm{O}_{3}$ in air. The concentrations of methanol and dimethyl ether (the reference compound) were measured by FTIR spectroscopy. The measured rate coefficient ratio of $k(\mathrm{HO}$ + methanol $) / k(\mathrm{HO}+$ dimethyl ether $)=0.314 \pm 0.024$ is placed on an absolute basis using the rate coefficient $k(\mathrm{HO}+$ dimethyl ether) $=2.86 \times 10^{-12} \mathrm{~cm}^{3}$ molecule $\mathrm{e}^{-1} \mathrm{~s}^{-1}$ at $300 \mathrm{~K}$ (IUPAC, current recommendation).

(b) $\mathrm{HO}$ radicals were generated by the photolysis of $\mathrm{CH}_{3} \mathrm{ONO}$ in air at $>300 \mathrm{~nm}$. The concentrations of methanol and cyclohexane (the reference compound) were measured by GC. The measured rate coefficient ratio of $k(\mathrm{HO}+$ methanol $) / k(\mathrm{HO}$ + cyclohexane $)$ is placed on an absolute basis using a rate coefficient of $k(\mathrm{HO}+$ cyclohexane $)=6.97 \times 10^{-12} \mathrm{~cm}^{3}$ molecule ${ }^{-1} \mathrm{~s}^{-1}$ at $298 \mathrm{~K}$ (Atkinson, 2003).

(c) $\mathrm{HO}$ radicals were generated by the photolysis of $\mathrm{H}_{2} \mathrm{O}_{2}$ in air at 254 and $310 \mathrm{~nm}$. The concentrations of methanol and $n$-pentane (the reference compound) were measured by GC. The measured rate coefficient ratio, $k(\mathrm{HO}+$ methanol $) / k(\mathrm{HO}$ 
$+n$-pentane $)$, is placed on an absolute basis using a rate coefficient of $k(\mathrm{HO}+n$-pentane $)=3.80 \times 10^{-12} \mathrm{~cm}^{3} \mathrm{molecule}-1$ $\mathrm{s}^{-1}$ at $298 \mathrm{~K}$ (Atkinson, 2003).

(d) $\mathrm{HO}$ radicals were generated by the photolysis of $\mathrm{CH}_{3} \mathrm{ONO}$ in air at $>300 \mathrm{~nm}$. The concentrations of methanol and ethanol (the reference compound) were measured by GC. The measured rate coefficient ratio of $k(\mathrm{HO}+\mathrm{methanol}) / k(\mathrm{HO}$ + ethanol $)=0.30 \pm 0.03$ is placed on an absolute basis using a rate coefficient of $k(\mathrm{HO}+$ ethanol $)=3.2 \times 10^{-12} \mathrm{~cm}^{3}$ molecule ${ }^{-1} \mathrm{~s}^{-1}$ at $298 \mathrm{~K}$ (IUPAC, current recommendation).

(e) $\mathrm{HO}$ radicals were generated by the photolysis of $\mathrm{CH}_{3} \mathrm{ONO}$ in air at 1.0 bar (750 Torr). The concentrations of methanol and acetylene or ethene (the reference compounds) were measured by in situ FTIR spectroscopy. The measured rate coefficient ratios of $k(\mathrm{HO}+$ methanol $) / k(\mathrm{HO}+$ acetylene $)=1.01 \pm 0.06$ and $k(\mathrm{HO}+$ methanol $) / k(\mathrm{HO}+\mathrm{ethene})=0.095$ \pm 0.006 are placed on an absolute basis using rate coefficients of $k(\mathrm{HO}+$ acetylene $)=7.8 \times 10^{-13} \mathrm{~cm}^{3} \mathrm{molecule}^{-1} \mathrm{~s}^{-1}$ at 750 Torr pressure of air or $\mathrm{O}_{2}$ and $296 \pm 2 \mathrm{~K}$ (Sørensen et al., 2003) and $k(\mathrm{HO}+$ ethene $)=8.61 \times 10^{-12} \mathrm{~cm}^{3} \mathrm{molecule}-1$ $\mathrm{s}^{-1}$ at $296 \mathrm{~K}$ and atmospheric pressure of air (Atkinson, 1997). No effect of the presence of $\mathrm{NaCl}$ or $\mathrm{NH}_{4} \mathrm{NO}_{3}$ aerosol was observed.

(f) Relative to acetylene.

(g) Relative to ethene.

(h) Derived from measurements of the rate coefficients for the reactions of the $\mathrm{HO}$ radical with $\mathrm{CH}_{3} \mathrm{OH}, \mathrm{CD}_{3} \mathrm{OH}$ and $\mathrm{CD}_{3} \mathrm{OD}$ and of the DO radical with $\mathrm{CH}_{3} \mathrm{OH}, \mathrm{CH}_{3} \mathrm{OD}, \mathrm{CD}_{3} \mathrm{OH}$ and $\mathrm{CD}_{3} \mathrm{OD}$, assuming that secondary kinetic isotope effects are negligible.

\section{Preferred Values}

$k=9.0 \times 10^{-13} \mathrm{~cm}^{3}$ molecule $\mathrm{e}^{-1} \mathrm{~s}^{-1}$ at $298 \mathrm{~K}$.

$k=2.85 \times 10^{-12} \exp (-345 / T) \mathrm{cm}^{3}$ molecule $\mathrm{s}^{-1} \mathrm{~s}^{-1}$ over the temperature range $210-300 \mathrm{~K}$.

$k_{2} / k=0.15$ at $298 \mathrm{~K}$.

\section{Reliability}

$\Delta \log k= \pm 0.08$ at $298 \mathrm{~K}$.

$\Delta(E / R)= \pm 150 \mathrm{~K}$.

$\Delta k_{2} / k= \pm 0.10$ at $298 \mathrm{~K}$.

\section{Comments on Preferred Values}

The preferred rate coefficient is obtained by fitting the absolute rate coefficients of Wallington and Kurylo (1987), Hess and Tully (1989), Jiménez et al. (2003) and Dillon et al. (2005) to the three parameter expression $k=C T^{2} \exp (-D / T$ ). This results in $k=6.38 \times 10^{-18} T^{2} \exp (144 / T) \mathrm{cm}^{3}$ molecule ${ }^{-1} \mathrm{~s}^{-1}$ over the temperature range $210-866 \mathrm{~K}$. The preferred Arrhenius expression, $k=A \exp (-B / T)$, is centered at $245 \mathrm{~K}$, and is derived from the three parameter equation with $A=C e^{2} T^{2}$ and $B=D+2 T$. Note that the Arrhenius expression should not be used outside of the stated temperature range (210-300 $\mathrm{K})$; rather the three-parameter expression $k=6.38 \times 10^{-18} T^{2} \exp (144 / T) \mathrm{cm}^{3}$ molecule $\mathrm{s}^{-1}$ should be employed. The absolute room temperature rate coefficients of Overend and Paraskevopoulos (1978), Ravishankara et al. (1978), McCaulley et al. (1989) and Nelson et al. (1990) are in good agreement with the preferred values, as are the room temperature relative rate coefficients of Tuazon et al. (1983), Nelson et al. (1990), Picquet et al. (1998), Oh and Andino (2001) and Sørensen et al. (2002).

The kinetic (McCaulley et al., 1989) and product (Hägele et al., 1983; Meier et al., 1984) studies show that the reaction proceeds mainly by channel(1) at room temperature, as expected from the thermochemistry of the reaction pathways (1) and (2).

\section{References}

Atkinson, R.: J. Phys. Chem. Ref. Data 26, 215, 1997.

Atkinson, R.: Atmos. Chem. Phys., 3, 2233, 2003. 
Bott, J. F. and Cohen, N.: Int. J. Chem. Kinet., 23, 1075, 1991.

Dillon, T. J., Hölscher, D., Sivakumaran, V., Horowitz, A. and Crowley, J. N.: Phys. Chem. Chem. Phys. 7, 349, 2005.

Hägele, J., Lorenz, K., Rhäsa, D., and Zellner, R.: Ber. Bunsenges. Phys. Chem., 87, 1023, 1983.

Hess, W. P. and Tully, F. P.: J. Phys. Chem., 93, 1944, 1989.

IUPAC: http://www.iupac-kinetic.ch.cam.ac.uk/, 2005.

Jiménez, E., Gilles, M. K. and Ravishankara, A. R.: J. Photochem. Photobiol. A: Chem. 157, 237, 2003.

McCaulley, J. A., Kelly, N., Golde, M. F., and Kaufman, F.: J. Phys. Chem., 93, 1014, 1989.

Meier, U., Grotheer, H. H., and Just, Th.: Chem. Phys. Lett., 106, 97, 1984.

Nelson, L., Rattigan, O., Neavyn, R., Sidebottom, H., Treacy, J., and Nielsen, O. J.: Int. J. Chem. Kinet., 22, 1111, 1990.

Oh, S. and Andino, J. M.: Int. J. Chem. Kinet., 33, 422, 2001.

Overend, R. and Paraskevopoulos, G.: J. Phys. Chem., 82, 1329, 1978.

Picquet, B., Heroux, S., Chebbi, A., Doussin, J.-F., Durand-Jolibois, R., Monod, A., Loirat, H., and Carlier, P.: Int. J. Chem. Kinet., 30, 839, 1998.

Ravishankara, A. R. and Davis, D. D.: J. Phys. Chem., 82, 2852, 1978.

Sørensen, M., Hurley, M. D., Wallington, T. J., Dibble, T. S. and Nielsen, O. J.: Atmos. Environ. 36, 5947, 2002.

Sørensen, M., Kaiser, E. W., Hurley, M. D., Wallington, T. J. and Nielsen, O. J.: Int. J. Chem. Kinet. 35, 191, 2003.

Tuazon, E. C., Carter, W. P. L., Atkinson, R., and Pitts Jr., J. N.: Int. J. Chem. Kinet., 15, 619, 1983.

Wallington, T. J. and Kurylo, M. J.: Int. J. Chem. Kinet., 19, 1015, 1987. 
II.A2.26

$$
\begin{aligned}
\mathrm{HO}+\mathrm{C}_{2} \mathrm{H}_{5} \mathrm{OH} & \rightarrow \mathrm{H}_{2} \mathrm{O}+\mathrm{CH}_{2} \mathrm{CH}_{2} \mathrm{OH} \\
& \rightarrow \mathrm{H}_{2} \mathrm{O}+\mathrm{CH}_{3} \mathrm{CHOH} \\
& \rightarrow \mathrm{H}_{2} \mathrm{O}+\mathrm{CH}_{3} \mathrm{CH}_{2} \mathrm{O}
\end{aligned}
$$

$$
\begin{aligned}
& \Delta H^{\circ}(1)=-67 \mathrm{~kJ} \cdot \mathrm{mol}^{-1} \\
& \Delta H^{\circ}(2)=-95.8 \mathrm{~kJ} \cdot \mathrm{mol}^{-1} \\
& \Delta H^{\circ}(3)=-59.7 \mathrm{~kJ} \cdot \mathrm{mol}^{-1}
\end{aligned}
$$

Rate coefficient data $\left(k=k_{1}+k_{2}+k_{3}\right)$

\begin{tabular}{lllc}
\hline$k / \mathrm{cm}^{3}$ molecule ${ }^{-1} \mathrm{~s}^{-1}$ & Temp./K & Reference & Technique/Comments \\
\hline $\begin{array}{l}\text { Absolute Rate Coefficients } \\
1.25 \times 10^{-11} \mathrm{exp}[-(360 \pm 52) / T]\end{array}$ & $255-459$ & Greenhill and O'Grady, 1986 & FP-RA \\
$(3.40 \pm 0.17) \times 10^{-12}$ & 293 & & \\
$7.4 \times 10^{-12} \exp [-(240 \pm 110) / T]$ & $240-440$ & Wallington and Kurylo, 1987 & FP-RF \\
$(3.33 \pm 0.23) \times 10^{-12}$ & 296 & & \\
$(3.26 \pm 0.14) \times 10^{-12}$ & 293 & Hess and Tully, 1988 & PLP-LIF (a,b) \\
$(3.33 \pm 0.14) \times 10^{-12}$ & 326.5 & & \\
$(3.63 \pm 0.15) \times 10^{-12}$ & 380 & & \\
$(3.94 \pm 0.16) \times 10^{-12}$ & 441 & & \\
$(3.32 \pm 0.16) \times 10^{-12}$ & 295 & Hess and Tully, 1988 & PLP-LIF (b,c) \\
$(5.47 \pm 0.34) \times 10^{-12}$ & 599 & & \\
$(3.04 \pm 0.25) \times 10^{-12}$ & $298 \pm 2$ & Nelson et al., 1990 & PR-RA \\
$k_{2}+k_{3}=(8.80 \pm 1.32) \times 10^{-12}$ & $1204 \pm 16$ & Bott and Cohen, 1991 & SH-RA (d) \\
$4.3 \times 10^{-12}$ exp[-(85 \pm 35$\left.) / T\right]$ & $227-360$ & Jiménez et al., 2003 & PLP-LIF \\
$(3.1 \pm 0.4) \times 10^{-12}$ & 298 & & \\
$4.0 \times 10^{-12}$ exp[-(42 \pm 10$\left.) / T\right]$ & $216-368$ & Dillon et al., 2005 & PLP-LIF \\
$(3.35 \pm 0.17) \times 10^{-12}$ & $298 \pm 2$ & & \\
& & & \\
Relative Rate Coefficients & & & \\
$(3.22 \pm 0.49) \times 10^{-12}$ & $298 \pm 2$ & Nelson et al., 1990 & RR (e) \\
$(3.64 \pm 0.11) \times 10^{-12}$ & $298 \pm 4$ & Picquet et al., 1998 & RR (f) \\
$(2.79 \pm 0.28) \times 10^{-12}$ & $298 \pm 2$ & Oh and Andino, 2001 & RR (e) \\
$(2.72 \pm 0.25) \times 10^{-12}$ & $298 \pm 2$ & Oh and Andino, 2001 & RR (g) \\
$(3.39 \pm 0.24) \times 10^{-12}$ & $296 \pm 2$ & Sørensen et al. , 2002 & RR (h,i) \\
$(3.36 \pm 0.35) \times 10^{-12}$ & $296 \pm 2$ & Sørensen et al., 2002 & RR (h,j) \\
$(3.37 \pm 0.25) \times 10^{-12}$ & $295 \pm 2$ & Wu et al., , 2003 & RR (k) \\
\hline
\end{tabular}

\section{Comments}

(a) Reaction of $\mathrm{H}^{16} \mathrm{O}$ radicals.

(b) Thermal decomposition of the $\mathrm{H}^{16} \mathrm{OCH}_{2} \mathrm{CH}_{2}$ radical formed by $\mathrm{H}$-atom abstraction from the $-\mathrm{CH}_{3}$ group to regenerate $\mathrm{H}^{16} \mathrm{O}$ radicals occurs at temperatures $>500 \mathrm{~K}$, and hence the $\mathrm{H}^{16} \mathrm{O}$ rate coefficient data do not yield the rate coefficient $k=\left(k_{1}+k_{2}+k_{3}\right)$ above $\sim 500 \mathrm{~K}$. Since thermal decomposition of the $\mathrm{H}^{16} \mathrm{OCH}_{2} \mathrm{CH}_{2}$ radical does not lead to regeneration of the $\mathrm{H}^{18} \mathrm{O}$ radical, the $\mathrm{H}^{18} \mathrm{O}$ rate coefficient data yield the overall reaction rate coefficient, $k=\left(k_{1}+k_{2}+k_{3}\right)$.

(c) Rate coefficients for reaction of the $\mathrm{H}^{18} \mathrm{O}$ radical. $\mathrm{H}^{18} \mathrm{O}$ radicals were generated from pulsed laser photolysis of $\mathrm{H}_{2}{ }^{18} \mathrm{O}$, with $\mathrm{H}^{18} \mathrm{O}$ radicals being detected by LIF. 
(d) HO radicals were generated by the thermal decomposition of $t$-butyl hydroperoxide in a shock tube, with detection by resonance absorption at $309 \mathrm{~nm}$. The measured rate coefficient corresponds to $\left(k_{2}+k_{3}\right)$ because of the rapid thermal decomposition of the $\mathrm{CH}_{2} \mathrm{CH}_{2} \mathrm{OH}$ radical formed in reaction channel (1) [this is the same radical as formed from the addition of $\mathrm{HO}$ radicals to ethene].

(e) $\mathrm{HO}$ radicals were generated by photolysis of $\mathrm{CH}_{3} \mathrm{ONO}$ in air. The ethanol and cyclohexane (the reference organic) concentrations were measured by GC. The measured rate coefficient ratio is placed on an absolute basis by use of a rate coefficient of $k(\mathrm{HO}+$ cyclohexane $)=6.97 \times 10^{-12} \mathrm{~cm}^{3}$ molecule ${ }^{-1} \mathrm{~s}^{-1}$ (Atkinson, 2003).

(f) $\mathrm{HO}$ radicals were generated by the photolysis of $\mathrm{H}_{2} \mathrm{O}_{2}$ in air at 254 and $310 \mathrm{~nm}$. The concentrations of ethanol and $n$-hexane (the reference compound) were measured by GC. The measured rate coefficient ratio, $k(\mathrm{HO}+$ ethanol $) / k(\mathrm{HO}+$ $n$-hexane), is placed on an absolute basis using a rate coefficient of $k(\mathrm{HO}+n$-hexane $)=5.20 \times 10^{-12} \mathrm{~cm}^{3} \mathrm{molecule}^{-1} \mathrm{~s}^{-1}$ at $298 \mathrm{~K}$ (Atkinson, 2003).

(g) $\mathrm{HO}$ radicals were generated by photolysis of $\mathrm{CH}_{3} \mathrm{ONO}$ in air. The ethanol and $p$-xylene (the reference organic) concentrations were measured by GC. The measured rate coefficient ratio of $k(\mathrm{HO}+$ ethanol $) / k(\mathrm{HO}+p$-xylene $)=0.19 \pm 0.01$ is placed on an absolute basis by use of a rate coefficient of $k(\mathrm{HO}+p$-xylene $)=1.43 \times 10^{-11} \mathrm{~cm}^{3}$ molecule ${ }^{-1} \mathrm{~s}^{-1}$ (Calvert et al., 2002).

(h) $\mathrm{HO}$ radicals were generated by the photolysis of $\mathrm{CH}_{3} \mathrm{ONO}$ in air at 1.0 bar (750 Torr). The concentrations of ethanol and acetylene or ethene (the reference compounds) were measured by in situ FTIR spectroscopy. The measured rate coefficient ratios of $k(\mathrm{HO}+$ ethanol $) / k(\mathrm{HO}+$ acetylene $)=4.35 \pm 0.30$ and $k(\mathrm{HO}+$ ethanol $) / k(\mathrm{HO}+$ ethene $)=0.39 \pm$ 0.04 are placed on an absolute basis using rate coefficients of $k(\mathrm{HO}+$ acetylene $)=7.8 \times 10^{-13} \mathrm{~cm}^{3}$ molecule ${ }^{-1} \mathrm{~s}^{-1}$ at 750 Torr pressure of air or $\mathrm{O}_{2}$ and $296 \pm 2 \mathrm{~K}$ (Sørensen et al., 2003) and $\mathrm{k}(\mathrm{HO}+$ ethene $)=8.61 \times 10^{-12} \mathrm{~cm}^{3} \mathrm{molecule}^{-1}$ $\mathrm{s}^{-1}$ at $296 \mathrm{~K}$ and atmospheric pressure of air (Atkinson, 1997). No effect of the presence of $\mathrm{NaCl}$ or $\mathrm{NH}_{4} \mathrm{NO}_{3}$ aerosol was observed.

(i) Relative to acetylene.

(j) Relative to ethene.

(k) $\mathrm{HO}$ radicals were generated by the photolysis of $\mathrm{H}_{2} \mathrm{O}_{2}$ in 1 atmosphere of air at $254 \mathrm{~nm}$. The concentrations of ethanol and propane (the reference compound) were measured by GC. The measured rate coefficient ratio, $k(\mathrm{HO}+$ ethanol $) / k(\mathrm{HO}$ + propane $)$, is placed on an absolute basis using a rate coefficient of $k(\mathrm{HO}+$ propane $)=1.07 \times 10^{-12} \mathrm{~cm}^{3} \mathrm{molecule}^{-1}$ $\mathrm{s}^{-1}$ at $295 \mathrm{~K}$ (Atkinson, 2003; IUPAC, current recommendation).

\section{Preferred Values}

$k=3.2 \times 10^{-12} \mathrm{~cm}^{3}$ molecule $\mathrm{e}^{-1} \mathrm{~s}^{-1}$ at $298 \mathrm{~K}$.

$k=3.0 \times 10^{-12} \exp (20 / T) \mathrm{cm}^{3}$ molecule $\mathrm{s}^{-1} \mathrm{~s}^{-1}$ over the temperature range $210-300 \mathrm{~K}$.

$k_{1} / k=0.05$ at $298 \mathrm{~K}$.

$k_{3} / k=0.05$ at $298 \mathrm{~K}$.

\section{Reliability}

$\Delta \log k= \pm 0.08$ at $298 \mathrm{~K}$.

$\Delta(E / R)= \pm 150 \mathrm{~K}$.

$\Delta k_{1} / k={ }_{-0.05}^{+0.10}$ at $298 \mathrm{~K}$.

$\Delta k_{3} / k={ }_{-0.05}^{+0.10}$ at $298 \mathrm{~K}$.

\section{Comments on Preferred Values}

There is substantial scatter in the room temperature rate coefficients measured to date. The most definitive absolute rate studies are those of Wallington and Kurylo (1987), Hess and Tully (1988), Jiménez et al. (2003) and Dillon et al. (2005). The preferred rate coefficient is derived from fitting the $\mathrm{H}^{18} \mathrm{O}$ and (for temperatures $<500 \mathrm{~K}$ ) the $\mathrm{H}^{16} \mathrm{O}$ rate coefficients of Hess and Tully (1988) and the absolute rate constants determined by Wallington and Kurylo (1987), Jiménez et al. (2003) and Dillon et al. (2005) to the three parameter expression $k=C T^{2} \exp (-D / T)$. This results in $k=6.70 \times 10^{-18} T^{2} \exp (511 / T) \mathrm{cm}^{3}$ 
molecule $\mathrm{e}^{-1} \mathrm{~s}^{-1}$ over the temperature range $216-599 \mathrm{~K}$. The preferred Arrhenius expression, $k=A \exp (-B / T)$ is centered at $245 \mathrm{~K}$ and is derived from this three parameter expression with $A=C e^{2} T^{2}$ and $B=D+2 T$. Note that the Arrhenius expression should not be used outside of the stated temperature range $(210-300 \mathrm{~K})$; rather the three-parameter expression $k$ $=6.70 \times 10^{-18} T^{2} \exp (511 / T) \mathrm{cm}^{3}$ molecule ${ }^{-1} \mathrm{~s}^{-1}$ should be employed. The rate coefficient calculated from the preferred Arrhenius expression at $255 \mathrm{~K}$ is $14 \%$ higher than the lowest temperature rate coefficient reported by Greenhill and O'Grady (1986). The preferred $298 \mathrm{~K}$ rate coefficient is in good agreement with the absolute and relative rate coefficients of Nelson et al. (1990), Picquet et al. (1998), Sørensen et al. (2002) and Wu et al. (2003), but is $\sim 15 \%$ higher than the relative rate data of Oh and Andino (2001). The rate coefficient measured by Bott and Cohen (1991) at $1204 \mathrm{~K}$, and ascribed to $\left(k_{2}+k_{3}\right)$, is consistent with the value of $\left(k_{1}+k_{2}+k_{3}\right)$ calculated from the recommended three parameter expression and with the rate coefficient $k_{1}$ at $1204 \mathrm{~K}$ estimated using the procedure of Kwok and Atkinson (1987).

Meier et al. (1985) determined that at room temperature the reaction proceeds mainly $(75 \pm 15 \%)$ via formation of the $\mathrm{CH}_{3} \mathrm{CHOH}$ radical, consistent with the thermochemistry of the reaction steps. The kinetic data of Hess and Tully (1988) for the reactions of the $\mathrm{H}^{16} \mathrm{O}$ and $\mathrm{H}^{18} \mathrm{O}$ radicals with ethanol indicate that channel (1) accounts for $\sim 15 \%$ of the overall reaction at $600 \mathrm{~K}$, in agreement with the calculated value of $17 \%$ from the estimation procedure of Kwok and Atkinson (1995). This agreement allows a rate coefficient ratio of $k_{1} / k=0.05$ at $298 \mathrm{~K}$ to be estimated. Assuming that $\mathrm{H}$-atom abstraction from the -OH group in ethanol [channel (3)] has a similar rate coefficient to the analogous channel for methanol (IUPAC, current evaluation) allows $k_{3} / k=0.05$ at $298 \mathrm{~K}$ to be estimated. The resulting value of $k_{2} / k=0.90$ at $298 \mathrm{~K}$ is just consistent with the product data of Meier et al. (1985).

\section{References}

Atkinson, R.: J. Phys. Chem. Ref. Data, 26, 215, 1997.

Atkinson, R.: Atmos. Chem. Phys., 3, 2233, 2003.

Bott, J. F. and Cohen, N.: Int. J. Chem. Kinet., 23, 1075, 1991.

Calvert, J. G., Atkinson, R., Becker, K. H., Kamens, R. M., Seinfeld, J. H., Wallington, T. J., and Yarwood, G.: The Mechanisms of Atmospheric Oxidation of Aromatic Hydrocarbons, Oxford University Press, New York, NY, 2002.

Dillon, T. J., Hölscher, D., Sivakumaran, V., Horowitz, A. and Crowley, J. N.: Phys. Chem. Chem. Phys. 7, 349, 2005.

Greenhill, P. G. and O'Grady, B. V.: Aust. J. Chem., 39, 1775, 1986.

Hess, W. P. and Tully, F. P.: Chem. Phys. Lett., 152, 183, 1988.

IUPAC,: http://www.iupac-kinetic.ch.cam.ac.uk/, 2005.

Jiménez, E., Gilles, M. K. and Ravishankara, A. R.: J. Photochem. Photobiol. A: Chem. 157, 237, 2003.

Kwok, E. S. C. and Atkinson, R.: Atmos. Environ. 29, 1685, 1995.

Meier, U., Grotheer, H. H., Riekert, G., and Just, Th.: Chem. Phys. Lett., 115, 221, 1985.

Nelson, L., Rattigan, O., Neavyn, R., Sidebottom, H., Treacy, J., and Nielsen, O. J.: Int. J. Chem. Kinet., 22, 1111, 1990.

Oh, S. and Andino, J. M.: Int. J. Chem. Kinet., 33, 422, 2001.

Picquet, B., Heroux, S., Chebbi, A., Doussin, J.-F., Durand-Jolibois, R., Monod, A., Loirat, H., and Carlier, P.: Int. J. Chem. Kinet., 30, 839, 1998.

Sørensen, M., Hurley, M. D., Wallington, T. J., Dibble, T. S. and Nielsen, O. J.: Atmos. Environ. 36, 5947, 2002.

Sørensen, M., Kaiser, E. W., Hurley, M. D., Wallington, T. J. and Nielsen, O. J.: Int. J. Chem. Kinet. 35, 191, 2003.

Wallington, T. J. and Kurylo, M. J.: Int. J. Chem. Kinet., 19, 1015, 1987.

Wu, H., Mu, Y., Zhang, X. and Jiang, G.: Int. J. Chem. Kinet. 35, 81, 2003. 
II.A2.27

$\mathrm{HO}+\mathrm{CH}_{3} \mathrm{CH}_{2} \mathrm{CH}_{2} \mathrm{OH} \rightarrow$ products

\section{Rate coefficient data}

\begin{tabular}{|c|c|c|c|}
\hline $\mathrm{k} / \mathrm{cm}^{3}$ molecule $^{-1} \mathrm{~s}^{-1}$ & Temp./K & Reference & Technique/Comments \\
\hline $\begin{array}{l}\text { Absolute Rate Coefficients } \\
(5.33 \pm 0.54) \times 10^{-12}\end{array}$ & $296 \pm 2$ & Overend and Paraskevopoulos, 1978 & FP-RA \\
\hline$(5.34 \pm 0.39) \times 10^{-12}$ & 296 & Wallington and Kurylo, 1987 & FP-RF \\
\hline$(5.64 \pm 0.48) \times 10^{-12}$ & $298 \pm 2$ & Nelson et al., 1990 & PR-RA \\
\hline $\begin{array}{l}4.68 \times 10^{-12} \exp [(68 \pm 41) / T] \\
(5.83 \pm 0.18) \times 10^{-12}\end{array}$ & $\begin{array}{l}263-372 \\
298\end{array}$ & Yujing and Mellouki, 2001 & PLP-LIF \\
\hline Relative Rate Coefficients & 292 & Camnhellet al 1976 & $\mathrm{RR}(\mathrm{a})$ \\
\hline$(5.12 \pm 0.41) \times 10^{-12}$ & $298 \pm 2$ & Nelson et al., 1990 & $\mathrm{RR}(\mathrm{b})$ \\
\hline$(4.42 \pm 0.26) \times 10^{-12}$ & $298 \pm 2$ & Oh and Andino, 2000 & $\mathrm{RR}(\mathrm{c}, \mathrm{d})$ \\
\hline$(6.44 \pm 0.43) \times 10^{-12}$ & $298 \pm 2$ & Oh and Andino, 2000 & $\mathrm{RR}(\mathrm{c}, \mathrm{e})$ \\
\hline$(5.11 \pm 0.19) \times 10^{-12}$ & 273 & Cheema et al., 2002 & $R R(f)$ \\
\hline$(5.50 \pm 0.17) \times 10^{-12}$ & 298 & & \\
\hline$(5.74 \pm 0.33) \times 10^{-12}$ & 313 & & \\
\hline$(6.20 \pm 0.17) \times 10^{-12}$ & 343 & & \\
\hline
\end{tabular}

\section{Comments}

(a) $\mathrm{HO}$ radicals were generated by the dark reaction of $\mathrm{H}_{2} \mathrm{O}_{2}-\mathrm{NO}_{2}$ mixtures in the presence of $\mathrm{CO}$ and an organic compound. From sequential experiments using $n$-butane and 1-propanol, a rate coefficient ratio of $k(\mathrm{HO}+1$-propanol $) / k(\mathrm{HO}+n$ butane) $=1.67 \pm 0.27$ (two standard deviations) was derived. This rate coefficient ratio is placed on an absolute basis by use of a rate coefficient of $k(\mathrm{HO}+n$-butane $)=2.22 \times 10^{-12} \mathrm{~cm}^{3}$ molecule ${ }^{-1} \mathrm{~s}^{-1}$ at $292 \mathrm{~K}$ (IUPAC, current recommendation).

(b) $\mathrm{HO}$ radicals were generated by the photolysis of $\mathrm{CH}_{3} \mathrm{ONO}$ in air, and the concentrations of 1-propanol and cyclohexane (the reference compound) were measured by GC The measured rate coefficient ratio $k(\mathrm{HO}+1$-propanol $) / k(\mathrm{HO}+$ cyclohexane $)$ is placed on an absolute basis by use of a rate coefficient of $k(\mathrm{HO}+$ cyclohexane $)=6.97 \times 10^{-12} \mathrm{~cm}^{3} \mathrm{molecule}^{-1}$ $\mathrm{s}^{-1}$ at $298 \mathrm{~K}$ (Atkinson, 2003).

(c) $\mathrm{HO}$ radicals were generated by the photolysis of $\mathrm{CH}_{3} \mathrm{ONO}$ in air, and the concentrations of 1-propanol and $n$-hexane and $p$-xylene (the reference compounds) were measured by GC. The measured rate coefficient ratios of $k(\mathrm{HO}+1$ propanol $) / k(\mathrm{HO}+n$-hexane $)=0.85 \pm 0.05$ and $k(\mathrm{HO}+1$-propanol $) / k(\mathrm{HO}+p$-xylene $)=0.45 \pm 0.03$ are placed on an absolute basis by use of rate coefficients at $298 \mathrm{~K}$ of $k\left(\mathrm{HO}+n\right.$-hexane) $=5.20 \times 10^{-12} \mathrm{~cm}^{3}$ molecule $\mathrm{s}^{-1} \mathrm{~s}^{-1}$ (Atkinson, 2003) and $k(\mathrm{HO}+p$-xylene $)=1.43 \times 10^{-11} \mathrm{~cm}^{3}$ molecule ${ }^{-1} \mathrm{~s}^{-1}$ (Calvert et al., 2002).

(d) Relative to $\mathrm{HO}+n$-hexane.

(e) Relative to $\mathrm{HO}+p$-xylene.

(f) $\mathrm{HO}$ radicals were generated by the photolysis of $\mathrm{CH}_{3} \mathrm{ONO}$ in air, and the concentrations of 1-propanol and 2,3dimethylbutane (the reference compound) were measured by GC. The measured rate coefficient ratios of $k(\mathrm{HO}+1-$ propanol $) / k(\mathrm{HO}+2,3$-dimethylbutane $)$ are placed on an absolute basis by use of a rate coefficient of $k(\mathrm{HO}+2,3-$ dimethylbutane) $=1.66 \times 10^{-17} T^{2} \exp (407 / T) \mathrm{cm}^{3}$ molecule $\mathrm{s}^{-1} \mathrm{~s}^{-1}$ (Atkinson, 2003).

\section{Preferred Values}

$k=5.8 \times 10^{-12} \mathrm{~cm}^{3}$ molecule ${ }^{-1} \mathrm{~s}^{-1}$ at $298 \mathrm{~K}$.

$k=4.6 \times 10^{-12} \exp (70 / T) \mathrm{cm}^{3}$ molecule $\mathrm{s}^{-1} \mathrm{~s}^{-1}$ over the temperature range $260-380 \mathrm{~K}$. 


\section{Reliability}

$\Delta \log k= \pm 0.10$ at $298 \mathrm{~K}$.

$\Delta(E / R)= \pm 100 \mathrm{~K}$.

\section{Comments on Preferred Values}

The preferred values are based on the temperature-dependent absolute rate study of Yujing and Mellouki (2001). At room temperature, the rate coefficients measured by Yujing and Mellouki (2001) are in good agreement with the absolute rate coefficients of Overend and Paraskevopoulos (1976), Wallington and Kurylo (1987) and Nelson et al. (1990), and with the relative rate constant of Nelson et al. (1990). The experimental technique of Campbell et al. (1976) was possibly prone to unrecognized problems, and the relative rate constants of Oh and Andino (2000) measured relative to $n$-hexane and $p$-xylene are respectively $25 \%$ higher and $11 \%$ lower than the preferred value. The rate coefficients determined by Cheema et al. (2002) relative to that for 2,3-dimethylbutane are in good agreement with the preferred values (to within 15\%), although the Cheema et al. (2002) data indicate a positive temperature dependence in contrast to that observed by Yujing and Mellouki (2001) and used as the basis for the preferred values.

\section{References}

Atkinson, R.: Atmos. Chem. Phys., 3, 2233, 2003

Calvert, J. G., Atkinson, R., Becker, K. H., Kamens, R. M., Seinfeld, J. H., Wallington, T. J., and Yarwood, G.: The Mechanisms of Atmospheric Oxidation of Aromatic Hydrocarbons, Oxford University Press, New York, NY, 2002.

Campbell, I. M., McLaughlin, D. F., and Handy, B. J.: Chem. Phys. Lett., 38, 362, 1976.

Cheema, S. A., Holbrook, K. A., Oldershaw, G. A., and Walker, R. W.: Int. J. Chem. Kinet., 34, 110, 2002.

IUPAC: http://www.iupac-kinetic.ch.cam.ac.uk/.

Nelson, L., Rattigan, O., Neavyn, R., Sidebottom, H., Treacy, J., and Nielsen, O. J.: Int. J. Chem. Kinet., 22, 1111, 1990.

Oh, S. and Andino, J. M.: Atmos. Environ., 34, 2901, 2000.

Overend, R. and Paraskevopoulos, G.: J. Phys. Chem., 82, 1329, 1976.

Wallington, T. J. and Kurylo, M. J.: Int. J. Chem. Kinet., 19, 1015, 1987.

Yujing, M. and Mellouki, A.: Chem. Phys. Lett., 333, 63, 2001. 
II.A2.28

$$
\begin{aligned}
\mathrm{HO}+\mathrm{CH}_{3} \mathrm{CH}(\mathrm{OH}) \mathrm{CH}_{3} & \rightarrow \mathrm{H}_{2} \mathrm{O}+\left(\mathrm{CH}_{3}\right)_{2} \mathrm{CHO} \\
& \rightarrow \mathrm{H}_{2} \mathrm{O}+\mathrm{CH}_{3} \mathrm{C}(\mathrm{OH}) \mathrm{CH}_{3} \\
& \rightarrow \mathrm{H}_{2} \mathrm{O}+\mathrm{CH}_{3} \mathrm{CH}(\mathrm{OH}) \mathrm{CH}_{2}
\end{aligned}
$$

$\Delta H^{\circ}(1)=-58.8 \mathrm{~kJ} \cdot \mathrm{mol}^{-1}$

Rate coefficient data $\left(k=k_{1}+k_{2}+k_{3}\right)$

\begin{tabular}{lllc}
\hline$k / \mathrm{cm}^{3}$ molecule ${ }^{-1} \mathrm{~s}^{-1}$ & Temp./K & Reference & Technique/Comments \\
\hline $\begin{array}{l}\text { Absolute Rate Coefficients } \\
(5.48 \pm 0.55) \times 10^{-12}\end{array}$ & $296 \pm 2$ & Overend and Paraskevopoulos, 1978 & FP-RA \\
$5.8 \times 10^{-12} \exp [-(30 \pm 90) / T]$ & $240-440$ & Wallington and Kurylo, 1987 & FP-RF \\
$(5.81 \pm 0.34) \times 10^{-12}$ & 296 & & \\
$(5.69 \pm 1.09) \times 10^{-12}$ & $298 \pm 2$ & Nelson et al., 1990 & PR-RA \\
$1.044 \times 10^{-17} T^{1.86} \exp (736 / T)$ & $293-587$ & Dunlop and Tully, 1993 & PLP-LIF (a) \\
$(5.10 \pm 0.21) \times 10^{-12}$ & 293 & & \\
$2.80 \times 10^{-12} \exp [(184 \pm 40) / T]$ & $253-372$ & Yujing and Mellouki, 2001 & PLP-LIF \\
$(5.17 \pm 0.23) \times 10^{-12}$ & 298 & & \\
& & & \\
Relative Rate Coefficients & $298 \pm 2$ & Nelson et al., 1990 & RR (b) \\
$(5.38 \pm 0.70) \times 10^{-12}$ & & & \\
\hline
\end{tabular}

\section{Comments}

(a) The reactions of $\mathrm{H}^{16} \mathrm{O}$ radicals were studied over the temperature range $293 \mathrm{~K}$ to $745 \mathrm{~K}$ and the reactions of $\mathrm{H}^{18} \mathrm{O}$ radicals were studied at $548 \mathrm{~K}$ and $587 \mathrm{~K}$. Non-exponential decays of $\mathrm{H}^{16} \mathrm{O}$ radicals were observed over the temperature range $504 \mathrm{~K}$ to $600 \mathrm{~K}$ and, while exponential $\mathrm{H}^{16} \mathrm{O}$ radical decays were observed above $600 \mathrm{~K}$, the rate coefficients were significantly lower than expected from extrapolation of the lower temperature data. These observations are consistent with thermal decomposition of the $\mathrm{CH}_{3} \mathrm{CH}(\mathrm{OH}) \mathrm{CH}_{2}$ radical formed in reaction channel (3) [the same radical as formed from $\mathrm{HO}$ radical addition to propene] at temperatures $>500 \mathrm{~K}$. Hence using $\mathrm{H}^{16} \mathrm{O}$ radicals, values of $\left(k_{1}+k_{2}+k_{3}\right)$ were measured at temperatures $\leq 500 \mathrm{~K}$ and $\left(k_{1}+k_{2}\right)$ at temperatures $>600 \mathrm{~K}$. No regeneration of $\mathrm{H}^{18} \mathrm{O}$ radicals from thermal decomposition of the $\mathrm{CH}_{3} \mathrm{CH}\left({ }^{16} \mathrm{OH}\right) \mathrm{CH}_{2}$ radical can occur, and hence the measured $\mathrm{H}^{18} \mathrm{O}$ rate coefficients are those for $\left(k_{1}+k_{2}+k_{3}\right)$.

(b) $\mathrm{HO}$ radicals were generated by the photolysis of $\mathrm{CH}_{3} \mathrm{ONO}$ in air. The concentrations of 2-propanol and cyclohexane (the reference organic) were measured by GC. The measured rate coefficient ratio $k(\mathrm{HO}+2$-propanol $) / k(\mathrm{HO}+$ cyclohexane $)$ is placed on an absolute basis by use of a rate coefficient of $k(\mathrm{HO}+$ cyclohexane $)=6.97 \times 10^{-12} \mathrm{~cm}^{3}$ molecule ${ }^{-1} \mathrm{~s}^{-1}$ at 298 K (Atkinson, 2003).

\section{Preferred Values}

$k=5.1 \times 10^{-12} \mathrm{~cm}^{3}$ molecule $\mathrm{e}^{-1} \mathrm{~s}^{-1}$ at $298 \mathrm{~K}$.

$k=2.6 \times 10^{-12} \exp (200 / T) \mathrm{cm}^{3}$ molecule $\mathrm{e}^{-1} \mathrm{~s}^{-1}$ over the temperature range $250-360 \mathrm{~K}$.

\section{Reliability}

$\Delta \log k= \pm 0.08$ at $298 \mathrm{~K}$.

$\Delta(E / R)= \pm 100 \mathrm{~K}$. 


\section{Comments on Preferred Values}

The absolute rate coefficients measured by Dunlop and Tully (1993) and Yujing and Mellouki (2001) are in excellent agreement over the temperature range common to both studies (293-378 K), and the preferred rate coefficients are derived from these two studies (Dunlop and Tully, 1993; Yujing and Melloui, 2001). The $\mathrm{H}^{18} \mathrm{O}$ rate coefficients at $548 \mathrm{~K}$ and $587 \mathrm{~K}$ and the $\mathrm{H}^{16} \mathrm{O}$ rate coefficients at $\leq 502 \mathrm{~K}$ obtained by Dunlop and Tully (1993) and the rate coefficients of Yujing and Mellouki (2001) $(253-372 \mathrm{~K})$ were fitted to the three parameter expression $k=C T^{2} \exp (-D / T)$, resulting in $k=4.03 \times 10^{-18} T^{2} \exp (792 / T) \mathrm{cm}^{3}$ molecule ${ }^{-1} \mathrm{~s}^{-1}$ over the temperature range $253-587 \mathrm{~K}$. The preferred Arrhenius expression, $k=A \exp (-B / T)$, is centered at $295 \mathrm{~K}$ and is derived from the three parameter expression with $A=C \mathrm{e}^{2} T^{2}$ and $B=D+2 T$. The preferred rate coefficients are within $15 \%$ of those measured by Wallington and Kurylo (1987) over the temperature range $250 \mathrm{~K}$ to $360 \mathrm{~K}$ and are in agreement within the cited error limits with the room temperature absolute and relative rate coefficients of Overend and Paraskevopoulos (1978) and Nelson et al. (1990).

\section{References}

Atkinson, R.: Atmos. Chem. Phys., 3, 2233, 2003.

Dunlop, J. R. and Tully, F. P.: J. Phys. Chem., 97, 6457, 1993.

Nelson, L., Rattigan, O., Neavyn, R., Sidebottom, H., Treacy, J., and Nielsen, O. J.: Int. J. Chem. Kinet., 22, 1111, 1990.

Overend, R. and Paraskevopoulos, G.: J. Phys. Chem., 82, 1329, 1978.

Wallington, T. J. and Kurylo, M. J.: Int. J. Chem. Kinet., 19, 1015, 1987.

Yujing, M. and Mellouki, A.: Chem. Phys. Lett., 333, 63, 2001. 
II.A2.29

$$
\mathrm{HO}+\mathrm{CH}_{3} \mathrm{CH}_{2} \mathrm{CH}_{2} \mathrm{CH}_{2} \mathrm{OH} \rightarrow \text { products }
$$

\section{Rate coefficient data}

\begin{tabular}{|c|c|c|c|}
\hline$k / \mathrm{cm}^{3}$ molecule $^{-1} \mathrm{~s}^{-1}$ & Temp./K & Reference & Technique/Comments \\
\hline $\begin{array}{l}\text { Absolute Rate Coefficients } \\
(8.31 \pm 0.63) \times 10^{-12}\end{array}$ & 296 & Wallington and Kurylo, 1987 & FP-RA \\
\hline$(7.80 \pm 0.20) \times 10^{-12}$ & $298 \pm 2$ & Nelson et al., 1990 & PR-RA \\
\hline $\begin{array}{l}5.30 \times 10^{-12} \exp [(146 \pm 92) / T] \\
(8.47 \pm 0.34) \times 10^{-12}\end{array}$ & $\begin{array}{l}263-372 \\
298\end{array}$ & Yujing and Mellouki, 2001 & PLP-LIF \\
\hline $\begin{array}{l}\text { Relative Rate Coefficients } \\
(6.7 \pm 1.3) \times 10^{-12}\end{array}$ & & & \\
\hline$(7.97 \pm 0.66) \times 10^{-12}$ & $298 \pm 2$ & Nelson et al., 1990 & RR (b) \\
\hline$(1.03 \pm 0.05) \times 10^{-11}$ & $298 \pm 2$ & Oh and Andino, 2001 & $\mathrm{RR}(\mathrm{c})$ \\
\hline
\end{tabular}

\section{Comments}

(a) $\mathrm{HO}$ radicals were generated by the dark reaction of $\mathrm{H}_{2} \mathrm{O}_{2}-\mathrm{NO}_{2}$ mixtures in the presence of $\mathrm{CO}$ and an organic compound. From sequential experiments using $n$-butane and 1-butanol, a rate coefficient ratio of $k(\mathrm{HO}+1$-butanol $) / k(\mathrm{HO}+n$-butane $)$ $=3.00 \pm 0.56$ (two standard deviations) was derived. This rate coefficient ratio is placed on an absolute basis by use of a rate coefficient of $k(\mathrm{HO}+n$-butane $)=2.22 \times 10^{-12} \mathrm{~cm}^{3}$ molecule ${ }^{-1} \mathrm{~s}^{-1}$ at $292 \mathrm{~K}$ (IUPAC, current recommendation).

(b) $\mathrm{HO}$ radicals were generated by the photolysis of $\mathrm{CH}_{3} \mathrm{ONO}$ in air, and the concentrations of 1-butanol and cyclohexane (the reference compound) were measured by GC. The measured rate coefficient ratio $k(\mathrm{HO}+1$-butanol $) / k(\mathrm{HO}+$ cyclohexane $)$ is placed on an absolute basis by use of a rate coefficient of $k(\mathrm{HO}+$ cyclohexane $)=6.97 \times 10^{-12} \mathrm{~cm}^{3}$ molecule $\mathrm{s}^{-1}$ at 298 K (Atkinson, 2003).

(c) $\mathrm{HO}$ radicals were generated by the photolysis of $\mathrm{CH}_{3} \mathrm{ONO}$ in air, and the concentrations of 1-butanol and $p$-xylene (the reference compound) were measured by GC. The measured rate coefficient ratio $k(\mathrm{HO}+1$-butanol $) / k(\mathrm{HO}+p$-xylene $)=$ $0.72 \pm 0.03$ is placed on an absolute basis by use of a rate coefficient of $k(\mathrm{HO}+p$-xylene $)=1.43 \times 10^{-11} \mathrm{~cm}^{3} \mathrm{molecul}^{-1}$ $\mathrm{s}^{-1}$ at $298 \mathrm{~K}$ (Calvert et al., 2002).

\section{Preferred Values}

$k=8.5 \times 10^{-12} \mathrm{~cm}^{3}$ molecule ${ }^{-1} \mathrm{~s}^{-1}$ at $298 \mathrm{~K}$.

$k=5.3 \times 10^{-12} \exp (140 / T) \mathrm{cm}^{3}$ molecule $\mathrm{e}^{-1} \mathrm{~s}^{-1}$ over the temperature range $260-380 \mathrm{~K}$.

\section{Reliability}

$\Delta \log k= \pm 0.15$ at $298 \mathrm{~K}$.

$\Delta(E / R)= \pm 200 \mathrm{~K}$.

\section{Comments on Preferred Values}

The absolute rate study of Yujing and Mellouki (2001), the sole temperature-dependence study, is used to derive the preferred values. The $298 \mathrm{~K}$ coefficient from the study of Yujing and Mellouki (2001) is in good agreement with the room temperature absolute and relative rate coefficients of Wallington and Kurylo (1987) and Nelson et al. (1990), but is $18 \%$ lower than the relative rate coefficient of Oh and Andino (2001). The experimental technique of Campbell et al. (1976) was possibly prone to unrecognized problems. 


\section{References}

Atkinson, R.: Atmos. Chem. Phys., 3, 2233, 2003.

Calvert, J. G., Atkinson, R., Becker, K. H., Kamens, R. M., Seinfeld, J. H., Wallington, T. J., and Yarwood, G.: The Mechanisms of Atmospheric Oxidation of Aromatic Hydrocarbons, Oxford University Press, New York, NY, 2002.

Campbell, I. M., McLaughlin, D. F., and Handy, B. J.: Chem. Phys. Lett., 38, 362, 1976.

IUPAC: http://www.iupac-kinetic.ch.cam.ac.uk/.

Nelson, L., Rattigan, O., Neavyn, R., Sidebottom, H., Treacy, J., and Nielsen, O. J.: Int. J. Chem. Kinet., $22,1111,1990$. Oh, S. and Andino, J. M.: Int. J. Chem. Kinet. 33, 422, 2001.

Wallington, T. J. and Kurylo, M. J.: Int. J. Chem. Kinet., 19, 1015, 1987.

Yujing, M. and Mellouki, A.: Chem. Phys. Lett., 333, 63, 2001. 
II.A2.30

$$
\mathrm{HO}+\mathrm{CH}_{3} \mathrm{CH}(\mathrm{OH}) \mathrm{CH}_{2} \mathrm{CH}_{3} \rightarrow \text { products }
$$

\section{Rate coefficient data}

\begin{tabular}{|c|c|c|c|}
\hline $\mathrm{k} / \mathrm{cm}^{3}$ molecule $^{-1} \mathrm{~s}^{-1}$ & Temp./K & Reference & Technique/Comments \\
\hline $\begin{array}{l}\text { Relative Rate Coefficients } \\
(8.58 \pm 0.49) \times 10^{-12}\end{array}$ & $296 \pm 2$ & Chew and Atkinson, 1996 & $\mathrm{RR}(\mathrm{a})$ \\
\hline$(8.80 \pm 0.14) \times 10^{-12}$ & $297 \pm 3$ & Baxley and Wells, 1998 & $\mathrm{RR}(\mathrm{b}, \mathrm{c})$ \\
\hline$(7.57 \pm 0.44) \times 10^{-12}$ & $297 \pm 3$ & Baxley and Wells, 1998 & $\mathrm{RR}(\mathrm{b}, \mathrm{d})$ \\
\hline
\end{tabular}

\section{Comments}

(a) $\mathrm{HO}$ radicals were generated by the photolysis of $\mathrm{CH}_{3} \mathrm{ONO}$ in air, and the concentrations of 2-butanol and cyclohexane (the reference compound) were measured by GC. The measured rate coefficient ratio of $k(\mathrm{HO}+2$-butanol $) / k(\mathrm{HO}+$ cyclohexane $)=1.24 \pm 0.07$ is placed on an absolute basis by use of a rate coefficient of $k(\mathrm{HO}+$ cyclohexane $)=6.92 \times 10^{-12} \mathrm{~cm}^{3}$ molecule ${ }^{-1} \mathrm{~s}^{-1}$ at $296 \mathrm{~K}$ (Atkinson, 2003).

(b) $\mathrm{HO}$ radicals were generated by the photolysis of $\mathrm{CH}_{3} \mathrm{ONO}$ in air, and the concentrations of 2-butanol and $n$-nonane and dodecane (the reference compounds) were measured by GC. The measured rate coefficient ratios of $k(\mathrm{HO}+2$ butanol $) / k(\mathrm{HO}+n$-nonane $)$ and $k(\mathrm{HO}+2$-butanol $) / k(\mathrm{HO}+$ dodecane $)$ are placed on an absolute basis by use of rate coefficients at $297 \mathrm{~K}$ of $k(\mathrm{HO}+n$-nonane $)=9.69 \times 10^{-12} \mathrm{~cm}^{3}$ molecule $\mathrm{e}^{-1} \mathrm{~s}^{-1}$ and $k(\mathrm{HO}+$ dodecane $)=1.32 \times 10^{-11} \mathrm{~cm}^{3}$ molecule $\mathrm{e}^{-1} \mathrm{~s}^{-1}$ (Atkinson, 2003).

(c) Relative to $\mathrm{HO}+n$-nonane.

(d) Relative to $\mathrm{HO}+$ dodecane.

\section{Preferred Values}

$k=8.7 \times 10^{-12} \mathrm{~cm}^{3}$ molecule $\mathrm{e}^{-1} \mathrm{~s}^{-1}$ at $298 \mathrm{~K}$.

\section{Reliability}

$\Delta \log k= \pm 0.15$ at $298 \mathrm{~K}$.

\section{Comments on Preferred Values}

The preferred value is based on the relative rate coefficient of Chew and Atkinson (1996) and that of Baxley and Wells (1998) relative to $\mathrm{HO}+n$-nonane, which are in excellent agreement. The rate coefficient of Baxley and Wells (1998) measured relative to that for $\mathrm{HO}+$ dodecane, while in agreement with the other two rate coefficients (Chew and Atkinson, 1996; Baxley and Wells, 1998), is more uncertain because of the small data-base for $\mathrm{HO}+$ dodecane, and hence this rate coefficient is not used in the evaluation.

\section{References}

Atkinson, R.: Atmos. Chem. Phys., 3, 2233, 2003.

Baxley, J. S. and Wells, J. R.: Int. J. Chem. Kinet., 30, 745, 1998.

Chew, A. A. and Atkinson, R.: J. Geophys. Res., 101, 28649, 1996. 
II.A2.31

$$
\mathrm{OH}+\left(\mathrm{CH}_{3}\right)_{2} \mathrm{C}(\mathrm{OH}) \mathrm{CH}=\mathrm{CH}_{2} \rightarrow \text { products }
$$

\section{Rate coefficient data}

\begin{tabular}{|c|c|c|c|}
\hline$k / \mathrm{cm}^{3}$ molecule $^{-1} \mathrm{~s}^{-1}$ & Temp./K & Reference & Technique/Comments \\
\hline $\begin{array}{l}\text { Absolute Rate Coefficients } \\
8.2 \times 10^{-12} \exp [(610 \pm 50) / T] \\
(6.4 \pm 0.6) \times 10^{-11}\end{array}$ & $\begin{array}{l}231-300 \\
298\end{array}$ & Rudich et al., 1995 & PLP-LIF (a) \\
\hline $\begin{array}{l}\text { Relatve Rate Coefficients } \\
(3.81 \pm 0.80) \times 10^{-11} \\
(4.27 \pm 1.80) \times 10^{-11} \\
(6.43 \pm 0.54) \times 10^{-11} \\
(7.35 \pm 0.78) \times 10^{-11} \\
(5.64 \pm 0.13) \times 10^{-11}\end{array}$ & $\begin{array}{l}298 \pm 2 \\
298 \pm 2 \\
295 \pm 1 \\
295 \pm 1 \\
296 \pm 2\end{array}$ & $\begin{array}{l}\text { Fantechi et al., 1998a } \\
\text { Fantechi et al., 1998a } \\
\text { Ferronato et al., } 1998 \\
\text { Ferronato et al., } 1998 \\
\text { Papagni et al., } 2001\end{array}$ & $\begin{array}{l}\operatorname{RR}(b, c) \\
\operatorname{RR}(b, d) \\
\operatorname{RR}(e, f) \\
\operatorname{RR}(e, g) \\
\operatorname{RR}(h)\end{array}$ \\
\hline
\end{tabular}

\section{Comments}

(a) Rate coefficients for the reactions of $\mathrm{HO}, \mathrm{H}^{18} \mathrm{O}$ and DO radicals with 2-methyl-3-buten-2-ol were measured, in the presence and absence of $\mathrm{O}_{2}$ (up to $13.5 \mathrm{Torr}\left(18 \mathrm{mbar}\right.$ ) $\mathrm{O}_{2}$ in the case of the $\mathrm{HO}$ radical reaction), over the temperature range $231-410 \mathrm{~K}$. Above $\sim 350 \mathrm{~K}$ the rate coefficients decreased with increasing temperature faster than predicted based on extrapolation of the lower temperature data. For the $\mathrm{HO}$ radical reaction, the rate coefficients in the presence of 2-13.5 Torr of $\mathrm{O}_{2}$ were up to $15-20 \%$ higher than in the absence of $\mathrm{O}_{2}$, while the measured rate coefficients for the DO radical reaction were invariant to the presence or absence of $\mathrm{O}_{2}$. $\mathrm{HO}$ radicals were observed to be formed in the DO radical reaction, and the rate coefficients of the $\mathrm{DO}$ radical and $\mathrm{H}^{18} \mathrm{O}$ radical reactions were essentially identical to those for the $\mathrm{HO}$ radical reactions in the presence of $\mathrm{O}_{2}$. These data indicated that the measured rate coefficients from the $\mathrm{HO}$ radical reaction in the absence of $\mathrm{O}_{2}$ are low because of $\mathrm{HO}$ radical regeneration, whereas $\mathrm{H}^{18} \mathrm{O}$ and $\mathrm{DO}$ radical regeneration does not occur from reactions of $\mathrm{H}^{18} \mathrm{O}$ and DO radicals with 2-methyl-3-buten-2-ol (HO radicals being formed by elimination of the -OH group in the 2-methyl-3-buten-2-ol in the absence of $\mathrm{O}_{2}$ ). The rate coefficient cited is derived (Rudich et al., 1995) from the rate coefficients measured for the $\mathrm{HO}$ and $\mathrm{DO}$ radical reactions in the presence of $\mathrm{O}_{2}$ over the temperature range $230-300 \mathrm{~K}$, and is expected to be applicable to atmospheric conditions.

(b) $\mathrm{HO}$ radicals were generated by the photolysis of $\mathrm{H}_{2} \mathrm{O}_{2}$ at $253.7 \mathrm{~nm}$ in air at $987 \pm 7$ mbar pressure. The concentrations of 2-methyl-3-buten-2-ol and isoprene (or propene) [the reference compounds] were measured during the experiments by FTIR spectroscopy. The measured rate coefficient ratios $k(\mathrm{HO}+2$-methyl-3-buten-2-ol $) / k(\mathrm{HO}+$ isoprene $)$ and $k(\mathrm{HO}$ + 2-methyl-3-buten-2-ol $) / k(\mathrm{HO}+$ propene $)$ are placed on an absolute basis by use of rate coefficients at $298 \mathrm{~K}$ and atmospheric pressure of $k(\mathrm{HO}+$ isoprene $)=1.00 \times 10^{-10} \mathrm{~cm}^{3}$ molecule $\mathrm{e}^{-1} \mathrm{~s}^{-1}$ (Atkinson and Arey, 2003; IUPAC, current recommendation) and $k(\mathrm{HO}+$ propene $)=2.63 \times 10^{-11} \mathrm{~cm}^{3}$ molecule $\mathrm{e}^{-1} \mathrm{~s}^{-1}$ (Atkinson and Arey, 2003).

(c) Relative to $k(\mathrm{HO}+$ isoprene) .

(d) Relative to $k(\mathrm{HO}+$ propene $)$.

(e) $\mathrm{HO}$ radicals were generated by the photolysis of ${ }^{13} \mathrm{CH}_{3} \mathrm{ONO}-\mathrm{NO}-\left(\mathrm{CH}_{3}\right)_{2} \mathrm{C}(\mathrm{OH}) \mathrm{CH}=\mathrm{CH}_{2}$-propene (or ethene) [the reference compounds]-air mixtures at 933 mbar pressure. The concentrations of 2-methyl-3-buten-2-ol and propene (or ethene) were measured by FTIR spectroscopy. The measured rate coefficient ratios of $k(\mathrm{HO}+2$-methyl-3-buten-2-ol $) / k(\mathrm{HO}+$ propene $)=2.4 \pm 0.2$ and $k(\mathrm{HO}+2$-methyl-3-buten-2-ol $) / k(\mathrm{HO}+$ ethene $)=8.5 \pm 0.9$ are placed on an absolute basis by use of rate coefficients at $295 \mathrm{~K}$ and atmospheric pressure of air of $k(\mathrm{HO}+$ propene $)=2.68 \times 10^{-11} \mathrm{~cm}^{3}$ molecule $\mathrm{s}^{-1}$ and $k(\mathrm{HO}+$ ethene $)=8.65 \times 10^{-12} \mathrm{~cm}^{3}$ molecule $\mathrm{s}^{-1} \mathrm{~s}^{-1}$ (Atkinson and Arey, 2003).

(f) Relative to $k(\mathrm{HO}+$ propene $)$.

(g) Relative to $k(\mathrm{HO}+$ ethene $)$. 
(h) $\mathrm{HO}$ radicals were generated by the photolysis of $\mathrm{CH}_{3} \mathrm{ONO}-\mathrm{NO}-\left(\mathrm{CH}_{3}\right)_{2} \mathrm{C}(\mathrm{OH}) \mathrm{CH}=\mathrm{CH}_{2}-1,3,5$-trimethylbenzene (the reference compound)-air mixtures at 987 mbar pressure. The concentrations of 2-methyl-3-buten-2-ol and 1,3,5trimethylbenzene were measured by GC. The measured rate coefficient ratio of $k(\mathrm{HO}+2$-methyl-3-buten-2-ol $) / k(\mathrm{HO}$ $+1,3,5$-trimethylbenzene $)=0.995 \pm 0.022$ is placed on an absolute basis by use of a rate coefficient at $296 \mathrm{~K}$ of $k(\mathrm{HO}+$ 1,3,5-trimethylbenzene) $=5.67 \times 10^{-11} \mathrm{~cm}^{3}$ molecule $^{-1} \mathrm{~s}^{-1}$ (Atkinson and Arey, 2003).

\section{Preferred Values}

$k=8.2 \times 10^{-12} \exp (610 / T) \mathrm{cm}^{3}$ molecule ${ }^{-1} \mathrm{~s}^{-1}$ over the temperature range $230-300 \mathrm{~K}$.

$k=6.4 \times 10^{-11} \mathrm{~cm}^{3}$ molecule ${ }^{-1} \mathrm{~s}^{-1}$ at $298 \mathrm{~K}$.

\section{Reliability}

$\Delta \log k= \pm 0.15$ at $298 \mathrm{~K}$.

$\Delta(E / R)= \pm 200 \mathrm{~K}$.

\section{Comments on Preferred Values}

The room temperature rate coefficients of Rudich et al. (1995), Ferronato et al. (1998) and Papagni et al. (2001) are in reasonable agreement, although the rate coefficient of Ferronato et al. (1998) relative to ethene is somewhat higher than those of Rudich et al. (1995) and Papagni et al. (2001) and that of Ferronato et al. (1998) relative to propene. The two relative rate coefficients of Fantechi et al. (1998a) are significantly lower than the values measured by Rudich et al. (1995), Ferronato et al. (1998) and Papagni et al. (2001). The preferred $298 \mathrm{~K}$ rate coefficient is the average of the absolute and relative rate coefficients of Rudich et al. (1995), Ferronato et al. (1998) and Papagni et al. (2001), and is identical to the $298 \mathrm{~K}$ absolute rate coefficient cited by Rudich et al. (1995). The preferred temperature dependence is that reported by Rudich et al. (1995).

The reaction proceeds almost totally by initial addition of $\mathrm{HO}$ to the $\mathrm{C}=\mathrm{C}$ bond (Fantechi et al., 1998b; Ferronato et al., 1998; Alvarado et al., 1999; Spaulding et al., 2002; Reisen et al., 2003). In the presence of NO at atmospheric pressure of air the observed products are formaldehyde, acetone, glycolaldehyde, 2-hydroxy-2-methylpropanal $\left[\left(\mathrm{CH}_{3}\right)_{2} \mathrm{C}(\mathrm{OH}) \mathrm{CHO}\right]$, and dihydroxynitrates [presumed to be $\left(\mathrm{CH}_{3}\right)_{2} \mathrm{C}(\mathrm{OH}) \mathrm{CH}(\mathrm{OH}) \mathrm{CH}_{2} \mathrm{ONO}_{2}$ and $\left(\mathrm{CH}_{3}\right)_{2} \mathrm{C}(\mathrm{OH}) \mathrm{CH}\left(\mathrm{ONO}_{2}\right) \mathrm{CH}_{2} \mathrm{OH}$ ] $(\mathrm{Fantechi}$ et al., 1998b; Ferronato et al., 1998; Alvarado et al., 1999; Spaulding et al., 2002; Reisen et al., 2003). Based on the product studies of Ferronato et al. (1998), Alvarado et al. (1999) and Reisen et al. (2003) carried out in the presence of NO, the product yields are: formaldehyde, $35 \pm 4 \%$ (Ferronato et al., 1998) and 29 $\pm 3 \%$ (Alvarado et al., 1999); acetone, $52 \pm 5 \%$ (Ferronato et al., 1998) and 58 $\pm 4 \%$ (Alvarado et al., 1999); glycolaldehyde, $50 \pm 5 \%$ (Ferronato et al., 1998)

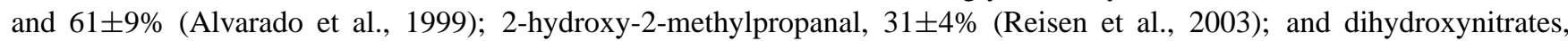
$5 \pm 2 \%$ (Alvarado et al., 1999). The reaction mechanism is discussed in detail in Alvarado et al. (1999). Reactions of the $\left(\mathrm{CH}_{3}\right)_{2} \mathrm{C}(\mathrm{OH}) \mathrm{CH}(\mathrm{OH}) \mathrm{CH}_{2} \mathrm{OO}$ and $\left(\mathrm{CH}_{3}\right)_{2} \mathrm{C}(\mathrm{OH}) \mathrm{CH}(\mathrm{OO}) \mathrm{CH}_{2} \mathrm{OH}$ peroxy radicals (formed after addition of $\mathrm{O}_{2}$ to the initially formed $\left(\mathrm{CH}_{3}\right)_{2} \mathrm{C}(\mathrm{OH}) \mathrm{CH}(\mathrm{OH}) \mathrm{CH}_{2}$ and $\left(\mathrm{CH}_{3}\right)_{2} \mathrm{C}(\mathrm{OH}) \mathrm{CHCH}_{2} \mathrm{OH}$ radicals) with $\mathrm{NO}$ lead to the formation predominantly of the dinitrates $\left(\mathrm{CH}_{3}\right)_{2} \mathrm{C}(\mathrm{OH}) \mathrm{CH}(\mathrm{OH}) \mathrm{CH}_{2} \mathrm{ONO}_{2}$ and $\left(\mathrm{CH}_{3}\right)_{2} \mathrm{C}(\mathrm{OH}) \mathrm{CH}\left(\mathrm{ONO}_{2}\right) \mathrm{CH}_{2} \mathrm{OH}$ or $\mathrm{NO}_{2}$ plus the dihydroxyalkoxy radicals $\left(\mathrm{CH}_{3}\right)_{2} \mathrm{C}(\mathrm{OH}) \mathrm{CH}(\mathrm{OH}) \mathrm{CH}_{2} \mathrm{O}$ and $\left(\mathrm{CH}_{3}\right)_{2} \mathrm{C}(\mathrm{OH}) \mathrm{CH}(\mathrm{O}) \mathrm{CH}_{2} \mathrm{OH}$. These dihydroxyalkoxy radicals appear to dominantly decompose at room temperature and atmospheric pressure:

$$
\begin{array}{cc}
\left(\mathrm{CH}_{3}\right)_{2} \mathrm{C}(\mathrm{OH}) \mathrm{CH}(\mathrm{OH}) \mathrm{CH}_{2} \mathrm{O} \rightarrow & \mathrm{HCHO}+\left(\mathrm{CH}_{3}\right)_{2} \mathrm{C}(\mathrm{OH}) \mathrm{CHOH} \\
\downarrow & \left(\mathrm{O}_{2}\right. \\
& \\
& \\
\left(\mathrm{CH}_{3}\right)_{2} \mathrm{C}(\mathrm{OH}) \mathrm{CHO}+\mathrm{HO}_{2} & \\
& \left(\mathrm{CH}_{3}\right)_{2} \mathrm{C}(\mathrm{OH}) \mathrm{CHO}+\mathrm{CH}_{2} \mathrm{OH} \\
\downarrow \mathrm{O}_{2} \\
\mathrm{HCHO}+\mathrm{HO}_{2}
\end{array}
$$

and/or

$$
\begin{gathered}
\left(\mathrm{CH}_{3}\right)_{2} \mathrm{C}(\mathrm{OH}) \mathrm{CH}(\mathrm{O}) \mathrm{CH}_{2} \mathrm{OH} \rightarrow\left(\mathrm{CH}_{3}\right)_{2} \mathrm{COH}+\mathrm{HOCH}_{2} \mathrm{CHO} \\
\downarrow \mathrm{O}_{2} \\
\mathrm{CH}_{3} \mathrm{C}(\mathrm{O}) \mathrm{CH}_{3}+\mathrm{HO}_{2}
\end{gathered}
$$


Hence, as observed, the yield of $\mathrm{HCHO}$ equals that of $\left(\mathrm{CH}_{3}\right)_{2} \mathrm{C}(\mathrm{OH}) \mathrm{CHO}$, and the yield of $\mathrm{HOCH}_{2} \mathrm{CHO}$ equals that of $\mathrm{CH}_{3} \mathrm{C}(\mathrm{O}) \mathrm{CH}_{3}$ (Ferronato et al., 1998; Alvarado et al., 1999; Reisen et al., 2003).

\section{References}

Alvarado, A., Tuazon, E. C., Aschmann, S. M., Arey, J., and Atkinson, R.: Atmos. Environ., 33, 2893, 1999. Atkinson, R. and Arey, J.: Chem. Rev., 103, 4605, 2003.

Fantechi, G., Jensen, N. R., Hjorth, J., and Peeters, J.: Int. J. Chem. Kinet., 30, 589, 1998 a.

Fantechi, G., Jensen, N. R., Hjorth, J., and Peeters, J.: Atmos. Environ., 32, 3547, 1998b.

Ferronato, C., Orlando, J. J., and Tyndall, G. S.: J. Geophys. Res., 103, 25 579, 1998.

IUPAC, http://www.iupac-kinetic.ch.cam.ac.uk/.

Papagni, C., Arey, J., and Atkinson, R.: Int. J. Chem. Kinet., 33, 142, 2001.

Reisen, F., Aschmann, S. M., Atkinson, R., and Arey, J.: Environ. Sci. Technol., 37, 4664, 2003.

Rudich, Y., Talukdar, R. K., Burkholder, J. B., and Ravishankara, A. R.: J. Phys. Chem. 99, 12 188, 1995.

Spaulding, R., Charles, M. J., Tuazon, E. C., and Lashley, M.: J. Am. Soc. Mass Spectrom., 13, 530, 2002. 
II.A2.32

$$
\mathrm{HO}+\mathrm{CH}_{3} \mathrm{OCH}_{3} \rightarrow \mathrm{H}_{2} \mathrm{O}+\mathrm{CH}_{3} \mathrm{OCH}_{2}
$$

\section{Rate coefficient data}

\begin{tabular}{|c|c|c|c|}
\hline $\mathrm{k} / \mathrm{cm}^{3}$ molecule $^{-1} \mathrm{~s}^{-1}$ & Temp./K & Reference & Technique/Comments \\
\hline \multicolumn{4}{|l|}{ Absolute Rate Coefficients } \\
\hline $\begin{array}{l}1.29 \times 10^{-11} \exp [-(388 \pm 151) / T] \\
(3.50 \pm 0.35) \times 10^{-12}\end{array}$ & $\begin{array}{l}299-424 \\
299\end{array}$ & Perry et al., 1977 & FP-RF \\
\hline $\begin{array}{l}1.04 \times 10^{-11} \exp [-(372 \pm 34) / T] \\
(2.95 \pm 0.12) \times 10^{-12}\end{array}$ & $\begin{array}{l}295-442 \\
295\end{array}$ & Tully and Droege, 1987 & PLP-LIF \\
\hline $\begin{array}{l}6.7 \times 10^{-12} \exp [-(300 \pm 70) / T] \\
(2.49 \pm 0.22) \times 10^{-12}\end{array}$ & $\begin{array}{l}240-440 \\
296\end{array}$ & Wallington et al., 1988 & FP-RF \\
\hline$(2.35 \pm 0.24) \times 10^{-12}$ & $298 \pm 2$ & Nelson et al., 1990 & PR-RA \\
\hline $\begin{array}{l}6.38 \times 10^{-12} \exp [-(234 \pm 34) / T] \\
(2.82 \pm 0.21) \times 10^{-12}\end{array}$ & $\begin{array}{l}230-372 \\
295\end{array}$ & Mellouki et al., 1995 & PLP-LIF \\
\hline $\begin{array}{l}3.39 \times 10^{-24} T^{4.11} \exp [(1221 \pm 252) / T] \\
(2.95 \pm 0.21) \times 10^{-12}\end{array}$ & $\begin{array}{l}295-650 \\
295\end{array}$ & Arif et al., 1997 & PLP-LIF \\
\hline $\begin{array}{l}3.02 \times 10^{-20} T^{2.85} \exp [(618 \pm 13) / T] \\
(2.67 \pm 0.07) \times 10^{-12}\end{array}$ & $\begin{array}{l}295-618 \\
298\end{array}$ & Bonard et al., 2002 & PLP-LIF \\
\hline \multicolumn{4}{|l|}{ Relative Rate Coefficients } \\
\hline$(2.11 \pm 0.21) \times 10^{-12}$ & $295 \pm 3$ & Wallington et al., 1989 & $\mathrm{RR}(\mathrm{a})$ \\
\hline$(2.97 \pm 0.66) \times 10^{-12}$ & $298 \pm 2$ & Nelson et al., 1990 & $\mathrm{RR}(\mathrm{b})$ \\
\hline $2.41 \times 10^{-12}$ & 263 & DeMore and Bayes, 1999 & $\mathrm{RR}(\mathrm{c}, \mathrm{d})$ \\
\hline $2.47 \times 10^{-12}$ & 273 & & \\
\hline $2.70 \times 10^{-12}$ & 293 & & \\
\hline $2.72 \times 10^{-12}$ & 298 & & \\
\hline $3.03 \times 10^{-12}$ & 313 & & \\
\hline $3.23 \times 10^{-12}$ & 333 & & \\
\hline $3.39 \times 10^{-12}$ & 351 & & \\
\hline $3.04 \times 10^{-12}$ & 295 & DeMore and Bayes, 1999 & $\mathrm{RR}(\mathrm{c}, \mathrm{e})$ \\
\hline $3.25 \times 10^{-12}$ & 305 & & \\
\hline $3.16 \times 10^{-12}$ & 318 & & \\
\hline $3.42 \times 10^{-12}$ & 328 & & \\
\hline $3.81 \times 10^{-12}$ & 336 & & \\
\hline $3.62 \times 10^{-12}$ & 345 & & \\
\hline $3.86 \times 10^{-12}$ & 364 & & \\
\hline $3.18 \times 10^{-12}$ & 306 & DeMore and Bayes, 1999 & $\mathrm{RR}(\mathrm{c}, \mathrm{f})$ \\
\hline $3.33 \times 10^{-12}$ & 324 & & \\
\hline $3.62 \times 10^{-12}$ & 351 & & \\
\hline $3.82 \times 10^{-12}$ & 361 & & \\
\hline
\end{tabular}

\section{Comments}

(a) $\mathrm{HO}$ radicals were generated by the photolysis of $\mathrm{CH}_{3} \mathrm{ONO}-\mathrm{NO}$-air mixtures at atmospheric pressure. The concentrations of dimethyl ether and $n$-butane (the reference compound) were measured by GC. The measured rate coefficient ratio of $k\left(\mathrm{CH}_{3} \mathrm{OCH}_{3}\right) / k(n$-butane $)=0.918 \pm 0.090$ is placed on an absolute basis by using a rate coefficient of $k(n$-butane $)=$ $2.30 \times 10^{-12} \mathrm{~cm}^{3}$ molecule $\mathrm{s}^{-1} \mathrm{~s}^{-1}$ (IUPAC, current recommendation).

(b) $\mathrm{HO}$ radicals were generated by the photolysis of $\mathrm{CH}_{3} \mathrm{ONO}-\mathrm{NO}$-air mixtures at atmospheric pressure. The concentrations of dimethyl ether and cyclohexane (the reference compound) were measured by GC. The measured rate coeffi- 
cient ratio $k\left(\mathrm{CH}_{3} \mathrm{OCH}_{3}\right) / k($ cyclohexane $)$ is placed on an absolute basis by use of a rate coefficient of $k($ cyclohexane $)=$ $6.97 \times 10^{-12} \mathrm{~cm}^{3}$ molecule $\mathrm{s}^{-1} \mathrm{~s}^{-1}$ at $298 \mathrm{~K}$ (Atkinson, 2003).

(c) $\mathrm{HO}$ radicals were generated by the photolysis of $\mathrm{O}_{3}$ at $254 \mathrm{~nm}$ in the presence of water vapor. The concentrations of dimethyl ether and the reference compound were measured by GC.

(d) Relative to $k(\mathrm{HO}+n$-butane $)$. The measured rate coefficient ratios $k(\mathrm{HO}+$ dimethyl ether $) / k(\mathrm{HO}+n$-butane $)$ are placed on an absolute basis by use of a rate coefficient of $k(\mathrm{HO}+n$-butane $)=1.81 \times 10^{-17} T^{2} \exp (114 / T) \mathrm{cm}^{3} \mathrm{molecule}^{-1} \mathrm{~s}^{-1}$ (IUPAC, current recommendation).

(e) Relative to $k(\mathrm{HO}+n$-pentane $)$. The measured rate coefficient ratios $k(\mathrm{HO}+$ dimethyl ether $) / k(\mathrm{HO}+n$-pentane $)$ are placed on an absolute basis by use of a rate coefficient of $k(\mathrm{HO}+n$-pentane $)=2.52 \times 10^{-17} T^{2} \exp (158 / T) \mathrm{cm}^{3} \mathrm{molecule}^{-1} \mathrm{~s}^{-1}$ (Atkinson, 2003).

(f) Relative to $k(\mathrm{HO}+$ cyclohexane $)$. The measured rate coefficient ratios $k(\mathrm{HO}+$ dimethyl ether $) / k(\mathrm{HO}+\mathrm{cyclohexane})$ are placed on an absolute basis by use of a rate coefficient of $k(\mathrm{HO}+$ cyclohexane $)=3.26 \times 10^{-17} T^{2} \exp (262 / T) \mathrm{cm}^{3}$ molecule $\mathrm{s}^{-1}$ (Atkinson, 2003).

\section{Preferred Values}

$k=2.8 \times 10^{-12} \mathrm{~cm}^{3}$ molecule ${ }^{-1} \mathrm{~s}^{-1}$ at $298 \mathrm{~K}$.

$k=5.7 \times 10^{-12} \exp (-215 / T) \mathrm{cm}^{3}$ molecule ${ }^{-1} \mathrm{~s}^{-1}$ over the temperature range $230-300 \mathrm{~K}$.

\section{Reliability}

$\Delta \log k= \pm 0.08$ at $298 \mathrm{~K}$.

$\Delta(E / R)= \pm 100 \mathrm{~K}$.

\section{Comments on Preferred Values}

The reported room temperature absolute (Perry et al., 1977; Tully and Droege, 1987; Wallington et al., 1988; Nelson et al., 1990; Mellouki et al., 1995; Arif et al., 1997; Bonard et al., 2002) and relative (Nelson et al., 1990; Wallington et al., 1989; DeMore and Bayes, 1999) rate coefficients exhibit appreciable scatter, covering a range of a factor of 1.6. The measured temperature dependencies (Perry et al., 1977; Tully and Droege, 1987; Wallington et al., 1988; Mellouki et al., 1995; Arif et al., 1997; Bonard et al., 2002; DeMore and Bayes, 1999) are in reasonable agreement. The preferred values are based on the absolute rate coefficient studies of Tully and Droege (1987), Mellouki et al. (1995), Arif et al. (1997) and Bonard et al. (2002), the rate coefficients of which are in good agreement and which are between those of the other two absolute temperature-dependent studies of Perry et al. (1977) and Wallington et al. (1988).

Because Arrhenius plots of the data of Mellouki et al. (1995), Arif et al. (1997) and Bonard et al. (2002) show curvature, the rate coefficients of Tully and Droege (1987), Mellouki et al. (1995), Arif et al. (1997) and Bonard et al. (2002) have been fitted to the expression $k=C T^{2} \exp (-D / T)$, resulting in $k=1.14 \times 10^{-17} T^{2} \exp (303 / T) \mathrm{cm}^{3} \mathrm{molecule}^{-1} \mathrm{~s}^{-1}$ over the temperature range $230-650 \mathrm{~K}$. The preferred Arrhenius expression $k=A \exp (-B / T)$ is centered at $260 \mathrm{~K}$ and is derived from the three-parameter expression with $A=C \mathrm{e}^{2} T^{2}$ and $B=D+2 T$. The rate coefficients determined by DeMore and Bayes (1999) relative to that for the reaction of $\mathrm{HO}$ radicals with $n$-butane are in excellent agreement with the recommendation; however the rate coefficients determined by DeMore and Bayes (1999) relative to those for the reactions of HO radicals with $n$-pentane and cyclohexane are uniformly $\sim 10 \%$ higher than the preferred values.

The significant deuterium isotope effect observed by Tully and Droege (1987) indicates that reaction proceeds by initial H-atom abstraction.

\section{References}

Arif, M., Dellinger, B., and Taylor, P. H.: J. Phys. Chem. A, 101, 2436, 1997.

Atkinson, R.: Atmos. Chem. Phys., 3, 2233, 2003.

Bonard, A., Daële, V., Delfau, J.-L., and Vovelle, C.: J. Phys. Chem. A, 106, 4384, 2002.

DeMore, W. B. and Bayes, K. D.: J. Phys. Chem. A, 103, 2649, 1999.

IUPAC: http://www.iupac-kinetic.ch.cam.ac.uk/. 
Mellouki, A., Teton, S., and Le Bras, G.: Int. J. Chem. Kinet., 27, 791, 1995.

Nelson, L., Rattigan, O., Neavyn, R., Sidebottom, H., Treacy, J., and Nielsen, O. J.: Int. J. Chem. Kinet., 22, 1111, 1990.

Perry, R. A., Atkinson, R., and Pitts Jr., J. N.: J. Chem. Phys., 67, 611, 1977.

Tully, F. P. and Droege, A. T.: Int. J. Chem. Kinet., 19, 251, 1987.

Wallington, T. J., Andino, J. M., Skewes, L. M., Siegl, W. O., and Japar, S. M.: Int. J. Chem. Kinet., 21, 993, 1989.

Wallington, T. J., Liu, R., Dagaut, P., and Kurylo, M. J.: Int. J. Chem. Kinet., 20, 41, 1988. 
II.A2.33

HO + 3-Methylfuran $\rightarrow$ products

\section{Rate coefficient data}

\begin{tabular}{|c|c|c|c|}
\hline$k / \mathrm{cm}^{3}$ molecule $^{-1} \mathrm{~s}^{-1}$ & Temp./K & Reference & Technique/Comments \\
\hline $\begin{array}{l}\text { Relative Rate Coefficients } \\
(9.26 \pm 0.24) \times 10^{-11}\end{array}$ & $296 \pm 2$ & Atkinson et al., 1989 & RR (a) \\
\hline
\end{tabular}

\section{Comments}

(a) Relative rate method carried out at atmospheric pressure of air. HO radicals were generated by the photolysis of methyl nitrite-NO-air mixtures, and the concentrations of 3-methylfuran and 2,3-dimethyl-2-butene (the reference compound) were measured by GC. The measured rate coefficient ratio of $k(\mathrm{HO}+3$-methylfuran $) / k(\mathrm{HO}+2,3$-dimethyl-2butene $)=0.842 \pm 0.021$ is placed on an absolute basis by use of a rate coefficient of $k(\mathrm{HO}+2,3$-dimethyl-2-butene $)=$ $1.10 \times 10^{-10} \mathrm{~cm}^{3}$ molecule ${ }^{-1} \mathrm{~s}^{-1}$ at $296 \mathrm{~K}$ (Atkinson, 1997).

\section{Preferred Values}

$k=9.3 \times 10^{-11} \mathrm{~cm}^{3}$ molecule ${ }^{-1} \mathrm{~s}^{-1}$ at $298 \mathrm{~K}$.

\section{Reliability}

$\Delta \log k= \pm 0.3$ at $298 \mathrm{~K}$.

\section{Comments on Preferred Values}

The preferred value is based on the sole study of this reaction by Atkinson et al. (1989). The reaction of HO radicals with 3-methylfuran is expected to proceed almost exclusively by initial $\mathrm{HO}$ radical addition to the $\mathrm{C}=\mathrm{C}$ bonds (Atkinson et al., 1989).

\section{References}

Atkinson, R., Aschmann, S. M., Tuazon, E. C., Arey, J., and Zielinska, B.: Int. J. Chem. Kinet., 21, 593, 1989. Atkinson, R.: J. Phys. Chem. Ref. Data, 26, 215, 1997. 
II.A2.34

$$
\mathrm{HO}+\mathrm{CH}_{3} \mathrm{C}(\mathrm{O}) \mathrm{CH}_{2} \mathrm{OH} \rightarrow \text { products }
$$

\section{Rate coefficient data}

\begin{tabular}{lllc}
\hline$k / \mathrm{cm}^{3}$ molecule & \\
\hline $\begin{array}{l}\text { Absolute Rate Coefficients } \\
(3.0 \pm 0.3) \times 10^{-12}\end{array}$ & Temp./K & Reference & Technique/Comments \\
$(2.8 \pm 0.2) \times 10^{-12}$ & 298 & Dagaut et al., 1989 & FP-RF \\
& $\sim 298$ & Chowhury et al., 2001 & PLP-LIF (a) \\
$\begin{array}{l}\text { Relative Rate Coefficients } \\
(2.52 \pm 0.27) \times 10^{-12}\end{array}$ & 298 & & \\
$(3.52 \pm 0.32) \times 10^{-12}$ & 298 & Orlando et al., 1999 & RR (b,c) \\
& & & RR (b,d) \\
\hline
\end{tabular}

\section{Comments}

(a) $\mathrm{HO}$ radicals generated by the $193 \mathrm{~nm}$ photolysis of $\mathrm{CH}_{3} \mathrm{C}(\mathrm{O}) \mathrm{CH}_{2} \mathrm{OH}$.

(b) $\mathrm{HO}$ radicals were generated by the photolysis of methyl nitrite in synthetic air at 1 bar total pressure. Hydroxyacetone and methanol and ethanol (the reference compounds) were monitored by FTIR spectroscopy. The measured rate coefficient ratios $k(\mathrm{HO}+$ hydroxyacetone $) / k(\mathrm{HO}+$ methanol $)=2.8 \pm 0.3$ and $k(\mathrm{HO}+$ hydroxyacetone $) / k(\mathrm{HO}+$ ethanol $)=1.1 \pm 0.1$ are placed on an absolute basis using rate coefficients of $k(\mathrm{HO}+$ methanol $)=9.0 \times 10^{-13} \mathrm{~cm}^{3}$ molecule ${ }^{-1} \mathrm{~s}^{-1}$ and $k(\mathrm{HO}$ + ethanol) $=3.2 \times 10^{-12} \mathrm{~cm}^{3}$ molecule ${ }^{-1} \mathrm{~s}^{-1}$ at $298 \mathrm{~K}$, respectively (IUPAC, current recommendation).

(b) Relative to $\mathrm{OH}+$ methanol.

(c) Relative to $\mathrm{OH}+$ ethanol.

\section{Preferred Values}

$k=3.0 \times 10^{-12} \mathrm{~cm}^{3}$ molecule ${ }^{-1} \mathrm{~s}^{-1}$ at $298 \mathrm{~K}$.

\section{Reliability}

$\Delta \log k= \pm 0.15$ at $298 \mathrm{~K}$.

\section{Comments on Preferred Values}

The preferred value is an average of the absolute and relative rate coefficients of Dagaut et al. (1989), Orlando et al. (1999) and Chowdhury et al. (2001) which are in reasonable agreement.

\section{References}

Chowdhury, P. K., Upadhyaya, H. P., Naik, P. D. and Mittal, J. P.: Chem. Phys. Lett. 351, 201, 2001.

Dagaut, P., Liu, R., Wallington, T. J., and Kurylo, M. J.: J. Phys. Chem., 93, 7838, 1989.

Orlando, J. J., Tyndall, G. S., Fracheboud, J.-M., Estupiñan, E. G., Haberkorn, S., and Zimmer, A.: Atmos. Environ., 33, $1621,1999$. 
II.A2.35

$$
\mathrm{OH}+\left(\mathrm{CH}_{3}\right)_{2} \mathrm{C}(\mathrm{OH}) \mathrm{CHO} \rightarrow \text { products }
$$

\section{Rate coefficient data}

\begin{tabular}{lclc}
\hline$k / \mathrm{cm}^{3}$ molecule & Temp./K & Reference & Technique/Comments \\
\hline $\begin{array}{l}\text { Relative Rate Coefficients } \\
(1.51 \pm 0.22) \times 10^{-11}\end{array}$ & $296 \pm 2$ & Baker et al., 2004 & RR(a) \\
\hline
\end{tabular}

\section{Comments}

(a) $\mathrm{HO}$ radicals were generated by the photolysis of $\mathrm{CH}_{3} \mathrm{ONO}-\mathrm{NO}$-air mixtures at wavelengths $>300 \mathrm{~nm}$. $(\mathrm{CH})_{2} \mathrm{C}(\mathrm{OH}) \mathrm{CHO}$ was generated in situ from the reaction of $\mathrm{HO}$ radicals with $\left(\mathrm{CH}_{3}\right)_{2} \mathrm{C}(\mathrm{OH}) \mathrm{CH}=\mathrm{CH}_{2}$ and its concentration was measured during the reactions using solid phase microextraction fibers pre-coated with $O$-(2,3,4,5,6pentafluorobenzyl)hydroxylamine for on-fiber derivatization of carbonyl compounds, with subsequent GC analyses. From the time-concentration behavior of $\left(\mathrm{CH}_{3}\right)_{2} \mathrm{C}(\mathrm{OH}) \mathrm{CHO}$ during the reactions, the rate coefficient ratio $\left.k\left(\mathrm{HO}+\left(\mathrm{CH}_{3}\right)_{2} \mathrm{C}(\mathrm{OH}) \mathrm{CHO}\right) / k \mathrm{HO}+\left(\mathrm{CH}_{3}\right)_{2} \mathrm{C}(\mathrm{OH}) \mathrm{CH}=\mathrm{CH}_{2}\right)=0.234 \pm 0.033$ was derived. This rate coefficient ratio is placed on an absolute basis by use of a rate coefficient at $296 \mathrm{~K}$ of $k\left(\mathrm{HO}+\left(\mathrm{CH}_{3}\right)_{2} \mathrm{C}(\mathrm{OH}) \mathrm{CH}=\mathrm{CH}_{2}\right)=6.44 \times 10^{-11} \mathrm{~cm}^{3}$ molecule ${ }^{-1} \mathrm{~s}^{-1}$ (IUPAC, current recommendation).

\section{Preferred Values}

$k=1.5 \times 10^{-11} \mathrm{~cm}^{3}$ molecule ${ }^{-1} \mathrm{~s}^{-1}$ at $298 \mathrm{~K}$.

\section{Reliability}

$\Delta \log k= \pm 0.3$ at $298 \mathrm{~K}$

\section{Comments on Preferred Values}

The preferred value is based on the sole study of this reaction. The reaction is expected to proceed mainly by $\mathrm{H}$-atom abstraction from the -CHO group (Baker et al., 2004).

\section{References}

Baker, J., Arey, J., and Atkinson, R.: J. Phys. Chem. A, 108, 7032, 2004.

IUPAC, http://www.iupac-kinetic.ch.cam.ac.uk/. 
II.A2.36

$$
\begin{aligned}
\mathrm{HO}+\mathrm{CH}_{3} \mathrm{OOH} & \rightarrow \mathrm{H}_{2} \mathrm{O}+\mathrm{CH}_{2} \mathrm{OOH} \\
& \rightarrow \mathrm{H}_{2} \mathrm{O}+\mathrm{CH}_{3} \mathrm{OO}
\end{aligned}
$$

$\Delta H^{\circ}(2)=-139 \mathrm{~kJ} \cdot \mathrm{mol}^{-1}$

Rate coefficient data $\left(k=k_{1}+k_{2}\right)$

\begin{tabular}{lllc}
\hline$k / \mathrm{cm}^{3}$ molecule ${ }^{-1} \mathrm{~s}^{-1}$ & Temp./K & Reference & Technique/Comments \\
\hline Absolute Rate Coefficients & & & \\
$2.93 \times 10^{-12} \exp [(190 \pm 14) / T]$ & $223-423$ & Vaghjiani and Ravishankara, 1989 & (a) \\
$5.54 \times 10^{-12}$ & 298 & & (a) \\
$k_{2}=1.78 \times 10^{-12} \exp [(220 \pm 21) / T]$ & $203-348$ & Vaghjiani and Ravishankara, 1989 & \\
$k_{2}=(3.85 \pm 0.23) \times 10^{-12}$ & 298 & & \\
& & & RR (b) \\
Relative Rate Coefficients & $\sim 298$ & Niki et al., 1983 & RR (c) \\
$(1.02 \pm 0.08) \times 10^{-11}$ & $\sim 298$ & Niki et al., 1983 & \\
$(1.02 \pm 0.11) \times 10^{-11}$ & & &
\end{tabular}

\section{Comments}

(a) $\mathrm{H}^{16} \mathrm{O}, \mathrm{H}^{18} \mathrm{O}$ and $\mathrm{DO}$ radicals were generated by flash photolysis or pulsed laser photolysis of the following precursors: for $\mathrm{H}^{16} \mathrm{O}, \mathrm{CH}_{3} \mathrm{OOH}, \mathrm{H}_{2}{ }^{16} \mathrm{O}$ and $\mathrm{O}_{3}-\mathrm{H}_{2}^{16} \mathrm{O}$; for $\mathrm{H}^{18} \mathrm{O}, \mathrm{H}_{2}{ }^{18} \mathrm{O}$ and $\mathrm{O}_{3}-\mathrm{H}_{2}^{18} \mathrm{O}$; and for $\mathrm{DO}, \mathrm{D}_{2} \mathrm{O}, \mathrm{O}_{3}-\mathrm{D}_{2} \mathrm{O}$ and $\mathrm{O}_{3}-\mathrm{D}_{2}$, and $\mathrm{H}^{16} \mathrm{O}, \mathrm{H}^{18} \mathrm{O}$ and DO radicals were monitored by LIF. Rate coefficients $\left(k_{1}+k_{2}\right)$ were obtained from measurements of the decay rates of $\mathrm{H}^{18} \mathrm{O}$ and $\mathrm{DO}$ radicals in the presence of excess $\mathrm{CH}_{3} \mathrm{OOH}$. Rate coefficients $k_{2}$ were obtained from the decay rates of $\mathrm{H}^{16} \mathrm{O}$ radicals in the presence of $\mathrm{CH}_{3} \mathrm{OOH}$. The $\mathrm{CH}_{2} \mathrm{OOH}$ radical formed in reaction channel (1) rapidly decomposes to $\mathrm{HO}+\mathrm{HCHO}$, and hence the use of $\mathrm{H}^{16} \mathrm{O}$ allowed only the rate coefficient $k_{2}$ to be measured.

(b) $\mathrm{HO}$ radicals were generated by the photolysis of $\mathrm{CH}_{3} \mathrm{ONO}$ or $\mathrm{C}_{2} \mathrm{H}_{5} \mathrm{ONO}$ in air. The concentrations of $\mathrm{CH}_{3} \mathrm{OOH}$ and ethene (the reference compound) were measured by FTIR absorption spectroscopy. The measured rate coefficientratio of $k\left(\mathrm{HO}+\mathrm{CH}_{3} \mathrm{OOH}\right) / k(\mathrm{HO}+$ ethene $)=1.20 \pm 0.09$ is placed on an absolute basis by use of a rate coefficient of $k(\mathrm{HO}+$ ethene) $=8.52 \times 10^{-12} \mathrm{~cm}^{3}$ molecule $\mathrm{e}^{-1} \mathrm{~s}^{-1}$ at $298 \mathrm{~K}$ and atmospheric pressure of air (Atkinson, 1997).

(c) $\mathrm{HO}$ radicals were generated by the photolysis of $\mathrm{CH}_{3} \mathrm{ONO}$ in air and the concentrations of $\mathrm{CH}_{3} \mathrm{OOH}$ and $\mathrm{CH}_{3} \mathrm{CHO}$ (the reference compound) were measured by FTIR absorption spectroscopy. The measured rate coefficient ratio of $k(\mathrm{HO}+$ $\left.\mathrm{CH}_{3} \mathrm{OOH}\right) / k\left(\mathrm{HO}+\mathrm{CH}_{3} \mathrm{CHO}\right)=0.68 \pm 0.07$ is placed on an absolute basis by use of a rate coefficient of $k\left(\mathrm{HO}+\mathrm{CH}_{3} \mathrm{CHO}\right)$ $=1.5 \times 10^{-11} \mathrm{~cm}^{3}$ molecule ${ }^{-1} \mathrm{~s}^{-1}$ at $298 \mathrm{~K}$ (IUPAC, current recommendation).

\section{Preferred Values}

$k=5.5 \times 10^{-12} \mathrm{~cm}^{3}$ molecule ${ }^{-1} \mathrm{~s}^{-1}$ at $298 \mathrm{~K}$.

$k=2.9 \times 10^{-12} \exp (190 / T) \mathrm{cm}^{3}$ molecule ${ }^{-1} \mathrm{~s}^{-1}$ over the temperature range $220-430 \mathrm{~K}$.

$k_{1} / k=0.35$ over the temperature range $220-430 \mathrm{~K}$.

\section{Reliability}

$\Delta \log k= \pm 0.2$ at $298 \mathrm{~K}$.

$\Delta(E / R)= \pm 150 \mathrm{~K}$.

$\Delta\left(k_{1} / k\right)= \pm 0.15$ at $298 \mathrm{~K}$. 


\section{Comments on Preferred Values}

The preferred values are those of Vaghjiani and Ravishankara (1989). The reasons for the factor of $\sim 2$ discrepancy with the relative rate data of Niki et al. (1983) are not known (Vaghjiani and Ravishankara, 1989). The preferred branching ratio, also taken from the absolute rate coefficient study of Vaghjiani and Ravishankara (1989), is in reasonable agreement with the earlier measurement of Niki et al. (1983).

\section{References}

Atkinson, R.: J. Phys. Chem. Ref. Data, 26, 215, 1997.

IUPAC: http://www.iupac-kinetic.ch.cam.ac.uk/.

Niki, H., Maker, P. D., Savage, C. M., and Breitenbach, L. P.: J. Phys. Chem., 87, 2190, 1983.

Vaghjiani, G. L. and Ravishankara, A. R.: J. Phys. Chem., 93, 1948, 1989. 
II.A2.37

$$
\mathrm{HO}+\mathrm{HC}(\mathrm{O}) \mathrm{OH} \rightarrow \text { products }
$$

\section{Rate coefficient data}

\begin{tabular}{lllc}
\hline$k / \mathrm{cm}^{3}$ molecule ${ }^{-1} \mathrm{~s}^{-1}$ & Temp./K & Reference & Technique/Comments \\
\hline Absolute Rate Coefficients & & & \\
$(4.62 \pm 0.78) \times 10^{-13}$ & $298-430$ & Wine et al., 1985 & FP/PLP-RF (a) \\
$(4.90 \pm 0.12) \times 10^{-13}$ & 296 & Jolly et al., 1986 & PLP-RA (b) \\
$2.91 \times 10^{-13} \exp [(102 \pm 194) / T]$ & $297-445$ & Singleton et al., 1988 & PLP-RA \\
$(4.47 \pm 0.28) \times 10^{-13}$ & 297 & & \\
$(3.7 \pm 0.4) \times 10^{-13}$ & 298 & Dagaut et al., 1988 & FP-RF \\
\hline
\end{tabular}

\section{Comments}

(a) $\mathrm{H}$ atom formation was also measured by resonance fluorescence, and an $\mathrm{H}$-atom formation yield of $0.75 \pm 0.25$ measured. At $298 \mathrm{~K}$, the measured rate coefficient for the reaction of the $\mathrm{HO}$ radical with $\mathrm{DC}(\mathrm{O}) \mathrm{OH}$ was identical to that for $\mathrm{HO}$ radical reaction with $\mathrm{HC}(\mathrm{O}) \mathrm{OH}$.

(b) Experiments with added $\mathrm{O}_{2}$ led to non-exponential and slower $\mathrm{HO}$ radical decays, indicating the formation of $\mathrm{H}$ atoms from the $\mathrm{HO}$ radical reaction with $\mathrm{HC}(\mathrm{O}) \mathrm{OH}$.

\section{Preferred Values}

$k=4.5 \times 10^{-13} \mathrm{~cm}^{3}$ molecule $\mathrm{s}^{-1} \mathrm{~s}^{-1}$, independent of temperature over the range $290-450 \mathrm{~K}$.

\section{Reliability}

$\Delta \log k= \pm 0.15$ at $298 \mathrm{~K}$.

$\Delta(E / R)= \pm 250 \mathrm{~K}$.

\section{Comments on Preferred Values}

A major problem with the determination of the rate coefficient for this reaction concerns the ready dimerization of $\mathrm{HC}(\mathrm{O}) \mathrm{OH}$. The studies of Wine et al. (1985), Jolly et al. (1986) and Singleton et al. (1988) monitored formic acid in the experimental systems used by UV absorption spectroscopy. The data from these studies (Wine et al., 1985; Jolly et al., 1986; Singleton et al., 1988) agree well, and are in reasonable agreement with the room temperature rate coefficient of Dagaut et al. (1988). The data of Wine et al. (1985) and Singleton et al. (1988) show that the temperature dependence of the rate coefficient is zero within the experimental uncertainties. The average of the rate coefficients of Wine et al. (1985), Jolly et al. (1986) and Singleton et al. (1988) has been used to derive the preferred rate coefficient.

The studies of Wine et al. (1985) and Jolly et al. (1986) showed that $\mathrm{H}$ atoms are produced in this reaction, with a yield of $0.75 \pm 0.25$ (Wine et al., 1985). Furthermore, Wine et al. (1985) and Singleton et al. (1988) showed that within the experimental uncertainties the rate coefficient for the reaction of the $\mathrm{HO}$ radical with $\mathrm{DC}(\mathrm{O}) \mathrm{OH}$ is identical to that for $\mathrm{HC}(\mathrm{O}) \mathrm{OH}$ at $298 \mathrm{~K}$. Also, the room temperature rate coefficients for the reactions of the $\mathrm{DO}$ radical with $\mathrm{HC}(\mathrm{O}) \mathrm{OD}$ and $\mathrm{DC}(\mathrm{O}) \mathrm{OD}$ are significantly lower than those for the reactions of the $\mathrm{HO}$ radical with $\mathrm{HC}(\mathrm{O}) \mathrm{OH}$ and $\mathrm{DC}(\mathrm{O}) \mathrm{OH}$ (Singleton et al., 1988). The reaction then appears to proceed by,

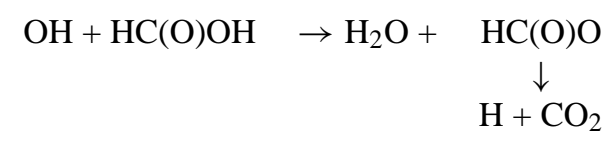

with overall abstraction of the $\mathrm{H}$ (or $\mathrm{D}$ ) atom from the - $\mathrm{OH}$ (or -OD) group being the major pathway at room temperature. 


\section{References}

Dagaut, P., Wallington, T. J., Liu, R., and Kurylo, M. J.: Int. J. Chem. Kinet., 20, 331, 1988.

Jolly, G. S., McKenney, D. J., Singleton, D. L., Paraskevopoulos, G., and Bossard, A. R.: J. Phys. Chem., 90, $6557,1986$. Singleton, D. L., Paraskevopoulos, G., Irwin, R. S., Jolly, G. S., and McKenney, D. J.: J. Am. Chem. Soc., $110,7786,1988$. Wine, P. H., Astalos, R. J., and Mauldin III, R. L.: J. Phys. Chem., 89, 2620, 1985. 
II.A2.38

$$
\mathrm{HO}+\mathrm{CH}_{3} \mathrm{C}(\mathrm{O}) \mathrm{OH} \rightarrow \text { products }
$$

\section{Rate coefficient data}

\begin{tabular}{lllc}
\hline$k / \mathrm{cm}^{3}$ molecule ${ }^{-1} \mathrm{~s}^{-1}$ & Temp./K & Reference & Technique/Comments \\
\hline Absolute Rate Coefficients & & & \\
$1.3 \times 10^{-12} \exp [-(170 \pm 20) / T]$ & $298-440$ & Dagaut et al., 1988 & FP-RF (a) \\
$(7.4 \pm 0.6) \times 10^{-13}$ & 298 & & \\
$(8.67 \pm 0.65) \times 10^{-13}$ & 296.8 & Singleton et al., 1989 & PLP-RA \\
$(5.63 \pm 0.44) \times 10^{-13}$ & 326.2 & & \\
$(4.88 \pm 0.17) \times 10^{-13}$ & 356.4 & & \\
$(4.09 \pm 0.14) \times 10^{-13}$ & 396.8 & & \\
$(3.95 \pm 0.07) \times 10^{-13}$ & 446.2 & & DF-CIMS (b) \\
$2.2 \times 10^{-14} \exp [(1012 \pm 80) / T]$ & $229-300$ & Butkovskaya et al., 2004 & \\
$(6.6 \pm 1.1) \times 10^{-13}$ & 300 & & \\
\hline
\end{tabular}

\section{Comments}

(a) Rate coefficient also measured at $240 \mathrm{~K}$ where the major species present was expected to be the dimer. Assuming that the monomer and dimer were equally reactive towards the HO radical (but see Butkovskaya et al., 2004), a rate coefficient of $(6.4 \pm 0.9) \times 10^{-13} \mathrm{~cm}^{3}$ molecule $\mathrm{s}^{-1}$ at $240 \mathrm{~K}$. was obtained.

(b) Experiments were carried out in a turbulent flow system at $\sim 200$ Torr (267 mbar) pressure. Combined with the rate data of Singleton et al. (1989), the expression $\left.k=2.45 \times 10^{-16}(T / 298)^{5.24} \exp (2358 \pm 189) / T\right) \mathrm{cm}^{3}$ molecule $\mathrm{e}^{-1} \mathrm{~s}^{-1}$ over the temperature range 229-446 K was obtained. The $\mathrm{CO}_{2}$ yield was measured by CIMS to be $64 \pm 17 \%$, independent of temperature over the range $249-298 \mathrm{~K}$.

\section{Preferred Values}

$k=7.4 \times 10^{-13} \mathrm{~cm}^{3}$ molecule $\mathrm{e}^{-1} \mathrm{~s}^{-1}$ at $298 \mathrm{~K}$.

$k=4.2 \times 10^{-14} \exp (855 / T) \mathrm{cm}^{3}$ molecule $\mathrm{s}^{-1} \mathrm{~s}^{-1}$ over the temperature range 220-300 $\mathrm{K}$.

\section{Reliability}

$\Delta \log k= \pm 0.15$ at $298 \mathrm{~K}$.

$(E / R)= \pm 400 \mathrm{~K}$.

\section{Comments on Preferred Values}

At room temperature, the rate coefficients of Dagaut et al. (1988), Singleton et al. (1989) and Butkovskaya et al., 2004 are in reasonable agreement. However, the measured temperature dependencies disagree significantly. At temperatures above 298 K, Dagaut et al. (1988) observed the rate coefficient to increase with increasing temperature, while Singleton et al. (1989) observed the rate coefficient to decrease in a non-Arrhenius manner with increasing temperature. The rate coefficients of Singleton et al. (1989) and Butkovskaya et al. (2004) are consistent in that the rate coefficient increases with decreasing temperature and exhibits a reasonably linear Arrhenius plot below $300 \mathrm{~K}$. The rate coefficients of Singleton et al. (1989) and Butkovskaya et al. (2004) have been fitted to the three-parameter expression $k=C T^{2} \exp (-D / T)$, resulting in $k=8.60 \times$ $10^{-20} T^{2} \exp (1363 / T) \mathrm{cm}^{3}$ molecule ${ }^{-1} \mathrm{~s}^{-1}$ over the temperature range 229-446 $\mathrm{K}$. The preferred Arrhenius expression, $k=$ $A \exp (-B / T)$, is centered at $255 \mathrm{~K}$ and is derived from the three-parameter equation with $A=C e^{2} T^{2}$ and $B=D+2 T$. The three-parameter expression $k=8.60 \times 10^{-20} T^{2} \exp (1363 / T) \mathrm{cm}^{3}$ molecule $\mathrm{s}^{-1} \mathrm{~s}^{-1}$ and that reported by Butkovskaya et al. (2004), from combination of their data and those of Singleton et al. (1989), of $k=2.45 \times 10^{-16}(T / 298)^{5.24} \exp (1363 / T) \mathrm{cm}^{3}$ molecule $\mathrm{e}^{-1} \mathrm{~s}^{-1}$ result in rate coefficients which agree to within $\sim 10 \%$ over the temperature range $229-446 \mathrm{~K}$. 
The rate coefficients of Singleton et al. (1989) for the reactions of the $\mathrm{HO}$ radical with $\mathrm{CH}_{3} \mathrm{C}(\mathrm{O}) \mathrm{OH}, \mathrm{CD}_{3} \mathrm{C}(\mathrm{O}) \mathrm{OH}$ and $\mathrm{CD}_{3} \mathrm{C}(\mathrm{O}) \mathrm{OD}$ indicate that at room temperature the major reaction channel involves overall $\mathrm{H}$-atom abstraction from the $-\mathrm{OH}$ bond:

$$
\mathrm{HO}+\mathrm{CH}_{3} \mathrm{C}(\mathrm{O}) \mathrm{OH} \rightarrow \mathrm{H}_{2} \mathrm{O}+\mathrm{CH}_{3} \mathrm{C}(\mathrm{O}) \mathrm{O}
$$

This is confirmed by the measured $\mathrm{CO}_{2}$ yields of $64 \pm 17 \%$ over the temperature range 249-298 $\mathrm{K}$ (Butkovskaya et al. (2004) and $64 \pm 14 \%$ at $290 \mathrm{~K}$ (De Smedt et al., 2005), with the $\mathrm{CO}_{2}$ arising from decomposition of the $\mathrm{CH}_{3} \mathrm{C}(\mathrm{O}) \mathrm{O}$ radical:

$$
\mathrm{CH}_{3} \mathrm{C}(\mathrm{O}) \mathrm{O} \rightarrow \mathrm{CH}_{3}+\mathrm{CO}_{2}
$$

\section{References}

Butkovskaya, N. I., Kukui, A., Pouvesle, N. and Le Bras, G.: J. Phys. Chem. A 108, 7021, 2004.

Dagaut, P., Wallington, T. J., Liu, R. and Kurylo, M. J.: Int. J. Chem. Kinet. 20, 331, 1988.

De Smedt, F., Bui, X. V., Nguyen, T. L., Peeters, J. and Vereecken, L.: J. Phys. Chem. A 109, 2401, 2005.

Singleton, D. L., Paraskevopoulos, G. and Irwin, R. S.: J. Am. Chem. Soc. 111, 5248, 1989. 
II.A2.39

$$
\mathrm{HO}+\mathrm{C}_{2} \mathrm{H}_{5} \mathrm{C}(\mathrm{O}) \mathrm{OH} \rightarrow \text { products }
$$

\section{Rate coefficient data}

\begin{tabular}{lllc}
\hline$k / \mathrm{cm}^{3}$ molecule ${ }^{-1} \mathrm{~s}^{-1}$ & Temp./K & Reference & Technique/Comments \\
\hline Absolute Rate Coefficients & & & \\
$1.8 \times 10^{-12} \exp [-(120 \pm 30) / T]$ & $298-440$ & Dagaut et al., 1988 & FP-RF \\
$(1.22 \pm 0.12) \times 10^{-12}$ & 298 & & \\
$(1.07 \pm 0.05) \times 10^{-12}$ & $298-445$ & Singleton et al., 1989 & PLP-RA \\
$(1.02 \pm 0.55) \times 10^{-12}$ & 298 & & \\
\hline
\end{tabular}

\section{Preferred Values}

$k=1.2 \times 10^{-12} \mathrm{~cm}^{3}$ molecule $\mathrm{e}^{-1} \mathrm{~s}^{-1}$, independent of temperature over the range $290-450 \mathrm{~K}$.

\section{Reliability}

$\Delta \log k= \pm 0.2$ at $298 \mathrm{~K}$.

$\Delta(E / R)= \pm 300 \mathrm{~K}$.

\section{Comments on Preferred Values}

The rate coefficients measured by Dagaut et al. (1988) and Singleton et al. (1989) are in good agreement and indicate that the rate coefficient for this reaction is independent of temperature over the range $298-445 \mathrm{~K}$. The preferred value is an average of all of the rate coefficients of Dagaut et al. (1988) and Singleton et al. (1989), combined with a zero temperature dependence. The reaction is expected to proceed by $\mathrm{H}$-atom abstraction from the $\mathrm{C}-\mathrm{H}$ bonds of the $-\mathrm{CH}_{3}$ group and the O-H bond of the $-\mathrm{C}(\mathrm{O}) \mathrm{OH}$ group.

\section{References}

Dagaut, P., Wallington, T. J., Liu, R., and Kurylo, M. J.: Int. J. Chem. Kinet., 20, 331, 1988.

Singleton, D. L., Paraskevopoulos, G., and Irwin, R. S.: J. Am. Chem. Soc., 111, 5248, 1989. 
II.A2.40

$$
\mathrm{HO}+\mathrm{CH}_{3} \mathrm{ONO}_{2} \rightarrow \text { products }
$$

\section{Rate coefficient data}

\begin{tabular}{lllc}
\hline$k / \mathrm{cm}^{3}$ molecule ${ }^{-1} \mathrm{~s}^{-1}$ & Temp./K & Reference & Technique/Comments \\
\hline Absolute Rate Coefficients & & & \\
$(3.4 \pm 0.4) \times 10^{-14}$ & 298 & Gaffney et al., 1986 & DF-RF (a) \\
$8.8 \times 10^{-15} \exp [(1050 \pm 180) / T]$ & $298-393$ & Nielsen et al., 1991 & PR-RA (b) \\
$(3.2 \pm 0.5) \times 10^{-13}$ & $298 \pm 2$ & & \\
$8.2 \times 10^{-13} \exp [-(1020 \pm 60) / T)$ & $221-414$ & Talukdar et al., 1997 & PLP-LIF (c) \\
$(2.36 \pm 0.16) \times 10^{-14}$ & 298 & & \\
$4.1 \times 10^{-13} \exp [-(604 \pm 121) / T]$ & $298-423$ & Shallcross et al., 1997 & DF-RF (d) \\
$(4.7 \pm 1.0) \times 10^{-14}$ & 298 & & \\
& & & \\
Relative Rate Coefficients & & & RR (e) \\
$(3.8 \pm 1.0) \times 10^{-13}$ & $303 \pm 2$ & Kerr and Stocker, 1986 & RR (f) \\
$(3.1 \pm 0.7) \times 10^{-13}$ & $298 \pm 2$ & Nielsen et al., 1991 & RR (g) \\
$(3.0 \pm 0.7) \times 10^{-14}$ & $307 \pm 3$ & Kakesu et al., 1997 & \\
\hline
\end{tabular}

\section{Comments}

(a) Conducted at 2.6-4.2 mbar (2.0-3.2 Torr) of He.

(b) Conducted at 1 bar Ar.

(c) In addition to measuring rate coefficients for the reaction of the $\mathrm{HO}$ radical with $\mathrm{CH}_{3} \mathrm{ONO}_{2}$, rate coefficients were measured for the reactions of the $\mathrm{HO}$ radical with $\mathrm{CD}_{3} \mathrm{ONO}_{2}(298-409 \mathrm{~K})$, the DO radical with $\mathrm{CH}_{3} \mathrm{ONO}_{2}(246-353 \mathrm{~K})$ and the $\mathrm{H}^{18} \mathrm{O}$ radical with $\mathrm{CH}_{3} \mathrm{ONO}_{2}(253-298 \mathrm{~K})$. $\mathrm{HO}, \mathrm{H}^{18} \mathrm{O}$ and DO radicals were generated by the pulsed laser photolysis of $\mathrm{HONO}$ at $355 \mathrm{~nm}$ and of $\mathrm{O}_{3}-\mathrm{H}_{2} \mathrm{O}$ mixtures at $266 \mathrm{~nm}$, photolysis of $\mathrm{O}_{3}-\mathrm{H}_{2}^{18} \mathrm{O}$ mixtures at $266 \mathrm{~nm}$, and photolysis of DONO at $355 \mathrm{~nm}$ and of $\mathrm{O}_{3}-\mathrm{D}_{2} \mathrm{O}$ mixtures at $266 \mathrm{~nm}$, respectively. The diluent gas pressure was varied from $67 \mathrm{mbar}$ (50 Torr) He plus 67 mbar (50 Torr) $\mathrm{SF}_{6}$ to 133 mbar (100 Torr) He and to $400 \mathrm{mbar}$ (300 Torr) $\mathrm{SF}_{6}$, and up to $67 \mathrm{mbar}$ (50 Torr) of $\mathrm{O}_{2}$ was included in certain experiments. No effect of total pressure, nature of the diluent gas, or presence of $\mathrm{O}_{2}$ on the measured rate coefficients was observed. The rate coefficients for the reactions of the $\mathrm{H}^{18} \mathrm{O}$ radical with $\mathrm{CH}_{3} \mathrm{ONO}_{2}$ were essentially identical to those for the corresponding $\mathrm{HO}$ radical reaction, while the measured rate coefficients for the DO radical reaction were $\sim 10-20 \%$ higher than the HO radical reaction. No evidence for formation of $\mathrm{HO}$ radicals was observed from these $\mathrm{H}^{18} \mathrm{O}$ and DO radical reactions. The rate coefficients for the reaction of the HO radical with $\mathrm{CD}_{3} \mathrm{ONO}_{2}$ were a factor of 3 to 4 lower than those for $\mathrm{HO}+\mathrm{CH}_{3} \mathrm{ONO}_{2}$ over the temperature range studied (298-409 K).

(d) The rate coefficient at $298 \mathrm{~K}$ was measured over the pressure range $2.7-27$ mbar (2-20 Torr) of He, with no effect of pressure being observed. Rate coefficients at 333-423 K were measured over the pressure range 1.3-4.0 mbar (1-3 Torr) of He.

(e) HO radicals were generated from the photolysis of HONO-air mixtures at atmospheric pressure. The concentrations of methyl nitrate and ethene (the reference compound) were measured by GC. The measured rate coefficient ratio of $k(\mathrm{HO}+$ methyl nitrate $) / k(\mathrm{HO}+$ ethene $)=0.046 \pm 0.011$ placed on an absolute basis by use of $k(\mathrm{HO}+$ ethene $)=8.32 \times 10^{-12} \mathrm{~cm}^{3}$ molecule $\mathrm{e}^{-1} \mathrm{~s}^{-1}$ at $303 \mathrm{~K}$ and one atmosphere of air (Atkinson, 1997).

(f) $\mathrm{HO}$ radicals generated by the photolysis of $\mathrm{CH}_{3} \mathrm{ONO}-\mathrm{NO}$-air mixtures at atmospheric pressure. The decays of $\mathrm{CH}_{3} \mathrm{ONO}_{2}$ and $\left(\mathrm{CH}_{3}\right)_{3} \mathrm{CH}$ (the reference compound) were measured by GC. The rate coefficient ratio was placed on an absolute basis by use of $k\left(\mathrm{HO}+\left(\mathrm{CH}_{3}\right)_{3} \mathrm{CH}\right)=2.12 \times 10^{-12} \mathrm{~cm}^{3}$ molecule ${ }^{-1} \mathrm{~s}^{-1}$ (Atkinson, 2003). 
(g) $\mathrm{HO}$ radicals were generated by photolysis of $\mathrm{O}_{3}-\mathrm{H}_{2} \mathrm{O}-\mathrm{O}_{2}$ mixtures at atmospheric pressure at $\sim 290-310 \mathrm{~nm}$. Methyl nitrate and the reference compounds (methane, ethane and HFC-152a) were monitored by GC. The measured rate coefficient ratios are placed on an absolute basis by use of rate coefficients of $k\left(\mathrm{HO}+\mathrm{CH}_{4}\right)=1.85 \times 10^{-12} \exp (-1690 / T) \mathrm{cm}^{3}$ molecule $\mathrm{s}^{-1} \mathrm{~s}^{-1}, k\left(\mathrm{HO}+\mathrm{C}_{2} \mathrm{H}_{6}\right)=6.9 \times 10^{-12} \exp (-1000 / T) \mathrm{cm}^{3}$ molecule ${ }^{-1} \mathrm{~s}^{-1}$ and $k\left(\mathrm{HO}+\mathrm{CH}_{3} \mathrm{CHF}_{2}\right)=1.0 \times 10^{-12} \exp (-$ $990 / T) \mathrm{cm}^{3}$ molecule ${ }^{-1} \mathrm{~s}^{-1}$ (IPUPAC, current recommendation). The cited rate coefficient is the unweighted average, with a two standard deviation error limit.

\section{Preferred Values}

$k=2.3 \times 10^{-14} \mathrm{~cm}^{3}$ molecule ${ }^{-1} \mathrm{~s}^{-1}$ at $298 \mathrm{~K}$.

$k=4.0 \times 10^{-13} \exp (-845 / T) \mathrm{cm}^{3}$ molecule $\mathrm{s}^{-1} \mathrm{~s}^{-1}$ over the temperature range $220-300 \mathrm{~K}$.

\section{Reliability}

$\Delta \log k={ }_{-0.2}^{+0.5}$ at $298 \mathrm{~K}$.

$\Delta(E / R)= \pm 400 \mathrm{~K}$.

\section{Comments on Preferred Values}

There are serious discrepancies between the room temperature rate coefficients of Gaffney et al. (1986), Talukdar et al. (1997) and Kakesu et al. (1997) and those of Kerr and Stocker (1986) and Nielsen et al. (1991), of a factor of $\sim 10$. Additionally, the temperature dependencies of Nielsen et al. (1991) and Talukdar et al. (1997) differ by $\sim 2000 \mathrm{~K}$. The positive temperature-dependence observed by Talukdar et al. (1997) is supported, qualitatively, by the low-pressure absolute rate study of Shallcross et al. (1997), although the rate coefficients of Shallcross et al. (1997) are a factor of $\sim 1.3-2.0$ higher than those of Talukdar et al. (1997) over the temperature range 298-423 K. The reasons for these various discrepancies are not presently known, but we favor the results of the Talukdar et al. (1997) study which are consistent with H- (or D-) atom abstraction to form $\mathrm{H}_{2} \mathrm{O}+\mathrm{CH}_{2} \mathrm{ONO}$. The extensive absolute study of Talukdar et al. (1997) shows no effect of the measured rate coefficient on pressure or diluent gas ( $133 \mathrm{mbar} \mathrm{He}$ to $400 \mathrm{mbar} \mathrm{SF}_{6}$ ) nor on the presence or absence of up to $67 \mathrm{mbar}$ of $\mathrm{O}_{2}$. The experiments of Talukdar et al. (1997) on the reactions $\mathrm{HO}+\mathrm{CH}_{3} \mathrm{ONO}_{2}, \mathrm{H}^{18} \mathrm{O}+\mathrm{CH}_{3} \mathrm{ONO}_{2}, \mathrm{DO}+\mathrm{CH}_{3} \mathrm{ONO}_{2}$ and $\mathrm{HO}+\mathrm{CH}_{3} \mathrm{ONO}$ show no formation of $\mathrm{HO}$ radicals from the $\mathrm{H}^{18} \mathrm{O}$ and $\mathrm{DO}$ radical reactions with $\mathrm{CH}_{3} \mathrm{ONO}$, and the deuterium isotope effect of $k_{\mathrm{H}} / k_{\mathrm{D}} \sim 4$ at $298 \mathrm{~K}$ is totally consistent with $\mathrm{H}$ - (or D-) atom abstraction.

The preferred values are obtained from a unit-weighted least-squares analysis of the 221-298 K rate coefficients of Talukdar et al. (1997). Because of the significant discrepancies between the various studies (Gaffney et al., 1986; Kakesu et al., 1997; Kerr and Stocker, 1986; Nielsen et al., 1991; Shallcross et al., 1997; Talakdur et al., 1997), large uncertainty limits are assigned to the $298 \mathrm{~K}$ rate coefficient and the temperature dependence. Clearly, further absolute rate studies at atmospheric pressure of air are needed.

\section{References}

Atkinson, R.: Atmos. Chem. Phys., 3, 2233, 2003.

Atkinson, R.: J. Phys. Chem. Ref. Data, 26, 215, 1997.

Gaffney, J. S., Fajer, R., Senum, G. I., and Lee, J. H.: Int. J. Chem. Kinet., 18, 399, 1986.

IUPAC: http://www.iupac-kinetic.ch.cam.ac.uk/.

Kakesu, M., Bandow, H., Takenaka, N., Maeda, Y., and Washida, N.: Int. J. Chem. Kinet., 29, 933, 1997.

Kerr, J. A. and Stocker, D. W.: J. Atmos. Chem., 4, 253, 1986.

Nielsen, O. J., Sidebottom, H. W., Donlon, M., and Treacy, J.: Chem. Phys. Lett., 178, 163, 1991.

Shallcross, D. E., Biggs, P., Canosa-Mas, C. E., Clemitshaw, K. C., Harrison, M. G., Reyes López Alañón, M., Pyle, J. A., Vipond, A., and Wayne, R. P.: J. Chem. Soc. Faraday Trans., 93, 2807, 1997.

Talukdar, R. K., Herndon, S. C., Burkholder, J. B., Roberts, J. M., and Ravishankara, A. R.: J. Chem. Soc. Faraday Trans., 93, 2787, 1997. 
II.A2.41

$\mathrm{HO}+\mathrm{C}_{2} \mathrm{H}_{5} \mathrm{ONO}_{2} \rightarrow$ products

\section{Rate coefficient data}

\begin{tabular}{lllc}
\hline $\mathrm{k} / \mathrm{cm}^{3}$ molecule ${ }^{-1} \mathrm{~s}^{-1}$ & Temp./K & Reference & Technique/Comments \\
\hline $\begin{array}{l}\text { Absolute Rate Coefficients } \\
4.7 \times 10^{-14} \exp [(716 \pm 138) / T]\end{array}$ & $298-373$ & Nielsen et al., 1991 & PR-RA (a) \\
$(5.3 \pm 0.6) \times 10^{-13}$ & $298 \pm 2$ & & \\
$3.68 \times 10^{-12} \exp [-(1077 / T)]$ & $223-394$ & Talukdar et al., 1997 & PLP-LIF (b) \\
$+5.32 \times 10^{-14} \exp (126 / T)$ & & & \\
$(1.80 \pm 0.12) \times 10^{-13}$ & 298 & & \\
$3.30 \times 10^{-12} \exp [-(699 \pm 140) / T]$ & $298-373$ & Shallcross et al., 1997 & DF-RF (c) \\
$(3.30 \pm 0.68) \times 10^{-13}$ & 298 & & \\
& & & \\
Relative Rate Coefficients & $303 \pm 2$ & Kerr and Stocker, 1986 & RR (d) \\
$(4.9 \pm 2.1) \times 10^{-13}$ & $298 \pm 2$ & Nielsen et al., 1991 & RR (e) \\
$(4.2 \pm 0.3) \times 10^{-13}$ & $304 \pm 6$ & Kakesu et al., 1997 & RR (f) \\
$(2.2 \pm 0.8) \times 10^{-13}$ & & &
\end{tabular}

\section{Comments}

(a) Conducted at 1 bar Ar.

(b) Extensive study of the reactions of ethyl nitrate with $\mathrm{HO}$ radicals $(223-394 \mathrm{~K}), \mathrm{H}^{18} \mathrm{O}$ radicals $(300 \mathrm{~K})$ and DO radicals $(229-378 \mathrm{~K}) . \mathrm{HO}, \mathrm{H}^{18} \mathrm{O}$ and DO radicals were produced from the pulsed laser photolysis of $\mathrm{HONO}$ at $355 \mathrm{~nm}$, of $\mathrm{O}_{3}-\mathrm{H}_{2}^{18} \mathrm{O}$ mixtures at $248 \mathrm{~nm}$, and of DONO at $355 \mathrm{~nm}$, respectively. The diluent gas and total pressures were $\mathrm{He}$ [67-400 mbar (50-300 Torr)], $\mathrm{N}_{2}$ [400 mbar (300 Torr)], $\mathrm{SF}_{6}$ [267 mbar (200 Torr)] or $\mathrm{He}_{-} \mathrm{SF}_{6}$ [133-400 mbar (100-300 Torr)], and $\mathrm{O}_{2}$ partial pressures of 67 mbar (50 Torr) were used in certain experiments. No effects on the measured rate coefficients were observed on varying the total pressure, the diluent gas, or the partial pressure of $\mathrm{O}_{2}$. The measured rate coefficients for the reactions of the $\mathrm{H}^{18} \mathrm{O}$ and DO radicals with ethyl nitrate were 11-16\% higher than that for the $\mathrm{HO}$ radical reaction, and no formation of $\mathrm{HO}$ radicals was observed in the $\mathrm{H}^{18} \mathrm{O}$ and $\mathrm{DO}$ radical reactions.

(c) The rate coefficient at $298 \mathrm{~K}$ was measured over the pressure range 5.7-27 mbar (4.3-19.9 Torr) of He, with no effect of pressure being observed. The rate coefficients at $313 \mathrm{~K}$ and $373 \mathrm{~K}$ were measured over the pressure range $1.3-4.0 \mathrm{mbar}$ (1-3 Torr) of He.

(d) HO radicals generated by photolysis of HONO-air mixtures at atmospheric pressure. The concentrations of ethyl nitrate and ethene (the reference organic) were measured by GC. The measured rate coefficient ratio of $k(\mathrm{HO}+$ ethyl nitrate $) / k(\mathrm{HO}+$ ethene $)=0.059 \pm 0.025$ is placed on an absolute basis by use of a rate coefficient $k(\mathrm{HO}+$ ethene $)=$ $8.32 \times 10^{-12} \mathrm{~cm}^{3}$ molecule $\mathrm{s}^{-1} \mathrm{~s}^{-1}$ at $303 \mathrm{~K}$ and atmospheric pressure of air (Atkinson, 1997).

(e) $\mathrm{HO}$ radicals were generated by photolysis of $\mathrm{CH}_{3} \mathrm{ONO}-\mathrm{NO}$-air mixtures at atmospheric pressure. The concentrations of ethyl nitrate and 2-methylpropane (the reference organic) were measured by $\mathrm{GC}$, and the measured rate coefficient ratio is placed on an absolute basis by use of a rate coefficient of $k(\mathrm{HO}+2$-methylpropane $)=2.12 \times 10^{-12} \mathrm{~cm}^{3}$ molecule $^{-1} \mathrm{~s}^{-1}$ (Atkinson, 2003).

(f) Relative rate method. $\mathrm{HO}$ radicals were generated by the photolysis of $\mathrm{O}_{3}-\mathrm{H}_{2} \mathrm{O}-\mathrm{O}_{2}$ mixtures at atmospheric pressure at $\sim 290-310 \mathrm{~nm}$. The concentrations of ethyl nitrate and the reference compounds ethane and 2-methylpropane were measured by GC. The measured rate coefficient ratios are placed on an absolute basis by use of rate coefficients of $k(\mathrm{HO}+$ ethane $)=6.9 \times 10^{-12} \exp (-1000 / T) \mathrm{cm}^{3}$ molecule ${ }^{-1} \mathrm{~s}^{-1}$ and $k(\mathrm{HO}+2$-methylpropane $)=1.17 \times 10^{-17} T^{2} \exp (213 / T) \mathrm{cm}^{3}$ molecule $\mathrm{e}^{-1} \mathrm{~s}^{-1}$ (Atkinson, 2003; IUPAC, current recommendation). The cited rate coefficient is the unweighted average with a two standard deviation error limit. 


\section{Preferred Values}

$k=1.8 \times 10^{-13} \mathrm{~cm}^{3}$ molecule ${ }^{-1} \mathrm{~s}^{-1}$ at $298 \mathrm{~K}$.

$k=6.7 \times 10^{-13} \exp (-395 / T) \mathrm{cm}^{3}$ molecule ${ }^{-1} \mathrm{~s}^{-1}$ over the temperature range $230-300 \mathrm{~K}$.

\section{Reliability}

$\Delta \log k= \pm 0.3$ at $298 \mathrm{~K}$.

$\Delta(E / R)= \pm 400 \mathrm{~K}$.

\section{Comments on Preferred Values}

There are serious discrepancies between the absolute and relative rate studies of Kerr and Stocker (1986) and Nielsen et al. (1991) carried out at $\sim 1$ bar total pressure and the absolute rate and the relative rate studies of Talukdar et al. (1997) and Kakesu et al. (1997), respectively, in both the room temperature rate coefficient (Nielsen et al., 1991; Talukdar et al., 1997; Kerr and Stocker, 1986; Kakesu et al., 1997) and the temperature dependence (Nielsen et al., 1991; Talukdar et al., 1997). The positive temperature-dependence observed by Talukdar et al. (1997) is supported, qualitatively, by the low-pressure absolute rate study of Shallcross et al. (1997), although the rate coefficients of Shallcross et al. (1997) are a factor of $\sim 1.8$ higher than those of Talukdar et al. (1997). The reasons for these discrepancies are not known, but we favor the results of the extensive Talukdar et al. (1997) study which are consistent with H- (or D-) atom abstraction. The study of Talukdar et al. (1997) showed no effect of total pressure, diluent gas [ranging from $67 \mathrm{mbar}$ (50 Torr) of He to $267 \mathrm{mb}$ (200 Torr) of $\mathrm{SF}_{6}$ or 400 mbar (300 Torr) $\mathrm{N}_{2}$ ] or the presence or absence of $\mathrm{O}_{2}$ at a partial pressure of 67 mbar (50 Torr) on the measured rate coefficients.

While the study of Talukdar et al. (1997) was not carried out in air at 1 bar pressure, the data obtained strongly suggest that the rate coefficient is consistent with an $\mathrm{H}$-atom abstraction process and that the measured rate coefficients should be appropriate for atmospheric purposes. The Arrhenius plots of the HO and DO radical reactions exhibit significant curvature (Talukdar et al., 1997). The preferred values are based on a unit-weighted least-squares fit of the 233-298 K rate coefficients of Talukdar et al. (1997) to the Arrhenius expression, $k=A \exp (-B / T)$. Large uncertainty limits are assigned because of the discrepancies between the various studies (Kakesu et al., 1997; Kerr and Stocker, 1986; Nielsen et al., 1991; Shallcross et al., 1997; Talukdar et al., 1997) noted above. Further absolute rate studies conducted at atmospheric pressure of air are required.

\section{References}

Atkinson, R.: J. Phys. Chem. Ref. Data, 26, 215, 1997.

Atkinson, R.: Atmos. Chem. Phys., 3, 2233, 2003.

IUPAC: http://www.iupac-kinetic.ch.cam.ac.uk/.

Kakesu, M., Bandow, H., Takenaka, H., Maeda, Y., and Washida, N.: Int. J. Chem. Kinet., 29, 933, 1997.

Kerr, J. A. and Stocker, D. W.: J. Atmos. Chem., 4, 253, 1986.

Nielsen, O. J., Sidebottom, H. W., Donlon, M., and Treacy, J.: Chem. Phys. Lett., 178, 163, 1991.

Shallcross, D. E., Biggs, P., Canosa-Mas, C. E., Clemitshaw, K. C., Harrison, M. G., Reyes López Alañón, M., Pyle, J. A., Vipond, A., and Wayne, R. P.: J. Chem. Soc. Faraday Trans., 93, 2807, 1997.

Talukdar, R. K., Herndon, S. C., Burkholder, S. B., Roberts, J. M., and Ravishankara, A. R.: J. Chem. Soc. Faraday Trans., 93, 2787, 1997. 
II.A2.42

$$
\mathrm{HO}+1-\mathrm{C}_{3} \mathrm{H}_{7} \mathrm{ONO}_{2} \rightarrow \text { products }
$$

\section{Rate coefficient data}

\begin{tabular}{|c|c|c|c|}
\hline$k / \mathrm{cm}^{3}$ molecule $^{-1} \mathrm{~s}^{-1}$ & Temp./K & Reference & Technique/Comments \\
\hline $\begin{array}{l}\text { Absolute Rate Coefficients } \\
5.0 \times 10^{-13} \exp [(140 \pm 144) / T] \\
(8.2 \pm 0.8) \times 10^{-13}\end{array}$ & $\begin{array}{l}298-368 \\
298 \pm 2\end{array}$ & Nielsen et al., 1991 & PR-RA (a) \\
\hline $\begin{array}{l}\text { Relative Rate Coefficients } \\
(7.2 \pm 2.3) \times 10^{-13} \\
(5.8 \pm 1.0) \times 10^{-13} \\
(7.0 \pm 0.8) \times 10^{-13}\end{array}$ & $\begin{array}{l}303 \pm 2 \\
298 \pm 2 \\
298 \pm 2\end{array}$ & $\begin{array}{l}\text { Kerr and Stocker, } 1986 \\
\text { Atkinson and Aschmann, } 1989 \\
\text { Nielsen et al., } 1991\end{array}$ & $\begin{array}{l}\text { RR (b) } \\
\text { RR (c) } \\
\text { RR (d) }\end{array}$ \\
\hline
\end{tabular}

\section{Comments}

(a) Carried out in 1 bar Ar.

(b) HO radicals were generated by the photolysis of HONO-air mixtures at atmospheric pressure. The decay rates of 1-propyl nitrate and ethene (the reference organic) were measured by GC and rate coefficient ratio $k(\mathrm{HO}+1$-propyl nitrate $) / k(\mathrm{HO}$ + ethene $)=0.086 \pm 0.027$ is placed on an absolute basis by use of a rate coefficient of $k(\mathrm{HO}+$ ethene $)=8.32 \times 10^{-12} \mathrm{~cm}^{3}$ molecule ${ }^{-1} \mathrm{~s}^{-1}$ at $303 \mathrm{~K}$ and atmospheric pressure of air (Atkinson, 1997).

(c) $\mathrm{HO}$ radicals were generated by the photolysis of $\mathrm{CH}_{3} \mathrm{ONO}$ at $\sim 1$ bar air at $>300 \mathrm{~nm}$. Experiments were carried out in a 6400 liter Teflon chamber. The concentrations of 1-propyl nitrate and cyclohexane (the reference organic) were measured by $\mathrm{GC}$, and irradiations in the absence of $\mathrm{CH}_{3} \mathrm{ONO}$ allowed the photolysis of 1-propyl nitrate to be accurately taken into account in the data analysis. The measured rate coefficient ratio of $k(\mathrm{HO}+1$-propyl nitrate $) / k(\mathrm{HO}+$ cyclohexane $)$ $=0.083 \pm 0.013$ is placed on an absolute basis by use of a rate coefficient of $k(\mathrm{HO}+$ cyclohexane $)=6.97 \times 10^{-12} \mathrm{~cm}^{3}$ molecule ${ }^{-1} \mathrm{~s}^{-1}$ at $298 \mathrm{~K}$ (Atkinson, 2003).

(d) $\mathrm{HO}$ radicals were generated from the photolysis of $\mathrm{CH}_{3} \mathrm{ONO}$ in 1 bar air at $>290 \mathrm{~nm}$. The concentrations of 1-propyl nitrate and 2-methylpropane (the reference organic) were measured by GC. The measured rate coefficient ratio $k(\mathrm{HO}$ +1 -propyl nitrate $) / k(\mathrm{HO}+2$-methylpropane $)$ is placed on an absolute basis by use of a rate coefficient of $k(\mathrm{HO}+2$ methylpropane) $=2.12 \times 10^{-12} \mathrm{~cm}^{3}$ molecule $\mathrm{s}^{-1} \mathrm{~s}^{-1}$ at $298 \mathrm{~K}$ (Atkinson, 2003).

\section{Preferred Values}

$k=5.8 \times 10^{-13} \mathrm{~cm}^{3}$ molecule ${ }^{-1} \mathrm{~s}^{-1}$ at $298 \mathrm{~K}$ and 1 bar air.

\section{Reliability}

$\Delta \log k= \pm 0.3$ at $298 \mathrm{~K}$.

\section{Comments on Preferred Values}

The absolute and relative rate coefficients of Kerr and Stocker (1986), Atkinson and Aschmann (1989) and Nielsen et al. (1991) are in reasonable agreement at room temperature. All studies have been carried out at $\sim 1$ bar pressure.

The absolute rate coefficient study of Talukdar et al. (1997) for the $\mathrm{HO}$ radical reactions with $\mathrm{CH}_{3} \mathrm{ONO}_{2}$ and $\mathrm{C}_{2} \mathrm{H}_{5} \mathrm{ONO}_{2}$ is in serious disagreement (by a factor of 13-16 for $\mathrm{CH}_{3} \mathrm{ONO}_{2}$ and a factor of 2.3-2.9 for $\mathrm{C}_{2} \mathrm{H}_{5} \mathrm{ONO}_{2}$ ) with the rate coefficients from the studies of Kerr and Stocker (1986) and Nielsen et al. (1991), while for 2- $\mathrm{C}_{3} \mathrm{H}_{7} \mathrm{ONO}_{2}$ the $298 \mathrm{~K}$ rate coefficients of Talukdar et al. (1997) and Atkinson and Aschmann (1989) disagree by 33\% (suggesting for one that the discrepancies decrease as the reactivity of the alkyl nitrate increases). Accordingly, the $298 \mathrm{~K}$ rate coefficient of Atkinson and Aschmann (1989) is 
used for the preferred value and no temperature dependence is recommended (note that by analogy with the reaction of the $\mathrm{OH}$ radical with 2-propyl nitrate (IUPAC, this evaluation), the temperature dependence of the rate coefficient is likely to be small). That 1-propyl nitrate is more reactive than 2-propyl nitrate is expected from structure-reactivity relationships (Atkinson and Aschmann, 1989) based on assuming that the reaction proceeds by H-atom abstraction, as concluded by Talukdar et al. (1997) for methyl nitrate, ethyl nitrate and 2-propyl nitrate.

\section{References}

Atkinson, R.: J. Phys. Chem. Ref. Data, 26, 215, 1997.

Atkinson, R.: Atmos. Chem. Phys., 3, 2233, 2003.

Atkinson, R. and Aschmann, S. M.: Int. J. Chem. Kinet., 21, 1123, 1989.

Kerr, J. A. and Stocker, D. W.: J. Atmos. Chem., 4, 253, 1986.

Nielsen, O. J., Sidebottom, H. W., Donlon, M., and Treacy, J.: Chem. Phys. Lett., 178, 163, 1991.

Talukdar, R. K., Herndon, S. C., Burkholder, J. B., Roberts, J. M., and Ravishankara, A. R.: J. Chem. Soc. Faraday Trans., 93, 2787, 1997. 
II.A2.43

$\mathrm{HO}+2-\mathrm{C}_{3} \mathrm{H}_{7} \mathrm{ONO}_{2} \rightarrow$ products

\section{Rate coefficient data}

\begin{tabular}{lllc}
\hline$k / \mathrm{cm}^{3}$ molecule ${ }^{-1} \mathrm{~s}^{-1}$ & Temp./K & Reference & Technique/Comments \\
\hline $\begin{array}{l}\text { Absolute Rate Coefficients } \\
4.3 \times 10^{-12} \exp (-1250 / T)\end{array}$ & $233-395$ & Talukdar et al., 1997 & PLP-LIF (a) \\
$+2.5 \times 10^{-13} \exp (-32 / T)$ & & & \\
$(2.88 \pm 0.19) \times 10^{-13}$ & 298 & & \\
& & & \\
Relative Rate Coefficients & & & RR (b) \\
$(1.68 \pm 0.42) \times 10^{-13}$ & $299 \pm 2$ & Atkinson et al., 1982 & RR (c) \\
$(5.3 \pm 2.1) \times 10^{-13}$ & $295 \pm 2$ & Becker and Wirtz, 1989 & RR (d) \\
$(3.83 \pm 0.49) \times 10^{-13}$ & $298 \pm 2$ & Atkinson and Aschmann, 1989 & \\
\hline
\end{tabular}

\section{Comments}

(a) Experiments were carried out as a function of total pressure and with different diluent gases (133 mbar He to $400 \mathrm{mbar}$ $\mathrm{SF}_{6}$ ) and with up to 80 mbar $\mathrm{O}_{2}$ present. No effect of pressure, diluent gas or presence or absence of $\mathrm{O}_{2}$ on the measured rate coefficients was observed. Rate coefficients for the reactions of $\mathrm{H}^{18} \mathrm{O}$ and DO radicals with 2-propyl nitrate were also measured over the temperature ranges $233-298 \mathrm{~K}$ and $230-403 \mathrm{~K}$, respectively, with $298 \mathrm{~K}$ rate coefficients of $(3.15 \pm 0.20) \times 10^{-13} \mathrm{~cm}^{3}$ molecule $\mathrm{s}^{-1} \mathrm{~s}^{-1}$ and $(3.6 \pm 0.4) \times 10^{-13} \mathrm{~cm}^{3}$ molecule $\mathrm{s}^{-1}$, respectively.

(b) $\mathrm{HO}$ radicals were generated from the photolysis of $\mathrm{CH}_{3} \mathrm{ONO}$ in $\sim 1$ bar air at $>300 \mathrm{~nm}$. Experiments were carried out in an $\sim 75$ liter Teflon chamber and concurrent photolysis of 2-propyl nitrate was indicated from the data analysis. The concentrations of 2-propyl nitrate and cyclohexane (the reference organic) were measured by GC. The measured rate coefficient ratio of $k(\mathrm{HO}+2$-propyl nitrate $/ k(\mathrm{HO}+$ cyclohexane $)=0.024 \pm 0.006$ is placed on an absolute basis by use of a rate coefficient of $k(\mathrm{HO}+$ cyclohexane $)=7.00 \times 10^{-12} \mathrm{~cm}^{3}$ molecule ${ }^{-1} \mathrm{~s}^{-1}$ at $299 \mathrm{~K}$ (Atkinson, 2003).

(c) $\mathrm{HO}$ radicals were generated from the photolysis of $\mathrm{CH}_{3} \mathrm{ONO}$ in 1 bar air at $280 \mathrm{~nm}$ to $450 \mathrm{~nm}$. Experiments were carried out in a 36.5 liter quartz chamber, and photolysis of 2-propyl nitrate was indicated from the data analysis. The concentrations of 2-propyl nitrate and $n$-butane (the reference organic) were measured by GC-MS and GC, respectively. The measured rate coefficient ratio of $k(\mathrm{HO}+2$-propyl nitrate $) / k(\mathrm{HO}+n$-butane $)=0.23 \pm 0.09$ is placed on an absolute basis by use of a rate coefficient of $k\left(\mathrm{HO}+n\right.$-butane) $=2.30 \times 10^{-12} \mathrm{~cm}^{3}$ molecule ${ }^{-1} \mathrm{~s}^{-1}$ at $295 \mathrm{~K}$ (IUPAC, current recommendation).

(d) $\mathrm{HO}$ radicals were generated by the photolysis of $\mathrm{CH}_{3} \mathrm{ONO}$ in $\sim 1$ bar air at $>300 \mathrm{~nm}$. Experiments were carried out in a 6400 liter Teflon chamber. The concentrations of 2-propyl nitrate and cyclohexane (the reference organic) were measured by $\mathrm{GC}$, and irradiations in the absence of $\mathrm{CH}_{3} \mathrm{ONO}$ allowed the photolysis of 2-propyl nitrate to be accurately taken into account in the data analysis. The measured rate coefficient ratio of $k(\mathrm{HO}+2$-propyl nitrate $) / k(\mathrm{HO}+$ cyclohexane $)$ $=0.055 \pm 0.007$ is placed on an absolute basis by use of a rate coefficient of $k(\mathrm{HO}+$ cyclohexane $)=6.97 \times 10^{-12} \mathrm{~cm}^{3}$ molecule $\mathrm{s}^{-1}$ at $298 \mathrm{~K}$ (Atkinson, 2003). This study supersedes the earlier study of Atkinson et al. (1982).

\section{Preferred Values}

$k=2.9 \times 10^{-13} \mathrm{~cm}^{3}$ molecule ${ }^{-1} \mathrm{~s}^{-1}$ at $298 \mathrm{~K}$.

$k=6.2 \times 10^{-13} \exp (-230 / T) \mathrm{cm}^{3}$ molecule $\mathrm{s}^{-1} \mathrm{~s}^{-1}$ over the temperature range $230-300 \mathrm{~K}$.

\section{Reliability}

$\Delta \log k= \pm 0.2$ at $298 \mathrm{~K}$.

$\Delta(E / R)= \pm 300 \mathrm{~K}$. 


\section{Comments on Preferred Values}

The preferred values are based on the absolute $233-300 \mathrm{~K}$ rate coefficients of Talukdar et al. (1997). The extensive study of Talukdar et al. (1997) provided no evidence for the rate coefficient $k$ to depend on total pressure, nature of the diluent gas, or the presence of $\mathrm{O}_{2}$ at pressures up to $80 \mathrm{mbar}(60 \mathrm{Torr})$. Additionally, the use of DO radicals showed no evidence for the formation of $\mathrm{HO}$ radicals as a reaction product. However, as noted in the data sheets for the reactions of the $\mathrm{HO}$ radical with $\mathrm{CH}_{3} \mathrm{ONO}_{2}$ and $\mathrm{C}_{2} \mathrm{H}_{5} \mathrm{ONO}_{2}$, the experiments of Talukdar et al. (1997) were not actually carried out in air at 1 bar total pressure.

Arrhenius plots of the rate coefficients for the reactions of $\mathrm{HO}, \mathrm{H}^{18} \mathrm{O}$ and DO radicals with 2-propyl nitrate exhibit significant curvature (especially pronounced for the DO radical reaction for which the measured rate coefficient was independent of temperature over the range $230-269 \mathrm{~K}$ ). The measured temperature dependencies at around $298 \mathrm{~K}$ and below are quite small. The room temperature relative rate coefficient of Atkinson and Aschmann (1989) (which supersedes the earlier data of Atkinson et al., 1982) is 33\% higher than the recommended $298 \mathrm{~K}$ rate coefficient, which may be considered reasonable agreement because of the low rate coefficient (on the low end of those reported by that research group) and hence small fraction of 2-propyl nitrate reacted during the experiments. The relative rate coefficient of Becker and Wirtz (1989) is almost a factor of 2 higher than the recommendations, but has high cited uncertainties.

We attach rather large uncertainties to the recommended values of the $298 \mathrm{~K}$ rate coefficient and $E / R$ until the data of Talukdar et al. (1997) are confirmed by absolute techniques in air at 1 bar pressure.

\section{References}

Atkinson, R.: Atmos. Chem. Phys., 3, 2233, 2003.

Atkinson, R. and Aschmann, S. M.: Int. J. Chem. Kinet., 21, 1123, 1989.

Atkinson, R., Aschmann, S. M., Carter, W. P. L., and Winer, A. M.: Int. J. Chem. Kinet., 14, 919, 1982.

Becker, K. H. and Wirtz, K.: J. Atmos. Chem., 9, 419, 1989.

IUPAC: http://www.iupac-kinetic.ch.cam.ac.uk/.

Talukdar, R. K., Herndon, S. C., Burkholder, J. B., Roberts, J. M., and Ravishankara, A. R.: J. Chem. Soc. Faraday Trans., 93, 2787, 1997. 
II.A2.44

$$
\mathrm{HO}+1-\mathrm{C}_{4} \mathrm{H}_{9} \mathrm{ONO}_{2} \rightarrow \text { products }
$$

\section{Rate coefficient data}

\begin{tabular}{|c|c|c|c|}
\hline$k / \mathrm{cm}^{3}$ molecule $^{-1} \mathrm{~s}^{-1}$ & Temp./K & Reference & Technique/Comments \\
\hline $\begin{array}{l}\text { Absolute Rate Coefficients } \\
(1.74 \pm 0.19) \times 10^{-12}\end{array}$ & $298 \pm 2$ & Nielsen et al., 1991 & PR-RA (a) \\
\hline Relative Rate Coefficients & & & \\
\hline$(1.31 \pm 0.10) \times 10^{-12}$ & $299 \pm 2$ & Atkinson et al., 1982 & $\mathrm{RR}(\mathrm{b}, \mathrm{c})$ \\
\hline$(1.65 \pm 0.18) \times 10^{-12}$ & $298 \pm 2$ & Atkinson and Aschmann, 1989 & $\mathrm{RR}(\mathrm{b}, \mathrm{d})$ \\
\hline$(1.47 \pm 0.08) \times 10^{-12}$ & $298 \pm 2$ & Nielsen et al., 1991 & $\mathrm{RR}(\mathrm{b}, \mathrm{e})$ \\
\hline
\end{tabular}

\section{Comments}

(a) Carried out at a total pressure of 1 bar Ar.

(b) $\mathrm{HO}$ radicals were generated by the photolysis of $\mathrm{CH}_{3} \mathrm{ONO}$ in air at atmospheric pressure (0.97 bar to 1.0 bar). The concentrations of 1-butyl nitrate and the reference organic were measured by GC.

(c) The measured rate coefficient ratio of $k(\mathrm{HO}+1$-butyl nitrate $) / k(\mathrm{HO}+$ cyclohexane $)=0.187 \pm 0.014$ is placed on an absolute basis by use of a rate coefficient of $k\left(\mathrm{HO}+\right.$ cyclohexane) $=7.00 \times 10^{-12} \mathrm{~cm}^{3}$ molecule $\mathrm{s}^{-1}$ at $299 \mathrm{~K}$ (Atkinson, 2003). Experiments were carried out in an $\sim 75$ liter Teflon chamber, and the data were interpreted as involving concurrent photolysis of 1-butyl nitrate.

(d) Experiments were carried out in a 6400 liter Teflon chamber, and irradiations were also carried out in the absence of $\mathrm{CH}_{3} \mathrm{ONO}$, allowing the photolysis rate to be accurately allowed for in the data analysis. The measured rate coefficient ratio of $k(\mathrm{HO}+1$-butyl nitrate $) / k(\mathrm{HO}+$ cyclohexane $)=0.237 \pm 0.025$ is placed on an absolute basis by use of a rate coefficient of $k(\mathrm{HO}+$ cyclohexane $)=6.97 \times 10^{-12} \mathrm{~cm}^{-3}$ molecule ${ }^{-1} \mathrm{~s}^{-1}$ at $298 \mathrm{~K}$ (Atkinson, 2003). These data supersede those of Atkinson et al. (1982).

(e) The measured rate coefficient ratio $k(\mathrm{HO}+1$-butyl nitrate $) / k(\mathrm{HO}+2$-methylpropane $)$ is placed on an absolute basis by use of a rate coefficient of $k(\mathrm{HO}+2$-methylpropane $)=2.12 \times 10^{-12} \mathrm{~cm}^{3}$ molecule ${ }^{-1} \mathrm{~s}^{-1}$ at $298 \mathrm{~K}$ (Atkinson, 2003).

\section{Preferred Values}

$k=1.6 \times 10^{-12} \mathrm{~cm}^{3}$ molecule ${ }^{-1} \mathrm{~s}^{-1}$ at $298 \mathrm{~K}$.

\section{Reliability}

$\Delta \log k= \pm 0.2$ at $298 \mathrm{~K}$.

\section{Comments on Preferred Values}

The absolute and relative rate coefficients of Atkinson and Aschmann (1989) (which supersedes the earlier data of Atkinson, 1982) and Nielsen et al. (1991) are in good agreement. The preferred value is an average of the absolute and relative rate constants of Atkinson and Aschmann (1989) and Nielsen et al. (1991). By analogy with the reaction of the HO radical with 2-propyl nitrate (this evaluation), the temperature dependence of the rate coefficient at temperatures below $300 \mathrm{~K}$ is likely to be small. 


\section{References}

Atkinson, R.: Atmos. Chem. Phys., 3, 2233, 2003.

Atkinson, R. and Aschmann, S. M.: Int. J. Chem. Kinet., 21, 1123, 1989.

Atkinson, R., Aschmann, S. M., Carter, W. P. L., and Winer, A. M.: Int. J. Chem. Kinet., 14, 919, 1982.

Nielsen, O. J., Sidebottom, H. W., Donlon, M., and Treacy, J.: Chem. Phys. Lett., 178, 163, 1991. 
II.A2.45

$$
\mathrm{HO}+2-\mathrm{C}_{4} \mathrm{H}_{9} \mathrm{ONO}_{2} \rightarrow \text { products }
$$

\section{Rate coefficient data}

\begin{tabular}{llll}
\hline$k / \mathrm{cm}^{3}$ molecule & & Technique/Comments \\
\hline Relative Rate Coefficients & Temp./K & Reference & \\
$(6.4 \pm 1.0) \times 10^{-13}$ & & & $\mathrm{RR}(\mathrm{a}, \mathrm{b})$ \\
$(8.6 \pm 1.5) \times 10^{-13}$ & $299 \pm 2$ & Atkinson et al., 1982 & $\mathrm{RR}(\mathrm{a}, \mathrm{c})$ \\
\hline
\end{tabular}

\section{Comments}

(a) $\mathrm{HO}$ radicals were generated by the photolysis of $\mathrm{CH}_{3} \mathrm{ONO}$ in one atmosphere of air. The concentrations of 2-butyl nitrate and the reference organic were measured by GC.

(b) Experiments were carried out in an $\sim 75$ liter Teflon chamber, and the data were interpreted as involving concurrent photolysis of 2-butyl nitrate. The measured rate constant ratio of $k(\mathrm{HO}+2$-butyl nitrate $) / k(\mathrm{HO}+$ cyclohexane $)=0.091 \pm 0.013$ is placed on an absolute basis by use of a rate coefficient of $k(\mathrm{HO}+$ cyclohexane $)=7.00 \times 10^{-12} \mathrm{~cm}^{3}$ molecule $\mathrm{s}^{-1}$ at 299 K (Atkinson, 2003).

(c) Experiments were carried out in a 6400 liter Teflon chamber, and irradiations were also carried out in the absence of $\mathrm{CH}_{3}$ ONO allowing the photolysis rate to be accurately allowed for in the data analysis. The measured rate coefficient ratio of $k(\mathrm{HO}+2$-butyl nitrate $) / k(\mathrm{HO}+$ cyclohexane $)=0.123 \pm 0.021$ is placed on an absolute basis by use of a rate coefficient of $k(\mathrm{HO}+$ cyclohexane $)=6.97 \times 10^{-12} \mathrm{~cm}^{3}$ molecule ${ }^{-1} \mathrm{~s}^{-1}$ at $298 \mathrm{~K}$ (Atkinson, 2003). These data supersede those of Atkinson et al. (1982).

\section{Preferred Values}

$k=8.6 \times 10^{-13} \mathrm{~cm}^{3}$ molecule ${ }^{-1} \mathrm{~s}^{-1}$ at $298 \mathrm{~K}$.

\section{Reliability}

$\Delta \log k= \pm 0.3$ at $298 \mathrm{~K}$.

\section{Comments on Preferred Values}

The preferred value is based on the rate coefficient of Atkinson and Aschmann (1989), which supersedes the earlier study of Atkinson et al. (1982). By analogy with the reaction of the HO radical with 2-propyl nitrate (this evaluation), the temperature dependence of the rate coefficient at temperatures below $300 \mathrm{~K}$ is likely to be small.

\section{References}

Atkinson, R.: Atmos. Chem. Phys., 3, 2233, 2003.

Atkinson, R. and Aschmann, S. M.: Int. J. Chem. Kinet., 21, 1123, 1989.

Atkinson, R., Aschmann, S. M., Carter, W. P. L., and Winer, A. M.: Int. J. Chem. Kinet., 14, 919, 1982. 
II.A2.46

$$
\mathrm{HO}+\mathrm{CH}_{3} \mathrm{C}(\mathrm{O}) \mathrm{OONO}_{2} \rightarrow \text { products }
$$

\section{Rate coefficient data}

\begin{tabular}{lllc}
\hline$k / \mathrm{cm}^{3}$ molecule ${ }^{-1} \mathrm{~s}^{-1}$ & Temp./K & Reference & Technique/Comments \\
\hline $\begin{array}{l}\text { Absolute Rate Coefficients } \\
\leq 1.7 \times 10^{-13}\end{array}$ & $299 \pm 1$ & Winer et al., 1977 & FP-RF \\
$1.23 \times 10^{-12} \exp [-(651 \pm 229) / T]$ & $273-297$ & Wallington et al., 1984 & FP-RF \\
$(1.37 \pm 0.05) \times 10^{-13}$ & $297 \pm 2$ & & \\
$(7.5 \pm 1.4) \times 10^{-14}$ & $298 \pm 2$ & Tsalkani et al., 1988 & DF-EPR \\
$<3.0 \times 10^{-14}$ & 298 & Talukdar et al., 1995 & FP/PLP-LIF (a) \\
\hline
\end{tabular}

\section{Comments}

(a) Experiments were carried out over the temperature range 253-298 K, using pulsed laser photolysis of $\mathrm{HONO}$ at $355 \mathrm{~nm}$, pulsed laser photolysis of $\mathrm{O}_{3}-\mathrm{H}_{2} \mathrm{O}$ mixtures at $266 \mathrm{~nm}$, or flash photolysis of $\mathrm{H}_{2} \mathrm{O}$ at $165-185 \mathrm{~nm}$ to generate $\mathrm{HO}$ radicals. The measured $\mathrm{HO}$ radical decay rates corresponded to rate coefficients in the range $(0.82-2.50) \times 10^{-14} \mathrm{~cm}^{3}$ molecule ${ }^{-1}$ $\mathrm{s}^{-1}$ with no obvious dependence on temperature. The measured $\mathrm{HO}$ radical decay rates were attributed to the reaction of $\mathrm{HO}$ radicals with $\mathrm{HCHO}$ impurity, and a conservative upper limit to the rate coefficient $k$ was cited (see table).

\section{Preferred Values}

$k<3 \times 10^{-14} \mathrm{~cm}^{3}$ molecule ${ }^{-1} \mathrm{~s}^{-1}$ at $298 \mathrm{~K}$.

\section{Comments on Preferred Values}

The preferred upper limit to the $298 \mathrm{~K}$ rate coefficient is the upper limit reported by Talukdar et al. (1995) from an extensive and careful study. The higher rate coefficients measured by Wallington et al. (1984) and Tsalkani et al. (1988) were almost certaintly due to the presence of reactive impurities.

\section{References}

Talukdar, R. K., Burkholder, J. B., Schmoltner, A.-M., Roberts, J. M., Wilson, R. R., and Ravishankara, A. R.: J. Geophys. Res., 100, 14 163, 1995.

Tsalkani, N., Mellouki, A., Poulet, G., Toupance, G., and Le Bras, G.: J. Atmos. Chem., 7, 409, 1988.

Wallington, T. J., Atkinson, R., and Winer, A. M.: Geophys. Res. Lett., 11, 861, 1984.

Winer, A. M., Lloyd, A. C., Darnall, K. R., Atkinson, R., and Pitts Jr., J. N.: Chem. Phys. Lett., 51, 221, 1977. 
II.A2.47

$$
\mathrm{HO}+\mathrm{CH}_{3} \mathrm{C}(\mathrm{O}) \mathrm{CH}_{2} \mathrm{ONO}_{2} \rightarrow \text { products }
$$

\section{Rate coefficient data}

\begin{tabular}{|c|c|c|c|}
\hline$k / \mathrm{cm}^{3}$ molecule ${ }^{-1} \mathrm{~s}^{-1}$ & Temp./K & Reference & Technique/Comments \\
\hline $\begin{array}{l}\text { Relative Rate Coefficients } \\
<4.0 \times 10^{-13}\end{array}$ & $298 \pm 2$ & Zhu et al., 1991 & RR (a) \\
\hline
\end{tabular}

\section{Comments}

(a) $\mathrm{HO}$ radicals were generated by the photolysis of $\mathrm{CH}_{3} \mathrm{ONO}-\mathrm{NO}-\mathrm{N}_{2}-\mathrm{O}_{2}$ mixtures at 1 bar pressure. The concentrations of $\mathrm{CH}_{3} \mathrm{C}(\mathrm{O}) \mathrm{CH}_{2} \mathrm{ONO}_{2}$ and $n$-butane were measured during the experiments by $\mathrm{GC}$, and the measured rate constant ratio of $k\left(\mathrm{HO}+\mathrm{CH}_{3} \mathrm{C}(\mathrm{O}) \mathrm{CH}_{2} \mathrm{ONO}_{2}\right) / k(\mathrm{HO}+n$-butane $)<0.17$ is placed on an absolute basis by use of a rate coefficient of $k(\mathrm{HO}$ $+n$-butane $)=2.3 \times 10^{-12} \mathrm{~cm}^{3}$ molecule ${ }^{-1} \mathrm{~s}^{-1}$ (IUPAC, current recommendation).

\section{Preferred Values}

$k<1 \times 10^{-12} \mathrm{~cm}^{3}$ molecule ${ }^{-1} \mathrm{~s}^{-1}$ at $298 \mathrm{~K}$.

\section{Comments on Preferred Values}

The preferred value is based on the sole study of Zhu et al. (1991), but with a higher upper limit to reflect additional uncertainties.

\section{References}

IUPAC: http://www.iupac-kinetic.ch.cam.ac.uk/.

Zhu, T., Barnes, I., and Becker, K. H.: J. Atmos. Chem., 13, 301, 1991. 
II.A2.48

$$
\mathrm{HO}+\mathrm{CH}_{3} \mathrm{CH}_{2} \mathrm{C}(\mathrm{O}) \mathrm{CH}_{2} \mathrm{ONO}_{2} \rightarrow \text { products }
$$

\section{Rate coefficient data}

\begin{tabular}{|c|c|c|c|}
\hline $\mathrm{k} / \mathrm{cm}^{3}$ molecule $^{-1} \mathrm{~s}^{-1}$ & Temp./K & Reference & Technique/Comments \\
\hline $\begin{array}{l}\text { Relative Rate Coefficients } \\
(8.21 \pm 1.38) \times 10^{-13}\end{array}$ & $298 \pm 2$ & Zhu et al., 1991 & $\mathrm{RR}$ (a) \\
\hline
\end{tabular}

\section{Comments}

(a) $\mathrm{HO}$ radicals were generated by the photolysis of $\mathrm{CH}_{3} \mathrm{ONO}-\mathrm{NO}-\mathrm{N}_{2}-\mathrm{O}_{2}$ mixtures at 1 bar pressure. The concentrations of $\mathrm{CH}_{3} \mathrm{CH}_{2} \mathrm{C}(\mathrm{O}) \mathrm{CH}_{2} \mathrm{ONO}_{2}$ and $n$-butane were measured during the experiments by $\mathrm{GC}$, and the measured rate constant ratio of $k\left(\mathrm{HO}+\mathrm{CH}_{3} \mathrm{CH}_{2} \mathrm{C}(\mathrm{O}) \mathrm{CH}_{2} \mathrm{ONO}_{2}\right) / k(\mathrm{HO}+n$-butane $)=0.357 \pm 0.060$ is placed on an absolute basis by use of a rate coefficient of $k(\mathrm{HO}+n$-butane $)=2.3 \times 10^{-12} \mathrm{~cm}^{3}$ molecule ${ }^{-1} \mathrm{~s}^{-1}$ (IUPAC, current recommendation).

\section{Preferred Values}

$k=8.2 \times 10^{-13} \mathrm{~cm}^{3}$ molecule ${ }^{-1} \mathrm{~s}^{-1}$ at $298 \mathrm{~K}$.

\section{Reliability}

$\Delta \log k= \pm 0.3$ at $298 \mathrm{~K}$.

\section{Comments on Preferred Values}

The preferred value is based on the sole study of Zhu et al. (1991) but with a higher uncertainty.

\section{References}

IUPAC: http://www.iupac-kinetic.ch.cam.ac.uk/.

Zhu, T., Barnes, I., and Becker, K. H.: J. Atmos. Chem., 13, 301, 1991. 
II.A2.49

$$
\mathrm{HO}+\mathrm{CH}_{3} \mathrm{CH}\left(\mathrm{ONO}_{2}\right) \mathrm{C}(\mathrm{O}) \mathrm{CH}_{3} \rightarrow \text { products }
$$

\section{Rate coefficient data}

\begin{tabular}{|c|c|c|c|}
\hline$k / \mathrm{cm}^{3}$ molecule ${ }^{-1} \mathrm{~s}^{-1}$ & Temp./K & Reference & Technique/Comments \\
\hline $\begin{array}{l}\text { Relative Rate Coefficients } \\
(1.15 \pm 0.13) \times 10^{-12}\end{array}$ & $298 \pm 2$ & Zhu et al., 1991 & RR (a) \\
\hline
\end{tabular}

\section{Comments}

(a) $\mathrm{HO}$ radicals were generated by the photolysis of $\mathrm{CH}_{3} \mathrm{ONO}-\mathrm{NO}-\mathrm{N}_{2}-\mathrm{O}_{2}$ mixtures at 1 bar pressure. The concentrations of $\mathrm{CH}_{3} \mathrm{CH}\left(\mathrm{ONO}_{2}\right) \mathrm{C}(\mathrm{O}) \mathrm{CH}_{3}$ and $n$-butane were measured during the experiments by $\mathrm{GC}$, and the measured rate constant ratio of $k\left(\mathrm{HO}+\mathrm{CH}_{3} \mathrm{CH}\left(\mathrm{ONO}_{2}\right) \mathrm{C}(\mathrm{O}) \mathrm{CH}_{3}\right) / k(\mathrm{HO}+n$-butane $)=0.499 \pm 0.056$ is placed on an absolute basis by use of a rate coefficient of $k(\mathrm{HO}+n$-butane $)=2.3 \times 10^{-12} \mathrm{~cm}^{3}$ molecule ${ }^{-1} \mathrm{~s}^{-1}$ (IUPAC, current recommendation).

\section{Preferred Values}

$k=1.2 \times 10^{-12} \mathrm{~cm}^{3}$ molecule ${ }^{-1} \mathrm{~s}^{-1}$ at $298 \mathrm{~K}$.

\section{Reliability}

$\Delta \log k= \pm 0.3$ at $298 \mathrm{~K}$.

\section{Comments on Preferred Values}

The preferred value is based on the sole study of Zhu et al. (1991) but with a higher uncertainty.

\section{References}

IUPAC: http://www.iupac-kinetic.ch.cam.ac.uk/.

Zhu, T., Barnes, I., and Becker, K. H.: J. Atmos. Chem., 13, 301, 1991. 
II.A2.50

$$
\mathrm{HO}+\mathrm{CH}_{2}=\mathrm{C}\left(\mathrm{CH}_{3}\right) \mathrm{C}(\mathrm{O}) \mathrm{OONO}_{2}(\mathrm{MPAN}) \rightarrow \text { products }
$$

\section{Rate coefficient data}

\begin{tabular}{lllc}
\hline$k / \mathrm{cm}^{3}$ molecule ${ }^{-1} \mathrm{~s}^{-1}$ & Temp./K & Reference & Technique/Comments \\
\hline Relative Rate Coefficients & & & \\
$(3.33 \pm 0.40) \times 10^{-12}$ & $298 \pm 2$ & Grosjean et al., 1993 & RR (a) \\
$(3.76 \pm 0.58) \times 10^{-11}$ & $275 \pm 3$ & Orlando et al., 2002 & RR (b,c) \\
$(2.88 \pm 0.46) \times 10^{-11}$ & $275 \pm 3$ & Orlando et al., 2002 & RR (b,d) \\
\hline
\end{tabular}

\section{Comments}

(a) Relative rate method carried out at atmospheric pressure of air. HO radicals were generated by the photolysis (using natural sunlight) of ethyl nitrite-air mixtures, and the concentrations of $\mathrm{CH}_{2}=\mathrm{C}\left(\mathrm{CH}_{3}\right) \mathrm{C}(\mathrm{O}) \mathrm{OONO}_{2}$ (MPAN) and 1-butyl nitrate (the reference compound) were measured by GC with electron capture detection. The measured rate coefficient ratio of $k(\mathrm{HO}+\mathrm{MPAN}) / k(\mathrm{HO}+1$-butyl nitrate $)=2.08 \pm 0.25$ is placed on an absolute basis by use of a rate coefficient of $k(\mathrm{HO}+1$-butyl nitrate $)=1.6 \times 10^{-12} \mathrm{~cm}^{3}$ molecule ${ }^{-1} \mathrm{~s}^{-1}$ at $298 \mathrm{~K}$ (IUPAC, current recommendation).

(b) Relative rate method carried out in synthetic air at $0.93-0.97$ bar. $\mathrm{HO}$ radicals were generated by the photolysis of ethyl nitrite-NO-air mixtures, and the concentrations of $\mathrm{CH}_{2}=\mathrm{C}\left(\mathrm{CH}_{3}\right) \mathrm{C}(\mathrm{O}) \mathrm{OONO}_{2}(\mathrm{MPAN})$ and ethene and propene (the reference compounds) were measured by in situ FTIR spectroscopy. Experiments were carried out at $275 \pm 3 \mathrm{~K}$ to decrease the rate of thermal decomposition of MPAN (IUPAC, current recommendation) in the presence of NO. The measured rate coefficient ratios of $k(\mathrm{HO}+\mathrm{MPAN}) / k(\mathrm{HO}+$ ethene $)=3.9 \pm 0.6$ and $k(\mathrm{HO}+\mathrm{MPAN}) / k(\mathrm{HO}+$ propene $)=$ $0.95 \pm 0.15$ are placed on an absolute basis by use of rate coefficients at $275 \mathrm{~K}$ and atmospheric pressure of air of $k(\mathrm{HO}+$ ethene $)=9.64 \times 10^{-12} \mathrm{~cm}^{3}$ molecule ${ }^{-1} \mathrm{~s}^{-1}$ and $k\left(\mathrm{HO}+\right.$ propene) $=3.03 \times 10^{-11} \mathrm{~cm}^{3}$ molecule $\mathrm{s}^{-1} \mathrm{~s}^{-1}$ (Atkinson, 1997).

(c) Relative to $\mathrm{HO}+$ ethene.

(d) Relative to $\mathrm{HO}+$ propene.

\section{Preferred Values}

$k=2.9 \times 10^{-11} \mathrm{~cm}^{3}$ molecule $\mathrm{e}^{-1} \mathrm{~s}^{-1}$ at $298 \mathrm{~K}$.

\section{Reliability}

$\Delta \log k={ }_{-0.5}^{+0.2}$ at $298 \mathrm{~K}$.

\section{Comments on Preferred Values}

The rate coefficients measured in the two studies of Grosjean et al. (1993) and Orlando et al. (2002) disagree by a factor of $\sim 10$, for reasons which are not known. The reaction of $\mathrm{HO}$ radicals with $\mathrm{CH}_{2}=\mathrm{C}\left(\mathrm{CH}_{3}\right) \mathrm{C}(\mathrm{O}) \mathrm{OONO}_{2}$ is expected to proceed almost exclusively by initial $\mathrm{HO}$ radical addition to the $\mathrm{C}=\mathrm{C}$ bond (Grosjean et al., 1993; Orlando et al., 2002), and is expected to have a small (and probably negative) temperature dependence at around room temperature. Support for the Orlando et al. (2002) study arises from the structurally similar compound $\mathrm{CH}_{2}=\mathrm{C}\left(\mathrm{CH}_{3}\right) \mathrm{C}(\mathrm{O}) \mathrm{OCH}_{3}$ having a rate coefficient for its $\mathrm{HO}$ radical reaction of $(2.6 \pm 0.5) \times 10^{-11} \mathrm{~cm}^{3}$ molecule $\mathrm{s}^{-1} \mathrm{~s}^{-1}$ at $298 \mathrm{~K}$ (Saunders et al., 1994), which is similar to that measured by Orlando et al. (2002) for HO + MPAN. Accordingly, the preferred value is based on the rate coefficients measured by Orlando et al. (2002) at $275 \mathrm{~K}$, adjusted to $298 \mathrm{~K}$ using the temperature dependence observed for HO + propene (Atkinson, 1997), and with appropriately large and asymmetric uncertainties. Formaldehyde and hydroxyacetone have been observed as products of this reaction (Grosjean et al., 1993; Orlando et al., 2002). 


\section{References}

Atkinson, R.: J. Phys. Chem. Ref. Data, 26, 215, 1997.

Grosjean, D., Williams II, E. L., and Grosjean, E.: Int. J. Chem. Kinet., 25, 921, 1993.

IUPAC: http://www.iupac-kinetic.ch.cam.ac.uk/.

Orlando, J. J., Tyndall, G. S., Bertman, S. B., Chen, W., and Burkholder, J. B.: Atmos. Environ., 36, $1895,2002$.

Saunders, S. M., Baulch, D. L., Cooke, K. M., Pilling, M. J., and Smurthwaite, P. I.: Int. J. Chem. Kinet., $26,113,1994$. 
II.A2.51

$$
\mathrm{HO}+\mathrm{HCN} \rightarrow \text { products }
$$

\section{Rate coefficient data}

\begin{tabular}{|c|c|c|c|}
\hline$k / \mathrm{cm}^{3}$ molecule ${ }^{-1} \mathrm{~s}^{-1}$ & Temp./K & Reference & Technique/Comments \\
\hline $\begin{array}{l}\text { Absolute Rate Coefficients } \\
1.2 \times 10^{-13} \exp (-400 / T) \\
(3.0 \pm 1.0) \times 10^{-14}\end{array}$ & $\begin{array}{l}296-433 \\
298\end{array}$ & Fritz et al., 1984 & FP-RA (a) \\
\hline
\end{tabular}

\section{Comments}

(a) The measured rate coefficients were observed to be pressure dependent over the range $\sim 13-600$ mbar $(\sim 10-450$ Torr $)$ of $\mathrm{N}_{2}$ diluent. The cited rate coefficients are those extrapolated to the high-pressure limit $\left(k_{\infty}\right)$ using a simple Lindemann extrapolation.

\section{Preferred Values}

$k=3 \times 10^{-14} \mathrm{~cm}^{3}$ molecule ${ }^{-1} \mathrm{~s}^{-1}$ at $298 \mathrm{~K}$ and 1 bar.

$k=1.2 \times 10^{-13} \exp (-400 / T) \mathrm{cm}^{3}$ molecule $\mathrm{e}^{-1} \mathrm{~s}^{-1}$ over the temperature range $290-440 \mathrm{~K}$ at $1 \mathrm{bar}$.

\section{Reliability}

$\Delta \log k= \pm 0.5$ at $298 \mathrm{~K}$.

$\Delta(E / R)= \pm 300 \mathrm{~K}$.

\section{Comments on Preferred Values}

The preferred values are those of Fritz et al. (1984) with wider error limits. The rate coefficient increases with increasing pressure over this temperature range, and the rate coefficients cited are those extrapolated by Fritz et al. (1984) to the highpressure limit.

The reaction proceeds by HO radical addition over this temperature range. At higher temperatures the available rate coefficient data indicate a direct abstraction reaction (Atkinson, 1989).

\section{References}

Atkinson, R.: J. Phys. Chem. Ref. Data, Monograph, 1, 1, 1989.

Fritz, B., Lorenz, K., Steinert, W., and Zellner, R.: Oxid. Comm., 6, 363, 1984. 
II.A2.52

$$
\mathrm{HO}+\mathrm{CH}_{3} \mathrm{CN} \rightarrow \text { products }
$$

\section{Rate coefficient data}

\begin{tabular}{lllc}
\hline$k / \mathrm{cm}^{3}$ molecule & & Technique/Comments \\
\hline $\begin{array}{l}\text { Relative Rate Coefficients } \\
(2.1 \pm 0.3) \times 10^{-14}\end{array}$ & Temp./K & Reference & \\
$(8.6 \pm 1) \times 10^{-14}$ & $295 \pm 2$ & Poulet et al., 1984 & DF-EPR \\
$6.28 \times 10^{-13} \exp (-1030 / T)$ & 393 & & \\
$(1.94 \pm 0.37) \times 10^{-14}$ & $250-363$ & Kurylo and Knable, 1984 & FP-RF \\
$\left.1.1 \times 10^{-12} \exp [-(1130 \pm 90) / T)\right]$ & 298 & & \\
$(2.48 \pm 0.38) \times 10^{-14}$ & $256-388$ & Hynes and Wine, 1991 & PLP-LIF (a) \\
\hline
\end{tabular}

\section{Comments}

(a) No definitive evidence for a pressure dependence of the rate coefficient for the $\mathrm{HO}+\mathrm{CH}_{3} \mathrm{CN}$ reaction was observed over the pressure range 61-933 mbar (46-700 Torr) of $\mathrm{N}_{2}$ diluent or 40-840 mbar (30-630 Torr) of He diluent. In the presence of $\mathrm{O}_{2}$, the $\mathrm{HO}$ radical decays were non-exponential indicating regeneration of $\mathrm{HO}$ radicals.

\section{Preferred Values}

$k=2.2 \times 10^{-14} \mathrm{~cm}^{3}$ molecule $\mathrm{s}^{-1}$ at $298 \mathrm{~K}(1 \mathrm{bar})$.

$k=8.1 \times 10^{-13} \exp (-1080 / T) \mathrm{cm}^{3}$ molecule ${ }^{-1} \mathrm{~s}^{-1}$ over the temperature range $250-390 \mathrm{~K}$ at $1 \mathrm{bar}$.

\section{Reliability}

$\Delta \log k= \pm 0.15$ at $298 \mathrm{~K}$.

$\Delta(E / R)= \pm 200 \mathrm{~K}$.

\section{Comments on Preferred Values}

The preferred $298 \mathrm{~K}$ rate coefficient is a unit-weighted average of the rate coefficients of Poulet et al. (1984), Kurylo and Knable (1984) and Hynes and Wine (1991). The temperature dependence is the mean of those determined by Kurylo and Knable (1984) and Hynes and Wine (1991). Hynes and Wine (1991) observed no definitive evidence for a pressure dependence of the rate coefficient for the $\mathrm{HO}+\mathrm{CH}_{3} \mathrm{CN}$ reaction in $\mathrm{N}_{2}$ or He diluent over the pressure ranges 61-933 mbar (46-700 Torr) or 40-840 mbar (30-630 Torr), respectively. In the presence of $\mathrm{O}_{2}$, the $\mathrm{HO}$ radical decays were non-exponential (Hynes and Wine, 1991), indicating regeneration of HO radicals. Combined with analogous data for the reactions of HO radicals with $\mathrm{CD}_{3} \mathrm{CN}$ (for which the rate coefficient was pressure dependent over the pressure range 53-923 mbar (40-692 Torr) of $\mathrm{N}_{2}$ diluent) (Hynes and Wine, 1991) and of DO radicals with $\mathrm{CH}_{3} \mathrm{CN}$ and $\mathrm{CD}_{3} \mathrm{CN}$ (Hynes and Wine, 1991), it appears that the initial $\mathrm{HO}$ radical reaction proceeds by $\mathrm{H}$-atom abstraction from the $\mathrm{CH}_{3}$ group and $\mathrm{HO}$ radical addition to the $\mathrm{CN}$ group (Hynes and Wine, 1991).

$$
\begin{array}{ll}
\mathrm{HO}+\mathrm{CH}_{3} \mathrm{CN} & \rightarrow \mathrm{H}_{2} \mathrm{O}+\mathrm{CH}_{2} \mathrm{CN} \\
\mathrm{HO}+\mathrm{CH}_{3} \mathrm{CN} & \rightarrow\left[\mathrm{CH}_{3} \mathrm{CNOH}\right]^{\ddagger}
\end{array}
$$

Subsequent reactions of the addition adduct in the presence of $\mathrm{O}_{2}$ then lead to the regeneration of $\mathrm{HO}$ radicals. In view of the possibility of a pressure dependence of the $298 \mathrm{~K}$ rate coefficient at low total pressures (Hynes and Wine, 1991) $(\leq 0.1$ bar), the preferred values are applicable to atmospheric conditions.

Tyndall et al. (2001) have observed the formation of formyl cyanide, $\mathrm{HC}(\mathrm{O}) \mathrm{CN}$, from reaction of $\mathrm{HO}$ radicals with $\mathrm{CH}_{3} \mathrm{CN}$ at atmospheric pressure of synthetic air using FTIR spectroscopy, and a formation yield of $\mathrm{HC}(\mathrm{O}) \mathrm{CN}$ of $40 \pm 20 \%$ was obtained. The details of the reaction mechanism, including that for formation of $\mathrm{HC}(\mathrm{O}) \mathrm{CN}$, are presently not known. 


\section{References}

Hynes, A. J. and Wine, P. H.: J. Phys. Chem., 95, 1232, 1991.

Kurylo, M. J. and Knable, G. L.: J. Phys. Chem., 88, 3305, 1984.

Poulet, G., Laverdet, G., Jourdain, J. L., and Le Bras, G.: J. Phys. Chem., 88, 6259, 1984.

Tyndall, G. S., Orlando, J. J., Wallington, T. J., and Hurley, M. D.: J. Phys. Chem. A, 105, 5380, 2001. 


\section{Appendix A2a: HOx + VOC continued reactions}

\section{II.A2a.53}

$$
\begin{aligned}
\mathrm{HO}_{2}+\mathrm{CH}_{3} \mathrm{O}_{2} & \rightarrow \mathrm{O}_{2}+\mathrm{CH}_{3} \mathrm{OOH} \\
& \rightarrow \mathrm{O}_{2}+\mathrm{HCHO}+\mathrm{H}_{2} \mathrm{O}
\end{aligned}
$$

$$
\begin{aligned}
& \Delta H^{\circ}(1)=-155 \mathrm{~kJ} \cdot \mathrm{mol}^{-1} \\
& \Delta H^{\circ}(2)=-374 \mathrm{~kJ} \cdot \mathrm{mol}^{-1}
\end{aligned}
$$

Rate coefficient data $\left(k=k_{1}+k_{2}\right)$

\begin{tabular}{lllc}
\hline$k / \mathrm{cm}^{3}$ molecule ${ }^{-1} \mathrm{~s}^{-1}$ & Temp./K & Reference & Technique/Comments \\
\hline Absolute Rate Coefficients & & & \\
$7.7 \times 10^{-14} \exp [(1296 \pm 364) / T]$ & $274-338$ & Cox and Tyndall, 1980 & MM-AS (a) \\
$(6.5 \pm 1.0) \times 10^{-12}$ & 298 & & \\
$(5.4 \pm 1.1) \times 10^{-12}$ & 300 & Jenkin et al., 1988 & MM-IR-AS (b) \\
$3.0 \times 10^{-13} \exp [(720 \pm 100) T]$ & $228-380$ & Dagaut et al., 1988 & FP-AS (c) \\
$(2.9 \pm 0.4) \times 10^{-12}$ & 298 & & \\
$(4.8 \pm 0.2) \times 10^{-12}$ & 300 & Moortgat et al., 1989 & MM-IR-AS (d) \\
$4.4 \times 10^{-13} \exp [(780 \pm 55) / T]$ & $248-573$ & Lightfoot et al., 1990 & FP-AS (e) \\
$(6.2 \pm 1.0) \times 10^{-12}$ & 298 & & \\
$\left.2.9 \times 10^{-13} \exp (862 \pm 44) / T\right]$ & $248-700$ & Lightfoot et al., 1991 & FP-AS (f) \\
$(5.13 \pm 0.55) \times 10^{-12}$ & 298 & Boyd et al., 2003 & PLP-AS (g) \\
Branching Ratios & & & \\
$k_{1} / k=0.92 \pm 0.05$ & 295 & Wallington and Japar, 1990; & P-FTIR (h) \\
$k_{2} / k=1 /[1+498 \exp (-1160 / T)]$ & $218-298$ & Wallington, 1991 & \\
$k_{2} / k=0.11 \pm 0.02$ & 298 & & DF-CIMS (i) \\
\hline
\end{tabular}

\section{Comments}

(a) $\mathrm{MM}$ study of photolysis of $\mathrm{Cl}_{2}$ in the presence of $\mathrm{CH}_{4}-\mathrm{H}_{2}-\mathrm{O}_{2}$ mixtures at 1013 mbar (760 Torr) pressure. $\mathrm{CH}_{3} \mathrm{O}_{2}$ and $\mathrm{HO}_{2}$ radicals were monitored by absorption at $250 \mathrm{~nm}$ and $210 \mathrm{~nm}$, respectively.

(b) $\mathrm{MM}$ study of photolysis of $\mathrm{Cl}_{2}$ in the presence of $\mathrm{CH}_{4}-\mathrm{H}_{2} \mathrm{O}_{2}-\mathrm{O}_{2}$ mixtures. $\mathrm{HO}_{2}$ radicals were monitored by IR absorption with a tunable diode laser and $\mathrm{CH}_{3} \mathrm{O}_{2}$ monitored by UV absorption at $260 \mathrm{~nm} . \sigma\left(\mathrm{CH}_{3} \mathrm{O}_{2}\right)=3.53 \times 10^{-18} \mathrm{~cm}^{2}$ molecule ${ }^{-1}$ was determined at $260 \mathrm{~nm}$. $k$ determined from observed perturbation of the second-order kinetics of the $\mathrm{HO}_{2}$ radical selfreaction by the presence of $\mathrm{CH}_{3} \mathrm{O}_{2}$ in large excess. Experiments were carried out at a total pressure of $13 \mathrm{mbar}$ (10 Torr). Similar experiments on mixtures of $\mathrm{Cl}_{2}-\mathrm{H}_{2}-\mathrm{CH}_{4}-\mathrm{O}_{2}$ were performed at $1013 \mathrm{mbar}$ ( 760 Torr) total pressure and $303 \mathrm{~K}$ and yielded $k=(6.8 \pm 0.9) \times 10^{-12} \mathrm{~cm}^{3}$ molecule ${ }^{-1} \mathrm{~s}^{-1}$, which was taken as confirmation of the value obtained at $13 \mathrm{mbar}$ (10 Torr).

(c) FP-UV absorption study involving $\mathrm{Cl}_{2}-\mathrm{CH}_{3} \mathrm{OH}-\mathrm{CH}_{4}-\mathrm{O}_{2}-\mathrm{N}_{2}$ mixtures at total pressures of 133 mbar (100 Torr); $\sigma\left(\mathrm{HO}_{2}\right)$ and $\sigma\left(\mathrm{CH}_{3} \mathrm{O}_{2}\right)$ were determined over the wavelength range $215 \mathrm{~nm}$ to $280 \mathrm{~nm}$. At $250 \mathrm{~nm} \sigma\left(\mathrm{CH}_{3} \mathrm{O}_{2}\right)=3.3 \times 10^{-18} \mathrm{~cm}^{2}$ molecule ${ }^{-1}$ was determined. First- or second-order kinetics conditions were not obtainable for either $\mathrm{HO}_{2}$ or $\mathrm{CH}_{3} \mathrm{O}_{2}$ and $k$ was determined from computer modeling of the absorption decay curves.

(d) Study of the photooxidation of $\mathrm{CH}_{3} \mathrm{CHO}$ at $933 \mathrm{mbar}$ (700 Torr), with double multipath spectrometer, combining both IR and UV absorption spectrometry for monitoring reactants and products, together with modulated photolysis for transient detection. Transient absorptions were assigned to peroxy radicals and the rate coefficient was obtained from kinetic analysis by computer simulation. 
(e) FP-UV absorption study of $\mathrm{Cl}_{2}-\mathrm{CH}_{3} \mathrm{OH}-\mathrm{CH}_{4}-\mathrm{O}_{2}-\mathrm{N}_{2}$ mixtures at pressures of $160 \mathrm{mbar}$ or $1013 \mathrm{mbar}$ (120 Torr or 760 Torr). Revised cross-section data were used, $\sigma\left(\mathrm{HO}_{2}\right)=5.3 \times 10^{-18} \mathrm{~cm}^{2}$ molecule ${ }^{-1}$ at $210 \mathrm{~nm}$ and $\sigma\left(\mathrm{CH}_{3} \mathrm{O}_{2}\right)=$ $3.6 \times 10^{-18} \mathrm{~cm}^{2}$ molecule ${ }^{-1}$ at $260 \mathrm{~nm}$.

(f) FP-UV absorption study of $\mathrm{Cl}_{2}-\mathrm{CH}_{3} \mathrm{OH}-\mathrm{CH}_{4}-\mathrm{O}_{2}-\mathrm{N}_{2}$ mixtures at 1013 mbar (760 Torr) and over the temperature range $600 \mathrm{~K}$ to $719 \mathrm{~K}$. The temperature-dependent rate coefficient listed above was derived by the authors from a re-analysis of all of their data, including previous studies from flash photolysis experiments.

(g) PLP-UV absorption study of $\mathrm{H}_{2} \mathrm{O}_{2}-\mathrm{CH}_{4}-\mathrm{O}_{2}-\mathrm{N}_{2}$ mixtures at 1013 mbar (760 Torr) and $298 \mathrm{~K}$. Conditions were chosen such that $\mathrm{HO}_{2}$ was in excess, with initial concentration ratios $\left[\mathrm{HO}_{2}\right] /\left[\mathrm{CH}_{3} \mathrm{O}_{2}\right]$ in the range 4-10. $k$ was determined from simulation of transient decay traces recorded at $270 \mathrm{~nm}$ and either $210 \mathrm{~nm}$ or $220 \mathrm{~nm}$. The signal at $270 \mathrm{~nm}$ was dominated by $\mathrm{CH}_{3} \mathrm{O}_{2}$ absorption, with its decay being almost entirely due to the reaction with $\mathrm{HO}_{2}$. The signal at $210 \mathrm{~nm}$ or $220 \mathrm{~nm}$ was mainly due to $\mathrm{HO}_{2}$ absorption, with its self-reaction making the major contribution to its removal.

(h) Photolysis of $\mathrm{F}_{2}$ in the presence of $\mathrm{CH}_{4}$ and $\mathrm{H}_{2}$ in synthetic air or $\mathrm{O}_{2}$ at total pressures in the range 20 mbar (15 Torr) to 933 mbar (700 Torr). $\mathrm{CH}_{3} \mathrm{OOH}, \mathrm{CH}_{4}$, and a number of minor products were monitored by FTIR.

(i) Turbulent fast-flow system operating at total pressures of $133 \mathrm{mbar}$ (100 Torr). $\mathrm{CH}_{3} \mathrm{O}_{2}$ was produced by reaction of $\mathrm{CH}_{4}$ with $\mathrm{F}$ atoms and subsequent addition of $\mathrm{O}_{2}$. The $\mathrm{CH}_{3} \mathrm{O}_{2}$ was mixed with $\mathrm{HO}_{2}$ produced by the $\mathrm{H}+\mathrm{O}_{2}+\mathrm{M}$ reaction. Concentrations of $\mathrm{CH}_{3} \mathrm{O}_{2}, \mathrm{CH}_{3} \mathrm{OOH}, \mathrm{CH}_{2} \mathrm{O}$, and $\mathrm{HO}_{2}$ were monitored by time-resolved CIMS. Values of $k_{2}$ were derived by detailed modelling of the $\left[\mathrm{CH}_{2} \mathrm{O}\right]$ profile. Values of the branching ratio are based on the NASA expression for $k$ (NASA Evaluation, 1997).

\section{Preferred Values}

$k=5.2 \times 10^{-12} \mathrm{~cm}^{3}$ molecule $\mathrm{e}^{-1} \mathrm{~s}^{-1}$ at $298 \mathrm{~K}$.

$k=3.8 \times 10^{-13} \exp (780 / T) \mathrm{cm}^{3}$ molecule $\mathrm{e}^{-1} \mathrm{~s}^{-1}$ over the temperature range $225-580 \mathrm{~K}$.

$k_{2} / k=0.1$ at $298 \mathrm{~K}$.

$k_{2} / k=1 /[1+498 \exp (-1160 / T)]$ over the temperature range $220-300 \mathrm{~K}$.

\section{Reliability}

$\Delta \log k= \pm 0.3$ at $298 \mathrm{~K}$.

$\Delta(E / R)= \pm 500 \mathrm{~K}$.

$\Delta\left(k_{2} / k\right)= \pm 0.1$ at $298 \mathrm{~K}$.

$\Delta\left(E_{2} / R-E / R\right)= \pm 500 \mathrm{~K}$.

\section{Comments on Preferred Values}

The discrepancies in the data for this reaction, due in part to the different values of the UV absorption cross sections used in various studies, remain unresolved.

The preferred rate coefficient at $298 \mathrm{~K}$ is the mean of the values of Cox and Tyndall (1980), Jenkin et al. (1988), Dagaut et al. (1988), Moortgat et al. (1989), Lightfoot et al. (1990) and Boyd et al. (2003). The recommended temperature coefficient is that reported by Lightfoot et al. (1991), selected on the basis of their wider range of temperatures than previous studies (Cox and Tyndall, 1980; Dagaut et al., 1988). The A-factor was then adjusted to fit the preferred value of $k$ at $298 \mathrm{~K}$.

The studies of Kurylo et al. (1987), Jenkin et al. (1988) and Lightfoot et al. (1990) show that the room temperature rate coefficient is independent of pressure over the range 13 mbar to $1013 \mathrm{mbar}$ (10 Torr to 760 Torr).

The most direct studies of the branching ratio are those of Wallington and Japar (1990), Wallington (1991) and Elrod et al. (2001). These studies confirm that the contribution of channel (2) is small at $298 \mathrm{~K}\left(k_{2} / k \approx 0.1\right)$, supporting the earlier findings of Jenkin et al. (1988), Moortgat et al. (1989) and Lightfoot et al. (1991). The only information on the temperature dependence of the branching ratio comes from the study of Elrod et al. (2001) and suggests that it increases significantly in going to lower temperatures, reaching a value of $k_{2} / k \approx 0.31$ at $218 \mathrm{~K}$. Provisionally the expression for $k_{2} / k$ derived by Elrod et al. (2001) is accepted with substantial error limits until confirmatory studies on both the temperature and pressure dependence are available. 


\section{References}

Boyd, A. A., Flaud, P.-M., Daugey, M., and Lesclaux, R.: J. Phys. Chem. A, 107, 818, 2003.

Cox, R. A. and Tyndall, G. S.: J. Chem. Soc. Faraday Trans., 2, 76, 153, 1980.

Dagaut, P., Wallington, T. J., and Kurylo, M. J.: J. Phys. Chem., 92, 3833, 1988.

Elrod, M. J., Ranschaert, D. L., and Schneider, N. J.: Int. J. Chem. Kinet., 33, 363, 2001.

Jenkin, M. E., Cox, R. A., Hayman, G. D., and Whyte, L. J.: J. Chem. Soc. Faraday Trans., 2, 84, 913, 1988.

Kurylo, M. J., Dagaut, P., Wallington, T. J., and Neuman, D. M.: Chem. Phys. Lett., 139, 513, 1987.

Lightfoot, P. D., Veyret, B., and Lesclaux, R.: J. Phys. Chem., 94, 708, 1990.

Lightfoot, P.D., Roussel, P., Caralp, F., and Lesclaux, R.: J. Chem. Soc. Faraday Trans., 87, 3213, 1991.

Moortgat, G. K., Cox, R. A., Schuster, G., Burrows, J. P., and Tyndall, G. S.: J. Chem. Soc. Faraday Trans., 2, 85, 809, 1989.

NASA, Evaluation No. 12, 1997.

Wallington, T. J.: J. Chem. Soc. Faraday Trans., 87, 2379, 1991.

Wallington, T. J. and Japar, S. M.: Chem. Phys. Lett., 167, 513, 1990. 
II.A2a.54

$$
\begin{aligned}
\mathrm{HO}_{2}+\mathrm{HOCH}_{2} \mathrm{O}_{2} & \rightarrow \mathrm{O}_{2}+\mathrm{HOCH}_{2} \mathrm{O}_{2} \mathrm{H} \\
& \rightarrow \mathrm{O}_{2}+\mathrm{HC}(\mathrm{O}) \mathrm{OH}+\mathrm{H}_{2} \mathrm{O}
\end{aligned}
$$

$\Delta H^{\circ}(2)=-473.1 \mathrm{~kJ} \cdot \mathrm{mol}^{-1}$

Rate coefficient data $\left(k=k_{1}+k_{2}\right)$

\begin{tabular}{lllc}
\hline$k / \mathrm{cm}^{3}$ molecule $\mathrm{s}^{-1}$ & Temp./K & Reference & Technique/Comments \\
\hline Absolute Rate Coefficients & & & \\
$5.6 \times 10^{-15} \exp [(2300 \pm 1100) / T]$ & $275-333$ & Veyret et al., 1989 & FP-AS (a) \\
$(1.2 \pm 0.4) \times 10^{-11}$ & 295 & & \\
$(1.2 \pm 0.3) \times 10^{-11}$ & 298 & Burrows et al., 1989 & MM-IR (b) \\
& & & \\
Branching Ratios & 298 & Burrows et al., 1989 & MM-IR (c) \\
$k_{2} / k=0.40 \pm 0.15$ & & & \\
\hline
\end{tabular}

\section{Comments}

(a) Flash photolysis of $\mathrm{Cl}_{2}$ in the presence of $\mathrm{HCHO}$ or $\mathrm{CH}_{3} \mathrm{OH}$ and $\mathrm{O}_{2}$ at total pressures of $110 \mathrm{mbar}$ to $230 \mathrm{mbar}$ (85 Torr to 170 Torr), with time-resolved absorption spectroscopy detection of $\mathrm{HO}_{2}$ and $\mathrm{HOCH}_{2} \mathrm{O}_{2}$ radicals. The rate coefficient $k$ was obtained from a computer simulation of the absorption profiles based on a mechanism of nine elementary reactions.

(b) $\mathrm{MM}$ study of $\mathrm{Cl}_{2}-\mathrm{HCHO}-\mathrm{O}_{2}$ mixtures at total pressures of $930 \mathrm{mbar}$ (700 Torr), with diode laser IR spectroscopy detection of $\mathrm{HO}_{2}$ and $\mathrm{HOCH}_{2} \mathrm{O}_{2}$ radicals. The rate coefficient $k$ was obtained from a computer simulation of $\left[\mathrm{HO}_{2}\right]$ absorption profiles based on a mechanism of eight elementary reactions.

(c) Same experimental system as for comment (b). The branching ratio was determined from a computer simulation of the quantum yields of $\mathrm{HC}(\mathrm{O}) \mathrm{OH}$ formation.

\section{Preferred Values}

$k=1.2 \times 10^{-11} \mathrm{~cm}^{3}$ molecule $\mathrm{e}^{-1} \mathrm{~s}^{-1}$ at $298 \mathrm{~K}$.

$k=5.6 \times 10^{-15} \exp (2300 / T) \mathrm{cm}^{3}$ molecule ${ }^{-1} \mathrm{~s}^{-1}$ over the temperature range $275-335 \mathrm{~K}$.

$k_{2} / k=0.4$ at $298 \mathrm{~K}$.

\section{Reliability}

$\Delta \log k= \pm 0.3$ at $298 \mathrm{~K}$.

$\Delta(E / R)= \pm 1500 \mathrm{~K}$

$\Delta\left(k_{2} / k\right)=0.4$ at $298 \mathrm{~K}$.

\section{Comments on Preferred Values}

The two studies (Veyret et al., 1989; Burrows et al., 1989) of the rate coefficient at $298 \mathrm{~K}$ are in good agreement and confirm that this reaction is fast compared with the $\mathrm{HO}_{2}$ radical reactions with $\mathrm{CH}_{3} \mathrm{O}_{2}$ and $\mathrm{C}_{2} \mathrm{H}_{5} \mathrm{O}_{2}$ radicals. The reaction is presumed to proceed via a six-membered cyclic intermediate, analogous to that proposed for the formation of $\mathrm{HCHO}, \mathrm{CH}_{3} \mathrm{OH}$ and $\mathrm{O}_{2}$ from the interaction of $\mathrm{CH}_{3} \mathrm{O}_{2}$ radicals (Jenkin et al., 1988). Both the temperature dependence and the branching ratio require independent confirmation. In addition, there is the possibility that the rate coefficient could be both pressure and bath-gas dependent. 


\section{References}

Burrows, J. P., Moortgat, G. K., Tyndall, G. S., Cox, R. A., Jenkin, M. E., Hayman, G. D., and Veyret, B.: J. Phys. Chem., 93, $2375,1989$.

Jenkin, M. E., Cox, R. A., Hayman, G. D., and Whyte, L. J.: J. Chem. Soc. Faraday Trans., 2, 84, 913, 1988.

Veyret, B., Lesclaux, R., Rayez, M.-T., Rayez, J.-C., Cox, R. A., and Moortgat, G. K.: J. Phys. Chem., 93, 2368, 1989. 
II.A2a.55

$$
\mathrm{HO}_{2}+\mathrm{C}_{2} \mathrm{H}_{5} \mathrm{O}_{2} \rightarrow \mathrm{O}_{2}+\mathrm{C}_{2} \mathrm{H}_{5} \mathrm{OOH}
$$

$\Delta H^{\circ}=-159 \mathrm{~kJ} \cdot \mathrm{mol}^{-1}$

\section{Rate coefficient data}

\begin{tabular}{lllc}
\hline $\mathrm{k} / \mathrm{cm}^{3}$ molecule ${ }^{-1} \mathrm{~s}^{-1}$ & Temp./K & Reference & Technique/Comments \\
\hline $\begin{array}{l}\text { Absolute Rate Coefficients } \\
(6.3 \pm 0.9) \times 10^{-12}\end{array}$ & 295 & Cattell et al., 1986 & MM-IR-AS (a) \\
$5.6 \times 10^{-13} \exp [(650 \pm 125) / T]$ & $248-380$ & Dagaut et al., 1988 & FP-AS (b) \\
$(5.3 \pm 1.0) \times 10^{-12}$ & 298 & & \\
$1.6 \times 10^{-13} \exp [(1260 \pm 130) / T]$ & $248-480$ & Fenter et al., 1993 & FP-AS (c) \\
$(1.10 \pm 0.21) \times 10^{-11}$ & 298 & & \\
$6.9 \times 10^{-13} \exp [(702 \pm 69) / T]$ & $210-363$ & Maricq and Szente, 1994 & FP-AS (d) \\
$(8.3 \pm 1.5) \times 10^{-12}$ & 295 & & \\
$(8.14 \pm 0.38) \times 10^{-12}$ & 298 & Boyd et al., 2003 & PLP-AS (e) \\
\hline
\end{tabular}

\section{Comments}

(a) $\mathrm{MM}$ spectrometry system with $\mathrm{HO}_{2}$ and $\mathrm{C}_{2} \mathrm{H}_{5} \mathrm{O}_{2}$ radicals generated simultaneously by photolysis of $\mathrm{Cl}_{2}$ in the presence of $\mathrm{C}_{2} \mathrm{H}_{6}-\mathrm{CH}_{3} \mathrm{OH}-\mathrm{O}_{2}-\mathrm{N}_{2}$ mixtures at pressures of $3.2 \mathrm{mbar}$ (2.4 Torr). $\mathrm{HO}_{2}$ radicals were monitored by IR absorption with a tunable diode laser and $\mathrm{C}_{2} \mathrm{H}_{5} \mathrm{O}_{2}$ radicals were monitored by $\mathrm{UV}$ absorption at $260 \mathrm{~nm}$. The rate coefficient, $k$, was determined from the observed perturbation of the second-order kinetics of the $\mathrm{HO}_{2}$ self-reaction when $\mathrm{C}_{2} \mathrm{H}_{5} \mathrm{O}_{2}$ was present in large excess, and shown to be essentially independent of pressure over the range 3.2 mbar to $1013 \mathrm{mbar}$ (2.4 Torr to 760 Torr).

(b) Flash photolysis of $\mathrm{Cl}_{2}$ in the presence of $\mathrm{C}_{2} \mathrm{H}_{6}-\mathrm{CH}_{3} \mathrm{OH}-\mathrm{O}_{2}-\mathrm{N}_{2}$ mixtures at total pressures of 33 mbar to 533 mbar (25 Torr to 400 Torr). Composite transient absorption decay curves for $\mathrm{HO}_{2}$ and $\mathrm{C}_{2} \mathrm{H}_{5} \mathrm{O}_{2}$ radicals were measured at $230 \mathrm{~nm}$, $250 \mathrm{~nm}$ and $280 \mathrm{~nm}$. Kinetic analysis derived from computer modeling of experimental data.

(c) FP-UV absorption study of $\mathrm{Cl}_{2}-\mathrm{C}_{2} \mathrm{H}_{6}-\mathrm{O}_{2}-\mathrm{N}_{2}$ mixtures at 1013 mbar (760 Torr) total pressure. Rate coefficients were derived from simultaneous computer analyses of several decay curves collected at different wavelengths.

(d) FP-UV absorption study of $\mathrm{F}_{2}-\mathrm{H}_{2}-\mathrm{C}_{2} \mathrm{H}_{6}-\mathrm{O}_{2}-\mathrm{N}_{2}$ mixtures at a total pressure of $\sim 270$ mbar ( $\sim 200$ Torr). Rate coefficients were derived from computer simulation of time-resolved decay curves.

(e) PLP-UV absorption study of $\mathrm{H}_{2} \mathrm{O}_{2}-\mathrm{C}_{2} \mathrm{H}_{6}-\mathrm{O}_{2}-\mathrm{N}_{2}$ mixtures at $1013 \mathrm{mbar}$ (760 Torr) and $298 \mathrm{~K}$. Conditions were chosen such that $\mathrm{HO}_{2}$ was in excess, with initial concentration ratios $\left[\mathrm{HO}_{2}\right] /\left[\mathrm{C}_{2} \mathrm{H}_{5} \mathrm{O}_{2}\right]$ in the range 4-10. $k$ was determined from simulation of transient decay traces recorded at $270 \mathrm{~nm}$ and either $210 \mathrm{~nm}$ or $220 \mathrm{~nm}$. The signal at $270 \mathrm{~nm}$ was dominated by $\mathrm{C}_{2} \mathrm{H}_{5} \mathrm{O}_{2}$ absorption, with its decay being almost entirely due to the reaction with $\mathrm{HO}_{2}$. The signal at $210 \mathrm{~nm}$ or $220 \mathrm{~nm}$ was mainly due to $\mathrm{HO}_{2}$ absorption, with its self-reaction making the major contribution to its removal.

\section{Preferred Values}

$k=7.8 \times 10^{-12} \mathrm{~cm}^{3}$ molecule $\mathrm{e}^{-1} \mathrm{~s}^{-1}$ at $298 \mathrm{~K}$.

$k=3.8 \times 10^{-13} \exp (900 / T) \mathrm{cm}^{3}$ molecule ${ }^{-1} \mathrm{~s}^{-1}$ over the temperature range $200-500 \mathrm{~K}$.

\section{Reliability}

$\Delta \log k= \pm 0.2$ at $298 \mathrm{~K}$.

$\Delta(E / R)= \pm 400 \mathrm{~K}$. 


\section{Comments on Preferred Values}

The room temperature rate coefficients of Fenter et al. (1993), Maricq and Szente (1994) and Boyd et al. (2003) are in reasonable agreement with the previous direct studies of Cattell et al. (1986) and Dagaut et al. (1988). We have based our recommendations on the average value of $k_{298}$ from these five studies. However, the temperature coefficient of Fenter et al. (1993) is almost a factor of two higher than those of Dagaut et al. (1988) and Maricq and Szente (1994), indicating a systematic error in one or more of the studies. The rate coefficients determined in all of these studies depend upon the values of $\sigma\left(\mathrm{HO}_{2}\right)$ and $\sigma\left(\mathrm{C}_{2} \mathrm{H}_{5} \mathrm{O}_{2}\right)$, the latter of which is not well established. Clearly more work is needed on this reaction and in the meantime we recommend an $E / R$ value corresponding to the rounded-off mean of the three determinations (Dagaut et al., 1988; Fenter et al., 1993; Maricq and Szente, 1994), with relatively large error limits.

The FTIR spectroscopic product study of Wallington and Japar (1990) has shown that this reaction is dominated by a single channel at $298 \mathrm{~K}$, to yield $\mathrm{C}_{2} \mathrm{H}_{5} \mathrm{OOH}+\mathrm{O}_{2}$. The results of Spittler et al. (2000) and Hasson et al. (2004) have confirmed this, with the former study demonstrating that this continues to be the case over the temperature range $284 \mathrm{~K}$ to $312 \mathrm{~K}$.

\section{References}

Boyd, A. A., Flaud, P.-M., Daugey, M., and Lesclaux, R.: J. Phys. Chem. A, 107, 818, 2003.

Cattell, F. C., Cavanagh, J., Cox, R. A., and Jenkin, M. E.: J. Chem. Soc. Faraday Trans., 2, 82, 1999, 1986.

Dagaut, P., Wallington, T. J., and Kurylo, M. J.: J. Photochem. Photobiol., 48, 187, 1989.

Fenter, F. F., Catoire, V., Lesclaux, R., and Lightfoot, P. D.: J. Phys. Chem., 97, 3530, 1993.

Hasson, A. S., Tyndall, G. S., and Orlando, J. J.: J. Phys. Chem. A, 108, 5979, 2004.

Maricq, M. M. and Szente, J. J.: J. Phys. Chem., 98, 2078, 1994.

Spittler, M., Barnes, I., Becker, K. H., and Wallington, T. J.: Chem. Phys. Lett., 321, 57, 2000.

Wallington, T. J. and Japar, S. M.: Chem. Phys. Lett., 166, 495, 1990. 
II.A2a.56

$$
\begin{aligned}
\mathrm{HO}_{2}+\mathrm{CH}_{3} \mathrm{C}(\mathrm{O}) \mathrm{O}_{2} & \rightarrow \mathrm{O}_{2}+\mathrm{CH}_{3} \mathrm{C}(\mathrm{O}) \mathrm{OOH} \\
& \rightarrow \mathrm{O}_{3}+\mathrm{CH}_{3} \mathrm{C}(\mathrm{O}) \mathrm{OH} \\
& \rightarrow \mathrm{O}_{2}+\mathrm{OH}+\mathrm{CH} 3 \mathrm{C}(\mathrm{O}) \mathrm{O}
\end{aligned}
$$

$$
\begin{aligned}
& \Delta H^{\circ}(1)=-180 \mathrm{~kJ} \cdot \mathrm{mol}^{-1} \\
& \Delta H^{\circ}(2)=-132 \mathrm{~kJ} \cdot \mathrm{mol}^{-1} \\
& \Delta H^{\circ}(3)=-13 \mathrm{~kJ} \cdot \mathrm{mol}^{-1}
\end{aligned}
$$

Rate coefficient data $\left(k=k_{1}+k_{2}+k_{3}\right)$

\begin{tabular}{llll}
\hline$k / \mathrm{cm}^{3}$ molecule $\mathrm{s}^{-1}$ & Temp./K & Reference & Technique/Comments \\
\hline $\begin{array}{l}\text { Absolute Rate Coefficients } \\
4.3 \times 10^{-13} \exp [(1040 \pm 100) / T]\end{array}$ & $253-368$ & Moortgat et al., 1989 & FP-AS (a) \\
$(1.3 \pm 0.3) \times 10^{-11}$ & 298 & & \\
$3.9 \times 10^{-13} \exp [(1350 \pm 250) / T]$ & $269-363$ & Crawford et al., 1999 & PLP-IR-AS (b) \\
$(4.4 \pm 1.6) \times 10^{-11}$ & 297 & & \\
$6.4 \times 10^{-13} \exp [(925 \pm 120) / T]$ & $273-403$ & Tomas et al., 2001 & FP-AS (c) \\
$(1.51 \pm 0.07) \times 10^{-11}$ & 293 & & \\
& & & \\
Branching Ratios & 298 & Niki et al., 1985 & \\
$k_{1} / k \approx 0.75$ & & & FTIR (d) \\
$k_{2} / k \approx 0.25$ & $253-368$ & Moortgat et al., 1989 & \\
$k_{2} / k=0.33 \pm 0.07$ & $263-333$ & Horie and Moortgat, 1992 & FP-AS (e) \\
$k_{1} / k_{2}=3.3 \times 10^{2} \exp [(-1430 \pm 480 / T)]$ & FTIR (f) \\
$k_{1} / k_{2}=2.7$ & 298 & & PLP-FTIR (g) \\
$k_{2} / k=0.12 \pm 0.04$ & 295 & Crawford et al., 1999 & FP-AS (h) \\
$k_{2} / k=0.20 \pm 0.02$ & $298-373$ & Tomas et al., 2001 & UVP-FTIR/HPLC (i) \\
$k_{1} / k=0.40 \pm 0.16$ & 298 & Hasson et al., 2004 & \\
$k_{2} / k=0.20 \pm 0.08$ & 298 & & \\
$k_{3} / k=0.40 \pm 0.16$ & 298 & & \\
\hline
\end{tabular}

\section{Comments}

(a) Flash photolysis of $\mathrm{Cl}_{2}$ in the presence of $\mathrm{CH}_{3} \mathrm{CHO}-\mathrm{CH}_{3} \mathrm{OH}-\mathrm{N}_{2}$ mixtures at total pressures of 800 mbar to $866 \mathrm{mbar}$ (600 Torr to 650 Torr). $\left[\mathrm{CH}_{3} \mathrm{C}(\mathrm{O}) \mathrm{O}_{2}\right]$ was monitored by $\mathrm{UV}$ absorption over the wavelength range $195 \mathrm{~nm}$ to $280 \mathrm{~nm}$ and the absorption cross-section measured relative to $\sigma\left(\mathrm{HO}_{2}\right)=5.3 \times 10^{-18} \mathrm{~cm}^{2}$ molecule ${ }^{-1}$ at $210 \mathrm{~nm}$. Rate coefficients were derived from a computer simulation of absorption traces at a range of wavelengths, based on a mechanism including secondary removal of $\mathrm{CH}_{3} \mathrm{C}(\mathrm{O}) \mathrm{O}_{2}$. The mechanism assumed that the $\mathrm{CH}_{3} \mathrm{C}(\mathrm{O}) \mathrm{O}_{2}+\mathrm{HO}_{2}$ reaction proceeds by channels (1) and (2).

(b) Pulsed laser photolysis of $\mathrm{Cl}_{2}-\mathrm{CH}_{3} \mathrm{OH}-\mathrm{CH}_{3} \mathrm{CHO}-\mathrm{O}_{2}-\mathrm{N}_{2}$ mixtures at a total pressure of about 67 mbar (50 Torr). The progress of the reaction was followed by time-resolved UV absorption measurements over the range $200 \mathrm{~nm}$ to $300 \mathrm{~nm}$ and by monitoring $\left[\mathrm{HO}_{2}\right]$ by infrared laser diode absorption at $1117.5 \mathrm{~cm}^{-1}$. Because of the difficulty of deconvoluting the UV spectra, values of $k$ were determined from the infrared measurements by fitting the $\left[\mathrm{HO}_{2}\right]$ profiles using a detailed mechanism. The mechanism assumed that the $\mathrm{CH}_{3} \mathrm{C}(\mathrm{O}) \mathrm{O}_{2}+\mathrm{HO}_{2}$ reaction proceeds by channels (1) and (2).

(c) Flash photolysis of $\mathrm{Cl}_{2}-\mathrm{CH}_{3} \mathrm{CHO}-\mathrm{CH}_{3} \mathrm{OH}-\mathrm{O}_{2}-\mathrm{N}_{2}$ mixtures. The progress of the reaction was followed by time-resolved UV absorption measurements at $207 \mathrm{~nm}$ and $250 \mathrm{~nm}$. Values of $k$ were derived by simulation of the absorption measurements at $207 \mathrm{~nm}$, using a detailed chemical mechanism. The mechanism assumed that the $\mathrm{CH}_{3} \mathrm{C}(\mathrm{O}) \mathrm{O}_{2}+\mathrm{HO}_{2}$ reaction proceeds by channels (1) and (2). 
(d) FTIR study of irradiated $\mathrm{Cl}_{2}-\mathrm{HCHO}-\mathrm{CH}_{3} \mathrm{CHO}-\mathrm{O}_{2}$ mixtures. The branching ratio was based on the analysis of the products $\mathrm{CH}_{3} \mathrm{C}(\mathrm{O}) \mathrm{OOH}, \mathrm{CH}_{3} \mathrm{C}(\mathrm{O}) \mathrm{OH}$ and $\mathrm{O}_{3}$, with the assumption that the reaction proceeds via channels (1) and (2).

(e) Derived from the same experiments as in Comment (a) by making allowance for absorption by $\mathrm{O}_{3}$ product.

(f) FTIR study of irradiated $\mathrm{CH}_{3} \mathrm{C}(\mathrm{O}) \mathrm{C}(\mathrm{O}) \mathrm{CH}_{3}$ in the presence of $\mathrm{Ar}-\mathrm{O}_{2}$ mixtures at total pressures of 973 mbar to $1026 \mathrm{mbar}$ (730 Torr to 770 Torr). The reaction products $\mathrm{CO}_{2}, \mathrm{CO}, \mathrm{HCHO}, \mathrm{HC}(\mathrm{O}) \mathrm{OH}, \mathrm{CH}_{3} \mathrm{C}(\mathrm{O}) \mathrm{OH}, \mathrm{CH}_{3} \mathrm{C}(\mathrm{O}) \mathrm{OOH}, \mathrm{CH}_{3} \mathrm{OH}, \mathrm{H}_{2} \mathrm{O}_{2}$ and $\mathrm{O}_{3}$ were analyzed by matrix-isolation FTIR spectroscopy combined with a molecular-beam sampling technique. The branching ratio $\left(k_{1} / k_{2}\right)$ was derived from the yields of $\mathrm{CH}_{3} \mathrm{C}(\mathrm{O}) \mathrm{OH}$ and $\mathrm{O}_{3}$.

(g) UV irradiation of $\mathrm{Cl}_{2}-\mathrm{CH}_{3} \mathrm{CHO}-\mathrm{CH}_{3} \mathrm{OH}$-air mixtures in a smog chamber fitted with an FTIR detection system. Branching ratios were derived from the yields of $\mathrm{CH}_{3} \mathrm{C}(\mathrm{O}) \mathrm{OOH}$ and $\mathrm{CH}_{3} \mathrm{C}(\mathrm{O}) \mathrm{OH}$ which gave $k_{2} / k=0.10 \pm 0.02$ at $295 \mathrm{~K}$. Branching ratios were also derived from the $\mathrm{O}_{3}$ yields determined from the kinetics traces at long reaction times in experiments performed to obtain the rate coefficient [see Comment (b)]. These experiments gave $k_{2} / k=0.16 \pm 0.04$ at $295 \mathrm{~K}$. The value cited in the Table is a weighted mean of values from all the experiments. The $\mathrm{O}_{3}$ yield measurements suggest only a small increase in $k_{2} / k$ as temperature is lowered from $359 \mathrm{~K}$ to $265 \mathrm{~K}$. The interpretation of the results assumed that the $\mathrm{CH}_{3} \mathrm{C}(\mathrm{O}) \mathrm{O}_{2}+\mathrm{HO}_{2}$ reaction proceeds by channels (1) and (2).

(h) Branching ratios were derived from the $\mathrm{O}_{3}$ yields at long reaction times in experiments described in Comment (c). There was no detectable change in $k_{2} / k$ with change in temperature from $298 \mathrm{~K}$ to $373 \mathrm{~K}$.

(i) Continuous photolysis of $\mathrm{Cl}_{2}$ in the presence of $\mathrm{CH}_{3} \mathrm{CHO}-\mathrm{CH}_{3} \mathrm{OH}-\mathrm{O}_{2}-\mathrm{N}_{2}$ mixtures at a total pressure of $1066 \mathrm{mbar}$ (800 Torr). Yields of $\mathrm{CH}_{3} \mathrm{OOH}$ and $\mathrm{CH}_{3} \mathrm{C}(\mathrm{O}) \mathrm{OOH}$ (by $\mathrm{HPLC}$ ) and $\mathrm{CH}_{3} \mathrm{OOH}, \mathrm{CH}_{3} \mathrm{C}(\mathrm{O}) \mathrm{OOH}, \mathrm{CH}_{3} \mathrm{C}(\mathrm{O}) \mathrm{OH}$ and $\mathrm{CO}_{2}$ (by FTIR) were measured as a function of the initial concentration ratio $\left[\mathrm{CH}_{3} \mathrm{OH}\right]_{0} /\left[\mathrm{CH}_{3} \mathrm{CHO}\right]_{0}$ over the range 0 to 5 , corresponding to conditions over which dominant removal of $\mathrm{CH}_{3} \mathrm{C}(\mathrm{O}) \mathrm{O}_{2}$ changes from its self reaction to the reaction with $\mathrm{HO}_{2}$. The results were analysed by simulation using a detailed chemical mechanism taking account of the sequential formation of $\mathrm{CH}_{3} \mathrm{O}_{2}$ in the system.

\section{Preferred Values}

$k=1.4 \times 10^{-11} \mathrm{~cm}^{3}$ molecule ${ }^{-1} \mathrm{~s}^{-1}$ at $298 \mathrm{~K}$.

$k=5.2 \times 10^{-13} \exp (980 / T) \mathrm{cm}^{3}$ molecule $\mathrm{e}^{-1} \mathrm{~s}^{-1}$ over the temperature range $250-400 \mathrm{~K}$.

\section{Reliability}

$\Delta \log k= \pm 0.3$ at $298 \mathrm{~K}$.

$\Delta(E / R)= \pm 500 \mathrm{~K}$.

\section{Comments on Preferred Values}

Several studies have obtained evidence for the existence of reaction channels (1) and (2) (Niki et al., 1985; Moortgat et al., 1989; Horie and Moortgat, 1992; Crawford et al., 1999; Tomas et al., 2001), with reasonably consistent branching ratios being reported. However, the product yields measured in the recent study of Hasson et al. (2004), and their dependence on reagent conditions (see comment (i)), cannot be interpreted in terms of the reaction of $\mathrm{CH}_{3} \mathrm{C}(\mathrm{O}) \mathrm{O}_{2}$ with $\mathrm{HO}_{2}$ proceeding via channels (1) and (2) alone. Hasson et al. (2004) interpreted their observations in terms of a major contribution to the reaction being made by the $\mathrm{HO}$ radical-forming channel (3), which also leads to subsequent formation of $\mathrm{CH}_{3} \mathrm{O}_{2}$. The results of the original product study of Niki et al. (1985) at high $\left[\mathrm{HO}_{2}\right] /\left[\mathrm{CH}_{3} \mathrm{C}(\mathrm{O}) \mathrm{O}_{2}\right]$ (i.e. when $\mathrm{CH}_{3} \mathrm{C}(\mathrm{O}) \mathrm{O}_{2}$ is mainly removed via reaction with $\mathrm{HO}_{2}$ ) also provide some support for this interpretation, through the reported observation of significant formation of $\mathrm{CH}_{3} \mathrm{OOH}$, and because the products of channels (1) and (2), $\mathrm{CH}_{3} \mathrm{C}(\mathrm{O}) \mathrm{OH}$ and $\mathrm{CH}_{3} \mathrm{C}(\mathrm{O}) \mathrm{OOH}$, only account for $\approx 50 \%$ of the loss of the $\mathrm{CH}_{3} \mathrm{C}(\mathrm{O}) \mathrm{O}_{2}$ precursor, $\mathrm{CH}_{3} \mathrm{CHO}$. The participation of channel (3) leads to potential errors in both the absolute and relative branching ratios in the majority of the earlier studies, through possible secondary formation of $\mathrm{CH}_{3} \mathrm{C}(\mathrm{O}) \mathrm{OH}$ from the reaction of $\mathrm{CH}_{3} \mathrm{O}_{2}$ with $\mathrm{CH}_{3} \mathrm{C}(\mathrm{O}) \mathrm{O}_{2}$, and the regeneration of both $\mathrm{CH}_{3} \mathrm{C}(\mathrm{O}) \mathrm{O}_{2}$ and $\mathrm{HO}_{2}$ from reactions of $\mathrm{HO}$. However, the relative branching ratio determination of Horie and Moortgat (1992) relied on the observed formation of $\mathrm{CH}_{3} \mathrm{C}(\mathrm{O}) \mathrm{OOH}$ and $\mathrm{O}_{3}$, which are almost certainly specific products of reaction channels (1) and (2), respectively. The $298 \mathrm{~K}$ value of $k_{1} / k_{2}=2.7$ of Horie and Moortgat (1992) is in reasonable agreement with the value of 2 reported by Hasson et al. (2004). Independent verification of the participation of channel (3) is required. 
There are substantial differences among the available kinetics measurements of $k$, which are also subject to further potential uncertainty because channel (3) was generally not taken into account in the analyses. Prior to recognition of this, Tyndall et al. (2001) have made a comparison of the studies of Moortgat et al. (1989) and Crawford et al. (1999) using updated absorption cross-sections and taking into account present understanding of the effects of the $\mathrm{HO}_{2}+\mathrm{CH}_{3} \mathrm{CHO}$ reaction. Their reanalysis of the $\left[\mathrm{HO}_{2}\right]$ decay traces published in these studies favours the values of $k$ obtained by Moortgat et al. (1989). Tyndall et al. (2001) also point out that the values of $k$ reported by Crawford et al. (1999) are high compared with those from analogous $\mathrm{RO}_{2}+\mathrm{HO}_{2}$ reactions. Their conclusions are supported by the more recent study of Tomas et al. (2001) who used sufficiently low concentrations to avoid effects due to the $\mathrm{HO}_{2}+\mathrm{CH}_{3} \mathrm{CHO}$ reaction. Their results are in excellent agreement with those of Moortgat et al. (1989). Our preferred expression for $k$ is therefore provisionally based on the mean of the values of $E / R$ obtained by Moortgat et al. (1989) and Tomas et al. (2001), combined with an $A$-factor to give a value of $k$ at $298 \mathrm{~K}$ which is the mean of the values obtained in the same two studies. It is recognised, however, that the likely regeneration of both $\mathrm{CH}_{3} \mathrm{C}(\mathrm{O}) \mathrm{O}_{2}$ and $\mathrm{HO}_{2}$ from channel (3) under the experimental conditions employed in all the reported kinetics studies, leads to the possibility that the observed removal kinetics may underestimate the overall rate coefficient: although the extent of any underestimate could only be obtained from reanalysis of the original data. This is reflected in the uncertainty assigned to the preferred values.

\section{References}

Crawford, M. A., Wallington, T. J., Szente, J. J., Maricq, M. M., and Francisco, J. S.: J. Phys. Chem. A, 103, 365, 1999.

Hasson, A. S., Tyndall, G. S., and Orlando, J. J.: J. Phys. Chem. A, 108, 5979, 2004.

Horie, O. and Moortgat, G. K.: J. Chem. Soc. Faraday Trans., 88, 3305, 1992.

Moortgat, G. K., Veyret, B., and Lesclaux, R.: Chem. Phys. Lett., 160, 443, 1989.

Niki, H., Maker, P. D., Savage, C. M., and Breitenbach, L. P.: J. Phys. Chem., 89, 588, 1985.

Tomas, A., Villenave, E., and Lesclaux, R.: J. Phys. Chem. A, 105, 3505, 2001.

Tyndall, G. S., Cox, R. A., Granier, C., Lesclaux, R., Moortgat, G. K., Pilling, M. J., Ravishankara, A. R., and Wallington, T. J.: J. Geophys. Res., 106, 12 157, 2001. 
II.A2a.57

$$
\mathrm{HO}_{2}+\mathrm{HOCH}_{2} \mathrm{CH}_{2} \mathrm{O}_{2} \rightarrow \text { products }
$$

\section{Rate coefficient data}

\begin{tabular}{|c|c|c|c|}
\hline$k / \mathrm{cm}^{3}$ molecule $^{-1} \mathrm{~s}^{-1}$ & Temp./K & Reference & Technique/Comments \\
\hline $\begin{array}{l}\text { Absolute Rate coefficients } \\
(4.8 \pm 1.5) \times 10^{-12}\end{array}$ & 298 & Jenkin and Cox, 1991 & MM-AS (a) \\
\hline$\sim 2.0 \times 10^{-11}$ & 298 & Anastasi et al., 1991 & PR-AS (b) \\
\hline$(1.2 \pm 0.3) \times 10^{-11}$ & 296 & Murrells et al., 1991 & PLP-AS (c) \\
\hline$(1.17 \pm 0.22) \times 10^{-11}$ & 298 & Boyd et al., 2003 & PLP-AS (d) \\
\hline
\end{tabular}

\section{Comments}

(a) MM study with $\mathrm{HOCH}_{2} \mathrm{CH}_{2} \mathrm{O}_{2}$ radicals being generated from the photolysis of $\mathrm{HOCH}_{2} \mathrm{CH}_{2} \mathrm{I}$ in the presence of $\mathrm{O}_{2}$ and $\mathrm{N}_{2}$ at total pressures of 13 mbar, $133 \mathrm{mbar}$ and $1013 \mathrm{mbar}$ (10 Torr, 100 Torr, and 760 Torr) in a slow flow system. The modulated absorption spectrum in the range $205 \mathrm{~nm}$ to $310 \mathrm{~nm}$ showed that additional transient species were absorbing, and these were ascribed to $\mathrm{HOCH}_{2} \mathrm{CH}_{2} \mathrm{OOI}$ and $\mathrm{HO}_{2}$. The rate coefficient was obtained from computer simulations of the time-resolved absorption waveforms at $220 \mathrm{~nm}$ to $310 \mathrm{~nm}$ for experiments at $13 \mathrm{mbar}$ (10 Torr) pressure.

(b) Pulse radiolysis study, with $\mathrm{HOCH}_{2} \mathrm{CH}_{2} \mathrm{O}_{2}$ radicals being generated from $\mathrm{C}_{2} \mathrm{H}_{4}-\mathrm{O}_{2}-\mathrm{H}_{2} \mathrm{O}-\mathrm{SF}_{6}$ and $\mathrm{CH}_{3} \mathrm{CH}_{2} \mathrm{OH}-\mathrm{O}_{2}-\mathrm{SF}_{6}$ mixtures at total pressures of $1013 \mathrm{mbar}$ (760 Torr). [ $\left.\mathrm{HOCH}_{2} \mathrm{CH}_{2} \mathrm{O}_{2}\right]$ was monitored by absorption at $230 \mathrm{~nm}$ and $k$ derived from kinetic modelling of absorption profiles.

(c) Pulsed laser photolysis study, with $\mathrm{HOCH}_{2} \mathrm{CH}_{2} \mathrm{O}_{2}$ radicals being generated from photolysis of $\mathrm{HOCH}_{2} \mathrm{CH}_{2} \mathrm{Cl}$ in the presence of $\mathrm{O}_{2}$ and $\mathrm{N}_{2}$ at total pressures of $973 \mathrm{mbar}$ ( 730 Torr). The rate coefficient was obtained by modelling the observed absorption profiles on the basis of a simplified mechanism of four reactions.

(d) PLP-UV absorption study of $\mathrm{H}_{2} \mathrm{O}_{2}-\mathrm{C}_{2} \mathrm{H}_{4}-\mathrm{O}_{2}-\mathrm{N}_{2}$ mixtures at $1013 \mathrm{mbar}$ (760 Torr) and $298 \mathrm{~K}$. Conditions were chosen such that $\mathrm{HO}_{2}$ was in excess, with initial concentration ratios $\left[\mathrm{HO}_{2}\right] /\left[\mathrm{HOCH}_{2} \mathrm{CH}_{2} \mathrm{O}_{2}\right]$ in the range 4-10. $k$ was determined from simulation of transient decay traces recorded at $270 \mathrm{~nm}$ and either $210 \mathrm{~nm}$ or $220 \mathrm{~nm}$. The signal at $270 \mathrm{~nm}$ was dominated by $\mathrm{HOCH}_{2} \mathrm{CH}_{2} \mathrm{O}_{2}$ absorption, with its decay being almost entirely due to the reaction with $\mathrm{HO}_{2}$. The signal at $210 \mathrm{~nm}$ or $220 \mathrm{~nm}$ was mainly due to $\mathrm{HO}_{2}$ absorption, with its self-reaction making the major contribution to its removal.

\section{Preferred Values}

$k=1.2 \times 10^{-11} \mathrm{~cm}^{3}$ molecule ${ }^{-1} \mathrm{~s}^{-1}$ at $298 \mathrm{~K}$.

\section{Reliability}

$\Delta \log k= \pm 0.2$ at $298 \mathrm{~K}$.

\section{Comments on Preferred Values}

The preferred value of $k$ is based on the results of the pulsed laser photolysis studies of Murrells et al. (1991) and Boyd et al. (2003), which are in excellent agreement.

The earlier determinations of Jenkin and Cox (1991) and Anastasi et al. (1991) were subject to errors in the magnitude and shape of the $\mathrm{HOCH}_{2} \mathrm{CH}_{2} \mathrm{O}_{2}$ absorption spectrum, respectively, which influenced the derived values of $k$. Murrells et al. (2001) demonstrated that cross-sections reported by Jenkin and Cox (1991), from molecular modulation studies of the photolysis of $\mathrm{HOCH}_{2} \mathrm{CH}_{2} \mathrm{I}$, are low by a factor of approximately two. Jenkin and Cox (1991) made the assumption that the photolysis of $\mathrm{HOCH}_{2} \mathrm{CH}_{2} \mathrm{I}$ in their system yielded entirely $\mathrm{HOCH}_{2} \mathrm{CH}_{2} \mathrm{O}_{2}$ radicals, which was apparently not the case. Increasing $\sigma_{230}\left(\mathrm{HOCH}_{2} \mathrm{CH}_{2} \mathrm{O}_{2}\right)$ by a factor of two in a re-interpretation (Murrells et al., 1991) of the data of Jenkin and Cox (1991) yielded a revised value of $k=(8.4 \pm 3.0) \times 10^{-12} \mathrm{~cm}^{3}$ molecule ${ }^{-1} \mathrm{~s}^{-1}$ at $13 \mathrm{mbar}$ pressure, in fair agreement with the current 
recommendation. The approximate value of $k$ derived by Anastasi et al. (1991) from pulsed radiolysis experiments is almost a factor of two higher than our recommended value. We have not taken this value of Anastasi et al. (1991) into account, because of the differences in the absorption spectrum of the radical observed compared with the consistent spectra shapes reported by Jenkin and Cox (1991) and Murrells et al. (1991) (see the data sheet for the reaction: $2 \mathrm{HOCH}_{2} \mathrm{CH}_{2} \mathrm{O}_{2} \rightarrow$ products).

\section{References}

Anastasi, C., Muir, D. J., Simpson, V. J., and Pagsberg, P.: J. Phys. Chem., 95, 5791, 1991.

Boyd, A. A., Flaud, P-M., Daugey, M., and Lesclaux, R.: J. Phys. Chem. A, 107, 818, 2003.

Jenkin, M. E. and Cox, R. A.: J. Phys. Chem., 95, 3229, 1991.

Murrells, T. P., Jenkin, M. E., Shalliker, S. J., and Hayman, G. D.: J. Chem. Soc. Faraday Trans., 87, 2351, 1991. 
II.A2a.58

$$
\begin{aligned}
\mathrm{HO}_{2}+\mathrm{CH}_{3} \mathrm{OCH}_{2} \mathrm{O}_{2} & \rightarrow \mathrm{O}_{2}+\mathrm{CH}_{3} \mathrm{OCH}_{2} \mathrm{OOH} \\
& \rightarrow \mathrm{O}_{2}+\mathrm{CH}_{3} \mathrm{OCHO}+\mathrm{H}_{2} \mathrm{O}
\end{aligned}
$$

\begin{tabular}{|c|c|c|c|}
\hline $\mathrm{k} / \mathrm{cm}^{3}$ molecule $^{-1} \mathrm{~s}^{-1}$ & Temp./K & Reference & Technique/Comments \\
\hline $\begin{array}{l}\text { Branching Ratios } \\
k_{1} / k=0.53 \pm 0.08 \\
k_{2} / k=0.40 \pm 0.04\end{array}$ & 295 & Wallington et al., 1993 & P-FTIR (a) \\
\hline
\end{tabular}

Rate coefficient data $\left(k=k_{1}+k_{2}\right)$

\section{Comments}

(a) $\mathrm{HO}_{2}$ and $\mathrm{CH}_{3} \mathrm{OCH}_{2} \mathrm{O}_{2}$ radicals were generated from the steady-state photolysis of $\mathrm{Cl}_{2}$ in the presence of $\mathrm{CH}_{3} \mathrm{OH}$ $\mathrm{CH}_{3} \mathrm{OCH}_{3}-\mathrm{O}_{2}$ mixtures at a total pressure of 930 mbar (700 Torr). Branching ratios were derived from FTIR analyses of $\mathrm{CH}_{3} \mathrm{OCHO}$ and $\mathrm{CH}_{3} \mathrm{OCH}_{2} \mathrm{OOH}$ products, which accounted for $93 \pm 12 \%$ of the $\mathrm{CH}_{3} \mathrm{OCH}_{3}$ loss.

\section{Preferred Values}

$k_{1} / k=0.60$ at $298 \mathrm{~K}$.

$k_{2} / k=0.40$ at $298 \mathrm{~K}$.

\section{Reliability}

$\Delta\left(k_{1} / k\right)= \pm 0.10$ at $298 \mathrm{~K}$.

$\Delta\left(k_{2} / k\right)= \pm 0.10$ at $298 \mathrm{~K}$.

Comments on Preferred Values

The reaction between $\mathrm{HO}_{2}$ radicals and $\mathrm{CH}_{3} \mathrm{OCH}_{2} \mathrm{O}_{2}$ radicals is analogous to that between $\mathrm{HO}_{2}$ radicals and $\mathrm{HOCH}_{2} \mathrm{O}_{2}$ radicals in that there are two channels of nearly equal importance at room temperature producing (i) the hydroperoxide plus $\mathrm{O}_{2}$ and (ii) a carbonyl product, $\mathrm{H}_{2} \mathrm{O}$ and $\mathrm{O}_{2}$. In contrast, the $\mathrm{HO}_{2}$ reactions with unsubstituted alkyl peroxy radicals, $\mathrm{RO}_{2}$, appear to have only a single channel, producing the alkyl hydroperoxide.

It has been proposed (Wallington et al., 1993) that the reaction between $\mathrm{HO}_{2}$ and substituted $\mathrm{RO}_{2}$ radicals yielding the carbonyl compounds proceeds through a six-member transition state similar to that suggested by Russell (1957) to explain the molecular products from the interactions of $\mathrm{RO}_{2}$ radicals.

\section{References}

Russell, G.: J. Am. Chem. Soc., 79, 387, 1957.

Wallington, T. J., Hurley, M. D., Ball, J. C., and Jenkin, M. E.: Chem. Phys. Lett., 211, 41, 1993. 
II.A2a.59

$$
\begin{aligned}
\mathrm{HO}_{2}+\mathrm{CH}_{3} \mathrm{C}(\mathrm{O}) \mathrm{CH}_{2} \mathrm{O}_{2} & \rightarrow \mathrm{O}_{2}+\mathrm{CH}_{3} \mathrm{C}(\mathrm{O}) \mathrm{CH}_{2} \mathrm{OOH} \\
& \rightarrow \mathrm{O}_{2}+\mathrm{HO}+\mathrm{CH}_{3} \mathrm{C}(\mathrm{O}) \mathrm{CH}_{2} \mathrm{O}
\end{aligned}
$$

$\Delta H^{\circ}=-161 \mathrm{~kJ} \cdot \mathrm{mol}^{-1}$

Rate coefficient data $\left(k=k_{1}+k_{2}\right)$

\begin{tabular}{lllc}
\hline$k / \mathrm{cm}^{3}$ molecule ${ }^{-1} \mathrm{~s}^{-1}$ & Temp./K & Reference & Technique/Comments \\
\hline $\begin{array}{l}\text { Absolute Rate Coefficients } \\
(9.0 \pm 1.0) \times 10^{-12}\end{array}$ & 298 & Bridier et al., 1993 & FP-AS (a) \\
& & & \\
Branching Ratios & 298 & Hasson et al., 2004 & UVP-FTIR/HPLC (b) \\
$k_{1} / k=0.33 \pm 0.10$ & 298 & & \\
$k_{2} / k=0.67 \pm 0.20$ & & & \\
\hline
\end{tabular}

\section{Comments}

(a) Flash photolysis of $\mathrm{Cl}_{2}$ in the presence of $\mathrm{CH}_{3} \mathrm{C}(\mathrm{O}) \mathrm{CH}_{3}-\mathrm{CH}_{3} \mathrm{OH}-\mathrm{O}_{2}-\mathrm{N}_{2}$ mixtures at a total pressure of 1013 mbar (760 Torr). The rate coefficient $k$ was derived from a kinetic analysis of absorption-time profiles measured at $210 \mathrm{~nm}$ and $230 \mathrm{~nm}$.

(b) Continuous photolysis of $\mathrm{Cl}_{2}$ in the presence of $\mathrm{CH}_{3} \mathrm{C}(\mathrm{O}) \mathrm{CH}_{3}-\mathrm{CH}_{3} \mathrm{OH}-\mathrm{O}_{2}-\mathrm{N}_{2}$ mixtures at atal pressure of 1066 mbar (800 Torr). Yields of $\mathrm{CH}_{3} \mathrm{OOH}, \mathrm{CH}_{3} \mathrm{C}(\mathrm{O}) \mathrm{OOH}$ and $\mathrm{CH}_{3} \mathrm{C}(\mathrm{O}) \mathrm{CH}_{2} \mathrm{OOH}$ (by HPLC) and $\mathrm{CH}_{3} \mathrm{C}(\mathrm{O}) \mathrm{OOH}, \mathrm{HCHO}, \mathrm{CO}$ and $\mathrm{CO}_{2}$ (by FTIR) were measured as a function of the initial concentration ratio $\left[\mathrm{CH}_{3} \mathrm{OH}\right]_{0} /\left[\mathrm{CH}_{3} \mathrm{C}(\mathrm{O}) \mathrm{CH}_{3}\right]_{0}$ over the range 0 to 0.5 , corresponding to conditions over which dominant removal of $\mathrm{CH}_{3} \mathrm{C}(\mathrm{O}) \mathrm{CH}_{2} \mathrm{O}_{2}$ changes from its self reaction to the reaction with $\mathrm{HO}_{2}$. The results were analysed by simulation using a detailed chemical mechanism taking account of the sequential formation of $\mathrm{CH}_{3} \mathrm{C}(\mathrm{O}) \mathrm{O}_{2}$ and $\mathrm{CH}_{3} \mathrm{O}_{2}$ in the system.

\section{Preferred Values}

$k=9.0 \times 10^{-12} \mathrm{~cm}^{3}$ molecule ${ }^{-1} \mathrm{~s}^{-1}$ at $298 \mathrm{~K}$.

\section{Reliability}

$\Delta \log k= \pm 0.3$ at $298 \mathrm{~K}$.

\section{Comments on Preferred Values}

The preferred value of $k$ is provisionally based on the sole determination, reported by Bridier et al. (1993). Although this value seems reasonable in comparison with other $\mathrm{RO}_{2}+\mathrm{HO}_{2}$ reactions, it has been obtained from the kinetic analysis of a complex chemical system, with only product channel (1) represented in the mechanism. The yields of $\mathrm{CH}_{3} \mathrm{C}(\mathrm{O}) \mathrm{CH}_{2} \mathrm{OOH}$ measured in the recent product study of Hasson et al. (2004) suggest that other channels occur, with the best interpretation of the results obtained from inclusion of the $\mathrm{HO}$ radical-forming channel (2) as the main product channel. Under these circumstances, the likely regeneration of both $\mathrm{CH}_{3} \mathrm{C}(\mathrm{O}) \mathrm{CH}_{2} \mathrm{O}_{2}$ and $\mathrm{HO}_{2}$ under the experimental conditions employed by Bridier et al. (1993) leads to the possibility that the observed removal kinetics may underestimate the overall rate coefficient: although the extent of any underestimate could only be obtained from reanalysis of the original data. Independent verification of the participation of channel (2) is therefore required, in addition to further kinetics studies to reduce the uncertainty in the preferred value. 
R. Atkinson et al.: Evaluated kinetic and photochemical data for atmospheric chemistry

\section{References}

Bridier, I., Veyret, B., Lesclaux, R., and Jenkin, M. E.: J. Chem. Soc. Faraday Trans., 89, 2993, 1993.

Hasson, A. S., Tyndall, G. S., and Orlando, J. J.: J. Phys. Chem. A, 108, 5979, 2004. 
II.A2a.60

$$
\mathrm{HO}_{2}+\mathrm{HCHO} \rightarrow \mathrm{HOCH}_{2} \mathrm{OO}
$$

$\Delta H^{\circ}=-68.1 \mathrm{~kJ} \cdot \mathrm{mol}^{-1}$

\section{Rate coefficient data}

\begin{tabular}{llll}
\hline$k / \mathrm{cm}^{3}$ molecule ${ }^{-1} \mathrm{~s}^{-1}$ & Temp./K & Reference & Technique/Comments \\
\hline Absolute Rate Coefficients & & & \\
$(1.1 \pm 0.4) \times 10^{-13}$ & 273 & Barnes et al., 1985 & S-FTIR (a) \\
$7.7 \times 10^{-15} \exp [(625 \pm 550) / T]$ & $275-333$ & Veyret et al., 1989 & FP-AS (b) \\
$(6.0 \pm 0.7) \times 10^{-14}$ & 295 & & \\
\hline
\end{tabular}

\section{Comments}

(a) FTIR spectroscopic study in a $420 \mathrm{~L}$ reaction chamber. $\mathrm{HO}_{2}$ radicals were generated from the thermal decomposition of $\mathrm{HO}_{2} \mathrm{NO}_{2}$ in the presence of $\mathrm{HCHO}, \mathrm{NO}_{2}$ and synthetic air at a total pressure of $530 \mathrm{mbar}$ ( $400 \mathrm{Torr}$ ). The rate coefficient, $k$, was obtained from a computer simulation of the rates of decay of $\mathrm{HCHO}$ and rates of formation of $\mathrm{HC}(\mathrm{O}) \mathrm{OH}$ and $\mathrm{HOCH}_{2} \mathrm{O}_{2} \mathrm{NO}_{2}$, based on a reaction scheme consisting of nine elementary reactions.

(b) Flash photolysis of $\mathrm{Cl}_{2}$ in the presence of $\mathrm{HCHO}$ or $\mathrm{CH}_{3} \mathrm{OH}$ and $\mathrm{O}_{2}$ with long-path absorption measurements of $\mathrm{HO}_{2}$ and $\mathrm{HOCH}_{2} \mathrm{O}_{2}$ radicals at total pressures of $110 \mathrm{mbar}$ to $230 \mathrm{mbar}$ ( 85 Torr to 170 Torr). The rate coefficient, $k$, was obtained from a computer simulation of the absorption profiles based on a mechanism of five elementary reactions.

\section{Preferred Values}

$k=7.9 \times 10^{-14} \mathrm{~cm}^{3}$ molecule $\mathrm{e}^{-1} \mathrm{~s}^{-1}$ at $298 \mathrm{~K}$.

$k=9.7 \times 10^{-15} \exp (625 / T) \mathrm{cm}^{3}$ molecule ${ }^{-1} \mathrm{~s}^{-1}$ over the temperature range $275-333 \mathrm{~K}$.

\section{Reliability}

$\Delta \log k= \pm 0.3$ at $298 \mathrm{~K}$.

$\Delta(E / R)= \pm 600 \mathrm{~K}$.

\section{Comments on Preferred Values}

The studies of Barnes et al. (1985) and of Veyret et al. (1989) are in excellent agreement regarding this rate coefficient, and both are in good agreement with the earlier data of Veyret et al. (1982). The preferred expression for the rate coefficient is derived by taking an average value of the rate coefficients of Barnes et al. (1985) $\left[k(273 \mathrm{~K})=1.1 \times 10^{-13} \mathrm{~cm}^{3} \mathrm{molecule}^{-1} \mathrm{~s}^{-1}\right]$ and Veyret et al. (1989) $\left[k(275 \mathrm{~K})=8.0 \times 10^{-14} \mathrm{~cm}^{3}\right.$ molecule $\left.{ }^{-1} \mathrm{~s}^{-1}\right]$ together with the value of $E / R$ determined by Veyret et al. (1989).

This reaction is believed to proceed via the initial formation of the adduct radical, $\mathrm{HO}_{2} \mathrm{CH}_{2} \mathrm{O}$, which rapidly isomerizes to the product radical, $\mathrm{HOCH}_{2} \mathrm{OO}$ via $\mathrm{H}$-atom transfer.

\section{References}

Barnes, I., Becker, K. H., Fink, E. H., Reimer, A., Zabel, F., and Niki, H.: Chem. Phys. Lett., 115, 1, 1985.

Veyret, B., Rayez, J.-C., and Lesclaux, R.: J. Phys. Chem., 86, 3424, 1982.

Veyret, B., Lesclaux, R., Rayez, M.-T., Rayez, J.-C., Cox, R. A., and Moortgat, G. K.: J. Phys. Chem., 93, 2368, 1989. 
II.A2a.61

$\mathrm{HOCH}_{2} \mathrm{OO} \rightarrow \mathrm{HO}_{2}+\mathrm{HCHO}$

$\Delta H^{\circ}=68.1 \mathrm{~kJ} \cdot \mathrm{mol}^{-1}$

Rate coefficient data

\begin{tabular}{lllc}
\hline$k / \mathrm{s}^{-1}$ & Temp./K & Reference & Technique/Comments \\
\hline Absolute Rate Coefficients & & & \\
$20_{-10}^{+20}$ & 273 & Barnes et al., 1985 & S-FTIR (a) \\
$2.0 \times 10^{12} \exp [-(7000 \pm 2000) / T]$ & $275-333$ & Veyret et al., 1989 & FP-AS (b) \\
$100 \pm 50$ & 295 & & \\
\hline
\end{tabular}

\section{Comments}

(a) FTIR spectroscopic study in a $420 \mathrm{~L}$ reaction chamber. $\mathrm{HO}_{2}$ radicals were generated from thermal decomposition of $\mathrm{HO}_{2} \mathrm{NO}_{2}$ in the presence of $\mathrm{HCHO}, \mathrm{NO}_{2}$ and synthetic air at a total pressure of $533 \mathrm{mbar}$ (400 Torr). The rate coefficient, $k$, was derived from a computer simulation of the rates of decay of $\mathrm{HCHO}$ and rates of formation of $\mathrm{HCOOH}$ and $\mathrm{HOCH}_{2} \mathrm{O}_{2} \mathrm{NO}_{2}$ based on a reaction scheme consisting of nine elementary reactions.

(b) Flash photolysis of $\mathrm{Cl}_{2}$ in the presence of $\mathrm{HCHO}$ or $\mathrm{CH}_{3} \mathrm{OH}$ and $\mathrm{O}_{2}$ with long-path absorption measurements of $\left[\mathrm{HO}_{2}\right]$ and $\left[\mathrm{HOCH}_{2} \mathrm{O}_{2}\right]$ at total pressures of $113 \mathrm{mbar}$ to $227 \mathrm{mbar}$ ( 85 Torr to 170 Torr). The rate coefficient, $k$, was obtained from a computer simulation of the absorption profiles based on a mechanism of five elementary reactions.

\section{Preferred Values}

$k=1.5 \times 10^{2} \mathrm{~s}^{-1}$ at $298 \mathrm{~K}$.

$k=2.4 \times 10^{12} \exp (-7000 / T) \mathrm{s}^{-1}$ over the temperature range $275-330 \mathrm{~K}$.

\section{Reliability}

$\Delta \log k= \pm 0.3$ at $298 \mathrm{~K}$.

$\Delta(E / R)= \pm 2000 \mathrm{~K}$.

\section{Comments on Preferred Values}

The studies of Barnes et al. (1985) and of Veyret et al. (1989) are in good agreement regarding the rate coefficient of this reaction. The preferred rate equation has been obtained by taking the average of the rate coefficients at $273 \mathrm{~K}$ to $275 \mathrm{~K}$ from these studies together with the $E / R$ determined by Veyret et al. (1989). It should be pointed out that the value of the equilibrium constant, $K_{1}$, for the reaction $\mathrm{HO}_{2}+\mathrm{HCHO} \rightleftharpoons \mathrm{HOCH}_{2} \mathrm{O}_{2}(1,-1), K_{1}=5.0 \times 10^{-16} \mathrm{~cm}^{3}$ molecule ${ }^{-1}$ at $298 \mathrm{~K}$, derived from the kinetic study of Veyret et al. (1989) (which is identical to the value obtained from our recommended data for $k_{1}$ and $k_{-1}$ ), is in excellent agreement with the value of $K_{1}=4.0 \times 10^{-16} \mathrm{~cm}^{3}$ molecule ${ }^{-1}$ at $298 \mathrm{~K}$ obtained independently by Burrows et al. (1989) from molecular modulation studies. The above value of $K_{1}$ is, however, considerably smaller than the value of $K_{1}=3.4 \times 10^{-15} \mathrm{~cm}^{3}$ molecule ${ }^{-1}$ at $298 \mathrm{~K}$ reported by Zabel et al. (1987) from EPR spectroscopic measurements of the ratio of concentrations of $\mathrm{HO}_{2}$ and $\mathrm{HOCH}_{2} \mathrm{O}_{2}$ radicals in the photolysis of $\mathrm{HCHO}-\mathrm{O}_{2}$ mixtures.

\section{References}

Barnes, I., Becker, K. H., Fink, E. H., Reimer, A., Zabel, F., and Niki, H.: Chem. Phys. Lett., 115, 1, 1985.

Burrows, J. P., Moortgat, G. K., Tyndall, G. S., Cox, R. A., Jenkin, M. E., Hayman, G. D., and Veyret, B.: J. Phys. Chem., 93, 2375, 1989.

Veyret, B., Lesclaux, R., Rayez, M.-T., Rayez, J.-C., Cox, R. A., and Moortgat, G. K.: J. Phys. Chem., 93, 2368, 1989.

Zabel, F., Sahetchian, K. A., and Chachaty, C.: Chem. Phys. Lett., 134, 433, 1987. 
Appendix A3: $\mathrm{NO}_{3}+$ VOC

II.A3.62

$$
\mathrm{NO}_{3}+\mathrm{CH}_{4} \rightarrow \mathrm{HNO}_{3}+\mathrm{CH}_{3}
$$

$\Delta H^{\circ}=12.4 \mathrm{~kJ} \cdot \mathrm{mol}^{-1}$

\section{Rate coefficient data}

\begin{tabular}{lllc}
\hline$k / \mathrm{cm}^{3}$ molecule ${ }^{-1} \mathrm{~s}^{-1}$ & Temp./K & Reference & Technique/Comments \\
\hline $\begin{array}{l}\text { Absolute Rate Coefficients } \\
<4 \times 10^{-16}\end{array}$ & 298 & Burrows et. al., 1985 & (a) \\
$\leq 2 \times 10^{-17}$ & $298 \pm 2$ & Wallington et. al., 1986 & FP-A (b) \\
$\leq 8 \times 10^{-19}$ & 302 & Boyd et. al., 1991 & (c) \\
$\begin{array}{l}\text { Relative Rate Coefficients } \\
<5 \times 10^{-21}\end{array}$ & $\sim 298$ & Cantrell et. al., 1987 & (d) \\
\hline
\end{tabular}

\section{Comments}

(a) $\mathrm{NO}_{3}$ radicals were generated by the modulated photolysis of $\mathrm{Cl}_{2}-\mathrm{ClONO}_{2}-\mathrm{N}_{2}$ or $\mathrm{F}_{2}-\mathrm{HNO}_{3}-\mathrm{N}_{2}$ mixtures and monitored by optical absorption at $662 \mathrm{~nm}$.

(b) $\mathrm{NO}_{3}$ radicals were generated by the flash photolysis of $\mathrm{ClONO}_{2}-\mathrm{He}$ mixtures and detected by optical absorption at $662 \mathrm{~nm}$.

(c) Stopped-flow system with optical absorption detection of $\mathrm{NO}_{3}$ radicals at $662 \mathrm{~nm}$. The occurrence of secondary reactions was expected to lead to a stoichiometry factor of $\geq 2$, resulting in the upper limit to the rate coefficient cited in the table.

(d) Relative rate method. Upper limit to the rate coefficient was derived from the absence of observed $\mathrm{CO}$ and $\mathrm{CO}_{2}$ formation after addition of $\mathrm{CH}_{4}$ to $\mathrm{N}_{2} \mathrm{O}_{5}-\mathrm{NO}_{3}-\mathrm{NO}_{2}-\mathrm{N}_{2}$ mixtures. An equilibrium constant for the $\mathrm{NO}_{2}+\mathrm{NO}_{3} \leftrightarrow \mathrm{N}_{2} \mathrm{O}_{5}$ reactions of $2.90 \times 10^{-11} \mathrm{~cm}^{3}$ molecule ${ }^{-1}$ at $298 \mathrm{~K}$ (IUPAC, current recommendation) has been used to derive the rate coefficient cited.

\section{Preferred Values}

$k<1 \times 10^{-18} \mathrm{~cm}^{3}$ molecule $\mathrm{e}^{-1} \mathrm{~s}^{-1}$ at $298 \mathrm{~K}$.

\section{Comments on Preferred Values}

The preferred value is based on the upper limits to the rate coefficients obtained by Cantrell et al. (1987) and Boyd et al. (1991), and is consistent with the higher upper limits reported by Burrows et al. (1985) and Wallington et al. (1986).

\section{References}

Boyd, A. A., Canosa-Mas, C. E., King, A. D., Wayne, R. P., and Wilson, M. R.: J. Chem. Soc. Faraday Trans., 87, $2913,1991$. Burrows, J. P., Tyndall, G. S., and Moortgat, G. K.: J. Phys. Chem., 89, 4848, 1985.

Cantrell, C. A., Davidson, J. A., Shetter, R. E., Anderson, B. A., and Calvert, J. G.: J. Phys. Chem., 91, 6017, 1987.

IUPAC: http://www.iupac-kinetic.ch.cam.ac.uk/.

Wallington, T. J., Atkinson, R., Winer, A. M., and Pitts Jr., J. N.: J. Phys. Chem., 90, 4640, 1986. 
II.A3.63

$$
\mathrm{NO}_{3}+\mathrm{C}_{2} \mathrm{H}_{2} \rightarrow \text { products }
$$

\section{Rate coefficient data}

\begin{tabular}{lllc}
\hline$k / \mathrm{cm}^{3}$ molecule ${ }^{-1} \mathrm{~s}^{-1}$ & Temp./K & Reference & Technique/Comments \\
\hline $\begin{array}{l}\text { Absolute Rate Coefficients } \\
4.9 \times 10^{-13} \exp [-(2742 \pm 542) / T]\end{array}$ & $295-523$ & Canosa-Mas et al., 1988a, b & DF-A \\
$(5.1 \pm 3.5) \times 10^{-17}$ & $295 \pm 2$ & & \\
$\begin{array}{l}\text { Relative Rate Coefficients } \\
\leq 3.0 \times 10^{-17}\end{array}$ & $298 \pm 2$ & Atkinson et al., 1987 & RR (a) \\
\hline
\end{tabular}

\section{Comments}

(a) $\mathrm{NO}_{3}$ radicals were generated by the thermal decomposition of $\mathrm{N}_{2} \mathrm{O}_{5}$. The concentrations of acetylene and ethene (the reference organic) were measured by GC. The measured rate coefficient ratio of $k\left(\mathrm{NO}_{3}+\mathrm{C}_{2} \mathrm{H}_{2}\right) / k\left(\mathrm{NO}_{3}+\mathrm{C}_{2} \mathrm{H}_{4}\right) \leq 0.14$ at $298 \pm 2 \mathrm{~K}$ is placed on an absolute basis by use of a rate coefficient of $k\left(\mathrm{NO}_{3}+\mathrm{C}_{2} \mathrm{H}_{4}\right)=2.1 \times 10^{-16} \mathrm{~cm}^{3}$ molecule ${ }^{-1} \mathrm{~s}^{-1}$ (IUPAC, current recommendation).

\section{Preferred Values}

$k<10^{-16} \mathrm{~cm}^{3}$ molecule ${ }^{-1} \mathrm{~s}^{-1}$ at $298 \mathrm{~K}$.

\section{Comments on Preferred Values}

The measurement of rate coefficients for low reactivity organics is complicated by the possibility of secondary reactions, leading to erroneously high measured rate coefficients. The relative rate measurements of Atkinson et al. (1987) show $\mathrm{C}_{2} \mathrm{H}_{2}$ to be significantly less reactive than $\mathrm{C}_{2} \mathrm{H}_{4}$. The preferred value of the upper limit to the rate coefficient is sufficiently high to be consistent with the data of Canosa-Mas et al. (1988a). Until there are confirmatory data for the reported temperature dependence of this rate coefficient (Canosa-Mas et al. (1988b), no temperature dependence is recommended.

\section{References}

Atkinson, R., Aschmann, S. M., and Goodman, M. A.: Int. J. Chem. Kinet., 19, 299, 1987.

Canosa-Mas, C., Smith, S. J., Toby, S., and Wayne, R. P.: J. Chem. Soc. Faraday Trans., 2, 84, 247, 1988 a.

Canosa-Mas, C., Smith, S. J., Toby, S., and Wayne, R. P.: J. Chem. Soc. Faraday Trans., 2, 84, 263, 1988 b.

IUPAC: http://www.iupac-kinetic.ch.cam.ac.uk/. 
II.A3.64

$$
\mathrm{NO}_{3}+\mathrm{C}_{2} \mathrm{H}_{4} \rightarrow \text { products }
$$

\section{Rate coefficient data}

\begin{tabular}{lllc}
\hline$k / \mathrm{cm}^{3}$ molecule ${ }^{-1} \mathrm{~s}^{-1}$ & Temp./K & Reference & Technique/Comments \\
\hline $\begin{array}{l}\text { Absolute Rate Coefficients } \\
6.29 \times 10^{-12} \exp [-(3103 \pm 145) / T]\end{array}$ & $295-523$ & Canosa-Mas et al., 1988a, b & DF-A \\
$(1.85 \pm 0.24) \times 10^{-16}$ & $295 \pm 2$ & & \\
$(1.7 \pm 0.5) \times 10^{-16}$ & 300 & Biggs et al., 1991; Boyd et al., 1991 & (a) \\
& & & \\
$\begin{array}{l}\text { Relative Rate Coefficients } \\
(2.16 \pm 0.20) \times 10^{-16}\end{array}$ & $296 \pm 2$ & Atkinson et al., 1988 & RR (b) \\
\hline
\end{tabular}

\section{Comments}

(a) Stopped-flow technique with optical absorption of the $\mathrm{NO}_{3}$ radical at $662 \mathrm{~nm}$. The influence of the reaction $\mathrm{NO}_{2}+\mathrm{NO}_{3}+\mathrm{He} \rightarrow \mathrm{N}_{2} \mathrm{O}_{5}+\mathrm{He}$ was taken into account by numerical modeling, leading to a stoichiometry factor for $\mathrm{NO}_{3}$ radical decays of $\sim 1.9$ and the cited rate coefficient for the elementary $\mathrm{NO}_{3}+$ ethene reaction.

(b) $\mathrm{NO}_{3}$ radicals were generated by the thermal decomposition of $\mathrm{N}_{2} \mathrm{O}_{5}$. A series of rate coefficient ratios were measured, with the concentrations of the organic compounds involved being measured by GC. Based on rate coefficient ratios for the sets of organic compounds ethene vs. 2,3-dimethylbutane, 2,3-dimethylbutane vs. tetrahydrofuran, tetrahydrofuran vs. propene, propene vs. thiophene, thiophene vs. bicyclo[2.2.2]-2-octene, and bicyclo[2.2.2]-2-octene vs. trans-2-butene, a rate coefficient ratio of $k\left(\mathrm{NO}_{3}+\right.$ ethene $) / k\left(\mathrm{NO}_{3}+\right.$ trans-2-butene $)=0.000554 \pm 0.000050$ was obtained. This rate coefficient ratio is placed on an absolute basis by use of a rate coefficient of $k\left(\mathrm{NO}_{3}+\right.$ trans-2-butene $)=3.89 \times 10^{-13} \mathrm{~cm}^{3}$ molecule $\mathrm{e}^{-1} \mathrm{~s}^{-1}$ at $296 \mathrm{~K}$ (Atkinson, 1997).

\section{Preferred Values}

$k=2.1 \times 10^{-16} \mathrm{~cm}^{3}$ molecule ${ }^{-1} \mathrm{~s}^{-1}$ at $298 \mathrm{~K}$.

$k=3.3 \times 10^{-12} \exp (-2880 / T) \mathrm{cm}^{3}$ molecule $\mathrm{e}^{-1} \mathrm{~s}^{-1}$ over the temperature range $270-340 \mathrm{~K}$.

\section{Reliability}

$\Delta \log k= \pm 0.2$ at $298 \mathrm{~K}$.

$\Delta(E / R)= \pm 500 \mathrm{~K}$.

\section{Comments on Preferred Values}

The preferred rate coefficient is derived using the absolute rate coefficient data of Canosa-Mas et al. (1988a, b) and the relative rate coefficient of Atkinson et al. (1988). These data were fitted to the three parameter expression $k=C T^{2} \exp (-$ $D / T)$, resulting in $k=4.88 \times 10^{-18} T^{2} \exp (-2282 / T) \mathrm{cm}^{3}$ molecule ${ }^{-1} \mathrm{~s}^{-1}$ over the temperature range $295-523 \mathrm{~K}$. The preferred Arrhenius expression, $k=A \exp (-B / T)$, is centered at $300 \mathrm{~K}$ and is derived from the three parameter expression with $A=C e^{2} T^{2}$ and $B=D+2 T$.

The preferred rate coefficient is in agreement with the $300 \mathrm{~K}$ rate coefficient of Biggs et al. (1991) and Boyd et al. (1991).

\section{References}

Atkinson, R.: J. Phys. Chem. Ref. Data, 26, 215, 1997.

Atkinson, R., Aschmann, S. M., and Pitts Jr., J. N.: J. Phys. Chem., 92, 3454, 1988.

Biggs, P., Boyd, A. A., Canosa-Mas, C. E., Joseph, D. M., and Wayne, R. P.: Meas. Sci. Technol., 2, 675, 1991. 
Boyd, A. A., Canosa-Mas, C. E., King, A. D., Wayne, R. P., and Wilson, M. R.: J. Chem. Soc. Faraday Trans., 87, $2913,1991$. Canosa-Mas, C., Smith, S. J., Toby, S., and Wayne, R. P.: J. Chem. Soc. Faraday Trans., 2, 84, 247, 1988 a.

Canosa-Mas, C., Smith, S. J., Toby, S., and Wayne, R. P.: J. Chem. Soc. Faraday Trans., 2, 84, 263, 1988 b. 
II.A3.65

$$
\mathrm{NO}_{3}+\mathrm{C}_{2} \mathrm{H}_{6} \rightarrow \mathrm{HNO}_{3}+\mathrm{C}_{2} \mathrm{H}_{5}
$$

$\Delta H^{\circ}=-3.9 \mathrm{~kJ} \cdot \mathrm{mol}^{-1}$

\section{Rate coefficient data}

\begin{tabular}{lllc}
\hline$k / \mathrm{cm}^{3}$ molecule ${ }^{-1} \mathrm{~s}^{-1}$ & Temp./K & Reference & Technique/Comments \\
\hline Absolute Rate Coefficients & & & \\
$\leq 4 \times 10^{-18}$ & $298 \pm 2$ & Wallington et al., 1986 & FP-A (a) \\
$5.7 \times 10^{-12} \exp [-(4426 \pm 337) / T]$ & $453-553$ & Bagley et al., 1990 & DF-A \\
$2.0 \times 10^{-18}$ & $298^{*}$ & & \\
$\leq(2.7 \pm 0.2) \times 10^{-17}$ & 302 & Boyd et al., 1991 & $(\mathrm{b})$ \\
\hline
\end{tabular}

\section{Comments}

(a) $\mathrm{NO}_{3}$ radicals were generated by the flash photolysis of $\mathrm{ClONO}_{2}-\mathrm{He}$ mixtures and detected by optical absorption at $662 \mathrm{~nm}$.

(b) Stopped-flow system with optical absorption detection of the $\mathrm{NO}_{3}$ radical at $662 \mathrm{~nm}$. Secondary reactions were expected to lead to a stoichiometry factor of $\geq 2$, leading to the upper limit to the rate coefficient cited in the table.

\section{Preferred Values}

$k<1 \times 10^{-17} \mathrm{~cm}^{3}$ molecule $\mathrm{s}^{-1}$ at $298 \mathrm{~K}$.

\section{Comments on Preferred Values}

Extrapolation of the absolute rate coefficients obtained by Bagley et al. (1990) over the temperature range 453-553 K to $298 \mathrm{~K}$ leads to a $298 \mathrm{~K}$ rate coefficient of $2 \times 10^{-18} \mathrm{~cm}^{3}$ molecule $\mathrm{e}^{-1} \mathrm{~s}^{-1}$, probably uncertain to at least a factor of 2 due to the long extrapolation and possible non-Arrhenius behavior of the rate coefficient for this reaction. The preferred upper limit is based on the upper limit of Wallington et al. (1986) and extrapolation to $298 \mathrm{~K}$ of the elevated temperature rate coefficients of Bagley et al. (1990).

\section{References}

Bagley, J. A., Canosa-Mas, C., Little, M. R., Parr, A. D., Smith, S. J., Waygood, S. J., and Wayne, R. P.: J. Chem. Soc. Faraday Trans., 86, 2109, 1990.

Boyd, A. A., Canosa-Mas, C. E., King, A. D., Wayne, R. P., and Wilson, M. R.: J. Chem. Soc. Faraday Trans., 87, $2913,1991$. Wallington, T. J., Atkinson, R., Winer, A. M., and Pitts Jr., J. N.: J. Phys. Chem., 90, 4640, 1986. 
II.A3.66

$$
\mathrm{NO}_{3}+\mathrm{C}_{3} \mathrm{H}_{6} \rightarrow \text { products }
$$

\section{Rate coefficient data}

\begin{tabular}{llll}
\hline$k / \mathrm{cm}^{3}$ molecule ${ }^{-1} \mathrm{~s}^{-1}$ & Temp./K & Reference & Technique/Comments \\
\hline $\begin{array}{l}\text { Absolute Rate Coefficients } \\
\left.\left.4.74 \times 10^{-13} \text { exp[-(1171 } \pm 66\right) / T\right]\end{array}$ & $298-423$ & Canosa-Mas et al., 1991 & DF-A \\
$(9.3 \pm 1.2) \times 10^{-15}$ & 298 & & \\
& & & \\
Relative Rate Coefficients & 300 & Morris and Niki, 1974 & RR (a) \\
$(5.4 \pm 1.4) \times 10^{-15}$ & 300 & Japar and Niki, 1975 & RR (a) \\
$(9.2 \pm 0.6) \times 10^{-15}$ & $298 \pm 1$ & Atkinson et al., 1984 & RR (a) \\
$(6.4 \pm 1.3) \times 10^{-15}$ & $298 \pm 1$ & Atkinson et al., 1984 & RR (b) \\
$(7.4 \pm 2.0) \times 10^{-15}$ & $296 \pm 2$ & Atkinson et al., 1988 & RR (c) \\
$(9.45 \pm 0.47) \times 10^{-15}$ & &
\end{tabular}

\section{Comments}

(a) $\mathrm{NO}_{3}$ radicals were generated from the thermal decomposition of $\mathrm{N}_{2} \mathrm{O}_{5}$. The experimental data were relative to the equilibrium coefficient $K$ for the $\mathrm{NO}_{3}+\mathrm{NO}_{2} \leftrightarrow \mathrm{N}_{2} \mathrm{O}_{5}$ reactions, and are placed on an absolute basis by use of $K=2.90 \times 10^{-11} \mathrm{~cm}^{3}$ molecule ${ }^{-1}$ at $298 \mathrm{~K}$ and $2.26 \times 10^{-11} \mathrm{~cm}^{3}$ molecule ${ }^{-1}$ at $300 \mathrm{~K}$ (IUPAC, current recommendation).

(b) $\mathrm{NO}_{3}$ radicals were generated from the thermal decomposition of $\mathrm{N}_{2} \mathrm{O}_{5}$. The concentrations of propene and trans-2butene were measured by $\mathrm{GC}$, and a rate coefficient ratio of $k\left(\mathrm{NO}_{3}+\right.$ propene $) / k\left(\mathrm{NO}_{3}+\right.$ trans-2-butene $)=0.019 \pm 0.005$ obtained. This rate coefficient ratio is placed on an absolute basis by use of a rate coefficient of $k\left(\mathrm{NO}_{3}+\right.$ trans-2-butene $)$ $=3.90 \times 10^{-13} \mathrm{~cm}^{3}$ molecule $\mathrm{s}^{-1} \mathrm{~s}^{-1}$ at $298 \mathrm{~K}$ (Atkinson, 1997).

(c) $\mathrm{NO}_{3}$ radicals were generated by the thermal decomposition of $\mathrm{N}_{2} \mathrm{O}_{5}$. A series of rate coefficient ratios were measured, with the concentrations of the organic compounds involved being measured by GC. Based on rate coefficient ratios for the sets of organic compounds, propene vs. thiophene, thiophene vs. bicyclo[2.2.2]-2-octene, and bicyclo[2.2.2]-2-octene vs. trans-2-butene, a rate coefficient ratio of $k\left(\mathrm{NO}_{3}+\right.$ propene $) / k\left(\mathrm{NO}_{3}+\right.$ trans-2-butene $)=0.0243 \pm 0.0012$ at $296 \pm 2 \mathrm{~K}$ was obtained. This rate coefficient ratio is placed on an absolute basis by use of a rate coefficient of $k\left(\mathrm{NO}_{3}+\right.$ trans-2-butene $)$ $=3.89 \times 10^{-13} \mathrm{~cm}^{3}$ molecule $\mathrm{e}^{-1} \mathrm{~s}^{-1}$ at $296 \mathrm{~K}$ (Atkinson, 1997).

\section{Preferred Values}

$k=9.5 \times 10^{-15} \mathrm{~cm}^{3}$ molecule $\mathrm{e}^{-1} \mathrm{~s}^{-1}$ at $298 \mathrm{~K}$.

$k=4.6 \times 10^{-13} \exp (-1155 / T) \mathrm{cm}^{3}$ molecule $\mathrm{e}^{-1} \mathrm{~s}^{-1}$ over the temperature range $290-430 \mathrm{~K}$.

\section{Reliability}

$\Delta \log k= \pm 0.2$ at $298 \mathrm{~K}$.

$\Delta(E / R)= \pm 300 \mathrm{~K}$.

\section{Comments on Preferred Values}

The preferred values are derived using the room temperature relative rate coefficient of Atkinson et al. (1988) and the 298$423 \mathrm{~K}$ absolute rate coefficients of Canosa-Mas et al. (1991). The preferred $298 \mathrm{~K}$ rate coefficient is in reasonable agreement with the relative rate measurements of Morris and Niki (1974), Japar and Niki (1975) and Atkinson et al. (1984) when the differing values of the equilibrium constant used for the $\mathrm{N}_{2} \mathrm{O}_{5} \leftrightarrow \mathrm{NO}_{3}+\mathrm{NO}_{2}$ reactions are taken into account, and considering the uncertainties in this equilibrium constant. 
The $\mathrm{NO}_{3}$ radical reaction with propene proceeds by initial addition, leading to the formation under simulated tropospheric conditions of $\mathrm{HCHO}, \mathrm{CH}_{3} \mathrm{CHO}$ and $\mathrm{CH}_{3} \mathrm{C}(\mathrm{O}) \mathrm{CH}_{2} \mathrm{ONO}_{2}$ (Bandow et al., 1980; Shepson et al., 1985; Barnes et al., 1990; Hjorth et al., 1990; Atkinson, 1997).

\section{References}

Atkinson, R.: J. Phys. Chem. Ref. Data, 26, 215, 1997.

Atkinson, R., Aschmann, S. M., and Pitts Jr., J. N.: J. Phys. Chem., 92, 3454, 1988.

Atkinson, R., Plum, C. N., Carter, W. P. L., Winer, A. M., and Pitts Jr., J. N.: J. Phys. Chem., 88, 1210, 1984.

Bandow, H., Okuda, M., and Akimoto, H.: J. Phys. Chem., 84, 3604, 1980.

Barnes, I., Bastian, V., Becker, K. H., and Tong, Z.: J. Phys. Chem., 94, 2413, 1990.

Canosa-Mas, C. E., Smith, S. J., Waygood, S. J., and Wayne, R. P.: J. Chem. Soc. Faraday Trans., 87, 3473, 1991.

Hjorth, J., Lohse, C., Nielsen, C. J., Skov, H., and Restelli, G.: J. Phys. Chem., 94, 7494, 1990.

IUPAC: http://www.iupac-kinetic.ch.cam.ac.uk/.

Japar, S. M. and Niki, H.: J. Phys. Chem., 79, 1629, 1975.

Morris Jr., E. D. and Niki, H.: J. Phys. Chem., 78, 1337, 1974.

Shepson, P. B., Edney, E. O., Kleindienst, T. E., Pittman, J. H., Namie, G. R., and Cupitt, L. T.: Environ. Sci. Technol., 19, 849, 1985. 
II.A3.67

$$
\begin{aligned}
\mathrm{NO}_{3}+\mathrm{C}_{3} \mathrm{H}_{8} & \rightarrow \mathrm{HNO}_{3}+\mathrm{CH}_{3} \mathrm{CH}_{2} \mathrm{CH}_{2} \\
& \rightarrow \mathrm{HNO}_{3}+\mathrm{CH}_{3} \mathrm{CHCH}_{3}
\end{aligned}
$$

$\Delta H^{0}(1)=-3.5 \mathrm{~kJ} \cdot \mathrm{mol}^{-1}$

$\Delta H^{0}(2)=-17.7 \mathrm{~kJ} \cdot \mathrm{mol}^{-1}$

\section{Rate coefficient data}

\begin{tabular}{llll}
\hline$k / \mathrm{cm}^{3}$ molecule ${ }^{-1} \mathrm{~s}^{-1}$ & Temp./K & Reference & Technique/Comments \\
\hline $\begin{array}{l}\text { Absolute Rate Coefficients } \\
\leq(4.8 \pm 1.7) \times 10^{-17}\end{array}$ & 298 & Boyd et al., 1991 & (a) \\
\hline
\end{tabular}

\section{Comments}

(a) Stopped-flow system with optical absorption detection of the $\mathrm{NO}_{3}$ radical at $662 \mathrm{~nm}$. The occurrence of secondary reactions is expected to lead to a stoichiometry factor of $\geq 2$, resulting in the upper limit to the rate coefficient cited in the table.

\section{Preferred Values}

$k \leq 7 \times 10^{-17} \mathrm{~cm}^{3}$ molecule ${ }^{-1} \mathrm{~s}^{-1}$ at $298 \mathrm{~K}$.

\section{Comments on Preferred Values}

The preferred value is based on the upper limit derived by Boyd et al. (1991).

\section{References}

Boyd, A., Canosa-Mas, C. E., King, A. D., Wayne, R. P., and Wilson, M. R.: J. Chem. Soc. Faraday Trans., 87, $2913,1991$. 
II.A3.68

$$
\mathrm{NO}_{3}+n-\mathrm{C}_{4} \mathrm{H}_{10} \rightarrow \text { products }
$$

\section{Rate coefficient data}

\begin{tabular}{lllc}
\hline$k / \mathrm{cm}^{3}$ molecule & Temp./K & Reference & Technique/Comments \\
\hline Absolute Rate Coefficients & & & \\
$\leq 2 \times 10^{-17}$ & $298 \pm 2$ & Wallington et al., 1986 & FP-A (a) \\
$(4.5 \pm 0.6) \times 10^{-17}$ & 298 & Bagley et al., 1990 & DF-A \\
$(1.44 \pm 0.12) \times 10^{-16}$ & 333 & & \\
$(4.6 \pm 1.2) \times 10^{-16}$ & 373 & & \\
$(1.12 \pm 0.12) \times 10^{-15}$ & 423 & & \\
$(3.2 \pm 0.3) \times 10^{-15}$ & 473 & & \\
$(9.0 \pm 0.4) \times 10^{-15}$ & 523 & & \\
& & & RR (b) \\
Absolute Rate Coefficients & & & \\
$(6.6 \pm 1.7) \times 10^{-17}$ & $296 \pm 2$ & Atkinson et al., 1984 & \\
\hline
\end{tabular}

\section{Comments}

(a) $\mathrm{NO}_{3}$ radicals were generated by the flash photolysis of $\mathrm{ClONO}_{2}$ at wavelengths $>180 \mathrm{~nm}$ and monitored by optical absorption at $662 \mathrm{~nm}$.

(b) $\mathrm{NO}_{3}$ radicals were produced by the thermal decomposition of $\mathrm{N}_{2} \mathrm{O}_{5}$, and the concentrations of $n$-butane and $n$-heptane (the reference organic) were measured by GC. A rate coefficient ratio of $k\left(\mathrm{NO}_{3}+n\right.$-butane $) / k\left(\mathrm{NO}_{3}+n\right.$-heptane $)=0.48 \pm 0.12$ was obtained and is placed on an absolute basis by use of a rate coefficient of $k\left(\mathrm{NO}_{3}+n\right.$-heptane $)=1.37 \times 10^{-16} \mathrm{~cm}^{3}$ molecule $\mathrm{e}^{-1} \mathrm{~s}^{-1}$ at $296 \mathrm{~K}$ (Atkinson, 1991).

\section{Preferred Values}

$k=4.6 \times 10^{-17} \mathrm{~cm}^{3}$ molecule ${ }^{-1} \mathrm{~s}^{-1}$ at $298 \mathrm{~K}$.

$k=2.8 \times 10^{-12} \exp (-3280 / T) \mathrm{cm}^{3}$ molecule ${ }^{-1} \mathrm{~s}^{-1}$ over the temperature range $290-430 \mathrm{~K}$.

\section{Reliability}

$\Delta \log k= \pm 0.2$ at $298 \mathrm{~K}$.

$\Delta(E / R)= \pm 400 \mathrm{~K}$.

\section{Comments on Preferred Values}

The preferred values are based on the absolute rate coefficients measured by Bagley et al. (1990) over the temperature range $298-423 \mathrm{~K}$ (at temperatures above $423 \mathrm{~K}$ the Arrhenius plot exhibits upward curvature, especially above $473 \mathrm{~K}$ ). A leastsquares analysis of the 298-423 K rate coefficients of Bagley et al. (1990) results in the preferred Arrhenius expression. The preferred rate coefficient at $298 \mathrm{~K}$ is at least a factor of 2 higher than the upper limit reported by Wallington et al. (1986), but is in agreement within the measurement uncertainties with the relative rate coefficient of Atkinson et al. (1984). At room temperature and below the reaction proceeds mainly by $\mathrm{H}$-atom abstraction from the $\mathrm{CH}_{2}$ groups (Bagley et al., 1990; Atkinson, 1991).

\section{References}

Atkinson, R.: J. Phys. Chem. Ref. Data, 20, 459, 1991.

Atkinson, R., Plum, C. N., Carter, W. P. L., Winer, A. M., and Pitts Jr., J. N.: J. Phys. Chem., 88, 2361, 1984. 
Bagley, J. A., Canosa-Mas, C., Little, M. R., Parr, A. D., Smith, S. J., Waygood, S. J., and Wayne, R. P.: J. Chem. Soc. Faraday Trans., 86, 2109, 1990.

Wallington, T. J., Atkinson, R., Winer, A. M., and Pitts Jr., J. N.: J. Phys. Chem., 90, 4640, 1986. 
II.A3.69

$$
\mathrm{NO}_{3}+\mathrm{CH}_{2}=\mathrm{C}\left(\mathrm{CH}_{3}\right) \mathrm{CH}=\mathrm{CH}_{2} \text { (isoprene) } \rightarrow \text { products }
$$

\section{Rate coefficient data}

\begin{tabular}{lllc}
\hline$k / \mathrm{cm}^{3}$ molecule $\mathrm{s}^{-1}$ & Temp./K & Reference & Technique/Comments \\
\hline $\begin{array}{l}\text { Absolute Rate Coefficients } \\
(1.3 \pm 0.14) \times 10^{-12}\end{array}$ & 298 & Benter and Schindler, 1988 & \\
$3.03 \times 10^{-12} \exp [-(450 \pm 70) / T]$ & $251-381$ & Dlugokencky and Howard, 1989 & DF-MS \\
$(6.52 \pm 0.78) \times 10^{-13}$ & 297 & & F-LIF (a) \\
$(7.30 \pm 0.44) \times 10^{-13}$ & 298 & Wille et al., 1991 & \\
$(8.26 \pm 0.60) \times 10^{-13}$ & 298 & Wille et al., 1991; Lancar et al., 1991 & DF-MS \\
$(1.07 \pm 0.20) \times 10^{-12}$ & $295 \pm 2$ & Ellermann et al., 1992 & PF-MS \\
$(7.3 \pm 0.2) \times 10^{-13}$ & $298 \pm 2$ & Suh et al., 2001 & F-CIMS (c) \\
& & & \\
Relative Rate Coefficients & & & RR (d) \\
$(5.94 \pm 0.16) \times 10^{-13}$ & $295 \pm 1$ & Atkinson et al., 1984 & RR (e) \\
$(1.21 \pm 0.20) \times 10^{-12}$ & $298 \pm 2$ & Barnes et al., 1990 & RR (f) \\
$(6.86 \pm 0.55) \times 10^{-13}$ & 298 & Berndt and Böge, 1997 & \\
\hline
\end{tabular}

\section{Comments}

(a) $\mathrm{NO}_{3}$ radicals were generated by thermal decomposition of $\mathrm{N}_{2} \mathrm{O}_{5}$ in a flow system at total pressures of 1.0-1.1 Torr (1.3$1.5 \mathrm{mbar}$ ), and monitored by LIF.

(b) $\mathrm{NO}_{3}$ radicals were generated by pulse radiolysis of $\mathrm{SF}_{6}-\mathrm{HNO}_{3}$-isoprene mixtures at 1 bar total pressure, and monitored by optical absorption at $662 \mathrm{~nm}$.

(c) $\mathrm{NO}_{3}$ radicals were generated by thermal decomposition of $\mathrm{N}_{2} \mathrm{O}_{5}$ in a flow system at total pressures of 5.1-6.0 Torr (6.88.0 mbar), and monitored by CIMS using the reaction $\mathrm{NO}_{3}+\mathrm{SF}_{6}^{-} \rightarrow \mathrm{NO}_{3}^{-}+\mathrm{SF}_{6}$.

(d) Relative rate method carried out at atmospheric pressure of air. $\mathrm{NO}_{3}$ radicals were generated by thermal decomposition of $\mathrm{N}_{2} \mathrm{O}_{5}$. The concentrations of isoprene and trans-2-butene (the reference compound) were measured by GC. Small corrections (2-4\%) to the measured isoprene concentrations were made to take into account the gas-phase reaction of isoprene with $\mathrm{NO}_{2}$ (Atkinson et al., 1984; Atkinson, 1997). The resulting rate coefficient ratio of $k\left(\mathrm{NO}_{3}+\right.$ isoprene $) / k\left(\mathrm{NO}_{3}\right.$ + trans-2-butene $)=1.53 \pm 0.04$ is placed on an absolute basis by use of a rate coefficient of $k\left(\mathrm{NO}_{3}+\right.$ trans-2-butene $)=$ $3.88 \times 10^{-13} \mathrm{~cm}^{3}$ molecule ${ }^{-1} \mathrm{~s}^{-1}$ at $295 \mathrm{~K}$ (Atkinson, 1997).

(e) Relative rate method carried out at atmospheric pressure of synthetic air. $\mathrm{NO}_{3}$ radicals were generated by thermal decomposition of $\mathrm{N}_{2} \mathrm{O}_{5}$. The concentrations of isoprene and trans-2-butene (the reference compound) were measured by GC. No corrections for the reaction of isoprene with $\mathrm{NO}_{2}$ were found to be necessary. The measured rate coefficient ratio of $k\left(\mathrm{NO}_{3}+\right.$ isoprene $) / k\left(\mathrm{NO}_{3}+\right.$ trans-2-butene $)=3.1 \pm 0.5$ is placed on an absolute basis by use of a rate coefficient of $k\left(\mathrm{NO}_{3}\right.$ + trans-2-butene) $=3.90 \times 10^{-13} \mathrm{~cm}^{3}$ molecule ${ }^{-1} \mathrm{~s}^{-1}$ at $298 \mathrm{~K}$ (Atkinson, 1997).

(f) Relative rate method carried out in a flow system at a total pressure of $6.8 \mathrm{mbar}$ (5.1 Torr) of $\mathrm{N}_{2} . \mathrm{NO}_{3}$ radicals were generated by thermal decomposition of $\mathrm{N}_{2} \mathrm{O}_{5}$. The concentrations of isoprene and trans-2-butene (the reference compound) were measured by GC. The measured rate coefficient ratio of $k\left(\mathrm{NO}_{3}+\right.$ isoprene $) / k\left(\mathrm{NO}_{3}+\right.$ trans-2-butene $)=1.76 \pm 0.14$ is placed on an absolute basis by use of a rate coefficient of $k\left(\mathrm{NO}_{3}+\right.$ trans-2-butene $)=3.90 \times 10^{-13} \mathrm{~cm}^{3}$ molecule ${ }^{-1} \mathrm{~s}^{-1}$ at 298 K (Atkinson, 1997).

\section{Preferred Values}

$k=7.0 \times 10^{-13} \mathrm{~cm}^{3}$ molecule ${ }^{-1} \mathrm{~s}^{-1}$ at $298 \mathrm{~K}$.

$k=3.15 \times 10^{-12} \exp (-450 / T) \mathrm{cm}^{3}$ molecule $\mathrm{e}^{-1} \mathrm{~s}^{-1}$ over the temperature range $250-390 \mathrm{~K}$. 


\section{Reliability}

$\Delta \log k= \pm 0.2$ at $298 \mathrm{~K}$.

$\Delta(E / R)= \pm 200 \mathrm{~K}$.

\section{Comments on Preferred Values}

The measured room temperature rate coefficients range over a factor of 2.2, irrespective of whether absolute or relative rate methods were used. The study of Wille et al. (1991) is stated to supersede the earlier study of Benter and Schindler (1988) carried out over a more restricted range of conditions (and in which heterogeneous reactions between isoprene and $\mathrm{F}_{2}$ could have occurred; Wille et al., 1991). The only temperature dependent measurements of the kinetics of this reaction are from Dlugokencky and Howard (1989). The preferred $298 \mathrm{~K}$ rate coefficient is an average of the room temperature absolute and relative rate coefficients of Dlugokencky and Howard (1989), Wille et al. (1991), Lancar et al. (1991), Suh et al. (2001), Atkinson et al. (1984) and Berndt and Böge (1997), which are in reasonably good agreement. The temperature dependence of Dlugokencky and Howard (1989) is accepted, and the pre-exponential factor is calculated from the $298 \mathrm{~K}$ preferred rate coefficient and the temperature dependence.

The reaction proceeds by initial addition of the $\mathrm{NO}_{3}$ radical to the carbon-carbon double bonds (Atkinson, 1997). At low pressures the products are $\mathrm{NO}_{2}$ plus an oxirane (Atkinson, 1997). The formation yield of the oxirane decreases with increasing total pressure and with increasing $\mathrm{O}_{2}$ concentration (Atkinson, 1997), with oxirane formation at atmospheric pressure of air being of no importance (Atkinson, 1997; Skov et al., 1994). Using in situ FTIR spectroscopy, Skov et al. (1992) reported that the products formed at atmospheric pressure of air are $\mathrm{O}_{2} \mathrm{NOCH}_{2} \mathrm{C}\left(\mathrm{CH}_{3}\right)=\mathrm{CHCHO}$ as the major product, and with $\mathrm{O}_{2} \mathrm{NOCH}_{2} \mathrm{CH}=\mathrm{C}\left(\mathrm{CH}_{3}\right) \mathrm{CHO}, \mathrm{O}_{2} \mathrm{NOCH}_{2} \mathrm{C}(\mathrm{O}) \mathrm{C}\left(\mathrm{CH}_{3}\right)=\mathrm{CH}_{2}, \mathrm{O}_{2} \mathrm{NOCH}_{2} \mathrm{CH}(\mathrm{OH}) \mathrm{C}\left(\mathrm{CH}_{3}\right)=\mathrm{CH}_{2}$ and $\mathrm{O}_{2} \mathrm{NOCH}_{2} \mathrm{C}\left(\mathrm{CH}_{3}\right)=\mathrm{CHCH}_{2} \mathrm{OH}$ as minor products. Using atmospheric pressure ionization tandem mass spectrome-

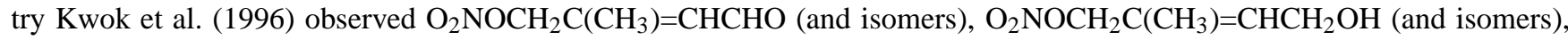
$\mathrm{O}_{2} \mathrm{NOCH}_{2} \mathrm{C}\left(\mathrm{CH}_{3}\right)=\mathrm{CHCH}_{2} \mathrm{OOH}$ (and isomers), and $\mathrm{HOCH}_{2} \mathrm{C}\left(\mathrm{CH}_{3}\right)=\mathrm{CHCHO}$ (and isomers) as products of the reaction (again at atmospheric pressure of air). Kwok et al. (1996) also observed the formation of methacrolein and methyl vinyl ketone, with measured formation yields of each of these $\alpha, \beta$-unsaturated carbonyls being $3.5 \pm 1.4 \%$.

The FTIR study of Skov et al. (1992) indicates that the $\mathrm{NO}_{3}$ radical adds dominantly to the 1- and 4-positions, in a 3.5:1 ratio. At atmospheric pressure of air, the reaction then proceeds mainly by,

$$
\begin{array}{cc}
\mathrm{NO}_{3}+\mathrm{CH}_{2}=\mathrm{C}\left(\mathrm{CH}_{3}\right) \mathrm{CH}=\mathrm{CH}_{2} \rightarrow \quad & \mathrm{O}_{2} \mathrm{NOCH}_{2} \mathrm{C}\left(\mathrm{CH}_{3}\right) \mathrm{CH}=\mathrm{CH}_{2} \\
& \mathrm{O}_{2} \mathrm{NOCH}_{2} \mathrm{C}\left(\mathrm{CH}_{3}\right)=\mathrm{CHCH}_{2}
\end{array}
$$

followed by addition of $\mathrm{O}_{2}$ to form the corresponding peroxy radicals $\mathrm{O}_{2} \mathrm{NOCH}_{2} \mathrm{C}(\mathrm{OO})\left(\mathrm{CH}_{3}\right) \mathrm{CH}=\mathrm{CH}_{2}$ and $\mathrm{O}_{2} \mathrm{NOCH}_{2} \mathrm{C}\left(\mathrm{CH}_{3}\right) \mathrm{CH}=\mathrm{CH}_{2} \mathrm{OO}$. These peroxy radicals then react with $\mathrm{NO}, \mathrm{NO}_{2}, \mathrm{HO}_{2}$ and organic peroxy radicals (Atkinson, 1997), depending on the concentrations of these species.

\section{References}

Atkinson, R.: J. Phys. Chem. Ref. Data, 26, 215, 1997.

Atkinson, R., Aschmann, S. M., Winer, A. M., and Pitts Jr., J. N.: Environ. Sci. Technol., 18, 370, 1984.

Barnes, I., Bastian, V., Becker, K. H., and Tong, Z.: J. Phys. Chem., 94, 2413, 1990.

Benter, T. H. and Schindler, R. N.: Chem. Phys. Lett., 145, 67, 1988.

Berndt, T. and Böge, O.: Int. J. Chem. Kinet., 29, 755, 1997.

Dlugokencky, E. J. and Howard, C. J.: J. Phys. Chem., 93, 1091, 1989.

Ellermann, T., Nielsen, O. J., and Skov, H.: Chem. Phys. Lett., 200, 224, 1992.

Kwok, E. S. C., Aschmann, S. M., Arey, J., and Atkinson, R.: Int. J. Chem. Kinet., 28, 925, 1996.

Lancar, I. T., Daële, V., Le Bras, G., and Poulet, G.: J. Chim. Phys., 88, 1777, 1991.

Skov, H., Benter, Th., Schindler, R. N., Hjorth, J., and Restelli, G.: Atmos. Environ., 28, 1583, 1994.

Skov, H., Hjorth, J., Lohse, C., Jensen, N. R., and Restelli, G.: Atmos. Environ., 26A, 2771, 1992.

Suh, I., Lei, W., and Zhang, R.: J. Phys. Chem. A, 105, 6471, 2001.

Wille, U., Becker, E., Schindler, R. N., Lancar, I. T., Poulet, G., and Le Bras, G.: J. Atmos. Chem., 13, 183, 1991. 
II.A3.70

$$
\mathrm{NO}_{3}+\alpha \text {-Pinene } \rightarrow \text { products }
$$

\section{Rate coefficient data}

\begin{tabular}{lllc}
\hline$k / \mathrm{cm}^{3}$ molecule ${ }^{-1} \mathrm{~s}^{-1}$ & Temp./K & Reference & Technique/Comments \\
\hline Absolute Rate Coefficients & & & \\
$1.19 \times 10^{-12} \exp [(490 \pm 70) / T]$ & $261-384$ & Dlugokencky and Howard, 1989 & F-LIF(a) \\
$(6.18 \pm 0.74) \times 10^{-12}$ & 298 & & \\
$3.5 \times 10^{-13} \exp [(841 \pm 144) / T]$ & $298-423$ & Martinez et al., 1998 & DF-LIF(b) \\
$(5.9 \pm 0.8) \times 10^{-12}$ & 298 & & \\
& & & \\
Relative Rate Coefficients & $295 \pm 1$ & Atkinson et al., 1984 & \\
$(5.82 \pm 0.16) \times 10^{-12}$ & $298 \pm 2$ & Barnes et al., 1990 & RR(c) \\
$(6.56 \pm 0.94) \times 10^{-12}$ & & & RR(d) \\
\hline
\end{tabular}

\section{Comments}

(a) $\mathrm{NO}_{3}$ radicals were generated by the thermal decomposition of $\mathrm{N}_{2} \mathrm{O}_{5}$ at $\sim 400 \mathrm{~K}$. Experiments were carried out in a lowpressure flow tube at $\sim 1.3-1.4$ mbar of He diluent. The $\mathrm{NO}_{2}$ yield at $1.3 \mathrm{mbar} \mathrm{He}$ and $298 \mathrm{~K}$ was $67 \%$.

(b) Carried out under conditions such that a second-order kinetic analysis was necessary.

(c) $\mathrm{NO}_{3}$ radicals were generated by the thermal decomposition of $\mathrm{N}_{2} \mathrm{O}_{5}$. The concentrations of $\alpha$-pinene and 2-methyl-2butene (the reference compound) were monitored by GC in reacting $\mathrm{N}_{2} \mathrm{O}_{5}-\mathrm{NO}_{2}-\alpha$-pinene-2-methyl-2-butene-air mixtures at 980 mbar pressure in a $\sim 6400 \mathrm{~L}$ Teflon chamber. The measured rate coefficient ratio $k\left(\mathrm{NO}_{3}+\alpha\right.$-pinene $) / k\left(\mathrm{NO}_{3}+\right.$ 2-methyl-2-butene $)=0.621 \pm 0.017$ is placed on an absolute basis by use of a rate coefficient at $295 \mathrm{~K}$ of $k\left(\mathrm{NO}_{3}+2\right.$ methyl-2-butene) $=9.37 \times 10^{-12} \mathrm{~cm}^{3}$ molecule ${ }^{-1} \mathrm{~s}^{-1}$ (Atkinson and Arey, 2003a).

(d) $\mathrm{NO}_{3}$ radicals were generated by the thermal decomposition of $\mathrm{N}_{2} \mathrm{O}_{5}$. The concentrations of $\alpha$-pinene and 2-methyl-2butene (the reference compound) were monitored by GC in reacting $\mathrm{N}_{2} \mathrm{O}_{5}-\alpha$-pinene-2-methyl-2-butene-air mixtures at 1 bar pressure in a $420 \mathrm{~L}$ glass reaction vessel. The measured rate coefficient ratio $k\left(\mathrm{NO}_{3}+\alpha\right.$-pinene $) / k\left(\mathrm{NO}_{3}+2\right.$-methyl2-butene $)=0.70 \pm 0.10$ is placed on an absolute basis by use of a rate coefficient at $298 \mathrm{~K}$ of $k\left(\mathrm{NO}_{3}+2\right.$-methyl-2-butene $)$ $=9.37 \times 10^{-12} \mathrm{~cm}^{3}$ molecule ${ }^{-1} \mathrm{~s}^{-1}$ (Atkinson and Arey, 2003a).

\section{Preferred Values}

$k=6.2 \times 10^{-12} \mathrm{~cm}^{3}$ molecule ${ }^{-1} \mathrm{~s}^{-1}$ at $298 \mathrm{~K}$.

$k=1.2 \times 10^{-12} \exp (490 / T) \mathrm{cm}^{3}$ molecule ${ }^{-1} \mathrm{~s}^{-1}$ over the temperature range $260-390 \mathrm{~K}$.

\section{Reliability}

$\Delta \log k= \pm 0.10$ at $298 \mathrm{~K}$.

$\Delta(E / R)= \pm 300 \mathrm{~K}$.

\section{Comments on Preferred Values}

The room temperature relative rate coefficients of Atkinson et al. (1984) and Barnes et al. (1990) and the absolute rate coefficients of Dlugokencky and Howard (1989) and Martínez et al. (1998) are in excellent agreement. However, the temperature dependencies obtained by Dlugokencky and Howard (1989) and Martínez et al. (1998) differ significantly. Because the study of Dlugokency and Howard (1989) extends to lower temperatures representative of the troposphere, the data from the studies of Atkinson et al. (1984), Dlugokencky and Howard (1989) and Barnes et al. (1990) are used in the evaluation of the rate coefficient for this reaction. The preferred values are obtained from a least-squares fit of the rate coefficients of Atkinson 
et al. (1984), Dlugokencky and Howard (1989) and Barnes et al. (1990). The is no evidence for a pressure dependence of the rate coefficient over the range $\sim 1-1000$ mbar, at least at room temperature.

The reaction proceeds by initial addition of $\mathrm{NO}_{3}$ to the $\mathrm{C}=\mathrm{C}$ bond. At low pressures or in the absence of $\mathrm{O}_{2}$, the initially formed nitrooxyalkyl radicals eliminate $\mathrm{NO}_{2}$ and form $\alpha$-pinene oxide (Dlugokencky and Howard, 1989; Atkinson, 1991; Berndt and Böge, 1997). At atmospheric pressure of air, $\mathrm{O}_{2}$ addition to the nitrooxyalkyl radicals forms two nitrooxyalkyl peroxy radicals, although some $\alpha$-pinene oxide ( $3 \pm 0.5 \%)$ is still observed at 1 bar of air (Wängberg et al., 1997). The nitrooxyalkyl peroxy radicals then react with $\mathrm{HO}_{2}$ radicals, organic peroxy radicals, $\mathrm{NO}, \mathrm{NO}_{2}$, and $\mathrm{NO}_{3}$ radicals, leading to the observed products (Atkinson and Arey, 2003a, b). Under laboratory conditions, the observed products and their yields at atmospheric pressure of air are: pinonaldehyde, 62 $\pm 4 \%$ (Wängberg et al., 1997) and 69\% (Hallquist et al., 1999); 2-hydroxypinan-3nitrate, $5 \pm 0.4 \%$ (Wängberg et al., 1997); 3-oxopinan-2-nitrate, $3 \pm 0.2 \%$ (Wängberg et al., 1997); and $\alpha$-pinene oxide, $3 \pm 0.5 \%$ (Wängberg et al., 1997), with a total organic nitrate yield of 14-19\% (Wängberg et al., 1997; Hallquist et al., 1999). Note that the products formed in the atmosphere, and their yields, may be different from those observed in laboratory studies, because of the differing concentrations (both absolute and relative) of $\mathrm{HO}_{2}, \mathrm{RO}_{2}$ and $\mathrm{NO}_{3}$ radicals and $\mathrm{NO}$ and $\mathrm{NO}_{2}$.

\section{References}

Atkinson, R.: J. Phys. Chem. Ref. Data, 20, 459, 1991.

Atkinson, R. and Arey, J.: Chem. Rev., 103, 4605, 2003 a.

Atkinson, R. and Arey, J.: Atmos. Environ., 37 Suppl. 2, S197, 2003b.

Atkinson, R., Aschmann, S. M., Winer, A. M., and Pitts Jr., J. N.: Environ. Sci. Technol., 18, $370,1984$.

Barnes, I., Bastian, V., Becker, K. H., and Tong, Z.: J. Phys. Chem., 94, 2413, 1990.

Berndt, T. and Böge, O.: J. Chem. Soc. Faraday Trans., 93, 3021, 1997.

Dlugokencky, E. J. and Howard, C. J.: J. Phys. Chem., 93, 1091, 1989.

Hallquist, M., Wängberg, I., Ljungström, E., Barnes, I., and Becker, K.-H.: Environ. Sci. Technol., 33, 553, 1999.

Martínez, E., Cabañas, B., Aranda, A., and Martin, P.: Environ. Sci. Technol., 32, 3730, 1998.

Wängberg, I., Barnes, I., and Becker, K. H.: Environ. Sci. Technol., 31, 2130, 1997. 
II.A3.71

$$
\mathrm{NO}_{3}+\mathrm{HCHO} \rightarrow \mathrm{HNO}_{3}+\mathrm{HCO}
$$

$\Delta H^{\circ}=-57.1 \mathrm{~kJ} \cdot \mathrm{mol}^{-1}$

\section{Rate coefficient data}

\begin{tabular}{lclc}
\hline$k / \mathrm{cm}^{3}$ molecule ${ }^{-1} \mathrm{~s}^{-1}$ & Temp./K & Reference & Technique/Comments \\
\hline $\begin{array}{l}\text { Absolute Rate Coefficients } \\
5.6 \times 10^{-16}\end{array}$ & $298 \pm 2$ & Cantrell et al., 1985 & (a) \\
& & & \\
Relative Rate Coefficients & & & \\
$(5.01 \pm 0.41) \times 10^{-16}$ & $298 \pm 1$ & Atkinson et al., 1984 & $(\mathrm{b}, \mathrm{c})$ \\
$(8.4 \pm 1.5) \times 10^{-16}$ & $298 \pm 2$ & Cantrell et al., 1985 & $(\mathrm{c}, \mathrm{d})$ \\
$(1.21 \pm 0.25) \times 10^{-15}$ & $295 \pm 2$ & Hjorth et al., 1988 & $(\mathrm{~b}, \mathrm{c}, \mathrm{d}, \mathrm{e})$ \\
\hline
\end{tabular}

\section{Comments}

(a) $\mathrm{NO}_{3}$ radicals were generated in situ from the reaction $\mathrm{NO}_{2}+\mathrm{O}_{3} \rightarrow \mathrm{NO}_{3}+\mathrm{O}_{2}$. $\mathrm{NO}_{3}$ radical concentrations were measured by differential optical absorption spectroscopy (DOAS), and the rate coefficient derived from the concentrations of reactants and products measured by FTIR absorption spectroscopy and by DOAS (for the $\mathrm{NO}_{3}$ radical and $\mathrm{NO}_{2}$ ).

(b) $\mathrm{NO}_{3}$ radicals were generated by the thermal decomposition of $\mathrm{N}_{2} \mathrm{O}_{5}$.

(c) Relative to the equilibrium coefficient $K$ for the reactions $\mathrm{NO}_{2}+\mathrm{NO}_{3} \leftrightarrow \mathrm{N}_{2} \mathrm{O}_{5}$. The experimental data are placed on an absolute basis by use of an equilibrium coefficient of $K=2.90 \times 10^{-11} \mathrm{~cm}^{3}$ molecule ${ }^{-1}$ at $298 \mathrm{~K}$ and $4.22 \times 10^{-11} \mathrm{~cm}^{3}$ molecule ${ }^{-1}$ at $295 \mathrm{~K}$ (IUPAC, current recommendation).

(d) $\mathrm{NO}_{3}$ radicals were generated in situ from the reaction $\mathrm{NO}_{2}+\mathrm{O}_{3} \rightarrow \mathrm{NO}_{3}+\mathrm{O}_{2}$.

(e) Note that while the equilibrium coefficient used in the data analysis of Hjorth et al. (1988) was stated to be from Graham and Johnston (1978) $\left(3.43 \times 10^{-11} \mathrm{~cm}^{3}\right.$ molecule ${ }^{-1}$ at $\left.295 \mathrm{~K}\right)$, the value used (Hjorth et al., 1988) was $1.88 \times 10^{-11} \mathrm{~cm}^{3}$ molecule ${ }^{-1}$.

\section{Preferred Values}

$k=5.6 \times 10^{-16} \mathrm{~cm}^{3}$ molecule ${ }^{-1} \mathrm{~s}^{-1}$ at $298 \mathrm{~K}$.

\section{Reliability}

$\Delta \log k= \pm 0.3$ at $298 \mathrm{~K}$.

\section{Comments on Preferred Values}

The relative rate coefficients measured by Atkinson et al. (1984), Cantrell et al. (1985) and Hjorth et al. (1988) disagree by a factor of $\sim 2.5$ when a consistent temperature-dependent equilibrium coefficient for the $\mathrm{NO}_{2}+\mathrm{NO}_{3} \leftrightarrow \mathrm{N}_{2} \mathrm{O}_{5}$ reactions is used to place the rate coefficients on an absolute basis. The rate coefficient obtained by Cantrell et al. (1985) from experiments in which $\mathrm{NO}_{3}$ radicals were measured directly by DOAS (and hence derivation of the rate coefficient does not involve the equilibrium coefficient for the $\mathrm{NO}_{2}+\mathrm{NO}_{3} \leftrightarrow \mathrm{N}_{2} \mathrm{O}_{5}$ reactions) falls within the range of these relative rate coefficients (Atkinson et al., 1984; Cantrell et al., 1985; Hjorth et al., 1988).

Accordingly, the preferred value of $k=5.6 \times 10^{-16} \mathrm{~cm}^{3}$ molecule $\mathrm{e}^{-1} \mathrm{~s}^{-1}$ at $298 \mathrm{~K}$ is based on the absolute rate measurements of Cantrell et al. (1985), with the uncertainty limits reflecting the single absolute study. While no temperature dependence of the rate coefficient has been measured to date, by analogy with the $\mathrm{NO}_{3}$ radical reaction with $\mathrm{CH}_{3} \mathrm{CHO}$ a pre-exponential factor of $\sim 2 \times 10^{-12} \mathrm{~cm}^{3}$ molecule ${ }^{-1} \mathrm{~s}^{-1}$ is expected, and hence $k\left(\mathrm{NO}_{3}+\mathrm{HCHO}\right) \sim 2 \times 10^{-12} \exp (-2440 / \mathrm{T}) \mathrm{cm}^{3} \mathrm{molecule}^{-1}$ 
$\mathrm{s}^{-1}$. This reaction proceeds by $\mathrm{H}$-atom abstraction.

$$
\mathrm{NO}_{3}+\mathrm{HCHO} \rightarrow \mathrm{HNO}_{3}+\mathrm{HCO}
$$

\section{References}

Atkinson, R., Plum, C. N., Carter, W. P. L., Winer, A. M., and Pitts Jr., J. N.: J. Phys. Chem., 88, 1210, 1984.

Cantrell, C. A., Stockwell, W. R., Anderson, L. G., Busarow, K. L., Perner, D., Schmeltekopf, A., Calvert, J. G., and Johnston, H. S.: J. Phys. Chem., 89, 139, 1985.

Graham, R. A. and Johnston, H. S.: J. Phys. Chem., 82, 254, 1978.

Hjorth, J., Ottobrini, G., and Restelli, G.: J. Phys. Chem., 92, 2669, 1988.

IUPAC: http://www.iupac-kinetic.ch.cam.ac.uk/. 
II.A3.72

$$
\mathrm{NO}_{3}+\mathrm{CH}_{3} \mathrm{CHO} \rightarrow \mathrm{HNO}_{3}+\mathrm{CH}_{3} \mathrm{CO}
$$

$\Delta H^{\circ}=-53.0 \mathrm{~kJ} \cdot \mathrm{mol}^{-1}$

\section{Rate coefficient data}

\begin{tabular}{llll}
\hline$k / \mathrm{cm}^{3}$ molecule ${ }^{-1} \mathrm{~s}^{-1}$ & Temp./K & Reference & Technique/Comments \\
\hline Absolute Rate Coefficients & & & \\
$1.44 \times 10^{-12} \exp [-(1860 \pm 300) / T]$ & $264-374$ & Dlugokencky and Howard, 1989 & F-LIF (a) \\
$(2.74 \pm 0.33) \times 10^{-15}$ & 298 & & \\
$6.2 \times 10^{-11} \exp [-(2826 \pm 866) / T]$ & $298-433$ & Cabañas et al., 2001 & DF-LIF (b) \\
$(3.2 \pm 0.8) \times 10^{-15}$ & $298 \pm 2$ & & \\
& & & \\
Relative Rate Coefficients & 300 & Morris and Niki, 1974 & \\
$(2.17 \pm 0.55) \times 10^{-15}$ & $298 \pm 1$ & Atkinson et al., 1984 & RR (c) \\
$(2.08 \pm 0.52) \times 10^{-15}$ & $299 \pm 1$ & Cantrell et al., 1986 & RR (c) \\
$(2.69 \pm 0.52) \times 10^{-15}$ & $298 \pm 2$ & D'Anna et al., 2001a, b & RR (c) \\
$(2.62 \pm 0.29) \times 10^{-15}$ & & & RR (d) \\
\hline
\end{tabular}

\section{Comments}

(a) $\mathrm{NO}_{3}$ radicals were generated by the thermal dissociation of $\mathrm{N}_{2} \mathrm{O}_{5}$ in a flow system. Initial $\mathrm{NO}_{3}$ radical concentrations were $(0.6-3.0) \times 10^{10}$ molecule $\mathrm{cm}^{-3}$.

(b) Initial $\mathrm{NO}_{3}$ radical concentrations were $(0.6-3.0) \times 10^{12}$ molecule $\mathrm{cm}^{-3}$.

(c) The cited rate coefficients are relative to the equilibrium coefficient $K$ for the reactions $\mathrm{NO}_{3}+\mathrm{NO}_{2} \leftrightarrow \mathrm{N}_{2} \mathrm{O}_{5}$, with values of $\mathrm{K}=2.90 \times 10^{-11} \mathrm{~cm}^{3}$ molecule ${ }^{-1}$ at $298 \mathrm{~K}, 2.56 \times 10^{-11} \mathrm{~cm}^{3}$ molecule ${ }^{-1}$ at $299 \mathrm{~K}$ and $2.26 \times 10^{-11} \mathrm{~cm}^{3} \mathrm{molecule}^{-1}$ at $300 \mathrm{~K}$ being used (IUPAC, current recommendation) to place the measured rate coefficient ratios on an absolute basis.

(d) Relative rate method, with $\mathrm{NO}_{3}$ radicals being generated by the thermal dissociation of $\mathrm{N}_{2} \mathrm{O}_{5}$. Experiments were carried out in 1 atmosphere of air with measurements of acetaldehyde and 1-butene (the reference compound) by FTIR spectroscopy. The measured rate coefficient ratio $k\left(\mathrm{NO}_{3}+\right.$ acetaldehyde $) / k\left(\mathrm{NO}_{3}+1\right.$-butene $)=0.194 \pm 0.021$ is placed on an absolute basis by use of a rate coefficient of $k\left(\mathrm{NO}_{3}+1\right.$-butene) $=1.35 \times 10^{-14} \mathrm{~cm}^{3}$ molecule ${ }^{-1} \mathrm{~s}^{-1}$ at $298 \mathrm{~K}$ (Atkinson, 1997). Experiments with acetaldehyde-d $\mathrm{d}_{1}\left(\mathrm{CH}_{3} \mathrm{CDO}\right)$ yielded a rate coefficient ratio $k\left(\mathrm{NO}_{3}+\mathrm{CH}_{3} \mathrm{CHO}\right) / k\left(\mathrm{NO}_{3}+\right.$ $\left.\mathrm{CH}_{3} \mathrm{CDO}\right)=2.37 \pm 0.08$ at $298 \pm 2 \mathrm{~K}$ (D'Anna et al., 2001b).

\section{Preferred Values}

$k=2.7 \times 10^{-15} \mathrm{~cm}^{3}$ molecule ${ }^{-1} \mathrm{~s}^{-1}$ at $298 \mathrm{~K}$.

$k=1.4 \times 10^{-12} \exp (-1860 / T) \mathrm{cm}^{3}$ molecule ${ }^{-1} \mathrm{~s}^{-1}$ over the temperature range 260-380 K.

\section{Reliability}

$\Delta \log k= \pm 0.2$ at $298 \mathrm{~K}$.

$\Delta(E / R)= \pm 500 \mathrm{~K}$.

\section{Comments on Preferred Values}

The rate coefficients measured relative to the equilibrium coefficient for the reactions $\mathrm{NO}_{2}+\mathrm{NO}_{3} \leftrightarrow \mathrm{N}_{2} \mathrm{O}_{5}$ are subject to significant uncertainties arising from uncertainties in the equilibrium coefficient for these reactions, and the relative rate coefficients of Morris and Niki (1974), Atkinson et al. (1984) and Cantrell et al. (1986) are therefore not used in the evaluation 
of the rate coefficient for this reaction (although they are in agreement with the absolute room temperature rate coefficient of Dlugokencky and Howard (1989)). The room temperature rate coefficient of D'Anna et al. (2001a, b), determined relative to that for the reaction of $\mathrm{NO}_{3}$ radicals with 1-butene, is in excellent agreement with the absolute rate coefficient measured by Dlugokencky and Howard (1989). The absolute study of Cabañas et al. (2001) employed much higher initial $\mathrm{NO}_{3}$ radical concentrations than did Dlugokencky and Howard (1989) (by a factor of 100) and the measured rate coefficients (Cabañas et al., 2001) are significantly less precise and show a significantly higher temperature dependence.

The preferred values are based upon the absolute rate coefficient study of Dlugokencky and Howard (1989). The significant deuterium isotope effect observed by D'Anna et al. (2001b) indicates that, as expected, the reaction proceeds by H- (or D-) atom abstraction from the $-\mathrm{CHO}$ (or - $\mathrm{CDO}$ ) group.

\section{References}

Atkinson, R.: J. Phys. Chem. Ref. Data, 26, 215, 1997.

Atkinson, R., Plum, C. N., Carter, W. P. L., Winer, A. M., and Pitts Jr., J. N.: J. Phys. Chem., 88, 1210, 1984.

Cabañas, B., Martín, P., Salgado, S., Ballesteros, B., and Martínez, E.: J. Atmos. Chem., 40, 23, 2001.

Cantrell, C. A., Davidson, J. A., Busarow, K. L., and Calvert, J. G.: J. Geophys. Res.,91, 5347, 1986.

D’Anna, B., Andresen, Ø., Gefen, Z., and Nielsen, C. J.: Phys. Chem. Chem. Phys., 3, 3057, 2001 a.

D’Anna, B., Langer, S., Ljungström, E., Nielsen, C. J., and Ullerstam, M.: Phys. Chem. Chem. Phys., 3, 1631, 2001 b.

Dlugokencky, E. J. and Howard, C. J.: J. Phys. Chem., 93, 1091, 1989.

IUPAC: http://www.iupac-kinetic.ch.cam.ac.uk/.

Morris Jr., E. D. and Niki, H.: J. Phys. Chem., 78, 1337, 1974. 
II.A3.73

$$
\mathrm{NO}_{3}+\mathrm{CH}_{3} \mathrm{CH}_{2} \mathrm{CHO} \rightarrow \text { products }
$$

\section{Rate coefficient data}

\begin{tabular}{lclc}
\hline$k / \mathrm{cm}^{3}$ molecule ${ }^{-1} \mathrm{~s}^{-1}$ & Temp./K & Reference & Technique/Comments \\
\hline $\begin{array}{l}\text { Absolute Rate Coefficients } \\
\left.\left.1.7 \times 10^{-11} \text { exp[-(2250 } \pm 192\right) / T\right]\end{array}$ & $298-433$ & Cabañas et al., 2001 & DF-LIF \\
$(6.0 \pm 0.6) \times 10^{-15}$ & $298 \pm 2$ & & \\
& & & \\
Relative Rate Coefficients & & & RR (a) \\
$(5.80 \pm 0.48) \times 10^{-15}$ & $298 \pm 2$ & D'Anna and Nielsen, 1997 & RR (b) \\
$(7.28 \pm 0.41) \times 10^{-15}$ & $296 \pm 2$ & Papagni et al., 2000 & RR (a) \\
$(6.18 \pm 0.57) \times 10^{-15}$ & $298 \pm 2$ & D'Anna et al., 2001 & \\
\hline
\end{tabular}

\section{Comments}

(a) Relative rate method, with $\mathrm{NO}_{3}$ radicals being generated by the thermal dissociation of $\mathrm{N}_{2} \mathrm{O}_{5}$. Experiments were carried out in 1 atmosphere of air with measurements of propanal and propene (the reference compound) by FTIR spectroscopy. The measured rate coefficient ratios $k\left(\mathrm{NO}_{3}+\right.$ propanal $) / k\left(\mathrm{NO}_{3}+\right.$ propene $)=0.61 \pm 0.05$ (D'Anna and Nielsen, 1997) and $0.65 \pm 0.06$ (D'Anna et al., 2001) are placed on an absolute basis by use of a rate coefficient of $k\left(\mathrm{NO}_{3}+\right.$ propene $)=$ $9.5 \times 10^{-15} \mathrm{~cm}^{3}$ molecule $\mathrm{s}^{-1} \mathrm{~s}^{-1}$ at $298 \mathrm{~K}$ (IUPAC, current recommendation).

(b) Relative rate method, with $\mathrm{NO}_{3}$ radicals being generated by the thermal dissociation of $\mathrm{N}_{2} \mathrm{O}_{5}$. Experiments were carried out in 1 atmosphere of air with measurements of propanal and methacrolein (the reference compound) by GC. The measured rate coefficient ratio $k\left(\mathrm{NO}_{3}+\right.$ propanal $) / k\left(\mathrm{NO}_{3}+\right.$ methacrolein $)=2.14 \pm 0.12$ is placed on an absolute basis by use of a rate coefficient of $k\left(\mathrm{NO}_{3}+\right.$ methacrolein $)=3.4 \times 10^{-15} \mathrm{~cm}^{3}$ molecule ${ }^{-1} \mathrm{~s}^{-1}$ at $296 \mathrm{~K}$ (IUPAC, current recommendation).

\section{Preferred Values}

$k=6.4 \times 10^{-15} \mathrm{~cm}^{3}$ molecule ${ }^{-1} \mathrm{~s}^{-1}$ at $298 \mathrm{~K}$.

\section{Reliability}

$\Delta \log k= \pm 0.2$ at $298 \mathrm{~K}$.

\section{Comments on Preferred Values}

The preferred $298 \mathrm{~K}$ rate coefficient is the average of the room temperature relative rate coefficients of D'Anna et al. (1997, 2001) and Papagni et al. (2000), which are in reasonable agreement and which also agree with the absolute room temperature rate coefficient of Cabañas et al. (2001). Because of the higher temperature dependence obtained by Cabañas et al. (2001) for the reactions of $\mathrm{NO}_{3}$ radicals with acetaldehyde and butanal than by other investigators (IUPAC, this evaluation) and because the rate coefficient at $298 \mathrm{~K}$ calculated from the Arrhenius expression of Cabañas et al. (2001) is 50\% higher than their measured value, the Cabañas et al. (2001) data are not used in the evaluation of the rate coefficient for this reaction, and no recommendation is made concerning the temperature dependence for this reaction.

\section{References}

Cabañas, B., Martín, P., Salgado, S., Ballesteros, B., and Martínez, E.: J. Atmos. Chem., 40, 23, 2001.

D'Anna, B. and Nielsen, C. J.: J. Chem. Soc. Faraday Trans., 93, 3479, 1997.

D’Anna, B., Andresen, Ø., Gefen, Z., and Nielsen, C. J.: Phys. Chem. Chem. Phys., 3, 3057, 2001.

IUPAC: http://www.iupac-kinetic.ch.cam.ac.uk/.

Papagni, C., Arey, J., and Atkinson, R.: Int. J. Chem. Kinet., 32, 79, 2000. 
II.A3.74

$$
\mathrm{NO}_{3}+\mathrm{CH}_{3} \mathrm{CH}_{2} \mathrm{CH}_{2} \mathrm{CHO} \rightarrow \text { products }
$$

\section{Rate coefficient data}

\begin{tabular}{lllc}
\hline $\mathrm{k} / \mathrm{cm}^{3}$ molecule ${ }^{-1} \mathrm{~s}^{-1}$ & Temp./K & Reference & Technique/Comments \\
\hline Absolute Rate Coefficients & & & \\
$1.26 \times 10^{-12} \exp (-1478 / T)$ & $267-332$ & Ullerstam et al., 2000 & DF-RA (a) \\
$(1.1 \pm 0.1) \times 10^{-14}$ & 296 & & \\
$7.6 \times 10^{-11} \exp [-(2466 \pm 505) / T]$ & $298-433$ & Cabañas et al., 2001 & DF-LIF \\
$(1.46 \pm 0.16) \times 10^{-14}$ & $298 \pm 2$ & & \\
& & & \\
Relative Rate Coefficients & $298 \pm 2$ & D'Anna and Nielsen, 1997 & RR (b) \\
$(1.09 \pm 0.09) \times 10^{-14}$ & $297 \pm 2$ & Ullerstam et al., 2000 & RR (c) \\
$(1.04 \pm 0.11) \times 10^{-14}$ & $296 \pm 2$ & Papagni et al., 2000 & RR (d) \\
$(1.15 \pm 0.06) \times 10^{-14}$ & $298 \pm 2$ & D'Anna et al., 2001 & RR (b) \\
$(1.23 \pm 0.11) \times 10^{-14}$ & & &
\end{tabular}

\section{Comments}

(a) Carried out in the presence of $20 \% \mathrm{O}_{2}$ in the diluent gas to minimize secondary reactions (experiments in the absence of $\mathrm{O}_{2}$ yielded rate coefficents a factor of $\sim 3$ higher (Ullerstam et al., 2000)). The Arrhenius expression cited in the table is obtained from a least-squares analysis of the measured rate coefficients at $267 \mathrm{~K}, 296 \mathrm{~K}$ and $332 \mathrm{~K}$.

(b) Relative rate method, with $\mathrm{NO}_{3}$ radicals being generated by the thermal dissociation of $\mathrm{N}_{2} \mathrm{O}_{5}$. Experiments were carried out in 1 atmosphere of air with measurements of butanal and 1-butene (the reference compound) by FTIR spectroscopy. The measured rate coefficient ratios $k\left(\mathrm{NO}_{3}+\right.$ butanal $) / k\left(\mathrm{NO}_{3}+1\right.$-butene $)=0.81 \pm 0.06$ (D'Anna and Nielsen, 1997) and $0.91 \pm 0.08$ (D'Anna et al., 2001) are placed on an absolute basis by use of a rate coefficient of $k\left(\mathrm{NO}_{3}+1\right.$-butene) $=$ $1.35 \times 10^{-14} \mathrm{~cm}^{3}$ molecule ${ }^{-1} \mathrm{~s}^{-1}$ at $298 \mathrm{~K}$ (Atkinson, 1997).

(c) Relative rate method, with $\mathrm{NO}_{3}$ radicals being generated by the thermal dissociation of $\mathrm{N}_{2} \mathrm{O}_{5}$. Experiments were carried out in 1 atmosphere of synthetic air or $\mathrm{N}_{2}$ with measurements of butanal and propene (the reference compound) by FTIR spectroscopy. The measured rate coefficient ratios $k\left(\mathrm{NO}_{3}+\right.$ butanal $) / k\left(\mathrm{NO}_{3}+\right.$ propene $)=1.1 \pm 0.1$ is placed on an absolute basis by use of a rate coefficient of $k\left(\mathrm{NO}_{3}+\right.$ propene) $=9.42 \times 10^{-15} \mathrm{~cm}^{3}$ molecule $\mathrm{s}^{-1}$ at $297 \mathrm{~K}$ (IUPAC, current recommendation). The rate coefficient ratio was independent of the presence or absence of $\mathrm{O}_{2}$.

(d) Relative rate method, with $\mathrm{NO}_{3}$ radicals being generated by the thermal dissociation of $\mathrm{N}_{2} \mathrm{O}_{5}$. Experiments were carried out in 1 atmosphere of air with measurements of butanal and methacrolein (the reference compound) by GC. The measured rate coefficient ratio $k\left(\mathrm{NO}_{3}+\right.$ butanal $) / k\left(\mathrm{NO}_{3}+\right.$ methacrolein $)=3.38 \pm 0.15$ is placed on an absolute basis by use of a rate coefficient of $k\left(\mathrm{NO}_{3}+\right.$ methacrolein $)=3.4 \times 10^{-15} \mathrm{~cm}^{3}$ molecule $\mathrm{e}^{-1} \mathrm{~s}^{-1}$ at $296 \mathrm{~K}$ (IUPAC, current recommendation).

\section{Preferred Values}

$k=1.1 \times 10^{-14} \mathrm{~cm}^{3}$ molecule ${ }^{-1} \mathrm{~s}^{-1}$ at $298 \mathrm{~K}$.

$k=1.7 \times 10^{-12} \exp (-1500 / T) \mathrm{cm}^{3}$ molecule ${ }^{-1} \mathrm{~s}^{-1}$ over the temperature range $260-340 \mathrm{~K}$.

\section{Reliability}

$\Delta \log k= \pm 0.15$ at $298 \mathrm{~K}$.

$\Delta(E / R)= \pm 500 \mathrm{~K}$. 


\section{Comments on Preferred Values}

The preferred $298 \mathrm{~K}$ rate coefficient is the average of the room temperature relative rate coefficients of D'Anna and Nielsen (1977), D'Anna et al. (2001), Ullerstam et al. (2000) and Papagni et al. (2001) and the absolute rate coefficient of Ullerstam et al. (2000) (measured in the presence of $\mathrm{O}_{2}$ ). The absolute rate coefficient measured at $298 \mathrm{~K}$ by Cabañas et al. (2001) is 20-40\% higher than the other absolute and relative rate coefficients (D'Anna and Nielsen, 1997; D'Anna et al., 2001; Papagni et al., 2000; Ullerstam et al., 2000), possibly indicating the occurrence of secondary reactions. The two measurements of the temperature dependence (Cabañas et al., 2001; Ullerstam et al., 2000) disagree significantly, with the pre-exponential factor derived from the study of Cabañas et al. (2001) being within a factor of $\sim 5$ of gas kinetic. The preferred temperature dependence is that obtained from the study of Ullerstam et al. (2000), with a high uncertainty.

\section{References}

Atkinson, R.: J. Phys. Chem. Ref. Data, 26, 215, 1997.

Cabañas, B., Martín, P., Salgado, S., Ballesteros, B., and Martínez, E.: J. Atmos. Chem., 40, 23, 2001.

D’Anna, B. and Nielsen, C. J.: J. Chem. Soc. Faraday Trans., 93, 3479, 1997.

D’Anna, B., Andresen, Ø., Gefen, Z., and Nielsen, C. J.: Phys. Chem. Chem. Phys., 3, 3057, 2001.

IUPAC: http://www.iupac-kinetic.ch.cam.ac.uk/.

Papagni, C., Arey, J., and Atkinson, R.: Int. J. Chem. Kinet., 32, 79, 2000.

Ullerstam, M., Langer, S., and Ljungström, E.: Int. J. Chem. Kinet., 32, 294, 2000. 
II.A3.75

$$
\mathrm{NO}_{3}+\mathrm{CH}_{2}=\mathrm{C}\left(\mathrm{CH}_{3}\right) \mathrm{CHO} \text { (methacrolein) } \rightarrow \text { products }
$$

\section{Rate coefficient data}

\begin{tabular}{llll}
\hline$k / \mathrm{cm}^{3}$ molecule ${ }^{-1} \mathrm{~s}^{-1}$ & Temp./K & Reference & Technique/Comments \\
\hline $\begin{array}{l}\text { Absolute Rate Coefficients } \\
\leq 8 \times 10^{-15}\end{array}$ & 298 & Rudich et al., 1996 & F-A (a) \\
& & & \\
$\begin{array}{l}\text { Relative Rate Coefficients } \\
(4.46 \pm 0.58) \times 10^{-15}\end{array}$ & $296 \pm 2$ & Kwok et al., 1996 & RR (b) \\
$(3.08 \pm 0.18) \times 10^{-15}$ & $298 \pm 2$ & Chew et al., 1998 & RR (c) \\
$(3.50 \pm 0.15) \times 10^{-15}$ & $298 \pm 2$ & Chew et al., 1998 & RR (d) \\
$(3.72 \pm 0.47) \times 10^{-15}$ & $296 \pm 2$ & Canosa-Mas et al., 1999 & RR (e) \\
\hline
\end{tabular}

\section{Comments}

(a) $\mathrm{NO}_{3}$ radicals were generated by thermal decomposition of $\mathrm{N}_{2} \mathrm{O}_{5}$ in a flow system at total pressures of 1.5-3 Torr (24 mbar), and monitored by absorption at $661.9 \mathrm{~nm}$.

(b) Relative rate method carried out at atmospheric pressure of air. $\mathrm{NO}_{3}$ radicals were generated by thermal decomposition of $\mathrm{N}_{2} \mathrm{O}_{5}$. The concentrations of methacrolein and propene (the reference compound) were measured by GC. The measured rate coefficient ratio of $k\left(\mathrm{NO}_{3}+\right.$ methacrolein $) / k\left(\mathrm{NO}_{3}+\right.$ propene $)=0.48 \pm 0.06$ is placed on an absolute basis by use of a rate coefficient of $k\left(\mathrm{NO}_{3}+\right.$ propene $)=9.29 \times 10^{-15} \mathrm{~cm}^{3}$ molecule ${ }^{-1} \mathrm{~s}^{-1}$ at $296 \mathrm{~K}$ (IUPAC, current recommendation).

(c) Relative rate method carried out at atmospheric pressure of air. $\mathrm{NO}_{3}$ radicals were generated by thermal decomposition of $\mathrm{N}_{2} \mathrm{O}_{5}$. The concentrations of methacrolein and propene (the reference compound) were measured by GC. The measured rate coefficient ratio of $k\left(\mathrm{NO}_{3}+\right.$ methacrolein $) / k\left(\mathrm{NO}_{3}+\right.$ propene $)=0.324 \pm 0.017$ is placed on an absolute basis by use of a rate coefficient of $k\left(\mathrm{NO}_{3}+\right.$ propene $)=9.5 \times 10^{-15} \mathrm{~cm}^{3}$ molecule ${ }^{-1} \mathrm{~s}^{-1}$ at $298 \mathrm{~K}$ (IUPAC, current recommendation).

(d) Relative rate method carried out at atmospheric pressure of air. $\mathrm{NO}_{3}$ radicals were generated by thermal decomposition of $\mathrm{N}_{2} \mathrm{O}_{5}$. The concentrations of methacrolein and 1-butene (the reference compound) were measured by GC. The measured rate coefficient ratio of $k\left(\mathrm{NO}_{3}+\right.$ methacrolein $) / k\left(\mathrm{NO}_{3}+1\right.$-butene $)=0.259 \pm 0.011$ is placed on an absolute basis by use of a rate coefficient of $k\left(\mathrm{NO}_{3}+1\right.$-butene $)=1.35 \times 10^{-14} \mathrm{~cm}^{3}$ molecule ${ }^{-1} \mathrm{~s}^{-1}$ at $298 \mathrm{~K}$ (Atkinson, 1997).

(e) Relative rate method carried out at atmospheric pressure of $\mathrm{N}_{2} \cdot \mathrm{NO}_{3}$ radicals were generated by thermal decomposition of $\mathrm{N}_{2} \mathrm{O}_{5}$. The concentrations of methacrolein and propene (the reference compound) were measured by GC. The measured rate coefficient ratio of $k\left(\mathrm{NO}_{3}+\right.$ methacrolein $) / k\left(\mathrm{NO}_{3}+\right.$ propene $)=0.40 \pm 0.05$ is placed on an absolute basis by use of a rate coefficient of $k\left(\mathrm{NO}_{3}+\right.$ propene $)=9.29 \times 10^{-15} \mathrm{~cm}^{3}$ molecule ${ }^{-1} \mathrm{~s}^{-1}$ at $296 \mathrm{~K}$ (IUPAC, current recommendation). An absolute rate coefficient of $(9.6 \pm 2.0) \times 10^{-15} \mathrm{~cm}^{3}$ molecule ${ }^{-1} \mathrm{~s}^{-1}$ was also measured at $300 \pm 7 \mathrm{~K}$ using a discharge flow system with LIF detection of $\mathrm{NO}_{3}$ radicals.

\section{Preferred Values}

$k=3.4 \times 10^{-15} \mathrm{~cm}^{3}$ molecule $\mathrm{e}^{-1} \mathrm{~s}^{-1}$ at $298 \mathrm{~K}$.

\section{Reliability}

$\Delta \log k= \pm 0.15$ at $298 \mathrm{~K}$. 


\section{Comments on Preferred Values}

The $298 \mathrm{~K}$ preferred value is the average of the relative rate coefficients of Chew et al. (1998) (which supersedes the earlier and less extensive study of Kwok et al., 1996) and Canosa-Mas et al. (1999), which are in good agreement and are consistent with the upper limit reported by Rudich et al. (1996).

The room temperature rate coefficient is similar to that for reaction of $\mathrm{NO}_{3}$ radicals with acetaldehyde (IUPAC, this evaluation), and the reaction is expected to proceed mainly by $\mathrm{H}$-atom abstraction from the $\mathrm{CHO}$ group.

\section{References}

Atkinson, R.: J. Phys. Chem. Ref. Data, 26, 215, 1997.

Canosa-Mas, C. E., Carr, S., King, M. D., Shallcross, D. E., Thompson, K. C., and Wayne, R. P.: Phys. Chem. Chem. Phys., 1, 4195, 1999.

Chew, A. A., Atkinson, R., and Aschmann, S. M.: J. Chem. Soc. Faraday Trans., 94, 1083, 1998.

IUPAC: http://www.iupac-kinetic.ch.cam.ac.uk/.

Kwok, E. S. C., Aschmann, S. M., Arey, J., and Atkinson, R.: Int. J. Chem. Kinet., 28, 925, 1996.

Rudich, Y., Talukdar, R. K., Fox, R. W., and Ravishankara, A. R.: J. Phys. Chem., 100, 5374, 1996. 
II.A3.76

$\mathrm{NO}_{3}+\mathrm{CH}_{3} \mathrm{C}(\mathrm{O}) \mathrm{CH}=\mathrm{CH}_{2}$ (methyl vinyl ketone) $\rightarrow$ products

\section{Rate coefficient data}

\begin{tabular}{llll}
\hline$k / \mathrm{cm}^{3}$ molecule ${ }^{-1} \mathrm{~s}^{-1}$ & Temp./K & Reference & Technique/Comments \\
\hline $\begin{array}{l}\text { Absolute Rate Coefficients } \\
\leq 1.2 \times 10^{-16}\end{array}$ & 298 & Rudich et al., 1996 & F-A (a) \\
$\begin{array}{l}\text { Relative Rate Coefficients } \\
<6 \times 10^{-16}\end{array}$ & $296 \pm 2$ & Kwok et al., 1996 & RR (b) \\
$(5.0 \pm 1.2) \times 10^{-16}$ & $296 \pm 2$ & Canosa-Mas et al., 1999 & RR (c) \\
\hline
\end{tabular}

\section{Comments}

(a) $\mathrm{NO}_{3}$ radicals were generated by thermal decomposition of $\mathrm{N}_{2} \mathrm{O}_{5}$ in a flow system at total pressures of 1.5-3 Torr (2$4 \mathrm{mbar}$ ), and monitored by absorption at $661.9 \mathrm{~nm}$. A rate coefficient of $(1.0 \pm 0.2) \times 10^{-16} \mathrm{~cm}^{3}$ molecule ${ }^{-1} \mathrm{~s}^{-1}$ was measured but an upper limit cited because of the difficulty in measuring such low reaction rate coefficients (Rudich et al., 1996).

(b) Relative rate method carried out at atmospheric pressure of air. $\mathrm{NO}_{3}$ radicals were generated by thermal decomposition of $\mathrm{N}_{2} \mathrm{O}_{5}$. The concentrations of methyl vinyl ketone and propene (the reference compound) were measured by GC. The measured upper limit to the rate coefficient ratio of $k\left(\mathrm{NO}_{3}+\right.$ methyl vinyl ketone $) / k\left(\mathrm{NO}_{3}+\right.$ propene $)<0.06$ is placed on an absolute basis by use of a rate coefficient of $k\left(\mathrm{NO}_{3}+\right.$ propene) $=9.29 \times 10^{-15} \mathrm{~cm}^{3}$ molecule ${ }^{-1}-1$ at $296 \mathrm{~K}$ (IUPAC, current recommendation).

(c) Relative rate method carried out at atmospheric pressure of $\mathrm{N}_{2} . \mathrm{NO}_{3}$ radicals were generated by thermal decomposition of $\mathrm{N}_{2} \mathrm{O}_{5}$. The concentrations of methyl vinyl ketone and ethene (the reference compound) were measured by GC. The measured rate coefficient ratio of $k\left(\mathrm{NO}_{3}+\right.$ methyl vinyl ketone $) / k\left(\mathrm{NO}_{3}+\right.$ ethene $)=2.53 \pm 0.59$ is placed on an absolute basis by use of a rate coefficient of $k\left(\mathrm{NO}_{3}+\right.$ ethene) $=1.96 \times 10^{-16} \mathrm{~cm}^{3}$ molecule ${ }^{-1} \mathrm{~s}^{-1}$ at $296 \mathrm{~K}$ (IUPAC, current recommendation). An absolute rate coefficient of $(3.2 \pm 0.6) \times 10^{-16} \mathrm{~cm}^{3}$ molecule ${ }^{-1} \mathrm{~s}^{-1}$ was also measured at $296 \pm 1 \mathrm{~K}$ using a discharge flow system with LIF detection of $\mathrm{NO}_{3}$ radicals.

\section{Preferred Values}

$k<6 \times 10^{-16} \mathrm{~cm}^{3}$ molecule $\mathrm{e}^{-1} \mathrm{~s}^{-1}$ at $298 \mathrm{~K}$.

\section{Comments on Preferred Values}

The rate coefficient measured in the relative rate study of Canosa-Mas et al. (1999) is consistent with the upper limit obtained by Kwok et al. (1996) but not with the rate coefficient (or cited upper limit) determined in the absolute rate study of Rudich et al. (1996). Although Canosa-Mas et al. (1999) also obtained an absolute rate coefficient in reasonable agreement with their relative rate coefficient, the absolute rate coefficient must be viewed as an upper limit because of the potential for secondary reactions (as observed by Canosa-Mas et al. (1999) in the same study for the reactions of $\mathrm{NO}_{3}$ radicals with acrolein and methacrolein).

The preferred upper limit to the rate coefficient is that measured by Kwok et al. (1996) and is sufficiently high to encompass the rate coefficients obtained by Canosa-Mas et al. (1999).

\section{References}

Canosa-Mas, C. E., Carr, S., King, M. D., Shallcross, D. E., Thompson, K. C., and Wayne, R. P.: Phys. Chem. Chem. Phys., 1, 4195, 1999.

IUPAC: http://www.iupac-kinetic.ch.cam.ac.uk/. 
Kwok, E. S. C., Aschmann, S. M., Arey, J., and Atkinson, R.: Int. J. Chem. Kinet., 28, 925, 1996.

Rudich, Y., Talukdar, R. K., Fox, R. W., and Ravishankara, A. R.: J. Phys. Chem., 100, 5374, 1996. 
II.A3.77

$$
\mathrm{NO}_{3}+\text { Pinonaldehyde } \rightarrow \text { products }
$$

\section{Rate coefficient data}

\begin{tabular}{|c|c|c|c|}
\hline$k / \mathrm{cm}^{3}$ molecule $^{-1} \mathrm{~s}^{-1}$ & Temp./K & Reference & Technique/Comments \\
\hline $\begin{array}{l}\text { Relative Rate Coefficients } \\
(2.40 \pm 0.38) \times 10^{-14}\end{array}$ & $299 \pm 2$ & Hallquist et al.. 1997 & RR (a) \\
\hline$(6.0 \pm 2.0) \times 10^{-14}$ & $300 \pm 5$ & Glasius et al., 1997 & RR (b) \\
\hline$(1.99 \pm 0.52) \times 10^{-14}$ & $296 \pm 2$ & Alvarado et al., 1998 & $\mathrm{RR}(\mathrm{c}, \mathrm{d})$ \\
\hline$(2.16 \pm 0.53) \times 10^{-14}$ & $296 \pm 2$ & Alvarado et al., 1998 & $\mathrm{RR}(\mathrm{c}, \mathrm{e})$ \\
\hline$(1.93 \pm 0.44) \times 10^{-14}$ & $296 \pm 2$ & Alvarado et al., 1998 & $\mathrm{RR}(\mathrm{c}, \mathrm{f})$ \\
\hline
\end{tabular}

\section{Comments}

(a) $\mathrm{NO}_{3}$ radicals were generated by the thermal decomposition of $\mathrm{N}_{2} \mathrm{O}_{5}$ in $\mathrm{N}_{2} \mathrm{O}_{5}$-pinonaldehyde-propene (the reference compound)-air mixtures at $1013 \pm 5$ mbar pressure. The concentrations of pinonaldehyde and propene were measured by FTIR spectroscopy. Dark decays of pinonaldehyde in the $153 \mathrm{~L}$ chamber used were observed, and taken into account in the data analysis. The measured rate coefficient ratio $k\left(\mathrm{NO}_{3}+\right.$ pinonaldehyde $) / k\left(\mathrm{NO}_{3}+\right.$ propene $)$ is placed on an absolute basis by use of a rate coefficient of $k\left(\mathrm{NO}_{3}+\right.$ propene) $=9.5 \times 10^{-15} \mathrm{~cm}^{3}$ molecule ${ }^{-1} \mathrm{~s}^{-1}$ at $298 \mathrm{~K}$ (IUPAC, current recommendation).

(b) $\mathrm{NO}_{3}$ radicals were generated by the thermal decomposition of $\mathrm{N}_{2} \mathrm{O}_{5}$ in $\mathrm{N}_{2} \mathrm{O}_{5}$-pinonaldehyde-1-butene (the reference compound)-air mixtures at $987 \pm 7$ mbar pressure. The concentrations of pinonaldehyde and 1-butene were measured by FTIR spectroscopy. Dark decays of pinonaldehyde in the $480 \mathrm{~L}$ chamber used were observed, and taken into account in the data analysis. The measured rate coefficient ratio $k\left(\mathrm{NO}_{3}+\right.$ pinonaldehyde $) / k\left(\mathrm{NO}_{3}+1\right.$-butene $)$ is placed on an absolute basis by use of a rate coefficient of $k\left(\mathrm{NO}_{3}+1\right.$-butene) $=1.38 \times 10^{-14} \mathrm{~cm}^{3}$ molecule ${ }^{-1} \mathrm{~s}^{-1}$ at $300 \mathrm{~K}$ (Atkinson and Arey, 2003).

(c) $\mathrm{NO}_{3}$ radicals were generated by the thermal decomposition of $\mathrm{N}_{2} \mathrm{O}_{5}$ in $\mathrm{N}_{2} \mathrm{O}_{5}$-pinonaldehyde-reference compound (propene, 1-butene or thiophene)-air mixtures at 987 mbar pressure. The concentrations of pinonaldehyde, propene, 1-butene and thiophene were measured by GC. No dark decays of pinonaldehyde $(<5 \%)$ were observed in the 7000 $\mathrm{L}$ Teflon chamber used. The measured rate coefficient ratios $k\left(\mathrm{NO}_{3}+\right.$ pinonaldehyde $) / k\left(\mathrm{NO}_{3}+\right.$ propene $)=2.09 \pm 0.54$, $k\left(\mathrm{NO}_{3}+\right.$ pinonaldehyde $) / k\left(\mathrm{NO}_{3}+1\right.$-butene $)=1.64 \pm 0.40$ and $k\left(\mathrm{NO}_{3}+\right.$ pinonaldehyde $) / k\left(\mathrm{NO}_{3}+\right.$ thiophene $)=0.49 \pm 0.11$ are placed on an absolute basis by use of rate coefficients at $296 \mathrm{~K}$ of $k\left(\mathrm{NO}_{3}+\right.$ propene $)=9.5 \times 10^{-15} \mathrm{~cm}^{3}$ molecule $\mathrm{s}^{-1}$ (IUPAC, current recommendation), $k\left(\mathrm{NO}_{3}+1\right.$-butene) $=1.32 \times 10^{-14} \mathrm{~cm}^{3}$ molecule ${ }^{-1} \mathrm{~s}^{-1}$ (Atkinson and Arey, 2003) and $k\left(\mathrm{NO}_{3}+\right.$ thiophene) $=3.93 \times 10^{-14} \mathrm{~cm}^{3}$ molecule ${ }^{-1} \mathrm{~s}^{-1}$ (Atkinson, 1991).

(d) Relative to $k\left(\mathrm{NO}_{3}+\right.$ propene $)$.

(e) Relative to $k\left(\mathrm{NO}_{3}+1\right.$-butene) .

(f) Relative to $k\left(\mathrm{NO}_{3}+\right.$ thiophene).

\section{Preferred Values}

$k=2.0 \times 10^{-14} \mathrm{~cm}^{3}$ molecule $\mathrm{e}^{-1} \mathrm{~s}^{-1}$ at $298 \mathrm{~K}$.

\section{Reliability}

$\Delta \log k= \pm 0.25$ at $298 \mathrm{~K}$. 


\section{Comments on Preferred Values}

Pinonaldehyde is a low volatility product of the atmospheric reactions of $\alpha$-pinene which is prone to wall losses, making measurement of its reaction rate coefficients difficult. The available rate coefficients are all from relative rate studies carried out at room temperature, and range over a factor of $\sim 3$ (Hallquist et al., 1997; Glasius et al., 1997; Alvarado et al., 1998). The rate coefficient measured by Glasius et al. (1997) is a factor of $\sim 2.5-3$ higher than those of Hallquist et al. (1997) and Alvarado et al. (1998), possibly because of unresolved wall adsorption problems. The preferred values are based on the study of Alvarado et al. (1998) carried out in a large volume Teflon chamber in which no wall losses of pinonaldehyde were observed.

\section{References}

Alvarado, A., Arey, J., and Atkinson, R.: J. Atmos. Chem., 31, 281, 1998.

Atkinson, R.: J. Phys. Chem. Ref. Data, 20, 459, 1991.

Atkinson, R. and Arey, J.: Chem. Rev., 103, 4605, 2003.

Glasius, M., Calogirou, A., Jensen, N. R., Hjorth, J., and Nielsen, C. J.: Int. J. Chem. Kinet., 29, 527, 1997.

Hallquist, M., Wängberg, I., and Ljungström, E.: Environ. Sci. Technol., 31, 3166, 1997.

IUPAC, http://www.iupac-kinetic.ch.cam.ac.uk/. 
II.A3.78

$$
\mathrm{NO}_{3}+\mathrm{CH}_{3} \mathrm{C}(\mathrm{O}) \mathrm{CH}_{3} \rightarrow \mathrm{HNO}_{3}+\mathrm{CH}_{3} \mathrm{C}(\mathrm{O}) \mathrm{CH}_{2}
$$

$\Delta H^{\circ}=-15.5 \mathrm{~kJ} \cdot \mathrm{mol}^{-1}$

Rate coefficient data

\begin{tabular}{llll}
\hline$k / \mathrm{cm}^{3}$ molecule & & \\
\hline $\begin{array}{l}\text { Absolute Rate Coefficients } \\
\mathrm{s}^{-1}\end{array}$ & Temp./K & Reference & Technique/Comments \\
$\leq(8.5 \pm 2.5) \times 10^{-18}$ & 302 & Boyd et al., 1991 & (a) \\
\hline
\end{tabular}

\section{Comments}

(a) Stopped flow system with detection of the $\mathrm{NO}_{3}$ radical by optical absorption at $662 \mathrm{~nm}$. Secondary reactions were believed to be important and a stoichiometry factor of $\geq 2$ has been used to obtain the cited upper limit to the rate coefficient.

\section{Preferred Values}

$k<3 \times 10^{-17} \mathrm{~cm}^{3}$ molecule $\mathrm{s}^{-1} \mathrm{~s}^{-1}$ at $298 \mathrm{~K}$.

Comments on Preferred Values

The upper limit to the preferred value is derived from the overall rate coefficient of $(1.7 \pm 0.5) \times 10^{-17} \mathrm{~cm}^{3}$ molecule $\mathrm{s}^{-1}$ measured by Boyd et al. (1991), with no account taken of the expected greater than unity stoichiometry.

\section{References}

Boyd, A., Canosa-Mas, C. E., King, A. D., Wayne, R. P., and Wilson, M. R.: J. Chem. Soc. Faraday Trans., 87, $2913,1991$. 
II.A3.79

$$
\mathrm{NO}_{3}+3 \text {-methylfuran } \rightarrow \text { products }
$$

\section{Rate coefficient data}

\begin{tabular}{|c|c|c|c|}
\hline $\mathrm{k} / \mathrm{cm}^{3}$ molecule $^{-1} \mathrm{~s}^{-1}$ & Temp./K & Reference & Technique/Comments \\
\hline $\begin{array}{l}\text { Relative Rate Coefficients } \\
(1.31 \pm 0.02) \times 10^{-11}\end{array}$ & $296 \pm 2$ & Alvarado et al., 1996 & RR (a) \\
\hline$(2.86 \pm 0.06) \times 10^{-11}$ & $295 \pm 2$ & Kind et al., 1996 & $\mathrm{RR}$ (b) \\
\hline
\end{tabular}

\section{Comments}

(a) Relative rate method carried out at one atmosphere of air. $\mathrm{NO}_{3}$ radicals were generated by thermal decomposition of $\mathrm{N}_{2} \mathrm{O}_{5}$. The concentrations of 3-methylfuran and 2-methyl-2-butene (the reference compound) were measured by GC. The measured rate coefficient ratio of $k\left(\mathrm{NO}_{3}+3\right.$-methylfuran $) / k\left(\mathrm{NO}_{3}+2\right.$-methyl-2-butene $)=1.40 \pm 0.02$ is placed on an absolute basis by use of a rate coefficient of $k\left(\mathrm{NO}_{3}+2\right.$-methyl-2-butene) $=9.37 \times 10^{-12} \mathrm{~cm}^{3}$ molecule ${ }^{-1} \mathrm{~s}^{-1}$ (Atkinson, 1997).

(b) Relative rate method carried out in a flow system at a total pressure of 6.8 mbar of $\mathrm{N}_{2} . \mathrm{NO}_{3}$ radicals were generated by thermal decomposition of $\mathrm{N}_{2} \mathrm{O}_{5}$. The concentrations of 3-methylfuran and 2,3-dimethyl-2-butene (the reference compound) were measured by GC. The measured rate coefficient ratio of $k\left(\mathrm{NO}_{3}+3\right.$-methylfuran $) / k\left(\mathrm{NO}_{3}+2,3\right.$-dimethyl-2butene $)=0.50 \pm 0.01$ is placed on an absolute basis by use of a rate coefficient of $k\left(\mathrm{NO}_{3}+2,3\right.$-dimethyl-2-butene $)=$ $5.72 \times 10^{-11} \mathrm{~cm}^{3}$ molecule ${ }^{-1} \mathrm{~s}^{-1}$ (Atkinson, 1997). In the same study, the measured rate coefficient for the reaction of $\mathrm{NO}_{3}$ radicals with furan was shown to be independent of total pressure (of $\mathrm{N}_{2}$ diluent) over the range 6.8-200 mbar.

\section{Preferred Values}

$k=1.9 \times 10^{-11} \mathrm{~cm}^{3}$ molecule ${ }^{-1} \mathrm{~s}^{-1}$ at $298 \mathrm{~K}$.

\section{Reliability}

$\Delta \log k= \pm 0.5$ at $298 \mathrm{~K}$.

\section{Comments on Preferred Values}

The rate coefficients measured in the relative rate studies of Alvarado et al. (1996) and Kind et al. (1996) disagree by a factor of 2.2, for unknown reasons. The preferred value is a simple average of the rate coefficients from these two studies (Alvarado et al., 1996; Kind et al., 1996), with a large uncertainty limit. The reaction of $\mathrm{NO}_{3}$ radicals with 3-methylfuran proceeds by initial addition of the $\mathrm{NO}_{3}$ radical to the $\mathrm{C}=\mathrm{C}$ bonds (Kind et al., 1996).

\section{References}

Alvarado, A., Atkinson, R., and Arey, J.: Int. J. Chem. Kinet., 28, 905, 1996.

Atkinson, R.: J. Phys. Chem. Ref. Data, 26, 215, 1997.

Kind, I., Berndt, T., Böge, O., and Rolle, W.: Chem. Phys. Lett., 256, 679, 1996. 
II.A3.80

$$
\mathrm{NO}_{3}+\mathrm{CH}_{2}=\mathrm{C}\left(\mathrm{CH}_{3}\right) \mathrm{C}(\mathrm{O}) \mathrm{OONO}_{2}(\mathrm{MPAN}) \rightarrow \text { products }
$$

\section{Rate coefficient data}

\begin{tabular}{lclc}
\hline$k / \mathrm{cm}^{3}$ molecule ${ }^{-1} \mathrm{~s}^{-1}$ & Temp./K & Reference & Technique/Comments \\
\hline $\begin{array}{l}\text { Relative Rate Coefficients } \\
(1.6 \pm 0.6) \times 10^{-16}\end{array}$ & $296 \pm 2$ & Canosa-Mas et al., 1999 & RR (a) \\
\hline
\end{tabular}

\section{Comments}

(a) Relative rate method carried out at one atmosphere of air. $\mathrm{CH}_{2}=\mathrm{CH}\left(\mathrm{CH}_{3}\right) \mathrm{C}(\mathrm{O}) \mathrm{OONO}_{2}(\mathrm{MPAN})$ was prepared in situ from the reaction of $\mathrm{NO}_{3}$ radicals (generated from the thermal decomposition of $\mathrm{N}_{2} \mathrm{O}_{5}$ ) with methacrolein. After complete consumption of $\mathrm{N}_{2} \mathrm{O}_{5}$ and methacrolein, ethene (the reference compound) was added and several additions of $\mathrm{N}_{2} \mathrm{O}_{5}$ were made to the collapsible $56 \mathrm{~L}$ chamber. The concentrations of MPAN and ethene were measured during the experiments by FTIR spectroscopy. The measured rate coefficient ratio of $k\left(\mathrm{NO}_{3}+\mathrm{MPAN}\right) / k\left(\mathrm{NO}_{3}+\right.$ ethene) $=0.79 \pm 0.28$ (two standard deviations) is placed on an absolute basis by use of a rate coefficient of $k\left(\mathrm{NO}_{3}+\right.$ ethene $)=2.0 \times 10^{-16} \mathrm{~cm}^{3}$ molecule ${ }^{-1}$ $\mathrm{s}^{-1}$ at $296 \mathrm{~K}$ (IUPAC, current recommendation). Dark decays of MPAN and dilution due to successive additions of $\mathrm{N}_{2} \mathrm{O}_{5}$ to the chamber were taken into account in the data analysis.

\section{Preferred Values}

$k=1.6 \times 10^{-16} \mathrm{~cm}^{3}$ molecule ${ }^{-1} \mathrm{~s}^{-1}$ at $298 \mathrm{~K}$.

\section{Reliability}

$\Delta \log k= \pm 0.7$ at $298 \mathrm{~K}$.

\section{Comments on Preferred Values}

The preferred value is based on the sole study of this reaction by Canosa-Mas et al. (1999), with large uncertainty limits because of the difficult nature of the experiments and the need for large dilution corrections (cited as being up to 40\%). The reaction of $\mathrm{NO}_{3}$ radicals with MPAN proceeds by initial addition of the $\mathrm{NO}_{3}$ radical to the $\mathrm{C}=\mathrm{C}$ bond (Canosa-Mas et al., 1999). On the basis of the recommended rate coefficients for the reactions of MPAN with $\mathrm{HO}$ radicals and $\mathrm{O}_{3}$ and those for the reactions of ethene, propene and 2-methylpropene with $\mathrm{HO}$ and $\mathrm{NO}_{3}$ radicals and $\mathrm{O}_{3}$ (Atkinson, 1997; IUPAC, current recommendation), the rate coefficient for the reaction of $\mathrm{NO}_{3}$ radicals with MPAN may be expected to be significantly higher than the measured value (i.e., $\sim 10^{-15} \mathrm{~cm}^{3}$ molecule ${ }^{-1} \mathrm{~s}^{-1}$ at $298 \mathrm{~K}$ ).

\section{References}

Atkinson, R.: J. Phys. Chem. Ref. Data, 26, 215, 1997.

Canosa-Mas, C. E., King, M. D., Shallcross, D. E., and Wayne, R. P.: Phys. Chem. Chem. Phys., 1, 2411, 1999.

IUPAC: http://www.iupac-kinetic.ch.cam.ac.uk/. 
II.A3.81

$$
\mathrm{NO}_{3}+\mathrm{CH}_{3} \mathrm{OH} \rightarrow \text { products }
$$

\section{Rate coefficient data}

\begin{tabular}{lllc}
\hline$k / \mathrm{cm}^{3}$ molecule ${ }^{-1} \mathrm{~s}^{-1}$ & Temp./K & Reference & Technique/Comments \\
\hline Absolute Rate Coefficients & & & \\
$\leq 6 \times 10^{-16}$ & $298 \pm 2$ & Wallington et al., 1987 & FP-A \\
$1.25 \times 10^{-12} \exp [-(2562 \pm 241) / T]$ & $294-473$ & Canosa-Mas et al., 1989 & DF-A \\
$(2.1 \pm 1.1) \times 10^{-16}$ & 294 & & \\
$1.06 \times 10^{-12} \exp [-(2093 \pm 803) / T]$ & $258-367$ & Langer and Ljungström, 1995 & DF-A (a) \\
$(1.32 \pm 0.24) \times 10^{-16}$ & 295 & & \\
\hline
\end{tabular}

\section{Comments}

(a) The cited Arrhenius expression leads to a rate coefficient at $295 \mathrm{~K}$ of $8.8 \times 10^{-16} \mathrm{~cm}^{3}$ molecule $\mathrm{s}^{-1}$, clearly in disagreement with the measured value. A unit-weighted least-squares analysis of the rate coefficients measured by Langer and Ljungström (1995) (Table 3 of Langer and Ljungström, 1995) leads to $k=9.36 \times 10^{-13} \exp [-(2652 \pm 312) / T] \mathrm{cm}^{3}$ molecule ${ }^{-1} \mathrm{~s}^{-1}$, where the indicated error is one standard deviation.

\section{Preferred Values}

$k=1.3 \times 10^{-16} \mathrm{~cm}^{3}$ molecule $\mathrm{e}^{-1} \mathrm{~s}^{-1}$ at $298 \mathrm{~K}$.

$k=9.4 \times 10^{-13} \exp (-2650 / T) \mathrm{cm}^{3}$ molecule ${ }^{-1} \mathrm{~s}^{-1}$ over the temperature range $250-370 \mathrm{~K}$.

\section{Reliability}

$\Delta \log k= \pm 0.5$ at $298 \mathrm{~K}$.

$\Delta(E / R)= \pm 700 \mathrm{~K}$.

\section{Comments on Preferred Values}

The reported rate coefficients of Canosa-Mas et al. (1989) are higher by factors of 1.6-2.1 than those of Langer and Ljungström (1995) over the temperature range common to both studies (294-373 K). Clearly there are systematic errors in one or both of these studies. Based on the observation that for the $\mathrm{NO}_{3}$ radical reaction with 2-propanol the data of Langer and Ljungström (1995) may still be an upper limit to the rate coefficient, the preferred values were derived from the data of Langer and Ljungström (1995) using the Arrhenius parameters given in Comment (a). The preferred $298 \mathrm{~K}$ rate coefficient is calculated from the resulting Arrhenius expression. It is possible that the preferred values are still high because of the potential for secondary reactions in slowly reacting systems using absolute rate methods.

\section{References}

Canosa-Mas, C. E., Smith, S. J., Toby, S., and Wayne, R. P.: J. Chem. Soc. Faraday Trans., 2, 85, 709, 1989.

Langer, S. and Ljungström, E.: J. Chem. Soc. Faraday Trans., 91, 405, 1995.

Wallington, T. J., Atkinson, R., Winer, A. M., and Pitts Jr., J. N.: Int. J. Chem. Kinet., 19, 243, 1987. 
II.A3.82

$$
\mathrm{NO}_{3}+\mathrm{C}_{2} \mathrm{H}_{5} \mathrm{OH} \rightarrow \text { products }
$$

\section{Rate coefficient data}

\begin{tabular}{lllc}
\hline$k / \mathrm{cm}^{3}$ molecule & & Technique/Comments \\
\hline Absolute Rate Coefficients & Temp./K & Reference & \\
$\leq 9 \times 10^{-16}$ & & & \\
$6.99 \times 10^{-13} \exp [-(1815 \pm 419) / \mathrm{T}]$ & $298 \pm 2$ & Wallington et. al., 1987 & FP-A \\
$(1.81 \pm 0.26) \times 10^{-15}$ & 297 & Langer and Ljungström, 1995 & DF-A \\
\hline
\end{tabular}

\section{Preferred Values}

$k<2 \times 10^{-15} \mathrm{~cm}^{3}$ molecule $\mathrm{s}^{-1} \mathrm{~s}^{-1}$ at $298 \mathrm{~K}$.

\section{Comments on Preferred Values}

By analogy with the data for the reaction of the $\mathrm{NO}_{3}$ radical with 2-propanol, it is likely that the rate coefficients of Langer and Ljungstrm (1995) are high because of the occurrence of secondary reactions. The preferred value is based on the upper limit to the rate coefficient determined by Wallington et al. (1987), and is consistent with the $298 \mathrm{~K}$ rate coefficient of Langer and Ljungström (1995) calculated from their Arrhenius expression. No recommendation is made concerning the temperature dependence.

\section{References}

Langer, S. and Ljungström, E.: J. Chem. Soc. Faraday Trans., 91, 405, 1995.

Wallington, T. J., Atkinson, R., Winer, A. M., and Pitts Jr., J. N.: Int. J. Chem. Kinet., 19, 243, 1987. 
II.A3.83

$$
\begin{aligned}
\mathrm{NO}_{3}+\mathrm{CH}_{3} \mathrm{CH}(\mathrm{OH}) \mathrm{CH}_{3} & \rightarrow \mathrm{HNO}_{3}+\mathrm{CH}_{3} \mathrm{C}(\mathrm{OH}) \mathrm{CH}_{3} \\
& \rightarrow \mathrm{HNO}_{3}+\mathrm{CH}_{2} \mathrm{CH}(\mathrm{OH}) \mathrm{CH}_{3}
\end{aligned}
$$

Rate coefficient data $\left(k=k_{1}+k_{2}\right)$

\begin{tabular}{lllc}
\hline$k / \mathrm{cm}^{3}$ molecule ${ }^{-1} \mathrm{~s}^{-1}$ & Temp./K & Reference & Technique/Comments \\
\hline $\begin{array}{l}\text { Absolute Rate Coefficients } \\
\leq 2.3 \times 10^{-15}\end{array}$ & $298 \pm 2$ & Wallington et al., 1987 & \\
$1.54 \times 10^{-12} \exp [-(1743 \pm 1009) / T]$ & $273-364$ & Langer and Ljungström, 1995 & FP-A \\
$\begin{array}{l}3.13 \pm 0.64) \times 10^{-15} \\
\text { Relative Rate Coefficients }\end{array}$ & 295 & & DF-A \\
$\leq(1.8 \pm 0.2) \times 10^{-15}$ & $298 \pm 2$ & Chew et al., 1998 & \\
$k_{1}=(1.4 \pm 0.3) \times 10^{-15}$ & $298 \pm 2$ & Chew et al., 1998 & RR (a) \\
\hline
\end{tabular}

\section{Comments}

(a) $\mathrm{NO}_{3}$ radicals were generated by the thermal decomposition of $\mathrm{N}_{2} \mathrm{O}_{5}$ in air at atmospheric pressure. Experiments were carried out in a $\sim 7000$ liter Teflon chamber, and the concentrations of 2-propanol and methacrolein (the reference organic) were measured by GC. Rate coefficient ratios $k\left(\mathrm{NO}_{3}+2\right.$-propanol) $/ k\left(\mathrm{NO}_{3}+\right.$ methacrolein) were measured as a function of initially added $\mathrm{NO}_{2}$ over the range $(0-2.4) \times 10^{14}$ molecule $\mathrm{cm}^{-3}\left(\sim 2 \times 10^{16}\right.$ molecule $\mathrm{cm}^{-3}$ of ethane were added when no $\mathrm{NO}_{2}$ was initially added). The rate coefficient ratios were independent of initial $\mathrm{NO}_{2}$ concentration in the range $(0-4.8) \times 10^{13}$ molecule $\mathrm{cm}^{-3}$, but increased for initial $\mathrm{NO}_{2}$ concentrations $\geq 9.6 \times 10^{13}$ molecule $\mathrm{cm}^{-3}$. Acetone was observed as a reaction product, presumably from channel (1) followed by,

$$
\mathrm{CH}_{3} \mathrm{C}(\mathrm{OH}) \mathrm{CH}_{3}+\mathrm{O}_{2} \rightarrow \mathrm{CH}_{3} \mathrm{C}(\mathrm{O}) \mathrm{CH}_{3}+\mathrm{HO}_{2}
$$

with a yield of $\sim 0.76 \pm 0.09$ at initial $\mathrm{NO}_{2}$ concentrations of $(0-4.8) \times 10^{13}$ molecule $\mathrm{cm}^{-3}$, decreasing at higher initial $\mathrm{NO}_{2}$ concentrations. The values of $k\left(\mathrm{NO}_{3}+2\right.$-propanol) (yield of acetone $) / k\left(\mathrm{NO}_{3}+\right.$ methacrolein) were independent of initial $\mathrm{NO}_{2}$ concentration over the entire range studied $\left((0-2.4) \times 10^{14}\right.$ molecule $\left.\mathrm{cm}^{-3}\right)$, with an average value of $0.40 \pm 0.06$ for experiments with initial $\mathrm{NO}_{2}$ concentrations of $(0-4.8) \times 10^{13}$ molecule $\mathrm{cm}^{-3}$. The observed behavior is interpreted as involving a gas-phase reaction of 2-propanol with the $\mathrm{NO}_{3}$ radical and a reaction (gas-phase or heterogeneous) of $\mathrm{N}_{2} \mathrm{O}_{5}$ with 2-propanol to form nitrates (Langer and Ljungström, 1995). The rate coefficient $k$ is obtained from the rate coefficient ratio $k\left(\mathrm{NO}_{3}+2\right.$-propanol $) / k\left(\mathrm{NO}_{3}+\right.$ methacrolein $)=0.519 \pm 0.053$ at low added $\mathrm{NO}_{2}$ concentrations, combined with a rate coefficient ratio of $k\left(\mathrm{NO}_{3}+\right.$ methacrolein) $=3.4 \times 10^{-15} \mathrm{~cm}^{3}$ molecule ${ }^{-1} \mathrm{~s}^{-1}$ at $298 \pm 2 \mathrm{~K}$ (IUPAC, current recommendation). This overall rate coefficient could still be an upper limit, and the true rate coefficient may be the value obtained for $k_{1}$ obtained from the ratio $k\left(\mathrm{NO}_{3}+2\right.$-propanol)(yield of 2-acetone $) / k_{2}\left(\mathrm{NO}_{3}+\right.$ methacrolein) $=$ $0.40 \pm 0.06$ and the rate coefficient of $k\left(\mathrm{NO}_{3}+\right.$ methacrolein) (IUPAC, current recommendation).

\section{Preferred Values}

$k=1.4 \times 10^{-15} \mathrm{~cm}^{3}$ molecule ${ }^{-1} \mathrm{~s}^{-1}$ at $298 \mathrm{~K}$.

$k_{1} / k=1.0$ at $298 \mathrm{~K}$.

\section{Reliability}

$\Delta \log k= \pm 0.3$ at $298 \mathrm{~K}$.

$\Delta\left(k_{1} / k\right)= \pm 0.3$ at $298 \mathrm{~K}$. 


\section{Comments on Preferred Values}

The room temperature values for the overall reaction rate coefficient $k$ and for $k_{1}$ obtained by Chew et al. (1998) are consistent with the upper limit to the rate coefficient of Wallington et al. (1987), but are a factor of $\sim 2$ lower than the absolute rate coefficient of Langer and Ljungström (1995). It is expected that the reaction of the $\mathrm{NO}_{3}$ radical occurs almost entirely by $\mathrm{H}$-atom abstraction from the tertiary $\mathrm{C}-\mathrm{H}$ bond (and hence that $k_{1} / k \sim 1.0$ ) (Atkinson, 1991). This expectation is consistent with the data of Chew et al. (1998). The $298 \mathrm{~K}$ preferred value is based on the value of $k_{1}$ obtained by Chew et al. (1998) with the expectation that $k_{1} / k=1.0$ (Atkinson, 1991). No temperature dependence is recommended.

\section{References}

Atkinson, R.: J. Phys. Chem. Ref. Data, 20, 459, 1991.

Chew, A. A., Atkinson, R., and Aschmann, S. M.: J. Chem. Soc. Faraday Trans., 94, 1083, 1998.

IUPAC: http://www.iupac-kinetic.ch.cam.ac.uk/.

Langer, S. and Ljungström, E.: J. Chem. Soc. Faraday Trans., 91, 405, 1995.

Wallington, T. J., Atkinson, R., Winer, A. M., and Pitts, Jr., J. N.: Int. J. Chem. Kinet., 19, 243, 1987. 
II.A3.84

$$
\begin{aligned}
\mathrm{NO}_{3}+\mathrm{CH}_{3} \mathrm{CH}(\mathrm{OH}) \mathrm{CH}_{2} \mathrm{CH}_{3} & \rightarrow \mathrm{HNO}_{3}+\mathrm{CH}_{3} \mathrm{C}(\mathrm{OH}) \mathrm{CH}_{2} \mathrm{CH}_{3} \\
& \rightarrow \mathrm{HNO}_{3}+\mathrm{CH}_{2} \mathrm{CH}(\mathrm{OH}) \mathrm{CH}_{2} \mathrm{CH}_{3} \\
& \rightarrow \mathrm{HNO}_{3}+\mathrm{CH}_{3} \mathrm{CH}(\mathrm{OH}) \mathrm{CHCH}_{3} \\
& \rightarrow \mathrm{HNO}_{3}+\mathrm{CH}_{3} \mathrm{CH}(\mathrm{OH}) \mathrm{CH}_{2} \mathrm{CH}_{2}
\end{aligned}
$$

\begin{tabular}{|c|c|c|c|}
\hline $\mathrm{k} / \mathrm{cm}^{3}$ molecule $^{-1} \mathrm{~s}^{-1}$ & Temp./K & Reference & Technique/Comments \\
\hline Relative Rate Coefficients & & & \\
\hline $\begin{array}{l}\leq(2.0 \pm 0.3) \times 10 \\
k_{1}=(2.0 \pm 0.3) \times 10^{-15}\end{array}$ & $\begin{array}{l}298 \pm 2 \\
298 \pm 2\end{array}$ & $\begin{array}{l}\text { Chew et al., } 1998 \\
\text { Chew et al., } 1998\end{array}$ & $\begin{array}{l}\text { RR (a) } \\
\operatorname{RR}(a)\end{array}$ \\
\hline
\end{tabular}

Rate coefficient data $\left(k=k_{1}+k_{2}+k_{3}+k_{4}\right)$

\section{Comments}

(a) $\mathrm{NO}_{3}$ radicals were generated by the thermal decomposition of $\mathrm{N}_{2} \mathrm{O}_{5}$ in air at atmospheric pressure. Experiments were carried out in a $\sim 7000$ liter Teflon chamber, and the concentrations of 2-butanol and methacrolein (the reference organic) were measured by GC. Rate coefficient ratios $k\left(\mathrm{NO}_{3}+2\right.$-butanol $) / k\left(\mathrm{NO}_{3}+\right.$ methacrolein) were measured as a function of initially added $\mathrm{NO}_{2}$ over the range $(0-2.4) \times 10^{-14}$ molecule $\mathrm{cm}^{3}\left(\sim 2 \times 10^{16}\right.$ molecule $\mathrm{cm}^{-3}$ of ethane were added when no $\mathrm{NO}_{2}$ was initially added). The rate coefficient ratios were independent of initial $\mathrm{NO}_{2}$ concentration in the range $(0-4.8) \times 10^{13}$ molecule $\mathrm{cm}^{-3}$, but increased for initial $\mathrm{NO}_{2}$ concentrations $\geq 9.6 \times 10^{13}$ molecule $\mathrm{cm}^{-3}$. 2-Butanone was observed as a reaction product, presumably from channel (1) followed by,

$$
\mathrm{CH}_{3} \mathrm{C}(\mathrm{OH}) \mathrm{CH}_{2} \mathrm{CH}_{3}+\mathrm{O}_{2} \rightarrow \mathrm{CH}_{3} \mathrm{C}(\mathrm{O}) \mathrm{CH}_{2} \mathrm{CH}_{3}+\mathrm{HO}_{2}
$$

with a yield of $\sim 0.79 \pm 0.09$ at initial $\mathrm{NO}_{2}$ concentrations of $(0-4.8) \times 10^{13}$ molecule $\mathrm{cm}^{-3}$, and decreasing at higher initial $\mathrm{NO}_{2}$ concentrations. The values of $k\left(\mathrm{NO}_{3}+2\right.$-butanol) (yield of 2-butanone) $/ k\left(\mathrm{NO}_{3}+\right.$ methacrolein) were independent of initial $\mathrm{NO}_{2}$ concentration over the entire range studied $\left((0-2.4) \times 10^{14}\right.$ molecule $\left.\mathrm{cm}^{-3}\right)$, with an average value of $0.60 \pm 0.07$ for experiments with initial $\mathrm{NO}_{2}$ concentrations of $(0-4.8) \times 10^{13}$ molecule $\mathrm{cm}^{-3}$. The observed behavior is interpreted as involving a gas-phase reaction of 2-butanol with the $\mathrm{NO}_{3}$ radical and a reaction (gas-phase or heterogeneous) of $\mathrm{N}_{2} \mathrm{O}_{5}$ with 2-butanol to form nitrates (Langer and Ljungström, 1995). The rate coefficient $k$ is obtained from the rate coefficient ratio $k\left(\mathrm{NO}_{3}+2\right.$-butanol $) / k\left(\mathrm{NO}_{3}+\right.$ methacrolein $)=0.754 \pm 0.065$ at low added $\mathrm{NO}_{2}$ concentrations, combined with a rate coefficient ratio of $k\left(\mathrm{NO}_{3}+\right.$ methacrolein) $=3.4 \times 10^{-15} \mathrm{~cm}^{3}$ molecule ${ }^{-1} \mathrm{~s}^{-1}$ at $298 \pm 2 \mathrm{~K}$ (IUPAC, current recommendation). This overall rate coefficient could still be an upper limit, and the true-rate coefficient may be the value obtained for $k_{1}$ obtained from the ratio $k\left(\mathrm{NO}_{3}+2\right.$-butanol)(yield of 2-butanone) $/ k_{2}\left(\mathrm{NO}_{3}+\right.$ methacrolein) $=0.60 \pm 0.07$ and the rate coefficient $k\left(\mathrm{NO}_{3}+\right.$ methacrolein) (IUPAC, current recommendation).

\section{Preferred Values}

$k=2.0 \times 10^{-15} \mathrm{~cm}^{3}$ molecule ${ }^{-1} \mathrm{~s}^{-1}$ at $298 \mathrm{~K}$.

$k_{1} / k=1.0$ at $298 \mathrm{~K}$.

\section{Reliability}

$\Delta \log k= \pm 0.3$ at $298 \mathrm{~K}$.

$\Delta\left(k_{1} / k\right)= \pm 0.3$ at $298 \mathrm{~K}$.

\section{Comments on Preferred Values}

The preferred values are based on the sole study of Chew et al. (1998). In view of the magnitude of the rate coefficient compared to that for the reaction of the $\mathrm{NO}_{3}$ radical with $n$-butane (IUPAC, current recommendation), the reaction is expected to occur almost totally at the tertiary C-H bond (i.e., $k_{1} / k=1.0$ ). The preferred value therefore uses the measured rate coefficient $k_{1}$ combined with the expectation that $k_{1} / k=1.0$. 


\section{References}

Chew, A. A., Atkinson, R., and Aschmann, S. M.: J. Chem. Soc. Faraday Trans., 94, 1083, 1998.

IUPAC: http://www.iupac-kinetic.ch.cam.ac.uk/.

Langer, S. and Ljungström, E.: J. Chem. Soc. Faraday Trans., 91, 405, 1995. 
II.A3.85

$$
\mathrm{NO}_{3}+\left(\mathrm{CH}_{3}\right)_{2} \mathrm{C}(\mathrm{OH}) \mathrm{CH}=\mathrm{CH}_{2} \rightarrow \text { products }
$$

\section{Rate coefficient data}

\begin{tabular}{lllc}
\hline$k / \mathrm{cm}^{3}$ molecule $\mathrm{s}^{-1}$ & Temp./K & Reference & Technique/Comments \\
\hline $\begin{array}{l}\text { Absolute Rate Coefficients } \\
4.6 \times 10^{-14} \mathrm{exp}[-(400 \pm 35) / T]\end{array}$ & $267-400$ & Rudich et al., 1996 & F-A (a) \\
$(1.21 \pm 0.09) \times 10^{-14}$ & 298 & & \\
$(2.1 \pm 0.3) \times 10^{-14}$ & 294 & Hallquist et al., 1996 & DF-A \\
& & & \\
Relative Rate Coefficients & & & \\
$(1.55 \pm 0.55) \times 10^{-14}$ & 294 & Hallquist et al., 1996 & RR (b) \\
$(8.7 \pm 3.0) \times 10^{-15}$ & $298 \pm 2$ & Fantechi et al., 1998a & RR (c) \\
$(1.0 \pm 0.2) \times 10^{-14}$ & $297 \pm 2$ & Noda et al., 2002 & RR (d) \\
$(1.1 \pm 0.1) \times 10^{-14}$ & $297 \pm 2$ & Noda et al., 2002 & RR (e) \\
\hline
\end{tabular}

\section{Comments}

(a) $\mathrm{NO}_{3}$ radicals were generated by the thermal decomposition of $\mathrm{N}_{2} \mathrm{O}_{5}$ at $400 \mathrm{~K}$ in a flow system, and $\mathrm{NO}_{3}$ radical concentrations were measured by visible tunable diode laser absorption at $661.9 \mathrm{~nm}$.

(b) $\mathrm{NO}_{3}$ radicals were generated by the thermal decomposition of $\mathrm{N}_{2} \mathrm{O}_{5}$ in

$\mathrm{N}_{2} \mathrm{O}_{5}-\left(\mathrm{CH}_{3}\right)_{2} \mathrm{C}(\mathrm{OH}) \mathrm{CH}=\mathrm{CH}_{2}$-propene (the reference compound)-diluent (not specified) mixtures at 1013 mbar pressure. The concentrations of 2-methyl-3-buten-2-ol and propene were measured by FTIR spectroscopy, and the measured rate coefficient ratio $k\left(\mathrm{NO}_{3}+2\right.$-methyl-3-buten-2-ol $) / k\left(\mathrm{NO}_{3}+\right.$ propene $)$ is placed on an absolute basis by use of a rate coefficient of $k\left(\mathrm{NO}_{3}+\right.$ propene) $=9.0 \times 10^{-15} \mathrm{~cm}^{3}$ molecule ${ }^{-1} \mathrm{~s}^{-1}$ at $294 \mathrm{~K}$ (IUPAC, current recommendation).

(c) $\mathrm{NO}_{3}$ radicals were generated by the thermal decomposition of $\mathrm{N}_{2} \mathrm{O}_{5}$ in

$\mathrm{N}_{2} \mathrm{O}_{5}-\left(\mathrm{CH}_{3}\right)_{2} \mathrm{C}(\mathrm{OH}) \mathrm{CH}=\mathrm{CH}_{2}$-propene (the reference compound)-air mixtures at $987 \pm 7 \mathrm{mbar}$ pressure. The concentrations of 2-methyl-3-buten-2-ol and propene were measured by FTIR spectroscopy, and the measured rate coefficient ratio $k\left(\mathrm{NO}_{3}+2\right.$-methyl-3-buten-2-ol $) / k\left(\mathrm{NO}_{3}+\right.$ propene $)$ is placed on an absolute basis by use of a rate coefficient of $k\left(\mathrm{NO}_{3}+\right.$ propene) $=9.5 \times 10^{-15} \mathrm{~cm}^{3}$ molecule ${ }^{-1} \mathrm{~s}^{-1}$ at $298 \mathrm{~K}$ (IUPAC, current recommendation).

(d) $\mathrm{NO}_{3}$ radicals were generated by the thermal decomposition of $\mathrm{N}_{2} \mathrm{O}_{5}$ in $\mathrm{N}_{2} \mathrm{O}_{5}-\left(\mathrm{CH}_{3}\right)_{2} \mathrm{C}(\mathrm{OH}) \mathrm{CH}=\mathrm{CH}_{2}$-propene (the reference compound)-air (or $\mathrm{N}_{2}$ ) mixtures at $\sim 1.02$ bar pressure. The concentrations of 2-methyl-3-buten-2-ol and propene were measured by FTIR spectroscopy, and the measured rate coefficient ratio $k\left(\mathrm{NO}_{3}+2\right.$-methyl-3-buten-2-ol $) / k\left(\mathrm{NO}_{3}+\right.$ propene $)$ is placed on an absolute basis by use of a rate coefficient of $k\left(\mathrm{NO}_{3}+\right.$ propene $)=9.4 \times 10^{-15} \mathrm{~cm}^{3}$ molecule $\mathrm{s}^{-1} \mathrm{~s}^{-1}$ at $297 \mathrm{~K}$ (IUPAC, current recommendation).

(e) $\mathrm{NO}_{3}$ radicals were generated by the thermal decomposition of $\mathrm{N}_{2} \mathrm{O}_{5}$ in

$\mathrm{N}_{2} \mathrm{O}_{5}-\left(\mathrm{CH}_{3}\right)_{2} \mathrm{C}(\mathrm{OH}) \mathrm{CH}=\mathrm{CH}_{2}$-butanal (the reference compound)-air (or $\mathrm{N}_{2}$ ) mixtures at $1.01 \pm 0.01$ bar pressure. The concentrations of 2-methyl-3-buten-2-ol and butanal were measured by collection onto solid phase microextraction fibers with GC analyses. The measured rate coefficient ratio $k\left(\mathrm{NO}_{3}+2\right.$-methyl-3-buten-2-ol $) / k\left(\mathrm{NO}_{3}+\right.$ butanal $)$ is placed on an absolute basis by use of a rate coefficient of $k\left(\mathrm{NO}_{3}+\right.$ butanal) $=1.1 \times 10^{-14} \mathrm{~cm}^{3}$ molecule $\mathrm{s}^{-1}$ at $297 \mathrm{~K}$ (IUPAC, current recommendation).

\section{Preferred Values}

$k=1.2 \times 10^{-14} \mathrm{~cm}^{3}$ molecule $\mathrm{e}^{-1} \mathrm{~s}^{-1}$ at $298 \mathrm{~K}$.

$k=4.6 \times 10^{-14} \exp (-400 / T) \mathrm{cm}^{3}$ molecule ${ }^{-1} \mathrm{~s}^{-1}$ over the temperature range $260-400 \mathrm{~K}$. 


\section{Reliability}

$\Delta \log k= \pm 0.2$ at $298 \mathrm{~K}$.

$\Delta(E / R)= \pm 200 \mathrm{~K}$.

\section{Comments on Preferred Values}

At room temperature, the relative rate coefficients of Hallquist et al. (1996), Fantechi et al. (1998a) and Noda et al. (2002) are in agreement, within the combined error limits, with the absolute rate coefficient of Rudich et al. (1996). However, the absolute rate coefficient of Hallquist et al. (1996) is a factor of 1.7 higher than that of Rudich et al. (1996). The absolute data of Rudich et al. (1996) are the basis for the preferred values. The reaction proceeds by initial addition of $\mathrm{NO}_{3}$ to the $\mathrm{C}=\mathrm{C}$ bond (Fantechi et al., 1998b; Noda et al., 2000), forming (after addition of $\mathrm{O}_{2}$ ) the peroxy radicals $\left(\mathrm{CH}_{3}\right)_{2} \mathrm{C}(\mathrm{OH}) \mathrm{CH}\left(\mathrm{ONO}_{2}\right) \mathrm{CH}_{2} \mathrm{OO}$ and $\left(\mathrm{CH}_{3}\right)_{2} \mathrm{C}(\mathrm{OH}) \mathrm{CH}(\mathrm{OO}) \mathrm{CH}_{2} \mathrm{ONO}_{2}$ (and mainly the $\left(\mathrm{CH}_{3}\right)_{2} \mathrm{C}(\mathrm{OH}) \mathrm{CH}(\mathrm{OO}) \mathrm{CH}_{2} \mathrm{ONO}_{2}$ radical (see below)). Reactions of these peroxy radicals with $\mathrm{HO}_{2}$ radicals, organic peroxy radicals, $\mathrm{NO}, \mathrm{NO}_{2}$, and $\mathrm{NO}_{3}$ radicals will lead to the products observed in the atmosphere (Atkinson and Arey, 2003). Under laboratory conditions, the observed products at atmospheric pressure of air are acetone and $\mathrm{O}_{2} \mathrm{NOCH}_{2} \mathrm{CHO}$, with measured molar yields of $68.7 \pm 7.1 \%$ (Fantechi et al., 1998b) and $63 \pm 6 \%$ (Noda et al., 2000) for acetone and $67 \pm 8 \%$ for 2-nitrooxyacetaldehyde (Noda et al., 2000). These observed products presumably arise from self-reaction of the $\left(\mathrm{CH}_{3}\right)_{2} \mathrm{C}(\mathrm{OH}) \mathrm{CH}(\mathrm{OO}) \mathrm{CH}_{2} \mathrm{ONO}_{2}$ peroxy radical, followed by decomposition of the resulting $\left(\mathrm{CH}_{3}\right)_{2} \mathrm{C}(\mathrm{OH}) \mathrm{CH}(\mathrm{O}) \mathrm{CH}_{2} \mathrm{ONO}_{2}$ radical:

$$
\begin{aligned}
& 2\left(\mathrm{CH}_{3}\right)_{2} \mathrm{C}(\mathrm{OH}) \mathrm{CH}(\mathrm{OO}) \mathrm{CH}_{2} \mathrm{ONO}_{2} \rightarrow 2\left(\mathrm{CH}_{3}\right)_{2} \mathrm{C}(\mathrm{OH}) \mathrm{CH}(\mathrm{O}) \mathrm{CH}_{2} \mathrm{ONO}_{2}+\mathrm{O}_{2} \\
&\left(\mathrm{CH}_{3}\right)_{2} \mathrm{C}(\mathrm{OH}) \mathrm{CH}(\mathrm{O}) \mathrm{CH}_{2} \mathrm{ONO}_{2} \rightarrow \quad\left(\mathrm{CH}_{3}\right)_{2} \mathrm{COH}+\mathrm{HC}(\mathrm{O}) \mathrm{CH}_{2} \mathrm{ONO}_{2} \\
& \downarrow \mathrm{O}_{2} \\
& \mathrm{CH}_{3} \mathrm{C}(\mathrm{O}) \mathrm{CH}_{3}+\mathrm{HO}_{2}
\end{aligned}
$$

\section{References}

Atkinson, R. and Arey, J.: Chem. Rev., 103, 4605, 2003.

Fantechi, G., Jensen, N. R., Hjorth, J., and Peeters, J.: Int. J. Chem. Kinet., 30, 589, 1998a.

Fantechi, G., Jensen, N. R., Hjorth, J., and Peeters, J.: Atmos. Environ., 32, 3547, 1998b.

Hallquist, M., Langer, S., Ljungström, E., and Wängberg, I.: Int. J. Chem. Kinet., 28, 467, 1996.

IUPAC, http://www.iupac-kinetic.ch.cam.ac.uk/.

Noda, J., Hallquist, M., Langer, S., and Ljungström, E.: Phys. Chem. Chem. Phys., 2, 2555, 2000.

Rudich, Y., Talukdar, R. K., Fox, R. W., and Ravishankara, A. R.: J. Phys. Chem., 100, 5374, 1996. 
Appendix A4: Carbon radical Reactions

\section{II.A4.86}

$$
\mathrm{CH}_{3}+\mathrm{O}_{2}+\mathrm{M} \rightarrow \mathrm{CH}_{3} \mathrm{O}_{2}+\mathrm{M}
$$

$\Delta H^{\circ}=-136.0 \mathrm{~kJ} \cdot \mathrm{mol}^{-1}$

\section{Low-pressure rate coefficients}

\section{Rate coefficient data}

\begin{tabular}{lllc}
\hline$k_{0} / \mathrm{cm}^{3}$ molecule ${ }^{-1} \mathrm{~s}^{-1}$ & Temp./K & Reference & Technique/Comments \\
\hline Absolute Rate Coefficients & & & \\
$2.6 \times 10^{-31}\left[\mathrm{~N}_{2}\right]$ & 298 & Basco et al., 1972 & FP-AS (a) \\
$3.1 \times 10^{-31}\left[\mathrm{~N}_{2}\right]$ & 298 & Parkes, 1977 & MM-AS (b) \\
$4.5 \times 10^{-31}\left[\mathrm{~N}_{2}\right]$ & 296 & Selzer and Bayes, 1983 & PLP-MS (c) \\
$(7.0 \pm 1.0) \times 10^{-31}[\mathrm{Ar}]$ & 298 & Cobos et al., 1985 & PLP-AS (d) \\
$(8.0 \pm 1.0) \times 10^{-31}\left[\mathrm{~N}_{2}\right]$ & 298 & & \\
$(4.8 \pm 0.6) \times 10^{-31}[\mathrm{Ar}]$ & 298 & Pilling and Smith, 1985 & PLP-AS (e) \\
$(1.0 \pm 0.3) \times 10^{-30}(\mathrm{~T} / 300)^{-3.3}[\mathrm{Ar}]$ & $334-582$ & Keiffer et al., 1987 & PLP-AS (f) \\
& & & \\
Relative Rate Coefficients & & & \\
$6.1 \times 10^{-33} \mathrm{exp}(1000 / T)\left[\mathrm{N}_{2}\right]$ & $259-339$ & Washida and Bayes, 1976 & DF-MS (g) \\
$1.8 \times 10^{-31}\left[\mathrm{~N}_{2}\right]$ & 298 & & \\
$8.0 \times 10^{-32} \mathrm{exp}(243 / T)[\mathrm{Ar}]$ & $230-568$ & Pratt and Wood, 1984 & (h) \\
$1.8 \times 10^{-31}[\mathrm{Ar}]$ & 298 & & \\
$(7.56 \pm 1.1) \times 10^{-31}(\mathrm{~T} / 300)^{-3.64}[\mathrm{~N} 2]$ & $264-370$ & Kaiser, 1993 & $(\mathrm{i})$ \\
\hline
\end{tabular}

\section{Comments}

(a) Pressure range 40 mbar to 500 mbar. Lindemann-Hinshelwood plot was used for extrapolation to $k_{0}$ and $k_{\infty}$

(b) Molecular modulation spectroscopy. Pressure range 25 mbar to 1000 mbar. Lindemann-Hinshelwood extrapolation to $k_{0}$ and $k_{\infty}$.

(c) Pressure varied between 0.6 mbar and 8 mbar.

(d) Pressure of the bath gases $\mathrm{N}_{2}$, Ar and $\mathrm{O}_{2}$ varied between 0.2 mbar and 150 bar. Falloff curves were constructed with $F_{c}=0.27, \mathrm{~N}=1.47$ and $k_{\infty}=2.2 \times 10^{-12} \mathrm{~cm}^{3}$ molecule ${ }^{-1} \mathrm{~s}^{-1}$. The low value of the theoretically modeled $F_{c}$ leads to a high limiting value of $k_{0}$ extracted from the measurements.

(e) Pressures of bath gas Ar varied between 4.2 mbar and 645 mbar. Falloff curves constructed using $F_{c}=0.57$ (including strong and weak collision contributions).

(f) Measurements in the pressure range 25 mbar to 790 mbar. Falloff curves constructed with $F_{c}=0.6$. Various fitting procedures were applied and discussed.

(g) The rate coefficients $k\left(\mathrm{CH}_{3}+\mathrm{O}_{2}+\mathrm{M} \rightarrow \mathrm{CH}_{3} \mathrm{O}_{2}+\mathrm{M}\right)$ plus $k\left(\mathrm{CH}_{3}+\mathrm{O}_{2} \rightarrow \mathrm{HCHO}+\mathrm{HO}\right)$ were measured relative to $k(\mathrm{O}+\mathrm{CH} 3$ $\rightarrow$ products). Evaluation with $k\left(\mathrm{O}+\mathrm{CH}_{3}\right)=1.0 \times 10^{-10} \mathrm{~cm}^{3}$ molecule $\mathrm{s}^{-1}$. Extrapolation to $k_{0}$.

(h) Discharge-flow system at pressures of 2.6 mbar to 13 mbar. $\mathrm{CH}_{3}$ radicals were produced from the $\mathrm{H}+\mathrm{C}_{2} \mathrm{H}_{4}$ reaction. Reaction rates were determined from the effect of added $\mathrm{O}_{2}$ on the radical combination products. Falloff curves were constructed assuming that $k_{\infty}$ and $F_{c}$ are independent of temperature. 
(i) Mixtures of $\mathrm{Cl}_{2}, \mathrm{CH}_{4}$, diluent $\left(\mathrm{N}_{2}, \mathrm{Ar}, \mathrm{He}\right.$, or $\left.\mathrm{SF}_{6}\right)$ were irradiated with a fluorescent lamp. The $\mathrm{CH}_{4}$ loss and $\mathrm{CH}_{3} \mathrm{Cl}$ formation were measured by GC. Data were obtained (for $\mathrm{N}_{2}$ or $\mathrm{O}_{2}$ ) between $3 \mathrm{mbar}$ and 13 bar at $297 \mathrm{~K}, 25 \mathrm{mbar}$ and 2 bar at $370 \mathrm{~K}$ and $50 \mathrm{mbar}$ and $15 \mathrm{bar}$ at $264 \mathrm{~K}$. The data were fitted using $F_{c}=0.48$ at $264 \mathrm{~K}, 0.46$ at $297 \mathrm{~K}$ and 0.42 at $370 \mathrm{~K}$.

\section{Preferred Values}

$k_{0}=1.0 \times 10^{-30}(T / 300)^{-3.3}\left[\mathrm{~N}_{2}\right] \mathrm{cm}^{3}$ molecule ${ }^{-1} \mathrm{~s}^{-1}$ over the temperature range 200-300 K.

\section{Reliability}

$\Delta \log k_{0}= \pm 0.2$ at $298 \mathrm{~K}$.

$\Delta n= \pm 1$.

\section{Comments on Preferred Values}

The evaluation uses the results of Keiffer et al. (1987) and Kaiser (1993), although different values of $F_{c}$ were employed. The temperature dependence of $F_{c}$ applied in Keiffer et al. (1987) does not extend to temperatures below $300 \mathrm{~K}$. The calculated values of $F_{c}$ from Cobos et al. (1985) are preferred, i.e., $F_{c}=0.27$ at $300 \mathrm{~K}$.

\section{High-pressure rate coefficients}

\section{Rate coefficient data}

\begin{tabular}{lllc}
\hline$k_{\infty} / \mathrm{cm}^{3}$ molecule ${ }^{-1} \mathrm{~s}^{-1}$ & Temp./K & Reference & Technique/Comments \\
\hline $\begin{array}{l}\text { Absolute Rate Coefficients } \\
1.8 \times 10^{-12}\end{array}$ & 298 & Van den Bergh and Callear, 1971 & FP-AS (a) \\
$5 \times 10^{-13}$ & 298 & Basco et al., 1972 & FP-AS (b) \\
$1.2 \times 10^{-12}$ & 298 & Parkes, 1977 & FP-AS (c) \\
$2.2 \times 10^{-12}$ & 295 & Hochanadel et al., 1977 & FP-AS (d) \\
$(2.2 \pm 0.3) \times 10^{-12}(T / 300)^{0.94}$ & $200-400$ & Cobos et al., 1985 & PLP-AS (e) \\
$(1.05 \pm 0.12) \times 10^{-12}$ & 298 & Pilling and Smith, 1985 & PLP-AS (f) \\
$(1.2 \pm 0.2) \times 10^{-12}(T / 300)^{1.2}$ & $334-582$ & Keiffer et al., 1987 & PLP-AS (g) \\
Relative Rate Coefficients & & & \\
$1.7 \times 10^{-12}$ & & & Laufer and Bass, 1975 \\
$(1.31 \pm 0.1) \times 10^{-12}(T / 300)^{1.2}$ & $298-370$ & Kaiser, 1993 & (j) \\
\hline
\end{tabular}

\section{Comments}

(a) Pressure range 40 mbar to 400 mbar of $\mathrm{C}_{3} \mathrm{H}_{8}$. RRKM extrapolation to $k_{\infty}$.

(b) See comment (a) for $k_{0}$.

(c) See comment (b) for $k_{0}$.

(d) 12 percent falloff correction applied using the results of Basco et al. (1972).

(e) See comment (d) for $k_{0}$.

(f) See comment (e) for $k_{0}$.

(g) See comment (f) for $k_{0}$.

(h) See comment (g) for $k_{0}$. 
(i) Pressure range 66 mbar to 920 mbar, RRKM extrapolation to $k_{\infty}$. Rate measured relative to $\mathrm{CH}_{3}+\mathrm{CH}_{3} \rightarrow \mathrm{C}_{2} \mathrm{H}_{6}$ and evaluated with $k\left(\mathrm{CH}_{3}+\mathrm{CH}_{3} \rightarrow \mathrm{C}_{2} \mathrm{H}_{6}\right)=9.5 \times 10^{-11} \mathrm{~cm}^{3}$ molecule ${ }^{-1} \mathrm{~s}^{-1}$ from the same work.

(j) See comment (i) for $k_{0}$.

\section{Preferred Values}

$k=9.5 \times 10^{-13} \mathrm{~cm}^{3}$ molecule $\mathrm{e}^{-1} \mathrm{~s}^{-1}$ at $298 \mathrm{~K}$ and 1 bar of air.

$k_{\infty}=1.8 \times 10^{-12} \exp (T / 300)^{1.1} \mathrm{~cm}^{3}$ molecule ${ }^{-1} \mathrm{~s}^{-1}$ over the temperature range $200-300 \mathrm{~K}$.

\section{Reliability}

$\Delta \log k_{\infty}= \pm 0.3$ at $298 \mathrm{~K}$.

$\Delta n= \pm 1$.

\section{Comments on Preferred Values}

The preferred value is an average of earlier results from Cobos et al. (1985) and Keiffer et al. (1987) and the more recent determination by Kaiser (1993).

\section{References}

Basco, N., James, D. G. L., and James, F. C.: Int. J. Chem. Kinet., 4, 129, 1972.

Cobos, C. J., Hippler, H., Luther, K., Ravishankara, A. R., and Troe, J.: J. Phys. Chem., 89, 4332, 1985.

Hochanadel, C. J., Ghormley, J. A., Boyle, J. W., and Ogren, P. J.: J. Phys. Chem., 81, 3, 1977.

Kaiser, E. W.: J. Phys. Chem. 97, 11 681, 1993.

Keiffer, M., Pilling, M. J., and Smith, M. J. C.: J. Phys. Chem., 91, 6028, 1987.

Laufer, A. H. and Bass, A. M.: Int. J. Chem. Kinet., 7, 639, 1975.

Parkes, D. A.: Int. J. Chem. Kinet., 9, 451, 1977.

Pilling, M. J. and Smith, M. J. C.: J. Phys. Chem., 89, 4713, 1985.

Pratt, G. L. and Wood, S. W.: J. Chem. Soc. Faraday Trans., 1, 80, 3419, 1984.

Selzer, E. A. and Bayes, K. D.: J. Phys. Chem., 87, 392, 1983.

Van den Bergh, H. and Callear, A. B.: Trans. Faraday Soc., 67, 2017, 1971.

Washida, N. and Bayes, K. D.: Int. J. Chem. Kinet., 8, 777, 1976. 
II.A4.87

$$
\mathrm{CH}_{3}+\mathrm{O}_{3} \rightarrow \text { products }
$$

\begin{tabular}{lllc}
\hline$k / \mathrm{cm}^{3}$ molecule $\mathrm{s}^{-1}$ & Temp./K & Reference & Technique/Comments \\
\hline Absolute Rate Coefficients & & & \\
$5.1 \times 10^{-12} \exp [-(210 \pm 84) / T]$ & $243-384$ & Ogryzlo et al., 1981; & FP-MS (a) \\
$(2.53 \pm 0.54) \times 10^{-12}$ & 298 & Paltenghi et al., 1984 & \\
$(2.2 \pm 0.3) \times 10^{-12}$ & 298 & Albaladejo et al., 2002 & PLP-LIF (b) \\
\hline
\end{tabular}

\section{Comments}

(a) Flash photolysis of $\mathrm{CH}_{3} \mathrm{NO}_{2}$ at $193 \mathrm{~nm}$ in a flow system with $\mathrm{He}$ carrier gas at pressures of $\sim 2.7 \mathrm{mbar}$ ( $\sim 2$ Torr). [ $\left.\mathrm{CH}_{3}\right]$ was monitored by photoionization MS under pseudo-first-order conditions; no product analyses. The original data of Ogryzlo et al. (1981) were revised by Paltenghi et al. (1984) on the basis of a correction for the pressure drop along the flow tube between the reaction vessel and the manometer.

(b) Pulsed laser photolysis of $\mathrm{CH}_{3} \mathrm{Br}$ at $193 \mathrm{~nm}$ and $133 \mathrm{mbar}$ (100 Torr) He coupled with laser-excited fluorescence detection of $\mathrm{CH}_{3} \mathrm{O}$ at $292.4 \mathrm{~nm}$ in a slow-flow cell. The rate coefficient for total removal of $\mathrm{CH}_{3}$ was determined by numerical analysis of the temporal profiles of the $\mathrm{CH}_{3} \mathrm{O}$ signal. The calibration of the $\mathrm{CH}_{3} \mathrm{O}$ concentration was performed by comparing LIF signals with those for the reaction $\mathrm{CH}_{3}+\mathrm{NO}_{2}$ obtained under identical conditions. The $\mathrm{CH}_{3} \mathrm{O}$ absolute yield from the $\mathrm{CH}_{3}+\mathrm{O}_{3}$ reaction was measured to be $0.044 \pm 0.013$ and leads to $k=(9.68 \pm 1.10) \times 10^{-14} \mathrm{~cm}^{3} \mathrm{molecule}^{-1}$ $\mathrm{s}^{-1}$ for the reaction channel $\mathrm{CH}_{3}+\mathrm{O}_{3} \rightarrow \mathrm{CH}_{3} \mathrm{O}+\mathrm{O}_{2}$.

\section{Preferred Values}

$k=2.3 \times 10^{-12} \mathrm{~cm}^{3}$ molecule ${ }^{-1} \mathrm{~s}^{-1}$ at $298 \mathrm{~K}$.

$k=4.7 \times 10^{-12} \exp (-210 / T) \mathrm{cm}^{3}$ molecule ${ }^{-1} \mathrm{~s}^{-1}$ over the temperature range $240-400 \mathrm{~K}$.

\section{Reliability}

$\Delta \log k= \pm 0.3$ at $298 \mathrm{~K}$.

$\Delta(E / R)= \pm 200 \mathrm{~K}$.

\section{Comments on Preferred Values}

The preferred values are based on the mean of the revised calculations by Paltenghi et al. (1984) of the earlier data of Ogryzlo et al. (1981) and of the data of Albaladejo et al. (2002).

\section{References}

Albaladejo, J., Jiménez, E., Notario, A., Cabañas, B., and Martínez, E.: J. Phys. Chem. A, 106, 2512, 2002. Ogryzlo, E. A., Paltenghi, R., and Bayes, K. D.: Int. J. Chem. Kinet., 13, 667, 1981. Paltenghi, R., Ogryzlo, E. A., and Bayes, K. D.: J. Phys. Chem., 88, 2595, 1984. 
II.A4.88

$$
\mathrm{C}_{2} \mathrm{H}_{5}+\mathrm{O}_{2} \rightarrow \mathrm{C}_{2} \mathrm{H}_{4}+\mathrm{HO}_{2}
$$

$\Delta H^{\circ}=-54.1 \mathrm{~kJ} \cdot \mathrm{mol}^{-1}$

\section{Rate coefficient data}

\begin{tabular}{lllc}
\hline$k / \mathrm{cm}^{3}$ molecule $\mathrm{s}^{-1}$ & Temp./K & Reference & Technique/Comments \\
\hline $\begin{array}{l}\text { Absolute Rate Coefficients } \\
(2.1 \pm 0.5) \times 10^{-13}\end{array}$ & 295 & $\begin{array}{l}\text { Plumb and Ryan, 1981 } \\
\text { Wagner et al., 1990 }\end{array}$ & (a) \\
$<10^{-13}$ & 1000 & & \\
& & & \\
Relative Rate Coefficients & & Kaiser et al., 1990 & (c) \\
$1.9 \times 10^{-14}(133$ mbar, air $)$ & 298 & & \\
$3.8 \times 10^{-15}(1$ bar, air $)$ & 298 & & \\
$9.8 \times 10^{-16}(8$ bar, air $)$ & 298 & & \\
\hline
\end{tabular}

\section{Comments}

(a) Discharge flow system. $\mathrm{C}_{2} \mathrm{H}_{5}$ radicals were generated from the reaction $\mathrm{Cl}+\mathrm{C}_{2} \mathrm{H}_{6} \rightarrow \mathrm{HCl}+\mathrm{C}_{2} \mathrm{H}_{5} . \mathrm{C}_{2} \mathrm{H}_{5}$ and $\mathrm{C}_{2} \mathrm{H}_{4}$ were measured directly by MS. The rate coefficient $k$ was determined from the measured yields of $\mathrm{C}_{2} \mathrm{H}_{4} . k$ found to be independent of pressure (0.8 mbar to 13 mbar).

(b) Experimental and theoretical study of the $\mathrm{C}_{2} \mathrm{H}_{5}+\mathrm{O}_{2}$ reaction. Experiments were carried out in tubular flame reactor. $\mathrm{C}_{2} \mathrm{H}_{5}$ radicals were formed by laser photolysis of $\mathrm{C}_{2} \mathrm{H}_{5} \mathrm{Br}$ or $\mathrm{CCl}_{4}-\mathrm{C}_{2} \mathrm{H}_{6}$ mixtures. Concentrations of $\mathrm{C}_{2} \mathrm{H}_{5}$ and $\mathrm{C}_{2} \mathrm{H}_{4}$ were monitored by photoionization MS.

(c) Study of the yields of $\mathrm{C}_{2} \mathrm{H}_{4}$ produced relative to the $\mathrm{C}_{2} \mathrm{H}_{6}$ consumed ( $\mathrm{GC}$ analysis) in a system in which $\mathrm{C}_{2} \mathrm{H}_{5}$ radicals were generated from UV irradiation of $\mathrm{Cl}_{2}-\mathrm{C}_{2} \mathrm{H}_{6}-\mathrm{O}_{2}-\mathrm{N}_{2}$ (or air) mixtures. Up to 8 bar the percentage of $\mathrm{C}_{2} \mathrm{H}_{4}$ produced, relative to the $\mathrm{C}_{2} \mathrm{H}_{6}$ consumed, decreased from $12 \%$ to $0.02 \%$, following a $P^{-(0.8 \pm 0.1)}$ pressure dependence in air. The listed pressure-dependent $k$ values are relative to values of $k\left(\mathrm{C}_{2} \mathrm{H}_{5}+\mathrm{O}_{2}+\mathrm{M} \rightarrow \mathrm{C}_{2} \mathrm{H}_{5} \mathrm{O}_{2}+\mathrm{M}\right)$ calculated from the recommended values of Baldwin et al. (1980).

\section{Preferred Values}

$k=3.8 \times 10^{-15} \mathrm{~cm}^{3}$ molecule $\mathrm{e}^{-1} \mathrm{~s}^{-1}$ at $298 \mathrm{~K}$ and 1 bar of air.

$k=1.9 \times 10^{-14} \mathrm{~cm}^{3}$ molecule $\mathrm{e}^{-1} \mathrm{~s}^{-1}$ at $298 \mathrm{~K}$ and 0.133 bar of air.

\section{Reliability}

$\Delta \log k= \pm 0.5$ at $298 \mathrm{~K}$.

\section{Comments on Preferred Values}

The recommended pressure-dependent values of $k_{298}$ are from the product study of Kaiser et al. (1990). Increasing the pressure, therefore, decreases the apparent rate coefficient of this reaction. At a given pressure, increasing the temperature leads to an increasing yield of $\mathrm{C}_{2} \mathrm{H}_{4}$.

For a full discussion of the mechanism of the $\mathrm{C}_{2} \mathrm{H}_{5}+\mathrm{O}_{2}$ reaction see Wagner et al. (1990), Miller et al. (2000) and Miller and Klippenstein (2001). It is clear that for atmospheric conditions the interaction of $\mathrm{C}_{2} \mathrm{H}_{5}$ with $\mathrm{O}_{2}$ to form $\mathrm{C}_{2} \mathrm{H}_{5} \mathrm{O}_{2}$ radicals is by far the dominant pathway. The work of Kaiser (1995) provides information on the mechanism of $\mathrm{C}_{2} \mathrm{H}_{4}$ formation. According to this, the reaction proceeds via a rearrangement of the excited $\mathrm{C}_{2} \mathrm{H}_{5} \mathrm{O}_{2}$ adduct with an energy barrier of $(4.6 \pm 1.0) \mathrm{kJ} \cdot \mathrm{mol}^{-1}$. 


\section{References}

Baldwin, R. R., Pickering, I. A., and Walker, R. W.: J. Chem. Soc. Faraday Trans., 1, 76, $2374,1980$.

Kaiser, E. W.: J. Phys. Chem. 99, 707. 1995.

Kaiser, E. W., Lorkovic, I. M., and Wallington, T. J.: J. Phys. Chem., 94, 3352, 1990.

Miller, J. A. and Klippenstein, S. J.: Int. J. Chem. Kinet., 33, 654, 2001.

Miller, J. A., Klippenstein, S. J., and Robertson, S. H.: Proc. Combust. Inst., 28, 1479, 2000.

Plumb, I. C. and Ryan, K. R.: Int. J. Chem. Kinet., 13, 1011, 1981.

Wagner, A. F., Slagle, I. R., Sarzynski, D., and Gutman, D.: J. Phys. Chem., 94, 1853, 1990. 
II.A4.89

$$
\mathbf{C}_{2} \mathbf{H}_{5}+\mathbf{O}_{2}+\mathbf{M} \rightarrow \mathbf{C}_{2} \mathbf{H}_{5} \mathbf{O}_{2}+\mathbf{M}
$$

$\Delta H^{\circ}=-149.6 \mathrm{~kJ} \cdot \mathrm{mol}^{-1}$

\section{Low-pressure rate coefficients}

\section{Rate coefficient data}

\begin{tabular}{|c|c|c|c|}
\hline$k_{0} / \mathrm{cm}^{3}$ molecule ${ }^{-1} \mathrm{~s}^{-1}$ & Temp./K & Reference & Technique/Comments \\
\hline $\begin{array}{l}\text { Absolute Rate Coefficients } \\
(7.5 \pm 2) \times 10^{-29}[\mathrm{He}]\end{array}$ & 295 & Plumb and Ryan, 1981 & DF-MS (a) \\
\hline $7.5 \times 10^{-29}[\mathrm{He}]$ & 298 & Slagle et al., 1984 & DF-MS (b) \\
\hline $1.96 \times 10^{-5} T^{-8.24} \exp (-2150 / T)[\mathrm{He}]$ & $296-850$ & Wagner et al., 1990 & PLP-MS (c) \\
\hline $5.9 \times 10^{-29}[\mathrm{He}]$ & 298 & & \\
\hline $\begin{array}{l}\text { Relative Rate Coefficients } \\
(6.5 \times 2.0) \times 10^{-29}[\mathrm{He}]\end{array}$ & 298 & Kaiser et al., 1990 & (d) \\
\hline
\end{tabular}

\section{Comments}

(a) Measurements at $2 \times 10^{16}$ molecule $\mathrm{cm}^{-3}$ to $3.4 \times 10^{17}$ molecule $\mathrm{cm}^{-3}$ of $\mathrm{He}$, extrapolated to $k_{0}$ and $k_{\infty}$ with $F_{c}=0.85$.

(b) Bath gas concentration varied between $1.6 \times 10^{16}$ molecule $\mathrm{cm}^{-3}$ and $2.4 \times 10^{17}$ molecule $\mathrm{cm}^{-3}$. Data in agreement with values measured by Plumb and Ryan (1981).

(c) Experiments carried out in a heatable tubular reactor. He pressures from $0.7 \mathrm{mbar}$ to $20 \mathrm{mbar}$ were used.

(d) $\mathrm{C}_{2} \mathrm{H}_{5}$ radicals were produced by $\mathrm{UV}$ irradiation of mixtures of $\mathrm{Cl}_{2}-\mathrm{C}_{2} \mathrm{H}_{6}-\mathrm{O}_{2}$. The consumed $\mathrm{C}_{2} \mathrm{H}_{6}$ was determined by either FTIR or GC with flame ionization detection (which also allowed the amount of $\mathrm{C}_{2} \mathrm{H}_{5} \mathrm{Cl}$ formed to be measured). Rate coefficients were measured as a function of pressure ( $4 \mathrm{mbar}$ to $2000 \mathrm{mbar}$ ) relative to that of the reaction $\mathrm{C}_{2} \mathrm{H}_{5}+\mathrm{Cl}_{2} \rightarrow \mathrm{C}_{2} \mathrm{H}_{2} \mathrm{Cl}+\mathrm{Cl}$, and placed on an absolute basis by use of a rate coefficient of $k\left(\mathrm{C}_{2} \mathrm{H}_{5}+\mathrm{Cl}_{2}\right)=2.9 \times 10^{-12} \mathrm{~cm}^{3}$ molecule ${ }^{-1} \mathrm{~s}^{-1}$ at 7 mbar.

\section{Preferred Values}

$k_{0}=5.9 \times 10^{-29}(T / 300)^{-3.8} \mathrm{~cm}^{3}$ molecule ${ }^{-1} \mathrm{~s}^{-1}$ over the temperature range $200-300 \mathrm{~K}$.

\section{Reliability}

$\Delta \log k_{0}= \pm 0.3$ at $298 \mathrm{~K}$.

$\Delta n= \pm 1$.

\section{Comments on Preferred Values}

We prefer the extensive results from Wagner et al. (1990) because the falloff extrapolation $k_{0}$ was done with a careful theoretical analysis. Falloff extrapolations were made with theoretically derived (Wagner et al., 1990) values of $F_{c}=0.64$ at $200 \mathrm{~K}$ and 0.54 at $300 \mathrm{~K}$. 


\section{High-pressure rate coefficients}

\section{Rate coefficient data}

\begin{tabular}{lllc}
\hline$k_{\infty} / \mathrm{cm}^{3}$ molecule ${ }^{-1} \mathrm{~s}^{-1}$ & Temp./K & Reference & Technique/Comments \\
\hline $\begin{array}{l}\text { Absolute Rate Coefficients } \\
(4.4 \pm 0.5) \times 10^{-12}\end{array}$ & 295 & Plumb and Ryan, 1981 & DF-MS (a) \\
$4.4 \times 10^{-12}$ & 300 & Slagle et al., 1984 & DF-MS (b) \\
$1.3 \times 10^{-12} \exp (420 / T)$ & $298-400$ & Munk et al., 1986 & (c) \\
$5.3 \times 10^{-12}$ & 298 & & \\
$3.67 \times 10^{-14} T^{0.772} \exp (287 / T)$ & $296-850$ & Wagner et al., 1990 & PLP-MS (d) \\
$7.8 \times 10^{-12}$ & 298 & & \\
& & & \\
Relative Rate Coefficients & 298 & Kaiser et al., 1990 & (e) \\
$(9.2 \pm 0.9) \times 10^{-12}$ & $260-380$ & Kaiser, 1995 & (f) \\
$(8.1 \pm 0.3) \times 10^{-12}$ & $243-475$ & Dilger et al., 1996 & (g) \\
$2.9 \times 10^{-12} \exp (289 / T)$ & 298 & & \\
$7.6 \times 10^{-12}$ & & & \\
\hline
\end{tabular}

\section{Comments}

(a) See comment (a) for $k_{0}$.

(b) See comment (b) for $k_{0}$.

(c) Pulse radiolysis in $\mathrm{H}_{2}$ at 1 bar. $\mathrm{C}_{2} \mathrm{H}_{5}$ radicals were generated from the reaction of $\mathrm{H}+\mathrm{C}_{2} \mathrm{H}_{4} \cdot \mathrm{C}_{2} \mathrm{H}_{5} \mathrm{O}_{2}$ radicals were monitored by absorption at $240 \mathrm{~nm}$.

(d) See comment (c) for $k_{0}$.

(e) See comment (d) for $k_{0}$.

(f) Photolysis of $\mathrm{Cl}_{2}$ in the presence of $\mathrm{C}_{2} \mathrm{H}_{6}, \mathrm{O}_{2}$ and $\mathrm{M}=\mathrm{He}$ or $\mathrm{N}_{2}$ at a pressure of 773 mbar. $k_{\infty}$ was measured relative to the reaction $\mathrm{C}_{2} \mathrm{H}_{5}+\mathrm{Cl}_{2} \rightarrow \mathrm{C}_{2} \mathrm{H}_{5} \mathrm{Cl}+\mathrm{Cl}$ for which a rate coefficient of $1.04 \times 10^{-11} \exp (300 / T) \mathrm{cm}^{3} \mathrm{molecule}^{-1} \mathrm{~s}^{-1}$ was employed (Kaiser, 1990; Timonen and Gutman, 1986).

(g) Muon relaxation method in longitudinal magnetic fields. $\mathrm{MuCH}_{2} \mathrm{CH}_{2}$ radicals were generated by addition of muonium $\left(\mathrm{Mu}=\mu^{+} \mathrm{e}^{-}\right)$to $\mathrm{C}_{2} \mathrm{H}_{4}$. Total pressures of $\mathrm{N}_{2}$ varied between 1.5 bar and 60 bar.

\section{Preferred Values}

$k=7.0 \times 10^{-12} \mathrm{~cm}^{3}$ molecule $\mathrm{e}^{-1} \mathrm{~s}^{-1}$ at $298 \mathrm{~K}$ and 1 bar of air.

$k_{\infty}=7.8 \times 10^{-12} \mathrm{~cm}^{3}$ molecule $\mathrm{s}^{-1}$, independent of temperature over the range $200-300 \mathrm{~K}$.

\section{Reliability}

$\Delta \log k_{\infty}= \pm 0.2$ over the temperature range $200-300 \mathrm{~K}$.

\section{Comments on Preferred Values}

As for $k_{0}$, we prefer the extensive data from Wagner et al. (1990) because of the careful theoretical analysis. We assume a temperature independent rate coefficient $k_{\infty}$ below $300 \mathrm{~K}$. Falloff curves were fitted (Wagner et al., 1990) with an expression $F_{c}=[0.58 \exp (-T / 1250)+0.42 \exp (-T / 183)]$ which leads to $F_{c}=0.64$ at $200 \mathrm{~K}$ and 0.54 at $300 \mathrm{~K}$. Within the stated error limits, the available data all agree with the preferred values based on Wagner et al. (1990). QRRK calculations (Bozzelli and Dean, 1990) of the reaction are less realistic than the RRKM calculations of Wagner et al. (1990). The analysis of the reaction system is complicated because there is a coupling of the addition reaction with the reaction forming $\mathrm{C}_{2} \mathrm{H}_{4}$, i.e., $\mathrm{C}_{2} \mathrm{H}_{5}+\mathrm{O}_{2} \rightarrow \mathrm{C}_{2} \mathrm{H}_{4}+\mathrm{HO}_{2}$ (see the analysis in Wagner et al., 1990; Miller et al., 2000; Miller and Klippenstein, 2001). 


\section{References}

Bozzelli, J. W. and Dean, A. M.: J. Phys. Chem., 94, 3313, 1990.

Dilger, H., Schwager, M., Tregenna-Piggott, P. L. W., Roduner, E., Reid, I. D., Arseneau, D. J., Pan, J. J., Senba, M., Shelley, M., and Fleming, D. G.: J. Phys. Chem., 100, 6561, 1996; J. Phys. Chem., 100, 16 445, 1996.

Kaiser, E. W.: J. Phys. Chem., 99, 707, 1995.

Kaiser, E. W., Wallington, T. J., and Andino, J. M.: Chem. Phys. Lett., 168, 309, 1990.

Miller, J. A. and Klippenstein, S. J.: Int. J. Chem. Kinet., 33, 654, 2001.

Miller, J. A., Klippenstein, S. J., and Robertson, S. H.: Proc. Combust. Inst., 28, 1479, 2000.

Munk, J., Pagsberg, P., Ratajczak, E., and Sillesen, A.: J. Phys. Chem., 90, 2752, 1986.

Plumb, C. and Ryan, K. R.: Int. J. Chem. Kinet., 13, 1011, 1981.

Slagle, I. R., Feng, Q., and Gutman, D.: J. Phys. Chem., 88, 3648, 1984.

Timonen, R. S. and Gutman, D.: J. Phys. Chem., 90, 2987, 1986.

Wagner, A. F., Slagle, I. R., Sarzynski, D., and Gutman, D.: J. Phys. Chem., 94, 1853, 1990. 
II.A4.90

$$
n-\mathbf{C}_{3} \mathbf{H}_{7}+\mathbf{O}_{2}+\mathbf{M} \rightarrow n-\mathbf{C}_{3} \mathbf{H}_{7} \mathbf{O}_{2}+\mathbf{M}
$$

High-pressure rate coefficients

\begin{tabular}{|c|c|c|c|}
\hline$k_{\infty} / \mathrm{cm}^{3}$ molecule ${ }^{-1} \mathrm{~s}^{-1}$ & Temp./K & Reference & Technique/Comments \\
\hline $\begin{array}{l}\text { Absolute Rate Coefficients } \\
(5.5 \pm 0.9) \times 10^{-12} \\
6 \times 10^{-12}\end{array}$ & $\begin{array}{l}298 \\
297\end{array}$ & $\begin{array}{l}\text { Ruiz and Bayes, } 1984 \\
\text { Slagle et al., } 1985\end{array}$ & $\begin{array}{l}\text { FP-MS (a) } \\
\text { PLP-MS (b) }\end{array}$ \\
\hline
\end{tabular}

\section{Comments}

(a) No pressure dependence detected between 1.3 mbar and 5 mbar of $\mathrm{He}$ or $\mathrm{N}_{2}$.

(b) $n-\mathrm{C}_{3} \mathrm{H}_{7}$ radicals were produced by $\mathrm{CO}_{2}$ laser photolysis of $\mathrm{C}_{6} \mathrm{~F}_{5} \mathrm{C}_{4} \mathrm{H}_{9}$. Only weak pressure dependences were observed over the range of $\mathrm{He}$ or $\mathrm{N}_{2}$ pressures from 0.5 mbar to 9 mbar. The rate coefficient decreased from $6 \times 10^{-12} \mathrm{~cm}^{3}$ molecule $\mathrm{e}^{-1} \mathrm{~s}^{-1}$ to $2.8 \times 10^{-13} \mathrm{~cm}^{3}$ molecule ${ }^{-1} \mathrm{~s}^{-1}$ over the temperature range $297 \mathrm{~K}$ to $635 \mathrm{~K}$.

\section{Preferred Values}

$k=6 \times 10^{-12} \mathrm{~cm}^{3}$ molecule ${ }^{-1} \mathrm{~s}^{-1}$ at $298 \mathrm{~K}$ and $1 \mathrm{mbar}$ to $10 \mathrm{mbar}$ of air.

$k \approx k_{\infty}$ at $298 \mathrm{~K}$ and 1 bar of air.

$k_{\infty}=8 \times 10^{-12} \mathrm{~cm}^{3}$ molecule $\mathrm{s}^{-1} \mathrm{~s}^{-1}$, independent of temperature over the range $200-300 \mathrm{~K}$.

\section{Reliability}

$\Delta \log k_{\infty}= \pm 0.2$ over the range $200-300 \mathrm{~K}$.

Comments on Preferred Values

The available experimental data are consistent with each other (Ruiz and Bayes, 1984; Slagle et al., 1985). Because they were obtained at total pressures below $130 \mathrm{mbar}$, we estimate that some falloff corrections have to be applied and these are taken into account in the preferred values. These values are consistent with experiments for the reactions $\mathrm{C}_{2} \mathrm{H}_{5}+\mathrm{O}_{2}+\mathrm{M} \rightarrow \mathrm{C}_{2} \mathrm{H}_{5} \mathrm{O}_{2}+\mathrm{M}$ and $i-\mathrm{C}_{3} \mathrm{H}_{7}+\mathrm{O}_{2}+\mathrm{M} \rightarrow i-\mathrm{C}_{3} \mathrm{H}_{7} \mathrm{O}_{2}+\mathrm{M}$ (see this evaluation).

\section{References}

Ruiz, R. P. and Bayes, K. D.: J. Phys. Chem., 88, 2592, 1984.

Slagle, I. R., Park, J.-Y., and Gutman, D.: 20th Int. Symp. on Combustion, Combustion Institute, Pittsburgh, pp. 733-741, 1985. 
II.A4.91

$$
i-\mathbf{C}_{3} \mathbf{H}_{7}+\mathbf{O}_{2}+\mathbf{M} \rightarrow i-\mathbf{C}_{3} \mathbf{H}_{7} \mathbf{O}_{2}+\mathbf{M}
$$

$\Delta H^{\circ}=-158.9 \mathrm{~kJ} \cdot \mathrm{mol}^{-1}$

\section{High-pressure rate coefficients}

\section{Rate coefficient data}

\begin{tabular}{lllc}
\hline$k_{\infty} / \mathrm{cm}^{3}$ molecule & & Technique/Comments \\
\hline Absolute Rate Coefficients & Temp./K & Reference & \\
$(1.41 \pm 0.24) \times 10^{-11}$ & 298 & Ruiz and Bayes, 1984 & FP-MS (a) \\
$8.3 \times 10^{-12}$ & 300 & Munk et al., 1986 & (b) \\
\hline
\end{tabular}

\section{Comments}

(a) No pressure dependence detected for $\mathrm{He}$ or $\mathrm{N}_{2}$ pressures from 1.3 mbar to 5 mbar.

(b) Pulse radiolysis in $\mathrm{H}_{2}$ at 1 bar. $i-\mathrm{C}_{3} \mathrm{H}_{7}$ radicals were generated by the addition of $\mathrm{H}$ atoms to $\mathrm{C}_{3} \mathrm{H}_{6}$ and $i-\mathrm{C}_{3} \mathrm{H}_{7} \mathrm{O}_{2}$ detected by $\mathrm{UV}$ absorption at $253 \mathrm{~nm}$. Absorption spectrum of $i-\mathrm{C}_{3} \mathrm{H}_{7}$ was also detected.

\section{Preferred Values}

$k \approx k_{\infty}$ at $298 \mathrm{~K}$ and 1 bar of air.

$k_{\infty}=1.1 \times 10^{-11} \mathrm{~cm}^{3}$ molecule ${ }^{-1} \mathrm{~s}^{-1}$, independent of temperature over the range 200-300 K.

\section{Reliability}

$\Delta \log k_{\infty}= \pm 0.3$ over the range $200-300 \mathrm{~K}$.

\section{Comments on Preferred Values}

The preferred values are the average of the results from Ruiz and Bayes (1984) and Munk et al. (1986). Falloff corrections are probably within the uncertainties of the average. The rate coefficient $k_{\infty}$ for this reaction appears consistent with those for the reactions $\mathrm{C}_{2} \mathrm{H}_{5}+\mathrm{O}_{2}+\mathrm{M} \rightarrow \mathrm{C}_{2} \mathrm{H}_{5} \mathrm{O}_{2}+\mathrm{M}$ and $n-\mathrm{C}_{3} \mathrm{H}_{7}+\mathrm{O}_{2}+\mathrm{M} \rightarrow n-\mathrm{C}_{3} \mathrm{H}_{7} \mathrm{O}_{2}+\mathrm{M}$ (see this evaluation).

\section{References}

Munk, J., Pagsberg, P., Ratajczak, E., and Sillesen, A.: Chem. Phys. Lett., 132, 417, 1986.

Ruiz, R. P. and Bayes, K. D.: J. Phys. Chem., 88, 2592, 1984. 
II.A4.92

$$
\mathbf{1}-\mathrm{C}_{4} \mathrm{H}_{9}+\mathrm{O}_{2}+\mathrm{M} \rightarrow \mathbf{1}-\mathrm{C}_{4} \mathrm{H}_{9} \mathrm{O}_{2}+\mathrm{M}
$$

\section{High-pressure rate coefficients}

\section{Rate coefficient data}

\begin{tabular}{lllc}
\hline$k_{\infty} / \mathrm{cm}^{3}$ molecule & & Technique/Comments \\
\hline $\begin{array}{l}\text { Absolute Rate Coefficients } \\
(7.5 \pm 1.4) \times 10^{-12}\end{array}$ & Temp./K & Reference & \\
\hline
\end{tabular}

\section{Comments}

(a) 1-Butyl radicals were generated by the flash photolysis of 1-butyl iodide and detected by MS. No pressure dependence of the rate coefficients was observed over the range 1.3 mbar to 5.3 mbar of $\mathrm{He}$.

\section{Preferred Values}

$k_{\infty}=7.5 \times 10^{-12} \mathrm{~cm}^{3}$ molecule ${ }^{-1} \mathrm{~s}^{-1}$ at $298 \mathrm{~K}$.

Reliability

$\Delta \log k_{\infty}= \pm 0.5$ at $298 \mathrm{~K}$.

Comments on Preferred Values

The preferred value is based on the study of Lenhardt et al. (1980). Because this is the only study of this reaction, we assign large error limits. This reaction should be close to the high pressure limit at atmospheric pressure.

\section{References}

Lenhardt, T. M., McDade, C. E., and Bayes, K. D.: J. Chem. Phys., 72, 304, 1980. 
II.A4.93

$$
\mathbf{2}-\mathrm{C}_{4} \mathrm{H}_{9}+\mathbf{O}_{2}+\mathbf{M} \rightarrow \mathbf{2 -}-\mathrm{C}_{4} \mathrm{H}_{9} \mathbf{O}_{2}+\mathbf{M}
$$

\section{High-pressure rate coefficients}

\section{Rate coefficient data}

\begin{tabular}{|c|c|c|c|}
\hline$k_{\infty} / \mathrm{cm}^{3}$ molecule ${ }^{-1} \mathrm{~s}^{-1}$ & Temp./K & Reference & Technique/Comments \\
\hline $\begin{array}{l}\text { Absolute Rate Coefficients } \\
(1.66 \pm 0.22) \times 10^{-11}\end{array}$ & 300 & Lenhardt et al., 1980 & FP-MS (a) \\
\hline
\end{tabular}

\section{Comments}

(a) 2-Butyl radicals were generated by the flash photolysis of 2-butyl iodide and detected by MS. No pressure dependence of the rate coefficients was observed over the range $1.3 \mathrm{mbar}$ to $5.3 \mathrm{mbar}$ of $\mathrm{He}$.

\section{Preferred Values}

$k_{\infty}=1.7 \times 10^{-11} \mathrm{~cm}^{3}$ molecule $\mathrm{s}^{-1} \mathrm{~s}^{-1}$ at $298 \mathrm{~K}$.

Reliability

$\Delta \log k_{\infty}= \pm 0.5$ at $298 \mathrm{~K}$.

Comments on Preferred Values

The preferred value is based on the study of Lenhardt et al. (1980).

\section{References}

Lenhardt, T. M., McDade, C. E., and Bayes, K. D.: J. Chem. Phys., 72, 304, 1980. 
II.A4.94

$$
\mathrm{CH}_{3} \mathrm{C}(\mathrm{O}) \mathrm{CH}_{2}+\mathrm{O}_{2}+\mathrm{M} \rightarrow \mathrm{CH}_{3} \mathrm{C}(\mathrm{O}) \mathrm{CH}_{2} \mathrm{O}_{2}+\mathrm{M}
$$

\section{High-pressure rate coefficients}

\section{Rate coefficient data}

\begin{tabular}{|c|c|c|c|}
\hline$k_{\infty} / \mathrm{cm}^{3}$ molecule ${ }^{-1} \mathrm{~s}^{-1}$ & Temp./K & Reference & Technique/Comments \\
\hline $\begin{array}{l}\text { Absolute Rate Coefficients } \\
1.45 \times 10^{-12}\end{array}$ & 298 & Cox et al., 1990 & (a) \\
\hline
\end{tabular}

\section{Comments}

(a) Pulse radiolysis of $\mathrm{CH}_{3} \mathrm{C}(\mathrm{O}) \mathrm{CH}_{3}-\mathrm{O}_{2}-\mathrm{SF}_{6}$ mixtures at 1 bar of $\mathrm{SF}_{6} \cdot \mathrm{CH}_{3} \mathrm{C}(\mathrm{O}) \mathrm{CH}_{2}$ radicals were formed from the reaction of $\mathrm{F}$ atoms with $\mathrm{CH}_{3} \mathrm{C}(\mathrm{O}) \mathrm{CH}_{3}$. At the monitoring wavelength of $310 \mathrm{~nm}$ both $\mathrm{CH}_{3} \mathrm{C}(\mathrm{O}) \mathrm{CH}_{2}$ and $\mathrm{CH}_{3} \mathrm{C}(\mathrm{O}) \mathrm{CH}_{2} \mathrm{O}_{2}$ absorb, with the absorption cross-section of the peroxy radical being a factor of 1.7 greater than that of the $\mathrm{CH}_{3} \mathrm{C}(\mathrm{O}) \mathrm{CH}_{2}$ radical. The rate coefficient was evaluated by simulations of the above reaction together with the reaction $\mathrm{CH}_{3} \mathrm{C}(\mathrm{O}) \mathrm{CH}_{2}+\mathrm{CH}_{3} \mathrm{C}(\mathrm{O}) \mathrm{CH}_{2} \mathrm{O}_{2} \rightarrow 2 \mathrm{CH}_{3} \mathrm{C}(\mathrm{O}) \mathrm{CH}_{2} \mathrm{O}$.

\section{Preferred Values}

$k \approx k_{\infty}$ at $298 \mathrm{~K}$ and 1 bar of air.

$k_{\infty}=1.5 \times 10^{-12} \mathrm{~cm}^{3}$ molecule $\mathrm{s}^{-1}$ at $298 \mathrm{~K}$.

\section{Reliability}

$\Delta \log k_{\infty}= \pm 0.5$ at $298 \mathrm{~K}$.

\section{Comments on Preferred Values}

The preferred values are based on the study of Cox et al. (1990). Because this is the only study of this reaction, we assign large error limits. Near atmospheric pressure this reaction should be close to the high pressure limit.

\section{References}

Cox, R. A., Munk, J., Nielsen, O. J., Pagsberg, P., and Ratajczak, E.: Chem. Phys. Lett., 173, 206, 1990. 
II.A4.95

$$
\mathrm{HCO}+\mathrm{O}_{2} \rightarrow \mathrm{CO}+\mathrm{HO}_{2}
$$

$\Delta H^{\circ}=-139.0 \mathrm{~kJ} \cdot \mathrm{mol}^{-1}$

\section{Rate coefficient data}

\begin{tabular}{llll}
\hline$k / \mathrm{cm}^{3}$ molecule ${ }^{-1} \mathrm{~s}^{-1}$ & Temp./K & Reference & Technique/Comments \\
\hline $\begin{array}{l}\text { Absolute Rate Coefficients } \\
(5.6 \pm 0.9) \times 10^{-12}\end{array}$ & 300 & Shibuya et al., 1977 & \\
$5.5 \times 10^{-11} T^{-(0.4 \pm 0.3)}$ & $298-503$ & Veyret and Lesclaux, 1981 & FP-AS (a) \\
$(5.6 \pm 0.6) \times 10^{-12}$ & 298 & & \\
$(4.65 \pm 0.6) \times 10^{-12}$ & 295 & Langford and Moore, 1984 & PLP-AS (c) \\
$1.3 \times 10^{-11} \exp [-(204 \pm 180) / T]$ & $295-713$ & Timonen et al., 1988 & PLP-MS (d) \\
$6.2 \times 10^{-12}$ & 295 & & \\
$3.2 \times 10^{-12} \exp (87 / T)$ & $200-398$ & Stief et al., 1990 & DF-MS (e) \\
$4.3 \times 10^{-12}$ & 298 & & \\
$4.3 \times 10^{-12}$ & 298 & Dóbé et al., 1995 & DF-LMR (f) \\
$(2.2) \times 10^{-12} \exp [(170 \pm 22) / T]$ & $200-298$ & Nesbitt et al., 1999 & DF-MS (g) \\
$(4.0 \pm 0.6) \times 10^{-12}$ & 298 & & \\
$(5.9 \pm 0.5) \times 10^{-12}$ & 295 & Ninomiya et al., 2000 & PLP-AS (h) \\
$(5.0 \pm 0.7) \times 10^{-12}$ & $294 \pm 2$ & Hanoune et al., 2001 & PLP-AS (i) \\
& & & \\
Relative Rate Coefficients & & & RR (j) \\
$(5.7 \pm 1.2) \times 10^{-12}$ & 297 & Washida et al., 1974 & RR (k) \\
$(6.3 \pm 1.5) \times 10^{-12}$ & 295 & Ninomiya et al., 2000 & \\
\hline
\end{tabular}

\section{Comments}

(a) Flash photolysis of $\mathrm{CH}_{3} \mathrm{CHO}-\mathrm{O}_{2}$ mixtures; $\mathrm{HCO}$ monitored by time-resolved absorption at $613.8 \mathrm{~nm}$. There was no pressure effect on $k$ for pressures of up to 690 mbar (520 Torr) of He.

(b) Flash photolysis of $\mathrm{HCHO}$ and $\mathrm{CH}_{3} \mathrm{CHO}$; $\mathrm{HCO}$ was monitored by laser absorption at $614.5 \mathrm{~nm}$ at total pressures of 17 mbar to 660 mbar (13 Torr to 500 Torr).

(c) Pulsed laser photolysis of $\mathrm{HCHO}$ or $(\mathrm{CHO})_{2}$ with monitoring of $\mathrm{HCO}$ by absorption at total pressures of up to 1330 mbar (1000 Torr).

(d) Pulsed laser photolysis of $\mathrm{CH}_{3} \mathrm{CHO}$; $\mathrm{HCO}$ was monitored by photoionization $\mathrm{MS}$ at pressures of 0.69 mbar to $1.22 \mathrm{mbar}$ (0.52 Torr to 0.92 Torr).

(e) Discharge-flow system. $\mathrm{HCO}$ radicals were generated from $\mathrm{Cl}+\mathrm{HCHO}$ and monitored by photoionization MS.

(f) $\mathrm{HCO}$ radicals were generated by the reaction of $\mathrm{F}$ atoms with $\mathrm{HCHO}$. The total pressure was $1.7 \mathrm{mbar}$ of He. The yield of $\mathrm{HO}_{2}$ radicals was measured relative to the formation yield of $\mathrm{HO}_{2}$ radicals from the reaction of $\mathrm{F}$ atoms with $\mathrm{H}_{2} \mathrm{O}_{2}$, and determined to be $1.00 \pm 0.05$.

(g) Same experimental technique as in comment (e). The rate constant measured at $398 \mathrm{~K}$ seems to indicate a slight positive temperature dependence for $T>300 \mathrm{~K}$ in qualitative agreement with Timonen et al. (1988).

(h) Pulsed laser photolysis of $\mathrm{CH}_{3} \mathrm{CHO}$ at $266 \mathrm{~nm}$; $\mathrm{HCO}$ was monitored by cavity ring-down spectroscopy at $613.5 \mathrm{~nm}$ at total pressures of 5.32-13.3 mbar (4-10 Torr) of $\mathrm{N}_{2}$. 
(i) Pulsed laser photolysis of a mixture of $\mathrm{H}_{2} \mathrm{CO}$ and $\mathrm{Cl}_{2}$ at $355 \mathrm{~nm}$ with monitoring of the $\mathrm{R} 5$ or $\mathrm{R} 6$ transition in $\mathrm{CO}$ by tunable diode laser absorption in the range 6.4-62.0 mbar (4.8-46.5 Torr). Only data with $\left[\mathrm{O}_{2}\right]>5 \times 10^{15} \mathrm{molecule} \mathrm{cm}^{-3}$ have been used in the analysis.

(j) Discharge flow system with $\mathrm{HCO}$ being monitored by photoionization $\mathrm{MS}$. $k$ measured relative to $k(\mathrm{O}+\mathrm{HCO} \rightarrow$ products) $=2.1 \times 10^{-10} \mathrm{~cm}^{3}$ molecule $\mathrm{s}^{-1} \mathrm{~s}^{-1}$ (measured in the same apparatus) by observing the effect of $\mathrm{O}_{2}$ on [HCO] in a flowing mixture of $\mathrm{O}_{2}-\mathrm{C}_{2} \mathrm{H}_{4} ; k / k(\mathrm{O}+\mathrm{HCO})=(2.74 \pm 0.21) \times 10^{-2}$.

(k) Based on the ratio of the rate coefficients $k\left(\mathrm{HCO}+\mathrm{O}_{2}\right) / k\left(\mathrm{HCO}+\mathrm{Cl}_{2}\right)=0.85 \pm 0.02$ measured in a smog chamber coupled to FTIR detection. The absolute value of $k\left(\mathrm{HCO}+\mathrm{Cl}_{2}\right)$ used to place the relative rate on an absolute basis was $(7.4 \pm$ 1.7) $\times 10^{-12} \mathrm{~cm}^{3}$ molecule $\mathrm{s}^{-1}$.

\section{Preferred Values}

$k=5.1 \times 10^{-12} \mathrm{~cm}^{3}$ molecule ${ }^{-1} \mathrm{~s}^{-1}$, independent of temperature over the range $200-300 \mathrm{~K}$.

\section{Reliability}

$\Delta \log k= \pm 0.15$ at $298 \mathrm{~K}$.

$\Delta(E / R)= \pm 150 \mathrm{~K}$.

\section{Comments on Preferred Values}

The preferred value of the rate coefficient at $298 \mathrm{~K}$ is the average of the room-temperature rate coefficients of Shibuya et al. (1977), Veyret and Lesclaux (1981), Langford and Moore (1984), Timonen et al. (1988), Stief et al. (1990), Dóbé et al. (1995), Nesbitt et al. (1999), Ninomiya et al. (2000) and Hanoune et al. (2001). Taken together, the temperature-dependent studies of Veyret and Lesclaux (1981), Timonen et al. (1988), Stief et al. (1990) and Nesbitt et al. (1999) suggest that the rate coefficient of this reaction has a slight negative temperature dependence over the range 200 to $298 \mathrm{~K}$ and possibly a small positive temperature dependence above $300 \mathrm{~K}$. However, within the measurement uncertainties the rate coefficient can be considered to be independent of temperature over the range $200-400 \mathrm{~K}$.

\section{References}

Dobé, S., Wagner, H. G., and Ziemer, H.: React. Kinet. Catal. Lett., 54, 271, 1995.

Hanoune, B., Dusanter, S., El Maimouni, L., Devolder, P., and Lemoine, B.: Chem. Phys. Lett., 343, $527,2001$.

Langford, A. O. and Moore, C. B.: J. Chem. Phys., 80, 4211, 1984.

Nesbitt, F. L., Gleason, J. F., and Stief, L. J.: J. Phys. Chem. A, 103, 3038, 1999.

Ninomiya, Y., Goto, M., Hashimoto, S., Kagawa, J., Yoshizawa, K., Kawasaki, M., Wallington, T. J., and Hurley, M. D.: J. Phys. Chem. A, 104, 7556, 2000.

Shibuya, K., Ebata, T., Obi, K., and Tanaka, I.: J. Phys. Chem., 81, 2292, 1977.

Stief, L. J., Nesbitt, R. L., and Gleason, J. F.: Abstracts of papers presented at the International Symposium of Gas Kinetics, Assisi, Italy, Sept. 1990.

Timonen, R. S., Ratajczak, E., and Gutman, D.: J. Phys. Chem., 92, 651, 1988.

Veyret, B. and Lesclaux, R.: J. Phys. Chem., 85, 1918, 1981.

Washida, N., Martinez, R. I., and Bayes, K. D.: Z. Naturforsch., 29a, 251, 1974. 
II.A4.96

$$
\mathrm{CH}_{3} \mathrm{CO}+\mathrm{O}_{2}+\mathrm{M} \rightarrow \mathrm{CH}_{3} \mathrm{C}(\mathrm{O}) \mathrm{O}_{2}+\mathrm{M}
$$

$\Delta H^{\circ}=-162.0 \mathrm{~kJ} \cdot \mathrm{mol}^{-1}$

\section{High-pressure rate coefficients}

\section{Rate coefficient data}

\begin{tabular}{|c|c|c|c|}
\hline$k_{\infty} / \mathrm{cm}^{3}$ molecule ${ }^{-1} \mathrm{~s}^{-1}$ & Temp./K & Reference & Technique/Comments \\
\hline $\begin{array}{l}\text { Absolute Rate Coefficients } \\
(2.0 \pm 0.4) \times 10^{-12}\end{array}$ & 298 & McDade et al., 1982 & (a) \\
\hline$(5.4 \pm 1.9) \times 10^{-12}$ & 296 & Kaiser and Wallington, 1995 & $\mathrm{RR}(\mathrm{b})$ \\
\hline$(5.7 \pm 1.9) \times 10^{-12}$ & $295 \pm 2$ & Tyndall et al., 1997 & $\mathrm{RR}(\mathrm{c})$ \\
\hline$(5.9 \pm 1.9) \times 10^{-12}$ & 228 & & \\
\hline$(4.4 \pm 0.7) \times 10^{-12}$ & 295 & Sehested et al., 1998 & PR-AS (d) \\
\hline
\end{tabular}

\section{Comments}

(a) Flow system with $\mathrm{CH}_{3} \mathrm{CO}$ generated from pulsed photolysis of $\mathrm{CH}_{3} \mathrm{C}(\mathrm{O}) \mathrm{CH}_{3}$ or $\mathrm{CH}_{3} \mathrm{C}(\mathrm{O}) \mathrm{CH}_{2} \mathrm{COCH}_{3}$. [CH $\mathrm{CH}_{3} \mathrm{CO}$ was monitored by photoionization mass spectrometry and kinetics evaluated from pseudo-first-order decays of $\mathrm{CH}_{3} \mathrm{CO}$. The pressure range was $1.3 \mathrm{mbar}$ to $5 \mathrm{mbar}$.

(b) Measurement of the rate coefficient ratio for $k\left(\mathrm{CH}_{3} \mathrm{CO}+\mathrm{Cl}_{2}\right) / k\left(\mathrm{CH}_{3} \mathrm{CO}+\mathrm{O}_{2}\right)=7.9 \pm 0.5$ at 930 mbar total pressure. This rate coefficient ratio is placed on an absolute basis by use of a rate coefficient of $k\left(\mathrm{CH}_{3} \mathrm{CO}+\mathrm{Cl}_{2}\right)=(4.3 \pm 1.5) \times 10^{-11} \mathrm{~cm}^{3}$ molecule $\mathrm{e}^{-1} \mathrm{~s}^{-1}$ (Tyndall et al., 1999).

(c) Measurement of the rate coefficient ratios $k\left(\mathrm{CH}_{3} \mathrm{CO}+\mathrm{Cl}_{2}\right) / k\left(\mathrm{CH}_{3} \mathrm{CO}+\mathrm{O}_{2}\right)$ at $228 \mathrm{~K}$ and $298 \mathrm{~K}$ over the pressure range 0.13 mbar to 1460 mbar. The rate constant $k$ was observed to increase with increasing pressure, with the rate coefficient $k$ approaching the high-pressure limit above $\sim 400$ mbar. The rate coefficient ratio is placed on an absolute basis by use of a rate coefficient of $k\left(\mathrm{CH}_{3} \mathrm{CO}+\mathrm{Cl}_{2}\right)=(4.3 \pm 1.5) \times 10^{-11} \mathrm{~cm}^{3}$ molecule $\mathrm{e}^{-1} \mathrm{~s}^{-1}$ (Tyndall et al., 1999).

(d) Pulse radiolysis of a mixture of $\mathrm{CH}_{3} \mathrm{CHO}$ and $\mathrm{O}_{2}$ in 1 bar of $\mathrm{SF}_{6}$ coupled with transient $\mathrm{UV}$ absorption spectroscopy of $\mathrm{CH}_{3} \mathrm{C}(\mathrm{O}) \mathrm{O}_{2}$ at $260 \mathrm{~nm}$. Numerical modeling was used with a complex reaction mechanism.

\section{Preferred Values}

$k_{\infty}=5.1 \times 10^{-12} \mathrm{~cm}^{3}$ molecule $\mathrm{e}^{-1} \mathrm{~s}^{-1}$, independent of temperature over the range $220-300 \mathrm{~K}$.

Reliability

$\Delta \log k_{\infty}= \pm 0.2$ over the temperature range $220-300 \mathrm{~K}$.

\section{Comments on Preferred Values}

The preferred values are based on the data of Sehested et al. (1998) and Tyndall et al. (1997) using the temperatureindependent reference rate constant for $\mathrm{CH}_{3} \mathrm{CO}+\mathrm{Cl}_{2}$ of Tyndall et al. (1999). 


\section{References}

Kaiser, E. W. and Wallington, T. J.: J. Phys. Chem., 99, 8669, 1995.

McDade, C. E., Lenhardt, T. M., and Bayes, K. D.: J. Photochem., 20, 1, 1982.

Sehested, J., Christensen, L. K., Nielsen, O. J., and Wallington, T. J.: Int. J. Chem. Kinet., 30, 913, 1998.

Tyndall, G. S., Orlando, J. J., Wallington, T. J., and Hurley, M. D.: Int. J. Chem. Kinet., 29, 655, 1997.

Tyndall, G. S., Orlando, Kegley-Owen, C. S., Wallington, T. J., and Hurley, M. D.: Int. J. Chem. Kinet., $31,776,1999$. 
II.A4.97

$$
\mathrm{CH}_{2} \mathrm{OH}+\mathrm{O}_{2} \rightarrow \mathrm{HCHO}+\mathrm{HO}_{2}
$$

$\Delta H^{\circ}=-76.2 \mathrm{~kJ} \cdot \mathrm{mol}^{-1}$

\section{Rate coefficient data}

\begin{tabular}{lllc}
\hline$k / \mathrm{cm}^{3}$ molecule ${ }^{-1} \mathrm{~s}^{-1}$ & Temp./K & Reference & Technique/Comments \\
\hline $\begin{array}{l}\text { Absolute Rate Coefficients } \\
(9.5 \pm 2.5) \times 10^{-12}\end{array}$ & 298 & Grotheer et al., 1985 & DF-MS (a) \\
$(1.06 \pm 0.25) \times 10^{-11}$ & 296 & Dóbé et al., 1985 & DF-LMR (b) \\
$(1.05 \pm 0.47) \times 10^{-11}$ & 296 & & \\
$(8.6 \pm 2.0) \times 10^{-12}$ & 298 & Payne et al., 1988 & DF-MS (c) \\
$2.5 \times 10^{-9} T^{-1.0}+$ & $370-684$ & Grotheer et al., 1988 & DF-MS (d) \\
$4.0 \times 10^{-10} \exp (-2525 / T)$ & & & \\
$5.6 \times 10^{-9} \exp (-1700 / T)$ & $215-250$ & Nesbitt et al., 1988 & DF-MS (e) \\
$(8.61 \pm 1.14) \times 10^{-12}$ & 300 & & \\
$(8.8 \pm 0.2) \times 10^{-12}$ & 298 & Pagsberg et al., 1989 & PR-AS (f) \\
$(1.17 \pm 0.12) \times 10^{-11}$ & 296 & Miyoshi et al., 1990 & PLP-MS (g) \\
$(1.00 \pm 0.14) \times 10^{-11}$ & 294 & Hanoune et al., 2001 & PLP-AS (h) \\
\hline
\end{tabular}

\section{Comments}

(a) $\mathrm{CH}_{2} \mathrm{OH}$ was generated from $\mathrm{Cl}+\mathrm{CH}_{3} \mathrm{OH}$ at total pressures of 0.4 mbar to $1.2 \mathrm{mbar}$ ( 0.3 Torr to 0.9 Torr). $k$ was derived from the rate of disappearance of $\mathrm{CH}_{2} \mathrm{OH}$ in excess $\mathrm{O}_{2}$ by MS.

(b) $\mathrm{CH}_{2} \mathrm{OH}$ was generated from $\mathrm{F}+\mathrm{CH}_{3} \mathrm{OH}$ at total pressures of 0.69 mbar to $6.5 \mathrm{mbar}$ (0.52 Torr to 4.9 Torr). Two values of $k$ were derived from the rate of disappearance of $\mathrm{CH}_{2} \mathrm{OH}$ and of the appearance of $\mathrm{HO}_{2}$, both monitored by LMR spectroscopy.

(c) $\mathrm{CH}_{2} \mathrm{OH}$ was generated from $\mathrm{Cl}+\mathrm{CH}_{3} \mathrm{OH}$ at total pressures of $\sim 1.3 \mathrm{mbar}(\sim 1 \mathrm{Torr}) . k$ was derived from the rate of disappearance of $\mathrm{CH}_{2} \mathrm{OH}$ in excess $\mathrm{O}_{2}$ by MS.

(d) As for comment (a) at pressures of $\sim 1.1$ mbar ( $\sim 0.8$ Torr).

(e) As for comment (c) at pressures of $\sim 1.3$ mbar ( $\sim 1$ Torr).

(f) $\mathrm{CH}_{2} \mathrm{OH}$ was generated from $\mathrm{F}+\mathrm{CH}_{3} \mathrm{OH}$ at total pressures of 1 bar (760 Torr). $k$ was derived from the rate of disappearance of $\mathrm{CH}_{2} \mathrm{OH}$ in excess of $\mathrm{O}_{2}$ by absorption at $285.5 \mathrm{~nm}$.

(g) Pulsed laser photolysis of $\mathrm{CH}_{3} \mathrm{C}(\mathrm{O}) \mathrm{CH}_{2} \mathrm{OH}$, with the decay of $\mathrm{CH}_{2} \mathrm{OH}$ being monitored by photoionization MS, at total pressures of $1.7 \mathrm{mbar}$ to $7.3 \mathrm{mbar}$ (1.3 Torr to 5.5 Torr).

(h) Pulsed laser photolysis of a mixture of $\mathrm{CH}_{3} \mathrm{OH}$ and $\mathrm{Cl}_{2}$ at $355 \mathrm{~nm}$ with monitoring of $\mathrm{HCHO}$ at $1707.9 \mathrm{~cm}^{-1}$ by tunable diode laser absorption in the range 7.71-20.22 mbar (5.8-15.2 Torr). Only data with $\left[\mathrm{O}_{2}\right]>2 \times 10^{15}$ molecule $\mathrm{cm}^{-3}$ have been used in the analysis.

\section{Preferred Values}

$k=9.7 \times 10^{-12} \mathrm{~cm}^{3}$ molecule ${ }^{-1} \mathrm{~s}^{-1}$ at $298 \mathrm{~K}$. 


\section{Reliability}

$\Delta \log k= \pm 0.12$ at $298 \mathrm{~K}$.

\section{Comments on Preferred Values}

The rate coefficient at $298 \mathrm{~K}$ is now well established for this reaction, and our recommendation is the average of the results of Grotheer et al. (1985), Dóbé et al. (1985), Payne et al. (1988), Nesbitt et al. (1988), Pagsberg et al. (1989), Miyoshi et al. (1990) and Hanoune et al. (2001). The earlier data of Wang et al. (1984) and Radford (1980) are rejected on the basis that they involved high concentrations of radicals, leading to mechanistic complications (Radford, 1980). The two studies of the temperature dependence of this reaction (Grotheer et al., 1989, Nesbitt et al., 1988) indicate that the rate coefficient follows a complicated non-Arrhenius behavior over the range $200 \mathrm{~K}$ to $700 \mathrm{~K}$. The existing data on the temperature dependence are difficult to explain and more work is needed to confirm the observed temperature dependence of this reaction before a recommendation can be made.

Grotheer et al. (1988) have carried out experiments replacing $\mathrm{CH}_{3} \mathrm{OH}$ by $\mathrm{CH}_{3} \mathrm{OD}$ and have observed no kinetic isotope effect for the $\mathrm{CH}_{2} \mathrm{OH} / \mathrm{CH}_{2} \mathrm{OD}+\mathrm{O}_{2}$ reactions.

\section{References}

Dóbé, S., Temps, F., Böhland, R., and Wagner, H. Gg.: Z. Naturforsch., 40A, 1289, 1985.

Grotheer, H.-H., Riekert, G., Meier, U., and Just, Th.: Ber. Bunsenges. Phys. Chem., 89, 187, 1985.

Grotheer, H.-H., Riekert, G., Walter, E., and Just, Th.: J. Phys. Chem., 92, 4028, 22nd International Symposium on Combustion, Combustion Institute, Pittsburgh, PA, pp. 963-972, 1989.

Hanoune, B., Dusanter, S., El Maimouni, L., Devolder, P., and Lemoine, B.: Chem. Phys. Lett., 343, 527, 2001.

Miyoshi, A., Matsui, H. and Washida, N.: J. Phys. Chem. 94, 3016, 1990.

Nesbitt, F. L., Payne, W. A., and Stief, L. J.: J. Phys. Chem., 92, 4030, 1988.

Pagsberg, P., Munk, J., Anastasi, C., and Simpson, V. J.: J. Phys. Chem., 93, 5162, 1989.

Payne, W. A., Brunning, J., Mitchell, M. B., and Stief, L. J.: Int. J. Chem. Kinet., 20, 63, 1988.

Radford, H. E.: Chem. Phys. Lett., 71, 195, 1980.

Wang, W. C., Suto, M., and Lee, L. C.: J. Chem. Phys., 81, 31, 1984. 
II.A4.98

$$
\mathrm{CH}_{3} \mathrm{CHOH}+\mathrm{O}_{2} \rightarrow \mathrm{CH}_{3} \mathrm{CHO}+\mathrm{HO}_{2}
$$

$\Delta H^{\circ}=-87.6 \mathrm{~kJ} \cdot \mathrm{mol}^{-1}$

\section{Rate coefficient data}

\begin{tabular}{lllc}
\hline$k / \mathrm{cm}^{3}$ molecule ${ }^{-1} \mathrm{~s}^{-1}$ & Temp./K & Reference & Technique/Comments \\
\hline $\begin{array}{l}\text { Absolute Rate Coefficients } \\
1.4 \times 10^{-8} T^{-1.2}+\end{array}$ & $300-682$ & Grotheer et al., 1988 & DF-MS (a) \\
$8.0 \times 10^{-10} \exp (-2525 / T)$ & & & \\
$1.56 \times 10^{-11}$ & 300 & & \\
$(1.3 \pm 0.2) \times 10^{-11}$ & 300 & Anastasi et al., 1989 & PR-AS (b) \\
$(2.8 \pm 0.2) \times 10^{-11}$ & 293 & Miyoshi et al., 1989 & PLP-MS (c) \\
\hline
\end{tabular}

\section{Comments}

(a) $\mathrm{CH}_{3} \mathrm{CHOH}$ was generated from $\mathrm{Cl}+\mathrm{C}_{2} \mathrm{H}_{5} \mathrm{OH}$ in the presence of a large excess of $\mathrm{O}_{2}$ at total pressures of $\sim 1 \mathrm{mbar}$ ( $\sim 0.8$ Torr). The rate coefficient $k$ was derived from the disappearance of $\mathrm{CH}_{3} \mathrm{CHOH}$, as monitored by low electron energy MS.

(b) Pulsed radiolysis of $\mathrm{Ar}-\mathrm{SF}_{6}-\mathrm{HCl}-\mathrm{C}_{2} \mathrm{H}_{5} \mathrm{OH}-\mathrm{O}_{2}$ mixtures at total pressures of 1 bar (760 Torr) and with $\left[\mathrm{SF}_{6}\right] \gg$ $[\mathrm{HCl}] \gg\left[\mathrm{C}_{2} \mathrm{H}_{5} \mathrm{OH}\right] \gg\left[\mathrm{O}_{2}\right] . \mathrm{CH}_{3} \mathrm{CHOH}$ was generated from $\mathrm{Cl}+\mathrm{C}_{2} \mathrm{H}_{5} \mathrm{OH}$ and monitored by $\mathrm{UV}$ absorption at $260 \mathrm{~nm}$.

(c) Pulsed laser photolysis of $\mathrm{CH}_{3} \mathrm{C}(\mathrm{O}) \mathrm{CH}(\mathrm{OH}) \mathrm{CH}_{3}$ in a large excess of He at total pressures of 2.7 mbar to $9.3 \mathrm{mbar}$ (2 Torr to 7 Torr). $\mathrm{CH}_{3} \mathrm{CHOH}$ was monitored by photoionization $\mathrm{MS}$ in the presence of excess $\mathrm{O}_{2}$.

\section{Preferred Values}

$k=1.9 \times 10^{-11} \mathrm{~cm}^{3}$ molecule ${ }^{-1} \mathrm{~s}^{-1}$ at $298 \mathrm{~K}$.

\section{Reliability}

$\Delta \log k= \pm 0.3$ at $298 \mathrm{~K}$.

\section{Comments on Preferred Values}

The preferred value of $k_{298}$ is the mean of the results of Grotheer et al. (1989), Anastasi et al. (1989) and Miyoshi et al. (1989). The rather large discrepancy between the data of Miyoshi et al. (1989) and the other two studies (Grotheer et al., 1989; Anastasi et al., 1989) could be due to the different sources of generation of the $\mathrm{CH}_{3} \mathrm{CHOH}$ radical. $\mathrm{CH}_{3} \mathrm{CHOH}$ radical generation involving $\mathrm{Cl}$ attack on $\mathrm{C}_{2} \mathrm{H}_{5} \mathrm{OH}$ (Grotheer et al., 1989; Anastasi et al., 1989) may not be as clean a source as is the photolysis of $\mathrm{CH}_{3} \mathrm{C}(\mathrm{O}) \mathrm{CH}(\mathrm{OH}) \mathrm{CH}_{3}$ (Miyoshi et al., 1989).

The temperature dependence of the rate coefficient determined by Grotheer et al. (1989) shows a marked non-Arrhenius behavior, but this needs to be confirmed before a recommendation can be made. Evidence for the reaction between $\mathrm{CH}_{3} \mathrm{CHOH}$ and $\mathrm{O}_{2}$ yielding $\mathrm{CH}_{3} \mathrm{CHO}$ as a major product comes from the product study of the photooxidation of ethanol by Carter et al. (1979).

\section{References}

Anastasi, C., Simpson, V., Munk, J., and Pagsberg, P.: Chem. Phys. Lett., 164, 18, 1989.

Carter, W. P. L., Darnall, K. R., Graham, R. A., Winer, A. M., and Pitts, Jr., J. N.: J. Phys. Chem., 83, 2305, 1979. 
Grotheer, H.-H., Riekert, G., Walter, D., and Just, Th: 22nd International Symposium on Combustion, Combustion Institute, Pittsburgh, PA, pp. 963-972, 1989.

Miyoshi, A., Matsui, H., and Washida, N.: Chem. Phys. Lett., 160, 291, 1989. 
II.A4.99

$$
\mathrm{CH}_{2} \mathrm{CH}_{2} \mathrm{OH}+\mathrm{O}_{2} \rightarrow \text { products }
$$

\section{Rate coefficient data}

\begin{tabular}{|c|c|c|c|}
\hline $\mathrm{k} / \mathrm{cm}^{3}$ molecule ${ }^{-1} \mathrm{~s}^{-1}$ & Temp./K & Reference & Technique/Comments \\
\hline $\begin{array}{l}\text { Absolute Rate Coefficients } \\
(3.0 \pm 0.4) \times 10^{-12}\end{array}$ & 293 & Miyoshi et al., 1989 & PLP-MS (a) \\
\hline
\end{tabular}

\section{Comments}

(a) Pulsed laser photolysis of $\mathrm{ClCH}_{2} \mathrm{CH}_{2} \mathrm{OH}$ and $\mathrm{BrCH}_{2} \mathrm{CH}_{2} \mathrm{OH}$ in a large excess of $\mathrm{He}$ at total pressures of 2.7 mbar to 9.3 mbar (2 Torr to 7 Torr). $\mathrm{CH}_{2} \mathrm{CH}_{2} \mathrm{OH}$ radicals were monitored by photoionization MS in the presence of excess $\mathrm{O}_{2}$.

\section{Preferred Values}

$k=3.0 \times 10^{-12} \mathrm{~cm}^{3}$ molecule ${ }^{-1} \mathrm{~s}^{-1}$ at $298 \mathrm{~K}$.

\section{Reliability}

$\Delta \log k= \pm 0.3$ at $298 \mathrm{~K}$.

\section{Comments on Preferred Values}

The direct measurements of this rate coefficient (Miyoshi et al., 1989), from the pulsed laser photolysis of either $\mathrm{ClCH}_{2} \mathrm{CH}_{2} \mathrm{OH}$ or $\mathrm{BrCH}_{2} \mathrm{CH}_{2} \mathrm{OH}$ as the radical source, showed a good level of consistency. By analogy with the reactions $\mathrm{C}_{2} \mathrm{H}_{5}+\mathrm{O}_{2}+\mathrm{M} \rightarrow \mathrm{C}_{2} \mathrm{H}_{5} \mathrm{O}_{2}+\mathrm{M}$ and $\mathrm{CH}_{3} \mathrm{CO}+\mathrm{O}_{2}+\mathrm{M} \rightarrow \mathrm{CH}_{3} \mathrm{CO}_{3}+\mathrm{M}$ (this evaluation), the rate coefficient for this reaction is expected to be close to the high-pressure limit under the experimental conditions employed. The UV absorption spectrum of the $\mathrm{HOCH}_{2} \mathrm{CH}_{2} \mathrm{O}_{2}$ radical has been observed by pulse radiolysis of $\mathrm{SF}_{6}-\mathrm{H}_{2} \mathrm{O}$ mixtures (Anastasi et al., 1991) and pulsed laser photolysis of $\mathrm{H}_{2} \mathrm{O}_{2}$ in the presence of $\mathrm{C}_{2} \mathrm{H}_{4}$ and $\mathrm{O}_{2}$ (Murrells et al., 1991). These observations indicate that the reaction between $\mathrm{CH}_{2} \mathrm{CH}_{2} \mathrm{OH}$ radicals and $\mathrm{O}_{2}$ leads predominantly to the adduct peroxy radical.

\section{References}

Anastasi, C., Muir, D. J., Simpson, V. J., and Pagsberg, P.: J. Phys. Chem., 95, 5791, 1991.

Miyoshi, A., Matsui, H., and Washida, N.: Chem. Phys. Lett., 160, 291, 1989.

Murrells, T. P., Jenkin, M. E., Shalliker, S. J., and Hayman, G. D.: J. Chem. Soc. Faraday Trans., 87, 2351, 1991. 
Appendix A5: $\mathbf{R}+\mathbf{O}_{2}$

II.A5.100

$$
\mathrm{CH}_{3} \mathrm{O}+\mathrm{O}_{2} \rightarrow \mathrm{HCHO}+\mathrm{HO}_{2}
$$

$\Delta H^{\circ}=-111.2 \mathrm{~kJ} \cdot \mathrm{mol}^{-1}$

\section{Rate coefficient data}

\begin{tabular}{llll}
\hline$k / \mathrm{cm}^{3}$ molecule ${ }^{-1} \mathrm{~s}^{-1}$ & Temp./K & Reference & Technique/Comments \\
\hline Absolute Rate Coefficients & & & \\
$1.05 \times 10^{-13} \exp (-1310 / T)$ & $413-628$ & Gutman et al., 1982 & PLP-LIF (a) \\
$1.3 \times 10^{-15}$ & 298 & & \\
$5.5 \times 10^{-14} \exp (-1000 / T)$ & $298-450$ & Lorenz et al., 1985 & PLP-LIF (b) \\
$1.9 \times 10^{-15}$ & 298 & & \\
$2.3 \times 10^{-14}(1000 / T)^{-9.5}$ & $298-973$ & Wantuck et al., 1987 & PLP-LIF (c) \\
$\times \exp (2768 / T)$ & & & \\
$2.1 \times 10^{-15}$ & 298 & & \\
\hline
\end{tabular}

\section{Comments}

(a) $\mathrm{CH}_{3} \mathrm{O}$ generated from pulsed laser photolysis of $\mathrm{CH}_{3} \mathrm{ONO}$ at $266 \mathrm{~nm}$. [ $\left[\mathrm{CH}_{3} \mathrm{O}\right]$ was monitored by LIF at a total pressure of 53 mbar (40 Torr).

(b) Pulsed laser photolysis of $\mathrm{CH}_{3} \mathrm{ONO}$ with monitoring of $\mathrm{CH}_{3} \mathrm{O}$ by LIF, at pressures of $100 \mathrm{mbar}$ (75 Torr) of He. At $298 \mathrm{~K}$ the rate coefficient was shown to be independent of pressure over the range $10 \mathrm{mbar}$ to $200 \mathrm{mbar}$ ( 7.5 Torr to 150 Torr) of He.

(c) Pulsed laser photolysis of $\mathrm{CH}_{3} \mathrm{OH}$ or $\mathrm{CH}_{3} \mathrm{ONO}$ at $193 \mathrm{~nm}$ in the presence of $\mathrm{O}_{2}$ plus 33 mbar (25 Torr) of $\mathrm{Ar} \mathrm{CH}_{3} \mathrm{O}$ radicals were monitored by LIF. Non-Arrhenius behavior was observed over entire temperature range and fitted by the cited empirical equation. Rate coefficients combined with the data of Gutman et al. (1982) and Lorenz et al. (1985) were found to obey a double exponential expression, with $k=\left(1.5 \times 10^{-10} \exp (-6028 / T)+3.6 \times 10^{-14} \exp (-880 / T)\right) \mathrm{cm}^{3}$ molecule $\mathrm{e}^{-1} \mathrm{~s}^{-1}$.

\section{Preferred Values}

$k=1.9 \times 10^{-15} \mathrm{~cm}^{3}$ molecule $\mathrm{e}^{-1} \mathrm{~s}^{-1}$ at $298 \mathrm{~K}$.

$k=7.2 \times 10^{-14} \exp (-1080 / T) \mathrm{cm}^{3}$ molecule ${ }^{-1} \mathrm{~s}^{-1}$ over the temperature range $290-610 \mathrm{~K}$.

\section{Reliability}

$\Delta \log k= \pm 0.2$ at $298 \mathrm{~K}$.

$\Delta(E / R)= \pm 300 \mathrm{~K}$.

\section{Comments on Preferred Values}

The direct measurements of the rate coefficients by Lorenz et al. (1985) (298 K to 450 K) and Wantuck et al. (1987) (298 K to $973 \mathrm{~K}$ ) are in good agreement with the similar measurements of Gutman et al. (1982) (413 K to $608 \mathrm{~K}$ ), where the temperature ranges overlap. The preferred values are derived from a least-squares analysis of these three sets of data (Gutman et al., 1982; Lorenz et al., 1985; Wantuck et al., 1987) over the temperature range $298 \mathrm{~K}$ to $608 \mathrm{~K}$. The higher temperature measurements of Wantuck et al. (1987) give a clear indication of non-Arrhenius behavior over the extended temperature range. The anomalously low A-factor for a simple $\mathrm{H}$-atom transfer reaction and the possibility of a more complicated mechanism have both been noted (NASA, 1997). 


\section{References}

Gutman, D., Sanders, N., and Butler, J. E.: J. Phys. Chem., 86, 66, 1982.

Lorenz, K., Rhäsa, D., Zellner, R., and Fritz, B.: Ber. Bunsenges. Phys. Chem., 89, 341, 1985.

NASA Evaluation No. 12, 1997 (see references in Introduction).

Wantuck, P. J., Oldenborg, R. C., Baughcum, J. L., and Winn, K. R.: J. Phys. Chem., 91, 4653, 1987. 
II.A5.101

$$
\mathrm{C}_{2} \mathrm{H}_{5} \mathrm{O}+\mathrm{O}_{2} \rightarrow \mathrm{CH}_{3} \mathrm{CHO}+\mathrm{HO}_{2}
$$

$\Delta H^{\circ}=-135.7 \mathrm{~kJ} \cdot \mathrm{mol}^{-1}$

\section{Rate coefficient data}

\begin{tabular}{lllc}
\hline$k / \mathrm{cm}^{3}$ molecule ${ }^{-1} \mathrm{~s}^{-1}$ & Temp./K & Reference & Technique/Comments \\
\hline Absolute Rate Coefficients & & & \\
$8.0 \times 10^{-15}$ & 296 & Gutman et al., 1982 & PLP-LIF (a) \\
$9.8 \times 10^{-15}$ & 353 & & \\
$7.1 \times 10^{-14} \exp [-(552 \pm 64) / T]$ & $295-411$ & Hartmann et al., 1990 & PLP-LIF (b) \\
$(1.08 \pm 0.20) \times 10^{-14}$ & 295 & & \\
$2.4 \times 10^{-14} \exp [-(325 \pm 120) / T]$ & $295-354$ & Fittschen et al., 1999 & PLP-LIF (c) \\
$8.1 \times 10^{-15}$ & 298 & & \\
\hline
\end{tabular}

\section{Comments}

(a) Pulsed laser photolysis of $\mathrm{C}_{2} \mathrm{H}_{5} \mathrm{ONO}$ at $266 \mathrm{~nm}$, with $\mathrm{C}_{2} \mathrm{H}_{5} \mathrm{O}$ radicals being monitored by LIF at a total pressure of 53 mbar (40 Torr).

(b) Pulsed laser photolysis of $\mathrm{C}_{2} \mathrm{H}_{5} \mathrm{ONO}$ at $266 \mathrm{~nm}$ in $\mathrm{C}_{2} \mathrm{H}_{5} \mathrm{ONO}-\mathrm{O}_{2}-\mathrm{He}$ mixtures, with LIF monitoring of $\mathrm{C}_{2} \mathrm{H}_{5} \mathrm{O}$ radicals in the wavelength range $310 \mathrm{~nm}$ to $330 \mathrm{~nm}$. Studies were carried out at a total pressure of $35 \mathrm{mbar}$ (26 Torr).

(c) Pulsed laser photolysis of $\mathrm{C}_{2} \mathrm{H}_{5} \mathrm{ONO}$ at $248 \mathrm{~nm}$ in $\mathrm{C}_{2} \mathrm{H}_{5} \mathrm{ONO}-\mathrm{O}_{2}-\mathrm{He}$ mixtures at 133 mbar (100 Torr) with LIF detection of $\mathrm{C}_{2} \mathrm{H}_{5} \mathrm{O}$ radicals excited at $323 \mathrm{~nm}$ and fluorescence detection to the red of $375 \mathrm{~nm}$. The upper temperature limit was set by the unimolecular decomposition rate of ethoxy radical.

\section{Preferred Values}

$k=8.1 \times 10^{-15} \mathrm{~cm}^{3}$ molecule $\mathrm{e}^{-1} \mathrm{~s}^{-1}$ at $298 \mathrm{~K}$.

$k=2.4 \times 10^{-14} \exp (-325 / T) \mathrm{cm}^{3}$ molecule $^{-1} \mathrm{~s}^{-1}$ over the temperature range $295-354 \mathrm{~K}$.

\section{Reliability}

$\Delta \log k= \pm 0.2$ at $298 \mathrm{~K}$.

$\Delta(E / R)= \pm 300 \mathrm{~K}$.

\section{Comments on Preferred Values}

The preferred rate constant at $298 \mathrm{~K}$ is that of Gutman et al. (1982) and Fittschen et al. (1999). Their temperature dependence over the common range $296-353 \mathrm{~K}$ is in excellent agreement and is therefore recommended here. The relative rate measurements of Zabarnick and Heicklen (1985) yield a value of $k_{298}$ which is consistent with the preferred value within the recommended error limits.

It should be noted that the A-factor for the above reaction is very low, but in keeping with that for the analogous reaction $\mathrm{CH}_{3} \mathrm{O}+\mathrm{O}_{2} \rightarrow \mathrm{HCHO}+\mathrm{HO}_{2}$.

\section{References}

Fittschen, C., Frenzel, A., Imrik, K., and Devolder, P.: Int. J. Chem. Kin., 31, 860, 1999.

Gutman, D., Sanders, N., and Butler, J. E.: J. Phys. Chem., 86, 66, 1982.

Hartmann, D., Karthäuser, J., Sawerysyn, J. P., and Zellner, R.: Ber. Bunsenges. Phys. Chem., 94, 639, 1990.

Zabarnick, S. and Heicklen, J.: Int. J. Chem. Kinet., 17, 455, 1985. 
II.A5.102

$$
1-\mathrm{C}_{3} \mathrm{H}_{7} \mathrm{O}+\mathrm{O}_{2} \rightarrow \mathrm{C}_{2} \mathrm{H}_{5} \mathrm{CHO}+\mathrm{HO}_{2}
$$

$\Delta H^{\circ}=-131.4 \mathrm{~kJ} \cdot \mathrm{mol}^{-1}$

\section{Rate coefficient data}

\begin{tabular}{llll}
\hline$k / \mathrm{cm}^{3}$ molecule ${ }^{-1} \mathrm{~s}^{-1}$ & Temp./K & Reference & Technique/Comments \\
\hline Absolute Rate Coefficients & & & \\
$1.4 \times 10^{-14} \exp [-(108 \pm 61) / T]$ & $223-303$ & Mund et al., 1998 & PLP-LIF (a) \\
$9.8 \times 10^{-15}$ & 298 & & \\
$2.5 \times 10^{-14} \exp [-(240 \pm 60) / T]$ & $289-381$ & Fittschen et al., 1999 & PLP-LIF (b) \\
$1.1 \times 10^{-14}$ & 298 & & \\
& & & \\
Relative Rate Coefficients & & & RR (c) \\
$2.8 \times 10^{-13} \exp [-(879 \pm 117) / T]$ & $247-393$ & Zabarnick and Heicklen, 1985 & \\
$1.5 \times 10^{-14}$ & 298 & & \\
\hline
\end{tabular}

\section{Comments}

(a) Pulsed laser photolysis of propyl nitrite at $351 \mathrm{~nm}$ with laser-induced fluorescence detection of $n$-propoxy radical in the range 6-110 mbar He.

(b) Pulsed laser photolysis of $1-\mathrm{C}_{3} \mathrm{H}_{7} \mathrm{ONO}$ at $351 \mathrm{~nm}$ in $1-\mathrm{C}_{3} \mathrm{H}_{7} \mathrm{ONO}-\mathrm{O}_{2}-\mathrm{He}$ mixtures in the range 40-133 mbar (30100 Torr) with LIF detection of $1-\mathrm{C}_{3} \mathrm{H}_{7} \mathrm{O}$ excited at $349 \mathrm{~nm}$ and fluorescence detection to the red of $375 \mathrm{~nm}$. The upper temperature limit is set by the unimolecular decomposition rate of $n$-propoxy radical.

(c) Photolysis at $366 \mathrm{~nm}$ of $n-\mathrm{C}_{3} \mathrm{H}_{7} \mathrm{ONO}$ in a static system in the presence of $\mathrm{NO}, \mathrm{O}_{2}$, and $\mathrm{N}_{2}$ at total pressures of $>200 \mathrm{mbar}$ ( $>150$ Torr). Rate data were based on the measured quantum yields of $\mathrm{C}_{2} \mathrm{H}_{5} \mathrm{CHO}$ product. The rate coefficient $k$ was measured relative to $n-\mathrm{C}_{3} \mathrm{H}_{7} \mathrm{O}+\mathrm{NO} \rightarrow$ products with $k\left(n-\mathrm{C}_{3} \mathrm{H}_{7} \mathrm{O}+\mathrm{O}_{2}\right) / k\left(n-\mathrm{C}_{3} \mathrm{H}_{7} \mathrm{O}+\mathrm{NO}\right)=6.8 \times 10^{-3} \exp (-879 / T)$, and is placed on an absolute basis by use of $k\left(n-\mathrm{C}_{3} \mathrm{H}_{7} \mathrm{O}+\mathrm{NO}\right)=4.1 \times 10^{-11} \mathrm{~cm}^{3}$ molecule ${ }^{-1} \mathrm{~s}^{-1}$, independent of temperature.

\section{Preferred Values}

$k=1.0 \times 10^{-14} \mathrm{~cm}^{3}$ molecule ${ }^{-1} \mathrm{~s}^{-1}$ at $298 \mathrm{~K}$.

$k=2.6 \times 10^{-14} \exp (-253 / T) \mathrm{cm}^{3}$ molecule $\mathrm{s}^{-1}$ over the temperature range 220-380 K.

\section{Reliability}

$\Delta \log k= \pm 0.2$ at $298 \mathrm{~K}$.

$\Delta(E / R)= \pm 500 \mathrm{~K}$.

\section{Comments on Preferred Values}

The preferred values are based on the absolute rate study of Fittschen et al. (1999), which is in excellent agreement with that of Mund et al. (1998) in the overlapping temperature range. The temperature dependence is that of both data sets taking into account the A factor that differs by a factor of two. The rate coefficients derived from the relative rate study of Zabarnick and Heicklen (1985) are in significant disagreement with the absolute rate data (Mund et al., 1998; Fittschen et al., 1999). 
R. Atkinson et al.: Evaluated kinetic and photochemical data for atmospheric chemistry

\section{References}

Mund, Ch., Fockenberg, Ch., and Zellner, R.: Ber. Bunsenges. Phys. Chem., 102, 709, 1998.

Fittschen, C., Frenzel, A., Imrik, K., and Devolder, P.: Int. J. Chem. Kin., 31, 860, 1999.

Zabarnick, S. and Heicklen, J.: Int. J. Chem. Kinet., 17, 455, 1985. 
II.A5.103

$$
2-\mathrm{C}_{3} \mathrm{H}_{7} \mathrm{O}+\mathrm{O}_{2} \rightarrow \mathrm{CH}_{3} \mathrm{C}(\mathrm{O}) \mathrm{CH}_{3}+\mathrm{HO}_{2}
$$

$\Delta H^{\circ}=-150.3 \mathrm{~kJ} \cdot \mathrm{mol}^{-1}$

\section{Rate coefficient data}

\begin{tabular}{lllc}
\hline$k / \mathrm{cm}^{3}$ molecule ${ }^{-1} \mathrm{~s}^{-1}$ & Temp./K & Reference & Technique/Comments \\
\hline Absolute Rate Coefficients & & & \\
$1.51 \times 10^{-14} \exp [-(200 \pm 140 / T)]$ & $294-384$ & Balla et al., 1985 & PLP-LIF (a) \\
$7.72 \times 10^{-15}$ & 298 & & \\
$1.4 \times 10^{-14} \exp [-(217 \pm 49) / T]$ & $288-313$ & Mund et al., 1998, 1999 & PLP-LIF (b) \\
$6.8 \times 10^{-15}$ & 298 & & \\
$1.6 \times 10^{-14} \exp [-(265 \pm 24) / T]$ & $218-364$ & Fittschen et al., 1999 & PLP-LIF (c) \\
$6.6 \times 10^{-15}$ & 298 & & \\
$(8.7 \pm 2.5) \times 10^{-15}$ & 296 & Deng et al., 2000 & PLP-LIF (d) \\
\hline
\end{tabular}

\section{Comments}

(a) Pulsed laser photolysis of 2-propyl nitrite at $355 \mathrm{~nm}$, with LIF detection of $2-\mathrm{C}_{3} \mathrm{H}_{7} \mathrm{O}$ radicals. The pressure range was $1.3 \mathrm{mbar}$ to $67 \mathrm{mbar}$ (1 Torr to 50 Torr).

(b) Pulsed laser photolysis of 2-propyl nitrite at $351 \mathrm{~nm}$ with laser-induced fluorescence detection of $i$-propoxy radical in the range 6-110 mbar He.

(c) Pulsed laser photolysis of $2-\mathrm{C}_{3} \mathrm{H}_{7} \mathrm{ONO}$ at $351 \mathrm{~nm}$ in $2-\mathrm{C}_{3} \mathrm{H}_{7} \mathrm{ONO}-\mathrm{O}_{2}-\mathrm{He}$ mixtures in the range 67-267 mbar (50200 Torr) with LIF detection of $2-\mathrm{C}_{3} \mathrm{H}_{7} \mathrm{O}$ excited at $347 \mathrm{~nm}$ and fluorescence detection to the red of $375 \mathrm{~nm}$. The upper temperature limit is set by the unimolecular decomposition rate of $i$-propoxy radical.

(d) Pulsed laser photolysis of 2-propyl nitrite at $355 \mathrm{~nm}$ with laser-induced fluorescence detection of $i$-propoxy radical.

\section{Preferred Values}

$k=7.0 \times 10^{-15} \mathrm{~cm}^{3}$ molecule $\mathrm{e}^{-1} \mathrm{~s}^{-1}$ at $298 \mathrm{~K}$.

$k=1.5 \times 10^{-14} \exp (-230 / T) \mathrm{cm}^{3} \mathrm{molecule}^{-1} \mathrm{~s}^{-1}$ over the temperature range $210-390 \mathrm{~K}$.

\section{Reliability}

$\Delta \log k= \pm 0.2$ at $298 \mathrm{~K}$.

$\Delta(E / R)= \pm 200 \mathrm{~K}$.

\section{Comments on Preferred Values}

The results of Balla et al. (1985), Mund et al. (1998, 1999) and Fittschen et al. (1999) are in excellent agreement. The preferred values are based on the temperature-dependent data of Balla et al. (1985), Mund et al. $(1998,1999)$ and Fittschen et al. (1999).

\section{References}

Balla, R. J., Nelson, H. H., and McDonald, J. R.: Chem. Phys., 99, 323, 1985.

Deng, W., Wang, C., Katz, D. R., Gawinski, G. R., Davis, A. J., and Dibble, T. S.: Chem. Phys. Lett., 330, 541, 2000.

Fittschen, C., Frenzel, A., Imrik, K., and Devolder, P.: Int. J. Chem. Kin., 31, 860, 1999. 
Mund, Ch., Fockenberg, Ch., and Zellner, R.: Ber. Bunsenges. Phys. Chem., 102, 709, 1998.

Mund, Ch., Fockenberg, Ch., and Zellner, R.: Phys. Chem. Chem. Phys., 1, 2037, 1999. 
II.A5.104

\section{$\mathrm{CH}_{3} \mathrm{CH}_{2} \mathrm{CH}_{2} \mathrm{CH}_{2} \mathrm{O}+\mathrm{O}_{2} \rightarrow \mathrm{CH}_{3} \mathrm{CH}_{2} \mathrm{CH}_{2} \mathrm{CHO}+\mathrm{HO}_{2}$}

$\Delta H^{\circ}=-127.4 \mathrm{~kJ} \cdot \mathrm{mol}^{-1}$

\section{Rate coefficient data}

\begin{tabular}{lllc}
\hline$k / \mathrm{cm}^{3}$ molecule ${ }^{-1} \mathrm{~s}^{-1}$ & Temp./K & Reference & Technique/Comments \\
\hline $\begin{array}{l}\text { Absolute Rate Coefficients } \\
7.7 \times 10^{-15}\end{array}$ & 298 & Hoffmann et al., 1992 & PLP-LIF (a) \\
$(1.4 \pm 0.7) \times 10^{-14}$ & 293 & Hein et al., 1999 & PLP-AS/LIF (b) \\
& & & \\
Relative Rate Coefficients & & & RR (c) \\
$6.8 \times 10^{-13} \exp [-(1178 \pm 176) / T]$ & $265-393$ & Morabito and Heicklen, 1987 & \\
$1.3 \times 10^{-14}$ & 298 & & \\
\hline
\end{tabular}

\section{Comments}

(a) Pulsed laser photolysis of $\mathrm{Cl}_{2}$ in the presence of $n-\mathrm{C}_{4} \mathrm{H}_{10}-\mathrm{O}_{2}-\mathrm{NO}$ mixtures in a flow system at total pressures of $10-$ 50 mbar (6.7-37.5 Torr). Time-resolved monitoring of $\mathrm{HO}$ radicals was carried out by CW-laser absorption, and of $\mathrm{NO}_{2}$ by LIF. The rate coefficient was derived from a computer simulation of $\mathrm{HO}$ radical and $\mathrm{NO}_{2}$ temporal profiles.

(b) Pulsed laser photolysis at $248 \mathrm{~nm}$ of a mixture of 1-bromobutane, $\mathrm{O}_{2}$ and $\mathrm{NO}$ in $\mathrm{N}_{2}$ at 50 mbar total pressure in a slow-flow system. $\mathrm{HO}$ and $\mathrm{NO}_{2}$ were monitored in real-time using laser long-path absorption at $308.417 \mathrm{~nm}$ and cw laser-excited fluorescence after excitation at $488 \mathrm{~nm}$, respectively. The rate coefficient was derived from a computer simulation of the $\mathrm{HO}$ and $\mathrm{NO}_{2}$ temporal concentration profiles.

(c) Photolysis of 1-butyl nitrite at $366 \mathrm{~nm}$ in the presence of $\mathrm{NO}$ and $\mathrm{O}_{2}$. Rate data were derived from the quantum yields of product formation, and a rate coefficient ratio of $k\left(1-\mathrm{C}_{4} \mathrm{H}_{9} \mathrm{O}+\mathrm{O}_{2}\right) / k\left(1-\mathrm{C}_{4} \mathrm{H}_{9} \mathrm{O}+\mathrm{NO}\right)=1.67 \times 10^{-2} \exp [-$ $(1178 \pm 176) / T$ ] was obtained. This rate coefficient ratio is placed on an absolute basis using a rate cofficient of $k(1-$ $\mathrm{C}_{4} \mathrm{H}_{9} \mathrm{O}+\mathrm{NO}$ ) $=4.1 \times 10^{-11} \mathrm{~cm}^{3}$ molecule ${ }^{-1} \mathrm{~s}^{-1}$, independent of temperature (see data sheet for $2-\mathrm{C}_{3} \mathrm{H}_{7} \mathrm{O}+\mathrm{NO}$ this evaluation).

\section{Preferred Values}

$k=1.4 \times 10^{-14} \mathrm{~cm}^{3}$ molecule $\mathrm{e}^{-1} \mathrm{~s}^{-1}$ at $298 \mathrm{~K}$.

$k=8.9 \times 10^{-14} \exp (-550 / T) \mathrm{cm}^{3}$ molecule $\mathrm{e}^{-1} \mathrm{~s}^{-1}$ over range $270-340 \mathrm{~K}$.

\section{Reliability}

$\Delta \log k= \pm 0.3$ at $298 \mathrm{~K}$.

$\Delta(E / R)= \pm 300 \mathrm{~K}$.

\section{Comments on Preferred Values}

$k(298 \mathrm{~K})$ based on the indirect study of Hein et al. (1999), which is in good agreement with the relative rate technique by Morabito and Heicklen (1987) at $298 \mathrm{~K}$. Temperature dependence adopts $(E / R)$ estimated by Atkinson (1997), based on available data for smaller alkoxy radicals, and an $A$-factor to give the preferred value at $298 \mathrm{~K}$. 


\section{References}

Atkinson, R., J. Phys. Chem. Ref. Data, 26, 215, 1997; Int. J. Chem. Kinet., 29, 99, 1997.

Hein, H., Hoffmann, A., and Zellner, R.: Phys. Chem. Chem. Phys., 1, 3743, 1999.

Hoffmann, A., Mörs, V., and Zellner, R.: Ber. Bunsenges. Phys. Chem., 96, 437, 1992.

Morabito, P. and Heicklen, J.: Bull. Chem. Soc. Jpn, 60, 2641, 1987. 


\section{II.A5.105}

\section{$\mathrm{CH}_{3} \mathrm{CH}_{2} \mathrm{CH}_{2} \mathrm{CH}_{2} \mathrm{O}+\mathrm{M} \rightarrow \mathrm{CH}_{2} \mathrm{CH}_{2} \mathrm{CH}_{2} \mathrm{CH}_{2} \mathrm{OH}+\mathrm{M}$}

$\Delta H^{\circ}=-14.7 \mathrm{~kJ} \cdot \mathrm{mol}^{-1}$

\section{Rate coefficient data}

\begin{tabular}{lllc}
\hline $\mathrm{k} / \mathrm{s}^{-1}$ & Temp./K & Reference & Technique/Comments \\
\hline $\begin{array}{l}\text { Absolute Rate Coefficients } \\
(3.5 \pm 2) \times 10^{4}\end{array}$ & 293 & Hein et al., 1999 & PLP-AS/LIF (a) \\
& & & \\
$\begin{array}{l}\text { Relative Rate Coefficients } \\
2.2 \times 10^{5}\end{array}$ & 303 & Carter et al., 1979 & S-GC (b) \\
$(2.1 \pm 0.5) \times 10^{5}$ & 296 & Cox et al., 1981 & S-GC (c) \\
$(2.7 \pm 0.2) \times 10^{5}$ & 298 & Niki et al., 1981 & S-FTIR (d) \\
$9.5 \times 10^{10} \exp (-3864 / T)$ & $265-393$ & Morabito and Heicklen, 1987 & S-GC (e) \\
$2.2 \times 10^{5}$ & & & \\
$(2.7 \pm 0.9) \times 10^{5}$ & 298 & Geiger et al., 2002 & S-FTIR (f) \\
$1.8 \times 10^{10} \exp (-3270 / T)$ & $250-318$ & Cassanelli et al., 2005 & FR-GC (g) (h) \\
$3.0 \times 10^{5}$ & 298 & & \\
$4.9 \times 10^{10} \exp (-3570 / T)$ & $253-295$ & Cassanelli et al., 2006 & S-FTIR (i) (h) \\
$3.1 \times 10^{5}$ & 298 & & \\
\hline
\end{tabular}

\section{Comments}

(a) Pulsed laser photolysis at $248 \mathrm{~nm}$ of a mixture of 1-bromobutane, $\mathrm{O}_{2}$ and $\mathrm{NO}$ in $\mathrm{N}_{2}$ at 50 mbar total pressure in a slow-flow system. $\mathrm{HO}$ and $\mathrm{NO}_{2}$ were monitored in real-time using laser long-path absorption at $308.417 \mathrm{~nm}$ and cw laser-excited fluorescence after excitation at $488 \mathrm{~nm}$, respectively. The rate coefficient was derived from a computer simulation of the $\mathrm{HO}$ and $\mathrm{NO}_{2}$ temporal concentration profiles and is believed to be in the fall-off range.

(b) Smog chamber photolysis of $n-\mathrm{C}_{4} \mathrm{H}_{10}-\mathrm{NO}_{\mathrm{x}}$-air mixtures at 1 bar pressure in a $5870 \mathrm{~L}$ chamber at wavelengths $>300$ nm. End-product analysis of $\mathrm{C}_{3} \mathrm{H}_{7} \mathrm{CHO}$ by GC. $k / k\left(1-\mathrm{C}_{4} \mathrm{H}_{9} \mathrm{O}+\mathrm{O}_{2}\right)=1.6 \times 10^{19}$ molecule $\mathrm{cm}^{-3}$ obtained from yields of $\mathrm{C}_{3} \mathrm{H}_{7} \mathrm{CHO}$ and the rate of disappearance of $n-\mathrm{C}_{4} \mathrm{H}_{10}$. The above value of $k$ is calculated by using a rate coefficient of $k=$ $1.4 \times 10^{-14} \mathrm{~cm}^{3}$ molecule ${ }^{-1} \mathrm{~s}^{-1}$ for the reference reaction $1-\mathrm{C}_{4} \mathrm{H}_{9} \mathrm{O}+\mathrm{O}_{2} \rightarrow \mathrm{C}_{3} \mathrm{H}_{7} \mathrm{CHO}+\mathrm{HO}_{2}$ at $298 \mathrm{~K}$ (this evaluation).

(c) Smog chamber photolysis of $n-\mathrm{C}_{4} \mathrm{H}_{10}-\mathrm{HONO}$-air mixtures at 1 bar (760 Torr) pressure. End product analysis of $\mathrm{C}_{3} \mathrm{H}_{7} \mathrm{CHO}$ by GC. $k / k\left(1-\mathrm{C}_{4} \mathrm{H}_{9} \mathrm{O}+\mathrm{O}_{2}\right)=(1.5 \pm 0.5) \times 10^{19}$ molecule $\mathrm{cm}^{-3}$ was derived from the yields of $\mathrm{C}_{3} \mathrm{H}_{7} \mathrm{CHO}$ and the rate of disappearance of $n-\mathrm{C}_{4} \mathrm{H}_{10}$ as a function of $\left[\mathrm{O}_{2}\right]$. Above value of $k$ was calculated by using a rate coefficient of $k=1.4 \times 10^{-14} \mathrm{~cm}^{3}$ molecule ${ }^{-1} \mathrm{~s}^{-1}$ for the reference reaction, $1-\mathrm{C}_{4} \mathrm{H}_{9} \mathrm{O}+\mathrm{O}_{2} \rightarrow \mathrm{C}_{3} \mathrm{H}_{7} \mathrm{CHO}+\mathrm{HO}_{2}$ at $298 \mathrm{~K}$ (this evaluation).

(d) Photolysis of $1-\mathrm{C}_{4} \mathrm{H}_{9} \mathrm{ONO}-\mathrm{NO}-\mathrm{O}_{2}-\mathrm{N}_{2}$ mixtures at 930 mbar (700 Torr) pressure in an FTIR cell. $k / k(1-$ $\left.\mathrm{C}_{4} \mathrm{H}_{9} \mathrm{O}+\mathrm{O}_{2}\right)=(1.9 \pm 0.2) \times 10^{19}$ molecule $\mathrm{cm}^{-3}$ was derived from yields of $\mathrm{C}_{3} \mathrm{H}_{7} \mathrm{CHO}$ and the rate of disappearance of $1-\mathrm{C}_{4} \mathrm{H}_{9} \mathrm{ONO}$ measured by calibrated FTIR spectroscopy. Above value of $k$ calculated using a rate coefficient of $k=1.4 \times 10^{-14} \mathrm{~cm}^{3}$ molecule ${ }^{-1} \mathrm{~s}^{-1}$ for the reference reaction, $1-\mathrm{C}_{4} \mathrm{H}_{9} \mathrm{O}+\mathrm{O}_{2} \rightarrow \mathrm{C}_{3} \mathrm{H}_{7} \mathrm{CHO}+\mathrm{HO}_{2}$ at $298 \mathrm{~K}$ (this evaluation).

(e) Photolysis of $1-\mathrm{C}_{4} \mathrm{H}_{9} \mathrm{ONO}$-air mixtures at 1013 mbar $\left(760\right.$ Torr) pressure. Analysis by GC. $k / k\left(1-\mathrm{C}_{4} \mathrm{H}_{9} \mathrm{O}+\mathrm{NO}\right)=$ $(2.5 \pm 0.2) \times 10^{-23} \mathrm{~cm}^{3}$ molecule ${ }^{-1} \mathrm{~s}^{-1}$ was derived from $\left[\mathrm{O}_{2}\right]$-dependence of yields of $\mathrm{C}_{3} \mathrm{H}_{7} \mathrm{CHO}$ and the rate of disappearance of $1-\mathrm{C}_{4} \mathrm{H}_{9} \mathrm{ONO}$. Above value of $k$ calculated using a rate coefficient of $k=2.3 \times 10^{-11} \exp (150 / T) \mathrm{cm}^{3}$ molecule $\mathrm{e}^{-1} \mathrm{~s}^{-1}$ for the reference reaction, $1-\mathrm{C}_{4} \mathrm{H}_{9} \mathrm{O}+\mathrm{NO} \rightarrow \mathrm{C}_{4} \mathrm{H}_{9} \mathrm{ONO}$, recommended by Atkinson (1997). 
(f) Photolysis of $1-\mathrm{C}_{4} \mathrm{H}_{9} \mathrm{I}-\mathrm{NO}-\mathrm{O}_{2}-\mathrm{N}_{2}$ mixtures at 1013 mbar $(760$ Torr $)$ pressure. $k / k\left(1-\mathrm{C}_{4} \mathrm{H}_{9} \mathrm{O}+\mathrm{O}_{2}\right)=(1.8 \pm 0.6) \times$ $10^{19}$ molecule $\mathrm{cm}^{-3}$ was derived from yields of $\mathrm{C}_{3} \mathrm{H}_{7} \mathrm{CHO}$ and the rate of disappearance of $1-\mathrm{C}_{4} \mathrm{H}_{9} \mathrm{ONO}$ measured by calibrated FTIR spectroscopy. The observed $\left[\mathrm{O}_{2}\right]$ dependence of this ratio was attributed to influence of $10-20 \%$ production of 'hot' 1-butoxy produced in the $\mathrm{RO}_{2}+\mathrm{NO}$ reaction. Cited value of the ratio $k$ refers to the thermally relaxed 1-butoxy and $k$ is calculated using a rate coefficient of $k\left(1-\mathrm{C}_{4} \mathrm{H}_{9} \mathrm{O}+\mathrm{O}_{2}\right)=1.4 \times 10^{-14} \mathrm{~cm}^{3} \mathrm{molecule}^{-1} \mathrm{~s}^{-1}$ for the reference reaction, $1-\mathrm{C}_{4} \mathrm{H}_{9} \mathrm{O}+\mathrm{O}_{2} \rightarrow \mathrm{C}_{3} \mathrm{H}_{7} \mathrm{CHO}+\mathrm{HO}_{2}$ at $298 \mathrm{~K}$ (this evaluation).

(g) Photolysis of $1-\mathrm{C}_{4} \mathrm{H}_{9} \mathrm{ONO}-\mathrm{NO}-\mathrm{O}_{2}-\mathrm{N}_{2}$ mixtures or $n-\mathrm{C}_{4} \mathrm{H}_{10}-\mathrm{HONO}$ (or $\mathrm{CH}_{3} \mathrm{ONO}$ )-NO-O $-\mathrm{N}_{2}$ mixtures at 1013 mbar (760 Torr) pressure. Analysis by GC. $k / k\left(1-\mathrm{C}_{4} \mathrm{H}_{9} \mathrm{O}+\mathrm{O}_{2}\right)=(1.98 \pm 0.50) \times 10^{23} \exp \{-(2720 \pm 470) / T\} \mathrm{molecule} \mathrm{cm}^{-3}$ was derived from $\left[\mathrm{O}_{2}\right]$-dependence of yields of $\mathrm{C}_{3} \mathrm{H}_{7} \mathrm{CHO}$ and the rate of disappearance of 1- $\mathrm{C}_{4} \mathrm{H}_{9} \mathrm{ONO}$. Evidence for the influence of $10 \%$ production of 'hot' 1-butoxy produced in the photolysis of $1-\mathrm{C}_{4} \mathrm{H}_{9} \mathrm{ONO}$. Cited value of the ratio $k$ refers to the thermally relaxed 1-butoxy.

(h) Above value of $k$ calculated using a rate coefficient of $k=8.9 \times 10^{-14} \exp (-550 / T) \mathrm{cm}^{3} \mathrm{molecule}^{-1} \mathrm{~s}^{-1}$ for the reference reaction, $1-\mathrm{C}_{4} \mathrm{H}_{9} \mathrm{O}+\mathrm{O}_{2} \rightarrow \mathrm{C}_{3} \mathrm{H}_{7} \mathrm{CHO}+\mathrm{HO}_{2}$, based on $k(298 \mathrm{~K})=1.4 \times 10^{-14} \mathrm{~cm}^{3} \mathrm{molecule}^{-1} \mathrm{~s}^{-1}$ from this evaluation, and the temperature dependence recommended by Atkinson $(1997 ; 2000): E / R=550 \mathrm{~K}$.

(i) Photolysis of $1-\mathrm{C}_{4} \mathrm{H}_{9} \mathrm{ONO}$-air mixtures at 930 mbar $(700$ Torr $)$ pressure. Analysis by $\mathrm{FTIR} \cdot k / k\left(1-\mathrm{C}_{4} \mathrm{H}_{9} \mathrm{O}+\mathrm{O}_{2}\right)=$ $5.5 \times 10^{23} \exp \{-(3020 \pm 110) / T\}$ molecule $\mathrm{cm}^{-3}$ was derived from $\left[\mathrm{O}_{2}\right]$-dependence of relative yields of $\mathrm{C}_{3} \mathrm{H}_{7} \mathrm{CHO}$ and $\mathrm{HOC}_{3} \mathrm{H}_{7} \mathrm{CHO}$ (the main product formed following isomerisation), adjusted to take account of secondary reactions.

\section{Preferred Values}

$k=4.6 \times 10^{10} \exp (-3570 / T) \mathrm{s}^{-1}$ at $298 \mathrm{~K}$ over the temperature range $250-350 \mathrm{~K}$ and 1 bar pressure.

$k=2.9 \times 10^{5} \mathrm{~s}^{-1}$ at $298 \mathrm{~K}$ and 1 bar pressure.

\section{Reliability}

$\Delta \log k= \pm 0.2$ at $298 \mathrm{~K}$.

$\Delta(E / R)= \pm 300 \mathrm{~K}$.

\section{Comments on Preferred Values}

The preferred rate coefficient at room temperature is the mean from the relative rate studies of Cassanelli et al. (2005; 2006) and Geiger et al. (2002), which both take into account influence of 'hot' 1-butoxy radicals. The studies of Carter et al. (1979), Cox et al. (1981), Niki et al. (1981), Morabito and Heicklen, (1987) all give similar results. The values of $k$ are all calculated using a rate coefficient of $k\left(1-\mathrm{C}_{4} \mathrm{H}_{9} \mathrm{O}+\mathrm{O}_{2}\right)=8.9 \times 10^{-14} \exp (-550 / T) \mathrm{cm}^{3} \mathrm{molecule}^{-1} \mathrm{~s}^{-1}$ for the reference reaction (this evaluation). The direct measurement of Hein et al. (1999) at 50 mbar total pressure shows that the reaction is in the fall-off region below 1 bar. The preferred value of $E / R$ is a mean of the results from the 2 studies of Cassanelli et al. (2005; 2006) and that of Morabito and Heicklen, (1987), and the $A$-factor fitted to give the recommended $k_{298}$. The pre-exponential factor obtained is lower than estimated by Atkinson (1997), but is consistent with the theoretical calculations of Vereecken and Peters (2003) using a rigorous multirotamer TST treatment.

\section{References}

Atkinson, R.: Int. J. Chem. Kinet. 29, 99, 1997.

Baldwin, A. C., Barker, J. R., Golden, D. M., and Hendry, D. G.: J. Phys. Chem. 81, 2483, 1977.

Carter, W. P. L., Lloyd, A. C., Sprung, J. L., and Pitts, Jr., J. N.: Int. J. Chem. Kinet. 11, 45, 1979.

Cassanelli, P., Johnson, D. and Cox, R. A., Phys. Chem. Chem. Phys. 7, 3702, 2005.

Cassanelli, P., Cox, R. A., Orlando, J. J. and Tyndall, G. S.: J. Photochem. Photobiol. A: Chem., 177, $109,2006$.

Cox, R. A., Patrick, K. F. and Chant, S. A.: Environ. Sci. Technol. 15, 587, 1981.

Geiger, H., Barnes, I., Becker, K. H., Bohn, B., Brauers, T., Donner, B., Dorn, H. P., Elend, M., Freitas Dinis, C. M., Grossmann, D., Hass, H., Hein, H., Hoffmann, A., Hoppe, L., Hülsemann, F., Kley, D., Klotz, B., Libuda, H. G., Maurer, T., Mihelcic, D., Moortgat, G. K., Olariu, R., Neeb, P., Poppe, D., Ruppert, L., Sauer, C. G., O., Somnitz, H., Stockwell, W. R., Thüner, L. P., A., Wiesen, P., Zabel, F., Zellner, R. and Zetzsch, C.:J. Atm. Chem., 2002, 42, 323-357. 
Hein, H., Hoffmann, A., and Zellner, R.: Phys. Chem. Chem. Phys. 1, 3743, 1999.

Morabito, P. and Heicklen, J.: Bull. Chem. Soc. Jpn., 60, 2641, 1987.

Niki, H., Maker, P. D., Savage, C. M., and Breitenbach, L. P.: J. Phys. Chem. 85, 2698, 1981.

Somnitz, H. and Zellner, R., Phys. Chem. Chem. Phys., 2, 1907, 2000.

Vereecken, L. and Peeters, J., J. Chem. Phys., 119, 5159, 2003. 
II.A5.106

$$
\begin{aligned}
& \mathrm{CH}_{3} \mathrm{OCH}_{2} \mathrm{O}+\mathrm{O}_{2} \rightarrow \mathrm{CH}_{3} \mathrm{OCHO}+\mathrm{HO}_{2} \\
& \mathrm{CH}_{3} \mathrm{OCH}_{2} \mathrm{O}+\mathrm{M} \rightarrow \mathrm{CH}_{3} \mathrm{OCHO}+\mathrm{H}+\mathrm{M}
\end{aligned}
$$

\begin{tabular}{|c|c|c|c|}
\hline$k_{1} \cdot k_{2}^{-1} / \mathrm{cm}^{3}$ molecule $^{-1}$ & Temp./K & Reference & Technique/Comments \\
\hline$k_{1}\left[\mathrm{O}_{2}\right] \sim k_{2}(1 \mathrm{bar}$, air $)$ & 295 & Jenkin et al., 1993 & RR (a) \\
\hline
\end{tabular}

\section{Rate coefficient data}

\section{Comments}

(a) Steady-state photolysis of $\mathrm{Cl}_{2}-\mathrm{CH}_{3} \mathrm{OCH}_{3}-\mathrm{O}_{2}-\mathrm{N}_{2}$ mixtures at pressures of $13.3 \mathrm{mbar}$ to $1013 \mathrm{mbar}$ (10 Torr to 760 Torr) with long-path FTIR analyses, and molecular modulation studies of similar reactant mixtures with UV absorption monitoring of $\mathrm{CH}_{3} \mathrm{OCH}_{2} \mathrm{O}_{2}$ radicals. In both systems, kinetic treatments indicate that Reactions (1) and (2) were competing under the conditions of the experiments.

\section{Preferred Values}

No quantitative recommendations.

\section{Comments on Preferred Values}

Although the results listed above for the reactions of the $\mathrm{CH}_{3} \mathrm{OCH}_{2} \mathrm{O}$ radical are not quantitative, for the purposes of atmospheric modelling studies it is recommended that the above qualitative information on the ratios $k_{1} / k_{2}$ be used to decide if one or the other of the alkoxy radical reaction pathways predominates, or if both pathways should be considered.

\section{References}

Jenkin, M. D., Hayman, G. D., Wallington, T. J., Hurley, M. D., Ball, J. C., Nielsen, O. J., and Ellermann, T.: J. Phys. Chem., 97, $11712,1993$. 
II.A5.107

$$
\begin{array}{ll}
\mathrm{CH}_{3} \mathrm{C}(\mathrm{O}) \mathrm{CH}_{2} \mathrm{O}+\mathrm{O}_{2} & \rightarrow \mathrm{CH}_{3} \mathrm{C}(\mathrm{O}) \mathrm{CHO}+\mathrm{HO}_{2} \\
\mathrm{CH}_{3} \mathrm{C}(\mathrm{O}) \mathrm{CH}_{2} \mathrm{O}+\mathrm{M} & \rightarrow \mathrm{CH}_{3} \mathrm{CO}+\mathrm{HCHO}+\mathrm{M}
\end{array}
$$

\section{Rate coefficient data}

\begin{tabular}{lllc}
\hline$k_{1} \cdot k_{2}^{-1} / \mathrm{cm}^{3}$ molecule $^{-1}$ & Temp./K & Reference & Technique/Comments \\
\hline$k_{1}\left[\mathrm{O}_{2}\right] \ll k_{2}(1 \mathrm{bar}$, air $)$ & 298 & Jenkin et al., 1993 & RR (a) \\
$k_{1}\left[\mathrm{O}_{2}\right] \ll k_{2}(1 \mathrm{bar}$, air $)$ & 298 & Bridier et al., 1993 & RR (b) \\
$k_{1}\left[\mathrm{O}_{2}\right] \ll k_{2}\left(1 \mathrm{bar}, \mathrm{O}_{2} / \mathrm{N}_{2}\right)$ & $225-298$ & Orlando et al., 2000 & S-FTIR (c) \\
\hline
\end{tabular}

\section{Comments}

(a) Steady-state photolysis of $\mathrm{Cl}_{2}-\mathrm{CH}_{3} \mathrm{C}(\mathrm{O}) \mathrm{CH}_{3}-\mathrm{O}_{2}-\mathrm{N}_{2}$ mixtures at $930 \mathrm{mbar}$ (700 Torr) with long-path FTIR and long-path UV visible diode array spectroscopy analyses of products. Data indicate that Reaction (2) predominated over Reaction (1) under the conditions of the experiments.

(b) Flash photolysis of $\mathrm{Cl}_{2}-\mathrm{CH}_{3} \mathrm{C}(\mathrm{O}) \mathrm{CH}_{3}$-air mixtures at 1 bar pressure with $\mathrm{UV}$ absorption monitoring of $\mathrm{CH}_{3} \mathrm{C}(\mathrm{O}) \mathrm{CH}_{2} \mathrm{O}_{2}$ radicals. Data indicate that Reaction (2) predominated over Reaction (1) under the conditions of the experiments.

(c) Mixtures of $\mathrm{Cl}_{2}$-acetone- $\mathrm{O}_{2}$ pressurised to $1 \mathrm{~atm}$ with $\mathrm{N}_{2}$ with and without $\mathrm{NO}_{\mathrm{x}}$ were irradiated in a static chamber using a filtered Xe-arc lamp. The diagnostic products $\mathrm{HCHO}$ and methylglyoxal $\left(\mathrm{CH}_{3} \mathrm{C}(\mathrm{O}) \mathrm{CHO}\right)$ and others were monitored using in situ long pathlength FTIR absorption. The independence of $\mathrm{HCHO}$ and $\mathrm{CH}_{3} \mathrm{C}(\mathrm{O}) \mathrm{CHO}$ yields on the $\mathrm{O}_{2}$ partial pressure varied from 66 to 865 mbar was taken as an indication of the predominance of (2) over (1) across the entire temperature range $225-298 \mathrm{~K}$, even at $1 \mathrm{~atm}$ of $\mathrm{O}_{2}: k_{2} / k_{1}=1.5 \times 10^{20}$ and $1.0 \times 10^{20}$ molecule $\mathrm{cm}^{-3}$ at 298 and $225 \mathrm{~K}$, respectively.

\section{Preferred Values}

No quantitative recommendations.

\section{Comments on Preferred Values}

Although the results listed above for the reactions of the $\mathrm{CH}_{3} \mathrm{C}(\mathrm{O}) \mathrm{CH}_{2} \mathrm{O}$ radical are not quantitative, for the purposes of atmospheric modelling studies it is recommended that the above qualitative information on the ratios $k_{1} / k_{2}$ be used to decide if one or the other of the alkoxy radical reaction pathways predominates, or if both pathways should be considered. All three studies listed above point towards the predominance of the decomposition pathway under atmospheric conditions down to $225 \mathrm{~K}$.

\section{References}

Bridier, I., Veyret, B., Lesclaux, R., and Jenkin, M. E.: J. Chem. Soc. Faraday Trans., 89, 2993, 1993.

Jenkin, M. E., Cox, R. A., Emrich, M., and Moortgat, G. K.: J. Chem. Soc. Faraday Trans., 89, 2983, 1993.

Orlando, J., Tyndall, G. S., Vereecken, L., and Peeters, J.: J. Phys. Chem. A, 104, 11 578, 2000. 
II.A5.108

\section{$\mathrm{CH}_{3} \mathrm{CH}(\mathrm{O}) \mathrm{CH}_{2} \mathrm{CH}_{3}+\mathrm{O}_{2} \rightarrow \mathrm{CH}_{3} \mathrm{C}(\mathrm{O}) \mathrm{CH}_{2} \mathrm{CH}_{3}+\mathrm{HO}_{2}$}

$\Delta H^{\circ}=-154.4 \mathrm{~kJ} \cdot \mathrm{mol}^{-1}$

\section{Rate coefficient data}

\begin{tabular}{lllc}
\hline$k / \mathrm{cm}^{3}$ molecule $\mathrm{s}^{-1}$ & Temp./K & Reference & Technique/Comments \\
\hline Absolute Rate Coefficients & & & \\
$(6.5 \pm 2.0) \times 10^{-15}$ & 293 & Hein et al., 1999 & PLP-AS/LIF (a) \\
$1.33 \times 10^{-15} \exp [(659 \pm 83) / T]$ & $223-311$ & Deng et al., 2000 & PLP/LIF (b) \\
$(1.2 \pm 0.4) \times 10^{-14}$ & 298 & & \\
$1.2 \times 10^{-15} \exp [(553 \pm 193) / T]$ & $221-266$ & Deng et al., 2001 & PLP/LIF (c) \\
$7.7 \times 10^{-15}$ & $298^{*}$ & & \\
$(9 \pm 3) \times 10^{-15}$ & 295 & Falgayrac et al., 2004 & PLP/LIF (d) \\
\hline
\end{tabular}

\section{Comments}

(a) Pulsed laser photolysis at $248 \mathrm{~nm}$ of a mixture of 2-bromobutane, $\mathrm{O}_{2}$ and $\mathrm{NO}$ in $\mathrm{N}_{2}$ at 50 mbar total pressure in a slow-flow system. $\mathrm{HO}$ and $\mathrm{NO}_{2}$ were monitored in real-time using laser long-path absorption at $308.417 \mathrm{~nm}$ and cw laser-excited fluorescence after excitation at $488 \mathrm{~nm}$, respectively. The rate coefficient was derived from a computer simulation of the $\mathrm{HO}$ and $\mathrm{NO}_{2}$ temporal concentration profiles.

(c) Laser photolysis $\left(355 \mathrm{~nm}\right.$ ) of 2- $\mathrm{C}_{4} \mathrm{H}_{9} \mathrm{ONO}-\mathrm{N}_{2}-\mathrm{O}_{2}$ mixtures; LIF detection of 2-butoxy radicals. No pressure dependence observed.

(c) Repeat study as in (b) but with improved experimental arrangement, giving less potential problems with secondary chemistry. $k(298 \mathrm{~K})$ obtained by extrapolation.

(d) Laser photolysis $(351 \mathrm{~nm})$ of $2-\mathrm{C}_{4} \mathrm{H}_{9} \mathrm{ONO}-\mathrm{He}-\mathrm{O}_{2}$ mixtures; LIF detection of 2-butoxy radicals. The same value of $k$ was obtained at 291 and $295 \mathrm{~K}$ but investigation over a larger temperature range was not possible due to experimental constraints. An uncertainty of $\pm 30 \%$ was estimated for the rate coefficient.

\section{Preferred Values}

$k=7.6 \times 10^{-15} \mathrm{~cm}^{3}$ molecule ${ }^{-1} \mathrm{~s}^{-1}$ at $298 \mathrm{~K}$.

$k=1.5 \times 10^{-14} \exp (-200 / T) \mathrm{cm}^{3}$ molecule $\mathrm{s}^{-1} \mathrm{~s}^{-1}$ over the temperature range $250-350 \mathrm{~K}$.

\section{Reliability}

$\Delta \log k= \pm 0.3$ at $298 \mathrm{~K}$.

$\Delta(E / R)= \pm 300 \mathrm{~K}$.

\section{Comments on Preferred Values}

The measurements of Hein et al. (1999), Falgayrac et al. (2004) and Deng et al. (2001) are in reasonable agreement. The preferred value for $k(298 \mathrm{~K})$ is the mean of these values. The second study of Deng et al. (2001) suggests problems in their earlier study (Deng et al., 2001). Although Deng et al. (2000; 2001) report a negative temperature dependence, we prefer to adopt the temperature dependence estimated by Atkinson (1997), $(E / R=200 \mathrm{~K})$, based on available data for smaller alkoxy radicals, and an $A$-factor adjusted to give the preferred value at $298 \mathrm{~K}$. 


\section{References}

Atkinson, R.: J. Phys. Chem. Ref. Data, 26, 215, 1997; Int. J. Chem. Kinet., 29, 99, 1997.

Deng, W., Davis, A. J., Zhang, L., Katz, D. R. and Dibble, T. S.: J. Phys. Chem. A 105, 8985, 2001.

Deng, W., Wang, C., Katz, D. R., Gawinski, G. R., Davis, A. J. and Dibble, T. S.: Chem.Phys.Lett,330, 541, 2000.

Falgayrac, G., Caralp, F., Sokolowski-Gomez, N., Devolder, P. and Fittschen, C.: Phys. Chem. Chem. Phys., 6, $4127,2004$.

Hein, H., Hoffmann, A. and Zellner, R.: Phys. Chem. Chem. Phys. 1, 3743, 1998. 
II.A5.109

$$
\begin{aligned}
\mathrm{CH}_{3} \mathrm{CH}(\mathrm{O}) \mathrm{CH}_{2} \mathrm{CH}_{3}+\mathrm{M} & \rightarrow \mathrm{CH}_{3} \mathrm{CHO}+\mathrm{C}_{2} \mathrm{H}_{5}+\mathrm{M} \\
& \rightarrow \mathrm{CH}_{3}+\mathrm{C}_{2} \mathrm{H}_{5} \mathrm{CHO}+\mathrm{M}
\end{aligned}
$$

$\Delta H^{\circ}(1)=24.6 \mathrm{~kJ} \cdot \mathrm{mol}^{-1}$

$\Delta H^{\circ}(2)=28.5 \mathrm{~kJ} \cdot \mathrm{mol}^{-1}$

\section{Rate coefficient data}

\begin{tabular}{lllc}
\hline$k / \mathrm{s}^{-1}$ & Temp./K & Reference & Technique/Comments \\
\hline $\begin{array}{l}\text { Absolute Rate Coefficients } \\
k_{1}=(3.5 \pm 2) \times 10^{3}\end{array}$ & 293 & Hein et al., 1998 & PLP-AS/LIF (a) \\
$k_{\infty}=1.1 \times 10^{14} \exp (-6450 / T)$ & $291-348$ & Falgayrac et al., 2004 & PLP/LIF (b) \\
$k_{0}=3.2 \times 10^{-8} \exp (-4320 / T)[\mathrm{He}]$ & & & \\
$k=2.9 \times 10^{4}\left(1\right.$ bar $\left.\mathrm{N}_{2}\right)$ & 298 & & \\
$\begin{array}{l}\text { Relative Rate Coefficients } \\
k_{1}=6.3 \times 10^{14} \exp (-7700 / T)\end{array}$ & $440-471$ & Batt and McCulloch, 1976 & S-GC (c) \\
$k_{1}=3.8 \times 10^{3}$ & 298 & & \\
$k_{1}=2.2 \times 10^{4}$ & 303 & Carter et al., 1979 & S-GC (d) \\
$k_{1}=1.95 \times 10^{4}$ & 296 & Cox et al., 1981 & S-GC (e) \\
$k_{1}=6.3 \times 10^{13} \exp (-7600 / T)$ & $363-503$ & Heiss et al., 1991 & F-TLC/ \\
$k_{1}=5.3 \times 10^{2}$ & 298 & & HPLC (f) \\
$k_{1}=3.0 \times 10^{12} \exp (-5663 / T)$ & $280-313$ & Libuda et al., 2002 & S-FTIR (g) (h) \\
$k_{1}=2.2 \times 10^{4}$ & & & \\
$k_{1}=2.2 \times 10^{4}$ & 298 & Meunier et al., 2003 & S-FTIR (i) (h) \\
$k_{1}=4.1 \times 10^{12} \exp (-5904 / T)$ & $250-318$ & Cassanelli et al., 2005 & FR-GC (j) (h) \\
$k_{1}=2.0 \times 10^{4}$ & & & \\
Branching Ratios & & & \\
$k_{1} / k_{2}=0.59 \exp (1350 / T)$ & $399-493$ & Drew et al., 1985 & S-GC (k) \\
$k_{1} / k_{2}=55$ & 298 & & \\
\hline
\end{tabular}

\section{Comments}

(a) Pulsed laser photolysis at 193 or $248 \mathrm{~nm}$ of a mixture of 2-bromobutane, $\mathrm{O}_{2}$ and $\mathrm{NO}$ in $\mathrm{N}_{2}$ at 50 mbar total pressure in a slow-flow system. $\mathrm{HO}$ and $\mathrm{NO}_{2}$ were monitored in real-time using laser long-path absorption at $308.417 \mathrm{~nm}$ and cw laser-excited fluorescence after excitation at $488 \mathrm{~nm}$, respectively. The rate coefficient was derived from a computer simulation of the $\mathrm{HO}$ and $\mathrm{NO}_{2}$ temporal concentration profiles and is in the fall-off region at the total pressure used.

(b) Laser photolysis $\left(351 \mathrm{~nm}\right.$ ) of $2-\mathrm{C}_{4} \mathrm{H}_{9} \mathrm{ONO}-\mathrm{He}$ mixtures with LIF detection of 2-butoxy radicals. The temperature and pressure dependence of the unimolecular decomposition was measured at total pressures between $0.01<\mathrm{p}<0.8$ bar of helium and at four temperatures between 291 and $348 \mathrm{~K}$. The low and the high pressure limiting rate coefficients as well as the broadening factor $F_{\text {cent }}$ have been extracted from a falloff analysis of the experimental results: $k_{3,0, \mathrm{He}}=3.2 \times$ $10^{-8} \exp \left(-35.9 \mathrm{~kJ} \mathrm{~mol}^{-1} / \mathrm{R} T\right) \mathrm{cm}^{3} \mathrm{~s}^{-1}, k_{\infty}=1.1 \times 10^{14} \exp \left(-53.6 \mathrm{~kJ} \mathrm{~mol}^{-1} / \mathrm{R} T\right) \mathrm{s}^{-1}$, and $F_{3, \mathrm{c}}=0.87-T / 870 \mathrm{~K}$. The rate coefficient at $1 \mathrm{bar}, 298 \mathrm{~K}$ was calculated from these expressions. An uncertainty of $\pm 30 \%$ was estimated for these rate coefficients.

(c) Pyrolysis of 2-butyl nitrite in the presence of $\mathrm{NO}$ at pressures of $\sim 1$ bar ( $\sim 760$ Torr) in a static system. End-product analysis of $\mathrm{CH}_{3} \mathrm{CHO}$ by GC. Results were derived relative to the reaction $2-\mathrm{C}_{4} \mathrm{H}_{9} \mathrm{O}+\mathrm{NO} \rightarrow 2-\mathrm{C}_{4} \mathrm{H}_{9} \mathrm{ONO}$ for which a value of $k=4.2 \times 10^{-11} \mathrm{~cm}^{3}$ molecule ${ }^{-1} \mathrm{~s}^{-1}$ was taken, independent of temperature.

(d) Smog chamber photolysis of $n-\mathrm{C}_{4} \mathrm{H}_{10}-\mathrm{NO}_{\mathrm{x}}$-air mixtures at 1 bar pressure. End-product analysis of $\mathrm{CH}_{3} \mathrm{CHO}$ and $\mathrm{CH}_{3} \mathrm{C}(\mathrm{O}) \mathrm{C}_{2} \mathrm{H}_{5}$ by GC yielded $k_{1} / k_{2}\left(2-\mathrm{C}_{4} \mathrm{H}_{9} \mathrm{O}+\mathrm{O}_{2}\right)=3.15 \times 10^{18}$ molecule $\mathrm{cm}^{-3}$. The above value of $k_{1}$ was obtained taking $k=7 \times 10^{-15} \mathrm{~cm}^{3}$ molecule ${ }^{-1} \mathrm{~s}^{-1}$ for the reference reaction $2-\mathrm{C}_{4} \mathrm{H}_{9} \mathrm{O}+\mathrm{O}_{2} \rightarrow \mathrm{CH}_{3} \mathrm{C}(\mathrm{O}) \mathrm{C}_{2} \mathrm{H}_{5}+\mathrm{HO}_{2}$ (see this evaluation). 
(e) Similar experiments as in comment (b) with $n$ - $\mathrm{C}_{4} \mathrm{H}_{10}$-HONO-air mixtures yielding $k_{1} / k_{2}(2-$ $\left.\mathrm{C}_{4} \mathrm{H}_{9} \mathrm{O}+\mathrm{O}_{2}\right)=(2.60 \pm 0.35) \times 10^{18}$ molecule $\mathrm{cm}^{-3}$. The above value of $k_{1}$ was obtained taking $k=7.6 \times 10^{-15} \mathrm{~cm}^{3}$ molecule ${ }^{-1} \mathrm{~s}^{-1}$ for the reference reaction $2-\mathrm{C}_{4} \mathrm{H}_{9} \mathrm{O}+\mathrm{O}_{2} \rightarrow \mathrm{CH}_{3} \mathrm{C}(\mathrm{O}) \mathrm{C}_{2} \mathrm{H}_{5}+\mathrm{HO}_{2}$ (see this evaluation).

(f) Pyrolysis of $\left(2-\mathrm{C}_{4} \mathrm{H}_{7} \mathrm{O}\right)_{2}$ in a stream of $\mathrm{O}_{2}-\mathrm{N}_{2}$ with end-product analyses. Rate data derived from a computer simulation of yields of $\mathrm{CH}_{3} \mathrm{CHO}$ and $\mathrm{CH}_{3} \mathrm{C}(\mathrm{O}) \mathrm{C}_{2} \mathrm{H}_{5}$ and assuming that $k=2.6 \times 10^{-14} \exp (-100 / T) \mathrm{cm}^{3}$ molecule ${ }^{-1} \mathrm{~s}^{-1}$ for the competing reaction 2- $\mathrm{C}_{4} \mathrm{H}_{9} \mathrm{O}+\mathrm{O}_{2} \rightarrow \mathrm{CH}_{3} \mathrm{C}(\mathrm{O}) \mathrm{C}_{2} \mathrm{H}_{5}+\mathrm{HO}_{2}$.

(g) Photolysis of $2-\mathrm{C}_{4} \mathrm{H}_{9} \mathrm{I}-\mathrm{NO}-\mathrm{O}_{2}-\mathrm{N}_{2}$ mixtures at 1013 mbar $\left(760\right.$ Torr) pressure. $k / k\left(2-\mathrm{C}_{4} \mathrm{H}_{9} \mathrm{O}+\mathrm{O}_{2}\right)=(2.0 \pm 0.5) \times$ $10^{26} \exp (-5463 / T)$ molecule $\mathrm{cm}^{-3}$ was derived from yields of $\mathrm{C}_{3} \mathrm{H}_{7} \mathrm{CHO}$ and $\mathrm{CH}_{3} \mathrm{CHO}$ products, measured by calibrated FTIR spectroscopy. The observed $\left[\mathrm{O}_{2}\right]$ dependence of this ratio was attributed to influence of 6-10\% production of 'hot' 2-butoxy produced in the $\mathrm{RO}_{2}+\mathrm{NO}$ reaction. Pressure dependence of a factor $\sim 1.6$ increase in the rate coefficient ratio was observed over range 100-1000 mbar.

(h) Cited value of the ratio $k$ refers to the thermally relaxed 1-butoxy and $k(1 \mathrm{bar})$ is calculated using a rate coefficient of $k\left(2-\mathrm{C}_{4} \mathrm{H}_{9} \mathrm{O}+\mathrm{O}_{2}\right)=1.5 \times 10^{-14} \exp (-200 / T) \mathrm{cm}^{3}$ molecule ${ }^{-1} \mathrm{~s}^{-1}$ (Atkinson, 1997).

(i) Photolysis $\left(420 \mathrm{~nm}\right.$ ) of $2-\mathrm{C}_{4} \mathrm{H}_{9} \mathrm{ONO}-\mathrm{NO}-\mathrm{O}_{2}-\mathrm{N}_{2}$ mixtures or $n-\mathrm{C}_{4} \mathrm{H}_{10}-\mathrm{HONO}\left(\right.$ or $\left.\mathrm{CH}_{3} \mathrm{ONO}\right)-\mathrm{NO}-\mathrm{O}_{2}-\mathrm{N}_{2}$ mixtures at 1013 mbar (760 Torr) pressure. Analysis by FTIR. $k / k\left(1-\mathrm{C}_{4} \mathrm{H}_{9} \mathrm{O}+\mathrm{O}_{2}\right)=(2.9 \pm 0.4) \times 10^{18}$ molecule $\mathrm{cm}^{-3}$ was derived from $\left[\mathrm{O}_{2}\right]$-dependence of yields of $\mathrm{C}_{3} \mathrm{H}_{7} \mathrm{CHO}$ and $\mathrm{CH}_{3} \mathrm{CHO}$ products. No chemical activation observed at this photolysis wavelength.

(j) Photolysis $(360 \mathrm{~nm})$ of $2-\mathrm{C}_{4} \mathrm{H}_{9} \mathrm{ONO}-\mathrm{NO}-\mathrm{O}_{2}-\mathrm{N}_{2}$ mixtures at 1013 mbar $(760$ Torr) pressure. Analysis by GC. $k / k(2-$ $\left.\mathrm{C}_{4} \mathrm{H}_{9} \mathrm{O}+\mathrm{O}_{2}\right)=5.4 \times 10^{26} \exp \{-(5704 \pm 350) / T\}$ molecule $\mathrm{cm}^{-3}$ was derived from $\left[\mathrm{O}_{2}\right]$-dependence of $\mathrm{C}_{3} \mathrm{H}_{7} \mathrm{CHO}$ and $\mathrm{CH}_{3} \mathrm{CHO}$ products. Evidence for the influence of production of 'hot' 2-butoxy produced in the photolysis of $2-\mathrm{C}_{4} \mathrm{H}_{9} \mathrm{ONO}$ ( $5 \%$ at $283 \mathrm{~K} ; 9 \%$ at $298 \mathrm{~K}$ ). Cited value of the ratio $k$ refers to the thermally relaxed 2-butoxy.

(k) Static thermal generation of radicals from $\mathrm{F}+2-\mathrm{C}_{4} \mathrm{H}_{9} \mathrm{OH}$ with end-product analysis of $\mathrm{CH}_{3} \mathrm{CHO}$ and $\mathrm{C}_{2} \mathrm{H}_{5} \mathrm{CHO}$ by GC.

\section{Preferred Values}

$k_{1}=7.2 \times 10^{12} \exp (-5780 / T) \mathrm{s}^{-1}$ over the temperature range $240-340 \mathrm{~K}$ and 1 bar pressure.

$k_{1}=2 \times 10^{4} \mathrm{~s}^{-1}$ at $298 \mathrm{~K}$ and 1 bar pressure.

\section{Reliability}

$\Delta \log k_{1}= \pm 0.3$ at $298 \mathrm{~K}$.

$\Delta\left(E_{1} / R\right)= \pm 500 \mathrm{~K}$.

\section{Comments on Preferred Values}

The recent results of Libuda et al. (2002) and Cassenelli et al. (2005) for the temperature dependence of the relative rate coefficients agree well with the room temperature data of Carter et al. (1979), Cox et al. (1981 and Meunier et al. (2003), especially when the small effects of 'hot' 2-butoxy production are taken into account. The preferred $298 \mathrm{~K}$ value of $k$ is a mean value based on the measured ratios of $k / k\left(2\right.$-butoxy $\left.+\mathrm{O}_{2}\right)$ of Libuda et al. (2002) and Cassanelli et al. (2005), using a rate coefficient of $k\left(2\right.$-butoxy $\left.+\mathrm{O}_{2}\right)=1.5 \times 10^{-14} \exp (-200 / T) \mathrm{cm}^{3}$ molecule ${ }^{-1} \mathrm{~s}^{-1}$ recommended by Atkinson (1997) and IUPAC (current evaluation). The temperature-dependence is based on a mean activation energy from these two studies, and a pre-exponential factor adjusted to fit the recommended $298 \mathrm{~K}$ value.

The recent comprehensive temperature and pressure dependence study of Falgayrac et al. (2004) confirms the earlier indications from measurements of Hein et al (1998) and Libuda et al. (2002) that decomposition is in the fall-off region below 1 bar. The low and the high pressure limiting rate constants as well as the broadening factor $F_{\text {cent }}$ extracted from a falloff analysis of their experimental results can be used to calculate rate constants at other pressures (Falgayrac et al. 2004). The absolute rate coefficient at 1 bar pressure and $298 \mathrm{~K}\left(=2.9 \times 10^{4} \mathrm{~s}^{-1}\right)$ (Falgayrac et al. 2004) is consistent with the preferred value within experimental error. The results are in good agreement with predictions from several theoretical studies of this unimolecular decomposition (Somnitz and Zellner (2000), Mereau et al. (2000) and Fittschen et al. (2000)). 
Although the branching ratio $\left(k_{1} /\left(k_{2}\right)\right.$ reported by Drew et al. (1985) seems reasonable, it requires further confirmation before a recommendation can be made. None of the other studies of the decomposition of the 2- $\mathrm{C}_{4} \mathrm{H}_{9} \mathrm{O}$ radicals has reported $\mathrm{C}_{2} \mathrm{H}_{5} \mathrm{CHO}$ as a product of the decomposition reaction.

\section{References}

Batt, L. and McCulloch, R. D.: Int. J. Chem. Kinet. 8, 911, 1976.

Carter, W. P. L., Lloyd, A. C., Sprung, J. L., and Pitts, Jr., J. N.: Int. J. Chem. Kinet. 11, 45, 1979.

Cassanelli, P., Johnson, D. and Cox, R. A., Phys. Chem. Chem. Phys. 7, 3702, 2005.

Cox, R. A., Patrick, K. F., and Chant, S. A.: Environ. Sci. Technol. 15, 587, 1981.

Drew, R. M., Kerr, J. A., and Olive, J.: Int. J. Chem. Kinet. 17, 167, 1985.

Falgayrac, G., Caralp, F., Sokolowski-Gomez, N., Devolder, P. and Fittschen, C., Phys. Chem. Chem. Phys., 6, $4127,2004$.

Fittschen, C., Hippler, H. and Viskolcz, B.: Phys. Chem. Chem. Phys., 2, 1677-1683, 2000.

Hein, H., Hoffmann, A., and Zellner, R.: Ber. Bunsenges. Phys. Chem. 102, 1840, 1998.

Heiss, A., Tardieu de Maleissye, J., Viossat, V., Sahetchian, K. A., and Pitts, I. G.: Int. J. Chem. Kinet. $23,607,1991$.

Libuda, H.G., Shestakov, O., Theloke J. and Zabel, F.: Phys. Chem. Chem. Phys., 4, 2579-2586. 2002.

Méreau, R., Rayez, M.-T., Caralp, F. and Rayez, J.-C.: Phys. Chem. Chem. Phys., 2, 3765, 2000.

Meunier, N., Doussin, J. F., Chevallier, E., Durand-Jolibois, Picquet-Varrault, B. and Carlier, P.: Phys. Chem. Chem. Phys., 5, 4834-4839, 2003.

Somnitz, H. and Zellner, R.: Phys. Chem. Chem. Phys., 2, 1907, 2000. 
II.A5.110

$$
\begin{array}{ll}
\mathrm{CH}_{3} \mathrm{O}+\mathrm{NO}+\mathrm{M} & \rightarrow \mathrm{CH}_{3} \mathrm{ONO}+\mathrm{M} \\
\mathrm{CH}_{3} \mathrm{O}+\mathrm{NO} & \rightarrow \mathrm{HCHO}+\mathrm{HNO}
\end{array}
$$

$\Delta H^{\circ}(1)=-172.7 \mathrm{~kJ} \cdot \mathrm{mol}^{-1}$

$\Delta H^{\circ}(2)=-103.1 \mathrm{~kJ} \cdot \mathrm{mol}^{-1}$

\section{Low-pressure rate coefficients}

\section{Rate coefficient data}

\begin{tabular}{lllc}
\hline$k_{01} / \mathrm{cm}^{3}$ molecule ${ }^{-1} \mathrm{~s}^{-1}$ & Temp./K & Reference & Technique/Comments \\
\hline Absolute Rate Coefficients & & & \\
$1.35 \times 10^{-29}(T / 298)^{-3.8}[\mathrm{Ar}]$ & $296-573$ & Frost and Smith, 1990 & PLF-LIF (a) \\
$1.8 \times 10^{-29}(T / 300)^{-3.2}[\mathrm{Ar}]$ & $220-473$ & McCaulley et al., 1990 & DF-LIF (b) \\
$k_{2}=(4.8 \pm 0.4) \times 10^{-12}$ & 298 & Daële et al., 1995 & DF-LIF (c) \\
$2.65 \times 10^{-29}(T / 298)^{-2.8}[\mathrm{He}, \mathrm{Ar}]$ & $248-473$ & Caralp et al., 1998 & DF/PLP-LIF (d) \\
$k_{2}=1.25 \times 10^{-11} \exp (-1015 / T)$ & & & \\
$+1.92 \times 10^{-12}(T / 298)^{-2.56}$ & & & \\
\hline
\end{tabular}

\section{Comments}

(a) Rate coefficients were measured up to $165 \mathrm{mbar}$ of $\mathrm{Ar}$ or $\mathrm{CF}_{4}$ diluent. Evaluation of the chemical activation system $\mathrm{CH}_{3} \mathrm{O}+\mathrm{NO} \rightarrow \mathrm{CH}_{3} \mathrm{ONO}^{*}, \mathrm{CH}_{3} \mathrm{ONO}^{*}+\mathrm{M} \rightarrow \mathrm{CH}_{3} \mathrm{ONO}+\mathrm{M}$, and $\mathrm{CH}_{3} \mathrm{ONO}^{*} \rightarrow \mathrm{HCHO}+\mathrm{HNO}$ were carried out using an extended Lindemann-Hinshelwood mechanism. At low pressures the disproportionation reaction $\mathrm{CH}_{3} \mathrm{O}+\mathrm{NO} \rightarrow \mathrm{HCHO}+\mathrm{HNO}$ dominates $\left(k_{2}=5.0 \times 10^{-12}(T / 298)^{-0.6} \mathrm{~cm}^{3}\right.$ molecule $\left.\mathrm{s}^{-1} \mathrm{~s}^{-1}\right)$. Assuming that Reactions (1) and (2) involve the same intermediate complex, $k_{2}$ is expected to decrease with increasing pressure following the relationship $k_{2}=k_{02} k_{1} / k_{01}$.

(b) Measurements were made over the pressure range 1 mbar to $6.6 \mathrm{mbar}$ in $\mathrm{He}$ or Ar. The disproportionation reaction $\mathrm{CH}_{3} \mathrm{O}+\mathrm{NO} \rightarrow \mathrm{HCHO}+\mathrm{HNO}$ was measured by molecular beam MS $\left(k_{2}=1.3 \times 10^{-12} \exp (250 / T) \mathrm{cm}^{3}\right.$ molecule $\left.^{-1} \mathrm{~s}^{-1}\right)$.

(c) Analysis by LIF and mass spectrometry. Experiments at $298 \mathrm{~K}$ and $1.3 \mathrm{mbar}$ of $\mathrm{He}$.

(d) Two sets of experiments, using DF over the range 0.6-7 mbar and 248-473 K, or PLP over the range 39-658 mbar and 284-364 K. Results with the bath gases He (mostly used) and $\mathrm{Ar}$ (some experiments) essentially agreed. Extensive RRKM modelling allowed to separate $k_{1}$ and $k_{2}$. Falloff curves for $k_{1}$ evaluated with $F_{C}=\exp (-T / 900)$. The overall rate constant is assumed to be of the form $k=k_{1}([\mathrm{M}])+k_{2}$.

\section{Preferred Values}

$k_{01}=2.6 \times 10^{-29}(T / 300)^{-2.8}\left[\mathrm{~N}_{2}\right] \mathrm{cm}^{3}$ molecule $\mathrm{e}^{-1} \mathrm{~s}^{-1}$ over the temperature range 200-400 K.

$k_{2}=2.3 \times 10^{-12}(T / 300)^{-0.7} \mathrm{~cm}^{3}$ molecule $\mathrm{s}^{-1} \mathrm{~s}^{-1}$ over the temperature range $200-300 \mathrm{~K}$.

\section{Reliability}

$\Delta \log k_{01}= \pm 0.1$ at $298 \mathrm{~K}$.

$\Delta n= \pm 0.5$

$\Delta \log k_{2}= \pm 0.2$ at $298 \mathrm{~K}$. 


\section{Comments on Preferred Values}

The preferred values are based on the extensive work by Caralp et al. (1998) which includes and supersedes the earlier results from Frost and Smith (1990), McCaulley et al. (1990) and Daële et al. (1995) as well as by Ohmori et al. (1993) in the middle of the falloff curve. The results are represented in the form of $k=k_{1}([\mathrm{M}])+k_{2}$, where $k_{1}(\mathrm{M})$ is based on $k_{01}$ such as preferred here, $k_{\infty 1}$ such as given below and $F_{c}=\exp (-T / 900)$ for $\mathrm{M}=\mathrm{He}$, Ar and $\mathrm{N}_{2}$. It remains to be investigated whether $k_{2}$ decreases with increasing pressure (common intermediate of Reactions (1) and (2)) or is pressure independent (direct Reaction (2)).

\section{High-pressure rate coefficients}

\section{Rate coefficient data}

\begin{tabular}{lllc}
\hline$k_{\infty 1} / \mathrm{cm}^{3}$ molecule ${ }^{-1} \mathrm{~s}^{-1}$ & Temp./K & Reference & Technique/Comments \\
\hline Absolute Rate Coefficients & & & \\
$2.1 \times 10^{-11}$ & $440-473$ & Batt et al., 1977 & (a) \\
$(2.08 \pm 0.12) \times 10^{-11}$ & 298 & Sanders et al., 1980 & (b) \\
$1.4 \times 10^{-11}$ & 298 & Zellner, 1987 & PLP-AS (c) \\
$3.6 \times 10^{-11}(T / 298)^{-0.6}$ & $296-573$ & Frost and Smith, 1990 & PLF-LIF (d) \\
$(2.45 \pm 0.31) \times 10^{-11}$ & 300 & Dóbé et al., 1994 & DF-LIF (e) \\
$3.26 \times 10^{-11}(T / 298)^{-0.6}$ & $248-473$ & Caralp et al., 1998 & PLP-LIF (f) \\
\hline
\end{tabular}

\section{Comments}

(a) Thermal decomposition of methyl nitrite in the presence of $\mathrm{NO}$ and $\left(\mathrm{CH}_{3}\right)_{3} \mathrm{CH}$. Combination of these data with the equilibrium constant gives the value indicated. For the second channel, $k\left(\mathrm{CH}_{3} \mathrm{O}+\mathrm{NO} \rightarrow \mathrm{CH}_{2} \mathrm{O}+\mathrm{HNO}\right) / k_{\infty}\left(\mathrm{CH}_{3} \mathrm{O}+\mathrm{NO} \rightarrow \mathrm{CH}_{3} \mathrm{ONO}\right)=0.17$ was estimated.

(b) Photolysis of methyl nitrite at $266 \mathrm{~nm}$ with $\mathrm{CH}_{3} \mathrm{O}$ detection by LIF at $\mathrm{He}$ pressure of 13 mbar to $66 \mathrm{mbar}$. $\mathrm{HNO}$ as a reaction product was also detected by LIF; however, no absolute estimate of its yield could be made.

(c) Falloff curve was measured over the range 5 mbar to 500 mbar. Extrapolations carried out using $F_{c}=0.6$.

(d) See comment (a) for $k_{0}$.

(e) $\mathrm{CH}_{3} \mathrm{O}$ radicals and $\mathrm{HCHO}$ from Reaction (2) detected by LIF. The branching ratio for HCHO formation varied between 0.84 and 0.26 over the pressure range 1 mbar to 11 mbar.

(f) See comment (d) for $k_{0}$.

\section{Preferred Values}

$k_{\infty 1}=3.3 \times 10^{-11}(T / 300)^{-0.6} \mathrm{~cm}^{3}$ molecule $\mathrm{e}^{-1} \mathrm{~s}^{-1}$ over the temperature range $200-400 \mathrm{~K}$.

\section{Reliability}

$\Delta \log k_{\infty 1}= \pm 0.5$ at $298 \mathrm{~K}$.

$\Delta n= \pm 0.5$

\section{Comments on Preferred Values}

The recommended value is from the most extensive study by Caralp et al. (1998) which supersedes and includes earlier work. The results are in accord with an RRKM modelling of the chemical activation system. Batt (1987) cites a rate coefficient ratio of $k_{2} / k<0.05$ from a study at $433-473 \mathrm{~K}$, consistent with our preferred values. 


\section{References}

Batt, L.: Int. Rev. Phys. Chem., 6, 53, 1987.

Batt, L., Milne, R. T., and McCulloch, R. D.: Int. J. Chem. Kinet., 9, 567, 1977.

Caralp, F., Rayez, M.-Th., Forst, W., Gomez, N., Delcroix, B., Fittschen, C., and Devolder, P.: J. Chem. Soc. Faraday Trans., 94, 3321, 1998.

Daële, V., Laverdet, G., LeBras, G., and Poulet, G.: J. Phys. Chem., 99, 1470, 1995.

Dóbé, S., Lendvay, G., Szilagyi, I., and Bérces, T.: Int. J. Chem. Kinet., 26, 887, 1994.

Frost, M. J. and Smith, I. W. M.: J. Chem. Soc. Faraday Trans., 86, 1757, 1990.

McCaulley, J. A., Moyle, A. M., Golde, M. F., Anderson, S. M., and Kaufman, F.: J. Chem. Soc. Faraday Trans., 86, 4001, 1990.

Ohmori, K., Yamasaki, K., and Matsui, H.: Bull. Chem. Soc. Jpn., 66, 51, 1993.

Sanders, N., Butler, J. E., Pasternack, L. R., and McDonald, J. R.: Chem. Phys., 48, 203, 1980.

Zellner, R.: J. Chim. Phys., 84, 403, 1987. 
II.A5.111

$$
\begin{array}{ll}
\mathrm{C}_{2} \mathrm{H}_{5} \mathrm{O}+\mathrm{NO}+\mathrm{M} & \rightarrow \mathrm{C}_{2} \mathrm{H}_{5} \mathrm{ONO}+\mathrm{M} \\
\mathrm{C}_{2} \mathrm{H}_{5} \mathrm{O}+\mathrm{NO} & \rightarrow \mathrm{CH}_{3} \mathrm{CHO}+\mathrm{HNO}
\end{array}
$$

$\Delta H^{\circ}(1)=-178.5 \mathrm{~kJ} \cdot \mathrm{mol}^{-1}$

$\Delta H^{\circ}(2)=-127.6 \mathrm{~kJ} \cdot \mathrm{mol}^{-1}$

\section{Low-pressure rate coefficients}

\begin{tabular}{|c|c|c|c|}
\hline$k_{01} / \mathrm{cm}^{3}$ molecule ${ }^{-1} \mathrm{~s}^{-1}$ & Temp./K & Reference & Technique/Comments \\
\hline $\begin{array}{l}\text { Absolute Rate Coefficients } \\
(2.2 \pm 1.2) \times 10^{-28}[\mathrm{He}]\end{array}$ & 298 & Daële et al., 1995 & DF-LIF/MS (a) \\
\hline
\end{tabular}

\section{Rate coefficient data}

\section{Comments}

(a) $\mathrm{C}_{2} \mathrm{H}_{5} \mathrm{O}$ radicals were generated by the reaction of $\mathrm{F}$ atoms with $\mathrm{C}_{2} \mathrm{H}_{5} \mathrm{OH}$. Measurements were carried out at 0.7 mbar, $1.3 \mathrm{mbar}$ and $2.6 \mathrm{mbar}$. The rate coefficient $k_{01}$ was obtained from a Lindemann-Hinshelwood analysis, assuming identical intermediates in Reactions (1) and (2); $k_{2}=(1.1 \pm 0.5) \times 10^{-11} \mathrm{~cm}^{3}$ molecule $\mathrm{e}^{-1} \mathrm{~s}^{-1}$ was derived.

\section{Preferred Values}

$k_{01}=2.2 \times 10^{-28}\left[\mathrm{~N}_{2}\right] \mathrm{cm}^{3}$ molecule $\mathrm{c}^{-1} \mathrm{~s}^{-1}$ at $298 \mathrm{~K}$.

$k_{2}=1.1 \times 10^{-11} \mathrm{~cm}^{3}$ molecule $\mathrm{s}^{-1} \mathrm{~s}^{-1}$ at $298 \mathrm{~K}$.

\section{Reliability}

$\Delta \log k_{01}= \pm 0.3$ at $298 \mathrm{~K}$.

$\Delta \log k_{2}= \pm 0.5$ at $298 \mathrm{~K}$.

\section{Comments on Preferred Values}

The preferred values are from Daële et al. (1995) assuming that Reactions (1) and (2) can be separated by LindemannHinshelwood extrapolation and $k=k_{1}([\mathrm{M}])+k_{2}$. We assume equal values of $k_{01}$ for $\mathrm{He}$ and $\mathrm{N}_{2}$ as third bodies. In contrast to the simple Lindemann-Hinshelwood evaluation of Daële et al. (1995) corresponding to $F_{c}=1$, we recommend to use $F_{c}=0.6$ for a construction of the falloff curve for $k_{1}([\mathrm{M}])$.

\section{High-pressure rate coefficients}

\section{Rate coefficient data}

\begin{tabular}{lllc}
\hline$k_{\infty 1} / \mathrm{cm}^{3}$ molecule ${ }^{-1} \mathrm{~s}^{-1}$ & Temp./K & Reference & Technique/Comments \\
\hline Absolute Rate Coefficients & & & \\
$(4.4 \pm 0.4) \times 10^{-11}$ & 298 & Frost and Smith, 1990 & PLP-LIF (a) \\
$(3.1 \pm 0.8) \times 10^{-11}$ & 298 & Daële et al., 1995 & DF-LIF/MS (b) \\
$(3.7 \pm 0.7) \times 10^{-11}(T / 300)^{0.2}$ & $286-388$ & Fittschen et al., 1999 & PLP-LIF (c) \\
\hline
\end{tabular}




\section{Comments}

(a) The rate coefficient $k_{1}$ is found not to depend on the pressure between 20 mbar and 130 mbar of Ar.

(b) See comment (a) for $k_{0}$.

(c) Measurements over the range 39-658 mbar of He. Results assumed to be in the high pressure range. Values taken from table of results, not abstract.

\section{Preferred Values}

$k_{\infty 1}=4.4 \times 10^{-11} \mathrm{~cm}^{3}$ molecule $\mathrm{e}^{-1} \mathrm{~s}^{-1}$ over the temperature range $200-400 \mathrm{~K}$.

\section{Reliability}

$\Delta \log k_{\infty 1}= \pm 0.3$ at $298 \mathrm{~K}$.

$\Delta n= \pm 0.5$

\section{Comments on Preferred Values}

The preferred value of $k_{\infty 1}$ is from Frost and Smith (1990), in close agreement with Fittschen et al. (1999). For the falloff curve of Reaction (1), $F_{c}=0.6$ is chosen. The value of $k_{2}$ derived in Daële et al. (1995) with the preferred $k_{\infty} 1$ is in good agreement with the ratio $k_{2} / k_{\infty 1}=0.3$ observed in Baker and Shaw (1965).

\section{References}

Baker, G. and Shaw, R.: J. Chem. Soc. A, 6965, 1965.

Daële, V., Ray, A., Vassalli, I., Poulet, G., and LeBras, G.: Int. J. Chem. Kinet., 27, 1121, 1995.

Fittschen, C., Frenzel, A., Imrik, K., and Devolder, P.: Int. J. Chem. Kinet., 31, 800, 1999.

Frost, M. J. and Smith, I. W. M.: J. Chem. Soc. Faraday Trans, 86, 1757, 1990. 
II.A5.112

$$
n-\mathrm{C}_{3} \mathrm{H}_{7} \mathrm{O}+\mathrm{NO}+\mathrm{M} \rightarrow n-\mathrm{C}_{3} \mathrm{H}_{7} \mathrm{ONO}+\mathrm{M}
$$

\section{High-pressure rate coefficients}

\section{Rate coefficient data}

\begin{tabular}{|c|c|c|c|}
\hline$k_{\infty} / \mathrm{cm}^{3}$ molecule ${ }^{-1} \mathrm{~s}^{-1}$ & Temp./K & Reference & Technique/Comments \\
\hline $\begin{array}{l}\text { Absolute Rate Coefficients } \\
(3.8 \pm 0.1) \times 10^{-11}(T / 300)^{-1.2}\end{array}$ & $289-380$ & Fittschen et al., 1999 & PLP-LIF (a) \\
\hline
\end{tabular}

\section{Comments}

(a) Measurements over the range 40-133 mbar of He. Results assumed to be in the high pressure range. The observed temperature dependence may be the result of falloff effects.

\section{Preferred Values}

$k_{\infty}=3.8 \times 10^{-11} \mathrm{~cm}^{3}$ molecule ${ }^{-1} \mathrm{~s}^{-1}$ at $298 \mathrm{~K}$.

Reliability

$\Delta \log k_{\infty}= \pm 0.3$ at $298 \mathrm{~K}$.

Comments on Preferred Values

The only available measurement from Fittschen et al. (1999) gives similar results as for $i-\mathrm{C}_{3} \mathrm{H}_{7} \mathrm{O}+\mathrm{NO}+\mathrm{M} \rightarrow i$ $\mathrm{C}_{3} \mathrm{H}_{7} \mathrm{ONO}+\mathrm{M}$. The apparent temperature dependence may be due to falloff effects (its origin needs to be clarified).

\section{References}

Fittschen, C., Frenzel, A., Imrik, K., and Devolder, P.: Int. J. Chem. Kinet., 31, 800, 1999. 
II.A5.113

$$
\begin{array}{ll}
i-\mathrm{C}_{3} \mathrm{H}_{7} \mathrm{O}+\mathrm{NO}+\mathrm{M} & \rightarrow i-\mathrm{C}_{3} \mathrm{H}_{7} \mathrm{ONO}+\mathrm{M} \\
i-\mathrm{C}_{3} \mathrm{H}_{7} \mathrm{O}+\mathrm{NO} & \rightarrow \mathrm{CH}_{3} \mathrm{C}(\mathrm{O}) \mathrm{CH}_{3}+\mathrm{HNO}
\end{array}
$$

$\Delta H^{\circ}(2)=-142.2 \mathrm{~kJ} \cdot \mathrm{mol}^{-1}$

\section{High-pressure rate coefficients}

\section{Rate coefficient data}

\begin{tabular}{lllc}
\hline$k_{\infty 1} / \mathrm{cm}^{3}$ molecule ${ }^{-1} \mathrm{~s}^{-1}$ & Temp./K & Reference & Technique/Comments \\
\hline Absolute Rate Coefficients & & & \\
$3.4 \times 10^{-11}$ & 298 & Balla et al., 1985 & PLP-LIF (a) \\
$(3.3 \pm 0.1) \times 10^{-11}(T / 300)^{-1.3}$ & $286-389$ & Fittschen et al., 1999 & PLP-LIF (b) \\
\hline
\end{tabular}

\section{Comments}

(a) No pressure dependence of the rate coefficient was observed over the range 1.3-6 mbar. The small negative temperature dependence $\left[k=1.2 \times 10^{-11} \exp (310 / T) \mathrm{cm}^{3}\right.$ molecule $\left.{ }^{-1} \mathrm{~s}^{-1}\right]$ observed over the range 298-383 K may be attributed to falloff effects.

(b) Measurements over the range 40-667 mbar of He. Results assumed to be in the high pressure range. The observed temperature dependence corresponding to $k_{\infty 1}=8.9 \times 10^{-12} \exp (397 / T)$ may be attributed to falloff effects.

\section{Preferred Values}

$k_{\infty 1}=3.4 \times 10^{-11} \mathrm{~cm}^{3}$ molecule ${ }^{-1} \mathrm{~s}^{-1}$ at $298 \mathrm{~K}$.

$k_{2}=6.5 \times 10^{-12} \mathrm{~cm}^{3}$ molecule $\mathrm{s}^{-1} \mathrm{~s}^{-1}$ at $298 \mathrm{~K}$ and $27-270$ mbar pressure.

\section{Reliability}

$\Delta \log k_{\infty 1}= \pm 0.3$ at $298 \mathrm{~K}$.

$\Delta \log k_{2}= \pm 0.5$ at $298 \mathrm{~K}$.

\section{Comments on Preferred Values}

The preferred value of $k_{\infty 1}$ is based on the studies of Balla et al. (1985) and Fittschen et al. (1999). The apparent temperature coefficient of $k_{\infty 1}$ differs from that of $k_{\infty 1}$ for $\mathrm{C}_{2} \mathrm{H}_{5} \mathrm{O}+\mathrm{NO}+\mathrm{M}$. It remains to be clarified whether falloff effects are responsible for the different behavior. The value of $k_{2}$ is obtained from the preferred $k_{\infty 1}$ and the rate coefficient ratio $k_{2} / k_{1}=0.19 \pm 0.03$ (independent of temperature) cited in Batt and Milne (1977).

\section{References}

Balla, R. J., Nelson, H. H., and McDonald, J. R.: Chem Phys., 99, 323, 1985.

Batt, L. and Milne, R. T.: Int. J. Chem. Kinet., 9, 141, 1977.

Fittschen, C., Frenzel, A., Imrik, K., and Devolder, P.: Int. J. Chem. Kinet., 31, 800, 1999. 
II.A5.114

$$
\left(\mathrm{CH}_{3}\right)_{3} \mathrm{CO}+\mathrm{NO}+\mathrm{M} \rightarrow\left(\mathrm{CH}_{3}\right)_{3} \mathrm{CONO}+\mathrm{M}
$$

\section{High-pressure rate coefficients}

\section{Rate coefficient data}

\begin{tabular}{llll}
\hline$k_{\infty} / \mathrm{cm}^{3}$ molecule & Temp./K & Reference & Technique/Comments \\
\hline Absolute Rate Coefficients & & & \\
$(4.17 \pm 0.12) \times 10^{-11}(T / 200)^{-1.27}$ & $200-390$ & Blitz et al., 1999 & LP-LIF (a) \\
$(2.74 \pm 0.5) \times 10^{-11}(T / 300)^{-1.52}$ & $223-304$ & Lotz and Zellner, 2000 & LP-LIF (b) \\
\hline
\end{tabular}

\section{Comments}

(a) Pulsed excimer laser photolysis of tert-butyl nitrite at $351 \mathrm{~nm}$ with and without added NO, using LIF detection of tertbutoxy and NO. Experiments in 92-658 mbar of He showed no pressure dependence of the rate coefficient.

(b) Pulsed excimer laser photolysis of di-tert-butyl peroxide with added NO using LIF of tert-butoxy. No pressure dependence detected over the range 6.6-105 mbar of $\mathrm{N}_{2}$.

\section{Preferred Values}

$k_{\infty}=2.6 \times 10^{-11}(T / 300)^{-1.4} \mathrm{~cm}^{3}$ molecule ${ }^{-1} \mathrm{~s}^{-1}$ over the temperature range $200-400 \mathrm{~K}$.

\section{Reliability}

$\Delta \log k_{\infty}= \pm 0.3$ at $298 \mathrm{~K}$.

$\Delta n= \pm 0.5$.

\section{Comments on Preferred Values}

The studies of Blitz et al. (1999) and Lotz and Zellner (2000) using different sources of tert-butoxy radicals are in good agreement. The preferred values present the average of the two results.

\section{References}

Blitz, M., Pilling, M. J., Robertson, S. H., and Seakins, P. W.: Phys. Chem. Chem. Phys., 1, 73, 999.

Lotz, Ch. and Zellner, R.: Phys. Chem. Chem. Phys., 2, 2353, 2000. 
II.A5.115

$$
2-\mathrm{C}_{4} \mathrm{H}_{9} \mathrm{O}+\mathrm{NO}+\mathrm{M} \rightarrow 2-\mathrm{C}_{4} \mathrm{H}_{9} \mathrm{ONO}+\mathrm{M}
$$

\section{High-pressure rate coefficients}

\section{Rate coefficient data}

\begin{tabular}{lllc}
\hline$k_{\infty} / \mathrm{cm}^{3}$ molecule & & \\
\hline $\begin{array}{l}\text { Absolute Rate Coefficients } \\
(2.48 \pm 0.5) \times 10^{-11}(T / 300)^{-1.2}\end{array}$ & Temp./K & Reference & Technique/Comments \\
\hline
\end{tabular}

\section{Comments}

(a) Measurements over the range 66-230 mbar of $\mathrm{N}_{2}$. Results assumed to be in the high pressure range. The observed temperature dependence may be the result of falloff effects.

\section{Preferred Values}

$k_{\infty}=2.5 \times 10^{-11} \mathrm{~cm}^{3}$ molecule $\mathrm{s}^{-1}$ at $298 \mathrm{~K}$.

Reliability

$\Delta \log k_{\infty}= \pm 0.5$ at $298 \mathrm{~K}$

Comments on Preferred Values

The only available measurement from Deng et al. (2000) gives similar results as for smaller alkoxy radicals reacting with NO. The apparent temperature coefficient may be due to falloff effects (its origin needs to be clarified).

\section{References}

Deng, W., Wang, C., Katz, D. R., Gawinski, G. G., Davis, A. J., and Dibble, T. S.: Chem. Phys. Lett., $330,541,2000$. 
II.A5.116

$$
\begin{array}{ll}
\mathrm{CH}_{3} \mathrm{O}+\mathrm{NO}_{2}+\mathrm{M} & \rightarrow \mathrm{CH}_{3} \mathrm{ONO}_{2}+\mathrm{M} \\
\mathrm{CH}_{3} \mathrm{O}+\mathrm{NO}_{2} & \rightarrow \mathrm{HCHO}+\mathrm{HONO}
\end{array}
$$

$\Delta H^{\circ}(1)=-171.5 \mathrm{~kJ} \cdot \mathrm{mol}^{-1}$

$\Delta H^{\circ}(2)=-238.5 \mathrm{~kJ} \cdot \mathrm{mol}^{-1}$

\section{Low-pressure rate coefficients}

\section{Rate coefficient data}

\begin{tabular}{lllc}
\hline$k_{01} / \mathrm{cm}^{3}$ molecule $^{-1} \mathrm{~s}^{-1}$ & Temp./K & Reference & Technique/Comments \\
\hline Absolute Rate Coefficients & & & \\
$2.6 \times 10^{-29}(T / 300)^{-4.5}[\mathrm{He}]$ & $220-473$ & McCaulley et al., 1985 & DF-LIF (a) \\
$(5.2 \pm 1.9) \times 10^{-29}[\mathrm{He}]$ & 298 & Frost and Smith, 1990 & PLP-LIF (b) \\
$(9.0 \pm 1.9) \times 10^{-29}[\mathrm{Ar}]$ & 298 & & \\
$(11 \pm 3) \times 10^{-29}\left[\mathrm{CF}_{4}\right]$ & 298 & & \\
$(4.9 \pm 1.2) \times 10^{-29}[\mathrm{Ar}]$ & 390 & & \\
$(5.3 \pm 0.2) \times 10^{-29}[\mathrm{He}]$ & 298 & Biggs et al., 1993 & DF-LIF (c) \\
$(5.3 \pm 0.3) \times 10^{-29}(\mathrm{~T} / 297)^{-4.4}[\mathrm{Ar}]$ & $233-356$ & Wollenhaupt and Crowley, 2000 & PLP-LIF (d) \\
$(3.93 \pm 0.05) \times 10^{-29}(\mathrm{~T} / 300)^{-1.74}[\mathrm{He}]$ & $250-390$ & Martínez et al., 2000 & PLP-LIF (e) \\
\hline
\end{tabular}

\section{Comments}

(a) $\mathrm{CH}_{3} \mathrm{O}$ radicals were produced by IR laser dissociation of $\mathrm{C}_{6} \mathrm{~F}_{5} \mathrm{OCH}_{3}$ to yield $\mathrm{CH}_{3}$, followed by $\mathrm{CH}_{3}+\mathrm{NO}_{2} \rightarrow \mathrm{CH}_{3} \mathrm{O}+\mathrm{NO}_{\text {. }}$ Pressure range $0.8 \mathrm{mbar}$ to $5 \mathrm{mbar}$. Direct measurements of the branching ratio $k_{1} / k_{2}$ were not possible. A separation was performed by assuming that Reaction (1) was in the low pressure limit. A value of $k_{2}=9.6 \times 10^{-12} \exp (-1150 / T) \mathrm{cm}^{3}$ molecule $\mathrm{s}^{-1}$ (with relatively large error limits) was estimated.

(b) Pulsed laser photolysis of $\mathrm{CH}_{3} \mathrm{ONO}-\mathrm{NO}$ mixtures at $266 \mathrm{~nm}$. Rate coefficients were measured over the pressure ranges $40 \mathrm{mbar}$ to $130 \mathrm{mbar}$ of $\mathrm{He}, 8 \mathrm{mbar}$ to $130 \mathrm{mbar}$ of $\mathrm{Ar}$, and $40 \mathrm{mbar}$ to $100 \mathrm{mbar}$ of $\mathrm{CF}_{4}$. Falloff curves were fitted to the experimental data using $F_{c}$ values of $0.41,0.44$, and 0.48 for $\mathrm{He}$, Ar, and $\mathrm{CF}_{4}$, respectively. The recombination Reaction (1) appears to dominate over Reaction (2).

(c) Pressures of He varied from 1.3 mbar to 13 mbar. Extrapolations were performed using $F_{c}=0.6$, an RRKM analysis was also done. A value $k_{01}=5.9 \times 10^{-29}[\mathrm{He}] \mathrm{cm}^{3}$ molecule ${ }^{-1} \mathrm{~s}^{-1}$ was obtained.

(d) Pulsed laser photolysis of $\mathrm{CH}_{3} \mathrm{ONO}$. Rate coefficients were measured over the range 13-263 mbar of Ar. Falloff curves represented with temperature-independent $F_{c}=0.6$, alternatively temperature-dependent $F_{c}$ between 0.66 at $223 \mathrm{~K}$ and 0.55 at $356 \mathrm{~K}$ was used. $k_{2} / k_{1} \approx 0.1$ at $13 \mathrm{mbar}$ and $356 \mathrm{~K}$, whereas $k_{2} / k_{1}<0.01$ was derived at $13 \mathrm{mbar}$ and $233 \mathrm{~K}$.

(e) Measurements over the pressure range 66-789 mbar. Falloff extrapolation with $F_{c}=0.6$.

\section{Preferred Values}

$k_{01}=8.1 \times 10^{-29}(T / 300)^{-4.5}\left[\mathrm{~N}_{2}\right] \mathrm{cm}^{3}$ molecule ${ }^{-1} \mathrm{~s}^{-1}$ over the temperature range $200-400 \mathrm{~K}$.

$k_{2}=9.6 \times 10^{-12} \exp (-1150 / T) \mathrm{cm}^{3}$ molecule ${ }^{-1} \mathrm{~s}^{-1}$ over the temperature range $200-400 \mathrm{~K}$.

\section{Reliability}

$\Delta \log k_{01}= \pm 0.3$ at $298 \mathrm{~K}$.

$\Delta n= \pm 1$.

$\Delta \log k_{2}= \pm 0.5$ at $298 \mathrm{~K}$. 


\section{Comments on Preferred Values}

The agreement between the studies of Frost and Smith (1990, 1993), Biggs et al. (1993), Wollenhaupt and Crowley (2000) and Martínez et al. (2000) appears satisfactory, in particular if the different ways of treating the falloff curve are taken into account. We assume similar values of $k_{01}$ for $\mathrm{M}=\mathrm{Ar}$ and $\mathrm{N}_{2}$. Falloff curves are constructed with $F_{c}=0.44$ at $300 \mathrm{~K}$ such as chosen in Frost and Smith $(1990,1993)$. The preferred value is average of the results from Frost and Smith $(1990,1993)$ and Wollenhaupt and Crowley (2000) after reevaluation of the data from Wollenhaupt and Crowley (2000) with $F_{c}=0.44$. Reaction (2) appears to play only a minor role at pressures above 10 mbar. The value of $k_{2}$ remains relatively uncertain.

\section{High-pressure rate coefficients}

\section{Rate coefficient data}

\begin{tabular}{lllc}
\hline$k_{\infty 1} / \mathrm{cm}^{3}$ molecule $\mathrm{s}^{-1}$ & Temp./K & Reference & Technique/Comments \\
\hline $\begin{array}{l}\text { Absolute Rate Coefficients } \\
(2.0 \pm 0.4) \times 10^{-11}\end{array}$ & 295 & Frost and Smith, 1990 & \\
$(1.86 \pm 0.05) \times 10^{-11}(T / 297)^{-1.87}$ & $233-356$ & Wollenhaupt and Crowley, 2000 & PLP-LIF (a) \\
$(2.40 \pm 0.02) \times 10^{-11}(T / 300)^{-0.88}$ & $250-390$ & Martínez et al., 2000 & PLP-LIF (b) \\
$(1.3 \pm 0.1) \times 10^{-11}$ & 300 & Kukui et al., 2000 & PLP-LIF (c) \\
& & & PLP-LIF (d) \\
Relative Rate Coefficients & 298 & Wiebe et al., 1973 & \\
$1.5 \times 10^{-11}$ & $392-420$ & Batt and Rattray, 1979 & (e) \\
$(1.0 \pm 0.5) \times 10^{-11}$ & 298 & Biggs et al., 1993 & (f) \\
$(1.4 \pm 0.1) \times 10^{-11}$ & & & DF-LIF (g) \\
& & & \\
Branching Ratios & 298 & Wiebe et al., 1973 & (e) \\
$k_{1} / k=0.92 \pm 0.08$ & $384-424$ & Batt and Rattray, 1979 & (f) \\
$k_{2} / k_{1} \leq 0.05$ & & & \\
\hline
\end{tabular}

\section{Comments}

(a) See comment (b) for $k_{0}$.

(b) See comment (d) for $k_{0}$.

(c) See comment (e) for $k_{0}$.

(d) Photolysis of $\mathrm{CH}_{3} \mathrm{SSCH}_{3}-\mathrm{NO}_{2}$ mixtures with LIF detection of $\mathrm{CH}_{3} \mathrm{O}$. Measurements over the range 16-805 mbar of He. The given value is for about 750 mbar. No falloff extrapolation.

(e) Steady-state photolysis of $\mathrm{CH}_{3} \mathrm{ONO}$ in the presence of $\mathrm{NO}-\mathrm{O}_{2}$ and $\mathrm{NO}-\mathrm{NO}_{2}-\mathrm{N}_{2}$ mixtures at 10 mbar to 500 mbar. Relative rate coefficients were derived from $\Phi\left(\mathrm{CH}_{3} \mathrm{ONO}_{2}\right)$, with $k\left(\mathrm{CH}_{3} \mathrm{O}+\mathrm{NO}\right) / k=1.3$ at $298 \mathrm{~K}$. This rate coefficient ratio is placed on an absolute basis by use of a rate coefficient of $k\left(\mathrm{CH}_{3} \mathrm{O}+\mathrm{NO} \rightarrow \mathrm{CH}_{3} \mathrm{ONO}\right)=2 \times 10^{-11} \mathrm{~cm}^{3}$ molecule ${ }^{-1} \mathrm{~s}^{-1}$ over the range $200 \mathrm{~K}$ to $400 \mathrm{~K}$.

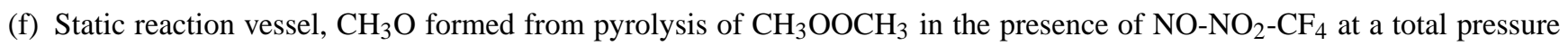
of 675 mbar. Relative rate coefficients were determined from end-product analysis of $\mathrm{CH}_{3} \mathrm{ONO}$ and $\mathrm{CH}_{3} \mathrm{ONO}_{2}$ by GC. $k\left(\mathrm{CH}_{3} \mathrm{O}+\mathrm{NO} \rightarrow \mathrm{CH}_{3} \mathrm{ONO}\right) / k=2.03 \pm 0.47$ was obtained over the range $392 \mathrm{~K}$ to $420 \mathrm{~K}$. This rate coefficient ratio is placed on an absolute basis by use of a rate coefficient of $k\left(\mathrm{CH}_{3} \mathrm{O}+\mathrm{NO} \rightarrow \mathrm{CH}_{3} \mathrm{ONO}\right)=2 \times 10^{-11} \mathrm{~cm}^{3}$ molecule $^{-1} \mathrm{~s}^{-1}$ over the range $200 \mathrm{~K}$ to $400 \mathrm{~K}$. $k_{1} / k_{2}$ was determined from pyrolysis of $\mathrm{CH}_{3} \mathrm{OOCH}_{3}$ in the presence of $\mathrm{NO}_{2}$ and $\mathrm{N}_{2}$ and shown to be pressure dependent.

(g) See comment (c) for $k_{0}$. An RRKM extrapolation leads to the value $k_{\infty}=2.1 \times 10^{-11} \mathrm{~cm}^{3}$ molecule $\mathrm{e}^{-1} \mathrm{~s}^{-1}$. 


\section{Preferred Values}

$k_{1}=1.5 \times 10^{-11} \mathrm{~cm}^{3}$ molecule ${ }^{-1} \mathrm{~s}^{-1}$ at $298 \mathrm{~K}$ and 1 bar of air.

$k_{\infty 1}=2.1 \times 10^{-11} \mathrm{~cm}^{3}$ molecule ${ }^{-1} \mathrm{~s}^{-1}$, independent of temperature over the range $200-400 \mathrm{~K}$.

\section{Reliability}

$\Delta \log k_{\infty}= \pm 0.3$ at $298 \mathrm{~K}$.

$\Delta n= \pm 0.5$

\section{Comments on Preferred Values}

The preferred $k_{\infty 1}$ value is based on Frost and Smith (1990, 1993), Wollenhaupt and Crowley (2000), Martínez et al. (2000) and Kukui et al. (2000). Falloff curves are constructed with $F_{c}=0.44$ from Frost and Smith (1990, 1993). Reaction (2) appears to be only of minor importance. Differences in the apparent temperature dependences of $k_{\infty}$ in part are due to different $F_{c}$-values used in the falloff extrapolations.

\section{References}

Batt, L. and Rattray, G. N.: Int. J. Chem. Kinet., 11, 1183, 1979.

Biggs, P., Canosa-Mas, C. E., Fracheboud, J.-M., Parr, A. D., Shallcross, D. E., Wayne, R. P., and Caralp, F.: J. Chem. Soc. Faraday Trans., 89, 4163, 1993.

Frost, M. J. and Smith, I. W. M.: J. Chem. Soc. Faraday Trans., 86, 1751, 1990; J. Chem. Soc. Faraday Trans., 89, 4251, 1993, (corrigendum).

Kukui, A., Bossoutrot, V., Laverdet, G., and Le Bras, G.: J. Phys. Chem. A, 104, 935, 2000.

Martínez, E., Albaladejo, J., Jiménez, E., Notario, A., and Díaz de Mera, Y.: Chem. Phys. Lett., 329, 191, 2000.

McCaulley, J. A., Anderson, S. M., Jeffries, J. B., and Kaufman, F.: Chem. Phys. Lett., 115, 180, 1985.

Wiebe, H. A., Villa, A., Hellman, T. M., and Heicklen, J.: J. Am. Chem. Soc., 95, 7, 1973.

Wollenhaupt, M. and Crowley, J. N.: J. Phys. Chem. A, 104, 6429, 2000. 
II.A5.117

$$
\begin{array}{ll}
\mathrm{C}_{2} \mathrm{H}_{5} \mathrm{O}+\mathrm{NO}_{2}+\mathrm{M} & \rightarrow \mathrm{C}_{2} \mathrm{H}_{5} \mathrm{ONO}_{2}+\mathrm{M} \\
\mathrm{C}_{2} \mathrm{H}_{5} \mathrm{O}+\mathrm{NO}_{2} & \rightarrow \mathrm{CH}_{3} \mathrm{CHO}+\mathrm{HONO}
\end{array}
$$

$\Delta H^{\circ}(1)=-171.7 \mathrm{~kJ} \cdot \mathrm{mol}^{-1}$

$\Delta H^{\circ}(2)=-263.2 \mathrm{~kJ} \cdot \mathrm{mol}^{-1}$

\section{High-pressure rate coefficients}

\begin{tabular}{|c|c|c|c|}
\hline$k_{\infty 1} / \mathrm{cm}^{3}$ molecule $^{-1} \mathrm{~s}^{-1}$ & Temp./K & Reference & Technique/Comments \\
\hline $\begin{array}{l}\text { Absolute Rate Coefficients } \\
(2.8 \pm 0.3) \times 10^{-11}\end{array}$ & 295 & Frost and Smith, 1990 & PLP-LIF (a) \\
\hline
\end{tabular}

\section{Rate coefficient data}

\section{Comments}

(a) The same rate coefficients were measured in the presence of 2 mbar or $130 \mathrm{mbar}$ of He.

\section{Preferred Values}

$k_{\infty 1}=2.8 \times 10^{-11} \mathrm{~cm}^{3}$ molecule ${ }^{-1} \mathrm{~s}^{-1}$, independent of temperature over the range 200-300 K.

\section{Reliability}

$\Delta \log k_{\infty 1}= \pm 0.3$ at $298 \mathrm{~K}$.

$\Delta n= \pm 0.5$

\section{Comments on Preferred Values}

The value of $k_{\infty 1}$ is based on the data of Frost and Smith (1990), being consistent with values for related reactions such as $\mathrm{RO}+\mathrm{NO}+\mathrm{M} \rightarrow \mathrm{RONO}+\mathrm{M}$ (with $\mathrm{M}=\mathrm{CH}_{3}, \mathrm{C}_{2} \mathrm{H}_{5}$, and $i-\mathrm{C}_{3} \mathrm{H}_{7}$ ) or $\mathrm{CH}_{3} \mathrm{O}+\mathrm{NO}_{2}+\mathrm{M} \rightarrow \mathrm{CH}_{3} \mathrm{ONO}_{2}+\mathrm{M}$. Reaction (2) appears to be of minor importance, with a rate coefficient ratio of $k_{2} / k_{1}=0.1 \pm 0.01$ at $\sim 450 \mathrm{~K}$ being cited by Batt (1987).

\section{References}

Batt, L.: Int. Rev. Phys. Chem., 6, 53, 1987.

Frost, M. J. and Smith, I. W. M.: J. Chem. Soc. Faraday Trans., 86, 1751, 1990. 
II.A5.118

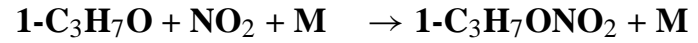

$$
\begin{aligned}
& 1-\mathrm{C}_{3} \mathrm{H}_{7} \mathrm{O}+\mathrm{NO}_{2} \rightarrow \mathrm{CH}_{3} \mathrm{CH}_{2} \mathrm{CHO}+\mathrm{HONO}
\end{aligned}
$$

$\Delta H^{\circ}(1)=-165.9 \mathrm{~kJ} \cdot \mathrm{mol}^{-1}$

$\Delta H^{\circ}(2)=-258.7 \mathrm{~kJ} \cdot \mathrm{mol}^{-1}$

\section{High-pressure rate coefficients}

\section{Rate coefficient data}

\begin{tabular}{|c|c|c|c|}
\hline$k_{\infty 1} / \mathrm{cm}^{3}$ molecule $^{-1} \mathrm{~s}^{-1}$ & Temp./K & Reference & Technique/Comments \\
\hline $\begin{array}{l}\text { Absolute Rate Coefficients } \\
(3.6 \pm 0.4) \times 10^{-11}\end{array}$ & 296 & Mund et al., 1998 & PLP-LIF (a) \\
\hline
\end{tabular}

\section{Comments}

(a) The rate coefficient was observed to be independent of total pressure over the range 6.7 mbar to 53 mbar of He.

\section{Preferred Values}

$k_{\infty 1}=3.6 \times 10^{-11} \mathrm{~cm}^{3}$ molecule $\mathrm{s}^{-1} \mathrm{~s}^{-1}$ at $298 \mathrm{~K}$.

\section{Reliability}

$\Delta \log k_{\infty 1}= \pm 0.3$ at $298 \mathrm{~K}$.

\section{Comments on Preferred Values}

The preferred value is based on the sole study of Mund et al. (1998) with expanded uncertainty limits. The rate coefficient is of a similar magnitude to other $\mathrm{RO}+\mathrm{NO}_{2}$ reactions (see data sheets in this evaluation for $\mathrm{CH}_{3} \mathrm{O}+\mathrm{NO}_{2}, \mathrm{C}_{2} \mathrm{H}_{5} \mathrm{O}+\mathrm{NO}_{2}$ and 2- $\mathrm{C}_{3} \mathrm{H}_{7} \mathrm{O}+\mathrm{NO}_{2}$ ).

Although no statement on the branching ratio $k_{1} / k_{2}$ may be made on the basis of this work, it is expected that $k_{1} / k_{2}>0.2$.

\section{References}

Mund, C., Fockenberg, Ch., and Zellner, R.: Ber. Bunsenges. Phys. Chem., 102, 709, 1998. 
II.A5.119

$$
\begin{aligned}
& 2-\mathrm{C}_{3} \mathrm{H}_{7} \mathrm{O}+\mathrm{NO}_{2}+\mathrm{M} \rightarrow \mathbf{2}-\mathrm{C}_{3} \mathrm{H}_{7} \mathrm{ONO}_{2}+\mathrm{M} \\
& 2-\mathrm{C}_{3} \mathrm{H}_{7} \mathrm{O}+\mathrm{NO}_{2} \rightarrow \mathrm{CH}_{3} \mathrm{C}(\mathrm{O}) \mathrm{CH}_{3}+\mathrm{HONO}
\end{aligned}
$$

$\Delta H^{\circ}(1)=-171.7 \mathrm{~kJ} \cdot \mathrm{mol}^{-1}$

$\Delta H^{\circ}(2)=-277.6 \mathrm{~kJ} \cdot \mathrm{mol}^{-1}$

\section{High-pressure rate coefficients}

\section{Rate coefficient data}

\begin{tabular}{llll}
\hline$k_{\infty 1} / \mathrm{cm}^{3}$ molecule ${ }^{-1} \mathrm{~s}^{-1}$ & Temp./K & Reference & Technique/Comments \\
\hline Absolute Rate Coefficients & & & \\
$3.5 \times 10^{-11}$ & 298 & Balla et al., 1985 & PLP-LIF (a) \\
$(3.3 \pm 0.3) \times 10^{-11}$ & 296 & Mund et al., 1998 & PLP-LIF (b) \\
\hline
\end{tabular}

\section{Comments}

(a) By extrapolation to zero laser power, a rate coefficient of $k_{\infty 1}=1.5 \times 10^{-11} \exp [(250 \pm 200) / T] \mathrm{cm}^{3} \mathrm{molecule}^{-1} \mathrm{~s}^{-1}$ was derived from measurements over the temperature range $295 \mathrm{~K}$ to $384 \mathrm{~K}$. No pressure dependence was observed between $1.3 \mathrm{mbar}$ and 13 mbar.

(b) The measured rate coefficient was observed to be independent of total pressure over the range 6.7 mbar to 106 mbar of He.

\section{Preferred Values}

$k_{\infty 1}=3.4 \times 10^{-11} \mathrm{~cm}^{3}$ molecule ${ }^{-1} \mathrm{~s}^{-1}$, independent of temperature over the range 200-300 K.

\section{Reliability}

$\Delta \log k_{\infty 1}= \pm 0.2$ at $298 \mathrm{~K}$.

\section{Comments on Preferred Values}

The recommendation is based on the data of Balla et al. (1985) and Mund et al. (1998). The value of $k_{\infty 1}$ is consistent with other related reactions such as $\mathrm{RO}+\mathrm{NO}+\mathrm{M} \rightarrow \mathrm{RONO}+\mathrm{M}$ and $\mathrm{RO}+\mathrm{NO}_{2}+\mathrm{M} \rightarrow \mathrm{RONO}_{2}+\mathrm{M}$ (with $\mathrm{R}=\mathrm{CH}_{3}, \mathrm{C}_{2} \mathrm{H}_{5}, i-\mathrm{C}_{3} \mathrm{H}_{7}$, see this evaluation). It is estimated that $k_{2} / k_{\infty 1}<0.2$. Batt (1987) cites a rate coefficient ratio of $k_{2} / k_{1}=0.027 \pm 0.006$ at $\sim 450 \mathrm{~K}$, indicating that reaction (2) is of negligible importance under atmospheric conditions.

\section{References}

Balla, R. J., Nelson, H. H., and McDonald, J. R.: Chem. Phys., 99, 323, 1985.

Mund, Ch., Fockenberg, Ch., and Zellner, R.: Ber. Bunsenges. Phys. Chem., 102, 709, 1998.

Batt, L.: Int. Rev. Phys. Chem., 6, 53, 1987. 


\section{Appendix A6: $\mathrm{RO}_{2}$ reactions}

\section{II.A6.120}

$$
\mathrm{CH}_{3} \mathrm{O}_{2}+\mathrm{NO} \rightarrow \mathrm{CH}_{3} \mathrm{O}+\mathrm{NO}_{2}
$$

$\Delta H^{\circ}=-48.8 \mathrm{~kJ} \cdot \mathrm{mol}^{-1}$

\section{Rate coefficient data}

\begin{tabular}{lllc}
\hline$k / \mathrm{cm}^{3}$ molecule $\mathrm{s}^{-1}$ & Temp./K & Reference & Technique/Comments \\
\hline Absolute Rate Coefficients & & & \\
$(8.0 \pm 2.0) \times 10^{-12}$ & 295 & Plumb et al., 1979 & DF-MS (a) \\
$(3.0 \pm 1.7) \times 10^{-12}$ & 298 & Adachi and Basco, 1979 & FP-AS \\
$(7.1 \pm 1.4) \times 10^{-12}$ & 298 & Sander and Watson, 1980 & FP-AS (b) \\
$(6.5 \pm 2.0) \times 10^{-12}$ & 298 & Cox and Tyndall, 1979, 1980 & MMS-AS (c) \\
$(8.1 \pm 1.6) \times 10^{-12}$ & $240-339$ & Ravishankara et al., 1981 & PLP-LIF (d) \\
$2.1 \times 10^{-12} \exp [(380 \pm 250) / T]$ & $218-365$ & Simonaitis and Heicklen, 1981 & FP-AS (e) \\
$(7.7 \pm 0.9) \times 10^{-12}$ & 298 & & DF-MS (f) \\
$(8.6 \pm 2.0) \times 10^{-12}$ & 295 & Plumb et al., 1981 & PLP-AS (g) \\
$(7 \pm 2) \times 10^{-12}$ & 298 & Zellner et al., 1986 & PR-UV (h) \\
$(8.8 \pm 1.4) \times 10^{-12}$ & 295 & Sehested et al., 1993 & PLP-MS (i) \\
$(11.2 \pm 1.4) \times 10^{-12}$ & 298 & Masaki et al., 1994 & F-CIMS (j) \\
$2.8 \times 10^{-12} \exp [(285 \pm 60) / T]$ & $199-429$ & Villalta et al., 1995 & DF-MS (k) \\
$(7.5 \pm 1.3) \times 10^{-12}$ & 298 & & F-CIMS (l) \\
$(7.5 \pm 1.0) \times 10^{-12}$ & 298 & Helleis et al., 1996 & \\
$9.2 \times 10^{-13} \exp [(600 \pm 140) / T]$ & $203-295$ & Scholtens et al., 1999 & F-CIMS (m) \\
$(7.8 \pm 2.2) \times 10^{-12}$ & 298 & & LP-MS (n) \\
$1.75 \times 10^{-12} \operatorname{exp[(435\pm 35)/T]}$ & $193-300$ & Bacak et al., 2004 & \\
$(7.42 \pm 0.27) \times 10^{-12}$ & 298 & & \\
$(9.9 \pm 2.1) \times 10^{-12}$ & 298 & Xing et al., 2004 &
\end{tabular}

\section{Comments}

(a) Flow tube at $11 \pm 2.6$ mbar He. Direct detection of $\mathrm{CH}_{3} \mathrm{O}_{2}$ (generated in $\mathrm{O}_{+} \mathrm{C}_{2} \mathrm{H}_{4}+\mathrm{O}_{2}$ ) via electron impact mass spectrometry.

(b) Data obtained at 100, 467 and 933 mbar $\mathrm{He}$, and 933 mbar $\mathrm{N}_{2} \cdot \mathrm{CH}_{3} \mathrm{O}_{2}$ formed by $\mathrm{Cl}+\mathrm{CH}_{4}+\mathrm{O}_{2}$.

(c) Data obtained at 720 mbar $\mathrm{N}_{2}+\mathrm{O}_{2} \cdot \mathrm{CH}_{3} \mathrm{O}_{2}$ formed by $\mathrm{Cl}+\mathrm{CH}_{4}+\mathrm{O}_{2}$.

(d) $\mathrm{CH}_{3} \mathrm{O}_{2}$ generated by photolysis of $\mathrm{CH}_{3} \mathrm{~N}_{2} \mathrm{CH}_{3}$ in presence of $\mathrm{O}_{2}$. Rate data obtained via LIF detection of $\mathrm{NO}_{2}$.

(e) Pressures of 93 to $800 \mathrm{mbar}^{\mathrm{CH}_{4}} \cdot \mathrm{CH}_{3} \mathrm{O}_{2}$ formed by $\mathrm{Cl}+\mathrm{CH}_{4}+\mathrm{O}_{2}$.

(f) Flow tube at 7.7 mbar $\mathrm{He}$, direct detection of $\mathrm{CH}_{3} \mathrm{O}_{2}$ (generated in $\mathrm{Cl}+\mathrm{CH}_{4}+\mathrm{O}_{2}$ ) via electron impact mass spectrometry.

(g) Experiments conducted at 13.3 mbar He or $\mathrm{N}_{2} \cdot \mathrm{CH}_{3} \mathrm{O}_{2}$ generated by photolysisof $\mathrm{CH}_{3} \mathrm{~N}_{2} \mathrm{CH}_{3}$ in presence of $\mathrm{O}_{2}$. Rate data obtained by measuring $\mathrm{CH}_{3} \mathrm{O}_{2}$ by absorption spectroscopy, LIF used to observe formation of $\mathrm{CH}_{3} \mathrm{O}$.

(h) Experiments conducted in 1013 mbar $\mathrm{SF}_{6}$ and $\mathrm{O}_{2} \cdot \mathrm{CH}_{3} \mathrm{O}_{2}$ generated in $\mathrm{F}+\mathrm{CH}_{4}\left(+\mathrm{O}_{2}\right)$ and $\mathrm{NO}_{2}$ formation monitored to derive kinetic information.

(i) Experiments conducted in 4-8 mbar $\mathrm{N}_{2}+\mathrm{O}_{2}$. Mass spectrometry using photo-ionisation detection of $\mathrm{CH}_{3} \mathrm{O}_{2}$, which was formed in the $193 \mathrm{~nm}$ photo-dissociation of acetone in the presence of $\mathrm{O}_{2}$. 
(j) Experiments conducted in 2.7-7.3 mbar He. $\mathrm{CH}_{3} \mathrm{O}_{2}$ generated by thermal decomposition of $\mathrm{CH}_{3} \mathrm{CH}_{2} \mathrm{ONO}$ in the presence of $\mathrm{O}_{2}$. Mass spectrometry using chemi-ionisation detection of $\mathrm{CH}_{3}^{+}$generated in $\mathrm{O}_{2}^{+}+\mathrm{CH}_{3} \mathrm{O}_{2}$.

(k) Experiments conducted in 2.3 mbar $\mathrm{He}, \mathrm{CH}_{3} \mathrm{O}_{2}$ generated in $\mathrm{F}+\mathrm{CH}_{4}\left(+\mathrm{O}_{2}\right)$. Electron impact detection of $\mathrm{CH}_{3} \mathrm{O}_{2}$ in excess NO. Measurements using deuterated methyl peroxy gave $k\left(\mathrm{CD}_{3} \mathrm{O}_{2}+\mathrm{NO}\right)=(8.6 \pm 1.0) \times 10^{-12} \mathrm{~cm}^{3} \mathrm{molecule}^{-1} \mathrm{~s}^{-1}$ at $298 \mathrm{~K}$.

(1) Turbulent flow reactor at 133 mbar $\mathrm{N}_{2}$ total pressure. $\mathrm{CH}_{3} \mathrm{O}_{2}$ generated in $\mathrm{F}+\mathrm{CH}_{4}\left(+\mathrm{O}_{2}\right)$ and detected as $\mathrm{CH}_{3} \mathrm{OOH}^{+}\left(\mathrm{H}_{2} \mathrm{O}\right)_{n}$ following proton transfer from $\mathrm{H}_{3} \mathrm{O}^{+}$.

(m) Turbulent flow reactor at 133 mbar or 266 mbar $\mathrm{N}_{2}$ total pressure. $\mathrm{CH}_{3} \mathrm{O}_{2}$ generated in $\mathrm{F}_{+} \mathrm{CH}_{4}\left(+\mathrm{O}_{2}\right)$ and detected as $\mathrm{FO}_{2}^{-}$following reaction with $\mathrm{SF}_{6}^{-}$. Yield of $\mathrm{NO}_{2}$ was found to be $1.0 \pm 0.1$ at $298 \mathrm{~K}$.

(n) $\mathrm{CH}_{3} \mathrm{O}_{2}$ generated by reaction of $\mathrm{CH}_{3}$ with $\mathrm{O}_{2}$, whereby $\mathrm{CH}_{3}$ radicals were generated in the $193 \mathrm{~mm}$ photolysis of $\mathrm{CH}_{3} \mathrm{C}(\mathrm{O}) \mathrm{CH}_{3}$, or the $248 \mathrm{~nm}$ photolysis of $\mathrm{CH}_{3} \mathrm{I}$. The data obtained using $\mathrm{CH}_{3} \mathrm{I}$ are reported to be more reliable. $\mathrm{CH}_{3} \mathrm{O}_{2}$ was detected as the negative parent ion following electron transfer from high Rydberg state rare gas atoms. The total pressure was 5.3 mbar of the diluent containing 2.7 mbar $\mathrm{O}_{2}$.

\section{Preferred Values}

$k=7.7 \times 10^{-12} \mathrm{~cm}^{3}$ molecule ${ }^{-1} \mathrm{~s}^{-1}$ at $298 \mathrm{~K}$.

$k=2.3 \times 10^{-12} \exp (360 / T) \mathrm{cm}^{3}$ molecule $\mathrm{e}^{-1} \mathrm{~s}^{-1}$ over the temperature range $200-430 \mathrm{~K}$.

\section{Reliability}

$\Delta \log k= \pm 0.05$ at $298 \mathrm{~K}$.

$\Delta(E / R)= \pm 100 \mathrm{~K}$.

\section{Comments on Preferred Values}

This reaction has been subject of intensive investigation using several different experimental techniques. With the exception of the data of Adachi and Basco (1979), Masaki et al. (1994) and Xing et al. (2004), the remaining datasets at room temperature are in good agreement. The recommended value of the rate coefficient at $298 \mathrm{~K}$ is the average of the results from Scholtens et al. (1999), Helleis et al. (1996), Villalta et al. (1995), Ravishankara et al. (1981) and Bacak et al. (2004). The temperature dependence of the rate coefficient is described by four sets of data which are in good agreement at temperatures above $230 \mathrm{~K}$. At lower temperatures there is some deviation, with the datasets of Scholtens et al. (1999) and Simonaitis and Heicklen (1981) deviating from Arrhenius behaviour. These data sets were obtained at higher pressures than that of Villalta et al. (1995) and the possibility of a pressure dependence in the rate coefficient at low temperatures has been discussed (Scholtens et al., 1999). The latest data on this reaction (Bacak et al., 2004) do not, however, support this.

The datasets of Villalta et al. (1995) and Bacak et al., (2004) which cover the largest temperature range, provide the basis of the recommended temperature dependence, which has been adjusted for the average $298 \mathrm{~K}$ rate coefficient.

The formation of $\mathrm{CH}_{3} \mathrm{O}$ and $\mathrm{NO}_{2}$ products has been confirmed (Ravishankara et al., 1981; Zellner et al., 1986; Bacak et al, 2004), whereas the alternative reaction channel of the peroxy + NO reaction leading to the formation of alkyl nitrate has never been observed for $\mathrm{CH}_{3} \mathrm{O}_{2}$ and accounts for $<1 \%$ of the overall reaction at room temperature and below. This is consistent with an upper limit of $0.3 \%$ for formation of $\mathrm{CH}_{3} \mathrm{ONO}$ at $295 \mathrm{~K}$ and $100 \mathrm{Torr}_{2}$ (Scholtens et al., 1999).

\section{References}

Adachi, H. and Basco, N.: Chem. Phys. Lett., 63, 490, 1979.

Bacak, A., Bardwell, M. W., Raventos, M. T., Percival, C. J., Sanchez-Reyna, G. and Shallcross, D. E.: J. Phys. Chem. A 108, 10681, 2004.

Cox, R. A. and Tyndall, G. S.: J. Chem. Soc. Faraday Trans., 2, 76, 153, 1980.

Helleis, F., Moortgat, G. K., and Crowley, J. N.: J. Phys. Chem., 100, 17 846, 1996.

Masaki, A., Tsunashima, S., and Washida, N.: Chem. Phys. Lett., 218, 523, 1994.

Plumb, I. C., Ryan, K. R., Steven, J. R., and Mulcahy, M. F. R.: Chem. Phys. Lett., 63, 255, 1979.

Plumb, I. C., Ryan, K. R., Steven, J. R., and Mulcahy, M. F. R.: J. Phys. Chem., 85, 3136, 1981. 
Ravishankara, A. R., Eisele, F. L., Kreutter, N. M., and Wine, P. H.: J. Chem. Phys., 74, 2267, 1981.

Sander, S. P. and Watson, R. T.: J. Phys. Chem., 84, 1664, 1980.

Scholtens, K. W., Messer, B. M., Cappa, C. D., and Elrod, M. J.: J. Phys. Chem., 103, 4378, 1999.

Sehested, J., Nielsen, O. J., and Wallington, T. J.: Chem. Phys. Lett., 213, 457, 1993.

Simonaitis, R. and Heicklen, J.: J. Phys. Chem., 85, 2946, 1981.

Villalta, P. W., Huey, L. G., and Howard, C. J.: J. Phys. Chem., 99, 12 829, 1995.

Xing, J.-H., Nagai, Y., Kusuhara, M. and Miyoshi, A.: J. Phys. Chem. A 108, 10458, 2004.

Zellner, R., Fritz, B., and Lorenz, K.: J. Atmos. Chem., 4, 241, 1986. 
II.A6.121

$$
\begin{array}{lll}
\mathrm{C}_{2} \mathrm{H}_{5} \mathrm{O}_{2}+\mathrm{NO} & \rightarrow \mathrm{C}_{2} \mathrm{H}_{5} \mathrm{O}+\mathrm{NO}_{2} \\
\mathrm{C}_{2} \mathrm{H}_{5} \mathrm{O}_{2}+\mathrm{NO}+\mathrm{M} & \rightarrow \mathrm{C}_{2} \mathrm{H}_{5} \mathrm{ONO}_{2}+\mathrm{M}
\end{array}
$$

$\Delta H^{\circ}(1)=-45.2 \mathrm{~kJ} \cdot \mathrm{mol}^{-1}$

$\Delta H^{\circ}(2)=-217.0 \mathrm{~kJ} \cdot \mathrm{mol}^{-1}$

Rate coefficient data $\left(k=k_{1}+k_{2}\right)$

\begin{tabular}{lllc}
\hline$k / \mathrm{cm}^{3}$ molecule ${ }^{-1} \mathrm{~s}^{-1}$ & Temp./K & Reference & Technique/Comments \\
\hline $\begin{array}{l}\text { Absolute Rate Coefficients } \\
(2.7 \pm 0.2) \times 10^{-12}\end{array}$ & 298 & Adachi and Basco, 1979 & FP-AS \\
$(8.9 \pm 3.0) \times 10^{-12}$ & 295 & Plumb et al., 1982 & DF-MS \\
$(8.5 \pm 1.2) \times 10^{-12}$ & 298 & Sehested et al., 1993 & PR-AS \\
$(8.2 \pm 1.6) \times 10^{-12}$ & 295 & Däele et al., 1995 & DF-MS (a) \\
$2.6 \times 10^{-12} \exp [(380 \pm 70) / T]$ & $207-403$ & Eberhard and Howard, 1996 & F-CIMS (b) \\
$(9.3 \pm 1.6) \times 10^{-12}$ & 298 & & \\
$3.1 \times 10^{-12} \exp [(330 \pm 110) / T]$ & $220-355$ & Maricq and Szente, 1996 & PLP-AS (c) \\
$(10.0 \pm 1.5) \times 10^{-12}$ & 295 & & \\
$3.8 \times 10^{-12} \exp [(290 \pm 110) / T]$ & $213-299$ & Ranschaert et al., 2000 & F-CIMS (d) \\
$(10.1 \pm 0.9) \times 10^{-12}$ & 299 & & \\
& & & \\
Branching Ratio & & & \\
$k_{2} / k \leq 0.014(1 \mathrm{bar})$ & 299 & Atkinson et al., 1982 & $(\mathrm{e})$ \\
$k_{2} / k=1.2 \times 10^{-3} \exp (610 / T)$ & $213-298$ & Ranschaert et al., 2000 & $(\mathrm{f})$ \\
$k_{2} / k=0.006\left(133 \mathrm{mbar} \mathrm{N}_{2}\right)$ & 298 & & \\
$k_{2} / k=0.02\left(133 \mathrm{mbar} \mathrm{N}_{2}\right)$ & 213 & & \\
\hline
\end{tabular}

\section{Comments}

(a) Conventional discharge flow system with LIF detection of $\mathrm{C}_{2} \mathrm{H}_{5} \mathrm{O}$ product. $k$ determined by simulation of experimental $\mathrm{C}_{2} \mathrm{H}_{5} \mathrm{O}$ profiles.

(b) Ethylperoxy radicals formed by the thermal decomposition of $n$-propyl nitrite in the presence of $\mathrm{O}_{2}$, or by RF discharge through $\mathrm{C}_{2} \mathrm{H}_{5} \mathrm{I}$ (also in the presence of $\mathrm{O}_{2}$ ). Pseudo first order kinetics with excess $\mathrm{NO}$ and CIMS detection of $\mathrm{C}_{2} \mathrm{H}_{5} \mathrm{O}_{2}$ as the ethyl peroxy negative ion.

(c) Excimer laser photolysis of $\mathrm{Cl}_{2}-\mathrm{C}_{2} \mathrm{H}_{6}-\mathrm{NO}-\mathrm{O}_{2}-\mathrm{N}_{2}$ mixtures. Time-resolved measurements of $\mathrm{C}_{2} \mathrm{H}_{5} \mathrm{O}_{2}$ decay and $\mathrm{C}_{2} \mathrm{H}_{5} \mathrm{ONO}$ formation using diode array $\mathrm{UV}$ absorption spectroscopy, and of $\mathrm{NO}$ loss and $\mathrm{NO}_{2}$ formation using diode laser absorption spectroscopy.

(d) Turbulent flow reactor at 100 Torr $\left(133\right.$ mbar) $\mathrm{N}_{2}$ total pressure. $\mathrm{C}_{2} \mathrm{H}_{5} \mathrm{O}_{2}$ detected as $\mathrm{C}_{2} \mathrm{H}_{5} \mathrm{OOH}^{+}\left(\mathrm{H}_{2} \mathrm{O}\right)_{n}$ and $\mathrm{C}_{2} \mathrm{H}_{5} \mathrm{ONO}_{2}$ detected as $\mathrm{C}_{2} \mathrm{H}_{5} \mathrm{ONO}_{2} \mathrm{H}^{+}\left(\mathrm{H}_{2} \mathrm{O}\right)_{n}$ following proton transfer from $\mathrm{H}_{3} \mathrm{O}^{+}$.

(e) $\mathrm{GC}$ analysis of $\mathrm{C}_{2} \mathrm{H}_{5} \mathrm{ONO}_{2}$ product from photo-oxidation of $\mathrm{C}_{2} \mathrm{H}_{6}$ in $\mathrm{Cl}_{2}-\mathrm{C}_{2} \mathrm{H}_{6}$-NO-air mixtures.

(f) Ranschaert et al. (2000) also present temperature dependent values of the rate coefficient $k_{2}=1.6 \times 10^{-15} \exp (1160 / T)$ for the temperature range 213 to $299 \mathrm{~K}$ and $100 \mathrm{Torr}(133 \mathrm{mbar}) \mathrm{N}_{2}$ pressure. The authors state that the branching ratios are associated with large errors as the measurements were conducted near the detection limit for $\mathrm{C}_{2} \mathrm{H}_{5} \mathrm{ONO}_{2}$ and were complicated by secondary chemistry. 


\section{Preferred Values}

$k=9.2 \times 10^{-12} \mathrm{~cm}^{3}$ molecule ${ }^{-1} \mathrm{~s}^{-1}$ at $298 \mathrm{~K}$.

$k=2.6 \times 10^{-12} \exp (380 / T) \mathrm{cm}^{3}$ molecule ${ }^{-1} \mathrm{~s}^{-1}$ over the temperature range $200-410 \mathrm{~K}$.

$k_{2} / k \leq 0.014$ at $298 \mathrm{~K}$ and 1 bar pressure.

\section{Reliability}

$\Delta \log k= \pm 0.1$ at $298 \mathrm{~K}$.

$\Delta(E / R)= \pm 50 \mathrm{~K}$.

\section{Comments on Preferred Values}

With the exception of the measurement of Adachi and Basco (1979), all measurements at room temperature are in excellent agreement. The preferred value of the rate coefficient at room temperature is an average of the data from Plumb et al. (1982), Sehested et al. (1993), Däele et al. (1995), Eberhard and Howard (1996), Maricq and Szente (1996) and Ranschaert et al. (2000). The temperature coefficients $(E / R)$ from the three temperature dependent studies (Eberhard and Howard, 1996; Maricq and Szente, 1996; Ranschaert et al., 2000) also show good agreement. The preferred value was obtained from a weighted fit (using the authors estimated errors) to the data of all three studies, and reflects the higher precision of the Eberhard and Howard (1996) dataset. The two sets of data (Ranschaert et al., 2000; Atkinson et al., 1982) for the branching ratio for $\mathrm{C}_{2} \mathrm{H}_{5} \mathrm{ONO}_{2}$ formation are self consistent at the common temperature of $298 \mathrm{~K}$, and show that this channel is minor under atmospheric conditions.

\section{References}

Adachi, H. and Basco, N.: Chem. Phys. Lett., 64, 431, 1979.

Atkinson, R., Aschmann, S. M., Carter, W. P. L., Winer, A. M., and Pitts Jr., J. N.: J. Phys. Chem., 86, 4563, 1982.

Däele, V., Ray, A., Vassalli, I., Poulet, G., and Le Bras, G.: Int. J. Chem. Kinet., 27, 1121, 1995.

Eberhard, J. and Howard, C. J.: Int. J. Chem. Kinet., 28, 731, 1996.

Maricq, M. M. and Szente, J. J.: J. Phys. Chem. 100, 12 374, 1996.

Plumb, I. C., Ryan, K. R., Steven, J. R., and Mulcahy, M. F. R.: Int. J. Chem. Kinet., 14, 183, 1982.

Ranschaert, D. L., Schneider, N. J., and Elrod, M. J.: J. Phys. Chem. A, 104, 5758, 2000.

Sehested, J., Nielsen, O. J., and Wallington, T. J.: Chem. Phys. Lett., 213, 457, 1993. 
II.A6.122

$\mathrm{HOCH}_{2} \mathrm{CH}_{2} \mathrm{O}_{2}+\mathrm{NO} \rightarrow \mathrm{HOCH}_{2} \mathrm{CH}_{2} \mathrm{O}+\mathrm{NO}_{2}$

Rate coefficient data

\begin{tabular}{|c|c|c|c|}
\hline$k / \mathrm{cm}^{3}$ molecule $^{-1} \mathrm{~s}^{-1}$ & Temp./K & Reference & Technique/Comments \\
\hline $\begin{array}{l}\text { Absolute Rate Coefficients } \\
(9 \pm 4) \times 10^{-12}\end{array}$ & 298 & Becker et al., 1991 & PLP-LIF (a) \\
\hline
\end{tabular}

\section{Comments}

(a) Pulsed laser photolysis of $\mathrm{H}_{2} \mathrm{O}_{2}$ in the presence of $\mathrm{C}_{2} \mathrm{H}_{4}-\mathrm{O}_{2}-\mathrm{NO}$ mixtures at a total pressure of 1 bar [760 \pm 5 Torr]. Relative HO radical concentrations were determined as a function of time using LIF, and simulated by a mechanism consisting of 11 reactions, of which $k$ of above reaction was the most sensitive.

\section{Preferred Values}

$k=9 \times 10^{-12} \mathrm{~cm}^{3}$ molecule ${ }^{-1} \mathrm{~s}^{-1}$ at $298 \mathrm{~K}$.

\section{Reliability}

$\Delta \log k= \pm 0.5$ at $298 \mathrm{~K}$.

\section{Comments on Preferred Values}

The rate coefficient reported by Becker et al. (1991), which is recommended, is consistent with the rate coefficients of the reactions of other peroxy radicals with NO. Independent confirmation is needed to reduce the error limits. The hydroxy-alkoxy product has been shown to be formed with sufficient internal energy that prompt dissociation can take place as well as thermal decomposition and reaction with $\mathrm{O}_{2}$ of the collisionally stabilised radical (Orlando et al., 1998; Vereecken et al., 1999).

\section{References}

Becker, K. H., Geiger, H., and Wiesen, P.: Chem. Phys. Lett., 184, 256, 1991.

Orlando, J. J., Tyndall, G. S., Bilde, M., Ferronato, C., Wallington, T. J., Vereecken, L., and Peeters, J.: J. Phys. Chem. A, 102, 8116, 1998.

Vereecken, L., Peeters, J., Orlando, J. J., Tyndall, G. S., and Ferronato, C.: J. Phys. Chem. A, 103, 4693, 1999. 
II.A6.123

$$
\begin{array}{ll}
n-\mathbf{C}_{3} \mathbf{H}_{7} \mathbf{O}_{2}+\mathbf{N O} & \rightarrow n-\mathbf{C}_{3} \mathbf{H}_{7} \mathbf{O}+\mathbf{N O}_{2} \\
n-\mathbf{C}_{3} \mathrm{H}_{7} \mathbf{O}_{2}+\mathrm{NO}+\mathrm{M} & \rightarrow n-\mathbf{C}_{3} \mathbf{H}_{7} \mathbf{O N O}_{2}+\mathbf{M}
\end{array}
$$

Rate coefficient data $\left(k=k_{1}+k_{2}\right)$

\begin{tabular}{llll}
\hline$k / \mathrm{cm}^{3}$ molecule ${ }^{-1} \mathrm{~s}^{-1}$ & Temp./K & Reference & Technique/Comments \\
\hline $\begin{array}{l}\text { Absolute Rate Coefficients } \\
2.9 \times 10^{-12} \exp [(350 \pm 60) / T]\end{array}$ & $201-402$ & Eberhard and Howard, 1996 & F-CIMS(a) \\
$(9.4 \pm 1.6) \times 10^{-12}$ & 298 & & \\
& & & \\
$\begin{array}{l}\text { Branching Ratio } \\
k_{2} / k=0.020 \pm 0.009(1 \text { bar })\end{array}$ & 299 & Atkinson et al., 1982; & Carter and Atkinson, 1989 \\
& & (b)
\end{tabular}

\section{Comments}

(a) $n-\mathrm{C}_{3} \mathrm{H}_{7} \mathrm{O}_{2}$ radicals were produced by pyrolysis of $n-\mathrm{C}_{3} \mathrm{H}_{7} \mathrm{ONO}_{2}$ in the presence of $\mathrm{O}_{2}$ and detected by CIMS. Pseudo-first order kinetics with excess NO.

(b) Based on yield of $n-\mathrm{C}_{3} \mathrm{H}_{7} \mathrm{ONO}_{2}$ product from photo-oxidation of $\mathrm{C}_{3} \mathrm{H}_{8}$ in $\mathrm{NO}_{\mathrm{x}}$-air mixtures. Carter and Atkinson (1989) revised the analysis of original data to provide the value quoted.

\section{Preferred Values}

$k=9.4 \times 10^{-12} \mathrm{~cm}^{3}$ molecule $\mathrm{s}^{-1}$ at $298 \mathrm{~K}$.

$k=2.9 \times 10^{-12} \exp (350 / T) \mathrm{cm}^{3}$ molecule ${ }^{-1} \mathrm{~s}^{-1}$ over the temperature range $200-410 \mathrm{~K}$.

$k_{2} / k=0.020$ at $298 \mathrm{~K}$ and 1 bar pressure.

\section{Reliability}

$\Delta \log k= \pm 0.2$ at $298 \mathrm{~K}$.

$\Delta(E / R)= \pm 100 \mathrm{~K}$.

$\Delta \log k_{2} / k= \pm 0.02$ at $298 \mathrm{~K}$ and 1 bar pressure.

\section{Comments on Preferred Values}

The measurements of Eberhard and Howard (1996) provide the only experimental data on this rate coefficient. The value of $k_{298}$ is in line with the most recent measurements for reactions of ethyl peroxy and 2-propyl peroxy radicals with NO. The negative temperature coefficient is also consistent with that observed for the rate coefficient for other $\mathrm{RO}_{2}+\mathrm{NO}$ reactions. The recommendation accepts the Arrhenius expression of Eberhard and Howard (1996).

The preferred branching ratio for $n$-propyl nitrate formation is that measured by Atkinson et al. (1982), as revised by Carter and Atkinson (1989).

\section{References}

Atkinson, R., Aschmann, S. M., Carter, W. P. L., Winer, A. M., and Pitts Jr., J. N.: J. Phys. Chem., 86, $4563,1982$. Carter, W. P. L. and Atkinson, R.: J. Atmos. Chem., 8, 165, 1989.

Eberhard, J. and Howard, C. J.: Int. J. Chem. Kinet., 28, 731, 1996. 
II.A6.124

$$
\begin{array}{ll}
i-\mathrm{C}_{3} \mathrm{H}_{7} \mathbf{O}_{2}+\mathrm{NO} & \rightarrow i-\mathrm{C}_{3} \mathrm{H}_{7} \mathrm{O}+\mathrm{NO}_{2} \\
i-\mathrm{C}_{3} \mathrm{H}_{7} \mathbf{O}_{2}+\mathrm{NO}+\mathrm{M} & \rightarrow i-\mathrm{C}_{3} \mathrm{H}_{7} \mathbf{O N O} \mathbf{O N}_{2}+\mathrm{M}
\end{array}
$$

$\Delta H^{\circ}(1)=-40.5 \mathrm{~kJ} \cdot \mathrm{mol}^{-1}$

$\Delta H^{\circ}(2)=-212.2 \mathrm{~kJ} \cdot \mathrm{mol}^{-1}$

\begin{tabular}{|c|c|c|c|}
\hline$k / \mathrm{cm}^{3}$ molecule $^{-1} \mathrm{~s}^{-1}$ & Temp./K & Reference & Technique/Comments \\
\hline \multicolumn{4}{|l|}{ Absolute Rate Coefficients } \\
\hline$(3.5 \pm 0.3) \times 10^{-12}$ & 298 & Adachi and Basco, 1982 & FP-AS \\
\hline$(5.0 \pm 1.2) \times 10^{-12}$ & 290 & Peeters et al., 1992 & DF-MS (a) \\
\hline $2.7 \pm 10^{-12} \exp [(360 \pm 60) / T]$ & $201-401$ & Eberhard et al., 1996 & F-CIMS (b) \\
\hline$(9.0 \pm 1.5) \times 10^{-12}$ & 298 & & \\
\hline$(9.1 \pm 1.5) \times 10^{-12}$ & 298 & Eberhard and Howard, 1996 & F-CIMS (c) \\
\hline $4.3 \times 10^{-12} \exp [(268 \pm 56) / T]$ & $213-298$ & Chow et al., 2003 & F-CIMS (d) \\
\hline$(1.05 \pm 0.14) \times 10^{-11}$ & 298 & & \\
\hline$(8.0 \pm 1.5) \times 10^{-12}$ & 298 & Xing et al., 2005 & LP-MS (e) \\
\hline \multicolumn{4}{|l|}{ Branching Ratio } \\
\hline$k_{2} / k=0.042 \pm 0.003$ (1 bar air $)$ & 299 & $\begin{array}{l}\text { Atkinson et al., 1982; } \\
\text { Carter and Atkinson, } 1989\end{array}$ & (f) \\
\hline $\begin{array}{l}k_{2} / k=1.815 \times 10^{-4} \exp (1020 / T) \\
\left(133 \mathrm{mb} \mathrm{N}_{2}\right)\end{array}$ & $213-298$ & Chow et al., 2003 & F-CIMS (d) \\
\hline$k_{2} / k=0.005\left(133 \mathrm{mb} \mathrm{N}_{2}\right)$ & 298 & & \\
\hline
\end{tabular}

Rate coefficient data $\left(k=k_{1}+k_{2}\right)$

\section{Comments}

(a) Low pressure flow tube at 2.7 mbar He. Rate constant derived from analysis of $\mathrm{NO}_{2}$ growth profiles.

(b) $i-\mathrm{C}_{3} \mathrm{H}_{7} \mathrm{O}_{2}$ radicals produced by reaction of $\mathrm{O}_{2}$ with $i-\mathrm{C}_{3} \mathrm{H}_{7}$ radicals produced by thermal decomposition of isobutyl nitrate. $i-\mathrm{C}_{3} \mathrm{H}_{7} \mathrm{O}_{2}$ was detected as its parent negative ion formed by reaction with $\mathrm{O}_{2}^{-} \cdot k$ determined by pseudo-first order loss of $i-\mathrm{C}_{3} \mathrm{H}_{7} \mathrm{O}_{2}$ in the presence of NO.

(c) $i-\mathrm{C}_{3} \mathrm{H}_{7} \mathrm{O}_{2}$ produced by reaction of $\mathrm{O}_{2}$ with $i-\mathrm{C}_{3} \mathrm{H}_{7}$ produced in a low frequency RF discharge through $i$-propyl iodide.

(d) Turbulent flow reactor at $133 \mathrm{mb} \mathrm{N}$ total pressure. $\mathrm{C}_{3} \mathrm{H}_{7} \mathrm{O}_{2}$ radicals were generated by the reaction of $\mathrm{Cl}$ atoms with $\mathrm{C}_{3} \mathrm{H}_{8}$ in the presence of $\mathrm{O}_{2}$, thus both $n-\mathrm{C}_{3} \mathrm{H}_{7} \mathrm{O}_{2}$ and $i-\mathrm{C}_{3} \mathrm{H}_{7} \mathrm{O}_{2}$ were present and the rate coefficients measured are overall values for both isomers, which were detected as $\mathrm{CH}_{3} \mathrm{H}_{7} \mathrm{OOH}^{+}\left(\mathrm{H}_{2} \mathrm{O}\right)_{3}$ following reaction with $\mathrm{H}^{+}\left(\mathrm{H}_{2} \mathrm{O}\right)_{4}$ ions. For branching ratio measurements, $i-\mathrm{C}_{3} \mathrm{H}_{7} \mathrm{O}_{2}$ was selectively generated from the reaction of $\mathrm{H}$ atoms with $\mathrm{C}_{3} \mathrm{H}_{6}$ in the presence of $\mathrm{O}_{2} . i-\mathrm{C}_{3} \mathrm{H}_{7} \mathrm{ONO}_{2}$ was detected using $\mathrm{H}^{+}\left(\mathrm{H}_{2} \mathrm{O}\right)_{4}$ ions; $\mathrm{NO}_{2}$ was detected as $\mathrm{NO}_{2}^{-}$following electron transfer from $\mathrm{SF}_{6}^{-}$.

(e) $i-\mathrm{C}_{3} \mathrm{H}_{7} \mathrm{O}_{2}$ generated by reaction of $i-\mathrm{C}_{3} \mathrm{H}_{7}$ with $\mathrm{O}_{2}$, whereby $i-\mathrm{C}_{3} \mathrm{H}_{7}$ radicals were generated in the 193 nm photolysis of $i-\mathrm{C}_{3} \mathrm{H}_{7} \mathrm{Br}$, or the 248 photolysis of $i-\mathrm{C}_{3} \mathrm{H}_{7} \mathrm{I}$. $i-\mathrm{C}_{3} \mathrm{H}_{7} \mathrm{O}_{2}$ was detected as the negative parent ion following electron transfer from high Rydberg state Xe atoms. The bath gas was $4-5.3 \mathrm{mb}$ of He. Owing to poor sensitivity, and resultant side/secondary reactions the rate coefficient was extracted by numerical modelling of a complx reaction scheme.

(f) Photolysis of $\mathrm{CH}_{3} \mathrm{ONO}-\mathrm{NO}-\mathrm{C}_{3} \mathrm{H}_{8}$-air or $\mathrm{Cl}_{2}-\mathrm{NO}-\mathrm{C}_{3} \mathrm{H}_{8}$-air mixtures at a total pressure of 1 bar. The branching ratio was determined from the measured yields of $i-\mathrm{C}_{3} \mathrm{H}_{7} \mathrm{ONO}_{2}$ and the consumption of $\mathrm{C}_{3} \mathrm{H}_{8}$. Carter and Atkinson (1989) have re-evaluated the branching ratio, cited above, from the original data (Atkinson et al., 1982) on the basis of revised data for the rate coefficients of the $\mathrm{HO}$ radical reactions with alkanes. 


\section{Preferred Values}

$k=9.0 \times 10^{-12} \mathrm{~cm}^{3}$ molecule ${ }^{-1} \mathrm{~s}^{-1}$ at $298 \mathrm{~K}$.

$k=2.7 \times 10^{-12} \exp (360 / T) \mathrm{cm}^{3}$ molecule ${ }^{-1} \mathrm{~s}^{-1}$ over the temperature range $200-410 \mathrm{~K}$.

$k_{2} / k=0.042$ at $298 \mathrm{~K}$ and 1 bar pressure.

\section{Reliability}

$\Delta \log k= \pm 0.1$ at $298 \mathrm{~K}$.

$\Delta(E / R)= \pm 100 \mathrm{~K}$.

$\Delta \log \left(k_{2} / k\right)= \pm 0.3$ at $298 \mathrm{~K}$ and 1 bar pressure.

\section{Comments on Preferred Values}

The data from Eberhard et al. (1996) give a rate coefficient at $298 \mathrm{~K}$ which is significantly larger than the values obtained by Adachi and Basco (1982) or Peeters et al. (1992), and is close to the value obtained for a range of alkyl peroxy radicals at $298 \mathrm{~K}$. In addition, the data of Chow et al. (2003), who measured a weighted average value for $n-\mathrm{C}_{3} \mathrm{H}_{7} \mathrm{O}_{2}$ and $i-\mathrm{C}_{3} \mathrm{H}_{7} \mathrm{O}_{2}$ are in good agreement, which confirms that $n-\mathrm{C}_{3} \mathrm{H}_{7} \mathrm{O}_{2}$ and $i-\mathrm{C}_{3} \mathrm{H}_{7} \mathrm{O}_{2}$ have similar rate coefficients for reaction with NO. The rather indirect measurement of Xing et al., (2005) is also in broad agreement. The preferred value for $k_{298}$ and the temperature dependence is that reported by Eberhard et al. (1996).

There are two studies of the branching ratio to $i-\mathrm{C}_{3} \mathrm{H}_{7} \mathrm{ONO}_{2}$ formation. Chow et al., (2003) report values at 133 mbar $\mathrm{N}_{2}$ that vary from $\approx 0.005$ at room temperature to 0.02 at $213 \mathrm{~K}$, whereas Carter and Atkinson (1989) report 0.042 at $298 \mathrm{~K}$ and 1 bar air. The differences in these results are a result of the pressure difference in the two experiments reported, implying that $k_{2}$ is in the third-order limit at 133 mbar $\mathrm{N}_{2}$. For purpose of atmospheric modelling of the lower troposphere, the recommended branching ratio is that reported by Carter and Atkinson (1989). Chow et al. (2003) note that their temperature dependence is reproduced using a model based on $\mathrm{C}_{3}-\mathrm{C}_{8}$ hydrocarbons (Arey et al., 2001).

\section{References}

Adachi, H. and Basca, N.: Int. J. Chem. Kinet. 14, 1243, 1982.

Arey, J., Aschmann, S. M., Kwok, E. S. C. and Atkinson, R.: J. Phys. Chem. A 105, 1020, 2001.

Atkinson, R., Aschmann, S. M., Carter, W. P. L., Winer, A. M. and Pitts Jr., J. N.: J. Phys. Chem., 86, 4563, 1982.

Carter, W. P. L. and Atkinson, R.: J. Atmos. Chem., 8, 165, 1989.

Chow, J. M., Miller, A. M. and Elrod, M. J.: J. Phys. Chem. A 107, 3040, 2003.

Eberhard, J. and Howard, C. J.: Int. J. Chem. Kinet., 28, 731, 1996.

Eberhard, J., Villalta, P. W., and Howard, C. J.: J. Phys. Chem., 100, 993, 1996.

Peeters, J., Vertommen, J., and Langhans, I.: Ber. Bunsenges. Phys. Chem., 96, 431, 1992.

Xing, J,-H. and Miyoshi, A.: J. Phys. Chem. A 109, 4095, 2005. 
II.A6.125

$$
\mathrm{CH}_{3} \mathrm{C}(\mathrm{O}) \mathrm{CH}_{2} \mathrm{O}_{2}+\mathrm{NO} \rightarrow \mathrm{CH}_{3} \mathrm{C}(\mathrm{O}) \mathrm{CH}_{2} \mathrm{O}+\mathrm{NO}_{2}
$$

\section{Rate coefficient data}

\begin{tabular}{lllc}
\hline$k / \mathrm{cm}^{3}$ molecule ${ }^{-1} \mathrm{~s}^{-1}$ & Temp./K & Reference & Technique/Comments \\
\hline $\begin{array}{l}\text { Absolute Rate Coefficients } \\
(8.0 \pm 2.0) \times 10^{-12}\end{array}$ & 295 & Sehested et al., 1998 & PR-AS (a) \\
\hline
\end{tabular}

\section{Comments}

(a) $\mathrm{CH}_{3} \mathrm{C}(\mathrm{O}) \mathrm{CH}_{2} \mathrm{O}_{2}$ was formed in the pulsed radiolysis of $\mathrm{CH}_{3} \mathrm{C}(\mathrm{O}) \mathrm{CH}_{3}-\mathrm{SF}_{6}-\mathrm{O}_{2}$ mixtures, and the kinetics of the title reaction followed by monitoring formation of $\mathrm{NO}_{2}$ in real time by absorption spectroscopy. The influence of secondary chemistry on formation of $\mathrm{NO}_{2}$ was estimated by numerical simulation of an assumed reaction scheme.

\section{Preferred Values}

$k=8 \times 10^{-12} \mathrm{~cm}^{3}$ molecule ${ }^{-1} \mathrm{~s}^{-1}$ at $298 \mathrm{~K}$.

\section{Reliability}

$\Delta \log k= \pm 0.3$ at $298 \mathrm{~K}$.

\section{Comments on Preferred Values}

The recommendation is based on the sole study of the reaction of Sehested et al. (1998), with appropriately expanded error limits. The value of the rate coefficient at room temperature is consistent with reactions of other unsubstituted peroxy radicals with NO. The temperature dependence of the rate coefficient is also expected to be consistent with other $\mathrm{RO}_{2}+\mathrm{NO}$ reactions, and the expression: $k=2.8 \times 10^{-12} \exp (300 / T) \mathrm{cm}^{3}$ molecule ${ }^{-1} \mathrm{~s}^{-1}$ has been recommended (Tyndall et al., 2001).

\section{References}

Sehested, J., Christensen, L. K., Nielsen, O. J., Bilde, M., Wallington, T. J., Schneider, W. F., Orlando, J. J., and Tyndall, G. S.: Int. J. Chem. Kin., 30, 475, 1998.

Tyndall, G. S., Cox, R. A., Granier, C., Lesclaux, R., Moortgat, G. K., Pilling, M. J., Ravishankara, A. R., and Wallington, T. J.: J. Geophys. Res., 106, 12 157, 2001. 
II.A6.126

\section{$\mathrm{CH}_{3} \mathrm{C}(\mathrm{O}) \mathrm{O}_{2}+\mathrm{NO} \rightarrow \mathrm{CH}_{3} \mathrm{C}(\mathrm{O}) \mathrm{O}+\mathrm{NO}_{2}$}

$\Delta H^{\circ}=-93 \mathrm{~kJ} \cdot \mathrm{mol}^{-1}$

\section{Rate coefficient data}

\begin{tabular}{lllc}
\hline $\mathrm{k} / \mathrm{cm}^{3}$ molecule ${ }^{-1} \mathrm{~s}^{-1}$ & Temp./K & Reference & Technique/Comments \\
\hline Absolute Rate Coefficients & & & \\
$2.1 \times 10^{-12} \exp [(570 \pm 140) / T]$ & $228-354$ & Maricq and Szente, 1996 & PLP-AS (a) \\
$(1.4 \pm 0.2) \times 10^{-11}$ & 298 & & \\
$8.1 \times 10^{-12} \exp [(270 \pm 60) / T]$ & $200-402$ & Villalta and Howard, 1996 & F-CIMS (b) \\
$(2.0 \pm 0.3) \times 10^{-11}$ & 298 & & \\
$(2.0 \pm 0.3) \times 10^{-11}$ & 295 & Sehested et al., 1998 & PR-A (c) \\
$6.0 \times 10^{-12} \exp [(320 \pm 40) / T]$ & $218-370$ & Moise et al., 1999 & F-CIMS (d) \\
$(2.0 \pm 0.3) \times 10^{-11}$ & 296 & & \\
& & & \\
Relative Rate Coefficients & & & \\
$8.9 \times 10^{-12} \exp [(312 \pm 46) / T](1$ bar air $)$ & $247-298$ & Seefeld et al., 1997 & (e) \\
$(2.5 \pm 0.4) \times 10^{-11}(1$ bar air $)$ & 298 & & \\
$(2.17 \pm 0.23) \times 10^{-11}(0.93$ bar $)$ & 295 & Sehested et al., 1998 & (f) \\
\hline
\end{tabular}

\section{Comments}

(a) Pulsed laser photolysis of $\mathrm{Cl}_{2}-\mathrm{CH}_{3} \mathrm{CHO}-\mathrm{O}_{2}-\mathrm{NO}$ mixtures at $351 \mathrm{~nm}$. Time-resolved absorption spectroscopy using a gated diode array for $\mathrm{CH}_{3} \mathrm{C}(\mathrm{O}) \mathrm{O}_{2}$ in the $\mathrm{UV}$ and using a diode laser for $\mathrm{NO}$ and $\mathrm{NO}_{2}$ in the IR. Correction to $k$ required for competing reactions of $\mathrm{CH}_{3} \mathrm{C}(\mathrm{O}) \mathrm{O}_{2}$.

(b) $\mathrm{CH}_{3} \mathrm{C}(\mathrm{O}) \mathrm{O}_{2}$ produced by thermal decomposition of peroxyacetyl nitrate and detected by CIMS through its reaction with $\mathrm{SF}_{6}^{-}$. $\mathrm{NO}_{2}, \mathrm{CH}_{3}$ and $\mathrm{CO}_{2}$ were positively identified as products implying rapid decomposition of $\mathrm{CH}_{3} \mathrm{C}(\mathrm{O}) \mathrm{O}$ to $\mathrm{CH}_{3}$ and $\mathrm{CO}_{2}$. Experiments conducted at pressures of 1.2-6 Torr (1.6-8 mbar) He.

(c) Pulse radiolysis of $\mathrm{CH}_{3} \mathrm{CHO}-\mathrm{O}_{2}-\mathrm{CO}_{2}-\mathrm{NO}$ and $\mathrm{CH}_{3} \mathrm{CHO}-\mathrm{O}_{2}-\mathrm{SF}_{6}-\mathrm{NO}$ mixtures at 1 bar pressure. The rate coefficient was obtained from the formation of $\mathrm{NO}_{2}$, measured by absorption at $400.5 \mathrm{~nm}$.

(d) $\mathrm{CH}_{3} \mathrm{C}(\mathrm{O}) \mathrm{O}_{2}$ produced by thermal decomposition of peroxyacetyl nitrate and detected by CIMS through its reaction with $\mathrm{SF}_{6}^{-}$. Experiments conducted at 2-5 Torr (2.7-6.7 mbar) He.

(e) $\mathrm{CH}_{3} \mathrm{C}(\mathrm{O}) \mathrm{O}_{2}$ produced by steady state photolysis of biacetyl in the presence of $\mathrm{O}_{2}$. Yields of peroxyacetyl nitrate were measured as a function of the $[\mathrm{NO}] /\left[\mathrm{NO}_{2}\right]$ ratio. Data gave $k / k\left(\mathrm{CH}_{3} \mathrm{C}(\mathrm{O}) \mathrm{O}_{2}+\mathrm{NO}_{2}\right)=2.44 \pm 0.18$ at 1 bar, independent of temperature over the range $247 \mathrm{~K}$ to $298 \mathrm{~K}$. The expression in the table is calculated using the recommended value for $k\left(\mathrm{CH}_{3} \mathrm{C}(\mathrm{O}) \mathrm{O}_{2}+\mathrm{NO}_{2}\right)$ at 1 bar pressure (IUPAC, this evaluation).

(f) $\mathrm{CH}_{3} \mathrm{C}(\mathrm{O}) \mathrm{O}_{2}$ radicals were produced by photolysis of $\mathrm{Cl}_{2}-\mathrm{CH}_{3} \mathrm{CHO}-\mathrm{O}_{2}$ mixtures, and reactants and products monitored by FTIR spectroscopy. The measured rate coefficient ratio $k\left(\mathrm{CH}_{3} \mathrm{C}(\mathrm{O}) \mathrm{O}_{2}+\mathrm{NO}\right) / k\left(\mathrm{CH}_{3} \mathrm{C}(\mathrm{O}) \mathrm{O}_{2}+\mathrm{NO}_{2}\right)=2.07 \pm 0.21$ at 932 mbar $\mathrm{N}_{2}$ is placed on an absolute basis using the recommended value of $k\left(\mathrm{CH}_{3} \mathrm{C}(\mathrm{O}) \mathrm{O}_{2}+\mathrm{NO}_{2}\right.$ ) (IUPAC, this evaluation).

\section{Preferred Values}

$k=2.0 \times 10^{-11} \mathrm{~cm}^{3}$ molecule ${ }^{-1} \mathrm{~s}^{-1}$ at $298 \mathrm{~K}$.

$k=7.5 \times 10^{-12} \exp (290 / T) \mathrm{cm}^{3}$ molecule ${ }^{-1} \mathrm{~s}^{-1}$ over the temperature range $200-350 \mathrm{~K}$. 


\section{Reliability}

$\Delta \log k= \pm 0.15$ at $298 \mathrm{~K}$.

$\Delta(E / R)= \pm 250 \mathrm{~K}$.

\section{Comments on Preferred Values}

The direct measurements at $298 \mathrm{~K}$ of Villalta and Howard (1996), Moise et al. (1999) and Sehested et al. (1998) are in excellent agreement, all obtaining values of $2 \times 10^{-11} \mathrm{~cm}^{3}$ molecule ${ }^{-1} \mathrm{~s}^{-1}$, and provide the basis of the $298 \mathrm{~K}$ recommendation. Those of Maricq and Szente (1996) give a value of $k(298)$ approximately $30 \%$ lower. Of the three temperature dependent data sets, those of Villalta and Howard (1996) and Moise et al. (1999) agree within the error limits and present a significantly weaker dependence than the more highly scattered data of Maricq and Szente (1996). The recommended temperature dependence was obtained by weighted least squares fitting to the data of Villalta and Howard (1996) and Moise et al. (1999).

The earlier data for $k$, obtained relative to $k\left(\mathrm{CH}_{3} \mathrm{C}(\mathrm{O}) \mathrm{O}_{2}+\mathrm{NO}_{2}\right)$ (Cox et al., 1976; Cox and Roffey, 1977; Hendry and Kenley, 1977; Kirchner et al., 1990; Tuazon et al., 1991), are generally consistent with this recommendation.

\section{References}

Cox, R. A. and Roffey, M. J.: Environ. Sci. Technol., 11, 900, 1977.

Cox, R. A., Derwent, R. G., Holt, P. M., and Kerr, J. A.: J. Chem. Soc. Faraday Trans., 72, 2061, 1976.

Hendry, D. G. and Kenley, R. A.: J. Am. Chem. Soc., 99, 3198, 1977.

Kirchner, F., Zabel, F., and Becker, K. H.: Ber. Bunsenges. Phys. Chem., 94, 1379, 1990.

Maricq, M. M. and Szente, J. J.: J. Phys. Chem. 100, 12 380, 1996.

Moise, T., Denzer, W., and Rudich, Y.: J. Phys. Chem. A, 103, 6766, 1999.

Seefeld, S., Kinnison, D. J., and Kerr, J. A.: J. Phys. Chem. A, 101, 55, 1997.

Sehested, J., Christensen, L. K., Mogelberg, T., Nielsen, O. J., Wallington, T. J., Guschin, A., Orlando, J. J., and Tyndall, G. S.: J. Phys. Chem. A, 102, 1779, 1998.

Tuazon, E. C., Carter, W. P. L., and Atkinson, R.: J. Phys. Chem., 95, 2434, 1991.

Villalta, P. W. and Howard, C. J.: J. Phys. Chem., 100, 13 624, 1996. 
II.A6.127

$$
\mathrm{C}_{2} \mathrm{H}_{5} \mathrm{C}(\mathrm{O}) \mathrm{O}_{2}+\mathrm{NO} \rightarrow \mathrm{C}_{2} \mathrm{H}_{5} \mathrm{C}(\mathrm{O}) \mathrm{O}+\mathrm{NO}_{2}
$$

\section{Rate coefficient data}

\begin{tabular}{llll}
\hline$k / \mathrm{cm}^{3}$ molecule ${ }^{-1} \mathrm{~s}^{-1}$ & Temp./K & Reference & Technique/Comments \\
\hline $\begin{array}{l}\text { Absolute Rate Coefficients } \\
(6.7 \pm 1.7) \times 10^{-12} \exp [(340 \pm 80) / T]\end{array}$ & $226-406$ & Froyd and Lovejoy, 1999 & F-CIMS(a) \\
$(2.1 \pm 0.2) \times 10^{-11}$ & 298 & & \\
& & & \\
Relative Rate Coefficients & $249-302$ & Seefeld and Kerr, 1997 & RR(b) \\
$1.25 \times 10^{-11} \exp (240 / T)$ & 298 & & \\
$(2.8 \pm 0.4) \times 10^{-11}$ & 302 & Kerr and Stocker, 1985 & RR(c) \\
$(2.3 \pm 0.2) \times 10^{-11}$ & & & \\
\hline
\end{tabular}

\section{Comments}

(a) Low pressure flow tube at 1.5 to 15 Torr (2-20 mbar) $\mathrm{He}$ or $\mathrm{N}_{2} \cdot \mathrm{C}_{2} \mathrm{H}_{5} \mathrm{C}(\mathrm{O}) \mathrm{O}_{2}$ was formed by thermal decomposition of $\mathrm{C}_{2} \mathrm{H}_{5} \mathrm{C}(\mathrm{O}) \mathrm{ONO}_{2}$ and detected as $\mathrm{C}_{2} \mathrm{H}_{5} \mathrm{C}(\mathrm{O}) \mathrm{O}_{2}^{-}$or $\mathrm{C}_{2} \mathrm{H}_{5} \mathrm{C}(\mathrm{O}) \mathrm{O}^{-}$following reaction with $\mathrm{SF}_{6}^{-}$or $\mathrm{I}^{-}$. Results at 15 Torr $\mathrm{N}_{2}$ analysed to set an upper limit to the association reaction of $k_{0}(298 \mathrm{~K})<1.9 \times 10^{-30} \mathrm{~cm}^{6}$ molecule $\mathrm{s}^{-2}$.

(b) Ratio $k / k\left(\mathrm{C}_{2} \mathrm{H}_{5} \mathrm{C}(\mathrm{O}) \mathrm{O}_{2}+\mathrm{NO}_{2}\right)=2.33 \pm 0.38$, independent of temperature over the range 249-302 $\mathrm{K}$. $\mathrm{C}_{2} \mathrm{H}_{5} \mathrm{C}(\mathrm{O}) \mathrm{O}_{2}$ produced by photolysis of $\mathrm{C}_{2} \mathrm{H}_{5} \mathrm{C}(\mathrm{O}) \mathrm{Cl}$ in a flow system at $1 \mathrm{~atm}$ pressure with analysis of $\mathrm{C}_{2} \mathrm{H}_{5} \mathrm{C}(\mathrm{O}) \mathrm{O}_{2} \mathrm{NO}_{2}$ by GC, as a function of the $[\mathrm{NO}] /\left[\mathrm{NO}_{2}\right]$ ratio. $k$ calculated with $k\left(\mathrm{C}_{2} \mathrm{H}_{5} \mathrm{C}(\mathrm{O}) \mathrm{O}_{2}+\mathrm{NO}_{2}\right)=k\left(\mathrm{CH}_{3} \mathrm{C}(\mathrm{O}) \mathrm{O}_{2}+\mathrm{NO}_{2}\right)$ from the present evaluation [in Arrhenius form, $k_{\infty}\left(\mathrm{CH}_{3} \mathrm{C}(\mathrm{O}) \mathrm{O}_{2}+\mathrm{NO}_{2}\right)=5.4 \times 10^{-12} \exp (240 / T) \mathrm{cm}^{3}$ molecule ${ }^{-1} \mathrm{~s}^{-1}$ over the range $250 \mathrm{~K}$ to $300 \mathrm{~K}$ (IUPAC, this evaluation)]. Also showed that the above rate constant ratio was $11 \%$ lower than the corresponding ratio for $\mathrm{CH}_{3} \mathrm{C}(\mathrm{O}) \mathrm{O}_{2}$, which is consistent with a higher rate coefficient for the $\mathrm{RO}_{2}+\mathrm{NO}_{2}(+\mathrm{M})$ reaction for the $\mathrm{C}_{3}$ acylperoxy radical.

(c) Ratio $k / k\left(\mathrm{C}_{2} \mathrm{H}_{5} \mathrm{C}(\mathrm{O}) \mathrm{O}_{2}+\mathrm{NO}_{2}\right)=1.89 \pm 0.21 . k$ calculated with $k\left(\mathrm{C}_{2} \mathrm{H}_{5} \mathrm{C}(\mathrm{O}) \mathrm{O}_{2}+\mathrm{NO}_{2}\right)=k_{\infty}\left(\mathrm{CH}_{3} \mathrm{C}(\mathrm{O}) \mathrm{O}_{2}+\mathrm{NO}_{2}\right)$ from the present evaluation (in Arrhenius form, $k_{\infty}\left(\mathrm{CH}_{3} \mathrm{C}(\mathrm{O}) \mathrm{O}_{2}+\mathrm{NO}_{2}\right)=5.4 \times 10^{-12} \exp (240 / T) \mathrm{cm}^{3}$ molecule $\mathrm{s}^{-1} \mathrm{~s}^{-1}$ over the range $250 \mathrm{~K}$ to $300 \mathrm{~K}$ (IUPAC, this evaluation)].

\section{Preferred Values}

$k=2.1 \times 10^{-11} \mathrm{~cm}^{3}$ molecule $\mathrm{e}^{-1} \mathrm{~s}^{-1}$ at $298 \mathrm{~K}$.

$k=6.7 \times 10^{-12} \exp (340 / T) \mathrm{cm}^{3}$ molecule $\mathrm{e}^{-1} \mathrm{~s}^{-1}$ over the temperature range $220-410 \mathrm{~K}$.

\section{Reliability}

$\Delta \log k= \pm 0.15$ at $298 \mathrm{~K}$.

$\Delta(E / R)= \pm 200 \mathrm{~K}$.

\section{Comments on Preferred Values}

The preferred values are based on the absolute determination of Froyd and Lovejoy (1999). The relative rate measurements (Seefeld and Kerr, 1997; Kerr and Stocker, 1985) are in agreement with this number, but suffer from the lack of an absolute measurement for $k\left(\mathrm{C}_{2} \mathrm{H}_{5} \mathrm{C}(\mathrm{O}) \mathrm{O}_{2}+\mathrm{NO}_{2}\right)$, the reference reaction rate coefficient (see comments above). 


\section{References}

Froyd, K. D. and Lovejoy, E. R.: Int. J. Chem. Kin., 31, 221, 1999.

Kerr, J. A. and Stocker, D. W.: J. Photochem., 28, 475, 1985.

Seefeld, S. and Kerr, J. A.: Environ. Sci. Technol., 31, 2949, 1997. 
II.A6.128

$$
\mathrm{CH}_{3} \mathrm{O}_{2}+\mathrm{NO}_{2}+\mathrm{M} \rightarrow \mathrm{CH}_{3} \mathrm{O}_{2} \mathrm{NO}_{2}+\mathrm{M}
$$

$\Delta H^{\circ}=-92.7 \mathrm{~kJ} \cdot \mathrm{mol}^{-1}$

\section{Low-pressure rate coefficients}

\section{Rate coefficient data}

\begin{tabular}{llll}
\hline$k_{0} / \mathrm{cm}^{3}$ molecule ${ }^{-1} \mathrm{~s}^{-1}$ & Temp./K & Reference & Technique/Comments \\
\hline Absolute Rate Coefficients & & & \\
$(2.33 \pm 0.08) \times 10^{-30}\left[\mathrm{~N}_{2}\right]$ & 298 & Sander and Watson, 1980 & FP-AS (a) \\
$2.2 \times 10^{-30}(\mathrm{~T} / 300)^{-2.5}\left[\mathrm{~N}_{2}\right]$ & $253-353$ & Ravishankara et al., 1980 & FP-AS (b) \\
$(1.46 \pm 0.50) \times 10^{-30}\left[\mathrm{SF}_{6}\right]$ & 295 & Wallington et al., 1999 & PR-AS (c) \\
\hline
\end{tabular}

\section{Comments}

(a) Pressure range 70 mbar to 900 mbar for the bath gases $\mathrm{He}, \mathrm{N}_{2}$, and $\mathrm{SF}_{6}$. Analysis of the falloff curve was carried out with a theoretical $F_{c}$ value of 0.39 , in good agreement with the fitted value of $F_{c}=0.4 \pm 0.10$.

(b) Pressure range 100 mbar to 950 mbar. Analyses of the falloff curves at $253 \mathrm{~K}, 298 \mathrm{~K}$ and $353 \mathrm{~K}$ were carried out with $F_{c}=0.4$ independent of temperature.

(c) Pulse radiolysis study in $0.5-14$ bar of $\mathrm{SF}_{6}$. Evaluating the falloff curve with $F_{c}=0.40$.

\section{Preferred Values}

$k_{0}=2.5 \times 10^{-30}(T / 300)^{-5.5}\left[\mathrm{~N}_{2}\right] \mathrm{cm}^{3}$ molecule ${ }^{-1} \mathrm{~s}^{-1}$ over the temperature range $250-350 \mathrm{~K}$.

\section{Reliability}

$\Delta \log k_{0}= \pm 0.3$ at $298 \mathrm{~K}$.

$\Delta n= \pm 1$.

\section{Comments on Preferred Values}

The preferred values are based on the results from Sander and Watson (1980) and the theoretical analysis from Destriau and Troe (1990). These values are based on a theoretically determined value of $F_{c}=0.36$ at $300 \mathrm{~K}$.

\section{High-pressure rate coefficients}

\section{Rate coefficient data}

\begin{tabular}{llll}
\hline$k_{\infty} / \mathrm{cm}^{3}$ molecule ${ }^{-1} \mathrm{~s}^{-1}$ & Temp./K & Reference & Technique/Comments \\
\hline Absolute Rate Coefficients & & & \\
$(8.0 \pm 1.0) \times 10^{-12}$ & 298 & Sander and Watson, 1980 & FP-AS (a) \\
$7 \times 10^{-12}(T / 298)^{-3.5}$ & $253-353$ & Ravishankara et al., 1980 & FP-AS (b) \\
$(1.8 \pm 0.25) \times 10^{-11}$ & 295 & Wallington et al., 1999 & PR-AS (c) \\
\hline
\end{tabular}




\section{Comments}

(a) See comment (a) for $k_{0}$.

(b) See comment (b) for $k_{0}$. The large negative temperature coefficient is probably an artifact of the interpretation. If a larger negative temperature exponent for $k_{0}$ and a smaller $F_{c}$ value at higher temperature are used, the large negative temperature exponent of $k_{\infty}$ will decrease.

(c) See comment (c) for $k_{0}$.

\section{Preferred Values}

$k=4.0 \times 10^{-12} \mathrm{~cm}^{3}$ molecule $\mathrm{s}^{-1} \mathrm{~s}^{-1}$ at $298 \mathrm{~K}$ and 1 bar of air.

$k_{\infty}=1.8 \times 10^{-11} \mathrm{~cm}^{3}$ molecule $\mathrm{s}^{-1}$, independent of temperature over the range $250-350 \mathrm{~K}$.

\section{Reliability}

$\Delta \log k_{\infty}= \pm 0.3$ at $298 \mathrm{~K}$.

$\Delta n= \pm 0.5$

\section{Comments on Preferred Values}

The preferred values are based on the high pressure study from Wallington et al. (1999). An experimental value of $F_{c}=0.36$ at $298 \mathrm{~K}$ appears well established. Less complete information on the falloff range is obtained from the experiments by Cox and Tyndall (1980), who measured $k=1.6 \times 10^{-12} \mathrm{~cm}^{3}$ molecule $\mathrm{s}^{-1}$ at $700 \mathrm{mbar}^{-1} \mathrm{~N}_{2}$ and $1.2 \times 10^{-12} \mathrm{~cm}^{3} \mathrm{molecule}^{-1} \mathrm{~s}^{-1}$ at $66 \mathrm{mbar}$ of Ar at $275 \mathrm{~K}$, and Bridier et al. (1992) who measured $k=(4.4 \pm 0.4) \times 10^{-12} \mathrm{~cm}^{3} \mathrm{molecule}^{-1} \mathrm{~s}^{-1}$ at $298 \mathrm{~K}$ in 1 bar of air. The apparent observation of a pressure independent rate coefficient $k$ over the range 66 mbar to 760 mbar of Ar reported by Adachi and Basco (1980) is not confirmed by Sander and Watson (1980) and Ravishankara et al. (1980). $\Delta H$ is taken from the equilibrium measurements of Bridier et al. (1992).

\section{References}

Adachi, H. and Basco, N.: Int. J. Chem. Kinet., 12, 1, 1980.

Bridier, I., Lesclaux, R., and Veyret, B.: Chem. Phys. Lett., 119, 259, 1992.

Cox, R. A. and Tyndall, G. S.: J. Chem. Soc. Faraday Trans., 2, 76, 153, 1980.

Destriau, M. and Troe, J.: Int. J. Chem. Kinet., 22, 915, 1990.

Ravishankara, A. R., Eisele, F. L., and Wine, P. H.: J. Chem. Phys., 73, 3743, 1980.

Sander, S. P. and Watson, R. T.: J. Phys. Chem., 84, 1664, 1980.

Wallington, T. J., Nielsen, O. J., and Sehested, K.: Chem. Phys. Lett., 313, 456, 1999. 
II.A6.129

$$
\mathrm{CH}_{3} \mathrm{O}_{2} \mathrm{NO}_{2}+\mathrm{M} \rightarrow \mathrm{CH}_{3} \mathrm{O}_{2}+\mathrm{NO}_{2}+\mathrm{M}
$$

$\Delta H^{\circ}=92.7 \mathrm{~kJ} \cdot \mathrm{mol}^{-1}$

\section{Low-pressure rate coefficients}

\section{Rate coefficient data}

\begin{tabular}{llll}
\hline$k_{0} / \mathrm{s}^{-1}$ & Temp./K & Reference & Technique/Comments \\
\hline Absolute Rate Coefficients & & & \\
$9.0 \times 10^{-5} \exp (-9694 / T)\left[\mathrm{N}_{2}\right]$ & $248-273$ & Zabel et al., 1989 & (a) \\
$6.7 \times 10^{-19}\left[\mathrm{~N}_{2}\right]$ & $298^{*}$ & & \\
\hline
\end{tabular}

\section{Comments}

(a) Rate of decomposition of $\mathrm{CH}_{3} \mathrm{O}_{2} \mathrm{NO}_{2}$ followed by FTIR spectroscopy after generation in a reaction chamber, with subsequent addition of $\mathrm{NO}$ to scavenge $\mathrm{CH}_{3} \mathrm{O}_{2}$ radicals. Falloff curves were fitted with $F_{c}=0.4$.

\section{Preferred Values}

$k_{0}=6.8 \times 10^{-19}\left[\mathrm{~N}_{2}\right] \mathrm{s}^{-1}$ at $298 \mathrm{~K}$.

$k_{0}=9 \times 10^{-5} \exp (-9690 / T)\left[\mathrm{N}_{2}\right] \mathrm{s}^{-1}$ over the temperature range $250-300 \mathrm{~K}$.

\section{Reliability}

$\Delta \log k_{0}= \pm 0.3$ at $298 \mathrm{~K}$.

$\Delta(E / R)= \pm 500 \mathrm{~K}$.

\section{Comments on Preferred Values}

The preferred values correspond to the data and analysis from Zabel et al. (1989). A theoretical analysis of these data and those of the reverse reaction from Sander and Watson (1980) and Ravishankara et al. (1980) in Destriau and Troe (1990) gave an internally consistent picture (with $\Delta H^{\circ}=88.5 \mathrm{~kJ} \mathrm{~mol}^{-1}$ ). Slightly lower limiting rate coefficients were obtained in Bridier et al. (1992) where a value of $F_{c}=0.6$ was used. Direct measurements of the equilibrium constant $K_{c}=k / k_{1}=2.73 \times 10^{-28}$ $\exp (10910 / T) \mathrm{cm}^{3}$ molecule ${ }^{-1}$ from Bridier et al. (1992) lead to $\Delta H=92.7 \mathrm{~kJ} \mathrm{~mol}^{-1}$ and provide an indication for the internal consistency of the rate data.

\section{High-pressure rate coefficients}

\section{Rate coefficient data}

\begin{tabular}{llll}
\hline$k_{\infty} / \mathrm{s}^{-1}$ & Temp./K & Reference & Technique/Comments \\
\hline Absolute Rate Coefficients & & & \\
$2.1 \times 10^{16} \exp (-10920 / T)$ & $256-268$ & Bahta et al., 1982 & (a) \\
2.6 & $298^{*}$ & & \\
$1.1 \times 10^{16} \exp (-10560 / T)$ & $248-273$ & Zabel et al., 1989 & (b) \\
4.5 & $298^{*}$ & & \\
\hline
\end{tabular}




\section{Comments}

(a) $\mathrm{CH}_{3} \mathrm{O}_{2} \mathrm{NO}_{2}$ generated by photolysis of $\mathrm{Cl}_{2}$ in the presence of $\mathrm{NO}_{2}, \mathrm{CH}_{4}$ and $\mathrm{O}_{2}$. Kinetics were monitored in the presence of NO by UV absorption at $250 \mathrm{~nm}$. At $460 \mathrm{mbar}, k=6 \times 10^{15} \exp (-10620 / T) \mathrm{s}^{-1}$. The given value of $k_{\infty}$ is derived with $F_{c}=0.6$. The data depend to some extent on the rate coefficient for the reaction $\mathrm{CH}_{3} \mathrm{O}_{2}+\mathrm{NO} \rightarrow \mathrm{CH}_{3} \mathrm{O}+\mathrm{NO}_{2}$.

(b) See comment (a) for $k_{0}$.

\section{Preferred Values}

$k=1.8 \mathrm{~s}^{-1}$ at $298 \mathrm{~K}$ and 1 bar of air.

$k_{\infty}=4.5 \mathrm{~s}^{-1}$ at $298 \mathrm{~K}$.

$k_{\infty}=1.1 \times 10^{16} \exp (-10560 / T) \mathrm{s}^{-1}$ over the temperature range $250-300 \mathrm{~K}$.

\section{Reliability}

$\Delta \log k_{\infty}= \pm 0.3$ at $298 \mathrm{~K}$.

$\Delta(E / R)= \pm 500 \mathrm{~K}$.

\section{Comments on Preferred Values}

See comments on preferred values of $k_{0}$.

\section{References}

Bahta, A., Simonaitis, R., and Heicklen, J.: J. Phys. Chem., 86, 1849, 1982.

Bridier, I., Lesclaux, R., and Veyret, B.: Chem. Phys. Lett., 191, 259, 1992.

Destriau, M. and Troe, J.: Int. J. Chem. Kinet., 22, 915, 1990.

Ravishankara, A. R., Eisele, F. L., and Wine, P. H..: J. Chem. Phys., 73, 3743. 1980.

Sander, S. P. and Watson, R. T.: J. Phys. Chem., 84, 1664, 1980.

Zabel, F., Reimer, A., Becker, K. H., and Fink, E. H.: J. Phys. Chem., 93, 5500, 1989. 
II.A6.130

$$
\mathrm{C}_{2} \mathrm{H}_{5} \mathrm{O}_{2}+\mathrm{NO}_{2}+\mathrm{M} \rightarrow \mathrm{C}_{2} \mathrm{H}_{5} \mathrm{O}_{2} \mathrm{NO}_{2}+\mathrm{M}
$$

$\Delta H^{\circ}=-67.7 \mathrm{~kJ} \cdot \mathrm{mol}^{-1}$

\section{Low-pressure rate coefficients}

\section{Rate coefficient data}

\begin{tabular}{llll}
\hline$k_{0} / \mathrm{cm}^{3}$ molecule & \\
\hline $\begin{array}{l}\text { Absolute Rate Coefficients } \\
4.8 \times 10^{-29}\left[\mathrm{~N}_{2}\right]\end{array}$ & Temp./K & Reference & Technique/Comments \\
\hline
\end{tabular}

\section{Comments}

(a) Thermal decomposition of $\mathrm{C}_{2} \mathrm{H}_{5} \mathrm{O}_{2} \mathrm{NO}_{2}$ in a glass reaction chamber in the presenceof differing initial $\left.\left[\mathrm{NO}_{2}\right] / \mathrm{NO}\right]$ ratios at total pressures of 10 mbar to 1000 mbar. $\mathrm{C}_{2} \mathrm{H}_{5} \mathrm{O}_{2} \mathrm{NO}_{2}$ was prepared in situ by the photolysis of $\mathrm{Cl}_{2}-\mathrm{C}_{2} \mathrm{H}_{6}-\mathrm{O}_{2}-\mathrm{NO}_{2}-\mathrm{N}_{2}$ mixtures. $\mathrm{C}_{2} \mathrm{H}_{5} \mathrm{O}_{2} \mathrm{NO}_{2}, \mathrm{NO}_{2}$ and $\mathrm{NO}$ concentrations were monitored by longpath FTIR absorption and rate coefficient ratios for the reaction of $\mathrm{C}_{2} \mathrm{H}_{5} \mathrm{O}_{2}$ with $\mathrm{NO}$ and $\mathrm{NO}_{2}$ were obtained. The reported rate coefficient for $\mathrm{C}_{2} \mathrm{H}_{5} \mathrm{O}_{2}+\mathrm{NO}_{2}$ was derived using a rate coefficient of $8.9 \times 10^{-12} \mathrm{~cm}^{3}$ molecule $\mathrm{s}^{-1} \mathrm{~s}^{-1}$ for the reaction $\mathrm{C}_{2} \mathrm{H}_{5} \mathrm{O}_{2}+\mathrm{NO} \rightarrow \mathrm{C}_{2} \mathrm{H}_{5} \mathrm{O}+\mathrm{NO}_{2}$. Falloff curves were constructed based on the theoretical analysis from Destriau and Troe (1990) with $F_{c}=0.31$ and $k_{\infty}=7.5 \times 10^{-12} \mathrm{~cm}^{3}$ molecule $\mathrm{s}^{-1}$.

\section{Preferred Values}

$k_{0}=1.3 \times 10^{-29}(T / 300)^{-6.2}\left[\mathrm{~N}_{2}\right] \mathrm{cm}^{3}$ molecule ${ }^{-1} \mathrm{~s}^{-1}$ over the temperature range 200-300 K.

\section{Reliability}

$\Delta \log k_{0}= \pm 0.3$ at $298 \mathrm{~K}$.

$\Delta n= \pm 1$.

\section{Comments on Preferred Values}

The preferred values are based on the data from Elfers et al. (1990) and the analysis from Destriau and Troe (1990). The temperature dependence is from the theoretical analysis of Destriau and Troe (1990). Falloff extrapolations were made with $F_{c}=0.31$ at $250 \mathrm{~K}$ to $300 \mathrm{~K}$ such as given from the theoretical analysis of Destriau and Troe (1990).

\section{High-pressure rate coefficients}

\section{Rate coefficient data}

\begin{tabular}{|c|c|c|c|}
\hline$k_{\infty} / \mathrm{cm}^{3}$ molecule ${ }^{-1} \mathrm{~s}^{-1}$ & Temp./K & Reference & Technique/Comments \\
\hline $\begin{array}{l}\text { Absolute Rate Coefficients } \\
1.0 \times 10^{-11}\end{array}$ & 254 & Elfers et al., 1990 & (a) \\
\hline
\end{tabular}

\section{Comments}

(a) See comment (a) for $\mathrm{k}_{0}$. 


\section{Preferred Values}

$k=6.1 \times 10^{-12} \mathrm{~cm}^{3}$ molecule $\mathrm{e}^{-1} \mathrm{~s}^{-1}$ at $298 \mathrm{~K}$ and 1 bar of air.

$k_{\infty}=8.8 \times 10^{-12} \mathrm{~cm}^{3}$ molecule $\mathrm{e}^{-1} \mathrm{~s}^{-1}$, independent of temperature over the range $200-300 \mathrm{~K}$.

\section{Reliability}

$\Delta \log k_{\infty}= \pm 0.3$ over the temperature range $200-300 \mathrm{~K}$.

\section{Comments on Preferred Values}

See comments on $\mathrm{k}_{0}$. The theoretical analysis in Destriau and Troe (1990) also includes information from studies of the reverse reaction measured in Zabel et al. (1989).

\section{References}

Destriau, M. and Troe, J.: Int. J. Chem. Kinet., 22, 915, 1990.

Elfers, F., Zabel, F., and Becker, K. H.: Chem. Phys. Lett., 168, 14, 1990.

Zabel, F., Reimer, A., Becker, K. H., and Fink, E. H.: J. Phys. Chem., 93, 5500, 1989. 
II.A6.131

$$
\mathrm{C}_{2} \mathrm{H}_{5} \mathrm{O}_{2} \mathrm{NO}_{2}+\mathrm{M} \rightarrow \mathrm{C}_{2} \mathrm{H}_{5} \mathrm{O}_{2}+\mathrm{NO}_{2}+\mathrm{M}
$$

$\Delta H^{\circ}=67.7 \mathrm{~kJ} \cdot \mathrm{mol}^{-1}$

\section{Low-pressure rate coefficients}

Rate coefficient data

\begin{tabular}{lclc}
\hline$k_{0} / \mathrm{s}^{-1}$ & Temp./K & Reference & Technique/Comments \\
\hline $\begin{array}{l}\text { Absolute Rate Coefficients } \\
4.8 \times 10^{-4} \exp (-9285 / T)\left[\mathrm{N}_{2}\right]\end{array}$ & $245-273$ & Zabel et al., 1989 & FTIR (a) \\
\hline
\end{tabular}

\section{Comments}

(a) Unimolecular decay of $\mathrm{C}_{2} \mathrm{H}_{5} \mathrm{O}_{2} \mathrm{NO}_{2}$ followed at total pressures ranging from 10 mbar to 800 mbar. Falloff extrapolation with $F_{c}=0.3$.

\section{Preferred Values}

$k_{0}=1.4 \times 10^{-17}\left[\mathrm{~N}_{2}\right] \mathrm{s}^{-1}$ at $298 \mathrm{~K}$.

$k_{0}=4.8 \times 10^{-4} \exp (-9285 / T)\left[\mathrm{N}_{2}\right] \mathrm{s}^{-1}$ over the temperature range $250-300 \mathrm{~K}$.

\section{Reliability}

$\Delta \log k_{0}= \pm 0.5$ at $298 \mathrm{~K}$.

$\Delta(E / R)= \pm 1000 \mathrm{~K}$.

Comments on Preferred Values

The dissociation data are consistent with experimental recombination data from Elfers et al. (1989) and the theoretical analysis from Zabel et al. (1989) and Destriau and Troe (1990). Falloff curves are constructed with $F_{c}=0.31$ (over the range $250 \mathrm{~K}$ to $300 \mathrm{~K})$.

\section{High-pressure rate coefficients}

\section{Rate coefficient data}

\begin{tabular}{lclc}
\hline$k_{\infty} / \mathrm{s}^{-1}$ & Temp./K & Reference & Technique/Comments \\
\hline Absolute Rate Coefficients & & & \\
$8.8 \times 10^{15} \exp (-10440 / T)$ & $245-273$ & Zabel et al., 1989 & FTIR(a) \\
\hline
\end{tabular}

\section{Comments}

(a) See comment (a) for $k_{0}$.

\section{Preferred Values}

$k=4.0 \mathrm{~s}^{-1}$ at $298 \mathrm{~K}$ and 1 bar of air.

$k_{\infty}=5.4 \mathrm{~s}^{-1}$ at $298 \mathrm{~K}$.

$k_{\infty}=8.8 \times 10^{15} \exp (-10440 / T) \mathrm{s}^{-1}$ over the temperature range $250-300 \mathrm{~K}$. 


\section{Reliability}

$\Delta \log k_{\infty}= \pm 0.5$ at $300 \mathrm{~K}$.

$\Delta(E / R)= \pm 1000 \mathrm{~K}$.

\section{Comments on Preferred Values}

See comments on $k_{0}$.

\section{References}

Destriau, M. and Troe, J.: Int. J. Chem. Kinet., 22, 915, 1990.

Elfers, G., Zabel, F., and Becker, K. H.: Chem. Phys. Lett., 168, 14, 1990.

Zabel, F., Reimer, A., Becker, K. H., and Fink, E. H.: J. Phys. Chem., 93, 5500, 1989. 
II.A6.132

$$
\mathrm{CH}_{3} \mathrm{C}(\mathrm{O}) \mathrm{O}_{2}+\mathrm{NO}_{2}+\mathrm{M} \rightarrow \mathrm{CH}_{3} \mathrm{C}(\mathrm{O}) \mathrm{O}_{2} \mathrm{NO}_{2}+\mathrm{M}
$$

$\Delta H^{\circ}=-119 \mathrm{~kJ} \cdot \mathrm{mol}^{-1}$

\section{Low-pressure rate coefficients}

\section{Rate coefficient data}

\begin{tabular}{llll}
\hline$k_{0} / \mathrm{cm}^{3}$ molecule ${ }^{-1} \mathrm{~s}^{-1}$ & Temp./K & Reference & Technique/Comments \\
\hline Absolute Rate Coefficients & & & \\
$5.1 \times 10^{-29}\left[\mathrm{~N}_{2}\right]$ & 298 & Basco and Parmar, 1987 & FP-AS (a) \\
$(2.7 \pm 1.5) \times 10^{-28}(T / 298)^{-7.1}[$ air $]$ & $248-393$ & Bridier et al., 1991 & FP-AS (b) \\
\hline
\end{tabular}

\section{Comments}

(a) Photolysis of $\mathrm{Cl}_{2}-\mathrm{CH}_{3} \mathrm{CHO}-\mathrm{O}_{2}-\mathrm{N}_{2}$ and $\mathrm{NO}_{2}$ at total pressures of 100 mbar to 800 mbar. Extrapolation of falloff curve with theoretically modeled value of $F_{c}=0.19$.

(b) The falloff curves were fitted using $F_{c}=0.30$. The discrepancy with the data of Basco and Parmar (1987) is attributed to an oversimplified kinetic scheme used in Basco and Parmar (1987).

\section{Preferred Values}

$k_{0}=2.7 \times 10^{-28}(T / 300)^{-7.1}\left[\mathrm{~N}_{2}\right] \mathrm{cm}^{3}$ molecule ${ }^{-1} \mathrm{~s}^{-1}$ over the temperature range $250-300 \mathrm{~K}$.

\section{Reliability}

$\Delta \log k_{0}= \pm 0.4$ at $298 \mathrm{~K}$.

$\Delta n= \pm 2$.

\section{Comments on Preferred Values}

The data from Basco and Parmar (1987) and Addison et al. (1980) are a factor of 2-3 lower than those from Bridier et al. (1991). The more extensive and internally consistent study of $\mathrm{CH}_{3} \mathrm{C}(\mathrm{O}) \mathrm{OONO}_{2}(\mathrm{PAN})$ formation and dissociation in Bridier et al. (1991) is preferred. Falloff extrapolations were performed with a modeled value of $F_{c}=0.3$.

\section{High-pressure rate coefficients}

\section{Rate coefficient data}

\begin{tabular}{|c|c|c|c|}
\hline$k_{\infty} / \mathrm{cm}^{3}$ molecule ${ }^{-1} \mathrm{~s}^{-1}$ & Temp./K & Reference & Technique/Comments \\
\hline \multicolumn{4}{|l|}{ Absolute Rate Coefficients } \\
\hline $6.1 \times 10^{-12}$ & 298 & Basco and Parmar, 1987 & FP-AS (a) \\
\hline$(1.21 \pm 0.05) \times 10^{-11}(T / 298)^{-0.9}$ & $248-393$ & Bridier et al., 1991 & FP-AS (b) \\
\hline$(1.0 \pm 0.2) \times 10^{-11}(0.93$ bar $)$ & 295 & Sehested et al., 1998 & PR-A (c) \\
\hline
\end{tabular}




\section{Comments}

(a) See comment (a) for $k_{0}$.

(b) See comment (b) for $k_{0}$.

(c) $\mathrm{CH}_{3} \mathrm{C}(\mathrm{O}) \mathrm{O}_{2}$ radicals were generated from the pulsed radiolysis of $\mathrm{CH}_{3} \mathrm{CHO}-\mathrm{O}_{2}-\mathrm{CO}_{2}-\mathrm{NO}_{2}$ and $\mathrm{CH}_{3} \mathrm{CHO}_{-} \mathrm{SF}_{6}-\mathrm{O}_{2}-\mathrm{NO}_{2}$ mixtures and the disappearance rate of $\mathrm{NO}_{2}$ monitored by absorption at 400.5 and $452 \mathrm{~nm}$.

\section{Preferred Values}

$k=1.0 \times 10^{-11} \mathrm{~cm}^{3}$ molecule $\mathrm{e}^{-1} \mathrm{~s}^{-1}$ at $298 \mathrm{~K}$ and 1 bar of air.

$k_{\infty}=1.2 \times 10^{-11}(T / 300)^{-0.9} \mathrm{~cm}^{3}$ molecule $\mathrm{s}^{-1} \mathrm{~s}^{-1}$ over the temperature range $250-300 \mathrm{~K}$.

\section{Reliability}

$\Delta \log k_{\infty}= \pm 0.2$ at $298 \mathrm{~K}$.

$\Delta n= \pm 1$.

\section{Comments on Preferred Values}

See comments on $k_{0}$. The measurement of Sehested et al. (1998) is in very good agreement with the results from Bridier et al. (1991) which form the basis of the preferred value.

\section{References}

Addison, M. C., Burrows, J. P., Cox, R. A., and Patrick, R.: Chem. Phys. Lett., 73, 283, 1980.

Basco, N. and Parmar, S. S.: Int. J. Chem. Kinet., 19, 115, 1987.

Bridier, I., Caralp, F., Loirat, H., Lesclaux, R., Veyret, B., Becker, K. H., Reimer, A., and Zabel, F.: J. Phys. Chem., 95, 3594 , 1991.

Sehested, J., Christensen, L. K., Møgelberg, T., Nielsen, O. J., Wallington, T. J., Guschin, A., Orlando, J. J., and Tyndall, G. S.: J. Phys. Chem. A, 102, 1779, 1998. 
II.A6.133

$$
\mathrm{CH}_{3} \mathrm{C}(\mathrm{O}) \mathrm{O}_{2} \mathrm{NO}_{2}+\mathrm{M} \rightarrow \mathrm{CH}_{3} \mathrm{C}(\mathrm{O}) \mathrm{O}_{2}+\mathrm{NO}_{2}+\mathrm{M}
$$

$\Delta H^{\circ}=119 \mathrm{~kJ} \cdot \mathrm{mol}^{-1}$

Low-pressure rate coefficients

Rate coefficient data

\begin{tabular}{llll}
\hline$k_{0} / \mathrm{s}^{-1}$ & Temp./K & Reference & Technique/Comments \\
\hline Absolute Rate Coefficients & & & \\
$(4.9 \pm 0.3) \times 10^{-3} \exp (-12100 / T)\left[\mathrm{N}_{2}\right]$ & $300-330$ & Bridier et al., 1991 & FTIR (a) \\
$1.1 \times 10^{-20}\left[\mathrm{~N}_{2}\right]$ & $298^{*}$ & & \\
\hline
\end{tabular}

\section{Comments}

(a) Rate of the thermal decomposition of $\mathrm{CH}_{3} \mathrm{C}(\mathrm{O}) \mathrm{OONO}_{2}(\mathrm{PAN})$ measured by FTIR absorption spectroscopy in the presence of an excess of $\mathrm{NO}$ to scavenge $\mathrm{CH}_{3} \mathrm{CO}_{3}$ radicals. Pressure range $10 \mathrm{mbar}$ to $790 \mathrm{mbar}$ of $\mathrm{N}_{2}$. Falloff curves were analyzed with $F_{c}=0.30$.

\section{Preferred Values}

$k_{0}=1.1 \times 10^{-20}\left[\mathrm{~N}_{2}\right] \mathrm{s}^{-1}$ at $298 \mathrm{~K}$.

$k_{0}=4.9 \times 10^{-3} \exp (-12100 / T)\left[\mathrm{N}_{2}\right] \mathrm{s}^{-1}$ over the temperature range $300-330 \mathrm{~K}$.

\section{Reliability}

$\Delta \log k_{0}= \pm 0.3$ at $298 \mathrm{~K}$.

$\Delta(E / R)= \pm 1000 \mathrm{~K}$.

\section{Comments on Preferred Values}

The data base of Bridier et al. (1991) is large enough to allow for a falloff extrapolation to $k_{0}$, in part because falloff curves for PAN dissociation and recombination were measured independently. Falloff extrapolations were made with a modeled value of $F_{c}=0.3$; see the evaluation of the data from Bridier et al. (1991) in Zabel (1995).

\section{High-pressure rate coefficients}

\section{Rate coefficient data}

\begin{tabular}{llll}
\hline$k_{\infty} / \mathrm{s}^{-1}$ & Temp./K & Reference & Technique/Comments \\
\hline Absolute Rate Coefficients & & & \\
$(3.3 \pm 0.2) \times 10^{-4}$ & 297 & Niki et al., 1985 & FTIR (a) \\
$2.2 \times 10^{-4}$ & 298 & Senum et al., 1986 & FTIR (b) \\
$2.52 \times 10^{16} \exp (-13573 / T)$ & $283-313$ & Tuazon et al., 1991 & FTIR (c) \\
$4.2 \times 10^{-4}$ & 298 & & \\
$\left.(4.0 \pm 0.8) \times 10^{16} \exp (-13600) / T\right]$ & $300-330$ & Bridier et al., 1991 & $(\mathrm{d})$ \\
$6.1 \times 10^{-4}$ & $298^{*}$ & & \\
$2.5 \times 10^{17} \exp [-(14340 \pm 250) / T]$ & $302-323$ & Roberts and Bertman, 1992 & GC (e) \\
$3.2 \times 10^{-4}$ & $298^{*}$ & & \\
$3.1 \times 10^{-4}$ & 298 & Roumelis and Glavas, 1992 & GC (f) \\
$1.6 \times 10^{16} \exp [-(13539 \pm 1060) / T]$ & $288-298$ & Grosjean et al., 1994 & GC (g) \\
$3.0 \times 10^{-4}$ & 298 & & \\
\hline
\end{tabular}




\section{Comments}

(a) Decay of $\mathrm{CH}_{3} \mathrm{C}(\mathrm{O}) \mathrm{O}_{2}{ }^{15} \mathrm{NO}_{2}$ in the presence of ${ }^{14} \mathrm{NO}_{2}$ at a total pressure of 900 mbar of $\mathrm{N}_{2}$.

(b) Decay of $\mathrm{CH}_{3} \mathrm{C}(\mathrm{O}) \mathrm{O}_{2} \mathrm{NO}_{2}(\mathrm{PAN})$ in the presence of $\mathrm{NO}$ at a total pressure of 16 mbar.

(c) Thermal decomposition of PAN in an environmental chamber in the presence of 970 mbar of synthetic air or $\mathrm{N}_{2}$.

(d) See comment (a) for $k_{0}$.

(e) Thermal decomposition of PAN at 1 bar total pressure. PAN concentrations were measured by GC with electron capture detection.

(f) Thermal decomposition of PAN in $\mathrm{N}_{2}$ as well as in the presence of $\mathrm{O}_{2}, \mathrm{NO}_{2}$ and $\mathrm{NO}$ at 1 bar total pressure. The products methyl nitrate and $\mathrm{NO}_{2}$ in PAN-N $\mathrm{N}_{2}$ mixtures were measured by GC. In the presence of large amounts of $\mathrm{O}_{2}$, no methyl nitrate was formed at $333 \mathrm{~K}$, indicating that the decomposition of PAN to methyl nitrate and $\mathrm{CO}_{2}$ does not occur. The data obtained were simulated with 23 reactions.

(g) Thermal decomposition of PAN in 1 bar of air. PAN was measured by GC with electron capture detection.

\section{Preferred Values}

$k=3.3 \times 10^{-4} \mathrm{~s}^{-1}$ at $298 \mathrm{~K}$ and 1 bar of air.

$k_{\infty}=3.8 \times 10^{-4} \mathrm{~s}^{-1}$ at $298 \mathrm{~K}$.

$k_{\infty}=5.4 \times 10^{16} \exp (-13830 / T) \mathrm{s}^{-1}$ over the temperature range $300-330 \mathrm{~K}$.

\section{Reliability}

$\Delta \log k_{\infty}= \pm 0.3$ at $298 \mathrm{~K}$.

$\Delta(E / R)= \pm 300 \mathrm{~K}$.

\section{Comments on Preferred Values}

The reported values from Bridier et al. (1991), Tuazon et al. (1991), Roberts and Bertman, (1992) and Roumelis and Glavas (1992) as well as the selected more recent measurements from Sehested et al. (1998) are all in very good agreement at $298 \mathrm{~K}$ and are preferred here. The direct PAN decompositions to methyl nitrate and $\mathrm{CO}_{2}$ (Roumelis and Glavas, 1992; Orlando et al., 1992) or to $\mathrm{CH}_{3} \mathrm{C}(\mathrm{O}) \mathrm{O}$ and $\mathrm{NO}_{3}$ (Orlando et al., 1992) are very slow compared to the decomposition to $\mathrm{CH}_{3} \mathrm{C}(\mathrm{O}) \mathrm{O}_{2}+\mathrm{NO}_{2}$.

\section{References}

Bridier, I., Caralp, F., Loirat, H., Lesclaux, R., Veyret, B., Becker, K. H., Reimer, A., and Zabel, F.: J. Phys. Chem., 95, 3594, 1991.

Grosjean, D., Grosjean, E., and Williams II, E. L.: Air and Waste 44, 391. 1994.

Niki, H., Maker, P. D., Savage, C. M., and Breitenbach, L. P. : Int. J. Chem. Kinet., 17, 525, 1985.

Orlando, J. J., Tyndall, G. S., and Calvert, J. G.: Atmos. Environ., 26A, 3111, 1992.

Roberts, J. M. and Bertman, S. B.: Int. J. Chem. Kinet., 24, 297, 1992.

Roumelis, N. and Glavas, S.: Monatshefte für Chemie., 123, 63, 1992.

Sehested, J., Christensen, L. K., Møgelberg, T., Nielsen, O. J., Wallington, T. J., Guschin, A., Orlando, J. J., and Tyndall, G. S.: J. Phys. Chem. A, 102, 1779, 1998.

Senum, G. I., Fajer, R., and Gaffney, J. S.: J. Phys. Chem., 90, 152, 1986.

Tuazon, E. C., Carter, W. P. L., and Atkinson, R.: J. Phys. Chem., 95, 2434, 1991.

Zabel, F.: Z. Phys. Chem., 188, 119, 1995. 
II.A6.134

$$
\mathrm{C}_{2} \mathrm{H}_{5} \mathrm{C}(\mathrm{O}) \mathrm{O}_{2} \mathrm{NO}_{2}+\mathrm{M} \rightarrow \mathrm{C}_{2} \mathrm{H}_{5} \mathrm{C}(\mathrm{O}) \mathrm{O}_{2}+\mathrm{NO}_{2}+\mathrm{M}
$$

\section{Low-pressure rate coefficients}

\section{Rate coefficient data}

\begin{tabular}{llll}
\hline$k_{0} / \mathrm{s}^{-1}$ & Temp./K & Reference & Technique/Comments \\
\hline Absolute Rate Coefficients & & & \\
$1.7 \times 10^{-3} \exp (-11280 / T)\left[\mathrm{N}_{2}\right]$ & $291-320$ & Kirchner et al., 1999 & (a) \\
\hline
\end{tabular}

\section{Comments}

(a) Experiments in a $420 \mathrm{~L}$ reaction chamber with photolytic generation of radicals forming peroxynitrates. Decomposition of propionyl peroxynitrate followed in the dark by FTIR spectrometry. Experiments between 11.5 and 1013 mbar of $\mathrm{N}_{2}$. Falloff extrapolations with $F_{c}=0.36$.

\section{Preferred Values}

$k_{0}=6.2 \times 10^{-20}\left[\mathrm{~N}_{2}\right] \mathrm{s}^{-1}$ at $298 \mathrm{~K}$.

$k_{0}=1.7 \times 10^{-3} \exp (-11280 / T)\left[\mathrm{N}_{2}\right] \mathrm{s}^{-1}$ over the temperature range $290-320 \mathrm{~K}$.

\section{Reliability}

$\Delta \log k_{0}= \pm 0.5$ at $298 \mathrm{~K}$.

$\Delta(E / R)= \pm 2000 \mathrm{~K}$.

\section{Comments on Preferred Values}

The only available low pressure data from Kirchner et al. (1999) appear consistent with the more extensive data base for the high-pressure range. The falloff curve is constructed with $F_{c}=0.36$.

\section{High-pressure rate coefficients}

\section{Rate coefficient data}

\begin{tabular}{llll}
\hline$k_{\infty} / \mathrm{s}^{-1}$ & Temp./K & Reference & Technique/Comments \\
\hline Absolute Rate Coefficients & & & \\
$2 \times 10^{15} \exp (-12800 / T)$ & $300-315$ & Mineshos and Glavas, 1991 & (a) \\
$4.4 \times 10^{-4}$ & $298^{*}$ & & (b) \\
$8.3 \times 10^{16} \exp (-13940 / T)$ & $291-320$ & Kirchner et al., 1999 & (298 \\
$4.0 \times 10^{-4}$ & 298 & & \\
\hline
\end{tabular}

\section{Comments}

(a) Thermal decomposition of propionyl peroxynitrate (PPN) in a 4.5 liter glass flask in the presence of 1 bar of $\mathrm{N}_{2}$. PPN and the products ethyl nitrate, $\mathrm{NO}_{2}$, and methyl nitrate were analyzed by $\mathrm{GC}$ at $323 \mathrm{~K}$. In the presence of $\mathrm{NO}$, ethyl nitrate was the major product observed.

(b) See comment (a) for $k_{0}$. Limited data from earlier work are also considered. 


\section{Preferred Values}

$k=3.6 \times 10^{-4} \mathrm{~s}^{-1}$ at $298 \mathrm{~K}$ and 1 bar of air.

$k_{\infty}=4.0 \times 10^{-4} \mathrm{~s}^{-1}$ at $298 \mathrm{~K}$.

$k_{\infty}=8.3 \times 10^{16} \exp (-13940 / T) \mathrm{s}^{-1}$ over the temperature range $290-320 \mathrm{~K}$.

\section{Reliability}

$\Delta \log k_{\infty}= \pm 0.2$ at $298 \mathrm{~K}$.

$\Delta(E / R)= \pm 1000 \mathrm{~K}$.

\section{Comments on Preferred Values}

The values from Kirchner et al. (1999) and Minoshos and Glavas (1991) are in good agreement.

\section{References}

Kirchner, F., Mayer-Figge, A., Zabel, F., and Becker, K. H.: Int. J. Chem. Kinet., 31, 127, 1999.

Mineshos, G. and Glavas, S : React. Kinet. Catal. Lett., 45, 30, 5, 1991. 
II.A6.135

$$
\mathrm{CH}_{3} \mathrm{C}(\mathrm{O}) \mathrm{CH}_{2} \mathrm{O}_{2} \mathrm{NO}_{2}+\mathrm{M} \rightarrow \mathrm{CH}_{3} \mathrm{C}(\mathrm{O}) \mathrm{CH}_{2} \mathrm{O}_{2}+\mathrm{NO}_{2}+\mathrm{M}
$$

\section{High-pressure rate coefficients}

\section{Rate coefficient data}

\begin{tabular}{llll}
\hline$k_{\infty} / \mathrm{s}^{-1}$ & Temp./K & Reference & Technique/Comments \\
\hline Absolute Rate Coefficients & & & \\
$1.9 \times 10^{16} \exp (-10830 / T)$ & $250-298$ & Sehested et al., 1998 & (a) \\
$\sim 3$ & 295 & & \\
$1.0 \times 10^{16} \exp (-10630 / T)$ & $246-262$ & Kirchner et al., 1999 & (b) \\
\hline
\end{tabular}

\section{Comments}

(a) Loss of $\mathrm{CH}_{3} \mathrm{C}(\mathrm{O}) \mathrm{CH}_{2} \mathrm{O}_{2} \mathrm{NO}_{2}$, which was produced by static photolysis in a 1401 pyrex reaction chamber at pressure of 933 mbar, was followed by long path FTIR. $k$ at room temperature $(295 \mathrm{~K})$ obtained by fitting acetonyl peroxynitrate decay with a complex mechanism. Data for low temperature (250-275 K) were obtained directly from the decay of preformed $\mathrm{CH}_{3} \mathrm{C}(\mathrm{O}) \mathrm{CH}_{2} \mathrm{O}_{2} \mathrm{NO}_{2}$ after the addition of excess $\mathrm{NO}$.

(b) Experiments in a $420 \mathrm{~L}$ reaction chamber with photolytic generation of radicals forming peroxynitrates. Decomposition of acetonyl peroxynitrate in the dark followed by FTIR spectrometry. Measurements in 10, 100, and $800 \mathrm{mbar}$ of $\mathrm{N}_{2}$. Rate coefficients at 10 mbar are about a factor of 2 smaller than at 800 mbar.

\section{Preferred Values}

$k_{\infty}=1.4 \times 10^{16} \exp (-10730 / T) \mathrm{s}^{-1}$ over the temperature range $240-260 \mathrm{~K}$.

\section{Reliability}

$\Delta \log k_{\infty}= \pm 0.3$ at $250 \mathrm{~K}$.

$\Delta(E / R)= \pm 200 \mathrm{~K}$.

\section{Comments on Preferred Values}

The results from the two experimental studies are essentially in agreement, and are consistent with data for related reactions. The preferred Arrhenius parameters are a simple mean of the reported experimental values. The measured rate coefficients are expected, by analogy with the corresponding PAN decomposition at 1 bar of air (IUPAC, this evaluation), to be very close to the high pressure limit.

\section{References}

Kirchner, F., Mayer-Figge, A., Zabel, F. and Becker, K. H.: Int. J. Chem. Kinet. 31, 127, 1999.

Sehested, J., Christenson, L. K., Nielsen, O. J., Bilde, M., Wallington, T. J.,Schneider, W. F., Orlando, J. J. and Tyndall, G. S.: Int. J. Chem. Kinet. 30, 475, 1998. 
II.A6.136

$$
\mathrm{CH}_{2}=\mathrm{C}\left(\mathrm{CH}_{3}\right) \mathrm{C}(\mathrm{O}) \mathrm{OONO}_{2}+\mathrm{M} \rightarrow \mathrm{CH}_{2}=\mathrm{C}\left(\mathrm{CH}_{3}\right) \mathrm{CO}_{3}+\mathrm{NO}_{2}+\mathrm{M}
$$

\section{Rate coefficient data}

\begin{tabular}{llll}
\hline$k / \mathrm{s}^{-1}$ & Temp./K & Reference & Technique/Comments \\
\hline Absolute Rate Coefficients & & & \\
$1.58 \times 10^{16} \exp [-(13488 \pm 504) / T]$ & $302.25-323.55$ & Roberts and Bertman, 1992 & (a) \\
$3.5 \times 10^{-4}$ & $298^{*}$ & & \\
\hline
\end{tabular}

\section{Comments}

(a) The thermal decomposition of $\mathrm{CH}_{2}=\mathrm{C}\left(\mathrm{CH}_{3}\right) \mathrm{C}(\mathrm{O}) \mathrm{OONO}_{2}$ (MPAN) was studied in one atmosphere of air, with added NO to ensure that $\mathrm{CH}_{2}=\mathrm{C}\left(\mathrm{CH}_{3}\right) \mathrm{C}(\mathrm{O}) \mathrm{OO}$ radicals reacted with $\mathrm{NO}$ (to form $\mathrm{NO}_{2}+\mathrm{CO}_{2}+\mathrm{CH}_{2}=\mathrm{CCH}_{3}$ ) rather than reacting with $\mathrm{NO}_{2}$ to reform MPAN. MPAN concentrations were measured by $\mathrm{GC}$ with electron capture detection.

\section{Preferred Values}

$k=3.5 \times 10^{-4} \mathrm{~s}^{-1}$ at $298 \mathrm{~K}$ and 1 bar.

$k=1.6 \times 10^{16} \exp (-13500 / T) \mathrm{s}^{-1}$ over the temperature range $290-330 \mathrm{~K}$ at $1 \mathrm{bar}$.

\section{Reliability}

$\Delta \log k= \pm 0.3$ at $298 \mathrm{~K}$.

$\Delta(E / R)= \pm 1000 \mathrm{~K}$.

\section{Comments on Preferred Values}

The preferred values are based on the sole study of this reaction by Roberts and Bertman (1992). The preferred values for the decomposition of MPAN are very similar to those for the thermal decomposition of $\mathrm{CH}_{3} \mathrm{C}(\mathrm{O}) \mathrm{OONO}_{2}(\mathrm{PAN})$ (Roberts and Bertman, 1992; IUPAC, see also this evaluation). The rate coefficients measured by Roberts and Bertman (1992) are expected, by analogy with the corresponding PAN decomposition (IUPAC, this evaluation), to be very close to the high pressure limit at 1 bar of air.

\section{References}

Roberts, J. M. and Bertman, S. B.: Int. J. Chem. Kinet., 24, 297, 1992. 
II.A6.137

$$
\begin{aligned}
\mathrm{CH}_{3} \mathrm{O}_{2}+\mathrm{NO}_{3} & \rightarrow \mathrm{CH}_{3} \mathrm{O}+\mathrm{NO}_{2}+\mathrm{O}_{2} \\
& \rightarrow \text { other products }
\end{aligned}
$$

$\Delta H^{\circ}(1)=-32.3 \mathrm{~kJ} \cdot \mathrm{mol}^{-1}$

Rate coefficient data $\left(k=k_{1}+k_{2}\right)$

\begin{tabular}{lclc}
\hline$k / \mathrm{cm}^{3}$ molecule ${ }^{-1} \mathrm{~s}^{-1}$ & Temp./K & Reference & Technique/Comments \\
\hline Absolute Rate Coefficients & & & \\
$(2.3 \pm 0.7) \times 10^{-12}$ & 298 & Crowley et al., 1990 & MMS-AS (a) \\
$(1.0 \pm 0.6) \times 10^{-12}$ & 298 & Biggs et al., 1994a, b & DF-LIF/AS (b) \\
$(1.2 \pm 0.6) \times 10^{-12}$ & 298 & Daële et al., 1995 & DF-LIF/MS (c) \\
$(1.3 \pm 0.2) \times 10^{-12}$ & 298 & Helleis et al., 1996 & DF-MS (d) \\
& & & \\
Branching Ratios & 298 & Kukui et al., 1995 & DF-LIF/MS (e) \\
$k_{1} / k>0.9$ & & &
\end{tabular}

\section{Comments}

(a) Computer simulation of $\mathrm{NO}_{3}$ absorption profiles formed in the modulated photolysis of $\mathrm{HNO}_{3}$ in the presence of $\mathrm{CH}_{4}$ and $\mathrm{O}_{2}$.

(b) $\mathrm{CH}_{3} \mathrm{O}$ product of Reaction (1) measured by LIF; $\mathrm{NO}_{3}$ by visible absorption spectroscopy. Pressure $=3.5$ mbar. Modelling of $\mathrm{CH}_{3} \mathrm{O}$ time-dependence gave $k / k\left(\mathrm{CH}_{3} \mathrm{O}+\mathrm{NO}_{3}\right)=0.43 \pm 0.09$. $k$ calculated with $k\left(\mathrm{CH}_{3} \mathrm{O}+\mathrm{NO}_{3}\right)=(2.3 \pm 0.7) \times 10^{-12} \mathrm{~cm}^{3}$ molecule $\mathrm{e}^{-1} \mathrm{~s}^{-1}$ obtained in a similar study in the same apparatus.

(c) $\mathrm{CH}_{3} \mathrm{O}$ measured by LIF; $\mathrm{NO}_{3}$ by titration with 2,3-dimethyl-2-butene. The rate coefficient was extracted by numerical simulation from the $\mathrm{CH}_{3} \mathrm{O}+\mathrm{NO}_{3}$ reactant system.

(d) $\mathrm{CD}_{3} \mathrm{O}_{2}$ decay measured directly in excess $\mathrm{NO}_{3}$. Numerical simulation to take into account the re-formation of $\mathrm{CD}_{3} \mathrm{O}_{2}$ from $\mathrm{CD}_{3} \mathrm{O}+\mathrm{NO}_{3}$.

(e) Based on observations of DCDO formation from the $\mathrm{CD}_{3} \mathrm{O}+\mathrm{NO}_{3}$ reaction and the relative rates of reactions of $\mathrm{CD}_{3} \mathrm{O}$ and $\mathrm{CD}_{3} \mathrm{O}_{2}$ with $\mathrm{NO}_{3}$.

\section{Preferred Values}

$k=1.3 \times 10^{-12} \mathrm{~cm}^{3}$ molecule $\mathrm{s}^{-1} \mathrm{~s}^{-1}$ at $298 \mathrm{~K}$.

$k_{2} / k=0$ at $298 \mathrm{~K}$.

\section{Reliability}

$\Delta \log k= \pm 0.3$ at $298 \mathrm{~K}$.

\section{Comments on Preferred Values}

None of the experimental studies for this reaction can be described as definitive or direct. In the flow tube measurements, a quasi-equilibrium between $\mathrm{CH}_{3} \mathrm{O}_{2}$ and $\mathrm{CH}_{3} \mathrm{O}$ radicals is established and concentrations and decay kinetics are influenced by reactions of both radicals. The ratio $k_{1} / k\left(\mathrm{CH}_{3} \mathrm{O}+\mathrm{NO}_{3}\right)$ should be well determined but values of 0.43 (Biggs et al., $1994 \mathrm{~b}$ ), 0.66 (Biggs et al., 1994a) and 0.30 (Daële et al., 1995) were obtained. The quasi-equilibrium is avoided by using $\mathrm{O}_{2}$ to scavenge $\mathrm{CH}_{3} \mathrm{O}$ in the work of Crowley et al. (1990) but the need to simulate a complex reaction system, and the possible influence of a dark reaction (Crowley et al., 1993) that generated $\mathrm{NO}_{3}$ reduce the reliability of these experiments. 
The method used by Helleis et al. (1996) to determine $k_{1}$ is the most direct. Their analysis considers all of the available information on the secondary chemistry and their value is recommended with wide error limits. The value reported by Kukui et al. (1995) differs substantially from those of Biggs et al. (1994a, b), Daële et al. (1995) and Helleis et al. (1996) and was not included in the evaluation of the rate coefficient. Their work (Kukui et al., 1995) suggests channel (1) is the predominant pathway, with $k_{2} / k<0.10$.

\section{References}

Biggs, P., Canosa-Mas, C. E., Fracheboud, J. -M., Shallcross, D. E., and Wayne, R. P.: J. Chem. Soc. Faraday Trans., 90, 1197, 1994a.

Biggs, P., Canosa-Mas, C. E., Fracheboud, J. -M., Shallcross, D. E., and Wayne, R. P.: J. Chem. Soc. Faraday Trans., 90, 1205, 1994b.

Crowley, J. N., Burrows, J. P., Moortgat, G. K., Poulet, G., and Le Bras, G.: Int. J. Chem. Kinet., 22, 673, 1990.

Crowley, J. N., Burrows, J. P., Moortgat, G. K., Poulet, G., and Le Bras, G.: Int. J. Chem. Kinet., 25, 795, 1993.

Daële, V., Laverdet, G., Le Bras, G., and Poulet, G.: J. Phys. Chem., 99, 1470, 1995.

Helleis, F., Moortgat, G. K., and Crowley, J. N.: J. Phys. Chem., 100, 17 846, 1996.

Kukui, A. S., Jungkamp, T. P. W., and Schindler, R. N.: Ber. Bunsenges. Phys. Chem., 99, 1565, 1995. 
II.A6.138

$$
\begin{aligned}
\mathrm{C}_{2} \mathrm{H}_{5} \mathrm{O}_{2}+\mathrm{NO}_{3} & \rightarrow \mathrm{C}_{2} \mathrm{H}_{5} \mathrm{O}+\mathrm{NO}_{2}+\mathrm{O}_{2} \\
& \rightarrow \text { other products }
\end{aligned}
$$

$\Delta H^{\circ}(1)=-28.7 \mathrm{~kJ} \cdot \mathrm{mol}^{-1}$

\begin{tabular}{|c|c|c|c|}
\hline$k / \mathrm{cm}^{3}$ molecule $^{-1} \mathrm{~s}^{-1}$ & Temp./K & Reference & Technique/Comments \\
\hline $\begin{array}{l}\text { Absolute Rate Coefficients } \\
(2.5 \pm 1.5) \times 10^{-12}\end{array}$ & 298 & Biggs et al., 1995 & DF-LIF/AS (a) \\
\hline$(2.3 \pm 0.5) \times 10^{-12}$ & 298 & Ray et al., 1996 & DF-LIF/MS (b) \\
\hline
\end{tabular}

Rate coefficient data $\left(k=k_{1}+k_{2}\right)$

\section{Comments}

(a) LIF detection of $\mathrm{C}_{2} \mathrm{H}_{5} \mathrm{O}$. Detection of $\mathrm{NO}_{3}$ by absorption spectroscopy at $662 \mathrm{~nm}$. $k$ was derived by modelling the kinetics of $\mathrm{C}_{2} \mathrm{H}_{5} \mathrm{O}_{2}+\mathrm{NO}_{3}$ in systems using $\mathrm{C}_{2} \mathrm{H}_{5}+\mathrm{O}_{2}$ and $\mathrm{C}_{2} \mathrm{H}_{5} \mathrm{O}+\mathrm{NO}_{3}$ to generate $\mathrm{C}_{2} \mathrm{H}_{5} \mathrm{O}_{2}$. Pressure $=2.9 \mathrm{mbar}$ of He.

(b) LIF detection of $\mathrm{C}_{2} \mathrm{H}_{5} \mathrm{O}$. MS detection of $\mathrm{NO}_{3}$. $k$ was derived from a model simulation of system using $\mathrm{C}_{2} \mathrm{H}_{5} \mathrm{O}_{2}$ as initial reactant, with $\mathrm{NO}_{3}$ in excess.

\section{Preferred Values}

$k_{1}=2.3 \times 10^{-12} \mathrm{~cm}^{3}$ molecule $\mathrm{s}^{-1} \mathrm{~s}^{-1}$ at $298 \mathrm{~K}$.

\section{Reliability}

$\Delta \log k= \pm 0.2$ at $298 \mathrm{~K}$.

\section{Comments on Preferred Values}

Both studies of this reaction used basically the same technique and gave similar results (Biggs et al., 1995; Ray et al., 1996). Extraction of values for $k$ relies on modelling of the reaction system because radical concentrations are controlled by coupling between the $\mathrm{C}_{2} \mathrm{H}_{5} \mathrm{O}_{2}+\mathrm{NO}_{3}$ reaction and the reaction of the product $\mathrm{C}_{2} \mathrm{H}_{5} \mathrm{O}$ with $\mathrm{NO}_{3}$, which regenerates $\mathrm{C}_{2} \mathrm{H}_{5} \mathrm{O}_{2}$. The study of Ray et al. (1996) gave better defined $k$ values and is the basis of the recommendation. Channel (1) is most important, and Biggs et al. (1995) suggest that $k_{1} / k \approx 0.8$.

\section{References}

Biggs, P., Canosa-Mas, C. E., Fracheboud, J.-M., Shallcross, D. E., and Wayne, R. P.: J. Chem. Soc. Faraday Trans., 91, 817, 1995.

Ray, A., Daële, V., Vassalli, I., Poulet, G., and LeBras, G.: J. Phys. Chem., 100, 5737, 1996. 
II.A6.139

$$
\begin{aligned}
\mathrm{CH}_{3} \mathrm{O}_{2}+\mathrm{CH}_{3} \mathrm{O}_{2} & \rightarrow \mathrm{CH}_{3} \mathrm{OH}+\mathrm{HCHO}+\mathrm{O}_{2} \\
& \rightarrow 2 \mathrm{CH}_{3} \mathrm{O}+\mathrm{O}_{2} \\
& \rightarrow \mathrm{CH}_{3} \mathrm{OOCH}+\mathrm{O}_{2}
\end{aligned}
$$

$\Delta H^{\circ}(1)=-331.0 \mathrm{~kJ} \cdot \mathrm{mol}^{-1}$

$\Delta H^{\circ}(2)=13.6 \mathrm{~kJ} \cdot \mathrm{mol}^{-1}$

$\Delta H^{\circ}(3)=-146.5 \mathrm{~kJ} \cdot \mathrm{mol}^{-1}$

Rate coefficient data $\left(k=k_{1}+k_{2}+k_{3}\right)$

\begin{tabular}{lllc}
\hline$k / \mathrm{cm}^{3}$ molecule $\mathrm{s}^{-1}$ & Temp./K & Reference & Technique/Comments \\
\hline $\begin{array}{l}\text { Absolute Rate Coefficients } \\
(5.2 \pm 0.9) \times 10^{-13}\end{array}$ & 298 & Cox and Tyndall, 1980 & MM-UVAS (a,b) \\
$(3.7 \pm 0.7) \times 10^{-13}$ & 298 & Sander and Watson, 1980 & FP-UVAS (a,c) \\
$1.40 \times 10^{-13} \exp [(223 \pm 41) / T]$ & $250-420$ & Sander and Watson, 1981 & FP-UVAS (a,d) \\
$(3.0 \pm 0.5) \times 10^{-13}$ & 298 & & \\
$(4.4 \pm 1.0) \times 10^{-13}$ & 298 & McAdam et al., 1987 & FP-UVAS (a,e) \\
$1.3 \times 10^{-13} \exp [(220 \pm 70 / T)]$ & $228-380$ & Kurylo and Wallington, 1987 & FP-UVAS (a,f) \\
$(2.7 \pm 0.45) \times 10^{-13}$ & 298 & & \\
$(3.5 \pm 0.5) \times 10^{-13}$ & 298 & Jenkin et al., 1988 & MM-UVAS (a,g) \\
$(3.6 \pm 0.55) \times 10^{-13}$ & 300 & Simon et al., 1990 & MM-UVAS (a,h) \\
$1.3 \times 10^{-13} \exp (365 / T)$ & $248-573$ & Lightfoot et al.,, 1990 & FP-UVAS (a,i) \\
$(4.1 \pm 0.9) \times 10^{-13}$ & 300 & & \\
Branching Ratios & & & \\
$k_{2} / k=1 /\{1+\exp [(1131 \pm 30) / T] /(17 \pm 5)\}$ & $223-333$ & Horie et al., 1990 & \\
$k_{2} / k=0.30$ & 298 & & \\
$k_{2} / k=0.41 \pm 0.04$ & 296 & Tyndall et al., 1998 & P-FTIR (j) \\
$k_{3} / k<0.06$ & 296 & & \\
\hline
\end{tabular}

\section{Comments}

(a) $k$ is defined by $-d\left[\mathrm{CH}_{3} \mathrm{O}_{2}\right] / d t=2 k\left[\mathrm{CH}_{3} \mathrm{O}_{2}\right]^{2}$ and was derived from the measured overall second-order decay of $\mathrm{CH}_{3} \mathrm{O}_{2}$ radicals $k_{\text {obs }}$ by correcting for secondary removal of the $\mathrm{CH}_{3} \mathrm{O}_{2}$ radicals.

(b) $\left[\mathrm{CH}_{3} \mathrm{O}_{2}\right]$ determined by absorption at $250 \mathrm{~nm}$ in modulated photolysis of $\mathrm{Cl}_{2}-\mathrm{CH}_{4}-\mathrm{O}_{2}$ mixtures. $k / \sigma(250 \mathrm{~nm})=1.33 \times 10^{5} \mathrm{~cm} \mathrm{~s}^{-1}, \sigma=3.9 \times 10^{-18} \mathrm{~cm}^{2}$ molecule $^{-1}$ at $250 \mathrm{~nm}$.

(c) Flash-photolysis of $\left(\mathrm{CH}_{3}\right)_{2} \mathrm{~N}_{2}-\mathrm{O}_{2}$ and $\mathrm{Cl}_{2}-\mathrm{CH}_{4}-\mathrm{O}_{2}$ mixtures. $\left[\mathrm{CH}_{3} \mathrm{O}_{2}\right]$ monitored by long path $\mathrm{UV}$ absorption giving $k / \sigma=(1.06 \pm 0.07) \times 10^{5} \mathrm{~cm} \mathrm{~s}^{-1}$ at $245 \mathrm{~nm}$ and $(2.84 \pm 0.36) \times 10^{5} \mathrm{~cm} \mathrm{~s}^{-1}$ at $270 \mathrm{~nm}$. Value quoted is a mean value using $\sigma$ values obtained by Hochanadel et al. (1977). Small effects of varying $\mathrm{O}_{2}$ and adding $\mathrm{CO}$ are reported.

(d) Flash-photolysis of $\mathrm{Cl}_{2}-\mathrm{CH}_{4}-\mathrm{O}_{2}$ mixtures. $\sigma$ determined from absorption at $t=0$ extrapolated from decay curves and estimate of $\left[\mathrm{CH}_{3} \mathrm{O}_{2}\right]_{0}$ from change in $\mathrm{Cl}_{2}$ concentration in flash. $\sigma(250 \mathrm{~nm})=(2.5 \pm 0.4) \times 10^{-18} \mathrm{~cm}^{2}$ molecule ${ }^{-1}$ at $298 \mathrm{~K}$, and $k / \sigma(250 \mathrm{~nm})=(5.6 \pm 0.8) \times 10^{4} \exp [(223 \pm 41) / T] \mathrm{cm} \mathrm{s}^{-1}(250 \mathrm{~K}$ to $420 \mathrm{~K})$ were obtained.

(e) Flash-photolysis of $\mathrm{Cl}_{2}$ in the presence of $\mathrm{CH}_{4}$ and $\mathrm{O}_{2}$ over the pressure range 169 mbar to 530 mbar (120 Torr to 400 Torr). $\left[\mathrm{CH}_{3} \mathrm{O}_{2}\right]$ monitored by UV absorption. $k_{\mathrm{obs}} / \sigma(250 \mathrm{~nm})=1.34 \times 10^{5} \mathrm{~cm} \mathrm{~s}^{-1}$ and $\sigma(250 \mathrm{~nm})=4.4 \times 10^{-18} \mathrm{~cm}^{2} \mathrm{molecule}^{-1}$ were obtained. $k_{\mathrm{obs}} / k$ taken to be 1.35 . 
(f) Flash-photolysis of $\mathrm{Cl}_{2}$ in the presence of $\mathrm{CH}_{4}-\mathrm{O}_{2}-\mathrm{N}_{2}$ mixtures at pressures between 67 mbar and 530 mbar $(50$ Torr and 400 Torr $) . \quad k_{\text {obs }}=(1.7 \pm 0.4) \times 10^{-13} \exp [(220 \pm 70) / T] \mathrm{cm}^{3}$ molecule $\mathrm{s}^{-1} \mathrm{~s}^{-1}$ determined from measured values of $k_{\text {obs }} / \sigma(250)$ by taking $\sigma(250)=3.30 \times 10^{-18} \mathrm{~cm}^{2}$ molecule ${ }^{-1}$ as previously determined by same authors. Here we have taken $k_{\mathrm{obs}} / k=1.35$ to calculate $k$. $k_{\mathrm{obs}}$ shown to be independent of pressure over the range $67 \mathrm{mbar}$ to $530 \mathrm{mbar}$ (50 Torr to 400 Torr) at $298 \mathrm{~K}$.

(g) Modulated photolysis of $\mathrm{Cl}_{2}$ in the presence of $\mathrm{CH}_{4}-\mathrm{O}_{2}$ mixtures at a total pressure of 1 bar (760 Torr). $k_{\text {obs }} / \sigma(250 \mathrm{~nm})=1.11 \times 10^{5} \mathrm{~cm} \mathrm{~s}^{-1}$ and $\sigma(250 \mathrm{~nm})=(4.25 \pm 0.5) \times 10^{-18} \mathrm{~cm}^{2}$ molecule $^{-1}$ were obtained leading to $k_{\text {obs }}=(4.7 \pm 0.5) \times 10^{-13} \mathrm{~cm}^{3}$ molecule ${ }^{-1} \mathrm{~s}^{-1}$. Cited value of $k$ obtained by taking $k_{\mathrm{obs}} / k=1.35$ to allow for secondary removal of $\mathrm{CH}_{3} \mathrm{O}_{2}$.

(h) Modulated photolysis of $\mathrm{Cl}_{2}$ in the presence of $\mathrm{CH}_{4}-\mathrm{O}_{2}$ mixtures at pressures of $320 \mathrm{mbar}\left(240\right.$ Torr). $k_{\mathrm{obs}} / \sigma(250 \mathrm{~nm})=$ $1.16 \times 10^{5} \mathrm{~cm} \mathrm{~s}^{-1}$ and $\sigma(250 \mathrm{~nm})=4.14 \times 10^{-18} \mathrm{~cm}^{2}$ molecule ${ }^{-1}$ were obtained, leading to $k_{\text {obs }}=(4.8 \pm 0.5) \times 10^{-13} \mathrm{~cm}^{3}$ molecule ${ }^{-1} \mathrm{~s}^{-1}$. The cited value of $k$ was obtained by taking $k_{\text {obs }} / k=1.35$ to allow for secondary removal of $\mathrm{CH}_{3} \mathrm{O}_{2}$.

(i) Flash-photolysis of $\mathrm{Cl}_{2}$ in the presence of $\mathrm{CH}_{4}-\mathrm{O}_{2}-\mathrm{N}_{2}$ mixtures over the pressure range 270 mbar to 930 mbar (200 Torr to 700 Torr). $\mathrm{CH}_{3} \mathrm{O}_{2}$ radicals were monitored by UV absorption. The values $k_{\text {obs }} / \sigma(210 \mathrm{~nm}$ to $260 \mathrm{~nm})=1.17 \times 10^{5} \mathrm{~cm}$ $\mathrm{s}^{-1}$ and $\sigma(250 \mathrm{~nm})=4.8 \times 10^{-18} \mathrm{~cm}^{2}$ molecule ${ }^{-1}$ were obtained. $k_{\mathrm{obs}} / k$ taken to be 1.35 . At temperatures $>373 \mathrm{~K}$, the second-order decays of $\mathrm{CH}_{3} \mathrm{O}_{2}$ were affected by $\mathrm{HO}_{2}$ radical reactions. The branching ratio was obtained from the effect of $\left[\mathrm{HO}_{2}\right]$ on the $\mathrm{CH}_{3} \mathrm{O}_{2}$ decays.

(j) Study of the photooxidation of $\mathrm{CH}_{4}$, initiated by $\mathrm{Cl}$ atoms generated from $\mathrm{Cl}_{2}$, in a slow-flow system under steady-state illumination. Analysis of $\mathrm{HCHO}, \mathrm{CH}_{3} \mathrm{OH}$ and $\mathrm{HC}(\mathrm{O}) \mathrm{OH}$ products by FTIR spectroscopy.

(k) Photolysis of $\mathrm{CH}_{3} \mathrm{~N}_{2} \mathrm{CH}_{3}-\mathrm{O}_{2}$ and $\mathrm{Cl}_{2}-\mathrm{CH}_{4}-\mathrm{O}_{2}$ mixtures, with analyses of reactants and products by FTIR spectroscopy.

\section{Preferred Values}

$k=3.5 \times 10^{-13} \mathrm{~cm}^{3}$ molecule ${ }^{-1} \mathrm{~s}^{-1}$ at $298 \mathrm{~K}$.

$k=1.03 \times 10^{-13} \exp (365 / T) \mathrm{cm}^{3}$ molecule $\mathrm{s}^{-1}$ over the temperature range $200-400 \mathrm{~K}$.

$k_{2}=1.3 \times 10^{-13} \mathrm{~cm}^{3}$ molecule $\mathrm{s}^{-1} \mathrm{~s}^{-1}$ at $298 \mathrm{~K}$.

$k_{2}=7.4 \times 10^{-13} \exp (-520 / T) \mathrm{cm}^{3}$ molecule $\mathrm{s}^{-1}$ over the temperature range 220-330 K.

\section{Reliability}

$\Delta \log k= \pm 0.12$ at $298 \mathrm{~K}$.

$\Delta(E / R)= \pm 200 \mathrm{~K}$

$\Delta \log k_{2}= \pm 0.15$ at $298 \mathrm{~K}$.

$\Delta\left(E_{2} / R\right)= \pm 300 \mathrm{~K}$.

\section{Comments on Preferred Values}

The room temperature measurements of $k_{\mathrm{obs}} / \sigma$ of Cox and Tyndall (1980), Sander and Watson (1980,1981), McAdam et al. (1987), Kurylo and Wallington (1987), Jenkin et al. (1988), Simon et al. (1988) and Lightfoot et al. (1990) are in excellent agreement and lead to the recommended value of $k_{\mathrm{obs}} / \sigma(250 \mathrm{~nm})=1.24 \times 10^{5} \mathrm{~cm} \mathrm{~s}^{-1}$. The measurements of the absorption cross-section by Simon et al. (1990) form the basis of our recommendation of $\sigma(250 \mathrm{~nm})=3.9 \times 10^{-18} \mathrm{~cm}^{2} \mathrm{molecule}^{-1}$. Thus, we recommend $k_{\mathrm{obs}}=4.8 \times 10^{-13} \mathrm{~cm}^{3}$ molecule ${ }^{-1} \mathrm{~s}^{-1}$ at $298 \mathrm{~K}$. Taking the branching ratio of $k_{2} / k=0.37$ at $298 \mathrm{~K}$ yields the value of $k$ at $298 \mathrm{~K}$ given above.

The temperature dependence of $k$ reported by Lightfoot et al. (1990) is in excellent agreement with the studies of Sander and Watson (1981), Kurylo and Wallington (1987) and Jenkin and Cox (1991). Here we have recommended the $E / R$ value of Lightfoot et al. (1990) on the basis of their more extensive temperature range, and the temperature-dependent branching ratio $k_{2} / k$. The recommended Arrhenius equation follows from the recommended values of $k_{298}$ and $E / R$.

There have been a number of measurements of the branching ratio, $k_{2} / k$, which have been carefully reanalysed by Tyndall et al. (1998). The values of $k_{2} / k$ at $298 \mathrm{~K}$ range from 0.30 to 0.45 . Tyndall et al. (1998) recommend the average of $0.37 \pm 0.06$ which is also accepted in the review of Tyndall et al. (2001). This value is taken as our preferred value at $298 \mathrm{~K}$, with enhanced error limits. The two studies (Lightfoot et al., 1990; Horie et al., 1990) of the temperature dependence of 
the branching ratio involve different temperature ranges. Here we have selected the results of Horie et al. (1990) over the more atmospherically relevant temperature range of $200 \mathrm{~K}$ to $330 \mathrm{~K}$, modified to reproduce our recommended value of $k_{2} / k$ at $298 \mathrm{~K}$. This has been combined with our recommended expression for $k$ to obtain the preferred expression for $k_{2}$. There is no convincing evidence for any contribution from channel (3) (Tyndall et al., 1998).

It should be noted that, from an analysis of their own data (Horie et al., 1990) together with the results of Lightfoot et al. (1990), Anastasi et al. (1978), Kan et al. (1980), Parkes (1977), Niki et al. (1981) and Weaver et al. (1975), the equation $k_{2} / k=1 /(1+[\exp (1330 / T)] / 33)$ was obtained by Horie et al. (1990) for the more extensive temperature range $223 \mathrm{~K}$ to $573 \mathrm{~K}$. This equation shows slight non-Arrhenius behavior. Lightfoot et al. (1990) observed no pressure dependence of the branching ratio, $k_{2} / k$, over the range 0.28 bar to 1 bar.

\section{References}

Anastasi, C., Smith, I. W. M., and Parkes, D. A.: J. Chem. Soc. Faraday Trans., 1, 74, 1693, 1978.

Cox, R. A. and Tyndall, G. S.: J. Chem. Soc. Faraday Trans., 2, 76, 153, 1980.

Hochanadel, C. J., Ghormley, A., Boyle, J. W., and Ogren, P. J.: J. Phys. Chem., 81, 3, 1977.

Horie, O., Crowley, J. N. and Moortgat, G. K.: J. Phys. Chem., 94, 8198, 1990.

Jenkin, M. E. and Cox, R. A.: J. Phys. Chem. 95, 3229, 1991.

Jenkin, M. E., Cox, R. A., Hayman, G. D., and Whyte, L. J.: J. Chem. Soc. Faraday Trans., 2, 84, 913, 1988.

Kan, C. S., Calvert, J. G., and Shaw, J. H.: J. Phys. Chem., 84, 3411, 1980.

Kurylo, M. J. and Wallington, T. J.: Chem. Phys. Lett., 138, 543, 1987.

Lightfoot, P. D., Lesclaux, R., and Veyret, B.: J. Phys. Chem., 94, 700, 1990.

McAdam, K., Veyret, B., and Lesclaux, R.: Chem. Phys. Lett., 133, 39, 1987.

Niki, H., Maker, P. D., Savage, C. M., and Breitenbach, L. P.: J. Phys. Chem., 85, 877, 1981.

Parkes, D. A.: Int. J. Chem. Kinet., 9, 451, 1977.

Sander, S. P. and Watson, R. T.: J. Phys. Chem., 84, 1664, 1980.

Sander, S. P. and Watson, R. T.: J. Phys. Chem., 85, 2960, 1981.

Simon, F. G., Schneider, W., and Moortgat, G. K.: Int. J. Chem., 22, 791, 1990.

Tyndall, G. S., Cox, R. A., Granier, C., Lesclaux, R., Moortgat, G. K., Pilling, M. J., Ravishankara, A. R., and Wallington, T. J.: J. Geophys. Res., 106, 12 157, 2001.

Tyndall, G. S., Wallington, T. J., and Ball, J. C.: J. Phys. Chem A, 102, 2547, 1998.

Weaver, J., Meagher, J., Shortridge, R., and Heicklen, J.: J. Photochem., 4, 341, 1975. 
II.A6.140

$$
\begin{aligned}
\mathrm{CH}_{3} \mathrm{O}_{2}+\mathrm{CH}_{3} \mathrm{C}(\mathrm{O}) \mathrm{O}_{2} & \rightarrow \mathrm{CH}_{3} \mathrm{O}+\mathrm{CH}_{3} \mathrm{C}(\mathrm{O}) \mathrm{O}+\mathrm{O}_{2} \\
& \rightarrow \mathrm{CH}_{3} \mathrm{C}(\mathrm{O}) \mathrm{OH}+\mathrm{HCHO}+\mathrm{O}_{2}
\end{aligned}
$$

$\Delta H^{\circ}(1)=-27.3 \mathrm{~kJ} \cdot \mathrm{mol}^{-1}$

$\Delta H^{\circ}(2)=-378 \mathrm{~kJ} \cdot \mathrm{mol}^{-1}$

\begin{tabular}{|c|c|c|c|}
\hline$k / \mathrm{cm}^{3}$ molecule $^{-1} \mathrm{~s}^{-1}$ & Temp./K & Reference & Technique/Comments \\
\hline \multicolumn{4}{|l|}{ Absolute Rate Coefficients } \\
\hline$k_{1}=(8.8 \pm 1.5) \times 10^{-12}$ & 298 & Roehl et al., 1996 & PLP-UVAS (a) \\
\hline$k_{2}=(1.0 \pm 0.5) \times 10^{-12}$ & 298 & & \\
\hline $8.5 \times 10^{-13} \exp [(726 \pm 25) / T]$ & $209-358$ & Maricq and Szente, 1996 & PLP-UVAS (b) \\
\hline$(1.0 \pm 0.2) \times 10^{-11}$ & 298 & & \\
\hline$(8.2 \pm 0.6) \times 10^{-12}$ & 298 & Villenave and Lesclaux, 1996 & FP-UVAS (c) \\
\hline
\end{tabular}

Rate coefficient data $\left(k=k_{1}+k_{2}\right)$

\section{Comments}

(a) Acetyl radicals were produced from the photolysis of $\mathrm{Cl}_{2}-\mathrm{CH}_{3} \mathrm{CHO}-\mathrm{O}_{2}$ mixtures. $\mathrm{CH}_{3} \mathrm{O}_{2}$ radicals were produced as secondary products, or through added $\mathrm{CH}_{4} . \quad k$ depends on $\sigma\left[\mathrm{CH}_{3} \mathrm{C}(\mathrm{O}) \mathrm{O}_{2}\right]$ for which values of $3.21 \times 10^{-18} \mathrm{~cm}^{2}$ molecule $\mathrm{e}^{-1}$ at $240 \mathrm{~nm}$ and $6.67 \times 10^{-18} \mathrm{~cm}^{2}$ molecule ${ }^{-1}$ at $207 \mathrm{~nm}$ were obtained, relative to the $\mathrm{UV}$ spectrum of $\mathrm{C}_{2} \mathrm{H}_{5} \mathrm{O}_{2}$ $\left[\sigma(240 \mathrm{~nm})=4.36 \times 10^{-18} \mathrm{~cm}^{2}\right.$ molecule $\left.{ }^{-1}\right]$. A value of $k_{1} / k=0.9$ was used in the data analysis.

(b) Technique as for (a) but with UV spectra recorded on a gated diode array spectrometer. $\sigma\left[\mathrm{CH}_{3} \mathrm{C}(\mathrm{O}) \mathrm{O}_{2}\right]=6.5 \times 10^{-18} \mathrm{~cm}^{2}$ molecule ${ }^{-1}$ at $206 \mathrm{~nm}$ and $2.9 \times 10^{-18} \mathrm{~cm}^{2}$ molecule ${ }^{-1}$ at $250 \mathrm{~nm}$. On the basis of the HCHO kinetics observed it was concluded that channel (2) was dominant over the entire temperature range covered ( $209 \mathrm{~K}$ to $358 \mathrm{~K}$ ). A value of $k_{1} / k=0$ was used in the data analysis.

(c) $\mathrm{CH}_{3} \mathrm{O}_{2}$ radicals were generated simultaneously with $\mathrm{CH}_{3} \mathrm{C}(\mathrm{O}) \mathrm{O}_{2}$ radicals from the flash photolysis of $\mathrm{Cl}_{2}-\mathrm{CH}_{3} \mathrm{CHO}_{-}$ $\mathrm{CH}_{4}-\mathrm{O}_{2}$ mixtures. In the derivation of $k$, the branching ratio, $\alpha_{c}\left(=k_{1} / k\right)$ was assumed to be 0.65 but $k$ was found to vary by less than $15 \%$ upon varying $\alpha$ between 0.5 and 1.0 . Overall uncertainty was estimated to be $42 \%$ from error propagation analysis. A value of $k_{1} / k=0.65$ was used in the data analysis.

\section{Preferred Values}

$k=1.1 \times 10^{-11} \mathrm{~cm}^{3}$ molecule $\mathrm{e}^{-1} \mathrm{~s}^{-1}$ at $298 \mathrm{~K}$.

$k=2.0 \times 10^{-12} \exp (500 / T) \mathrm{cm}^{3}$ molecule ${ }^{-1} \mathrm{~s}^{-1}$ over the temperature range $200-350 \mathrm{~K}$.

$k_{1} / k=0.9$ at $298 \mathrm{~K}$.

$k_{2} / k=0.1$ at $298 \mathrm{~K}$.

\section{Reliability}

$\Delta \log k= \pm 0.15$ at $298 \mathrm{~K}$.

$\Delta(E / R)= \pm 250 \mathrm{~K}$.

$\Delta\left(k_{1} / k\right)=\Delta\left(k_{2} / k\right)= \pm 0.1$ at $298 \mathrm{~K}$.

\section{Comments on Preferred Values}

The three cited studies, which all used UV spectroscopy with similar values of the relevant absorption cross-sections to monitor the progress of the reaction are, apparently, in good agreement. However, the values of $k$ derived depend upon the value of $k_{1} / k$ used in the data analysis and since the three studies used values ranging from 0 to 0.9 their close agreement 
must be, to some degree, fortuitous. Tyndall et al. (2001) show that, using our preferred value for $k_{1} / k$, the studies of Roehl et al. (1996), Maricq and Szente (1996) and Villenave and Lesclaux (1996), give values of $k$ in the range $(0.98-2) \times 10^{-11} \mathrm{~cm}^{3}$ molecule $\mathrm{s}^{-1} \mathrm{~s}^{-1}$. We accept the analysis of Tyndall et al. (2001) and take the value of $k$ which they recommend, based on the studies of Villenave and Lesclaux (1996) and Roehl et al. (1996), as our preferred value at $298 \mathrm{~K}$. The temperature dependence is based on that observed for analogous reactions.

There is conflicting evidence on the branching ratios. At $298 \mathrm{~K}$ Moortgat et al. (1989) estimate that $k_{1} / k=0.5$, whilst Roehl et al (1996) find that $k_{1} / k=0.9$ and Maricq and Szente (1996) conclude that, essentially, the reaction proceeds entirely by channel (2). Further information comes from a study of Crawford et al. (1999) on the $\mathrm{HO}_{2}+\mathrm{CH}_{3} \mathrm{C}(\mathrm{O}) \mathrm{O}_{2}$ reaction in which the yields of the products $\mathrm{CH}_{3} \mathrm{C}(\mathrm{O}) \mathrm{OOH}$ and $\mathrm{CH}_{3} \mathrm{C}(\mathrm{O}) \mathrm{OH}$ were monitored. Tyndall et al. (2001) have re-analysed the results reported by Crawford et al. (1999) and have shown that the product yields observed require that the $\mathrm{CH}_{3} \mathrm{O}_{2}+\mathrm{CH}_{3} \mathrm{C}(\mathrm{O}) \mathrm{O}_{2}$ reaction, which could also contribute to the $\mathrm{CH}_{3} \mathrm{C}(\mathrm{O}) \mathrm{OH}$ in the experiments of Crawford et al. (1999), must occur with $k_{1} / k$ close to unity. Based on the studies of Moortgat et al. (1989), Horie and Moortgat (1992) and Roehl et al. (1996), Tyndall et al. (2001) recommend values of $k_{1} / k=0.9$ and $k_{2} / k=0.1$ at $298 \mathrm{~K}$. These are adopted as our preferred values for the branching ratios. Moortgat et al. (1989) have reported values for the temperature dependence of $k_{1}$ and $k_{2}$ but they imply a difference in activation energy for the two channels of $32 \mathrm{~kJ} \mathrm{~mol}^{-1}$ which is much greater than found for analogous peroxy radical reactions. No recommendation is made for the temperature dependence of the branching ratio at this stage.

\section{References}

Crawford, M. A., Wallington, T. J., Szente, J. J., Maricq, M. M., and Francisco, J. S.: J. Phys. Chem. A, 103, 365, 1999.

Horie, O. and Moortgat, G. K.: J. Chem. Soc. Faraday Trans., 88, 3305, 1992.

Maricq, M. M. and Szente, J. J.: J. Phys. Chem., 100, 4507, 1996.

Moortgat, G. K., Veyret, B., and Lesclaux, R.: J. Phys. Chem., 93, 2362, 1989.

Roehl, C. M., Bauer, D., and Moortgat, G. K.: J. Phys. Chem., 100, 4038, 1996.

Tyndall, G. S., Cox, R. A., Granier, C., Lesclaux, R., Moortgat, G. K., Pilling, M. J., Ravishankara, A. R., and Wallington, T. J.: J. Geophys. Res., 106, 12 157, 2001.

Villenave, E. and Lesclaux, R.: J. Phys. Chem., 100, 14 372, 1996. 
II.A6.141

$$
\begin{aligned}
\mathrm{CH}_{3} \mathrm{O}_{2}+\mathrm{CH}_{3} \mathrm{C}(\mathrm{O}) \mathrm{CH}_{2} \mathrm{O}_{2} & \rightarrow \mathrm{CH}_{3} \mathrm{OH}+\mathrm{CH}_{3} \mathrm{C}(\mathrm{O}) \mathrm{CHO}+\mathrm{O}_{2} \\
& \rightarrow \mathrm{HCHO}+\mathrm{CH}_{3} \mathrm{C}(\mathrm{O}) \mathrm{CH}_{2} \mathrm{OH}+\mathrm{O}_{2} \\
& \rightarrow \mathrm{CH}_{3} \mathrm{O}+\mathrm{CH}_{3} \mathrm{C}(\mathrm{O}) \mathrm{CH}_{2} \mathrm{O}+\mathrm{O}_{2}
\end{aligned}
$$

$\Delta H^{\circ}(1)=-319.7 \mathrm{~kJ} \cdot \mathrm{mol}^{-1}$

$\Delta H^{\circ}(2)=-322.6 \mathrm{~kJ} \cdot \mathrm{mol}^{-1}$

Rate coefficient data $\left(k=k_{1}+k_{2}+k_{3}\right)$

\begin{tabular}{lllc}
\hline$k / \mathrm{cm}^{3}$ molecule ${ }^{-1} \mathrm{~s}^{-1}$ & Temp./K & Reference & Technique/Comments \\
\hline $\begin{array}{l}\text { Absolute Rate Coefficients } \\
(3.8 \pm 0.4) \times 10^{-12}\end{array}$ & 298 & Bridier et al., 1993 & FP-UVA (a) \\
& & & \\
$\begin{array}{l}\text { Branching Ratios } \\
k_{1} / k=0.5 \pm 0.1\end{array}$ & 298 & Jenkin et al., 1993 & P-FTIR (b) \\
$k_{2} / k=0.2 \pm 0.1$ & 298 & & \\
$k_{3} / k=0.3 \pm 0.1$ & 298 & Bridier et al., 1993 & FP-UVA (c) \\
\hline
\end{tabular}

\section{Comments}

(a) Flash photolysis of $\mathrm{Cl}_{2}$ in the presence of $\mathrm{CH}_{3} \mathrm{C}(\mathrm{O}) \mathrm{CH}_{3}-\mathrm{O}_{2}-\mathrm{CH}_{4}-\mathrm{N}_{2}$ mixtures at a total pressure of 1 bar (760 Torr). The overall rate coefficient $k$ was derived from a kinetic analysis of absorption-time profiles measured at $230 \mathrm{~nm}$ and $260 \mathrm{~nm}$.

(b) Steady-state photolysis of $\mathrm{Cl}_{2}$ in the presence of $\mathrm{CH}_{3} \mathrm{C}(\mathrm{O}) \mathrm{CH}_{3}-\mathrm{N}_{2}$ mixtures at a total pressure of 930 mbar (700 Torr). Branching ratios were deduced from measurements of $\mathrm{HCHO}$ and $\mathrm{CH}_{3} \mathrm{C}(\mathrm{O}) \mathrm{CHO}$ products by long-path FTIR spectroscopy and long-path UV-VIS diode-array spectroscopy.

(c) Derived from a kinetic analysis of the time-profiles obtained in the experiments described in Comment (a).

\section{Preferred Values}

$$
\begin{aligned}
& k=3.8 \times 10^{-12} \mathrm{~cm}^{3} \text { molecule } \mathrm{e}^{-1} \mathrm{~s}^{-1} \text { at } 298 \mathrm{~K} . \\
& k_{1} / k=0.5 \text { at } 298 \mathrm{~K} . \\
& k_{2} / k=0.2 \text { at } 298 \mathrm{~K} . \\
& k_{3} / k=0.3 \text { at } 298 \mathrm{~K} .
\end{aligned}
$$

\section{Reliability}

$\Delta \log k= \pm 0.3$ at $298 \mathrm{~K}$.

$\Delta\left(k_{1} / k\right)=\Delta\left(k_{2} / k\right)=\Delta\left(k_{3} / k\right)= \pm 0.15$ at $298 \mathrm{~K}$.

Comments on Preferred Values

The preferred values of the rate coefficient and branching ratios are based on the measurements of Bridier et al. (1993) and Jenkin et al. (1993), and require independent confirmation to reduce the assigned error limits.

\section{References}

Bridier, I., Veyret, B., Lesclaux, R., and Jenkin, M. E.: J. Chem. Soc. Faraday Trans., 89, 2993, 1993.

Jenkin, M. E., Cox, R. A., Emrich, M., and Moortgat, G. K.: J. Chem. Soc. Faraday Trans., 89, 2983, 1993. 
II.A6.142

$$
\begin{aligned}
\mathbf{H O C H}_{2} \mathrm{O}_{2}+\mathrm{HOCH}_{2} \mathrm{O}_{2} & \rightarrow \mathrm{HC}(\mathrm{O}) \mathrm{OH}+\mathrm{CH}_{2}(\mathrm{OH})_{2}+\mathrm{O}_{2} \\
& \rightarrow \mathbf{2} \mathrm{HOCH}_{2} \mathrm{O}+\mathbf{O}_{2}
\end{aligned}
$$

\begin{tabular}{|c|c|c|c|}
\hline$k / \mathrm{cm}^{3}$ molecule $^{-1} \mathrm{~s}^{-1}$ & Temp./K & Reference & Technique/Comments \\
\hline \multicolumn{4}{|l|}{ Absolute Rate Coefficients } \\
\hline$k_{1}=5.65 \times 10^{-14} \exp [(750 \pm 400) / T]$ & $275-323$ & Veyret et al., 1989 & FP-UVA $(a, b)$ \\
\hline$k_{1}=(7.0 \pm 2.1) \times 10^{-13}$ & 295 & & \\
\hline$k_{1}=(5.6 \pm 2.8) \times 10^{-13}$ & 298 & Burrows et al., 1989 & MM-IR-AS (a,c) \\
\hline \multicolumn{4}{|l|}{ Relative Rate Coefficients } \\
\hline$k_{1}=(5.5 \pm 1.1) \times 10^{-12}$ & 298 & Burrows et al., 1989 & MM-IR-AS (a,c) \\
\hline
\end{tabular}

Rate coefficient data $\left(k=k_{1}+k_{2}\right)$

\section{Comments}

(a) $k$ is defined by $-d\left[\mathrm{HOCH}_{2} \mathrm{O}_{2}\right] / d t=2 k\left[\mathrm{HOCH}_{2} \mathrm{O}_{2}\right]^{2}$.

(b) Flash photolysis of $\mathrm{Cl}_{2}$ in the presence of $\mathrm{HCHO}$ or $\mathrm{CH}_{3} \mathrm{OH}$ and $\mathrm{O}_{2}$, with time-resolved absorption spectroscopy for the detection of $\mathrm{HO}_{2}$ and $\mathrm{HOCH}_{2} \mathrm{O}_{2}$ radicals. The rate coefficient $k_{1}$ was obtained from a computer fit of the absorption profiles of $\mathrm{HOCH}_{2} \mathrm{O}_{2}$ radicals at $250 \mathrm{~nm}$. Channel (2) leads to the regeneration of $\mathrm{HO}_{2}$ radicals and was thus not observable in this system.

(c) Molecular modulation study of $\mathrm{Cl}_{2}-\mathrm{HCHO}-\mathrm{O}_{2}$ mixtures with diode laser infrared spectroscopy for the detection of $\mathrm{HO}_{2}$ radicals and UV spectroscopy for $\mathrm{HOCH}_{2} \mathrm{O}_{2}$ radicals. The rate coefficient, $\mathrm{k}_{2}$, was obtained from a computer simulation of quantum yields for $\mathrm{HC}(\mathrm{O}) \mathrm{OH}$ formation.

\section{Preferred Values}

$k_{1}=7.0 \times 10^{-13} \mathrm{~cm}^{3}$ molecule $\mathrm{e}^{-1} \mathrm{~s}^{-1}$ at $298 \mathrm{~K}$.

$k_{1}=5.7 \times 10^{-14} \exp (750 / T) \mathrm{cm}^{3}$ molecule $\mathrm{s}^{-1} \mathrm{~s}^{-1}$ over the temperature range $270-330 \mathrm{~K}$.

$k_{2}=5.5 \times 10^{-12} \mathrm{~cm}^{3}$ molecule $\mathrm{s}^{-1} \mathrm{~s}^{-1}$ at $298 \mathrm{~K}$.

\section{Reliability}

$\Delta \log k_{1}= \pm 0.3$ at $298 \mathrm{~K}$.

$\Delta\left(E_{1} / R\right)= \pm 750 \mathrm{~K}$.

$\Delta \log k_{2}= \pm 0.3$ at $298 \mathrm{~K}$.

\section{Comments on Preferred Values}

The parallel studies of Veyret et al. (1989) and Burrows et al. (1989) confirm that the interaction of $\mathrm{HOCH}_{2} \mathrm{O}_{2}$ radicals involves two channels. The two reports (Burrows et al., 1989; Veyret et al., 1989) of the rate coefficient, $k_{1}$, at room temperature are in good agreement, and indicate that this channel is a factor of $\sim 3$ to 4 faster than that for the analogous interaction of $\mathrm{CH}_{3} \mathrm{O}_{2}$ radicals. The rate coefficient, $k_{2}$, is even larger than $k_{1}$, with a value $\sim 50$ times greater than that for the analogous reaction of $\mathrm{CH}_{3} \mathrm{O}_{2}$ radicals. Confirmation of the temperature coefficient of $k_{1}$ is needed, as well as a determination of the temperature coefficient of $k_{2}$.

\section{References}

Burrows, J. P., Moortgat, G. K., Tyndall, G. S., Cox, R. A., Jenkin, M. E., Hayman, G. D., and Veyret, B.: J. Phys. Chem., 93, 2375, 1989.

Veyret, B., Lesclaux, R., Rayez, M.-T., Rayez, J.-C., Cox, R. A., and Moortgat, G. K.: J. Phys. Chem., 93, 2368, 1989. 
II.A6.143

$$
\begin{aligned}
\mathrm{C}_{2} \mathrm{H}_{5} \mathrm{O}_{2}+\mathrm{C}_{2} \mathrm{H}_{5} \mathrm{O}_{2} & \rightarrow \mathrm{C}_{2} \mathrm{H}_{5} \mathrm{OH}+\mathrm{CH}_{3} \mathrm{CHO}+\mathrm{O}_{2} \\
& \rightarrow 2 \mathrm{C}_{2} \mathrm{H}_{5} \mathrm{O}+\mathrm{O}_{2} \\
& \rightarrow \mathbf{C}_{2} \mathrm{H}_{5} \mathrm{OOC}_{2} \mathrm{H}_{5}+\mathrm{O}_{2}
\end{aligned}
$$

$\Delta H^{\circ}(1)=-345.8 \mathrm{~kJ} \cdot \mathrm{mol}^{-1}$

$\Delta H^{\circ}(2)=-23.8 \mathrm{~kJ} \cdot \mathrm{mol}^{-1}$

Rate coefficient data $\left(k=k_{1}+k_{2}+k_{3}\right)$

\begin{tabular}{lllc}
\hline$k / \mathrm{cm}^{3}$ molecule ${ }^{-1} \mathrm{~s}^{-1}$ & Temp./K & Reference & Technique/Comments \\
\hline $\begin{array}{l}\text { Absolute Rate Coefficients } \\
(1.0 \pm 0.1) \times 10^{-13}\end{array}$ & 298 & Adachi et al., 1979 & \\
$2.7 \times 10^{-13} \exp (-470 / T)$ & $302-373$ & Anastasi et al., 1983 & FP-UVA (a,b) \\
$5.6 \times 10^{-14}$ & 298 & & MM-UVA (a,c) \\
$8.1 \times 10^{-14}$ & $266-348$ & Cattell et al., 1986 & MM-UVA (a,d) \\
$8.5 \times 10^{-14} \exp [-(110 \pm 40) / T]$ & $228-380$ & Wallington et al., 1988 & FP-UVA (a,e) \\
$5.9 \times 10^{-14}$ & 298 & & \\
$6.7 \times 10^{-14} \exp [(60 \pm 40) / T]$ & $248-460$ & Fenter et al., 1993 & FP-UVA (a,f) \\
$(7.9 \pm 0.5) \times 10^{-14}$ & 298 & & \\
$2.49 \times 10^{-13} \exp (-518 / T)$ & $220-330$ & Bauer et al., 1992 & MM-UVA (a,g) \\
$+9.39 \times 10^{-16} \exp (960 / T)$ & & & \\
$6.7 \times 10^{-14}$ & 298 & & \\
$(7.3 \pm 2.4) \times 10^{-14}$ & 295 & Atkinson and Hudgens, 1997 & PLP-UVA (a,h) \\
Branching Ratios & & & \\
$k_{1} / k_{2}=0.76$ & 298 & Niki et al., 1982 & \\
$k_{1} / k_{2}=0.60$ & 298 & Anastasi et al., 1983 & P-FTIR (i) \\
$k_{1} / k_{2}=0.49$ & 298 & Wallington et al., 1989 & MM-GC (c) \\
\hline
\end{tabular}

\section{Comments}

(a) $k$ is defined by $-d\left[\mathrm{C}_{2} \mathrm{H}_{5} \mathrm{O}_{2}\right] / d t=2 k\left[\mathrm{C}_{2} \mathrm{H}_{5} \mathrm{O}_{5}\right]^{2}$ and is obtained from the overall decay constant $k_{\text {obs }}$ corrected for secondary removal of $\mathrm{C}_{2} \mathrm{H}_{5} \mathrm{O}_{2}$ radicals.

(b) $k$ determined by simulation of $\mathrm{C}_{2} \mathrm{H}_{5} \mathrm{O}_{2}$ radical decay using complex mechanism accounting for secondary removal of $\mathrm{C}_{2} \mathrm{H}_{5} \mathrm{O}_{2}$ radicals.

(c) Modulated photolysis of $\left(\mathrm{C}_{2} \mathrm{H}_{5}\right)_{2} \mathrm{~N}_{2}$ in the presence of $\mathrm{O}_{2}$ at pressures of 7 mbar to 200 mbar (5 Torr to 150 Torr) and $\mathrm{N}_{2}$ at pressures of $550 \mathrm{mbar}$ to $730 \mathrm{mbar}$ (410 Torr to $550 \mathrm{Torr}) . k / \sigma(240 \mathrm{~nm})$ and $\sigma(240 \mathrm{~nm})$ were found to be temperature dependent. Branching ratios were determined from analysis of products, $\mathrm{C}_{2} \mathrm{H}_{5} \mathrm{OH}$ and $\mathrm{CH}_{3} \mathrm{CHO}$, by GC. The data cited are derived from the rate coefficients $k_{1}$ and $k_{2}$ given in Table 6 of Anastasi et al. (1983).

(d) Modulated photolysis of $\mathrm{Cl}_{2}-\mathrm{C}_{2} \mathrm{H}_{6}-\mathrm{O}_{2}-\mathrm{N}_{2}$ mixtures at pressures of $3 \mathrm{mbar}$ to $1000 \mathrm{mbar}$ (2 Torr to 760 Torr). $k_{\mathrm{obs}} / \sigma(260 \mathrm{~nm})=(4.07 \pm 0.04) \times 10^{4} \mathrm{~cm} \mathrm{~s}^{-1}$ and $\sigma(260 \mathrm{~nm})=(3.20 \pm 0.38) \times 10^{-18} \mathrm{~cm}^{2}$ molecule ${ }^{-1}$ were obtained, leading to $k_{\mathrm{obs}}=(1.30 \pm 0.16) \times 10^{-13} \mathrm{~cm}^{3}$ molecule $\mathrm{s}^{-1} \mathrm{~s}^{-1}$. Cited value of $k$ obtained by taking $k_{\mathrm{obs}} / k=1.6$.

(e) $k_{\mathrm{obs}}=(1.41 \pm 0.19) \times 10^{-13} \exp [-(110 \pm 40) / T] \mathrm{cm}^{3}$ molecule ${ }^{-1} \mathrm{~s}^{-1}$ was obtained based on temperature independent value of $\sigma(250 \mathrm{~nm})=(3.89 \pm 0.54) \times 10^{-18} \mathrm{~cm}^{2}$ molecule $^{-1}$ and $k_{\mathrm{obs}} / k=1.66$.

(f) Flash photolysis-UV absorption study of $\mathrm{Cl}_{2}-\mathrm{C}_{2} \mathrm{H}_{6}-\mathrm{O}_{2}-\mathrm{N}_{2}$ mixtures at 1 bar (760 Torr) total pressure. Rate coefficients were derived from simultaneous computer analyses of several decay curves collected at different wavelengths. The value of $k_{\mathrm{obs}}=(1.40 \pm 0.11) \times 10^{-13} \exp [-(20 \pm 40) / T] \mathrm{cm}^{3}$ molecule ${ }^{-1} \mathrm{~s}^{-1}$ was corrected at each temperature by dividing by $(1+\alpha)$, where $\alpha=\beta /(1+\beta)$ and $\beta=10.2 \exp (-533 / T)$. 
(g) Molecular modulation study. $\mathrm{C}_{2} \mathrm{H}_{5} \mathrm{O}_{2}$ radicals were generated from the photolysis of flowing mixtures of $\mathrm{Cl}_{2}-\mathrm{C}_{2} \mathrm{H}_{6}-$ $\mathrm{O}_{2}-\mathrm{N}_{2}$ at a total pressure of 133 mbar (100 Torr) and monitored by UV absorption. Values of $k / \sigma$ were determined at $220 \mathrm{~nm}, 250 \mathrm{~nm}$ and $280 \mathrm{~nm}$, leading to values of $k_{\mathrm{obs}}$. The expression for $k$ was derived by fitting the function $k_{\text {obs }}=A_{1} \exp \left(B_{1} / T\right)+A_{2} \exp \left(B_{2} / T\right)=2 k_{1}+k_{2}$ to the observed values of $k_{\text {obs }}$ over the temperature range $220-330 \mathrm{~K}$, forcing the fit to a value of $k_{2} / k$ of 0.65 at $298 \mathrm{~K}$. The expressions for $k_{1}$ and $k_{2}$ obtained in this way gave $k_{1} / k_{2}=3.8 \times 10^{-3}$ $\exp (1478 / T)$.

(h) Pulsed laser photolysis of $\mathrm{Cl}_{2}-\mathrm{C}_{2} \mathrm{H}_{6}-\mathrm{O}_{2}$ - $\mathrm{Ar}$ mixtures at $7.3 \pm 1.0 \mathrm{mbar}$ (5.5 Torr) total pressure with $\mathrm{C}_{2} \mathrm{H}_{5} \mathrm{O}_{2}$ radicals being monitored by UV cavity ring-down spectroscopy at $265 \mathrm{~nm}$ and $270 \mathrm{~nm}$. The measured value of $k_{\mathrm{obs}}$ was corrected for secondary reactions by taking $k_{\mathrm{obs}} / k=1.7$.

(i) Photolysis of $\left(\mathrm{C}_{2} \mathrm{H}_{5}\right)_{2} \mathrm{~N}_{2}-\mathrm{O}_{2}$ mixtures and of $\mathrm{Cl}_{2}-\mathrm{C}_{2} \mathrm{H}_{6}-\mathrm{O}_{2}-\mathrm{N}_{2}$ mixtures at a total pressure of 920 mbar (700 Torr). Products $\mathrm{CH}_{3} \mathrm{CHO}, \mathrm{C}_{2} \mathrm{H}_{5} \mathrm{OH}$ and $\mathrm{C}_{2} \mathrm{H}_{5} \mathrm{OOH}$ monitored by FTIR.

(j) Photolysis of $\mathrm{Cl}_{2}-\mathrm{C}_{2} \mathrm{H}_{6}$ mixtures in $930 \mathrm{mbar}$ (700 Torr) air. Products monitored by FTIR.

\section{Preferred Values}

$k=6.4 \times 10^{-14} \mathrm{~cm}^{3}$ molecule $\mathrm{e}^{-1} \mathrm{~s}^{-1}$, independent of temperature over the range $250-450 \mathrm{~K}$.

$k_{2} / k=0.62$ at $298 \mathrm{~K}$.

\section{Reliability}

$\Delta \log k= \pm 0.12$ at $298 \mathrm{~K}$.

$\Delta(E / R)={ }_{-100}^{+300} \mathrm{~K}$

$\Delta\left(k_{2} / k\right)= \pm 0.1$ at $298 \mathrm{~K}$.

\section{Comments on Preferred Values}

The rate coefficients for this reaction have all been determined using UV absorption to monitor $\mathrm{C}_{2} \mathrm{H}_{5} \mathrm{O}_{2}$, and hence the measured quantity is $k / \sigma$ where $\sigma$ is the absorption cross-section at the monitoring wavelength. The data for $k_{298}$ are generally in good agreement. The most recent temperature coefficient reported by Fenter et al. (1993) $(E / R=-60 \mathrm{~K})$ agrees with the earlier data of Cattell et al. (1986) $(E / R \approx 0 \mathrm{~K})$ but less well with those of Anastasi et al. (1983) $(E / R=470 \mathrm{~K})$, Wallington et al. (1988) $(E / R=110 \mathrm{~K})$ or Bauer et al. (1992) $(E / R=-230 \mathrm{~K})$. In view of the small temperature coefficients reported in most of these studies, together with the relatively large associated error limits, we have selected a temperature-independent rate coefficient $k$ based on $k_{298}$. Thus, from the data of Adachi et al. (1979), Anastasi et al. (1983), Cattell et al. (1986), Wallington et al. (1988), Bauer et al. (1992) and Fenter et al. (1993), the average value of $k_{\mathrm{obs}}=1.03 \times 10^{-13} \mathrm{~cm}^{3}$ molecule $\mathrm{s}^{-1}$ at $298 \mathrm{~K}$ is obtained. Taking $k_{2} / k=0.62$ at $298 \mathrm{~K}$ (the mean of the data of Niki et al. (1982), Anastasi et al. (1983) and Wallington et al. (1989)) yields the recommended value of $k_{298}=6.4 \times 10^{-14} \mathrm{~cm}^{3}$ molecule ${ }^{-1} \mathrm{~s}^{-1}$. The data of Wallington et al. (1989) show that $k_{3} / k \leq 0.06$. The rate coefficient of Atkinson and Hudgens (1997) is in agreement with the recommendations.

The differences between the values of the branching ratios reported by Anastasi et al. (1983) and Bauer et al. (1992) require further study.

\section{References}

Adachi, H., Basco, N., and James, D. G. L.: Int. J. Chem. Kinet., 11, 1211, 1979.

Anastasi, C., D. J. Waddington, and A. Woolley, J. Chem. Soc. Faraday Trans., 1, 79, 505 (1983).

Atkinson, D. B. and Hudgens, J. W.: J. Phys. Chem. A, 101, 3901, 1997.

Bauer, D., Crowley, J. N., and Moortgat, G. K.: J. Photochem. Photobiol., A65, 329, 1992.

Cattell, F. C., Cavanagh, J., Cox, R. A., and Jenkin, M. E.: J. Chem. Soc. Faraday Trans., 2, 82, 1999, 1986.

Fenter, F. F., Catoire, V., Lesclaux, R., and Lightfoot, P. D.: J. Phys. Chem., 97, 3530, 1993.

Niki, H., Maker, P. D., Savage, C. M., and Breitenbach, L. P.: J. Phys. Chem., 86, 3825, 1982.

Wallington, T. J., Gierczak, C. A., Ball, J. C., and Japar, S. M.: Int. J. Chem. Kinet., 21, 1077, 1989.

Wallington, T. J., Dagaut, P., and Kurylo, M. J.: J. Photochem., 42, 173, 1988. 
II.A6.144

$$
\begin{aligned}
\mathrm{C}_{2} \mathrm{H}_{5} \mathrm{O}_{2}+\mathrm{CH}_{3} \mathrm{C}(\mathrm{O}) \mathrm{O}_{2} & \rightarrow \mathrm{C}_{2} \mathrm{H}_{5} \mathrm{O}+\mathrm{CH}_{3} \mathrm{C}(\mathrm{O}) \mathrm{O}+\mathrm{O}_{2} \\
& \rightarrow \mathrm{CH}_{3} \mathrm{CHO}+\mathrm{CH}_{3} \mathrm{C}(\mathrm{O}) \mathrm{OH}+\mathrm{O}_{2}
\end{aligned}
$$

$\Delta H^{\circ}(1)=-23.6 \mathrm{~kJ} \cdot \mathrm{mol}^{-1}$

$\Delta H^{\circ}(2)=-398.5 \mathrm{~kJ} \cdot \mathrm{mol}^{-1}$

Rate coefficient data $\left(k=k_{1}+k_{2}\right)$

\begin{tabular}{lllc}
\hline$k / \mathrm{cm}^{3}$ molecule ${ }^{-1} \mathrm{~s}^{-1}$ & Temp./K & Reference & Technique/Comments \\
\hline Absolute Rate Coefficients & & & \\
$(1.0 \pm 0.3) \times 10^{-11}$ & 298 & Villenave and Lesclaux, 1996 & FP-UVAS (a) \\
$5 \times 10^{-13} \exp [(1070 \pm 200) / T]$ & $220-440$ & Maricq and Szente, 2000 & PLP-UVAS (b) \\
$2.2 \times 10^{-11}$ & 295 & & \\
\hline
\end{tabular}

\section{Comments}

(a) Flash photolysis of $\mathrm{Cl}_{2}-\mathrm{C}_{2} \mathrm{H}_{6}-\mathrm{CH}_{3} \mathrm{CHO}-\mathrm{O}_{2}$ mixtures. $\mathrm{CH}_{3} \mathrm{C}(\mathrm{O}) \mathrm{O}_{2}$ and $\mathrm{C}_{2} \mathrm{H}_{5} \mathrm{O}_{2}$ radical concentrations were determined by fitting absorption-time data at $207 \mathrm{~nm}$ and $240 \mathrm{~nm}$, using cross-sections recommended in Lightfoot et al. (1992). Complex reaction mechanism with $\alpha_{c}\left(=k_{1} / k\right)$ assumed to be 0.82 . The overall uncertainty was estimated as $54 \%$.

(b) Pulsed laser photolysis at $351 \mathrm{~nm}$ of $\mathrm{CH}_{3} \mathrm{CHO}-\mathrm{C}_{2} \mathrm{H}_{6}-\mathrm{Cl}_{2}-\mathrm{O}_{2}-\mathrm{N}_{2}$ mixtures at total pressures of $167 \mathrm{mbar}$ to $192 \mathrm{mbar}$ (125 Torr to 144 Torr). The reaction progress was monitored by time-resolved UV absorption over the range $200 \mathrm{~nm}$ to $300 \mathrm{~nm}$. Values of $k$ were derived by fitting the spectral profiles using a detailed model. The cross-sections for the principal absorbing radicals $\left(\mathrm{CH}_{3} \mathrm{C}(\mathrm{O}) \mathrm{O}_{2}, \mathrm{C}_{2} \mathrm{H}_{5} \mathrm{O}_{2}\right.$, and $\left.\mathrm{CH}_{3} \mathrm{O}_{2}\right)$ were taken from the studies of Maricq and Szente (1996) and Maricq and Wallington (1992). A satisfactory fit to the spectra could be obtained using values of $\alpha_{c}\left(=k_{1} / k\right)$ in the range $1.0-0.80$.

\section{Preferred Values}

$k=1.6 \times 10^{-11} \mathrm{~cm}^{3}$ molecule $\mathrm{e}^{-1} \mathrm{~s}^{-1}$ at $298 \mathrm{~K}$.

$k=4.4 \times 10^{-13} \exp (1070 / T) \mathrm{cm}^{3}$ molecule ${ }^{-1} \mathrm{~s}^{-1}$ over the temperature range $220-400 \mathrm{~K}$.

\section{Reliability}

$\Delta \log k= \pm 0.5$ at $298 \mathrm{~K}$.

$\Delta(E / R)= \pm 500 \mathrm{~K}$.

\section{Comments on Preferred Values}

The two available experimental studies of this reaction report values of the rate coefficient at $298 \mathrm{~K}$ differing by a factor of 2. In both cases substantial error limits were assigned reflecting the difficulties in deconvoluting overlapping UV spectra and in accounting for complex secondary chemistry in deriving the rate coefficient. Villenave and Leclaux (1996) based their results on absorption measurements at only two wavelengths, whereas Maricq and Szente (2000) used spectra covering the range $200 \mathrm{~nm}$ to $300 \mathrm{~nm}$ but, until more definitive measurements are available, the preferred value at $298 \mathrm{~K}$ is taken as the mean of the studies of Villenave and Lesclaux (1996) and of Maricq and Szente (2000), with substantial error limits. The only determination of the temperature dependence of $k$ is that of Maricq and Szente (2000) who obtained a value of $E / R$ of $-1070 \mathrm{~K}$, which is consistent with values found for analogous reactions. The preferred expression for $k$ is obtained by combining the temperature dependence found by Maricq and Szente (2000) with an $A$-factor chosen to fit the preferred value of $k$ at $298 \mathrm{~K}$. Channel (1) is likely to be the main reaction channel at $298 \mathrm{~K}$. 


\section{References}

Lightfoot, P. D., Cox, R. A., Crowley, J. N., Destriau, M., Hayman, G. D., Jenkin, M. E., Moortgat, G. K., and Zabel, F.: Atmos. Environ., 26A, 1805, 1992.

Maricq, M. M. and Szente, J. J.: J. Phys. Chem., 100, 4507, 1996.

Maricq, M. M. and Szente, J. J.: J. Phys. Chem. A, 104, 7239, 2000.

Maricq, M. M. and Wallington, T. J.: J. Phys. Chem., 96, 986, 1992.

Villenave, E. and Lesclaux, R.: J. Phys. Chem., 100, 14372, 1996. 
II.A6.145

$$
\begin{aligned}
\mathrm{CH}_{3} \mathrm{OCH}_{2} \mathrm{O}_{2}+\mathrm{CH}_{3} \mathrm{OCH}_{2} \mathrm{O}_{2} & \rightarrow \mathrm{CH}_{3} \mathrm{OCH}_{2} \mathrm{OH}+\mathrm{CH}_{3} \mathrm{OCHO}+\mathrm{O}_{2} \\
& \rightarrow 2 \mathrm{CH}_{3} \mathrm{OCH}_{2} \mathrm{O}+\mathrm{O}_{2}
\end{aligned}
$$

Rate coefficient data $\left(k=k_{1}+k_{2}\right)$

\begin{tabular}{llll}
\hline$k / \mathrm{cm}^{3}$ molecule & \\
\hline $\begin{array}{l}\text { Absolute Rate Coefficients } \\
(2.1 \pm 0.3) \times 10^{-12}\end{array}$ & Temp./K & Reference & Technique/Comments \\
& 298 & Jenkin et al., 1993 & MM-AS (a,b) \\
Branching Ratios & & & \\
$k_{2} / k=0.67 \pm 0.11$ & 295 & Jenkin et al., 1993 & P-FTIR (c) \\
$k_{2} / k=0.67 \pm 0.13$ & 298 & Jenkin et al., 1993 & P-FTIR (d) \\
\hline
\end{tabular}

\section{Comments}

(a) $k$ is defined by $-d\left[\mathrm{CH}_{3} \mathrm{OCH}_{2} \mathrm{O}_{2}\right] / d t=2 k\left[\mathrm{CH}_{3} \mathrm{OCH}_{2} \mathrm{O}_{2}\right]^{2}$ and has beenderived from the measured overall second-order decay of $\mathrm{CH}_{3} \mathrm{OCH}_{2} \mathrm{O}_{2}$ radicals $\left(k_{\mathrm{obs}}\right)$.

(b) Molecular modulation study of $\mathrm{Cl}_{2}-\mathrm{CH}_{3} \mathrm{OCH}_{3}-\mathrm{O}_{2}-\mathrm{N}_{2}$ mixtures together with a pulsed radiolysis study of $\mathrm{SF}_{6}-\mathrm{CH}_{3} \mathrm{OCH}_{3}-$ $\mathrm{O}_{2}$ mixtures. $k_{\text {obs }}$ was found to be dependent on the total pressure over the range $23 \mathrm{mbar}$ to $1013 \mathrm{mbar}$ (17 Torr to 770 Torr) and on the composition of the reaction mixture. On the basis of a mechanism involving the generation of $\mathrm{H}$ atoms via the reaction $\mathrm{CH}_{3} \mathrm{OCH}_{2} \mathrm{O}+\mathrm{M} \rightarrow \mathrm{CH}_{3} \mathrm{OCHO}+\mathrm{H}+\mathrm{M}$, it was possible to derive the cited pressure-independent value of $k$.

(c) FTIR spectroscopic study of the steady-state photolysis of $\mathrm{Cl}_{2}$ in the presence of $\mathrm{CH}_{3} \mathrm{OCH}_{3}-\mathrm{O}_{2}-\mathrm{N}_{2}$ mixtures over the total pressure range $13 \mathrm{mbar}$ to $930 \mathrm{mbar}$ ( 10 Torr to $700 \mathrm{Torr}$ ). The branching ratio was determined from the yields of $\mathrm{CH}_{3} \mathrm{OCHO}$ and $\mathrm{CH}_{3} \mathrm{OCH}_{2} \mathrm{OOH}$. Minor amounts of $\mathrm{CH}_{3} \mathrm{OCH}_{2} \mathrm{OH}$ were also observed.

(d) Similar study to that described in Comment (c). The branching ratio and $k$ were derived from a kinetic analysis of the effects of $\left[\mathrm{O}_{2}\right]$ and $\left[\mathrm{Cl}_{2}\right]$ on $k_{\text {obs }}$, based on a mechanism including the production of $\mathrm{H}$ atoms from the reaction $\mathrm{CH}_{3} \mathrm{OCH}_{2} \mathrm{O}+\mathrm{M} \rightarrow \mathrm{CH}_{3} \mathrm{OCHO}+\mathrm{H}+\mathrm{M}$.

\section{Preferred Values}

$k=2.1 \times 10^{-12} \mathrm{~cm}^{3}$ molecule ${ }^{-1} \mathrm{~s}^{-1}$ at $298 \mathrm{~K}$.

$k_{2} / k=0.67$ at $298 \mathrm{~K}$.

\section{Reliability}

$\Delta \log k= \pm 0.3$ at $298 \mathrm{~K}$.

$\Delta\left(k_{2} / k\right)= \pm 0.1$ at $298 \mathrm{~K}$.

\section{Comments on Preferred Values}

The apparent effect of total pressure on $k$, the first reported for this type of reaction (Dagaut et al., 1989), has been shown to be an artifact by the more recent experiments of Jenkin et al. (1993). This comprehensive study, on which the recommendation is based, has shown that the pressure effect was due to secondary chemistry involving $\mathrm{H}$ atoms which arise from the reaction $\mathrm{CH}_{3} \mathrm{OCH}_{2} \mathrm{O}+\mathrm{M} \rightarrow \mathrm{CH}_{3} \mathrm{OCHO}+\mathrm{H}+\mathrm{M}$. A kinetic analysis of the molecular modulation system, allowing for secondary chemistry, yielded the preferred rate coefficient. At the same time the derived value of the branching ratio, $k_{2} / k$, is in excellent agreement with that obtained from a steady-state photolysis system with FTIR spectroscopic analyses (Jenkin et al., 1993). 


\section{References}

Dagaut, P., Wallington, T. J., and Kurylo, M. J.: J. Photochem. Photobiol., 48, 187, 1989.

Jenkin, M. E., Hayman, G. D., Wallington, T. J., Hurley, M. D., Ball, J. C., Nielsen, O. J., and Ellermann, T.: J. Phys. Chem., 97, 11712, 1993. 
II.A6.146

$$
\mathrm{CH}_{3} \mathrm{C}(\mathrm{O}) \mathrm{O}_{2}+\mathrm{CH}_{3} \mathrm{C}(\mathrm{O}) \mathrm{O}_{2} \rightarrow 2 \mathrm{CH}_{3} \mathrm{C}(\mathrm{O}) \mathrm{O}+\mathrm{O}_{2}
$$

$\Delta H^{\circ}=-71 \mathrm{~kJ} \cdot \mathrm{mol}^{-1}$

\section{Rate coefficient data}

\begin{tabular}{|c|c|c|c|}
\hline$k / \mathrm{cm}^{3}$ molecule $^{-1} \mathrm{~s}^{-1}$ & Temp./K & Reference & Technique/Comments \\
\hline \multicolumn{4}{|l|}{ Absolute Rate Coefficients } \\
\hline $2.8 \times 10^{-12} \exp [(530 \pm 100) / T]$ & $253-368$ & Moortgat et al., 1989 & FP-UVAS $(a, b)$ \\
\hline$(1.6 \pm 0.3) \times 10^{-11}$ & 298 & & \\
\hline$(1.36 \pm 0.19) \times 10^{-11}$ & 298 & Roehl et al., 1996 & PLP-UVAS (a,c) \\
\hline $3.0 \times 10^{-12} \exp [(504 \pm 114) / T]$ & $209-358$ & Maricq and Szente, 1996 & PLP-UVAS $(\mathrm{a}, \mathrm{d})$ \\
\hline $1.5 \times 10^{-11}$ & 298 & & \\
\hline
\end{tabular}

\section{Comments}

(a) $k$ is defined by $-d\left[\mathrm{CH}_{3} \mathrm{C}(\mathrm{O}) \mathrm{O}_{2}\right] / d t=2 k\left[\mathrm{CH}_{3} \mathrm{C}(\mathrm{O}) \mathrm{O}_{2}\right]^{2}$.

(b) $k$ was determined using absorption cross-sections for $\mathrm{CH}_{3} \mathrm{C}(\mathrm{O}) \mathrm{O}_{2}$ and $\mathrm{CH}_{3} \mathrm{O}_{2}$ radicals approximately $20 \%$ higher than later consensus values. $\mathrm{CH}_{3} \mathrm{C}(\mathrm{O}) \mathrm{O}_{2}$ radicals were produced by photolysis of $\mathrm{Cl}_{2}-\mathrm{CH}_{3} \mathrm{CHO}-\mathrm{O}_{2}$ mixtures.

(c) $k$ was determined using an absorption cross-section of $\sigma=6.67 \times 10^{-18} \mathrm{~cm}^{2}$ molecule ${ }^{-1}$ at $207 \mathrm{~nm}$ for $\mathrm{CH}_{3} \mathrm{C}(\mathrm{O}) \mathrm{O}_{2}$. Source of $\mathrm{CH}_{3} \mathrm{C}(\mathrm{O}) \mathrm{O}_{2}$ radicals as in (b). Detailed analysis of secondary chemistry.

(d) Based on $\sigma\left(\mathrm{CH}_{3} \mathrm{C}(\mathrm{O}) \mathrm{O}_{2}\right)=6.5 \times 10^{-18} \mathrm{~cm}^{2}$ molecule ${ }^{-1}$ at $206 \mathrm{~nm}$. Source of $\mathrm{CH}_{3} \mathrm{C}(\mathrm{O}) \mathrm{O}_{2}$ radicals as in (b). Detailed analysis of secondary chemistry.

\section{Preferred Values}

$k=1.6 \times 10^{-11} \mathrm{~cm}^{3}$ molecule ${ }^{-1} \mathrm{~s}^{-1}$ at $298 \mathrm{~K}$.

$k=2.9 \times 10^{-12} \exp (500 / T) \mathrm{cm}^{3}$ molecule ${ }^{-1} \mathrm{~s}^{-1}$ over the temperature range $200-370 \mathrm{~K}$.

\section{Reliability}

$\Delta \log k= \pm 0.1$ at $298 \mathrm{~K}$.

$\Delta(E / R)= \pm 200 \mathrm{~K}$.

\section{Comments on Preferred Values}

All three studies (Moortgat et al., 1989; Roehl et al., 1996; Maricq and Szente, 1996), taking account of the complex secondary chemistry following recombination of $\mathrm{CH}_{3} \mathrm{C}(\mathrm{O}) \mathrm{O}_{2}$ radicals and of the magnitude and overlap of the UV absorptions due to acetylperoxy, methylperoxy and hydroperoxy radicals, now give results in good agreement for $k$ and its temperature dependence. The recommendation is thus based on the data of Moortgat et al. (1989), Roehl et al. (1996) and Maricq and Szente (1996).

\section{References}

Maricq, M. M. and Szente, J. J.: J. Phys. Chem., 100, 4507, 1996.

Moortgat, G. K., Veyret, B., and Lesclaux, R.: J. Phys. Chem., 93, 2362, 1989.

Roehl, C. M., Bauer, D., and Moortgat, G. K.: J. Phys. Chem., 100, 4038, 1996. 
II.A6.147

$$
\begin{aligned}
\mathrm{CH}_{3} \mathrm{C}(\mathrm{O}) \mathrm{O}_{2}+\mathrm{CH}_{3} \mathrm{C}(\mathrm{O}) \mathrm{CH}_{2} \mathrm{O}_{2} & \rightarrow \mathrm{CH}_{3} \mathrm{C}(\mathrm{O}) \mathrm{OH}+\mathrm{CH}_{3} \mathrm{C}(\mathrm{O}) \mathrm{CHO}+\mathrm{O}_{2} \\
& \rightarrow \mathrm{CH}_{3} \mathrm{C}(\mathrm{O}) \mathrm{O}+\mathrm{CH}_{3} \mathrm{C}(\mathrm{O}) \mathrm{CH}_{2} \mathrm{O}+\mathrm{O}_{2}
\end{aligned}
$$

$\Delta H^{\circ}(1)=-369 \mathrm{~kJ} \cdot \mathrm{mol}^{-1}$

\begin{tabular}{|c|c|c|c|}
\hline$k / \mathrm{cm}^{3}$ molecule ${ }^{-1} \mathrm{~s}^{-1}$ & Temp./K & Reference & Technique/Comments \\
\hline $\begin{array}{l}\text { Absolute Rate Coefficients } \\
(5.0 \pm 2.0) \times 10^{-12} \\
k_{1} \leq 4 \times 10^{-12}\end{array}$ & $\begin{array}{l}298 \\
298\end{array}$ & Bridier et al., 1993 & FP-UVAS (a) \\
\hline $\begin{array}{l}\text { Branching Ratios } \\
k_{2} / k=0.5 \pm 0.2\end{array}$ & 298 & Jenkin et al., 1993 & P-FTIR-AS (b) \\
\hline
\end{tabular}

Rate coefficient data $\left(k=k_{1}+k_{2}\right)$

\section{Comments}

(a) Flash photolysis of $\mathrm{Cl}_{2}$ in the presence of $\mathrm{CH}_{3} \mathrm{C}(\mathrm{O}) \mathrm{CH}_{3}-\mathrm{CH}_{3} \mathrm{CHO}-\mathrm{N}_{2}$ mixtures at a total pressure of 1 bar (760 Torr). The rate coefficient $k$ was derived from a kinetic analysis of absorption-time profiles measured at $210 \mathrm{~nm}, 220 \mathrm{~nm}, 230 \mathrm{~nm}$ and $245 \mathrm{~nm}$, using the value of $k_{2} / k=0.5$ determined by Jenkin et al. (1993).

(b) Steady-state photolysis of $\mathrm{Cl}_{2}$ in the presence of $\mathrm{CH}_{3} \mathrm{C}(\mathrm{O}) \mathrm{CH}_{3}-\mathrm{N}_{2}$ mixtures at a total pressure of 930 mbar (700 Torr). The branching ratio was deduced from measurements of the concentrations of the $\mathrm{HCHO}$ and $\mathrm{CH}_{3} \mathrm{C}(\mathrm{O}) \mathrm{CHO}$ products by long-path FTIR spectroscopy and long-path UV-VIS diode-array spectroscopy.

\section{Preferred Values}

$k=5 \times 10^{-12} \mathrm{~cm}^{3}$ molecule ${ }^{-1} \mathrm{~s}^{-1}$ at $298 \mathrm{~K}$.

$k_{2} / k=0.5$ at $298 \mathrm{~K}$.

\section{Reliability}

$\Delta \log k= \pm 0.3$ at $298 \mathrm{~K}$.

$\Delta\left(k_{2} / k\right)= \pm 0.2$ at $298 \mathrm{~K}$.

\section{Comments on Preferred Values}

The preferred values of the rate coefficient and the branching ratio are from the studies of Bridier et al. (1993) and Jenkin et al. (1993), and require independent confirmation.

\section{References}

Bridier, I., Veyret, B., Lesclaux, R., and Jenkin, M. E.: J. Chem. Soc. Faraday Trans., 89, 2993, 1993.

Jenkin, M. E., Cox, R. A., Emrich, M., and Moortgat, G. K.: J. Chem. Soc. Faraday Trans., 89, 2983, 1993. 
II.A6.148

$$
\begin{aligned}
\mathrm{HOCH}_{2} \mathrm{CH}_{2} \mathrm{O}_{2}+\mathrm{HOCH}_{2} \mathrm{CH}_{2} \mathrm{O}_{2} & \rightarrow \mathrm{HOCH}_{2} \mathrm{CH}_{2} \mathrm{OH}+\mathrm{HOCH}_{2} \mathrm{CHO}+\mathrm{O}_{2} \\
& \rightarrow 2 \mathrm{HOCH}_{2} \mathrm{CH}_{2} \mathrm{O}+\mathrm{O}_{2}
\end{aligned}
$$

Rate coefficient data $\left(k=k_{1}+k_{2}\right)$

\begin{tabular}{lllc}
\hline$k / \mathrm{cm}^{3}$ molecule ${ }^{-1} \mathrm{~s}^{-1}$ & Temp./K & Reference & Technique/Comments \\
\hline Absolute Rate Coefficients & & & \\
$(2.2 \pm 0.3) \times 10^{-12}$ & 296 & Murrells et al., 1991 & PLP/MM-UVAS (a,b) \\
$(2.1 \pm 0.3) \times 10^{-12}$ & 298 & Jenkin and Hayman, 1995 & MM-UVAS (a,c) \\
$7.8 \times 10^{-14} \exp [(1000 \pm 80) / T]$ & $300-470$ & Boyd and Lesclaux, 1997 & PLP-UVAS (a,d) \\
$(2.2 \pm 0.3) \times 10^{-12}$ & 298 & & \\
& & & \\
Branching Ratios & 298 & Barnes et al., 1993 & P-FTIR (e) \\
$k_{2} / k=0.5 \pm 0.1$ & 298 & Boyd and Lesclaux, 1997 & PLP-UVAS (f) \\
$k_{2} / k=0.55$ & & & \\
\hline
\end{tabular}

\section{Comments}

(a) $k$ is defined by $-d\left[\mathrm{HOCH}_{2} \mathrm{CH}_{2} \mathrm{O}_{2}\right] / d t=2 k\left[\mathrm{HOCH}_{2} \mathrm{CH}_{2} \mathrm{O}_{2}\right]^{2}$.

(b) Separate pulsed laser photolysis and molecular modulation studies using the photolysis of $\mathrm{H}_{2} \mathrm{O}_{2}$ to produce $\mathrm{HO}$ radicals in the presence of ethene and air at a pressure of 1 bar $\left(760\right.$ Torr). $\mathrm{HOCH}_{2} \mathrm{CH}_{2} \mathrm{O}_{2}$ radicals were monitored by UV absorption at $250 \mathrm{~nm}$ with $\sigma_{250}=4.7 \times 10^{-18} \mathrm{~cm}^{2}$ molecule ${ }^{-1}$ (mean value). $k_{\mathrm{obs}} / \sigma_{250}=6.7 \times 10^{5} \mathrm{~cm} \mathrm{~s}^{-1} . k$ was calculated from the laser photolysis experiments with $k_{2} / k=0.36$.

(c) Identical technique to that in Comment (a). $k_{\mathrm{obs}} / \sigma_{250}=(7.1 \pm 0.6) \times 10^{5} \mathrm{~cm} \mathrm{~s}^{-1} . \quad k$ calculated using $k_{2} / k=0.5$ and, in addition, using data from Murrells et al. (1991).

(d) Pulsed laser photolysis of $\mathrm{H}_{2} \mathrm{O}_{2}$ at $248 \mathrm{~nm}$ in the presence of ethene and $\mathrm{O}_{2}$. $\mathrm{HOCH}_{2} \mathrm{CH}_{2} \mathrm{O}_{2}$ radicals were monitored by absorption at $250 \mathrm{~nm}$.

(e) Analysis of products by FTIR in the photolysis of $\mathrm{HOCH}_{2} \mathrm{CH}_{2} \mathrm{I}$ or $\mathrm{H}_{2} \mathrm{O}_{2}-\mathrm{C}_{2} \mathrm{H}_{4}$ mixtures in $\mathrm{O}_{2}+\mathrm{N}_{2}$. Pressure 150 mbar to 900 mbar (114 Torr to 680 Torr). Mean value given from both systems, which were in excellent agreement, and independent of total pressure or $\mathrm{O}_{2}$ concentration.

(f) Based on $\mathrm{HO}_{2}$ radical formation from the $\mathrm{HOCH}_{2} \mathrm{CH}_{2} \mathrm{O}+\mathrm{O}_{2}$ reaction, measured by $\mathrm{UV}$ absorption at $220 \mathrm{~nm}$.

\section{Preferred Values}

$k=2.2 \times 10^{-12} \mathrm{~cm}^{3}$ molecule $\mathrm{e}^{-1} \mathrm{~s}^{-1}$ at $298 \mathrm{~K}$.

$k=7.8 \times 10^{-14} \exp (1000 / T) \mathrm{cm}^{3}$ molecule $\mathrm{s}^{-1}$ over the temperature range $250-450 \mathrm{~K}$.

$k_{2} / k=0.5$ at $298 \mathrm{~K}$.

\section{Reliability}

$\Delta \log k= \pm 0.1$ at $298 \mathrm{~K}$.

$\Delta(E / R)= \pm 300 \mathrm{~K}$.

$\Delta\left(k_{2} / k\right)= \pm 0.5$ at $298 \mathrm{~K}$. 


\section{Comments on Preferred Values}

All the recent studies of this reaction provide consistent and seemingly reliable values for the rate coefficient and for the branching ratio (Murrells et al., 1991; Boyd and Lesclaux, 1997). The preferred value of $k$ at $298 \mathrm{~K}$ is a mean of the values reported by Murrells et al. (1991), Jenkin and Hayman (1995) and Boyd and Lesclaux (1997), and for the branching ratio the value of Barnes et al. (1993) is accepted. The temperature dependence of $k$ from the work of Boyd and Lesclaux (1997), is recommended but with wider error limits on $E / R$. A measurement of the temperature dependence of the branching ratio would be of value.

\section{References}

Barnes, I., Becker, K. H., and Ruppert, L.: Chem. Phys. Lett., 203, 295, 1993.

Boyd, A. A. and Lesclaux, R.: Int. J. Chem. Kinet., 29, 323, 1997.

Jenkin, M. E. and Hayman, G. D.: J. Chem. Soc. Faraday Trans., 91, 1911, 1995.

Murrells, T. P., Jenkin, M. E., Shalliker, S. J., and Hayman, G. D.: J. Chem. Soc. Faraday Trans., 87, 2351, 1991. 
II.A6.149

$$
\begin{aligned}
n-\mathbf{C}_{3} \mathbf{H}_{7} \mathbf{O}_{2}+n-\mathbf{C}_{3} \mathbf{H}_{7} \mathbf{O}_{2} & \rightarrow n-\mathbf{C}_{3} \mathbf{H}_{7} \mathbf{O H}+\mathbf{C}_{2} \mathbf{H}_{5} \mathbf{C H O}+\mathbf{O}_{2} \\
& \rightarrow 2 n-\mathbf{C}_{3} \mathbf{H}_{7} \mathbf{O}+\mathbf{O}_{2}
\end{aligned}
$$

Rate coefficient data $\left(k=k_{1}+k_{2}\right)$

\begin{tabular}{lllc}
\hline$k / \mathrm{cm}^{3}$ molecule ${ }^{-1} \mathrm{~s}^{-1}$ & Temp./K & Reference & Technique/Comments \\
\hline $\begin{array}{l}\text { Absolute Rate Coefficients } \\
(3.3 \pm 0.3) \times 10^{-13}\end{array}$ & 298 & Adachi and Basco, 1982 & FP-UVAS (a,b) \\
\hline
\end{tabular}

\section{Comments}

(a) $k$ is defined by $-d\left[n-\mathrm{C}_{3} \mathrm{H}_{7} \mathrm{O}_{2}\right] / d t=2 k\left[n-\mathrm{C}_{3} \mathrm{H}_{7} \mathrm{O}_{2}\right]^{2}$ and has been derived from the measured overall second order decay of $n-\mathrm{C}_{3} \mathrm{H}_{7} \mathrm{O}_{2}$ radicals $\left(k_{\text {obs }}\right)$ by correcting for secondary removal of the $n-\mathrm{C}_{3} \mathrm{H}_{7} \mathrm{O}_{2}$ radicals.

(b) The monitoring wavelength for $n-\mathrm{C}_{3} \mathrm{H}_{7} \mathrm{O}_{2}$ radicals was $260 \mathrm{~nm}$, with $\sigma=3.15 \times 10^{-18} \mathrm{~cm}^{2}$ molecule ${ }^{-1}$. The rate coefficient was derived from $k_{\mathrm{obs}}=(3.84 \pm 0.33) \times 10^{-13} \mathrm{~cm}^{3}$ molecule ${ }^{-1} \mathrm{~s}^{-1}$ on the basis of a mechanism with 12 secondary reactions.

\section{Preferred Values}

$k=3 \times 10^{-13} \mathrm{~cm}^{3}$ molecule ${ }^{-1} \mathrm{~s}^{-1}$ at $298 \mathrm{~K}$.

\section{Reliability}

$\Delta \log k= \pm 0.5$ at $298 \mathrm{~K}$.

\section{Comments on Preferred Values}

The recommended rate coefficient is the rounded-off value from the study of Adachi and Basco (1982). The room temperature rate coefficient requires substantiation along with a determination of the temperature coefficient.

The recommended value of $k_{2} 98$ is in line with the rate coefficients of the analogous reactions of the $\mathrm{CH}_{3} \mathrm{O}_{2}$ and $\mathrm{C}_{2} \mathrm{H}_{5} \mathrm{O}_{2}$ radicals. On the other hand, our recommended rate coefficient for the self-reaction of the $i-\mathrm{C}_{3} \mathrm{H}_{7} \mathrm{O}_{2}$ radical is considerably lower $\left(k_{298}=1.0 \times 10^{-15} \mathrm{~cm}^{3}\right.$ molecule $\left.\mathrm{e}^{-1} \mathrm{~s}^{-1}\right)$ and that reported (Anastasi et al., 1978) for the $t-\mathrm{C}_{4} \mathrm{H}_{9} \mathrm{O}_{2}$ radical is even lower still $\left(k_{298}=2.3 \times 10^{-17} \mathrm{~cm}^{3}\right.$ molecule $\left.{ }^{-1} \mathrm{~s}^{-1}\right)$. This trend is in keeping with that observed in the liquid phase for the $\mathrm{RO}_{2}$ radical interactions (Bennett et al., 1970), i.e., $k\left(\right.$ primary $\left.\mathrm{RO}_{2}\right)>k\left(\right.$ secondary $\left.\mathrm{RO}_{2}\right)>k\left(\right.$ tertiary $\left.\mathrm{RO}_{2}\right)$.

\section{References}

Adachi, H. and Basco, N.: Int. J. Chem. Kinet., 14, 1125, 1982.

Anastasi, C., Smith, I. W. M., and Parkes, D. A.: J. Chem. Soc. Faraday Trans., 1, 74, 1693, 1978.

Bennett, J. E., Brown, D. M., and Mile, B.: Trans. Faraday Soc., 66, 386, 1970. 
II.A6.150

$$
\begin{aligned}
i-\mathbf{C}_{3} \mathbf{H}_{7} \mathbf{O}_{2}+i-\mathbf{C}_{3} \mathbf{H}_{7} \mathbf{O}_{2} & \rightarrow i-\mathbf{C}_{3} \mathbf{H}_{7} \mathbf{O H}+\mathbf{C H}_{3} \mathbf{C}(\mathbf{O}) \mathbf{C H}_{3}+\mathbf{O}_{2} \\
& \rightarrow 2 i-\mathbf{C}_{3} \mathbf{H}_{7} \mathbf{O}+\mathbf{O}_{2}
\end{aligned}
$$

$\Delta H^{\circ}(1)=-352.1 \mathrm{~kJ} \cdot \mathrm{mol}^{-1}$

$\Delta H^{\circ}(2)=-33.0 \mathrm{~kJ} \cdot \mathrm{mol}^{-1}$

Rate coefficient data $\left(k=k_{1}+k_{2}\right)$

\begin{tabular}{lllc}
\hline$k / \mathrm{cm}^{3}$ molecule ${ }^{-1} \mathrm{~s}^{-1}$ & Temp./K & Reference & Technique/Comments \\
\hline $\begin{array}{l}\text { Absolute Rate Coefficients } \\
1.43 \times 10^{-12} \exp [-(2243 \pm 69) / T)\end{array}$ & $300-373$ & Kirsch et al., 1978 & MM-UVAS (a,b) \\
$8.10 \times 10^{-16}$ & 300 & & \\
$(1.3 \pm 0.4) \times 10^{-15}$ & 298 & Adachi and Basco, 1989 & FP-UVAS (a,c) \\
$(5.3 \pm 0.5) \times 10^{-14}$ & 298 & Munk et al., 1986 & PR-UVAS (a,d) \\
& & & \\
Branching Ratios & 302 & Kirsch et al., 1979 & P-GC (e) \\
$k_{1} / k_{2}=1.39 \pm 0.04$ & $302-372$ & Cowley et al., 1982 & P-GC (f) \\
$k_{2} / k_{1}=56.3 \exp (-1130 / T)$ & & & \\
\hline
\end{tabular}

\section{Comments}

(a) $k$ is defined by $-d\left[i-\mathrm{C}_{3} \mathrm{H}_{7} \mathrm{O}_{2}\right] / d t=2 k\left[i-\mathrm{C}_{3} \mathrm{H}_{7} \mathrm{O}_{2}\right]^{2}$ and has been derived from the observed overall second-order decay of $i-\mathrm{C}_{3} \mathrm{H}_{7} \mathrm{O}_{2}$ radicals $\left(k_{\mathrm{obs}}\right)$ by correcting for secondary removal of the $i-\mathrm{C}_{3} \mathrm{H}_{7} \mathrm{O}_{2}$ radicals.

(b) Molecular modulation study of the photolysis of 2,2'-azopropane in the presence of $\mathrm{O}_{2}$ and $\mathrm{N}_{2}$ at total pressures up to $950 \mathrm{mbar}$ ( 710 Torr). $i-\mathrm{C}_{3} \mathrm{H}_{7} \mathrm{O}_{2}$ radicals were monitored by absorption at $265 \mathrm{~nm}$. The rate coefficient, $k$, has been calculated from the experimental value of $k_{\mathrm{obs}}=(2.37 \pm 0.17) \times 10^{-12} \exp [-(2243 \pm 60) T] \mathrm{cm}^{3}$ molecule $\mathrm{s}^{-1}$ and the branching ratio $k_{2} / k_{1}=1.39$ at $302 \mathrm{~K}$ determined in the subsequent study (Kirsch et al. 1979).

(c) Flash photolysis of 2,2'-azopropane in the presence of $\mathrm{O}_{2}$ and added $\mathrm{N}_{2}$ at total pressures up to $960 \mathrm{mbar}$ (720 Torr). $i-\mathrm{C}_{3} \mathrm{H}_{7} \mathrm{O}_{2}$ radicals were monitored by absorption at $240 \mathrm{~nm}$, for which $\sigma(240 \mathrm{~nm})=4.86 \times 10^{-18} \mathrm{~cm}^{2}$ molecule $^{-1}$. The rate coefficient, $k$, has been calculated from the experimental value of $k_{\mathrm{obs}}=(2.03 \pm 0.58) \times 10^{-15} \mathrm{~cm}^{3} \mathrm{molecule}^{-1} \mathrm{~s}^{-1}$ at $298 \mathrm{~K}$, on the basis of a proposed mechanism of 12 elementary reactions including secondary consumption of $i-\mathrm{C}_{3} \mathrm{H}_{7} \mathrm{O}_{2}$ radicals.

(d) Pulsed radiolysis of $\mathrm{H}_{2}$ at 1 bar in the presence of $\mathrm{C}_{3} \mathrm{H}_{6} ; i-\mathrm{C}_{3} \mathrm{H}_{7}$ radicals were generated from the reaction of $\mathrm{H}$ atoms with $\mathrm{C}_{3} \mathrm{H}_{6}$. The absorption spectrum of the $i-\mathrm{C}_{3} \mathrm{H}_{7} \mathrm{O}_{2}$ radical was observed on the addition of $\mathrm{O}_{2}$ and the decay of $i$ $\mathrm{C}_{3} \mathrm{H}_{7} \mathrm{O}_{2}$ radicals monitored by UV absorption at $253 \mathrm{~nm}$, and found to obey second-order kinetics. It is not clear if the reported value of the rate coefficient is $k_{\mathrm{obs}}$ or $k$.

(e) Steady-state photolysis of 2,2'-azopropane in the presence of $\mathrm{O}_{2}$ and added $\mathrm{N}_{2}$ at total pressures up to $670 \mathrm{mbar}$ (500 Torr). Ratio of rate coefficients based on analyses of $\mathrm{CH}_{3} \mathrm{C}(\mathrm{O}) \mathrm{CH}_{3}$ and $\left(\mathrm{CH}_{3}\right)_{2} \mathrm{CHOH}$ by $\mathrm{GC}$.

(f) Extension of the experiments by Kirsch et al. (1979), to obtain $k_{2} / k_{1}$ at $333 \mathrm{~K}$ and $372 \mathrm{~K}$. The Arrhenius equation calculated from these data and a value of $k_{2} / k_{1}$ at $302 \mathrm{~K}$ was reported by Kirsch et al. (1979).

\section{Preferred Values}

$k=1.0 \times 10^{-15} \mathrm{~cm}^{3}$ molecule $\mathrm{e}^{-1} \mathrm{~s}^{-1}$ at $298 \mathrm{~K}$.

$k=1.6 \times 10^{-12} \exp (-2200 / T) \mathrm{cm}^{3}$ molecule $\mathrm{e}^{-1} \mathrm{~s}^{-1}$ over the temperature range $300-400 \mathrm{~K}$.

$k_{1} / k=0.44$ at $298 \mathrm{~K}$. 
$k_{1} / k=3.7 \times 10^{-2} \exp (740 / T)$ over the temperature range $300-400 \mathrm{~K}$.

$k_{2} / k=0.56$ at $298 \mathrm{~K}$.

$k_{2} / k=2.0 \exp (-380 / T)$ over the temperature range $300-400 \mathrm{~K}$.

\section{Reliability}

$\Delta \log k= \pm 0.3$ at $298 \mathrm{~K}$.

$\Delta(E / R)= \pm 300 \mathrm{~K}$.

$\Delta\left(k_{1} / k\right)=\Delta\left(k_{2} / k\right)= \pm 0.15$ at $298 \mathrm{~K}$.

\section{Comments on Preferred Values}

The recommended rate coefficient, $k$, at $298 \mathrm{~K}$ is the average of the rate coefficients from the data of Kirsch et al. (1978) and Adachi and Basco (1982), which are in reasonable agreement. We have not taken into account the rate coefficient reported by Munk et al. (1986), for which experimental details are lacking. The recommended temperature dependence of $k$ is based on the results of Kirsch et al. (1978), which have been rounded-off and adjusted to the recommended value of $k_{298}$.

The measurements of the branching ratio and its temperature dependence (Kirsch et al., 1979; Cowley et al., 1982) appear to be reliable and have been adopted here, but require further confirmation.

The value of $k_{298}$ is considerably lower than that for the analogous reaction of the $n-\mathrm{C}_{3} \mathrm{H}_{7} \mathrm{O}_{2}$ radical, which is consistent with the trend observed in studies of the interactions of alkylperoxy radicals in solution (Bennett et al., 1970) i.e., $k$ (primary $\left.\mathrm{RO}_{2}\right)>k\left(\right.$ secondary $\left.\mathrm{RO}_{2}\right)>k\left(\right.$ tertiary $\left.\mathrm{RO}_{2}\right)$.

\section{References}

Adachi, H. and Basco, N.: Int. J. Chem. Kinet., 14, 1125, 1982.

Bennett, J. E., Brown, D. M., and Mile, B.: Trans. Faraday Soc., 66, 386,1970.

Cowley, L. T., Waddington, D. J., and Woolley, A.: J. Chem. Soc. Faraday Trans., 1, 78, 2535 ,1982.

Kirsch, L. J., Parkes, D. A., Waddington, D. J., and Woolley, A.: J. Chem. Soc. Faraday. Trans., 1, 74, 2293, 1978.

Kirsch, L. J., Parkes, D. A., Waddington, D. J., and Woolley, A.: J. Chem. Soc. Faraday Trans., 1, 75, 2678, 1979.

Munk, J., Pagsberg, P., Ratajczak, E., and Sillesen, A.: Chem. Phys. Lett., 132, 417, 1986. 
II.A6.151

$$
\begin{aligned}
& \mathrm{CH}_{3} \mathrm{C}(\mathrm{O}) \mathrm{CH}_{2} \mathrm{O}_{2}+\mathrm{CH}_{3} \mathrm{C}(\mathrm{O}) \mathrm{CH}_{2} \mathrm{O}_{2} \\
\rightarrow & \mathrm{CH}_{3} \mathrm{C}(\mathrm{O}) \mathrm{CH}_{2} \mathrm{OH}+\mathrm{CH}_{3} \mathrm{C}(\mathrm{O}) \mathrm{CHO}+\mathrm{O}_{2} \\
\rightarrow & \mathbf{2} \mathrm{CH}_{3} \mathrm{C}(\mathrm{O}) \mathrm{CH}_{2} \mathrm{O}+\mathrm{O}_{2}
\end{aligned}
$$

\begin{tabular}{|c|c|c|c|}
\hline$k / \mathrm{cm}^{3}$ molecule $^{-1} \mathrm{~s}^{-1}$ & Temp./K & Reference & Technique/Comments \\
\hline \multicolumn{4}{|l|}{ Absolute Rate Coefficients } \\
\hline$\leq 8.3 \times 10^{-12}$ & 298 & Cox et al., 1990 & PR-UVA $(a, b)$ \\
\hline$(8.0 \pm 0.2) \times 10^{-12}$ & 298 & Bridier et al., 1993 & FP-UVA $(\mathrm{a}, \mathrm{c})$ \\
\hline \multicolumn{4}{|l|}{ Branching Ratios } \\
\hline$k_{2} / k=0.75 \pm 0.1$ & 298 & Bridier et al., 1993 & FP-UVA (d) \\
\hline$k_{2} / k=0.50 \pm 0.05$ & 298 & Emrich and Warneck, 2003 & UVP-GC (e) \\
\hline
\end{tabular}

$\Delta H^{\circ}(1)=-314 \mathrm{~kJ} \cdot \mathrm{mol}^{-1}$

Rate coefficient data $\left(k=k_{1}+k_{2}\right)$

\section{Comments}

(a) $k$ is defined by $-d\left[\mathrm{CH}_{3} \mathrm{C}(\mathrm{O}) \mathrm{CH}_{2} \mathrm{O}_{2}\right] / d t=2 k\left[\mathrm{CH}_{3} \mathrm{C}(\mathrm{O}) \mathrm{CH}_{2} \mathrm{O}_{2}\right]^{2}$.

(b) Derived value of $k_{o b s}=(8.3 \pm 1.6) \times 10^{-12} \mathrm{~cm}^{3}$ molecule $\mathrm{e}^{-1} \mathrm{~s}^{-1}$ at $298 \mathrm{~K}$ is an upper limit due to secondary reactions producing possible enhanced decay of $\mathrm{CH}_{3} \mathrm{C}(\mathrm{O}) \mathrm{CH}_{2} \mathrm{O}_{2}$ radicals.

(c) Flash photolysis of $\mathrm{Cl}_{2}$ in the presence of $\mathrm{CH}_{3} \mathrm{C}(\mathrm{O}) \mathrm{CH}_{3}-\mathrm{O}_{2}-\mathrm{N}_{2}$ mixtures at a total pressure of $1013 \mathrm{mbar}$ (760 Torr). The rate coefficient, $k$, was derived from a kinetic analysis of absorption-time profiles at $230 \mathrm{~nm}$ and $260 \mathrm{~nm}$, taking account of the information on the mechanism of the overall reaction obtained from the product study of Jenkin et al. (1993).

(d) Technique as in Comment (c). The branching ratio was obtained on the basis of absorption due to radicals formed in channel (2) and subsequent reactions.

(e) Continuous photolysis of $\mathrm{Cl}_{2}$ at $330 \mathrm{~nm}$, in the presence of $\mathrm{CH}_{3} \mathrm{C}(\mathrm{O}) \mathrm{CH}_{3}-\mathrm{O}_{2}-\mathrm{NO}_{2}-\mathrm{N}_{2}$ mixtures at a total pressure of $1020 \mathrm{mbar}$ (765 Torr). The branching ratio, $k_{2} / k$, was determined from the observed formation of peroxyacetyl nitrate (PAN), which is generated in the system from chemistry subsequent to the thermal decomposition of $\mathrm{CH}_{3} \mathrm{C}(\mathrm{O}) \mathrm{CH}_{2} \mathrm{O}$, using simulations with an explicit chemical mechanism. PAN was measured by GC coupled with indirect analysis, which involved conversion to NO in a heated molybdenum catalytic converter, followed by detection of NO by its chemiluminescent reaction with $\mathrm{O}_{3}$.

\section{Preferred Values}

$k=8.0 \times 10^{-12} \mathrm{~cm}^{3}$ molecule ${ }^{-1} \mathrm{~s}^{-1}$ at $298 \mathrm{~K}$.

$k_{2} / k=0.63$ at $298 \mathrm{~K}$.

\section{Reliability}

$\Delta \log k= \pm 0.3$ at $298 \mathrm{~K}$.

$\Delta\left(k_{2} / k\right)= \pm 0.2$ at $298 \mathrm{~K}$. 


\section{Comments on Preferred Values}

The rate coefficients for $\mathrm{CH}_{3} \mathrm{C}(\mathrm{O}) \mathrm{CH}_{2} \mathrm{O}_{2}$ radical decay obtained in the two studies (Cox et al., 1990; Bridier et al., 1993) are in good agreement, and the more rigorous analysis carried out by Bridier et al. (1993) on the basis of the product study of Jenkin et al. (1993) provides the basis for the preferred rate coefficient. The value of $k_{2} / k$ reported more recently by Emrich and Warneck (2003) is somewhat lower than that derived by Bridier et al. (1993), but the two determinations are in reasonable agreement, given the complexity of the chemical systems and the indirect nature of the determinations. The preferred branching ratio is the mean of the values reported in those two studies. Further verification of the overall rate coefficient and branching ratio is required, as are studies as a function of temperature.

\section{References}

Bridier, I., Veyret, B., Lesclaux, R., and Jenkin, M. E.: J. Chem. Soc. Faraday Trans., 89, 2993, 1993.

Cox, R. A., Munk, J., Nielsen, O. J., Pagsberg, P., and Ratajczak, E.: Chem. Phys. Lett., 173, 206, 1990.

Emrich, M. and Warneck, P.: Z. Naturforsch., 58a, 429, 2003.

Jenkin, M. E., Cox, R. A., Emrich, M., and Moortgat, G. K.: J. Chem. Soc. Faraday Trans., 89, 2983, 1993. 
II.A6.152

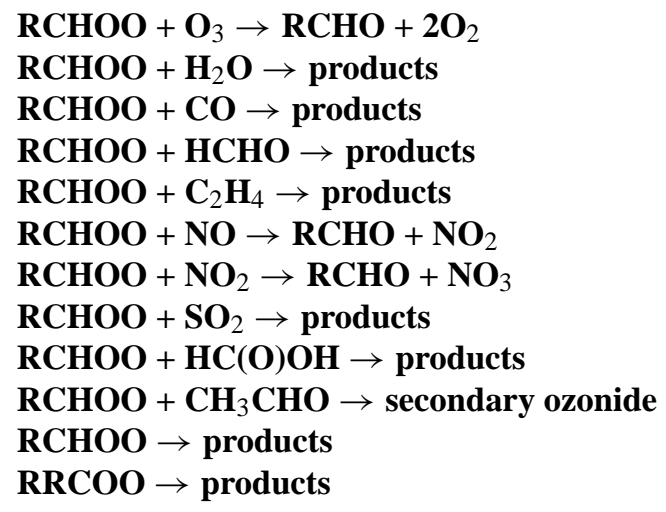

\section{$\mathbf{R}=\mathbf{H}$ or $\mathrm{CH}_{3}$}

Rate coefficient data

\begin{tabular}{lllll}
\hline$k / \mathrm{cm}^{3}$ molecule ${ }^{-1} \mathrm{~s}^{-1}$ & $\begin{array}{l}\text { Criegee } \\
\text { intermediate }\end{array}$ & Temp./K & Reference & Technique/Comments \\
\hline $\begin{array}{l}\text { Relative Rate Coefficients } \\
k_{2} / k_{8}=(6.1 \pm 0.3) \times 10^{-5}\end{array}$ & $\mathrm{CH}_{3} \mathrm{CHOO}$ & 295 & Calvert et al., 1978 & (a) \\
$k_{1}: k_{3}: k_{4}: k_{5}: k_{8}=2.5 \times 10^{-3}:$ & $\mathrm{CH}_{2} \mathrm{OO}$ & 296 & Su et al., 1980 & RR-FTIR (b) \\
$1.8 \times 10^{-3}: 2.5 \times 10^{-1}:$ & & & & \\
$2.5 \times 10^{-3}: 1.0$ & & & & \\
$k_{2} / k_{8}=(2.3 \pm 1) \times 10^{-4}$ & $\mathrm{CH}_{2} \mathrm{OO}$ & 298 & Suto et al., 1984 & (c) \\
$k_{7} / k_{8}=(1.4 \pm 0.4) \times 10^{-2}$ & $\mathrm{CH}_{2} \mathrm{OO}$ & 298 & Manzanares et al., 1987 & (d) \\
$k_{2} / k_{8}=(8.3 \pm 3.6) \times 10^{-4}$ & $\mathrm{CH}_{2} \mathrm{OO}$ & 298 & Becker et al., 1993 & RR-FTIR/TDLS (e) \\
$k_{2} / k_{8}=(4.1 \pm 2.2) \times 10^{-4}$ & $\left(\mathrm{CH}_{3}\right)_{2} \mathrm{COO}$ & 298 & Becker et al., 1993 & RR-FTIR/TDLS (f) \\
$k_{2} / k_{9}=7.1 \times 10^{-5}$ & $\mathrm{CH}_{2} \mathrm{OO}$ & 298 & Neeb et al., 1997 & RR-FTIR/HPLC (g) \\
& & & & \\
$\begin{array}{l}\text { Absolute Rate Coefficients } \\
k_{10}=1.0 \times 10^{-12}\end{array}$ & $\mathrm{CH}_{3} \mathrm{CHOO}$ & $\sim 298$ & Fenske et al., 2000 & FT-FTIR (h) \\
$k_{11}=76 \mathrm{~s}^{-1}$ & $\mathrm{CH}_{3} \mathrm{CHOO}$ & $\sim 298$ & Fenske et al., 2000 & (i) \\
$k_{12}=6.4 \mathrm{~s}^{-1}$ & $\left(\mathrm{CH}_{3}\right)_{2} \mathrm{COO}$ & 298 & Kroll et al., 2001 & LIF (j) \\
(measured at $\sim 130 \mathrm{mbar})$ & & & & \\
\hline & & & &
\end{tabular}

\section{Comments}

(a) Derived from a re-analysis of the data of Cox and Penkett (1972) from a study of the aerosol formation from $\mathrm{SO}_{2}$ in the presence of $\mathrm{O}_{3}-\mathrm{O}_{2}-c i s-2-\mathrm{C}_{4} \mathrm{H}_{8}$ mixtures at atmospheric pressure. In this system the Criegee intermediate involved is believed to be $\mathrm{CH}_{3} \mathrm{CHOO}$.

(b) FTIR study of the $\mathrm{C}_{2} \mathrm{H}_{4}-\mathrm{O}_{3}$ reaction in the presence of $\mathrm{O}_{2}-\mathrm{N}_{2}$ mixtures at a total pressure of 920 mbar and with added $\mathrm{CO}, \mathrm{HCHO}$, or $\mathrm{SO}_{2}$. Relative rate coefficients derived from a computer simulation of reactant consumption and product formation, based on a mechanism of 20 elementary reactions.

(c) Flow system involving $\mathrm{C}_{2} \mathrm{H}_{4}-\mathrm{O}_{3}-\mathrm{SO}_{2}-\mathrm{H}_{2} \mathrm{O}$ mixtures in which $\mathrm{H}_{2} \mathrm{SO}_{4}$ aerosol concentrations were monitored by scattered UV light. Relative rate coefficients obtained from the dependencies of the aerosol formation on the concentrations of $\mathrm{O}_{3}$, $\mathrm{SO}_{2}$ and $\mathrm{H}_{2} \mathrm{O}$.

(d) Similar study to that of Comment (c), with the inclusion of the effect of added $\mathrm{NO}_{2}$ on the formation of the $\mathrm{H}_{2} \mathrm{SO}_{4}$ aerosol. 
(e) Study of the $\mathrm{C}_{2} \mathrm{H}_{4}-\mathrm{O}_{3}$ reaction in the presence of 1 bar of synthetic air with and without added $\mathrm{SO}_{2} ; \mathrm{H}_{2} \mathrm{O}_{2}$ yields were measured by tunable diode laser absorption spectroscopy or by FTIR spectroscopy.

(f) Same study as for Comment (e) with $\left(\mathrm{CH}_{3}\right)_{2} \mathrm{C}=\mathrm{C}\left(\mathrm{CH}_{3}\right)_{2}$ as the reactant.

(g) Reaction carried out in a $570 \mathrm{~L}$ spherical glass reactor. Hydroxymethyl hydroperoxide (HMHP) concentrations monitored by HPLC and formic acid concentration by FTIR. Formation of $\mathrm{HC}(\mathrm{O}) \mathrm{OH}$ from HMHP shown to be due, in part, to heterogeneous processes. $k_{2} / k_{9}$ was derived by fitting $[\mathrm{HC}(\mathrm{O}) \mathrm{OH}]$ and [HMHP] as a function of time to a reaction scheme and using values of $k\left(\mathrm{O}_{3}+\mathrm{C}_{2} \mathrm{H}_{4}\right)=1.6 \times 10^{-18} \mathrm{~cm}^{3}$ molecule ${ }^{-1} \mathrm{~s}^{-1}, k\left(\mathrm{CH}_{3} \mathrm{OO}+\mathrm{H}_{2} \mathrm{O}\right)=1 \times 10^{-17} \mathrm{~cm}^{3}$ molecule $^{-1}$ $\mathrm{s}^{-1}$ and assuming that $47 \%$ of the Criegee biradicals are stabilized.

(h) Reaction studied in an atmospheric pressure flow-tube. An excess of acetaldehyde was added to the reaction mixture through a sliding injector such that all thermalised $\mathrm{CH}_{3} \mathrm{CHOO}$, post-injector, was converted to secondary ozonide (SOZ). SOZ was detected by FTIR. The temperature of the study was not reported.

(i) Unimolecular decomposition rate coefficient obtained relative to the reaction with acetaldehyde from a numerical analysis of the flow-tube data.

(j) HO observed by LIF in flow-tube experiments. The unimolecular rate coefficient was calculated by assuming that at 100 Torr pressure the observed formation of HO, over timescales of $\sim 100-1000 \mathrm{~ms}$, is due to the thermal decomposition of stabilised dimethylcarbonyl oxide.

\section{Preferred Values}

No recommendation for rate data.

\section{Comments on Preferred Values}

Vibrationally excited Criegee intermediates, $[\mathrm{RCHOO}]^{\ddagger}$, are produced from the reactions of $\mathrm{O}_{3}$ with alkenes (Atkinson and Carter, 1984). These species decompose unimolecularly to give molecular or radical products or undergo collisional deactivation to yield thermally equilibrated Criegee intermediates, RCHOO. Here we consider the kinetic and other information relating to the bimolecular reactions that have been proposed for these thermally equilibrated Criegee intermediates.

Studies have been made of the reactions of RCHOO with aldehydes (Su et al., 1980; Fenske et al., 2000; Cox and Penkett, 1972; Hanst et al., 1958; Kan et al., 1981; Niki et al., 1975, 1981; Neeb et al., 1995), $\mathrm{SO}_{2}$ (Calvert et al., 1978; Su et al., 1980, Cox and Penkett, 1972; Kerr and Calvert, 1984; Hatakeyama et al., 1986), $\mathrm{H}_{2} \mathrm{O}$ (Cox and Penkett, 1972; Akimoto et al., 1979; Kan et al., 1981), carboxylic acids (Neeb et al., 1995; Neeb et al., 1996) and methanol (Neeb et al., 1996), but detailed kinetic data are often lacking. Relative rate coefficients have been derived by Calvert et al. (1978), Su et al. (1980) and Suto et al. (1985) based on experimental measurements of the rates of consumption of molecular reactants relative to consumption of $\mathrm{SO}_{2}$ in systems involving $\mathrm{RCHOO}$ Criegee intermediates. The only compound, other than $\mathrm{SO}_{2}$, common to any of these studies is $\mathrm{H}_{2} \mathrm{O}$, for which the derived relative rate coefficients differ by a factor of $\sim 4$. Notwithstanding this discrepancy, these relative rate measurements are the only experimental basis on which to assess the rates of these reactions. It is apparent from these measurements that the reactions of the Criegee intermediates, $\mathrm{RCHOO}$, with $\mathrm{O}_{3}, \mathrm{CO}$ and alkenes are not important under atmospheric conditions. The reactions with $\mathrm{H}_{2} \mathrm{O}, \mathrm{RCHO}, \mathrm{NO}_{2}$ and $\mathrm{SO}_{2}$ need to be considered, although for most tropospheric conditions the only effective reaction of the Criegee intermediates is likely to be that with $\mathrm{H}_{2} \mathrm{O}$.

Previous reviewers (Kerr and Calvert, 1984; Atkinson and Lloyd, 1984) have made the reasonable assumption that the reaction of RCHOO with NO could also be significant, based on estimates of the energetics of the proposed reaction pathway $\mathrm{RCHOO}+\mathrm{NO} \rightarrow \mathrm{RCHO}+\mathrm{NO}_{2}$. Unfortunately, there is no direct experimental evidence for this reaction and very little information upon which to base an estimate of its rate coefficient. Atkinson and Lloyd (1984) have estimated the relative rate coefficients for RCHOO reacting with $\mathrm{NO}$ and $\mathrm{SO}_{2}$, corresponding to $k_{6} / k_{8}=10^{2}$, whereas Kerr and Calvert (1984) propose $k_{6} / k_{8}=1$. Experimental data on this ratio of rate coefficients are badly needed.

In the absence of direct kinetic measurements of the absolute rate coefficients for any of the RCHOO bimolecular reactions (excepting the recent measurement of Fenske et al. (2000) for $\mathrm{CH}_{3} \mathrm{CHOO}+\mathrm{CH}_{3} \mathrm{CHO}$ which cannot be used with any of the relative-rate measurements made to date), both Atkinson and Lloyd (1984) and Kerr and Calvert (1984) have suggested that $k_{6}$ should be equated to the rate coefficient for the structurally analogous reactions, $\mathrm{RO}_{2}+\mathrm{NO} \rightarrow \mathrm{RO}+\mathrm{NO}_{2}$, with $k_{6}=7 \times 10^{-12} \mathrm{~cm}^{3}$ molecule ${ }^{-1} \mathrm{~s}^{-1}$ at $298 \mathrm{~K}$. While this seems a reasonable proposition, it is desirable to obtain experimental verification. At present it is difficult to see how any direct measurements could be made with RCHOO systems involving 


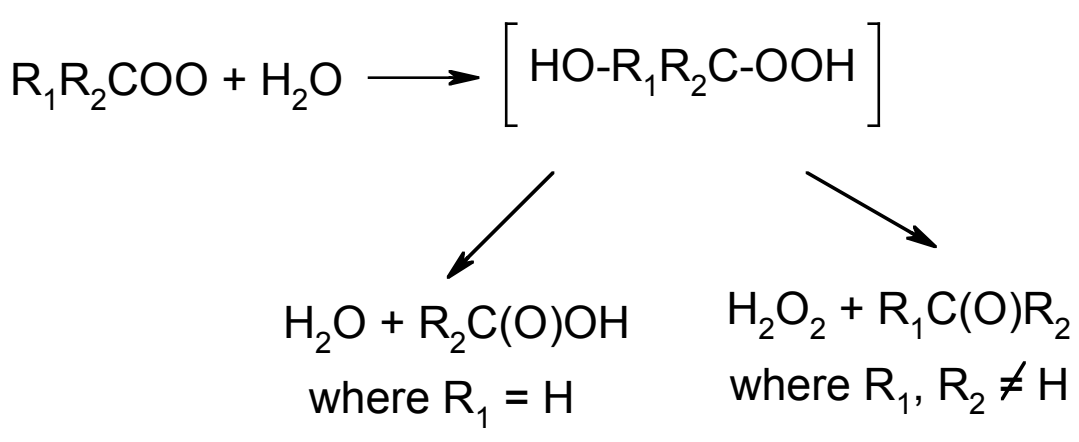

Fig. 5. See text.

$\mathrm{O}_{3}$-alkene reactions owing to the complex chemistry involved. In this regard the study of Hatakeyama et al. (1981) involving the generation of $\mathrm{CH}_{2} \mathrm{OO}$ Criegee intermediates from the reaction of $\mathrm{CH}_{2}\left({ }^{3} \mathrm{~B}_{1}\right)$ with $\mathrm{O}_{2}$ are of considerable interest.

In deriving the relative rate coefficients listed above, it has been necessary in some cases to compare data obtained from different $\mathrm{O}_{3}$-alkene systems and to assume that all the $\mathrm{RCHOO}$ Criegee intermediates have equal reactivity, e.g., $\mathrm{CH}_{2} \mathrm{OO}$ and $\mathrm{CH}_{3} \mathrm{CHOO}$. Again, while this seems to be a reasonable assumption, it requires experimental verification.

There is little direct experimental evidence on the products of the Reactions (1) to (9). Where the products are stated these have largely been suggested on the basis of analogy with related reactions.

Recent work of Neeb et al. (1997) shows that the reaction of the $\mathrm{CH}_{2} \mathrm{OO}$ Criegee intermediate with $\mathrm{H}_{2} \mathrm{O}$ leads initially to hydroxymethyl hydroperoxide $\left(\mathrm{HOCH}_{2} \mathrm{OOH}\right)$. The $\mathrm{HOCH}_{2} \mathrm{OOH}$ may then decompose to $\mathrm{HC}(\mathrm{O}) \mathrm{OH}$ and $\mathrm{H}_{2} \mathrm{O}$ but the extent to which this occurred by heterogeneous processes in the system used by Neeb et al. (1997) is uncertain. Hydroperoxides have been found in a number of other $\mathrm{O}_{3}$-alkene studies (Simonaitis et al., 1991; Martinez et al., 1981; Winterhalter et al., 2000) and are suggested to arise in a similar way, by direct interaction of the Criegee intermediate with $\mathrm{H}_{2} \mathrm{O}$. In addition to the expected formation of carboxylic acids from the reactions of the Criegee intermediates with $\mathrm{H}_{2} \mathrm{O}$, recent studies of the reactions of $\mathrm{O}_{3}$ with trans-2-butene (Becker et al., 1993; Simonaitis et al., 1991; Martinez et al., 1981), isoprene (Neeb et al., 1997; Simonaitis et al., 1991) and monoterpenes (Simonaitis et al., 1991; Martinez et al., 1981; Winterhalter et al., 2000) have reported varying amounts of $\mathrm{H}_{2} \mathrm{O}_{2}$ product. Since the yields of $\mathrm{H}_{2} \mathrm{O}_{2}$ were considerably enhanced by the presence of $\mathrm{H}_{2} \mathrm{O}$, it was proposed that $\mathrm{H}_{2} \mathrm{O}_{2}$ was formed in a direct reaction involving Criegee intermediates. Thus these observations may be rationalised in terms of the reactions depicted in Fig. 5. For the reaction of $\mathrm{CH}_{2} \mathrm{OO}$ with $\mathrm{H}_{2} \mathrm{O}, \mathrm{H}_{2} \mathrm{O}_{2}$ formation is a minor pathway.

Reaction of $\mathrm{R}_{1} \mathrm{R}_{2} \mathrm{COO}$ Criegee intermediates with aldehydes leads to the formation of the corresponding ozonides (Fenske et al., 2000; Niki et al., 1977, 1983, 1987). However, the formation of ethene ozonide has not been observed in the reaction of $\mathrm{CH}_{2} \mathrm{OO}$ with $\mathrm{HCHO}$ or in the $\mathrm{O}_{3}$-ethene reaction (Su et al., 1980; Kan et al., 1981; Niki et al., 1981, 1983). The proposal that the reaction of the $\mathrm{CH}_{2} \mathrm{OO}$ Criegee intermediate with $\mathrm{HCHO}$ leads to $\mathrm{HOCH}_{2} \mathrm{OCHO}$ (Su et al., 1980; Kan et al., 1981; Niki et al., 1981, 1983; Horie and Moortgat, 1991) has now been shown to be incorrect. The spectrum observed in the $\mathrm{CH}_{2} \mathrm{OO}-\mathrm{HCHO}$ reaction and assigned to $\mathrm{HOCH}_{2} \mathrm{OCHO}$ is now known to belong to $\mathrm{HOOCH}_{2} \mathrm{OCHO}$ (Neeb et al., 1995; Thamm et al., 1996), which is formed by the reaction of the $\mathrm{CH}_{2} \mathrm{OO}$ Criegee intermediate with $\mathrm{HC}(\mathrm{O}) \mathrm{OH}$.

Tobias and Zieman (2001) have determined rate coefficients for the reactions of the $\mathrm{CH}_{3}\left(\mathrm{CH}_{2}\right)_{11} \mathrm{CHOO}$ Criegee intermediate with acids, aldehydes and alcohols relative to the reaction with $\mathrm{H}_{2} \mathrm{O}$. The following rate coefficient ratios were obtained $\left(\mathrm{H}_{2} \mathrm{O}=1\right)$ : methanol, 22; 2-propanol, 50; formaldehyde, 2700; and heptanoic acid, 17000.

\section{References}

Akimoto, H., Bandow, H., Sakamaki, F., Inoue, G., Hoshino, M., and Okuda, M.: Research Report No. 9, R-9-79, National Institute for Environmental Studies, Japan, 1979.

Atkinson, R. and Carter, W. P. L.: Chem. Rev., 84, 437, 1984.

Atkinson, R. and Lloyd, A. C.: J. Phys. Chem. Ref. Data, 13, 315, 1984.

Becker, K. H., Brockmann, K. J., and Bechara, J.: Nature, 346, 256, 1990.

Becker, K. H., Bechara, J., and Brockmann, K. J.: Atmos. Environ., 27A, 57, 1993.

Calvert, J. G, Su, F., Bottenheim, J. W., and Strausz, O. P: Atmos. Environ., 12, 197, 1978.

Cox, R. A. and Penkett, S. A.: J. Chem. Soc. Faraday Trans., 1, 68, 1735, 1972.

Fenske, J. D., Hasson, A. S., Ho, A. W., and Paulson, S. E.: J. Phys. Chem. A, 104, 9921, 2000. 
Gäb, S., Hellpointer, E., Turner, W. V., and Kórte, F.: Nature, 316, 535, 1985.

Hanst, P. L., Stephens, E. R., Scott, W. E., and Doerr, R. C.: "Atmospheric Ozone-Olefin Reactions", Franklin Institute, Philadelphia, PA, 1958.

Hatakeyama, S., Bandow, H., Okuda, M., and Akimoto, H.: J. Phys. Chem., 85, 2249, 1981.

Hatakeyama, S., Kobayashi, H., Lin, Z.-Y., Takagi, H., and Akimoto, H.: J. Phys. Chem., 90, 4131, 1986.

Horie, O. and Moortgat, G. K.: Atmos. Environ., 25A, 1881, 1991.

Kan, C. S., Su, F., Calvert, J. G., and Shaw, J. H.: J. Phys. Chem., 85, 2359, 1981.

Kerr, J. A. and Calvert, J. G.: Chemical Transformation Modules for Eulerian Acid Deposition Models, Volume I. The Gas-Phase Chemistry, National Center for Atmospheric Research, Boulder, Colorado, December, 1984.

Kroll, J. H., Sahay, S. R., Anderson, J. G., Demerjian, K. L., and Donahue, N. M.: J. Phys. Chem., 105, 4446, 2001.

Manzanares, E. R., Suto, M., and Lee, L. C.: unpublished data, 1987.

Martinez, R. I., Herron, J. T., and Huie, R. E.: J. Am. Chem. Soc., 103, 3807, 1981.

Neeb, P., Horie, O., and Moortgat, G. K.: Chem. Phys. Lett., 246, 150, 1995.

Neeb, P., Horie, O., and Moortgat, G. K.: Int. J. Chem. Kinet., 28, 721, 1996.

Neeb, P., Sauer, F., Horie, O., and Moortgat, G.: Atmos. Environ., 31, 1417, 1997.

Niki, H., Maker, P. D., Savage, C. M., and Breitenbach, L. P.: presented at the International Conference on Environmental Sensing and Assessment, Las Vegas, NV, Vol. 2, p. 24-4, 1975.

Niki, H., Maker, P. D., Savage, C. M., and Breitenbach, L. P: Chem. Phys. Lett., 46, 327, 1977.

Niki, H., Maker, P. D., Savage, C. M., and Breitenbach, L. P.: J. Phys. Chem., 85, 1024, 1981.

Niki, H., Maker, P. D., Savage, C. M., and Breitenbach, L. P.: Environ. Sci. Technol., 17, 312A, 1983.

Niki, H., Maker, P. D., Savage, C. M., Breitenbach, L. P., and Hurley, D. M.: J. Phys. Chem., 91, 941, 1987.

Simonaitis. R., Olszyna, K. J., and Meagher, J. F.: Geophys. Res. Lett., 18, 9. 1991.

Su, F., Calvert, J. G., and Shaw, J. H.: J. Phys. Chem., 84, 239, 1980.

Suto, M., Manzanares, E. R., and Lee, L. C.: Environ. Sci. Technol., 19, 815, 1985.

Thamm, J., Wolff, S., Turner, W. V., Gäb, S., Thomas, W., Zabel, F., Fink, E. H., and Becker, K. H.: Chem. Phys. Lett., 258, $155,1996$.

Tobias, H. J. and Zieman, P. J.: J. Phys. Chem. A, 105, 6129, 2001.

Winterhalter, R., Neeb, P., Grossman, D., Kollof, A., Horie, O., and Moortgat, G: J. Atmos. Chem., 35, 165, 2000. 
Appendix A7: X + VOC

II.A7.165

$$
\mathbf{F}+\mathrm{CH}_{4} \rightarrow \mathbf{H F}+\mathrm{CH}_{3}
$$

$\Delta H^{\circ}=-131.5 \mathrm{~kJ} \cdot \mathrm{mol}^{-1}$

\section{Rate coefficient data}

\begin{tabular}{lllc}
\hline$k / \mathrm{cm}^{3}$ molecule ${ }^{-1} \mathrm{~s}^{-1}$ & Temp./K & Reference & Technique/Comments \\
\hline Absolute Rate Coefficients & & & \\
$5.5 \times 10^{-10} \exp [-(580 \pm 150) / T]$ & $250-350$ & Wagner et al., 1971 & DF-MS \\
$7.9 \times 10^{-11}$ & 298 & & \\
$7.2 \times 10^{-11}$ & 298 & Kompa and Wanner, 1972 & (a) \\
$(6.0 \pm 6.0) \times 10^{-11}$ & 298 & Clyne et al., 1973 & DF-MS \\
$(5.72 \pm 0.30) \times 10^{-11}$ & 298 & Fasano and Nogar, 1982 & (b) \\
$(5.3 \pm 0.3) \times 10^{-11}$ & 294 & Moore et al., 1994 & (c) \\
& & & \\
Relative Rate Coefficients & & & RR (d) \\
$9.0 \times 10^{-11} \exp (-137 / T)$ & $253-348$ & Foon and Reid, 1971 & \\
$5.7 \times 10^{-11}$ & 298 & & RR (e) \\
$1.3 \times 10^{-10} \exp (-215 / T)$ & $180-410$ & Persky, 1996 & \\
$6.2 \times 10^{-11}$ & 298 & & \\
\hline
\end{tabular}

\section{Comments}

(a) Flash photolysis of $\mathrm{WF}_{6}$. Overall rate coefficient was obtained by monitoring the decay of the HF chemical laser emission.

(b) Infrared multiphoton dissociation of $\mathrm{SF}_{6}$ in a mixture of $\mathrm{CH}_{4}, \mathrm{D}_{2}$ and Ar. First-order decay of [F] was monitored by chemiluminescence from either HF or DF. Dependence of decay rate on mixture composition gave values for $k$ and for $k\left(\mathrm{~F}+\mathrm{D}_{2}\right)$.

(c) Time-resolved vibrational chemiluminescence from HF monitored following the production of $\mathrm{F}$ atoms in the presence of $\mathrm{CH}_{4}$ by pulsed laser photolysis of $\mathrm{F}_{2}$ at $266 \mathrm{~nm}$. Rate coefficient values were also reported at $218 \mathrm{~K}, 179 \mathrm{~K}$ and $139 \mathrm{~K}$, with the values increasing at temperatures below about $200 \mathrm{~K}$.

(d) Competitive fluorination-consumption technique. Value of $k$ derived from measured ratio $k / k\left(\mathrm{~F}+\mathrm{H}_{2}\right)=0.82 \exp (313 / T)$ and $k\left(\mathrm{~F}+\mathrm{H}_{2}\right)=1.1 \times 10^{-10} \exp (-450 / T) \mathrm{cm}^{3}$ molecule $\mathrm{e}^{-1} \mathrm{~s}^{-1}$ (IUPAC, current evaluation).

(e) Competitive study using DF-MS technique. Value of $k$ derived from measured ratio $k / k\left(\mathrm{~F}+\mathrm{D}_{2}\right)=1.21 \exp (420 / T)$, the kinetic isotope effect $k\left(\mathrm{~F}+\mathrm{H}_{2}\right) / k\left(\mathrm{~F}+\mathrm{D}_{2}\right)=1.04 \exp (185 / T)\left(\right.$ Persky, 1973) and $k\left(\mathrm{~F}+\mathrm{H}_{2}\right)=1.1 \times 10^{-10} \exp (-450 / T) \mathrm{cm}^{3}$ molecule ${ }^{-1} \mathrm{~s}^{-1}$ (IUPAC, current evaluation).

\section{Preferred Values}

$k=6.3 \times 10^{-11} \mathrm{~cm}^{3}$ molecule ${ }^{-1} \mathrm{~s}^{-1}$ at $298 \mathrm{~K}$.

$k=1.3 \times 10^{-10} \exp (-215 / T) \mathrm{cm}^{3}$ molecule ${ }^{-1} \mathrm{~s}^{-1}$ over the temperature range $180-410 \mathrm{~K}$.

\section{Reliability}

$\Delta \log k= \pm 0.15$ at $298 \mathrm{~K}$.

$\Delta(E / R)= \pm 200 \mathrm{~K}$. 


\section{Comments on Preferred Values}

The preferred value at room temperature is based on the room temperature values reported in Wagner et al. (1971), Kompa and Wanner (1972), Clyne et al. (1973), Fasano and Nogar (1982), Moore et al. (1994), Foon and Reid (1971) and Persky (1973). The preferred temperature dependence is that reported by Persky (1973). Results reported in this study are preferred over the temperature dependences reported in the much earlier studies of Wagner et al. (1971) and Foon and Reid (1971).

\section{References}

Clyne, M. A. A., McKenney, D. J., and Walker, R. F.: Can. J. Chem., 51, 3596, 1973.

Fasano, D. M. and Nogar, N. S.: Chem. Phys. Lett., 92, 411, 1982.

Foon, R. and Reid, G. P.: Trans. Faraday Soc., 67, 3513, 1971.

IUPAC: http://www.iupac-kinetic.ch.cam.ac.uk/.

Kompa, K. L. and Wanner, J.: Chem. Phys. Lett., 12, 560, 1972.

Moore, C. M., Smith, I. W. M., and Stewart, D. W. A.: Int. J. Chem. Kinet., 26, 813, 1994.

Persky, A.: J. Chem. Phys., 59, 3612, 1973.

Persky, A.: J. Phys. Chem., 100, 689, 1996.

Wagner, H. Gg., Warnatz, J., and Zetzsch, C.: An. Assoc. Quim. Argentina, 59, 169, 1971. 
II.A7.166

$$
\mathrm{Cl}+\mathrm{CH}_{4} \rightarrow \mathbf{H C l}+\mathrm{CH}_{3}
$$

$\Delta H^{\circ}=7.6 \mathrm{~kJ} \cdot \mathrm{mol}^{-1}$

\section{Rate coefficient data}

\begin{tabular}{lllc}
\hline$k / \mathrm{cm}^{3}$ molecule ${ }^{-1} \mathrm{~s}^{-1}$ & Temp./K & Reference & Technique/Comments \\
\hline Absolute Rate Coefficients & & & \\
$7.94 \times 10^{-12} \exp [-(1260 \pm 35) / T]$ & $218-401$ & Watson et al., 1976 & FP-RF (a) \\
$(1.13 \pm 0.1) \times 10^{-13}$ & 298 & & \\
$7.93 \times 10^{-12} \exp [-(1272 \pm 51) / T]$ & $218-322$ & Manning and Kurylo, 1977 & FP-RF \\
$(1.04 \pm 0.1) \times 10^{-13}$ & 296 & & \\
$6.51 \times 10^{-12} \exp [-(1229 \pm 27) / T]$ & $200-299$ & Whytock et al., 1977 & FP-RF (b) \\
$(1.13 \pm 0.07) \times 10^{-13}$ & 299 & & \\
$(1.08 \pm 0.07) \times 10^{-13}$ & 298 & Michael and Lee, 1977 & DF-RF \\
$1.06 \times 10^{-11} \exp [-(1415 \pm 100) / T]$ & $268-423$ & Lin et al., 1978 & DF-MS \\
$(9.6 \pm 0.9) \times 10^{-14}$ & 296 & & \\
$8.2 \times 10^{-12} \exp [-(1320 \pm 20 / T]$ & $200-300$ & Zahniser et al., 1978 & DF-RF (c) \\
$(9.9 \pm 1.5) \times 10^{-14}$ & 298 & & \\
$7.4 \times 10^{-12} \exp [-(1291 \pm 68) / T]$ & $220-298$ & Keyser, 1978 & DF-RF (d) \\
$(1.01 \pm 0.02) \times 10^{-13}$ & 298 & & \\
$3.2 \times 10^{-12} \exp [-(1063 \pm 34) / T]$ & $221-298$ & Ravishankara and Wine, 1980 & PLP-RF (e) \\
$(9.65 \pm 0.55) \times 10^{-14}$ & 298 & & \\
$8.06 \times 10^{-12} \exp [-(1300 \pm 113) / T]$ & $233-338$ & Heneghan et al., 1981 & (f) \\
$(9.60 \pm 0.50) \times 10^{-14}$ & 298 & & \\
$(9.93 \pm 0.13) \times 10^{-14}$ & 298 & Dobis and Benson, 1987 & (f) \\
$(9.17 \pm 0.75) \times 10^{-14}$ & 294 & Sawerysyn et al., 1987 & DF-MS \\
$(9.40 \pm 0.40) \times 10^{-14}$ & 298 & Beichert et al., 1995 & DF-RF \\
$7.0 \times 10^{-12} \exp [-(1270 \pm 60) / T]$ & $181-291$ & Seeley et al., 1996 & (g) \\
$(9.9 \pm 0.3) \times 10^{-14}$ & 298 & & \\
$(1.00 \pm 0.10) \times 10^{-13}$ & 298 & Matsumi et al., 1997 & PLP-LIF \\
$3.7 \times 10^{-13}(T / 298)^{2.6} \exp (-385 / T)$ & $292-800$ & Pilgrim et al., 1997 & PLP (h) \\
$(9.3 \pm 0.9) \times 10^{-14}$ & 292 & & \\
$(1.07 \pm 0.03) \times 10^{-13}$ & 297 & Mellouki, 1998 & PLP-RF \\
$6.5 \times 10^{-12} \operatorname{exp[-(1235\pm 34)/T]}$ & $218-298$ & Wang and Keyser, 1999 & DF-RF \\
$(1.01 \pm 0.06) \times 10^{-13}$ & 298 & & \\
\hline
\end{tabular}

\section{Comments}

(a) These values were derived using the original data, but correcting for the presence of $\mathrm{C}_{2} \mathrm{H}_{6}$ (see Addenda to Watson, 1977).

(b) Non-linear Arrhenius behaviour was observed over the entire temperature range ( $200 \mathrm{~K}$ to $500 \mathrm{~K}$ ) of measurements. Data for the temperature range $200 \mathrm{~K}$ to $299 \mathrm{~K}$ are well represented by the Arrhenius expression given in the table (Whytock et al., 1977).

(c) Non-linear Arrhenius behaviour was observed over the entire temperature range ( $200 \mathrm{~K}$ to $504 \mathrm{~K}$ ) of measurements. Data for the temperature range $200 \mathrm{~K}$ to $300 \mathrm{~K}$ are well represented by the Arrhenius expression given in the table (Zahniser et al., 1978).

(d) Non-linear Arrhenius behaviour was observed over the entire temperature range ( $220 \mathrm{~K}$ to $423 \mathrm{~K}$ ) of measurements. Data for the temperature range $220 \mathrm{~K}$ to $298 \mathrm{~K}$ are well represented by the Arrhenius expression given in the table (Keyser, 1978). 
(e) Non-linear Arrhenius behaviour was observed. At temperatures at and below $240 \mathrm{~K}$ the apparent bimolecular rate constant was dependent upon the chemical composition of the reaction mixture. Ravishankara and Wine (1980) suggested that this was due to a non-equilibration of the ${ }^{2} \mathrm{P}_{1 / 2}$ and ${ }^{2} \mathrm{P}_{3 / 2}$ spin states of atomic chlorine at high values of the pseudo-first order rate constant, $k^{\prime}$, i.e., if the mixture did not contain an efficient spin equilibrator, e.g, $\mathrm{Ar}$ or $\mathrm{CCl}_{4}$, the bimolecular rate constant decreased at high $\mathrm{CH}_{4}$ concentrations, i.e., high values of $k^{\prime}$. The Arrhenius expression for $k$ between $221 \mathrm{~K}$ and $298 \mathrm{~K}$ was derived from the data shown in their Table II (excluding the high $\mathrm{CH}_{4}$ concentration data in the $\mathrm{He}_{-} \mathrm{Cl}_{2}-\mathrm{CH}_{4}$ system).

(f) Very low pressure reactor system with MS detection of reactants and products.

(g) Turbulent flow tube technique at pressures near 80 mbar (60 Torr). The $\mathrm{Cl}$ atom decay was monitored by RF.

(h) Pulsed laser photolysis of $\mathrm{CF}_{2} \mathrm{Cl}_{2}$ at $193 \mathrm{~nm}$. Time evolution of $\mathrm{HCl}$ product was monitored by continuous wave infrared long-path absorption at the R(3) line of the fundamental vibrational transition. Non-linear Arrhenius behavior was observed between $292 \mathrm{~K}$ and $800 \mathrm{~K}$ and was described by the modified Arrhenius expression given in the table.

\section{Preferred Values}

$k=1.0 \times 10^{-13} \mathrm{~cm}^{3}$ molecule ${ }^{-1} \mathrm{~s}^{-1}$ at $298 \mathrm{~K}$.

$k=6.6 \times 10^{-12} \exp (-1240 / T) \mathrm{cm}^{3}$ molecule ${ }^{-1} \mathrm{~s}^{-1}$ over the temperature range $200-300 \mathrm{~K}$.

\section{Reliability}

$\Delta \log k= \pm 0.06$ at $298 \mathrm{~K}$.

$\Delta(E / R)= \pm 200 \mathrm{~K}$.

\section{Comments on Preferred Values}

The preferred Arrhenius expression is derived from a least-squares fit to the experimental data between $200 \mathrm{~K}$ and $300 \mathrm{~K}$ reported in the studies of Watson et al. (1976), Manning and Kurylo (1977), Whytock et al. (1977), Michael and Lee (1977), Lin et al. (1978), Zahniser et al. (1978), Keyser (1978), Ravishankara and Wine (1980), Heneghan et al. (1981), Dobis and Benson (1987), Sawerysyn et al. (1987), Beichert et al. (1995), Seeley et al. (1996), Matsumi et al. (1997) and Pilgrim et al. (1997). The data used were restricted to the $200 \mathrm{~K}$ to $300 \mathrm{~K}$ temperature range because of the curvature in the Arrhenius plot at higher temperatures reported in the studies of Whytock et al. (1977), Zahniser et al. (1978), Keyser (1978), Ravishankara and Wine (1980) and Pilgrim et al. (1997). Therefore, for some studies only a subset of the data reported in the study was used. Results of the most recent studies of Mellouki et al. (1998) and Wang and Keyser (1999) are in excellent agreement with the preferred values. Results of relative rate studies were not used in this evaluation in the derivation of the preferred values. In general, the relative rate data (Lin et al., 1978; Watson, 1977; Pritchard et al., 1954; Pritchard et al., 1955; Knox, 1955) used in previous evaluations are in good agreement with the preferred values at room temperature, but are significantly lower than the preferred values at low temperatures.

\section{References}

Beichert, P., Wingen, L., Lee, J., Vogt, R., Ezell, M. J., Ragains, M., Neavyn, R., and Finlayson-Pitts, B. J.:J. Phys. Chem., 99, $13156,1995$.

Dobis, O. and Benson, S. W.: Int. J. Chem. Kinet., 19, 691, 1987.

Heneghan, S. P., Knoot, P. A., and Benson, S. W.: Int. J. Chem. Kinet., 13, 677, 1981.

Keyser, L. F.: J. Chem. Phys., 69, 214, 1978.

Knox, J. H. and Nelson, R. L.: Trans. Faraday Soc., 55, 937, 1959.

Knox, J. H.: Chem. Indust., 1631, 1955; modified by Lin et al., 1978.

Lin, C. L., Leu, M. T., and DeMore, W. B.: J. Phys. Chem., 82, 1772, 1978.

Manning, R. G. and Kurylo, M. J.: J. Phys. Chem., 81, 291, 1977.

Matsumi, Y., Izumi, K., Skorokhodov, V., Kawasaki, M., and Tanaka, N.: J. Phys. Chem. A, 101, 1216, 1997.

Mellouki, A.: J. Chim. Phys., 95, 513, 1998.

Michael, J. V. and Lee, J. H.: Chem. Phys. Lett., 51, 303, 1977. 
Pilgrim, J. S., McIlroy, A., and Taatjes, C. A.: J. Phys. Chem. A, 101, 1873, 1997.

Pritchard, H. O., Pyke, J. B., and Trotman-Dickenson, A. F.: J. Am. Chem. Soc., 76, 1201, 1954.

Pritchard, H. O., Pyke, J. B., and Trotman-Dickenson, A. F.: J. Am. Chem. Soc., 77, 2629, 1955.

Ravishankara, A. R. and Wine, P. H.: J. Chem. Phys. 72, 25, 1980.

Sawerysyn, J.-P., Lafage, C., Meriaux, B., and Tighezza, A.: J. Chim. Phys., 84, 1187, 1987.

Seeley, J. V., Jayne, J. T., and Molina, M. J.: J. Phys. Chem., 100, 4019, 1996.

Wang, J. J. and Keyser, L. F.: J. Phys. Chem. A, 103, 7460, 1999.

Watson, R. T., Machado, G., Fischer, S., and Davis, D. D.: J. Chem. Phys., 65, 2126, 1976.

Watson, R. T.: J. Phys. Chem. Ref. Data, 6, 871, 1977.

Whytock, D. A., Lee, J. H., Michael, J. V., Payne, W. A., and Stief, L. J.: J. Chem. Phys., 66, 2690, 1977.

Zahniser, M. S., Berquist, B. M., and Kaufman, F.: Int. J. Chem. Kinet., 10, 15, 1978. 
II.A7.167

$$
\mathrm{Cl}+\mathrm{C}_{2} \mathrm{H}_{2}+\mathrm{M} \rightarrow \mathrm{C}_{2} \mathrm{H}_{2} \mathrm{Cl}+\mathrm{M}
$$

\section{Low-pressure rate coefficients}

\section{Rate coefficient data}

\begin{tabular}{llll}
\hline$k_{0} / \mathrm{cm}^{3}$ molecule ${ }^{-1} \mathrm{~s}^{-1}$ & Temp./K & Reference & Technique/Comments \\
\hline $\begin{array}{l}\text { Absolute Rate Coefficients } \\
(3.15 \pm 0.30) \times 10^{-21} T^{-3.5}[\mathrm{Ar}]\end{array}$ & $\begin{array}{l}210-361 \\
6.9 \times 10^{-30}[\mathrm{Ar}]\end{array}$ & Brunning and Stief, 1985 & FP-RF (a) \\
& & & \\
Relative Rate Coefficients & & & \\
$(5.2 \pm 0.7) \times 10^{-30}[$ air] & 295 & Wallington et al., 1990 & RR (b) \\
$5.4 \times 10^{-30}(T / 300)^{-2.092}[$ air] & $252-370$ & Kaiser, 1992 & RR (c) \\
$(6.1 \pm 0.2) \times 10^{-30}[$ air] & 297 & Kaiser and Wallington, 1996 & RR (d) \\
\hline
\end{tabular}

\section{Comments}

(a) The concentration of the bath gas Ar was varied over the range $(2.7-120) \times 10^{17}$ molecule $\mathrm{cm}^{-3}$. Some experiments with $\mathrm{N}_{2}$ were also conducted. Falloff extrapolations were made using $F_{c}=0.6$.

(b) $\mathrm{Cl}$ atoms were generated by photolysis of $\mathrm{Cl}_{2}$ in the presence of $\mathrm{C}_{2} \mathrm{H}_{2}$ and $\mathrm{C}_{2} \mathrm{H}_{6}\left(\mathrm{or}_{2} \mathrm{H}_{5} \mathrm{Cl}\right)$. The decays of $\mathrm{C}_{2} \mathrm{H}_{2}, \mathrm{C}_{2} \mathrm{H}_{6}$ (or $\mathrm{C}_{2} \mathrm{H}_{5} \mathrm{Cl}$ ) were followed by FTIR spectroscopy. The measured rate coefficient ratios have been placed on an absolute basis using a rate coefficient of $k\left(\mathrm{Cl}+\mathrm{C}_{2} \mathrm{H}_{6}\right)=5.7 \times 10^{-11} \mathrm{~cm}^{3}$ molecule $\mathrm{e}^{-1} \mathrm{~s}^{-1}$. Measurements were conducted over the pressure range 0.013 mbar to 7.6 bar. Falloff extrapolations were made with $F_{c}=0.6$.

(c) Mixtures of $\mathrm{C}_{2} \mathrm{H}_{2}, \mathrm{C}_{2} \mathrm{H}_{6}, \mathrm{Cl}_{2}$ and diluent (air, $\mathrm{N}_{2}$, or $\mathrm{SF}_{6}$ ) were irradiated by a UV fluorescent lamp. $\mathrm{C}_{2} \mathrm{H}_{2}$ and $\mathrm{C}_{2} \mathrm{H}_{6}$ concentrations were determined by GC. The reaction was studied at pressures between 0.03 bar and 1.7 bar. The measured rate coefficient ratios are placed on an absolute basis using the rate coefficient $8.68 \times 10^{-11} \exp (-113 / T) \mathrm{cm}^{3} \mathrm{molecule}^{-1}$ $\mathrm{s}^{-1}$ for the reaction $\mathrm{Cl}+\mathrm{C}_{2} \mathrm{H}_{6} \rightarrow \mathrm{C}_{2} \mathrm{H}_{5}+\mathrm{HCl}$. Falloff extrapolations were made with a temperature independent $F_{c}=0.6$.

(d) Mixtures of $\mathrm{Cl}_{2}, \mathrm{C}_{2} \mathrm{H}_{2}, \mathrm{CH}_{4}, \mathrm{CH}_{3} \mathrm{Cl}, \mathrm{C}_{2} \mathrm{H}_{6}$ and $\mathrm{C}_{2} \mathrm{H}_{5} \mathrm{Cl}$ and the diluent gases air and $\mathrm{N}_{2}$ were irradiated with a UV fluorescent lamp. After irradiation $\mathrm{C}_{2} \mathrm{H}_{2}, \mathrm{CH}_{4}$ and $\mathrm{CH}_{3} \mathrm{Cl}$ were monitored by $\mathrm{GC}\left(0.4 \mathrm{mbar}\right.$ to $13 \mathrm{mbar}$ ). $\mathrm{CH}_{3} \mathrm{Cl}_{2} \mathrm{C}_{2} \mathrm{H}_{6}$ and $\mathrm{C}_{2} \mathrm{H}_{5} \mathrm{Cl}$ were determined by FTIR ( 13 mbar to $920 \mathrm{mbar}$ ). The following values were used for the reference abstraction reactions: $1.0 \times 10^{-13} \mathrm{~cm}^{3}$ molecule $\mathrm{s}^{-1}\left(\mathrm{Cl}+\mathrm{CH}_{4}\right), 4.9 \times 10^{-13} \mathrm{~cm}^{3}$ molecule $\mathrm{s}^{-1} \mathrm{~s}^{-1}\left(\mathrm{Cl}+\mathrm{CH}_{3} \mathrm{Cl}\right), 5.7 \times 10^{-11} \mathrm{~cm}^{3}$ molecule $\mathrm{s}^{-1}\left(\mathrm{Cl}+\mathrm{C}_{2} \mathrm{H}_{6}\right)$ and $8.05 \times 10^{-12} \mathrm{~cm}^{3}$ molecule ${ }^{-1} \mathrm{~s}^{-1}\left(\mathrm{Cl}+\mathrm{C}_{2} \mathrm{H}_{5} \mathrm{Cl}\right)$. The results were analyzed together with previous determinations performed between 0.13 bar and 7.9 bar and extrapolated with $F_{c}=0.6$ (Wallington et al., 1990).

\section{Preferred Values}

$k_{0}=6.1 \times 10^{-30}(T / 300)^{-3}\left[\mathrm{~N}_{2}\right] \mathrm{cm}^{3}$ molecule $\mathrm{c}^{-1} \mathrm{~s}^{-1}$ over the temperature range $200-300 \mathrm{~K}$.

\section{Reliability}

$\Delta \log k_{0}= \pm 0.3$ at $298 \mathrm{~K}$.

$\Delta n= \pm 1$.

\section{Comments on Preferred Values}

The preferred values are based on the room temperature measurements of Kaiser and Wallington (1996) which have been evaluated with $F_{c}=0.6$. The temperature dependence is a compromise of the results from Brunning and Stief (1985) and Kaiser (1992). 


\section{High-pressure rate coefficients}

\section{Rate coefficient data}

\begin{tabular}{lllc}
\hline$k_{\infty} / \mathrm{cm}^{3}$ molecule & & Technique/Comments \\
\hline $\begin{array}{l}\text { Absolute Rate Coefficients } \\
(1.52 \pm 0.15) \times 10^{-4} T^{-2.63}\end{array}$ & Temp./K & Reference & \\
$4.7 \times 10^{-11}$ & 298 & & FP-RF (a) \\
& & Brunning and Stief, 1985 & \\
Relative Rate Coefficients & & & \\
$(2.3 \pm 0.7) \times 10^{-10}$ & 295 & Wallington et al., 1990 & RR (b) \\
$2.13 \times 10^{-10}($ T/300) & & & RR (c) \\
$(2.0 \pm 0.1) \times 10^{-10}$ & $252-370$ & Kaiser, 1992 & RR (d) \\
\hline
\end{tabular}

\section{Comments}

(a) to (d) See comments (a) to (d) for $k_{0}$.

\section{Preferred Values}

$k=5.2 \times 10^{-11} \mathrm{~cm}^{3}$ molecule ${ }^{-1} \mathrm{~s}^{-1}$ at $298 \mathrm{~K}$ and 1 bar of air.

$k_{\infty}=2.0 \times 10^{-10} \mathrm{~cm}^{3}$ molecule ${ }^{-1} \mathrm{~s}^{-1}$, independent of temperature over the range $200-400 \mathrm{~K}$.

\section{Reliability}

$\Delta \log k_{\infty}= \pm 0.3$ at $298 \mathrm{~K}$.

$\Delta n= \pm 1$.

\section{Comments on Preferred Values}

The preferred values are based on the data of Kaiser and Wallington (1996) which cover the broadest pressure range (0.13 bar to 7.9 bar). They have been evaluated with $F_{c}=0.6$. Relative rate coefficients near 1 bar from Lee and Rowland (1977), Atkinson and Aschmann (1985) and Wallington et al. (1988) are in good agreement with the preferred values. A branching ratio of $0.19 \pm 0.05$ for formation of cis- vs trans-isomers of the $\mathrm{CHCl}=\mathrm{CH}$ adduct was determined by $\mathrm{Zhu}$ et al. (1994) around 1 bar of $\mathrm{N}_{2}$ and $295 \mathrm{~K}$.

\section{References}

Atkinson, R. and Aschmann, S. M.: Int. J. Chem. Kinet., 17, 33, 1985.

Brunning, J. and Stief, L. J. : J. Chem. Phys., 83, 1005, 1985.

Kaiser, E. W.: Int. J. Chem. Kinet., 24, 1791992.

Kaiser, E. W. and Wallington, T. J.: J. Phys. Chem., 100, 4111, 1996.

Lee, F. S. C. and Rowland, F. S.: J. Phys. Chem., 81, 684, 1977.

Wallington, T. J., Skewes, L. M., and Siegl, W. O.: J. Photochem. Photobiol. A: Chem., 45, 1671988.

Wallington, T. J., Andino, J. M., Lorkovic, I. M., Kaiser, E. W., and Marston, G.: J. Phys. Chem., 94, $3644,1990$.

Zhu, T., Yarwood, G., Chen, J., and Niki, H.: J. Phys. Chem., 98, 5065, 1994. 
II.A7.168

$$
\mathbf{C l}+\mathbf{C}_{2} \mathbf{H}_{4}+\mathbf{M} \rightarrow \mathbf{C}_{2} \mathbf{H}_{4} \mathbf{C l}+\mathbf{M}
$$

\section{Low-pressure rate coefficients}

\section{Rate coefficient data}

\begin{tabular}{lllc}
\hline$k_{0} / \mathrm{cm}^{3}$ molecule ${ }^{-1} \mathrm{~s}^{-1}$ & Temp./K & Reference & Technique/Comments \\
\hline $\begin{array}{l}\text { Absolute Rate Coefficients } \\
(1.4 \pm 0.2) \times 10^{-29}(T / 298)^{-2.0}\left[\mathrm{~N}_{2}\right]\end{array}$ & $218-297$ & Maricq et al., 1993 & \\
$(1.0 \pm 0.2) \times 10^{-29}[\mathrm{He}]$ & 293 & Stutz et al., 1997 & $(\mathrm{a})$ \\
& & & (b) \\
Relative Rate Coefficients & & & \\
$\left(1.6_{-0.3}^{+1}\right) \times 10^{-29}[$ air] & 295 & Wallington et al., 1990 & RR (c) \\
$(1.7 \pm 0.3) \times 10^{-29}(T / 298)^{-3.28}[$ air $]$ & $297-383$ & Kaiser and Wallington, 1996 & RR (d) \\
$(1.42 \pm 0.05) \times 10^{-29}[$ air] & 297 & & \\
$1.0 \times 10^{-29}[\mathrm{He}]$ & 297 & Kaiser and Wallington, 1998 & RR (d,e) \\
$1.85 \times 10^{-29}\left[\mathrm{~N}_{2}\right]$ & & & \\
\hline
\end{tabular}

\section{Comments}

(a) IR absorption measurements of $\mathrm{C}_{2} \mathrm{H}_{4}$ and $\mathrm{HCl}$ after laser photolysis of $\mathrm{Cl}_{2}$ in $\mathrm{Cl}_{2}-\mathrm{C}_{2} \mathrm{H}_{4}-\mathrm{O}_{2}-\mathrm{N}_{2}$ mixtures. Measurements at 39 mbar of $\mathrm{N}_{2}$, here evaluated without falloff corrections. $k$ also measured at 170 mbar and $297 \mathrm{~K}$.

(b) Fast-flow discharge study detecting $\mathrm{Cl}$ by resonance fluorescence at $135 \mathrm{~nm}$. Similar results by relative rate measurements.

(c) Measurements of $k$ performed by a relative rate technique. $\mathrm{Cl}$ atoms were generated by photolysis of $\mathrm{Cl}_{2}$ in the presence of $\mathrm{C}_{2} \mathrm{H}_{4}$, and $\mathrm{C}_{2} \mathrm{H}_{6}$ (or $\mathrm{C}_{2} \mathrm{H}_{5} \mathrm{Cl}$ ). Decay of $\mathrm{C}_{2} \mathrm{H}_{4}, \mathrm{C}_{2} \mathrm{H}_{6}\left(\right.$ or $\left.\mathrm{C}_{2} \mathrm{H}_{5} \mathrm{Cl}\right)$ monitored by FTIR spectroscopy. Using a value of $5.7 \times 10^{-11} \mathrm{~cm}^{3}$ molecule ${ }^{-1} \mathrm{~s}^{-1}$ for the rate coefficient for the $\mathrm{Cl}+\mathrm{C}_{2} \mathrm{H}_{6} \rightarrow \mathrm{C}_{2} \mathrm{H}_{5}+\mathrm{HCl}$ reaction, the relative data were placed on an absolute basis. The reaction was studied over the pressure range $13 \mathrm{mbar}$ to $4000 \mathrm{mbar}$ and the measured rate coefficients fitted with $F_{c}=0.6$.

(d) Mixtures of $\mathrm{Cl}_{2}, \mathrm{C}_{2} \mathrm{H}_{4}, \mathrm{CH}_{4}, \mathrm{CH}_{3} \mathrm{Cl}, \mathrm{CCl}_{3} \mathrm{H}, \mathrm{C}_{2} \mathrm{H}_{6}$ and $\mathrm{C}_{2} \mathrm{H}_{5} \mathrm{Cl}$ and the diluent gases air and $\mathrm{N}_{2}$ were irradiated with a UV fluorescent lamp. After irradiation, $\mathrm{C}_{2} \mathrm{H}_{4}$ and the above reference compounds were determined by GC or FTIR techniques. The experiments were performed at total pressures of 0.26 mbar to $130 \mathrm{mbar}$. The following values were used for the reference abstraction reactions: $1.0 \times 10^{-13} \mathrm{~cm}^{-3}$ molecule ${ }^{-1} \mathrm{~s}^{-1}\left(\mathrm{Cl}+\mathrm{CH}_{4}\right), 4.9 \times 10^{-13} \mathrm{~cm}^{3}$ molecule $\mathrm{s}^{-1}\left(\mathrm{Cl}+\mathrm{CH}_{3} \mathrm{Cl}\right), 1.1 \times 10^{-13} \mathrm{~cm}^{3}$ molecule $^{-1} \mathrm{~s}^{-1}\left(\mathrm{Cl}+\mathrm{CCl}_{3} \mathrm{H}\right), 5.7 \times 10^{-11} \mathrm{~cm}^{3}$ molecule $\mathrm{s}^{-1}\left(\mathrm{Cl}+\mathrm{C}_{2} \mathrm{H}_{6}\right)$ and $8.05 \times 10^{-12} \mathrm{~cm}^{3}$ molecule $\mathrm{s}^{-1} \mathrm{~s}^{-1}\left(\mathrm{Cl}+\mathrm{C}_{2} \mathrm{H}_{5} \mathrm{Cl}\right)$. The results were analyzed together with previous determinations conducted at 130 mbar to 4000 mbar of air (Wallington et al., 1990) and extrapolated with $F_{c}=0.6$.

(e) Falloff extrapolation with $F_{c}=0.4$.

\section{Preferred Values}

$k_{0}=1.85 \times 10^{-29}(T / 300)^{-3.3}[$ air $] \mathrm{cm}^{3}$ molecule $\mathrm{e}^{-1} \mathrm{~s}^{-1}$ over the temperature range $250-300 \mathrm{~K}$.

\section{Reliability}

$\Delta \log k_{0}= \pm 0.5$ at $298 \mathrm{~K}$.

$\Delta n= \pm 1$. 


\section{Comments on Preferred Values}

The preferred values are based on the most detailed results from Kaiser and Wallington $(1996,1998)$ which agree with the results from Maricq et al. (1993) and Stutz et al. (1997) (only for the bath gas He, but not $\mathrm{N}_{2}$ ). The given value of $k_{0}$ corresponds to a falloff extrapolation with $F_{c}=0.4$.

\section{High-pressure rate coefficients}

\section{Rate coefficient data}

\begin{tabular}{|c|c|c|c|}
\hline$k / \mathrm{cm}^{3}$ molecule $^{-1} \mathrm{~s}^{-1}$ & Temp./K & Reference & Technique/Comments \\
\hline \multicolumn{4}{|l|}{ Relative Rate Coefficients } \\
\hline $\left.3.05_{-04}^{+2}\right) \times 10^{-10}$ & 295 & Wallington et al., 1990 & RR (a) \\
\hline$(3.2 \pm 0.15) \times 10^{-10}$ & 297 & Kaiser and Wallington, 1996 & $\mathrm{RR}(\mathrm{b})$ \\
\hline $5.7 \times 10^{-10}$ & 297 & Kaiser and Wallington, 1998 & $\mathrm{RR}(\mathrm{c})$ \\
\hline
\end{tabular}

\section{Comments}

(a) See comment (c) for $k_{0}$.

(b) See comment (d) for $k_{0}$.

(c) See comments (d) and (e) for $k_{0}$.

\section{Preferred Values}

$k=1.1 \times 10^{-10} \mathrm{~cm}^{3}$ molecule $\mathrm{e}^{-1} \mathrm{~s}^{-1}$ at $298 \mathrm{~K}$ and 1 bar of air.

$k_{\infty}=6 \times 10^{-10} \mathrm{~cm}^{3}$ molecule $\mathrm{s}^{-1} \mathrm{~s}^{-1}$, independent of temperature over the range 250-300 K.

\section{Reliability}

$\Delta \log k_{\infty}= \pm 0.3$ at $298 \mathrm{~K}$.

$\Delta n= \pm 1$.

Comments on Preferred Values

The falloff extrapolation of the data from Wallington et al. (1990) is consistent with results in the intermediate falloff range from Maricq et al. (1993), Lee and Rowland (1977), Iyer et al. (1983), Atkinson and Aschmann (1985), Atkinson and Aschmann (1987) and Wallington et al. (1988). Measurements of the reverse decomposition of $\mathrm{C}_{2} \mathrm{H}_{4} \mathrm{Cl}$ in the falloff range at 400-480 K have been reported by Knyazev et al. (1999).

\section{References}

Atkinson, R. and Aschmann, S. M.: Int. J. Chem. Kinet., 17, 33, 1985.

Atkinson, R. and Aschmann, S. M.: Int. J. Chem. Kinet., 19, 1097, 1987.

Iyer, S. R., Rogers, P. J., and Rowland, F. S.: J. Phys. Chem., 87, 3799, 1983.

Kaiser, E. W. and Wallington, T. J.: J. Phys. Chem., 100, 4111, 1996.

Kaiser, E. W. and Wallington, T. J.: J. Phys. Chem. A, 102, 5054, 1998.

Knyazev, V. D., Kalinovski, I. J., and Slagle, I. R.: J. Phys. Chem. A, 103, 3216, 1999.

Lee, F. S. C. and Rowland, F. S.: J. Phys. Chem., 81, 1235, 1977.

Maricq, M. M., Szente, J. J., and Kaiser, E. W.: J. Phys. Chem., 97, 7970, 1993

Stutz, J., Ezell, M. J., and Finlayson-Pitts, B. J.: J. Phys. Chem. A, 101, 9187, 1997.

Wallington, T. J., Skewes, L. M., and Siegl, W. O.: J. Photochem. Photobiol. A: Chem., 45, 167, 1988.

Wallington, T.J., Andino, J. M., Lorkovic, I. M., Kaiser, E. W., and Marston, G.: J. Phys. Chem., 94, 3644, 1990. 
II.A7.169

$$
\mathrm{Cl}+\mathrm{C}_{2} \mathrm{H}_{6} \rightarrow \mathbf{H C l}+\mathrm{C}_{2} \mathrm{H}_{5}
$$

$\Delta H^{\circ}=-8.7 \mathrm{~kJ} \cdot \mathrm{mol}^{-1}$

\section{Rate coefficient data}

\begin{tabular}{lllc}
\hline$k / \mathrm{cm}^{3}$ molecule ${ }^{-1} \mathrm{~s}^{-1}$ & Temp./K & Reference & Technique/Comments \\
\hline $\begin{array}{l}\text { Relative Rate Coefficients } \\
(6.0 \pm 1.5) \times 10^{-11}\end{array}$ & 298 & Davis et al., 1970 & \\
$7.29 \times 10^{-11} \exp [-(61 \pm 44) / T]$ & $222-322$ & Manning and Kurylo, 1977 & FP-RF (a) \\
$(5.93 \pm 0.44) \times 10^{-11}$ & 296 & & FP-RF \\
$(5.95 \pm 0.28) \times 10^{-11}$ & 298 & Ray et al., 1980 & \\
$9.01 \times 10^{-11} \exp [-(133 \pm 15) / T]$ & $220-604$ & Lewis et al., 1980 & DF-MS \\
$(5.48 \pm 0.30) \times 10^{-11}$ & 298 & & DF-RF \\
$8.20 \times 10^{-11} \exp [-(86 \pm 10) / T]$ & $203-343$ & Dobis and Benson, 1991 & \\
$(6.10 \pm 0.11) \times 10^{-11}$ & 298 & & (b) \\
$(7.05 \pm 1.4) \times 10^{-11}$ & 298 & Kaiser et al., 1992 & \\
$(5.9 \pm 0.6) \times 10^{-11}$ & 297 & Stickel et al., 1992 & PLP-IRA \\
$(5.53 \pm 0.21) \times 10^{-11}$ & 298 & Beichert et al., 1995 & PLP-TDLS \\
$(5.75 \pm 0.45) \times 10^{-11}$ & 298 & Tyndall et al., 1997 & DF-RF \\
$8.6 \times 10^{-11} \exp [-(135 \pm 26)]$ & $292-600$ & Pilgrim et al., 1997 & FP-RF \\
$(5.5 \pm 0.2) \times 10^{-11}$ & 292 & & PLP (c) \\
$(6.5 \pm 0.3) \times 10^{-11}$ & 297 & Mellouki, 1998 & \\
$(5.85 \pm 0.55) \times 10^{-11}$ & 298 & Hitsuda et al., 2001 & PLP-RF \\
& & & PLP-LIF \\
Relative Rate Coefficients & & & \\
$(6.0 \pm 1.3) \times 10^{-11}$ & 296 & Hooshiyar and Niki, 1995 & \\
$(5.4 \pm 1.2) \times 10^{-11}$ & 298 & Beichert et al., 1995 & RR (d) \\
$(5.5 \pm 1.2) \times 10^{-11}$ & 297 & Tyndall et al., 1997 & RR (e) \\
$(5.7 \pm 0.5) \times 10^{-11}$ & 298 & Finlayson-Pitts et al., 1999 & RR (f) \\
\hline & & & RR (g) \\
\hline
\end{tabular}

\section{Comments}

(a) Reported value has been reduced by $10 \%$ as discussed previously (CODATA, 1980).

(b) Very low pressure reactor study. $\mathrm{Cl}$ atoms were generated by microwave discharge of $\mathrm{Cl}_{2}-\mathrm{He}$ mixtures, with $\mathrm{MS}$ analysis of reactants and products.

(c) $\mathrm{Cl}$ atoms generated from pulsed laser photolysis of $\mathrm{CF}_{2} \mathrm{Cl}_{2}$ at $193 \mathrm{~nm}$. Time evolution of $\mathrm{HCl}$ product was monitored by continuous wave infrared long-path absorpton at the $\mathrm{R}(3)$ line of the fundamental vibrational transition.

(d) $\mathrm{Cl}$ atoms generated by photolysis of $\mathrm{Cl}_{2}$ in $\mathrm{N}_{2}$ at 1 bar pressure. Relative disappearance rates of organics studied were measured by GC. Rate coefficient rato $k / k\left(\mathrm{Cl}+n-\mathrm{C}_{4} \mathrm{H}_{10}\right)=0.294 \pm 0.023$ is placed on an absolute basis by use of $k(\mathrm{Cl}+n$ $\left.\mathrm{C}_{4} \mathrm{H}_{10}\right)=2.05 \times 10^{-10} \mathrm{~cm}^{3}$ molecule $\mathrm{e}^{-1} \mathrm{~s}^{-1}$ (IUPAC, this evaluation).

(e) $\mathrm{Cl}$ atoms generated by photolysis of $\mathrm{Cl}_{2}$ in air at 1 bar pressure. Relative disappearance rates of organics studied were measured by GC. Rate coefficient ratio $k / k\left(\mathrm{Cl}+n-\mathrm{C}_{4} \mathrm{H}_{10}\right)=0.261 \pm 0.013$ is placed on absolute basis by use of $k(\mathrm{Cl}+$ $\left.n-\mathrm{C}_{4} \mathrm{H}_{10}\right)=2.05 \times 10^{-10} \mathrm{~cm}^{3}$ molecule ${ }^{-1} \mathrm{~s}^{-1}$ (IUPAC, this evaluation).

(f) $\mathrm{Cl}$ atoms generated by photolysis of $\mathrm{Cl}_{2}$ in air or $\mathrm{N}_{2}$ at a total pressure of $156 \mathrm{mbar}$ to $666 \mathrm{mbar}$ (117-500 Torr). Relative disappearance rates of organics studied were measured by GC or FTIR. Rate coefficient ratio $k / k(\mathrm{Cl}+n-$ $\left.\mathrm{C}_{4} \mathrm{H}_{10}\right)=0.267 \pm 0.037$ is placed on absolute basis by use of $k\left(\mathrm{Cl}+n-\mathrm{C}_{4} \mathrm{H}_{10}\right)=2.05 \times 10^{-10} \mathrm{~cm}^{3}$ molecule ${ }^{-1} \mathrm{~s}^{-1}$ (IUPAC, this evaluation). 
(g) $\mathrm{Cl}$ atoms generated by photolysis of $\mathrm{Cl}_{2}, \mathrm{SOCl}_{2}$, or $\mathrm{CCl}_{3} \mathrm{COCl}$ in air or $\mathrm{N}_{2}$ at 1 bar pressure. Rate coefficient ratio $k / k\left(\mathrm{Cl}+n-\mathrm{C}_{4} \mathrm{H}_{10}\right)=0.277 \pm 0.025$ is placed on absolute basis by use of $k\left(\mathrm{Cl}+n-\mathrm{C}_{4} \mathrm{H}_{10}\right)=2.05 \times 10^{-10} \mathrm{~cm}^{3}$ molecule $\mathrm{s}^{-1}$ (IUPAC, this evaluation).

\section{Preferred Values}

$k=5.9 \times 10^{-11} \mathrm{~cm}^{3}$ molecule ${ }^{-1} \mathrm{~s}^{-1}$ at $298 \mathrm{~K}$.

$k=8.3 \times 10^{-11} \exp (-100 / T) \mathrm{cm}^{3}$ molecule $\mathrm{s}^{-1} \mathrm{~s}^{-1}$ over the temperature range $220-600 \mathrm{~K}$.

\section{Reliability}

$\Delta \log k= \pm 0.06$ at $298 \mathrm{~K}$.

$\Delta(E / R)= \pm 100 \mathrm{~K}$.

\section{Comments on Preferred Values}

The $298 \mathrm{~K}$ rate coefficient is the average of the room temperature absolute rate coefficients of Davis et al. (1970), Manning and Kurylo (1977), Ray et al. (1980), Lewis et al. (1980), Dobis and Benson (1991), Kaiser et al. (1992), Stickel et al. (1992), Beichert et al. (1995), Tyndall et al. (1997), Pilgrim et al. (1997), Mellouki (1998) and Hitsuda et al. (2001). The temperature dependence is the average of those from the temperature-dependent studies of Manning and Kurylo (1977), Lewis et al. (1980), Dobis and Benson (1991) and Pilgrim et al. (1997). The room temperature relative rate values of Hooshiyar and Niki (1995), Beichert et al. (1995), Tyndall et al. (1997) and Finlayson-Pitts et al. (1999) are in good agreement with the preferred value, while those of Atkinson and Aschmann (1985) and Wallington et al. (1988) are 20\% to 30\% higher than the preferred value.

\section{References}

Atkinson, R. and Aschmann, S. M.: Int. J. Chem. Kinet., 17, 33, 1985.

Beichert, P., Wingen, L., Lee, J., Vogt, R., Ezell, M. J., Ragains, M., Neavyn, R., and Finlayson-Pitts, B. J.: J. Phys. Chem., 99, $13156,1995$.

CODATA, 1980 (see references in Introduction).

Davis, D. D., Braun, W., and Bass, A. M.: Int. J. Chem. Kinet., 2, 101, 1970.

Dobis, O. and Benson, S. W.: J. Am. Chem. Soc., 113, 6377, 1991.

Finlayson-Pitts, B. J., Keoshian, C. J., Buehler, B., and Ezell, A. A.: Int. J. Chem. Kinet., 31, 491, 1999.

Hitsuda, K., Takahashi, K., Matsumi, Y., and Wallington, T. J.: J. Phys. Chem. A, 105, 5131, 2001.

Hooshiyar, P. A. and Niki, H.: Int. J. Chem. Kinet., 27, 1197, 1995.

Kaiser, E. W., Rimai, L., Schwab, E., and Lim, E. C.: J. Phys. Chem., 96, 303, 1992.

Lewis, R. S., Sander, S. P., Wagner, S., and Watson, R. T.: J. Phys. Chem., 84, 2009, 1980.

Manning, R. G. and Kurylo, M. J.: J. Phys. Chem., 81, 291, 1977.

Mellouki, A.: J. Chim. Phys., 95, 513, 1998.

Pilgrim, J. S., McIlroy, A., and Taatjes, C. A.: J. Phys. Chem. A, 101, 1873, 1997.

Ray, G. W., Keyser, L. F., and Watson, R. T.: J. Phys. Chem., 84, 1674, 1980.

Stickel, R. E., Nicovich, J. M., Wang, S., Zhao, Z., and Wine, P. H.: J. Phys. Chem., 96, 9875, 1992.

Tyndall, G. S., Orlando, J. J., Wallington, T. J., Dill, M., and Kaiser, E. W.: Int. J. Chem. Kinet., 29, 43, 1997.

Wallington, T. J., Skewes, L. M., Siegl, W. O., Wu, C.-H., and Japar, S. M.: Int. J. Chem. Kinet., 20, 867, 1988. 
II.A7.170

$$
\mathrm{Cl}+\mathrm{C}_{3} \mathrm{H}_{6}+\mathrm{M} \rightarrow \mathbf{H C l}+\mathrm{C}_{3} \mathrm{H}_{6} \mathrm{Cl}+\mathrm{M}
$$

\section{Low-pressure rate coefficients}

\section{Rate coefficient data}

\begin{tabular}{|c|c|c|c|}
\hline$k_{0} / \mathrm{cm}^{3}$ molecule $^{-1} \mathrm{~s}^{-1}$ & Temp./K & Reference & Technique/Comments \\
\hline $\begin{array}{l}\text { Relative Rate Coefficients } \\
(4.0 \pm 0.4) \times 10^{-28}\left[\mathrm{~N}_{2}\right]\end{array}$ & 298 & Kaiser and Wallington, 1996 & $\mathrm{RR}$ (a) \\
\hline
\end{tabular}

\section{Comments}

(a) $\mathrm{Cl}$ atoms were generated by photolysis of $\mathrm{Cl}_{2}$ in the presence of $\mathrm{C}_{3} \mathrm{H}_{6}$ and $\mathrm{C}_{2} \mathrm{H}_{6}$ at 1 mbar to $900 \mathrm{mbar}$ of $\mathrm{N}_{2}$. $\mathrm{C}_{3} \mathrm{H}_{6}$ consumption was determined by FTIR or GC analysis, the major products being 3-chloropropene and 1,2-dichloropropane. At low pressure (below $12 \mathrm{mbar}$ ) 3-chloropropene is the major product indicating that abstraction of $\mathrm{H}$ by $\mathrm{Cl}$ from the $\mathrm{CH}_{3}$ group in $\mathrm{C}_{3} \mathrm{H}_{6}$ is the dominant channel. At pressures higher than $12 \mathrm{mbar}$, the primary product observed is 1,2dichloropropane, indicating that addition of a $\mathrm{Cl}$ atom to the double bond is the major channel. The limiting rate coefficients were obtained using $F_{c}=0.6$. A rate coefficient for the reference reaction $\mathrm{Cl}+\mathrm{C}_{2} \mathrm{H}_{6} \rightarrow \mathrm{C}_{2} \mathrm{H}_{5}+\mathrm{HCl}$ of $5.9 \times 10^{-11} \mathrm{~cm}^{3}$ molecule ${ }^{-1} \mathrm{~s}^{-1}$ was employed (Kaiser and Wallington, 1996; this evaluation).

\section{Preferred Values}

$k_{0}=4.0 \times 10^{-28}\left[\mathrm{~N}_{2}\right] \mathrm{cm}^{3}$ molecule $\mathrm{c}^{-1}$ at $298 \mathrm{~K}$.

\section{Reliability}

$\Delta \log k_{0}= \pm 0.5$ at $298 \mathrm{~K}$.

\section{Comments on Preferred Values}

The preferred value is based on the only value reported (Kaiser and Wallington, 1996). Due to this and to the uncertainty of the extrapolated $k_{0}$, a large error limit is assigned.

\section{High-pressure rate coefficients}

\section{Rate coefficient data}

\begin{tabular}{|c|c|c|c|}
\hline$k_{\infty} / \mathrm{cm}^{3}$ molecule $^{-1} \mathrm{~s}^{-1}$ & Temp./K & Reference & Technique/Comments \\
\hline $\begin{array}{l}\text { Relative Rate Coefficients } \\
(2.54 \pm 0.09) \times 10^{-10}\end{array}$ & 296 & Atkinson and Aschmann, 1985 & RR (a) \\
\hline$(2.94 \pm 0.13) \times 10^{-10}$ & 295 & Wallington et al., 1988 & RR (b) \\
\hline$(2.68 \pm 0.13) \times 10^{-10}$ & 298 & Kaiser and Wallington, 1996 & $\mathrm{RR}(\mathrm{c})$ \\
\hline
\end{tabular}

\section{Comments}

(a) $\mathrm{Cl}$ atoms generated by the photolysis of $\mathrm{Cl}_{2}-n-\mathrm{C}_{4} \mathrm{H}_{10}-\mathrm{C}_{3} \mathrm{H}_{6}$-air at 1 bar. The reaction was studied relative to the reaction $\mathrm{Cl}+n-\mathrm{C}_{4} \mathrm{H}_{10} \rightarrow$ products for which a rate coefficient $2.05 \times 10^{-10} \mathrm{~cm}^{3}$ molecule ${ }^{-1} \mathrm{~s}^{-1}$ is used (this evaluation). $\mathrm{C}_{3} \mathrm{H}_{6}$ and $n-\mathrm{C}_{4} \mathrm{H}_{10}$ were analyzed by GC. 
(b) $\mathrm{Cl}$ atoms were formed by photolysis of $\mathrm{Cl}_{2}$ in the presence of $\mathrm{C}_{3} \mathrm{H}_{6}$ and $n-\mathrm{C}_{4} \mathrm{H}_{10}$ at atmospheric pressure of synthetic air. The decay rate of $\mathrm{C}_{3} \mathrm{H}_{6}$ was measured relative to that of $n-\mathrm{C}_{4} \mathrm{H}_{10}$ and placed on an absolute basis using rate coefficients of $2.05 \times 10^{-10} \mathrm{~cm}^{3}$ molecule ${ }^{-1} \mathrm{~s}^{-1}$ for the reference reactions (this evaluation).

(c) See comment (a) for $k_{0}$. Rate coefficient at 933 mbar (700 Torr) pressure of $\mathrm{N}_{2}$ or air.

\section{Preferred Values}

$k=2.7 \times 10^{-10} \mathrm{~cm}^{3}$ molecule $\mathrm{e}^{-1} \mathrm{~s}^{-1}$ at $298 \mathrm{~K}$ and 1 bar of air.

$k_{\infty}=2.8 \times 10^{-10} \mathrm{~cm}^{3}$ molecule $\mathrm{e}^{-1} \mathrm{~s}^{-1}$ at $298 \mathrm{~K}$.

\section{Reliability}

$\Delta \log k_{\infty}= \pm 0.3$ at $298 \mathrm{~K}$.

\section{Comments on Preferred Values}

The preferred value at 1 bar of air is an average of earlier results from Atkinson and Aschmann (1985) and Wallington et al. (1988), and the more recent determination by Kaiser and Wallington (1996). At room temperature and atmospheric pressure, the addition of $\mathrm{Cl}$ atoms to the double bond accounts for approximately $90 \%$ of the reaction (Kaiser and Wallington, 1996). The $\mathrm{H}$ atom abstraction occurs from the C-H bonds of the methyl group (Kaiser and Wallington, 1996).

\section{References}

Atkinson, R. and Aschmann, S. M.: Int. J. Chem. Kinet., 17, 33, 1985.

Kaiser, E. W. and Wallington, T. J.: J. Phys. Chem., 100, 9788, 1996.

Wallington, T. J., Skewes, L. M., and Siegl, W. O.: J. Photochem. Photobiol. A: Chem., 45, 167, 1988. 
II.A7.171

$$
\begin{aligned}
\mathrm{Cl}+\mathrm{C}_{3} \mathrm{H}_{8} & \rightarrow \mathbf{H C l}+n-\mathbf{C}_{3} \mathrm{H}_{7} \\
& \rightarrow \mathbf{H C l}+i-\mathbf{C}_{3} \mathrm{H}_{7}
\end{aligned}
$$

$\Delta H^{\circ}(1)=-8.3 \mathrm{~kJ} \cdot \mathrm{mol}^{-1}$

$\Delta H^{\circ}(2)=-22.5 \mathrm{~kJ} \cdot \mathrm{mol}^{-1}$

\section{Rate coefficient data}

\begin{tabular}{lllc}
\hline$k / \mathrm{cm}^{3}$ molecule ${ }^{-1} \mathrm{~s}^{-1}$ & Temp./K & Reference & Technique/Comments \\
\hline Absolute Rate Coefficients $(k)$ & & & \\
$1.36 \times 10^{-10} \exp [(44 \pm 25) / T]$ & $220-607$ & Lewis et al., 1980 & DF-RF (a) \\
$(1.51 \pm 0.06) \times 10^{-10}$ & 298 & & \\
$(1.23 \pm 0.10) \times 10^{-10}$ & 298 & Beichert et al., 1995 & DF-RF (b) \\
$(1.38 \pm 0.03) \times 10^{-10}$ & $292-700$ & Pilgrim et al., 1997 & PLP (c) \\
$(1.31 \pm 0.03) \times 10^{-10}$ & 297 & Mellouki, 1998 & PLP-RF (d) \\
$(1.33 \pm 0.03) \times 10^{-10}$ & 298 & Hitsuda et al., 2001 & PLP-LIF (e) \\
& & & \\
Relative Rate Coefficients $(k)$ & & & \\
$(1.40 \pm 0.28) \times 10^{-10}$ & 296 & Atkinson and Aschmann, 1985 & RR (f) \\
$(1.45 \pm 0.28) \times 10^{-10}$ & 295 & Wallington et al., 1988 & RR (g) \\
$(1.34 \pm 0.28) \times 10^{-10}$ & 296 & Hooshiyar and Niki, 1995 & RR (h) \\
$(1.44 \pm 0.26) \times 10^{-10}$ & 298 & Beichert et al., 1995 & RR (i) \\
$(1.43 \pm 0.25) \times 10^{-10}$ & 297 & Tyndall et al., 1997 & RR (j) \\
\hline
\end{tabular}

\begin{tabular}{llll}
\hline$k / \mathrm{cm}^{3}$ molecule ${ }^{-1} \mathrm{~s}^{-1}$ & Temp./K & Reference & Technique/Comments \\
\hline Relative Rate Coefficients $\left(k_{1}\right.$ and $\left.k_{1}\right)$ & & & \\
$k_{1}=7.0 \times 10^{-11} \exp [(-31 \pm 33) / T]$ & $299-468$ & Sarzynski and Sztuba, 2002 & RR $(\mathrm{k})$ \\
$(6.25 \pm 0.17) \times 10^{-11}$ & 299 & & \\
$k_{2}=5.2 \times 10^{-11} \exp [(118 \pm 25) / T]$ & $299-468$ & & \\
$(7.73 \pm 0.14) \times 10^{-10}$ & 299 & & \\
& & & \\
Branching Ratios & 297 & Tyndall et al., 1997 & RR (j) \\
$k_{1} / k=(0.43 \pm 0.03)$ & & & \\
$k_{2} / k=(0.57 \pm 0.03)$ & $295-469$ & Sarzynski and Sztuba, 2002 & RR $(\mathrm{k})$ \\
$k_{1} / k=0.59 \exp [-(87 \pm 58) / T]$ & & & \\
$k_{1} / k=(0.45 \pm 0.02) 299$ & $295-469$ & & \\
$k_{2} / k=0.43 \exp [(76 \pm 55) / T]$ & 298 & & \\
$k_{2} / k=(0.55 \pm 0.02)$ & & \\
\hline
\end{tabular}

\section{Comments}

(a) Rate constant was measured at three temperatures: $220 \mathrm{~K}, 298 \mathrm{~K}$ and $607 \mathrm{~K}$. Within experimental uncertainty, the three values of $k$ were the same. Authors gave as an alternative rate expression the simple mean of the three values: $k=(1.58 \pm 0.13) \times 10^{-10} \mathrm{~cm}^{3}$ molecule ${ }^{-1} \mathrm{~s}^{-1}$.

(b) Both relative and absolute rate studies of reactions of $\mathrm{Cl}$ atoms with $\mathrm{C}_{1}-\mathrm{C}_{4}$ alkanes. Direct measurement of ratio $k / k\left(\mathrm{Cl}+\mathrm{C}_{2} \mathrm{H}_{6}\right)$ is in good agreement with the ratio of the absolute values.

(c) $\mathrm{Cl}$ atoms were generated from pulsed laser photolysis of $\mathrm{CF}_{2} \mathrm{Cl}_{2}$ at $193 \mathrm{~nm}$. Time evolution of $\mathrm{HCl}$ product was monitored by continuous wave infrared long-path absorption. 
(d) Experiments carried out in 80 mbar $\mathrm{He}$ bath gas. $\mathrm{O}_{2}$ added to prevent reformation of $\mathrm{Cl}$ atoms via $\mathrm{R}+\mathrm{Cl}_{2}$ which was used as $\mathrm{Cl}$ precursor ( $355 \mathrm{~nm}$ photolysis).

(e) $193 \mathrm{~nm}$ photolysis of $\mathrm{HCl}$ as $\mathrm{Cl}$ source. Detection of both $\mathrm{Cl}\left({ }^{2} \mathrm{P}_{1 / 2}\right)$ and $\mathrm{Cl}\left({ }^{2} \mathrm{P}_{3 / 2}\right)$ using VUV-LIF. The rate constants for $\mathrm{Cl}\left({ }^{2} \mathrm{P}_{1 / 2}\right)$ were found to be $\approx 30 \%$ of those for the $\mathrm{Cl}\left({ }^{2} \mathrm{P}_{3 / 2}\right)$ ground state. The rate constant for $\left.\mathrm{Cl}^{2} \mathrm{P}_{3 / 2}\right)$ with fully deuterated propane was found to be $0.86 \times 10^{-10} \mathrm{~cm}^{3}$ molecule $\mathrm{s}^{-1}$.

(f) $\mathrm{Cl}$ atoms were generated by photolysis of $\mathrm{Cl}_{2}$ in air at 1 bar pressure. Relative disappearance rates of organics studied were measured by GC. Rate coefficient ratio $k / k\left(\mathrm{Cl}+n-\mathrm{C}_{4} \mathrm{H}_{10}\right)=0.681 \pm 0.025$ is placed on absolute basis by use of $k(\mathrm{Cl}+n$ $\left.\mathrm{C}_{4} \mathrm{H}_{10}\right)=2.05 \times 10^{-10} \mathrm{~cm}^{3}$ molecule ${ }^{-1} \mathrm{~s}^{-1}$ (IUPAC, 2005).

(g) $\mathrm{Cl}$ atoms were generated by photolysis of $\mathrm{Cl}_{2}$ in air at 990 mbar (740 Torr) pressure. Relative disappearance rates of organics studied were measured by GC. Rate coefficient ratio $k / k\left(\mathrm{Cl}+n-\mathrm{C}_{4} \mathrm{H}_{10}\right)=0.711 \pm 0.019$ is placed on absolute basis by use of $k\left(\mathrm{Cl}+n-\mathrm{C}_{4} \mathrm{H}_{10}\right)=2.05 \times 10^{-10} \mathrm{~cm}^{3}$ molecule ${ }^{-1} \mathrm{~s}^{-1}$ (IUPAC, 2005).

(h) $\mathrm{Cl}$ atoms were generated by photolysis of $\mathrm{Cl}_{2}$ in $\mathrm{N}_{2}$ at 1 bar pressure. Relative disappearance rates of organics studied were measured by GC. Rate coefficient ratio $k / k\left(\mathrm{Cl}+n-\mathrm{C}_{4} \mathrm{H}_{10}\right)=0.656 \pm 0.009$ is placed on absolute basis by use of $k(\mathrm{Cl}+n-$ $\left.\mathrm{C}_{4} \mathrm{H}_{10}\right)=2.05 \times 10^{-10} \mathrm{~cm}^{3}$ molecule ${ }^{-1} \mathrm{~s}^{-1}$ (IUPAC, 2005).

(i) $\mathrm{Cl}$ atoms were generated by photolysis of $\mathrm{Cl}_{2}$ in air at 1 bar pressure. Relative disappearance rates of organics studied were measured by GC. Rate coefficient ratio $k / k\left(\mathrm{Cl}+\mathrm{C}_{2} \mathrm{H}_{6}\right)=2.44 \pm 0.26$ is placed on absolute basis by use of $k\left(\mathrm{Cl}+\mathrm{C}_{2} \mathrm{H}_{6}\right)=5.9 \times 10^{-11} \mathrm{~cm}^{3}$ molecule ${ }^{-1} \mathrm{~s}^{-1}$ (IUPAC, 2005).

(j) $\mathrm{Cl}$ atoms were generated by photolysis of $\mathrm{Cl}_{2}$ in air or $\mathrm{N}_{2}$ at a total pressure of 156 mbar to $666 \mathrm{mbar}$ (117 Torr to 500 Torr). Relative disappearance rates of organics studied were measured by GC or FTIR. Rate coefficient ratio $k / k\left(\mathrm{Cl}+\mathrm{C}_{2} \mathrm{H}_{6}\right)=2.42 \pm 0.10$ is placed on absolute basis by use of $k\left(\mathrm{Cl}+\mathrm{C}_{2} \mathrm{H}_{6}\right)=5.9 \times 10^{-11} \mathrm{~cm}^{3}$ molecule $\mathrm{s}^{-1}$ (IUPAC, 2005).

(k) Competitive photochlorination experiments with $\mathrm{Cl}$ atoms initially generated by the $420 \mathrm{~nm}$ photolysis of $\mathrm{Cl}_{2}$ in $\mathrm{N}_{2}$ at a total pressure of $\approx 133$ mbar. Formation rates of $\mathrm{CH}_{3} \mathrm{CH}_{2} \mathrm{CHCl}$ (abstraction of primary $\mathrm{H}$ ) and $\mathrm{CH}_{3} \mathrm{CHClCH}_{3}$ (Abstraction of secondary $\mathrm{H}$ ) were measured relative $\mathrm{CH}_{2} \mathrm{H}_{5} \mathrm{Cl}$ (from reference compound ethane) by GC. The absolute rate coefficients reported in the table were derived by use of $k\left(\mathrm{Cl}+\mathrm{CH}_{2} \mathrm{H}_{6}\right)=8.3 \times 10^{-11} \exp (-100 / T) \mathrm{cm}^{3}$ molecule ${ }^{-1}$ $\mathrm{s}^{-1}$ (IUPAC, 2005).

\section{Preferred Values}

$k=1.4 \times 10^{-10} \mathrm{~cm}^{3}$ molecule $\mathrm{e}^{-1} \mathrm{~s}^{-1}$, independent of temperature over the range 200-700 K.

$k_{1} / k=0.59 \exp (-90 / T)$

$k_{2} / k=0.43 \exp (75 / T)$

\section{Reliability}

$\Delta \log k= \pm 0.06$ at $298 \mathrm{~K}$.

$\Delta(E / R)= \pm 100 \mathrm{~K}$.

\section{Comments on Preferred Values}

The preferred value of the overall rate coefficient, $k$, at room temperature is the mean of the absolute values reported by Lewis et al. (1980), Beichert et al. (1995), Pilgrim et al. (1997), Mellouki (1998) and Hitsuda et al. (2001) and the relative values reported by Atkinson and Aschmann (1985), Wallington et al. (1988), Hooshiyar and Niki (1995), Beichert et al. (1995), Tyndall et al. (1997) and Sarzynski and Sztuba (2002). Lewis et al. (1980) and Pilgrim et al. (1997) have shown that the overall rate coefficient is independent of temperature between 220 and $700 \mathrm{~K}$. This is confirmed by the results of Sarzynski and Sztuba (2002) who showed that although $k_{1}$ and $k_{2}$ have weak temperature dependences, the sum of $k_{1}+k_{2}$ is independent of temperature between 299 and 468 K. The branching ratios derived by Tyndall et al. (1997) and Sarzynski and Sztuba (2002) are in good agreement at $298 \mathrm{~K}$. Temperature dependent branching ratios have only been determined by Sarzynski and Sztuba (2002), and their values are adopted. 


\section{References}

Atkinson, R. and Aschmann, S. M.: Int. J. Chem. Kinet., 17, 33, 1985.

Beichert, P., Wingen, L., Lee, J., Vogt, R., Ezell, M. J., Ragains, M., Neavyn, R. and Finlayson-Pitts, B. J.: J. Phys. Chem., 99, $13156,1995$.

Hitsuda, K., Takahashi, K., Matsumi, Y. and Wallington, T. J.: Chem. Phys. Lett., 346, 16, 2001.

Hooshiyar, P. A. and Niki, H.: Int. J. Chem. Kinet., 27, 1197, 1995.

IUPAC: http://www.iupac-kinetic.ch.cam.ac.uk/, 2005.

Lewis, R. S., Sander, S. P., Wagner, S. and Watson, R. T.: J. Phys. Chem., 84, 2009, 1980.

Mellouki, A.: J. Chim. Phys., 95, 513, 1998.

Pilgrim, J. S., McIlroy, A. and Taatjes, C. A.: J. Phys. Chem. A, 101, 1873, 1997.

Sarzynski, D. and Sztuba, B.: Int. J. Chem. Kin. 34, 651, 2002.

Tyndall, G. S., Orlando, J. J., Wallington, T. J., Dill, M. and Kaiser, E. W.: Int. J. Chem. Kinet., 29, $43,1997$.

Wallington, T. J., Skewes, L. M., Siegl, W. O., Wu, C.-H. and Japar, S. M.: Int. J. Chem. Kinet., $20,867,1988$. 
II.A7.172

$$
\begin{array}{ll}
\mathbf{C l}+n-\mathrm{C}_{4} \mathrm{H}_{10} & \rightarrow \mathbf{H C l}+\mathbf{1}-\mathbf{C}_{4} \mathbf{H}_{9} \\
\mathbf{C l}+n-\mathbf{C}_{4} \mathbf{H}_{10} & \rightarrow \mathbf{H C l}+2-\mathbf{C}_{4} \mathbf{H}_{9}
\end{array}
$$

\section{Rate coefficient data}

\begin{tabular}{lllc}
\hline$k / \mathrm{cm}^{3}$ molecule ${ }^{-1} \mathrm{~s}^{-1}$ & Temp./K & Reference & Technique/Comments \\
\hline Absolute Rate Coefficients & & & \\
$2.15 \times 10^{-10} \exp [(12 \pm 26) / T]$ & $298-598$ & Lewis et al., 1980 & DF-RF (a) \\
$(2.25 \pm 0.10) \times 10^{-10}$ & 298 & & \\
$(1.8 \pm 0.2) \times 10^{-10}$ & 298 & Nesbitt and Leone, 1982 & (b) \\
$(2.11 \pm 0.18) \times 10^{-10}$ & 298 & Beichert et al., 1995 & DF-RF (c) \\
$(2.15 \pm 0.15) \times 10^{-10}$ & 298 & Tyndall et al., 1997 & FP-RF (d) \\
$(1.91 \pm 0.10) \times 10^{-10}$ & 298 & Qian et al., 2002 & PLP-TDLS (e) \\
$(2.05 \pm 0.15) \times 10^{-10}$ & 298 & Hitsuda et al., 2001 & PLP-LIF (f) \\
& & & \\
Branching ratios & & & GC \\
$k_{1} / k=0.29 \pm 0.02$ & 298 & Tyndall et al., 1997 & GC \\
$k_{2} / k=0.71 \pm 0.02$ & 298 & Tyndall et al., 1997 & \\
\hline
\end{tabular}

\section{Comments}

(a) Rate constant was measured at three temperatures: $298 \mathrm{~K}, 422 \mathrm{~K}$ and $598 \mathrm{~K}$. Within experimental uncertainty, these three values were the same. Authors gave as an alternative rate expression the simple mean of the three values: $k=(2.20 \pm 0.10) \times 10^{-10} \mathrm{~cm}^{3}$ molecule ${ }^{-1} \mathrm{~s}^{-1}$.

(b) Laser photodissociation of $\mathrm{Cl}_{2}$ with time-resolved monitoring of infrared emission of $\mathrm{HCl}(\nu=1)$ product.

(c) Both relative and absolute rate studies of reactions of $\mathrm{Cl}$ atoms with $\mathrm{C}_{1}$ to $\mathrm{C}_{4}$ alkanes. Direct measurement of ratio $k / k\left(\mathrm{Cl}+\mathrm{C}_{2} \mathrm{H}_{6}\right)$ is in very good agreement with the ratio of the absolute values.

(d) Both relative and absolute rate studies of reactions of $\mathrm{Cl}$ atoms with $\mathrm{C}_{2} \mathrm{H}_{6}, \mathrm{C}_{3} \mathrm{H}_{8}$ and $n-\mathrm{C}_{4} \mathrm{H}_{10}$. Measurements of $k / k\left(\mathrm{Cl}+\mathrm{C}_{2} \mathrm{H}_{6}\right)$ over the temperature range $298 \mathrm{~K}$ to $540 \mathrm{~K}$ support the essentially zero temperature dependence for $k$ reported by Lewis et al. (1980). GC measurements at $298 \mathrm{~K}$ show that the reaction $\mathrm{Cl}+n-\mathrm{C}_{4} \mathrm{H}_{10}$ yields $29 \pm 2 \%$ 1-butyl radicals and $71 \pm 2 \%$ 2-butyl radicals.

(e) $193 \mathrm{~nm}$ Laser photolysis of $(\mathrm{ClOC})_{2}$ to form $\mathrm{Cl}$. Kinetics of reaction derived from $\mathrm{HCl}$ formation profiles, measured using infrared diode laser absorption spectroscopy.

(f) $193 \mathrm{~nm}$ photolysis of $\mathrm{HCl}$ as $\mathrm{Cl}$ source. Detection of both $\mathrm{Cl}\left({ }^{2} \mathrm{P}_{1 / 2}\right)$ and $\mathrm{Cl}\left({ }^{2} \mathrm{P}_{3 / 2}\right)$ using VUV-LIF. The rate coefficient for $\mathrm{Cl}\left({ }^{2} \mathrm{P}_{1 / 2}\right)$ was found to be $\approx 30 \%$ of that for $\mathrm{Cl}\left({ }^{2} \mathrm{P}_{3 / 2}\right)$ ground state.

\section{Preferred Values}

$k=2.05 \times 10^{-10} \mathrm{~cm}^{3}$ molecule ${ }^{-1} \mathrm{~s}^{-1}$, independent of temperature over the range 290-600 K.

\section{Reliability}

$\Delta \log k= \pm 0.06$ at $298 \mathrm{~K}$.

$\Delta(E / R)= \pm 100 \mathrm{~K}$. 


\section{Comments on Preferred Values}

The preferred value at room temperature is the mean of the values reported by Beichert et al. (1995), Tyndall et al. (1997), Qian et al. (2002) and Hitsuda et al. (2001). The temperature independence is based on the results of Lewis et al. (1980) over the range $298 \mathrm{~K}$ to $598 \mathrm{~K}$ and is supported by the relative measurements of Tyndall et al. (1997) over the range $298 \mathrm{~K}$ to $540 \mathrm{~K}$. Tyndall et al. (1997) studied the mechanism of the reaction at $298 \mathrm{~K}$ and reported the yield of 1-butyl radicals to be $29 \pm 2 \%$ and that of 2-butyl radicals to be $71 \pm 2 \%$.

\section{References}

Beichert, P., Wingen, L., Lee, J., Vogt, R., Ezell, M. J., Ragains, M., Neavyn, R., and Finlayson-Pitts, B. J.: J. Phys. Chem., 99, $13156,1995$.

Hitsuda, K., Takahashi, K., Matsumi, Y., and Wallington, T. J.: Chem. Phys. Lett., 346, 16, 2001.

Lewis, R. S., Sander, S. P., Wagner, S., and Watson, R. T.: J. Phys. Chem., 84, 2009, 1980.

Nesbitt, D. J. and Leone, S. R.: J. Phys. Chem., 86, 4962, 1982.

Qian, H.-B., Turpon, D., Seakins, P. W., and Pilling, M. J.: Int. J. Chem. Kinet., 34, 86, 2002.

Tyndall, G. S., Orlando, J. J., Wallington, T. J., Dill, M., and Kaiser, E. W.: Int. J. Chem. Kinet., 29, 43, 1997. 
II.A7.173

$$
\mathrm{Cl}+\mathrm{HCHO} \rightarrow \mathrm{HCl}+\mathrm{HCO}
$$

$\Delta H^{\circ}=-61.9 \mathrm{~kJ} \cdot \mathrm{mol}^{-1}$

\section{Rate coefficient data}

\begin{tabular}{lllc}
\hline$k / \mathrm{cm}^{3}$ molecule ${ }^{-1} \mathrm{~s}^{-1}$ & Temp./K & Reference & Technique/Comments \\
\hline $\begin{array}{l}\text { Absolute Rate Coefficients } \\
(7.48 \pm 0.50) \times 10^{-11}\end{array}$ & $200-500$ & Michael et al., 1979 & \\
$1.09 \times 10^{-10} \exp [-(131 \pm 98) / T]$ & $223-323$ & Anderson and Kurylo, 1979 & FP-RF \\
$(7.18 \pm 0.61) \times 10^{-11}$ & 293 & & FP-RF \\
$(7.40 \pm 0.7) \times 10^{-11}$ & 298 & Fasano and Nogar, 1981 & PLP-CL \\
$(6.98 \pm 0.69) \times 10^{-11}$ & 298 & Seakins et al., 2004 & LP-IR (a) \\
& & & \\
Relative Rate Coefficients & & Niki et al., 1978 & \\
$(7.6 \pm 0.6) \times 10^{-11}$ & 298 & Poulet et al., 1981 & RR (a) \\
$(6.8 \pm 1.4) \times 10^{-11}$ & 295 & & RR (b) \\
\hline
\end{tabular}

\section{Comments}

(a) $\mathrm{Cl}\left({ }^{2} \mathrm{P}_{3 / 2}\right.$ generated in $351 \mathrm{~nm}$ laser photolysis of $\mathrm{Cl}_{2}$. Kinetic data obtained by monitoring the HCL product by IR emission spectroscopy.

(b) Competitive photo-chlorination between $\mathrm{HCHO}$ and $\mathrm{C}_{2} \mathrm{H}_{6}$ using FTIR. The measured rate coefficient ratio $k / k\left(\mathrm{Cl}+\mathrm{C}_{2} \mathrm{H}_{6}\right)=1.3 \pm 0.1$ is placed on an absolute basis by use of $k\left(\mathrm{Cl}+\mathrm{C}_{2} \mathrm{H}_{6}\right)=5.9 \times 10^{-11} \mathrm{~cm}^{3}$ molecule $\mathrm{s}^{-1}$ (IUPAC, 2005).

(c) DF-MS study. Value of $k$ derived from measured ratio of $k / k\left(\mathrm{Cl}+\mathrm{C}_{2} \mathrm{H}_{6}\right)=1.16 \pm 0.12$ and $k\left(\mathrm{Cl}+\mathrm{C}_{2} \mathrm{H}_{6}\right)=5.9 \times 10^{-11} \mathrm{~cm}^{3}$ molecule ${ }^{-1} \mathrm{~s}^{-1}$ (IUPAC, 2005).

\section{Preferred Values}

$k=7.2 \times 10^{-11} \mathrm{~cm}^{3}$ molecule ${ }^{-1} \mathrm{~s}^{-1}$ at $298 \mathrm{~K}$.

$k=8.1 \times 10^{-11} \exp (-34 / T) \mathrm{cm}^{3}$ molecule ${ }^{-1} \mathrm{~s}^{-1}$ over the temperature range $200-500 \mathrm{~K}$.

\section{Reliability}

$\Delta \log k= \pm 0.06$ at $298 \mathrm{~K}$.

$\Delta(E / R)= \pm 100 \mathrm{~K}$.

\section{Comments on Preferred Values}

The preferred $298 \mathrm{~K}$ rate coefficient is an unweighted average of all studies listed above, which are in good agreement. The preferred temperature dependence is based on a least-squares fit to the 200-500 K data of Michael et al. (1979) and the 223-323 K data of Anderson and Kurylo (1979), with the pre-exponential factor adjusted to reproduce the recommended rate coefficient at $298 \mathrm{~K}$. The reaction generates vibrationally excited products, HCL and HCO (Dong et al., 2003), with $\approx(91 \pm$ 14) $\%$ of HCL Formation as $v=1$ (Seakins et al., 2004). Kinetic isotope effects have been determined in relative rate studies as $k(\mathrm{Cl}+\mathrm{HCHO}) / k(\mathrm{Cl}+\mathrm{DCDO})=1.30, k(\mathrm{Cl}+\mathrm{HCHO}) / k(\mathrm{Cl}+\mathrm{HCDO})=1.201, k(\mathrm{Cl}+\mathrm{HCHO}) / k\left(\mathrm{Cl}+\mathrm{HCH}^{18} \mathrm{O}\right)=1.08$ and $k\left(\mathrm{Cl}+\mathrm{H}^{13} \mathrm{CHO}\right) / k(\mathrm{Cl}+\mathrm{DCDO})=1.22$ (Beukes et al., 2000; Feilberg et al., 2004). 


\section{References}

Anderson, P. C. and Kurylo, M. J.: J. Phys. Chem. 83, 2053, 1979.

Beukes, J. A., D’Anna, B., Bakken, V. and Nielsen, C. J.: Phys. Chem. Chem. Phys. 2, 4049, 2000.

Dong, F., Du, Z., Zhang, Q. and Kong, F.: Chem. Phys. Lett, 371, 29, 2003.

Fasano, D. M. and Nogar, N. S.: Int. J. Chem. Kinet., 13, 325, 1981.

Feilberg, K. L., Johnson, M. S., Nielsen, C. J.: J. Phys. Chem. A. 108, 7393, 2004.

IUPAC: http://www.iupac-kinetic.ch.cam.ac.uk/, 2005.

Michael, J. V., Nava, D. F., Payne, W. A. and Stief, L. J.: J. Chem. Phys., 70, 1147, 1979.

Niki, H., Maker, P. D., Breitenbach, L. P. and Savage, C. M.: Chem. Phys. Lett., 57, 596, 1978.

Poulet, G., Laverdet, G. and Le Bras, G.: J. Phys. Chem., 85, 1892, 1981.

Seakins, P. W., Orlando, J. J. and Tyndall, G. S.: Phys. Chem. Chem. Phys. 6, 2224, 2004. 
II.A7.174

$$
\begin{aligned}
\mathrm{Cl}+\mathrm{CH}_{3} \mathrm{CHO} & \rightarrow \mathrm{HCl}+\mathrm{CH}_{3} \mathrm{CO} \\
& \rightarrow \mathrm{HCl}+\mathrm{CH}_{2} \mathrm{CHO}
\end{aligned}
$$

$\Delta H^{\circ}(1)=-57.8 \mathrm{~kJ} \cdot \mathrm{mol}^{-1}$

$\Delta H^{\circ}(2)=-37.3 \mathrm{~kJ} \cdot \mathrm{mol}^{-1}$

Rate coefficient data $\left(k=k_{1}+k_{2}\right)$

\begin{tabular}{lllc}
\hline$k / \mathrm{cm}^{3}$ molecule $\mathrm{s}^{-1}$ & Temp./K & Reference & Technique/Comments \\
\hline $\begin{array}{l}\text { Absolute Rate Coefficients } \\
(6.6 \pm 1.4) \times 10^{-11}\end{array}$ & $210-343$ & Payne et al., 1990 & FP-RF \\
$(7.3 \pm 0.7) \times 10^{-11}$ & 295 & Tyndall et al., 1999 & PLP-RF (a) \\
$(7.5 \pm 0.8) \times 10^{-11}$ & 298 & Kegley-Owen et al., 1999 & PLP-TDLAS (b) \\
& & & \\
Relative Rate Coefficients & & & \\
$(7.9 \pm 1.2) \times 10^{-11}$ & 298 & Niki et al., 1985 & RR (c) \\
$(8.1 \pm 0.8) \times 10^{-11}$ & $295 \pm 2$ & Wallington et al., 1988 & RR (d) \\
$(6.1 \pm 0.5) \times 10^{-11}$ & 298 & Bartels et al., 1989 & RR (e) \\
$(8.8 \pm 1.0) \times 10^{-11}$ & 298 & Tyndall et al., 1999 & RR (a) \\
Branching Ratios & & & \\
$k_{2} / k<0.01$ & 298 & Niki et al., 1985 & (c) \\
$k_{2} / k<0.07$ & 298 & Bartels et al., 1989 & (e) \\
\hline
\end{tabular}

\section{Comments}

(a) In the absolute study, $\mathrm{Cl}$ atoms were generated from the $308 \mathrm{~nm}$ photolysis of $\mathrm{Cl}_{2}$. 1 Torr (1.3 mbar) of $\mathrm{O}_{2}$ added to total pressure of 20-90 Torr (27-120 mbar) $\mathrm{N}_{2}$ or He to scavenge $\mathrm{CH}_{3} \mathrm{CO}$ and reduce regeneration of $\mathrm{Cl}$, some correction was however still necessary. In the relative rate study, broad band irradiation of $\mathrm{Cl}_{2}$ was the source of $\mathrm{Cl}$ atoms. Experiments were carried out in 700 Torr $\mathrm{N}_{2}$, with analysis of $\mathrm{CH}_{3} \mathrm{CHO}$ and reference compound $\left(\mathrm{C}_{2} \mathrm{H}_{6}\right.$ and $\left.\mathrm{C}_{2} \mathrm{H}_{4}\right)$ with FTIR. $k\left(\mathrm{Cl}+\mathrm{CH}_{3} \mathrm{CHO}\right) / k\left(\mathrm{Cl}+\mathrm{C}_{2} \mathrm{H}_{6}\right)=1.49 \pm 0.1, k\left(\mathrm{Cl}+\mathrm{CH}_{3} \mathrm{CHO}\right) / k\left(\mathrm{Cl}+\mathrm{C}_{2} \mathrm{H}_{4}\right)=0.90 \pm 0.05$. The data have been placed on an absolute basis using $k\left(\mathrm{Cl}+\mathrm{C}_{2} \mathrm{H}_{6}\right)=5.9 \times 10^{-11} \mathrm{~cm}^{3}$ molecule ${ }^{-1} \mathrm{~s}^{-1}$ (IUPAC, this evaluation).

(b) $\mathrm{Cl}$ atoms were generated from the $308 \mathrm{~nm}$ photolysis of $\mathrm{Cl}_{2}$ at total pressures of 10-50 Torr (13-67 mbar) $\mathrm{N}_{2}$. Kinetic parameters were derived by monitoring $\mathrm{HCl}$ formation $(v=0)$ by infra-red tunable diode laser absorption spectroscopy. $\mathrm{N}_{2} \mathrm{O}$ was added to quench vibrationally excited $\mathrm{HCl}, \mathrm{O}_{2}$ was added to reduce secondary regeneration of $\mathrm{Cl}$ via reaction of $\mathrm{CH}_{3} \mathrm{CO}$ with $\mathrm{Cl}_{2}$.

(c) $\mathrm{Cl}$ atoms were generated by photolysis of $\mathrm{Cl}_{2}$ at 930 mbar (700 Torr) total pressure of $\mathrm{N}_{2}$. Relative decay rates of $\mathrm{CH}_{3} \mathrm{CHO}$ and $\mathrm{C}_{2} \mathrm{H}_{6}$ measured, and the measured rate coefficient ratio is placed on an absolute basis by use of $k\left(\mathrm{Cl}+\mathrm{C}_{2} \mathrm{H}_{6}\right)=5.9 \times 10^{-11} \mathrm{~cm}^{3}$ molecule $\mathrm{s}^{-1} \mathrm{~s}^{-1}$ (IUPAC, this evaluation). The branching ratio was determined from FTIR spectroscopic product analysis.

(d) $\mathrm{Cl}$ atoms were generated from the photolysis of $\mathrm{Cl}_{2}$ in $\mathrm{Cl}_{2}-\mathrm{N}_{2}-\mathrm{CH}_{3} \mathrm{CHO}-\mathrm{C}_{2} \mathrm{H}_{6}$ mixtures and the relative decay rates of $\mathrm{CH}_{3} \mathrm{CHO}$ and $\mathrm{C}_{2} \mathrm{H}_{6}$ measured. The measured rate coefficient ratio is placed on an absolute basis by use of $k\left(\mathrm{Cl}+\mathrm{C}_{2} \mathrm{H}_{6}\right)=5.9 \times 10^{-11} \mathrm{~cm}^{3}$ molecule $\mathrm{s}^{-1}$ (IUPAC, this evaluation).

(e) DF-MS study. Relative decay rates of $\mathrm{CH}_{3} \mathrm{CHO}$ and $\mathrm{C}_{2} \mathrm{H}_{6}$ were monitored, and the measured rate coefficient ratio is placed on an absolute basis by use of $k\left(\mathrm{Cl}+\mathrm{C}_{2} \mathrm{H}_{6}\right)=5.9 \times 10^{-11} \mathrm{~cm}^{3}$ molecule ${ }^{-1} \mathrm{~s}^{-1}$ (IUPAC, this evaluation). The branching ratio was derived from the products observed by MS. 


\section{Preferred Values}

$k=8.0 \times 10^{-11} \mathrm{~cm}^{3}$ molecule $\mathrm{s}^{-1} \mathrm{~s}^{-1}$, independent of temperature over the range $210-340 \mathrm{~K}$.

$k_{2} / k<0.01$ at $298 \mathrm{~K}$.

\section{Reliability}

$\Delta \log k= \pm 0.07$ at $298 \mathrm{~K}$.

$\Delta(E / R)= \pm 300 \mathrm{~K}$.

\section{Comments on Preferred Values}

The preferred $298 \mathrm{~K}$ rate coefficient is the average of the absolute rate coefficients of Tyndall et al. (1999) and Kegley Owen et al. (1999) and the relative rate coefficients of Niki et al. (1985), Wallington et al. (1988) and Tyndall et al. (1999). The lack of a temperature dependence of the rate coefficient is consistent with the data of Payne et al. (1990). The branching ratio is derived from the data of Niki et al. (1985). The relative rate measurement of Scollard et al. (1993) was carried out relative to $\mathrm{CH}_{3} \mathrm{C}(\mathrm{O}) \mathrm{CH}_{3}$, which is not considered sufficiently well defined to derive an accurate relative rate coefficient. Deuterium kinetic isotope effects were determined to be: $k\left(\mathrm{Cl}+\mathrm{CH}_{3} \mathrm{CHO}\right) / k\left(\mathrm{Cl}+\mathrm{CH}_{3} \mathrm{CDO}\right)=1.34 \pm 0.02, k\left(\mathrm{Cl}+\mathrm{CH}_{3} \mathrm{CHO}\right) / k\left(\mathrm{Cl}+\mathrm{CD}_{3} \mathrm{CDO}\right)=1.32 \pm 0.02$, $k\left(\mathrm{Cl}+\mathrm{CD}_{3} \mathrm{CHO}\right) / k\left(\mathrm{Cl}+\mathrm{CH}_{3} \mathrm{CDO}\right)=1.35 \pm 0.02, k\left(\mathrm{Cl}+\mathrm{CD}_{3} \mathrm{CHO}\right) / k\left(\mathrm{Cl}+\mathrm{CD}_{3} \mathrm{CDO}\right)=1.39 \pm 0.02$ (Beukes et al., 2000).

\section{References}

Bartels, M., Hoyermann, K., and Lange, U.: Ber. Bunsenges. Phys. Chem., 93, 423, 1989.

Beukes, J. A., D’Anna, B., Bakken, V., and Nielsen, C. J.: Phys. Chem. Chem. Phys., 2, 4049, 2000.

Kegley-Owen, C. S., Tyndall, G. S., Orlando, J. J., and Fried, A.: Int. J. Chem. Kinet., 31, 766, 1999.

Niki, H., Maker, P. D., Savage, C. M., and Breitenbach, L. P.: J. Phys. Chem., 89, 588, 1985.

Payne, W. A., Nava, D. F., Nesbitt, F. L., and Stief, L. J.: J. Phys. Chem., 94, 7190, 1990.

Scollard, D. J., Treacy, J. J., Sidebottom, H. W., Balestra-Garcia, C., Laverdet, G., Le Bras, G., Mac Leod, H., and Téton, S.: J. Phys. Chem., 97, 4683, 1993.

Tyndall, G. S., Orlando, J. J., Kegley-Owen, C. S., Wallington, T. J., and Hurley, M. D.: Int. J. Chem. Kinet., 31, 776, 1999. Wallington, T. J., Skewes, L. M., Siegl, W. O., Wu, C.-H., and Japar, S. M.: Int. J. Chem. Kinet., 20, 867, 1988. 
II.A7.175

$$
\mathrm{Cl}+\mathrm{C}_{2} \mathrm{H}_{5} \mathrm{CHO} \rightarrow \text { products }
$$

\section{Rate coefficient data}

\begin{tabular}{|c|c|c|c|}
\hline$k / \mathrm{cm}^{3}$ molecule $^{-1} \mathrm{~s}^{-1}$ & Temp./K & Reference & Technique/Comments \\
\hline $\begin{array}{l}\text { Relative Rate Coefficients } \\
(1.17 \pm 0.10) \times 10^{-10}\end{array}$ & $295 \pm 2$ & Wallington et al., 1988 & $\mathrm{RR}(\mathrm{a})$ \\
\hline$(1.45 \pm 0.08) \times 10^{-10}$ & $298 \pm 3$ & Thévenet et al., 2000 & $\mathrm{RR}(\mathrm{b})$ \\
\hline$(1.20 \pm 0.07) \times 10^{-10}$ & $298 \pm 3$ & & (c) \\
\hline$(1.25 \pm 0.06) \times 10^{-10}$ & $298 \pm 3$ & & (d) \\
\hline$(1.41 \pm 0.10) \times 10^{-10}$ & $298 \pm 3$ & & (e) \\
\hline
\end{tabular}

\section{Comments}

(a) $\mathrm{Cl}$ atoms were generated by the photolysis of $\mathrm{Cl}_{2}$ in $\mathrm{Cl}_{2}$-air mixtures, and the decay rates of $\mathrm{C}_{2} \mathrm{H}_{5} \mathrm{CHO}$ and $\mathrm{C}_{2} \mathrm{H}_{6}$ monitored by GC. The measured rate coefficient ratio is placed on an absolute basis by use of $k\left(\mathrm{Cl}+\mathrm{C}_{2} \mathrm{H}_{6}\right)=5.9 \times 10^{-11} \mathrm{~cm}^{3}$ molecule $\mathrm{e}^{-1} \mathrm{~s}^{-1}$ (IUPAC, this evaluation).

(b) $\mathrm{Cl}$ atoms were generated by the photolysis of $\mathrm{Cl}_{2}$ in $\mathrm{Cl}_{2}$-air mixtures, and the decay rates of $\mathrm{C}_{2} \mathrm{H}_{5} \mathrm{CHO}$ and $\mathrm{C}_{2} \mathrm{H}_{6}$ monitored by GC. The measured rate coefficient ratio of $k\left(\mathrm{Cl}+\mathrm{C}_{2} \mathrm{H}_{5} \mathrm{CHO}\right) / k\left(\mathrm{Cl}_{+}+\mathrm{C}_{2} \mathrm{H}_{6}\right)=2.46 \pm 0.08$ is placed on an absolute basis by use of $k\left(\mathrm{Cl}+\mathrm{C}_{2} \mathrm{H}_{6}\right)=5.9 \times 10^{-11} \mathrm{~cm}^{3}$ molecule ${ }^{-1} \mathrm{~s}^{-1}$ (IUPAC, this evaluation).

(c) Method as (b) but $\mathrm{C}_{3} \mathrm{H}_{8}$ as reference gas. The measured rate coefficient ratio of $k\left(\mathrm{Cl}_{+} \mathrm{C}_{2} \mathrm{H}_{5} \mathrm{CHO}\right) / k\left(\mathrm{Cl}+\mathrm{C}_{3} \mathrm{H}_{8}\right)=0.85 \pm 0.05$ is placed on an absolute basis by use of $k\left(\mathrm{Cl}+\mathrm{C}_{3} \mathrm{H}_{8}\right)=1.4 \times 10^{-10} \mathrm{~cm}^{3}$ molecule ${ }^{-1} \mathrm{~s}^{-1}$ (IUPAC, this evaluation).

(d) Method as (b) but $n-\mathrm{C}_{4} \mathrm{H}_{10}$ as reference gas. The measured rate coefficient ratio of $k\left(\mathrm{Cl}+\mathrm{C}_{2} \mathrm{H}_{5} \mathrm{CHO}\right) / k(\mathrm{Cl}+n$ $\left.\mathrm{C}_{4} \mathrm{H}_{10}\right)=0.61 \pm 0.03$ is placed on an absolute basis by use of $k\left(\mathrm{Cl}+n-\mathrm{C}_{4} \mathrm{H}_{10}\right)=2.05 \times 10^{-10} \mathrm{~cm}^{3}$ molecule ${ }^{-1} \mathrm{~s}^{-1}$ (IUPAC, this evaluation).

(e) Method as (b) but $n$-hexane as reference gas. The measured rate coefficient ratio of $k\left(\mathrm{Cl}+\mathrm{C}_{2} \mathrm{H}_{5} \mathrm{CHO}\right) / k(\mathrm{Cl}+n$ hexane $)=0.44 \pm 0.02$ is placed on an absolute basis by use of $k(\mathrm{Cl}+n$-hexane $) / k(\mathrm{Cl}+n$-butane $)=1.56$ (average value from Tyndall et al., 1997, and Hooshiyar and Niki, 1995) and $k\left(\mathrm{Cl}+n\right.$-butane) $=2.05 \times 10^{-10} \mathrm{~cm}^{3}$ molecule ${ }^{-1} \mathrm{~s}^{-1}$ (IUPAC, this evaluation).

\section{Preferred Values}

$k=1.3 \times 10^{-10} \mathrm{~cm}^{3}$ molecule ${ }^{-1} \mathrm{~s}^{-1}$ at $298 \mathrm{~K}$.

\section{Reliability}

$\Delta \log k= \pm 0.2$ at $298 \mathrm{~K}$.

\section{Comments on Preferred Values}

The preferred value uses data from the relative rate studies of Wallington et al. (1988) and Thévenet et al. (2000), and is an average of the rate constants obtained in experiments in which, $\mathrm{C}_{2} \mathrm{H}_{6}, \mathrm{C}_{3} \mathrm{H}_{8}$ and $n-\mathrm{C}_{4} \mathrm{H}_{10}$ were used as reference gases, which have well defined rate coefficients for reaction with $\mathrm{Cl}$. 


\section{References}

Hooshiyar, P. A. and Niki, H.: Int. J. Chem. Kinet., 27, 1197, 1995.

Thévenet, R., Mellouki, A., and LeBras, G.: Int. J. Chem. Kinet., 32, 676, 2000.

Tyndall, G. S., Orlando, J. J., Wallington, T. J., Dill, M., and Kaiser, E. W.: Int. J. Chem. Kinet., $29,43,1997$.

Wallington, T. J., Skewes, L. M., Siegl, W. O., Wu, C.-H., and Japar, S. M.: Int. J. Chem. Kinet., 20, 867, 1988. 
II.A7.176

\section{$\mathrm{Cl}+\mathrm{CH}_{3} \mathrm{C}(\mathrm{O}) \mathrm{CH}_{3} \rightarrow \mathrm{HCl}+\mathrm{CH}_{3} \mathrm{C}(\mathrm{O}) \mathrm{CH}_{2}$}

$\Delta H^{\circ}=-20.3 \mathrm{~kJ} \cdot \mathrm{mol}^{-1}$

\section{Rate coefficient data}

\begin{tabular}{llll}
\hline$k / \mathrm{cm}^{3}$ molecule ${ }^{-1} \mathrm{~s}^{-1}$ & Temp./K & Reference & Technique/Comments \\
\hline $\begin{array}{l}\text { Absolute Rate Coefficients } \\
(3.06 \pm 0.38) \times 10^{-12}\end{array}$ & $298 \pm 2$ & Notario et al., 2000 & \\
$(2.93 \pm 0.29) \times 10^{-12}$ & $298 \pm 2$ & Albaladejo et al., 2003 & PLP-RF (a) \\
& & & PLP-RF (b) \\
Relative Rate Coefficients & & & \\
$(2.3 \pm 0.2) \times 10^{-12}$ & $295 \pm 2$ & Wallington et al., 1990 & RR (c) \\
$(1.7 \pm 0.3) \times 10^{-12}$ & $294 \pm 1$ & Olsson et al., 1997 & RR (d) \\
$3.1 \times 10^{-11} \exp [(815 \pm 150) / T]$ & $215-298$ & Orlando et al., 2000 & RR (e) \\
$(2.0 \pm 0.3) \times 10^{-12}$ & 298 & & \\
$(2.07 \pm 0.12) \times 10^{-12}$ & 296 & Christensen et al., 2000 & RR (f) \\
$(2.25 \pm 0.08) \times 10^{-12}$ & 296 & Christensen et al., 2000 & RR (g) \\
$(2.15 \pm 0.04) \times 10^{-12}$ & 296 & Christensen et al., 2000 & RR (h) \\
$(2.22 \pm 0.14) \times 10^{-12}$ & 296 & Christensen et al., 2000 & RR (i) \\
$(2.00 \pm 0.09) \times 10^{-12}$ & 298 & Sellevág and Nielsen, 2003 & RR (j) \\
$(2.12 \pm 0.05) \times 10^{-12}$ & 298 & Carr et al., 2003 & RR (k) \\
\hline
\end{tabular}

\section{Comments}

(a) Experiments carried out at pressures of 15 or 60 Torr $\left(20\right.$ or 80 mbar) $\mathrm{He}$ using the $355 \mathrm{~nm}$ photolysis of $\mathrm{Cl}_{2}$ as $\mathrm{Cl}$-atom source. Addition of 0.4 Torr $(0.53 \mathrm{mbar}) \mathrm{O}_{2}$ (to scavenge organic radicals and prevent secondary formation of $\mathrm{Cl}$ ) resulted in similar rate coefficients.

(b) Experiments carried out at pressures of 26.7, 80 and $267 \mathrm{mbar} \mathrm{He}$ using the $308 \mathrm{~nm}$ photolysis of $\mathrm{Cl}_{2}$ as $\mathrm{Cl}$-atom source.

(c) $\mathrm{Cl}$ atoms were generated by the photolysis of $\mathrm{Cl}_{2}$-air $\left(\right.$ or $\left.\mathrm{N}_{2}\right)-\mathrm{CH}_{3} \mathrm{C}(\mathrm{O}) \mathrm{CH}_{3}-\mathrm{C}_{2} \mathrm{H}_{5} \mathrm{Cl}$ mixtures. From the relative decays of $\mathrm{CH}_{3} \mathrm{COCH}_{3}$ and $\mathrm{C}_{2} \mathrm{H}_{5} \mathrm{Cl}$, a rate coefficient ratio of $k\left(\mathrm{Cl}+\mathrm{CH}_{3} \mathrm{C}(\mathrm{O}) \mathrm{CH}_{3}\right) / k\left(\mathrm{Cl}+\mathrm{C}_{2} \mathrm{H}_{5} \mathrm{Cl}\right)=0.295 \pm 0.015$ was obtained. Absolute rate coefficient obtained using $k\left(\mathrm{Cl}+\mathrm{C}_{2} \mathrm{H}_{5} \mathrm{Cl}\right)=7.8 \times 10^{-12} \mathrm{~cm}^{3}$ molecule $^{-1} \mathrm{~s}^{-1}$ (Wine et al, 1983; Bryukov et al., 2003).

(d) $\mathrm{Cl}$ atoms were generated by pulsed laser photolysis of $\mathrm{Cl}_{2}$ at $355 \mathrm{~nm}$ followed by competition between the reactions $\mathrm{Cl}+\mathrm{CH}_{3} \mathrm{C}(\mathrm{O}) \mathrm{CH}_{3}$ and $\mathrm{Cl}+\mathrm{ClONO}_{2} \rightarrow \mathrm{Cl}_{2}+\mathrm{NO}_{3}$. The formation of $\mathrm{NO}_{3}$ with and without acetone in the reaction mixture was monitored by TDLS at $661.8 \mathrm{~nm}$. The value recommended in Yokelson et al. (1995) for the value of the rate constant of the reference reaction $\left(\mathrm{Cl}+\mathrm{ClONO}_{2}\right)$ was used.

(e) $\mathrm{Cl}$ atoms were generated by the photolysis of $\mathrm{Cl}_{2}-\mathrm{CH}_{3} \mathrm{C}(\mathrm{O}) \mathrm{CH}_{3}-\mathrm{CH}_{2} \mathrm{Cl}_{2}$ mixtures. From the relative decays of $\mathrm{CH}_{3} \mathrm{C}(\mathrm{O}) \mathrm{CH}_{3}$ and $\mathrm{CH}_{2} \mathrm{Cl}_{2}$, temperature dependent rate coefficient ratios of $k\left(\mathrm{Cl}+\mathrm{CH}_{3} \mathrm{C}(\mathrm{O}) \mathrm{CH}_{3}\right) / k\left(\mathrm{Cl}+\mathrm{CH}_{2} \mathrm{Cl}_{2}\right)=5.39$ $(298 \mathrm{~K}), 5.83(267 \mathrm{~K}), 6.26(251 \mathrm{~K}), 6.69(240 \mathrm{~K}), 7.21(225 \mathrm{~K})$ and $7.72(215 \mathrm{~K})$ were derived. These ratios were placed on an absolute basis using $k\left(\mathrm{Cl}+\mathrm{CH}_{2} \mathrm{Cl}_{2}\right)=1.5 \times 10^{-11} \exp (-1100 / T) \mathrm{cm}^{3}$ molecule ${ }^{-1} \mathrm{~s}^{-1}$ (Orlando, 1999).

(f) $\mathrm{Cl}$ atoms were generated by the broad band photolysis of $\mathrm{Cl}_{2}$ in $\mathrm{O}_{2}+\mathrm{N}_{2}$ at 933 mbar. Consumption of $\mathrm{CH}_{3} \mathrm{C}(\mathrm{O}) \mathrm{CH}_{3}$ measured relative to $\mathrm{C}_{2} \mathrm{H}_{5} \mathrm{~F}$ to derive $k\left(\mathrm{Cl}+\mathrm{CH}_{3} \mathrm{C}(\mathrm{O}) \mathrm{CH}_{3}\right) / k\left(\mathrm{Cl}+\mathrm{C}_{2} \mathrm{H}_{5} \mathrm{~F}\right)=0.288 \pm 0.017$. Rate coefficient in table calculated using $k\left(\mathrm{Cl}+\mathrm{C}_{2} \mathrm{H}_{5} \mathrm{~F}\right)=7.2 \times 10^{-12} \mathrm{~cm}^{3}$ molecule $^{-1} \mathrm{~s}^{-1}$ (IUPAC, 2005).

(g) $\mathrm{Cl}$ atoms were generated by the broad band photolysis of $\mathrm{Cl}_{2}$ in $\mathrm{O}_{2}+\mathrm{N}_{2}$ at 933 mbar. Consumption of $\mathrm{CH}_{3} \mathrm{C}(\mathrm{O}) \mathrm{CH}_{3}$ measured relative to $\mathrm{CH}_{3} \mathrm{Cl}$ to derive $k\left(\mathrm{Cl}+\mathrm{CH}_{3} \mathrm{C}(\mathrm{O}) \mathrm{CH}_{3}\right) / k\left(\mathrm{Cl}+\mathrm{CH}_{3} \mathrm{Cl}\right)=4.69 \pm 0.16$. Rate coefficient in table calculated using $k\left(\mathrm{Cl}+\mathrm{CH}_{3} \mathrm{Cl}\right)=4.8 \times 10^{-13} \mathrm{~cm}^{3}$ molecule $\mathrm{s}^{-1}$ (IUPAC, 2005). 
(h) $\mathrm{Cl}$ atoms were generated by the broad band photolysis of $\mathrm{Cl}_{2}$ in $\mathrm{O}_{2}+\mathrm{N}_{2}$ at 933 mbar. Consumption of $\mathrm{CH}_{3} \mathrm{C}(\mathrm{O}) \mathrm{CH}_{3}$ measured relative to $\mathrm{CH}_{3} \mathrm{~F}$ to derive $k\left(\mathrm{Cl}+\mathrm{CH}_{3} \mathrm{C}(\mathrm{O}) \mathrm{CH}_{3}\right) / k\left(\mathrm{Cl}+\mathrm{CH}_{3} \mathrm{~F}\right)=6.15 \pm 0.26$. Rate coefficient in table calculated using $k\left(\mathrm{Cl}+\mathrm{CH}_{3} \mathrm{~F}\right)=3.5 \times 10^{-13} \mathrm{~cm}^{3}$ molecule ${ }^{-1} \mathrm{~s}^{-1}$ (IUPAC, 2005).

(i) $\mathrm{Cl}$ atoms were generated by the broad band photolysis of $\mathrm{Cl}_{2}$ in $\mathrm{O}_{2}+\mathrm{N}_{2}$ at 933 mbar. Consumption of $\mathrm{CH}_{3} \mathrm{C}(\mathrm{O}) \mathrm{CH}_{3}$ measured relative to $\mathrm{C}_{2} \mathrm{H}_{5} \mathrm{Cl}$ to derive $k\left(\mathrm{Cl}+\mathrm{CH}_{3} \mathrm{C}(\mathrm{O}) \mathrm{CH}_{3}\right) / k\left(\mathrm{Cl}+\mathrm{C}_{2} \mathrm{H}_{5} \mathrm{Cl}\right)=0.284 \pm 0.018$. Rate coefficient in table calculated using $k\left(\mathrm{Cl}+\mathrm{C}_{2} \mathrm{H}_{5} \mathrm{Cl}\right)=7.8 \times 10^{-12} \mathrm{~cm}^{3}$ molecule ${ }^{-1} \mathrm{~s}^{-1}$ (Wine et al, 1983; Bryukov et al., 2003).

(j) Broad band photolysis $(370 \mathrm{~nm})$ of $\mathrm{Cl}_{2}$ in presence of $\mathrm{CH}_{3} \mathrm{C}(\mathrm{O}) \mathrm{CH}_{3}$ and $\mathrm{CH}_{2} \mathrm{ClCH}_{2} \mathrm{Cl}$. Relative decay rates of $\mathrm{CH}_{3} \mathrm{C}(\mathrm{O}) \mathrm{CH}_{3}$ and $\mathrm{CH}_{2} \mathrm{ClCH}_{2} \mathrm{Cl}$ measured using FTIR. Value of $k\left(\mathrm{Cl}+\mathrm{CH}_{3} \mathrm{C}(\mathrm{O}) \mathrm{CH}_{3}\right) / k\left(\mathrm{Cl}+\mathrm{CH}_{2} \mathrm{ClCH}_{2} \mathrm{Cl}\right)=1.54 \pm$ 0.06 was placed on an absolute basis using $k\left(\mathrm{Cl}+\mathrm{CH}_{2} \mathrm{ClCH}_{2} \mathrm{Cl}\right)=1.3 \times 10^{-12} \mathrm{~cm}^{3}$ molecule ${ }^{-1} \mathrm{~s}^{-1}$ (Wallington et al., 1996).

(k) $\mathrm{Cl}$ atoms were generated by the broad band photolysis of $\mathrm{Cl}_{2}$ in air or $\mathrm{N}_{2}$ at 973-1013 mbar. Consumption of $\mathrm{CH}_{3} \mathrm{C}(\mathrm{O}) \mathrm{CH}_{3}$ measured relative to $\mathrm{CH}_{3} \mathrm{Cl}$ to derive $k\left(\mathrm{Cl}+\mathrm{CH}_{3} \mathrm{C}(\mathrm{O}) \mathrm{CH}_{3}\right) / k\left(\mathrm{Cl}+\mathrm{CH}_{3} \mathrm{Cl}\right)=4.42 \pm 0.11$. Rate coefficient in table calculated using $k\left(\mathrm{Cl}+\mathrm{CH}_{3} \mathrm{Cl}\right)=4.8 \times 10^{-13} \mathrm{~cm}^{3}$ molecule ${ }^{-1} \mathrm{~s}^{-1}$ (IUPAC, 2005).

\section{Preferred Values}

$k=2.1 \times 10^{-12} \mathrm{~cm}^{3}$ molecule ${ }^{-1} \mathrm{~s}^{-1}$ at $298 \mathrm{~K}$.

$k=3.2 \times 10^{-11} \exp (-815 / T) \mathrm{cm}^{3}$ molecule ${ }^{-1} \mathrm{~s}^{-1}$ over the temperature range $215-300 \mathrm{~K}$.

\section{Reliability}

$\Delta \log k= \pm 0.15$ at $298 \mathrm{~K}$.

$\Delta(E / R)= \pm 300 \mathrm{~K}$.

\section{Comments on Preferred Values}

Because of the potential for errors in the experimental technique of Olsson et al. (1997) (the assumption that $\mathrm{Cl}$ atoms only react with $\mathrm{ClONO}_{2}$ and acetone, the need for absolute concentration measurements of acetone and the experimental approach of sequential experiments in the presence and absence of acetone) these data are not considered when making the recommendation. For room temperature, an average of all the relative rate coefficients is taken, as these show excellent agreement despite use of several different reference reactants. The temperature dependent expression adopts the value of $E / R$ $=815 \mathrm{~K}$ from Orlando et al. (2000) with expanded error limits. The pre-exponential factor has been adjusted to yield the recommended rate coefficient at $298 \mathrm{~K}$.

\section{References}

Albaladejo, J., Notario, A., Cuevas, C. A., Ballesteros, B. and Martínez, E.: J. Atmos. Chem. 45, 35, 2003.

Bryukov, M. G., Slagle, I. R. and Knyazev, V. D.: J. Phys. Chem. A 107, 6565, 2003.

Carr, S., Shalcross, D. E., Canosa-Mas, C. E., Wenger, J. C., Sidebottom, H. W., Treacy, J. J. and Wayne, R. P.: Phys. Chem. Chem. Phys., 5, 3874, 2003.

Christensen, L. K., Ball, J. C. and Wallington, T. J.: J. Phys. Chem. A 104, 345, 2000.

IUPAC: http://www.iupac-kinetic.ch.cam.ac.uk/, 2005.

Notario, A., Mellouki, A. and Le Bras, G.: Int. J. Chem. Kinet., 32, 62, 2000.

Olsson, B. E. R., Hallquist, M., Ljungström, E. and Davidson, J.: Int. J. Chem. Kinet., 29, 195, 1997.

Orlando, J. J.: Int. J. Chem. Kinet., 31, 515, 1999.

Orlando, J. J., Tyndall, G. S., Vereecken, L. and Peeters, J.: J. Phys. Chem. A, 104, 11 578, 2000.

Sellevȧg, S. R. and Nielsen, C.J.: Asian. Chem. Lett., 7, 15, 2003.

Wallington, T. J., Andino, J. M., Ball, J. C. and Japar, S. M.: J. Atmos. Chem., 10, 301, 1990.

Wallington, T. J., Bilde, M., Mogelberg, T. E., Sehested, J. and Nielsen O. J.: J. Phys. Chem. 100, 5751, 1996.

Wine, P. H. and Semmes, D. H.: J. Phys. Chem. 87, 3572, 1983.

Yokelson, R. J., Burkholder, J. B., Goldfarb, L., Fox, R. W., Gilles, M. K. and Ravishankara, A. R.: J. Phys. Chem., 99, $13976,1995$. 
II.A7.177

$$
\mathrm{Cl}+\mathrm{CH}_{3} \mathrm{C}(\mathrm{O}) \mathrm{CH}_{2} \mathrm{CH}_{3} \rightarrow \text { products }
$$

\section{Rate coefficient data}

\begin{tabular}{lllc}
\hline$k / \mathrm{cm}^{3}$ molecule & Temp./K & Reference & Technique/Comments \\
\hline $\begin{array}{l}\text { Absolute Rate Coefficients } \\
(3.24 \pm 0.38) \times 10^{-11}\end{array}$ & $298 \pm 2$ & Notario et al., 2000 & LP-RF (a) \\
$(3.30 \pm 0.20) \times 10^{-11}$ & 298 & Albaladejo et al., 2003 & PLP-RF (b) \\
$\begin{array}{l}\text { Relative Rate Coefficients } \\
(4.28 \pm 0.59) \times 10^{-11}\end{array}$ & 295 & Wallington et al., 1990 & RR (c) \\
\hline
\end{tabular}

\section{Comments}

(a) Experiments carried out at pressures of 15 or 60 Torr $\left(20\right.$ or 80 mbar) $\mathrm{He}$ using the $355 \mathrm{~nm}$ photolysis of $\mathrm{Cl}_{2}$ as $\mathrm{Cl}$-atom source. Addition of 0.4 Torr $\left(0.53\right.$ mbar) $\mathrm{O}_{2}$ (to scavenge organic radicals and prevent secondary formation of $\mathrm{Cl}$ ) resulted in similar rate coefficients.

(b) $\mathrm{Cl}$ generated in the $308 \mathrm{~nm}$ photolysis of $\mathrm{Cl}_{2}$. Addition of $2 \times 10^{16}$ molecule $\mathrm{cm}^{-3}$ of $\mathrm{O}_{2}$ (scavenger of organic radicals) had no influence on the $\mathrm{Cl}$ decay kinetics.

(c) $\mathrm{Cl}$ atoms were generated by the photolysis of $\mathrm{Cl}_{2}$ in $\mathrm{Cl}_{2}-\mathrm{N}_{2}-\mathrm{CH}_{3} \mathrm{C}(\mathrm{O}) \mathrm{C}_{2} \mathrm{H}_{5}-\mathrm{C}_{2} \mathrm{H}_{6}$ mixtures at 930 mbar (700 Torr) total pressure, and the $\mathrm{CH}_{3} \mathrm{C}(\mathrm{O}) \mathrm{C}_{2} \mathrm{H}_{5}$ and $\mathrm{C}_{2} \mathrm{H}_{6}$ concentrations monitored by FTIR absorption spectroscopy. The measured rate coefficient ratio is placed on an absolute basis by use of $k\left(\mathrm{Cl}+\mathrm{C}_{2} \mathrm{H}_{6}\right)=5.9 \times 10^{-11} \mathrm{~cm}^{3}$ molecule ${ }^{-1} \mathrm{~s}^{-1}$ (IUPAC, 2005).

\section{Preferred Values}

$k=3.6 \times 10^{-11} \mathrm{~cm}^{3}$ molecule ${ }^{-1} \mathrm{~s}^{-1}$ at $298 \mathrm{~K}$.

\section{Reliability}

$\Delta \log k= \pm 0.15$ at $298 \mathrm{~K}$.

\section{Comments on Preferred Values}

The preferred value is an average result from the studies of Wallington et al. (1990), Notario et al. (2000) and Albaladejo et al. (2003). This result is supported by the value of $k=(3.8 \pm 0.3) \times 10^{-11} \mathrm{~cm}^{3}$ molecule ${ }^{-1} \mathrm{~s}^{-1}$ quoted in Niki et al. (1987) as unpublished results from that laboratory.

\section{References}

Albaladejo, J., Notario, A., Cuevas, C. A., Jiménez, E., Cabañas, B. and Martínez, E.: Atmos. Env. 27, 455, 2003.

IUPAC: http://www.iupac-kinetic.ch.cam.ac.uk/, 2005.

Niki, H., Maker, P. D., Savage, C. M., Breitenbach, L. P. and Hurley, M. D.: J. Phys. Chem., 91, 941, 1987.

Notario, A., Mellouki, A. and Le Bras, G.: Int. J. Chem. Kinet., 32, 62, 2000.

Wallington, T. J., Andino, J. M., Ball, J. C. and Japar, S. M.: J. Atmos. Chem., 10, 301, 1990. 
II.A7.178

$$
\mathrm{Cl}+\mathrm{CH}_{3} \mathrm{OH} \rightarrow \mathrm{HCl}+\mathrm{CH}_{2} \mathrm{OH}
$$

$\Delta H^{\circ}=-29.8 \mathrm{~kJ} \cdot \mathrm{mol}^{-1}$

\section{Rate coefficient data}

\begin{tabular}{|c|c|c|c|}
\hline $\mathrm{k} / \mathrm{cm}^{3}$ molecule $^{-1} \mathrm{~s}^{-1}$ & Temp./K & Reference & Technique/Comments \\
\hline \multicolumn{4}{|l|}{ Absolute Rate Coefficients } \\
\hline$(5.1 \pm 1.0) \times 10^{-11}$ & 298 & Payne et al., 1988 & DF-MS (a) \\
\hline$(6.14 \pm 0.67) \times 10^{-11}$ & $298 \pm 2$ & Dóbé et al., 1993 & DF-EPR \\
\hline$(5.1 \pm 0.4) \times 10^{-11}$ & $295 \pm 2$ & Tyndall et al., 1999 & PLP-RF \\
\hline \multicolumn{4}{|l|}{ Relative Rate Coefficients } \\
\hline$(4.73 \pm 0.42) \times 10^{-11}$ & $295 \pm 2$ & Wallington et al., 1988 & $\mathrm{RR}(\mathrm{b})$ \\
\hline$(5.0 \pm 0.34) \times 10^{-11}$ & $298 \pm 2$ & Nelson et al., 1990 & $\mathrm{RR}(\mathrm{c})$ \\
\hline$(5.5 \pm 0.6) \times 10^{-11}$ & 295 & Tyndall et al., 1999 & $\mathrm{RR}(\mathrm{d})$ \\
\hline
\end{tabular}

\section{Comments}

(a) Reaction between $\mathrm{Cl}$ and $\mathrm{CH}_{3} \mathrm{OD}$ was studied.

(b) $\mathrm{Cl}$ atoms were generated by the photolysis of $\mathrm{Cl}_{2}$ in $\mathrm{Cl}_{2}-\mathrm{CH}_{3} \mathrm{OH}-\mathrm{C}_{2} \mathrm{H}_{6}$-air $\left(\mathrm{N}_{2}\right)$ mixtures at 1 bar total pressure. Concentrations of $\mathrm{CH}_{3} \mathrm{OH}$ and $\mathrm{C}_{2} \mathrm{H}_{6}$ were monitored by $\mathrm{GC}$ and a rate coefficient ratio $k\left(\mathrm{Cl}+\mathrm{CH}_{3} \mathrm{OH}\right) / k\left(\mathrm{Cl}+\mathrm{C}_{2} \mathrm{H}_{6}\right)=0.802 \pm 0.071$ determined. This rate coefficient ratio is placed on an absolute basis by use of $k\left(\mathrm{Cl}+\mathrm{C}_{2} \mathrm{H}_{6}\right)=5.9 \times 10^{-11} \mathrm{~cm}^{3}$ molecule $^{-1}$ $\mathrm{s}^{-1}$ (IUPAC, this evaluation).

(c) $\mathrm{Cl}$ atoms were generated from the photolysis of $\mathrm{Cl}_{2}$ or $\mathrm{C}(\mathrm{O}) \mathrm{Cl}_{2}$ in $\mathrm{Cl}_{2}$ (or $\left.\mathrm{C}(\mathrm{O}) \mathrm{Cl}_{2}\right)-\mathrm{N}_{2}$ (or $\left.\mathrm{O}_{2}\right)-\mathrm{CH}_{3} \mathrm{OH}$-cyclohexane mixtures at 1 bar pressure. Concentrations of $\mathrm{CH}_{3} \mathrm{OH}$ and cyclohexane were measured by $\mathrm{GC}$, and the rate coefficient ratio is placed on an absolute basis by use of $k(\mathrm{Cl}+$ cyclohexane $) / k(\mathrm{Cl}+n$-butane $)=1.59$ (Aschmann and Atkinson, 1995) and $k(\mathrm{Cl}+n$-butane $)=2.05 \times 10^{-10} \mathrm{~cm}^{3}$ molecule ${ }^{-1} \mathrm{~s}^{-1}$ (IUPAC, this evaluation).

(d) Broad band irradiation of $\mathrm{Cl}_{2}$ as source of $\mathrm{Cl}$ atoms. Experiments were carried out in 700 Torr $\mathrm{N}_{2}$, with analysis of $\mathrm{CH}_{3} \mathrm{OH}$ and reference compound $\left(\mathrm{C}_{2} \mathrm{H}_{6}\right.$ and $\left.\mathrm{C}_{2} \mathrm{H}_{4}\right)$ with FTIR. $k\left(\mathrm{Cl}_{+}+\mathrm{CH}_{3} \mathrm{OH}\right) / k\left(\mathrm{Cl}+\mathrm{C}_{2} \mathrm{H}_{6}\right)=0.94 \pm 0.04$, $k\left(\mathrm{Cl}+\mathrm{CH}_{3} \mathrm{OH}\right) / k\left(\mathrm{Cl}+\mathrm{C}_{2} \mathrm{H}_{4}\right)=0.63 \pm 0.03$. The data have been place on an absolute basis using $k\left(\mathrm{Cl}+\mathrm{C}_{2} \mathrm{H}_{6}\right)=5.9 \times 10^{-11} \mathrm{~cm}^{3}$ molecule ${ }^{-1} \mathrm{~s}^{-1}$ (IUPAC, this evaluation).

\section{Preferred Values}

$k=5.5 \times 10^{-11} \mathrm{~cm}^{3}$ molecule $\mathrm{e}^{-1} \mathrm{~s}^{-1}$, independent of temperature over the range 200-500 K.

\section{Reliability}

$\Delta \log k= \pm 0.07$ at $298 \mathrm{~K}$.

$\Delta(E / R)= \pm 200 \mathrm{~K}$.

\section{Comments on Preferred Values}

The preferred $298 \mathrm{~K}$ value is the unweighted average of the absolute rate coefficients of Michael et al. (1979), Payne et al. (1988), Dóbé et al. (1993) and Tyndall et al. (1999), and the relative rate studies of Nelson et al. (1990) and Tyndall et al. (1999). The inclusion of the data of Payne et al. (1988) on $\mathrm{Cl}+\mathrm{CH}_{3} \mathrm{OD}$ is justified considering the strong body of evidence showing that the $\mathrm{H}$-abstraction proceeds solely at the $\mathrm{CH}_{2}$-group at room temperature (see Payne et al., 1988, Radford et al., 1981, Meier et al., 1984, Dóbé et al., 1994 and Jodkowski et al., 1998). The relative rate study of Wallington et al. (1988) has 
been superseded by a more recent study from the same group (Tyndall et al., 1999) and is not used in the evaluation. The zero temperature dependence is taken from the study of Michael et al. (1979) and is supported by time resolved measurement of relative $\mathrm{HO}_{2}$ and $\mathrm{CH}_{3} \mathrm{O}_{2}$ concentrations formed in the photolysis of $\mathrm{Cl}_{2}$ in the presence of $\mathrm{CH}_{4}$ and $\mathrm{CH}_{3} \mathrm{OH}$ and $\mathrm{O}_{2}$ (Lightfoot et al., 1990).

\section{References}

Aschmann, S. M. and Atkinson, R.: Int. J. Chem. Kinet., 27, 613, 1995.

Dóbé, S., Otting, M., Temps, F., Wagner, H. Gg., and Ziemer, H.: Ber. Bunsenges Phys. Chem., 97, 877, 1993.

Dóbé, S., Bérces, T., Temps, F., Wagner, H. Gg., and Ziemer, H.: 25th International Symposium on Combustion, The Combustion Institute, Pittsburgh, PA, pp. 775-781, 1994.

Jodkowski, J. T., Rayez, M.-T., Rayez, J.-C., Bérces, T., and Dóbé, S.: J. Phys. Chem. A, 102, 9230, 1998.

Lightfoot, P. D., Veyret, B., and Lesclaux, R.: J. Phys. Chem., 94, 708, 1990.

Meier, U., Grotheer, H. H., and Just, T.: Chem. Phys. Lett., 106, 97, 1984.

Michael, J. V., Nava, D. F., Payne, W. A., and Stief, L. J.: J. Chem. Phys., 70, 3652, 1979.

Nelson, L., Rattigan, O., Neavyn, R., Sidebottom, H., Treacy, J., and Nielsen, O. J.: Int. J. Chem. Kinet., 22, 1111, 1990.

Payne, W. A., Brunning, J., Mitchell, M. B., and Stief, L. J.: Int. J. Chem. Kinet., 20, 63, 1988.

Radford, H. E., Evenson, K. M., and Jennings, D. A.: Chem. Phys. Lett., 78, 589, 1981.

Tyndall, G. S., Orlando, J. J., Kegley-Owen, C. S., Wallington, T. J., and Hurley, M. D.: Int. J. Chem. Kinet., 31, $776,1999$. Wallington, T. J., Skewes, L. M., Siegl, W. O., Wu, C.-H., and Japar, S. M.: Int. J. Chem. Kinet., 20, 867, 1988. 
II.A7.179

$$
\begin{array}{ll}
\mathrm{Cl}+\mathrm{CH}_{3} \mathrm{CH}_{2} \mathrm{OH} & \rightarrow \mathrm{HCl}+\mathrm{CH}_{3} \mathrm{CHOH} \\
\mathrm{Cl}+\mathrm{CH}_{3} \mathrm{CH}_{2} \mathrm{OH} & \rightarrow \mathrm{HCl}+\mathrm{CH}_{2} \mathrm{CH}_{2} \mathrm{OH}
\end{array}
$$

Rate coefficient data $\left(k=k_{1}+k_{2}\right)$

\begin{tabular}{llll}
\hline$k / \mathrm{cm}^{3}$ molecule $\mathrm{s}^{-1}$ & Temp./K & Reference & Technique/Comments \\
\hline $\begin{array}{l}\text { Absolute Rate Coefficients } \\
\left.\left.(9.4 \pm 1.4) \times 10^{-11} \text { exp[(45 } \pm 32\right) / T\right]\end{array}$ & $295-600$ & Taatjes et al., 1999 \\
$(1.09 \pm 0.9) \times 10^{-10}$ & 295 & & LP-IR (a) \\
& & & \\
Relative Rate Coefficients & & & \\
$(8.75 \pm 0.95) \times 10^{-11}$ & $295 \pm 2$ & Wallington et al., 1988 & RR (b) \\
$(1.06 \pm 0.06) \times 10^{-10}$ & $298 \pm 2$ & Nelson et al., 1990 & RR (c) \\
$(8.3 \pm 1.8) \times 10^{-11}$ & 295 & Edelbüttel-Einhaus et al., 1992 & RR (d) \\
$(9.4 \pm 0.8) \times 10^{-11}$ & $296 \pm 2$ & Taatjes et al., 1999 & RR (e) \\
Branching Ratios & & & \\
$k_{2} / k_{1}=0.28 \exp (-350 / T)$ & $295-600$ & Taatjes et al., 1999 & \\
$k_{1} / k=0.92$ & 295 & & (e) \\
$k_{2} / k=0.08$ & 295 & & \\
\hline
\end{tabular}

\section{Comments}

(a) $\mathrm{Cl}$ atoms were generated by the $193 \mathrm{~nm}$ pulsed photolysis of $\mathrm{CF}_{2} \mathrm{Cl}_{2}$ or $\mathrm{CFCl}_{3}$, and kinetic parameters were obtained by analysis of $\mathrm{HCl}$ product formation profiles using transient IR absorption spectroscopy. Bath gas was $10 \mathrm{Torr}^{\mathrm{CO}_{2}}$ to quench vibrationally excited $\mathrm{HCl}$. Use of deuterated ethanol enabled site specific rate coefficients to be determined via measurement of $\mathrm{HCl}$ yields. Complementary FTIR product analysis confirmed the result.

(b) $\mathrm{Cl}$ atoms were generated by photolysis of $\mathrm{Cl}_{2}$ in $\mathrm{Cl}_{2}-\mathrm{C}_{2} \mathrm{H}_{5} \mathrm{OH}-\mathrm{C}_{2} \mathrm{H}_{6}$-air (or $\mathrm{N}_{2}$ ) mixtures at 1 bar total pressure. $\mathrm{C}_{2} \mathrm{H}_{5} \mathrm{OH}$ and $\mathrm{C}_{2} \mathrm{H}_{6}$ were monitored by $\mathrm{GC}$ and a rate coefficient ratio $k\left(\mathrm{Cl}+\mathrm{C}_{2} \mathrm{H}_{5} \mathrm{OH}\right) / k\left(\mathrm{Cl}+\mathrm{C}_{2} \mathrm{H}_{6}\right)=1.483 \pm 0.160$ determined. Placed on an absolute basis by use of $k\left(\mathrm{Cl}+\mathrm{C}_{2} \mathrm{H}_{6}\right)=5.9 \times 10^{-11} \mathrm{~cm}^{3}$ molecule ${ }^{-1} \mathrm{~s}^{-1}$ (IUPAC, this evaluation).

(c) $\mathrm{Cl}$ atoms were generated by photolysis of $\mathrm{Cl}_{2}$ or $\mathrm{C}(\mathrm{O}) \mathrm{Cl}_{2}$ in $\mathrm{Cl}_{2}$ (or $\left.\mathrm{C}(\mathrm{O}) \mathrm{Cl}_{2}\right)-\mathrm{N}_{2}$ (or $\mathrm{O}_{2}$ )-ethanol-cyclohexane mixtures at $1 \mathrm{bar}$ pressure. Concentrations of ethanol and cyclohexane were measured by $\mathrm{GC}$, and the rate coefficient ratio is placed on an absolute basis by use of $k(\mathrm{Cl}+$ cyclohexane $) / k(\mathrm{Cl}+n$-butane) $=1.59$ (Aschmann and Atkinson, 1995) and $k(\mathrm{Cl}+$ $n$-butane) $=2.05 \times 10^{-10} \mathrm{~cm}^{3}$ molecule ${ }^{-1} \mathrm{~s}^{-1}$ (IUPAC, this evaluation).

(d) Isothermal discharge flow reactor at 1 mbar pressure, with molecular beam sampling and analysis by mass spectrometry. $k / k\left(\mathrm{Cl}+\mathrm{C}_{2} \mathrm{H}_{6}\right)$ measured to be $1.4 \pm 0.3$. Placed on an absolute basis by use of $k\left(\mathrm{Cl}+\mathrm{C}_{2} \mathrm{H}_{6}\right)=5.9 \times 10^{-11} \mathrm{~cm}^{3}$ molecule ${ }^{-1}$ $\mathrm{s}^{-1}$ (IUPAC, this evaluation). Supersedes earlier value reported from same laboratory (Khatoon et al., 1989)

(e) $\mathrm{Cl}$ atoms were generated by the photolysis of $\mathrm{Cl}_{2}$ in $\mathrm{O}_{2}$ or $\mathrm{N}_{2}$ bath gas. Loss of $\mathrm{C}_{2} \mathrm{H}_{5} \mathrm{OH}$ was measured relative to $\mathrm{C}_{2} \mathrm{H}_{6}$ using in-situ FTIR absorption spectroscopy. $k\left(\mathrm{Cl}+\mathrm{C}_{2} \mathrm{H}_{5} \mathrm{OH}\right) / k\left(\mathrm{Cl}+\mathrm{C}_{2} \mathrm{H}_{6}\right)$ was measured to be $1.6 \pm 0.13$ and is placed on an absolute basis by use of $k\left(\mathrm{Cl}+\mathrm{C}_{2} \mathrm{H}_{6}\right)=5.9 \times 10^{-11} \mathrm{~cm}^{-3}$ molecule $^{-1} \mathrm{~s}^{-1}$ (IUPAC, this evaluation). The branching ratios were derived by product analysis.

\section{Preferred Values}

$k=1.0 \times 10^{-10} \mathrm{~cm}^{3}$ molecule $\mathrm{e}^{-1} \mathrm{~s}^{-1}$ at $298 \mathrm{~K}$.

$k_{1}=8.8 \times 10^{-11} \mathrm{~cm}^{3}$ molecule ${ }^{-1} \mathrm{~s}^{-1}$ at $298 \mathrm{~K}$.

$k_{2}=0.8 \times 10^{-11} \mathrm{~cm}^{3}$ molecule ${ }^{-1} \mathrm{~s}^{-1}$ at $298 \mathrm{~K}$.

$k=8.6 \times 10^{-11} \exp (45 / T) \mathrm{cm}^{3}$ molecule ${ }^{-1} \mathrm{~s}^{-1}$ over the temperature range $295-600 \mathrm{~K}$.

$k_{2} / k_{1}=0.28 \exp (-350 / T)$ 


\section{Reliability}

$\Delta \log k= \pm 0.08$ at $298 \mathrm{~K}$.

$\Delta(E / R)= \pm 100 \mathrm{~K}$.

\section{Comments on Preferred Values}

The preferred $298 \mathrm{~K}$ rate coefficient is the average of the single absolute rate measurement of Taatjes et al. (1999) and the relative rate studies of Wallington et al. (1988), Nelson et al. (1990), Edelbüttel-Einhaus et al. (1992) and Taatjes et al. (1999), which are in good agreement. The slight temperature dependence is taken from Taatjes et al. (1999) as are temperature dependent values for the branching ratios for $k_{1}$ and $k_{2}$.

\section{References}

Aschmann, S. M. and Atkinson, R.: Int. J. Chem. Kinet., 27, 613, 1995.

Edelbüttel-Einhaus, J., Hoyermann, K., Rohde, G., and Seeba, J.:24th International Symposium on Combustion, The Combustion Institute, Pittsburgh, PA, pp. 661-668, 1992.

Khatoon, T., Edelbüttel-Einhaus, J., Hoyermann, K., and Wagner, H. Gg.: Ber. Bunsenges. Phys. Chem., 93, 626, 1989.

Nelson, L., Rattigan, O., Neavyn, R., Sidebottom, H., Treacy, J., and Nielsen, O. J.: Int. J. Chem. Kinet., 22, 1111, 1990.

Taatjes, C. A., Christensen, L. K., Hurley M. D., and Wallington, T. J.: J. Phys. Chem. A, 103, 9805, 1999.

Wallington, T. J., Skewes, L. M., Siegl, W. O., Wu, C.-H., and Japar, S. M.: Int. J. Chem. Kinet., 20, 867, 1988. 
II.A7.180

$$
\begin{aligned}
\mathrm{Cl}+n-\mathrm{C}_{3} \mathrm{H}_{7} \mathrm{OH} & \rightarrow \mathrm{CH}_{3} \mathrm{CH}_{2} \mathrm{CHOH}+\mathrm{HCl} \\
& \rightarrow \mathrm{CH}_{3} \mathrm{CHCH}_{2} \mathrm{OH}+\mathrm{HCl} \\
& \rightarrow \mathrm{CH}_{2} \mathrm{CH}_{2} \mathrm{CH}_{2} \mathrm{OH}+\mathrm{HCl}
\end{aligned}
$$

Rate coefficient data $\left(k=k_{1}+k_{2}+k_{3}\right)$

\begin{tabular}{llll}
\hline$k / \mathrm{cm}^{3}$ molecule ${ }^{-1} \mathrm{~s}^{-1}$ & Temp./K & Reference & Technique/Comments \\
\hline Relative Rate Coefficients & & & \\
$(1.49 \pm 0.12) \times 10^{-10}$ & $295 \pm 2$ & Wallington et al., 1988 & RR (a) \\
$(1.53 \pm 0.07) \times 10^{-10}$ & $298 \pm 2$ & Nelson et al., 1990 & RR (b) \\
$2.68 \times 10^{-10} \exp [-(128 \pm 20) / T]$ & $273-342$ & Cheema et al., 2002 & RR (c) \\
$(1.69 \pm 0.20) \times 10^{-10}$ & 298 & & \\
& & & \\
Branching Ratios & 298 & Cheema et al., 2002 & RR (c) \\
$k_{1} / k=0.56$ & 298 & & \\
$k_{2} / k=0.30$ & 298 & & \\
$k_{3} / k=0.14$ & & & \\
\hline
\end{tabular}

\section{Comments}

(a) $\mathrm{Cl}$ atoms were generated by photolysis of $\mathrm{Cl}_{2}$ in $\mathrm{Cl}_{2}-n-\mathrm{C}_{3} \mathrm{H}_{7} \mathrm{OH}-\mathrm{C}_{2} \mathrm{H}_{6}$-air (or $\mathrm{N}_{2}$ ) mixtures at 990 mbar (740 Torr) total pressure. $n-\mathrm{C}_{3} \mathrm{H}_{7} \mathrm{OH}$ and $\mathrm{C}_{2} \mathrm{H}_{6}$ were monitored by $\mathrm{GC}$ and a rate coefficient ratio $k(\mathrm{Cl}+n$ $\left.\mathrm{C}_{3} \mathrm{H}_{7} \mathrm{OH}\right) / k\left(\mathrm{Cl}+\mathrm{C}_{2} \mathrm{H}_{6}\right)=2.518 \pm 0.202$ determined. Placed on an absolute basis by use of $k\left(\mathrm{Cl}+\mathrm{C}_{2} \mathrm{H}_{6}\right)=5.9 \times 10^{-11} \mathrm{~cm}^{3}$ molecule ${ }^{-1} \mathrm{~s}^{-1}$ (IUPAC, this evaluation).

(b) $\mathrm{Cl}$ atoms were generated by the photolysis of $\mathrm{Cl}_{2}$ or $\mathrm{C}(\mathrm{O}) \mathrm{Cl}_{2}$ in $\mathrm{Cl}_{2}$ (or $\left.\mathrm{C}(\mathrm{O}) \mathrm{Cl}_{2}\right)-\mathrm{N}_{2}$ (or $\mathrm{O}_{2}$ )- $n$-propanol-cyclohexane mixtures at 1 bar pressure. Decay rates of $n$-propanol and cyclohexane were measured by GC, and the rate coefficient ratio placed on an absolute basis by use of $k(\mathrm{Cl}+$ cyclohexane $) / k(\mathrm{Cl}+n$-butane $)=1.59$ (Aschmann and Atkinson, 1995) and $k(\mathrm{Cl}+n$-butane $)=2.05 \times 10^{-10} \mathrm{~cm}^{3}$ molecule ${ }^{-1} \mathrm{~s}^{-1}$ (IUPAC, this evaluation).

(c) The reaction was initiated in 100,250 or $1000 \mathrm{~cm}^{3}$ Pyrex vessels by photolysis of $\mathrm{Cl}_{2}$ in presence of $\mathrm{O}_{2}, \mathrm{NO}, n-\mathrm{C}_{3} \mathrm{H}_{7} \mathrm{OH}-$ $\mathrm{C}_{2} \mathrm{H}_{6}$ and $\mathrm{N}_{2}$ mixtures at 700 Torr total pressure. $n-\mathrm{C}_{3} \mathrm{H}_{7} \mathrm{OH}$ and $\mathrm{C}_{2} \mathrm{H}_{6}$ were monitored by GC and rate coefficient ratios $k\left(\mathrm{Cl}+n-\mathrm{C}_{3} \mathrm{H}_{7} \mathrm{OH}\right) / k\left(\mathrm{Cl}+\mathrm{C}_{2} \mathrm{H}_{6}\right)$ determined at temperatures between 273 and $342 \mathrm{~K}$. Placed on an absolute basis by use of $k\left(\mathrm{Cl}+\mathrm{C}_{2} \mathrm{H}_{6}\right)=8.3 \times 10^{-11} \exp (-100 / T) \mathrm{cm}^{3}$ molecule $^{-1} \mathrm{~s}^{-1}$ (IUPAC, this evaluation). Product analysis in separate FTIR experiments combined with an assumed reaction scheme to give branching ratios.

\section{Preferred Values}

$k=1.6 \times 10^{-10} \mathrm{~cm}^{3}$ molecule $\mathrm{e}^{-1} \mathrm{~s}^{-1}$ at $298 \mathrm{~K}$.

$k=2.5 \times 10^{-10} \exp (-130 / T) \mathrm{cm}^{3}$ molecule ${ }^{-1} \mathrm{~s}^{-1}$ over the temperature range $270-350 \mathrm{~K}$.

\section{Reliability}

$\Delta \log k= \pm 0.15$ at $298 \mathrm{~K}$.

$\Delta(E / R)= \pm 100 \mathrm{~K}$.

\section{Comments on Preferred Values}

The preferred $298 \mathrm{~K}$ rate coefficient is based on the data of Wallington et al. (1988), Nelson et al. (1990) and Cheema et al. (2002). The temperature dependence is taken from the single study (Cheema et al., 2002) that varied the temperature. The branching ratios are expected to be approximately independent of temperature over the atmospheric temperature range, but until this is confirmed, we make no recommendation. 


\section{References}

Aschmann, S. M. and Atkinson, R.: Int. J. Chem. Kinet., 27, 613, 1995.

Cheema, S. A., Holbrook, K. A., Oldershaw, G. A., and Walker, R. W.: Int. J. Chem. Kin., 34, 110, 2002.

Nelson, L., Rattigan, O., Neavyn, R., Sidebottom, H., Treacy, J., and Nielsen, O. J.: Int. J. Chem. Kinet., 22, 1111, 1990.

Wallington, T. J., Skewes, L. M., Siegl, W. O., Wu, C.-H., and Japar, S. M.: Int. J. Chem. Kinet., 20, 867, 1988. 
II.A7.181

$$
\mathrm{Cl}+i-\mathrm{C}_{3} \mathrm{H}_{7} \mathrm{OH} \rightarrow \text { products }
$$

\section{Rate coefficient data}

\begin{tabular}{lclc}
\hline$k / \mathrm{cm}^{3}$ molecule & \\
\hline $\begin{array}{l}\text { Relative Rate Coefficients } \\
(8.80 \pm 0.35) \times 10^{-11}\end{array}$ & Temp./K & Reference & Technique/Comments \\
\hline
\end{tabular}

\section{Comments}

(a) $\mathrm{Cl}$ atoms were generated by the photolysis of $\mathrm{Cl}_{2}$ or $\mathrm{C}(\mathrm{O}) \mathrm{Cl}_{2}$ in isopropyl alcohol-cyclohexane- $\mathrm{O}_{2}$ (or $\mathrm{N}_{2}$ ) mixtures at 1 bar pressure. The decay rates of isopropyl alcohol and cyclohexane were measured, and rate coefficient ratio placed on an absolute basis by use of $k(\mathrm{Cl}+$ cyclohexane $) / k(\mathrm{Cl}+n$-butane $)=1.59$ (Aschmann and Atkinson, 1995) and $k(\mathrm{Cl}+n$ butane) $=2.05 \times 10^{-10} \mathrm{~cm}^{3}$ molecule ${ }^{-1} \mathrm{~s}^{-1}$ (IUPAC, this evaluation).

\section{Preferred Values}

$k=8.6 \times 10^{-11} \mathrm{~cm}^{3}$ molecule ${ }^{-1} \mathrm{~s}^{-1}$ at $298 \mathrm{~K}$.

\section{Reliability}

$\Delta \log k= \pm 0.1$ at $298 \mathrm{~K}$.

\section{Comments on Preferred Values}

Based on the sole study of Nelson et al. (1990).

\section{References}

Aschmann, S. M. and Atkinson, R.: Int. J. Chem. Kinet., 27, 613, 1995.

Nelson, L., Rattigan, O., Neavyn, R., Sidebottom, H., Treacy, J., and Nielsen, O. J.: Int. J. Chem. Kinet., 22, 1111, 1990. 
II.A7.182

$$
\begin{aligned}
\mathrm{Cl}+\mathrm{CH}_{3} \mathrm{OOH} & \rightarrow \mathrm{HCl}+\mathrm{CH}_{3} \mathrm{O}_{2} \\
& \rightarrow \mathrm{HCl}+\mathrm{CH}_{2} \mathrm{OOH}
\end{aligned}
$$

$\Delta H^{\circ}(1)=-74 \mathrm{~kJ} \cdot \mathrm{mol}^{-1}$

Rate coefficient data $\left(k=k_{1}+k_{2}\right)$

\begin{tabular}{lclc}
\hline$k / \mathrm{cm}^{3}$ molecule & & \\
\hline $\begin{array}{l}\text { Relative Rate Coefficients } \\
(5.9 \pm 0.3) \times 10^{-11}\end{array}$ & Temp./K & Reference & Technique/Comments \\
\hline
\end{tabular}

\section{Comments}

(a) $\mathrm{Cl}$ atoms were generated by the photolysis of $\mathrm{Cl}_{2}$ in $\mathrm{Cl}_{2}-\mathrm{N}_{2}-\mathrm{CH}_{3} \mathrm{OOH}-\mathrm{C}_{2} \mathrm{H}_{6}$ mixtures at 930 mbar (700 Torr) total pressure, and the $\mathrm{CH}_{3} \mathrm{OOH}$ and $\mathrm{C}_{2} \mathrm{H}_{6}$ concentrations monitored by FTIR absorption spectroscopy. The measured rate coefficient ratio is placed on an absolute basis by use of $k\left(\mathrm{Cl}+\mathrm{C}_{2} \mathrm{H}_{6}\right)=5.9 \times 10^{-11} \mathrm{~cm}^{3}$ molecule ${ }^{-1} \mathrm{~s}^{-1}$ (IUPAC, this evaluation).

\section{Preferred Values}

$k=5.9 \times 10^{-11} \mathrm{~cm}^{3}$ molecule $\mathrm{s}^{-1}$ at $298 \mathrm{~K}$.

\section{Reliability}

$\Delta \log k= \pm 0.5$ at $298 \mathrm{~K}$.

\section{Comments on Preferred Values}

The sole study carried out to date is that of Wallington et al. (1990). The reaction may occur by the two pathways listed and the formation of $\mathrm{HO}$ radicals via decomposition of $\mathrm{CH}_{2} \mathrm{OOH}$ may have led to secondary reactions involving $\mathrm{HO}$ radicals. Since the room temperature rate coefficient for the $\mathrm{Cl}$ atom reaction with $\mathrm{H}_{2} \mathrm{O}_{2}$ is two orders of magnitude lower than that for $\mathrm{Cl}+\mathrm{CH}_{3} \mathrm{OOH}$ (IUPAC, current recommendation), it is expected that channel (2) will dominate. Wallington et al. (1990) concluded that secondary reactions involving $\mathrm{HO}$ radicals did not contribute $>15 \%$ to the observed $\mathrm{CH}_{3} \mathrm{OOH}$ consumption. The cited uncertainty limits on the preferred values reflect this possibility.

\section{References}

IUPAC: http://www.iupac-kinetic.ch.cam.ac.uk/.

Wallington, T. J., Andino, J. M., Ball, J. C., and Japar, S. M.: J. Atmos. Chem., 10, 301, 1990. 
II.A7.183

$$
\begin{aligned}
\mathrm{Cl}+\mathrm{HC}(\mathrm{O}) \mathrm{OH} & \rightarrow \mathrm{HCl}+\mathrm{HCO}_{2} \\
& \rightarrow \mathrm{HCl}+\mathrm{HOCO}
\end{aligned}
$$

$\Delta H^{\circ}(2)=-52 \mathrm{~kJ} \cdot \mathrm{mol}^{-1}$

\begin{tabular}{|c|c|c|c|}
\hline$k / \mathrm{cm}^{3}$ molecule ${ }^{-1} \mathrm{~s}^{-1}$ & Temp./K & Reference & Technique/Comments \\
\hline $\begin{array}{l}\text { Absolute Rate Coefficients } \\
(1.83 \pm 0.12) \times 10^{-13}\end{array}$ & $295 \pm 2$ & Li et al., 2000 & FP-IR (a) \\
\hline $\begin{array}{l}\text { Relative Rate Coefficients } \\
(2.15 \pm 0.12) \times 10^{-13} \\
(1.83 \pm 0.10) \times 10^{-13}\end{array}$ & $\begin{array}{l}295 \pm 2 \\
295 \pm 2\end{array}$ & $\begin{array}{l}\text { Wallington et al., } 1990 \\
\text { Wallington et al., } 1990\end{array}$ & $\begin{array}{l}\operatorname{RR}(b, c) \\
\operatorname{RR}(b, d)\end{array}$ \\
\hline
\end{tabular}

Rate coefficient data $\left(k=k_{1}+k_{2}\right)$

\section{Comments}

(a) $\mathrm{Cl}$-atoms made in the flash photolysis of $\mathrm{Cl}_{2}$ in $\mathrm{He}$ at 10 Torr. $\mathrm{O}_{2}$ was added to convert $\mathrm{HOCO}$ to $\mathrm{CO}_{2}$, which was monitored by transient IR absorption spectroscopy to obtain kinetic data. A small correction $(<10 \%)$ was applied to take $\mathrm{HC}(\mathrm{O}) \mathrm{OH}$ dimerisation into account.

(b) $\mathrm{Cl}$ atoms were generated by the photolysis of $\mathrm{Cl}_{2}$ in $\mathrm{Cl}_{2}$-air- $\mathrm{HC}(\mathrm{O}) \mathrm{OH}-\mathrm{CH}_{3} \mathrm{Cl}$ (or $\mathrm{CH}_{4}$ ) mixtures at 930 mbar (700 Torr) total pressure. $\mathrm{HC}(\mathrm{O}) \mathrm{OH}$ and $\mathrm{CH}_{3} \mathrm{Cl}\left(\right.$ or $\left.\mathrm{CH}_{4}\right)$ were monitored by FTIR absorption spectroscopy during the experiments.

(c) Relative to $k\left(\mathrm{Cl}+\mathrm{CH}_{3} \mathrm{Cl}\right)$. Placed on an absolute basis by use of $k\left(\mathrm{Cl}+\mathrm{CH}_{3} \mathrm{Cl}\right)=4.9 \times 10^{-13} \mathrm{~cm}^{3}$ molecule $\mathrm{s}^{-1}$ (IUPAC, current recommendation).

(d) Relative to $k\left(\mathrm{Cl}+\mathrm{CH}_{4}\right)$. Placed on an absolute basis by use of $k\left(\mathrm{Cl}+\mathrm{CH}_{4}\right)=9.9 \times 10^{-14} \mathrm{~cm}^{3}$ molecule ${ }^{-1} \mathrm{~s}^{-1}$ (IUPAC, this evaluation).

\section{Preferred Values}

$k=1.9 \times 10^{-13} \mathrm{~cm}^{3}$ molecule ${ }^{-1} \mathrm{~s}^{-1}$ at $298 \mathrm{~K}$.

\section{Reliability}

$\Delta \log k= \pm 0.15$ at $298 \mathrm{~K}$.

\section{Comments on Preferred Values}

The preferred $298 \mathrm{~K}$ rate coefficient is the average of the absolute rate coefficient of $\mathrm{Li}$ et al. (2000) and the relative rate coefficients obtained by Wallington et al. (1990).

Tyndall et al. (1991) have observed that $\mathrm{CO}_{2}$ is the sole carbon-containing product formed from this reaction in air or $\mathrm{N}_{2}$ diluent, and conclude from comparison of the rate coefficients for the reactions of the $\mathrm{Cl}$ atom with $\mathrm{HC}(\mathrm{O}) \mathrm{OH}, \mathrm{CH}_{3} \mathrm{C}(\mathrm{O}) \mathrm{OH}$ (Koch and Moortgat, 1990) and $\mathrm{CD}_{3} \mathrm{C}(\mathrm{O}) \mathrm{OH}$ (Koch and Moortgat, 1990) that reaction channel (2) dominates.

\section{References}

IUPAC: http://www.iupac-kinetic.ch.cam.ac.uk/.

Koch, S. and Moortgat, G. K.: Chem. Phys. Lett., 173, 531, 1990.

Li, Q., Osbourne, M. C., and Smith, I. W. M.: Int. J. Chem. Kinet., 32, 85, 2000.

Tyndall, G. S., Wallington, T. J., and Potts, A. R.: Chem. Phys. Lett., 186, 149, 1991.

Wallington, T. J., Andino, J. M., Ball, J. C., and Japar, S. M.: J. Atmos. Chem., 10, 301, 1990. 
II.A7.184

$$
\begin{aligned}
\mathrm{Cl}+\mathrm{CH}_{3} \mathrm{C}(\mathrm{O}) \mathrm{OH} & \rightarrow \mathrm{HCl}+\mathrm{CH}_{2} \mathrm{C}(\mathrm{O}) \mathrm{OH} \\
& \rightarrow \mathrm{HCl}+\mathrm{CH}_{3} \mathrm{C}(\mathrm{O}) \mathrm{O}
\end{aligned}
$$

$\Delta H^{\circ}(2)=11 \mathrm{~kJ} \cdot \mathrm{mol}^{-1}$

\begin{tabular}{|c|c|c|c|}
\hline$k / \mathrm{cm}^{3}$ molecule $^{-1} \mathrm{~s}^{-1}$ & Temp./K & Reference & Technique/Comments \\
\hline $\begin{array}{l}\text { Relative Rate Coefficients } \\
(2.8 \pm 0.4) \times 10^{-14}\end{array}$ & $298 \pm 1$ & Koch and Moortgat, 1990 & $\mathrm{RR}(\mathrm{a})$ \\
\hline$(2.5 \pm 0.3) \times 10^{-14}$ & $295 \pm 1$ & Crawford et al., 1999 & $\mathrm{RR}$ (b) \\
\hline
\end{tabular}

Rate coefficient data $\left(k=k_{1}+k_{2}\right)$

\section{Comments}

(a) $\mathrm{Cl}$ atoms were generated by the photolysis of $\mathrm{Cl}_{2}$ in $\mathrm{Cl}_{2}-\mathrm{CH}_{3} \mathrm{C}(\mathrm{O}) \mathrm{OH}-\mathrm{CH}_{4}-\mathrm{N}_{2}$ mixtures at 1 bar total pressure. The concentrations of $\mathrm{CH}_{3} \mathrm{C}(\mathrm{O}) \mathrm{OH}$ and $\mathrm{CH}_{4}$ were measured by IR absorption spectroscopy. The rate coefficient ratio $k\left(\mathrm{Cl}+\mathrm{CH}_{3} \mathrm{C}(\mathrm{O}) \mathrm{OH}\right) / k\left(\mathrm{Cl}+\mathrm{CH}_{4}\right)=0.28 \pm 0.04$ is placed on an absolute basis by use of $k\left(\mathrm{Cl}+\mathrm{CH}_{4}\right)=1.0 \times 10^{-13} \mathrm{~cm}^{3}$ molecule $\mathrm{s}^{-1}$ (IUPAC, 2005). An analogous experiment using $\mathrm{CD}_{3} \mathrm{C}(\mathrm{O}) \mathrm{OH}$ yielded a rate coefficient of $k\left(\mathrm{Cl}+\mathrm{CD}_{3} \mathrm{C}(\mathrm{O}) \mathrm{OH}\right)=(7.5 \pm 0.2) \times 10^{-15} \mathrm{~cm}^{3}$ molecule $^{-1} \mathrm{~s}^{-1}$, indicating that the reaction proceeds mainly by channel (1).

(b) $\mathrm{Cl}$ atoms were generated by the photolysis of $\mathrm{Cl}_{2}$ in $\mathrm{Cl}_{2}-\mathrm{CH}_{3} \mathrm{C}(\mathrm{O}) \mathrm{OH}-\mathrm{CH}_{4}$ mixtures in $\mathrm{N}_{2}$ or air at 933 mbar total pressure. The concentrations of $\mathrm{CH}_{3} \mathrm{C}(\mathrm{O}) \mathrm{OH}$ and $\mathrm{CH}_{4}$ were measured by IR absorption spectroscopy. The rate coefficient ratio $k\left(\mathrm{Cl}+\mathrm{CH}_{3} \mathrm{C}(\mathrm{O}) \mathrm{OH}\right) / k\left(\mathrm{Cl}+\mathrm{CH}_{4}\right)=0.25 \pm 0.03$ is placed on an absolute basis by use of $k\left(\mathrm{Cl}+\mathrm{CH}_{4}\right)=1.0 \times$ $10^{-13} \mathrm{~cm}^{3}$ molecule $\mathrm{s}^{-1}$ (IUPAC, 2005).

\section{Preferred Values}

$k=2.65 \times 10^{-14} \mathrm{~cm}^{3}$ molecule $\mathrm{e}^{-1} \mathrm{~s}^{-1}$ at $298 \mathrm{~K}$.

\section{Reliability}

$\Delta \log k= \pm 0.2$ at $298 \mathrm{~K}$.

\section{Comments on Preferred Values}

The preferred $298 \mathrm{~K}$ rate coefficient an average of the similar studies of Koch and Moortgat (1990) and Crawford et al. (1999). The measured rate coefficient ratio of $k\left(\mathrm{Cl}+\mathrm{CH}_{3} \mathrm{C}(\mathrm{O}) \mathrm{OH}\right) / k\left(\mathrm{Cl}+\mathrm{CD}_{3} \mathrm{C}(\mathrm{O}) \mathrm{OH}\right)=3.7$ at $298 \pm 1 \mathrm{~K}$ indicates that channel (1) dominates at $298 \mathrm{~K}$ (Koch and Moortgat, 1990).

\section{References}

Crawford, M. A., Wallington, T. J., Szente, J. J., Maricq, M. M. and Francisco, J. S.: J. Phys. Chem. A 103, 365, 1999. IUPAC: http://www.iupac-kinetic.ch.cam.ac.uk/, 2005.

Koch, S. and Moortgat, G. K.: Chem. Phys. Lett., 173, 531, 1990. 
II.A7.185

$$
\mathrm{Cl}+\mathrm{CH}_{3} \mathrm{ONO}_{2} \rightarrow \text { products }
$$

\section{Rate coefficient data}

\begin{tabular}{|c|c|c|c|}
\hline$k / \mathrm{cm}^{3}$ molecule $^{-1} \mathrm{~s}^{-1}$ & Temp./K & Reference & Technique/Comments \\
\hline $\begin{array}{l}\text { Relative Rate Coefficients } \\
(2.42 \pm 0.02) \times 10^{-13}\end{array}$ & $298 \pm 2$ & Nielsen et al., 1991 & RR (a) \\
\hline$(2.40 \pm 0.20) \times 10^{-13}$ & $295 \pm 2$ & Sokolov et al., 1999 & RR (b) \\
\hline
\end{tabular}

\section{Comments}

(a) $\mathrm{Cl}$ atoms were generated by the photolysis of $\mathrm{Cl}_{2}$ in $\mathrm{Cl}_{2}-\mathrm{CH}_{3} \mathrm{ONO}_{2}-\mathrm{C}_{2} \mathrm{H}_{6}-\mathrm{N}_{2}$ mixtures at 1 bar pressure. Concentrations of methyl nitrate and ethane were measured by $\mathrm{GC}$ and the rate coefficient ratio is placed on an absolute basis by use of $k\left(\mathrm{Cl}+\mathrm{C}_{2} \mathrm{H}_{6}\right)=5.9 \times 10^{-11} \mathrm{~cm}^{3}$ molecule $\mathrm{s}^{-1} \mathrm{~s}^{-1}$ (IUPAC, this evaluation).

(b) $\mathrm{Cl}$ atoms were generated by the photolysis of $\mathrm{Cl}_{2}$ in $\mathrm{Cl}_{2}-\mathrm{CH}_{3} \mathrm{ONO}_{2}-\mathrm{CH}_{3} \mathrm{Cl}$ or $\mathrm{Cl}_{2}-\mathrm{CH}_{3} \mathrm{ONO}_{2}-\mathrm{CH}_{4}$ mixtures at 700 Torr pressure of $\mathrm{N}_{2}$. Concentrations of methyl nitrate and the reference compounds measured in situ using FTIR. Relative rates were $k\left(\mathrm{Cl}+\mathrm{CH}_{3} \mathrm{ONO}_{2}\right) / k\left(\mathrm{Cl}+\mathrm{CH}_{3} \mathrm{Cl}\right)=0.50 \pm 0.04$ and $k\left(\mathrm{Cl}+\mathrm{CH}_{3} \mathrm{ONO}_{2}\right) / k\left(\mathrm{Cl}+\mathrm{CH}_{4}\right)=2.36 \pm 0.15$. The rate coefficient ratios were placed on an absolute basis by use of $k\left(\mathrm{Cl}+\mathrm{CH}_{3} \mathrm{Cl}\right.$ ) $=4.8 \times 10^{-13} \mathrm{~cm}^{3}$ molecule ${ }^{-1} \mathrm{~s}^{-1}$ (IUPAC, current recommendation) and $k\left(\mathrm{Cl}+\mathrm{CH}_{4}\right)=9.9 \times 10^{-14} \mathrm{~cm}^{3}$ molecule ${ }^{-1} \mathrm{~s}^{-1}$ (IUPAC, this evaluation) and averaged to give the final number.

\section{Preferred Values}

$k=2.4 \times 10^{-13} \mathrm{~cm}^{3}$ molecule ${ }^{-1} \mathrm{~s}^{-1}$ at $298 \mathrm{~K}$.

\section{Reliability}

$\Delta \log k= \pm 0.15$ at $298 \mathrm{~K}$.

\section{Comments on Preferred Values}

Based on the relative rate studies of Nielsen et al. (1991) and Sokolov et al. (1999). The reaction probably occurs via $\mathrm{H}$-atom abstraction from the $-\mathrm{CH}_{3}$ group (Nielsen et al., 1991).

\section{References}

IUPAC: http://www.iupac-kinetic.ch.cam.ac.uk/.

Nielsen, O. J., Sidebottom, H. W., Donlon, M., and Treacy, J.: Chem. Phys. Lett., 178, 1631991.

Sokolov, O., Hurley, M. D., Ball, J. C., Wallington, T. J., Nelsen, W., Barnes, I., and Becker, K. H.: Int. J. Chem. Kinet., 31, $357,1999$. 
II.A7.186

$$
\mathrm{Cl}+\mathrm{C}_{2} \mathrm{H}_{5} \mathrm{ONO}_{2} \rightarrow \text { products }
$$

\section{Rate coefficient data}

\begin{tabular}{lclc}
\hline$k / \mathrm{cm}^{3}$ molecule $\mathrm{s}^{-1} \mathrm{~s}^{-1}$ & Temp./K & Reference & Technique/Comments \\
\hline Relative Rate Coefficients & & & \\
$(5.5 \pm 0.8) \times 10^{-12}$ & $295 \pm 2$ & Wallington et al., 1990a & RR (a) \\
$(3.95 \pm 0.15) \times 10^{-12}$ & $298 \pm 2$ & Nielsen et al., 1991 & RR (b) \\
\hline
\end{tabular}

\section{Comments}

(a) $\mathrm{Cl}$ atoms were generated by the photolysis of $\mathrm{Cl}_{2}$ in $\mathrm{Cl}_{2}$-ethyl nitrate- $\mathrm{C}_{2} \mathrm{H}_{5} \mathrm{Cl}$-air mixtures at 1 bar pressure. Ethyl nitrate and $\mathrm{C}_{2} \mathrm{H}_{5} \mathrm{Cl}$ were measured by $\mathrm{GC}$, and a rate coefficient ratio of $k(\mathrm{Cl}+$ ethyl nitrate) $/ k\left(\mathrm{Cl}+\mathrm{C}_{2} \mathrm{H}_{5} \mathrm{Cl}\right)=0.46 \pm 0.03$ determined. Combined with $k\left(\mathrm{Cl}+\mathrm{C}_{2} \mathrm{H}_{5} \mathrm{Cl}\right) / k\left(\mathrm{Cl}+\mathrm{C}_{2} \mathrm{H}_{6}\right)=0.201 \pm 0.027$ (Wallington et al., 1990b) and $k\left(\mathrm{Cl}+\mathrm{C}_{2} \mathrm{H}_{6}\right)=5.9 \times 10^{-11} \mathrm{~cm}^{3}$ molecule ${ }^{-1} \mathrm{~s}^{-1}$ (IUPAC, this evaluation), the rate coefficient cited in the table is obtained.

(b) $\mathrm{Cl}$ atoms were generated by the photolysis of $\mathrm{Cl}_{2}$-ethyl nitrate- $\mathrm{C}_{2} \mathrm{H}_{6}-\mathrm{N}_{2}$ mixtures at atmospheric pressure. Concentrations of ethyl nitrate and ethane were measured by GC and the rate coefficient ratio placed on an absolute basis by use of $k\left(\mathrm{Cl}+\mathrm{C}_{2} \mathrm{H}_{6}\right)=5.9 \times 10^{-11} \mathrm{~cm}^{3}$ molecule $\mathrm{s}^{-1}$ (IUPAC, this evaluation).

\section{Preferred Values}

$k=4.7 \times 10^{-12} \mathrm{~cm}^{3}$ molecule ${ }^{-1} \mathrm{~s}^{-1}$ at $298 \mathrm{~K}$.

\section{Reliability}

$\Delta \log k= \pm 0.2$ at $298 \mathrm{~K}$.

\section{Comments on Preferred Values}

The preferred $298 \mathrm{~K}$ rate coefficient is the average of the data of Wallington et al. (1990a) and Nielsen et al. (1991). The reaction probably proceeds by $\mathrm{H}$ atom abstraction from the C-H bonds (Nielsen et al., 1991).

\section{References}

Nielsen, O. J., Sidebottom, H. W., Donlon, M., and Treacy, J.: Chem. Phys. Lett., 178, 163, 1991.

Wallington, T. J., Hinman, M. M., Andino, J. M., Siegl, W. O., and Japar, S. M.: Int. J. Chem. Kinet., 22, 665, 1990a.

Wallington, T. J., Andino, J. M., Ball, J. C., and Japar, S. M.: J. Atmos. Chem., 10, 301, 1990b. 
II.A7.187

$$
\mathrm{Cl}+n-\mathrm{C}_{3} \mathrm{H}_{7} \mathrm{ONO}_{2} \rightarrow \text { products }
$$

\section{Rate coefficient data}

\begin{tabular}{lclc}
\hline$k / \mathrm{cm}^{3}$ molecule $\mathrm{s}^{-1} \mathrm{~s}^{-1}$ & Temp./K & Reference & Technique/Comments \\
\hline Relative Rate Coefficients & & & \\
$(2.1 \pm 0.13) \times 10^{-11}$ & $295 \pm 2$ & Wallington et al., 1990a & RR (a) \\
$(2.28 \pm 0.14) \times 10^{-11}$ & $298 \pm 2$ & Nielsen et al., 1991 & RR (b) \\
\hline
\end{tabular}

\section{Comments}

(a) $\mathrm{Cl}$ atoms were generated by the photolysis of $\mathrm{Cl}_{2}$ in $\mathrm{Cl}_{2}-n$-propyl nitrate- $\mathrm{C}_{2} \mathrm{H}_{5} \mathrm{Cl}$-air mixtures at 1 bar pressure. $n$-Propyl nitrate and $\mathrm{C}_{2} \mathrm{H}_{5} \mathrm{Cl}$ concentrations were measured by $\mathrm{GC}$ and a rate coefficient ratio of $k(\mathrm{Cl}+n$-propyl nitrate) $/ k\left(\mathrm{Cl}+\mathrm{C}_{2} \mathrm{H}_{5} \mathrm{Cl}\right)=2.67 \pm 0.16$ determined. Rate coefficient in table calculated using $k\left(\mathrm{Cl}+\mathrm{C}_{2} \mathrm{H}_{5} \mathrm{Cl}\right)=7.8 \times 10^{-12}$ $\mathrm{cm}^{3}$ molecule ${ }^{-1} \mathrm{~s}^{-1}$ (Wine et al, 1983; Bryukov et al., 2003).

(b) $\mathrm{Cl}$ atoms were generated by the photolysis of $\mathrm{Cl}_{2}$ in $\mathrm{Cl}_{2}-n$-propyl nitrate- $\mathrm{C}_{2} \mathrm{H}_{6}-\mathrm{N}_{2}$ mixtures at 1 bar pressure. Concentrations of $n$-propyl nitrate and $\mathrm{C}_{2} \mathrm{H}_{6}$ were measured by GC, and the rate coefficient ratio is placed on an absolute basis by use of $k\left(\mathrm{Cl}+\mathrm{C}_{2} \mathrm{H}_{6}\right)=5.9 \times 10^{-11} \mathrm{~cm}^{3}$ molecule ${ }^{-1} \mathrm{~s}^{-1}$ (IUPAC, 2005).

\section{Preferred Values}

$k=2.2 \times 10^{-11} \mathrm{~cm}^{3}$ molecule ${ }^{-1} \mathrm{~s}^{-1}$ at $298 \mathrm{~K}$.

\section{Reliability}

$\Delta \log k= \pm 0.2$ at $298 \mathrm{~K}$.

\section{Comments on Preferred Values}

The preferred $298 \mathrm{~K}$ rate coefficient is the average of the data of Wallington et al. (1990a) and Nielsen et al. (1991). The reaction probably proceeds by $\mathrm{H}$-atom abstraction from the C-H bonds (Nielsen et al., 1991).

\section{References}

Bryukov, M. G., Slagle, I. R., and Knyazev, V. D.: J. Phys. Chem. A 107, 6565, 2003.

IUPAC: http://www.iupac-kinetic.ch.cam.ac.uk/, 2005.

Nielsen, O. J., Sidebottom, H. W., Donlon, M., and Treacy, J.: Chem. Phys. Lett., 178, 163, 1991.

Wallington, T. J., Hinman, M. M., Andino, J. M., Siegl, W. O., and Japar, S. M.: Int. J. Chem. Kinet., 22, 665, 1990a.

Wallington, T. J., Andino, J. M., Ball, J. C., and Japar, S. M.: J. Atmos. Chem., 10, 301, 1990b.

Wine, P. H., and Semmes, D. H.: J. Phys. Chem. 87, 3572, 1983. 
II.A7.188

$$
\mathrm{Cl}+i-\mathrm{C}_{3} \mathrm{H}_{7} \mathrm{ONO}_{2} \rightarrow \text { products }
$$

\section{Rate coefficient data}

\begin{tabular}{|c|c|c|c|}
\hline$k / \mathrm{cm}^{3}$ molecule $^{-1} \mathrm{~s}^{-1}$ & Temp./K & Reference & Technique/Comments \\
\hline $\begin{array}{l}\text { Relative Rate Coefficients } \\
(3.8 \pm 0.5) \times 10^{-12}\end{array}$ & $295 \pm 2$ & Wallington et al., 1990 & RR (a) \\
\hline
\end{tabular}

\section{Comments}

(a) $\mathrm{Cl}$ atoms were generated by the photolysis of $\mathrm{Cl}_{2}$ in $\mathrm{Cl}_{2}$-isopropyl nitrate- $\mathrm{C}_{2} \mathrm{H}_{5} \mathrm{Cl}$-air mixtures at 1 bar pressure. Concentrations of isopropyl nitrate and $\mathrm{C}_{2} \mathrm{H}_{5} \mathrm{Cl}$ were measured by $\mathrm{GC}$, and a rate coefficient ratio of $k(\mathrm{Cl}+$ isopropyl nitrate $) /\left(\mathrm{Cl}+\mathrm{C}_{2} \mathrm{H}_{5} \mathrm{Cl}\right)=0.49 \pm 0.06$ determined. Rate coefficient in table calculated using $k\left(\mathrm{Cl}+\mathrm{C}_{2} \mathrm{H}_{5} \mathrm{Cl}\right)=7.8 \times 10^{-12}$ $\mathrm{cm}^{3}$ molecule ${ }^{-1} \mathrm{~s}^{-1}$ (Wine et al., 1983; Bryukov et al., 2003).

\section{Preferred Values}

$k=3.8 \times 10^{-12} \mathrm{~cm}^{3}$ molecule ${ }^{-1} \mathrm{~s}^{-1}$ at $298 \mathrm{~K}$.

Reliability

$\Delta \log k= \pm 0.3$ at $298 \mathrm{~K}$.

Comments on Preferred Values

The preferred $298 \mathrm{~K}$ rate coefficient is based on the sole study of Wallington et al. (1990).

\section{References}

Bryukov, M. G., Slagle, I. R. and Knyazev, V. D.: J. Phys. Chem. A 107, 6565, 2003.

Wallington, T. J., Hinman, M. M., Andino, J. M., Siegl, W. O. and Japar, S. M.: Int. J. Chem. Kinet., 22, 665, 1990.

Wine, P. H. and Semmes, D. H.: J. Phys. Chem. 87, 3572, 1983. 
II.A7.189

$$
\mathrm{Cl}+n-\mathrm{C}_{4} \mathrm{H}_{9} \mathrm{ONO}_{2} \rightarrow \text { products }
$$

\section{Rate coefficient data}

\begin{tabular}{|c|c|c|c|}
\hline$k / \mathrm{cm}^{3}$ molecule $^{-1} \mathrm{~s}^{-1}$ & Temp./K & Reference & Technique/Comments \\
\hline $\begin{array}{l}\text { Relative Rate Coefficients } \\
(8.54 \pm 0.20) \times 10^{-11}\end{array}$ & 298 & Nielsen et al., 1991 & RR (a) \\
\hline
\end{tabular}

\section{Comments}

(a) $\mathrm{Cl}$ atoms were generated by the photolysis of $\mathrm{Cl}_{2}$ in $\mathrm{Cl}_{2}-n$-butyl nitrate- $\mathrm{C}_{2} \mathrm{H}_{6}-\mathrm{N}_{2}$ mixtures at 1 bar pressure. Concentrations of $n$-butyl nitrate and $\mathrm{C}_{2} \mathrm{H}_{6}$ were measured by $\mathrm{GC}$, and the rate coefficient ratio placed on an absolute basis by use of $k\left(\mathrm{Cl}+\mathrm{C}_{2} \mathrm{H}_{6}\right)=5.9 \times 10^{-11} \mathrm{~cm}^{3}$ molecule ${ }^{-1} \mathrm{~s}^{-1}$ (IUPAC, this evaluation).

\section{Preferred Values}

$k=8.5 \times 10^{-11} \mathrm{~cm}^{3}$ molecule $\mathrm{e}^{-1} \mathrm{~s}^{-1}$ at $298 \mathrm{~K}$.

\section{Reliability}

$\Delta \log k= \pm 0.3$ at $298 \mathrm{~K}$.

Comments on Preferred Values

Based on the sole study of Nielsen et al. (1991), with expanded uncertainty limits.

\section{References}

Nielsen, O. J., Sidebottom, H. W., Donlon, M., and Treacy, J.: Chem. Phys. Lett., 178, 163, 1991. 
II.A7.190

$$
\mathrm{Cl}+\mathrm{CH}_{3} \mathrm{C}(\mathrm{O}) \mathrm{OONO}_{2} \rightarrow \text { products }
$$

\section{Rate coefficient data}

\begin{tabular}{lllc}
\hline$k / \mathrm{cm}^{3}$ molecule $\mathrm{s}^{-1} \mathrm{~s}^{-1}$ & Temp./K & Reference & Technique/Comments \\
\hline $\begin{array}{l}\text { Absolute Rate Coefficients } \\
(3.7 \pm 1.7) \times 10^{-13}\end{array}$ & 298 & Tsalkani et al., 1988 & DF-EPR \\
$\begin{array}{l}\text { Relative Rate Coefficients } \\
<7 \times 10^{-15}\end{array}$ & $295 \pm 2$ & Wallington et al., 1990 & RR (a) \\
\hline
\end{tabular}

\section{Comments}

(a) $\mathrm{Cl}$ atoms were generated by the photolysis of $\mathrm{Cl}_{2}$ in $\mathrm{Cl}_{2}$-air- $\mathrm{CH}_{3} \mathrm{C}(\mathrm{O}) \mathrm{OONO}_{2}-\mathrm{CH}_{4}$ mixtures at 930 mbar (700 Torr) total pressure, with the $\mathrm{CH}_{3} \mathrm{C}(\mathrm{O}) \mathrm{OONO}_{2}$ and $\mathrm{CH}_{4}$ concentrations being monitored by FTIR absorption spectroscopy. Upper limit to relative rate coefficient ratio placed on an absolute basis by use of $k\left(\mathrm{Cl}+\mathrm{CH}_{4}\right)=9.9 \times 10^{-14} \mathrm{~cm}^{3}$ molecule $^{-1} \mathrm{~s}^{-1}$ (IUPAC, this evaluation).

\section{Preferred Values}

$k<2 \times 10^{-14} \mathrm{~cm}^{3}$ molecule $\mathrm{e}^{-1} \mathrm{~s}^{-1}$ at $298 \mathrm{~K}$.

\section{Comments on Preferred Values}

The preferred value is based on the relative rate coefficient measurement of Wallington et al. (1990), in which no reaction of $\mathrm{CH}_{3} \mathrm{C}(\mathrm{O}) \mathrm{OONO}_{2}$ was observed in the presence of $\mathrm{Cl}$ atoms. In both the relative rate study of Wallington et al. (1990) and the absolute rate study of Tsalkani et al. (1988), the major impurity in the $\mathrm{CH}_{3} \mathrm{C}(\mathrm{O}) \mathrm{OONO}_{2}$ samples would be the $\mathrm{C}_{12}$ or $\mathrm{C}_{13}$ alkane solvent, respectively. While this was of no consequence in the relative rate study of Wallington et al. (1990), the presence of $\sim 0.1 \%$ tridecane in the $\mathrm{CH}_{3} \mathrm{C}(\mathrm{O}) \mathrm{OONO}_{2}$ sample used by Tsalkani et al. (1988) could account for the $\mathrm{Cl}$ reaction rate observed; their $\mathrm{CH}_{3} \mathrm{C}(\mathrm{O}) \mathrm{OONO}_{2}$ sample was $>99 \%$ pure from IR measurements. The upper limit cited here is a factor of $\sim 3$ higher than measured by Wallington et al. (1990) to allow for greater uncertainties.

\section{References}

Tsalkani, N., Mellouki, A., Poulet, G., Toupance, G., and Le Bras, G.: J. Atmos. Chem., 7, 409, 1988.

Wallington, T. J., Andino, J. M., Ball, J. C., and Japar, S. M.: J. Atmos. Chem., 10, 301, 1990. 
II.A7.191

$$
\mathrm{Cl}+\mathrm{CH}_{3} \mathrm{CN} \rightarrow \text { products }
$$

\section{Rate coefficient data}

\begin{tabular}{lllc}
\hline$k / \mathrm{cm}^{3}$ molecule ${ }^{-1} \mathrm{~s}^{-1}$ & Temp./K & Reference & Technique/Comments \\
\hline $\begin{array}{l}\text { Absolute Rate Coefficients } \\
\leq 2.0 \times 10^{-15}\end{array}$ & 298 & Kurylo and Knable, 1984 & FP-RF \\
$3.46 \times 10^{-11} \exp [-(2785 \pm 115) / T]$ & $478-723$ & Poulet et al., 1984 & DF-MS (a) \\
$(8.89 \pm 1.24) \times 10^{-15}$ & 295 & & \\
$(1.24 \pm 0.20) \times 10^{-14}$ & 296 & Tyndall et al., 1996 & PLP-RF \\
& & & \\
Relative Rate Coefficients & & & RR (b) \\
$7.2 \times 10^{-12} \exp (-2200 / T)$ & $370-413$ & Olbregts et al., 1984 & RR (c) \\
$1.7 \times 10^{-11} \exp [-(2140 \pm 200) / T]$ & $274-345$ & Tyndall et al., 1996 & \\
$(1.22 \pm 0.15) \times 10^{-14}$ & 296 & & \\
\hline
\end{tabular}

\section{Comments}

(a) Data were obtained over the range $295 \mathrm{~K}$ to $723 \mathrm{~K}$, and a curved Arrhenius plot was observed.

(b) Relative formation rates of products were monitored in a competitive chlorination system between $\mathrm{CH}_{3} \mathrm{CN}$ and $\mathrm{CHCl}_{3}$. Placed on an absolute basis by use of $k\left(\mathrm{Cl}+\mathrm{CHCl}_{3}\right)=4.9 \times 10^{-12} \exp (-1240 / T) \mathrm{cm}^{3}$ molecule ${ }^{-1} \mathrm{~s}^{-1}$ (IUPAC, current recommendation).

(c) Relative decay rates of $\mathrm{CH}_{3} \mathrm{CN}$ and the reference gas were monitored by FTIR. For the temperature dependent study the reference compound was $\mathrm{CH}_{4}$. In a completely independent system, relative values at $296 \mathrm{~K}$ were also derived using as the reference compound $\mathrm{CD}_{4}, \mathrm{CF}_{3} \mathrm{CCl}_{2} \mathrm{H}$ or $\mathrm{CH}_{4}$. Based on three independent determinations by both absolute and relative rate methods the authors derived the value $k=(1.15 \pm 0.20) \times 10^{-14} \mathrm{~cm}^{3}$ molecule ${ }^{-1} \mathrm{~s}^{-1}$ at $296 \mathrm{~K}$ and the Arrhenius expression $k=1.6 \times 10^{-11} \exp [-(2140 \pm 200) / T] \mathrm{cm}^{3}$ molecule ${ }^{-1} \mathrm{~s}^{-1}$ over the temperature range $274-345 \mathrm{~K}$.

\section{Preferred Values}

$k=1.2 \times 10^{-14} \mathrm{~cm}^{3}$ molecule ${ }^{-1} \mathrm{~s}^{-1}$ at $298 \mathrm{~K}$.

$k=1.6 \times 10^{-11} \exp (-2140 / T) \mathrm{cm}^{3}$ molecule ${ }^{-1} \mathrm{~s}^{-1}$ over the temperature range $270-350 \mathrm{~K}$.

\section{Reliability}

$\Delta \log k= \pm 0.3$ at $298 \mathrm{~K}$.

$\Delta(E / R)= \pm 300 \mathrm{~K}$.

Comments on Preferred Values

The preferred values are based on the results reported by Tyndall et al. (1996). The results of this study over a wide range of experimental conditions, using both relative and absolute rate methods, are preferred over results of earlier studies by Kurylo and Knable (1984), Poulet et al. (1984) and Olbregts et al. (1984). In the study of Tyndall et al. (1996), the room temperature rate coefficient was found to be independent of pressure over the range $7 \mathrm{mbar}$ to $930 \mathrm{mbar}$ ( 5 Torr to 700 Torr). Analysis of end products in smog-chamber experiments indicate that the reaction proceeds predominantly if not exclusively by $\mathrm{H}$-abstraction (Tyndall et al., 1996, 2001). The atmospheric fate of the resultant $\mathrm{CH}_{2} \mathrm{CN}$ radical is discussed by Tyndall et al. (2001). 


\section{References}

IUPAC: http://www.iupac-kinetic.ch.cam.ac.uk/.

Kurylo, M. J. and Knable, G. L.: J. Phys. Chem., 88, 3305, 1984.

Olbregts, J., Brasseur, G., and Arijs, E.: J. Photochem., 24, 315, 1984.

Poulet, G., Laverdet, G., Jourdain, J. L., and Le Bras, G.: J. Phys. Chem., 88, 6259, 1984.

Tyndall, G. S., Orlando, J. J., Wallington, T. J., Sehested, J., and Nielsen, O. J.: J. Phys. Chem., 100, $660,1996$.

Tyndall, G. S., Orlando, J. J., Wallington, T. J., and Hurley, M. D.: J. Phys. Chem. A, 105, 5380, 2001. 
II.A7.192

$$
\mathrm{Br}+\mathrm{C}_{2} \mathrm{H}_{2}+\mathrm{M} \rightarrow \mathrm{BrC}_{2} \mathrm{H}_{2}+\mathrm{M}
$$

\section{Rate coefficient data}

\begin{tabular}{llll}
\hline$k / \mathrm{cm}^{3}$ molecule ${ }^{-1} \mathrm{~s}^{-1}$ & Temp./K & Reference & Technique/Comments \\
\hline $\begin{array}{l}\text { Absolute Rate Coefficients } \\
(4.0 \pm 0.8) \times 10^{-15}\end{array}$ & $210-393$ & Payne et al., 1986 & \\
& & & FP-RF (a) \\
& & & \\
Relative Rate Coefficients & 295 & Wallington et al., 1989 & RR (b) \\
$(4.5 \pm 0.9) \times 10^{-15}$ & Barnes et al., 1989 & RR (c) \\
$(3.90 \pm 0.16) \times 10^{-14}(1013$ mbar air $)$ & 298 & RR (d) \\
$(4.93 \pm 0.20) \times 10^{-14}(1013$ mbar air) & 298 & & \\
$(3.51 \pm 0.18) \times 10^{-14}(1013$ mbar air $)$ & 313 & & \\
$(2.44 \pm 0.10) \times 10^{-14}(1013$ mbar air $)$ & 333 & & \\
$(1.78 \pm 0.06) \times 10^{-14}(1013$ mbar air $)$ & 353 & & \\
$(3.94 \pm 0.28) \times 10^{-14}(940$ mbar air $)$ & 239 & Ramacher et al., 2001 & \\
$(3.59 \pm 0.25) \times 10^{-14}(940$ mbar air $)$ & 249 & & \\
$(3.72 \pm 0.26) \times 10^{-14}(940$ mbar air $)$ & 261 & & \\
$(3.24 \pm 0.23) \times 10^{-14}(940$ mbar air $)$ & 280 & & \\
$(2.55 \pm 0.18) \times 10^{-14}(940$ mbar air $)$ & 296 & & \\
\hline
\end{tabular}

\section{Comments}

(a) Flash photolysis of $\mathrm{CH}_{3} \mathrm{Br}(\lambda>195 \mathrm{~nm})$ as $\mathrm{Br}$ source. Rate coefficient was independent of pressure between 20 and 133 mbar Ar.

(b) $\mathrm{CW}$ photolysis of $\mathrm{Br}_{2}$ in the presence of $\mathrm{C}_{2} \mathrm{H}_{2}$ in 986 mbar (740 Torr) $\mathrm{N}_{2}$ and 2-methylpropane as reference reactant. Depletion of reactants followed by $\mathrm{GC}$ to derive $k\left(\mathrm{Br}+\mathrm{C}_{2} \mathrm{H}_{2}\right) / k(\mathrm{Br}+2$-methylpropane $)=2.96 \pm 0.11$. The rate coefficient was placed on an absolute basis using $k\left(\mathrm{Br}+2\right.$-methylpropane) $=1.52 \times 10^{-15} \mathrm{~cm}^{3}$ molecule ${ }^{-1} \mathrm{~s}^{-1}$ at $295 \mathrm{~K}$ (Russell et al., 1988).

(c) $\mathrm{CW}$ photolysis of $\mathrm{Br}_{2}(300-500 \mathrm{~nm})$ in the presence of $\mathrm{C}_{2} \mathrm{H}_{2}$ in 33-1013 mbar (25-760 Torr) $\mathrm{N}_{2} / \mathrm{O}_{2}$ bath gas and $\mathrm{CH}_{3} \mathrm{CHO}$ as reference reactant. At $298 \mathrm{~K}$ and a total pressure of 760 Torr air, $k\left(\mathrm{Br}+\mathrm{C}_{2} \mathrm{H}_{2}\right) / k\left(\mathrm{Br}+\mathrm{CH}_{3} \mathrm{CHO}\right)=(1.0 \pm 0.04) \times 10^{-2}$. Rate coefficient put on an absolute basis using $k\left(\mathrm{Br}+\mathrm{CH}_{3} \mathrm{CHO}\right)=3.9 \times 10^{-12} \mathrm{~cm}^{3}$ molecule $\mathrm{s}^{-1} \mathrm{~s}^{-1}$ (IUPAC, this evaluation).

(d) As (c) but using 2,2,4-trimethylpentane (TMP) as reference compound. Data put on absolute basis using $k(\mathrm{Br}+\mathrm{TMP})=(4.16 \pm 0.33) \times 10^{-12} \exp (-1820 / T)$ (Barnes et al., 1989), which itself was measured relative to $k(\mathrm{Br}+2-$ methylpropane) $=1.83 \times 10^{-10} \exp (-3452 / T) \mathrm{cm}^{3}$ molecule ${ }^{-1} \mathrm{~s}^{-1}$ (Russell et al., 1988).

(e) Photolysis of $\mathrm{Br}_{2}(\lambda>420 \mathrm{~nm})$ in presence of $\mathrm{C}_{2} \mathrm{H}_{2}$ in $933-946 \mathrm{mbar}$ (700-710 Torr) air, and $\mathrm{C}_{2} \mathrm{H}_{4}$ as reference reactant. Depletion of reactants followed by FTIR absorption spectroscopy. $k\left(\mathrm{Br}+\mathrm{C}_{2} \mathrm{H}_{2}\right) / \mathrm{k}\left(\mathrm{Br}+\mathrm{C}_{2} \mathrm{H}_{4}\right)=(6.9 \pm 0.5) \times 10^{-2}$ at $239 \mathrm{~K}$, $(7.9 \pm 0.5) \times 10^{-2}$ at $249 \mathrm{~K},(9.6 \pm 0.7) \times 10^{-2}$ at $261 \mathrm{~K},(13.5 \pm 0.9) \times 10^{-2}$ at $280 \mathrm{~K}$ and $(19.3 \pm 1.4) \times 10^{-2}$ at $296 \mathrm{~K}$. Rate coefficients placed on an absolute basis using $k\left(\mathrm{Br}+\mathrm{C}_{2} \mathrm{H}_{4}\right)=5.71 \times 10^{-13}, 4.54 \times 10^{-13}, 3.87 \times 10^{-13}, 2.40 \times 10^{-13}$ and $1.32 \times 10^{-13} \mathrm{~cm}^{3}$ molecule ${ }^{-1} \mathrm{~s}^{-1}$ at $239 \mathrm{~K}, 249 \mathrm{~K}, 261 \mathrm{~K}, 280 \mathrm{~K}$ and $296 \mathrm{~K}$, respectively (see $\mathrm{Br}+\mathrm{C}_{2} \mathrm{H}_{4}$ data sheet). The reference value for $k\left(\mathrm{Br}_{+} \mathrm{C}_{2} \mathrm{H}_{4}\right)$ at $261 \mathrm{~K}$ is the average of the values obtained using $\mathrm{HCHO}$ and $\mathrm{CH}_{3} \mathrm{CHO}$ as reference reactants.

\section{Preferred Values}

$k=2.6 \times 10^{-14} \mathrm{~cm}^{3}$ molecule ${ }^{-1} \mathrm{~s}^{-1}$ at $298 \mathrm{~K}$ and 1 bar air.

$k=6.35 \times 10^{-15} \exp (440 / T) \mathrm{cm}^{3}$ molecule ${ }^{-1} \mathrm{~s}^{-1}$ (for $\sim 1$ bar air) over the temperature range 230-300 K. 


\section{Reliability}

$\Delta \log k= \pm 0.2$ at $298 \mathrm{~K}$.

$\Delta(E / R)= \pm 200 \mathrm{~K}$.

\section{Comments on Preferred Values}

The measured rate coefficients reveal a strong dependence on total pressure (Barnes et al., 1989), temperature (Barnes et al., 1989, Ramacher et al., 2001) and the $\mathrm{O}_{2}$ partial pressure (Barnes et al., 1989). This has been taken to indicate (Barnes et al., 1989) that the mechanism involves formation of a $\mathrm{Br}-\mathrm{C}_{2} \mathrm{H}_{2}$ adduct, which can dissociate to reactants or react with $\mathrm{O}_{2}$ to form a peroxy radical. For this reason, the effective rate coefficient is significantly higher in air than in an oxygen free bath gas at total pressures of up to an atmosphere. There is insufficient data to describe the temperature, pressure and $\left[\mathrm{O}_{2}\right]$ dependencies of the rate coefficient, and our recommendation is restricted to air as bath gas, and pressures close to 1 bar. The data presented by Ramacher et al. (2001) using $\mathrm{C}_{2} \mathrm{H}_{4}$ as reference reactant is preferred over measurements relative to 2,2,4-trimethylpentane for reasons discussed by these authors, and form the basis of our recommendation. The temperature dependence of the rate coefficient was derived by least squares fitting of the data listed. Further studies of the rate coefficient in air at low pressures and temperatures would be useful to aid modelling of the role of this reaction at high altitudes.

The formation of stable products when the reaction is initiated in air (in absence of $\mathrm{NO}_{\mathrm{x}}$ ) appears to be independent of temperature (Ramacher et al., 2001) and involves bimolecular reactions of the initially formed $\mathrm{CHBr}=\mathrm{CH}$ radical with $\mathrm{O}_{2}$ to form $\mathrm{CO}, \mathrm{HC}(\mathrm{O}) \mathrm{OH}, \mathrm{HC}(\mathrm{O}) \mathrm{Br}$ and $\mathrm{CO}_{2}$ (for details see Barnes et al., 1989; Ramacher et al., 2001; Yarwood et al., 1991)

\section{References}

Barnes, I., Bastian, V., Becker, K. H., Overath, R., and Tong, Z.: Int. J. Chem. Kinet., 21, 499, 1989.

Payne, W. A., Nava, D. F., Brunning, J., and Stief, L. J.: J. Geophys. Res., 91, 4097, 1986.

Ramacher, B., Orlando, J. J., and Tyndall, G. S.: Int. J. Chem. Kinet., 33, 198, 2001.

Russell, J. J., Seetula, J. A., Timonen, R. A., Gutman, D., and Nava, D. F.: J. Am. Chem. Soc., 110, 3084, 1988.

Wallington, T. J., Skewes, L. M., Siegl, W. O., and Japar, S. M.: Int. J. Chem. Kinet., 21, 1069, 1989.

Yarwood, G., Peng, N., and Niki, H.: J. Phys. Chem., 95, 7330, 1991. 
II.A7.193

$$
\mathrm{Br}+\mathrm{C}_{2} \mathrm{H}_{4}+\mathrm{M} \rightarrow \mathrm{BrC}_{2} \mathbf{H}_{4}+\mathbf{M}
$$

$\Delta H=-28 \mathrm{~kJ} \cdot \mathrm{mol}^{-1}$ (Bedjanian et al., 1999)

\section{Rate coefficient data}

\begin{tabular}{|c|c|c|c|}
\hline$k / \mathrm{cm}^{3}$ molecule $^{-1} \mathrm{~s}^{-1}$ & Temp./K & Reference & Technique/Comments \\
\hline \multicolumn{4}{|l|}{ Absolute Rate Coefficients } \\
\hline $3.0 \times 10^{-33} \exp [(730 \pm 220) / T][\mathrm{He}]$ & $233-320$ & Bedjanian et al., 1999 & DF-MS (a) \\
\hline$(1.2 \pm 0.3) \times 10^{-15}(1.3 \mathrm{mbar} \mathrm{He})$ & 298 & & \\
\hline \multicolumn{4}{|l|}{ Relative Rate Coefficients } \\
\hline$<2.5 \times 10^{-13}$ & 295 & Wallington et al., 1989 & RR (b) \\
\hline $1.69 \times 10^{-13}(1013$ mbar air $)$ & 298 & Barnes et al., 1989 & $\mathrm{RR}(\mathrm{c})$ \\
\hline$(1.24 \pm 0.44) \times 10^{-14}(67$ mbar air $)$ & 298 & & $\mathrm{RR}(\mathrm{d})$ \\
\hline$(1.29 \pm 0.04) \times 10^{-13}(1013 \mathrm{mbar}$ air $)$ & 313 & & \\
\hline$(6.72 \pm 0.45) \times 10^{-14}(1013$ mbar air $)$ & 333 & & \\
\hline$(2.51 \pm 0.17) \times 10^{-14}(1013 \mathrm{mbar}$ air $)$ & 353 & & \\
\hline$(1.32 \pm 0.11) \times 10^{-13}(933$ mbar air $)$ & 296 & Yarwood et al., 1992 & $\mathrm{RR}(\mathrm{e})$ \\
\hline$(4.06 \pm 0.36) \times 10^{-13}(933 \mathrm{mbar}$ air $)$ & 261 & Ramacher et al., 2001 & $\mathrm{RR}(\mathrm{f})$ \\
\hline$(2.40 \pm 0.36) \times 10^{-13}(933$ mbar air $)$ & 280 & & \\
\hline$(1.22 \pm 0.18) \times 10^{-13}(933$ mbar air $)$ & 296 & & \\
\hline$(6.62 \pm 0.46) \times 10^{-13}(933 \mathrm{mbar}$ air $)$ & 228 & Ramacher et al., 2001 & RR (g) \\
\hline$(5.71 \pm 0.40) \times 10^{-13}(933$ mbar air $)$ & 239 & & \\
\hline$(4.54 \pm 0.32) \times 10^{-13}(933$ mbar air $)$ & 249 & & \\
\hline$(3.68 \pm 0.26) \times 10^{-13}(933$ mbar air $)$ & 261 & & \\
\hline
\end{tabular}

\section{Comments}

(a) Experiments conducted at pressures of 0.7-2.7 mbar (0.5-2 Torr) He. Rate coefficient cited is at the low pressure limit, $k=k_{0}$. $\mathrm{Br}$ was detected as $\mathrm{BrCl}$ after titration with $\mathrm{NOCl}$, and $\mathrm{Br}_{2}$ was added to partly convert the $\mathrm{BrC}_{2} \mathrm{H}_{4}$ radical to $\mathrm{BrC}_{2} \mathrm{H}_{4} \mathrm{Br}$, which was also detected. The kinetics of the title reaction were derived from fitting to an analytical expression that took loss of $\mathrm{BrC}_{2} \mathrm{H}_{4}$ by reaction with both $\mathrm{Br}_{2}$ and $\mathrm{Br}$ into account.

(b) $\mathrm{CW}$ photolysis of $\mathrm{Br}_{2}$ in the presence of $\mathrm{C}_{2} \mathrm{H}_{4}$ in 986 mbar (740 Torr) air and $\mathrm{CH}_{3} \mathrm{CHO}$ as reference reactant. The depletion of reactants was followed by $\mathrm{GC}$ to derive $k\left(\mathrm{Br}+\mathrm{C}_{2} \mathrm{H}_{4}\right) / k\left(\mathrm{Br}+\mathrm{CH}_{3} \mathrm{CHO}\right)<0.067$. An absolute upper limit was calculated using $k\left(\mathrm{Br}+\mathrm{CH}_{3} \mathrm{CHO}\right)=3.8 \times 10^{-12} \mathrm{~cm}^{3}$ molecule $\mathrm{e}^{-1} \mathrm{~s}^{-1}$ at $295 \mathrm{~K}$ (IUPAC, this evaluation).

(c) $\mathrm{CW}$ photolysis of $\mathrm{Br}_{2}(300-500 \mathrm{~nm})$ in the presence of $\mathrm{C}_{2} \mathrm{H}_{4}$ in 1013 mbar (760 Torr) $\mathrm{N}_{2}+\mathrm{O}_{2}$ bath gas and $\mathrm{CH}_{3} \mathrm{CHO}$ as reference compound. Depletion of reactants monitored by GC. The tabulated rate coefficient in air was obtained by extrapolation of data obtained with $\mathrm{O}_{2}$ partial pressures between 6.7 and $133 \mathrm{mbar}$ (5 to 100 Torr) to $210 \mathrm{mbar} \mathrm{O}_{2}$, and put on absolute basis using $k\left(\mathrm{Br}+\mathrm{CH}_{3} \mathrm{CHO}\right)=3.9 \times 10^{-12} \mathrm{~cm}^{3}$ molecule $\mathrm{e}^{-1} \mathrm{~s}^{-1}$ (IUPAC, this evaluation).

(d) CW photolysis of $\mathrm{Br}_{2}(300-500 \mathrm{~nm})$ in the presence of $\mathrm{C}_{2} \mathrm{H}_{4}$ in 33-1013 mbar (25-760 Torr) $\mathrm{N}_{2}+\mathrm{O}_{2}$ bath gas and 2,2,4trimethylpenane (TMP) as reference compound. Depletion of reactants monitored by GC or FTIR spectroscopy. Data put on absolute basis using $k(\mathrm{Br}+\mathrm{TMP})=(4.16 \pm 0.33) \times 10^{-12} \exp (-1820 / T) \mathrm{cm}^{3}$ molecule ${ }^{-1} \mathrm{~s}^{-1}$ (Barnes et al., 1989), which in turn was measured relative to $k(\mathrm{Br}+2$-methylpropane $)=1.83 \times 10^{-10} \exp (-3452 / T) \mathrm{cm}^{3}$ molecule $\mathrm{e}^{-1} \mathrm{~s}^{-1}$ (Bierbach et al., 1996).

(e) $\mathrm{CW}$ photolysis $(\lambda>400 \mathrm{~nm})$ of $\mathrm{Br}_{2}$ in presence of $\mathrm{C}_{2} \mathrm{H}_{4}$ and $\mathrm{HCHO}$ (reference reactant) in $933 \mathrm{mbar}$ (700 Torr) air or $\mathrm{N}_{2}+\mathrm{O}_{2}$ bath gas. The depletion of reactants was monitored by FTIR spectroscopy. A rate coefficient ratio of $k\left(\mathrm{Br}+\mathrm{C}_{2} \mathrm{H}_{4}\right) / k(\mathrm{Br}+\mathrm{HCHO})=0.12 \pm 0.01$ was determined for $296 \mathrm{~K}$ and 933 mbar (700 Torr) air, and $k\left(\mathrm{Br}+\mathrm{C}_{2} \mathrm{H}_{4}\right)$ was converted to an absolute value by use of $k(\mathrm{Br}+\mathrm{HCHO})=1.1 \times 10^{-12} \mathrm{~cm}^{3}$ molecule ${ }^{-1} \mathrm{~s}^{-1}$ (IUPAC, this evaluation). 
(f) $\mathrm{CW}$ photolysis $(\lambda>420 \mathrm{~nm})$ of $\mathrm{Br}_{2}$ in the presence of $\mathrm{C}_{2} \mathrm{H}_{4}$ and $\mathrm{HCHO}$ as reference reactant at total pressures of $933-946$ (700-710 Torr) air. Depletion of reactants was monitored by FTIR spectroscopy. The following rate coefficient ratios were obtained: $k\left(\mathrm{Br}+\mathrm{C}_{2} \mathrm{H}_{4}\right) / k(\mathrm{Br}+\mathrm{HCHO})=0.487 \pm 0.073$ at $261 \mathrm{~K}, 0.247 \pm 0.037$ at $280 \mathrm{~K}$ and $0.112 \pm 0.017$ at $296 \mathrm{~K}$. The tabulated absolute rate coefficients were derived using $k(\mathrm{Br}+\mathrm{HCHO})=7.7 \times 10^{-12} \exp (-580 / T) \mathrm{cm}^{3} \mathrm{molecule}^{-1} \mathrm{~s}^{-1}$ (IUPAC, this evaluation).

(g) As (f) but using $\mathrm{CH}_{3} \mathrm{CHO}$ as reference reactant. The following rate coefficient ratios were obtained: $k\left(\mathrm{Br}+\mathrm{C}_{2} \mathrm{H}_{4}\right) / k\left(\mathrm{Br}+\mathrm{CH}_{3} \mathrm{CHO}\right)=0.277 \pm 0.019$ at $228 \mathrm{~K}, 0.217 \pm 0.015$ at $239 \mathrm{~K}, 0.160 \pm 0.011$ at $249 \mathrm{~K}$, and $0.119 \pm 0.008$ at $261 \mathrm{~K}$. The absolute rate coefficients listed in the table were derived using $k\left(\mathrm{Br}+\mathrm{CH}_{3} \mathrm{CHO}\right)=1.8 \times 10^{-11} \exp (-460 / T) \mathrm{cm}^{3}$ molecule ${ }^{-1} \mathrm{~s}^{-1}$ (IUPAC, this evaluation).

\section{Preferred Values}

$k=1.3 \times 10^{-13} \mathrm{~cm}^{3}$ molecule $\mathrm{e}^{-1} \mathrm{~s}^{-1}$ at $296 \mathrm{~K}$ and 1 bar air.

$k=2.80 \times 10^{-13} \exp (224 / T) \times B /\left[B+8.5 \times 10^{12} \exp (-3200 / T)\right] \mathrm{cm}^{3}$ molecule ${ }^{-1} \mathrm{~s}^{-1}$ where $B=7.5 \times 10^{-12}\left[\mathrm{O}_{2}\right] \mathrm{s}^{-1}$ and $\left[\mathrm{O}_{2}\right]$ is in molecules $\mathrm{cm}^{-3}$. The temperature range is $240-300 \mathrm{~K}$.

\section{Reliability}

$\Delta \log k= \pm 0.15$ at $298 \mathrm{~K}$ and 1 bar air.

\section{Comments on Preferred Values}

The measured rate coefficients reveal a strong dependence on total pressure (Barnes et al., 1989), temperature (Barnes et al., 1989; Ramacher et al., 2001) and the $\mathrm{O}_{2}$ partial pressure (Barnes et al., 1989). This has been taken to indicate that the mechanism involves formation of a $\mathrm{Br}_{-} \mathrm{C}_{2} \mathrm{H}_{4}$ adduct, which can dissociate to reactants or react with $\mathrm{O}_{2}$ to form a peroxy radical. For this reason, the effective rate coefficient is significantly higher in air than in an oxyen free bath gas at total pressures of up to an atmosphere. The $298 \mathrm{~K}$ recommendation is based on the average of the results of Yarwood et al. (1992) and Ramacher et al. (2001) which were both obtained relative to HCHO and which are in excellent agreement. As noted by both Barnes et al. (1989) and Ramacher et al. (2001) there is an inconsistency between the data sets of Barnes et al. (1989) obtained using $\mathrm{CH}_{3} \mathrm{CHO}$ and 2,2,4-trimethylpentane/2-methylpropane as reference reactants, and the higher value of $k(298 \mathrm{~K})=1.69 \times 10^{-13} \mathrm{~cm}^{3}$ molecule $\mathrm{e}^{-1} \mathrm{~s}^{-1}$ obtained in that study is considered less reliable. The data of Ramacher et al. (2001) listed in the Table above, which yield consistent results with $\mathrm{HCHO}$ and $\mathrm{CH}_{3} \mathrm{CHO}$ as reference compounds and also using $\mathrm{C}_{2} \mathrm{HCl}_{3}$ as secondary standard, are used to derive the temperature dependence of the rate coefficient in one atmosphere air bath gas. The expression given describes the temperature dependence of the effective rate coefficient in one atmosphere of air, and constrains the difference in the activation energies of the forward and reverse processes of adduct formation and dissociation according to Bedjanian et al. (1999) and assumes a temperature independent value of $7.5 \times 10^{-12} \mathrm{~cm}^{3} \mathrm{molecule}^{-1}$ $\mathrm{s}^{-1}$ for the rate coefficient for the reaction of the $\mathrm{Br}-\mathrm{C}_{2} \mathrm{H}_{4}$ adduct with $\mathrm{O}_{2}$ at one atmosphere. Further details are given by Ramacher et al. (2001). Note that extrapolation to conditions very different from one atmosphere pressure air could lead to large errors, and is not recommended. Further studies of the rate coefficient in air at low pressures and temperatures would be useful to aid modelling of the role of this reaction at high altitudes.

Identification of brominated aldehydes, alcohols and acids in product studies provides evidence for the formation and subsequent reaction of the $\mathrm{BrC}_{2} \mathrm{H}_{4} \mathrm{O}_{2}$ peroxy radical in air (Barnes et al., 1989; Yarwood et al., 1992).

\section{References}

Barnes, I., Bastian, V., Becker, K. H., Overath, R., and Tong, Z.: Int. J. Chem. Kinet., 21, 499, 1989.

Bedjanian, Y., Poulet, G., and Le Bras, G.: J. Phys. Chem. A., 103, 4026, 1999.

Bierbach, A., Barnes, I., and Becker, K. H.: Int. J. Chem. Kinet., 28, 565, 1996.

Ramacher, B., Orlando, J. J., and Tyndall, G. S.: Int. J. Chem. Kinet., 33, 198, 2001.

Wallington, T. J., Skewes, L. M., Siegl, W. O., and Japar, S. M.: Int. J. Chem. Kinet., 21, 1069, 1989.

Yarwood, G., Peng, N., and Niki, H.: Int. J. Chem. Kinet., 24, 369, 1992. 
II.A7.194

$$
\begin{array}{ll}
\mathbf{B r}+\mathrm{C}_{3} \mathbf{H}_{6} & \rightarrow \mathrm{HBr}+\mathrm{C}_{3} \mathrm{H}_{5} \\
\mathrm{Br}+\mathrm{C}_{3} \mathbf{H}_{6}+\mathrm{M} & \rightarrow \mathrm{BrC}_{3} \mathrm{H}_{6}+\mathrm{M}
\end{array}
$$

$\Delta H(1)=-2.9 \mathrm{~kJ} \cdot \mathrm{mol}^{-1}$ (Bedjanian et al., 1998)

$\Delta H(2)=-32.2 \mathrm{~kJ} \cdot \mathrm{mol}^{-1}$ (Bedjanian et al., 1998)

Rate coefficient data $\left(k=k_{1}+k_{2}\right)$

\begin{tabular}{lllc}
\hline$k / \mathrm{cm}^{3}$ molecule ${ }^{-1} \mathrm{~s}^{-1}$ & Temp./K & Reference & Technique/Comments \\
\hline $\begin{array}{l}\text { Absolute Rate Coefficients } \\
k_{1}=8.3 \times 10^{-12} \exp [-(2200 \pm 300 / T)]\end{array}$ & $263-363$ & Kondo et al., 1988 & F-MS (a) \\
$k_{1}=8.15 \times 10^{-13} \exp [-(1250 \pm 160 / T)]$ & $233-320$ & Bedjanian et al., 1998 & DF-MS (b) \\
$k_{1}=1.2 \times 10^{-14}$ & 298 & & \\
$k_{2}=3.8 \times 10^{-33} \exp [(1200 \pm 50) / T][\mathrm{He}]$ & $233-320$ & & \\
& & & \\
Relative Rate Coefficients & 295 & Wallington et al., 1989 & RR (c) \\
$(4.2 \pm 0.5) \times 10^{-12}$ & 298 & Barnes et al., 1989 & RR (d) \\
$(2.9 \pm 0.3) \times 10^{-12}$ & & & \\
\hline
\end{tabular}

\section{Comments}

(a) Very low pressure reactor at $\approx 1 \times 10^{-3}$ mbar with bromine atoms detected directly using a mass spectrometer. The Arrhenius expression was derived from a calculated pre-exponential factor associated with a bent transition state, combined with the most reliable rate coefficient, which was that obtained at $363 \mathrm{~K}$.

(b) Experiments conducted at pressures of 0.7-2.7 mbar (0.5-2 Torr) $\mathrm{He}$. Br was detected as $\mathrm{BrCl}$ after titration with $\mathrm{NOCl}$. Consistent kinetic data for $k_{1}$ was derived by monitoring either $\mathrm{Br}, \mathrm{HBr}$ or $\mathrm{C}_{3} \mathrm{H}_{5} \mathrm{Br}$ (formed in $\mathrm{C}_{3} \mathrm{H}_{5}+\mathrm{Br}$ ). For determination of $k_{2}, \mathrm{Br}_{2}$ was added to partly convert the $\mathrm{BrC}_{3} \mathrm{H}_{6}$ radical to $\mathrm{BrC}_{3} \mathrm{H}_{6} \mathrm{Br}$, which could be detected, and to regenerate Br. Values of $k_{2}$ at pressures of 0.7 to $2.7 \mathrm{mbar}(0.5$ to $2 \mathrm{Torr}) \mathrm{He}$ and 233 to $308 \mathrm{~K}$ were then derived by fitting to an analytical expression assuming a steady state for $\mathrm{Br}$. An approximately linear dependence on He pressure was observed indicating that the derived values of $k_{2}$ are close to the low-pressure limit.

(c) $\mathrm{CW}$ photolysis of $\mathrm{Br}_{2}$ in the presence of $\mathrm{C}_{3} \mathrm{H}_{6}$ in 986 mbar (740 Torr) air and $\mathrm{CH}_{3} \mathrm{CHO}$ as reference reactant. The depletion of reactants was followed by $\mathrm{GC}$ to derive $k\left(\mathrm{Br}+\mathrm{C}_{3} \mathrm{H}_{6}\right) / k\left(\mathrm{Br}+\mathrm{CH}_{3} \mathrm{CHO}\right)=1.10 \pm 0.12$. An absolute rate coefficient was calculated using $k\left(\mathrm{Br}+\mathrm{CH}_{3} \mathrm{CHO}\right)=3.8 \times 10^{-12} \mathrm{~cm}^{3}$ molecule ${ }^{-1} \mathrm{~s}^{-1}$ at $295 \mathrm{~K}$ (IUPAC, this evaluation).

(d) $\mathrm{CW}$ photolysis of $\mathrm{Br}_{2}(300-500 \mathrm{~nm})$ in the presence of $\mathrm{C}_{3} \mathrm{H}_{6}$ in 1013 mbar $(760$ Torr $) \mathrm{N}_{2}+\mathrm{O}_{2}$ bath gas and $\mathrm{CH}_{3} \mathrm{CHO}$ as reference compound. Depletion of reactants monitored by FTIR to derive $k\left(\mathrm{Br}+\mathrm{C}_{3} \mathrm{H}_{6}\right) / k\left(\mathrm{Br}+\mathrm{CH} \mathrm{CHO}_{3} \mathrm{CHO}=0.75 \pm 0.07\right.$. An absolute rate coefficient was calculated using $k\left(\mathrm{Br}+\mathrm{CH}_{3} \mathrm{CHO}\right)=3.9 \times 10^{-12} \mathrm{~cm}^{3}$ molecule $^{-1} \mathrm{~s}^{-1}$ at $298 \mathrm{~K}$ (IUPAC, this evaluation).

\section{Preferred Values}

$k_{1}=1.2 \times 10^{-14} \mathrm{~cm}^{3}$ molecule $\mathrm{s}^{-1}$ at $298 \mathrm{~K}$.

$k_{1}=8.1 \times 10^{-13} \exp (-1250 / T) \mathrm{cm}^{3}$ molecule $\mathrm{e}^{-1} \mathrm{~s}^{-1}$ over the temperature range $230-320 \mathrm{~K}$.

$k=3.6 \times 10^{-12} \mathrm{~cm}^{3}$ molecule $\mathrm{s}^{-1} \mathrm{~s}^{-1}$ at $298 \mathrm{~K}$ and $1 \mathrm{bar}$ air.

\section{Reliability}

$\Delta \log k_{1}= \pm 0.2$ at $298 \mathrm{~K}$.

$\Delta\left(E_{1} / R\right)= \pm 500 \mathrm{~K}$.

$\Delta \log k= \pm 0.2$ at $298 \mathrm{~K}$ and 1 bar air. 


\section{Comments on Preferred Values}

The reaction proceeds via both direct abstraction $\left(k_{1}\right)$ and via a termolecular channel $\left(k_{2}\right)$ involving formation of a $\mathrm{BrC}_{3} \mathrm{H}_{6}$ adduct that can redissociate to products or react with $\mathrm{O}_{2}$. The effective overall rate coefficient therefore displays a dependence on temperature, total pressure and the oxygen partial pressure (Barnes et al., 1989). The study of Bedjanian et al. (1998) is considered the more reliable measurement of $k_{1}$ as the work of Kondo et al. (1988) may have been influenced by the presence of excited states of $\mathrm{Br}$. The recommended value for $k_{1}$ is therefore based on the work of Bedjanian et al. (1998), with expanded error limits.

In the absence of kinetic data for $k_{2}$ in the fall off regime it is not possible to derive a parameterisation of the rate coefficient for all atmospheric conditions. Instead, for the overall rate coefficient, we recommend an average of the results of the relative rate studies (Wallington et al., 1989; Barnes et al., 1989) at $298 \mathrm{~K}$ and note that the branching ratio to $k_{1}$ (i.e. to $\mathrm{HBr}$ formation) under atmospheric conditions is given by $k_{1} / k$. Pressure and temperature dependent studies in the fall-off regime are needed to model this reaction at high altitudes in the atmosphere where the pressure and temperature are lower. The structure of the radical product of the abstraction channel (1) is believed to be $\mathrm{CH}_{2}=\mathrm{CHCH}_{2}$ indicating that abstraction from the $\mathrm{CH}_{3}$ group is most important (Kondo et al., 1988).

\section{References}

Barnes, I., Bastian, V., Becker, K. H., Overath, R., and Tong, Z.: Int. J. Chem. Kinet., 21, 499, 1989.

Bedjanian, Y., Poulet, G., and Le Bras, G.: J. Phys. Chem. A., 102, 5867, 1998.

Kondo, O., Marshall, R. M., and Benson, S. W.: Int. J. Chem. Kinet., 20, 297, 1988.

Wallington, T. J., Skewes, L. M., Siegl, W. O., and Japar, S. M.: Int. J. Chem. Kinet., 21, 1069, 1989. 
II.A7.195

$$
\mathrm{Br}+\mathrm{HCHO} \rightarrow \mathrm{HBr}+\mathrm{HCO}
$$

$\Delta H^{\circ}=3.5 \mathrm{~kJ} \cdot \mathrm{mol}^{-1}$

\section{Rate coefficient data}

\begin{tabular}{lllc}
\hline$k / \mathrm{cm}^{3}$ molecule ${ }^{-1} \mathrm{~s}^{-1}$ & Temp./K & Reference & Technique/Comments \\
\hline Absolute Rate Coefficients & & & \\
$1.44 \times 10^{-11} \exp [-(750 \pm 112) / T]$ & $223-480$ & Nava et al., 1981 & FP-RF (a) \\
$(1.08 \pm 0.10) \times 10^{-12}$ & 298 & & \\
$2.97 \times 10^{-11} \exp [-(1015 \pm 70) / T]$ & $295-480$ & Poulet et al., 1981 & DF-MS \\
$(9.4 \pm 0.8) \times 10^{-13}$ & 295 & & \\
& & & \\
Relative Rate Coefficients & & & RR(b) \\
$5.0 \times 10^{-12} \exp [-(460 \pm 200) / T]$ & $250-296$ & Ramacher et al., 2000 & \\
$1.08 \times 10^{-12}$ & 296 & & \\
\hline
\end{tabular}

\section{Comments}

(a) There appears to be curvature in the Arrhenius plot above room temperature; using the low-temperature values at 223 , 254, and $298 \mathrm{~K}$ gives $E / R=584 \mathrm{~K}$.

(b) $\mathrm{Br}$ atoms were generated by photolysis of $\mathrm{Br}_{2}$ in the presence of $\mathrm{HCHO}$ and $\mathrm{CH}_{3} \mathrm{CHO}$ in 1 bar $\mathrm{N}_{2}$. Relative rates of decay of the two aldehydes were determined by an FTIR spectrometer system. The relative rates of decay were found to be independent of temperature over the range $250-296 \mathrm{~K}$ with the value $k\left(\mathrm{Br}+\mathrm{CH}_{3} \mathrm{CHO}\right) / k(\mathrm{Br}+\mathrm{HCHO})=3.60 \pm 0.29$. This temperature-independent rate coefficient ratio is placed on an absolute basis by the use of $k\left(\mathrm{Br}+\mathrm{CH}_{3} \mathrm{CHO}\right)=1.8 \times 10^{-11}$ $\exp [-(460) / T] \mathrm{cm}^{3}$ molecule ${ }^{-1} \mathrm{~s}^{-1}$ (this evaluation)

\section{Preferred Values}

$k=1.1 \times 10^{-12} \mathrm{~cm}^{3}$ molecule ${ }^{-1} \mathrm{~s}^{-1}$ at $298 \mathrm{~K}$.

$k=7.7 \times 10^{-12} \exp (-580 / T) \mathrm{cm}^{3}$ molecule $\mathrm{s}^{-1} \mathrm{~s}^{-1}$ over the temperature range $220-300 \mathrm{~K}$.

\section{Reliability}

$\Delta \log k= \pm 0.15$ at $298 \mathrm{~K}$.

$\Delta(E / R)= \pm 200 \mathrm{~K}$.

\section{Comments on Preferred Values}

In the derivation of the preferred rate expression only data at and below room temperature were used. The room temperature value is the average of the absolute rate coefficients reported by Nava et al. (1981) and Poulet et al. (1981), and is in excellent agreement with the derived value given in Ramacher et al. (2000). The temperature dependence is derived from the low temperature results of Nava et al. (1981) $(E / R=584 \mathrm{~K}$; see comment (a)), which is consistent with the relative rate data of Ramacher et al. (2000), and the A factor adjusted to yield the $298 \mathrm{~K}$ preferred values.

\section{References}

Nava, D. F., Michael, J. V., and Stief, L. J.: J. Phys. Chem., 85, 1896, 1981.

Poulet, G., Laverdet, G., and Le Bras, G.: J. Phys. Chem., 85, 1892, 1981.

Ramacher, B., Orlando, J. J., and Tyndall, G. S.: Int. J. Chem. Kinet., 32, 460, 2000. 
II.A7.196

$$
\mathrm{Br}+\mathrm{CH}_{3} \mathrm{CHO} \rightarrow \mathrm{HBr}+\mathrm{CH}_{3} \mathrm{CO}
$$

$\Delta H^{\circ}=7.6 \mathrm{~kJ} \cdot \mathrm{mol}^{-1}$

\section{Rate coefficient data}

\begin{tabular}{lllc}
\hline$k / \mathrm{cm}^{3}$ molecule ${ }^{-1} \mathrm{~s}^{-1}$ & Temp./K & Reference & Technique/Comments \\
\hline $\begin{array}{l}\text { Absolute Rate Coefficients } \\
(3.5 \pm 0.5) \times 10^{-12}\end{array}$ & 300 & Islam et al., 1984 & (a) \\
$1.51 \times 10^{-11} \exp [-(364 \pm 41) / T]$ & $255-400$ & Nicovich et al., 1990 & LP-RF \\
$4.45 \times 10^{-12}$ & 298 & & \\
$(3.5 \pm 0.3) \times 10^{-12}$ & 298 & Szilagyi et al., 1998 & F-RF \\
Relative Rate Coefficients & & & \\
$(3.7 \pm 0.1) \times 10^{-12}$ & 298 & Niki et al., 1985 & RR (b) \\
$2.6 \times 10^{-11} \exp [-(580 \pm 200) / T]$ & $250-296$ & Ramacher et al., 2000 & RR(c) \\
$4.0 \times 10^{-12}$ & 296 & & \\
\hline
\end{tabular}

\section{Comments}

(a) Very low pressure reactor study. $\mathrm{Br}$ atoms were generated by microwave discharge of $\mathrm{Br}_{2}$ in helium, with mass spectrometric detection of reactants and products.

(b) $\mathrm{Br}$ atoms were generated by photolysis of $\mathrm{Br}_{2}$ at $350 \mathrm{~nm}$ to $600 \mathrm{~nm}$ in $930 \mathrm{mbar}$ (700 Torr) total pressure of $\mathrm{N}_{2}$. The rate coefficient was determined relative to that for the reaction of $\mathrm{Br}$ atoms with $\mathrm{HCHO}$, with $k\left(\mathrm{Br}+\mathrm{CH}_{3} \mathrm{CHO}\right) / k(\mathrm{Br}+\mathrm{HCHO})=3.39 \pm 0.10$. This rate coefficient ratio is placed on an absolute basis by use of ate coefficient of $k(\mathrm{Br}+\mathrm{HCHO})=1.1 \times 10^{-12} \mathrm{~cm}^{3}$ molecule ${ }^{-1} \mathrm{~s}^{-1}$ (IUPAC, this evaluation).

(c) $\mathrm{Br}$ atoms were generated by photolysis of $\mathrm{Br}_{2}$ in the presence of $\mathrm{HCHO}$ and $\mathrm{CH}_{3} \mathrm{CHO}$ in 1 bar $\mathrm{N}_{2}$. Relative rates of decay of the two aldehydes were determined by an FTIR spectrometer system. The relative rates of decay were found to be independent of temperature over the range $250-296 \mathrm{~K}$ with the value $k\left(\mathrm{Br}+\mathrm{CH}_{3} \mathrm{CHO}\right) / k(\mathrm{Br}+\mathrm{HCHO})=3.60 \pm 0.29$. This temperature-independent rate coefficient ratio is placed on an absolute basis by the use of $k(\mathrm{Br}+\mathrm{HCHO})=7.7 \times 10^{-12}$ $\exp (-580 / T) \mathrm{cm}^{3}$ molecule ${ }^{-1} \mathrm{~s}^{-1}$ (this evaluation)

\section{Preferred Values}

$k=3.9 \times 10^{-12} \mathrm{~cm}^{3}$ molecule ${ }^{-1} \mathrm{~s}^{-1}$ at $298 \mathrm{~K}$.

$k=1.8 \times 10^{-11} \exp (-460 / T) \mathrm{cm}^{3}$ molecule ${ }^{-1} \mathrm{~s}^{-1}$ over the temperature range $250-400 \mathrm{~K}$.

\section{Reliability}

$\Delta \log k= \pm 0.2$ at $298 \mathrm{~K}$.

$\Delta E / R= \pm 200 \mathrm{~K}$.

\section{Comments on Preferred Values}

The room temperature value is the average of the rate coefficients reported by Islam et al. (1984), Nicovich et al. (1990), Szilagyi et al. (1998) and Niki et al. (1985), and is in excellent agreement with the relative rate value of Ramacher et al. (2000). The temperature dependence is derived from the results of Nicovich et al. (1990), which is consistent with the relative rate data of Ramacher et al. (2000), and the A factor adjusted to yield the $298 \mathrm{~K}$ preferred value. The preferred room temperature rate coefficient is consistent with the relative rate studies of Barnes et al. (1989) and Wallington et al. (1989) [which do not provide definitive data concerning the rate constant for the reaction of $\mathrm{Br}$ atoms with $\mathrm{CH}_{3} \mathrm{CHO}$ ]. 


\section{References}

Barnes, I., Bastian, V., Becker, K. H., Overath, R., and Tong, Z.: Int. J. Chem. Kinet., 21, 499, 1989.

Islam, T. S. A., Marshall, R. M., and Benson, S. W.: Int. J. Chem. Kinet., 16, 1161, 1984.

Nicovich, J. M., Shackelford, C. J., and Wine, P. H.: J. Photochem. Photobiol. A: Chemistry, 51, $141,1990$.

Niki, H., Maker, P. D., Savage, C. M., and Breitenbach, L. P.: Int. J. Chem. Kinet., 17, 525, 1985.

Ramacher, B., Orlando, J. J., and Tyndall, G. S.: Int. J. Chem. Kinet., 32, 460, 2000.

Szilagyi, I., Imrik, K., Dobe, S., and Berces, T.: Ber. Bunsenges. Phys. Chem., 102, 79, 1998.

Wallington, T. J., Skewes, L. M., Siegl, W. O., and Japar, S. M.: Int. J. Chem. Kinet., 21, 1069, 1989. 
Appendix A8: Organic Photochemistry

II.A8.197

$$
\mathbf{H C H O}+\mathbf{h} v \rightarrow \text { products }
$$

\section{Primary photochemical transitions}

\begin{tabular}{|c|c|c|c|}
\hline Reaction & & $\Delta \mathrm{H}_{298}^{\circ} / \mathrm{kJ} \cdot \mathrm{mol}^{-1}$ & $\lambda_{\text {threshold }} / \mathrm{nm}$ \\
\hline $\mathrm{HCHO}+\mathrm{h} v \rightarrow \mathrm{H}+\mathrm{HCO}$ & (1) & 369.7 & 324 \\
\hline$\rightarrow \mathrm{H}_{2}+\mathrm{CO}$ & (2) & -1.9 & \\
\hline
\end{tabular}

\section{Absorption cross-section data}

\begin{tabular}{llc}
\hline Wavelength range/nm & Reference & Comments \\
\hline $240-360$ & Moortgat and Schneider, 1989 & (a) \\
300-360 & Cantrell et al., 1990 & (b) \\
225-375 & Meller and Moortgat, 2000 & (c) \\
\hline
\end{tabular}

Quantum yield data $\left(\phi=\phi_{1}+\phi_{2}\right)$

\begin{tabular}{lllc}
\hline Measurement & Wavelength range/nm & Reference & Comments \\
\hline$\phi, \phi_{2} / \phi$ & $253-353$ & Moortgat et al., 1983 & (d) \\
$\phi_{1}$ & $269-339$ & Smith et al., 2002 & (e) \\
\hline
\end{tabular}

\section{Comments}

(a) Cross-sections measured at $220 \mathrm{~K}$ and $298 \mathrm{~K}$ at different concentrations of $\mathrm{HCHO}$ and extrapolated to zero concentration. This extrapolation procedure yielded virtually identical cross-sections with and without added $\mathrm{N}_{2}$.

(b) High-resolution FT spectroscopy used to measure cross-sections as a function of temperature (223 to $293 \mathrm{~K}$ ). Values at different concentrations of $\mathrm{HCHO}$ were extrapolated to zero concentration.

(c) Cross-section measurements with resolution of $0.025 \mathrm{~nm}$ at selected temperatures between $223-323 \mathrm{~K}$. HCHO pressure kept below 0.65 mbar to avoid saturation effects. Error limits on $\sigma \pm 5 \%$ and on temperature coefficients $<8 \%$. Results compared in detail with earlier work.

(d) Quantum yields of $\mathrm{CO}$ and $\mathrm{H}_{2}$ were measured as a function of wavelength for $\mathrm{HCHO}$ in low concentration in air. Previous results (Moortgat and Warneck, 1979) showing the pressure and temperature dependences of $\phi_{1}$ and $\phi_{2}$ were confirmed.

(e) The relative quantum yield for the production of radical products, $\mathrm{H}$ and $\mathrm{HCO}$, measured directly using an NO-chemical amplification method, with subsequent detection of $\mathrm{NO}_{2}$ by CIMS. All yields were measured at a pressure of 50 Torr ( $66 \mathrm{mbar}$ ) and were normalized to a quantum yield of $\phi_{2}=0.753$ at $303.75 \mathrm{~nm}$ based on the recommendation of DeMore et al. (2000). The quantum yields were measured with sufficient wavelength resolution $( \pm 0.62 \mathrm{~nm}$, fwhm), to observe structure which had not been previously reported. 


\section{Preferred Values}

\section{Absorption cross-sections at 298 and $223 \mathrm{~K}$ and Temperature Gradients of $\mathrm{HCHO}$ Averaged Over Intervals Used in Atmospheric Modelling}

\begin{tabular}{|c|c|c|c|c|}
\hline Wavelength $\lambda / \mathrm{nm}$ & Wavelength Range, $\lambda / \mathrm{nm}$ & $10^{20} \sigma(298 \mathrm{~K}) \mathrm{cm}^{2}$ & $10^{20} \sigma(223 \mathrm{~K}) \mathrm{cm}^{2}$ & $10^{24} \Gamma \mathrm{cm}^{2} \mathrm{~K}^{-1}$ \\
\hline 226.0 & $224.7-227.3$ & 0.0165 & & \\
\hline 228.6 & $227.3-229.9$ & 0.0181 & & \\
\hline 231.3 & 229.9-232.6 & 0.0302 & & \\
\hline 234.0 & $232.6-235.3$ & 0.0315 & & \\
\hline 236.7 & $235.3-238.1$ & 0.0625 & & \\
\hline 239.6 & $238.1-241.0$ & 0.0705 & & \\
\hline 242.5 & $241.0-243.9$ & 0.1268 & & \\
\hline 245.4 & $243.9-246.9$ & 0.1390 & & \\
\hline 248.5 & $246.9-250.0$ & 0.2537 & & \\
\hline 251.7 & $250.0-253.3$ & 0.2699 & 0.2642 & 0.76 \\
\hline 254.9 & $253.3-256.4$ & 0.4560 & 0.4427 & 1.78 \\
\hline 258.1 & $256.4-259.7$ & 0.4768 & 0.4363 & 5.40 \\
\hline 261.5 & $259.7-263.2$ & 0.7034 & 0.6933 & 1.35 \\
\hline 265.0 & $263.2-266.7$ & 0.7379 & 0.7008 & 4.97 \\
\hline 268.5 & $266.7-270.3$ & 1.1287 & 1.1074 & 2.86 \\
\hline 272.2 & $270.3-274.0$ & 1.2922 & 1.2631 & 3.88 \\
\hline 275.9 & $274.0-277.8$ & 1.8442 & 1.8865 & -5.64 \\
\hline 279.8 & $277.8-281.7$ & 1.8592 & 1.8874 & -3.76 \\
\hline 283.7 & $281.7-285.7$ & 2.5555 & 2.7238 & -22.43 \\
\hline 287.8 & $285.7-289.9$ & 2.3095 & 2.3613 & -6.90 \\
\hline 292.0 & 289.9-294.1 & 2.6653 & 2.9321 & -35.58 \\
\hline 296.3 & $294.1-298.5$ & 3.2939 & 3.2524 & 5.54 \\
\hline 300.8 & $298.5-303.0$ & 1.6046 & 1.5854 & 2.55 \\
\hline 305.4 & $303.0-307.7$ & 4.3944 & 4.4061 & -1.56 \\
\hline 310.1 & $307.7-312.5$ & 1.6318 & 1.6737 & -5.58 \\
\hline 315.0 & $312.5-317.5$ & 4.0853 & 4.0230 & 8.30 \\
\hline 320.0 & $317.5-322.5$ & 1.5290 & 1.4679 & 8.15 \\
\hline 325.0 & $322.5-327.5$ & 2.7908 & 2.7612 & 3.94 \\
\hline 330.0 & $327.5-332.5$ & 1.9889 & 1.9094 & 10.59 \\
\hline 335.0 & $332.5-337.5$ & 0.1959 & 0.1831 & 1.71 \\
\hline 340.0 & $337.5-342.5$ & 2.3872 & 2.2729 & 15.24 \\
\hline 345.0 & $342.5-347.5$ & 0.7586 & 0.7547 & 0.51 \\
\hline 350.0 & $347.5-352.5$ & 0.1947 & 0.2204 & -3.43 \\
\hline 355.0 & $352.5-357.5$ & 0.9604 & & \\
\hline 360.0 & $357.5-362.5$ & 0.0139 & & \\
\hline 365.0 & $362.5-367.5$ & 0.0100 & & \\
\hline 370.0 & $367.5-372.5$ & 0.0368 & & \\
\hline
\end{tabular}

* Wavelengths are calibrated in air.

To calculate the UV absorption spectrum at a given temperature $T$, the following equation is used:

$\sigma(\lambda, T)=\sigma(\lambda, 298 \mathrm{~K})+\Gamma(T-298 \mathrm{~K})$ 
Absorption Cross-Sections at 298 K, $\sigma(298$ K), Averaged Over 1 nm Intervals Centered at the Cited Wavelength, $\lambda$.

\begin{tabular}{|c|c|c|c|c|c|}
\hline$\lambda / \mathrm{nm}^{*}$ & $10^{21} \sigma(298 \mathrm{~K}) \mathrm{cm}^{2}$ & $\lambda / \mathrm{nm}^{*}$ & $10^{21} \sigma(298 \mathrm{~K}) \mathrm{cm}^{2}$ & $\lambda / \mathrm{nm}^{*}$ & $10^{21} \sigma(298 \mathrm{~K}) \mathrm{cm}^{2}$ \\
\hline 226 & 0.179 & 276 & 25.842 & 326 & 68.757 \\
\hline 227 & 0.169 & 277 & 15.731 & 327 & 43.702 \\
\hline 228 & 0.177 & 278 & 10.349 & 328 & 12.201 \\
\hline 229 & 0.190 & 279 & 24.514 & 329 & 31.200 \\
\hline 230 & 0.205 & 280 & 23.375 & 330 & 38.651 \\
\hline 231 & 0.166 & 281 & 15.624 & 331 & 14.121 \\
\hline 232 & 0.335 & 282 & 9.728 & 332 & 3.474 \\
\hline 233 & 0.262 & 283 & 7.224 & 333 & 2.135 \\
\hline 234 & 0.325 & 284 & 42.649 & 334 & 1.587 \\
\hline 235 & 0.363 & 285 & 40.504 & 335 & 0.967 \\
\hline 236 & 0.540 & 286 & 20.950 & 336 & 1.261 \\
\hline 237 & 0.770 & 287 & 11.532 & 337 & 3.825 \\
\hline 238 & 0.569 & 288 & 31.687 & 338 & 19.188 \\
\hline 239 & 0.681 & 289 & 32.245 & 339 & 53.814 \\
\hline 240 & 0.782 & 290 & 11.729 & 340 & 31.514 \\
\hline 241 & 0.775 & 291 & 18.358 & 341 & 9.783 \\
\hline 242 & 1.227 & 292 & 7.973 & 342 & 5.093 \\
\hline 243 & 1.591 & 293 & 31.281 & 343 & 19.221 \\
\hline 244 & 1.096 & 294 & 71.538 & 344 & 12.684 \\
\hline 245 & 1.313 & 295 & 40.535 & 345 & 4.369 \\
\hline 246 & 1.634 & 296 & 24.739 & 346 & 1.190 \\
\hline 247 & 1.511 & 297 & 13.672 & 347 & 0.441 \\
\hline 248 & 2.338 & 298 & 42.166 & 348 & 0.754 \\
\hline 249 & 3.178 & 299 & 31.745 & 349 & 0.379 \\
\hline 250 & 2.572 & 300 & 9.638 & 350 & 0.362 \\
\hline 251 & 2.039 & 301 & 16.246 & 351 & 0.893 \\
\hline 252 & 3.366 & 302 & 8.537 & 352 & 7.295 \\
\hline 253 & 2.894 & 303 & 30.211 & 353 & 22.752 \\
\hline 254 & 3.417 & 304 & 72.185 & 354 & 16.449 \\
\hline 255 & 4.502 & 305 & 47.520 & 355 & 6.964 \\
\hline 256 & 6.282 & 306 & 42.915 & 356 & 1.483 \\
\hline 257 & 4.430 & 307 & 17.807 & 357 & 0.345 \\
\hline 258 & 3.073 & 308 & 13.847 & 358 & 0.186 \\
\hline 259 & 6.174 & 309 & 32.521 & 359 & 0.111 \\
\hline 260 & 6.045 & 310 & 17.369 & 360 & 0.087 \\
\hline 261 & 6.591 & 311 & 4.623 & 361 & 0.100 \\
\hline 262 & 6.033 & 312 & 11.880 & 362 & 0.211 \\
\hline 263 & 10.773 & 313 & 9.064 & 363 & 0.141 \\
\hline 264 & 9.465 & 314 & 56.366 & 364 & 0.094 \\
\hline 265 & 5.305 & 315 & 55.650 & 365 & 0.088 \\
\hline 266 & 5.387 & 316 & 25.608 & 366 & 0.085 \\
\hline 267 & 13.604 & 317 & 57.770 & 367 & 0.091 \\
\hline 268 & 12.428 & 318 & 31.505 & 368 & 0.142 \\
\hline 269 & 9.908 & 319 & 9.779 & 369 & 0.297 \\
\hline 270 & 9.626 & 320 & 11.936 & 370 & 0.635 \\
\hline 271 & 19.409 & 321 & 15.976 & 371 & 0.571 \\
\hline 272 & 14.302 & 322 & 7.216 & 372 & 0.198 \\
\hline 273 & 8.106 & 323 & 3.281 & 373 & 0.113 \\
\hline 274 & 6.575 & 324 & 8.584 & 374 & 0.091 \\
\hline 275 & 21.432 & 325 & 15.779 & 375 & 0.087 \\
\hline
\end{tabular}

* Wavelengths are calibrated in air. 


\section{Quantum yields in air at 1 bar and $298 \mathrm{~K}^{*}$}

\begin{tabular}{ccc}
\hline$\lambda / \mathrm{nm}$ & $\phi_{1}$ & $\phi_{2}$ \\
\hline 240.00 & 0.270 & 0.490 \\
250.00 & 0.290 & 0.490 \\
260.00 & 0.300 & 0.490 \\
268.75 & 0.425 & 0.385 \\
278.75 & 0.570 & 0.320 \\
283.75 & 0.673 & 0.247 \\
288.75 & 0.746 & 0.214 \\
293.75 & 0.694 & 0.286 \\
298.75 & 0.642 & 0.348 \\
301.25 & 0.725 & 0.275 \\
303.75 & 0.780 & 0.220 \\
306.25 & 0.684 & 0.316 \\
308.75 & 0.735 & 0.265 \\
311.25 & 0.704 & 0.296 \\
313.75 & 0.715 & 0.285 \\
316.25 & 0.673 & 0.327 \\
321.25 & 0.663 & 0.337 \\
326.25 & 0.528 & 0.452 \\
328.75 & 0.373 & 0.577 \\
331.25 & 0.476 & 0.424 \\
333.75 & 0.311 & 0.489 \\
336.25 & 0.072 & 0.627 \\
338.75 & 0.041 & 0.559 \\
340.00 & 0.00 & 0.560 \\
350.00 & 0.00 & 0.210 \\
360.00 & 0.00 & 0.030 \\
\hline & & \\
\hline & &
\end{tabular}

${ }^{*} \phi_{1}$ values between $240-330 \mathrm{~nm}$

independent of temperature and

pressure

\section{Comments on Preferred Values}

The new cross-section measurements by Meller and Moortgat (2000) provide for the first time high-resolution data over the complete UV absorption band with minimised systematic error. These are the basis of the preferred values. The measured cross sections are 5-10\% higher than the values previously recommended by IUPAC, which were based on cross-sections reported by Moortgat and Schneider (1989) for $\lambda \leq 300 \mathrm{~nm}$ and of Cantrell et al. (1990) for $\lambda=301 \mathrm{~nm}$ to $356 \mathrm{~nm}$. The temperature dependence over the range 250-356 nm reported by Meller and Moortgat (2000) exhibits the same general changes on band shape as previously recommended spectra, but differs in the shape of the individual rotational bands. Resolution should not exceed $1 \mathrm{~nm}$ to assure correct representation of the temperature dependent cross sections.

The recent quantum yield measurements of Smith et al. (2002) are in good agreement with those determined by Moortgat et al. (1983) upon which the earlier IUPAC recommended data for atmospheric pressure and $298 \mathrm{~K}$ was based, but show for the first time structure in the wavelength dependence of $\phi_{1}$. These results are also consistent with earlier measurements of the quantum yields by Horowitz and Calvert (1978), Clark et al. (1978), Tang et al. (1979) and Moortgat et al. (1983)

The preferred values for $\phi_{1}$ are calculated from the relative values of Smith et al. (2002), using the value of $\phi_{1}=0.78$ at $302.5 \mathrm{~nm}$. These values are independent of pressure and temperature in the atmospheric range. The values for $\phi_{2}$ are obtained by the difference $\left(\phi_{T}-\phi_{1}\right)$, where $\phi_{T}$ is the sum of the two channels (1) and (2) at 1 bar and $298 \mathrm{~K}$, based on the data of Moortgat et al. (1983). Moortgat et al. $(1979,1983)$ show that for $\lambda>330 \mathrm{~nm}$, the quantum yields of $\mathrm{CO}$ and $\mathrm{H}_{2}$ production are pressure and temperature dependent; quenching parameters are given in Moortgat et al. (1983).

Photodissociation of HCHO involves both $\mathrm{S}^{0}$ and $\mathrm{T}^{1}$ excited states populated from the $\mathrm{S}^{1}$ state produced initially by photo-excitation in the near UV. The structure observed by Smith et al. (2002) provides evidence for the complicated competition among the various dissociation pathways of singlet and triplet excited formaldehyde to give: $\mathrm{H}+\mathrm{HCO}, \mathrm{H}+\mathrm{H}+\mathrm{CO}$ and 
$\mathrm{H}_{2}+\mathrm{CO}$, which has been diagnosed from numerous studies of the photo-dissociation dynamics of excited HCHO molecules. These studies reveal that several parallel unimolecular decomposition pathways exist, yielding the two sets of chemically distinct products: $\mathrm{H}+\mathrm{HCO}$ (1) and $\mathrm{H}_{2}+\mathrm{CO}$ (2) (Green et al., 1992). Reaction (1) can occur via both $\mathrm{S}^{0}$ and $\mathrm{T}^{1}$ states, while Reaction (2) occurs solely via $S^{0}$. Not only do the molecular and radical product channels compete, but distinct $S^{0}$ and $\mathrm{T}^{1}$ pathways can lead to the same products, i.e. H + HCO (Chuang et al., 1987).

Recent experimental studies (Valachovic et al., 2000) of the radical channel have defined the energetics governing the competition between the $S^{0}$ and $T^{1}$ pathways, which are consistent with earlier experiments (Chuang et al., 1987) and with ab initio calculations (Yamaguchi et al., 1998). The $\mathrm{T}^{1}$ route dominates at higher energies. For the molecular channel, the $\mathrm{S}^{0}$ route, which is pressure quenched at energies below the radical threshold, may be replaced above the threshold by an 'abstraction' mechanism (v. Zee et al., 1993). This mechanism involves access to large H-HCO distances in the excited state just prior to bond breaking, which facilitate $\mathrm{H}$-atom abstraction (Valachovic et al., 2000), producing $\mathrm{H}_{2}+\mathrm{CO}$. This may resolve some of the earlier discrepancies concerning the yields of molecular products at higher energies (Troe, 1984; Ho et al., 1982). Nevertheless, the branching ratios for $\lambda<300 \mathrm{~nm}$ should be treated with caution.

The new recommended quantum yields result in increases of at least $8 \%$ in the calculated $\mathrm{H} / \mathrm{HCO}$ production rate from formaldehyde photolysis in the troposphere.

\section{References}

Cantrell, C. A., Davidson, J. A., McDaniel, A. H., Shetter, R. E., and Calvert, J. G.: J. Phys. Chem., 94, 3902, 1990.

Chuang, C., Foltz, M. F., and Moore, C. B.: J. Chem. Phys., 87, 3855, 1987.

Clark, J. H., Moore, C. B., and Nogar, N. S.: J. Chem. Phys., 68, 1264, 1978.

Green, W. H., Moore, C. B., and Polik, W. F.: Ann. Rev. Phys. Chem., 43, 591, 1992.

Ho, P., Bamford, D. J., Buss, R. J., Lee, R. J., and Moore, C. B.: J. Chem. Phys., 76, 3630, 1982.

Horowitz, A. and Calvert, J. C.: Int. J. Chem. Kinet., 10, 805, 1978.

Meller, R. E. and Moortgat, G. K.: J. Geophys. Res., 105, 7089, 2000.

Moortgat, G. K. and Schneider, W.: unpublished data cited in IUPAC Supplement III, 1989.

Moortgat, G. K. and Warneck, P.: J. Chem. Phys., 70, 3639, 1979.

Moortgat, G. K., Seiler, W., and Warneck, P.: J. Chem. Phys., 78, 1185, 1983.

NASA, see references in the Introduction, 2000.

Smith, G. D., Molina, L. T., and Molina, M. J.: J. Phys. Chem A, 106, 1233, 2002.

Tang, K. Y., Fairchild, P. W., and Lee, E. K. C.: J. Phys. Chem., 83, 569, 1979. Troe, J.: J. Phys. Chem., 88, 4375, 1984.

v. Zee, R. D., Foltz, M. F., and Moore, C. B.: J. Chem. Phys., 99, 1664, 1993.

Valachovic, L. R., Tuchler, M. F., Dulligan, M., Droz-Georget, Th., Zyrianov, M., Kolessov, A., Reisler, H., and Wittig, C.: J. Chem. Phys., 112, 2752, 2000.

Yamaguchi, Y., Wesolowski, S. S., Van Huis, T. J., and Schaefer, H. F.: J. Chem. Phys., 108, 5281, 1998. 
II.A8.198

$$
\mathrm{CH}_{3} \mathrm{CHO}+\mathbf{h} v \rightarrow \text { products }
$$

Primary photochemical transitions

\begin{tabular}{llccc}
\hline Reaction & & & $\Delta \mathrm{H}_{298}^{\circ} / \mathrm{kJ} \cdot \mathrm{mol}^{-1}$ & $\lambda_{\text {threshold }} / \mathrm{nm}$ \\
\hline $\mathrm{CH}_{3} \mathrm{CHO}+\mathrm{h} v$ & $\rightarrow \mathrm{CH}_{4}+\mathrm{CO}$ & $(1)$ & -19.5 & \\
& $\rightarrow \mathrm{CH}_{3}+\mathrm{HCO}$ & $(2)$ & 355.3 & 337 \\
& $\rightarrow \mathrm{CH}_{3} \mathrm{CO}+\mathrm{H}$ & $(3)$ & 373.8 & 320 \\
\hline
\end{tabular}

Absorption cross-section data

\begin{tabular}{llr}
\hline Wavelength range/nm & Reference & Comments \\
\hline 202-365 & Martinez et al., 1992 & (a) \\
\hline
\end{tabular}

Quantum yield data $\left(\phi=\phi_{1}+\phi_{2}+\phi_{3}\right)$

\begin{tabular}{ccccc}
\hline Measurement & & Wavelength range/nm & Reference & Comments \\
\hline$\phi_{1}$ & $\phi_{2}$ & & & \\
0.46 & 0.31 & 260 & Meyrahn et al., 1982 & (b) \\
0.42 & 0.32 & 265 & & \\
0.31 & 0.39 & 270 & & \\
0.16 & 0.51 & 275 & & \\
0.05 & 0.58 & 280 & & \\
0.02 & 0.57 & 285 & & \\
0.01 & 0.53 & 290 & & \\
0.005 & 0.48 & 295 & & \\
0.0 & 0.43 & 300 & & \\
0.0 & 0.37 & 305 & & \\
0.0 & 0.28 & 310 & & \\
0.0 & 0.10 & 320 & & \\
0.0 & 0.04 & 325 & & \\
0.0 & 0.00 & 330 & & \\
\hline
\end{tabular}

\section{Comments}

(a) Double beam spectrophotometric measurements with $10 \mathrm{~cm}$ path length. Data obtained at $0.1 \mathrm{~nm}$ intervals with $0.5 \mathrm{~nm}$ resolution. Argon-acetaldehyde mixtures used at a total pressure of $133 \mathrm{mbar}$ and several acetaldehyde pressures in the range 1.3 mbar to 2.6 mbar. Cross-sections tabulated are averages over a $1 \mathrm{~nm}(\lambda>280 \mathrm{~nm})$ or $4 \mathrm{~nm}(\lambda<280 \mathrm{~nm})$ region centered on the corresponding wavelength (see Preferred Values).

(b) Quantum yields of $\mathrm{CH}_{4}$ and $\mathrm{CO}$ determined from the photolysis of $100 \mathrm{ppm}$ of $\mathrm{CH}_{3} \mathrm{CHO}$ in air or $\mathrm{N}_{2}$ at a total pressure of 1 bar. $\mathrm{H}_{2}$ was found only in trace quantities and hence it was concluded that the photolytic channel giving $\mathrm{CH}_{3} \mathrm{CO}+\mathrm{H}$ $\left(\lambda_{\text {threshold }}=320 \mathrm{~nm}\right)$ is negligible. Quantum yield data based on the assumption that $\phi_{1}+\phi_{2}+\phi_{a}=1$, where $\phi_{a}$ refers to the quenching process $\mathrm{CH}_{3} \mathrm{CHO}^{*}+\mathrm{M} \rightarrow \mathrm{CH}_{3} \mathrm{CHO}+\mathrm{M}$. Quantum yield data at 1 bar pressure were found to be independent of the diluent, $\mathrm{N}_{2}$, or air. $\phi_{\mathrm{CO}}$ both in $\mathrm{N}_{2}$ and in air increased as the total pressure was lowered. 
Preferred Values

Absorption Cross-Sections at $298 \mathrm{~K}$

\begin{tabular}{cccccc}
\hline$\lambda / \mathrm{nm}$ & $10^{20} \sigma / \mathrm{cm}^{2}$ & $\lambda / \mathrm{nm}$ & $10^{20} \sigma / \mathrm{cm}^{2}$ & $\lambda / \mathrm{nm}$ & $10^{20} \sigma / \mathrm{cm}^{2}$ \\
\hline 202 & 0.056 & 297 & 4.38 & 334 & 0.363 \\
206 & 0.053 & 298 & 4.41 & 335 & 0.350 \\
210 & 0.049 & 299 & 4.26 & 336 & 0.238 \\
214 & 0.048 & 300 & 4.16 & 337 & 0.222 \\
218 & 0.052 & 301 & 3.99 & 338 & 0.205 \\
222 & 0.065 & 302 & 3.86 & 339 & 0.219 \\
226 & 0.096 & 303 & 3.72 & 340 & 0.150 \\
230 & 0.151 & 304 & 3.48 & 341 & 0.074 \\
234 & 0.241 & 305 & 3.42 & 342 & 0.042 \\
238 & 0.375 & 306 & 3.42 & 343 & 0.031 \\
242 & 0.564 & 307 & 3.36 & 344 & 0.026 \\
246 & 0.818 & 308 & 3.33 & 345 & 0.021 \\
250 & 1.128 & 309 & 3.14 & 346 & 0.019 \\
254 & 1.524 & 310 & 2.93 & 347 & 0.015 \\
258 & 1.994 & 311 & 2.76 & 348 & 0.016 \\
262 & 2.44 & 312 & 2.53 & 349 & 0.010 \\
266 & 3.05 & 313 & 2.47 & 350 & 0.008 \\
270 & 3.42 & 314 & 2.44 & 351 & 0.007 \\
274 & 4.03 & 315 & 2.20 & 352 & 0.006 \\
278 & 4.19 & 316 & 2.04 & 353 & 0.005 \\
280 & 4.50 & 317 & 2.07 & 354 & 0.005 \\
281 & 4.69 & 318 & 1.979 & 355 & 0.004 \\
282 & 4.72 & 319 & 1.874 & 356 & 0.005 \\
283 & 4.75 & 320 & 1.723 & 357 & 0.003 \\
284 & 4.61 & 321 & 1.484 & 358 & 0.004 \\
285 & 4.49 & 322 & 1.402 & 359 & 0.002 \\
286 & 4.44 & 323 & 1.244 & 360 & 0.003 \\
287 & 4.59 & 324 & 1.091 & 361 & 0.002 \\
288 & 4.72 & 325 & 1.136 & 362 & 0.001 \\
289 & 4.77 & 326 & 1.074 & 363 & 0.000 \\
290 & 4.89 & 327 & 0.858 & 364 & 0.000 \\
291 & 4.78 & 328 & 0.747 & 365 & 0.000 \\
292 & 4.68 & 329 & 0.707 & & \\
293 & 4.53 & 330 & 0.688 & & \\
294 & 4.33 & 331 & 0.588 & & \\
295 & 4.27 & 332 & 0.530 & & \\
296 & 4.24 & 333 & 0.398 & & \\
\hline & & & & &
\end{tabular}




\section{Quantum yields in air at 1 bar and $298 \mathrm{~K}$}

\begin{tabular}{ccc}
\hline$\lambda / \mathrm{nm}$ & $\phi_{1}$ & $\phi_{2}$ \\
\hline 260 & 0.46 & 0.31 \\
270 & 0.31 & 0.39 \\
280 & 0.05 & 0.58 \\
290 & 0.01 & 0.53 \\
295 & 0.00 & 0.48 \\
300 & & 0.43 \\
305 & & 0.37 \\
310 & & 0.29 \\
315 & & 0.17 \\
320 & & 0.10 \\
325 & & 0.04 \\
330 & & 0.00 \\
\hline
\end{tabular}

\section{Comments on Preferred Values}

The preferred absorption cross-sections are from the extensive measurements of Martinez et al. (1992). Over the wavelength region $260 \mathrm{~nm}$ to $320 \mathrm{~nm}$ these cross-sections are within 5\% of the data of Calvert and Pitts (1966) and Weaver et al. (1976).

The preferred values for the quantum yields are those obtained by Meyrahn et al. (1982). Atkinson and Lloyd (1984) have evaluated the quantum yield data of Meyrahn et al. (1982) and of Horowitz and Calvert (1982), and derive values in very close agreement with those recommended here.

\section{References}

Atkinson, R. and Lloyd, A. C.: J. Phys. Chem. Ref. Data, 13, 315, 1984.

Calvert, J. G. and Pitts Jr., J. N.: Photochemistry, Wiley, New York, 1966.

Horowitz, A. and Calvert, J. G.: J. Phys. Chem., 86, 3105, 1982.

Martinez, R. D., Buitrago, A. A., Howell, N. W., Hearn, C. H., and Joens, J. A.: Atmos.Environ., 26A, 785, 1992.

Meyrahn, H., Moortgat, G. K., and Warneck, P.: presented at the XVth Informal Conference on Photochemistry, Stanford Research Institute, Stanford, California, July, 1982.

Weaver, J., Meagher, J., and Heicklen, J.: J. Photochem., 6, 111, 1976. 
II.A8.199

$$
\mathbf{C}_{2} \mathrm{H}_{5} \mathrm{CHO}+\mathbf{h} v \rightarrow \text { products }
$$

\section{Primary photochemical transitions}

\begin{tabular}{llccc}
\hline Reaction & & & $\Delta \mathrm{H}_{298}^{\circ} / \mathrm{kJ} \cdot \mathrm{mol}^{-1}$ & $\lambda_{\text {threshold }} / \mathrm{nm}$ \\
\hline $\mathrm{C}_{2} \mathrm{H}_{5} \mathrm{CHO}$ & $\rightarrow \mathrm{C}_{2} \mathrm{H}_{5}+\mathrm{HCO}$ & $(1)$ & 351.4 & 340 \\
& $\rightarrow \mathrm{C}_{2} \mathrm{H}_{6}+\mathrm{CO}$ & $(2)$ & -7.1 & \\
& $\rightarrow \mathrm{C}_{2} \mathrm{H}_{4}+\mathrm{HCHO}$ & $(3)$ & 131.0 & 913 \\
& $\rightarrow \mathrm{CH}_{3}+\mathrm{CH}_{2} \mathrm{CHO}$ & $(4)$ & 344.3 & 347 \\
\hline
\end{tabular}

\section{Absorption cross-section data}

\begin{tabular}{llr}
\hline Wavelength range/nm & Reference & Comments \\
\hline $202-365$ & Martinez et al., 1992 & (a) \\
280-330 & Chen and Zhu, 2001 & (b) \\
\hline
\end{tabular}

Quantum yield data $\left(\phi=\phi_{1}+\phi_{2}+\phi_{3}+\phi_{4}\right)$

\begin{tabular}{cccc}
\hline Measurement & Wavelength range/nm & Reference & Comments \\
\hline$\phi_{1}$ & & Heicklen et al., 1986 & (c) \\
0.89 & 294 & & \\
0.50 & 302 & & \\
0.26 & 325 & & \\
0.15 & 334 & Chen and Zhu, 2001 & (d) \\
$\phi_{1}$ & & & \\
$0.85 \pm 0.06$ & 280 & & \\
$1.01 \pm 0.07$ & 285 & & \\
$0.95 \pm 0.06$ & 290 & & \\
$0.98 \pm 0.06$ & 295 & & \\
$0.92 \pm 0.06$ & 300 & & \\
$0.95 \pm 0.08$ & 305 & & \\
$0.98 \pm 0.11$ & 310 & & \\
$0.91 \pm 0.05$ & 315 & & \\
$1.08 \pm 0.07$ & 320 & & \\
$1.07 \pm 0.14$ & 325 & & \\
$0.84 \pm 0.08$ & 330 & & \\
\hline
\end{tabular}

\section{Comments}

(a) Absorption measurements as a function of $\mathrm{C}_{2} \mathrm{H}_{5} \mathrm{CHO}$ pressure using a diode array spectrometer. Cross-sections are the average cross-section over a $1 \mathrm{~nm}(\lambda>280 \mathrm{~nm})$ or $4 \mathrm{~nm}(\lambda<280 \mathrm{~nm})$ region centered at the corresponding wavelength (see Preferred Values).

(b) Cross-sections determined from transmission of UV light at $5 \mathrm{~nm}$ intervals from tunable dye laser, as a function of $\mathrm{C}_{2} \mathrm{H}_{5} \mathrm{CHO}$ pressure. Overall uncertainty estimated to be 5-10\% at all wavelengths. Results agree with those from Martinez et al. (1992) except at 280 and $330 \mathrm{~nm}$, where values are $20-30 \%$ higher.

(c) Laser flash photolysis of $\mathrm{C}_{2} \mathrm{H}_{5} \mathrm{CHO}$ in the presence of air and steady-state photolysis of $\mathrm{C}_{2} \mathrm{H}_{5} \mathrm{CHO}$ in the presence of $\mathrm{O}_{2}$ at $263 \mathrm{~K}$ or $298 \mathrm{~K}$, as a function of wavelength and of $\mathrm{O}_{2}$ pressure. Quantum yields for radical channel from measurement 
of $\mathrm{C}_{2} \mathrm{H}_{5} \mathrm{O}_{2}$ and $\mathrm{HO}_{2}$ by UV absorption following laser photolysis. Quantum yields for $\mathrm{CO}$ and $\mathrm{C}_{2} \mathrm{H}_{6}$ were measured by GC. From the proposed mechanism it was deduced that $\phi_{1}=\left(\phi_{\infty}-\phi\left[\mathrm{C}_{2} \mathrm{H}_{6}\right]\right)$. The values of $\phi$ quoted are for 1 bar air.

(d) Tunable dye laser photolysis of $\mathrm{C}_{2} \mathrm{H}_{5} \mathrm{CHO}$ with time resolved measurement of $\mathrm{HCO}$ concentration by cavity ring down spectroscopy at $613.8 \mathrm{~nm}$. Absorbed flux was determined from photon fluence measurements using a calibrated Joulemeter. Absolute yields of $\mathrm{HCO}$ calculated from absorption cross sections, $\sigma(\mathrm{HCO})$ determined in situ from either photodissociation of $\mathrm{HCHO}$ or $\mathrm{Cl}_{2}+\mathrm{HCHO}$ mixtures (at 310-330 nm). A weak dependence of $\phi$ on $\mathrm{P}_{\mathrm{C} 2 \mathrm{H} 5 \mathrm{CHO}}$ was observed but no dependence of $\phi$ on $\mathrm{N}_{2}$ up to 1 bar. The values of $\phi$ quoted are for zero pressure, but the same values apply at 1 bar $\mathrm{N}_{2}$.

\section{Preferred Values}

\section{Absorption Cross-Sections at $298 \mathrm{~K}$}

\begin{tabular}{|c|c|c|c|c|c|}
\hline$\lambda / \mathrm{nm}$ & $10^{20} \sigma / \mathrm{cm}^{2}$ & $\lambda / \mathrm{nm}$ & $10^{20} \sigma / \mathrm{cm}^{2}$ & $\lambda / \mathrm{nm}$ & $10^{20} \sigma / \mathrm{cm}^{2}$ \\
\hline 202 & 0.049 & 295 & 5.57 & 330 & 0.575 \\
\hline 206 & 0.049 & 296 & 5.37 & 331 & 0.494 \\
\hline 210 & 0.057 & 297 & 5.16 & 332 & 0.466 \\
\hline 214 & 0.069 & 298 & 5.02 & 333 & 0.430 \\
\hline 218 & 0.080 & 299 & 5.02 & 334 & 0.373 \\
\hline 222 & 0.091 & 300 & 5.04 & 335 & 0.325 \\
\hline 226 & 0.115 & 301 & 5.09 & 336 & 0.280 \\
\hline 230 & 0.163 & 302 & 5.07 & 337 & 0.230 \\
\hline 234 & 0.257 & 303 & 4.94 & 338 & 0.185 \\
\hline 238 & 0.407 & 304 & 4.69 & 339 & 0.166 \\
\hline 242 & 0.622 & 305 & 4.32 & 340 & 0.155 \\
\hline 246 & 0.909 & 306 & 4.04 & 341 & 0.119 \\
\hline 250 & 1.287 & 307 & 3.81 & 342 & 0.076 \\
\hline 254 & 1.745 & 308 & 3.65 & 343 & 0.045 \\
\hline 258 & 2.25 & 309 & 3.62 & 344 & 0.031 \\
\hline 262 & 2.88 & 310 & 3.60 & 345 & 0.025 \\
\hline 266 & 3.43 & 311 & 3.53 & 346 & 0.019 \\
\hline 270 & 4.12 & 312 & 3.50 & 347 & 0.016 \\
\hline 274 & 4.59 & 313 & 3.32 & 348 & 0.014 \\
\hline 278 & 5.17 & 314 & 3.06 & 349 & 0.013 \\
\hline 280 & 5.16 & 315 & 2.77 & 350 & 0.010 \\
\hline 281 & 5.21 & 316 & 2.43 & 351 & 0.008 \\
\hline 282 & 5.35 & 317 & 2.18 & 352 & 0.007 \\
\hline 283 & 5.57 & 318 & 2.00 & 353 & 0.005 \\
\hline 284 & 5.78 & 319 & 1.864 & 354 & 0.004 \\
\hline 285 & 5.86 & 320 & 1.831 & 355 & 0.002 \\
\hline 286 & 5.82 & 321 & 1.777 & 356 & 0.001 \\
\hline 287 & 5.72 & 322 & 1.662 & 357 & 0.001 \\
\hline 288 & 5.59 & 323 & 1.577 & 358 & 0.000 \\
\hline 289 & 5.52 & 324 & 1.488 & 359 & 0.000 \\
\hline 290 & 5.56 & 325 & 1.300 & 360 & 0.000 \\
\hline 291 & 5.68 & 326 & 1.129 & 361 & 0.000 \\
\hline 292 & 5.81 & 327 & 0.996 & 362 & 0.000 \\
\hline 293 & 5.88 & 328 & 0.828 & 363 & 0.000 \\
\hline 294 & 5.80 & 329 & 0.685 & 364 & 0.000 \\
\hline
\end{tabular}


Quantum yields in air at 1 bar and $298 \mathrm{~K}$

\begin{tabular}{cc}
\hline$\lambda / \mathrm{nm}$ & $\phi_{1}$ \\
\hline 280 & 0.85 \\
285 & 0.90 \\
290 & 0.95 \\
295 & 1.00 \\
300 & 1.00 \\
305 & 1.00 \\
310 & 1.00 \\
\hline
\end{tabular}

\section{Preferred Quantum Yields}

No recommendation.

\section{Comments on Preferred Values}

The preferred absorption cross-sections are from the measurements of Martinez et al. (1992). Over the wavelength region $260 \mathrm{~nm}$ to $320 \mathrm{~nm}$ these cross-sections are within 5\% of the earlier data of Calvert and Pitts (1966), and the less precise measurements of Chen and Zhu (2001).

The quantum yields, $\phi_{1}$, reported by Chen and Zhu (2001) at wavelengths less than $310 \mathrm{~nm}$ and at 1 bar $\mathrm{N}_{2}$, agree well with those obtained for 1 bar air in the less direct study of Heicklen et al. (1986). However at wavelengths $>310 \mathrm{~nm}$ the results of Chen and Zhu (2001) do not show the fall off observed by Heicklen et al. (1986) in air. This could be due to quenching by $\mathrm{O}_{2}$ of the excited triplet state, which is believed to dissociate to give radical products (channel 1), or to errors in the interpretation of the more complex chemistry in the presence of $\mathrm{O}_{2}$. There are significant experimental uncertainties at the longer wavelengths associated with the weak absorption by propionaldehyde. Further work is needed to resolve this issue and we are unable to recommend values for $\phi_{1}$ in this region.

\section{References}

Calvert, J. G. and Pitts Jr., J. N.: Photochemistry, Wiley, New York, 1966.

Chen, Y. and Zhu, L.: J. Phys. Chem. A, 105, 9689, 2001.

Heicklen, J., Desai, J., Bahta, A., Harper, C., and Simonaitis, R.: J. Photochem., 34, 117, 1986.

Martinez, R. D., Buitrago, A. A., Howell, N. W., Hearn, C. H., and Joens, J. A.: Atmos. Environ., 26 A, $785,1992$. 
II.A8.200

$$
\text { pinonaldehyde }^{a}+\mathbf{h} v \rightarrow \text { products }
$$

Absorption cross-section data

\begin{tabular}{llc}
\hline Wavelength range/nm & Reference & Comments \\
\hline 275-345 & Hallquist et al., 1997 & (b) \\
\hline
\end{tabular}

Quantum yield data

\begin{tabular}{lclc}
\hline Measurement & Wavelength range/nm & Reference & Comments \\
\hline$\phi($ average $)=0.14 \pm 0.03$ & sunlight & RADICAL, 2002 & (c) \\
$\phi($ average $) \approx 0.4$ & sunlight & Jaoui and Kamens, 2003 & (d) \\
\hline
\end{tabular}

\section{Comments}

(a) (3-acetyl-2,2-dimethyl-cyclobutyl)-acetaldehyde.

(b) The UV spectrum was determined from long path $(39.1 \mathrm{~m})$ absorption measurements in a $0.48 \mathrm{~m}^{3}$ chamber. Measurements were made over the wavelength range $275-345 \mathrm{~nm}$, at a resolution of $0.6 \mathrm{~nm}$, using diode array spectroscopy. Cross sections were reported as averages over $5 \mathrm{~nm}$ intervals. Measurements were made at $300 \pm 1 \mathrm{~K}$ and low pressure $(<0.1 \mathrm{mbar})$, and calibrated through measurement of the pressure change on admission of pinonaldehyde to the reaction vessel. Pinonaldehyde was synthesized from the ozonolysis of $\alpha$-pinene. Its stated purity was $95 \%$, based on GC-MS and NMR analyses.

(c) Natural sunlight photolysis of pinonaldehyde-cyclohexane-air mixtures in a $180 \mathrm{~m}^{3}$ outdoor chamber (the European Photoreactor, EUPHORE). The photolysis rate of pinonaldehyde was determined from its measured decay (HPLC), following correction for its removal by wall loss and dilution (which accounted for ca. $60 \%$ of its removal). Cyclohexane was included in the reaction mixtures as an $\mathrm{HO}$ radical scavenger. An average photodissociation quantum yield was determined from the observed photolysis rate relative to a theoretical rate, which was calculated using the absorption cross sections of Hallquist et al. (1997), the measured actinic flux and the assumption of a unit quantum yield.

(d) Natural sunlight photolysis of pinonaldehyde-air and pinonaldehyde-cyclohexane-air mixtures in a $190 \mathrm{~m}^{3}$ outdoor chamber, with GC-MS detection. The system was characterized by simulation using a detailed chemical mechanism, which also included pinonaldehyde removal by wall loss and dilution (which accounted for $\sim 70-80 \%$ of its removal). An average photodissociation quantum yield was derived from the simulations, based on light absorption described by the cross sections of Hallquist et al. (1997) and the measured actinic flux. More than nine products were identified or tentatively identified and quantified using GC-MS.

\section{Preferred Values}

Absorption Cross-Sections for pinonaldehyde at $300 \mathrm{~K}$

\begin{tabular}{cccc}
\hline$\lambda / \mathrm{nm}$ & $10^{20} \sigma / \mathrm{cm}^{2}$ & $\lambda / \mathrm{nm}$ & $10^{20} \sigma / \mathrm{cm}^{2}$ \\
\hline 277.5 & 12.19 & 312.5 & 6.84 \\
282.5 & 12.96 & 317.5 & 4.90 \\
287.5 & 13.48 & 322.5 & 3.07 \\
292.5 & 12.94 & 327.5 & 1.72 \\
297.5 & 12.17 & 332.5 & 0.72 \\
302.5 & 10.62 & 337.5 & 0.29 \\
307.5 & 8.94 & 342.5 & 0.08 \\
\hline
\end{tabular}




\section{Quantum Yields}

No recommendation.

\section{Comments on Preferred Values}

The preferred absorption cross sections are from the study of Hallquist et al. (1997), which are the only measurements reported and appear to be reliable. As pointed out by Hallquist et al. (1997), the cross sections are consistent with additive contributions from the aldehyde and ketone groups in pinonaldehyde, based on cross sections reported for simple aldehydes and ketones.

The studies of RADICAL (2002) and Jaoui and Kamens (2003) are indicative of removal of pinonaldehyde through photolysis, with average quantum yields which are substantially below unity at wavelengths $>290 \mathrm{~nm}$. Large corrections for pinonaldehyde wall loss and dilution were required in both studies, such that no firm quantum yield recommendation is made. Jaoui and Kamens (2003) identified a series of products which provided evidence for photolysis via both molecular and radicalforming channels. Further studies of the quantum yield and photolysis product channels are required.

\section{References}

Hallquist, M., Wängberg, I., and Ljungström, E.: Environ. Sci. Technol., 31, 3166, 1997.

Jaoui, M. and Kamens, R. M.: Atmos. Environ., 37, 1835, 2003.

RADICAL: 'Evaluation of radical sources in atmospheric chemistry through chamber and laboratory studies', Final report on the EU project 'RADICAL', Co-ordinator, Moortgat, G. K., Report EUR 20254 EN., 2002. 
II.A8.201

$$
(\mathbf{C H O})_{2}+\mathbf{h} v \rightarrow \text { products }
$$

\section{Primary photochemical transitions}

\begin{tabular}{lllcc}
\hline Reaction & & & $\Delta \mathrm{H}_{298}^{\circ} / \mathrm{kJ} \cdot \mathrm{mol}^{-1}$ & $\lambda_{\text {threshold }} / \mathrm{nm}$ \\
\hline$(\mathrm{CHO})_{2}+\mathrm{h} \nu$ & $\rightarrow \mathrm{H}_{2}+2 \mathrm{CO}$ & $(1)$ & -9.1 & \\
& $\rightarrow 2 \mathrm{HCO}$ & $(2)$ & 298.1 & 401 \\
& $\rightarrow \mathrm{HCHO}+\mathrm{CO}$ & $(3)$ & -7.2 & \\
& $\rightarrow \mathrm{H}+\mathrm{CO}+\mathrm{HCO}$ & $(4)$ & 362.5 & 330 \\
\hline
\end{tabular}

\section{Absorption cross-section data}

\begin{tabular}{llc}
\hline Wavelength range/nm & Reference & Comments \\
\hline $230-462$ & Plum et al., 1983 & (a) \\
$210-450$ & Orlando and Tyndall, 2001 & (b) \\
$210-480$ & Horowitz et al., 2001 & (c) \\
\hline
\end{tabular}

Quantum yield data $\left(\phi=\phi_{1}+\phi_{2}+\phi_{3}+\phi_{4}\right)$

\begin{tabular}{lclc}
\hline Measurement & Wavelength range/nm & Reference & Comments \\
\hline$\phi=0.029 \pm 0.018$ & $325-470$ & Plum et al., 1983 & (d) \\
$\phi(\mathrm{HCO})=0.8 \pm 0.4$ & 308 & Langford and Moore, 1984 & (e) \\
$\phi(\mathrm{HCO})=0.42 \pm 0.22$ & 193 & Zhu et al., 1996 & (f) \\
$\phi(\mathrm{HCO})=0.54 \pm 0.24$ & 248 & & \\
$\phi(\mathrm{HCO})=0.70 \pm 0.30$ & 308 & & \\
$\phi(\mathrm{HCO})=1.50 \pm 0.6$ & 351 & & \\
\hline
\end{tabular}

\section{Comments}

(a) Conventional spectrophotometric study (Cary 17-D) using glyoxal pressures of $\sim 4$ mbar to 17 mbar.

(b) Diode array spectrometer with a spectral resolution of $0.6 \mathrm{~nm}$. Glyoxal, prepared by heating glyoxal trimer dihydrate in the presence of $\mathrm{P}_{2} \mathrm{O}_{5}$, was used at pressures in the range $(1.5-10) \times 10^{16}$ molecule $\mathrm{cm}^{3}$.

(c) Diode array spectrometer with a spectral resolution of $0.25 \mathrm{~nm}$. Glyoxal, prepared as in (b), was used at a range of pressures but small deviations from Beer-Lambert law were found at partial pressures $>\sim 0.4$ mbar. Cross sections reported were determined in the linear region with bath gas up to 960 mbar.

(d) Rate of photolysis of glyoxal in air mixtures at atmospheric pressure measured in an environmental chamber. The quantum yield for the photodissociation of glyoxal was obtained by comparison of the measured rate of removal of glyoxal with the rate of photolysis of $\mathrm{NO}_{2}$ under similar experimental conditions.

(e) Laser photolysis of 5.3 mbar glyoxal in 1.3 bar $\mathrm{N}_{2}$ at $295 \mathrm{~K}$. HCO product determined by time-resolved laser resonance absorption. Quantum yield determined by comparing the HCO radical absorption observed with the same signals following $\mathrm{HCHO}$ and $(\mathrm{CHO})_{2}$ photolyses.

(f) Excimer laser photolysis of flowing glyoxal- $\mathrm{N}_{2}$ mixtures. [HCO] monitored by time-resolved cavity ring-down spectroscopy. Yields of $\mathrm{HCO}$ determined by comparison of absorption with signals from photolysis of formaldehyde- $\mathrm{N}_{2}$ mixtures under similar conditions. Incident light intensities were measured by a Joulemeter calibrated by chemical actinometry. The HCO quantum yields were found to be independent of glyoxal pressure, total pressure ( $26 \mathrm{mbar}$ to 470 mbar), and light intensity. 
Preferred Values

Absorption Cross-Sections at $298 \mathrm{~K}$

\begin{tabular}{|c|c|c|c|c|c|}
\hline$\lambda / \mathrm{nm}$ & $10^{20} \sigma / \mathrm{cm}^{2}$ & $\lambda / \mathrm{nm}$ & $10^{20} \sigma / \mathrm{cm}^{2}$ & $\lambda / \mathrm{nm}$ & $10^{20} \sigma / \mathrm{cm}^{2}$ \\
\hline 210 & 1.46 & 298 & 3.87 & 384 & 1.81 \\
\hline 212 & 1.16 & 300 & 3.80 & 386 & 1.81 \\
\hline 214 & 0.94 & 302 & 3.59 & 388 & 2.83 \\
\hline 216 & 0.79 & 304 & 3.20 & 390 & 3.30 \\
\hline 218 & 0.66 & 306 & 3.09 & 392 & 3.35 \\
\hline 220 & 0.57 & 308 & 2.99 & 394 & 3.17 \\
\hline 222 & 0.52 & 310 & 3.01 & 396 & 3.47 \\
\hline 224 & 0.49 & 312 & 3.18 & 398 & 3.88 \\
\hline 226 & 0.47 & 314 & 2.93 & 400 & 3.92 \\
\hline 228 & 0.46 & 316 & 2.40 & 402 & 5.70 \\
\hline 230 & 0.48 & 318 & 2.09 & 404 & 5.73 \\
\hline 232 & 0.52 & 320 & 1.74 & 406 & 4.28 \\
\hline 234 & 0.54 & 322 & 1.69 & 408 & 3.59 \\
\hline 236 & 0.58 & 324 & 1.57 & 410 & 5.21 \\
\hline 238 & 0.66 & 326 & 1.55 & 412 & 6.99 \\
\hline 240 & 0.71 & 328 & 1.76 & 414 & 9.49 \\
\hline 242 & 0.76 & 330 & 1.47 & 416 & 7.65 \\
\hline 244 & 0.83 & 332 & 0.97 & 418 & 7.18 \\
\hline 246 & 0.95 & 334 & 0.85 & 420 & 6.76 \\
\hline 248 & 1.03 & 336 & 0.59 & 422 & 7.34 \\
\hline 250 & 1.09 & 338 & 0.58 & 424 & 9.50 \\
\hline 252 & 1.19 & 340 & 0.54 & 426 & 13.30 \\
\hline 254 & 1.34 & 342 & 0.49 & 428 & 16.06 \\
\hline 256 & 1.44 & 344 & 0.56 & 430 & 6.70 \\
\hline 258 & 1.50 & 346 & 0.66 & 432 & 5.86 \\
\hline 260 & 1.61 & 348 & 0.54 & 434 & 6.39 \\
\hline 262 & 1.77 & 350 & 0.37 & 436 & 10.21 \\
\hline 264 & 1.92 & 352 & 0.39 & 438 & 10.77 \\
\hline 266 & 2.03 & 354 & 0.38 & 440 & 17.34 \\
\hline 268 & 2.10 & 356 & 0.41 & 442 & 8.97 \\
\hline 270 & 2.24 & 358 & 0.44 & 444 & 12.39 \\
\hline 272 & 2.41 & 360 & 0.49 & 446 & 6.58 \\
\hline 274 & 2.65 & 362 & 0.58 & 448 & 4.66 \\
\hline 276 & 2.76 & 364 & 0.57 & 450 & 9.76 \\
\hline 278 & 2.85 & 366 & 0.65 & 452 & 20.37 \\
\hline 280 & 2.89 & 368 & 0.87 & 454 & 34.09 \\
\hline 282 & 3.08 & 370 & 1.01 & 456 & 9.66 \\
\hline 284 & 3.27 & 372 & 1.05 & 458 & 1.60 \\
\hline 286 & 3.52 & 374 & 1.18 & 460 & 1.13 \\
\hline 288 & 3.57 & 376 & 1.26 & 462 & 0.47 \\
\hline 290 & 3.52 & 378 & 1.42 & 464 & 0.32 \\
\hline 292 & 3.43 & 380 & 1.81 & 466 & 0.41 \\
\hline 29 & 3.53 & 382 & 2.00 & 468 & 0.09 \\
\hline 296 & 3.62 & & & & \\
\hline
\end{tabular}




\section{Comments on Preferred Values}

Glyoxal exhibits two distinct absorption regions relevant for atmospheric photolysis. The first region consists of a series of discrete bands between $360-460 \mathrm{~nm}$, super-imposed on a continuum. The second region shows a broad band with some structure with a maximum absorption near $300 \mathrm{~nm}$. The preferred values for the absorption cross-sections are based on those determined by Horowitz et al. (2001), which, except at $\lambda<240 \mathrm{~nm}$, are in excellent agreement with the data of Orlando and Tyndall (2001) and in satisfactory agreement with the earlier data of Plum et al. (1983). Zhu et al. (1996) have measured the cross-sections at $193 \mathrm{~nm}, 248 \mathrm{~nm}, 308 \mathrm{~nm}$ and $351 \mathrm{~nm}$. Where comparison is possible there is good agreement with the recommended data at all wavelengths. The values given above are averaged over $2 \mathrm{~nm}$ and are taken from the compilation in http://www.atmosphere.mpg.de/enid/, which also contains data at other resolution.

There are insufficient data on quantum yields to recommend values as a function of wavelength under atmospheric conditions. The overall quantum efficiency in the first absorption region is low, but the results of Zhu et al. (1996) suggest that dissociation to 2 HCO radicals is significant at wavelengths less than the dissociation threshold (401 nm). The "effective" quantum yield of $\phi=0.029$ reported by Plum et al. (1983) is valid only for the particular spectral distribution used in their study. They measured $(\phi \sigma)$ integrated over the range $325 \mathrm{~nm}$ to $470 \mathrm{~nm}$ and this may be used to calculate the rate of photolysis of glyoxal under tropospheric conditions within that spectral region. Since the recommended $\sigma$ values are $\sim 10 \%$ higher than reported by Plum et al. (1983) in this region, an "effective" quantum yield of $\phi=0.026$ should be used. The validity of this calculation has been supported by chamber studies of Klotz et al. (2000). Both Zhu et al. (1996) and Langford and Moore (1984) obtain a value of $\phi_{2} \approx 0.4$ at $308 \mathrm{~nm}$. The fall off in $\phi(\mathrm{HCO})$ below $350 \mathrm{~nm}$ may be due to occurrence of molecular channels (1) and (3), which can now be rationalised theoretically.

\section{References}

Horowitz, A., Meller, R. and Moortgat, G. K.: J. photochem. Photobiol., A: Chem. 146, 19, 2001.

Klotz, B., Graedler, F., Sorenson, S., Barnes, I., and Becker, K.-H.: Int. J. Chem. Kinet., 33, 9, 2001.

Langford, A. O. and Moore, C. B.: J. Chem. Phys., 80, 4211, 1984.

Li, X. and Schlegel, H. B.: J. Chem. Phys., 114, 8, 2001.

Plum, C. N., Sanhueza, E., Atkinson, R., Carter, W. P. L., and Pitts Jr., J. N.: Environ. Sci. Technol., 17, 479, 1983.

Zhu, L., Kellis, D., and Ding, C.-F.: Chem. Phys. Lett., 257, 487, 1996. 
II.A8.202

$\mathrm{HOCH}_{2} \mathrm{CHO}+\mathbf{h} v \rightarrow$ products

Primary photochemical transitions

\begin{tabular}{llccc}
\hline Reaction & & & $\Delta \mathrm{H}_{298}^{\circ} / \mathrm{kJ} \cdot \mathrm{mol}^{-1}$ & $\lambda_{\text {threshold }} / \mathrm{nm}$ \\
\hline $\mathrm{HOCH}_{2} \mathrm{CHO}+\mathrm{h} v$ & $\rightarrow \mathrm{CH}_{3} \mathrm{OH}+\mathrm{CO}$ & $(1)$ & -19.5 & \\
& $\rightarrow \mathrm{HOCH}_{2}+\mathrm{HCO}$ & $(2)$ & 355.3 & 337 \\
& $\rightarrow \mathrm{HOCH}_{2} \mathrm{CO}+\mathrm{H}$ & $(3)$ & 373.8 & 320 \\
\hline
\end{tabular}

Absorption cross-sections

\begin{tabular}{llr}
\hline Wavelength range/nm & Reference & Comments \\
\hline $205-335$ & Bacher et al., 2001 & (a) \\
\hline
\end{tabular}

Quantum yield data $\left(\phi=\phi_{1}+\phi_{2}+\phi_{3}\right)$

\begin{tabular}{lccc}
\hline Measurement & Wavelength range/nm & Reference & Comments \\
\hline $0.5<\phi<1.0$ & $285 \pm 25$ & Bacher et al., 2001 & (b) \\
\hline
\end{tabular}

\section{Comments}

(a) Diode array spectrophotometric measurements with $90 \mathrm{~cm}$ pathlength. Data obtained with $1 \mathrm{~nm}$ resolution. Beer-Lambert plot linear over range of glycolaldehyde pressure of 0.04-0.6 mbar. Cross-sections tabulated at $1 \mathrm{~nm}$ intervals. Peak cross section at $277 \mathrm{~nm}$ was $5.49 \times 10^{-20} \mathrm{~cm}^{2}$ molecule ${ }^{-1}$ with an error of $\pm 15 \%$.

(b) Overall quantum yields for the photolysis of $\sim 100 \mathrm{ppm}$ of $\mathrm{HOCH}_{2} \mathrm{CHO}$ in air at a total pressure of 1 bar, determined relative to a value of 0.3 determined for acetone in the same equipment. Products and mechanism of the steady state photolysis was deduced, which suggested that Reaction (2) was the main channel but with a significant contribution from Reaction (1).

\section{Preferred Values}

\section{Absorption Cross-Sections at $298 \mathrm{~K}$}

\begin{tabular}{cccccc}
\hline$\lambda / \mathrm{nm}$ & $10^{20} \sigma / \mathrm{cm}^{2}$ & $\lambda / \mathrm{nm}$ & $10^{20} \sigma / \mathrm{cm}^{2}$ & $\lambda / \mathrm{nm}$ & $10^{20} \sigma / \mathrm{cm}^{2}$ \\
\hline 205 & 39.1 & 250 & 2.36 & 295 & 3.59 \\
206 & 33.7 & 251 & 2.50 & 296 & 3.46 \\
207 & 28.7 & 252 & 2.65 & 297 & 3.29 \\
208 & 24.6 & 253 & 2.82 & 298 & 3.17 \\
209 & 21.2 & 254 & 2.97 & 299 & 3.02 \\
210 & 18.1 & 255 & 3.09 & 300 & 2.90 \\
211 & 15.3 & 256 & 3.21 & 301 & 2.74 \\
212 & 13.0 & 257 & 3.39 & 302 & 2.51 \\
213 & 11.2 & 258 & 3.59 & 303 & 2.26 \\
214 & 9.40 & 259 & 3.75 & 304 & 2.07 \\
215 & 7.84 & 260 & 3.89 & 305 & 1.91 \\
216 & 6.49 & 261 & 4.02 & 306 & 1.77 \\
217 & 5.30 & 262 & 4.13 & 307 & 1.64 \\
\hline
\end{tabular}




\begin{tabular}{cccccc}
\hline$\lambda / \mathrm{nm}$ & $10^{20} \sigma / \mathrm{cm}^{2}$ & $\lambda / \mathrm{nm}$ & $10^{20} \sigma / \mathrm{cm}^{2}$ & $\lambda / \mathrm{nm}$ & $10^{20} \sigma / \mathrm{cm}^{2}$ \\
\hline 218 & 4.26 & 263 & 4.24 & 308 & 1.50 \\
219 & 3.37 & 264 & 4.40 & 309 & 1.36 \\
220 & 2.65 & 265 & 4.60 & 310 & 1.25 \\
221 & 2.13 & 266 & 4.75 & 311 & 1.15 \\
222 & 1.65 & 267 & 4.85 & 312 & 1.03 \\
223 & 1.36 & 268 & 4.92 & 313 & 0.884 \\
224 & 1.12 & 269 & 4.99 & 314 & 0.771 \\
225 & 0.933 & 270 & 5.05 & 315 & 0.689 \\
226 & 0.783 & 271 & 5.14 & 316 & 0.597 \\
227 & 0.691 & 272 & 5.23 & 317 & 0.516 \\
228 & 0.637 & 273 & 5.36 & 318 & 0.455 \\
229 & 0.637 & 274 & 5.40 & 319 & 0.396 \\
230 & 0.649 & 275 & 5.41 & 320 & 0.329 \\
231 & 0.644 & 276 & 5.39 & 321 & 0.285 \\
232 & 0.680 & 277 & 5.42 & 322 & 0.249 \\
233 & 0.723 & 278 & 5.37 & 323 & 0.213 \\
234 & 0.785 & 279 & 5.34 & 324 & 0.185 \\
235 & 0.833 & 280 & 5.34 & 325 & 0.147 \\
236 & 0.880 & 281 & 5.37 & 326 & 0.128 \\
237 & 0.939 & 282 & 5.37 & 327 & 0.105 \\
238 & 1.03 & 283 & 5.25 & 328 & 0.087 \\
239 & 1.11 & 284 & 5.12 & 329 & 0.084 \\
240 & 1.20 & 285 & 5.01 & 330 & 0.068 \\
241 & 1.28 & 286 & 4.93 & 331 & 0.058 \\
242 & 1.38 & 287 & 4.80 & 332 & 0.043 \\
243 & 1.50 & 288 & 4.67 & 333 & 0.040 \\
244 & 1.59 & 289 & 4.58 & 334 & 0.040 \\
245 & 1.71 & 290 & 4.50 & 335 & 0.039 \\
246 & 1.83 & 291 & 4.41 & & \\
247 & 1.95 & 292 & 4.19 & & \\
248 & 2.09 & 293 & 3.96 & & \\
249 & 2.22 & 294 & 3.76 & & \\
\hline & & & & &
\end{tabular}

Quantum Yield: $\phi=0.75 \pm 0.25$ for $\lambda=260-310 \mathrm{~nm}$ in 1 bar air

\section{Comments on Preferred Values}

The preferred absorption cross-sections are from the study of Bacher et al. (2001), which are the only measurements reported and appear to be reliable. The preferred value for the overall quantum yield is based on the work of Bacher et al. (2001). The value was determined relative to $\phi\left(\mathrm{CH}_{3} \mathrm{C}(\mathrm{O}) \mathrm{CH}_{3}\right)=0.3$ in 1 bar air for the wavelength region $260-310 \mathrm{~nm}$, which is consistent with the work of Gierczak et al. (1998) which forms the basis of the current IUPAC evaluation. The most likely decomposition channel was shown to be HCO production in channel (2), but there is insufficient information to recommend a branching ratio.

\section{References}

Bacher, C., Tyndall, G. S., and Orlando, J. J.: J. Atm. Chem., 39, 171, 2001.

Gierczak, T., Burkholder, J. B., Bauerle, S., and Ravishankara, A. R.: Chem. Phys., 231, 229, 1998. 
II.A8.203

$$
\mathrm{CH}_{3} \mathrm{C}(\mathrm{O}) \mathrm{CHO}+\mathbf{h} v \rightarrow \text { products }
$$

\section{Primary photochemical transitions}

\begin{tabular}{lllcc}
\hline Reaction & & & $\Delta \mathrm{H}_{298}^{\circ} / \mathrm{kJ} \cdot \mathrm{mol}^{-1}$ & $\lambda_{\text {threshold }} / \mathrm{nm}$ \\
\hline $\mathrm{CH}_{3} \mathrm{C}(\mathrm{O}) \mathrm{CHO}+\mathrm{h} \nu$ & $\rightarrow \mathrm{CH}_{4}+2 \mathrm{CO}$ & $(1)$ & -24.7 & \\
& $\rightarrow \mathrm{CH}_{3} \mathrm{CO}+\mathrm{HCO}$ & $(2)$ & 304.2 & 393 \\
& $\rightarrow \mathrm{CH}_{3} \mathrm{CHO}+\mathrm{CO}$ & (3) & -5.2 & \\
\hline
\end{tabular}

\section{Absorption cross-section data}

\begin{tabular}{llc}
\hline Wavelength range/nm & Reference & Comments \\
\hline $220-480$ & Meller et al., 1991 & (a) \\
$205-480$ & Staffelbach et al., 1995 & (b) \\
$290-440$ & Chen et al., 2000 & (c) \\
\hline
\end{tabular}

Quantum yield data $\left(\phi=\phi_{1}+\phi_{2}+\phi_{3}\right)$

\begin{tabular}{lllc}
\hline Measurement & Wavelength range/nm & Reference & Comments \\
\hline$\phi(2)$ & & & \\
0.14 & $240-420$ & Staffelbach et al., 1995 & (d) \\
1.0 & $260-320$ & Koch and Moortgat, 1998 & (e) \\
$1.10 \pm 0.14$ & 380 & & \\
$0.47 \pm 0.09$ & 400 & & \\
$0.21 \pm 0.06$ & 420 & & \\
$0.08 \pm 0.02$ & 440 & Chen et al., 2000 & (f) \\
$0.82 \pm 0.06$ & 290 & & \\
$0.89 \pm 0.10$ & 300 & & \\
$0.97 \pm 0.08$ & 320 & & \\
$0.92 \pm 0.10$ & 380 & & \\
$0.56 \pm 0.09$ & 400 & & \\
$0.27 \pm 0.04$ & 420 & & \\
$0.17 \pm 0.02$ & 440 & & \\
\hline
\end{tabular}

\section{Comments}

(a) Measured over the range $220 \mathrm{~nm}$ to $480 \mathrm{~nm}$ by conventional UV spectroscopy in a cell of path length $63 \mathrm{~cm}$. Light was detected by a diode array camera and the spectral resolution was $0.07 \mathrm{~nm}$. As well as using methylglyoxal prepared external to the cell, methylglyoxal was generated in situ by the $\mathrm{Cl}$ atom-initiated modulated photo-oxidation of hydroxyacetone and the cross-sections were measured over the range $390 \mathrm{~nm}$ to $460 \mathrm{~nm}$ in these in situ studies.

(b) Cross-sections measured in a $90 \mathrm{~cm}$ cell using a diode array spectrometer. The spectral resolution was estimated to be $0.6 \mathrm{~nm}$. Pressures in the range $0.13 \mathrm{mbar}$ to 8.0 mbar were used and measurements were made at $248 \mathrm{~K}, 273 \mathrm{~K}$ and $298 \mathrm{~K}$.

(c) Cross-sections determined from transmission of UV light at $5 \mathrm{~nm}$ intervals from tunable dye laser, as a function of $\mathrm{CH}_{3} \mathrm{C}(\mathrm{O}) \mathrm{CHO}$ pressure. Overall uncertainty estimated to be $\sim 10 \%$ at all wavelengths, except at 280 and $330 \mathrm{~nm}$, where uncertainties are $20-30 \%$ higher. 
(d) Low concentrations of methylglyoxal in an $\mathrm{O}_{2}(20 \%) / \mathrm{N}_{2}(80 \%)$ mixture at 1 bar were photolysed with an Xe arc equipped with filters to isolate specific wavelength regions. Products $\left(\mathrm{HCHO}, \mathrm{CH}_{3} \mathrm{C}(\mathrm{O}) \mathrm{OH}, \mathrm{CH}_{3} \mathrm{C}(\mathrm{O}) \mathrm{O}_{2} \mathrm{H}, \mathrm{CH} 3 \mathrm{OH}, \mathrm{HC}(\mathrm{O}) \mathrm{OH}\right.$, $\mathrm{CO}, \mathrm{CO}_{2}$ ) were monitored by FTIR. Light intensity calibrated by photolysis of $\mathrm{Cl}_{2}-\mathrm{CH}_{3} \mathrm{OH}-\mathrm{O}_{2}-\mathrm{N}_{2}$ mixture. Quantum yields were derived by modeling product yields taking into account a number of important secondary reactions. Average $\phi$ value quoted.

(e) Static photolysis of $\mathrm{CH}_{3} \mathrm{C}(\mathrm{O}) \mathrm{CHO}$ in synthetic air. Quantum yields of molecular products $\mathrm{CO}$ and $\mathrm{HCHO}$ determined by GC. Pressure range 30-900 Torr (0.039-1.2 bar). For the short wavelength band $\phi$ was independent of pressure and wavelength; in the long wavelength band $\phi(\mathrm{CO})$ showed Stern-Volmer pressure quenching and $\phi(\mathrm{HCHO})$ increased with methylglyoxal pressure; zero pressure values of $\mathrm{CH}_{3} \mathrm{C}(\mathrm{O}) \mathrm{CHO}$ are quoted here. The primary process was attributed to Reaction (2) at all wavelengths.

(f) Tunable dye laser photolysis of $\mathrm{CH}_{3} \mathrm{C}(\mathrm{O}) \mathrm{CHO}$ with time resolved measurement of $\mathrm{HCO}$ concentration by cavity ring down spectroscopy at $613.8 \mathrm{~nm}$. Absorbed flux was determined from photon fluence measurements using a calibrated Joulemeter. Absolute yields of $\mathrm{HCO}$ calculated from absorption cross sections, $\sigma(\mathrm{HCO})$, determined by in situ calibration using either photo-dissociation of $\mathrm{HCHO}$ (at 290-310 nm) or $\mathrm{Cl}_{2}+\mathrm{HCHO}$ mixtures (at $310-440 \mathrm{~nm}$ ) to produce known amounts of HCO. A weak dependence of $\phi(\mathrm{HCO})$ on $\mathrm{P}_{\mathrm{CH}} \mathrm{COCHO}$ was observed and the values of $\phi$ quoted at selected wavelengths are for zero pressure, derived from Stern-Volmer plots. No dependence of $\phi(\mathrm{HCO})$ on $\mathrm{N}_{2}$ pressure up to 520 mbar was observed in the $270-390 \mathrm{~nm}$ region. Pressure quenching by $\mathrm{N}_{2}$ was observed in the long wavelength band (380-440 nm) and expressions were reported for the wavelength-dependent zero pressure quantum yield $\phi(\mathrm{HCO})_{0}=(3.63 \pm 0.32) \times 10^{-7}\left[\exp (-(5693 \pm 533) / \lambda(\mathrm{nm})]\right.$ and Stern-Volmer quenching constant by $\mathrm{N}_{2}\left(\mathrm{k}_{Q}\right.$ $\left(\right.$ Torr $\left.^{-1}\right)=(1.93 \pm 0.24) \times 10^{4}[\exp (-(5639 \pm 497) / \lambda(\mathrm{nm})])$. Values of $\phi(2)$ for 1 bar air were obtained by extrapolation, and atmospheric photolysis rates were calculated.

\section{Preferred Values}

Absorption cross-sections at $298 \mathrm{~K}$ at $5 \mathrm{~nm}$ intervals between $225 \mathrm{~nm}$ and $410 \mathrm{~nm}$

\begin{tabular}{cccc}
\hline$\lambda / \mathrm{nm}$ & $10^{20} \sigma / \mathrm{cm}^{2}$ & $\lambda / \mathrm{nm}$ & $10^{20} \sigma / \mathrm{cm}^{2}$ \\
\hline 225 & 1.268 & 320 & 1.511 \\
230 & 1.477 & 325 & 0.938 \\
235 & 1.803 & 330 & 0.652 \\
240 & 2.071 & 335 & 0.482 \\
245 & 2.304 & 340 & 0.323 \\
250 & 2.612 & 345 & 0.300 \\
255 & 2.859 & 350 & 0.394 \\
260 & 3.280 & 355 & 0.560 \\
265 & 3.618 & 360 & 0.695 \\
270 & 4.159 & 365 & 1.077 \\
275 & 4.413 & 370 & 1.475 \\
280 & 4.877 & 375 & 1.911 \\
285 & 4.719 & 380 & 2.429 \\
290 & 4.838 & 385 & 3.221 \\
295 & 4.362 & 390 & 4.029 \\
300 & 3.754 & 395 & 4.732 \\
305 & 3.361 & 400 & 5.664 \\
310 & 2.365 & 405 & 6.923 \\
315 & 1.891 & 410 & 8.459 \\
\hline
\end{tabular}


Absorption cross-sections at $298 \mathrm{~K}$ at $1 \mathrm{~nm}$ intervals between $401 \mathrm{~nm}$ and $475 \mathrm{~nm}$

\begin{tabular}{|c|c|c|c|}
\hline$\lambda / \mathrm{nm}$ & $10^{20} \sigma / \mathrm{cm}^{2}$ & $\lambda / \mathrm{nm}$ & $10^{20} \sigma / \mathrm{cm}^{2}$ \\
\hline 401 & 5.90 & 439 & 11.01 \\
\hline 402 & 6.07 & 440 & 9.94 \\
\hline 403 & 6.35 & 441 & 10.39 \\
\hline 404 & 6.54 & 442 & 10.20 \\
\hline 405 & 6.91 & 443 & 10.17 \\
\hline 406 & 7.20 & 444 & 11.17 \\
\hline 407 & 7.58 & 445 & 9.61 \\
\hline 408 & 7.94 & 446 & 8.90 \\
\hline 409 & 8.12 & 447 & 9.84 \\
\hline 410 & 8.52 & 448 & 9.18 \\
\hline 411 & 8.63 & 449 & 10.13 \\
\hline 412 & 9.07 & 450 & 8.67 \\
\hline 413 & 9.37 & 451 & 6.34 \\
\hline 414 & 9.62 & 452 & 6.33 \\
\hline 415 & 9.68 & 453 & 6.08 \\
\hline 416 & 9.71 & 454 & 4.46 \\
\hline 417 & 10.04 & 455 & 3.69 \\
\hline 418 & 10.07 & 456 & 3.08 \\
\hline 419 & 10.12 & 457 & 2.46 \\
\hline 420 & 10.21 & 458 & 1.81 \\
\hline 421 & 10.34 & 459 & 1.28 \\
\hline 422 & 10.51 & 460 & 0.914 \\
\hline 423 & 10.45 & 461 & 0.795 \\
\hline 424 & 10.15 & 462 & 0.642 \\
\hline 425 & 10.34 & 463 & 0.479 \\
\hline 426 & 10.24 & 464 & 0.332 \\
\hline 427 & 9.84 & 465 & 0.268 \\
\hline 428 & 10.01 & 466 & 0.227 \\
\hline 429 & 9.94 & 467 & 0.187 \\
\hline 430 & 10.41 & 468 & 0.160 \\
\hline 431 & 10.53 & 469 & 0.133 \\
\hline 432 & 9.79 & 470 & 0.108 \\
\hline 433 & 10.64 & 471 & 0.099 \\
\hline 434 & 10.54 & 472 & 0.089 \\
\hline 435 & 10.81 & 473 & 0.077 \\
\hline 436 & 11.13 & 474 & 0.067 \\
\hline 437 & 9.99 & 475 & 0.062 \\
\hline 438 & 10.59 & & \\
\hline
\end{tabular}

Quantum yields for zero pressure at $298 \mathrm{~K}$

$\phi(2)_{0}=(3.63 \pm 0.32) \times 10^{-7}[\exp (5693 \pm 533) / \lambda(\mathrm{nm})]$ for $380<\lambda<440 \mathrm{~nm}$

$\phi(2)_{0}=1.0$ for $280<\lambda<380 \mathrm{~nm}$

\section{Comments on Preferred Values}

The preferred values of the absorption cross-sections are taken from the work of Meller et al. (1991). The cross-sections of Staffelbach et al. (1995) and Chen et al. (2000) agree to within <10\% with those of Meller et al. (1991) across the whole range 
of the three studies. Staffelbach et al. (1995) also studied the cross-sections at three different temperatures, $248 \mathrm{~K}, 273 \mathrm{~K}$, and $298 \mathrm{~K}$. They found little variation in the cross-sections $(\leq 10 \%)$ over this temperature range.

The recent studies of Koch and Moortgat (1998) and Chen et al. (2000) provide for the first time information on the wavelength-resolved quantum yields for methylglyoxal photolysis, and the latter study gives direct measurements of the initial product of photodissociation by Reaction (2), HCO. This demonstrates conclusively that Reaction (2) is the predominant dissociation channel over the wavelength range $280-440 \mathrm{~nm}$. These results supercede the earlier work of Staffelbach et al. (1995), Raber and Moortgat (1997) and Plum et al. (1983), which used broad-band excitation.

The results of Koch and Moortgat (1998) and Chen et al. (2000) are in good agreement for the zero pressure quantum yields, and for the absence of pressure dependence of $\phi(2)$ at $\lambda<380 \mathrm{~nm}$. At the longer wavelengths $(380<\lambda<440 \mathrm{~nm})$ both studies observed a fall off in $\phi(2)$ with wavelength, and a complex pressure dependence. Koch and Moortgat (1998) interpret their $\mathrm{HCHO}$ yields using a mechanism with a reaction of excited methylglyoxal with the ground state. The quenching by $\mathrm{N}_{2}$ observed by Chen et al. (2000) in the long wavelength band (380-440 nm) did not exhibit Stern-Volmer behaviour, indicating the involvement of more than one excited precursor for HCO. There is a difference of up to a factor of 4 in the extrapolated values for the quantum yields in the range $\lambda=380-400 \mathrm{~nm}$ at atmospheric pressure reported from the two studies.

The preferred values are taken from Chen et al. (2000), since they were determined directly. The expression for the wavelength dependence of $\phi(2)_{0}$ (zero pressure) at $\lambda>380 \mathrm{~nm}$ is taken from their work. Values at higher pressures (of air) can be calculated using the expression for the wavelength dependence of the quenching constant obtained by approximating to the Stern Volmer relationship:

$$
1 / \phi(2)=1 / \phi(2)_{0}+\mathrm{k}_{Q} \mathrm{P}\left[\mathrm{N}_{2} \text { (Torr) }\right]
$$

where $\mathrm{k}_{Q}\left(\right.$ Torr $\left.^{-1}\right)=(1.93 \pm 0.24) \times 10^{4}[\exp (-(5639 \pm 497) / \lambda(\mathrm{nm})]$. In view of the departure from linearity this leads to an estimated uncertainty up to $\pm 50 \%$ in the overall quantum yield at 1 bar.

\section{References}

Chen, Y., Wang, W., and Zhu, L.: J. Phys. Chem. A, 104, 11 126, 2000.

Koch, S. and Moortgat, G. K.: J. Phys. Chem. A, 102, 9142, 1998.

Meller, R., Raber, W., Crowley, J. N., Jenkin, M. E., and Moortgat, G. K.: J. Photochem. Photobiol. A: Chemistry, 62, 163, 1991.

Plum, C. N., Sanhueza, E., Atkinson, R., Carter, W. P. L., and Pitts Jr., J. N.: Environ. Sci. Technol., 17, 479, 1983.

Raber, W. H. and Moortgat, G. K.: Photooxidation of Selected Carbonyl Compounds in Air: Methyl Ethyl Ketone, Methyl Vinyl Ketone, Methacrolein and Methylglyoxal, Chap. 9, in: 'Progress and Problems in Atmospheric Chemistry', edited by: Barker, J., World Scientific Publishing, Singapore, 1997.

Staffelbach, T. A., Orlando, J. J., Tyndall, G. S., and Calvert, J. G.: J. Geophys. Res., 100, 14 189, 1995. 
II.A8.204

$\mathrm{CH}_{3} \mathbf{C}(\mathrm{O}) \mathrm{CH}_{3}+\mathbf{h} v \rightarrow$ products

Primary photochemical transitions

\begin{tabular}{lllcc}
\hline Reaction & & $\Delta \mathrm{H}_{298}^{\circ} / \mathrm{kJ} \cdot \mathrm{mol}^{-1}$ & $\lambda_{\text {threshold }} / \mathrm{nm}$ \\
\hline $\mathrm{CH}_{3} \mathrm{C}(\mathrm{O}) \mathrm{CH}_{3}+\mathrm{h} v$ & $\rightarrow \mathrm{CH}_{3} \mathrm{CO}+\mathrm{CH}_{3}$ & $(1)$ & 353.6 & 338 \\
& $\rightarrow 2 \mathrm{CH}_{3}+\mathrm{CO}$ & (2) & 399.5 & 299 \\
\hline
\end{tabular}

Absorption cross-section data

\begin{tabular}{llc}
\hline Wavelength range/nm & Reference & Comments \\
\hline $202-355$ & Martinez et al., 1992 & (a) \\
$260-360$ & Hynes et al., 1992 & (b) \\
$215-350$ & Gierczak et al., 1998 & (c) \\
$240-350$ & Yujing and Mellouki, 2000 & (d) \\
\hline
\end{tabular}

Quantum yield data $\left(\phi=\phi_{1}+\phi_{2}\right)$

\begin{tabular}{lllc}
\hline Measurement & Wavelength range/nm & Reference & Comments \\
\hline$\phi_{1}=0.76-0.0033$ & $250-330$ & Meyrahn et al., 1986 & (e) \\
$\phi=1.0-0.016$ & $248-337$ & Gierczak et al., 1998 & (f) \\
$\phi_{1}=1.0-0.062$ & $280-330$ & Emrich and Warneck, 2000 & (g) \\
$\phi_{1}=1.0,0.28$ & 248,308 & Emrich and Warneck, 2000 & (h) \\
$\phi_{1}=1.0-0.01$ & $279-327.5$ & Blitz et al., 2004 & (i) \\
$\phi(\mathrm{CO})=0.45(20$ mbar) $)$ & 248 & Somnitz et al., 2005 & (j) \\
$0.25(900$ mbar $)$ & & & \\
\hline
\end{tabular}

\section{Comments}

(a) Cross-sections are the average cross-section over a $1 \mathrm{~nm}(\lambda>280 \mathrm{~nm})$ or $4 \mathrm{~nm}(\lambda<280 \mathrm{~nm})$ region centered at the corresponding wavelength. $\sigma_{\max }=5.07 \times 10^{-20} \mathrm{~cm}^{2}$ molecule $^{-1}$ at $278 \mathrm{~nm}$.

(b) Cross-sections measured as a function of temperature over the range $260 \mathrm{~K}$ to $360 \mathrm{~K}$. Data were presented in graphical form and show a marked decrease in cross-section with decreasing temperature at longer wavelengths.

(c) Measurements made using a diode array spectrometer with a $\mathrm{D}_{2}$ lamp source and temperature controlled cell with $200 \mathrm{~cm}$ path-length. Resolution $0.5 \mathrm{~nm}$. Temperature range $235-298 \mathrm{~K}$. Modest temperature dependence at $\lambda>300 \mathrm{~nm}$. Tabulated cross sections at $1 \mathrm{~nm}$ intervals and parameterisation of temperature dependence given. $\sigma_{\max }=4.94 \times 10^{-20} \mathrm{~cm}^{2}$ molecule $^{-1}( \pm 5 \%)$ at $278 \mathrm{~nm}$.

(d) Commercial diode array spectrometer with a $\mathrm{D}_{2}$ lamp source and $200 \mathrm{~cm}$ pathlength cell at $298 \mathrm{~K}$. Resolution $0.04 \mathrm{~nm}$. Tabulated cross sections at $1 \mathrm{~nm}$ intervals given. $\sigma_{\max }=4.97 \times 10^{-20} \mathrm{~cm}^{2}$ molecule ${ }^{-1}( \pm 5 \%)$ at $278 \mathrm{~nm}$.

(e) Study of the quantum yield of formation of $\mathrm{CO}_{2}$ and $\mathrm{CO}$ in the photolysis of dilute mixtures of acetone $(0.13 \mathrm{mbar}$ to $0.20 \mathrm{mbar})$ in air $(990 \mathrm{mbar})$ at room temperature. In addition, the quantum yields of formation of peroxyacetyl nitrate (PAN) were measured when trace amounts of $\mathrm{NO}_{2}\left(1.2 \times 10^{-4} \mathrm{mbar}\right)$ were added to the reactant mixtures. The listed values of $\phi_{1}$ are the quantum yields of PAN, which were taken as a measure of the extent of primary process (1). 
(f) Quantum yield determined using pulsed laser photolysis of static mixtures with measurement of the loss of acetone and formation of products. $\phi$ was determined as a function of pressure (30-1000 mbar air) and at nine discrete wavelengths in the stated range. At $\lambda>270 \mathrm{~nm} \phi$ showed Stern-Volmer pressure quenching. The zero pressure quantum yield increased as wavelength decreased to a value of unity near $290 \mathrm{~nm}$. At $308 \mathrm{~nm} \phi$ was independent of temperature between 298 and 195 K. Expression given for the variation with pressure and wavelength of $\phi$ for 1 bar air.

(g) Quantum yields for peroxyacetyl nitrate (PAN) production from photodissociation of acetone $(<1 \%)$ in air when trace amounts of $\mathrm{NO}_{2}$ were added to the reactant mixtures. The quantum yields of PAN formation used to determine $\phi_{1}$ at $10 \mathrm{~nm}$ intervals in the range given and at total pressures in the range 130-1000 mbar. Stern-Volmer pressure quenching observed at all wavelengths. Results interpreted in terms of the elementary processes involving the first excited singlet and triplet states of acetone, providing rate parameters for the competing processes as a function of excitation energy.

(h) Relative quantum yield for acetone photodissociation at the specified laser wavelengths with and without water present. At a total pressure of 133 mbar, $\mathrm{H}_{2} \mathrm{O}$ up to 12 mbar suppressed the quantum yield, the effect being stronger at $308 \mathrm{~nm}$.

(i) Quantum yields for $\mathrm{CH}_{3} \mathrm{CO}$ formation determined as a function of temperature (218-295 K) and pressure (0.46-540 mbar, [He, $\mathrm{N}_{2}$ or Air]) using time-resolved HO-photofragment spectroscopy to monitor acetyl radical production from PLP of acetone $\left(0.006\right.$ mbar). $\mathrm{HO}$ produced from $\mathrm{CH}_{3} \mathrm{CO}$ photolysis was monitored by LIF at $282 \mathrm{~nm}$ giving sensitivity of $<10^{8}$ molecule $\mathrm{cm}^{3}$. The total quantum yield $\phi_{\text {total }}(\lambda, \mathrm{p}, \mathrm{T})=\phi_{\mathrm{CH} 3 \mathrm{CO}}(\lambda, \mathrm{p}, \mathrm{T})+\phi_{\mathrm{CO}}(\lambda, \mathrm{T})=\phi_{1}+\phi_{2}$ was determined relative to the measured values of $\phi_{\text {total }}=1, \phi_{\mathrm{CH} 3 \mathrm{CO}}=0.65$ and $\phi_{\mathrm{CO}}=0.35$, at $248 \mathrm{~nm}$ and $295 \mathrm{~K}$, at the pressure limit $\mathrm{p}$ $=0$. Pressure dependence was represented by simple Stern-Volmer quenching at $\lambda<302 \mathrm{~nm}$, but at longer wavelengths an extended form of Stern-Volmer expression was necessary to represent the data. A substantial decline in $\phi_{\text {total }}$ with decreasing temperature was observed at wavelengths above $310 \mathrm{~nm}$. An empirical algorithm for the overall dissociation quantum yield, and for $\phi_{\mathrm{CH} 3 \mathrm{CO}}$ and $\phi_{\mathrm{CO}}$ in air, as a function of wavelength, temperature and pressure is given.

(j) Quantum yields for CO formation determined as a function of pressure (20-900 mbar, [ $\left.\mathrm{N}_{2}\right]$ ) at 298 K, using infrared diode laser absorption to monitor CO production from PLP of acetone at $248 \mathrm{~nm}$. Results are interpreted to show CO production results exclusively from channel (1) via $\mathrm{CH}_{3} \mathrm{CO}$ decomposition .

\section{Preferred Values}

Temperature dependent cross sections (215-349 nm)

\begin{tabular}{|c|c|c|c|c|c|c|c|c|c|}
\hline $\begin{array}{l}\lambda / \\
(\mathrm{nm})\end{array}$ & $\begin{array}{l}10^{20} \sigma \\
\left(\mathrm{cm}^{2}\right)\end{array}$ & $\begin{array}{l}10^{3} \mathrm{~A} \\
\left(\mathrm{~K}^{-1}\right)\end{array}$ & $\begin{array}{l}10^{5} \mathrm{~B} \\
\left(\mathrm{~K}^{-2}\right)\end{array}$ & $\begin{array}{l}10^{8} \mathrm{C} \\
\left(\mathrm{K}^{-3}\right)\end{array}$ & $\begin{array}{l}\lambda / \\
(\mathrm{nm})\end{array}$ & $\begin{array}{l}10^{20} \sigma \\
\left(\mathrm{cm}^{2}\right)\end{array}$ & $\begin{array}{l}10^{3} \mathrm{~A} \\
\left(\mathrm{~K}^{-1}\right)\end{array}$ & $\begin{array}{l}10^{5} \mathrm{~B} \\
\left(\mathrm{~K}^{-2}\right)\end{array}$ & $\begin{array}{l}10^{8} \mathrm{C} \\
\left(\mathrm{K}^{-3}\right)\end{array}$ \\
\hline 215 & 0.167 & -10.46 & 8.346 & 16.43 & 283 & 4.71 & 1.137 & -1.350 & 3.272 \\
\hline 216 & 0.180 & -9.192 & 7.357 & -14.51 & 284 & 4.62 & 0.8530 & -1.158 & 2.943 \\
\hline 217 & 0.196 & -6.233 & 5.039 & -10.0 & 285 & 4.54 & 0.6518 & -1.023 & 2.714 \\
\hline 218 & 0.212 & -3.190 & 2.651 & -5.359 & 286 & 4.44 & 0.4907 & -0.9154 & 2.531 \\
\hline 219 & 0.228 & -1.002 & 0.9314 & -2.003 & 287 & 4.36 & 0.3190 & -0.7992 & 2.332 \\
\hline 220 & 0.24 & 0.4104 & -0.1807 & 0.1679 & 288 & 4.28 & 0.1109 & 0.6586 & 2.092 \\
\hline 221 & 0.270 & 1.567 & -1.090 & 1.93 & 289 & 4.15 & -0.1230 & -0.5036 & 1.833 \\
\hline 222 & 0.294 & 2.962 & -2.183 & 4.058 & 290 & 4.06 & -0.3698 & -0.3426 & 1.568 \\
\hline 223 & 0.318 & 4.839 & -3.651 & 6.909 & 291 & 3.95 & -0.6430 & -0.1615 & 1.265 \\
\hline 224 & 0.346 & 6.940 & -5.293 & 10.09 & 292 & 3.82 & -0.9625 & 0.05796 & 0.8847 \\
\hline 225 & 0.380 & 8.598 & -6.588 & 12.60 & 293 & 3.71 & -1.316 & 0.306 & 0.4472 \\
\hline 226 & 0.419 & 9.380 & -7.200 & 13.79 & 294 & 3.57 & -1.650 & 0.535 & 0.0477 \\
\hline 227 & 0.456 & 9.551 & -7.336 & 14.06 & 295 & 3.42 & -1.905 & 0.699 & -0.2168 \\
\hline 228 & 0.492 & 9.705 & -7.462 & 14.31 & 296 & 3.26 & -2.084 & 0.796 & -0.3430 \\
\hline 229 & 0.535 & 10.08 & -7.761 & 14.89 & 297 & 3.11 & -2.234 & 0.867 & -0.4086 \\
\hline 230 & 0.584 & 10.41 & -8.023 & 15.41 & 298 & 2.98 & -2.391 & 0.942 & -0.4824 \\
\hline 231 & 0.637 & 10.39 & -8.002 & 15.36 & 299 & 2.82 & -2.590 & 1.055 & -0.6387 \\
\hline 232 & 0.693 & 10.01 & -7.707 & 14.79 & 300 & 2.67 & -2.915 & 1.277 & -1.020 \\
\hline 233 & 0.750 & 9.534 & -7.332 & 14.06 & 301 & 2.58 & -3.421 & 1.649 & -1.709 \\
\hline 234 & 0.815 & 9.138 & -7.022 & 13.46 & 302 & 2.45 & -4.008 & 2.091 & -2.543 \\
\hline 235 & 0.885 & 8.851 & -6.799 & 13.02 & 303 & 2.30 & -4.508 & 2.465 & -3.248 \\
\hline
\end{tabular}




\begin{tabular}{|c|c|c|c|c|c|c|c|c|c|}
\hline $\begin{array}{l}\lambda / \\
(\mathrm{nm})\end{array}$ & $\begin{array}{l}10^{20} \sigma \\
\left(\mathrm{cm}^{2}\right)\end{array}$ & $\begin{array}{l}10^{3} \mathrm{~A} \\
\left(\mathrm{~K}^{-1}\right)\end{array}$ & $\begin{array}{l}10^{5} \mathrm{~B} \\
\left(\mathrm{~K}^{-2}\right)\end{array}$ & $\begin{array}{l}10^{8} \mathrm{C} \\
\left(\mathrm{K}^{-3}\right)\end{array}$ & $\begin{array}{l}\lambda / \\
(\mathrm{nm})\end{array}$ & $\begin{array}{l}10^{20} \sigma \\
\left(\mathrm{cm}^{2}\right)\end{array}$ & $\begin{array}{l}10^{3} \mathrm{~A} \\
\left(\mathrm{~K}^{-1}\right)\end{array}$ & $\begin{array}{l}10^{5} \mathrm{~B} \\
\left(\mathrm{~K}^{-2}\right)\end{array}$ & $\begin{array}{l}10^{8} \mathrm{C} \\
\left(\mathrm{K}^{-3}\right)\end{array}$ \\
\hline 236 & 0.956 & 8.638 & -6.634 & 12.70 & 304 & 2.18 & -4.858 & 2.715 & -3.699 \\
\hline 237 & 1.03 & 8.471 & -6.504 & 12.45 & 305 & 2.05 & -5.120 & 2.880 & -3.959 \\
\hline 238 & 1.11 & 8.318 & -6.385 & 12.22 & 306 & 1.89 & -5.433 & 3.062 & -4.219 \\
\hline 239 & 1.21 & 8.125 & -6.235 & 11.93 & 307 & 1.75 & -6.010 & 3.429 & -4.805 \\
\hline 240 & 1.30 & 7.861 & -6.031 & 11.53 & 308 & 1.61 & -6.986 & 4.096 & -5.954 \\
\hline 241 & 1.40 & 7.554 & -5.793 & 11.07 & 309 & 1.49 & -8.135 & 4.899 & -7.370 \\
\hline 242 & 1.50 & 7.268 & -5.571 & 10.64 & 310 & 1.36 & -8.897 & 5.415 & -8.255 \\
\hline 243 & 1.60 & 7.035 & -5.390 & 10.29 & 311 & 1.24 & -8.923 & 5.378 & -8.097 \\
\hline 244 & 1.72 & 6.838 & -5.237 & 9.994 & 312 & 1.14 & -8.494 & 5.001 & -7.305 \\
\hline 245 & 1.83 & 6.649 & -5.093 & 9.718 & 313 & 1.06 & -8.228 & 4.754 & -6.772 \\
\hline 246 & 1.95 & 6.472 & -4.960 & 9.464 & 314 & 0.944 & -8.445 & 4.881 & -6.959 \\
\hline 247 & 2.07 & 6.326 & -4.850 & 9.256 & 315 & 0.837 & -8.966 & 5.240 & -7.592 \\
\hline 248 & 2.20 & 6.210 & -4.763 & 9.091 & 316 & 0.760 & -9.409 & 5.528 & -8.076 \\
\hline 249 & 2.33 & 6.099 & -4.680 & 8.936 & 317 & 0.684 & -9.584 & 5.588 & -8.085 \\
\hline 250 & 2.47 & 5.972 & -4.587 & 8.763 & 318 & 0.598 & -9.736 & 5.596 & -7.946 \\
\hline 251 & 2.60 & 5.832 & -4.486 & 8.576 & 319 & 0.523 & -10.39 & 5.958 & -8.433 \\
\hline 252 & 2.74 & 5.697 & -4.389 & 8.399 & 320 & 0.455 & -11.80 & 6.869 & -9.933 \\
\hline 253 & 2.87 & 5.581 & -4.306 & 8.249 & 321 & 0.411 & -13.48 & 7.962 & -11.75 \\
\hline 254 & 3.01 & 5.483 & -4.235 & 8.120 & 322 & 0.348 & -14.59 & 8.600 & -12.67 \\
\hline 255 & 3.15 & 5.385 & -4.164 & 7.989 & 323 & 0.294 & -14.98 & 8.670 & -12.47 \\
\hline 256 & 3.30 & 5.261 & -4.075 & 7.825 & 324 & 0.248 & -15.39 & 8.743 & -12.27 \\
\hline 257 & 3.44 & 5.101 & -3.961 & 7.620 & 325 & 0.210 & -16.28 & 9.187 & -12.77 \\
\hline 258 & 3.57 & 4.932 & -3.843 & 7.410 & 326 & 0.174 & -17.09 & 9.588 & -13.21 \\
\hline 259 & 3.69 & 4.802 & -3.756 & 7.262 & 327 & 0.141 & -17.21 & 9.471 & -12.68 \\
\hline 260 & 3.81 & 4.746 & -3.723 & 7.215 & 328 & 0.113 & -16.92 & 9.048 & -11.58 \\
\hline 261 & 3.94 & 4.744 & -3.730 & 7.239 & 329 & 0.0913 & -16.66 & 8.672 & -10.62 \\
\hline 262 & 4.07 & 4.734 & -3.729 & 7.246 & 330 & 0.0740 & -15.94 & 7.979 & -9.099 \\
\hline 263 & 4.20 & 4.651 & -3.674 & 7.155 & 331 & 0.0586 & -13.93 & 6.340 & -5.829 \\
\hline 264 & 4.32 & 4.482 & -3.559 & 6.956 & 332 & 0.0465 & -10.93 & 3.969 & -1.214 \\
\hline 265 & 4.41 & 4.271 & -3.416 & 6.712 & 333 & 0.0375 & -8.186 & 1.847 & 2.840 \\
\hline 266 & 4.49 & 4.087 & -3.296 & 6.513 & 334 & 0.0311 & -6.530 & 0.6289 & 5.067 \\
\hline 267 & 4.56 & 3.983 & -3.234 & 6.420 & 335 & 0.0248 & -5.692 & 0.1022 & 5.880 \\
\hline 268 & 4.64 & 3.969 & -3.235 & 6.440 & 336 & 0.0199 & -4.656 & -0.5382 & 6.860 \\
\hline 269 & 4.72 & 4.009 & -3.273 & 6.524 & 337 & 0.0162 & -2.090 & -2.355 & 10.09 \\
\hline 270 & 4.79 & 4.025 & -3.294 & 6.577 & 338 & 0.0135 & 3.113 & -6.237 & 17.33 \\
\hline 271 & 4.87 & 3.935 & -3.240 & 6.494 & 339 & 0.0113 & 11.01 & -12.26 & 28.77 \\
\hline 272 & 4.91 & 3.704 & -3.085 & 6.231 & 340 & 00912 & 20.02 & -19.22 & 42.15 \\
\hline 273 & 4.94 & 3.378 & -2.861 & 5.845 & 341 & 00729 & 27.20 & -24.83 & 53.03 \\
\hline 274 & 4.94 & 3.061 & -2.645 & 5.473 & 342 & 00583 & 29.63 & -26.80 & 56.96 \\
\hline 275 & 4.94 & 2.854 & -2.508 & 5.243 & 343 & 00494 & 25.97 & -24.04 & 51.78 \\
\hline 276 & 4.93 & 2.790 & -2.474 & 5.201 & 344 & 00365 & 16.35 & -16.63 & 37.55 \\
\hline 277 & 4.92 & 2.816 & -2.505 & 5.276 & 345 & 0,0301 & 3.774 & -6.858 & 18.72 \\
\hline 278 & 4.94 & 2.82 & $-2,518$ & 5.316 & 346 & 0.00235 & -2.414 & -1.987 & 9.304 \\
\hline 279 & 4.92 & 2.692 & -2.433 & 5.175 & 347 & 0.00158 & 7.880 & -9.888 & 24.53 \\
\hline 280 & 4.91 & 2.389 & -2.222 & 4.803 & 348 & 0.00111 & 29.52 & -26.61 & 56.78 \\
\hline 281 & 4.86 & 1.963 & -1.922 & 4.272 & 349 & 0.00107 & 41.03 & -35.51 & 73.95 \\
\hline 282 & 4.79 & 1.517 & -1.612 & 3.726 & & & & & \\
\hline
\end{tabular}

$\sigma(\lambda, T)=\sigma(\lambda, 298 \mathrm{~K})\left[1+\mathrm{A}(\lambda) T+\mathrm{B}(\lambda) T^{2}+\mathrm{C}(\lambda) T^{3}\right]$. 


\section{Quantum Yields}

$\phi_{\text {total }}(\lambda,[\mathbf{M}], \mathbf{T})=\phi_{\mathrm{CH} 3 \mathrm{CO}}(\lambda,[\mathbf{M}], \mathbf{T})+\phi_{\mathrm{CO}}(\lambda, \mathbf{T})$

For $\lambda=279-327.5 \mathrm{~nm}$

$$
\begin{array}{ll} 
& \phi_{\mathrm{CO}}(\lambda, \mathrm{T})=\mathrm{i} /\left(1+\mathrm{A}_{0}\right) \\
\text { where } \mathrm{A}_{0} & =\left[\mathrm{a}_{0} /\left(1-\mathrm{a}_{0}\right)\right] \exp \left[\mathrm{b}_{0}\{\lambda-248\}\right] \\
\mathrm{a}_{0} & =(0.350 \pm 0.003)(\mathrm{T} / 295)^{(-1.28 \pm 0.03)} \\
\mathrm{b}_{0} & =(0.068 \pm 0.002)(\mathrm{T} / 295)^{(-2.65 \pm 0.20)}
\end{array}
$$

For $\lambda=279-302.5 \mathrm{~nm}$

$$
\begin{array}{ll}
\phi_{\mathrm{CH} 3 \mathrm{CO}}(\lambda,[\mathrm{M}], \mathrm{T})=\left\{1-\phi_{\mathrm{CO}}(\lambda, \mathrm{T})\right\} /\left\{1+\mathrm{A}_{1}[\mathrm{M}]\right\} \\
\text { where } \mathrm{A}_{1} \quad=\mathrm{a}_{1} \exp \left[-\mathrm{b}_{1}\left\{\left(10^{7} / \lambda\right)-33113\right\}\right] \\
\begin{array}{ll}
\mathrm{a}_{1} & =(1.600 \pm 0.032) \times 10^{-19}(\mathrm{~T} / 295)^{(-2.38 \pm 0.08)} \\
\mathrm{b}_{1} & =(0.55 \pm 0.02) \times 10^{-3}(\mathrm{~T} / 295)^{(-3.19 \pm 0.13)}
\end{array}
\end{array}
$$

For $\lambda=302-327.5$ nm

$$
\begin{aligned}
& \phi_{\mathrm{CH} 3 \mathrm{CO}}(\lambda,[\mathrm{M}], \mathrm{T})=\left\{\left(1+\mathrm{A}_{4}[\mathrm{M}]+\mathrm{A}_{3}\right) /\left[\left(1+\mathrm{A}_{2}[\mathrm{M}]+\mathrm{A}_{3}\right)\left(1+\mathrm{A}_{4}[\mathrm{M}]\right)\right]\right\}\left\{1-\phi_{\mathrm{CO}}(\lambda, \mathrm{T})\right\} \\
& \text { where } \mathrm{A}_{2}=\mathrm{a}_{2} \exp \left[-\mathrm{b}_{2}\left\{\left(10^{7} / \lambda\right)-30488\right\}\right] \\
& \mathrm{a}_{2}=(1.62 \pm 0.06) \times 10^{-17}(\mathrm{~T} / 295)^{(-10.03 \pm 0.20)} \\
& \mathrm{b}_{2}=(1.79 \pm 0.02) \times 10^{-3}(\mathrm{~T} / 295)^{(-1.364 \pm 0.036)} \\
& \mathrm{A}_{3}=\mathrm{a}_{3} \exp \left[-\mathrm{b}_{3}\left\{\left(10^{7} / \lambda\right)-\mathrm{c}_{3}\right\}^{2}\right] \\
& \mathrm{a}_{3}=(26.29 \pm 0.88)(\mathrm{T} / 295)^{(-6.59 \pm 0.23)} \\
& \mathrm{b}_{3}=(5.72 \pm 0.20) \times 10^{-7}(\mathrm{~T} / 295)^{(-2.93 \pm 0.09)} \\
& \mathrm{c}_{3}=(30006 \pm 41)(\mathrm{T} / 295)^{(-0.064 \pm 0.004)} \\
& \mathrm{A}_{4}=\mathrm{a}_{4} \exp \left[-\mathrm{b}_{4}\left\{\left(10^{7} / \lambda\right)-30488\right\}\right] \\
& \mathrm{a}_{4}=(1.67 \pm 0.14) \times 10^{-15}(\mathrm{~T} / 295)^{(-7.25 \pm 0.54)} \\
& \mathrm{b}_{4}=(2.08 \pm 0.02) \times 10^{-3}(\mathrm{~T} / 295)^{(-1.16 \pm 0.15)}
\end{aligned}
$$

In all cases $[\mathrm{M}]$ is in molecule $\mathrm{cm}^{-3}, \lambda$ in $\mathrm{nm}$ and $T$ in $\mathrm{K}$.

\section{Comments on Preferred Values}

The preferred absorption cross-sections are based on the measurements of Gierczak et al. (1998). They agree well with the room temperature measurements of Martinez et al. (1992) and Yujing and Mellouki (2000). Over the wavelength region $260 \mathrm{~nm}$ to $320 \mathrm{~nm}$ these cross-sections are within 5\% of earlier recommendations based on the data of Calvert and Pitts (1966) and Meyrahn et al. (1986). The cross-sections reported by Hynes et al. (1992) at room temperature contain large error limits at $320 \mathrm{~nm}$ and $340 \mathrm{~nm}$ but are in reasonable agreement with those recommended here. The recommended temperature dependent cross sections for $1 \mathrm{~nm}$ intervals over the range $215-349 \mathrm{~nm}$, are based on the expression derived by Burkholder (as cited in the NASA Evaluation No 15, 2005), obtained by using a cubic fit to the data of Gierczak et al. (1998).

The recent studies of the quantum yield for photodissociation of acetone [Gierczak et al., 1998; Emrich and Warneck, 2000; Blitz et al., 2005; Somnitz et al., 2005] have provided reliable wavelength and pressure dependence of $\phi$ and $\phi_{1}$. The measured quantum yields and their pressure and wavelength dependence are essentially in agreement at wavelengths below $300 \mathrm{~nm}$, where there is little temperature dependence. Both $\phi_{\mathrm{CH} 3 \mathrm{CO}}$ and $\phi_{\mathrm{CO}}$ are quenched with pressure, and $\phi_{\mathrm{total}}$ at 1 bar falls off with wavelength above $280 \mathrm{~nm}$. The $\mathrm{p}=0$ limit value of $\phi_{\text {total }}$ is unity at $248 \mathrm{~nm}$. At longer wavelengths $(>310$ $\mathrm{nm}$ ) the study of Blitz et al. (2004) gave values of $\phi_{\mathrm{CH} 3 \mathrm{CO}}$ substantially smaller than reported earlier, with a decrease of $\phi$ with temperature which becomes larger with increasing wavelength. This study provides a more precise measurement of the quantum yields, and the optimized parameterization of the quantum yields for the range 279-327.5 nm, temperature 218 to 295 $\mathrm{K}$ and pressure up to $1000 \mathrm{mbar}$, given by Blitz et al. (2005) is recommended in this evaluation. These equations can be used to calculate the quantum yields in the range 279-327 nm and 218-295 K. Arnold et al.(2004) have discussed application of these data for atmospheric photolysis of acetone, and also the photodissociation mechanism. Dissociation occurs exclusively from the excited singlet state with an increasing fraction of decomposition via channel (2) at wavelengths below the threshold for this process at $299 \mathrm{~nm}$. The recent work of Somnitz et al. (2005) confirms that CO derives only from dissociation of excited $\mathrm{CH}_{3} \mathrm{CO}$ and not by a direct/concerted channel from the excited singlet state of acetone. 


\section{References}

Arnold, S. R., Chipperfield, M. P., Blitz, M. A., Heard, D. E. and Pilling, M. J.: Geophys. Res. Lett. L07110, doi:10.1029/2003GL019099, 2004.

Blitz, M. A., Heard, D. E., Pilling, M. J., Arnold S. R. and Chipperfield, M.: Geophys. Res. Lett. L06111, doi:10.1029/2003GL018793, 2004.

Calvert, J. G., and Pitts, Jr., J. N.: Photochemistry, Wiley, New York, 1966.

Emrich, M. and Warneck, P.: J. Phys. Chem. A 104, 9436, 2000.

Gierczak, T., Burkholder, J. B., Bauerle, S. and Ravishankara, A. R.: Chem. Phys. 231, 229, 1998.

Hynes, A. J., Kenyon, E. A., Pounds, A. J. and Wine, P. H.: Spectrochim. Acta 48A, 1235, 1992.

Martinez, R. D., Buitrago, A. A., Howell, N. W., Hearn, C. H. and Joens, J. A.: Atmos. Environ. 26A, 785, 1992.

Meyrahn, H., Pauly, J., Schneider, W. and Warneck, P.: J. Atmos. Chem. 4, 277, 1986.

Somnitz, H., Fida, M., Ufer, T. and Zellner, R.: Phys.Chem.Chem.Phys., 7, 3342, 2005.

Warneck, P.: Atm. Environ. 35, 5773, 2001.

Yujing, M. and Mellouki, A.: J. Photochem and Photobiol. A: Chemistry 134, 31, 2000. 
II.A8.205

$$
\mathrm{CH}_{3} \mathbf{C}(\mathbf{O}) \mathbf{C}_{2} \mathbf{H}_{5}+\mathbf{h} v \rightarrow \text { products }
$$

\section{Primary photochemical transitions}

\begin{tabular}{lllcc}
\hline Reaction & & & $\Delta \mathrm{H}_{298}^{\circ} / \mathrm{kJ} \cdot \mathrm{mol}^{-1}$ & $\lambda_{\text {threshold }} / \mathrm{nm}$ \\
\hline $\mathrm{CH}_{3} \mathrm{C}(\mathrm{O}) \mathrm{C}_{2} \mathrm{H}_{5}+\mathrm{h} \nu$ & $\rightarrow \mathrm{CH}_{3}+\mathrm{C}_{2} \mathrm{H}_{5} \mathrm{CO}$ & $(1)$ & 352.6 & 339 \\
& $\rightarrow \mathrm{C}_{2} \mathrm{H}_{5}+\mathrm{CH}_{3} \mathrm{CO}$ & $(2)$ & 349.4 & 342 \\
& $\rightarrow \mathrm{CH}_{3}+\mathrm{C}_{2} \mathrm{H}_{5}+\mathrm{CO}$ & $(3)$ & 395.3 & \\
\hline
\end{tabular}

\section{Absorption cross-section data}

\begin{tabular}{llc}
\hline Wavelength range/nm & Reference & Comments \\
\hline $202-355$ & Martinez et al., 1992 & (a) \\
$240-350$ & Yujing and Mellouki, 2000 & (b) \\
\hline
\end{tabular}

Quantum yield data $\left(\phi=\phi_{1}+\phi_{2}+\phi_{3}\right)$

\begin{tabular}{lclr}
\hline Measurement & Wavelength range/nm & Reference & Comments \\
\hline$\phi_{1}$ & & & \\
$0.34(1000 \mathrm{mbar})$ & $275-380$ & Raber and Moortgat, 1987 & (c) \\
$0.89(68 \mathrm{mbar})$ & & & \\
\hline
\end{tabular}

\section{Comments}

(a) Conventional double-beam spectrophotometric measurements on mixtures of 2-butanone and argon at a resolution of $0.5 \mathrm{~nm}$. The cross-sections are given as averages over a $1 \mathrm{~nm}(\lambda>280 \mathrm{~nm})$ or $4 \mathrm{~nm}(\lambda<280 \mathrm{~nm})$ region centered on the corresponding wavelength. $\sigma_{\max }=5.77 \times 10^{-20} \mathrm{~cm}^{2}$ molecule ${ }^{-1}$ at $278 \mathrm{~nm}$.

(b) Diode array spectrometer measurements on pure 2-butanone at a resolution of $0.04 \mathrm{~nm}$. The cross-sections are given over $1 \mathrm{~nm}$ intervals. Precision based on observed standard deviation was within $\pm 5 \%, \sigma_{\max }=5.65 \times 10^{-20} \mathrm{~cm}^{2} \mathrm{molecule}^{-1}$ at $278 \mathrm{~nm}$.

(c) 2-Butanone was photolyzed in synthetic air at several pressures in the range 68 mbar to 1 bar using a broad band radiation source $(275 \mathrm{~nm}$ to $380 \mathrm{~nm})$ and the product yields were monitored by FTIR. The quantum yield for photolysis of 2butanone was found to be pressure dependent decreasing from 0.89 at $68 \mathrm{mbar}$ to 0.34 at 1 bar. They also conclude that photolysis over the wavelength region used occurs to the extent of $80-90 \%$ by channel 2 . These results were derived by modelling the secondary chemistry in the system. 
Preferred Values

Absorption cross-sections at $298 \mathrm{~K}$

\begin{tabular}{cccccc}
\hline$\lambda / \mathrm{nm}$ & $10^{20} \sigma / \mathrm{cm}^{2}$ & $\lambda / \mathrm{nm}$ & $10^{20} \sigma / \mathrm{cm}^{2}$ & $\lambda / \mathrm{nm}$ & $10^{20} \sigma / \mathrm{cm}^{2}$ \\
\hline 202 & 1.412 & 292 & 4.60 & 324 & 0.229 \\
206 & 0.192 & 293 & 4.42 & 325 & 0.189 \\
210 & 0.160 & 294 & 4.24 & 326 & 0.156 \\
214 & 0.183 & 295 & 4.08 & 327 & 0.129 \\
218 & 0.225 & 296 & 3.93 & 328 & 0.105 \\
222 & 0.290 & 297 & 3.79 & 329 & 0.085 \\
226 & 0.391 & 298 & 3.65 & 330 & 0.067 \\
230 & 0.534 & 299 & 3.48 & 331 & 0.054 \\
234 & 0.742 & 300 & 3.30 & 332 & 0.042 \\
238 & 1.029 & 301 & 3.10 & 333 & 0.033 \\
242 & 1.410 & 302 & 2.89 & 334 & 0.025 \\
246 & 1.886 & 303 & 2.69 & 335 & 0.020 \\
250 & 2.45 & 304 & 2.50 & 336 & 0.014 \\
254 & 3.09 & 305 & 2.33 & 337 & 0.011 \\
258 & 3.74 & 306 & 2.17 & 338 & 0.008 \\
262 & 4.39 & 307 & 2.02 & 339 & 0.007 \\
266 & 4.96 & 308 & 1.876 & 340 & 0.005 \\
270 & 5.40 & 309 & 1.727 & 341 & 0.005 \\
274 & 5.68 & 310 & 1.575 & 342 & 0.003 \\
278 & 5.77 & 311 & 1.423 & 343 & 0.003 \\
280 & 5.74 & 312 & 1.276 & 344 & 0.002 \\
281 & 5.72 & 313 & 1.136 & 345 & 0.001 \\
282 & 5.68 & 314 & 1.009 & 346 & 0.001 \\
283 & 5.62 & 315 & 0.896 & 347 & 0.000 \\
284 & 5.54 & 316 & 0.794 & 348 & 0.001 \\
285 & 5.44 & 317 & 0.697 & 349 & 0.000 \\
286 & 5.35 & 318 & 0.611 & 350 & 0.000 \\
287 & 5.26 & 319 & 0.531 & 351 & 0.000 \\
288 & 5.17 & 320 & 0.457 & 352 & 0.001 \\
289 & 5.06 & 321 & 0.389 & 353 & 0.000 \\
290 & 4.94 & 322 & 0.328 & 354 & 0.000 \\
291 & 4.78 & 323 & 0.276 & 355 & 0.000 \\
\hline & & & & &
\end{tabular}

\section{Quantum Yields}

$\phi=0.34$ for $\lambda=275-380 \mathrm{~nm}$ at $1 \mathrm{bar}$

\section{Comments on Preferrred Values}

The preferred absorption cross-sections are taken from the measurements of Martinez et al. (1992) over the wavelength region $220 \mathrm{~nm}$ to $350 \mathrm{~nm}$. The values at the band maximim are 5\% higher than the recent data of Yujing and Mellouki (2000), but 5\% lower than those of McMillan, reported by Calvert and Pitts (1966). Raber and Moortgat (1987) have also given a spectrum which is in good agreement with these cross-sections.

The only quantum yield measurements are those of Raber and Moortgat (1987), which forms the basis for the preferred quantum yield at 1 bar. This data needs further experimental support. 


\section{References}

Calvert, J. G. and Pitts Jr., J. N.: Photochemistry, Wiley, New York, 1966.

Martinez, R. D., Buitrago, A. A., Howell, N. W., Hearn, C. H., and Joens, J. A.: Atmos. Environ., 26A, 785, 1992.

Raber, W. H. and Moortgat, G. K.: 'Photooxidation of Selected Carbonyl Compounds in Air: Methyl Ethyl Ketone, Methyl Vinyl Ketone, Methacrolein and Methylglyoxal', Chap. 9, in: Progress and Problems in Atmospheric Chemistry, edited by: Barker, J., World Scientific Publishing Singapore, 1987.

Yujing, M. and Mellouki, A.: J. Photochem. Photobiol. A: Chem., 134, 31, 2000. 
II.A8.206

$$
\mathbf{C H}_{2}=\mathbf{C}\left(\mathrm{CH}_{3}\right) \mathbf{C H O}+\mathbf{h} v \rightarrow \text { products }
$$

\section{Primary photochemical transitions}

\begin{tabular}{lllcc}
\hline Reaction & & $\Delta \mathrm{H}_{298}^{\circ} / \mathrm{kJ} \cdot \mathrm{mol}^{-1}$ & $\lambda_{\text {threshold }} / \mathrm{nm}$ \\
\hline $\mathrm{CH}_{2}=\mathrm{C}\left(\mathrm{CH}_{3}\right) \mathrm{CHO}+\mathrm{h} v$ & $\rightarrow \mathrm{CH}_{2}=\mathrm{CCH}_{3}+\mathrm{HCO}$ & $(1)$ & 320.5 & 373.1 \\
& $\rightarrow \mathrm{C}_{3} \mathrm{H}_{6}+\mathrm{CO}$ & (2) & 16.1 & 7428 \\
& $\rightarrow \mathrm{H}+\mathrm{CH}_{2}=\mathrm{C}\left(\mathrm{CH}_{3}\right) \mathrm{CO}$ & (3) & & \\
\hline
\end{tabular}

\section{Absorption cross-section data}

\begin{tabular}{llc}
\hline Wavelength range/nm & Reference & Comments \\
\hline $250-395$ & Gierczak et al., 1997 & (a) \\
$235-400$ & Raber and Moortgat., 1996 & (b) \\
\hline
\end{tabular}

Quantum yield data $\left(\phi=\phi_{1}+\phi_{2}\right)$

\begin{tabular}{lclc}
\hline Measurement & Wavelength range/nm & Reference & Comments \\
\hline$\phi=0.008(865 \mathrm{mbar})$ & 308 & Gierczak et al., 1997 & (c) \\
$\phi=0.005(33 \mathrm{mbar})$ & 308 & & \\
$\phi=0.005(865 \mathrm{mbar})$ & 351 & & \\
$\phi=0.003(33 \mathrm{mbar})$ & 351 & Raber and Moortgat, 1996 & (d) \\
$\phi<0.05$ at 1 bar & $275-370$ & &
\end{tabular}

\section{Comments}

(a) Measurements made using a diode array spectrometer with a $\mathrm{D}_{2}$ lamp source and temperature controlled cell with $200 \mathrm{~cm}$ path-length. Resolution $0.5 \mathrm{~nm}$. Temperature range $250-298 \mathrm{~K}$. Tabulated cross sections at $1 \mathrm{~nm}$ intervals. $\sigma_{\max }=7.2 \times 10^{-20} \mathrm{~cm}^{2}$ molecule ${ }^{-1}( \pm 5 \%)$ at $331 \mathrm{~nm}$ and $\sigma=(2.21 \pm 0.03) \times 10^{-17} \mathrm{~cm}^{2}$ molecule ${ }^{-1}$ at $213.86 \mathrm{~nm}$ (Zn lamp source). Small increase with decreasing temperature at $\lambda$ max.

(b) Measurements made at $298 \mathrm{~K}$ using a diode array spectrometer with a $\mathrm{D}_{2}$ lamp source. $\sigma_{\max }=7.64 \times 10^{-20} \mathrm{~cm}^{2}$ molecule ${ }^{-1}$ $( \pm 5 \%)$ at $330.7 \mathrm{~nm}$.

(c) Quantum yield determined using pulsed laser photolysis of static mixtures with measurement of the loss of $\mathrm{CH}_{2}=\mathrm{C}\left(\mathrm{CH}_{3}\right) \mathrm{CHO}$ (methacrolein) by GC. $\phi$ was determined at pressures of 25 and 650 Torr (33 and $865 \mathrm{mbar}$ ) air, and at 308 and $351 \mathrm{~nm}$. $\phi$ increased with pressure by a factor of $\sim 2$ over the range. Propene not observed as a product, in contrast to other studies.

(d) Broad band photolysis of static mixtures (bath gas is air) with measurement of the loss of $\mathrm{CH}_{2}=\mathrm{C}\left(\mathrm{CH}_{3}\right) \mathrm{CHO}$ and formation of products $\left(\mathrm{C}_{2} \mathrm{H}_{4}, \mathrm{C}_{3} \mathrm{H}_{6}, \mathrm{C}_{2} \mathrm{H}_{2}, \mathrm{CO}, \mathrm{CO}_{2}, \mathrm{HCHO}\right)$ by FTIR. Quantum yield from loss of $\mathrm{CH}_{2}=\mathrm{C}_{\left(\mathrm{CH}_{3}\right) \mathrm{CHO}}$ and formation of CO. Indication of a weak pressure effect with $\phi(50$ Torr $) / \phi$ (760 Torr) $\sim 2$. No firm information on the relative importance of the photolysis channels could be obtained from the product yields. 


\section{Preferred Values}

\section{Absorption cross-sections at $298 \mathrm{~K}$}

\begin{tabular}{|c|c|c|c|c|c|}
\hline$\lambda / \mathrm{nm}$ & $10^{20} \sigma / \mathrm{cm}^{2}$ & $\lambda / \mathrm{nm}$ & $10^{20} \sigma / \mathrm{cm}^{2}$ & $\lambda / \mathrm{nm}$ & $10^{20} \sigma / \mathrm{cm}^{2}$ \\
\hline 250 & 0.207 & 300 & 3.44 & 350 & 4.16 \\
\hline 251 & 0.194 & 301 & 3.61 & 351 & 3.85 \\
\hline 252 & 0.187 & 302 & 3.76 & 352 & 3.89 \\
\hline 253 & 0.180 & 303 & 3.91 & 353 & 4.35 \\
\hline 254 & 0.178 & 304 & 4.04 & 354 & 4.31 \\
\hline 255 & 0.177 & 305 & 4.19 & 355 & 4.14 \\
\hline 256 & 0.180 & 306 & 4.40 & 356 & 3.62 \\
\hline 257 & 0.180 & 307 & 4.58 & 357 & 3.53 \\
\hline 258 & 0.186 & 308 & 4.71 & 358 & 3.46 \\
\hline 259 & 0.193 & 309 & 4.81 & 359 & 3.81 \\
\hline 260 & 0.201 & 310 & 4.92 & 360 & 5.05 \\
\hline 261 & 0.211 & 311 & 5.13 & 361 & 4.28 \\
\hline 262 & 0.224 & 312 & 5.35 & 362 & 3.61 \\
\hline 263 & 0.241 & 313 & 5.50 & 363 & 2.86 \\
\hline 264 & 0.263 & 314 & 5.61 & 364 & 2.68 \\
\hline 265 & 0.283 & 315 & 5.70 & 365 & 2.33 \\
\hline 266 & 0.305 & 316 & 5.87 & 366 & 1.92 \\
\hline 267 & 0.333 & 317 & 6.04 & 367 & 1.62 \\
\hline 268 & 0.363 & 318 & 6.19 & 368 & 1.40 \\
\hline 269 & 0.398 & 319 & 6.28 & 369 & 1.31 \\
\hline 270 & 0.436 & 320 & 6.27 & 370 & 1.42 \\
\hline 271 & 0.479 & 321 & 6.18 & 371 & 1.67 \\
\hline 272 & 0.520 & 322 & 6.21 & 372 & 1.53 \\
\hline 273 & 0.567 & 323 & 6.34 & 373 & 1.43 \\
\hline 274 & 0.616 & 324 & 6.58 & 374 & 1.08 \\
\hline 275 & 0.673 & 325 & 6.74 & 375 & 0.977 \\
\hline 276 & 0.732 & 326 & 6.73 & 376 & 1.000 \\
\hline 277 & 0.793 & 327 & 6.68 & 377 & 1.07 \\
\hline 278 & 0.863 & 328 & 6.83 & 378 & 1.35 \\
\hline 279 & 0.936 & 329 & 7.07 & 379 & 2.18 \\
\hline 280 & 1.01 & 330 & 7.15 & 380 & 1.30 \\
\hline 281 & 1.09 & 331 & 7.16 & 381 & 0.984 \\
\hline 282 & 1.18 & 332 & 7.03 & 382 & 0.555 \\
\hline 283 & 1.26 & 333 & 6.69 & 383 & 0.456 \\
\hline 284 & 1.35 & 334 & 6.41 & 384 & 0.364 \\
\hline 285 & 1.45 & 335 & 6.08 & 385 & 0.331 \\
\hline 286 & 1.56 & 336 & 5.97 & 386 & 0.246 \\
\hline 287 & 1.67 & 337 & 6.25 & 387 & 0.205 \\
\hline 288 & 1.79 & 338 & 6.38 & 388 & 0.181 \\
\hline 289 & 1.90 & 339 & 6.37 & 389 & 0.161 \\
\hline 290 & 2.03 & 340 & 6.24 & 390 & 0.147 \\
\hline 291 & 2.16 & 341 & 6.02 & 391 & 0.156 \\
\hline 292 & 2.28 & 342 & 5.98 & 392 & 0.159 \\
\hline 293 & 2.40 & 343 & 6.58 & 393 & 0.153 \\
\hline 294 & 2.52 & 344 & 6.79 & 394 & 0.149 \\
\hline 295 & 2.68 & 345 & 6.53 & 395 & 0.123 \\
\hline 296 & 2.85 & 346 & 6.11 & & \\
\hline 297 & 2.99 & 347 & 5.63 & & \\
\hline 298 & 3.13 & 348 & 5.22 & & \\
\hline 299 & 3.26 & 349 & 4.55 & & \\
\hline
\end{tabular}




\section{Quantum Yields}

No recommendation

\section{Comments on Preferred Values}

The preferred absorption cross-sections are based on the measurements of Gierzak et al. (1997). The peak cross-section agrees within $10 \%$ with the measurements of Raber and Moortgat (1996).

The two studies (Gierczak et al., 1997; Raber and Moortgat, 1996) of the quantum yield for photodissociation of $\mathrm{CH}_{2}=\mathrm{C}\left(\mathrm{CH}_{3}\right) \mathrm{CHO}$ are not in good agreement, although both indicate very low quantum efficiencies with $\phi<0.05$. No firm recommendation can be given.

\section{References}

Gierczak, T., Burkholder, J. B., Talukdar, R. K., Mellouki, A., Barone, S. B., and Ravishankara, A. R.: J. Photochem. Photobiol. A: Chem., 110, 1, 1997.

Raber, W. H. and Moortgat, G. K.: in: 'Progress and Problems in Atmospheric Chemistry', edited by: Barker, J., pp. 318-373, World Scientific Publ. Co., Singapore, 1996. 
II.A8.207

$\mathrm{CH}_{3} \mathbf{C}(\mathrm{O}) \mathbf{C H}=\mathrm{CH}_{2}+\mathbf{h} v \rightarrow$ products

Primary photochemical transitions

\begin{tabular}{lllcc}
\hline Reaction & & $\Delta \mathrm{H}_{298}^{\circ} / \mathrm{kJ} \cdot \mathrm{mol}^{-1}$ & $\lambda_{\text {threshold }} / \mathrm{nm}$ \\
\hline $\mathrm{CH}_{3} \mathrm{C}(\mathrm{O}) \mathrm{CH}=\mathrm{CH}_{2}+\mathrm{h} v$ & $\rightarrow \mathrm{CH}_{2}=\mathrm{CHCO}+\mathrm{CH}_{3}$ & (1) & & \\
& $\rightarrow \mathrm{C}_{3} \mathrm{H}_{6}+\mathrm{CO}$ & (2) & 24.7 & 4842 \\
& $\rightarrow \mathrm{C}_{2} \mathrm{H}_{3}+\mathrm{CH}_{3} \mathrm{CO}$ & (3) & 405 & 295.3 \\
\hline
\end{tabular}

Absorption cross-section data

\begin{tabular}{llc}
\hline Wavelength range/nm & Reference & Comments \\
\hline $250-395$ & Gierczak et al., 1997 & (a) \\
$235-400$ & Raber and Moortgat, 1996 & (b) \\
\hline
\end{tabular}

Quantum yield data $\left(\phi=\phi_{1}+\phi_{2}\right)$

\begin{tabular}{lclc}
\hline Measurement & Wavelength range/nm & Reference & Comments \\
\hline$\phi=0.16(33 \mathrm{mbar})$ & 308 & Gierczak et al., 1997 & (c) \\
$\phi=0.04(33 \mathrm{mbar})$ & 337 & & \\
$\phi=0.01(33 \mathrm{mbar})$ & 351 & & \\
$\phi<0.04$ (1 bar) & $275-370$ & Raber and Moortgat, 1996 & (d) \\
\hline
\end{tabular}

\section{Comments}

(a) Measurements made using a diode array spectrometer with a $\mathrm{D}_{2}$ lamp source and temperature controlled cell with $200 \mathrm{~cm}$ path-length. Resolution $0.5 \mathrm{~nm}$. Temperature range 250-298 K. Tabulated cross sections at $1 \mathrm{~nm}$ intervals $\sigma_{\max }=7.2 \times 10^{-20} \mathrm{~cm}^{2}$ molecule ${ }^{-1}( \pm 5 \%)$ at $331 \mathrm{~nm}$ and $\sigma=(6.6 \pm 0.35) \times 10^{-18} \mathrm{~cm}^{2}$ molecule ${ }^{-1}$ at $213.86 \mathrm{~nm}(\mathrm{Zn} \mathrm{lamp}$ source). Small temperature dependence at $\lambda \max (<2 \%$ increase at $250 \mathrm{~K})$.

(b) Measurements made at $298 \mathrm{~K}$ using a diode array spectrometer with a $\mathrm{D}_{2}$ lamp source. $\sigma_{\max }=6.5 \times 10^{-20} \mathrm{~cm}^{2}$ molecule ${ }^{-1}$ $( \pm 5 \%)$ at $330.7 \mathrm{~nm}$.

(c) Quantum yield determined using pulsed laser photolysis of static mixtures with measurement of the loss of $\mathrm{CH}_{3} \mathrm{C}(\mathrm{O}) \mathrm{CH}=\mathrm{CH}_{2}$ (methyl vinyl ketone) by GC. $\phi$ was determined at pressures of 25 and 650 Torr (33 and 850 mbar) air, and at 308, 337 and $351 \mathrm{~nm}$. $\phi$ showed pressure quenching at 308 and $337 \mathrm{~nm}$ but not at $351 \mathrm{~nm}$. Expression given for the variation with pressure (for air up to 1 bar) and wavelength of $\phi: \phi_{0}(\lambda, \mathrm{P})<\exp [-0.055(\lambda-308)] /\left(5.5+9.2 \times 10^{-19}[\mathrm{M}]\right)$ where $\lambda$ is in $\mathrm{nm}$ and $\mathrm{M}$ in molecule $\mathrm{cm}^{-3}$.

(d) Broad band photolysis of static mixtures (bath gas is air) with measurement of the loss of $\mathrm{CH}_{3} \mathrm{C}(\mathrm{O}) \mathrm{CH}=\mathrm{CH}_{2}$ and formation of products $\left(\mathrm{C}_{3} \mathrm{H}_{6}, \mathrm{CO}, \mathrm{HCHO}\right.$ with minor amounts of $\mathrm{CO}_{2}, \mathrm{HC}(\mathrm{O}) \mathrm{OH}, \mathrm{CH}_{3} \mathrm{OH}, \mathrm{CH}_{3}(\mathrm{O}) \mathrm{OH}$ and $\left.\mathrm{C}_{2} \mathrm{H}_{3} \mathrm{C}(\mathrm{O}) \mathrm{OH}\right)$ by FTIR. Quantum yield from loss of $\mathrm{CH}_{3} \mathrm{C}(\mathrm{O}) \mathrm{CH}=\mathrm{CH}_{2}$ and formation of $\mathrm{CO}$. Indication of a weak pressure effect with $\phi(50$ Torr $) / \phi(760$ Torr $) \sim 2$. The relative importance of the photolysis channels could not be obtained accurately from the product yields. 
Preferred Values

Absorption cross-sections at $298 \mathrm{~K}$

\begin{tabular}{|c|c|c|c|c|c|}
\hline$\lambda / \mathrm{nm}$ & $10^{20} \sigma / \mathrm{cm}^{2}$ & $\lambda / \mathrm{nm}$ & $10^{20} \sigma / \mathrm{cm}^{2}$ & $\lambda / \mathrm{nm}$ & $10^{20} \sigma / \mathrm{cm}^{2}$ \\
\hline 250 & 0.241 & 299 & 3.70 & 348 & 5.77 \\
\hline 251 & 0.241 & 300 & 3.87 & 349 & 5.47 \\
\hline 252 & 0.224 & 301 & 4.04 & 350 & 5.20 \\
\hline 253 & 0.241 & 302 & 4.20 & 351 & 4.94 \\
\hline 254 & 0.241 & 303 & 4.35 & 352 & 4.72 \\
\hline 255 & 0.258 & 304 & 4.51 & 353 & 4.53 \\
\hline 256 & 0.275 & 305 & 4.66 & 354 & 4.32 \\
\hline 257 & 0.275 & 306 & 4.82 & 355 & 4.15 \\
\hline 258 & 0.293 & 307 & 4.96 & 356 & 4.03 \\
\hline 259 & 0.310 & 308 & 5.13 & 357 & 3.94 \\
\hline 260 & 0.327 & 309 & 5.30 & 358 & 3.89 \\
\hline 261 & 0.361 & 310 & 5.44 & 359 & 3.89 \\
\hline 262 & 0.379 & 311 & 5.58 & 360 & 3.68 \\
\hline 263 & 0.396 & 312 & 5.73 & 361 & 3.60 \\
\hline 264 & 0.430 & 313 & 5.87 & 362 & 3.49 \\
\hline 265 & 0.465 & 314 & 6.02 & 363 & 3.36 \\
\hline 266 & 0.499 & 315 & 6.14 & 364 & 3.29 \\
\hline 267 & 0.534 & 316 & 6.28 & 365 & 3.03 \\
\hline 268 & 0.568 & 317 & 6.42 & 366 & 2.77 \\
\hline 269 & 0.620 & 318 & 6.54 & 367 & 2.50 \\
\hline 270 & 0.654 & 319 & 6.63 & 368 & 2.20 \\
\hline 271 & 0.706 & 320 & 6.70 & 369 & 2.01 \\
\hline 272 & 0.757 & 321 & 6.76 & 370 & 1.88 \\
\hline 273 & 0.809 & 322 & 6.83 & 371 & 1.74 \\
\hline 274 & 0.878 & 323 & 6.85 & 372 & 1.58 \\
\hline 275 & 0.929 & 324 & 6.88 & 373 & 1.48 \\
\hline 276 & 0.998 & 325 & 6.95 & 374 & 1.39 \\
\hline 277 & 1.08 & 326 & 7.02 & 375 & 1.31 \\
\hline 278 & 1.15 & 327 & 7.09 & 376 & 1.26 \\
\hline 279 & 1.24 & 328 & 7.16 & 377 & 1.24 \\
\hline 280 & 1.33 & 329 & 7.23 & 378 & 1.20 \\
\hline 281 & 1.41 & 330 & 7.28 & 379 & 1.20 \\
\hline 282 & 1.50 & 331 & 7.30 & 380 & 1.05 \\
\hline 283 & 1.60 & 332 & 7.26 & 381 & 0.981 \\
\hline 284 & 1.70 & 333 & 7.18 & 382 & 0.912 \\
\hline 285 & 1.81 & 334 & 7.04 & 383 & 0.878 \\
\hline 286 & 1.91 & 335 & 6.94 & 384 & 0.929 \\
\hline 287 & 2.03 & 336 & 6.85 & 385 & 0.757 \\
\hline 288 & 2.15 & 337 & 6.70 & 386 & 0.637 \\
\hline 289 & 2.29 & 338 & 6.56 & 387 & 0.534 \\
\hline 290 & 2.43 & 339 & 6.47 & 388 & 0.447 \\
\hline 291 & 2.55 & 340 & 6.44 & 389 & 0.396 \\
\hline 292 & 2.67 & 341 & 6.42 & 390 & 0.344 \\
\hline 293 & 2.81 & 342 & 6.35 & 391 & 0.310 \\
\hline 294 & 2.93 & 343 & 6.35 & 392 & 0.293 \\
\hline 295 & 3.08 & 344 & 6.30 & 393 & 0.275 \\
\hline 296 & 3.24 & 345 & 6.23 & 394 & 0.241 \\
\hline 297 & 3.39 & 346 & 6.14 & 395 & 0.207 \\
\hline 298 & 3.56 & 347 & 6.08 & & \\
\hline
\end{tabular}




\section{Quantum Yields}

$\phi_{0}(\lambda, \mathrm{P})=\exp [-0.055(\lambda-308)] /\left(5.5+9.2 \times 10^{-19}[\mathrm{M}]\right)$

where $\lambda$ is in $\mathrm{nm}$ and $\mathrm{M}$ in molecule $\mathrm{cm}^{-3}$.

\section{Comments on Preferred Values}

The preferred absorption cross-sections are based on the measurements of Gierczak et al. (1997). They agree well with the measurements of Raber and Moortgat (1996) within 10\% over the range 290-365 nm.

The two studies (Gieczak et al., 1997; Raber and Moortgat, 1996) of the quantum yield for photodissociation of $\mathrm{CH}_{3} \mathrm{C}(\mathrm{O}) \mathrm{CH}=\mathrm{CH}_{2}$ are essentially in agreement. Both show low efficiency for photolysis $(\phi<0.1)$ and a weak pressure dependence in $\phi$ ( $\phi$ decreases with increasing pressure between 25 Torr $(33 \mathrm{mbar})$ and 760 Torr (1 bar)). Gierczak et al. (1997) also observe an increase at shorter wavelength. We recommend the empirical algorithm given by Gierczak et al. (1997) for the overall dissociation quantum yield in air as a function of wavelength and pressure, although this should be considered an upper limit. The results of Raber and Moortgat (1996) indicate that the photolysis channel leading to propene (channel 2) accounts for $60 \%$ of the $\mathrm{CH}_{3} \mathrm{C}(\mathrm{O}) \mathrm{CH}=\mathrm{CH}_{2}$ loss, with the balance occurring by the two radical channels (1) and (3) with equal probability.

\section{References}

Gierczak, T., Burkholder, J. B., Talukdar, R. K., Mellouki, A., Barone, S. B., and Ravishankara, A. R.: J. Photochem. Photobiol. A: Chem., 110, 1, 1997.

Raber, W. H. and Moortgat, G. K.: in: 'Progress and Problems in Atmospheric Chemistry', edited by: Barker, J., pp. 318-373, World Scientific Publ. Co., Singapore, 1996. 
II.A8.208

$$
n-\mathrm{C}_{3} \mathrm{H}_{7} \mathbf{C H O}+\mathbf{h} v \rightarrow \text { products }
$$

\section{Primary photochemical transitions}

\begin{tabular}{lllcc}
\hline Reaction & & & $\Delta \mathrm{H}_{298}^{\circ} / \mathrm{kJ} \cdot \mathrm{mol}^{-1}$ & $\lambda_{\text {threshold }} / \mathrm{nm}$ \\
\hline$n-\mathrm{C}_{3} \mathrm{H}_{7} \mathrm{CHO}$ & $\rightarrow n-\mathrm{C}_{3} \mathrm{H}_{7}+\mathrm{HCO}$ & $(1)$ & 355.7 & 336 \\
& $\rightarrow \mathrm{C}_{3} \mathrm{H}_{8}+\mathrm{CO}$ & $(2)$ & -3.2 & \\
& $\rightarrow \mathrm{C}_{2} \mathrm{H}_{4}+\mathrm{CH}_{2} \mathrm{CHOH}$ & $(3)$ & $\sim 136$ & 880 \\
& $\rightarrow \mathrm{CH}_{3}+\mathrm{CH}_{2} \mathrm{CH}_{2} \mathrm{CHO}$ & $(4)$ & & \\
& $\rightarrow \mathrm{C}_{3} \mathrm{H}_{6}+\mathrm{HCHO}$ & $(5)$ & 123.4 & 969 \\
\hline
\end{tabular}

\section{Absorption cross-section data}

\begin{tabular}{llc}
\hline Wavelength range/nm & Reference & Comments \\
\hline $202-365$ & Martinez et al., 1992 & (a) \\
$240-350$ & Tadic et al., 2001 & (b) \\
\hline
\end{tabular}

Quantum yield data $\left(\phi=\phi_{1}+\phi_{2}+\phi_{3}+\phi_{4}+\phi_{5}\right)$

\begin{tabular}{lclc}
\hline Measurement & Wavelength range/nm & Reference & Comments \\
\hline$\phi=0.48 \pm 0.02$ (100 Torr air) & $275-380$ & Tadic et al., 2001 & (c) \\
$\phi=0.38 \pm 0.02$ (700 Torr air) & $275-380$ & & \\
$\phi_{1}=0.21$ (1 bar, air) & $275-380$ & & \\
$\phi_{3}=0.10$ (1 bar, air) & $275-380$ & & \\
\hline
\end{tabular}

\section{Comments}

(a) Absorption measurements as a function of $\mathrm{C}_{3} \mathrm{H}_{7} \mathrm{CHO}$ pressure using a diode array spectrometer. Cross-sections are the average cross-section over a $1 \mathrm{~nm}(\lambda>280 \mathrm{~nm})$ or $4 \mathrm{~nm}(\lambda<280 \mathrm{~nm})$ region centered at the corresponding wavelength.

(b) Cross-sections determined from absorption measurements as a function of $\mathrm{C}_{3} \mathrm{H}_{7} \mathrm{CHO}$ pressure using a diode array spectrometer, with resolution of $0.25 \mathrm{~nm}$.

(c) Broad band (275-380 nm) steady-state photolysis of $\mathrm{C}_{3} \mathrm{H}_{7} \mathrm{CHO}$ in the presence of air at $298 \mathrm{~K}$. Products measured by FTIR were $\mathrm{CO}, \mathrm{C}_{2} \mathrm{H}_{4}, \mathrm{CH}_{3} \mathrm{CHO}, \mathrm{CH}_{2} \mathrm{CHOH}$ and $\mathrm{CO}_{2}$. Quantum yields of $\mathrm{CO}$ and $\mathrm{C}_{2} \mathrm{H}_{4}$ were measured as a function of wavelength and pressure, to provide values of $\phi_{1}$ and $\phi_{3}$. Overall quantum yields were pressure dependent over range 100-700 Torr, with the following Stern-Volmer expresssion: $1 / \phi=1.81+\left(1.931 \times 10^{-3}\right) \mathrm{P}[\mathrm{Torr}]$. 


\section{Preferred Values}

\section{Absorption cross-sections at $298 \mathrm{~K}$}

\begin{tabular}{|c|c|c|c|c|c|}
\hline$\lambda / \mathrm{nm}$ & $10^{20} \sigma / \mathrm{cm}^{2}$ & $\lambda / \mathrm{nm}$ & $10^{20} \sigma / \mathrm{cm}^{2}$ & $\lambda / \mathrm{nm}$ & $10^{20} \sigma / \mathrm{cm}^{2}$ \\
\hline 202 & 0.0178 & 295 & 6.03 & 330 & 0.868 \\
\hline 206 & 0.0316 & 296 & 5.87 & 331 & 0.734 \\
\hline 210 & 0.0475 & 297 & 5.69 & 332 & 0.647 \\
\hline 214 & 0.0623 & 298 & 5.56 & 333 & 0.602 \\
\hline 218 & 0.0771 & 299 & 5.46 & 334 & 0.554 \\
\hline 222 & 0.0850 & 300 & 5.42 & 335 & 0.485 \\
\hline 226 & 0.102 & 301 & 5.43 & 336 & 0.417 \\
\hline 230 & 0.133 & 302 & 5.44 & 337 & 0.346 \\
\hline 234 & 0.202 & 303 & 5.43 & 338 & 0.285 \\
\hline 238 & 0.316 & 304 & 5.32 & 339 & 0.242 \\
\hline 242 & 0.488 & 305 & 5.08 & 340 & 0.215 \\
\hline 246 & 0.724 & 306 & 4.79 & 341 & 0.191 \\
\hline 250 & 1.05 & 307 & 4.50 & 342 & 0.144 \\
\hline 254 & 1.45 & 308 & 4.29 & 343 & 0.093 \\
\hline 258 & 1.93 & 309 & 4.15 & 344 & 0.059 \\
\hline 262 & 2.52 & 310 & 4.07 & 345 & 0.041 \\
\hline 266 & 3.09 & 311 & 4.00 & 346 & 0.031 \\
\hline 270 & 3.81 & 312 & 3.92 & 347 & 0.026 \\
\hline 274 & 4.34 & 313 & 3.82 & 348 & 0.023 \\
\hline 278 & 5.02 & 314 & 3.69 & 349 & 0.018 \\
\hline 280 & 5.18 & 315 & 3.46 & 350 & 0.015 \\
\hline 281 & 5.22 & 316 & 3.17 & 351 & 0.014 \\
\hline 282 & 5.30 & 317 & 2.85 & 352 & 0.012 \\
\hline 283 & 5.45 & 318 & 2.57 & 353 & 0.010 \\
\hline 284 & 5.65 & 319 & 2.37 & 354 & 0.008 \\
\hline 285 & 5.81 & 320 & 2.25 & 355 & 0.006 \\
\hline 286 & 5.90 & 321 & 2.18 & 356 & 0.005 \\
\hline 287 & 5.89 & 322 & 2.07 & 357 & 0.004 \\
\hline 288 & 5.85 & 323 & 1.96 & 358 & 0.003 \\
\hline 289 & 5.80 & 324 & 1.82 & 359 & 0.002 \\
\hline 290 & 5.78 & 325 & 1.69 & 360 & 0.002 \\
\hline 291 & 5.83 & 326 & 1.55 & 361 & 0.002 \\
\hline 292 & 5.93 & 327 & 1.39 & 362 & 0.001 \\
\hline 293 & 6.05 & 328 & 1.22 & 363 & 0.001 \\
\hline 294 & 6.10 & 329 & 1.04 & 364 & 0.001 \\
\hline
\end{tabular}

\section{Quantum Yields}

$\phi_{3}=0.10 ; \phi_{1}=0.21$ for 1 bar air, over the wavelength range $290-380 \mathrm{~nm}$.

\section{Comments on Preferred Values}

The preferred absorption cross-sections are from the measurements of Martinez et al. (1992) The cross-section data of Tadic et al. (2001) are within 5\% of the Martinez data over the wavelength region $260 \mathrm{~nm}$ to $350 \mathrm{~nm}$.

The photolysis of long chain $\left(>\mathrm{C}_{4}\right)$ aldehydes undergo Norrish type I $\left(\phi_{1}\right)$ and Norrish type II $\left(\phi_{3}\right)$ dissociation in the first absorption band $(260-340 \mathrm{~nm})$. Channels 2,4 and 5 are unimportant at wavelengths $>280$ nm. The indirect quantum yield measurements for the two channels, $\phi_{1}$ and $\phi_{3}$ reported by Tadic et al. (2001) for photolysis of $n-\mathrm{C}_{3} \mathrm{H}_{7} \mathrm{CHO}_{\mathrm{appear}}$ reliable and are recommended here. Quantum yield measurements for the channel producing HCO $\left(\phi_{1}\right)$ from $n$-pentanal, obtained in the same study, agree with direct measurements for $n$-pentanal obtained by Cronin and Zhu (1998) using cavity ring-down 
detection of HCO. Weak pressure quenching of reported by Tadic et al. (2001) for photolysis of $n-\mathrm{C}_{3} \mathrm{H}_{7} \mathrm{CHO}$ can be used to obtain quantum yields at lower atmospheric pressures, assuming constant branching ratio for channels 1 and 3 .

\section{References}

Cronin, T. J. and Zhu, L.: J. Phys. Chem. A, 102, $10274,1998$.

Martinez, R. D., Buitrago, A. A., Howell, N. W., Hearn, C. H., and Joens, J. A.: Atmos. Environ., 26A, 785, 1992.

Tadic, J., Juranic, I., and Moortgat, G. K.: J. Photchem. Photobiol. A: Chem., 143, 169, 2001. 
II.A8.209

$$
\mathbf{C H}_{3} \mathrm{OOH}+\mathbf{h} v \rightarrow \text { products }
$$

Primary photochemical transitions

\begin{tabular}{llccc}
\hline Reaction & & & $\Delta \mathrm{H}_{298}^{\circ} / \mathrm{kJ} \cdot \mathrm{mol}^{-1}$ & $\lambda$ threshold $/ \mathrm{nm}$ \\
\hline $\mathrm{CH}_{3} \mathrm{OOH}+\mathrm{h} v$ & $\rightarrow \mathrm{CH}_{3} \mathrm{O}+\mathrm{HO}$ & $(1)$ & 185 & 645 \\
& $\rightarrow \mathrm{CH}_{3}+\mathrm{HO}_{2}$ & $(2)$ & 292 & 410 \\
& $\rightarrow \mathrm{CH}_{3} \mathrm{O}_{2}+\mathrm{H}$ & $(3)$ & 358 & 334 \\
\hline
\end{tabular}

\section{Absorption cross-section data}

\begin{tabular}{llc}
\hline Wavelength range/nm & Reference & Comments \\
\hline $210-365$ & Vaghjiani and Ravishankara, 1989 & (a) \\
\hline
\end{tabular}

Quantum yield data $\left(\phi=\phi_{1}+\phi_{2}+\phi_{3}\right)$

\begin{tabular}{lclc}
\hline Measurement & Wavelength range/nm & Reference & Comments \\
\hline$\phi_{1}=1.00 \pm 0.18$ & 248 & Vaghiiani and Ravishankara, 1990 & (b) \\
\hline
\end{tabular}

\section{Comments}

(a) $\mathrm{CH}_{3} \mathrm{OOH}$ prepared by methylation of $\mathrm{H}_{2} \mathrm{O}_{2}$ and shown by ${ }^{1} \mathrm{H}$ NMR to be $>97 \%$ pure [major impurity $\mathrm{C}_{2} \mathrm{H}_{5} \mathrm{OC}_{2} \mathrm{H}_{5}$ ]. A diode-array spectrometer was used to make relative absorption measurements over the whole wavelength range and the results were put on an absolute basis by measurement of the cross-sections at $213.9 \mathrm{~nm}$ (Zn line), and at $298.1 \mathrm{~nm}$, $326.1 \mathrm{~nm}, 340.4 \mathrm{~nm}$ and $361.1 \mathrm{~nm}$ using $\mathrm{Cd}$ lines. The $\mathrm{CH}_{3} \mathrm{OOH}$ concentration was determined by trapping the vapor at $77 \mathrm{~K}$ and titrating with $\mathrm{Fe}^{2+}$ or $\mathrm{I}^{-}$.

(b) Direct measurement of products, $\mathrm{HO}$ by LIF, and $\mathrm{O}\left({ }^{3} \mathrm{P}\right)$ and $\mathrm{H}$ atoms by resonance fluorescence. Quantum yields for the formation of $\mathrm{O}\left({ }^{3} \mathrm{P}\right)$ and $\mathrm{H}$ atoms of $<0.007$ and $0.038 \pm 0.007$, respectively, were obtained.

\section{Preferred Values}

\section{Absorption cross-sections at $298 \mathrm{~K}$}

\begin{tabular}{cccc}
\hline$\lambda / \mathrm{nm}$ & $10^{20} \sigma / \mathrm{cm}^{2}$ & $\lambda / \mathrm{nm}$ & $10^{20} \sigma / \mathrm{cm}^{2}$ \\
\hline 210 & 31.2 & 290 & 0.691 \\
215 & 20.9 & 295 & 0.551 \\
220 & 15.4 & 300 & 0.413 \\
225 & 12.2 & 305 & 0.313 \\
230 & 9.62 & 310 & 0.239 \\
235 & 7.61 & 315 & 0.182 \\
240 & 6.05 & 320 & 0.137 \\
245 & 4.88 & 325 & 0.105 \\
250 & 3.98 & 330 & 0.079 \\
255 & 3.23 & 335 & 0.061 \\
260 & 2.56 & 340 & 0.047 \\
265 & 2.11 & 345 & 0.035 \\
270 & 1.70 & 350 & 0.027 \\
275 & 1.39 & 355 & 0.021 \\
280 & 1.09 & 360 & 0.016 \\
285 & 0.863 & 365 & 0.012 \\
\hline
\end{tabular}




\section{Quantum Yields}

$\phi_{1}=1.0$ for $\lambda>290 \mathrm{~nm}$.

\section{Comments on Preferred Values}

The preferred absorption cross-section data are those of Vaghjiani and Ravishankara (1989), which are approximately $25 \%$ lower than the previously recommended data of Molina and Arguello (1979). The source of the discrepancy appears to lie in the determination of the concentrations of $\mathrm{CH}_{3} \mathrm{OOH}$ in the absorption cell. Molina and Arguello (1979) used a bubbler containing $\mathrm{Fe}^{2+}$ solution, which Vaghjiani and Ravishankara (1989) showed does not give quantitative trapping.

On the basis of the results of Vaghjiani and Ravishankara (1990), who showed that $\phi_{\mathrm{OH}} \sim 1.0$ at $\lambda=248 \mathrm{~nm}$, we recommend that the atmospheric photolysis of $\mathrm{CH}_{3} \mathrm{OOH} \phi_{1}$ be taken to be unity for wavelengths $>290 \mathrm{~nm}$.

\section{References}

Molina, M. J. and Arguello, G.: Geophys. Res. Lett., 6, 953, 1979.

Vaghjiani, G. L. and Ravishankara, A. R.: J. Geophys. Res., 94, 3487, 1989.

Vaghjiani, G. L. and Ravishankara, A. R.: J. Chem. Phys., 92, 996, 1990. 
II.A8.210

$\mathrm{HOCH}_{2} \mathrm{OOH}+\mathbf{h} v \rightarrow$ products

Primary photochemical transitions

\begin{tabular}{lccc}
\hline Reaction & $\Delta \mathrm{H}_{298}^{\circ} / \mathrm{kJ} \cdot \mathrm{mol}^{-1}$ & $\lambda_{\text {threshold }} / \mathrm{nm}$ \\
\hline $\mathrm{HOCH}_{2} \mathrm{OOH}+\mathrm{h} \nu$ & $\rightarrow \mathrm{HOCH}_{2} \mathrm{O}+\mathrm{HO}$ & $\sim 188$ & $\sim 637$ \\
\hline
\end{tabular}

Absorption cross-section data

\begin{tabular}{llc}
\hline Wavelength range/nm & Reference & Comments \\
\hline $205-360$ & Bauerle and Moortgat, 1999 & (a) \\
\hline
\end{tabular}

\section{Quantum yield data}

No data

\section{Comments}

(a) $\mathrm{HOCH}_{2} \mathrm{OOH}$ prepared by liquid phase reaction of $\mathrm{HCHO}$ with excess $\mathrm{H}_{2} \mathrm{O}_{2}$. A diode-array spectrometer was used to make relative absorption measurements over the whole wavelength range. The $\mathrm{HOCH}_{2} \mathrm{OOH}$ concentration was measured in situ by FTIR using a peak IR absorption coefficient of $\sigma=7.4 \times 10^{-19} \mathrm{~cm}^{2}$ molecule $\mathrm{e}^{-1}$ at $1049 \mathrm{~cm}^{-1}$. This cross section was determined in the same system by quantitative measurement of the decomposition products of $\mathrm{HOCH}_{2} \mathrm{OOH}(\mathrm{HCOOH}$ and $\mathrm{HCHO}$ ) using the yields of these products. The decomposition channels were previously established by Neeb et al. (1997).

\section{Preferred Values}

Absorption cross-sections at $298 \mathrm{~K}$

\begin{tabular}{cccc}
\hline$\lambda / \mathrm{nm}$ & $10^{20} \sigma / \mathrm{cm}^{2}$ & $\lambda / \mathrm{nm}$ & $10^{20} \sigma / \mathrm{cm}^{2}$ \\
\hline 205 & 26.91 & 290 & 0.63 \\
210 & 22.56 & 295 & 0.51 \\
215 & 18.75 & 300 & 0.40 \\
220 & 15.46 & 305 & 0.29 \\
225 & 12.47 & 310 & 0.22 \\
230 & 10.06 & 315 & 0.18 \\
235 & 7.89 & 320 & 0.13 \\
240 & 5.98 & 325 & 0.10 \\
245 & 4.68 & 330 & 0.073 \\
250 & 3.78 & 335 & 0.059 \\
255 & 2.88 & 340 & 0.045 \\
260 & 2.31 & 345 & 0.036 \\
265 & 1.81 & 350 & 0.028 \\
270 & 1.48 & 355 & 0.022 \\
275 & 1.21 & 360 & 0.017 \\
280 & 0.93 & 365 & 0.012 \\
285 & 0.75 & & \\
\hline
\end{tabular}




\section{Quantum Yields}

$\phi_{1}=1.0$ for $\lambda>290 \mathrm{~nm}$.

\section{Comments on Preferred Values}

The preferred absorption cross-section data are those of Bauerle and Moortgat (1999) which are the only data reported for the absorption spectrum of $\mathrm{HOCH}_{2} \mathrm{OOH}$. The values are close to those recommended for $\mathrm{CH}_{3} \mathrm{OOH}$ based on the measurements of Vaghjiani and Ravishankara (1990). The recommended quantum yields are based on an analogy with methyl hydroperoxide. Other channels may occur in photolysis at shorter wavelengths.

\section{References}

Bauerle, S. and Moortgat, G. K.: Chem. Phys. Lett., 309, 43, 1999.

Neeb, P., Sauer, F., Horie, O., and Moortgat, G. K.: Atmos. Environ., 31, 1417, 1997.

Vaghjiani, G. L. and Ravishankara, A. R.: J. Chem. Phys., 92, 996, 1990. 
II.A8.211

$$
\mathrm{CH}_{3} \mathrm{ONO}_{2}+\mathbf{h} v \rightarrow \text { products }
$$

\section{Primary photochemical transitions}

\begin{tabular}{lllcc}
\hline Reaction & & & $\Delta \mathrm{H}_{298}^{\circ} / \mathrm{kJ} \cdot \mathrm{mol}^{-1}$ & $\lambda_{\text {threshold }} / \mathrm{nm}$ \\
\hline $\mathrm{CH}_{3} \mathrm{ONO}_{2}+\mathrm{h} v$ & $\rightarrow \mathrm{CH}_{3} \mathrm{O}+\mathrm{NO}_{2}$ & $(1)$ & 170.1 & 703 \\
& $\rightarrow \mathrm{HCHO}+\mathrm{HONO}$ & $(2)$ & -68.4 & \\
& $\rightarrow \mathrm{CH}_{3} \mathrm{ONO}+\mathrm{O}\left({ }^{3} \mathrm{P}\right)$ & $(3)$ & 303.6 & 394 \\
\hline
\end{tabular}

\section{Absorption cross-section data}

\begin{tabular}{llc}
\hline Wavelength range/nm & Reference & Comments \\
\hline $270-315$ & Roberts and Fajer, 1989 & (a) \\
$220-335$ & Rattigan et al., 1992 & (b) \\
$236-344$ & Talukdar et al., 1997 & (c) \\
\hline
\end{tabular}

Quantum yield data $\left(\phi=\phi_{1}+\phi_{2}+\phi_{3}\right)$

\begin{tabular}{lclc}
\hline Measurement & Wavelength range/nm & Reference & Comments \\
\hline$\phi_{1}=0.9 \pm 0.2$ & 248 & Talukdar et al., 1997 & (d) \\
$\phi_{1}=1.3 \pm 0.3$ & 248 & & (e) \\
$\phi_{2}<0.05$ & 248 & & (d) \\
$\phi_{3}<0.1$ & 248 & & (d) \\
\hline
\end{tabular}

\section{Comments}

(a) Absorption cross-sections were measured in a $10.2 \mathrm{~cm}$ pathlength cell, using a single-beam spectrometer with a photometric accuracy of $\pm 0.5 \%$. Numerical data for cross-sections are available from Roberts (1990).

(b) Cross-sections were measured with a dual-beam diode array spectrometer with a spectral resolution of $0.3 \mathrm{~nm}$ over the temperature range $238 \mathrm{~K}$ to $294 \mathrm{~K}$. The temperature dependence of $\sigma$ was found to obey the equation, $\ln \sigma(\lambda, T)=\ln \sigma(\lambda$, $298 \mathrm{~K})+B(\lambda)(T-298)$.

(c) Absorption cross-sections were measured with a diode-array spectrometer. Absorbances were measured in $80 \mathrm{~nm}$ blocks, which were assembled to construct the spectrum. Cross-sections were measured at $298 \mathrm{~K}$ and 6 other temperatures in the range $240 \mathrm{~K}$ to $360 \mathrm{~K}$. The temperature dependence of $\sigma$ was found to obey the equation $\ln \sigma(\lambda$, $T)=\ln \sigma(\lambda, 298 \mathrm{~K})+B(\lambda)(T-298)$. The absorption cross-section at $213.86 \mathrm{~nm}$ ( $\mathrm{Zn} \mathrm{line)} \mathrm{was} \mathrm{also} \mathrm{measured.} \mathrm{A} \mathrm{value} \mathrm{of}$ $(1.67 \pm 0.08) \times 10^{-18} \mathrm{~cm}^{2}$ molecule ${ }^{-1}$ was obtained.

(d) Photolysis of methyl nitrate at $248 \mathrm{~nm}$ and $298 \mathrm{~K}$ in the presence of excess $\mathrm{O}_{2}$ to scavenge radicals. Actinometry based on $\mathrm{O}_{3}$ photolysis or $\mathrm{N}_{2} \mathrm{O}$ photolysis in experiments carried out with $193 \mathrm{~nm}$ radiation. Yields of the products $\mathrm{CH}_{3} \mathrm{ONO}$, $\mathrm{CH}_{2} \mathrm{O}, \mathrm{NO}_{2}$ and $\mathrm{NO}_{3}$ were measured by UVA, $\mathrm{NO}_{3}$ by time-resolved absorption at $662 \mathrm{~nm}$, and $\mathrm{H}$ and $\mathrm{O}$ by resonance fluorescence. Channels leading to $\mathrm{H}, \mathrm{O}$, and $\mathrm{NO}_{3}$ were found to make negligible contribution at $248 \mathrm{~nm}$, but high yields of $\mathrm{O}$ were obtained at $193 \mathrm{~nm}$. Small yields of $\mathrm{HO}$ observed were attributed to secondary reactions.

(e) Same technique as in (d), but $\mathrm{NO}$ was used to scavenge radicals instead of $\mathrm{O}_{2}$. 


\section{Preferred Values}

\section{Absorption cross-sections at $298 \mathrm{~K}$}

\begin{tabular}{cccc}
\hline$\lambda / \mathrm{nm}$ & $10^{20} \sigma / \mathrm{cm}^{2}$ & $\lambda / \mathrm{nm}$ & $10^{20} \sigma / \mathrm{cm}^{2}$ \\
\hline 240 & 5.88 & 295 & 0.568 \\
245 & 4.19 & 300 & 0.360 \\
250 & 3.59 & 305 & 0.214 \\
255 & 3.30 & 310 & 0.134 \\
260 & 3.06 & 315 & 0.0633 \\
265 & 2.77 & 320 & 0.0316 \\
270 & 2.39 & 325 & 0.0144 \\
275 & 2.00 & 330 & 0.00661 \\
280 & 1.58 & 335 & 0.00274 \\
285 & 1.19 & 340 & 0.00122 \\
290 & 0.85 & & \\
\hline
\end{tabular}

\section{Temperature dependence of the absorption cross-sections over} the range $240 \mathrm{~K}$ to $330 \mathrm{~K}$

\begin{tabular}{cccc}
\hline$\lambda / \mathrm{nm}$ & $10^{3} B / K^{-1}$ & $\lambda / \mathrm{nm}$ & $10^{3} B / K^{-1}$ \\
\hline 240 & 3.48 & 290 & 4.04 \\
245 & 3.29 & 295 & 4.47 \\
250 & 2.96 & 300 & 4.94 \\
255 & 2.82 & 305 & 5.56 \\
260 & 2.83 & 310 & 6.33 \\
265 & 2.92 & 315 & 7.34 \\
270 & 3.08 & 320 & 8.74 \\
275 & 3.28 & 325 & 9.97 \\
280 & 3.51 & 330 & 13.6 \\
285 & 3.78 & & \\
\hline The tabulated values of $B$ may be used to calculate $\sigma(\lambda, T)$ using the relationship \\
$\ln \sigma(\lambda, T)=\ln \sigma(\lambda, 298 K)+B(\lambda)(T-298)$.
\end{tabular}

\section{Quantum Yields}

$\phi_{1}=1.0$ for $\lambda \geq 248 \mathrm{~nm}$.

\section{Comments on Preferred Values}

The preferred values of the absorption cross-sections at $298 \mathrm{~K}$ are average values from the data of Roberts and Fajer (1989), Rattigan et al. (1992) and Talukdar et al. (1997), which are in excellent agreement over the whole wavelength range of the measurements. They are also in reasonable agreement with the absorption spectrum reported by Calvert and Pitts (1966) and with the cross-sections reported by Maria et al. (1973). The results of Taylor et al. (1980) are consistently higher than the values from the other studies (Roberts and Fajer, 1989; Rattigan et al., 1992; Talukar et al., 1997; Calvert and Pitts, 1966; Maria et al., 1973), by as much as a factor of two in the region $290 \mathrm{~nm}$ to $330 \mathrm{~nm}$.

The two studies of the effect of temperature on the cross-sections are also in very good agreement with differences only appearing at wavelengths beyond $320 \mathrm{~nm}$ where the absorption cross-sections become very small and the precision of the measurements falls away. The preferred values of $B(\lambda)$ are those of Talukdar et al. (1997) averaged over $5 \mathrm{~nm}$ intervals around the given wavelength.

The preferred value of the quantum yield is based on the work of Talukdar et al. (1997) who concluded that the photodissociation of methyl nitrate at $248 \mathrm{~nm}$ produces $\mathrm{NO}_{2}$ and $\mathrm{CH}_{3} \mathrm{O}$ with a quantum yield of essentially unity. This is in accord with 
the general assumption (Roberts, 1990) that the lack of structure in the absorption spectrum of $\mathrm{RONO}_{2}$ molecules indicates that the quantum yield for dissociation is unity, and is supported by the recently measured value for ethyl nitrate of $\phi_{1}=1.0 \pm 0.1$ at $308 \mathrm{~nm}$ (Zhu and Ding, 1997).

\section{References}

Calvert, J. G. and Pitts Jr., J. N.: Photochemistry, Wiley, New York, 1966.

Maria, H. J., McDonald, J. R., and McGlynn, S. P.: J. Am. Chem. Soc., 95, 1050, 1973.

Rattigan, O., Lutman, E., Jones, R. L., Cox, R. A., Clemitshaw, K., and Williams, J.: J. Photochem. Photobiol. A: Chem., 66, 313, 1992; corrigendum, ibid, 69, 125, 1992.

Roberts, J. M. and Fajer, R. W.: Environ. Sci. Technol., 23, 945, 1989.

Roberts, J. M.: Atmos. Environ., 24A, 243, 1990.

Talukdar, R. K., Burkholder, J. B., Hunter, M., Gilles, M. K., Roberts, J. M., and Ravishankara, A. R.: J. Chem. Soc. Faraday Trans., 93, 2797, 1997.

Taylor, W. D., Allston, T. D., Moscato, M. J., Fazekas, G. B., Kozlowski, R., and Takacs, G. A.: Int. J. Chem. Kinet., 12, 231, 1980.

Zhu, L. and Ding, C.-F.: Chem. Phys. Lett., 265, 177, 1997. 
II.A8.212

$$
\mathbf{C}_{2} \mathrm{H}_{5} \mathrm{ONO}_{2}+\mathbf{h} v \rightarrow \text { products }
$$

\section{Primary photochemical transitions}

\begin{tabular}{llccc}
\hline Reaction & & & $\Delta \mathrm{H}_{298}^{\circ} / \mathrm{kJ} \cdot \mathrm{mol}^{-1}$ & $\lambda_{\text {threshold }} / \mathrm{nm}$ \\
\hline $\mathrm{C}_{2} \mathrm{H}_{5} \mathrm{ONO}_{2}+\mathrm{h} v$ & $\rightarrow \mathrm{C}_{2} \mathrm{H}_{5} \mathrm{O}+\mathrm{NO}_{2}$ & $(1)$ & 171.7 & 697 \\
& $\rightarrow \mathrm{CH}_{3} \mathrm{CHO}+\mathrm{HONO}$ & $(2)$ & -91.3 & \\
& $\rightarrow \mathrm{C}_{2} \mathrm{H}_{5} \mathrm{ONO}+\mathrm{O}\left({ }^{3} \mathrm{P}\right)$ & $(3)$ & 299.4 & 400 \\
\hline
\end{tabular}

Absorption cross-section data

\begin{tabular}{llc}
\hline Wavelength range/nm & Reference & Comments \\
\hline $270-315$ & Roberts and Fajer, 1989 & (a) \\
$185-330$ & Turberg et al., 1990 & (b) \\
$265-340$ & Zhu and Ding, 1997 & (c) \\
$265-340$ & Clemitshaw et al., 1997 & (d) \\
$265-340$ & Talukdar et al., 1997 & (e) \\
\hline
\end{tabular}

Quantum yield data $\left(\phi=\phi_{1}+\phi_{2}+\phi_{3}\right)$

\begin{tabular}{lclr}
\hline Measurement & Wavelength range/nm & Reference & Comments \\
\hline$\phi_{1}=1.0 \pm 0.1$ & 308 & Zhu and Ding, 1997 & (f) \\
\hline
\end{tabular}

\section{Comments}

(a) Absorption cross-sections were measured in a $10.2 \mathrm{~cm}$ pathlength cell, using a single-beam spectrometer with a photometric accuracy of $\pm 0.5 \%$. Numerical data for cross-sections are available from Roberts (1990).

(b) Absorption cross-sections were measured in cells of $2 \mathrm{~cm}$ and $10 \mathrm{~cm}$ pathlengths with a range of pressures of $\mathrm{C}_{2} \mathrm{H}_{5} \mathrm{ONO}_{2}$. The spectral resolution was not specified.

(c) Cross-sections measured at $10 \mathrm{~nm}$ intervals, between $238 \mathrm{~K}$ and $298 \mathrm{~K}$, using cavity ring- down spectroscopy. Absorption cross-sections were obtained by measuring optical loss as a function of sample gas pressure ( $0.013 \mathrm{mbar}$ to $18 \mathrm{mbar})$. The purity of ethyl nitrate was checked by FTIR and cavity ring-down spectroscopy.

(d) Absorption cross-sections were measured with a dual-beam diode array spectrometer, with a spectral resolution of approximately $0.6 \mathrm{~nm}$, over the temperature range $233 \mathrm{~K}$ to $298 \mathrm{~K}$. The purity of the ethyl nitrate was checked by NMR and FTIR.

(e) Absorption cross-sections were measured with a diode-array spectrometer at $298 \mathrm{~K}$ and six other temperatures in the range $240 \mathrm{~K}$ to $360 \mathrm{~K}$. Absorbances were measured in $80 \mathrm{~nm}$ blocks which were assembled to construct the spectrum. Corrections were made for contributions to the spectrum from $\mathrm{NO}_{2}$ present in the ethyl nitrate.

(f) Excimer laser used to photodissociate ethyl nitrate in a cavity ring-down spectrometer. Time-resolved spectra of products observed. Only $\mathrm{NO}_{2}$ found as product, with undetectable yields of $\mathrm{HONO}$ and $\mathrm{C}_{2} \mathrm{H}_{5} \mathrm{ONO}$. Quantum yield measurements were made at $278 \mathrm{~K}, 283 \mathrm{~K}, 288 \mathrm{~K}, 293 \mathrm{~K}$ and $298 \mathrm{~K}$ with ethyl nitrate pressures of 1.3 mbar to $13 \mathrm{mbar}$ in a buffer gas of $\mathrm{N}_{2}$ at total pressures of 16 mbar to 1 bar. $\phi_{1}$ was found to be pressure and temperature independent. 


\section{Preferred Values}

\section{Absorption cross-sections at $298 \mathrm{~K}$ and their temperature dependence over the ranges $233 \mathrm{~K}$ to $360 \mathrm{~K}$ and $235 \mathrm{~nm}$ to} $340 \mathrm{~nm}$

\begin{tabular}{cccccc}
\hline$\lambda / \mathrm{nm}$ & $10^{20} \sigma / \mathrm{cm}^{2}$ & $10^{3} B / K^{-1}$ & $\lambda / \mathrm{nm}$ & $10^{20} \sigma / \mathrm{cm}^{2}$ & $10^{3} B / K^{-1}$ \\
\hline 185 & 1710 & & 265 & 3.6 & 2.9 \\
190 & 1710 & & 270 & 3.1 & 3.1 \\
195 & 1490 & & 275 & 2.7 & 3.3 \\
200 & 1140 & & 280 & 2.2 & 3.6 \\
205 & 738 & & 285 & 1.7 & 3.8 \\
210 & 400 & & 290 & 1.2 & 4.2 \\
215 & 195 & & 295 & 0.85 & 4.7 \\
220 & 91 & & 300 & 0.55 & 5.1 \\
225 & 45 & & 305 & 0.33 & 5.8 \\
230 & 24 & & 310 & 0.19 & 6.7 \\
235 & 11.9 & 1.4 & 315 & 0.10 & 7.9 \\
240 & 7.7 & 2.8 & 320 & 0.051 & 8.6 \\
245 & 5.4 & 2.9 & 325 & 0.026 & 10.4 \\
250 & 4.5 & 2.8 & 330 & 0.012 & 12.9 \\
255 & 4.1 & 2.6 & 335 & 0.0049 & 14.1 \\
260 & 3.9 & 2.6 & 340 & 0.0025 & 15.6 \\
\hline
\end{tabular}

The temperature variation of the absorption cross-section at a particular wavelength in the range $240 \mathrm{~nm}$ to $340 \mathrm{~nm}$ is expressed as $\ln \sigma(T)-\ln \sigma(298 K)=B(T-298)$.

\section{Quantum Yields}

$\phi_{1}=1.0 \pm 0.1$ at $308 \mathrm{~nm}$, independent of pressure over the temperature range $278-298 \mathrm{~K}$.

\section{Comments on Preferred Values}

The preferred values of the cross-sections at $298 \mathrm{~K}$ are those obtained by Turberg et al. (1990) over the range $185 \mathrm{~nm}$ to $230 \mathrm{~nm}$, where this is the only study, and for the range $235 \mathrm{~nm}$ to $340 \mathrm{~nm}$ averages are taken of the values from all of the five studies (Roberts and Fajer, 1989; Turberg et al., 1990; Zhu and Ding, 1997; Clemitshaw et al., 1997 and Talukdar et al., 1997) at the wavelengths where they overlap.

The temperature variation of the cross-sections has been studied by Zhu and Ding (1997), Clemitshaw et al. (1997) and Talukdar et al. (1997). These studies together cover the temperature range $233 \mathrm{~K}$ to $360 \mathrm{~K}$ and the wavelength range $235 \mathrm{~nm}$ to $340 \mathrm{~nm}$. It is found in all of the studies that the temperature variation of $\sigma$ can be expressed as $\ln \sigma(\lambda, T)-\ln \sigma(\lambda$, $298 \mathrm{~K})=B(\lambda)(T-298)$. The results from the three studies (Zhu and Ding, 1997; Clemitshaw et al., 1997 and Talukdar et al., 1997) are in good agreement and the preferred values of $B$ have been obtained by averaging values from the three studies (Zhu and Ding, 1997; Clemitshaw et al., 1997 and Talukdar et al., 1997).

The only direct measurement of the quantum yield is that of Zhu and Ding (1997). Their finding that at $308 \mathrm{~nm}$ the sole photodissociation channel was that leading to $\mathrm{NO}_{2}$ production with a quantum yield of unity is accepted for our preferred value of the quantum yield. It is in accord with the studies of Luke et al. $(1998,1989)$ who concluded that the measured rates of $\mathrm{NO}_{2}$ production from ethyl nitrate photolysis in sunlight could be accounted for by assuming that $\phi_{1}=1$ throughout the region $290 \mathrm{~nm}$ to $340 \mathrm{~nm}$. This is also supported by the measured value of unity for the same channel in the $248 \mathrm{~nm}$ photolysis of methyl nitrate (Talukdar et al., 1997).

\section{References}

Clemitshaw, K. C., Williams, J., Rattigan, O. V., Shallcross, D. E., Law, K. S., and Cox, R. A.: J. Photochem. Photobiol. A: Chem., 102, 117, 1997.

Luke, W. T. and Dickerson, R. R.: Geophys. Res. Lett., 15, 1181, 1988. 
Luke, W. T., Dickerson, R. R., and Nunnermacker, L. J.: J. Geophys. Res., 94, 14 905, 1989.

Roberts, J. M. and Fajer, R. W.: Environ. Sci. Technol., 23, 945, 1989.

Roberts, J. M.: Atmos. Environ., 24A, 243, 1990.

Talukdar, R. K., Burkholder, J. B., Hunter, M., Gilles, M. K., Roberts, J. M., and Ravishankara, A. R.: J. Chem. Soc. Faraday Trans., 93, 2797, 1997.

Turberg, M. P., Giolando, D. M., Tilt, C., Soper, T., Mason, S., Davies, M., Klingensmith, P., and Takacs, G. A.: J. Photochem. Photobiol., A51, 281, 1990.

Zhu, L. and Ding, C.-F.: Chem. Phys. Lett., 265, 177, 1997. 
II.A8.213

$$
n-\mathbf{C}_{3} \mathbf{H}_{7} \mathbf{O N O} \mathbf{O}_{2}+\mathbf{h} v \rightarrow \text { products }
$$

Primary photochemical transitions

\begin{tabular}{llccc}
\hline Reaction & & $\Delta \mathrm{H}_{298}^{\circ} / \mathrm{kJ} \cdot \mathrm{mol}^{-1}$ & $\lambda_{\text {threshold }} / \mathrm{nm}$ \\
\hline$n-\mathrm{C}_{3} \mathrm{H}_{7} \mathrm{ONO}_{2}+\mathrm{h} \nu$ & $\rightarrow n-\mathrm{C}_{3} \mathrm{H}_{7} \mathrm{O}+\mathrm{NO}_{2}$ & $(1)$ & 165.9 & 721 \\
& $\rightarrow \mathrm{C}_{2} \mathrm{H}_{5} \mathrm{CHO}+\mathrm{HONO}$ & $(2)$ & -92.8 & \\
& $\rightarrow \mathrm{C}_{3} \mathrm{H}_{7} \mathrm{ONO}+\mathrm{O}\left({ }^{3} \mathrm{P}\right)$ & $(3)$ & & \\
\hline
\end{tabular}

Absorption cross-section data

\begin{tabular}{llc}
\hline Wavelength range/nm & Reference & Comments \\
\hline $270-330$ & Roberts and Fajer, 1989 & (a) \\
$185-330$ & Turberg et al., 1990 & (b) \\
$220-340$ & Clemitshaw et al., 1997 & (c) \\
\hline
\end{tabular}

\section{Comments}

(a) Absorption cross-sections were measured in a cell of $10.2 \mathrm{~cm}$ pathlength using a single-beam spectrometer with a photometric accuracy of $\pm 0.5 \%$. No $\mathrm{NO}_{2}$ could be detected by FTIR in the $n$-propyl nitrate.

(b) Absorption cross-sections were measured in $2 \mathrm{~cm}$ and $10 \mathrm{~cm}$ pathlength cells with a range of pressures of $n-\mathrm{C}_{3} \mathrm{H}_{7} \mathrm{ONO}_{2}$ at an unspecified spectral resolution.

(c) Absorption cross-sections were measured with a dual-beam diode array spectrometer, with a spectral resolution of approximately $0.6 \mathrm{~nm}$. The purity of the $n$-propyl nitrate was checked by NMR and FTIR.

\section{Preferred Values}

\section{Absorption cross-sections at $298 \mathrm{~K}$}

\begin{tabular}{cccc}
\hline$\lambda / \mathrm{nm}$ & $10^{20} \sigma / \mathrm{cm}^{2}$ & $\lambda / \mathrm{nm}$ & $10^{20} \sigma / \mathrm{cm}^{2}$ \\
\hline 185 & 1810 & 265 & 3.6 \\
190 & 1800 & 270 & 3.2 \\
195 & 1600 & 275 & 2.8 \\
200 & 1260 & 280 & 2.3 \\
205 & 855 & 285 & 1.8 \\
210 & 489 & 290 & 1.3 \\
215 & 244 & 295 & 0.95 \\
220 & 105 & 300 & 0.57 \\
225 & 50 & 305 & 0.34 \\
230 & 27 & 310 & 0.19 \\
235 & 15 & 315 & 0.10 \\
240 & 8.9 & 320 & 0.053 \\
245 & 6.0 & 325 & 0.031 \\
250 & 4.8 & 330 & 0.022 \\
255 & 4.4 & 335 & 0.018 \\
260 & 4.0 & 340 & 0.016 \\
\hline
\end{tabular}




\section{Comments on Preferred Values}

Clemitshaw et al. (1997) have measured the absorption cross-sections at $298 \mathrm{~K}$ over the range $220 \mathrm{~nm}$ to $340 \mathrm{~nm}$. In the wavelength region where their measurements overlap with those of Roberts and Fajer (1989) (270 nm to $320 \mathrm{~nm}$ ), the two studies are in excellent agreement. Agreement with the results of Turberg et al. (1990) is also very good in the range $220 \mathrm{~nm}$ to $295 \mathrm{~nm}$, but the results of Turberg et al. (1990) deviate significantly from those of both Clemitshaw et al. (1997) and Roberts and Fajer (1989) at $\lambda>295 \mathrm{~nm}$. This tendency to obtain higher values than others of the absorption cross-section at longer wavelengths is noticeable in the results of Turberg et al. (1990) in all of their studies of the higher nitrates and could be due to traces of $\mathrm{NO}_{2}$ in their samples.

The preferred values of the absorption cross-section are those of Turberg et al. (1990) for the range $185 \mathrm{~nm}$ to $220 \mathrm{~nm}$ where theirs are the only measurements. Over the range $220 \mathrm{~nm}$ to $295 \mathrm{~nm}$ averages are taken of the results of Roberts and Fajer (1989), Turberg et al. (1990) and Clemitshaw et al. (1997) where their studies overlap, and over the range $295 \mathrm{~nm}$ to $340 \mathrm{~nm}$ the preferred values are based on the results of Roberts and Fajer (1989) and Clemitshaw et al. (1997).

There are no data on either the products of photodissociation or the quantum yields. However, the quantum yields for photodissociation of both ethyl and methyl nitrate to form $\mathrm{NO}_{2}$ have been shown to be unity at $308 \mathrm{~nm}$ and $248 \mathrm{~nm}$, respectively (see data sheets in this evaluation). Since the absorption spectra of organic nitrates are very similar, with structureless continua occurring in the same region of the spectrum, it seems likely that the photodissociation quantum yield for $n$-propyl nitrate will also be unity. Further support for this conclusion comes from direct measurements (Luke et al., 1989) of the rate of formation of $\mathrm{NO}_{2}$ from the photolyses of $n-\mathrm{C}_{3} \mathrm{H}_{7} \mathrm{ONO}_{2}$ in sunlight. These agreed well with the calculated rates of photolyses, based on measurements of the absorption cross-sections, solar irradiances, and an assumed value of $\phi_{1}=1$ throughout the wavelength region $290 \mathrm{~nm}$ to $340 \mathrm{~nm}$ (Luke et al., 1989).

\section{References}

Clemitshaw, K. C., Williams, J., Rattigan, O. V., Shallcross, D. E., Law, K. S., and Cox, R. A.: J. Photochem. Photobiol. A: Chem., 102, 117, 1997.

Luke, W. T., Dickerson, R. R., and Nunnermacker, L. J.: J. Geophys. Res., 94, 14 905, 1989.

Roberts, J. M. and Fajer, R. W.: Environ. Sci. Technol., 23, 945, 1989.

Turberg, M. P., Giolando, D. M., Tilt, C., Soper, T., Mason, S., Davies, M., Klingensmith, P., and Takacs, G. A.: J. Photochem. Photobiol., A51, 281, 1990. 
II.A8.214

$$
i-\mathbf{C}_{3} \mathrm{H}_{7} \mathrm{ONO}_{2}+\mathbf{h} v \rightarrow \text { products }
$$

Primary photochemical transitions

\begin{tabular}{lllcc}
\hline Reaction & & $\Delta \mathrm{H}_{298}^{\circ} / \mathrm{kJ} \cdot \mathrm{mol}^{-1}$ & $\lambda_{\text {threshold }} / \mathrm{nm}$ \\
\hline$i-\mathrm{C}_{3} \mathrm{H}_{7} \mathrm{ONO}_{2}+\mathrm{h} v$ & $\rightarrow 2-\mathrm{C}_{3} \mathrm{H}_{7} \mathrm{O}+\mathrm{NO}_{2}$ & $(1)$ & 171.7 & 697 \\
& $\rightarrow \mathrm{CH}_{3} \mathrm{C}(\mathrm{O}) \mathrm{CH}_{3}+\mathrm{HONO}$ & $(2)$ & -105.9 & \\
& $\rightarrow i-\mathrm{C}_{3} \mathrm{H}_{7} \mathrm{ONO}+\mathrm{O}$ & (3) & & \\
\hline
\end{tabular}

\section{Absorption cross-section data}

\begin{tabular}{llc}
\hline Wavelength range/nm & Reference & Comments \\
\hline $270-330$ & Roberts and Fajer, 1989 & (a) \\
$185-330$ & Turberg et al., 1990 & (b) \\
$220-340$ & Clemitshaw et al., 1997 & (c) \\
$240-360$ & Talukdar et al., 1997 & (d) \\
\hline
\end{tabular}

\section{Comments}

(a) Absorption cross-sections were measured in a $10.2 \mathrm{~cm}$ pathlength cell using a single-beam spectrophotometer with a photometric accuracy of $\pm 0.5 \%$. Numerical data for cross-sections are available from Roberts (1990). Samples were checked by FTIR for the presence of $\mathrm{NO}_{2}$, which was not found.

(b) Absorption cross-sections were measured in $2 \mathrm{~cm}$ and $10 \mathrm{~cm}$ pathlength cells, with a range of pressures of $i-\mathrm{C}_{3} \mathrm{H}_{7} \mathrm{ONO}_{2}$, at a bandwidth of $1 \mathrm{~nm}$.

(c) Absorption cross-sections were measured with a dual-beam diode array spectrometer, with a spectral resolution of approximately $0.6 \mathrm{~nm}$. The purity of the $i$-propyl nitrate was checked by NMR and FTIR.

(d) Absorption cross-sections were measured with a diode-array spectrometer at $298 \mathrm{~K}$ and 6 other temperatures in the range $240 \mathrm{~K}$ to $360 \mathrm{~K}$. Absorbances were measured in $80 \mathrm{~nm}$ blocks which were assembled to construct the spectrum.

\section{Preferred Values}

Absorption cross-sections at $298 \mathrm{~K}$ and their temperature dependence over the ranges $233 \mathrm{~K}$ to $360 \mathrm{~K}$ and $240 \mathrm{~nm}$ to $340 \mathrm{~nm}$

\begin{tabular}{cccccc}
\hline$\lambda / \mathrm{nm}$ & $10^{20} \sigma / \mathrm{cm}^{2}$ & $10^{3} B / K^{-1}$ & $10^{20} \sigma / \mathrm{cm}^{2}$ & $\lambda / \mathrm{nm}$ & $10^{3} B / K^{-1}$ \\
\hline 185 & 1790 & & 275 & 3.4 & 3.3 \\
188 & 1810 & & 280 & 2.8 & 3.6 \\
190 & 1790 & & 285 & 2.2 & 4.0 \\
195 & 1610 & & 290 & 1.6 & 4.4 \\
200 & 1260 & & 295 & 1.2 & 4.8 \\
205 & 867 & & 300 & 0.78 & 5.4 \\
210 & 498 & & 305 & 0.50 & 6.1 \\
215 & 247 & & 310 & 0.29 & 6.9 \\
220 & 125 & & 315 & 0.17 & 8.1 \\
225 & 62 & & 320 & 0.085 & 9.4 \\
230 & 34 & & 325 & 0.044 & 11.1 \\
235 & 18 & & 330 & 0.022 & 11.9 \\
240 & 11 & 2.8 & 335 & 0.011 & 14.0 \\
245 & 7.0 & 2.7 & 340 & 0.0053 & 13.9 \\
250 & 5.4 & 2.5 & 345 & 0.0018 & \\
255 & 4.9 & 2.5 & 350 & 0.00080 & \\
\hline
\end{tabular}




\begin{tabular}{cccccc}
\hline$\lambda / \mathrm{nm}$ & $10^{20} \sigma / \mathrm{cm}^{2}$ & $10^{3} B / K^{-1}$ & $\lambda / \mathrm{nm}$ & $10^{20} \sigma / \mathrm{cm}^{2}$ & $10^{3} B / K^{-1}$ \\
\hline 260 & 4.6 & 2.6 & 355 & 0.00029 & \\
265 & 4.3 & 2.8 & 360 & 0.00018 & \\
270 & 3.9 & 3.1 & & & \\
\hline
\end{tabular}

The temperature variation of the absorption cross-section at a particular wavelength in the range $240 \mathrm{~nm}$ to $340 \mathrm{~nm}$

is expressed as $\ln \sigma(T)-\ln \sigma(298 K)=B(T-298)$.

\section{Comments on Preferred Values}

Clemitshaw et al. (1997) have measured the absorption cross-sections at $298 \mathrm{~K}$ over the range $220 \mathrm{~nm}$ to $340 \mathrm{~nm}$ and Talukdar et al. (1997) have measured both the cross-sections at $298 \mathrm{~K}$ over the range $240 \mathrm{~nm}$ to $360 \mathrm{~nm}$ and their temperature dependence at temperatures in the range $240 \mathrm{~K}$ to $360 \mathrm{~K}$. The results of Clemitshaw et al. (1997) and of Talukdar et al. (1997) are in excellent agreement with the earlier results of Roberts and Fajer (1989) and Turberg et al. (1990) at wavelengths above where they overlap (in the range $220 \mathrm{~nm}$ to $330 \mathrm{~nm}$ ), except for the results of Turberg et al. (1990) at wavelengths $310 \mathrm{~nm}$ which deviate increasingly from those of the other studies as the wavelength increases. This tendency, to obtain higher values than others, in this wavelength region, is noticeable in the results of Turberg et al. (1990) for all of the higher nitrates and could be due to traces of $\mathrm{NO}_{2}$ present in their samples.

The preferred values of the absorption cross-sections at $298 \mathrm{~K}$ are those of Turberg et al. (1990) for the range $185 \mathrm{~nm}$ to $220 \mathrm{~nm}$, where theirs are the only values. Over the range $220 \mathrm{~nm}$ to $305 \mathrm{~nm}$ averages are taken of the results of Roberts and Fajer (1989), Turberg et al. (1990), Clemitshaw et al. (1997), and Talukdar et al. (1997), where their studies overlap, and over the range $310 \mathrm{~nm}$ to $360 \mathrm{~nm}$ the preferred values are based on the results of Roberts and Fajer (1989), Clemitshaw et al. (1997) and Talukdar et al. (1997).

The preferred values of the constant $B$, which characterize the temperature dependence of the absorption cross-sections are those of Talukdar et al. (1997).

There are no data on either the products of photodissociation or the quantum yields. However, the quantum yields for the photodissociation of both ethyl and methyl nitrate to form $\mathrm{NO}_{2}$ have been shown to be unity at $308 \mathrm{~nm}$ and $248 \mathrm{~nm}$, respectively (see data sheets in this evaluation). Since the absorption spectra of organic nitrates are very similar structureless continua occurring at similar wavelengths, it seems likely that the photodissociation quantum yield for isopropyl nitrate will also be unity. Further support for this conclusion comes from measurements of the rate of formation of $\mathrm{NO}_{2}$ from the photolyses of alkyl nitrates in sunlight (Luke et al., 1989). Thus the measured rate of formation of $\mathrm{NO}_{2}$ matched well with calculated rates of photolyses based on measurements of the absorption cross-section, solar irradiances, and an assumed value of $\phi_{1}=1$ throughout the wavelength region $290 \mathrm{~nm}$ to $330 \mathrm{~nm}$ (Luke et al., 1989).

\section{References}

Clemitshaw, K. C., Williams, J., Rattigan, O. V., Shallcross, D. E., Law, K. S., and Cox, R. A.: J. Photochem. Photobiol. A: Chem., 102, 117, 1997.

Luke, W. T., Dickerson, R. R., and Nunnermacker, L. J.: J. Geophys. Res. 94, 14 905,1989.

Roberts, J. M. and Fajer, R. W.: Environ. Sci. Technol., 23, 945, 1989.

Roberts, J. M.: Atmos. Environ., 24A, 243, 1990.

Talukdar, R. K., Burkholder, J. B., Hunter, M., Gilles, M. K., Roberts, J. M., and Ravishankara, A. R.: J. Chem. Soc. Faraday Trans., 93, 2797, 1997.

Turberg, M. P., Giolando, D. M., Tilt, C., Soper, T., Mason, S., Davies, M., Klingensmith, P., and Takacs, G. A.: J. Photochem. Photobiol., A51, 281, 1990. 
II.A8.215

$$
1-\mathrm{C}_{4} \mathrm{H}_{9} \mathrm{ONO}_{2}+\mathbf{h} v \rightarrow \text { products }
$$

Primary photochemical transitions

\begin{tabular}{llll}
\hline Reaction & & $\Delta \mathrm{H}_{298}^{\circ} / \mathrm{kJ} \cdot \mathrm{mol}^{-1}$ & $\lambda_{\text {threshold }} / \mathrm{nm}$ \\
\hline $1-\mathrm{C}_{4} \mathrm{H}_{9} \mathrm{ONO}_{2}+\mathrm{h} v$ & $\rightarrow 1-\mathrm{C}_{4} \mathrm{H}_{9} \mathrm{O}+\mathrm{NO}_{2}$ & $(1)$ & \\
& $\rightarrow 1-\mathrm{C}_{3} \mathrm{H}_{7} \mathrm{CHO}+\mathrm{HONO}$ & $(2)$ & \\
& $\rightarrow i-\mathrm{C}_{4} \mathrm{H}_{9} \mathrm{ONO}+\mathrm{O}$ & (3) & \\
\hline
\end{tabular}

\section{Absorption cross-section data}

\begin{tabular}{llc}
\hline Wavelength range/nm & Reference & Comments \\
\hline $270-315$ & Roberts and Fajer, 1989 & (a) \\
$185-320$ & Turberg et al., 1990 & (b) \\
$220-340$ & Clemitshaw et al., 1997 & (c) \\
\hline
\end{tabular}

\section{Comments}

(a) Absorption cross-sections were measured in a $10.2 \mathrm{~cm}$ pathlength cell using a single-beam spectrophotometer with a photometric accuracy of $\pm 0.5 \%$. Data are presented graphically but an expression for $\sigma$ as a function of $\lambda$ is derived from a least squares fit to the data at $\lambda \geq 270 \mathrm{~nm}$. Purity of the butyl nitrate was checked by FTIR.

(b) Absorption cross-sections were measured in $2 \mathrm{~cm}$ and $10 \mathrm{~cm}$ pathlength cells in a Varian Carey 219 spectrophotometer using a bandwidth of $1 \mathrm{~nm}$.

(c) Absorption cross-sections were measured with a dual-beam diode array spectrometer, with a spectral resolution of approximately $0.6 \mathrm{~nm}$. The purity of the 1-butyl nitrate was checked by NMR and FTIR.

\section{Preferred Values}

\section{Absorption cross-sections at $298 \mathrm{~K}$}

\begin{tabular}{cccc}
\hline$\lambda / \mathrm{nm}$ & $10^{20} \sigma / \mathrm{cm}^{2}$ & $\lambda / \mathrm{nm}$ & $10^{20} \sigma / \mathrm{cm}^{2}$ \\
\hline 185 & 1810 & 265 & 3.9 \\
190 & 1810 & 270 & 3.4 \\
195 & 1620 & 275 & 3.0 \\
200 & 1300 & 280 & 2.4 \\
205 & 889 & 285 & 1.9 \\
210 & 518 & 290 & 1.4 \\
215 & 263 & 295 & 0.89 \\
220 & 111 & 300 & 0.57 \\
225 & 58 & 305 & 0.34 \\
230 & 30 & 310 & 0.19 \\
235 & 17 & 315 & 0.10 \\
240 & 9.8 & 320 & 0.051 \\
245 & 6.3 & 325 & 0.031 \\
250 & 5.3 & 330 & 0.021 \\
255 & 4.6 & 335 & 0.016 \\
260 & 4.3 & 340 & 0.013 \\
\hline
\end{tabular}




\section{Comments on Preferred Values}

The results of Roberts and Fajer (1989), Turberg et al. (1990) and Clemitshaw et al. (1997) are in good agreement at wavelengths where the studies overlap (in the range $220 \mathrm{~nm}$ to $320 \mathrm{~nm}$ ), except for the results of Turberg et al. (1990) at wavelengths $\geq 300 \mathrm{~nm}$ which deviate increasingly from those of the other studies as the wavelength increases. This tendency to obtain higher values than others, in this wavelength region, is noticeable in the results of Turberg et al. (1990) for all of the higher nitrates and could be due to traces of $\mathrm{NO}_{2}$ present in their samples.

The preferred values of the absorption cross-sections are those of Turberg et al. (1990) for the range $185 \mathrm{~nm}$ to $220 \mathrm{~nm}$, where theirs are the only values. Over the range $220 \mathrm{~nm}$ to $295 \mathrm{~nm}$ averages are taken of the results of Roberts and Fajer (1989), Turberg et al. (1990) and Clemitshaw et al. (1997), where their studies overlap, and over the range $300 \mathrm{~nm}$ to $400 \mathrm{~nm}$ the preferred values are based on the results of Roberts and Fajer and Clemitshaw et al. (1997).

There are no data on either the products of photodissociation or the quantum yields. However, the quantum yields for the photodissociation of both ethyl and methyl nitrates to form $\mathrm{NO}_{2}$ have been shown to be unity at $308 \mathrm{~nm}$ and $248 \mathrm{~nm}$, respectively (see data sheets in this evaluation). Since the absorption spectra of alkyl nitrates are very similar structureless continua occurring at similar wavelengths, it seems likely that the photodissociation quantum yield for 1-butyl nitrate will also be unity. Further support for this conclusion comes from measurements of the rate of formation of $\mathrm{NO}_{2}$ from the photolyses of alkyl nitrates in sunlight (Luke et al., 1989). Thus the measured rate of formation of $\mathrm{NO}_{2}$ matched well with calculated rates of photolyses based on measurements of the absorption cross-sections, solar irradiances, and an assumed value of $\phi_{1}=1$ throughout the wavelength region $290 \mathrm{~nm}$ to $330 \mathrm{~nm}$ (Luke et al., 1989).

\section{References}

Clemitshaw, K. C., Williams, J., Rattigan, O. V., Shallcross, D. E., Law, K. S., and Cox, R. A.: J. Photochem. Photobiol. A: Chem., 102, 117, 1997.

Luke, W. T., Dickerson, R. R., and Nunnermacker, L. J.: J. Geophys. Res., 94, 14 905, 1989.

Roberts, J. M. and Fajer, R. W.: Environ. Sci. Technol., 23, 945, 1989.

Turberg, M. P., Giolando, D. M., Tilt, C., Soper, T., Mason, S., Davies, M., Klingensmith, P., and Takacs, G. A.: J. Photochem. Photobiol., A51, 281, 1990. 
II.A8.216

$$
2-\mathrm{C}_{4} \mathrm{H}_{9} \mathrm{ONO}_{2}+\mathbf{h} v \rightarrow \text { products }
$$

Primary photochemical transitions

\begin{tabular}{llll}
\hline Reaction & & $\Delta \mathrm{H}_{298}^{\circ} / \mathrm{kJ}^{\circ} \cdot \mathrm{mol}^{-1}$ & $\lambda_{\text {threshold }} / \mathrm{nm}$ \\
\hline $2-\mathrm{C}_{4} \mathrm{H}_{9} \mathrm{ONO}_{2}+\mathrm{h} v$ & $\rightarrow 2-\mathrm{C}_{4} \mathrm{H}_{9} \mathrm{O}+\mathrm{NO}_{2}$ & $(1)$ & \\
& $\rightarrow \mathrm{CH}_{3} \mathrm{C}(\mathrm{O}) \mathrm{C}_{2} \mathrm{H}_{5}+\mathrm{HONO}$ & $(2)$ \\
& $\rightarrow 2-\mathrm{C}_{4} \mathrm{H}_{9} \mathrm{ONO}+\mathrm{O}$ & (3) & \\
\hline
\end{tabular}

Absorption cross-section data

\begin{tabular}{llc}
\hline Wavelength range/nm & Reference & Comments \\
\hline $250-320$ & Roberts and Fajer, 1989 & (a) \\
\hline
\end{tabular}

\section{Comments}

(a) Absorption cross-sections were measured in a cell of $10.2 \mathrm{~cm}$ pathlength using a single beam spectrophotometer with a photometric accuracy of $\pm 0.5 \%$. The expression for $\sigma$ as a function of $\lambda$ was derived from a least-squares fit to the data at $\lambda \geq 270 \mathrm{~nm}$.

\section{Preferred Values}

\section{Absorption cross-sections at $298 \mathrm{~K}$}

\begin{tabular}{cccc}
\hline$\lambda / \mathrm{nm}$ & $10^{20} \sigma / \mathrm{cm}^{2}$ & $\lambda / \mathrm{nm}$ & $10^{20} \sigma / \mathrm{cm}^{2}$ \\
\hline 250 & 6.5 & 290 & 1.8 \\
255 & 5.6 & 295 & 1.3 \\
260 & 5.2 & 300 & 0.74 \\
265 & 4.8 & 305 & 0.50 \\
270 & 4.2 & 310 & 0.29 \\
275 & 3.7 & 315 & 0.15 \\
280 & 3.1 & 320 & 0.08 \\
285 & 2.4 & & \\
&
\end{tabular}

\section{Comments on Preferred Values}

The only available measurements of the absorption cross-sections are those of Roberts and Fajer (1989). Their measurements of cross-sections for other alkyl nitrates have agreed well with other studies, and their values are accepted as the preferred values for 2-butyl nitrate.

There are no data on either the products of photodissociation or the quantum yields. However, the quantum yields for the photodissociation of both ethyl and methyl nitrates to form $\mathrm{NO}_{2}$ have been shown to be unity at $308 \mathrm{~nm}$ and $248 \mathrm{~nm}$, respectively (see data sheets in this evaluation). Since the absorption spectra of alkyl nitrates are very similar structureless continua occurring at similar wavelengths, it seems likely that the photodissociation quantum yield for 2-butyl nitrate will also be unity. Further support for this conclusion comes from measurements of the rate of formation of $\mathrm{NO}_{2}$ from the photolyses of alkyl nitrates in sunlight (Luke et al., 1989). Thus the measured rate of formation of $\mathrm{NO}_{2}$ matched well with the calculated rates of photolyses based on measurement of the absorption cross-sections, solar irradiances, and an assumed value of $\phi=1$ throughout the wavelength region $290 \mathrm{~nm}$ to $330 \mathrm{~nm}$ (Luke et al., 1989). 


\section{References}

Luke, W. T., Dickerson, R. R., and Nunnermacker, L. J.: J. Geophys. Res., 94, 14 905, 1989.

Roberts, J. M. and Fajer, R. W.: Environ. Sci. Technol., 23, 945, 1989. 
II.A8.217

$$
\mathrm{CH}_{3} \mathrm{O}_{2} \mathrm{NO}_{2}+\mathbf{h} v \rightarrow \text { products }
$$

Primary photochemical transitions

\begin{tabular}{llccc}
\hline Reaction & & & $\Delta \mathrm{H}_{298}^{\circ} / \mathrm{kJ} \cdot \mathrm{mol}^{-1}$ & $\lambda_{\text {threshold }} / \mathrm{nm}$ \\
\hline $\mathrm{CH}_{3} \mathrm{O}_{2} \mathrm{NO}_{2}+\mathrm{h} \nu$ & $\rightarrow \mathrm{CH}_{3} \mathrm{O}_{2}+\mathrm{NO}_{2}$ & $(1)$ & 86 & 1391 \\
& $\rightarrow \mathrm{CH}_{3} \mathrm{O}+\mathrm{NO}_{3}$ & (2) & 135 & 886 \\
\hline
\end{tabular}

Absorption cross-section data

\begin{tabular}{llc}
\hline Wavelength range/nm & Reference & Comments \\
\hline $202-280$ & Bridier et al., 1992 & (a) \\
\hline
\end{tabular}

\section{Comments}

(a) Flash photolysis of $\mathrm{Cl}_{2}$ in the presence of $\mathrm{CH}_{4}-\mathrm{O}_{2}-\mathrm{NO}_{2}$ mixtures at a total pressure of 1 bar, with UV absorption to monitor the concentrations of $\mathrm{CH}_{3} \mathrm{O}_{2}$ radicals and $\mathrm{CH}_{3} \mathrm{O}_{2} \mathrm{NO}_{2}$.

\section{Preferred Values}

Absorption cross-sections at $298 \mathrm{~K}$

\begin{tabular}{cccc}
\hline$\lambda / \mathrm{nm}$ & $10^{20} \sigma / \mathrm{cm}^{2}$ & $\lambda / \mathrm{nm}$ & $10^{20} \sigma / \mathrm{cm}^{2}$ \\
\hline 200 & 500 & 265 & 20.0 \\
205 & 360 & 270 & 16.0 \\
210 & 240 & 275 & 13.0 \\
215 & 150 & 280 & 10.5 \\
220 & 105 & 285 & 6.2 \\
225 & 80 & 290 & 3.9 \\
230 & 68 & 295 & 2.4 \\
235 & 60 & 300 & 1.4 \\
240 & 53 & 305 & 0.85 \\
245 & 46 & 310 & 0.53 \\
250 & 39 & 315 & 0.39 \\
255 & 32 & 320 & 0.24 \\
260 & 26 & 325 & 0.15 \\
\hline
\end{tabular}

\section{Comments on Preferred Values}

In view of the thermal instability of $\mathrm{CH}_{3} \mathrm{O}_{2} \mathrm{NO}_{2}$, the measurement of the cross-sections for $\mathrm{CH}_{3} \mathrm{O}_{2} \mathrm{NO}_{2}$ presents considerable experimental problems. Nevertheless, the measurements of Bridier et al. (1992) are in moderately good agreement with previous data (Cox and Tyndall, 1979; Morel et al., 1980; Sander and Watson, 1980) at wavelengths $<255 \mathrm{~nm}$ and are taken as the preferred values in the range $200 \mathrm{~nm}$ to $280 \mathrm{~nm}$. At longer wavelengths the agreement is less good and the experimental data from Cox and Tyndall (1979), which are the only values extending into the wavelength region of importance for the atmosphere $(\lambda \geq 290 \mathrm{~nm})$, show large scatter. The preferred values given in the table for wavelengths $>280 \mathrm{~nm}$ are based on a comparison with the spectrum of $\mathrm{HO}_{2} \mathrm{NO}_{2}$.

There are no data to indicate the relative importance of the two photodissociation channels, and neither can be precluded on energetic grounds in the absorbing wavelength region. By analogy with other molecules containing the $-\mathrm{NO}_{2}$ chromophore 
(for example, $\mathrm{HNO}_{3}$ ), it is likely that absorption around $270 \mathrm{~nm}$ is associated with an orbitally forbidden $n-\pi^{*}$ transition which leads to dissociation of the molecule. Thus it is probable that $\phi_{1}+\phi_{2}=1$.

\section{References}

Bridier, I., Lesclaux, R., and Veyret, B.: Chem. Phys. Lett., 191, 259, 1992.

Cox, R. A. and Tyndall, G. S.: Chem. Phys. Lett., 65, 357, 1979.

Morel, O., Simonaitis, R., and Heicklen, J.: Chem. Phys. Lett., 73, 38, 1980.

Sander, S. P. and Watson, R. T.: J. Phys. Chem., 84, 1664, 1980. 
II.A8.218

$\mathrm{CH}_{3} \mathrm{C}(\mathrm{O}) \mathrm{OONO}_{2}+\mathbf{h} v \rightarrow$ products

Primary photochemical transitions

\begin{tabular}{lllcc}
\hline Reaction & & $\Delta \mathrm{H}_{298}^{\circ} / \mathrm{kJ} \cdot \mathrm{mol}^{-1}$ & $\lambda_{\text {threshold }} / \mathrm{nm}$ \\
\hline $\mathrm{CH}_{3} \mathrm{C}(\mathrm{O}) \mathrm{OONO}_{2}+\mathrm{h} v$ & $\rightarrow \mathrm{CH}_{3} \mathrm{C}(\mathrm{O}) \mathrm{O}_{2}+\mathrm{NO}_{2}$ & $(1)$ & 119 & 1004 \\
& $\rightarrow \mathrm{CH}_{3} \mathrm{CO}_{2}+\mathrm{NO}_{3}$ & (2) & 124 & 963 \\
\hline
\end{tabular}

Absorption cross-section data

\begin{tabular}{llc}
\hline Wavelength range/nm & Reference & Comments \\
\hline $220-325$ & Libuda and Zabel, 1995 & (a) \\
$196-350$ & Talukdar et al., 1995 & (b)
\end{tabular}

Quantum yield data $\left(\phi=\phi_{1}+\phi_{2}\right)$

\begin{tabular}{lccc}
\hline Measurement & Wavelength range/nm & Reference & Comments \\
\hline$\phi\left(\mathrm{NO}_{2}\right)$ & 248 & Mazely et al., 1995 & (c) \\
$\phi\left(\mathrm{NO}_{3}\right)$ & 248 & Mazely et al., 1997 & (d) \\
$\phi\left(\mathrm{NO}_{3}\right)$ & 248,308 & Harwood et al., 2003 & (e) \\
\hline
\end{tabular}

\section{Comments}

(a) Longpath (39.1 m) UV absorption cell with diode array detector used. The concentration of the $\mathrm{CH}_{3} \mathrm{C}(\mathrm{O}) \mathrm{OONO}_{2}(\mathrm{PAN})$ was determined by FTIR (pathlength $=51.6 \mathrm{~m}$ ) in the same cell. The UV spectral resolution was $0.6 \mathrm{~nm}$.

(b) Diode array spectrometer with a resolution of $0.2 \mathrm{~nm}$ used with temperature controlled $( \pm 1 \mathrm{~K})$ absorption cells of pathlengths $100 \mathrm{~cm}$ and $25 \mathrm{~cm} . \mathrm{CH}_{3} \mathrm{C}(\mathrm{O}) \mathrm{OONO}_{2}$ concentrations were determined by pressure measurements. Cross-sections were measured at $250 \mathrm{~K}, 273 \mathrm{~K}$ and $298 \mathrm{~K}$.

(c) Pulsed laser photolysis of PAN with LIF detection of $\mathrm{NO}_{2}$. The quantum yield for $\mathrm{NO}_{2}$ formation was measured relative to the photodissociation of $\mathrm{HNO}_{3}$ at $248 \mathrm{~nm}$, assuming a value of $\phi\left(\mathrm{NO}_{2}\right)$ from $\mathrm{HNO}_{3}$ of unity at this wavelength (see $\mathrm{HNO}_{3}$ photolysis data sheet http://www.iupac-kinetic.ch.cam.ac.uk/datasheets/photol/PNOx2_HONO2.pdf). A value of $\phi\left(\mathrm{NO}_{2}\right)=0.83 \pm 0.09$ for the photolysis of PAN at $248 \mathrm{~nm}$ was obtained.

(d) Pulsed laser photolysis of PAN at $248 \mathrm{~nm}$ with LIF detection of $\mathrm{NO}_{3}$. The quantum yield for $\mathrm{NO}_{3}$ formation was determined by comparison to the photodissociation of $\mathrm{N}_{2} \mathrm{O}_{5}$, assuming a value of $\phi\left(\mathrm{NO}_{2}\right)$ from $\mathrm{HNO}_{3}$ of unity at this wavelength (see $\mathrm{HNO}_{3}$ photolysis data sheet http://www.iupac-kinetic.ch.cam.ac.uk/datasheets/photol/PNOx2_HONO2.pdf). A value of $\phi\left(\mathrm{NO}_{3}\right)=0.3 \pm 0.1$ was obtained for PAN.

(e) Pulsed laser photolysis of PAN with LIF detection of $\mathrm{NO}_{3}$. The quantum yield for $\mathrm{NO}_{2}$ formation was measured relative to the photodissociation of $\mathrm{HNO}_{3}$ at $248 \mathrm{~nm}$, assuming a value of $\phi\left(\mathrm{NO}_{2}\right)$ from $\mathrm{HNO}_{3}$ of unity at this wavelength (see $\mathrm{HNO}_{3}$ photolysis data sheet http://www.iupac-kinetic.ch.cam.ac.uk/datasheets/photol/PNOx2_HONO2.pdf). Values of $\phi\left(\mathrm{NO}_{3}\right)$ $=0.19 \pm 0.04$ and $\phi\left(\mathrm{NO}_{3}\right)=0.41 \pm 0.10$ were obtained for the photolysis of PAN at $248 \mathrm{~nm}$ and $308 \mathrm{~nm}$ respectively. 


\section{Preferred Values}

Absorption cross-sections at $298 \mathrm{~K}$ and the temperature coefficient $\mathrm{B}^{a}$

\begin{tabular}{|c|c|c|c|c|c|c|}
\hline & $\lambda / \mathrm{nm}$ & $10^{20} \sigma / \mathrm{cm}^{2}$ & $10^{3} B / K^{-1}$ & $\lambda / \mathrm{nm}$ & $10^{20} \sigma / \mathrm{cm}^{2}$ & $10^{3} B / K^{-1}$ \\
\hline & 196 & 429 & 2.02 & 274 & 2.45 & 5.55 \\
\hline & 198 & 398 & 1.73 & 276 & 2.07 & 5.76 \\
\hline & 200 & 361 & 1.36 & 278 & 1.74 & 5.98 \\
\hline & 202 & 325 & 1.07 & 280 & 1.46 & 6.20 \\
\hline & 204 & 292 & 0.86 & 282 & 1.21 & 6.43 \\
\hline & 206 & 261 & 0.75 & 284 & 1.01 & 6.67 \\
\hline & 208 & 226 & 0.71 & 286 & 0.81 & 6.90 \\
\hline & 210 & 196 & 0.75 & 288 & 0.648 & 7.15 \\
\hline & 212 & 168 & 0.84 & 290 & 0.537 & 7.39 \\
\hline & 214 & 143 & 0.97 & 292 & 0.447 & 7.63 \\
\hline & 216 & 122 & 1.12 & 294 & 0.369 & 7.86 \\
\hline & 218 & 104 & 1.29 & 296 & 0.297 & 8.08 \\
\hline & 220 & 89.7 & 1.47 & 298 & 0.245 & 8.27 \\
\hline & 222 & 77.7 & 1.64 & 300 & 0.189 & 8.44 \\
\hline & 224 & 67.6 & 1.81 & 302 & 0.152 & 8.61 \\
\hline & 226 & 59.3 & 1.98 & 304 & 0.125 & 8.76 \\
\hline & 228 & 52.0 & 2.14 & 306 & 0.0998 & 8.87 \\
\hline & 230 & 45.8 & 2.30 & 308 & 0.0816 & 9.01 \\
\hline & 232 & 40.4 & 2.46 & 310 & 0.0666 & 9.13 \\
\hline & 234 & 35.5 & 2.63 & 312 & 0.0538 & 9.30 \\
\hline & 236 & 31.4 & 2.80 & 314 & 0.0462 & 9.46 \\
\hline$\lambda / \mathrm{nm}$ & $10^{20} \sigma / \mathrm{cm}^{2}$ & $10^{3} B / K^{-1}$ & $\lambda / \mathrm{nm}$ & $10^{20} \sigma / \mathrm{cm}^{2}$ & & $10^{3} B / K^{-1}$ \\
\hline 238 & 27.9 & 2.96 & 316 & 0.0363 & & 9.57 \\
\hline 240 & 24.4 & 3.11 & 318 & 0.0300 & & 9.75 \\
\hline 242 & 21.5 & 3.25 & 320 & 0.0252 & & 10.0 \\
\hline 244 & 18.8 & 3.39 & 322 & 0.0199 & & 10.2 \\
\hline 246 & 16.6 & 3.52 & 324 & 0.0166 & & 10.4 \\
\hline 248 & 14.6 & 3.64 & 326 & 0.0140 & & 10.6 \\
\hline 250 & 12.9 & 3.76 & 328 & 0.0117 & & 10.7 \\
\hline 252 & 11.4 & 3.87 & 330 & 0.0106 & & 10.9 \\
\hline 254 & 10.0 & 3.98 & 332 & 0.00857 & & 11.2 \\
\hline 256 & 8.86 & 4.10 & 334 & 0.00676 & & 11.5 \\
\hline 258 & 7.8 & 4.23 & 336 & 0.00615 & & 11.7 \\
\hline 260 & 6.85 & 4.38 & 338 & 0.00526 & & 11.9 \\
\hline 262 & 6.01 & 4.53 & 340 & 0.00502 & & 12.2 \\
\hline 264 & 5.23 & 4.68 & 342 & 0.00360 & & 12.4 \\
\hline 266 & 4.54 & 4.82 & 344 & 0.00241 & & 12.5 \\
\hline 268 & 3.94 & 4.97 & 346 & 0.00231 & & \\
\hline 270 & 3.37 & 5.14 & 348 & 0.00247 & & \\
\hline 272 & 2.87 & 5.34 & 350 & 0.00165 & & \\
\hline
\end{tabular}

${ }^{a}$ Absorption cross-sections at temperatures in the range $250 \mathrm{~K}$ to $298 \mathrm{~K}$ are calculated using the equation $\ln [\sigma(T) / \sigma(298 K)]=B(T-298)$.

\section{Quantum Yields}

$\phi_{1}=0.76 ; \phi_{2}=0.24$ at $248 \mathrm{~nm}$

$\phi_{1}=0.61 ; \phi_{2}=0.41$ at $308 \mathrm{~nm}$ 


\section{Comments on Preferred Values}

The preferred values of the absorption cross-sections at $298 \mathrm{~K}$ are based on the work of Libuda and Zabel (1995) and Talukdar et al. (1995), which agree to within a few percent at wavelengths below $290 \mathrm{~nm}$ and only slightly less well at longer wavelengths where the error limits on the measurements increase because of the difficulty of measuring the small cross-sections in that region of the spectrum.

Talukdar et al. (1995) have also measured the cross-sections at three temperatures and expressed their results in the form $\ln [\sigma(T) / \sigma(298 \mathrm{~K})]=B(T-298)$ where $B$ is a constant at a particular wavelength. The values of $B$ and $\sigma(298 \mathrm{~K})$ obtained by Talukdar et al. (1995) are listed as our preferred values.

Combination of the $\mathrm{NO}_{2}$ and $\mathrm{NO}_{3}$ formation quantum yields measured by Mazely et al. in their 1995 and 1997 studies suggests $\mathrm{NO}_{2}$ and $\mathrm{NO}_{3}$ are the sole N-containing photoproducts. at $248 \mathrm{~nm}$. It is therefore suggested that $\left(\phi_{1}+\phi_{2}\right)=1$ following absorption in the UV region. The values of $\phi_{2}$ from Harwood et al. (2003) and Mazely et al. (1997) are averaged for the recommended value at $248 \mathrm{~nm}$, and $\phi_{1}$ obtained by difference. The Harwood value for $\phi_{2}$ at $308 \mathrm{~nm}$ is accepted and $\phi_{1}$ obtained by difference.

\section{References}

Harwood, M. H., Roberts, J. M., Frost, G.J., Ravishankara, A.R. and J. B. Burkholder, J. Phys. Chem., A, 107, 1148, 2003. Libuda, H. G. and Zabel, F.: Ber. Bunsenges. Phys. Chem. 99, 1205, 1995.

Mazely, T. L., Friedl, R. R. and Sander, S. P.: J. Phys. Chem. 99, 8162, 1995.

Mazely, T. L., Friedl, R. R. and Sander, S. P.: J. Phys. Chem. 101, 7090, 1997.

Talukdar, R. A., Burkholder, J. B., Schmolter, A.-M., Roberts, J. M., Wilson, R. R. and Ravishankara, A. R.: J. Geophys. Res. 100, 14163, 1995. 